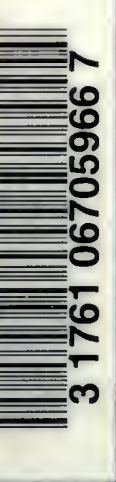




\section{PRESENTED}

To

THE UNIVERSITY OF TORONTO

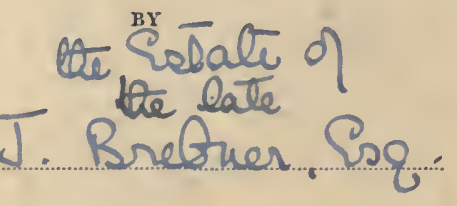


Digitized by the Internet Archive in 2007 with funding from Microsoft Corporation 



\section{POPULAR ENCYCLOPEDIA;}

BEING A GENERAL DICTIONARY OF

ARTS, SCIENCES, LITERATURE, BIOGRAPHY, HISTORY,

POLITICAL ECONOMY.

REPRINTED YROM THR AMIRICAN BDITION OF THE " CONVERSATIONS LEXICON, ; "

(WITH CORRECTIONS AND ADDITIONS,

SO AS TO RENDER IT SUITABLE TO THIS COUNTRY, AND BRING IT DOWN TO THE PRESENT TIME. )

with

\section{DISSERTATIONS}

ON THE RISE AND PROGRESS OF LITERATURE, BY SIR D. K. SANDFORD, A.M. Oxon., D.C.L.

ON THE PROGRESS OF SCIENCE,

BY THOMAS THOMSON, M.D., F.R.S.L. \& E., \&c. \&c.

AND

ON THE PROGRESS OF THE FINE ARTS,

B Y A L L N C U N I N G H M, Eso.

VOLUME I.-PART I.

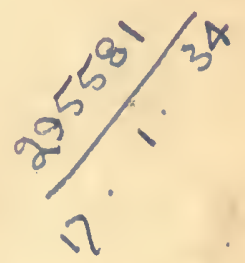

G L A S G O W :

B LA C K I \& S ON, 38, Q UEEN STREET, .AND 5, SOUTH COLLEGE STREET, EDINBURGH. 


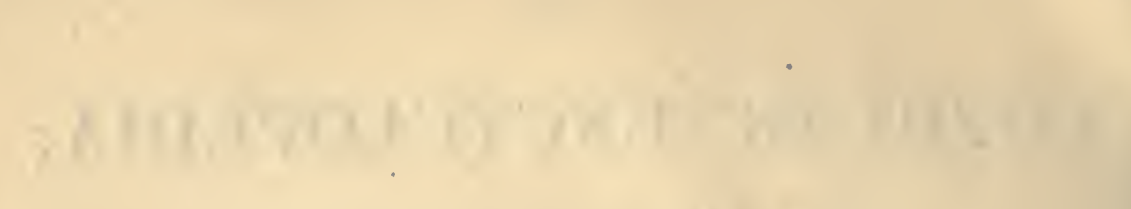




\section{NEW ISSUE, WITH EIGHT ADDITIONAL MAPS,}

BEING TIE TWENTIETH EDITION OF ONE THOUSAND EACII.

\section{THE \\ P O P UL A R E N C Y C L O P E D I A,}

OR

\section{"Conuergationg 3lexicon;"}

BEING A GENERAL DICTIONARY OF

\section{ARTS, SCIENCES, LITERATURE, BIOGRAPIIY, IIISTORY, AND POLITICS. \\ WITH DISSERTATIONS ON THE}

\section{PROGRESS OF SCIENCE, LITERATURE, AND THE FINE ARTS, \\ By THOMAS THO M O N, M.D., F.P.S., \&c. \\ REGIUS PROPESSOR OF CHEMISTRY IN THB UNIVERSITY OF GLASGON ;}

S I R D A I E L K. SA N D F O R D, D.C.L. Sc.

PROPESSOR OF GREER IN THE UNIVERSITY OF GLASGOW;

A N D A L L A N C U N N I G H A M, EsQ.

AUTHOR OF " LIVES OF BRIT!̣SH PAINTERS," eTC. ETC.

TERMS OF PUBLIGATION.

The Work is Printed on Royal 8ro, and will be completed, including Supplement and Index, in Fifty-six Parts, 2s. Gd. earli, ur Fourteen Half Volumes, at Ils. Illustrated by numerous Maps, Plates, and Diagrams. A Half Volume will be Pubished Monthly.

The "Conversations Lexicox" was originally published in Germany about fiftcen years ago, under the superintendence of several distinguished German literati: and such has been its popularity, that—although a Work consisting of TWELYE large volumes-it has already gone through SEven EdrTions in that country. It has also been translated into the Danish, Swedish, Dutch, Italian, and French Languages, and is altogether the most popular Work, of an extensive nature, upon the Continent. Nor is its reputation greater than its merits: for in completeness of information, accuracy of statement, impartiality of opinion, and elegance of language, it is equalled by no Work of a similar nature in the world. Unlike other Encyclopedias, it does not pay a disproportioned attention to the Sciences and their technicalities, but disposes of each and all of its subjects according to their relative importance. It partakes, indeed, of much of that cosmopolitanism which is said to distinguish the German character, being universal in its sympathies, as it is unlimited in its scopc. In Biograpliy, History, Geograply, Statistics, Commerce, and the Fine Arts, it is particularly complete; and it abounds in articles upon familiar and fire-side subjects, which aro not to be found treated of clsewhere, and which bestow upon the Work a peculiar charm and interest.

In bringing out an edition of a work which has attained such unprecedented popularity on the Continent of Europe and the United States of America, the Publishers have spared no exertion or expense to render it worthy of British patronage. Their first object has been, to present the public with a faithful edition of the original, for it is upon that certainly, that the great claims of their publication to distinction must eventually rest. No work of similar dimensions has ever enjoyed so wide a popularity in Europe as the Conversations Lexicon; and with the knowledge of this fact, the Publishers have felt the propriety of retaining in their edition almost the entire original, in the persuasion that what has been so lighly estimated elsewherc, can scarcely prove valueless in this country. The recommendation which it carries with it must be applicable to cvery quarter. This they felt more particularly when they came to prepare the work for the press. The information which it contained they found to be so new and complete-so far surpassing in extent and freshness of source, that of any British publication;-the metlod of arrangement and language they found to be so unexceptionable-that they considered it would be worse than useless to remodel or materially alter the work, and that any affectation of doing so would be its coudemnation. They, therefore, resolved to kecp very faithfully to the original; and they are thus enabled to present the British public, for the first time, with an English edition of the Conversations Lexicon.

Nearly Two Hundred of the most eminent German writers contributed to the original Work; and tle American edition, upon which thc present is formed, has bcen improved by a variety of original articles from cminent Amcrican writers, so that this edition will combine the excellencies both of the original and translated eopies. To render it still more worthy of public favour, and especially to suit it to the wants and interests of this country, it is carefully revised, and such additions made to it as are considered necessary for the English reader. These, of themselves, (besides the Original Dissertations,) will constitute nearly one-fourth of the hook, so tliat, independent of its cosmopolitan cliaracter, the reader may count on the fullest and most recent information on all subjects connected with the British empire.

In bestowing upon the present edition the title of The Popular Encyclopedia, the Publishers consider themselves justificd, not only by the nature of the Work, which is in crery respeot popular, being adapted to all tastes and necessitics, but by the the fact of its popularity, which exceeds that of any other work of tlic kind in Europc. More than one hundred thousand copics liave been sold in Germany alone, and it is making cqual progress throughout the other countries of Europe and the States of America. This fact may be considered as a guarantee of its usefulness; but that nothing may be wanting to render the present edition acceptable, it will be illustrated with Plates and Diagrams when neessary, the want of these having been found the only desideratum in the former cditions of the work. [For Reviews see following pages.]

\section{BLACKIE AND SON, QUEEN STREET, GLASGOW :}


"Ir completed on its present plan, it will bo one of the most useful works of reference that persons who havo not time for deep study can require."-Athenaeum.

"Wr have looked over tho two numbers already published. 'They contaln much useful and interesting knowledgo in a snuall compass; and tho possesslon of thls work, when coin pleted, will precludo tho necessity of reforring to scientific and biogruphical dictionaries, whose office it is well fitted to fulfilt."-Scottish Guardhan.

"It appears to us to bo the best Encyclopedia that has yet been projected or offered to tho peoplo of this country. It is beautifully printed, tho illustrations are in a superior style, while the arrangeineizts of the work aro simple and correct, and we feel confident, that in recommending the Popular Eincyclopedia to the attention of tho public, wo are dolng nothlng inore than our duty."-Glasgow Free press.

"IN our opinion, the 'Conversations Lexicon" is by fur the most useful and complete work of tho kind which has ever been glven to the world. It is concise and plain, without being imperfect or superficial. 'The edition beforo us is enriched by numerous additions, and in point of typography, \&c. is altogether calculated to secure for the work, in this country, even a higher degree of success than It has met with elsewhere."-Edinburgh Evening Post.

"THus work is well calculated to supply an important desideratum in tho literature of the country, namely, 8 condensed family library; and as it comes within the runge of al most every man's mens, wo doubt not it will bo purchased with avidity."-Greenoch Intelligencer.

"Ir would be a work of supererogation at this time of day to attempt to praise the general plan and execution of this celebrated Dictionary *** In this era of cheap publication, it would be unfnir to close our notice without stating what are the pretensions of the 'Popular Encyclopedia in this respect. It is got up in a handcome style, and must prove an oniament, extrinsically, to a gentleman's library, being well printed, on good paper, in royal octavo, and yet so economical in point of price, as to be easily within the reach of the largest and most important class of our population, to whom the knowledge it communicates may be invaluable. The es. sential addition, in such works, of illustrative engravings, is also supplied, though wanting in former editions; and we know of nothing which the spirited publishers have left undone to merit approbatlon, and the highest success of which their undertaking is susceptible."-Greenock Advertiser.

"AN undertaking like thls cannot fail to meet with the most ample encouragement, and if the publishers proceed as they have begun, the Popular Encyclopedia will be an indispensable requisite in every family where the English language is understood, and the value of rational learning is duly appreciated."-Liberator.

"A PART of this publication now lies before us, and whether we speak of the clear and enlighteningıdescriptive matter which it contains, or notice the beauty and elegance of the plates, two of which aro given witl each Part, we cunnot too much extol the spirit and ability of the conductors of it, nor too warmly recommend the work to the public as one of the best and cheapest Encyclopedias which has set appeared. A complete and very superior family library may thus be obtained for the small sum of six pounds. This is worthy the consideration of evely literary man." - York Herald.

"This Popular Encyclopedia is now submitted to the public, in a cheaper form than any former edition of it. Every body may now possess bimself of one of the best Tinerclopedias ever published "-Montrose Review.

"Or Encyclopedias it has been justly remarked, that they are generally too scientilic for the unlearned reader, and not enough so for the learned: this characteristic, however, does not attach itself to the present Popular Encyclopedia, which has had conferred upon it the flat. tering, but just distinction of "World-Renowned," -

Aberdeen Journal.

" $\mathrm{T}$ нIS is the reprint in Scolland of a valuable work,
| versations Lexicon,' and which obtrined great fame in that and in other countrles of Europe. This part is eloganily got up, the typography is clear, the engravings excellent, and the articles generally of a high order of merit."-Leels Mercury.

WE consider our city honoured by the reproduction of a work of so much utility, in a style of extreme neatuess, and at a cheap price. Unliko other Eucyclopedlus, it does not pay a disproportioned nttention to the sriences mul their tuchnicalities, but disposes of each and all its suljects according to their relatlve importance. In Blography, History, Geography, Statistics, Commerce, and tho Fine Arls, it is particularly complete; and it abounds in articles upon familiar and fireside subjects, which are not to be found treuted of elsewhere, and which hestow upon the work a particular charm and interest. We have examiued these numbers with some (चre, and they appear to us to contain ample evidenco of the redemption ot tho publishers' pledge of revisions and additions. If the work, inshort, prog resses as it has begun, itdeserves, and will, wo hope, meet with success adequate to tho enterprise of its spirited publishers." - Scots Times.

" $W_{E}$ have lookel through the articles carefully, and we find those treated exactly in tho manner that a per. son seeking for information would wish, of course every subject as it is brought upon the tapis is not exlanusted. As a book merely of reference, it is invaluable as it is amusing. Tho accompanying engravings are clearly cut, and are equal to tho letter-press that they so beautifully elucidate. If this enterprise do not prove successful, we certainly shall think that in England good taste has retrograded, and that even the progress of civilization his mido something like a pause." - Netropolitan Mag.

"For a book of reference we know of none equal to it. We are sure that it must win its way to popularity."-Metropolitan Mag. (Second notice.)

"It must provean excellent standard book."--Tait's Mtag.

"Turs is a reprint from the American Edition of the ' Conversations Jexicon,' with such additions and corrections as bring it down to the latest period, and render it suitable to this country. It has two new features-the introduction of plates and diagrams, and the addition of a series of original Dissertations on Science, Literature, and the Fine Arts.-On Science, from the pen of Dr Thomson, the distinguished Professor of Chemistry, in the University of Glasgow. ON THE Rase aNd $\mathbf{P}_{R O}$ gress of Litrraturz, by Sir Daniel K. Sandford, Professor of Greek in the same University. Such names would stamp any work as 'sterling.' *** The first three parts of the 'Popular Encyclopedia' are before us. They are carefully edited, and very neatly printed. Besides wood cuts and diagrams there are expensive steel engravings illustrative of Architecture, Astronomy, Aeronautics. Anatomy, Amphitheatre, Agriculture, and Aqueduct.-These articles struck us as being extremely well written-particularly Architecture, on which there is an elaborate essay. We are also much pleased with the notices of Africa, (including Lander's discoveries, and the colony of Liberia) Academy, Emperor Alexander, Angling (the best remarks on this head we ever met), A rabian Literature, and Sir Richarl Arkwright. -These three parts comprise from A to Augereau, occupying 334 pages. - In conclusion, we must say that this is one of the best Encyclopedias ever published, and at a price so low that nothing but a very great sale can repay the publishers."-Chesterfield Gazelle.

" WVITH this Number of the Conversations Lexicon is presented the commencement of a Discourse on the Progress of Physical Science by Professor Thomson of Glasgow. So far as it has yet proceeded, we must pronounce it at once an able and comprehensive treatise on the interesting subject to which the professor has directed his studies. It is written in a plain and popular manner, and while it conveys ample scientific details, it cannot fail tc be intelligible to the general reader at the same time. Indeed it is composed precisely in the style which ought to characterize all the articles of a Popular Encyclopedia." -Edinburgh Evening Post. (Escond notice.) origilially published in Germany, under the title of ' Con-? 
The following Extracts, from Reviews of the American Edition, will show in what estimation the work is held in that country. A few Letters from eminent individuals are also given. It may be proper to apprise the reader that the title bestowed on the American edition 2.8 " ENCYCLOP FDIA AMLRICANA."

ONs of the best Encjclopedias ever published. Athencum.

This Work deserves to be recommended to the great body of our peopie, as a library of 'self; -cheap, comprehensive, exceedingly well executed, and of the highest authority. Therecan be little doubt that it fully deserves the reputation it enjoys. A work, which has passed tlurough so many editions at home, and has been translated into so many languages abroad, must be-it cannot be otherwise- of great value, not only in the country in which it first appeared, but in every other, where it has been alluwed to re-appear. Men do not enter into such expensive undertakings without deliberation. They are unlike all others; and they cannot continue, year after year, unless they have something else to depend upon, than merely popular favour. Perhaps two hundred thousand crpies of the sriginal work have been distributed through Europe, in different languages, since its publication, in 1812; while probably not more than twenty-five thousand copies of the Library of Useful Knowledge have been disposed off. This fact, alone is sufficient to convinct us, that this age has produced nothing better fitted to the wants of society at large-to the necessities rather-for its circulation could not have been so extended, unless it had been regarded almost as a necessary of life.-Norlh American Revievo.

The high reputation of the contributors to this work, will not fail to insure it a favourable reception, and its own merits will do the rest.-Silliman's Journal.

The appearance of the first volume of this valuable work in this country, is an event not less creditable to its enterprising publishers, than it is likely to prove lastingly beneficial to the public. When completed, according to the model presented by the first volume, it will deserve to be regarded as the spirit of all the best Encyclopædias; since it comprises whatever is really desirable and necessary in them, and, in addition, a large proportion of articles entirely original, or expressly written for its pages. This is the condition of all the articles of American Biography, by Mr Walsh; those on Zoology, by Dr Godman; and those on Mineralogy and Chemistry, by a gentleman of Boston, distinguished for his successful devotion to those studies. The work abounds with interesting and useful matter, presented in a condensed and perspicuous style; nor is it one of its least commendations that it is to be comprised in twelve octavo volumes, which may be placed on an office table, or occupy a shelf in the parlour, ever ready for immediate reference, instead of requiring almost a room to itself, like its ponderous predecessors, the Britannica, Edinburgensis, \&o.

The vast circulation this work las had in Europe, where it has already been reprinted in four or five langunges, not to speak of the numerous German editions, of which seven have been published, speak loudly in favour of its intrinsic merit, without which such a celebrity could never have been attained. To every man engaged in public business, who needs a correct and ample book of reference on various topies of science and letters, the Encyclopredia A mericana will be almost invaluable.. To individuals obliged to go to situations where books are neither numerous nor easily procured, the rich contents of these twelve volumes will prove a mine which will a mply repay its purchaser, and be with difficulty exhausted, and we recommend it to their patronage in the full conviction ot its worth. Indeed it is difficult to say to what class of readers such a book would not prove useful, nay, almost indispensable, since it combines a grent amount of valua ble.matter in small compass, and at moderate expense, and is in every respect well suited to aug ment the reader's stock of ideas, and powers of conversation, without severely taxing time, or fatiguing attention. Theso, at least, are our conclusions, after a close and candid examination of the first volume.-Am. Dazly Advertiser.

A compendious library, and invaluable book of reference. $-N$. $Y$. Anterican.

This cannot but prove $\mathrm{a}$ valuable addition to the literature of the age $-\Delta m e r$. $A d v$.

The work will be a valuablo possession to every family or individual tbat canafford to purchase it, and we take pleasure, therefore, in extending the knowledge of its nerits. - National Intell.

We have seen and carefully examined the first volume of the Encyclopsedia Americana, just published by Carey, Lea, and Carey, and think our readers may be congratulated upon the opportunity of making such a valuable accession to their libraries.-Aurora.

The Encyclopedia Americana is a prodigious improve ment upon all that has gone before it; a thing for our country, as well as the country that gave it birth, to be proud of ; an inexhaustible treasury of useful, pleasant, and fumiliar learning on every possible subject, so arranged as to be speedily and safely referred to on emergency as well as on deliberate inquiry; and better still, adapted to the understanding, and put within the reach of the multitude. * * The Encyclopadia Americana is a work without which no library worthy of the name can hereafter be made up.-Yankee.

The variety of topics is of course vast, and they are treated in a manner which is at once so full of information and so interesting, that the work, instead of being merely referred to, might be regularly perused with as much pleasure as profit.-Baltimore American.

We view it as a publication worthy of the age and of the country, and cannot but believe the discrimination of our countrymen will sustain the publishers, and well reward them for this contribution to American literature.Baltimore Patriot.

The great number of Biographical Dictionaries and extensive Encyclopadias already in the libraries of opulent individuals or well-endowed literary institutions, might by some be urged as an argument against the necessity of such a work as the Encyclopxdia A mericana; but it appeass to us, that, for the very purposes for which Biographical Dictionaries were compiled and Encyclopadias written, this work is pre-eminently fitted : viz. -as a book of frequent and ready reference. It is a fact, that most of the Encyclopæedias are such heavy tomes, that they lie upon the shelves, monuments of physical and literary gravity, like the Stone Henges of England, to be gazed at for their size, and to excite admiration, less as to their usefulness than how they came there.

In forming the Encyclopædia Americana, care has been taken to insert all that would be likely to arrest the atten. tion in connection with general reading. Where the whole of a science would be necessary, the reader, insteatd of finding a superficial sketch, is referred at once to the proper treatise; but that species of infarmation which is so of ten the subject of inquiry, and which becomes necessary to the proper understanding of a great portion ot general reading, is gathered into the Encyclopædia Americana, and enriches every page that we have examined. The parts of the work that relate to American geography, biography, history, natural and physical, bolany, \&c. have been written in this country, by gentlemen of acknowledged talent and literary taste. We canıot doubt that the succeeding volumes will equal the first, and we hence warmly recommend the work to the. patronage of the public, as being by far the best work of the kind ever offered for sale in this country.-IT. S. Gazelle.

Thu work appears to abound in that sort of information most necessary for frequent reference.-Daily Chronicle.

We entertain no fear that our ingenuousness or judgment will be called in question for our praising, in warm terms, the plan, and, as far as may be judged by the. one volume, the execution, both literary, scientific, and mechanical, of the Encyclopæedia Americana. * * * The va lume before us includes the whole of the letter A, and B, as far as the word baltle. We liave been at the pains to compare it with Rees' Cyclopædia to the same extent, and feel no hesitation in saying that, while it embraces all the most important subjects to be found in that very voluminous and expensive Dictionary of the Arts and Sciences, they are treated with perfect perspicuity, and if not so much. certainly with sufficient minuteness, Without reference to the fact, that scarcely a copy of Rees' Cyclopædia is to be obtained, we camnot but consider the mere circumstance, that what in the one extends through so many quartos and costs such \& large sum, is in the other to be comprised 
iu mereivo rolumes, the moderato price of 2 - dollars inch. Is In itulf a recummendatlon whlch entitles the fisejrlopendla Americasa to extensivo patrongo.-Newo Yort Aarwing Pous.

Wo are flad to seo the unanlmlty wish whlch tho American editors bear evldence to tho value of the new Fuciclopardla Americana, whlch Is edlted by Dr Lieber, at Hoston, with the ald of MIr Wigglesworth. These Eeutiemen are emluently compefent to the extenslvo and inc ful task whlch they hare undertaken. Wu regard them both as literatl of cousiderablo attainments, indefinligable zeal, and soum judgment. Dr Leber is a Ger. man acbolar sufficlently arqusilnted with our tong ue to do justice to that part of the work whleh is to be derived from the pupular Conversitlons Lexlown, the most recent Gernian lincycloparlla, of which more than eighty thoucaud coples have been onld In Germany, and transhations already mado info several of the continental languages.

It must bo kuown to all general renders, that Winglish Ulbllography embrices no good " Popular Dictionary of Arts Sclences Literature, Hlstory, Politics, and Biography, brought down to the presen t time,"-nono without abundant rubbish or surplusage, - none that furnishes nivurate and compendlous information on all the topics $11 \mathrm{k}$ ly to occupy the attentlon of lutelligent lndividuals and enlightened circles. The compilation of Rees is too voluminous; much of Its Ingredients may be regarded as obsolete, and a number of its articles aro exeessively copious and heavy. According to the plan of Dr Lieber, a desideratum will bo supplied; tho substunce of contem. porary knowledge will be brought within a small compass -and the character and uses of a manual will be imparted to a kind of publleation heretofore reserved, on strong shelves, for occasional referenee. By those who understand the German language, the Conversation3 Iexicon is consulted ten times for one application to any English Encjelopadia. It is not the mere multitude of heads, or the length and depth of treatises, which constitute the chlef or proper worth of such productions; their merit and usefulness may lie principally ln the judicious exelusion of matters rarely emergent, and the skilful compressien of whatever belongs to the active fund of theory, tact, and Illustration. The possessor of the Encjclopadia should be enabled by it to understand all that he may peruse or hear in the ordinary routine of life: to satisfy that curiosity or need which may be casually created. Nintional Gazclle.

\section{Letter from Gronoz Ticksor, Esq. of Boston.}

Boston, Nov. 25, 1827.

S1z. - I sm not acquainted with any book in a foreign Innguage, which, I think, may be translated into English and publlshed in the United States, with the needful alteratluns, with so much success as the Conversations Lexlcon, of which so many editions have been published in Germany. It seems 20 me to be suited, in a particular manner, to the present condition and wants of this country, because it contains more of that information which is useful and interesting to well-educated persons of all elasecs, than any other work with which I am conversant. It has made the fortunes of its publishers in Germany. It Is about to be adapted to the wants of thesrest of the Continent, in a French translation just undertaken at Brussels; and I do not doubt, a similar adaptation of it to tho Unlted States, would be as fortunate and as successul as was the original work; because, the class of persons to whon it would be interesting is much greater in this country than it is in Germany.

GEORGE TICKNOR.

Dr Fraxcis Liezra.

\section{Letter from $\mathrm{DR}_{\mathrm{R}}$ Charles Follev, Instructor in} German in Harvard University.

CAMERI DGE, Nov. 23, 1827.

Sir,$M y$ opinion with respect to the translation, of the Uictiona ry of Canversation into English, as proposed by
Dr Lieber, coineides entirely with tho views which thlg gentleman and several eminent literary men of this couniry lave already expressed. The Dictionary for Conver. seition owes Its excellenee, as well as its signal success, principally to this elrcumstance, that in Germany every ono who aims at distinetion in any science or art, commonly devotes himself almost exclusively to his particular pursuit. This devotedness to a single object is a pt to bo uttencled with a very imperfuct acquaintance with otlier branches of knowledge, and it is this defeet whlels ocersioned tho editing of a work which brought within the reach of every one the most interesting risults of all the difierent departments of learning and industry. On tho other land, the profound knowledge contalised in the works of those who have made a particulir pursuit the object of their life, hasemabled the compilers of that Dietionary to present to tho public, in a coneise mamer, great number of articles which are generally interesting, without being superficial. It is satisfaetory not unly io the general reader and seholar, to the philosopher and the historian, but to those also who are engaged in any particular business or profession, as farmers, mechanics, merchants, physieians, lawyers, or theologians. 'Those artl. cles of tho work which do not fully deserve this praise, will certainly be improved in usefulness and intertst fur this country, by the translator and those literary men who are expected to asslst him in this useful and patriotic undertaking.

CHARLES FOLLEN.

\section{From George Bascrokt, Esø. one of the Princi- pals of Round-Hill Seminary, Northampton.}

Noвtвa y rton, Dec. $22,1827$.

$\mathrm{SIR}_{1 \mathrm{~B}}$ - I am very glad to hear that you seriously propose to publish the Conversations Lexieon among us. It is the most convenient book for general reference, with whieh I am acquaisted; and as for its popularity, the sale of more than seventy or a hundred thousand copies of $1 t$ in Germany establishes that point. It is for the past, what a newspaper is designed to be for the present, - a general summary of the most interesting things known, stated on the best authority, to which access eould readily be had. There is one circumstance which I think is much in its favour. We have had Encyclopadias, compiled in France and Great Britain, each eontuining the eurrent vieus on matters of science and letters, prevailing respectively in those countries. In the German work we shal: have the materials a little differently wrought. There has been nothing of the kind at once so popular, and so trust-worthy.

I remain, with best wishes and sincere regards, Respectfully yours

\section{GEORGE BANCROFT.}

\section{From Edward Everetr, Esq. Member of the louse of Representatives of the United States.}

\section{Winter-Hill, Chaplestox, Nov. 17, 1827.}

I ENTJREL concur in the opinion expressed in the foregoing pages, of the merit of the Lexicon for Conversation It is somewhat of the nature of an Encycloprdia, intended, however, for convenient and popular use. Although, of the great number of articles contained in it, all are not equally well executed, no work, that I am acquainted with, contains such an amount and varjety of information, in a form so accessible and commodious. The alterations proposed by Dr Lieber, seem to me calculated to reuder it still more valuable in this country; and with them, it will be, in my opinion, the best work for convenient general reference, in the English language. So deeply impressed have I been with the merit of the work, that without having heard of Dr Lieber's propnsal to undertake a translation, I had determined to recommend to some of the principal booksellers to endeavour to procure a translator of it.

EDWARD EVERET'L. 


\section{A D V ERT ISEM EN T.}

"THE "Conversations Lexicon". was originally published in Germany about fifteen years ago, under the superintendence of several distinguished German literati ; and such has been its popularity, that-although a work consisting of TwELvE large volumes-it has already gone through SEven Editions in that country. It has also been translated into the Danish, Swedish, Dutch, Italian, and French languages, and is altogether the most popular work, of an extensive nature, upon the continent. Nor is its reputation greater than its merits; for in completeness of information, impartiality of opinion, and elegance of language, it is equalled by no work of a similar nature in the world. Unlike other Encyclopedias, it does not pay a disproportioned attention to the Sciences and their technicalities, but disposes of each and all its subjects according to their relative importance. It partakes, indeed, of much of that cosmopolitanism which is said to distinguish the German character, being universal in its sympathies as it is unlimited in its scope. In Biography, History, Geography, Statistics, Commerce, and the Fine Arts, it is particularly complete; and it abounds in articles upon familiar and fireside subjects, which are not to be found treated of elsewhere, and which bestow upon the work a peculiar charm and interest.

In bringing out an edition of a work which has attained such unprecedented popularity on the continent of Europe and the United States of America, the Publishers have spared no exertion or expense to render it worthy of British patronage. Their first object has been, to present the public with a faithful edition of the original, for it is upon that, certainly, that the great claims of their publication to distinction must eventually rest. No work of similar dimensions has ever enjoyed so wide a popularity in Europe as the Conversations Lexicon; and, with the knowledge of this fact, the Publishers have felt the propriety of retaining in their edition almost the entire original, in the persuasion, that what has been so highly estimated elsewhere, can scarcely prove valueless in this country. The recommendation which it carries with it must be applicable to every quarter This they felt more particularly when they came to prepare the work for press. The information which it contained they found to be so new and complete-so far surpassing in extent and freshness of source that of any British publication; - the method of arrangement and language they found to be so unexceptionable-that they considered it would be worse than useless to remodel or materially alter the work, and that any affectation of doing so would be its condemnation. They, 
therefore, resolved to keep very faithfully to the original; and they are thus enabled to present the British public, for the first time, with an edition of the Conversations Lexicon. Their publication, which has been long in preparation, and which was advertised more than a year ago, differs essentially from the penny Cyclopedias lately started, which profess to be founded on the basis of the Conversations Lexicon, but which are so arranged that they convey no notion of that celebrated work.

Nearly 'T wo Hundred of the most eminent German writers contributed to the original work; and the American edition, upon which the present is formed, has been improved by a variety of original articles from emiuent American writers, so that this edition will combine the excellencies both of the original and corrected copies. To render it still more worthy of public favour, and especially to suit it to the wants and interests of this country, it is carefully revised, and such additions made to it as are considered necessary for the English reader. These, of themselves, will constitute nearly one-fourth of the book, so that, independent of its cosmopolitan character, the reader may count on the fullest and most recent infor: mation on all subjects connected with the British empire. In addition, the Publishers have resolved to give a series of Dissertations on Science, Literature, and the Fine Arts.

In bestowing, upon the present edition, the title of The Popular Encyclopedia, the Publishers consider themselves justified, not only by the nature of the work, which is in every respect popular, being adapted to all tastes and capacities, but by the fact of its popularity, which exceeds that of any other work of the kind in Europe. More than one hundred thousand copies have been sold in Germany alone, and it is making equal progress throughout the other countries of Europe and the States of America. This fact may be considered as a guarantee of its usefulness; but that nothing may be wanting to render the present edition acceptable, it will be illustrated with Plates and Diagrams when necessary-these having been found the only desiderata in the former editions of the work. 


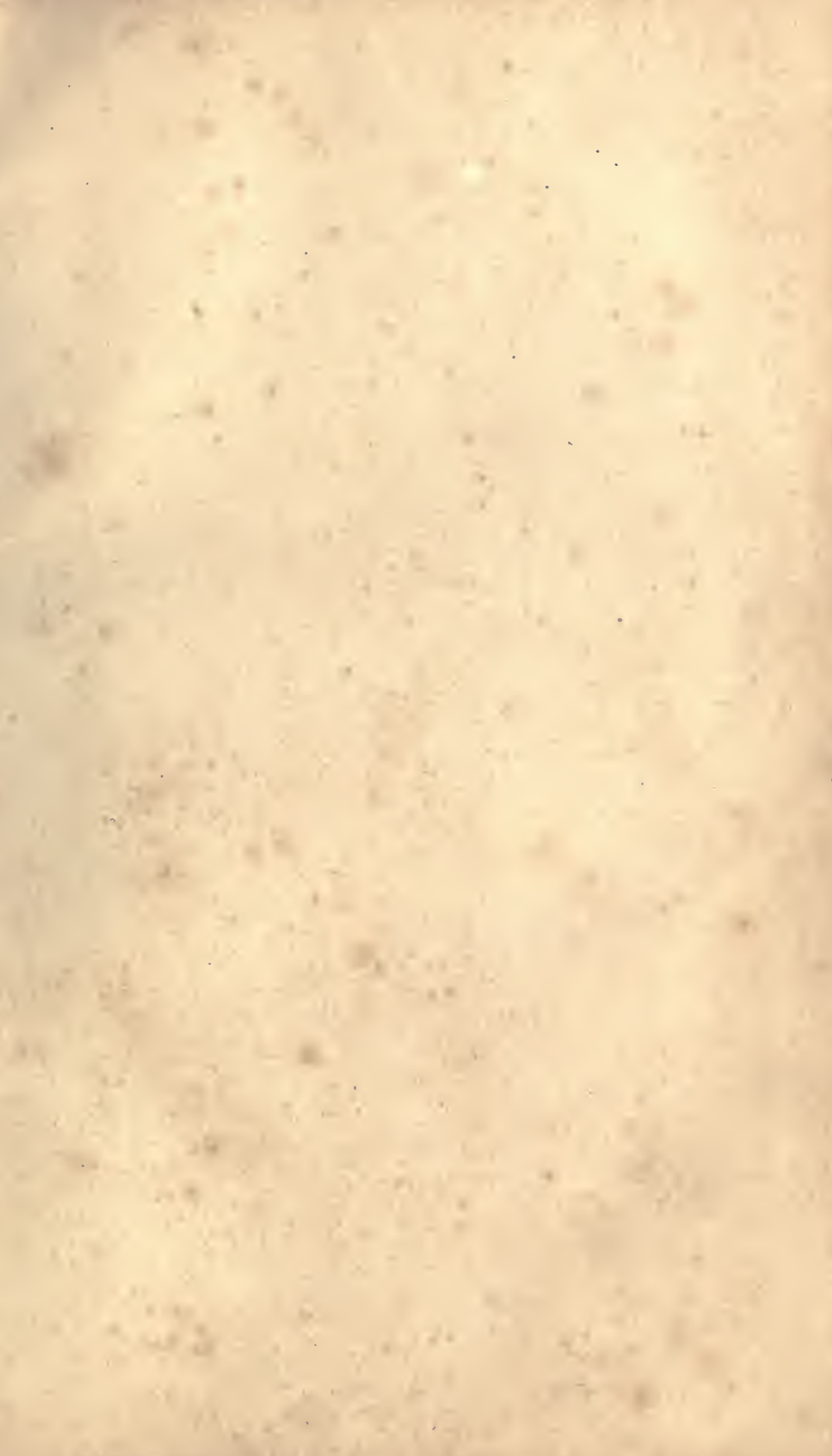




\section{ISTRONOII:}

PL.ITE' IVII.

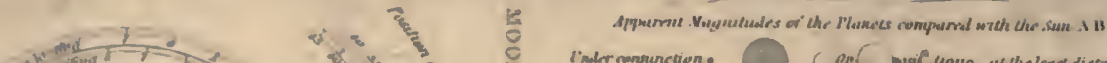
and

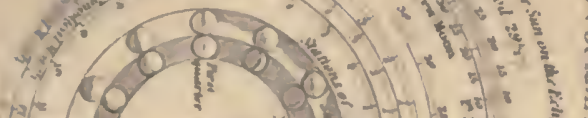

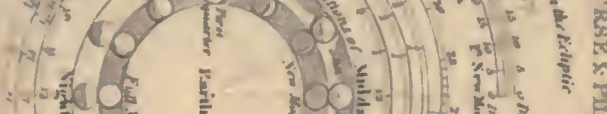

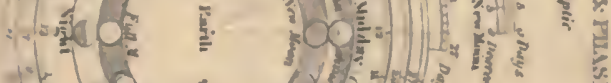
if 10 is 0 o 0

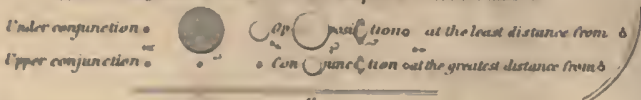

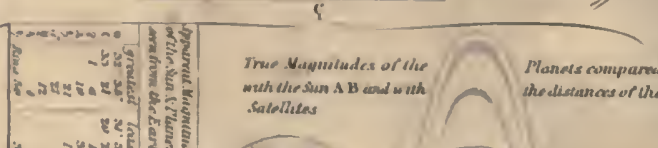

\section{$=\frac{0 \text { o }}{2}=$}

IIIHit

(1)

20

(3)

a

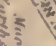

(n)

3.․ำ

(3)

ais

$\because$ ำ

ไม่

इं

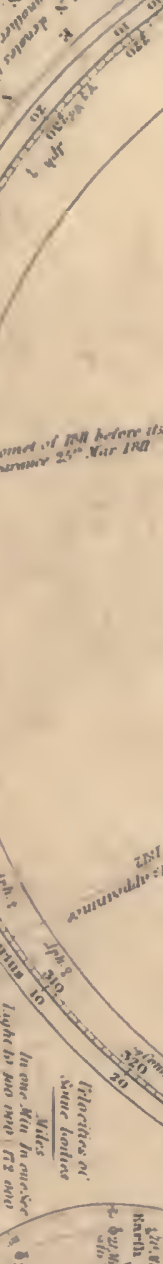

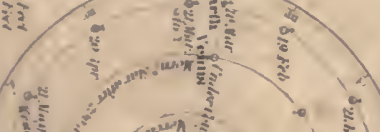

,

5y

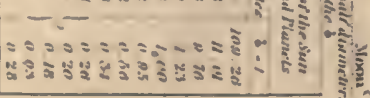

2)

(1)
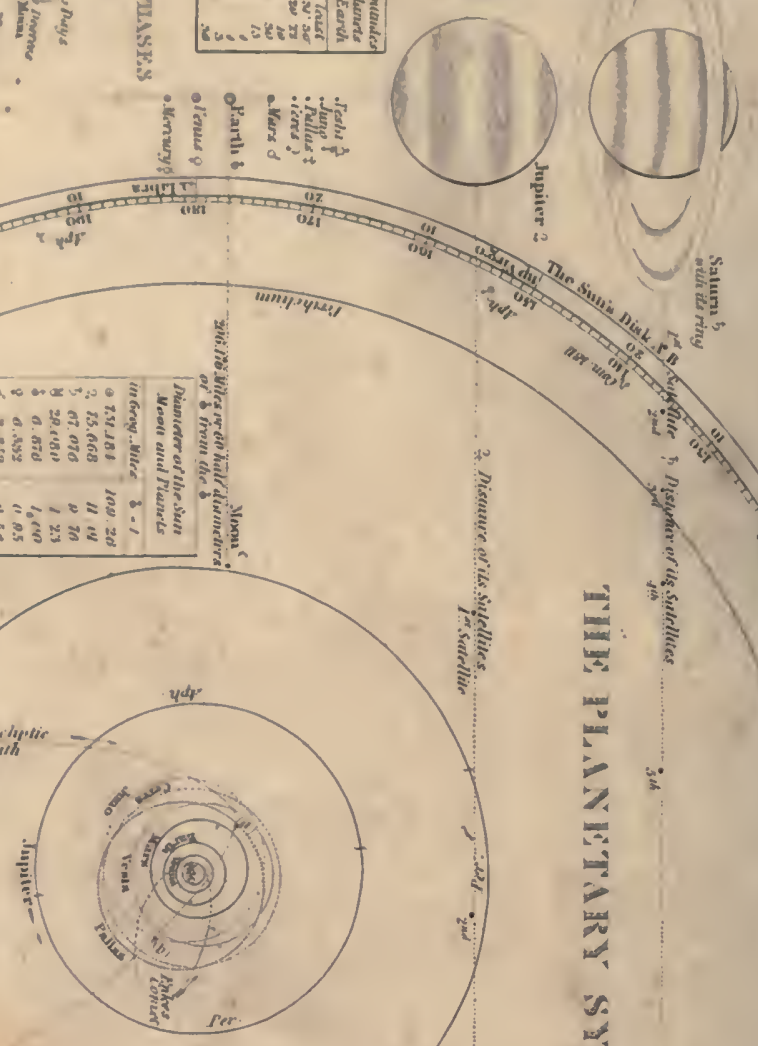

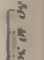

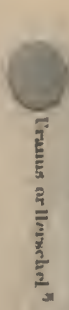



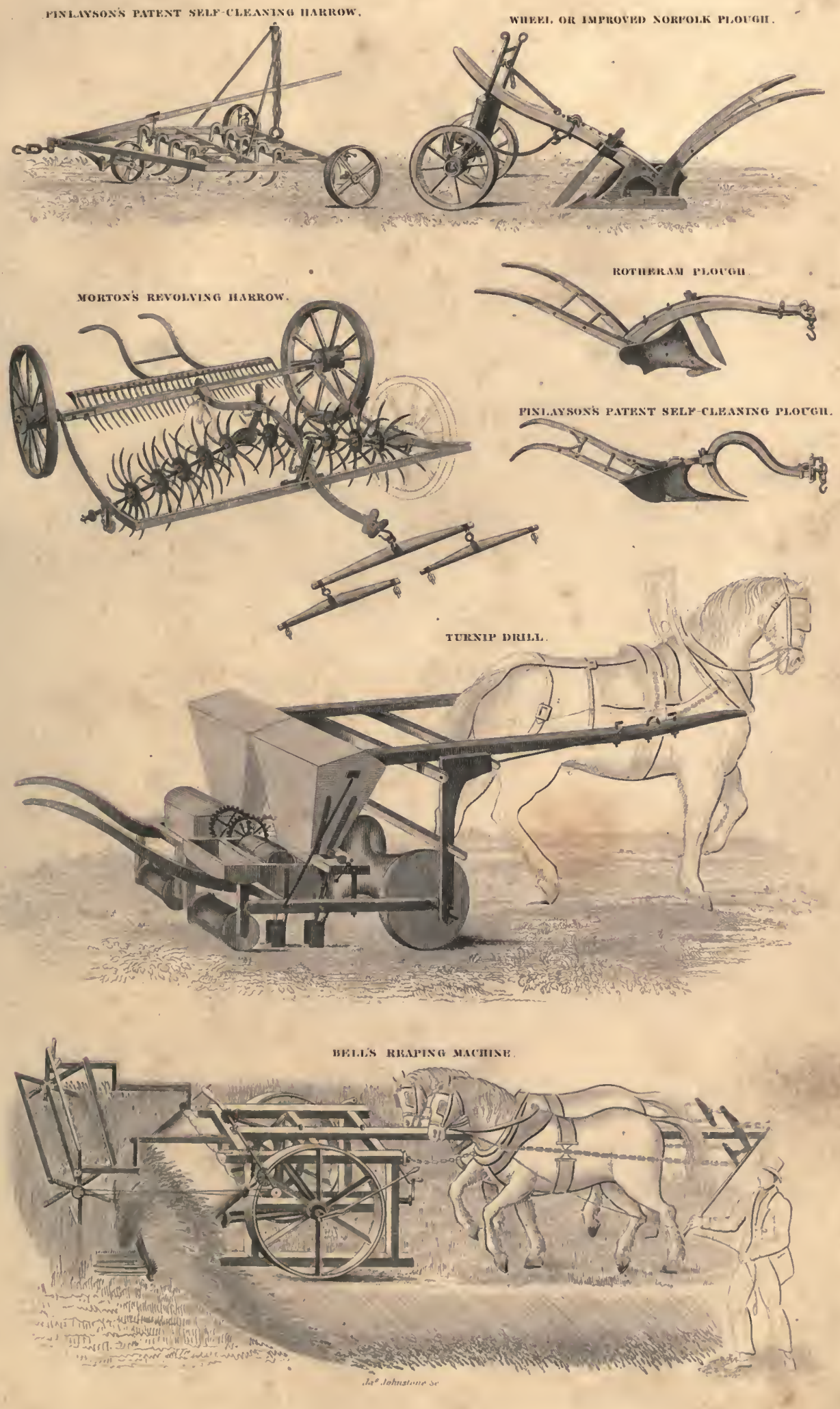


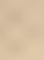

(8)

?

a<smiles>CCC</smiles>

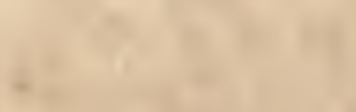
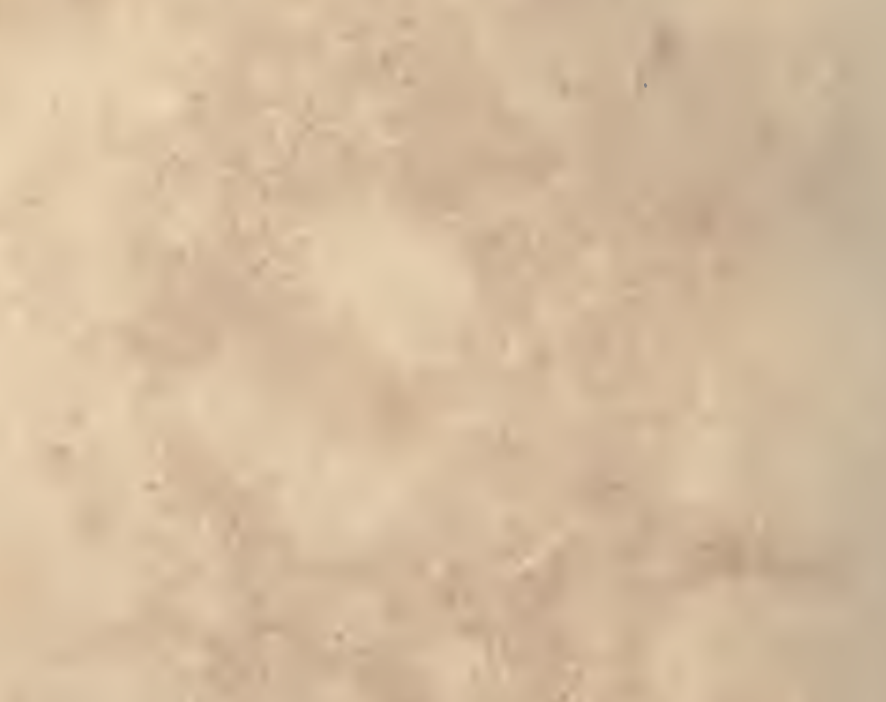

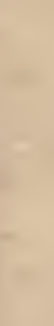

$*$

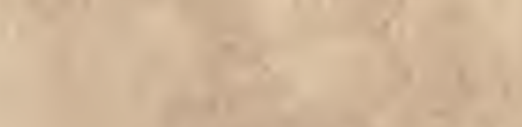

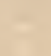

(n)

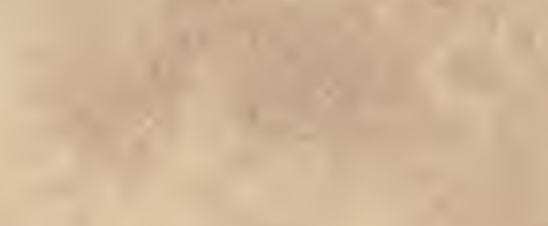

.

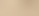

(n)
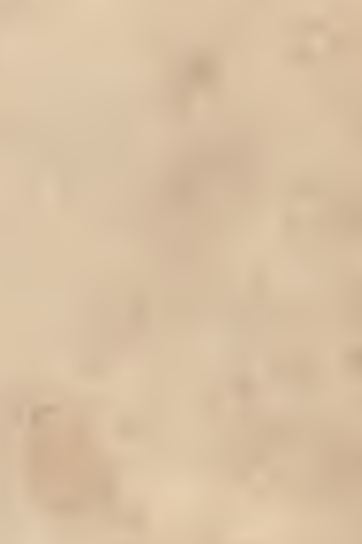

(1)

(2)

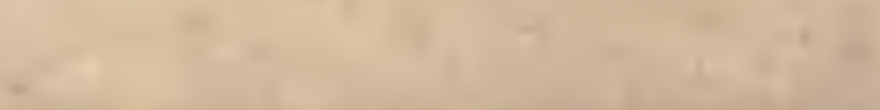

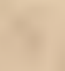




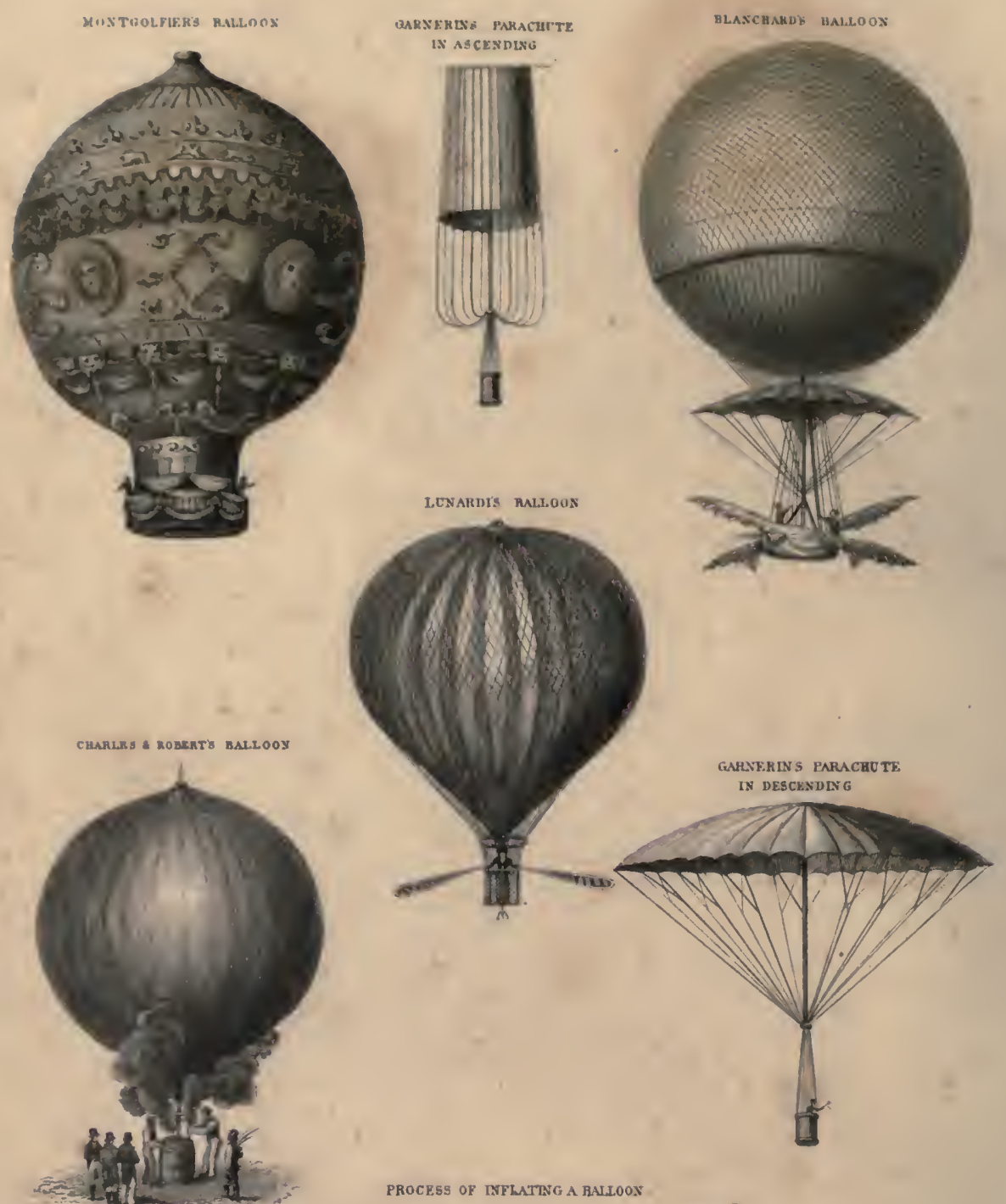

PROCESS OF INFLATTNG A RALLOON

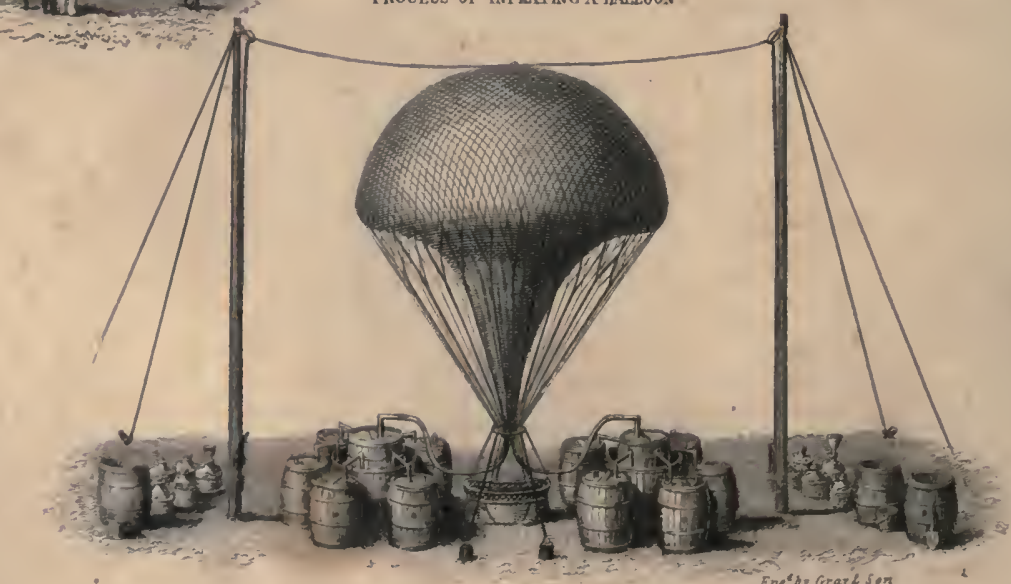

Publisbed by Blackic \& Son Glaskow 

<smiles>CC1CC1</smiles>

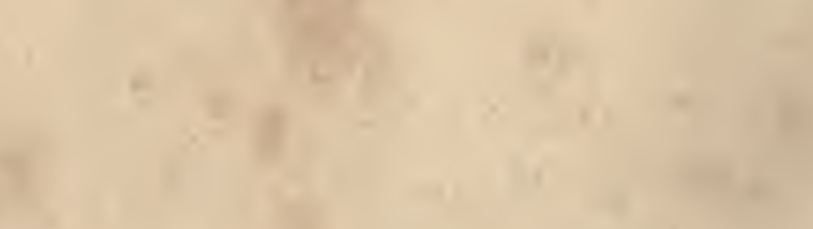

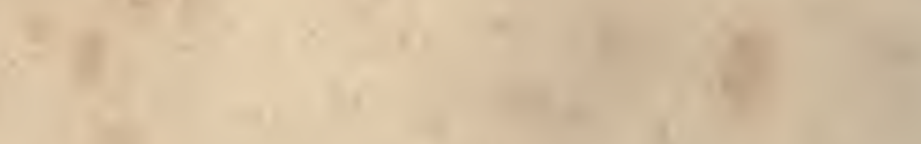

(n)<smiles>C1CCCCC1</smiles><smiles>[C-]C</smiles><smiles>C1CCCCC1</smiles><smiles>C1CCCC1</smiles><smiles>C1=CCC1</smiles><smiles>[CH]C</smiles>
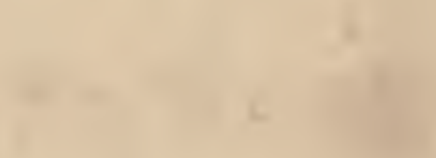

1<smiles>CCCC</smiles>

a

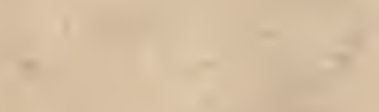

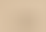

4t $=$<smiles>CCC</smiles><smiles>CCC</smiles> 


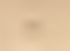

\section{$4+2 x+2=4$}

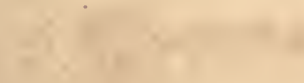

1
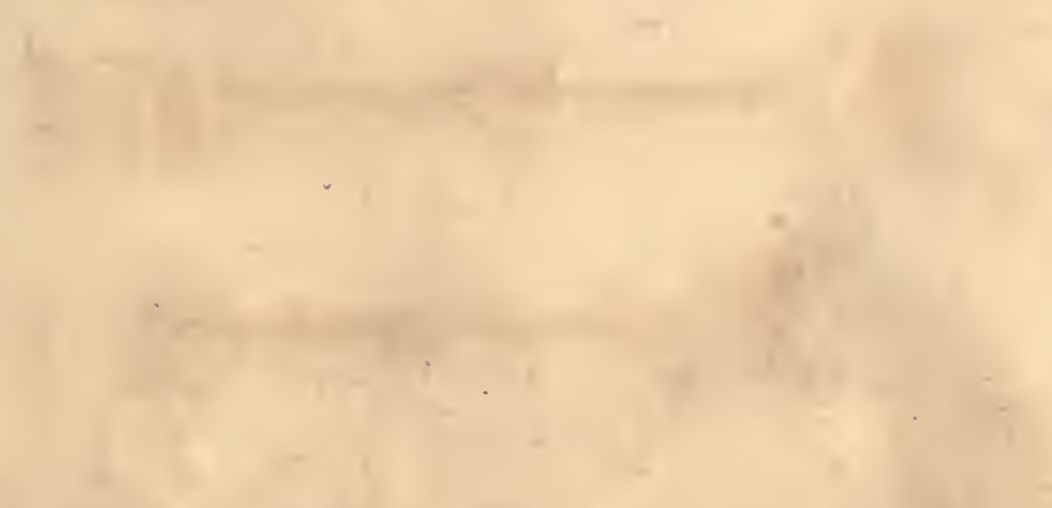

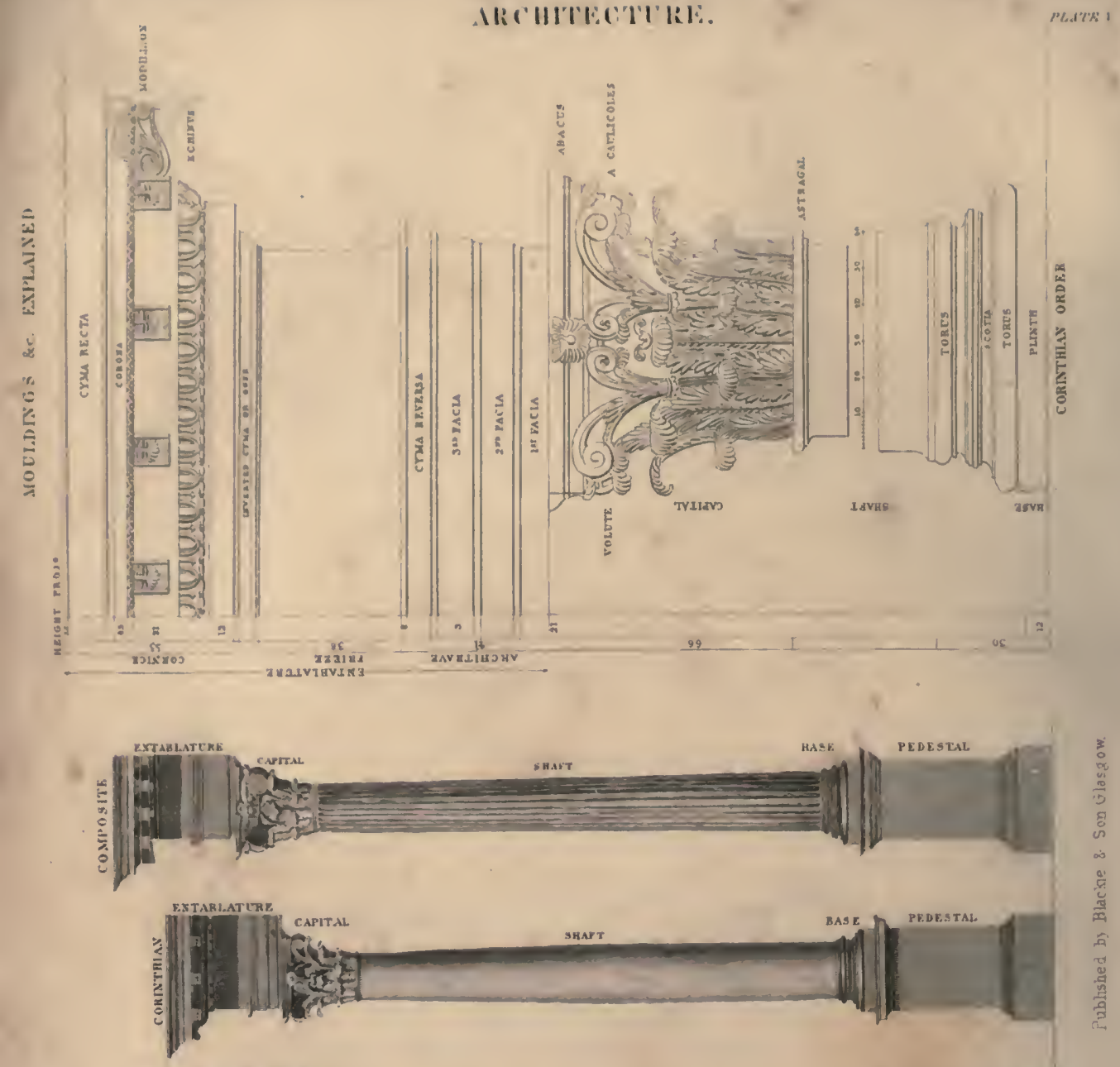

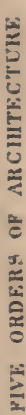
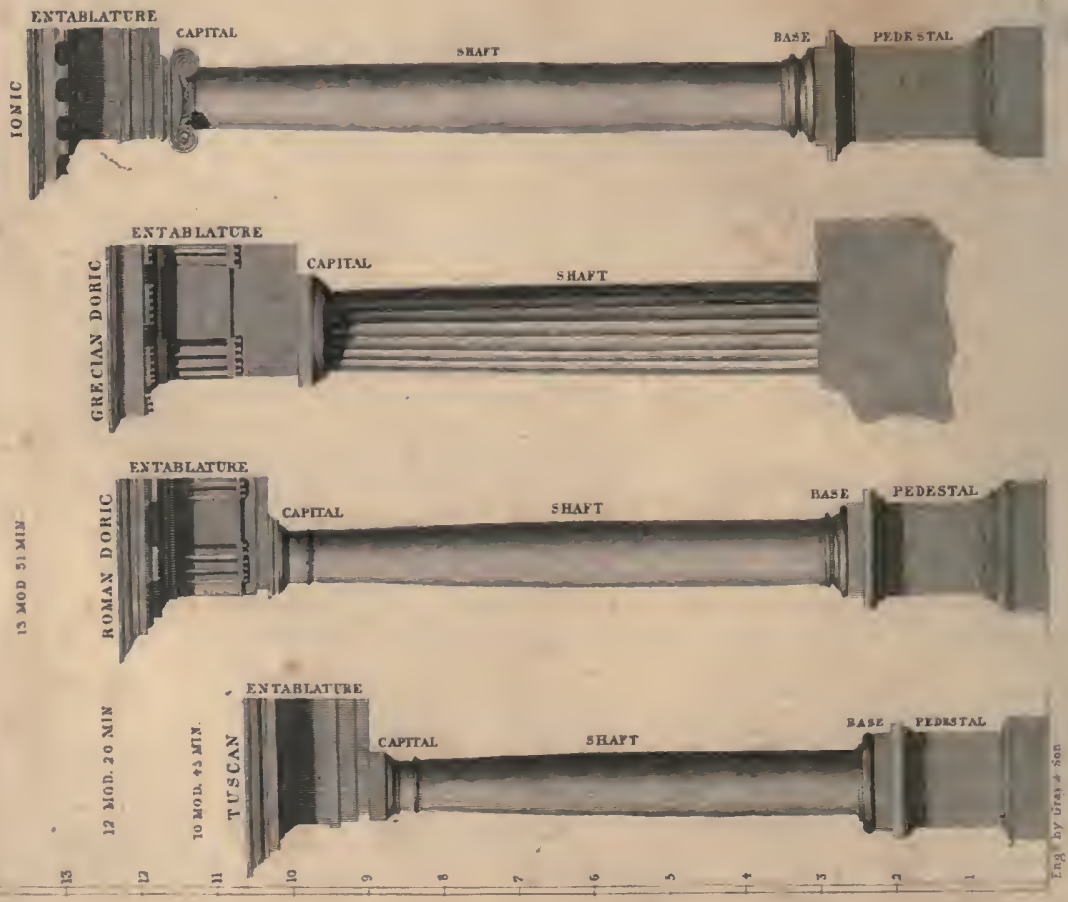

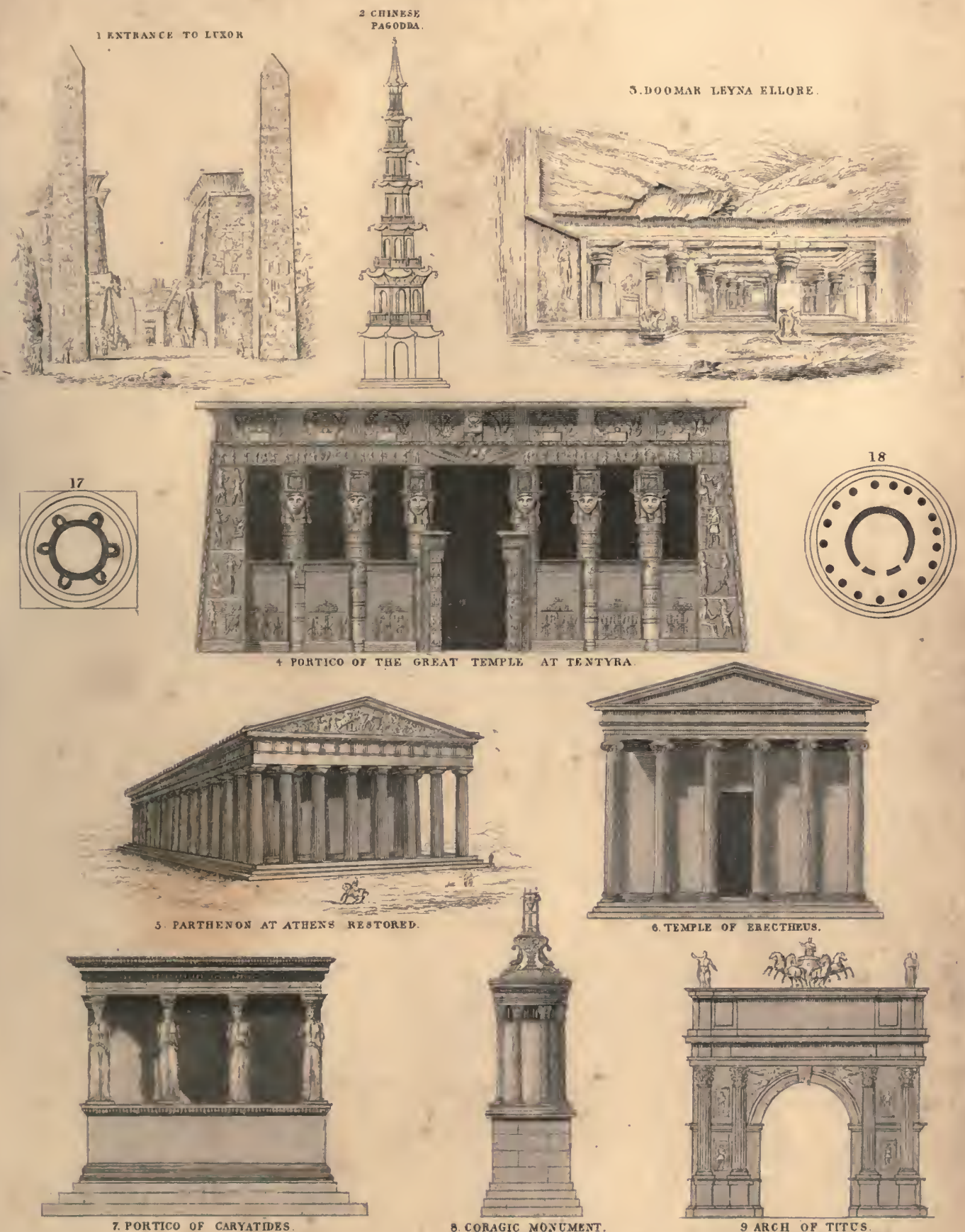

6. TEMPLE OF BRECTHEVS
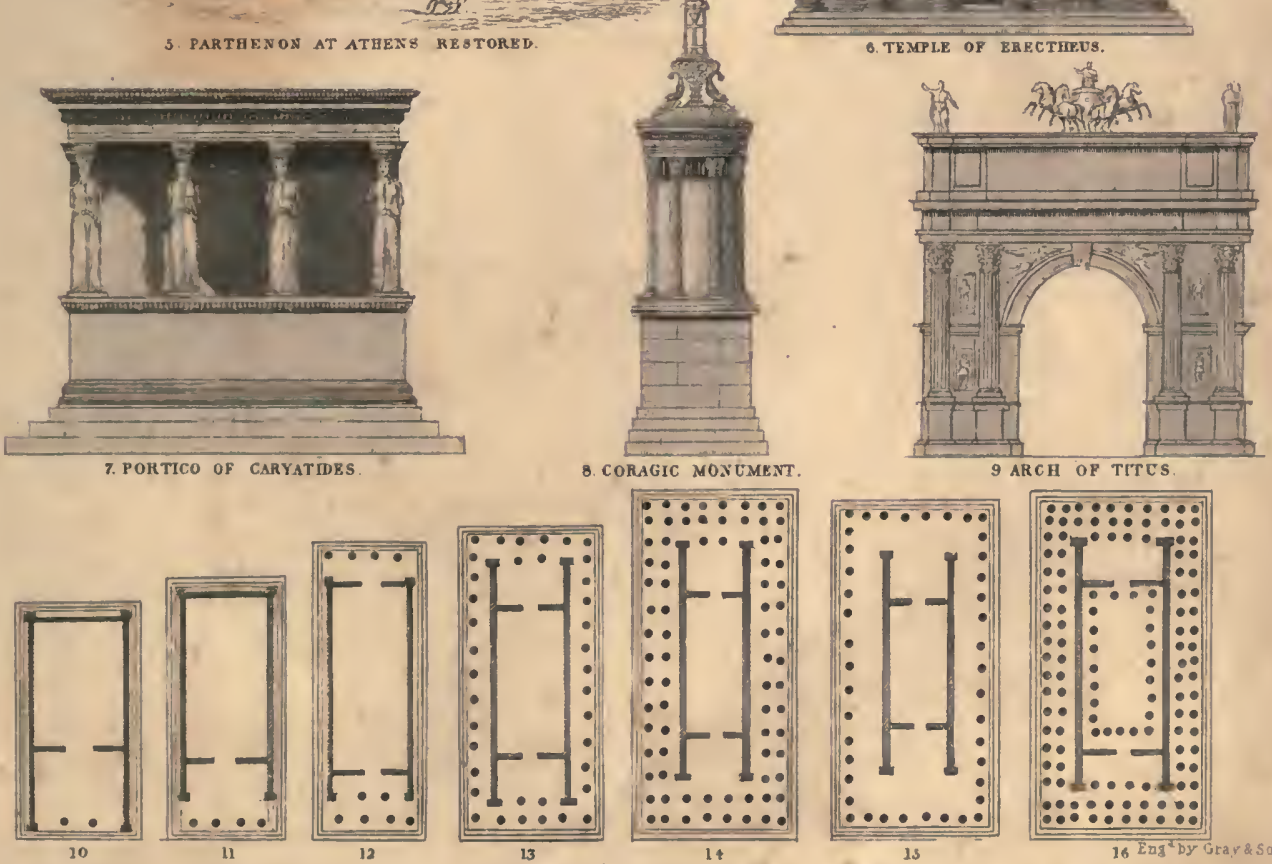

Published by Blacke \& Son Glasgrow. 


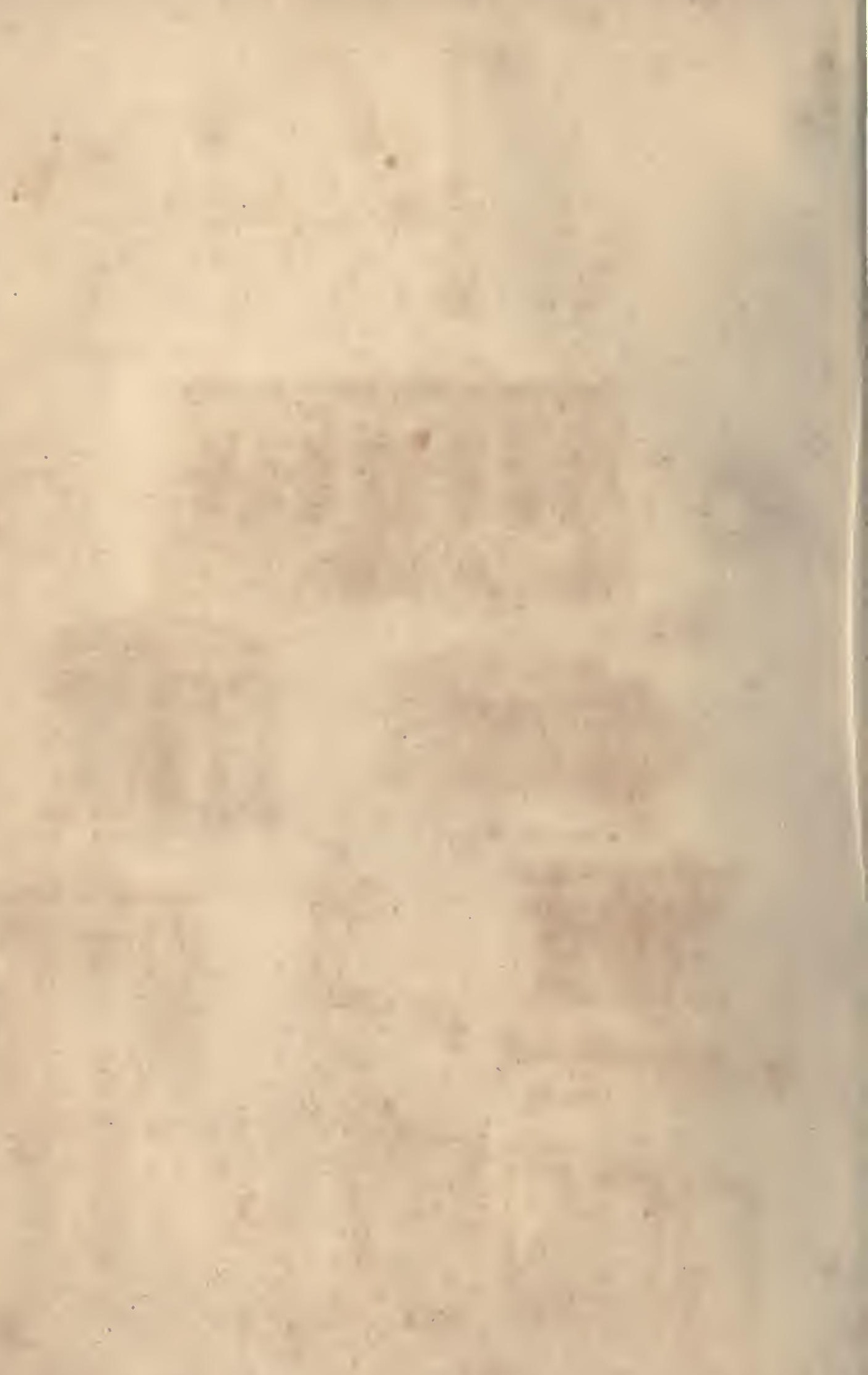


$\sqrt{2}+\frac{1}{2}$

$\cdot$

$-$

$+1$

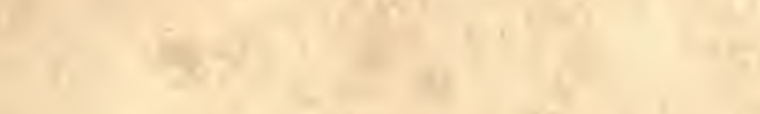

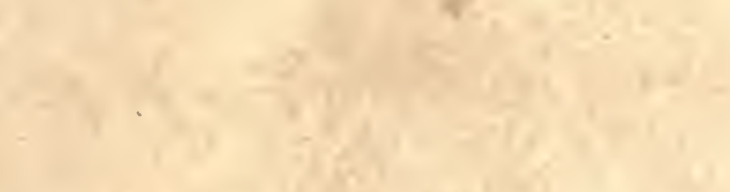

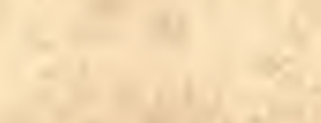

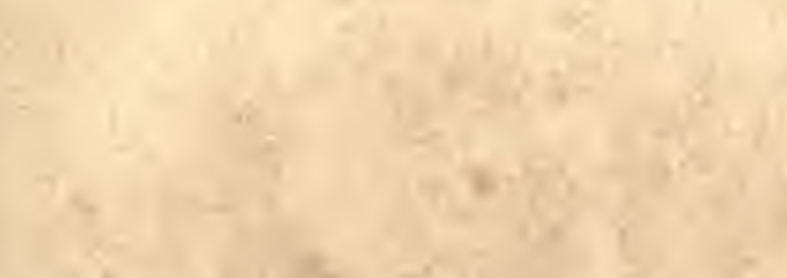

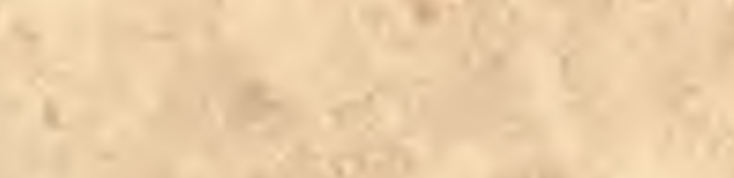$$
4
$$

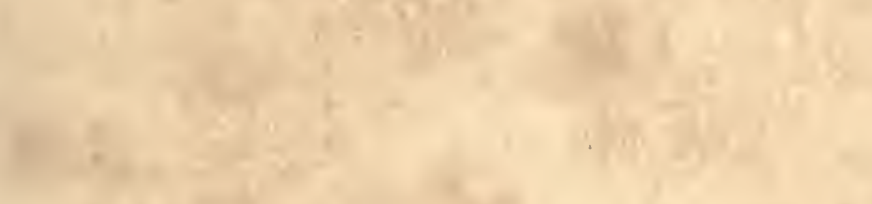

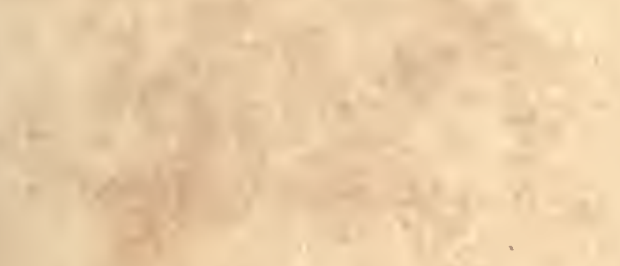

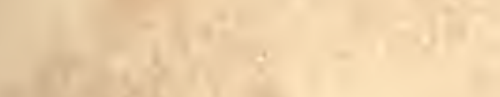

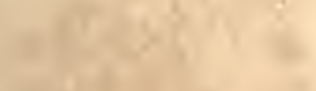$$
3+10
$$

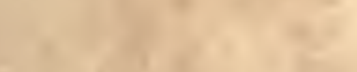

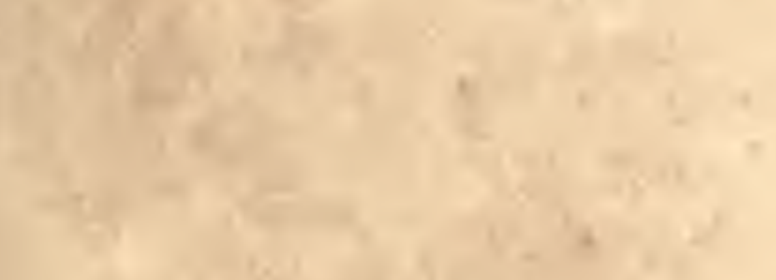

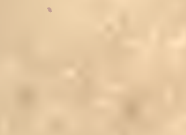

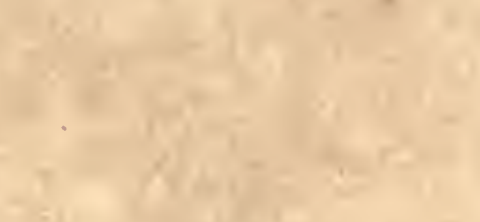$$
\text { the }
$$

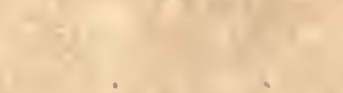

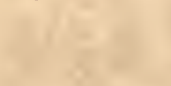

$$
\begin{aligned}
& 1
\end{aligned}
$$



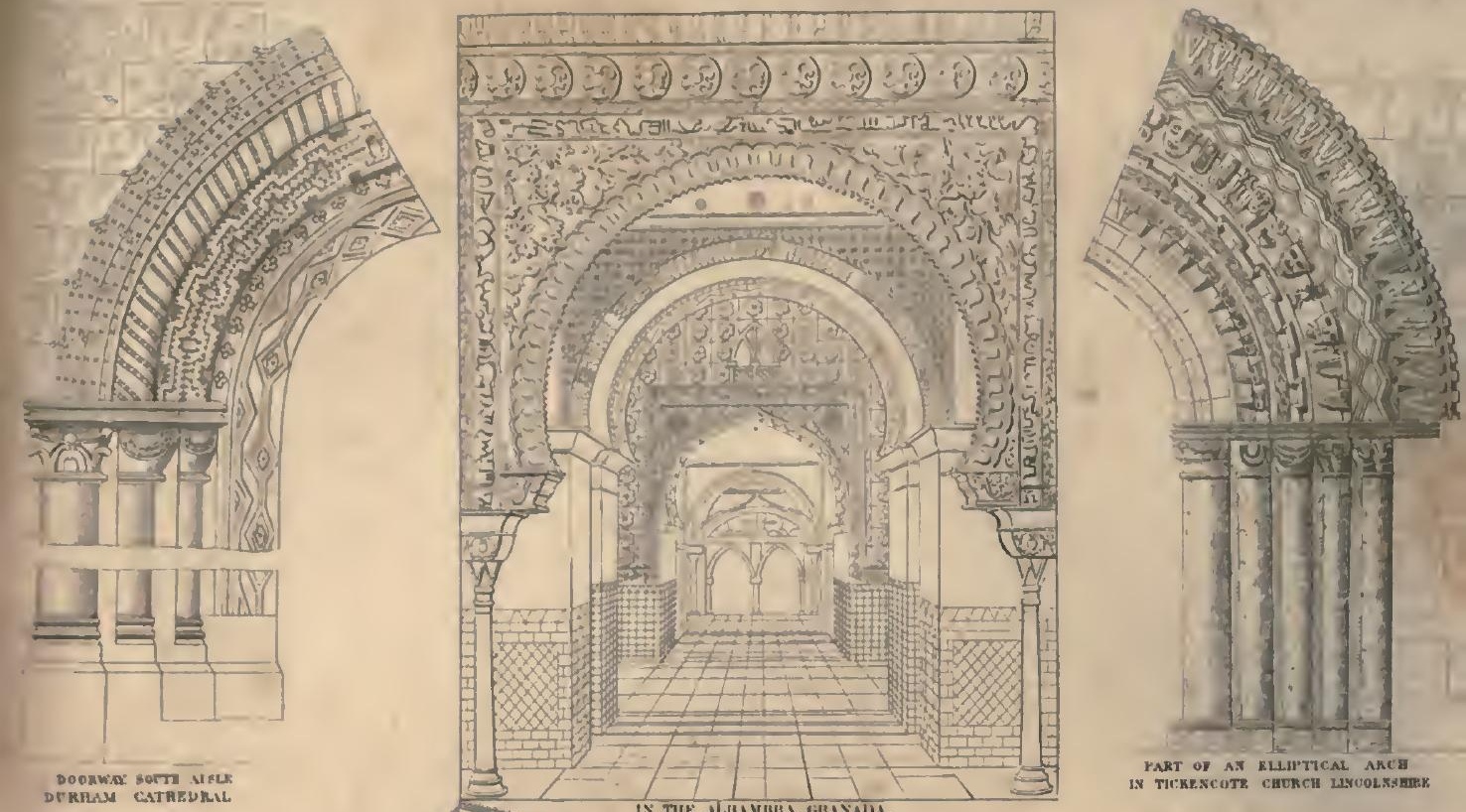

DOOAWA BOT MELE DFRHAM cstaEURLL

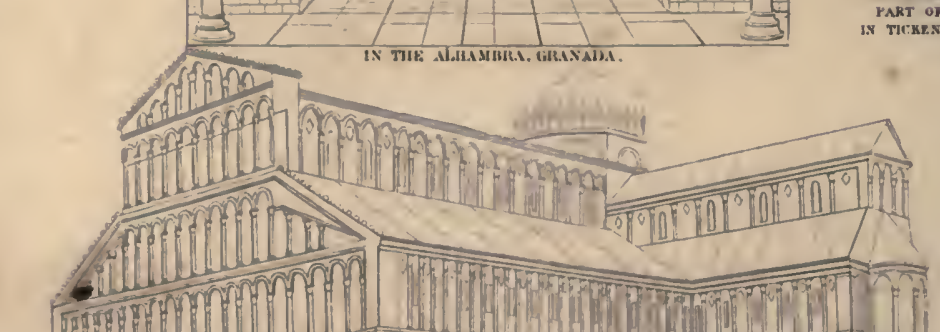

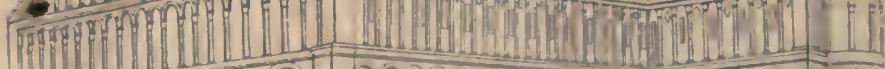

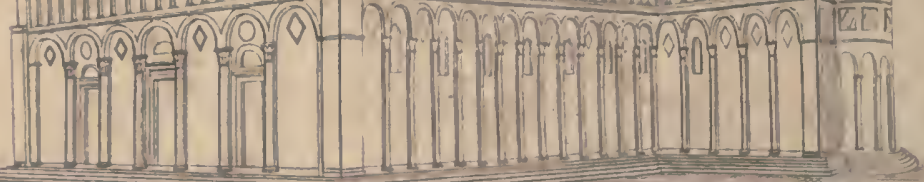

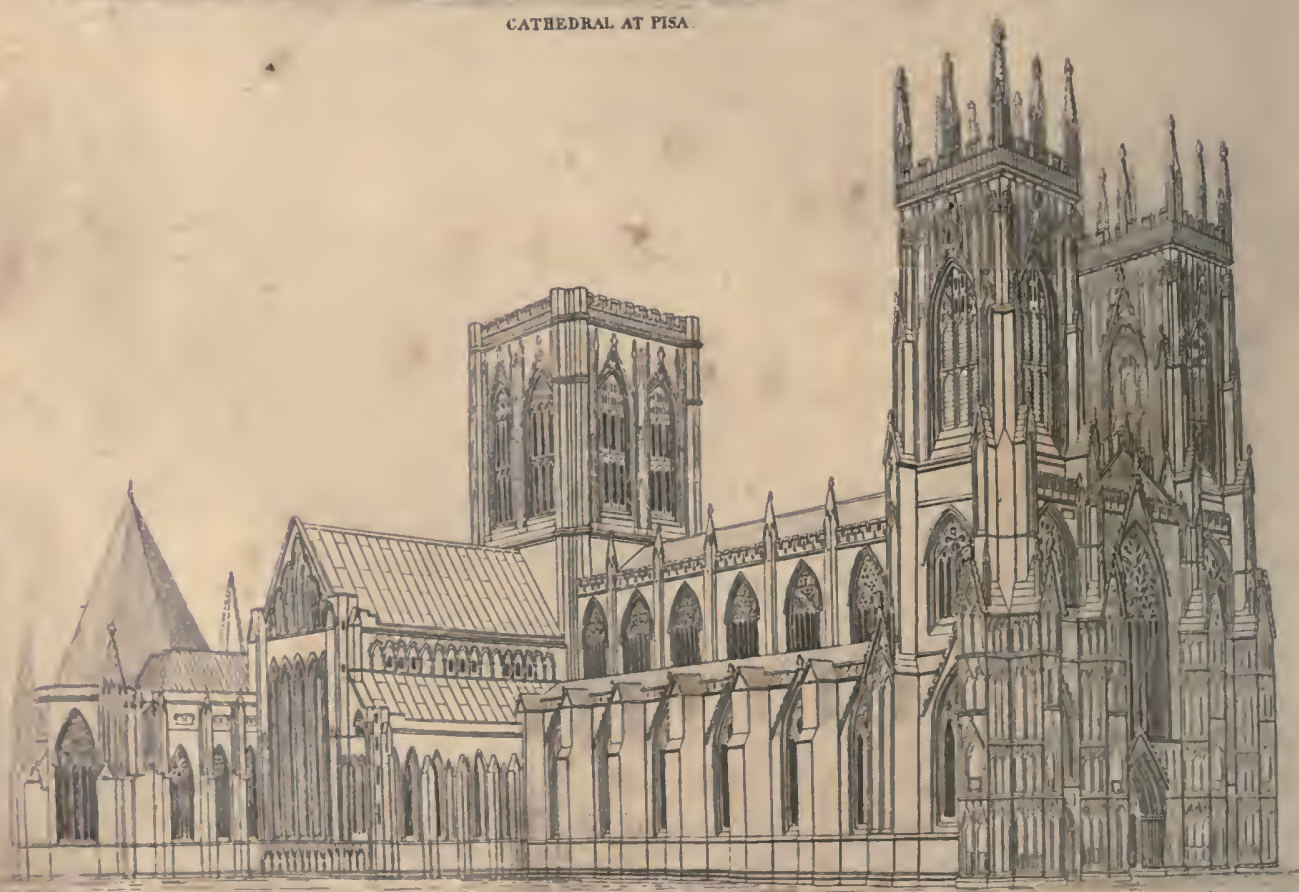


FLEVATIOX \& SECTTOX OF THE COLISECY AT ROAR

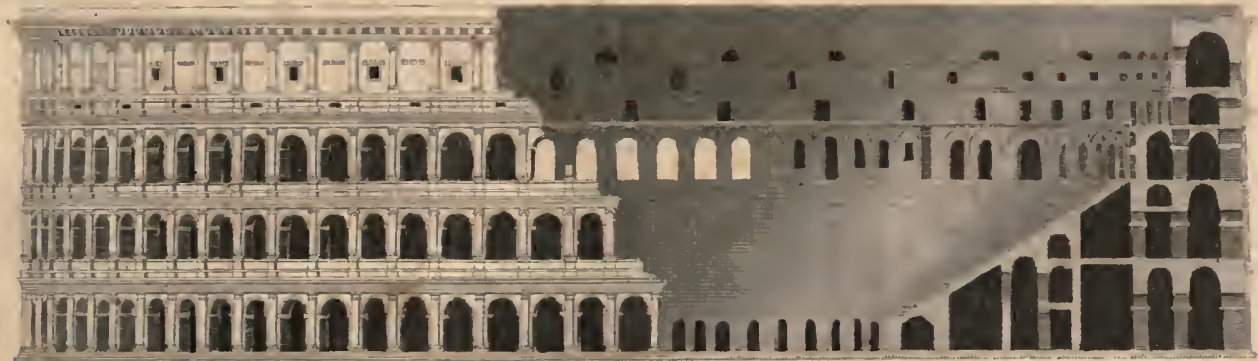
100 2001 Yee:

AOCEDCCT OP PYRGOS NEAR CONSTANTISOPLE

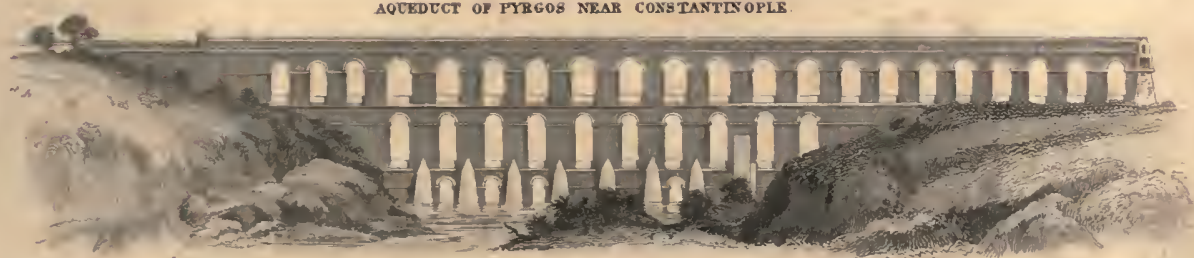

250 Tee

AQERDECT ON PONT DU GARD SEAR NISMES

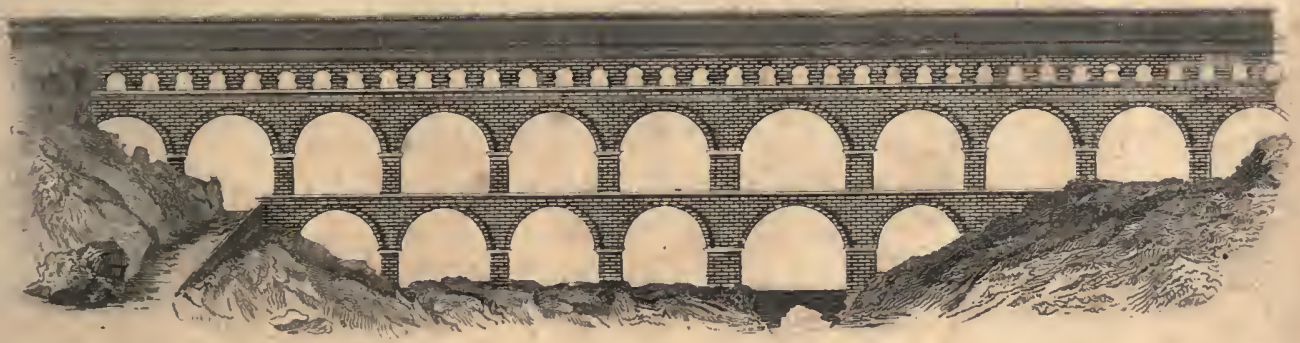

150 Fest
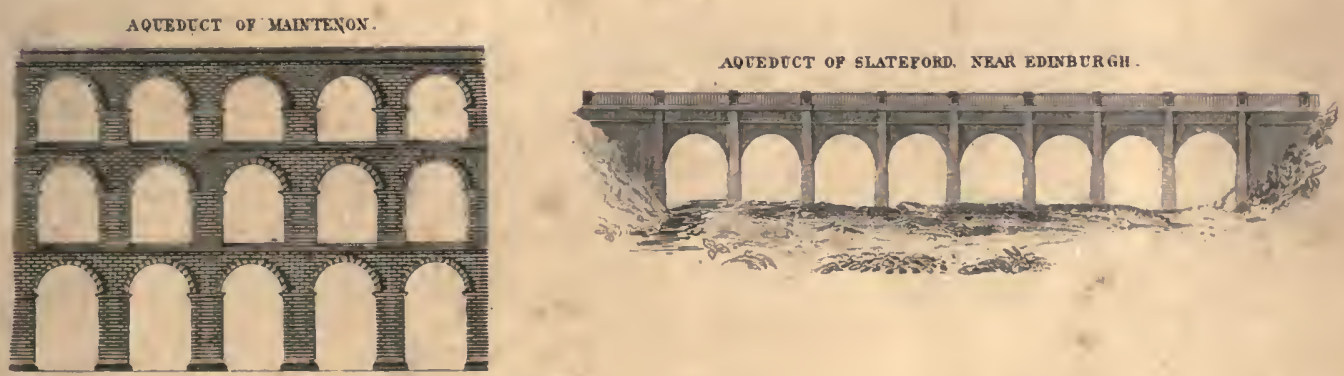

PONT "CYSYLTE AOERDUCT.

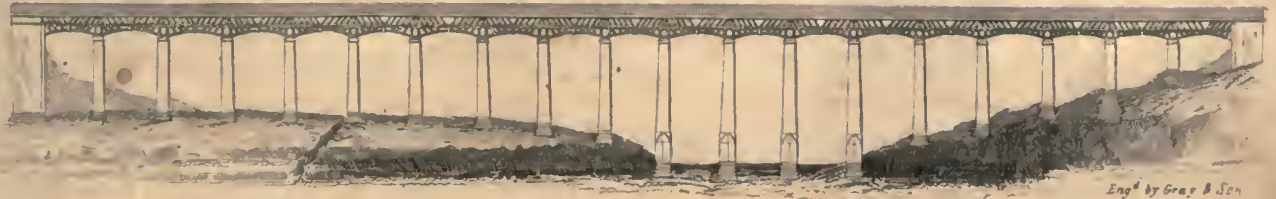




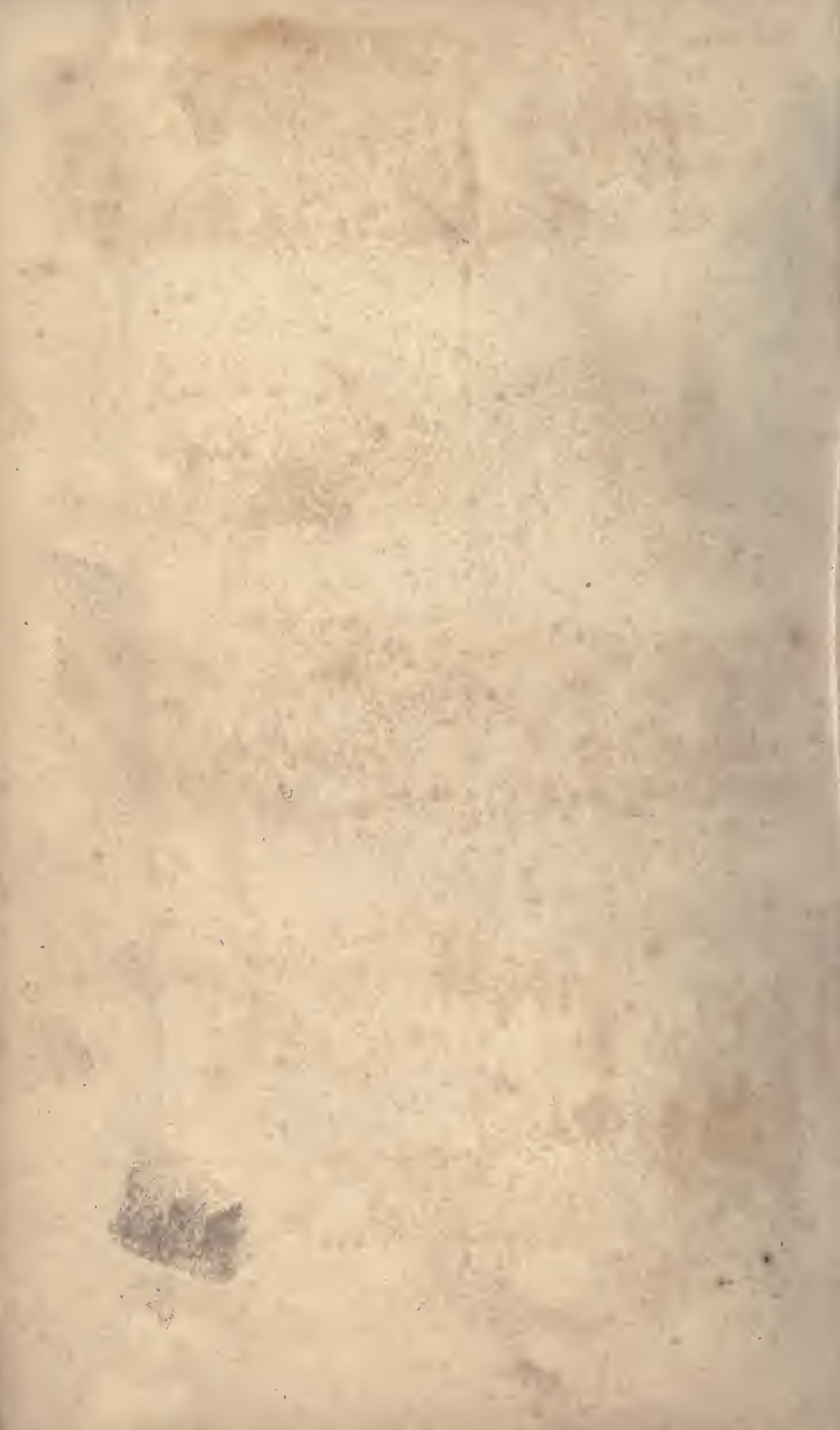





\section{S K E T C H}

OF THE

\section{PROGRESS OF PHYSICAL SCIENCE.}

By THOMAS THOMSON, M. D., F. R. S., L. \& E., \&c. \&c. 



\section{SKETCH}

OF THE

PROGRESS OF PHYSICAL SCIENCE.

THE cradle of the human race was beyond dispute the southern portion of Asia-a delightful climate, where the original inhabitants of the earth first lived and multiplied. Chaldea and India had attained a high degree of civilization long before the Greeks and Romans had begun to emerge from a state of barbarism; but we know comparatively little of the attainments in science whicl these nations had reached. The few facts which have been gleaned since the East India Company has established its dominion over Hindostan, will be stated in the course of this sketch. We are equally ignorant of the progress which mathematical and physical inquiries had made in China-not one of the treatises on Mathematics, Arithmetic, and Astronomy in the Chinese language having been translated into any of the languages of modern Europe. But the resemblance between the Chinese and the ancient Egyptians is so very striking, and so complete, that it is difficult to aroid suspecting. that they had a common origin. If this were so, China, from its contiguity to India and Chaldea, and from the delicious nature of its climate, must have been first furnished with inluabitants. And the Egyptians, if ever they were a colony of Chinese, must have been transplanted into Egypt long before the commencement of history. It was from Egypt that the Greeks drew the first rudiments of their mathematical and physical science; and the scientific acquisitions of that singular people constitute every thing that we know respecting the progress which the ancients lad made in the investigation of nature.

From the genial climate of the early inhabitants of the east, and the nature of the life which they led, it was natural to expect that the magnilicent spectacle of the heavens would speedily attract their attention. We are certain that the Chaldeans made astronomical observations at least as early as the 27tl and 28th years of the era of Nabonasser; that is to say, 719 and 720 years before the commencenent of the Christian era: for Ptolemy makes use of three observations of the eclipses of the moon, which took place during these years, and which he found in their records. Diogenez Laertius inforıns us that the Egyptians had preserved in their annals an account of 373 eclipses of the sun, and 832 of the moon, which had happened before the arrival of Alexander the Great in their country. Now these eclipses required between 1200 and 1300 years to happen. Alexander's visit to Egypt took place in the year 331 before the Christian era. If we add this number to the length of time during which the Egyptians continued to observe the eclipses of the sun and moon, we obtain 1631 years before the commencement of the Christian era for the period at which the Egyptians began to record their observations. This period is rather more than a century after the death of Moses, and is about twenty-four years before the institution of the Olympic games; constituting but a small part of the 48,863 years during which they boasted that they had been engaged in making astronomical observations. But this was obviously a fable, invented for the purpose of raising themselves in the opinion of the Macedonian conqueror.

What progress the Chaldeans and Egyptians had made in astronomy, it is hard to say. They certainly had become acquainted with the planets, but whether the Egyptians had discovered, as Macrobius assures us, that Mercury and Venus revolve round the sun, is not so clear. Their notions respecting the length of the solar year, and the mean length of a lunation, must have been a near approximation to the trutl. This is evident from the famous Claldean period called Saros $y$ It consisted of 223 lunar montlis, at the end of which the sun and moon were in the same situation with respect to each otlıer, as when the period began. This period includes a certain number of eclipses of each luminary, 
which are repeated every saros in the same oriles.

The Chaldeans appear to lave divided the day into twelve hours, and to liave constructed sumdials for pointing out tle hour. The sun-dial of Ahaz is mentioned in the Old Testanent, on the occasion of the recovery of Hezekiah; but nothing is said about its construction. Undonbtedly, liowever, such sun-dials would require a certiin knowledge of gnomonics, which therefore the Chaldeans must liave possessed.

That the ligyptians liad made sone progress in unatliematics admits of no doubt; as the Greeks inform us that they derived their first knowledge of that branch of science from the Egyptian priests. But that the inathematical knowledge of that people could not have been very extensire, is evident from the ecstasy into which l'ythagoras was thrown, when he discovered tlat the squire of the hypothenuse of a right angled triangle is equal to the square of the two sides. For ignorance of this very elementary, but important proposition, necessarily implies very little knowledge even of the most elementary parts of mathematics.

It was in Greece that pure mathematics first made decided progress. The works of three Greek mathematicians still remain, from which we lave obtained information of all or almost all the mathematical knowledge attained by the Greeks. These are Eurlid, Apollonius, and Arclimedes.

Euclid lived in Alexandria during the reign of the first Ptolemy. Nothing whatever is known respecting the place of his nativity; though it is certain that he lived in Greece, and that he died in Egypt, after the foundation of the celebrated Alexandrian school. He collected all the elementary facts known in mathematics before his time, and arranged them in such an admirable order-beginning with a fow simple axioms, and deducing from them his demonstrations, every subsequent demonstration depending on, and rigidly deduced from those that inmediately precede it-that no subsequent writer has been able to produce any thing superior or even equal. His Elements still continue to be taught in our schools, and could not be dispensed with, unless we were to give up somewhat of that rigour which has been always so muclı admired in the Greek geometricians. Perhaps, however, we carry this admiration a little too far. The geometrical axioms might be soinewhat enlarged, without drawing too much upon the faith of beginners. And were that method followed, considerable progress might be made in mathematics without encountering some of those difficult demonstrations that are apt to damp the ardour of beginners.
The Elements of Euclid cousist of thirteen books. In the first four he treats of the properties of lines, parallel lines, angles, triangles, and circles. 'The fifth and sixtl treat of proportion or ratios. The seventl, eighth, ninth, and tenth treat of numbers. The eleventh aud twelfti treat of solids; and the thirteenth of solids; also of certain preliminary propositions about cutting lines in extreme and mean ratio. It is the first four books of Euclid chiefly that are studied by modern geometricians. The rest have been, in a great mensure, superseded by more modern improvements.

Apollonius was born at Perga in Pampliylia, about the middle of the second century before the Cluristian era. Like Euclid, he repaired to Alexandria, and acquired his mathematical knowledge from the successors of that geonetrician. The writings of Apollonius wero numerous and profound; but it is upon his Treatise on the Conic Sections, in eight books, that his celebrity as a, mathematician clicfly depends.

The Conic Sections, which, after the circle, are the most important of all curves, were discovered by the mathematicians of the Platonic school; though who the discoverer was is not known. A considerable number of the properties of these curves were gradually developed by the Greek geometricians. And the first four books of Apollonius are a collection of overy thing known respecting these curves before his time. The last four books contain his own discoveries. In the fifth book he treats of the greatest and smallest lines which can be drawn from each point of their circunference, and many other intricate questions, which required the greatest sagacity and the most unremitting attention to investigate. The sixth book is not very important nor difficult; but the seventl contains many very important problems, and points out the singular analogy tliat exists between the properties of the various conic sections. The eighth book has not come down to us. The fifth, sixth, and seventh books were discovered by Borelli, in Arabic, in the library of the grand duke of Tuscany. He got then translated, and published his translation, with notes and illustrations, in the year 1661. Dr Halley published an edition of Apollonius in 1710, and bas supplied the eighth book from the account given by $\mathrm{Pap}$ pus of the nature of its contents.

Archimedes was, beyond dispute, the greatest mathenatician that antiquity produced. He was born in Sicily about the year 287 before the Cliristian era, and is said to have been a relation of Hiero, king of Syracuse. So ardent a culivivator was he of the nutlienatics, that he was 
accustomed to spend whole days in the deepest investigations, and was wont to neglect his food, and forget his ordinary meals, till his attention was called to them by the care of his domestics. His studies were particularly directed to the measurement of curvilinear spaces; and he invented a most ingeuious method of performing such measurements, well known by the name of the Method of Exhanstions.

When it is required to measure the space bounded by curve lines, the length of a curve, or the solid bounded by curve surfaces, the inrestigation does not fall within the range of elementary geometry. Rectilinear figures are compared on the principle of superposition; but this principle cannot be applied to curvilinear figures. It occurred to Archimedes, that by inscribing a rectilinear figure within, and another without the figures, two limite wonld be obtained, the one greater and the other smaller than the area required. It was evident that, by increasing the number, and diminisling the sides of these figures, these two limits were made continually to approach each other. Thus they came nearer and nearer to the curve area which was intermediate between them. He observed, by thus increasing the number of sides for a great number of times successively, that he approached a certain assignable rectilinear area, and could come nearer to it than any difference how small soever. It was evident that this rectilinear area was the real size of the curvilinear area to be measured. It was in this way that he found that two-thirds the rectangle under the abscissa and ordinate of a parabola, is equal to the area contained by the abscissa and ordinate, and that part of the circumference of the parabola lying between them. In the same way he obtained an approximate measure of the area of the circle, demonstrating that if the radius be unity, the circumference is less than $3 \frac{10}{10}$, and greater than $3 \frac{1}{1} \frac{0}{1}^{\circ}$ His two books on the sphere and cylinder were conducted by a similar method of reasoning. He measures the surface and solidity of these bodies, and terminates his treatise by demonstrating that the sphere (both in surface and solidity) is two-thirds of the circumscribed cylinder.

In the same spirit lis Treatise on Conoids and Spheroids was conducted. These names he gave to solids formed by the revolutions of the conic sections round their axis. We, pass over his researches on the spiral of Archimedes, as it is usually called, though in reality discovered by.Conon, one of his friends; but must notice the 'Ireatise entitled Psammiles, or Arenarius. Some persons had affirmed that no number, howcrer grcat, was sufficient to express the number of grains of sand situated on the sea-slore. This induced Archimedes to write lis treatise, in which he demonstrates that the fiftietl term of a decuplo increasing progression is more than suf. ficient to express all the grains of sand contained in a sphere, having for its diameter the distance between the eartl and sun, and totally filled with grains of sand. The treatise is short; but abstruse in consequence of the imperfect method of expressing numbers employed by the Greeks. Were our figures substituted for the Greek letters, the reasoning would be sufficiently simple and clear.

Archimedes did not confine himself to pure mathematics; he turned his attention likewise to mechanics, and may, in some measure, be con. sidered as the founder of that important brancl of physical science. He first laid down the true principles of statics and hydrostatics. Tho former he treats in his work entitled Isorropica or De Equiponderantibus. His statics are founded on the ingenious idea of the centre of gravity, which he first concoived, and which has been so advantageously employed by modern writers on statics. By means of this principle, and a few simple axioms, he demonstrates the reciprocity of the weight, and the distance in the lever and in balances, with unequal arms. He determined the centre of gravity of various figures, particllarly of the parabola, with great ingenuity.

His discoveries in hydrostatics were the consequence of a query put to him by king Hiero. This monarch had given a certain quantity of gold to a jeweller to fabricate a crown, and lie suspected that the artist had purloined a portion of the gold, and substituled silver in its place. Archimedes was requested to point out a method of determining how much gold had been purloined, and how much silver substituted. The method, it is said, occurred to him all at once, while in the bath, and he was so transported with joy, that he ran naked through the streets of

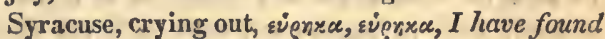
$i t$, Ihave found it. The discovery with which he was deservedly so delighted was this, "Every body plunged into a fluid loses as much of its weight as is equal to the weight of a quantity of the fluid equal in bulk to the body plunged in." This discovery furnished him with the method of determining the specific gravity of pure gold and pure silzer. These being known, he liad only to take the specific gravity of the crown, which (supposing no alteration in volume when the two inetals are melted together) would enable him to discover how much gold and how much silver it contailled.

This first principle being known, Archimedes deduced from it various other well-known liydro- 
statical principles, which he consigned in the first book of his treatise de Insidentibus in Fluido. The second book of that treatise is occupied with various difficult questions respecting the situation and stability of certain bodies immersed in a Suicl.

The ancients ascribe to him the invention of forty remarkable inechanical contrivances; but nothing more than some obscure notices of two or three of them have come down to us. His spliere, a machine by which he represented the movements of the stars and planets, is one of the most celebrated. It has been noticed by grave ,hilosophers, and sung by poets, as may be seen in the following epigran of Claudian :-

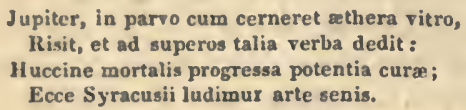

Archimedes wrote a description of this machine, under the name of Splæropæia; but it is lost, and with it every thing respecting the nature of the sphere has perished.

The burning mirrors, by which he is snid to have set fire to the Roman vessels in the harbour of Syracuse, were long considered as fabulous. But Buffon showed how, by placing a number of sinall mirrors so that every one of them should reflect the imnge of the sun to the same point, heat enough might be produced to kindle rood at the distance of 140 feet.

The protracted defence of Syracuse against the Romans, cliefly in consequence of the wonderful mechanical inventions of Arclimedes, is too well known to be enlarged on here.

If we except the discoveries of Archimedes in statics and liydrostatics, hardly any other brancls of physical science was much cultivated by the ancients. They had made, indeed, considerable progress in the knowledge of acoustics, so far as music is concerned. In optics they can scarcely be said to have made any progress of consequence; and, in astronomy, very little till the lime of Hipparchus, who may be considered as, in some measure, the founder of that sublime science.

After these preliminary remarks on the progress of physical science among the ancients, we shall proceed to take a brief view of the advances which have been made in it since the revival of letters, and to describe the present state of the various branches into which it has been divided, as far at least as is consistent with the very limited length to which our observations can be permitted to extend.

There are only two inethods by which the physiral sciences can be advanced. These are, 1. Observation and experiment; 2. The application of mathematical reasoning to deduce new truths from facts alrearly established. We slanll take a brief view of these two instruments of investigation in the first place; beginning with mathematics; because they were first employed.

\section{OF MATHEMATICS.}

The object of mathematics is the measurement or comparison of quantity. Now, there are two kinds of quantity, nanely, number and surfacc. That branch of mathematics which treats of numbers is called arithmetic, that which treats of surfaces, or rather of space, is called geometry. There is a third branch of mathematics, which treats of quantity in a general way, and which, therefore, applies equally to arithmetic and geometry. To this brancl, the name of algctra lias been given.

\section{ARITHMETIC.}

The ancients employed the letters of the alplanbet to represent numbers. This method seems to liave originated with the Egyptians or Phenicians, or, at any rate, the Greek mode of expressing numbers was obviously borrowed from the Hebrew.

The decimal mode of numeration las been adopted by almost all nations, evidently because man has ten fingers, and because men were in the habit at first of reckoning on the fingers, and after coming to an end, they began again. If the number of the fingers had been twelve instend of ten, the mode of numeration would certainly have been duodecimal instead of decimal -and this mode would have had its conveniences, which the decimal node wants.

The Hebrew alphabet has twenty-two letters. The first nine of these letters denoted the nine digits; thus, $N, 1 ; \beth, 2 ; 2,3 ; 7,4 ; \pi, 5 ; 1,6$; i, $7 ; \pi, 8 ; 0,9:$ the next nine letters denote the nine tens; thus,, $10 ; \supset, 20 ; \zeta, 30 ; \mathrm{D}, 40$; J, $50 ; \delta, 60 ; Y, 70 ; \exists, 80 ; \dddot{3}, 90$. The rest of the alphabet consisted only of four letters; but there are five of the letters that have a different form when at the end of a word. These are, $\supset, D$, $\jmath, \Xi, \rightrightarrows$, which are then written $T, \square, \eta, \ni, \ngtr$. By means of the last four letters, and these five final letters, they expressed the nine hundreds : thus, $P, 100 ; 7,200 ; ש, 300 ; \pi, 400 ; 7,500 ; \nabla$, $600 ;\}, 700 ; 7,800 ; i ;, 900$.

The Hebrews wrote from right to left, contrary to our method. Hence, when two numbers a re placed together, that on the right hand stands for tens, and that on the left for units. Thus, 2 , is 12 ; ק is 105, and so on. 
The Arabians likewise represent numbers by the letters of the alphabet, precisely as the Hebrews: the first nine letters representing the nine digits; the second nine, the nine tens; and the third nine, the nine hundreds. The twentyeighth letter of the Arabian alphabet represents 1000 .

The Greeks obviously borrowed their mode of expressing numbers from the Hebrews or Phenicians. The first five letters of the Greek alphabet represent the first five digits. As the Greeks have no letter corresponding to the $\mathrm{He}$ brew 7 , which denotes six, they introduced for - that purpose the mark $f$ or 5 , which they called episenum. The next three letters, $\zeta, n, \theta$, represent 7, 8, 9, corresponding with the Hebrew characters $i, \pi, \vartheta$, which stand for the same numbers. The next eight letters of the alphabet correspond with those of the Hebrew, and represent the numbers, $10,20,30,40,50,60,70,80$. There being no letter in the Greek alphabet corresponding with the Hebrew $\vec{y}$, which stands for 90 , the Greeks introduced for that purpose the character $\xi_{l}$, or 4 , or $S$, to which they gave the name of koppa, probably from the Hebrew letter kopl. The last eight letters of the Greek alphabet, beginning witl $\varrho$, denote $100,200,300$, $400,500,600,700,800$. To staud for 900 , they invented the mark $¥$, which they called sanpi. Thousands were denoted by the letters of the alphabet with an accent under them. Thus, $\alpha$ was $1 ; \propto, 1000 ; \gamma, 3$, and $\gamma 3000$, and so on.

The most defective mode of notation is that of the Romans, who employed the following letters: I for $1 ; \mathrm{V}$ for $5 ; \mathrm{X}$ for $10 ; \mathrm{L}$ for $50 ; \mathrm{D}$ for 500 ; and $\mathrm{MI}$ for 1000 . By means of these symbols, they contrived to represent moderate numbers. But such an imperfect method was incompatible with almost any progress in the most common rules of arithmetic. Accordingly, the Romans produced no mathematicians, nor any person skilled in the science of numbers.

The mode of expressing all numbers by the ten symbols, $1,2,3,4,5,6,7,8,9,0$, with which every body is familiar, seems to have originated in India. In that country it has been used from time inmemorial. Not the smallest proof remains that they erer made use of the letters of the alphabet for that purpose. The Arabians call the decimal scale of arithmetic, Hindosi, or Indian arithmetic, clearly pointing out the source from which their mode of notation was derived. Whether the Indians were the original contrivers of this astonishing improvement, or whether they borrowed it from some other nation, we have no means of determining. . The Chinese, it is said, possess treatises on arithmetic and geometry; but as no translation, or even abstract, of the contents of any such work has been published in Europe, we are ignorant how far their knowledge of these subjects extend. Had they been acquainted witl the Indian mode of notation, it is hardly possible, considering the numerous mercantile transactions which have taken place between them and Europeans, that it should have entirely escaped our knowledge.

The Arabians became acquainted with the Indian notation when they began to prosecuto science under the caliphs, and they had libernlity enough to be sensible of its superiority, and to adopt it. Along with the Mahomedan religion, it made its way into Spain; which, during the dark ages, was the most enlightened country in Europe, and to which all those resorted from every country, who wished to be initiated in the rudiments of science.

About the beginning of the tenth century, the monastery of Fleuri, of the order of St Benedict, had for its abbot, Abbon, who was a zealous cultivator of the sciences, particularly of those connected with mathematics. He rendered his monastery a celebrated school of knowledgo and of piety; and all the monks of St Benedict, who gave proofs of abilities, were sent thither to receive instruction. Among these was Gerbert (afterwards pope Sylvester II.), a native of Auvergne. After having acquired all the knowledge that Fleuri could furnish, he obtained leave to repair to Spain, where two celebrated schools at that time existed at Cordova and Grenada, which belonged to the Mahomedan conquerers of that country. These schools were much frequented botll by Mahomedans and Christians. Gerbert made such progress in mathematical knowledge, that he soon surpassed his masters. Arithmetic, music, geometry, and astronony, had occupied his attention; and, on his return to France, he communicated to his countrymen the knowledge which he had thus acquired. But the greatest boon which he conferred on Europe was the introduction of the Indian numbers, which he found in common use among the scientific Mahomedans in Spain. The date of this introduction must be fixed between the years 970 and 980.

With the knowledge of the Indian figures, the rules of arithmetic became also plain, and came to be familiarly understood. It is obvious from the translation of the Lilawati, by $D_{r}$ Taylor, a treatise on Arithmetic and Geometry, by Bhascora Acharya, who was born in the year 1114 , that in his time, the four common rules of arithmetic, the rule of three, the management of vulgar fractions, the method of extracting the square and cube roots, and most of the various rules at present met with in our books of arithmetic, were 'known in India. No doubt they were also taught at Cordova and Grenada, and 
brought by Gerbert into France. From that date, then, we may reckon the introduction of arithmetic, such as we have it at present, into common use; certainly one of the grentest boons ever conferred on mankind.

The next grent improvement introduced into suithnetic, was by Joln Muller, better known by lis Latinized name of liegiomontanus. He was born in Konigsberg, a small town in Franconia, in the year 1436. Scarcely liad he reached his 14th year, when lie becnine onamoured with the cliarms of mathematics and astronomy. He becane the favourite pupil and friend of l'urbach, who at that time was possessed of a ligh reputation. With him he resided till the tine of his death, engaged chiefly in astronomical observations. 'The labours of Regiomontanus wero incessant, and the reputation which he acquired was deservedly high. But we mention his name here, because it was to him that arithmetic owes the introduction of decinal fractions. 'Thus he gave to numerical computation its utmost degree of simplicity and eninrgement which it seems capable of reaching.

Regiomontanus was incessantly occupied with astronomical observations and calculations, which of course, rendered the perfection of trigonometry an object of the utmost importance; he did accordingly bring it nearly to the state of sim. plicity which it at present possesses. But the calculations necessary for such purposes are exceedingly laborious, and their labour necessarily incrensed as astronomy advanced, because it became essential to obtain more and more accurate results. The sines and tangents of angles could not be expressed with sufficient correctness, without decimal fractions, extending to five or six places; and when to three such numibers, a fourth proportional was to be found, the work of multiplication and division became exceedingly laborious. About the end of the 16 th century, the time and labour necessarily spent on such calculations, had become extremely burdensome to mathematicians and astronomers.

Napier of Mercliston, whose mind seems to liave had a bent towards arithmetical pursuits, was the person to whom the happy thought occurred of a method by which that labour might be prodigiously diminished by substituting aldition and subtraction, for multiplication and division; this he did by the discovery of logarithrus, and the constructions of logarithuic tables by himself, Briggs, Gellibrand, \&c.

He observed that when the numbers to be multiplied or divided, were parts of a geometrical series, or progression, provided ue know the progression, the product or quotient might be got at oace by inspection. Thus the $3 \mathrm{~d}$ term of a progression, multiplied into the 5th term, would make the 8th tern; and the 12th term, divided by the $3 \mathrm{t}$ term, would make the $9 t h$ term. Ho satisfied himself that all numbers might be intercalated between the terms of a geometrical progression; and he hit upon a most ingenious way of proving the truth of his proposition. What are called logarithms consist of numbers in an arithmetical progression, corresponding to all numbers supposed to exist in a geouetrical progression, and varions systems of logarithuns mny be constructed. The one which first oocurred to the inventor, though the simplest, was not so convenient, as the one which occurred soon after to hinself and his friend Briggs, and according to which, the tables now in use have been constructed. It is plain, that if we add together two logarithus, the logarithm constituting the sum of the two, will correspond with the number which would be obtained by multiplying the two numbers together; hence, by adding or subtracting logaritlıms, and looking up for the new logarithn in the tables, we find over against it, the number which would be obtained, if the numbers whose logarithms we use, were multiplied or divided by each other. What a prodigious saving of time and trouble is thus accomplished, must be evident at first sight. Nor lave the benefits conferred upon mathematics by loga. rithms been confined to this benefit, great as it is; they have spread themselves upon other branches of the science. In 1618, Briggs published the logarithms of the first 1000 numbers, under the title of Logarithmorum chilias prima; in 1624, he published the logarithms of all numbers, from 1 to 20,000 , and from 90,000 to 100,000 ; all calculated to the 14th decimal place. Death prevented Briggs from finishing his plan, but it was completed by Gellibrand, and published by him in lis Trigonometria Britannica, in 1633 .

11. OEOMETRY.

Wo have seen the progress which geometry lad made among the ancients, and how Archi medes by the method of exlaxustions, had succeeded in measuring spaces bounded by curve surfaces. This method though satisfactory, was exceedingly laborious, and being purely synthetical, it did not enable us to apply it to other discoveries of the same kind. A more compendious, and more analytical method was much to be wished for: and this great step was made by Cavalleri, in the year 1635, in his book entitled, Geometria indivisibilibus con. tinuorran nova quadam ratione promota. $\mathrm{Ca}$ valleri was born in Milan, in the year 1598. 
He entered into the society of Jesuits, was sent to the university of Pisa, where he acquired his geometrical knowledge, and was afterwards professor of astronomy in the university of Bologna.

Cavalleri proceded in lis geometry of indivisibles, on the following principle : areas may be considered as made up of an infinite number of parallel lines; solids, of an infinite number of parallel planes; and lines, of an infinite number of points. Thus, the cubature of a solid was reduced to the summation of a series of planes; and the quadrature of a curve, to the summation of a series of ordinates. Now the rule for summing an infinite series of terms in arithmetical progression, had been long known, and the application of it to find the area of a triangle, according to the method of indivisibles, was a matter of no difficulty. The next step was, supposing a series of lines in arithmetical progression, and squares to be described on ench of them, to find what ratio the sum of all these squares bears to the greatest square, taken as often as there are terms in the progression. Cavalleri showed that when the number of terms is infinitely great, the first of these sums is just one third of the second; this evidently led to the cubature of many solids. Proceeding one step further, he sought for the sum of the cubes of the same lines, and found it to be onefourth of the greatest, taken as often as there are terms; and continuing his investigations, he was able to assign the sum of the $n$th power of a series in arithmetical progression, supposing always, the difference of the terms to be infinitely small, and the number of terms to be infinitely great. The number of curious results obtained from these investigations was prodigious. It unay be considered as constituting as great a step over the calculus of exhaustions, as the integral calculus, was over the geometry of indivisibles.

The next general step, (for we are under the necessity of passing over many individual discoveries of great importance), in the extension of mathematics, was the arithmetic of infinites of Dr Wallis, first publislied in the year 1655 . Wallis was a native of Kent, where he was born at Ashford, in the year 1616. He was appointed Savillian professor of mathematics at Oxford, in 1649 ; which place he occupied till the year 1703, when he died.

The origin of the arithmetic of infinites, was an attempt by Wallis to discover the quadrature of the circle, after he becane acquainted with the method of indivisibles of Cavalleri. He began by observing, that if we have a series of numbers, arithmetically proportional (the natural numbers for example) beginning with 0 , and proceeding regularly on, the sum of this series, is equal to half the sum of the last term, repeated as many times as there are terms in the series. Thus,

$$
\frac{0+1}{1+1}=\frac{1}{2} ; \frac{0+1+2}{2+2+2}=\frac{3}{6}=\frac{1}{2} ; \frac{0+1+2+3}{3+3+3+3}=\frac{6}{12}=\frac{1}{2} .
$$

From this it follows, that a triangle is half a parallelogram, on the same, or equal basis, and between the same parallels. For a triangle may be considered as composed of an infinite number of lines, beginning at a point or 0 , and incrensing arithmetically, the grentest of which is the base; while a parallelogram consists of an infinite number of lines of equal length, and all equal to the base. From this analogy he deduced the quadrature of a variety of figures.

He next shows that the sum of an infinite series of numbers, beginning with 0 , and proceeding as the squares of the natural numbers, that is, the series $0,1,4,9,16,25,36,49, \& \mathrm{c}$. is to the last term, repeated as often as there are terms in the series, as 1 to 3 . From this he shows that the compliment of a semi-parabola is to the parallelogram contained between the corresponding absciss and ordinate, as 1 to 3 ; and deduces from the same analogy, many other of the quadratures of curvilinear spaces.

He then shows that the sum of an infinite series of quantities, increasing from 0 , as the cubes of the natural numbers, or the series 0 , $1,8,27,64,125,216, \& \mathrm{c}$., is to the sum of the last term, repeated as often as there are terms in the series, as 1 to 4. This analogy furnishes the quadrature of many figures.

But it would be too tedious to attempt an analysis of the whole of this curious book, which may be considered as furnishing the first germ of the integral calculus. There are however a few other particulars which it would be improper to omit. He was led by analogy to express the denominators of fractions by means of negative powers. The numbers

$$
\left.x^{3}, x^{2}, x^{1}, x^{y}, \text { (or } 1\right), \frac{1}{x^{2}}, \frac{1}{x^{2}}, \frac{1}{x^{3}} \text { \&c., }
$$

are in continued geometrical progression. This led him to express them in this way, $x^{3}, x^{2}, x^{1}$, $x^{0}, x^{-1}, x^{-2}, x^{-3}$. Simple as this improvement may appear, it has led to consequences of the greatest importance. It put him in possession of the measure of every space, the elements of which are reciprocally as any power of the abscissa. A prodigious number of new discoveries was the necessary consequence of these new views.

Most of the discoveries made by other mathematicians immediately after the publication of the Arithmetic of Infinites, were little else than developinents of the views of Wallis. Neil 
showed that the cubic parabola uight be rectified by one of Wallis's inethods; and Van Heuraet applied the same method to the rectification of several other parabolas.

Wo must pass over the discoveries of Barrow, though they are liighly entitled to attention, and hasten to Sir Isane Newton, who was destined to change the face of physical science-and who hitherto stands alone ainong mankind as the inveutor of a theory to explain the motions of the heavenly bodies, which lias stood the test of the most rigid examination, and which every subsequent improvement and discovery lias serred wnly to confirm and establish.

Nowton was boru in the year 1642 , on cluristnins, old style, at Woolsthorpe, in the county of Incoln. The family came originally from Newton, in Lancashire, and it appears from a letter published by Dr Reid, that, by the mother's side, he was of Scottish extraction. When young, he discovered a surprising turn for making nodels of mechanical instruments. His mathematical knowledge came to him with incredible facility. Euclid he merely turned over, considering it to contain nothing but common things. The first mathematical book that he read was Deseartes' Geometry, and the second Wallis's Aritlumetic of Infinites. On these books he wrote commentaries as he read then, and reaped a rich harrest of discoveries; or, more properly speaking, he made almost all his mathematical discoveries as he proceeded in their perusal. In 1667, he was elected fellow of Trinity College, Cambridge, and in 1669, Dr Barrow resigned his mathematical professorship to him. He resigned this claiir in 1703, two years after Mr Whiston had taught for him. He died in the year 1727 . He was a member of the convention parliament, in $\mathbf{1 7 8 9}$, and was, for a good many years, master of the mint.

His first mathematical discovery of importance was the binomial theorem. But his great mathematical discovery was the method of fuctions, or the integral and differential calculus, as it is called on the continent. This, he assures us, he was in possession of as early as $\mathbf{1 6 6 5}$ or 1666 . Barrow informs us, that soon after that period, there was put into his hands, by Newton, a manuscript treatise, the same which was afterwards published under the title of Analysis per IEquationes Numero terminorum infiritus, in which the principle of fluxions, though not fully explained, is yet distinctly pointed out. Barrow strongly exhorted Newton to publish this treasure to the world ; but an excess of modesty, almost amountlug to a disease, prevented his compliance.

For a long tine, the mathematical discoveries of Newton were known only to his friends. The first work in which he communicated any thing to the world on the subject, was the first edition of the Principia, in 1687, in the socond lemma of the second book. The principle of the calculus is there pointed ont; but nothing is said of the algorithm, which is so essential to that calculns. This only becane known to the world in 16!3, by the publication of the second volume of $\mathrm{W}$ al. lis's works (p. 390, \&c.) There is no ovidence that this notation existed earlier than 1692, thougl it is highly probable that it did. It was no less than ten years after this, or in 1704, that Newton himself published a work on the new calculus, his Quadrature of Curves, more than twenty-eight years after it liad been written.

These discoveries, however, even before they were comnitted to the press, could not remain altogether unknown in a country where mathenatics were cultivated with such zeal and success. Barrow comnunicated them to Oldenburgh, secretary of the Royal Society. By him they were partly communicated to Mr James Gregory, and likewise to Leibnitz, who had become acquainted with Oldenburgh during a visit which he had made to England in 1673. At that time Leibnitz knew very little of the mathematics; but having afterwards turned his attention to that science, lee was soon in a condition to malke discoveries. One of the first of these was a very remarkable series, which gives the value of a circular arch in terus of the tangent. This series he communicated to Oldenburgh, in 1674, and received, in return, an account of the progress made by Newton and Gregory, in the invention of series. In 1676, Newton described his method of quadratures, at the request of 01 denburgh, in order that it might be transmitted to Leibnitz.

The method of fluctions is not communicated in these letters; nor are the principles in any way suggested; though there are, in the last letter, two sentences, in transposed characters, which ascertain that Newton was then in possession of that method, and employed, in speaking of it, the same language in which it was afterwards made known. In the following year, Leibnitz, in a letter to Oldenburgh, introduced differentials, and the method of his calculus, for the first time. This letter clearly proves, that, in 1677, Leibnitz was in full possession of the principles of his calculus, and had even invented the algorithm and notation.

From these facts, it cannot, we think, bo doubted, that Newton was the first inventor of the fluxionary calculus; but that nothing was consmunicated to Leibnitz regarding the principles of that analysis. Leibnitz, therefore, when ho invented the differential calculus, was not assist. ed by any communications that could give him any idea of what had been done by Newtow. 
Newton was the first discoverer, and Leibuitz the second; both were originals, and both independent of each other. The algorithm of Leibnitz was much more perfect than that of Nerrton; and it had the great advantage of being first made known to the world-all account of it having been inserted in the first volume of the Acta Eruditorum, for 1684.

Thus, while Newton's discovery was known only to a few friends, Leibnitz's was rapidly spread orer the continent. John and James Berrioulli joined their talents to those of the orjginal inventor, and illustrated the new method by the solution of a great number of difficult and interesting probleins. Leibnitz's methods acquired perfection, while those of Newton remained unknown. The first work on the new geometry, was by Craig, who drew his information from the writings of Leibnitz and his friends.

Nothing however like hostility appeared between the two great discoverers, and Newton in the passage of the Principia above referred to, gives a highly farourable opinion on the subject of the discoreries of Leibnitz. A remark of Fatio de 1uillier, in a paper presented to the Royal Society in 1699 , lighted up a flame which a whole century has been scarcely sufficient to extinguish. In a paper on the line of swiftest descent, there occurred this sentence, "I hold Newton to have been the first inventor of this calculus, and the earliest by several years, induced by the evidence of facts; and whether Leibnitz, the second inventor, has borrowed any thing from the other, I leave to the judgment of those who have seen the letters and manuscripts of Newton." Leibnitz replied to this charge in the Leipsic Journal, without any asperity, simply stating himself to have been, as well as Newton, the inventor.

In the year 1705, on the publication of Newton's Quadrature of Curves, the same journalists insinuated, though with politeness and ambiguity, that Newton had been led to the notion of fluxions by the differentials of Leibnitz; just as Honoratus Fabri had been led to substitute the idea of progressive motion, for the indivisibles of Cavalleri. A charge so entirely unfounded, could not but call forth the indignation of Newton and his friends. In that indignation they were perfectly justifiable. But when the passions are leated, the injustice on one side is generally retaliated by an equal piece of injustice on the other. Accordingly, Keill who undertook the defence of Newton's claims, instead of endeavouring to establish the priority of his discoveries by an appeal to facts and to dates that could be accurately ascertained; undertook to prove that the communications of Newton to 1.eibnitz, were sufficient to put the latter in possession of the principles of the new analysis, after which he had only to substitute the notion of differentials, for that of fluxions. But in support of these charges he had nothing to offer but equivocal facts, and overstrained arguments, capable of convincing those only, who were already disposed to believe. They were accord. ingly received as accurate in England; rejected as absurd in Germany, and read without conviction by the mathematicians of France and Italy.

Leibnitz complained of Keill's statements to the Royal Society of London, who declined giving any opinion; but appointed a committee of its nembers to draw up a full and detailed report of all the communications which had passed between Newton and Leibnitz, or their friends, on subjects connected with the new analysis, from the time of Collins and Oldenburgh, to the date of Keill's letter to Sir Hans Sloane in 1711, of which Leibnitz had complained. This report forms what is called the Commercium Epistolicum. It was published the year following by order of the Royal Society; and, though in the main just and fair, seemed rather to lean to the side of their own president. Leibnitz complained of this publication, and alleged, that though nothing was inserted which was not contained in the original epistles, yet certain passages were suppressed which were favourable to his pretensions. He threatened an answer, but it never appeared. Some notes were added to the Commercium Epistolicum, which contained a good deal of asperity, and the review of this book inserted in the Philosophical Transactions for 1715, is still more liable to the same censure.

In the year 1713 , a paragraph was circulated among the mathematicians of Europe, written by John Bernoulli. It amounted to this, "That there is no reason to believe that the fluxionary calculus was invented before the differential." Bernoulli was doubtless well acquainted with the subject; but he was too much connected with Leibnitz, and had contributed too much to the progress of the differential calculus, to be an impartial judge.

The German mathematicians injured their own cause by attempting to fix on Newton a charge of plagiarism, which could be so triunphantly refuted. As much were the English mathematicians to blame when they retorted the same charge upon Leibnitz. It was not indeed physically impossible that Leibnitz night have borrowed his calculus, as Newton undoubtedly preceded him ; but the assertion is not supported by the slightest shadow of a proof.

-We shall pass over the subsequent defiances which passed mutually between the English and Continental mathematicians, and the harsh and $B-\mathrm{C} 2$ 
unmerited epithets which they reciprocally bestowed upon each other, to tho eternal disgrace of both parties, and the humiliation of mathematical science. The dispute was of a nature not capable of being decided by rensoning. Had Newton made knowu the uature of the Duxionary calculus when it first occurred to him, his claim as a discoverer would lave been universally allowed, and he would have conferred a boon of the greatest magnitude on mathemnticians. Leibuitz may lave been informed that Newton was in possession of an unknown calculus of the greatest power-this information may lave set his invention at work, and his exertions were irowned by the discovery of the differential calculus. 'This discovery, as soon as made, he gave to the public; and, with the assistance of the Bernoullis, soon brought it to a considerable degree of perfection. This proceeding, was much more calculated for the improvement of science than the morbid timidity of Newton. The algorithm of Leibnitz was better; his method was taken up by men of first rate abilities, and prosecuted with astonishing success. For it would be difficult to find a series of mathematicians to be compared with the two Bernoullis, Euler, and Lagrange, who devoted in succession their unrivalled powers to the improvement and extension of the differential and integral calculus.

In England, at, or before the time of Newton, the number of profound mathematicians was great. Wallis, Brounker, Wren, James Gregory, Barrow, were his immediate predecessors or contemporaries. Newton hinself stands unrivaled, as, perhaps, the greatest mathematical genius that ever existed. Of his successors, the most remarkable is Cotes, whose Harmonia Mensurcrum appeared in 1722. It contained the method of finding the fluents of fractional expressions, greatly generalized, and highly inproved, by means of a property of the circle discovered by himself, and justly reckoned among the most remarkable propositions in geometry. It is curious, that this book, notwithstanding its merit, has never acquired, among English mathematicians the popularity which it deserves, while, on the continent, it seems to be very little known.

Another rery original and profound writer of this period, was Dr Brook Taylor, who, in nis Method of Increments, published in 1715, added a new branch to the analysis of variable quantity. A single analytical formula in his Method of Increments, has conferred a celebrity on its author which rery voluminous works have of ten failed to bestow. It is known by the name of Taylor's theorcm, and expresses the value of any function of a variable quantity, in terms of the successive orders of increments, whether finite or infiuitely small. It is perhaps, without excep. tion, the most compreliensive proposition in ther whole range of mathenuatical science.

Maclaurin may be mentioned as anotlier mathematician, who did credit to his country.

The mathematicinns of Britain, and on the continent, though the algorithm used by earh was different, yet kept pace with oach other for a considerable time, except in one branch, the integration of differentinl or fluxional equations. In this the Britislı mathematicians had fallen considerably behind. And the distance between them, and tlose on the continent, continued to increase in proportion to the number and iniportance of the questions, physical and mathematical, which depended upon these integrations. The habit of reading only British mathematical works, produced at first by the admiration of Newton, and afterwards continued, in consequence of the difference of notation, prevented the British mathematicians from partaking in the pursuits of the mathematicins on the continent. Prodigious improvements were made in Italy, France, and Germany, in which the natives of Great Britain had little or no share.

Other causes, perhaps, may have contributed to draw away our neen of science from mathematical investigations. But by the middle of the last century, the race of British mathematicians, at one time so numerous and so splendid, was reduced to a very small number indeed. It is true that mathematics still continued to be cultivated in Cambridge: but they satisfied themselres with studying the Principia of Newton, and neglected or despised the splendid iniprovements and discoreries of the contineutal mathematicians.

A little after the middle of the last century, Mr West was appointed to teach the mathematical class in the university of St Andrews, in consequence of the illness of professor Vilant. West possessed an uncommon mathematical genius, as is evident from the slightest inspection of his Elementary System of Geometry, which he published while a teacher. His mode of teaching seems to have been admirable, and he liad the merit of infusing his own spirit into a num. ber of young men who have contributed not a little to the recovery of that high rank in mathematical science which formerly belonged to the British mathematicians. The late professor Playfair was not indeed the pupil of West, but he was his friend and contemporary, and both had been educated at the same university. It is not unlikely, therefore, that he may have been indebted for his passion for the science, to his intinacy with West. The late Sir John Leslie was a pupil of West, and indebted to him for all his mathematical knowledge. He was possessed 
of a true mathematical genjus, and though not ramiliar with the general analytical methods which are now in constant use, yet his matheInatical knowledge was respectable. Mr Glennie was another of Mr West's pupils. But the man who does the highest credit to Mr West, is Mr Ivory, who has raised himself to the very highest rank as a mathematician; who has cultivated every branch of the higher calculus with the most complete success; who is critically acquainted with the whole history of mathematical discoveries, and is now universally admitted to be the first matlematician at present in Europe. Thus he has rescued Great Britain from the stigma affixed to her, of inferiority in mathematical skill to the mathematicians on the continent. Cambridge also of late years has produced different eminent mathematicians, the most celebrated of whiom is Sir John Herschell.

It would be impossible in this hasty sketch, to give the slightest idea of the prodigious improvements which have been made in mathematics during the progress of the last century. The task is an herculean one. It has been frequently attempted, but never yet executed. The individual best qualified for such a task, is Mr Irory. Were he to execute it, he would confer a boon of no ordinary magnitude upon science, and add a new wreath to those with which Great Britain is already encircled.

\section{ALGEBRA}

The word algebra is Arabic, and is derived from $a l$, the, and jebr; contortion. It was atfirst applied to a particular arithınetical rule, in which the terms were transposed. There is some reason for suspecting that what we now call algebra, originated in India. Diophantus who lired about 150 years after the commencement of the Christian era, has left thirteen books of arithmetical questions, which are treated in a manner that may be considered as algebraic, The science was cultivated by the Arabians during the golden age of Mahomedan science. And a knowledge of it was first brouglit to Europe in the 13th century, by Leonardo, a merchant of Pisa, who having made many visits to the east, brought back with him a knowledge of algebra, on which he wrote a treatise in 1202 , and another in 1228, both of which still remain in manuscript.

But the first book printed in Europe on algebra, was that of Lucas de Borgo, a Franciscan, who towards the end of the 15th century, traveled into the East, and acquired a knowledge of the principles of algebra. The characters employed by him are merely abbreviations of words. The letters $p$ and $m$, are used for $p l u s$ and minus. And the rule is laid down, that in multiplication, plus into minus gives minus; but minus into minus gives plus. Thus algebra was originally merely an abbreviation of common language, applied to the solution of arithmetical problems.

The Indians and Arabians adranced as far as the solution of quadratic equations. Scipio Ferrei, professor of matlematics at Bologna, had, about the year 1508 , found out a method of solving one of the cases of cubic equations; which he either concealed, or at least communicated only to a few of his scholars. One of these, Florido, trusting to this secret, challenged Tartalea of Brescia to contend with him in the solution of algebraic problems. Florido had at first the advantage; but Tartalea being a man of ingenuity, soon discovered his rule, and likewise another much more general, in consequence of which le came off at last victorious. $\mathrm{By}$ the report of this victory, the curiosity of Cardan was strongly excited. For though he was himself an accomplished mathematician, he had not been able to discover a method of solving equations higher than the second degree. By the most importunate solicitations he wrung from Tartalea the secret of his rules; binding himself at the same time, by the most solemn promise, never to divulge them. Though Tartalea did not communicate the demonstration, Cardan soon found it out, and extended it in a very ingenious and systematic manner to all cubic equations whatever.

Being thus possessed of an important discovery, which was partly his own, he forgot his promises to Tartalea, and published the whole in 1545 , not concealing, however, what he owed to the latter. Thus was published the rule which still bears the name of Cardan; and which still marks a point in the progress of algebraic investigation, which all the efforts of succeeding analysts have liardly been able to pass.

Robert Recorde, an English mathematician, published about the middle of the 16th century, the first English treatise on algebra, and he there introduced the same sign of equality which is now in use.

The properties of algebraic equations were discovered very slowly. Pelitorius, a French mathematician, in 1558 , first observed that tho root of an equation, is the divisor of the last term. Bombelli soon after published a regular treatise on algebra, in which he considered with particular attention the irreducible case of Cardan's rule, and pointed out the method of solving problems falling under it by the trisection of an arcl.

- Vieta, marks an era in algebraic analysis. He was a Frenclıman, born at Fonterai, il Poitou, in the year 1540. Though maitre des 
requetes at Paris, a situation which employed much of his time, he found leisure to levote limself to algebra. He first employed letters to denote both the knowi and unknown quantities; so that it was with hiul that the language of algebra first becaune capable of expressing general truths, and acquired that extension which lias since rendered it such a powerful instrument of investigation. He likewise discovered the relation between the roots of an equation of any degree, and the coefticients of its terms, though ouly when none of the terms are wanting, and when all the terms are positive. This general truth, which Vieta only saw imperfectly, was further extended, in 1669, by Albert Gerard. But it was first developed in all its generality by Harriot, whose discoveries in algebra lave been so much extolled by Wallis.

These successive improvements brought algebra nearly to its present state, and prepared it for a step which was about to be taken by Descartes, and which forms one of the most important epochs in nuathematical science. This was tho application of algebraic analysis to define the nature, and investigate the properties of curre lines; and consequently to represent the notion of variable quantities. This invention opened up a vast field for succeeding mathematicians. The work in which it was contained, is a tract of no more than 106 quarto pages. Probably there is no book of the same size, which has conferred so great, and so well merited a reputation on its author.

It would be impossible in the short space to which we are obliged to confine ourselves, to give even an idea of the improvements which algebra has received during the two centuries which have elapsed since Descartes applied it to the investigation of curves. It cannot be said that any new principle has been discovered; but its langunge and symbols have been perfected, and it has been applied with effect to almost every kind of physical investigation. Indeed, if we consider the calculus of infinitesimal quantities as merely an extension of algebra, as might very well be done, we may say with truth, that it now constitutes the grand instrument by means of which physical-science is pronoted.

\section{OF OBSERVATION AND EXPERIMENT.}

IT was not to be expected that mankind should at first make any rapid progress in investigating the laws, which regulate the changes that take place in the material world. The ubjects were too numerous, and too varied, and escaped his attention by their very regularity. Every where in the early ages of the world, we neet witl descriptions of prodigies and wonders, while the regular operations of nature scarcely attracted attention. 'The method of investigating nature by observation and experinent was scarcely thought of, except by two individuals, who, by means of then, made some progress in meclianics and liydrostatics, and in astronomy; these were Archimedes and Hipparclus. The mechanical discoveries of Archimedes were slightly extended by Ctesibius and IJero, by Anthemius, and by Pappus; while the astronomical observations begun by Hipparclius, were continued by Ptolemy.

But at the revival of letters in the 16 th century, a spirit of observation and inquiry awoke, which notling could damp, and men began to pry into the secrets of nature, by the way of experiment. Galileo, in Italy, and Gilbert, in England, especially the former, constitute remarkable examples of successful investigation by experiment. But it was Francis Bacon, lord Verulam, who first investigated the laws according to which such experimental investigations sliould be conducted, who pointed out the necessity of following these laws in all attempts to extend the pliysical sciences, and who foretold the brilliant success that would one day repay those who should adopt the methods which lie pointed out. This he did in his Novum Orga num, published in the early part of the 17 th century.

Before laying down the rules to be followed in his new, or inductive process, Bacon enumerated the causes of error, which he divided into four sets, and distinguished, according to the fashion of the times, by the following fanciful. but expressive names:

Idols of the tribe,

Idols of the den,

Idols of the forum,

Idols of the theatre.

The Idols of the tribe, are the causes of error founded on human nature in general. Thus all men have a propensity to find in nature, a greater degree of order, simplicity, and regularity, than is actually indicated by ohservation. This propensity, usually distinguished by the title of spirit of system, is one of the greatest enemies to its progress, that science has to struggle with.

The Idols of the den, are those that spring from the peculiar character of the individual. Each individual, according to Bacon, has his own dark cave or den, into which the light is imperfectly admitted, and in the obscurity of which an idol lurks, at whose shrine the truth is often sacrificed. Some minds are best adapted to catch the differences, others the resemblances 
of things. Some proceed too rapidly, others too slowly. Almost every person has acquired a partiality for some branch of science, to which he is prone to fashion and force every other.

The idols of the forum are those which arise out of the intercourse of society, and especially from language, by means of which men communicate witl each other. - It is well known that words, in some measure, govern thought, and that we cannot think accurately unless we are able to express ourselves accurately. The same word does not convey the same idea to different persons. Hence many disputes are merely rerbal, though the disputants may not be aware of the circumstance.

The idols of the theatre are the deceptions which have taken their rise from the systems of different schools of philosophy. These errors affected the philosophy of the ancients more than that of the moderns. But they are not yet without their effect, and often act powerfully upon individuals without their being aware of their effect.

After an historical riew of science from its dawn among the Greeks to his own time, and pointing out the little progress which it had made, in consequence of the improper way in which it had been cultivated, Bacon proceeds, in his second book, to point out the true way of advancing science by induction.

The first object ought to be to prepare a history of the phenomena to be explained, in all their modifications and varieties. This history is to comprelsend not only all such facts as spontaneously offer themselves, but all the experiments instituted for the sake of discovery, or for any of the purposes of the useful arts. It ought to be composed with great care; the facts should be accurately related, and distinctly arranged-their authenticity carefully ascertained, and those that are doubtful should be narked as uncertain, with the grounds for the judgment formed. This record of facts Bacon calls natural history. .

The next object is a comparison of the different facts, to find out the cause of the phenomenon.

The method of induction here laid down. is applicable to all investigations where experience is the guide, whether in the moral or natural world.

It is obvious that all facts, even supposing thein truly and accurately recorded, are not of equal value in the discovery of truth. Some of them show the thing sought for in its highest degree, others in its lowest; some show it simple and uncombined, while others are confused with a variety of circumstances. Some facts are easily interpreted, others are very obscure, and are understood only in consequence of the light thrown on them by the former. This led Bacon to consider the comparative value of facts as means of discovery. He enunierates twentyseven different species; but we shall satisty ourselves here with noticing a few of the most important of them.

1. Instantice solitarie are examples of the same quality existing in two bodies, which have nothing else in common; or of a quality differing in two bodies, which are in all other respeits the same.

2. The instantice migrantes exhibit some natore or property of bodies passing from one condition to another, either from less to greater, or from greater to less. Thus, glass while entire is colourless, but becomes white when reduced to powder.

3. The instantice ostensive show some particular nature in its highest state of power or energy. In this way the thermometer shows the expansive power of heat, and the barometer the reight of air.

4. The instantice analogice consist of facts between which an analogy or resemblance is visible in some particulars, notwithstanding great diversity in all the rest. Such are the telescope and microscope in works of art, compared with the eye in the works of nature.

5. The instantia crucis is the division of this experimental logic which is the most frequently resorted to in the practice of inductive investigation. When in such an investigation, the understanding is, as it were, placed in equilibrio between two or nore causes, each of which accounts equally well for the appearances, as far as they are known, nothing remains but to look out for a fact which can be explained by the one of these causes, and not by the otlier. If such a fact can be found, the uncertainty is removed, and the true cause. becomes apparent. Such facts perform the office of a cross, erected at the meeting of two roads, to direct the traveler which way he is to go. On this account, Bacon gave them the name of instantice crucis. Suppose it were -inquired into why metals become heavier when calcined, rarious explanations might be conceived. But ilse experimentum crucis of Lavoisier removed the ambiguity. He enclosed a quantity of tin in a large glass vessel, which was hermetically sealed. Heat being then applied, the tin melted and was partly calcined. The process being tinished, the weight of the glass and its contents were found uuchanged. But the glass being opened, a quantity of air rushed in, amounting in weight to ten grains; and the tin was found to have increased in weight ten grains. It was obvious from this, that by the calcination of the tin a portion of the air had been absorbed, which had occasioned the increase of the weight. 
In cases where an experimentum erucis cannot be resorted to, there is often a great want of conclusive evidence. This is the case in agriculture, in medicine, in political economy, \&c. To make one experiment similar to another in all respects but one, is what the experimentum crucis, and the principlo of induction, in general, requires. But this, in the sciences just named, can seldom be accomplished. Hence the gareat difficulty of separating the causes, and allotting to each its due proportion of the effect. Men leceive themselves in consequence of this conlinually, and think thoy are reasoning from fact and experience, when, in reality, they are drawing their conclusions from a mixture of truth and falseliood. Faets so incorrectly apprehended only serve to render error more incorrigible.

Of tho twenty-seren classes into which instantia are arranged by Bacon, fifteen address themselres immediately to the understanding; five serre to correct or inform the senses; and seven to direct tho hand in raising the superstructure of art on the foundation of seience. The examples which we have selected, are from the first of these divisions. The other two are of inferior importance, and may be omitted in this imperfect summary.

Such are the rules laid down by Bacon for prosecuting the sciences by induction. The effects which were ultimately produced by the Novum Organum must have been very great. It nay be questioned, indeed, whether those who have contributed most effectually to the advancement of the sciences, have ever rigidly adhered to Bacon's rules. And, in general, such a rigid adherence is unnecessary; becauso so much assistance can, in general, be derived from what knowledge has been already acquired, that a rigid natural historical detail of all the phenomena becomes unnecessary. It was only in the infancy of science that such details were requisite. Boyle often draws them up in his inquiries into the cause of various phenomena, and his investigations were of considerable use in forwarding those branches of science which he cultivated. Bacon also was mistaken in conceiving that, by investigation, mankind may become acquainted with the essences of the powers and qualities residing in bodies. So far as science has hitherto advanced, no one essence has been discovered, either as to matter or as to any of its more extensive modifications. Thus we are still in doubt whether heat and electricity be qualities or substances. Yet we have discovered many important properties or laws, by means of which heat and electricity, whether properties or substances, are regulated. And from this knowledge, probably, we derive as much advantage as could be obtained from a complete knowledge of their essence.
Such are the two methods of advancing science. By experiment or observation all the new tacts in every seienee are acquired. By the application of mathematical reasoning to these facts they are reduced to the requisito simplicity, and the general principles which regulate every particular science determined. Let us now endeavour to trace the progress which las been made in the difierent physical sciences since these two powerful means of advancement wero fairly applied to theu.

\section{MRCHANICS,}

Stevinus, an engineer in the Low Countries, is the first person who passed beyond the point at which the ancients had stopped, by determining accurately the force necessary to sustain a body on a plane inclined at any angle to the horizon. This knowledgo he seems to have deduced from the fact, that a chain laid on an inclined plane, with a part of it hanging over at top in a perpendicular line, will be in equilibrio if the two ends of the chain reach down exactly to the same level. The first appearance of Stevinus's solution of this problem was in the year 1595. His works, as we now have them, were collected after his death by his countryman, Albert Gerard, and published at Leyden in 1634

But the man to whom mechanics is indebted for the first great steps which it made in advance is Galileo, who was born at Pisa in the year 1564, and who is, perhnps, the most remarkable man that appeared in that age, so prolific in men of first-rate genius. In 1592 he published a treatise, Della Scienza Mechanica, in which he has given the theory not only of the lever, but also of the inclined plane and screw, and in which he laid down this general proposition, that small weights are able to move large ones only by a great increase of velocity, or that weights are in equilibrio when the weight of each multiplied into its velocity is the same.

While a student at Pisa, he had made experiments on falling bodies, and diseovered the fact that light and heavy bodies fall to the ground in the same time, making allowance for the resist. ance of the air. From observing the vibrations of the lamps in the cathedral he had come to this rery important conclusion, that great and small vibrations of the pendulum are performed in the same time, and that this time depends only on the length of the pendulum.

These experiments drew upon him the dis. pleasure of his masters, who were offended that he should consult nature and experiment instead of Aristotle, and their commentaries on the dogmas of the Grecian sage. This was the origin of those perseeutions, proceeding from a mixture 
of bigotry and enry, with which he continued to be harassed throughout the rest of his life.

By means of the inclined plane he succeeded in demonstrating that the motion of a falling body, is a uniformly accelerated motion. His next step was to determine the path of a heary body, when obliquely projected. He showed this path to be a parabola. The theory of the inclined plane showed that if a circle be placed vertically, the chords of the different arches terminating in the lowest point of the circle are all descended through in the same space of time. But when Galileo applied this to account for great and small vibrations of a pendulum being performed in the same time, he fell into an error, which was first completely rectified by Huygens.

In the list of the mechanical discoveries of Galileo, may be placed the knowledge of the existence of the law of continuity, and the employment of it as a principle in lis reasonings on the phenomena of inotion.

Torricelli, the pupil and friend of Galileo, discovered a remarkable property of the centre of gravity, and a general principle with respect to the equilibrinm of bodies. It is this: If there be any number of heary bodies connected together, and so circumstanced, that by their motion their centre of gravity can neither ascend nor descend, these bodies will remain at rest.

Descartes, whose reputation was so great, and his pretensions so high, likewise treated of motion; but in general his opinions were so erroneous or unsound, that in the present rapid sketch they are not entitled to notice.

The laws which regulate the collision of bodies remained unknown, till they were recommended by the Royal Society to the particular attention of its members. Three papers soon appeared, in which these laws were correctly laid down, though no one of the autliors had any knowledge of the conclusions obtained by the other two. The first of these was read to the society, in November, 1668, by Dr Wallis of Oxford ; the next by Sir Christopher Wren, in the month following; and the third by Huygens, in January, 1669. The equality of action and re-action, and the maxim that the same force communicates to different bodies velocities which are inversely as their masses, are the principles on which these investigations are founded.

Huygens was the first person who explained the true relation between the length of the pendulum, and the time of its least vibrations, and who gave a rule by which the time of the rectilinear descent through a line equal in length to the pendulum, might from thence be deduced. He next applied the pendulum to regulate the motion of a clock, and gave an account of its construction, and the principles of it in his Horologium Oscillatorium, about the year 1670 , though the date of the invention goes as far back as 1656. Lastly, he showed how to correct the imperfection of a pendulum, by making it to vibrate between cycloidal cheelss, in consequence of which its vibrations, whether great or small, become precisely equal.

The appearance of the Principia of Newton, in 1687 , effected an almost total revolution in mechanics, by giving new powers and new directions to its researches. The composition of forces was treated independently of the composition of motion. From the equality of action and re-action, it was inferred, that the state of the centre of gravity of any system of bodies is not changed by the action of these bodies on each other. From this it follows, that the quantity of motion existing in nature, when estimated in any given direction, continues always of the same amount.

But the reduction of questions concerning force and motion, to questions of pure geometry, and the mensuration of mechanical action by its nascent effects, constitute the great glory of the Principia. A transition was there made from the consideration of forces acting at stated intervals, to that of forces acting continually; and from forces constant in quantity and direction, to those that converge to a point, and vary as any function of the distance from that point; the proportionality of the areas described about the centre of force, to the times of their description, the equality of the velocities generated in descending through the same space by whatever rout; the relations between the squares of the velocities produced or extinguished; and the sum of the accelerating or retarding forces, computed with a reference not to the times during which, but to the distance over which they have acted; may be mentioned as a fer of the dynamical and mechanical discoveries contained in that immortal work.

Leibnitz, the rival and antagonist of Newton, made some improvements in mechanical science, which though not capable of being compared with the profound discoveries of Newton, yet require to be noticed. Leibnitz seems to have been the first who announced in general terms the principle of a sufficient reason. This principle however was not new, for it had been assumed by Archimedes, and employed by Galileo. Stript of the metaphysical garb in which it was placed by Leibnitz, it means nothing more, than that nothing exists in any state, without a reason determining it to be in that state rather than in any other. This principle, though true in itself in a limited sense, was rather brought into discredit by the way in which Leibnitz employed 
it. Thus he inferred from it, that two particles of matter cannot possess exactly the same properties; for if they did, the Supreme Being conld have no reason for employing the one inore than the other, and consequently both would be of necessity rejerted-as if we were capable of judging in what way motires act upon the mind of the Deity, and-as if position might not be a sufficient inotive for employing one particle rather than another, supposing both possessed of exactly the same properties.

Another principle brought into view by Leibnitz, was the law of Continuity-according to which, nothing passes from one state to another, without passing through all the internediate states. Though Leibnitz considers himself as the first who pointed out this law, it is but fair to state that it was distinctly laid down by Galileo, who does not claim it as his own, but nscribes its discovery to Platw. This principle like the last, Leibnitz and his followers carried to a blamable excess. Thus John Bernoulli was induced by it to deny the existence of liard bodies altogether; hecause in the collision of such bodies a finite change must take place in an instant, which, according to the principles of the law of continuity is impossible. We can obviate the objection of Bernoulli without refusing, as Maclaurin does, to admit the law of continuity, by,admitting that the hard bodies begin to act on each other before they come into actual contact.

The last meclıanical improventent of Leibnitz introduced a controversy into mathematics, which was discussed by the most eminent inathematicians of Europe, for more than thirty years, with great keenness, and not a little rirulence; though neither side was able to produce any change of opinion in their antagonists. Leibnitz, in 1686, announced in the Leipsic Journal the demonstration of a great error committed by Descartes and others, in estimating the force of moving bodies. In this paper he endearours to show that the force of a moving body is not proportional to its velocity simply, but to the square of its velocity. And he supported this new doctrine by very plausible reasoning. A body projected upwards against gravity, with a double velocity, ascends four times the height; with a triple velocity, to nine times the height, and so on-the height ascended being always as thesquare of the velocity. Such was the reasoning, sufficiently simple and satisfactory.

The subject was soon taken up keenly, and the world of science was divided into two parties. The mathematicians of Germany, Holland, and Italy, adopted the opinion of Leibnitz; those of Great Britain the old opinion, that the force is proportional simply to the velocity; while those of France vere diviled between the two opinions Maclaurin, Stirling, Desaguliers, Jurin, Clarke. and Mairan, defended the old opinion; while Bernoulli, Hermann, Poleni, 'S Gravesende, and Muschenbroek, supported the opinion of Leibnitz.

What may appear at first sight singular in this dispute, is, that the two parties who adopted such different measures of force, when auy mechanical problem was proprosed concerning the action of bodies, whether at rest or in motion, resolved it in the same manner, and alrived exactly at the sane conclusions. It is clear from this, that their ideas or opinions exactly coincided. In reality, the two parties advanced positions not inconsistent witl each other; and both therefore were true. This was pointed out by $\mathrm{D}^{\prime}$ Alembert in his Dynamique, published in 1743.

We may measure the force of one moving body, by its effect upon another moving body. Hence there is no doubt that the forces of such bodies are as the quantities of matter multiplied into the velocities; because it is well known, that the forces of bodies in which these products are equal, if opposed, destroy each other. If we employ this mensure, it is evident that the forces vary not as the squares, but simply as the velocities.

When a moving body is opposed by pressure, or a resistance like that of gravity, the quantity of such resistance required to extinguish the motion must serve to measure the force of the body. But there are two ways of computing the a mount of these retarding forces, which lend to different results; both of them just, and neither of them to be assumed to the exclusion of the other. Suppose a body to be projected perpendicularly upwards, in a direction opposite to that of gravity, we may either inquire into the retardation which gravity produces during a given time, or while the body is moving over a given space. We may inquire how long the motion will continue, or how far it will carry the body before it be entirely exhausted. If we employ the first of these for the mensure of the force of a body, that force must be proportional to the velocity; for to this the time is manifestly proportional. If we employ the second, namely the length of the line which the moving body describes, as the measure of the force, then it must be as the square of the velocity; because to that quantity the lengtl of the line is known to be proportional.

Thus we obtain two values of the force; the one proportional to the relocity, the other to the square of the velocity. Who does not perceive, that the reason of this apparent inconsistency is the different menning applied to the term force in the two cases? 
So far as general principles are concerned, meclıanics were nearly brought to a state of perfection by Newton and the mathematicians of his tine. Perlaps the principle of the conservation of living forces, introduced by John Bernoulli, ouglit to be mentioned.

To understand what is meant by this principle, it may be requisite to observe, that to mere pressure Leibnitz gave the name of vis mortua, or dead force, and to the force of moving bodies the name of vis viva, or living force. By the conservation of living forces, Bernoulli meant that permanence, tlirough all the gradual changes of any system of connected bodies, in the aggregate of the products of their masses into the square of their velocities. It abridges the solution of various problems, and was adopted by Daniel Bernoulli, as the basis of his theory of lydrodynamics, published in 1738.

The task of composing a treatise on Dynamics, full and original in every part, was taken up by Euler. He bestowed upon it all the pains and all the resources of his penetrating genius. It appeared in 1736, in two quarto volumes, entitled Mechanics, or the Science of Motion, and contained the most elaborate and complete body of analytical investigation that had hitherto appeared.

D'Alembert published his Dynamics in 1743, and founded the whole of his reasoning upon a very simple general principle. In every system of bodies acting mutually, their several movements, at any instant of time, may be decomposed into two portions, one which is retained in the next instant, and the other spent; and since an equilibrium must obtain among the lost motions, an expression is thus obtained for the motions which are preserved. The most intricate questions in dynamics were thus reduced to mere statical problems, and solved constantly in the same easy and uniform way. Maclaurin's method of expounding forces by co-ordinates, facilitated still furtler the application of this principle, which D'Alembert in 1744 and 1752 extended also to hydrodynamics.

Segner's theory of the motion of tops deserves also to be mentioned. It was published in $175 \mathrm{~b}$. He shows that every body having a determinate figure, which after combined impulsicns is abandoned in free space, will, besides its progressive motion, perform simultaneously and without the smallest interference, a constant and uniform revolution about each of three principal axes, mutually perpendicular and passing through the centre of gravity. These axes of rotation possess some curious properties, which were afterwards, investigated by Euler.

In 1788, Lagrange, by combining the principle of I'Alembert with that of virtual velocities, converted the whole into an absolutely analy. tical science. He referred the efforts of every particle of a moving system to three mutual perpendiculars, and thence derived three several differential equations, which, being integrated, would give the final solution of the problem. But no general formula for integrating such equations has been hitherto discovered.

Such is a sketch of the gradual progress of the mathematical investigation of mechanics. To enumerate the application of these general principles to the solution of particular problems-to point out the gradual improvements which have been introduced into the construction of mechanical engines, and the immense advantages which have resulted from these improvements, especially in this country, where they have been carried to the greatest extent, would require a treatise of no ordinary length, and would be quite incompatible with the linnits within which we are under the necessity of confining ourselves.

\section{ASTRONOMY.}

THE ancients discovered the planets, and gave them names, and noticed their motions, at a very early period. The motions of the sun and moon could not fail to attract their attention, and the changes in the seasons which depended upon these motions. The phenomena of the eclipses of these luminaries, viewed with such apprehension by the common people, necessarily attracted the attention of the first observers of the heavenly bodies: they soon observed a certain regularity in these phenomena, and became, in consequence, capable of predicting them. All these appearances could not be familiar to them without some speculations about the motions of the heavenly bodies.

The stars appeared as so many luminous points fixed in the heavenly spliere, having the earth for a centre, and revolving on an axis having that earth for a centre in the space of twentyfour hours. All the stars were found not to partake of this diurnal motion in the same degree; some were carried slowly to the east, and their paths, after a certain interval of time, returned upon themselves. The astronomers of the Alexandrian school set themselves to ascertain the general laws of these motions. This could not well be done without a hypothesis; and the simplest was, that the planets move eastwards in circles, and at aniform rate.

It was soon found, however, that the motion eastward was not uniform. The planet began $t$. more slower and slower, and, at last, became 
atationary. It then acquired a motion in a contrary direction, and, after proceeding for a certain time westwards it became stationary, and then inored eastwards as at first. These motions wero not easily reconciled with a uniform circular motion. The explanation, howevor, was attempted by Apollonius Pergeus. He conceived that, in the circumference of a circle having the earth for its centre, there noved the centre of another eircle, in the circumference of which the planet actually revolved. The first of these circles was called the deferent, and the second, the epicycle; the motion in the circunference of each was supposed uniform. Lastly, it was conceived that the motion of the centre of the epicycle in the circumference of the deferent, and of the planet in the epicycle, were in opposite directions; the first being towards the east, and the second towards the west. In this way, the alterations from progressive to retrograde, with the intermediate stationary points, were readily explained; and Apollonius carried his investigation so far as to determine the ratio between the radius of the deferent and that of the epicycle, from knowing the stations and retrogradations of any particular planet.

Hipparchus, the greatest astronomer among the ancients, discovered the inequality of the sun's apparent motion round the earth. To express this irregularity, he imagined an epicycle of a small radius, with its centre moving uniformly in the circumference of a large circle having the earth for its centre, while the sun revolved uniformly in the circumference of the small circle, but in a contrary direction.

As other irregularities in the motions of the moon and planets were observed, other epicycles were introduced; and Ptolemy, in his Almagest, enumerated all which then appeared necessary, and assigned to them such dimensions as enabled them to express the phenomena with accuracy.

By this contrivance the system of the heavens became extremely complicated. But it had the advantage of subjecting all the motions of the sun, moon, and planets very readily to a geometrical construction, or an arithmetical calculation of no great difficulty. Hence the predictions of astronomical phenomena, the calculation of tables, and the comparison of these tables with observations, became easy; and upon this the progress of the science depends. We have no evidence that the ancient astronomers ever considered the epicycles and deforents, which they employed in their systems, as having a physical existence, or as serving to represent these motions, they merely employed them to enable them to calculate the apparent motious of the heavenly bodies.

When Europe began to awake from the lethargy of the dark ages, astronomy was the first of the sciences which drew the attention of mon of seience. Purbacl and Regiomontanus contributed nost towards its advancement during the 15th century. Purbach resided at Vienna, under the patronage of the einperor Frederick the Third, and devoted himself to astronomical observations. He published an edition of tho Almagest; and though he neither understond Greek nor Arabic, yet lis knowledge of the subject enabled him to make it much more perfect than any formor translation. Regiomontanus was a pupil of Purbach, and became nuch more celebrated than his master.

Copernicus, who had the merit of first divining the true system of the universe, was born at Thorn, in the year 1473, studied at Cracow, and ultimately went into the church. A decided taste for astronoiny led him, when very young, to the study of that science. It occurred to him, at a very early period, to consider what effect the motions of the heavenly bodies would have upon a spectator, transferring that motion to the objects observed, but ascribing to it an opposite direction. It became immediately obvious, that the rotation of the earth, on its axis from west to east, would produce the apparent motion of the heavens from east to west.

In considering the objections which might be made to the system of the earth's motion he reasons soundly, though he was not avare of the full force of his own argument. Ptolemy had alleged, that if the earth were to revolve on its axis, the violence of the motion would be sufficient to tear it in pieces, and dissipate the parts. Why, says Copernicus, was he not more alarmed for the safety of the heavens, if the diurnal motion be ascribed to them, as their motion must be more rapid in proportion as their magnitude is greater?

We need not mention that Copernicus placed the sun in the centre, and taught that all the planets moved round that luminary in orbits nearly circular. The moon revolved round the earth, and the apparent diurnal revolution of the heavens from east to west was owing to the real diurnal revolution of the earth from west to east. The fizst edition of the Astronomia Instaurata, in which these doctrines appeared, was dedicated to the pope, and was published in 1543, a few days before the death of the author.

After Copernicus, Tycho Brahe was the most distinguished astronomer of the sixteenth century. An eclipse of the sun, which he witnessed in 1560 , when he was a young man, in consequence of the exactness with which it answered the prediction, inspired him with a veneration for the science, and an anxious desire to become acquainted with it. ' Unfortunately for his pro- 
gress, lie belouged to a noble family in Denmark -a class of men entitled, by their rank, to disclaim the pursuit of lnowledge, and extremely jealous of the privilege of ignorance. But his enthusiasm enabled him to break through the trammels of his order. He even acquired the patronage of the king of Denmark, and was able, in consequence, to erect an observatory in the island of Huena, supplied with far better instruments than liad ever yet been applied to astronomical observations. Tycho, by means of them could measure angles to ten seconds, which was sixty times the accuracy of Ptolemy, or of any instruments that had belonged to the school of Alexandria.

His first object was a catalogue of the stars, which he was anxious to make more accurate than that of Hipparchus and Ptolemy. The great dificulty in executing this task, proceeded from the want of an easy niethod of determining the distance of one heavenly body east or west of another. The distance north or south was easily determined by the common method of meridian altitudes. For the equator is a plane, which, for any given place on the earth's surface, always retains the same position. But no plane passing through the poles retains a fixed position with respect to an observer. The natural substitute is the measure of time. But this was wanting both to the Greek astronomers and to Tycho. Hipparchus and Ptolemy determined the longitude of the fixed stars, by referring their places to those of the moon. Thus depending on the most irregular of the heavenly bodies for deternining the position of the most fixed. Tycho nade use of the planet Venus, instead of the moon; and his method, though more tedious, was more accurate than that of the Greek astronomers. His catalogue contained the place of 777 stars.

The irregularities of the moon's motion were the next subject of inquiry. The ancients had discorered the inequality of this planet, depending on the eccentricity of the centre, and now called the equation of the centre. Ptolemy had added the knowledge of another inequality in the moon's motion, to which the name of evection has been given, causing an increase of the former equation at the quarters, and a diminution of it at the times of new and full moon. Tycho discorered another inequality, which is greatest at the octants, and depends upon the difference between the longitude of the moon and of the sun. A fourth inequality, depending wholly on the sun's place, was known to 'Tycho, but included among the sun's equations. Besides, these observations made hin acquainted with the changes in the inclination of the plane of the moon's orbit; and, lastly, with the irregular motion of the nodes, which, instead of being always retrograde at the same rate, are subject to change that rate, and even to become progres* sive, according to their situation in respect of the sun. These constitute a!l the irregularities in the moon's motion known before the developement of the theory of gravitation, and all, except the two first, were discovered by Tycho.

The atmospherical refraction, by which the heavenly bodies are made to appear more elevated above the horizon than they really are, was suspected, indeed, before the time of Tycho; but not certainly known to exist. He first became acquainted with it by finding that the latitude of his observatory, as determined by obserrations at the solstices, and from observations of the greatest and least altitudes of the circumpolar stars, always differed about four minutes. He supposed the effect of refraction to be $34^{\prime}$ at the horizon, and to diminish from thence upwards to $45^{\circ}$, wliere it ceases altogether. This last opinion is erroneous; but at $45^{0}$ it is less than $l^{\prime}$, a quantity probably not discernible by his instruments in the altitudes measured. He contrived an instrument, on purpose to make the refraction distinctly visible. It was an equatorial circle of ten feet diameter, turning on an axis parallel to that of the earth. With the sights of this equatorial, he followed the sun on the day of the summer solstice, and found that, as it descended towards the horizon, it rose above the plane of the instrument. At its setting, the sun was raised above the horizon by more than its own diameter.

The comet of 1570 was observed by Tycho, and gave rise to a new theory of these bodies. Its parallax was $20^{\circ}$, showing that it was three times farther off than the noon. He considered comets, in consequence, as bodies placed far beyond the range of our atmosphere, and moving round the sun. His observations on the new star of 1572, deserve also to be noticed. It appeared in Cassiopeia, on the 7th of November, all at once, and surpassed all the stars in splendour, being scarcely inferior to Venus herself. In the month of January, 1573, it was rather less than Jupiter. From this time it was constantly diminishing in splendour, and disappenred altogether in the month of March, 1574. Pliny informs us that it was the appearance of a new star which led Hipparchus to think of making a catalogue of the stars.

Tycho, notwithstanding his merit as an obser. ver, could not prevail upon himself to adopt the Copernican system of the motion of the earth round the sun. He made the sun move round the'eartl, while it was at the same time the centre of the planetary motion.

Kepler followed Tycho. He was born in $\mathbf{1 5 7 0 ,}$ and at an early age applied himself to the study 
of the heavens. His first discussions related to astronomical refraction, and to the calculation of eclipses.

He observed that the orbits of the planets are in planes passing through the sum, and that of consequence the lines of their nodes all intersect in the centre of that luminary. The opposition of the planets, or their places when they pass the meridian at midnight, offer the most favourable opportunities for observing them, both because they are at that time nearest the earth, and because their places seen from thence is the same as if they were seen from the sun. But the true time of oppesition had litherto been mistaken by astrunomers, who lield it to be at the moment wheu the apparent place of the planet was opposite to the mean place of the sur. It ought to lave been when the apparent places of both were opposed to each other. This correction was made by Kepler, and though violently opposed by Tyclio, was finally acquiesred in.

Having undertaken to examine the orbit of Mars, in which the irregularities are most considerable, Kepler discovered by comparing togetlier seren oppositions of that planet, that its orbit is elliptical; that the sun is placed in one of the foci ; and that there is no point round which the angular motion is miform. In the pursuit of this inquiry he found that the same thing is true of the earth's orbit round the sun. It was reasonable to conclude by analegy, that the orbits of all the other planets are elliptical, larving tle sun in their common focus.

The industry and patience of Kepler, in these investigations, are almost incredible. Lorarithms did not yet exist, so that arithmetical calculations were extremely laborious. The computation of every opposition of Mars flled ten folio pages; and Kepler repeated each calculation ten times. Seven oppositions thus calculated filled 700 folio pages. In such calculations the introduction of lıypotheses was unaroidable. Kepler rejected them whenerer they appeared erroneous, witlout hesitation, regretting merely the time which they had uselessly cost him. He began with liypotheses, and ended by rejecting every thing hypothetical.

Though the angular motion of the planets was not found to be uniform, it was discovered that a rery simple law connected that motion with the rectilinear distance from the sun, the forner being every where inversely as the square of the latter. Hence it was easy to prove, that the area described by the line drawn from the planet to the sun incrensed at a uniform rate; and, therefore, that any two such arens were proportioned to the times in which they were described.

This was the second of Kepler's three famous laws; the third was not less remarkible. He was of opinion that some simple relation must exist between the periodical times of the planets and their distances from tho sun. After an infinite number of trials, lie discovered, to his great deliglit, that in any two planets the squares of the times of the revolntion are as the cubes of their mean distances from the sun.

It is lumiliating to be obliged to state, that these great discoveries were at first underrated by astronomers, and that they even reproaclied Kepler for making theı ; because, in calculating the place of a planet, they iutrodıced a problem too difficult to be resolved by elementary geometry.

While Kepler was thus perfecting the theory of the planetary motions, Galileo liad constructed a telescope, and directed it to the moon. The appearance of that luminary, under the telescope, is now so well known, that we need not describe it. The effect produced upon the nind of Galileo may be easily conceived, He becanı satisfied of the resemblance between the surface of the inoon and that of the earth. The telescope brought into view multitudes of fixed stars, which cannot be seen by the naked eye. In Jupiter he observed a large disc, approaching in size to the moon. Near it he saw, for the first time, three luminous points in a straight line; two of them on one side, and one on the other. By observing them, however, night after niglit, lie found these small stars to be four in number, and to be inoons or satellites accompanying Jupiter, and revolving round him as the moon does round the earth.

In Saturn he saw one large disc, with two smaller ones very near it, and diametrically opposite, and always seen in the same places. But more powerful telescopes were wanting before these appearances could be interpreted.

The horned figure of Venus, and the gibbosity of Mars, added to the evidence of the Copernican system, and verified the conjecture of its author, who ventured to say, that if the sight were sufficiently powerful, we should see Mercury and Venus exhibiting phases similar to those of tlie moon.

These discoveries were probably the mest splendid that ever fell to the lot of any individual. In a more enlightened age they would have secured the gratitude and admiration of the whole scientific world. But Galileo had raised a host of enemies, by attempting to overturn the Aristotelian doctrines, and the churcl itself was roused to action, because it land staked its infallibility in support of dogmas which the discoveries and reasoning of Galileo had overturned. Galileo was twice brought before the inquisition ; and a cenncil of seren cardinals pronounced the following sentence: "That to naintain the sun to be immovable, and without local motion in 
the centre of the world, is an absurd proposition, false in philosophy, heretical in religion, and contrary to the testimony of Scripture. That it is equally absurd and false in philosophy to assert, that the eartl is not unmovable in the centre of the world, and, considered theologically, equally erroneous and heretical."

Here was an example, among many others that might_be given, of a number of men who conceived that power was able to subdue truth. But the puny efforts of popes and cardinals are totally unable to stop the steady flow of human knowledge. The decree remains still in force among the infallible oracles of the Roman Catholic church. But who pays any regard to it?* A promise was extorted from Galileo that he would not teach the doctrine of the eartl's motion, either by speaking or writing. But this promise he did not keep. His third dialogue, published long afterwards, contains a full display of the beauty of the new system, and such an exposure of the inconsistencies of Ptolemy and Tycho, as completed the triumph of the new system.

In 1663, when he was serenty years of age, lie was again brought before the inquisition, and forced solemnly to disavow his belief in the earth's motion. He was condemned to perpetual imprisonment; though the sentence was afterwards mitigated, and he was allowed to return to Florence. This sentence sank heavily into his mind; he never after either talked or wrote on the subject of astronomy. But no decisions of popes or inquisitors could stop the progress of truth. The opinion that the earth is one of the planets, and that, like the others, it moves round the sun in an elliptical orbit, became more and more prevalent, and was soon universally embraced.

The time was now come when the notions of the hearenly bodies were to be compared with the laws of motion, as known on the earth. For this comparison, and for the derelopement of a new science, the sublimest that has hitherto been exposed to the eyes of mankind, the world is indebted to Newton. In the year 1666, when he was a very young man, he was driven from Cambridge by the plague. As he sat one day in his garden, musing on the nature of the mysterious force by which the phenomena at the earth's surface are so much regulated, he observed an apple

- In the edition of Newton's Principia Mathematica by the Jesuits, Le Seur and Jacquier, printed at Rome in the year 1742, there occurs at the beginning of the third book the following declaration, by the reverend editors: "Newton in this third book has assumed the hypothesis of the motion of the earth. The propositions of the author could not be explained without adopting that hypothesis. We were therefore forced, in consequence, to adopt the opinion of another person. But we acknowledge ourselves obedient 24 the decreas of the pope against the motion of the earth." fall from a tree. The thought occurred to him, since gravity is a tendency not confined to bodies on the very surface of the earth; but since it reaches to the tops of trees, and to the summits of the highest mountains, witlout its intensity suffering any sensible change, why may it not reach to a nuch greater distance, and even to the moon itself? And if so, may not the moon be retained in her orbit by gravity, and forced to describe a curve, like a projectile, on the surface of the earth? Here another consideration very naturally occurred. Though gravity be not seusibly weakened at small distances from the earth, yet it may be weakened at greater distances, and at the moon may be much less. To estimate the quantity of diminution, Newton seems to have reasoned thus: If the moon be retained in her orbit by the gravitation of the earth, it is probable that the planets likewise are carried round the sun, in consequence of a similar power directed to the centre of that luminary. He proceeded, therefore, to inquire by what law the gravitation of the planets to the sun must diminish, in order to correspond with Kepler's third law.

Such an investigation would have been beyond the power of most mathematicians of that age ; but Newton soon discovered that Kepler's law would require the force of gravity to diminish exactly as the square of the distance increased. The moon, therefore, being distant from the earth about sixty semi-diameters of the earth, the force of gravity at that distance must be reduced to the 3600 th part of what it is at the earth's surface. Was the deflexion of the moon, then, from the tangent of her orbit in a second of time, just the 3600 th part of the distance which a heavy body falls in a second at the earth's surface? This question could be precisely answered, supposing the moon's distance in feet known, and her angular velocity, or the time of her revolution in her orbit also known.

'Being at a distance from books, he took the common estimate of the earth's circumference then in use; according to which, a degree was held equal to sixty miles. This being an erroneous supposition, the result of the calculation did not represent the force as adequate to produce the effect. Hence Newton concluded that some otler cause than gravity nust act on the moon, and laid aside, in consequence, all further speculations on the subject for the time.

Some years after, his attention was again called to the subject by a letter from Dr Hooke. proposing, as a question, To determine the line in which a body let fall from a lieight descends to the ground, taking into consideration the motion of the earth on its axis. This led him to resume the subject of the moon's motion, and the mea- 
sure of a degree by Norwood laving now furnished unore exact data, he found that his calculation gave the preciso quantity for the moon's inomentary deflexion froin the tangent of her orbit, which was deduced from astronomical observation. The moon, therefore, has a tendency to descend to the earth from the sane couse that a stone at its surface lias; and if the descent of a stone in a second bo diminished in the ratio of 1 to 3600 , it will give the quantity which the noon descends in a second below tho tangent of her orbit. Thus is obtained an experimental proof that gravity decreases as the square of the distance increnses. He had already found that the times of the planetary rorolutions, supposing their orbits to be circular, led to the samo conclusion. He now proceeded, with a view to the solution of Hooke's problem, to inquire what their orbits must be, supposing the centripetal force to be inversely as the square of the distance, and the initial force to be any whatever. On this subject, we are told, that he composed about a dozen of propositions, probably those at the beginning of the Principia.

After this noble opening it is very surprising that he again dropt the investigation, and was not induced to take it up again till several years after, when Dr Halley paid him a visit at Cambridge, and prevailed upon him to renew and extend his researches.

He then found that the three laws of Kepler are direct consequences of the systen of gravitation. He showed that they all followed from the law that the planets gravitate to the sun, with a force inversely as the square of the distances. It added much to this evidence that the observations of Cassini had proved the same laws to prevail among the satellites of Jupiter.

Did the principle which appears to unite the great bodies of the universo act only on these bodies? Did it reside merely in their centres, or was it a force common to all the particles of matter? It could hardly be doubted that this tendency was common to all the particles of matter. For the centres of the great bodies had no properties but those derived from the particles distributed around them. But the question admitted of being brought to a better test than mere abstract reasoning. The bodies between which this tendency had been observed to take place were all round bodies, and nearly spherical, and whether large or small, they seemed to gravitate towards each other, according to the same law. The planets gravitate to the sun, the moon to the earth, the satellites of Jupiter to that planet-and gravity, in all these cases, varies inversely as the square of the distances. It was, therefore, safe to infer that however small the bodies, provided they were round, they would gravitate to each other with forces varying in rersely as the squares of the distances. It was probable, then, that gravity was the mutual tendency of all the particles of matter to each other. But this could not be concluded with certainty, till it was known whether great spherical bodies, composed of particles gravitating according to this law, would themselves gravitate according to the same.

This problem Newton undertook to solve. IIo reduced it to the quadrature of curves, and found, no doubt, with delight, that the law was the samo for the sphere as for the particles which compose it. That the gravitation was directed to the centre of the sphere, and was, as the quantity of matfer contained in it, divided by the square of the distance froin the centre. Thus a complete expression was obtained for the law of gravity, involving both the conditions on which it must depend, the quantity of matter in the gravitating bodies, and the distance at which the bodies are placed. There could be no doubt that this tendency was always mutual, and there was no exception to the rule that action and re-action are equal. So that if a stone gravitates to the earth, the earth equally gravitates to the stone; or, in other words, the two bodies approach each other with velocities which are inversely as their quantities of matter.

Newton went further, and showed how the quantity of matter, and even the density of the planets, might be determined. In the way already explained, he was enabled to compare the intensity of the earth's gravitation to the sun, with that of the moon to the earth, each being measured by the momentary deflexion from the tangent to the small arch of its orbit. A more detailed investigation showed that the intensity of the central force in different orbits, is as the mean distance divided by the square of the periodic time. And the same intensity being also, as the quantities of matter divided by the squares of the distances, it follows that these two quotients are equal to each other; and that, therefore, the quantities of matter are as the mean distances divided by the squares of the periodic times. Supposing, therefore, that the ratio of the mean distance of the sun from the earth, to the mean distance of the moon from the earth is given; as the ratio of their periodic times is also known, the ratio of the quantity of matter in the sun, to the quantity of matter in the earth, of consequence is found. And the same thing holds in all the planets which hare satellites moving round them. Hence also their mean dessities, or specific gravities, become known.

The Principia Plilosophice Naturalis, which contained all these discoveries, was puhlished in 
the year 1687; and many years elapsed before it becaine generally known and understood.

The principle of gravity thus fully established, and its consequences developed, was not mentioned by Newton for the first time. Some curious references to it are found in the writings of the ancients; and Copernicus, Kepler, and Hooke entertained opinions respecting it approaching much "nearer to accuracy. "I do not think," says Copernicus, "that gravity is any thing else than an appetency of the parts of the earth given by the providence of the Supreme Being, that by uniting together they may assume the form of a globe. It is probable that this same affection belongs to the sun, the moon, and the fixed stars, which are all of a round form."

Kepler, in his great work on the Motions of Mars, treats of gravity as a force acting naturally from planet to planet, and particularly from the earth to the moon. "If the moon and the earth were not retained by some animal or equivalent force, each in its orbit, the earth would ascend to the moon by a 54 th part of the interval between them, while the moon moved over the remaining fifty-three parts; that is, supposing them of the same density." This passage displays a curious mixture of ignorance and knowledge respecting the planetary motions.

Hooke made a nearer approach to truth than any of lis predecessors. In his attempt to prove the inotion of the earth in 1674, he lays it down as a principle, that the heavenly bodies have an attraction towards their own centres, which extends to other bodies within the sphere of their activity. The force of gravity he considered as greatest nearest the body, though he could not determine the rate of variation. These were considerable advances, though his opinions were mixed with much error and much ignorance. Yet he was disingenuous enough, when Newton had determined the law according to which gravitation varies, to lay claim himself to the discovery.

Of all the pliysical principles that have been hitherto made known, there is none so fruitful in consequences as that of gravitation. The same sagacity that led to the discovery was necessary to trace its consequences.

The mutual gravitation of all bodies being admitted, it was evident that, while the planets were describing their orbits round the sun, they must mutually attract one another; and hence, in their revolutions some irregularities, from the description of equal areas in equal times, might be expected. But hitherto such irregularities had been observed only in the revolutions of the moon. This led Newton to inquire what the forces were, which, according to the laws just discovered, cuuld produce the irregularities in question. Thie moon must be acted on not only by the earth, but also by the sun; and it was at once evident that the force which was sufficient to bend the orbit of the earth into the form of an ellipse, must have a sensible effect on the orbit of the moon. He showed that it is not the whole force which the sun exerts on the moon that disturbs her motion round the earth, but only tlie difference between that force and the force which the sun exerts on the earth. To obtain exact measures of the disturbing forces, he supposed the entire force of the sun on the moon to be resolved into two, of which one always passed through the centre of the earth, and the other was always parallel to the line joining the sun and earth, consequently to the direction of the force of the sun on the earth. The former of these forces being directed to the centre of the earth, does not prevent the moon from describing roind the earth equal areas in equal times. But the effect of it on the whole is to diminish the gravitation of the moon to the earth about one 358th part, to increase her meaul distance in the same proportion, and her angular motion by about a 179th. He proved, by a very subtle investigation, that these forces would not sensibly change the elliptical orbit of the moon, but that the orbit itself would be rendered movable; its longer axis having an angular and progressive motion, by which it advanced over a certain arc during each revolution of the moon. This afforded an explanation of the motion of the apsides of the lunar orbit, which had been observed to go forward at the rate of $3^{\circ} 4^{\prime}$ nearly, during the time of the moon's revolution, in respect of the fixed stars.

But the exact quantity of the motion of the apsides did not correspond with the diminution of the moon's gravity, as above assigned. There was, therefore, a cloud overshadowing this part of the lunar theory, which was not dissipated till a greater advance in mathematical knowledge put it in the power of subsequent astronomers to investigate the subject completely.

The line of the lunar nodes had been observed to retrograde at the rate of $3^{\prime} 10^{\prime \prime}$ every day. Newton showed that the second of the forces into whicb the solar action was resolved, being exerted not in the plane of the moon's orbit, but in that of the ecliptic,inclined to the former, at an angle somewhat greater than five degrees, its effect must be to draw down the moon to the plane of the ecliptic, sooner than it would otherwise arrive at it; in consequence of which, the intersection of the two planes would approach, as it were, towards the moon, or move in a direction opposite to that of the moon's motion, or become retrograde. From the quantity of the solar force, and the inclination of the moon's 
orbit, Newton deternined the mean quantity of this retrogradation, as well as the irregularities to which it is subject, and found both to agree, corresponding very accurately with observation.

The lunar inequality discovered by Tycho, and called by him the Variation, which consists in the alternate acceleration and retardation of the moon in each quarter of her revolution, was accurately determined from theory, such as it is found by observation. The snme remark applies to the annual equation, which liad been long confounded with the equation of time. It does not appear that Newton attempted an exact determination of the other inequalities of the lunar motion. He satisfied himself with the general truth, that the principle of the sun's disturbing force led to the supposition of inequalities of the same kind with those actually observed. The full knowledge of all these inequalities, and their exact accordance with theory, was reserved for a future period, when a more perfect state of the calculus enabled philosophers to investigate the whole subject.

The earth, in consequence of its rotation on its axis, is influenced by a centrifugal force, which must act most powerfully on the parts most distant from the axis. The amount of this centrifugal force is greatest at the equator; and being measured by the momentary recess of any point from the tangent, which was known from the earth's rotation, it could be compared with the force of gravity at the same place, measured in like manner by the descent of a heavy body in the first moment of its fall. Newton found that the centrifugal force at the equator is the 28.9th part of gravitation, diminishing continually as the cosine of the latitude, on going from the equator to the poles, where it vanishes altogether. From the combination of this force with that of gravity, it follows that the plumb line cannot tend exactly to the earth's centre, and that a true liorizontal line, such as is drawn by leveling, if continued from either pole in the plane of a meridian all round the earth, would not be a circle but an ellipse, having its greater axis in the plane of the equator, and its least in the direction of the axis of the earth's rotation. Now the surface of the ocean itself actually traces this level, as it extends from the equator to the poles Hence it follows, that the figure of the earth is an oblate spheroid, or a solid generated by the revolution of the elliptic meridian about its shorter axis. To determine the proportion of the axis of this splieroid, Newton conceived that, if the waters at the pole and at the equator were to communicate by a canal through the interior of the earth, one branch reaching from the pole to the centre, and the other at right angles to it from the centre to the circumference of the equa- tor, the water in this canal must be in equilibrio, or the weight of the fluid in the one branch just equal to that in the other. By a very subtle process of reasouing, he found that the length of the equatorial canal must be to that of the polar as 230 to 229. It was demonstrated afterwarls by Maclaurin and Clairaut, that this is in fact the ratio of the two dinmeters of the enrth, supposing its specific gravity to be honogeneous from circumference to centre. If its specific gravity increased from the circuinference to the centre, so as to be infinitely great at the centre, then the difference between the two diameters would be a minimum, and would amount only to one 578th part. Mr Ivory has exanined this subject with his usual sagacity and profound mathematical knowledge, and concludes that the true difference between the length of the two diameters is one 300th part. This determination, we may safely assume, as exceedingly near tlie truth.

From the figure of the earth thus determined, Newton showed that the intensity of gravity at any point of the surface, is inversely as the distance of that point from the centre. Its increase, therefore, in going from the equator to the poles, is as the square of the sine of the latitude, the same ratio in which the degrees of the meridinn increase. As gravity diminishes in going from the poles to the equator, it follows that a pendulum of a given length would vibrate slower when carried from Europe to the torrid zone. This had been already verified by the observations of Varin and De Hayes, made at Cayenne and Martinique.

What is called the precession of the equinoxes, or the retrogradation of the equinoctial points, had been long known. Its rate had been found to amount nearly to $50^{\prime \prime}$ annually, so as to complete an entire revolution of the hearens in 25,920 years. Nothing seeıned more difficult to explain than this phenomenon-no preceding astronomer had even thrown out a conjecture on the subject. It was reserved for the sagacity of Newton. He was directed by a certain analogy between the precession of the equinoxes, and the retrogradation of the moon's nodes, a phenomenon to which his calculus had been already successfully applied. The spheroidal shell, or ring of matter which surrounds the earth in the direction of the equator, being one half aboro the plane of the ecliptic, and one half below, is subjected to the action of the solar force, the tendency of which is to make this ring turn on the line of its intersection with the ecliptic, so as ultimately to coincide with the plane of that circle. This would have happened long since it the earth had not turned on its axis. The effect of the rotation of the spheroidal ring from west 
to east, at the same time that it is drawn down towards the plane of the ecliptic, is to preserve the inclination of these two planes unchanged, but to make their intersection move in a direction opposite to that of the diurnal rotation, that is, from enst to west, or contrary to the order of the signs; $10^{\prime \prime}$ appeared to be the part of the effect due to the moon's attraction, and $40^{\prime \prime}$ to the attraction of the sun. How Newton obtained these numbers does not appear; his data seem scarcely sufficient for the purpose; yet as his results are correct, the probability is that he was in possession of data which he has not stated to his readers. The subject was completed at the interval of a century, by the exertions of Lagrange and Laplace.

Nerton next turned his attention to the phenomena of the tides, the dependence of which on the sun and moon was sufficiently obvious to common observation. That the moon has the greatest effect in producing the tide, is evident from this, that high water always occurs at a place nearly at the time when the moon is in the same meridian, and that the daily retardation of the tide is synchronous with the retardation of the moon in her diurnal revolution. It is equally evident that the sun is concerned in the tides, as the highest tides happen when the sun, moon, and earth are all three in a straight line, and the lowest tides when the lines drawn from the sun and moon to the earth make right angles witl each other

Newton perceived that the waters revolving round the eartli are nearly in the condition of a satellite revolving about its primary, and liable to the same kind of disturbance from a third body. High water always takes place in the hemisphere where the moon is, and in the opposite hemisphere where the moon is not, nearly at the same time. Now if the action of the moon disturb the equilibrium of the ocean, just as the action of one planet disturbs the motion of a satellite moving round another, this is exactly what might be expected. It had been proved that the moon, when in conjunction with the sun, had her gravitation to the earth diminished, and when, in opposition to the sun, has it diminished very nearly by the same quantity. For at the new moon the moon is drawn to the sun more than the earth is, and at the full moon the earth is drawn to the sun more than the moon is, and nearly by the same quantity; the relative motion of the two bodies is, therefore, affected the same way in both cases, and the gravity of the moon to the earth is in both cases lessened.

The action of the moon on the waters of the ocean must be regulated by the same principle. In the hemisphere where the moon is, the waters are more drawn to the moon than the earth is; and its gravity being lessened, the column towards the middle of the henisphere lengthens in consequence of the pressure of the waters, which are at a distance from the middle point of which the weight is less diminished, or at the horizon even increased. In the opposite hemisphere the earth is more drawn to the moon than the waters, and their relative tendencies are changed in the same direction, and nearly by the same quantity.

The attraction of the sun and moon conspire to elevate the waters of the ocean, whether these luminaries be in opposition or conjunction. In both cases the solar and lunar tides are added together, and the tide actually observed is the sum of both. At the quadratures these two tides are opposed to one another, the high water of the lunar tide coinciding with the low water of the solar tide, and vice versa; so that the tide actually observed is the difference between the two.

Newton had no data for measuring the lunar force in producing the tides. But a measure for the solar force, as it acts on the moon, had been obtained. It had been shown to be $\frac{3}{17}$ th of the force which retains the moon in her orbit. This last is $\frac{2}{3600}$ th of the force of gravity at the earth's surface; and, therefore, the force with which the sun disturbs the moon's motion is $\frac{1}{178} \times \frac{\frac{1}{360}}{360}$ gravity at the earth's surface. This is the solar disturbing force on the moon, distant sixty semidiameters from the earth's centre; but on a body only one semi-diameter distant from that centre (that is, on the water of the ocean) the disturbing force will be sixty times less, or only $\frac{1}{38445009}$ of gravity at the earth's surface.

Now this being the mean force of the sun, is that by which it acts on the waters ninety degrees distant from the point where it is vertical, where it is added to gravity, and tends to increase tho weight and lower the level of the waters. At the point where the sun is vertical the force to raise the water is about double this; and, therefore, the whole force tending to raise the level of the high above that of the low water, is three times the preceding, or about $\frac{1}{18816100}$ of gravity. Newton had previously shown that the centrifugal force, amounting to $\frac{1}{28}$ of gravity, was able to raise the level of the ocean above serenteen miles. This enabled him to conclude, that the elevation of the waters, produced by the solar force, will come out 1.92 French feet. From a comparison of the spring and neap tides, that is, of the sum and difference of the lunar and solar forces, it appears that the force of the moon is to that of the gun as 4.48 to 1 . Hence the moon will raise the wilters 8.63 French feet. $n-F, 2$ 
making together 10.1 feet, which agrees pretty well with what is observed in the open sea at a distance from land.

From the force which the moon exerts on the waters of the ocenn, Newton concluded that the quantity of matter in the moon is to that in the earth ns 1 to $39 \cdot 78$, or, in round numbers, as 1 to 40. He found also the density of the moon to the density of the earth ns 11 to 9 .

Much lias been done upon the tides by Maclaurin, Bernoulli, Euler, and Laplace; but the original deduction of Newton, of which an idea has just been given, will be for ever menorable.

The motion of comets still remained to be discussed. They had only lately been placed beyond the range of tho earth's atmosphere; but with respect to their motion, astronomers were not agreed. Kepler thought that they moved in straight lines, Cassini that they moved in the planes of great circles, but with little curvature. Hevelius had shown the curvature of their path to be different in different parts, and to be greatest when nearest the sun. A parabola having its vertex in that point, seemed to him to be the line in which the comets moved. Newton, satisfied of the universality of gravitation, had no doubt that the orbits of the planets were conic sections, liaving the sun in one of the foci. The curve inight be an ellipse, a parabola, or an hyperbola, according to the relation between the force of projection and the force tending to the centre. As tho eccentricity of the orbit is very great, the portion of it that fell within our view could not differ much from a parabola. This rendered the calculation of the comet's place, when the position of the orbit was once ascertained, more ensy than in the case of the planets. From throe observations of the comet, the position of the orbit could be determined, though the geometrical problem was one of great difficulty. Newton gave a solution of it, and it was by this that his theory was to be brought to the test of experiment. If the orbit thus calculated was not the true one, the places of the comet calculated on the supposition that it was, and that it described equal are as in equal times about the sun, could not agree with the places actually observed. Newton showed, by the example of the remarkable comet then (1680) visible, that this agreement was as great as could reasonably be expected. 'Thus another proof was given in support of the principle of universal gravitation.

We have been thus particular in tracing the discoreries of Newton, because they constitute the most memorable, the most successful, the most difficult, and the most sublime set of inrestigations which had hitherto been attempted. The nore the doctrine of universal gravitation has been investigated, the more firmly lias its truth been established. Every inprovement in the infinitesinal calculus has given mathematicians (if the expression may be permitted) a firmer grasp of the universe. Now effects of the mutual action of the planets on each other lave been detected; but all according most harmoniously, or rather resultiug as a necessary consoquence of the law of universal gravitation, as laid down and investigated by Newton. No other department of science can be compared to this; no otlier brancl of human knowledge can be specified, which is built on a foundation so firm that every succeeding investigation has served only to render it more secure. No other theory can be exlibited so perfect, that every minnte fact might be deduced $a$ priori as a consequence of it; and which does not contain a single phenomenon within the whole range of the science that is not merely not inconsistent with it, but which does not directly flow from it.

The Principia appeared in 1687; and the doctrines which they contained were immediately embraced by the small number of British mathematicians who were able to read and understand that immortal work. But on the continent it was treated at first with neglect, and an indifference bordering on contempt. The only mathematical competitor that Newton had on the continent was Leibnitz, with his disciples and staunch adherents, the two Bernoullis. The question respecting the original dicoverer of tho fluctionary calculus was not yet agitated. Yet the German mathematicians do not seem to have giren themselves the trouble of making themselves masters of the Principia. Tho cautious mode of investigation which Newton had adopted did not quite accord with the genius of Leibnitz, who was fond of metaphysies, and in the habit of introducing them into most of his investigations.

France, which has since that period produced so many eminent mathematicians, owing to the fostering care of her government, could not at that time boast of any of very great eminence. The philosophy of Descartes was every where prevalent; and his vortices, which it was the object of the Principia to overturn and subvert, were too dear to the French to enable them to judge of the doctrines of Newton with the requisite impartiality. Accordingly, the first mathematician who ventured publicly to defend the doctrines of Newton was NIaupertuis. In the year 1732 he published a work, in which he drew a comparison between the systems of Descartes and Newton, and showed the superiority of the latter. Fontenelle, lowever, in his Eloge of Newton, inserted in the Memoires of the Academy for 1727, admits the infinite merit of 
the Principia, and states the universal shout of admiration, which, after a long interval of years, was raised from every country in its praise. But nothing conformable to the Newtonian principle had at that period appeared in France; we suspect, indeed, that we might say that nothing conformable to it had appeared in Europe.

It is curious, and contributes not a little to lead -us into the character of our lively neiglbours, that the great apostle of Newton in France, the person who contributed most to make his opinions known and adopted, was Voltaire.

Fontenelle continued a Cartesian to the end of his days. Cassini and Miraldi seem to have been quite unacquainted with the Newtonian system, and continued the most vague and imaginary hypotheses for calculating the paths of comets, after Halley had computed tables from which the motions of all the comets that had ever appeared, or ever could appear, might be easily deduced.

We must now proceed to notice the most important additions which have been made to astronomy since the appearance of the Principia.

1. The aberration of the Fixed Stars. Drs Bradley and Molineux, in the end of the year 1725, were occupied in searching for the parallax of the fixed stars by means of a zenith sector, which was erected at Kew. It was of great diameter, and furnished with a telescope twentyfour feet long, with which they proposed to observe the transits of stars near the zenith, according to a method first suggested by Hooke, and pursued by him so far as to induce him to think that he had actually discovered the parallax of $\gamma$ Draconis, the bright star in the head of the dragon, on which he made his observations. They began to observe the transits of the same star on the $3 \mathrm{~d}$ of December, wlien the distance from the zenith at which it passed was carefully marked. By the observations of the following days, the star seemed to be moving south; and about the beginning of March in the following year, it had got $20^{\prime \prime}$ to the south, and was then nearly stationary. In the beginning of June it had come back to the same situation where it was first observed; and from thence it continued its motion northwards till September, when it was about $20^{\prime \prime}$ north from where it was first seen; its whole declination amounting to $40^{\prime \prime}$.

This motion surprised the observers a good deal; as it lay the contrary way to what it would have done had it proceeded from the parallax of the star. But the repetition of the observations proved their accuracy. They were afterwards continued by Bradley, with another sector of smaller radius, but large enough for the purpose; which embraced a larger arch, and admitted the observation of stars which passed at a greater distance from the zenith. Eren with this addi. tion, the observations did not put Bradley in possession of the complete fact. They only gave him the motion of each star in declination, but not in right ascension.

After considering the subject with the greatest attention, and excluding all those causes which were inadequate to produce the effect, it occurred to him that the apparent motions might be produced from the progressive motion of light, combined with the motion of the earth in its orbit. If the earth were at rest, it is evident that a telescope, to admit a ray of light from a star to pass along its axis, must be directed to the star itself. But if the earth (and of course the telescope) be in motion, it must be inclined forward, so as to be in the diagonal of a parallelogram, the sides of which represent the motion of the earth and the motion of light, or in the direction of these motions, and in the ratio of their velo. cities. It is with the telescope just as with the vane at the mast-head of a slip. When the ship is at anchor the vane takes exactly the direction of the wind; but when the ship is under way it places itself in the diagonal of a parallelogram, of which one side represents the velocity of the ship, and the other the relocity of the wind.

The telescope, therefore, through which a star is viewed, and by the axis of which the position of the star is determined, must niake an angle with the straight line drawn to the star; except when the earth moves directly to the star, or directly from it. Hence it follows, that if the star be in the pole of the ecliptic, the telescope must be pointed forwards in the direction of the earth's motion, always by the same angle; so that the star would be seen out of its true place by that angle, and would appear to describe a circle round the pole of the ecliptic, the radius of which subtended at the earth an angle, of which the sine is to unity as the velocity of the earth to the velocity of light.

These velocities Bradley took at 1 to 10313 , as most suitable to his observations, which made the radius of the circle of aberration $20^{\prime \prime}$, and the transverse axis of the ellipse, or the whole clange of place, $40^{\prime \prime}$. It was the shorter axis which Bradley had actually observed in the case of $\gamma$ Draconis, that star being very near the solstitial colure, so that its changes of declination and of latitude are almost the same.

To show the truth of his theory, he computed the aberration of different stars, and, on comparing the results with observation, the coincidence appeared almost perfect, so that no doubt remained concerning the truth of the principle on which he had founded his calculations. He did not explain the rules themselves Clairaut 
published the first investigation of them in the Memoirs of the Acadeniy of Sciences for 1737. Simpson also gave a demonstration of them in his Essays, published in 1740 .

2. Figure of the earth. Newton, from the theory of universal gravitation, had shown that the figure of the earth was an oblate spheroid, flattened at the poles. But the trigonometrical measurement of France, begun by l'icard in 1675, and finished by Cassini in 1716, led to a different conclusiou. For the degrees on the north of Paris, instead of lengthening, as ought to have been the case, according to Newton's theory, were shorter by about $\frac{i}{130}$ th part than those to the south of that capital. 'This indicated the diameter of the earth through the poles longer than the equatorial diameter, in the proportion of 96 to 95 . This was laid hold of by the Cartesiaus in their reasonings against the Newtonian philosophy.

A clock, made by Gralıam, laving been carried out to Jamaica in 1732, by Colin Campbell, was ascertained by astronomical observations at the Black River, in latitude $18^{\circ}$, (allowing for the influence of heat on the pendulum) to go $1^{\prime} 58^{\prime \prime}$ every day slower tlasn in London. Bradley found that this variation exceeded what would suit the figure calculated by Newton. He, therefore, suspected sone diminution of gravity in the equatorial regions. But the subsequent investiga. tions of Maclaurin demonstrated the accuracy of the Newtonian conclusions. The French triangulation being resumed in 1740, an error was detected in the measurement of the base, and another not less considerable in the observation of the meridional arc. But the work was not terminated till the year 1754. In the extent of above eight degrees, their lengths appeared regularly to increase from Perpignan to Dunkirk by about $\frac{1}{1720}$ tl part, marking obriously the oblateness of the spheroid.

Condamine, in the year 1733, urged the Academy of Sciences to send a party to measure a degree under the equator. The academy adopted the project with zeal, and were lucky enough to obtain the concurrence and support of government. In May, 1735, the academicians, Condamine, Bouguer, and Godin sailed from Rochelle to Peru, where they were joined by Juan and Ulloa, two naval officers, deputed by the king of Spain. In the month of July, 1736, they met at Quito, under the line. They chose a valley of the Cordilleras, running about 200 miles southwards from that city, and enclosed on both sides by the loftiest ranges of the Audes. Divided into two sets, they carried a series of triangles along the flanks and summits of those unountains, and connected them with the base measured below. The task was peculiarly ardu. ous, owing to the severity of the climate, and the total want of accommodation. But eight years of indefatigable industry enabled then to finish the measurement assigned to them. Bouguer, the most emineut of them all, gave a complete narrative of all their various operations in his Treatise on the Figure of the Earth, not publish ed till 1749 ; and one of the most scientific works that has ever appeared. He concluded that the earth is not only an oblate spheroid, but so collsiderably flattened as to have its equatorial diameter to its axis as 179 to 178.

Meanwhile Maupertuis prevailed on the French minister, Maurepas, to despatcl another company, which he reluctantly consented to lead, for a sinilar purpose, to the arctic circle. The associates of Maupertuis were Monnier, Camus, Orthier, and Clairaut, by far the most eunineut of them all. They arrived in Stockholm in June, 1736, and were joined by Celsius, the professor of astronomy at Upsala, who had brought from London Graham's zenith sector and transit instruments. They proceeded to the bottom of the Gulf of Bothnia, and selected Torneo as their principal station. Their triangles extended from this town to Kittis, a distance of about sixty miles. The whole was finished in little more than a year; and the length of a degree of latitude at the Arctic circle was found to be $57,4.19$ toises, or 349 toises longer than the corresponding neasurement at Paris. This gare tho ratio of 178 to 179 to the polar and equatorial dia meters-very nearly agreeing with the more extensive operations afterwards perforned in Peru.

But this arctic triangulation, bearing evident marks of haste, became suspected of inaccuracy ; and at the suggestion of Melanderhielm, the Swe. dish academy, about the beginning of the present century, sent Svanberg, witl proper assistants, to resume the operations. They not only rectitied the former observations, but carried the measurement about forty miles farther north. It was determined that the length of a degree in Lapland is only 57,209 toises. This, compared with Cassini's measurement in France, reduces the oblateness to $\frac{1}{350}$ th of the axis. Comparing the measurements in Lapland and Peru, we obtain the ratio of 302 to 301 for the equatorial and polar diameters.

Other measurements were made at the Cape of Good Hope, in the papal territories, in England, in the East Indies, but as they have not served to diminish, but rather to increase the anomalies, we need not notice thein here. The convertible pendulum of captiain Kater, which he was very sanguine would furnish an invariable standard of lineal measure, has been also employed as a neans of deducing the figure of the earth. But 
the results vary not less than those obtained by trigonometrical measurement. Mr Irory, from a rritical examination of all the data, has concluded the ellipticity to be $\frac{1}{300}$. In this decision, from the consummate mathematical skill of the author of it, we are disposed to coincide.

3. Application of mathematics to calculate all the disturbances introduced by gravitation into the solar system.

The first person who improved the Newtonian theory of the moon was Calandrini, professor of Inathematics in Geneva, who superintended the printing of the Jesuits' copy of the Principia in 1739 and 1742. He investigated, by a direct method, the principal lunar equations, and likewise the smaller inequalities which Newton had left undemonstrated. He revised the investigation of the motion of the apsides; but his calculations only gave half the quantity derived from observation. Dr Matthew Stewart, professor of mathernatics in Edinburgh, discovered the true notion of the line of the apsides by a simple geometrical procedure. And in 1749, Walmesley produced a correct analytical investigation of the inotion of the lunar apogee, which he extended and completed in 1758 .

Clairaut began his investigations of the lunar theory in 1743. At first he was satisfied with merely studying the Newtonian procedure, and couverting it into analytical expressions; but he gradually pushed his investigations farther, and in 1747 comprised all the subordinate motions of the moon under the famous general problem of the three bodies. But after prodigious labour, his solution assigned for the variation of the lunar apogee only half the measure established by observation. Euler and D'Alembert arrived at a similar conclusion about the same time. Clairaut resumed the subject, and, after incredible labour, obtained a result which accorded perfectly with observation, and thus confirmed the simple law of gravity, as.laid down by Newton. The knowledge of this result induced Euler to resume his investigations, and by quite a different procedure he also obtained the true variation of the lunar apogee. D'Alembert juslied his calculations still farther, and approached still nearer the result of observation. Thus the law of attraction was for ever established on the secure basis of mathematical demonstration.

This great point being settled, mathematicians set themselves with eagerness to improve the lunar tables, which were obviously of such importance for finding the longitude at sea. Clairaut bestowed intense application on the subject, and produced a set of lunar tables, distinguished by their superior accuracy. Euler devoted to the same task the whole of his unrivaled analytical skill. But Mayer was the astronomer who dis. tinguished himself most in this important inves. tigation. He had been appointed director of the observatory of Gottingen in 1751, and laboured with so much intensity that he shortened his days. He derived the elements of his lunar tables from a discussion of numerous eclipses and occultations. He borrowed little from theory, though lie preferred the arrangement of the elements. adopted by Euler. He was the first person that eniployed conditional equations to find the true value of the co-efficients. His tables were inserted in the Gottingen transactions; and after the most careful corrections, he sent them in 1755 to Loll. don for the patronage of the Board of Longitude. At his death in 1762, he left two copies, greatly improved, one of which lis widow transinitted to that scientific body. After protracted deliberations, the sum of $£ 3000$ was at last awarded to his family, with a present of $£ 300$ to Euler for his excellent formulas. But another more com. plete copy having been afterwards presented, the Board of Longitude bestowed an additional reward of $£ 2000$ at the instance of Dr Maskelyne, who zealously undertook the editing of those tables in the year 1770 .

The next point to which mathematicians di. rected their attention, was the investigation of the disturbing influence or mutual perturbations of the larger and nearer planets. Euler, in 1747, sent to the Academy of Sciences a most ingenious memoir on the derangement of Saturn's motion, occasioned by the superior attraction of Jupiter. It was now that he discovered that there exist really no secular equations, but that all deviations from the regular course are strictly periodical, and return always in the same order, though separated at vast intervals. His first investigation was rather imperfect; but four years after he produced another dissertation, which gained the double prize of the academy. $\mathrm{He}$ found that the mean motions of Jupiter and Sa. turn are equally subject to a very slow increase or diminution, whicl alternates, however, in the lapse of 15,000 years. He gained the prizes for 1754 and 1756 , by his theory of the inequalities in the earth's motion caused by the planets. He discovered four small anomalies to result from their combined attractions, though it was scarcely possible, for want of proper data, to assign the precise measures of these aberrations. He estiinated the mean progression of the aphelin at $12^{\prime \prime}$ annually, and the diminution of the obliquity of the ecliptic at $49^{\prime \prime}$ in a century. He found that the eccentricities of the aphelia of Jupiter and Saturn are periodical, and complete their cycle in the space of 30,000 years.

The same subject was discussed by Clairaut in 1757. By comparing his formula with the ob- 
servations of Lacaille, he determined very vearly tho masses of the principal planets, and showed that tho greatest effect of their accumulated influence in deranging the earth's motion cau amount only to about a minute. His estiunte of the attraction of Venus has beeu confirmed by later and more elaborate calculation.

In 17.49 D'Alembert investigated rigorously the effects arising from tho moon's attraoting the spileroidal prominenee of tho earth. By the .ransformation of this general expression he found the precession or conical motions of the terrestrial nxis about the poles of the ecliptic to be $50^{\prime}$ annually, and the nutation, or alternate vibration on tho same plane to be only $18^{\prime \prime}$ during the period of the revolution of the lunar nodes. Comparing this quantity with observation, lie concluded, that at the surfince of the earth the attraction of the sun is to that of the moon as 3 to 7 ; which makes the satellite to have only the roth part of the mass of our planet.

Astronomers now turned their attention to the motions of the comets. These bodies describe elliptic orbits with very different inclinations, and so extremely elongated as to resemble parabolas, through a considerable part of their course. Being very small, they aro seen for a short space ouly in the vicinity of the sun, and become quite invisible when they approach the other oxtremity of their orbit, which is probably beyond the boundaries of our planetary system. The periodic time of comets depending upon the transverse axis of the ellipsis can seldom be determined witl accuracy. The few observations which can be made while it is near the perihelium are scarcely sufficient to assign its mean motion, and the places of its nodes and perihelium.

Halley applied the formulas of Nerton to the computation of twenty-four remarkable comets. But his attention was particularly fixed on the nearest of them, which had been obserred in 1531, 1607 , and 1682 , and seemed to be the sane with one noticed in old chronicles in 1080, 1155, 1230, 1305,1381 , and 1456. Hence it performed its revolutions in about $75 \frac{1}{2}$ years. He therefore rentured to predict its return about the end of 1753 or beginning of 1759 . The time of the expected return approaching excited intense curiosity in the scientific world. Clairaut applied his formulas to the investigation of the progress of this comet. He found that the last revolution would be retarded 618 days longer than the preceding, from the attractions of Jupiter and Saturn. He fixed the time of its appearance to the 4 th April. This exceeded that of observation by twelve days only. The discrepancy was probably owing to the influence of Uraus, which was not yet discorered. The comet was nirst seen by a peasant in Saxony on Christmas day; but soon becamo the admiration of Paris, and procured for Clairaut the enthusiasm of popular applause.

Clairaut, eager to complete a work in wlich he liad gatliered so many laurels, proceeded to calculate the disturbing influenco of Jupiter and Saturn on the placo of the nodes of the comet of 1682 and 1759, which has an inverted notion. Newton lad shown that the perturbations in tho planetary system always advance the perihelium and retract the nodes. But the case here was just reversed, and the quantity of recession thence determined agreed most exactly with observation.

But the comets in traversing our systen often suffer such derangements that the nrost select observations are insufficient to determiue, with any sort of precision, theit elliptical orbits. 'The famous comet of 1759 was calculated by Fuler and Lexell to perform its revolution in a period between 449 and 519 years, while Pingré assigned it a period of 1231 years. In some cases the observations have indicated an hyperbolic orbit. Conti, following the method of Gauss, found the comet of 1811 to revolve in $3056 \% 3$ years; but by a second computation, he reduced the time to 2301 years. Bessel gave tho comet of 1807 a period of 1953.2 years; but afterwards brought it down to 1483.3 years.

Though the comets suffer such great derangement from the large planets, they lave no sensible effect on our system. They must therefore be exceedingly small. They consist of a dark nucleus, invested with a cloudy or hazy excrescence, and usually provided with a very long tail. They have never disturbed our tilles, though having sometimes approached within the third part of the distance of the moon, they would, with the same mass, exert twenty-seveu times greater deranging force. But their passage was so rapid that time was not given to produco the requisite effect on the ocean.

In 1764, Lagrange, who, at tho early age of 23 , had invented the calculus of variations, gained the prize offered by the Acrdemy of Sciences, for his memoir on the libration of the moon. He explained in the most satisfactory manner, from the theory of attraction, the cause why the moon always presents nearly the same face towards the earth. He again resumed the subject in 1780 .

The theory of Jupiter's satellites is of great importance for finding the longitude. In 1766 , Lagrange embraced the subject in its fullest extent, by introducing into his equations, not only the attractive force of the sun, but the mutual attractions of the satellites themselves. His in restigation was a model of analytical research; yet it did not descend into all the practical de. tails. 
In 1773, Laplace having found that the variation of eccentricity of Jupiter's orbit must cause a corresponding alteration in the motion of the satellites, transferred the same idea to the perturbations of our moon, and thus discovered the true theory of the secular equation, or rather of that vast cycle in which the lunar revolutions are alternately accelerated and retarded. During this discussion he demonstrated that the attractive force or gravity must be transmitted 50 million times faster than light, which travels at tho rate of 200,000 miles in a second. We may therefore consider it as quite instantaneous. This conclusion is important, because it sets aside all mechanical attempts to explain gravitation by the interposition of an ether, \&c., and demonstrates it to be a priuciple ordained by the wisdom of the supreme architect. Laplace continuing his researches, at last discovered that the secular equation of the moon affecting her mean motion, and that of her perigee and her nodes, in the ratio of 4,12 , and 3 , is produced by the slow variation of the solar attraction, occasioned by the changing eccentricity of the earth's orbit, resulting from the influence of the larger planets, though they cannot alter the grent axis which determines the mean periodic revolution.

In 1785 he proved that Jupiter and Saturn can have no secular equations. But remarking that their mean periods are commensurable, and very nearly as 2 to 5 , he found their reciprocal acceleration and retardation to follow the same ratio. The cycle began in 1560 , and comprehends 929 years. So that, in 1750 , Saturn had his period shortened $48^{\prime} 44^{\prime \prime}$; while that of Jupiter was lengthened by $19^{\prime} 28^{\prime \prime}$. In 1788 he discovered two curious laws that connect the periods of Jupiter's satellites, and gave a complete theory of their motions, which served as the basis of Delaubre's excellent tables. In 1808, Lagrange gave a general solution of the problem of disturbing forces, and reduced his equations into a form of the utmost simplicity and elegance.

4. Lunar and solar parallaxes. The nearest celestial bodies are seen from the surface of the earth in a position somewhat different than if viewed from the centre. This difference, called purallax, is obviously greatest at the horizon, and liminishes constantly as we approach the zenith. To ascertain parallax, therefore, with tolerable precision, observations must be made at distant stations. Lacaille selected the Cape of Good Hope, where he determined the mean parallax of the moon to be $57^{\prime} 39^{\prime \prime}$. The parallax of the sun being very small, is more difficult to determine. Kepler had made it a minute, Halley estimated it at $25^{\prime \prime}$; but succeeding astronomers liad reduced it to $10^{\prime \prime}$. Halley proposed a very ingenious method of determining it with accuracy from the next transit of Venus, by measuring the acceleration of the time of her passage over the disc of the sun, as viewed from remote points on the surface of the globe. Aware that lis own life would not be prolonged till that event took place, he ivarmly exhorted his successors to prepare themselves for observing it on the 5 th of June, 1761. Astronomers were accordingly despatched by the maritime powers of Europe to all the stations that were considered as most accessible and eligible : but the result did not answer their expectations; some of the stations were not well chosen, some of the most expert astronomers had not reached the station assigned them, while others were prevented from observing by the state of the weather. Pingré deduced a parallax of $10 \frac{1}{2}$, while Short made it only $8:$." The uncertainty was finally removed by the numerous and skilful observations of the transit of the $3 \mathrm{~d}$ of June, 1769. The several results differed scarcely a quarter of a second, and their concurrence fixed the parallax at $8 " \cdot 6$. This agrees with the theoretic calculations of Laplace, from the lunar anomalies. Bessel, with immense labour, combined and reconiputed the original observations, and detected a small inaccuracy, the correcting of which reduces the parallax to $8^{\prime \prime} \cdot 575$. Consequently the mean distance of the sun is $95,158,440$ English miles.

5. Discovery of Uranus. Dr Herschell, who had devoted hinself to the construction of telescopes, and to an indefatigable observation of the hearens, announced to Dr Maskelyne, that, on the night of the 12:h of March, 1781, he observed a shifting star, which from its smallness he judged to be a comet, though it was distinguish. ed neither by a nebulosity nor by a tail. The notion of the star was so slow as to require distant observations to ascertain its path. It was for several months presumed to be a comet; but the lypothesis of a parabolic orbit led to very discordant results. The president Saron was the first who conceived it to be a planet, having inferred from the observations communicated to him that it described a circle with a radius about twelve times the mean distance of the earth fron the sun. Lexell, before the end of the year, had computed the elements of the new planet with considerable accuracy, making the great axis of its orbit nineteen times greater than that of the earth, and the period of its revolution eightyfour years. Bradley, mistaking it for a fixed star, had observed it on the 3d of December, 1753 , and it was again seen by Mayer on the 23d of September, 1756.

Herschell gave this new planet the name of the Georgium sidus; but the term Uranus, applied to it by Bode, is almost universally adopted. Herschell discovered the satellites of this 
planet, which are six in number. They revolve in a plane nearly perpendicular to the orbit of the planet, and contrary to the order of the signs. Both these primary and secondary bodies obey, in their revolutions, the laws of Kepler. The same remark applies to the satellites of Saturu, which Herschell increased to seven.

6. Discovery of four new planets. liepler was of opinion that the harmony of our system wanted a planet between Mars and Jupiter. A similar notion was entertained by Lambert, who thought it likely that such a planet might exist, though it was dark and invisible. The distances of the planets from the sum may be denoted by the series $4,7,10,16,28,52,100$; which numbers are couvertible into Kinglish miles by multiplying by $9 \frac{1}{2}$ millions. The dark or deficient planet corresponds to twenty-eight, or a distance of 260 millions of miles from the sun.

In the place assigned to this dark planet, four very snall bodies have been discovered; which some persons liave conjectured to be only fragments dissevered from the principal, and that other similar fragments may still remain undiscovered. The discovery of these very small planets distinguished the commencement of the present century. Piozzi discovered leres at Palermo, on the 1st of January, 1801; Ulbers discovered Pallas at Bremen, on the 28th of March, 1802; and Harding observed Juno on the 2d of September, 1804, and Vesta on the 29th of March, 1807. These small bodies differ from the other planets, not only by their diminutive size, but by the remarkable inclination of their orbits to the plane of the ecliptic; which, however, they intersect nearly in the same nodes.

7. Extent of the universe. Herschell, by means of his excellent reflecting telescopes, employed himself assiduously in observing the numerous clusters of nebulosities, and distinguished many of the changing and double stars; which, though suns of other systems, yet appear connected, and may, probably, circulate about their common centre of gravity. The subject has lately been carried a great deal further by Sir James South and Sir John Herschell, the latter of whom is preparing to go to the Cape of Good Hope, to examine the double stars of the southern hemisphere.

Sir William Herschell assuming that the instrument which he used could enable him to penetrate 497 times farther than Sirius, he reckoned 116,000 stars to pass in a quarter of an hour over the field of riew, which subtended an angle of only 15\%. If we compute from such a narrow zone, the whole celestial vault must display, within the range of telescopic vision, the stupendous number of more than five billions of stars. If each of these be a sun to a system similar to ours, aud if the same number of planets revolve round it, then the whole planets in the unirerse will be more than fifty-five billions, not reckoning the satellites, which may be much more numerous. What an unimportant portion of the universe is occupied by our earth, and how insignificant must its inhabitants, with all their cares, and pride, and vanity, appear to that Almighty being whose providence regulates and goverus at once suclı a prodigious number of worlds, witlı all their inmumerable inlabitants.

\section{OPTICS.}

TuE history of astronomy, the most perfect and the sublimest of all the sciences, has unaroidably extended itself to a considerable length. Optics is the next science in point of perfection. Like astronomy, it depends on observation, but is every where capable of the rigid application of mathematical calculation.

As light propagates itself in straight lines, it seems to offer itself spontaneously to the consideration of geometers. Euclid accordingly began the investigation at least fifty years before Archimedes had placed mechanics among the number of the mathematical sciences. Euclid only established two particulars: 1. That a point in any object is seen in the direction of a straight line from the eye to that object. 2. That when a point in an object is seen by reflection from a polished surface, the lines drawn from the eye and from the object to the point whence the reflection is made, are equally inclined to the reflecting surface. From a treatise on optics by Ptolemy, discovered some years ago in the king of France's library, it appears that many observations had been made on refraction, though the law followed had not been discovered.

About 1000 years after Ptolemy, or in the Ilth century, Alhazen wrote his treatise on optics. In it he solved a problem of very great difficulty, to find the point in a spherical speculum, at which a ray coming from one given point shall be reflected to another given point. Alhazen was acquainted with the anatomy of the eye, though he did not fully understand the uses of the different parts. On seeing single with two eyes, he made the very important remark, that when corresponding parts of the retina are affected we perceive but one image. Roger Bacon, who lived in the 13 th century, made a near approach to the knowledge of lenses, and their use in assisting vision. The date of the discovery of spectacles, for assisting the sight, may be carried back as far as 1313, but no farther. The in- 
rentor appears to have been a Florentine, called Salvino degl Armato. He was of a Patrician family. Maria Manni quotes the following inscription on his tomb, from an antiquarian author: Qui diace (giace) Salvino d'Armato degl' Armati, Firenze invento de egl' Occhiali, anno MeccXvil.

Two centuries later Maurolicus appeared. He was acquainted with the crystalline lens of the eye, and formed a correct judgment of the defects of short-sighted and long-sighted eyes. Baptisto Porta, a Neapolitan, invented the camera obscura about the year 1560. The light was admitted through a small hole in the window shutter of a dark room, and gave an inverted picture of the objects from which it proceeded on the opposite wall. A lens was not employed in the first construction of this apparatus, but afterwards used; and Porta went so far as to consider how the effect might be produced without inversion.

Kepler was the first person who explained the mechanical action of the eye in vision. He perceived the exact resemblance of this organ to the camera obscura, the rays entering the pupil being collected by the crystalline leus and the other humours of the eye into foci which paint on the retina the inverted images of external objects. The mind perceives these images and refers them at the same time to things without.

Antonio a' Dominis, Archbishop of Spalatro, was the first person who explained tie production of the rainbow. Having placed a bottle of water opposite to the sun, and a little above his eye, he saw a beam of light issue from the underside of the bottle, which acquired different colours in the same order and with the same brilliancy as the rainbow, when the bottle was a little raised or depressed. From comparing all the circumstances, he perceived that the rays had entered the bottle, and that after two refractions from the conves part, and a reflection from the concave, they returned to the eye tinged with different colours, according to the angle at which the ray had entered. The book containing this discovery was published in 1611 .

The telescope was invented about this time, but somewhat earlier. The honour of the discovery belongs to Middleburg, in Zealand. Two different workmen, Zachariah Jans and Joln Lapprey have each testimonies in their favour, between which it is difficult to decide. The former goes back to 1590 , the latter comes down to 1610. Zachariah Jans was an optician in Middleburg, and Boreel has published a letter from his son assigning 1590 as the date of the invention, and another from his sister assiguing 1610 as the date. From the account of Boreel it would appear that Jaus was the real inventor, and that the discovery of the telescope had been preceded by that of the microscope. News of this discovery was communicated to Galileo in 1610. He immediately constructed a telescope, turned it to tlie heavens, and made the interesting discoveries which have been already particularized.

The theory of the telescope required that the law of refraction should be discovered. This discovery was the work of Snellius, a mathematician of the Low Countries. To express this law he supposed a perpendicular to the refracting surface, at the point where the refraction is made, and also another line parallel to this perpendicular at any given distance from it. The refracted ray as it proceeds, will meet this parallel, and the incident ray is supposed to be produced till it do so likewise. Now, the general truth which Snellius found to hold, whatever was the position of the incident ray, is, that the segments of the refracted rny and of the incident ray, intercepted by these parallels, had always the same ratio to each other.

In the triangle formed by the two segments of the rays, and by the parallel which they intersect, the said segments have the same ratio with the sines of the opposite angles; that is with the sines of the angles of incidence and refraction. The law, therefore, comes to this, that in the refraction of light by the same mediums, the sine of the angle of incidence has to the sine of the angle of refraction always the same ratio. It was first stated in this way by Descartes in his Dioptrics, in 1637. But Snellius's law, which comes to the same thing, had been publicly taught in his lectures by professor.Hortensius, and must therefore have been known to Descartes.

Descartes next entered upon an inquiry, in which he was successful. In ordinary cases of refraction, by spherical and other surfaces, the rays are not collected into one point, but have their foci spread over a certain surface, the sections of which are the curres called caustic curves. The focus of opticians is only a point in this surface, where the rays are more condensed, and of course the illumination more intense than in other parts of it. But if refraction is to be employed either to produce heat or light, it would be a great advantage to have all the rays which come from the same point of an object united accurately after refraction, in the same point of the image. 'This led Descartes to inquire into the figure which the superficies separating two transparent media of different refracting powers must have, that all the rays diverging from a given point, might by refraction at the said superficies be made to converge to another given point. He slowed that curves proper for gener. 
ating such superficies by revolution have always two given points from which, if straight liues be drawn to any point iu the curve, the one of these, plus or minus that which has a given ratio to the other, is equal to a given line. When the given ratio is one of equnlity, the curre is a conic section, and the two points its foci. The curves in general are of the $4 \mathrm{th}$ or $2 \mathrm{nd}$ order, and have been distinguished by the name of the ovals of Descartes.

But no practical adrantige lias resulted from this investigation. The mechanical difficulties of working a surface into any figure but a spherical one, are so great that they liave never been overcome.

The next improver of optics was James Gregory, whose Optica Promota appeared in 1663. It contained an account of his reflecting telescope. The imperfection of the images formed by spherical lenses led him to substitute reflection for refraction in the construction of the telescope. Gregory thought it necessary that the specula should have a parabolic figure; and the execution proved so difficult, that the instrument, during his lifetime, was never brought to any perfection. After his death, the specula were constructed of the ordinary splierical form, and the Gregorian telescope, till the time of Hersclell, was more in use than the Newtonian. It is curious, that though the optics of Descartes had been published twenty-five years, Gregory was ignorant of the law of refraction, and found it out by his own unassisted exertions.

Barrow's lectures on optics, delivered at Cambridge in 1668, treated of all the more difficult questions which had occurred in the then state of the science, with the acuteness and depth which are found in all his writings.

About this time the Jesuit Grimaldi made known some optical phenomena, which liad litherto escaped detection. Having stretched a hair across a sun-beam, admitted through a hole in the window shutter of a dark chamber, he was surprised to find the shadow much larger than the natural divergence of the rays could have led him to expect. Other facts of the same kind made known the general law of the diffraction or inflexion of light, and showed that the rays are acted on by bodies, and turned out of their rectilinear course, even when not in contact, but at a measurable distance from the surfaces or edges of such bodies. Grimaldi gave an account of these facts in a treatise printed at Bologna in 1665.

The dioptrics of Huygens, though a posthumous work, was the production of his early youth, and is said to have been a favourite book with Newton himself. It contains a full development of every thing relating to the construction of telescopes, particularly in that which concerns the indistinctuess arising from the inperfect fori into which rays aro united by spherical lenses. Rules are deduced for constructing telescopes, which, though of different sizes, shall have the same degree of distinctness, \&c. Huygens was a practical optician; he constructed telescopes with his own hands, and some of his object glasses were of the enormous focal distance of 130 feet.

His theory of liglit was communicated to the Academy of Sciences of Paris in 1678, and afterwards published with enlargements in 1690 . Light, according to him, consists of certain undulations, communicated by luminous bodies to the etherial fluid which fills all space. This fluid is composed of the moct subtile matter, is lighly elastic, and the undulations are propagated through it with great velocity in splerical superficies, proceeding from a centre. The ingenuity of the theory appears most conspicuous in the explanation which it affords of the constant ratio which subsists between the sines of the angles of incidence and refraction in the same medium. But the happiest application of all, is to the explanation of the double refraction of Icelaud crystal, or transparent calcareous spar. This crystal lias not only the property of refracting light in the common manner of glass, water, and other transparent bodies; but it has also another power of refraction, by which even the rays falling perpendicularly on the surface of the crystal are turned out of their course, so that a double image is formed of all objects seen through these crystals. This property is not confined to calcareous spar; but belongs, in a greater or less degree, to all substances which are both crystallized and transparent.

The common refraction is explained by Huygens, on the supposition that the undulations in the luminous fluid are propagated in the form of spherical waves. The double refraction is explained on the supposition that the undusaunns of light, in passing through the calcareous spar, assume a spheroidal form; and this hypothesis, though it does apply with the same simplicity as the former, yet admits of such precision, that a proportion of the axes of the spheroids may be assigned, which will account for the precise quantity of the extraordinary refraction, and for all the phenomena dependent on it, which Huygens had studied with great care, and had reduced to a small number of general facts.

To render the theory of Huygens quite satisfactory, a reason ought to be assigned why the undulations of the luminous fluid are spheroidal in the case of crystals, and spherical in all other cases. This would render the generalization complete. But till a connexion is clearly esta- 
blished between the structure of crystallized bodies, and the property of double refraction, the theory must remain imperfect.

We now come to the discoveries of Newton, which constitute nearly as important an era in optical science as his theory of universal gravitation did in astronomy. His researches began in 1666 , when he was only twenty-three years of agre.

In hopes of improving the telescope, by giving to the glasses a figure different fiom the spherical, he had procured a glass prisin, in order, as he tells us, to try with it the celebrated phenomena of colours. These trials led to the discovery of the different refrangibility of the rays of light, now too well known to require to be par. ticularized.

Having admitted a ray of light into a dark chamber through a hole in the window-shutter, and made it fall on a glass prism, so placed as to cast it on the opposite wall, he was delighted to observe the brilliant colouring of the sun's image, and not less surprised to observe its figure, which, instead of being circular, was oblong in the direction perpendicular to the edges of the prism, so as to have the shape of a parallelogram, rounded at the two ends, and nearly five times as long as it was broad.

When he reflected on these appearances, he saw nothing that could explain the elongation of the inage, but the supposition, that some, of the rays of light, in passing through the prism, were more refracted than others; so that the rays which were parallel before they fell on the prisn, being some of them more refracted than others, diverged from one another after refraction, the rays that differed in refrangibility differing also in colour. The spectrum would thus consist of a series of circular images, partly covering one another, and partly projecting one beyond the other, from the red, or least refrangible ray, in succession to the orange, yellow, blue, indigo, and violet, the most refrangible of all.

But he did not adopt this as the true explanation, till he had tried every other hypothesis by the test of experiment, and proved its fallacy. Even after these rejections, his explanation had still to abide the sentence of an experimentum crucis.

Having admitted the light, and applied the prism as before, he received the coloured spectrum on a board about twelve feet distant from the prism, and pierced with a small hole. The coloured light, which passed through this second hole, was made to fall on a prism, and afterwards received on the opposite wall. It was then found, that the rays which had been most refracted by the first prism were also most refracted by the second, though no new colours were produced. It was also observed, that when the rays which fell on the second prism were all of the same colour, the image formed by refraction was truly ciscular, and of the same colour with the incident light.

When the sun's light is thus admitted, first through one aperture, and then through another at some distance from the first, and is afterwards made to fall on a prism, as the rays come only from a part of the sun's dise, the spectrum has nearly the same length as before; but the breadth is greatly diminished; in consequence of which, the light at each point is purer, it is free from penumbra, and the confines of the different colours can be more accurately traced. It was in this way that Newton measured the extent of each colour; and taking the mean of a great number of measurements, lie assigned the following proportions, dividing the whole length of the spectrum, exclusive of the rounded terninations, into 360 parts. Of these the

\begin{tabular}{|c|c|c|c|c|c|}
\hline Red occ & pied & & . & & \\
\hline Orange & & • & • & $\bullet$ & • \\
\hline Yellow & & - & • & • & . \\
\hline Green & & . & . & • & • \\
\hline Blue & - & • & - & • & • \\
\hline Indigo & & • & - & • & • \\
\hline Violet & . & . & . & . & . \\
\hline
\end{tabular}

Newton conceived that there was an identity between these numbers and the divisions of the monochord, by the notes of music. But it his been since observed, that the spaces occupied by these colours differ according to the kind of prism employed. Hence the relation was merely accidental.

Thus colours were found to be original properties of light, connected with the different degrees of refrangibility belonging to the different rays. Each of these colours, though primary, may be produced by a mixture of the two colours upon either side of it in the prism. Red and yellow make orange; yellow and blue make green; and so on. In general, two colours not very far distant in the natural series, when mixed, make up tlıe intermediate colour. All of them together constitute whiteness. Natural bodies of whatever colour, if viewed by simple and homogeneous light, are seen of the colour of that light, and no other.

Thus supplied with so many new and accurate notions respecting colours, it was natural for Newton to apply them to explain the rainbow. Every thing respecting that beautiful phenomenon had been already explained, except the colours. As these colours were the same as in the solar spectrum exhibited by the prism, and in the same order, it could hardly be donbted that they were owing to the same cause. He showed this to be the case, by calculating the ex- 
tont of the arch, the breadth of the coloured bow, the position of the secondary bow, its distance from the primary, and by explaining the inversion of the colours.

As all colour conies from the rays of light, we must conclude that the colour of every particular body is owing to its reflecting the particular kind of ray of which it exhibits the colour. If you cast upon a coloured body a homogeneous ray of light, it appears much more vivid; that is, it reflects much more light when the ray cast upon it is of its own colour. 'Transpareut bodies sometimes reflect one kiud of ray, and transmit auother.

But here a difficulty occurs. Suppose a body to reflect red or green light, what is it that decomposes the light, and separates the red or the green from the rest? It was this difficulty that led Newton to study the colours produced by light passing through thin plates of any transparent substance. When two transparent bodies, such as pieces of glass liaving their surfaces somewhat convex, are pressed together, a black spot is formed at the contact of the two, which is surrounded with coloured rings, more or less regular, according to the form of the surfaces. To analyse this phenomenon, Newton nade experiments with surfaces of a regular curvature, capable of being measured. He took two object glasses, one a plane convex for a fourteen feet telescope, the other a double convex for one of about fifty feet, and upon this last he laid the other, with its plane side undermost, pressing them gently together. At their contact, in the centre was a pellucid spot, through which the light passed without suffering any reflection, Round this spot was a coloured ring, exhibiting blue, white, yellow, and red. This was succeeded by a pellucid or dark ring; then a coloured ring of violet, blue, green, yellow, and red, all copious and vivid, except the green. The third coloured ring consisted of purple, blue, green, yellow, and red. The fourth consisted of green and red; those that succeeded became gradually more dilute, and ended in whiteness. It was possible to count as far as seven.

The colours of these rings were so marked by peculiarities in shade and vivacity, that Newton considered them as belonging to different orders; so that an eye accustomed to examine them, on any particular colour of a natural object being pointed out, would be able to determine to which order in this series it belonged.

Thus we have a system of rings or zenes surrounding a dark central spot, and themselves alternately dark and coloured; that is, alternately transmitting the light, and reflecting it. It is erident, that the thickness of the plates of air in- terposed between the glasses, at each of those rings, must be a material element in the arrangement of this system. Newton, therefore, undertook to compute their thickness. Having carefully measured the dianeters of the first six coloured rings, at the most lucid part of each, he found their squares to be as the progression of the odd numbers $1,3,5,7$, \&c. The squares of the distances, from the centre of the dark spot to each of these circumferences, were therefore in the same ratio; and, consequently, the thickness of the plates of air, or the intervals between the glisses, were as the numbers $1,3,5,7$, \&c. When the dianteters of the dark or pellucid rings, which separated the coloured rings, were measured, their squares were found to be as the even numbers $0,2,4,6$; and, therefure, the thickness of the plates, through which the light was wholly transmitted, were as these numbers.

The curvature of the convex glass being the thickness of the plates of air which corresponded to the difierent rings, was computed. An inch being divided into 178,000 parts, the thickness of the air for the first series, or for the luminous rings, was $\frac{1}{178000}, \frac{3}{178000}, \frac{5}{178000}$, \&c. inch. For the second series $\frac{2}{1780009}, \frac{4}{178000}, \& \mathrm{c}$. inch.

When the rings were exanined, by looking through the lenses in the opposite direction, the central spot appeared white, and in other rings red was opposite to blue, yellow to violet, and green to a compound of red and violet-the colours formed by the transmitted and reflecter light being what are now called complinentary, or nearly so, of one another; that is, such as when mixed produce white.

When the fluid between the glasses was differ. ent from air, as when it was water, the succession of rings was the same; the only difference was, that the rings themselves were narrower.

When experiments were made on thin plates in such a way that the plate was denser than the surrounding medium, as in the case of soap bubbles, the same phenomena were observed to take place.

To the different degrees of density, then, in transparent bodies, there seemed to be attached the powers of separating particular colours froul the mass of light, and of rendering them visible, sometimes by reflection, and in other cases by transmission. Now, as there is reason to think that the atoms of bodies are transparent, they may be conceived to act on light after the manner of thin plates, and to produce, each nccording to its thickness and density, its appropriate colour, which therefore becomes the colour of the surface.

But these experiments led to other conclusions, new and unexpected. It was impossible to observe, without wonder, the rings alternately 
luminous and dark, that were formed between the two plates of glass in the preceding experiments, and deterinined to be what they were by the different thickness of air between the plates, and having to that thickness the relation already specified. A plate, of which the thickness was equal to a certain quantity multiplied by an odd number, gave always a circle of the one kind; but when the thickness was the same quantity multiplied by an even number, the circle was of another kind; the light, in the first case, being reflected; in the second, transmitted.

Light penetrating a thin transparent plate, of which the thickness was $m, 3 m, 5 m, \&$ c, was decomposed and reflected; the same light penetrating the same plate, but of the thickness 0 , $2 m, 4 m$, \&c., was transmitted, though in a certain degree also decomposed. The sane light, therefore, was transmitted or reflected, according as the second surface of the plate of air, through which it passed, was distant from the first, by the intervals $0,2 m, 4 m$, or $m, 3 m, 5 m$; so that it became necessary to suppose the same ray to be successively disposed to be transmitted, and to be reflected at points of space separated from one another by the same interval $m$. This constitutes what Newton called Fits of easy transmission and easy reflection. It constitutes one of the most singular parts of his optical discoveries. It is a necessary inference from the phenomena; and though the cause cannot be assigned, it must, notwithstanding, be admitted as a general fact, which enables us to explain various phenomena that were unknown at the time when Newton lived.

Newton's explanation of refraction proceeds on the theory that light is an emanation of particles moving in straiglit lines with incredible velocity, and attracted by the particles of transparent bodies. When, therefore, light falls obliquely on the surface of such a body, its motion may be resolved into two; one parallel to that surface, and the other perpendicular to it. Of these the first is not affected by the attraction of the body, which is perpendicular to its own surface; and, therefore, it remains the same in the refracted as it was in the incident ray. But the velocity perpendicular to the surface is increased by the attraction of the body; and what ever be the quantity of that velocity, its square, on entering the same transparent body, will always be augmented by the same quantity. But it is easy to demonstrate, that if there be two right angled triangles, with a side in the one equal to a side in the other, the hypothenuse of the first being given, and the squares of their remaining sides differing by a given space, the sines of the angles opposite to the equal sides must hare a given ratio to eacl other. This vmounts to the same thing with saying, that, in the case before us, the sine of the angle of inci dence is to the sine of the angle of refraction in a given ratio. This explanation of the law of refraction is so satisfactory, that it affords a strong argument in favour of the system which considers light as an emanation of particles from luminous bodies.

Huygens, indeed, deduced from the hypothesis of the vibrations of an elastic fluid, an explanation of refraction which is highly ingenious, but not quite so satisfactory as the Newtonian; though it be the fashion at present to give a preference to the hypothesis of Huygens, we think that rery solid objections might be started against it, were this the proper place for suclı an attempt.

The square that is added to that of the perpendicular velocity of light, in consequence of the attractive force of the transparent substance, is properly the measure of the quantity of that attraction, and is the same with the differences of the squares of the velocities of the incident and the refracted light. This is readily deduced from the ratio of the augle of incidence to that of refraction. When this is done for different substances, it is found that the above measure of the refracting power of different bodies is nearly proportional to their densities, with the exception of those which contain much combustible matter, which is always accompanied by an increase of refracting power.

Thus the refracting power, (ascertained in the way just mentioned) when divided by the density, gives quotients not very different from one another, till we come to combustible bodies, when a great increase immediately takes place. In air, for instance, the quotient is 5208 , in rock crystal 5450 , in common glass nearly the same; but in spirit of wine, oil, and amber, the same quotients are 10121, 12607, 13654. In the diamond he found the quotient 14556. Hence he conjectured that the diamond was, at least in part, a combustible body. The refracting power of water being great for its density, its quotient being 7845 , he concluded that an inflammable substance enters into its composition-a conjecture, which was verified nearly a century afterwards by the synthetical experiments of Mr Cavendish.

The rcflection of light from the surfaces of opaque bodies, and from the anterior surfaces of transparent bodies, appears to be produced by a repulsive force exerted by those surfaces, at a determinate but very small distance; in consequence of which, there is stretched out over them an elastic web, through which the particles of light, notwithstanding their incredible velocity, are not always able to penetrate. In the case of a transparent body, the light which, when it arrives at this outwork is in a fit of easy reflec- 
tion, is reflected back again. The particles, on the other hand, which are in a state that disposes them to be transmitted, overcone the repulsive force, and entering the transparent body, are attracted and refracted as already explained. If these rays reach the second surfuce of the transparent body with a certain obliquity, the attraction will not suffer the rays to emerge into the rarer uediun, but will farce them to return back into the transparent body. Thus the reflection of light, at the second surface of a transparent body, is produced sot by the repulsion of the medium into which it is about to enter, but by the attraction of that which it was going to leare.

In consequence of t'lese discoreries, Newton perceived a defect in the refracting telescope, proceeding from the unequal refrangibility of the different rays. This defect he was of opinion it was inpossible to remedy, because he thought that the quantity of the refraction and of the dispersion in different substances bore always the same ratio to each other. Had this been so, the appearance of prismatic colours in a refracting telescope could never have been cured without destroying the refraction altogether. But this was one of the few points about which Newton was mistaken. The mistake was afterwards discovered by Dollond, who found that, by means of crown and flint glass, the dispersion might be counteracted without injuring the refraction. This great discovery enabled him prodigiously to improve the refracting telescope; and they are now reckoned so much preferable, that they are superseding the reflecting telescope altogether.

Newton turned his attention also to the inflection of light. He found that the ray, in passing the knife edge, had been both attracted and repelled, and that it liad begun to be acted on at the distance of $\frac{1}{200}$ th of an inch from the edge of the knife. The path of the ray, in passing the knife edge, was bent in opposite directions, so as to form a serpentine line, conrex and concare, towards the knife, according to the repulsive or attractive forces which acted at different distances. In his opinion, the refraction, reflection, and inflection of light are all produced by the same force differently modified, and do not arise from the collision of light with the particles of bodies.

The great improver of achromatic telescopes, after Dollond, was Fraunhofer. He observed, in examining the different-coloured rays of the spectrum, by means of a telescope, that though the coloured spaces appear not parted by any distinct boundaries, yet they are broken and subdivided by numerous white and black lines. $\mathrm{He}$ reckoned altogether above 600 lines: a few occur in the red; but they are numerous in the orange, yellow, green, and blue. A stripe, opened liy a tine white line, divides the red; other strines emerge at intervals between the orange and the blue, and two very broad approximating bars cross the violet. Other glass prisms, and even those filled with liquids, gave similar appearances. It would appear from this that refrnction proceeds by irregular bounds, sonewhat like Newton's easy fits of transmission and reflection

We shall finish this hasty sketch of upties, with noticing the discovery of what is called polarized rays of light, by Malus, a French officer of engineers. The double refracting properiy of Iceland spar, which had been so carefully examined by Iluygens, drew also the attention of Newton, who concluded that the ray which sufiers the unusual or extraordinary refraction must have its opposite sides affected by some virtue like magnetism, which gives them a tendency to polarity. This renark lay neglected for almost a century. Malus had early turned his attention to the more difficult problems in optics; and, after his return from foreign service, he resumed his farourite studies. In one of his frequent visits to the observatory, during his residence in Paris in the summer of 1809 , he was struck with the brilliant reflection of the setting sun, from one of the windows of the Luxembourg palace. On looking at the appearance through a prisu of rock crystal, which he slowly turned round, he remarked, with surprise, that one of the images changed regularly to brightness from obscurity. Next morning he repeated his observation with the same results; and soon found that light, reflected at a certain angle from the surface of glass, acquires the same character as the extraordinary ray in the double refracting prism. Water showed a similar disposition, but at a different angle of incidence. The law was traced through various reflecting surfaces, and Malus was prosecuting the subject with rapid success, when his career was cut short by a lingering disease, on the 23d of February, 1812. The subject of polarization bas been successfully prosecuted in this cour'ry by Herschell and Brewster; and on the continent by Biot, Arago, and Fresnel; but much still remains before it reaches the simplicity which characterizes the other branches of optics.

\section{HYDROSTATICS, \&c.}

Tuz law which determines the weight of bollies immersed in fluids had been discovered by Archimedes, and likewise the position of bodies floating on them. It was ascertained by Stevinus, that the pressure of fluids is proportional to their 


\title{
POPULAR ENCYCLOPEDIA;
}

\author{
OR,
}

\author{
CONVERSATUONS LEMUCON.
}

\section{A-ABACUS.}

A, in all known languages, but the Ethiopic, is the first letter of the alphabet, from the reason, perhaps, that if pronounced open, as in father, it is the simplest and easiest of all sounds. This is the only mode of pronouncing it in almost every country ex. cept England. To produce this sound, the mouth is merely opened, without the contraction or extension necessarily accompanying the utterance of either of the other rowels. A is the letter with which children generally begin to speak, and it serves to express many and even opposite emotions, e. $g$. admiration, pain, astonishment, laughter, (with the preceding $H$, ) disgust, pleasure, according to the mode in which it is uttered. For the same reason, $a$ is found, in all original languages, in many words which infants utter to designate the objects with which they are most nearly connected, $e . g$. in the names by which they call their parents. Hence, in Hebrew, $a m$ is mother, $a b$ father ; in old Greek and Gothic, atta is father; in Latin, mamma signifies the breast. Many philologists are of opinion, that $a$, (as in father) was the original rowel in most of those words which designate objects expressive of great strength, quickness, \&c., as these first attracted the attention of men; and it is true, that, in original languages, $a$ appears in very many words belonging to the class just mentioned. $A$ (as in father) is very rarely the predominating sound in the cries of animals. In these, the sounds $c e, o w, u$, and $a$, as in fate, generally prevail. We do not include the sounds of singing birds, which are inarticulate music, like that of wind instruments. The regularly arched roof of the human mouth, and the other fine organs of specch, with which the Creator has blessed mankind above all lower orders of animals, are necessary to pronounce the melodious sound $a$ (open.) A is, generally speaking, the favourite sound of singers, because it is the most musical and most capable of expansion. Several diphthongal sounds, as $i$ (in pine), are, in singing, to be resolved into $a$ (open) and another simple sound. The frequent occurrence of $a$ (open) in the Italian language, is one of the many causes which render the Tuscan dialect so favourable for music. The Scottish dialect possesses the same advantage. The English language is the only one among the cultivated modern tongues, which has four (according to others still more) sounds for the single character $a$. Most of the modem languages, as French, Italian, German, \&c. have only the open or Italian $a$, pronounced short or long. Other languages have also the sound of the English $a$, as in all, e. $\mathrm{g}$. the dialect of Finland. In Greek, this letter, when prefixed to a word, has the power of negation, like the syllable un in English, and hence it was called alpha privativum. In many English words derived from the Greek, the $a$ has the same power.-Among the Greeks and Romans, $a$ was used as an arithmetical sign: by the former, for 1 ; by the latter, for 500 . When a dash was placed on the top, thus, $\bar{A}$, it stood for 5000 . (See Abbreviations.) $-A$, in music, the sixth diatonic interval of the first or lowest octave of the modern scale : $a$ indicates the same interval in the second octave. As the capital $A$ is used in the first instance,and the small $a$ in the next, the former is called the great octave,

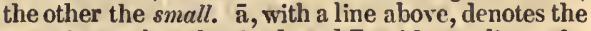
same interval in the third, and $\overline{\bar{a}}$, with two lines, the same interval in the fourth octave. The first of these, from each denomination of the note in the octave being designated by a line, is termed the onelined octave, the other the two-lined, and so on. $A$, major, is that key, in modern music, in which the sixth diatonic interval is assumed as the fundamental tone of the major key. To maintain the natural characteristic of the major, F, G, and c, must be made sharp, $r \neq G \neq c \neq$. According to Schubert's Characteristics of Music, this key conveys the expression of innocent love, content, and cheerfulness. (See $K e y$.$) If any numeral figure is added to the letter$ $A$, when prefixed to a vocal composition, it denotes the number of voices for which the piece is intended : thus, A 3 signifies for 3 voices.

AA, the name of a great number of rivers in Switzerland, Germany, France, and Holland; so, also, Aach, which is, in German, originally the same with $A a$, only pronounced with an aspirated termination.

AA, Peter Van der, a bookseller of Leyden, who carried on an extensive business from 1682, until his death in 1730 , during which time he compiled and published many collections of Voyages, Travels, \&c. in the Dutch and French languages; the most extensive of which was his "Galerie du Monde," in 66 vols. folio.

Aargau, Argovia, Argau, formerly a part of the cantons of Berne and Zurich, but since 1798 a separate canton. In 1803 it received a large accession of territory. Capital Arau; population, 132,763. Several liberals have fled, in molern times, from Germany, and lived for a while in A., protected by Government.

Aaron, (Heb. a mountaineer, ) the brother of Moses, and first high-priest of the Israelites. See Moses.

ABAcus signified, among the ancients, a kind of cup-board, or buffet. They were, in times of great luxury, plated with gold. It also signified a table 
coverel with dust, ou which the mathemaucians elrew their nathematical figures, as the pupils of the Iancasterian schools do at present. It also signified an instrument for facilitatimg arithmetical operations, which was with the ancients, very necessary, as their way of writing numbers reuderel nuy calculation very difficult. The iustrument consisted of a uunber of parallel chonls or wires, upon which balls or beads were strung, each wire being appropriated to mits, tens, hunireds, or thousands. 'Thus, the year of the Christim era 1832 would be represented :

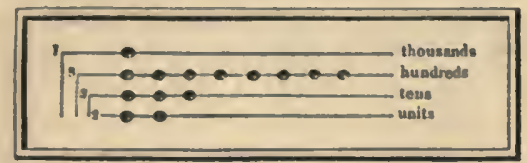

Various other instruments for facilitating, a ritlumetical calculations have been inventerl, the most recent as well as the most ingenious of which is that by $\mathrm{Mr}$ Babbage, which is scarcely yet completed. A ccounts of these will be found under the proper head of Arithmetic.-A bacus, in architecture, Vitruvius tells us, was originally intended to represent a square tile laid over an urn, or rather over a basket. The form of the abacus is not the same in all the orders of Greek architecture. Molern architects liave given different significations to the word abucus. See Architeccure.

Arascia, or Abcassia, the northern district of Georgia, in Asia, situated on the coast of the Black Sea.

Abatis, (Fr.) trees cut down and laid with their branches turned towards the enemy, in such a way as to form a defence for troops stationed behind them.

A Bauzrt, Firman, was born in Languedoc, 1679. In consequence of the revocation of the edict of Nantes, his mother, who was a Protestant, took refuge with her son in Genera. He engaged with such eagerness in his studies, that he made great proficiency in languages, theology, antiquities, and the exact sciences. At the age of nineteen, he travelled into Holland, where he became acquaisted with Bayle and Basuage. Thence he passed into England, where he was favourably noticed by Newton, and invited to remain by king William on very udvantageous conditions. He determined, however, to return to Genera, and, devoting himself to study, he rendered important assistance to a society engaged in translating the New Testament into French. In 1727, he was appointed public librarian in Geneva, and was presented with the freedom of the city. He died in 1767. Abauzit was a profound scholar, a true philosopher, and a sincere Christian. His conversation was unostentatious, but instructive and animated. He was simple in his manners, independent and decided in his opinions, but a friend to universal toleration. He defended the Principia, and ever detected an error in that work, when very few men could understand it. Newton declared him " a fit man to judge between Leibnitz and himself." Rousseau decribes him as the "wise and modest Abauzit ;" and Voltaire pronounced him "a great man." His knowledge was extensive in the whole circle of antiquities, in ancient history, geography, and chronology. In theology his researches were deep, and his moderation enabled him to avoid the violence of theological parties. His works are chiefly on theological subjects. An Essay on the Apocalypse, Reffections on the Eucharist and on the Mrsteries of Religion, are his principal writings. AвваdIE, James, an eminent French protestant divine. He accompanied King William III. into England, and was fust minister of a French church in Lombon, and afterwards Dean of Kitlaloe in Ireland. He died in 1727, leaving a political tract in defence of the revolution, and some theological works.

A BBE, betore the first French revolution, was the title of all those Freuclunen who devoted themsilves to divinity, or had at least pursuet a course of study in a theological seminary, in the hope that the king would confer on them a real abbey; that is, a certain part of the revenues of a monistery. Ondinited clergymen were those ouly who devoter themiselvers entirely to the performance of clerical duty: the others were engaged in every kind of literary oculpation. There were so many of the'm, poor und rich, men of quality and men of low birth, that they formed a particular class in society, and excrted an important influence on its character. Tliey wre seen every where; at court, in the lailis of justice, in the theatre, in the coffee-houses. In almost every wealthy family there was an abbé, occupying the post of familiar friend and spiritual adviser, and not seldoun that of the gallant of the larly I'hi'y corresponded, in a certain degree, to the philosophers who lived in the houses of the wealthy Rommus in the time of the emperors. A round toupet, a short, black, brown, or violet cont, completed the appearance of an abbé.

Abrés commandataires. The king of France had formerly the right of appointing abbots or(' 1 . two hundred and twenty-five monasteries. These ablots enjoyed a thind part of the revenues of the monastery, but had no authority over it, the charge of superintendence being committed to a prieur claustral. According to rule, every abbot ought to receive ordination in the course of a year, but the pone dispensed with the rule, and the abbe spent his incone (from 1200 to 150,000 French livres, abont $£ 50$ to $£ 6000$ ) wherever he pleased. This shocking abuse excited the indignation of the people, and was one of the causes of the revolution. The lower sinccures of this kind, the abbayes des savans, werc used as pensions for learned men; the richer to pro. vide for the younger sons of the nobility.

ABBEvilce, a town of France, situated on the river Somme, 120 miles N. N. W. from Paris. Its popu. lation exceeds 20,000 , and its manufactures are cliefly woollens of a fine quality.

Aввот, (Heb. abbas, father, was originally the name of every aged monk; but since the 8 th century, it denotes the head of a monastery. The Abbot requires unconditional obedience from his monks, and his office is to supervise the whole brotherhood, to enforce the observance of the rules of the order, and manage the property of the conrent. Since the 6 th century, abbots have always been priests; and, since the second council of Nice, in 787 , have enjoyed the power of conferring the lower orders of priesthood; but, in the essential points of jurisdiction, were every where subject to the diocesan bishop, till the 11th century, and independent of each other. The consequence of the abbots grew with the wealth of their monasteries; several, especially in those countries where the dif fusion of Christianity proceeded from the monastic establishments, received episcopal titles and privileges; all held a rank next to that of bishop, and had a rote in the ecclesiastical councils. Equal privileges and rights appertained to the abbesses as the superiors of the numneries, except that they have seldom been allowed to vote in synods; and the power of ordaining, the administration of the sacraments, and other sacerdotal offices, were expressly forbidden them, in the 9th century. About this time, by the favour or from the wants of the kings, abbeys frequently came into the hands of the laity, 
What avaricions barons had extorted from single conrents in the 8th century, the weakness of the Carlovingians accorded to their partisans, as a reward of fidelity and military merit, since the kings possessed the right of patronage over all abbeys established on their crown lands or family estates, and generally over all which derived their origin from the royal bounty. Thus, in the 10 th century, a number of the most considerable convents in the territory of the Roman cliurch had lay abbots, or abbot-counts, who appropriated to their own use the income of these institutions. In cloisters fallen to such worldly masters, the spiritual supervision was discharged by inferior abbots, deans, or priors. To the princes and princesses of the royal family, abbeys were presented, to defray the expenses of their tables : the richest were retained by the kings themselves; thus Hugh Capet was abbot of St Denis, near Paris, and of St Martin, at Tours. Nunneries were sometimes assigned to men, and monasteries to distinguished females. But this abuse, which had crept even into the Byzantine empire, rarely survived the laymen who had received the gifts. These were called commendatory abbots, because the form of the presentation was a recommendation of the convent to their protection. The zeal, which, in the beginning of the 10th century, urged a reform in monastic discipline, gradually succeeded in abolishing such donatives to the laity; and military abbots were now more rarely seen discharging, in person, the duties of a soldier, though the convents under royal patronage were for a long time retained, to reward the services of the crown vassals in war, by contributions of money and peasants. The superiors of the military clergy bore, in the camp, the name of field abbots, as the name of abbot was, in the niddle ages, frequently used to denote not only magistrates (as abbas populi, the prator at Genoa) and secular ecclesiastical dignitaries, but also the chiefs of religions and jovial fraternities, e. g. abbas cornardorum, stultorum, the abbot of misrule. In consequence of the reform commenced at Cluny, there arose new monasteries without abbots over which the ahbot of the convent of reformed Beriedictines, at this place, appointed priors or pro abbates, or even co-abbates, who remained dependent on him. Besides the Benedictines, only the grey monks of Vallombrosa, the Cistercians, Bermardines, Feuillans, Trappists, Grandmontani, Præmonstratenses, and some bodies of regular choristers, denominate their superiors abbots. In the other orders, the titles majores, ministri, priors, or rectors, were in use. Besides the female branches of the above orders, the nuns of Fontevraud and the female secular choristers have abbesses. These have always remained under the jurisdiction of their diocesan bishops. The abbots of many other convents, on the contrary, shook off the authority of the bishops, and acknowledged no master but the pope. The mitred abbots enjoyed the right, frequently conferred on the Beuedictines in the middle ages by the papal legate, of adopting the episcopal title and insignia. Only a few, however, possessed the episcopal power with dioceses of their own, of whom there was not one in France. Before the period of secularization, there were in Germany, but in Germany only, princely abbots and princely abbesses. These abbeys were secularized in 1803 , and became principalities. By rule, the choice of abbots appertains to the chapters of their convents. In the independent abbeys, this is followed by the papal confirmation; in the dependent, by the episcopal; yet, for a long time, many abbeys in Italy liave beon conferred by the pope, and, in France, by the king, notwithstauding the concordat of 1516. The secu- lar clergy, who enjoy these benefices without observing the rules of the order, are termed sccular abbots; on the other hand, their vicars in the convents themselves, like all abbots of the monkish order, are called regular abbots. Younger sons of distinguished families have often entered the ranks of the secular elergy, in order to become secular abbots, and to receive the income of an abbey, without being restricted by monastic rules. As such expectants were called in France abbés, this became a general appellation for young secular clergy who were out of office. (See $A b b \dot{e}$.) Since the revolution, which changed the abbeys into national property, and took froin those expectants the object of their exertions, this class has diminished in trance; but it is yet numerous in Italy, where young scholars are called $a b b o t s$, merely from having undergone the tonsure, though not in orders. - Napoleon led a whole army of Italian abbots to Corsica, where they lived on reduced incomes, till the restoration scattered them again over Italy. At the time of the re. formation, several abbeys and convents were retained for the benefit of the clergy and the support of unmarried females. Some protestant clergymen, therefore, still bear the title of abbot, with which dignity the right of sitting in the diet of the states is united ; as, for example, in the Wurtemberg assembly. There are also Protestant ladies who are called abbesses. In lower Saxony, this dignity was indeed abolished, at the time of the confiscation of the cloisters, \&c., under the French Westphalian government; but in some countries, e. g. in the kingdom of Hanover, it has been restored. In the Greek church, the superiors of a convent are called higume$n i$, mandoce, and the abbots general, archimandrites.

Аввот, Charles, froin 1802 to 1817 speaker of the house of commons; was born in 1755 , and studied at Westminster. His father was $\mathrm{Dr}$ Abbot, minister of All Saints' church, at Colchester. Impelled by the desire of distinction, he devoted himself to the study of the law, though possessed of a considerable fortune. His object, however, was not professional reputation, though he had an extensive practice in the court of chancery. On account of a latin poem which he wrote on the empress of Russia, Catherine II., the Russian ambassador in London presented him, in the name of the empress, with a gold medal. He wrote some treatises on legal subjects, and was cliosen in 1790, 1796, and 1802, into the house of commons. As a member of parliament he exerted himself to introduce better order into the printing and distribution of the acts of parliament ; and endeavoured, though in vain, to effect. a reform in the phraseology, of the statites, which should make them more perspicuous. In 1795, he supported Pitt's famous Riot Act, and always attached himself to the ministerial party. In 1796, he proposed, as chnirman of the committee of finance, an amendment in the promulgation of the laws, which was accepted. In 1799 , he supported the imposition of the income tax. In 1800 , he proposed to impose upon the collectors of the public revenues the interest of the sums uncollected, in order to prevent deficits in their returis; and voted to continue the Mutiny Bill till 1807 . He was successively first secretary of state in Ireland, and lord cominissioner of the treasury; was made privy councillor, and in 1802 speaker of the house of commons. This post is fatiguing, but lucrative, on account of the large fees for the enrolment of private bills which pass the house. These bills are referred to a committee, whose reports are almost always accepted, unless they propose an innovation on some established usage. 'The speaker is very watchful to prevent the occurrence of any thing informal in the wording of the bills, 
asd to check all personal ities in dehate. This superintenlence, $A$. is said tw have exercised with much Impartiality. When the opposition made a motion in the honse of comnons to impeach lond Melville, (I)undas,) the votes were equal, and the motion was lecided in the affirmative lig .1.'s casting rote. In 1817 , he resigned his office of spenker, on account of weakness in his eyes, and entered the house of lorils, huving been created viscount Colchester. He was author of a treatise on commerce and maritime law, according to the principles of the British ministry, (I.ond. 1802, a third edit. 1808.) Died Muy 8, 1829.

Aввот, George, archibishop of Canterbury, was born Oct. 29, 1562, and studied at Oxford. When the translation of the Bible was begun, in 160\%, by onter of king Sames, Abbot was one of the eight divines to whom it was committed. In 1609, he went to Scolland to assist in effecting $n$ union between the kirk of that country and the church of England, and conducted the business with much moderation and address. In Dec. 1609, he was made bishop of Litchfield and Coventry; in Jan. 1610, bishop of Iondon ; and in Nov. following, archbishop of Canterbury. His enemies ascribed his rapid promotion to flattery of the king. In 1613, however, he opposed Janes's project of a dirorce between lady Frances Howard and the earl of Essex, and, in 1618, the royal declaration, permitting Sunday sports, which he prolibited the reading of in church. His health declining, he went to Hanpslire for recreation, and, being invited to a hunt by lord Zouch, had the misfortune to shoot the game-keeper with an arrow aimed at $\mathrm{n}$ deer from a cross-bow. The accident affected him so nuch, that, besides settling an annuity of $20 \%$. on the widow, he kept, during the remainder of his life, a monthly fast on Tuesday, the day of the unhappy event. Though tronbled with the gout, he perfurmed the ceremony of crowning Charles I. He was never much in this monarch's favour, and was suspended from the exercise of his functions as primate, on refusing to license a sermon preached by Dr Sibthorpe, in justification of a loan demanded by the king. At a meeting of parliament, he was restored, and died at Croydon, Aug. 5, 1633, aged 71. During his life, he published several works, chiefly theological and many of his letters and speeches are to be found in various collections. He had a brother named RoserT, who pursued the same course of education with himself, and died bishop of Salisbury, in 1617. Comparing the two, Fuller says, that George was the more plausible preacher, Robert was the greater scholar; George the abler statesman, Robert the deeper divine.

ABBOTSFORD, the well-known country seat of Sir Walter Scott, destined to be in all ages a shrine for the wandering worshippers of genius. It is situated on the banks of the Tweed, in Roxburghshire, in the neighbourhood of the public road between Melrose and Selkirk. The great and good man who gave a name and a glory to this spot has now gone down to the dust, honoured and lamented by the whole civilized world; and although, on his demise, fears were entertained that the place upon which he had so strongly set his affections should fall into the hands of strangers, it is now little doubted but that his family shall be left to enjoy it, and the country saved from the disgrace which any other result would bring upon it. Abbotsford was erected by Sir Walter himself, and the surrounding grounds owe much of their beauty, as they do the interest connected with them, to their gifted proprietor. The building is of very extraordinary proportions, presenting to the eye various fantastic gables, parapets, eares, chimneys, balconits, \&c., which although irregular in their dc- tails, are eminently striking in their general effect. Many of its ontlines and ornaments are takeu from celebrited places in Scotland; for example, a gateway from linlithgow Palace, n roof from Roslin Chapel, a chimmey piece from Melrose Abbey, a posteri from the Edinburgh Tolbooth (the Heart of Mid Lothian), and the walls of the vestibule are paneled with pieces of old carved onk, which forinerly figured in Holyrood palace. 'The house itself alrounds in apartments, of all shapes and dimensions, which are decorated in a singular but tasteful and appropriate mauner. T'lroughout these are arrangod inmmenble relies of the older time, as also a variety of striking articles of modern clays. Not this least interesting of the apartinents is the Library, which is an oblong of about fifty feet by thirty: the roof and the bookcases are of carved oak, and the collection of books is extensive, containing wany of a rare and valuable claaracter. Beyond the lihrary is situated what wns the sanctum or stucly of the author, who gathered unto himself so rich a harvest of fame. This is a small room furnisted with $n$ writing table and two chairs only, but decorated around the walls with several antique cabinets, busts, targets, claymores, \&c., together with two portrits, one of Claverhouse, and a small full-length of Rob Roy. In one corner of the study there is a closet, which opens into the gardens, and which also leads, by a private staircase, to the anthor's bed rooms. The view from all the principal apartments is betutiful. You look out from among bowers over a lawn of sweet turf, upon the Tweed, fringed with the wildest of birch woods, and backed with the green lills of Ettrick Forest. Altogether, as an American writer says, the place destined to receive so many pilgrimages, contains within itself beauties not un. worthy of the associations. Few poets ever inhabited such a place; none, ere now, ever created one. It is the realization of dreams-a romance in stune and lime.

Arbreviations; (called by the Romans note: hence notarius, a short-hand writer.) The desire of saving time and space, or of secrecy, led to the invention of abbreviations in writing. The abbreviations of the Romans were of three sorts: 1 . Words and syllables were abbreviated, sigla ; 2 . One letter was substituted for another, for the purpose of secrecy ; 3. Arbitrary signs were used, like those of matlie matics. The sigle are again of three kinds, according as the abbreviations relate to syllables, words, or phrases. The two last kinds of sigla are sometimes called nota Tironana, from Cicero's freed man, Tullius Tiro. Ennius, however, had already invented 1100 of those signs, to which Tiro added the pre positions. Others increased their number still more, and Lucius Annæus Seneca collected and arranged 3000 of them. But even Ennins was not their inventor. Every avritten language has such abbreviations. Many of them are indeterminate and uncertain, and the contents of many old writings and inscriptions remain, on that account ambiguons. The oldest and most common abbreviations are those of names, titles, and formulas; e. g. M. Marcus, EEd. adilis, Cos. consul, Coss. consules, \&c. The monks, in the middle ages, made use of many abbreviations in copying the classic authors, on which account the manuseripts of that time caunot be read with ease, except by practised eyes. These abbreviations often give rise to different rendings. They have been much less used since the invention of printing. The Germans employed them for ordinary words, in greater proportion than other civilized nations. The abbreviations in the English law are numerous; there are also a great many in English titles. Many words in the modern lauguage 
arose from abbreviations of Latin terms, as they were taken by the ignorant for the words thenselves. The following list contains many of the abbreviations in common use alphabetically arranged.-A. B., or 13. A., bachelor of arts :-Albp., archbishop: A. C., ante Christum. A. D., anno Domini, A. M., ante meridiem, forenoon; also, anno mundi, in the year of the world; and artium magister, master of arts; B. C., before Christ: B. D., bachelor of divinity ; B. M., bachelor of medicine: Bp., bishop: B. V.,

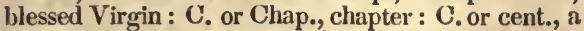
hundred: C.B., companion of the Bath: C.C., Caius college: Cwt., hundred weight: $\mathbf{D}$. $\boldsymbol{D}$., doctor of divinity: D. F., defender of the faith: D. G., Dei gratia: D.T., doctor of theology: Dwt. pennyweight: L. G., exempli gratia: Ex., example: Exr., executor: F.A.S., fullow of the antiquarian society : F. L. S., fellow of the Linnean society: F. R. S., and A. S., fellow and associate of the royal society: F.S. A., fellow of the society of arts: Gal, gallon: G. C. B., knight grand cross of the Bath: G. R., Gulieimus rex, king William: Hhd, hogshead: H. M. S., his majesty's ship: lb. or Ibid. ibidem, in the same place: Id. idem, the same: I. e. id est, that is : + I. H.S., Jesus hominum Salvator: I. H. S., in hac cruce salus : Incog., incognito, unknown : Inst., instant or of this month: J. U. D., juris utritsque doctor : K. B., knight of the Bath: K. C. B., knight commander of the Bath: L. or libra, pound: L. D., lady day: Idp., lordship: Lea., leagues: Lieut., lieutenant: LL. D., legum doctor, doctor of laws: L. S., locus sigilli, the place of the seal: M. C., member of the congress: M. D., doctor of medicine : Messrs. messieurs, gentlemen : M. P., member of parliament : MS., manuscript : MSS., manuscripts: $\mathbf{N}$. B., nota bene, take notice : Nem. con. or Nem. diss., nemine contradicente, or nemine dissentiente, unanimously : $\mathbf{N}$. S., new style: Obt., obedient: O.S., old style : Oxon., Oxford: Oz., ounces: Per cent., per centum, by the hundred: P. M., post meridiem: P. S., postscript: Q., question: Q. E. D., quod erat demonstrandum : Q.E.F., quod erat faciendum: Q. S, quantum sufficit: Q. V., quid vide: Rev., reverend: $R$. N., royal navy: Rt. Hon., right honourable: Rt. Wpful., right worshipful: S., south: S. or St. saint: Sec., secretary : Sc. scilicet: St., street: Ult., ultimo, last: U. S., United states: V. vide, see : Viz., videlicet: Xmas., Christmas : Xn., Christian : 'Xper., Christopher: $Y^{\mathbf{m}}$, them: $Y^{n}$, then: $Y^{r}$, your and year: $\mathbf{Y}^{\mathbf{s}}$, this: $\mathbf{Y}^{\bullet}$, the : $\mathbf{Y}^{\natural}$, that.

Abireviatori, officers in the court of Rome, appointed to assist the vice chancellor in drawing up the pope's briefs, and relucing petitions, when granted by the pope, into proper form, to be converted into bulls. The 12 first have the dress and rank of prelates; 22 others belong to the lower clergy; the rest are laymen. The salary of an $\mathbf{A}$. of the first rank in the last century was 2000 scudi, (between $£ 400$ and $£ 500$.)

Aвв's, St, Head, a promontory of Berwickshire, situated on the north sea, at the extreme entrance to the Frith of Forth from the soutliward.

Aввт, 'Thomas, a philosophical writer, was born Nov. 25, 1738, at Ulm in Suabia, and early manifested distinguished talents, and taste for the sciences. In 1756, he entered the university of Halle, where he applied himself to metaphysics and mathematics, quitting theology, to which he had at first devoted himself. In 1760, he was invited $\omega$ join the university of Frankfort, on the Oder, as professor extraordinary. Here he wrote, amidst the tilmult of war, his treatise on Death for one's Contriry. In the following year, after he had accepted an appointment as professor of mathematics, at Rinteln, le lived six montlis at Berlin, where he became intimate with both the Eulers, Mendelsuln, and Nicolai; and took an active part in the Letter on literature, (Literaturbriefen.) He died in 1766 , in the prime of life, at the residence of one of the minor German princes, his intimate friend and protector. A.'s writings exhibit acuteness, imagination, and spirit, and abound with practical philosophy, particularly his treatise on "Merit." He certainly would have ranked among the most distinguished writers, if he had lived till his inind was fully matured. Young as he was, he deserves to be numbered among the writers who, in the time of Lessing, laboured with united zeal to raise and refine German literature.

Abnals, a sect of fanatics in the East Indies, of a dangerous character, as they count it meritorious to destroy those of a different religion. In the height of their enthusiasm, they sometimes rush into the streets, and stab all that they meet.

ABDEra, a city on the Thracian coast, which is said to have been founded by Hercules. Though it boasted of being the native place of Democrtius and Protagoras, yet it was regarded among the ancients as notorious for stupidity.

ABDication, properly speaking, is only a voluntary resignation of a dignity, particularly the supreme. Of royal abdications, the more famous are those of the emperors Diocletian and Maximinn, in 305; of the emperor Charles V., in 1556; of queen Christina of Sweden, in 1654. They have been the most frequent in Spain. Charles I. in 1556; Philip V., in 1724; Charles IV., in 1808: next in Savoy and Sardinia; Amadeus I., in 1440; Victor Amadeus II., in 1730 : but only a few individuals have remained faithful to their resolutions; e. g. Diocletian, Charles V., and Victor Emanuel, king of Sardinia, who abdicated in favour of his brother Felix, in 1821. (See Piedmont, revolution of.) Victor A madeus, of Sardinia, attempting to rcsume the government by force, was imprisoned by his son, Charles Emanuel III. Involuntary resignations also are called abdications; e. g. Napoleon's abdication at Fontainbleau. The right of a prince to resign the crown cannot be disputed; but the resignation, as some say, can affect only his personal right to the crown, and cannot prejudice lis descendents; still less force upon the state another constitution, or another familyThe abdication of Charles IV. of Spain, according to them, could only take effect in favour of the legitimate successor, but could not entitle a foreign sovereign to establish a new dynasty. The abdicated prince is sometimes allowed exterior marks of homage, the title of majesty, \&c."but sovereign powers he can no longer exercise. Out of his own country, he enjoys not the honours of a monarch, nor, in general, jurisdiction over his suite. If he, in whose favour the abdication was made, dies, or declines the offered dignity, the right of the abdicated prince is revested. Thus Philip V. of Spain resumed the throne unon the death of his son I,ouis, whicl took place half a yenr after he had resigned in his favour. But queen Christina of Sweden made a similar attempt in vain. Voluntary abdications, as they are called, are often involuntary, and the effects of comt intrigue.

Asdollatipr, a celebrated Arabian philosopher and physician of the 12th ccitury. He was bon at Bagdad in 1161, and died in 12:3. Of numerous treatises which he wrote, only one has come down to us, viz. A Compend of the History of Egypt, the MS. of which was brought to England by Dr Pococke, and an edition of it published in Arabic and Iatin, in the year 1800 .

A DDosen, in anatomical language, the brily.

$A B E L$, the second son of Adam, a twin bruthicr of 
Cain. The latter was a tiller of the gromed, A. a his nistress rather than his wife, and had formerly shephent. Both brought an offering before the written to him that she wonld not deprive the world Lonl; Cain the first fruits of the gronnd; $\lambda$. the of so great a man by domestic cares, at last consented. firstlings of his tlock. Gal accepted the offering of The marriage was performet, anl, in order to keep A.; the offering of Cain he rejreted. The latter, it sccreh lleloise remained with lier uncle, whilst $A$. instigated by eniry, Imurlered his brother in the fielcl. retuined his former lodgings, ant eontimed his lec. Thus the first munder on earth was connitted. The tures. They saw each other but seldom; Fulbert, opinion of several Cliristian fathers, that A. clied m- however, thought the reputation of his niece would Inarriel, las given rise to the sect of Alelites or be injured by this secret union, and made it known; Abelonites, (q. v.) The church considers the offer- but Heloise, valuing A.'s fame higher than her own iug of $\mathrm{A}$. as the pattern of a pure and holy offering, good name, denied her marriage with an vath. Fulpleasing to God, and Christ himself calls hin the just. bert manifested his anger by ill treatment; to deliver

A bezard, 'eter, originally Abailard, a monk of licr from which, A. carried her away a second time, tho onler of St Benedict, equally famous for his and placed her in the convent of Argenteuil. Fullcarning and for his unfortnnatc love of Heloise, was bert erroneously believed it was intended to force her born in 1079, near Nantes, in the little villagc of to tike the veil, and under the influctice of rage, lie Palais, which was the property of his father Berenger. Ifis inclination led him to the study of the sciences; and in order to devote himself fully to philosopliy, he cederl to his hrothers his rights of priungeniture and lis cstates. He studicd poctry, rhctoric, philosophy, jurisprudence, and theology, the Grcek, Hebrew, and I atin languages, and soon becane familiar with then; but scholastic philosophy chiefly engaged his attention. Though Bretagne then possessed many distinguished scholars, A. soon acquired all they conld tcach. He went therefore to Paris, the university of which attracted students from all parts of Europe. William de Champeaux was the most skilful disputant of his time. A. made so good use of his instructions, that he was often victurious over his master, in contests of wit and logical acumen. The friendship of Champenux was soon succeeded by enmity, in which his other scholas took part, and A., who liad not yet completed his $22 \mathrm{~d}$ year, escrped the consequences of their illwill, by fixing himsclf at Melun, where he was soon followed by a multitude of young $m c n$, who were indnced by his reputation, to leave the schools of Paris, in order to attend his lectures. Envy pursued him here, and lie left Melun for Corbeil, where he was no less admired and persecuted. In compliance with the advice of his physicians, he soon after remitted his labours, for the purpose of restoring his disordered liealth by a journey to his untive place. After two years, he returned with renorated strength to Paris, became reconciled to his former teacher, and opened a school of rhetoric, the fame of which soon deprived all the others of their pupils. He lectured on rhetoric, philosophy, and theology, and educated many distinguished scholars, among whom were the future pope, Celestin II., Peter of Lombardy, bishop of Paris, Berenger, bishop of Poictiers, and St Bernard. At this time, there resided at Paris, a young lady, by name Heloise, niece to Fulbert, a canon of that city, then of the age of 17 years. Fery ladies surpassed her in beanty, none equalled her in genius and knowledge. A., though already of the age of 39 years, became inspired with such violent love for Heloise as to forget his duty, lis lecturcs, and his fame. Heloise was no less susceptible. Under the pretext of finishing her education, A. obtained Fulbert's permission to visit her, and finally hecame a resident in the house of the canon. The lovers lived sereral months in the utmost happiness, occupied more with their love than with their studies. But the verses in which $A$. celebrated his passion were circulated in Paris, and fnally reached the eyes of Fulbert. He separated the lovers, but too late; Heloise was already pregnant, A. fled with her to Bretagne, where she was delivered of a son, who died, however, early. He now resolved to marry her secretly. F. was obliged to give his consent, and Heloise, who, from a talse delicacy, preferred to be subjected A. to an ignominious mutilation. $A$. be:came, in consequence, a monk in the abbry of St Denis, and Heloise took the veil at Argentenil. After time land somewluat moderated his griet, lie resumed lis lectures, and ineurred new persecutions his enemies accused him of heresy at the conneil of Soissons, 1122, on account of his Essiy on the Trinity. They succeedcd in having it declared lereti$\mathrm{cal}$, and he was condemncl to burn it with his own hands. Continued persecutions obliged him at last to leave the albbey of St Dcnis, and to retire to a place ncar Nogent-sur-Seine, where he built an oratory, which he dedicated to the Holy Ghost, and called it Paraclete. Being subsequently appointed abbot of St Gildas de Ruys, he invited Heloise and her religious sisterhood to reside at his chapel, Paraclete, and received them there. The lovers saw each other licre again for the first time after a separation of 11 years. A. lived afterwards at St Gildas, which afforded him but a gloomy residence, troubled by unsuccessful attempts to reform the inonastery, and struggling always with his love for Heloise, and the hatred of the monks, who even threatened his life. St Bernard, who liad long refused to proceed against a man whom he esteemed, finally yielded to the repeated remonstrances of his friends, laid the doctrines of $A$. before the council of Sens, in 1140, had them condemned by the pope, and obtained an onler for lis imprisonment. A. appealed to the pope, published his defence, and went to Rome. Passing through Cluny, he visited Peter the Venerable, who was abbot there. This humane and enlightened divine effected a reconciliation between lim and his enemies; but A. resolved to end his days in retirement. The severe penances which he imposed upon himself, together with the grief, which nercr left his heart, gradually consumed his strength, and lie died, a pattern of monastic discipline, in 1142, at the abbey of St Marcel, near Clialons-sur-Saone, at the age of 63 years. Heloise begged his body, and lat him buried in the Paraclete, with the view of reposing in death by his side. In 1800 , the ashes of both were carried to the museum of French monuments at $l^{3} \mathrm{a}$ ris, and, in Nov. 1817, were deposited under a chipel within the precincts of the Church of Monamy. A. was distinguished as a grammarian, orator, logician, poet,musician, philosopher, theologian, and mathematician; but lie has left nothing to justify the reputation which he enjoyed among his contemporaries. He excelled in the art of disputation. His doc. trines were often reprehensible, and his behaviour censurable. His love and his misfortunes have secured his name from oblivion; and the man, whom his own century admired as a profound divine, is now celebrated as the martyr of love. 'The letters of $A$. and Heloise have been often published, in the original and in translations.

A Becrres, Abelians, or Abelonians. St Augustine gives this name to a Christian sect, which probably 
spraifg from the Guostics. They abstained from inatrimony, to avoid propagating original sin, but aropted the children of others, and brought them up in their own principles. This society existed towards the end of the 4th century, among the people who dwelt near Hippo, in the northern part of A trica, and borrowed their name from Abel, the son of Adam, because he died unmarried and without chilIren. They have found followers in the Shakers, (q. v.)

A Berbrothick. See Arbroath.

A BERCORN, a parish and village of Linlithgowshire, where stood one of the most ancient monasteries in Scotland, and also a castle, originally a Roman fort, of great strength. It belongs chiefly to the Hopeton family, and gives title of marquis to a branch of the house of Hamilton.

ABErcromby, Alexander, a Scottish lawyer and judge of the last century, was born in 1745, and died ii 1795. He was brother to Sir Ralph Abercromby, and is now chiefly remembered as being a valuable contributor to the Mirror and Lounger, two periodicals published at Edinburgh, which have taken their place among the most classical of the British essayists.

А векскомву, John, the author of several esteemed works on gardening, was born near Edinburgh, and going up early in life to London, obtained employment in the Royal Gardens. He died in 1801 . He was author of 'The Gardener's Calendar,' 'The Universal Dictionary of Gardening and Botany,' and other works on the same subjects.

A Bercromby, Patrick, physician to James II., was born in the county of Angus in 1656, and educated at St Andrews. He travelled for some time on the continent, and died in 1716 or 1726 . He compiled ' The Martial Achievements of the Scots Nation,' which was published in 1711-15, in 2 vols. fol., and translated a French work, entitled 'The Campaigns in Scotland in 1548 and 1549,' which was published in 1707.

A BErcromby, Sir Ralph, a distinguished British general officer, was born in 1738, at Tullibody, in Clackmannanshire. His first commission was that of cornet in the $3 d$ regiment of dragoon guards, in 1756 ; and he gradually passed through all the ranks of the service, until he became a major general, in 1787. On the commencement of the war with France, he was employed in Flanders and Holland with the local rank of lieutenant-general, and in that critical service, displayed equal skill and humanity. In 1795 , he received the onder of the Bath, and was appointed commander-in-chief of the forces in the West Indies. In this expedition he captured the islands of Grenada, St Lucia, St Vincent, and Trinidad, with the settlements of Demerara and Essequibo. On his return, he was appointed commander-in-chief in Ireland; but, for reasons very honourable to himself, was quickly removed to the correspondent commind in Scotland. In the attempt upon Holland, in 1799, sir Ralph had the sole command on the first landing, and both his troops and himself greatly distinguished themselves. His royal highness the duke of York subsequently arrived, under whom sir Ralph acted. The final failure of the expedition is well known. The next and concluding service of this able and meritorious officer was in the expedition to Egypt, of which he was commander-in-chief. He landed, after a severe contest, at Aboukir, Mar. 8, 1801; and on the 21 of the same month, was fought the battle of Alexandria, in which sir Ralph was unhorsed and wounded in two places; notwithstanding which he disarmed his antagonist, and gave the sword to sir Sidney Smith. The general kept the field during the day, and was then conveyed on board the admiral's ship, where he survived abont a week. His boly was conveyed to Malta, and interred beneath the castle of St Elmo, and a monument was voted to him, by parliament, in St Faul's cathedral. His widow was also created baroness Abercromby, with remainder to the issue male of her late husband; and a pension of $2000 l$. a year was granted in support of the dignity. Sir Ralph A. leti four sons; George, a barrister at law ; John, a major-general; James, and Alexander.

AberdeEnshire, an extensive county in the north of Scotland, bounded on the east and north by the German ocean, on the south by Perthshire, Angus, and Kincardineshire, and on the west by the shires of Banff, Moray, and Inverness. Its superficial extent is estimated at 1200 square miles, and it is divided into 85 parishes. Its western parts are rugged and mountainous, and in many places covered with extensive forests. Towards the east and north-east, the county is more level, fertile, and capable of cultivation. The mountains are chiefly composed of granite, which is the prevailing rock throughout the county, and great quantities of which are annually exported to London and other places. The principal rivers of $A$. are the Don, the Dee, the Ythan, the Bogie, the Uri, the Cruden, and the Deveron. Nearly all these abound in salmon, much of which is sent in a fresh state to the London market. The sea-coast also abounds with excellent fish, the catching of which affords employment for a great number of fishing vessels from the ports of Frazerburgh, Peterhead, and Aberdeen. The two latter places employ a number of vessels in the whale fishery. Although generally poor as an agricultural county, Aberdeenshire is rich in natural resources, and its scenery is in many places peculiarly wild and picturesque. It also contains a number of the chief seats of the Scottish nobility, besides many elegant residences belonging to private gentlemen. The population is estimated at 177,651 . The capital of the shire is NEw ABERDEEN, which is a royal burgh, and the chief city as well as principal seaport of the north of Scotland. It is a large and handsome town, situated near the mouth of the Dee, with a population of 32,912 . The inhabitants carry on a very considerable business both in trade and manufactures, and the place has been long celebrated as a seat of learning, by possessing the Marischal College and University, founded by George, earl Marischal, in 1530. OLD ABERDEEN is a mile distant from the new town, and not far from the Don. It was anciently an episcopal see, and it also has its university, called King's College, founded in 1494 by Bishop Elphinstone. Population of O. A. 25,107, including the parish of Old Machar.

AвERLI, John Lewis, a landscape painter, farnous for his Views of Switzerland; was born in 1723, at Winterthur. He relinquished the manner of his teacher, Meyer, an indifferent artist, went to Berne, received better instruction from John Grimm, and at first painted portraits. But his inclination for landscape painting gained the ascendency. He went, in 1759, with his pupil Zingg, to Paris, and returned, esteemed and admired, to Berne, where he died in 1786. His manner has been very often initated, and his sketches have always maintained the reputation of being the best in their kind.

A bernethy, John, an eminent Irish presbyterian divine, was born at Londonderry in 1680, educated partly in Glasgow and partly in Edinburgh, and died in 1740. He distinguished himself chiefly by his zeal for religious liberty, and his resistance to what he deemed oppressive authority on the part of the Irish presbytery. Besides occasional sermons and controversial tracts, he wasautlior of Discours's 
ou the Being and Attributes of God, which are highly esterined.

AstiknstuY, John; n propular surgeon of the present eentury, who practisit in I.ondon. He: was born in 1763-4, but whether in S'colland or Ireland is strangely enough dispusted. Farly in lite ho became the pupil, and subsequently the friend of the celer brited John Hunter. In 1780, he becaue assistantsurgeon to St Bartholomew's Hospital, and shortly afterwards took the phice of lecturer on anatomy anil surgery. Under his anspices the Hospital attained a celebrity which it haul never before enjoyed. He published "Surgical Observations" in 2 vols., and "Lectures" in one vol., explanatory of Mr Hunter's opinions of the vital processes; besides smaller essiys. In one of his essays, he gives an account of urses in which he lnd tied the external ilinc artery, a bold and meritorious operation which established his time. He died on the 18th of April, 1831. He was noted for his eccentric habits and the roughness of his manner in adkressing patients. Exercise and liet were his principal means of cure ; and it was not uncommon for him to aldress sickly or dyspeptical patients of the higher classes thus :- "Madam, keep your money to buy a skipping rope!" or "Sir, live on sixpence a day - and earn it?" Yet his roughness was all on the outsile; for at heart he was sympathizing and generous; being known, in the midst of the most distinguished practice, to devote unuch of his time and talents to the poor and destitute.

A Berration of light. We see an object because the rays of light proceeding from it strike our eyes, and we see the place of the object in the direction in which they proceed. Let us now inagine the earth in its circuit round the sun, just arrived opposite to a fixed star, which sends off rays perpendicularly to the direction of the earth's motion. The eye of the spectator inects the rays, and, as he perceives not his own motion, he supposes the light to be moving in an opposite direction; as, when wc sail in a boat, the trees on the shore appear to pass along by us. Thus the eyc misses the perpendicular ray, but mects an oblique one, and thence receives the impression of the light in the direction which results from this compound motion, namely, in the diagonal of a parallelogram, the sides of which represcnt the real motiou of the light, and the apparent one, (i. e. the motion of the earth,) which take place at the same time. The spectator sees the star in its true place only when he is either approaching it, or rcceding frum it, in a straight line. Wher moving in any other direction, the star appears a little in advance of its true position in the same direction (the maximum is $20-25$ ); and we call by the namc of aberration of light these apparent changes in the situation of the heavenly bories, occasioned by the motion of the earth. We easily see that these clianges are common to all those heavenly bodies, and ure only more striking in the case of the fixed stars. They afford an additional proof of the motion of the earth. In conseguence of this abcrration, the fixed stars appear, during the revolution of the earth about the sun, sccording as they are situated, either in the plane of the ecliptic, or in its poles, or somewhere between them, in the first case to deviate in a straight line to the right or left of their true place, in the second to describe a circle, in the third an ellipse about that point, which further observationdetermines to be their real situation. This discorery we owe to Bradley. (q. v.) For the aberration of light, see the elementary works on astronomy, the dictionarics of natural philosophy by Gehler, Fischer, \&c. There is a very good account of it in Biot's Traité Elementaire d' Astronomie Physique, Paris, 1811, 2d Treatise, vol 3, page 120 , et seq. Tables of aber- ration, accompanied with explanations, are to be found ill the baron von 'Lach's works, Gotha, 1806, and in the sane unthor's Nonvelles 'Tables d' Aberration et de Nutation pour 1404 Etoiles; avec une Table generule d' Aberration pour les Plunetes et les Cometes, Marseilles, 1812, and Supplement, 1813.

A Bacdgand, Nicolai Albraham, historical painter to the king of Denmark, and knight of the order of banebrog. He wus born at Copenlagen, in 1744, and dient there in 1809, director and professor of the academy of fine arts. He was undoubtedly the furest painter that Denmark ever possessed. Five years' residence in Italy completed the elucation which he had received in the actulemy of arts at Copenhagen, yet his works never lost the character of originality. The creations of his productive ima. gination were sometimes of a gloomy, and always of II grand and solemn character. Miodern printing can hardly show finer colouring. A considerable number of his large pictures in the apartments of the royal palace of Cliristiansburg, were bumed in 1794 Several, however, still exist in and ont of Copenhagen. A. acquired reputation as a writer by some short essays, the object of which was, partly, to correct a false taste in regard to the arts, partly to illustrate the earlier works of art.

A bisgton, Frances; a popular comic actress of the last century, whose maiden name was Barton, She was born in London in 1731, and made her first appearance in 175l, at the Haymarket theatre. She afterwards performed at Drury Lane and Covent Garden with Garrick, enacting the principal characters of the comedies of Shakspeare, Ben Jonson, Congreve, Cibber, \&c. In 1799 shc retreated to private life and died in 1815 , much respected.

Abrponrass, a warlike tribc of Indians, between $28^{\circ}$ and $30^{\circ} \mathrm{S}$. lat. on the banks of Rio de la Plata, consisting of 5000 persons, who pay little attention to agriculture, but employ themselves principally in hunting and fishing. During the five rainy months they resort to the islands of the Rio de la Plata, or to the tops of trees. The Abiponians prefer the flesh of tigers to every other meat, superstitiously br lieving that it gives new courage to the warrior. Iong lances, and arrows with iron points, are their weapons. They are often at war with the Spaniards. Their wives are not much browner thnn the Spanish ladies. The men are tall, with aquiline noses, are good swimmers, and fond of painting figures on their skin. Their caziques are, in times of peace, their judges ; in war, their leaders. In peace, however, their authority is very limited; for if a cazique should attempt an unpopular innoration, the multitude would leave him, and join other tribes.

Anjuration, oath of; an oath by which a person obliged himself not to acknowledge any right in the pretender to the British thronc. It signifies, also, according to 25, Charles IJ., an oath abjuring particular doctrines of the church of Rome.

A Bo, a town in Finland, which contained 1100 houses, and 11,300 inhabitants. Here in 1743, Swcden concluded peace with Russia. Since 1817 , it has ceased to be the capital of the goverument of Finland. The Russian administration has endeavoured, however, to support it by other means; and it continues to be the capital city of a district, as well as the seat of a Lutheran bishopric, (in 1817, raised to an archbishopric) and of the supreme court of justice for South Finland. The mouth of the river Aurajocki, protected by a promontory of the gulf of Bothnia, forms the harbour of the city, which, since 1817 , has been the chief place of export from Finland to Sweden, and evelt to the Mediterranean. It has important sugarworks, and manufactures of leather linen, sail-cloth, 
conlage, glass, coarse broad-clotl, \&c. Many ships are built in its docks. The academy which Gustavus Adolphus established in 1628 was changed by Christira, queen of Sweden, into a university, whicl was endowed still more liberally by the emperor Alexander. It had in 1824, forty professors, and more than 500 students, a library of 30,000 vols., a botanical garden, an observatory, \&c. In the autumn of 1827, the whole city, including the buildings and library of the university, was burnt down. The Russian government has taken energetic measures for rebuilding it.

Abourios of slavery. The society for mitigating and gradually abolishing the state of Slavery throughout the British dominions, commonly called the Antislavery Society, was formed under the patronage of this royal highness the duke of Gloucester, who was president of the society. In the list of the vice-presidents were the names of many of the most distinguished philanthropists, and, among them, that of the great champion of the negro's cause, $\mathrm{Mr}$ Wilberforce. The society published several works illustrative of the state of slavery, and pointing out its evils in a commercial, political, and religious point of view. (See Slavery and Colonization Society.) The more immediate objects of the society were to ameliorate the condition of the slaves, and to facilitate the means by which they might obtain their freedom; and for the accomplishment of these purposes,-To remove all the obstructions to the manumission of slaves: To cause the slaves to cease to be chattels in the eye of the law: To prevent their removal, as slaves, from colony to colony, and, under certain modifications, their sale or transfer, except with the land to which they may be attached: To abolish markets and compulsory labour on Sunday, and to make it a day of rest, as well as of religious worship and instruction; and also to secure to the slaves equivalent time in each week, in lieu of Sunday, and in addition to any time which, independently of Sunday, was afforded them; for cultivating their provision grounds : To protect the slaves, by law, in the possession and transmission of the property they might thus or in any other way acquire: To enable the slave to purchase his freedom by the payment at once of a fair price for his redemption, or of a fifth part of that price at a time, in return for an additional day in the week to be employed for his own benefit: 'To make the testimony of slaves available in courts of justice, both in civil and criminal cases: To relieve all negroes and persons of colour from the burden of legally proving their freedom, when brought into question, and to throw on the claimant of their persons the burden of legally proving his right to them: To provide the means of religious instruction for the black and coloured population, and of Christian education for their children : To institute marriage among the slaves, and to protect that state from violation and from either forcible or voluntary disruption: To put an end to the driving system: To put. an end, also, to the arbitrary punishment of slaves, and to put their persons as well as property under the guarclianship of the law: To provide that all children born after a certain day should be free,-care being taken of their education and maintenance until they should be capable of acting for themselves: To provide that no colonial goveruor, judge, attorney-general, or fiscal, should be a possessor of slaves, or should have a direct and obvious reversionary interest in such property, or should be the agent of the proprietors of slaves. The society further proposed, that the final extinction of slavery should be accomplisied by the redemption of all females of the lowest age, to about 40 ; by which means all their posterity would be lorn free. The cost of this measure was estj- mated at $£ 300,000$. The parent suciecy was supported by many auxiliaries, as well as by the almost universal feeling of the nation, whose roiceat length became too strong to be resisted by an interested faction; and ministers, in 1833, brought forward a bill for the entire abolition of slavery throughout the British colonies. This bill, by making a sacrifice of $£ 20,000,000$ to the slave-holders, to be distributed among them on their complying with the provisions of the act, was fully carried, and came into operation on the first of August, 1834. An abstract of its leading clauses will be given in the article Slavery. It is remarkable, that Mr Wilberforce died imme. diately after the completion of this great measure.

Aborigines; the name given to the oldest inhabitants of a country, of whuse origin nothing certain is known. The Roman historians gave this name to the people who dwelt in the vicinity of Rome, before the arrival of the Trojans. For the right of aborigines to the soil, see Indians, and Occupancy, right of.

AвобKIR, the ancient Canopus, is at present a village with 100 Arabian inhabitants: it has a strong castle on the western side of a spacious bay, protected by a projecting point of land and several small islands, and is situated on the Egyptian coast, 10 miles east of Alexandria. This place has become distinguished, in inodern times, by the naval battle, in which the English admiral, Nelson, annihilated the French fleet, between the first and the third of $\mathrm{Au}$ gust, 1798. The latter sailed on May 19, 1798, from the harbour of Toulon, to convey an army to Egypt, under the command of general Bonaparte. As soon as the English admiral, St Vincent, who was cruising before Cadiz, received information of this, he dispatched rear-admiral Nelson, with 14 ships of the line, to the Mediterranean, with orders to seek and attack the French fleet. Aug. 1, Nelson cauglit a glimpse of the French ships in the road of $A$. and gave the signal of battle. The French captains, who were just then assembled on board the admiral's ship, had hardly time to retire to their posts, before the first English ship began the attack. Although the French fieet was disposed in a curved line as near as possible to a small island, protected by a battery of cannon and mortars, Nelson suddenly ordered half of his force to break through, between the island and the French liue of battle, and to sail under the shore, in the rear, while the other half approached their front, and anchored within pistol shot; so that the French ships were attacked from all sides. At sunset, about half-past 6 o'clock in the evening, the battle began. At the end of an hour, 5 French ships were dismasted and taken. The French admiral Brueys, was killed by a caunonball; his ship, l'Orient, however, continued the battle with great spirit, until she took fire. About 10 o'clock, this splendid vessel, of 120 guns, blew up. Of 1000 menl, but 70 or 80 were saved. Capt. Casabianca was mortally wounded, and his son, a boy 12 years old, voluntarily remained in the burning ship, and shared his fate. The other ships continued the cannonade till the morning, which witnessed the entire defeat of the French fleet. But two ships of the line and two frigates escaped to Malta and Corfu; 9 ships of the line were taken, olse blown up, and another, together with a frigate, burned by the French themselves; one frigate, lowv. ever, was sunk. Thus the naval power of Prance in the Mediterranean was for a time anuililated, the British flag waved triumphant from Gibraltar to Alexandria ; 13onaparte's communication will France was cut off, and his enemies, with rellovated force united again, in the sulserquent year, in a new cua. 1itıon. 
A BRACADABRA ; a term of ineantation, which was lonmerly believel to have the power of curing ferens, especially the slow fevers, the internittent of 4 days, and the hemitritaeus, so called by Hypocrates, which was generally fatal. At present, this word is, for the most part, nsed in jest, without any parlicular merning, like hocus pocus. According to $\mathbf{Q}$. serenus Sammonicus, it onghi to be written so us to fornu a inngic triaugle, in orker to produce the supposed effect; vic.

$$
A \text { A }
$$

The triangle, thus formed, reads Abrcueudulora, begiming with $A$, and thence passing over to any line you please, and stopping at the last letter of the first line. Greek amulets, which bear the inscription $\triangle B P A C \triangle \triangle A B P A$, leave no douldt "that this magic word, properly, ought to be pronounced Abrasadabra, though the Jews say also Abracalan. Abrasudabra probably means divine decree, and is derived from the sacred name of the Supreme Being, Abrasux', or Abras. Some are of opinion that the tern Alvosax took its origin from the first letters of the Helorew words $A b$, Ben, Ruach hakodesh, (Father, Son, Holy Ghost,) and from the initials of the Greek wonds, cosmeva $\alpha \pi 0 \xi u \lambda \circ v$, (salvation from the cross.) 13nt Abrascix is neither an Agyptian, nor Greek, nur Helorew, but a Persiaı name, which denotes the Persian deity, Mithras. - Superstitious people, moreover, used to write the word Abrasadabru, in the manner above-mentioned, on a square piece of raper; then folded it so as to cover the writing, sewed it together with white thread, hung it, by a piece of tape, around the neck, so as to reach the heart, wore it for 9 days, and theu went, before sanrise, in profound silence, to a river which flowed to the east, took it from the neck, and threw it, but without opening or reading it, over their heads into the water.

A GRAHAM; the father, and most celebrated patriarch of the Jews, with whom their history commenCPS, as likewise, the promises given them by God, and the miracles performed in their farour. He was born at Ur, in Chaldea, abont $2000 \mathrm{~B}$. C., and lescended in the eighth generation from Shem, Noah's eldest son. He passed his early days in the house of his father, Terah, where he was kept fmm idolatry, which prevailed in his family. Obedient to the voice of God, which pointed out his noble destiny, and commanded him to settle in Canaan, he went to that country with his father, his wife, and his nephew, and fixed his abode at Haran, in Mesopotamia. After his father's death, he led a wandering life, in obedience to the will of God. He visited Sichein, Bethel, and Gerar, whence he returned to Betliel. Frequent dissensions between his servants and those of Lot caused their final separation. A. remained at Mamre, but Lot settled at Goinorrah. Aftervards, on hearing that four Arabian chiefs had invaded Gomorrah, and carried off Lot with his family and property, A. pursued them with 318 servants, conquered them, and rescued his nephew, and all that belonged to him. God revealed futurity to A., and ratified his covenant with him and his postuity, by the law of circumcision. The ad- vancerl age of $A$. and Sarals seesued to mender cloubtul the fulfilment of these promises, when three angels, in the shape of travellers, came u visit theni. They were sent to punish Sodon and Gomorah for their wickedness, and announced that, at their return, Sarals would be a mother. Though sine was 90 rears old, she conceived and bore Isaac, at the time designated by the angel. When Isaac had reached his 25th year, God wish. ed to put A.'s ficlelity to a new trial, and commanted him to sacrifice his only son, on mount Moriah. The old nall was realy to obey. The victin wns already placed on the altar, and about to receive the fatal stroke, when Goxl, convinced of the obedience of his servant, stopped lis lifted arin. Sarah died, but A. married Keturah, who bore him 6 more children. He died at the age of 175, and was buried nenr Saral, in a cave which he had bought for his sepulchre from the sons of Heth. Not only the dews, but also the Arabians, derive their origin from this patriarch: the Greek and Roman clrurches liave. introlucerl his name into their legends. He is also mentioned in the Koran, and some of the Mahommedan writers assert that $\mathbf{A}$. went to Mecca, and commencel the erection of the temple. The Jews have at all times honoured his tomb and his memory. His history, as given by the rabbins, is a mixture of truth and fiction.

Abrayam ì Sancta Clara; boru in Krahenheimstetten, in Suabia, June 4,1642. His true nane was Ulrich Megerle. He was distinguished as a preacher, for the originality of his conceptions. At Marienbmum, in the south of Austria, he joined, ir. 1662, the barefooted friars of the orler of St Augustine, applied himself to philosophy and theology, in a monastery of his onler at Vienua, was then $\mathrm{em}$ ployed as preacher in the convent of Taxa, in Bavaria, and soon culled to preach at the imperial court of Viema, where he continued till the year 1709, when he died, 67 years old. His sermons are burlesque, and full of the strangest notions. His striking peculiarities, agreeable, however, to the spirit of his age, procured him a numerous audience, and his sermons were not without effect, since they treated of popular subjects, and were sensoned with much sarcasm, adapted to all ranks. The titles of some of his writings show the tone in which they are composed : as, Fy on the World, or, about I'irtue and Vice; Salutary Nixture; Abrahum is Suncta Clara's Nest of neuly hatched Fools, or curious Workshop of various Fuols, both male and female, etc. A. was, by natıre, a popular orator ; he joined to an odd exterior a strong mind, endowed svith a thorough knowledge of mankind, and a fervent love of truth. With the boldest frankness, he scourge's the follies of his age, and vigorously attacks the weak mysticism and pedantry of most preachers of his time.

Arrahamites, Abrahamians, or Deists of Bohemia, were a number of ignorant peasants, who cane forth from their obscurity in 1782, confiding in the edict of toleration published by Joseph II., and a vowed the same belief which Aluraham professed before the law of circumcision. The doctrine of the unity of God, and the Lord's prayer, were all which they regarled in the Bible. Their petition for fieedom in religions worship was, however, rejected, because they refused to declare themselves Jews, or members of any of the established Christian sects. The emperur Juseph, less enlightened in matters of religion than is generally believed, drove these honest people, in 1783, from their possessions, because they resisted all attempts macle for their conversion, and lispersed them, by military force, from various places, on the boundarie's of 
Hungary, Transylvania, and Sclavonia, where they were compelled to embracc the Romnn catholic faith, and the men to join the froutier militia. Many of them adhered firmly to thcir religious principles.

ABranres; a city of 3,500 inhabitants, on the right bank of the Tagus, in the province of Estremadura, in Portugal. It is considered as of great military importance, on account of its situation on a number of steep hills, forming a defile ; by reason, likewise, of its old castle, converted into a citadel; and of tire river, which is navigable, as far as this place. The Portnguese, in this tortress, braved the spaniards, as early as 1762. III 1808, the army under $\mathfrak{J}$ unot arrived at $\boldsymbol{A}$, after a dangerous and tedious march along the banks of the 'Tagus, through the woody, mountainous, and barren Beira. Jumot ordered the castle, as well as the city, which he formd ungarrisoned, to be placed in a state of defence; and, in spite of the great fatigue of his troops, hastened to Lisbon, then occupied by 15,000 Portuguese soldiers, and inhabited by 350,000 souls. The quickness of his march, and the daring conrage with which he took possession of this capital, at the head of only 1500 grenadiers, induced Napoleon to nuke him duke of Abrantes. At a later period, however, he committed gross mistakes. At the capitulation of Cintra, $A$. was surrendered to the English, who made it still stronger. It was, however, of no importance during the remainder of the war, except to Massena, who reconnoitred it at the time when lie sat down before the strong position of the duke of Wellington, between Santarem and Peniche.

Abraxas Stones, or Abrasax Stones, are very mumerous, and represent the human body, with the head of a cock, and the feet of a reptile. The inscription Abraxas or Abrasax is often found on them, in Greek characters, which betray, however, a foreign origin. Bellermann, in his Essay on the Gems of the Ancients, bearing the Image of Abraxas, Berlin, 1817, declares only those having the above inscriptions to be genurne. The gems which lave been imported into Europe from Egypt and Asia, and are also found in Spain in great abundance, belonged, according to his opinion, to the religious sect of the Basilidians, and were used partly as means to teach secret doctrines, partly as symbols, partly as annulets or talismans. Grotefeud derives the name from the Persian language; Bellermann thinks it to be a composition of the Egyptian words Abac and Sax, and renders it "the holy word of bless," which reminds is of the Tetragrammaton of the Jews. Differcnt explanations have been proposed by others. The ancients attempted to give meaning to the word by considering the Ictters as Greek numerals, which make together 365.- The name of Abraxas stone is, in molern times, applied to a variety of gems that exhibit enigmatical compositions, strange words in foreign claracters, as Ablanathanalba, \&c., and even to those which bear the cmblems of Sebaism, the sur and moon, with other symbols, which want, however, the charactcristic type of the Basilidians. These are more properly called Alraxoids. The Basilidian names, seen on many stones of this class, are explained by Bellermann, by the aid of the Temetic langurges. The interesting disquisition on this subject by Neander, professor at the university of Berlin, deserves to be carefully compared with the opinions advanced by Bellermann.

ArRuzzo, the northern extremity of the kingdom of Naples, is bounded on the north and west by the states of the church, on the east by the Adriatic, on the south by Puglia and Terra di Lavoro. It conLains 628,600 inliabitants, and is clivided into A. ul- terior, which comprises the north-westcrn, and A. citerior, which comprises the south-easten part. The highest. part of the chain of the Apennines crosses this mountainous country. In A. ulterior especially, it is very lofty, with steep cliffs, and throws extraordinary obstacles in the way of internal communication. The rivers which rise in $A$, the Trento, Trontino, etc., gencrally flow in a di. rect course into the Adriatic sea, and have the Pescaro and Tangro excepted) the character of tor. rents. They are often suddenly swollen by the rains, especially in the spring, and then sweep away the bridges and all means of communication. The climate of $A$. is severe. The summits of the momntains are covered with snow from October to April. Thick woods crown the eminences; the valleys only are productive; and even they (as the inlabitants are mostly shepherds) afford but a very scanty supply of grain. Almond, walnut, and other fruit-trees thrive everywhere; olives, in the lower regions, near the sea. The finest herds of all kinds of cattle feed on the heights and in the valleys, and constitute the only article of export. The most important cities are Aquilla, Pescara, (both fortresses, ) and Sulmona. The importance of $A$. consists, principally, in its military sites. Projecting like a bastion 60 . geographical miles, far into the territory of the church, it becomes especially important from the circiunstance, that but one military road, and that an extremely difficult one to an army, leads into the kingdom; therefore, had the Neapolitans a warlike spirit, the possession of A., whenever attacked, would not be obtained without a great sacrifice. But when a people is destitute of courage and energy, when the soldiers, sunk in cowardly apathy, rum away at the mere ides of a battle, the most favourable ground is of no advantage. This is the reason that $A$. is of so little use for a defensive war, aud that Naples has Leen the prey, sometimes of the Austrians, at other times of the French or the Spaniards. The inhabitants of $\mathrm{A}$. are gencrally banditti, who render the frontiers of Naples and of the territories of the church extremely insecure. These banditti consist of the peasants living in the monntains, who possess property and families, but, in addition to their agricultural concerus, make a trade of robbery. Urged by rapacity and poverty to murder and plunder, they unite, and fall sipon the traveller, and not unfrequently upon the inlabitants and houses of the plains.

Absalom, (in Danish, $\mathrm{Axel}$,) bishop of Roeskilde or Rotheschild, and archbishop of Denmark from 1158 to 1201 ; renowried as a clergyman, statesman, gencral, and navigator. From his early youth, lie was a friend and counsellor of $\mathrm{king}$ Waldcmar I., whose ability in peace and war procured lim the surname of Great. He was active, lumane, and learned; set an cxample of indistry to the monks, and improved the condition of the church in Denmark. In his youth, he studied at Paris. Under his direction, Saxo wrote the valuable Danish Chroniele. A. never abused his power, or the fat. vour of the king; so that Waldcmar ever remained his friend. He had the honour of being the founder of the chief city of Denmark, Copenhagen. He built the castle, called after him, Axelburg, and the city, Axelstadt. This castle, enlarged and im. proved, servel the kings of Denmark afterwards for their residence, till the 18th century. A. died, A. D. 1201, in the 73d year of his age. His grave is still scen in Soroe, then a convent in Zealand.

A BSENTER; a word in modern times particularly applied to those lium-owners and churchmen of Ircland who reside in England, or in foreign countries. 
Ia1715, a tax of four shillings in the pount was Jevied on all profits, fies, pensions, \&.c., derived from Ireland, in all cases where the persons receiving them should not reside in that country for sir months in the year; power to grant lenve of alsence being reserved to the crown. In 1753, the tux ceased.

A bsolutron. In the ancient christian church sbsolution was a julicial act, by which the priest, in the uame of the community, invoking the favour of God, announced to the penitent lis remission from ecclesirstical punishment, and readmission into the bosom of the church. Private absolution having become prevalent for four centuries, through priests acting in the place of the bishop, the opinion was spread among the people, that they had the power of absolving by their own authority, and without the consent of the church. But down to the 12 li century, they used only the formula, "may Goul or Clurist absolve thee;" which is still the form in the Greek church, and, in the Komish, makes a part of the ceremony. The council of T'rent, sess. xiv. cap. 3, declares the essence of the saerament of penance to lie in the words of absolution. Among protestants, absolution is chiefly used for a sentence, by which a person who stands excommunicated, is released from that punishment. The formula of absolution in the Romish chureh has been said to be absolute, in the Greek church, deprecatory, and in the Protestant churches, declarative; but this is a matter strongly contested between protestants and romanists. The fathers of the church and the best modern theologinns are unanimous in the belief, that Gol alone can forgive and deliver from sin ; and that a judicial power uve the souls of cliristians is conferred neither on priests ior teachers.

ABstivence, is the habit of refraining from indulging in certain things or articles of food, which are agreeable to our fancies or appetites. Thus the Jews were commanded by the laws of Moses to refrain from the eating of certain meats, and the Malommedans are forbidden, by their Alcoran, to eat pork or drink wine. And at the council lield at Jerusalem by the apostles, the converts to the christian religion were enjoined to abstain from the flesh of aninals which had been strangled, as also from blood, from fornication, and idolatry. By such enactments it was intended to mortify and restrain the passions of mankind, and thereby humble them, so as to awaken their minds to a due sense of religious devotion. But by abstinence in a general sense, is also understood a sparing indulgence in diet, somewhat below what is generally considered the usual standard. In medical writings, various instances are recorded of persons, who have employed abstinence as a means of curing or alleviating severe chronic and painful diseases; such as cancers, ulcers, obstinate headachs, \&c. And a book is in existence written by Cornaro, a nobleman of Venice, giving a very extraordinary account of his own particular case and of the great benefit he had derived from the employment of abstinence ; - for being, at the age of forty, abandoned by lis physicians, who pronounced his recovery hopeless, he gave up medicine and betook himself to a very spare regimen, by means of which he was enabled to vanquish all his romplaints, and attain to the age of ninety-uine years; thereby passing the latter half of his life in a degree of ease and comfort which he had nerer before experienced. Few persons probably are aware with what facility life may be supported upon a very slender diet. The primitive christians of the east, who were induced to fiy to the desert, to escape from the bloorly malice of their heathen persecutors, attaineyl to very advaneerl periods of life: living cheerlully aut licalthily upon a daily allowance of twelve ounces of coarse breud, wilh a beverage of water only. In this manner it is recorded by Cassian that St Anthony lived to the age of 105, James the Hermit to 101,-Arsenius, tutor of the Emperor Arcadius, 120,-St Epiphanius, 115:Simeon the Stylite, 112:-8nd St Rommald, 120. Buchanan the Scottish historian has recorded that one Lawrence his countryman reached the grent age of 140 years, by the force of temperament and conl. stant exercise. And St Kentigern, called also St Mungo or Mongay, also a Scotsman, is recorded by Spottiswood as having lived to the very extraordinary age of 185 years, by the same hieans. And, indeed, it may be safely asserted that no persous have ever attained a very advanced age, such as a century and upwards, who have not been in the liabit of practising abstinence. 'This was decilledly the opinion of $\mathrm{U}_{\mathrm{r}}$ Cheyne, who also states, that most of the chronical diseases and short lives of Euglishmen niay be traced up to their habits of great indulgence in eating and drinking; and, that there nre but few lingering maladies, which may not be either prevented, cured, or alleviated by a contrary course of life. Almost all the instances of persons now a days who exceed a century in their existence, are found either amongst the poor or at least amongst those who either from necessity or inclination have adopted : very limited scale of diet. The wrestlers and gladintors of the ancients, lived in perpetual abstinence from all kinds of sensible pleasure so as to render their bodies more robust and hardy; -and when they were not cut off by violent deaths are stated to have lived to very advanced periods. In our own country, misers (provided they do not starve themselves too much) generally live to be very old. It is true that many persons have irreparably injured their constitutions by excessive parsimony; and it has been said that those who, either from design or accident, have fasted too long or too often, seldon enjoy good health afterwards: but this can only apply to such as absolutely fast altogether, not to those who are only very moderats: in the use of food. And here it may be necessary to notice that serious errors have sometimes taken place in believing that particular articles of food are sufficient to support life, when taken in small quantities, and that beef-ten, mutton broth, and other concentrated soups and gravies would be adequate for this purpose. But the fact is, that fuid food alone, will not support human life in a state of health. Unfortunately a very foolish experinent of this kind, was made some years ago, in the Milbank Penitentiary in London, by the committee, who put all the prisoners there on a soup diet only, and without any solid meat, and the consequences were very dreadful and fatal. The most terrible diseases of debility, such as sea scurvy, bloody flux and weakness of sight, came on, and the mortality which followed was quite unprecedented. But on putting these poor unfortunate wretches on a more liberal scale of diet, the pestilence was stayed. Magistrates ought to know that prisoners (if worked) caunot be kept in health on a very low diet.

A BSTRACTION; an operation of the minl, by which we detach from our conceptions all those circumstances that render them particular, and thereby fil them to denote a whole rank or class of beings.

Adulfaragius, Gregory, bishop of Lacabera, was born in Aruenia in 1226; diel 1284. He wrote various works, but is chiefly known by an Abridgment of universal History, which was published with a latin version by Dr Pocorke at Oxford in 1663, 2 rols. 4 to. 
ARUIFED. ; known by the nane Ismael, prince of Hannah, In Syria, surnamed the victorious king and the pillar of religion. This Arabian, famous as an historian and geographer, was born at Dannascus, in the year of the Hegira 672, A.D. 1273. He sprumg from the family of the Ayubites, which had already given birth to the famous Saladin, and was renowned for the valour of its menbers. While a youth, he distinguished himself in various campaigns. $\mathrm{From}$ his uncle he inherited the principality of Hamah; but, on account of a quarrel with his brother, he did not come into possession of it for several years ; after which he remained undisturbed thcrein till lis death, in the year of the Hegira 732, A.D. 1333. All writers who niention him represent him as a prince of the greatest talents, equally remarkuble for courage and coolness in war, and for wiselom in conncil. Amid the cares of government, he devoted himself with zeal to study, clrew the learned around him, and rendered his power and wealth subservient to the cause of science. He was well acquainted with history, jurisprudence, medicine, botany, mathematics, and astronomy, and has bequeathed to us the fruits of his long inquiries in several valuable works, of which his history of the human race, and his geography, entitled The true Situation of Countries, are the inost famous. We have several partial translations and editions of them. viz. of the historical works, Ist, Annales Moslemici Arab. et Lat. Op. et Stud. Reiskii, 1789-94, 5 vols. 2nd, De Vita et Rebus gestis Molnammedis, ed. Gagnier, 1723, to which Schultens has annexed an appendix. For portions of his geography, we are indebted to Grzevius, Reiske, Muratori, Michaelis, Rink, Eichhom, Rosenmuller, Paulus, and Rommel. Abulfeda's own manuscript is at Paris. He is a trust-worthy author, and his style is good.

AвYDos; an ancient city of Asia, on the eastern side of the Dardanelles, famous for the bridge of boats, which Xerxes is related to have thrown here across the Hellespont, and for the loves of Hero and Leander. This city defended itself with great courage against Philip of Macedon. Another Abydos was an ancient town of Upper Egypt, which contained the palace of Memnon, and the celebrated temiple of Osiris built by Osymandyas. Under Augustus, the town was reduced to ruins, but to the west of it, in the present village of EI-Berbi, magnificent ruins are still found.

ABYLA ; a mountain in Africa, one of the pillars of Hercules, as they were anciently called; being directly opposite to Calpe, (now Gibraltar) in Spain, from which it is distant only 18 miles. Between these mountains are the straits of Gibraltar.

ABYssinIa ; an extensive kingdom of Africa, bounded on the cast by the red sea, on the north by Sennaar, on the west and south partly by Sennaar and Cordofan, and partly by rast and barbarous regions, of which the names have scarcely reached us. Pinkerton makes Abyssinia 770 miles in length, and 550 in breadth. The number of inhabitants is from 4 to 5 millions, the grcater part of whom are of Arabian extraction, mixed with Jews, Turks, and Negrnes. The ancients called this country, and some of the parts adjacent, in a peculiar sense, Ethiopia. They also gave the same nane, indefinitely to the interior of Africa, and eren to a great part of $\Lambda$ sia. The Ethiopian kingdoms, of which the ancients had any distinct knowledge, were two. The first, and the only one known to the earliest writers, is Meroe, or the peninsula, which they supposed to be an island, formed by the successive union of the Nile with the Astaboris and the Astapus, (Blue River and Tacazze.) The chief city of Meroe was placed by

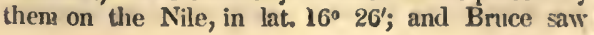

near Chendi, in Sennaar, immense ruins, which probably belonged to this ancient capital. The vther kingdom was not kuown until the Greeks, under the successors of Alexauder, had extendecl their navigation along the eastern coast of $A$ frica. It was that of the Axunitie, situated upon the Red sea, and occupying part of the Abyssinian province of 'Tigre. The capital, Axum, still remains, though in a state of decay. Its port, Adulis, was the channel by which the finest ivory then known was exported, and a commercial intercourse maintained with the coasts both of the Red sea and the Indiau ocean.-The Abyssinians boast that their country was the Sheba of Scripture, and that it was converted to Judaism several centuries bofore the Christian era. It is much more certain, that, prior to the middle of the fourth century, the nation was converted to Christianity, which it has ever since professed. This is, however, more tinctured with Judaism than among other nations. Boys and girls, are circuncised; the Mosaic laws in regard to clean and unclean meats are respected the seventh day is their Sabbath, and their altars have the form of the ark of the covenant. In their dogmas, thicy follow the Monophysitic doctrine. (See Monophysites.) In the church service they use the Bible, with the apocryphal books, in the 'iligre or -Gheez language, which is their language of literature. Baptism and the Eucharist are adininistered according to the ritual of the Greek church, of which they have all the festivals and fasts. It is, however, peculiar to the Abyssinians, that persons of rank receive larger pieces of bread at the Lord's supper, and that no one is admitted to it before his 25th year, because they pretend that no one is accountable for sin before that age, and that all who die prior to it are sure of salvation. They consider the bodies of the dead as unclean, and hasten their interment. Their small, round, conical churches stand on hills, near running water, surrounded by cedars, and are full of pictures. During the service every body is obliged to stand, as in the Greek churches. The shoes are left at the loor, and pass. ing horsemen must dismount. The service, like that of the Greek church, consists in reading parts of the Bible and praying. The clergy, who are very ignorant, generally marry, and are distinguished by a cross, which they offer to passengers to be kissed. The head of the Abyssinian church is called Abunci, (our father,) and is generally taken from the Coptic priests, as the Abyssinians and the Copts keep up a communication with each other in Cairo. Under the abuna are the kamosats, or the chief priests of the secular clergy, the learned thcologians and monks. The latter pretend to be of the order of St Augustine, and are divided into two classes. The members of the one, living unmarried, reside in wealthy convents; those of the other, with their wives and children, live around the churches, supported by agriculture. Both sorts, as well as the numerous nuns, travel about the country, trade in the markets, and do not appear scrupulously observant of their vow of chastity. The Abyssinian clergy have neither a particular dress nor peculiar privilcges. A, is now divided into three separate states, Tigre, Amlara, and Efat. The negus, or negush, as the king of all $A$. was called before its division, lives at Gongar, in Amhara, eujoying only a riominal sorereignty, and watched by the chicf of that state. The pope has several times attempted to gain over A. An opportunity of reducing the Abyssinians to the Ronan church was offered by their war will the Turks, in which the regent Helcna sought assis. tance for David II., the minor negus, from the Portuguese, 1516. In 1520, a Portugnese fleet, 
with soldiers and priests, arrived in A., and after the Turks and Gallas (a warlike, nountain people, in the south and west of $\mathbf{A}$.) land beeu repulsed, by the assistance of the Portiguese, towards the end of the 16th century, the zealous catholics obtained a footing, of which the pope knew how to take advantage. He sent Jesuits to convert the inhabitants to the Roman catholic religion, and a Portuguese colony supported their enterprise. In the beginning of the 1 th eentury, the Roman catholie ritual was introdnced; the Jesuit, Alphonso Mendez was elected patriarch of A., in 1626, the eelebration of the 7th day as the Sablath abolished, and the whole religious system accommodated to the catholic molel. But this farourable turn of affairs was of sliort duration. The negus Basilidas began his administration in 1632, by yielding to the vishes of the majority of the people, who were opposed to the Roman catholic faith. He banished the monks witlı the patriareh, and ordered the Jesuits who remained to be hanged. Almost all the catholic missionaries have since suffered death, and all the attempts of the Roman propaganda to establish the catholie faith in A., until the end of the last eentury, have proved fruitless.-In the western part of this country, an independent government of Jews has long existed. They call themselves Falashas, that is, exiles; the state is called Falasjan. They have their own government, whieh is allowed by the negus, on consideration of their paying a certain tribute. Bruce found there a Jewish king, Gideon, and a queen, Judith. - The eustoms of the Abyssinians are described by Bruee and Salt as exceedingly savage. They eat the raw and still quivering flesh of cattle, whose roaring is to be heand at their feasts. A perpetual state of eivil war seems the main cause of their peeuliar brutality and barbarism. Dead bodies ure seen lying in the streets, and serve as food to dogs and hyrenas. Marriage is there a very slight eonnexion, formed and dissolved at pleasure; conjugal fidelity is but little regarded. The rulers are unlimited despots in ecclesiastical and eivil affairs, disposing of the lives of their subjects at pleasure. $-A$. is full of high ranges of mountains, in which the Nile takes its rise. The elimate, on the whole, is fine, and the soil exeeedingly fertile. The vegetable and animal kingdoms are very rich, and afford many speeies peculiar to this country. One of the most important natural productions of $\boldsymbol{A}$. is salt, covering a great plain, which occupies part of the tract between Amphilia and Massuah. The plain of salt is about four days' journey across. For about half a mile the salt is soft, but afterwards becomes hard, like snow which has been partially thawed, and consolidated. It is perfectly pure : it is cut with an adze, and carried off by caravans. The country is rich in gold, iron, grain, and fruits. Commerce is in the hands of the Jews, Armenians, and Turks.

Acaera, Egyptian Thorn, or Binding Bean-tree ; in the Linnxan system, a species of mimusa. 'The flowers of this plant are used by the Chinese to produce that yellow colour which we see in their silks and stuffs. They make a decoction of the dried flowers, and add alum and caleined oyster-shells. In the materia medica, acacia is the inspissated juice of the pods of the mimosa Nilotica of Linnæus.

Aеаргму; an association of scholars or artists, for the promotion of the sciences or arts, sometimes established by goreriment, sometimes voluntary unions of private individuals. The academies at Paris, Stockholm, and Berlin, are in part institıtions for the purpose of instruction; but at first their only object was the one above-mentioned. The members of an academy either select their own branehes of study or pursuc those whieh the government as signs to them. The results of their labours are read in the regular meetings, aud printed among their proceedings. The unne is derived from the Athenian acndeiny, belonging to a eertain Academus, a fumous school for gymnnstie exercises, and the plnee where Plato tanglit. The appellation, academy, is also used to slenote the various plilosuplical sects, whose doctrines were tringit in tlat institution. In this sense we speak of the first, second, and third academies; the founders of which were Plato, Arcesilaus, and Lacyclas or Carneades. The first institution of antiquity, whicl merits the name of academy, in the modern sense of the term, was at Alexandria. Attracted by the generosity of the Ptolemies, a numerous associntion of scholars was collected here, who were to hinve laboured for the extension and perfeetion of luman knowledge, but soon fell into idleness, or the exercise of grainmatical subtleties. From Alexandria the Jews horrowed the euston of founding academies, which were established, after the close of the first century, in the eities on the Euphrates, Sora, Ncharia, and Punebidita. From them the Nestorians learned, in the sixth century, to value science, and imparted the same spirit to the Arabs, whose excellent caliphs, Almansor, Harın al Raschid, and Almamun, founded a number of academies, which were extended from Cordova to Bocliara in the farthest east, with the greatest success. At the court, ton, of Charlemagne, we find an academy, founded by the emperor, at the suggestion of his instruetor, Alcuin, of which he was himself a member. This useful institution was dissolved after the death of Aleuin, and we afterwards find no academies, properly so called, till the time-of the conquest of Constanturople by the 'Turks, when several Greeinn sehılars were compelled to fiy to Italy. Lorenzo de Medici then founded, at Florence, the flrst Greeian academy, under the care of Argyropylus, Theodore Gaza, and Chalcondylas. Cosmo afterwarls established the Platonic academy, the object of which was the study of the writings of Plato, and the restoration of his philosophy. These establisliments did not subsist long, but their places were filled by others of a more general charaeter, which spreal themselves over all the cities of Europe. We will arrange the most important older ones, that still exist, aecording to the subjects to which they are deroted.

General scientific Academies. The Academia Seeretorum Naturx, founded at Naples in 1560 , for the promotion of the mathematical and physical seiences, was abolished by the papal interdict. It was followed by the Accademia del Iincei, founded at Rome, by prince Cesi, about the end of the same century; of which Gallileo was a member. The? Accademia del Cimento arose in the beginning of the 17th eentury, under the patronage of prince Leopold, afterwards, cardinal de Medici, and numberel among its members Paolo di Buono, Borelli, Viviani, Redi, Magalotti, and other distinguished men. The Aecademia degl' Inquieti, at Bologna, afterwards incorporated with the Accademia delln Traceia, published several excellent treatises under the title Pensieri Fisico-Matematiei, 1667. In 1714, it was united with the Institute at Bologna, and has since been called the Academy of the institute, or the Clementine Academy, (from Clement XI.) It possesses a large collection of natural euriosities and a numerous library. The Academy of Seienees at Bologna, or the Institute of Bologna, was estal)lished in 1712, by count Marsigli. (See Bolognt.) In 1540, an academy was established at Rossano, ir: the territory of Naples, under the name Socicis 
Scientifica Rossanense degl' Incuriosi, at first for the belles lettres, but since 1695 for the sciences also. 'Tlie Royal Academy at Naples has existed' since 1779. Its publications contain some instructive disquisitions on mathematical subjects. Of the Italian academies, we would also mention those at Turin, Padua, Milan, Sienna, Verona, Genoa, all of which have published their transactions. Italy may be called the mother of academic institutions. Jarchius enumerates 550 of them in his catalogue.-The French-Academy of Sciences at Paris, Academie Royale des Sciences, founded in 1666, by Colbert, received the royal ratification in 1699 . The menbers were divided into four classes-honorary members, active members or pensionaries (receiving salaries), associés and élèves. The first class was to sontain ten, and each of the three others twenty persons. The president was appointed by the king out of the first class. From the second, a secretary and treasurer were selected. The duke of Orleans, when regent, abolished the class of élèves, and substituted for it two new classes, the one of which comprised twelve adjuncts, and the other, six associés; to which latter class no particular branch of science was assigned. A vice-president was to be appointed annually by the king from the first class, and a director and sub-director from the second. In 1785, the king added classes for natural history, agriculture, mineralogy, and physics; so that the whole now consisted of eight classes. He also incorporated the associés and the adjuncts (adjoints). This academy has rendered many services to science, especially by the measurement of a degree of the meridian. Since 1699, it has, with a few late exceptions, annually published a volume of its transactions, which constitute a series of 139 volumes. Rouille de Meslay founded two prizes, which the academy annually distributed; the first, of 2500 livres, for the promotion of physical astronomy ; the second, of 2000 livres, for that of navigation and commerce. In 1793, the academy was abolished; and the National Institute took its place, and that of the other academies; but they were restored by Louis XVIII. Important academies, besides those of Paris, still exist in the principal cities of France, e. g. at Caen, since 1705; at Toulouse, the first volume of whose transactions appeared in 1782; at Rouen, since 1736; at Bondeaux, since 1703; at Soissons, since 1674; at Marseilles, since 1726; at Lyons, since 1700 ; at. Montauban, since 1744 ; at Amiens, since 1750 ; at Dijon, since 1740 ; \&c.An Academy of Arts and Sciences was founded in Berlin in 1700, by king Frederic I; some changes in it were made in 1710 ; principally relating to the presidency. The members were divided into four classes ; the first were to devote themselves to natural philosophy, medicine, and chemistry ; the second to mathematics, astronomy, and mechanics; the third to the history and language of Germany; the fourth to oriental literature, with a view to the conversion of the heathen. Each class chooses a director for life. The first president was the famous Leibnitz. The institution began truly to flourish under Frederic II, who invited distinguished scholars from foreign countries, and appointed Maupertuis president. Public sessions were held semi-annually, on the birth-day of the king and the anniversary of his accession to the throne. In the latter, a prize medal of 50 ducats is adjudged to him who has best answered the question proposed by the academy. since that time; their transactions have appeared in a series' of volumes, under the title Mémoires de l'Académie Royale des Sciences et Bclles Lettres it Berlin. 'They are now, however, always published in the Germau language. New alterations were made in 1798, in order to give a more useful diroc tion to the labours of the academy : among other things, tne royal library and the cabinet of arts were united with it.-At Manheim, in 1755, the elector Cliarles Theodore, established an academy, according to the plan of Schopflin. It consisted, at first of two classes, the historical and physical ; the latter was divided, in 1780 , into the physical, properly so called, and the meteorological. The transactions in the departments of history and physic have appeared under the title Acta Academice Theodoro. Palatince in the branch of meteorology, under the title Ephemerides Societatis Meteorologice Palatina. - The academy at Munich has existed since 1759, but was much enlarged when Bavaria was exalted to a kingdom. Its memoirs are entitled Abhandlungen der baierschen Akademie.-Peter the Great had projected the establishment of the Imperial Academy of Sciences at St Petersburg, and consulted Wolf and Leibnitz on the subject ; but his death prevented the execution of his project, which was completed by Catharine I. Its first sitting was held, Dec. 1725. The empress appropriated about 30,000 roubles a year for the support of the academy; fifteen distinguished scholars in different departments received pensions as members, with the title of professors. The most famous of them were Nicholas and Daniel Bernouilli, the two de Lisles, Bulfinger, and Wolf. Under Peter II. the academy languished; but revived under the empress Anna, and declined again after her death. Under Elizabeth, it flourished anew. It was enlarged and improved, and an academy of arts added in 1747, which was separated again in 1764. Its annual income amounts to 60,000 roubles. This academy has contributed much to a more accurate knowledge of the interior of Russia, by sending men like Pallas, Gmelin, Stolberg, Guldenstadt, and Klaproth, to travel through single provinces, and has thereby given rise to some excellent works. The number of active members, besides the president and director, amounts to fifteen. In addition to these, there are four adjuncts, who attend the sittings, and are admitted, on the first vacancies, to the rank of members. The academy has an excellent collection of books and manuscripts, a valuable cabinet of medals, and a rich collection in natural history. Its transactions appeared from 1728 to 1747 , during which period they amount to 14 volumes, under the title Commentarii Academice Scientice Imperialis Petropolitance. From that time till 1777, they were published under the title Nove Commentarii, in 20 volumes. They were subsequently entitled Acta Academice, and at present the new series is called Nova Acta. The Commentariz are all in Latin; the Acta are partly in Latin, partly in French.-The Royal Academy of Sciences at Stockholm originated in a private association of six learned men, among whom was Linnæeus, and held its first session, June 23, 1739. In the same year appeared its first memoirs. The association soon attracted public attention, and, March 31 , 1741, the king conferred on it the name of the Royal Academy of Sweden. It receives, howerer, no pension from the crown, and is conducted by its own members. A professor of experimental philosophy only, and two secretaries are paid from the funds of the society, which are considerable, arising from legacies and donations. The presidency is held in turn by the members residing at Stockholm, each one remaining in office three months. The treatises read in the sittings appear quarterly. The first forty volumes, till 1779, are called the Old Transactions; the subsequent volumes are called the new. The papers relating to agriculture appear under the title
OEconomica Acts. Prizes, consisting of money and 
gold medals, are annually offerml. The Royal Acalemy at Copeuhngen spraug from a society of six literary men, to whom Christian VI. committel, in 1742 , the care of his cabinet of metals. They subsequently enlargerl their plan, so as to form a regular academy. One of these literary men was the Cotnt of Holstein, at whose suggestion Cluristian VI. took the acalemy under his protection in 1743, endowed it with a fund, and directed the nembers to extend their studies to natural history, physics, and mathematics. It has published fifteen volumes, in the Danish language: some of these have been translated into Iatin. - The Royal Irish Academy at Dublin was formed in 1782, mostly of the members of the university, who assembled weekly. Its transactions lave appeared regularly sinee 1758. As early as 1683 , there was an academy in Dublin, but, owing to the distracted state of the country, it soun declined. In 1740, a Plrysico-Historical Society was instituted there, which published two volumes of transactions, still extant. 'This also soon declined.-In Lisbon, the late queen established an academy of scienee, agrieulture, arts, commerce, and economy in general, consisting of three classes; those of natural seienee, inathematics, and national literature, and comprising sixty members. It las published Memorias de Litteratura Portugueza, $\mathrm{Me}$ morias Economicas, together with scicutific transaetions, and a Collecço de Livros ineditos de Historia Portugueza.

Academies for the promotion of particular departments of Science.-1. Medical. The Academia Naturae Curiosorum at Vienna, called also Leopold's Academy, was formed in 1652. At first, it published its treatises separately, but after 1684, in volumes. Under Leopold I. who favoured it in a high degree, it adopted the name Casareo-Leopoldina Nature Curiosorum Academia. Similar academies were establishod at Palermo,.1645; in Spain, 1652; at Venice, 1701; and at Geneva, 1715.-2. Surgical. A surgical academy was established at Paris, 1731, which proposes annually a prize question. The prize is a gold medal of the value of 500 livres. A surgical academy was founded at Vienna in 1783. Three prize medals, each of the value of 50 guilders, are yearly adjudged to the most successful students.-3. An academy of theology was established, in 1687, at Bologna.-4. Coronelli founded, in the beginning of the 18th century, a geographical academy at Venice, under the title of the Argonauts : the olject is to publish good maps and descriptions of countries. -5 . Historical. King John V. founded, in 1720, a royal academy of Portuguese history at Lisbon, consisting of a director, fuur censors, a seeretary, and fifty members : the subject of their study is the ecclesiastical and political history of Portugal. In Madrid, an association of scholars was institnted about 1730 , for the purpose of investigating and explaining the historical monuments of Spain. It was formed into an-academy by king Plilip V. in 1738. It consists of 24 members, and has published several ancient historical works; some for the first time, some in new editions. The Academy of Suabian History, at Tubingen, was established for the purpose of publishing the best historical works, and the lives of the best historians, as well as for compiling new memoirs. -6 . For the study of antiquities. An academy exists at Cortona, in Italy, for the study of Etrurian antiquities ; another at Upsal, in Sweden, for the elucidation of the northern languages, and the antiquities of Sweden. Both have published valuable works. The academy which Paul II. established in Rome, for the same purpose, soon came to an end, and the one. founded by Leo $\mathrm{X}$. uset with the same fate, after it had fourished some time. Others, less important, rose on theil ruins, but all similar institutions were surpassed by the Academie des Inscriptions, at Paris, founded by Colbert, iu J663, for the study of aneient monuments, and for the perpetination of the remarkable occurrenees of their own country, by means of medals, statues, inscriptions, \&e. At first, it had but four inembers, who were ehosen from those of the Freneh academy ; but in 1701 , the number was fixel at ten honorary members, ten associés, ten pensionaires, and ten élèves. They met semi-weekly in the I.ouvre, and held every year two public sessions. The class of élc̀ves was finally abolishexl. The king aunually appointed their president and vice-president. The seeretary and treasurer held their offices for life. Their memoirs (from 1701-93) constitute 50 vols. in 4 to. It experienced the fate of all the French academies, and is now restored. The Herculanean Academy was instituted at Naples in $\mathbf{1 7 5 5}$ by the minister Tanucei, to explain the ancient monuments found in Herculaneum, Pompeii, \&c. Their labours have appeared, since 1775 , under the title Antichitd di Ercolano. In 1807, Joseph Bonaparte founded an academy of history and anticuities at Naples, which has fallen into decay. The academy founded in the same year at Florence, for the explanation of T'uscan antiquities, has published some volumes of memuirs. In the same year, likewise, a Celtie acadenny was established at Paris, the objects of which were the elueidation of the history, manners, antiquities, and monuments of the Celts, especially those in France; also researches into the etymology of all European languages by the aid of the Celto-Breton, Welsh, and Erse dialeets; together with investigations respecting the Druidical worship. Lenoir is its president. Its transaetions appear under the title Memoires de l'Academie Celtique.-7. For the improvement of language. The Académia della Crusca, or Academia Furfuratorum, was formed in 1582, and first attraeted attention by its attacks on 'Tasso. Its prineipal merit consists in having compiled an excellent dietionary, and edited with care several of the aneient poets of Italy. The Académie Frangaise, formed in 1629, was then a private association; six years after, it was raised by Richelieu to the dignity of an academy of the French language, grammar, poetry, and eloquence. The number of members was fixed at 40 , and from them a direetor and a chancellor were elected every two months, and a secretary for life. Besides many other valuable works, it has published a dictionary of the French langrage, (first edition in 1694.) At Madrid, the duke of Escalona founded an academy for the improvement of the Spanish language, in 1714 , which the king endowed with various privileges. It has done mueh towards purifying and perfecting the language, especially by the compilation of a dictionary. In Petersburg, an academy for the improvement of the. Russian language was founded in 1783, and united with the Academy of Scienees. In Sweden, also, a royal academy of language was instituted in 1789.-Many literary societies are distinguished only by name from academies. Such are the Royal Society of Scienees, at Gottingen, founded in 1750, the Royal Society of England, founded in 1645. This society has made observations and experiments on most of the works of nature; has improved agrieulture, navigation, naval, civil, and military architecture, \&c. It has registered experiments, observations, \&c., and, from time to time, published the most valuable, under the title of Philosophical Transactions. The Royal Society of Dublin, for the encouragement of husbandry and the arts, established in 1731, has been one of the must aetive establishments of the kind in Europe. The 
Ioyal Society of Edlinburgh was established in 1783. Besides these, there are the Society of Antiquaries of London, 1751; the Literary and Philosophical Society of Manchester, 1781 ; the literary associations of Haarlem, Flushing, Rotterdam, Brussels, Amsterdam, Copenhagen, Upsal, \&c. From Europe they have spread to the other quarters of the globe. In Asia there has been a society of arts and sciences, at Batavia, since 1778 ; a society of sciences at Calcutta, in Bengal, since 1784; and one at Bombay, to which we are indebted for the most important information respecting India and other parts of the East. The principal learned acatemies and societies in the U.S. of America, are the following: 1. The American Philosophical Society, Philadelphia, founded in 1769 . This society Jas published nine volumes, 4to, of Transactions. In 1815, it appointed a large committee to superintend an historical department, which has published one vol. 8vo.-2. The Massachusetts Historical Society, Boston, founded in 1791. It has printed 22 vols. 8vo, of Collections. 3. The Connecticut Academy of Arts and Sciences, New Haven, founded in 1799, has published one rol. of Transactions. 4. The American Academy of Arts and Sciences, Boston, founded in 1780, has published four vols. 4to, of Transactions. 5. The Historical Society of New York, founded in 1809, has published four vols. 8vo, of Collections. 6. The Literary and Philosophical Society of New York, founded in 1815, has published two vols. 4to, of Transactions. 7. The Academy of Natural Science, Philadelphia, founded in 1818, has published five vols. 8vo. 8. The Lyceum of Natural History, New York, founded in 1818, has published two vols. 8ro. There are, besides, the Historical Society of Concord, New Hampshire, the Essex Historical Society, Salem, Massachusetts, the Columbian Institute, at Washington, D. C., and some others; but their publications have been few.

Acculemies devoted to the promotion of the fine arts sprung up in the middle of the 16th century. The academy of Paris has been a model for many subsequent institutions of a similar character. The earliest union of painters, for objects similar to those of modern academies of art, was the fraternity, formed at Venice in 1345, under the name of San Luca, which sprang from a society under the patronage of St Sophia. However, neither this nor the society of San Luca, established at Florence, in 1350, bore the name of an academy. The Accademie di San Lucr, founded at Rome in 1593, by Frd. Zucchero, first obtained a settled character in 1715. The academy at Milan may have preceded the time of Leonardo da Vinci, who is generally regarded as its founder. The academies of Bologna, Parma, Padua, Mantua, Turin, are all of recent origin, and have never obtained the importance which such institutions acquire in large capitals, where the finest works of art serve as guides and incentives to genius. 'The Academy of Painting at Paris was established by Louis XIV. in 1648, and the Academy of Architecture by Colbert, in 1671. This latter now exists under the name of Ecole Spéciale des Beaux Arts, and is divided into departments, in a way which inight serve as a model. Since 1391, the painters of Paris have been united in a society called the Fraternity of St Luke, which has received charters from several kings. Among the towns of France, Bordeaux lad the carliest academy. We now find one in almost every town of consequence. The French academy at Rome, in the Villa Medici, is a branch of the academy of Paris. Nuremberg liad the first establishment of this kind in Germany. Its academy, founded by Sandrart, 1662, and loug con- ducted by him, gained new distinction from the celebrity of Preissler. The academy of Berlin was founded in 1694, was remodelled and received a fresh impulse in 1786; that of Dresden, established in 1697, was united with those of Leipsic and Meissen in 1764, and has still the form given it by Hagedorn. The academy of Vienna was founded by Joseph I. and completed by Charles VI. in 1726 ; that of Munich was established in 1770; those of Dusseldorff and Manheim are more valuable now than they were originally. Weimar, Cassel, Frankfort, Berne, should not be omitted in this enumeration. The Acadeny of Painting at Madrid had its origin in 1752; the Royal Academy of Painting at London, in 1768. Lately, a branch of the London academy has been established at Rome, which, we have reason to hope, will prore more useful than the parent society. Edinburgh has possessed a similar society since 1754. At Brussels, Amsterdam, Antwerp, there are distinguished academies. Stockholm has had, since 1733, an academy of the fine arts, founded by count Tessin. Since 1738, one has existed at Copenhagen, but its privileges were conferred on it in 1754. This academy lias exercised an important influence. The academy of Petersburg was founded in 1757, and extended in 1764. Its infuence in awakening diligence and enterprise among the Russian artists has been lately very apparent.-For schools of music, see Conserva. tory.

Acantuus; the name of an ancient town in Egypt, also one in Caria, and another in Macedonia (ilear mount Athos), \&c.-Also, a genus of plants (commonly called bear's-breech), of the order angiospermia, class didynamia. The leaves of the $A$. are large, and very beautiful. It grows wild in Italy. - In architecture, an ornament resembling the leaves of the acanthus, used in the capitals of the Corinthian and Composite orders.

Acapulco is the best Mexican harbour on the Pacific ocean ; lon. $98^{\circ} 50^{\prime}$ W., lat. $16^{\circ} 50^{\prime} \mathrm{N}$.; pop. mostly people of colour. Both the harbour and the road-stead are deep, with a secure anchorage from storms. It is the most considerable port on the S. W. side of Mexico. Heavily laden ships can lie at anchor, close to the granite rocks, which environ the road-stead and harbour. On account of the steepness of these rocks, the coast has a wild and barren appearance. At the entrance of the harbour is situated an island, Roqueta or Grifo, which forms a western entrance of 700 or 800 feet broad, aud an eastern, a mile or a mile and a half broad, and from 24 to 33 fathoms deep. On the north-west lies the city, defended by fort San Diego, situated on an eminence. It has not more than $\mathbf{4 0 0 0}$ inhabitants, mostly people of colour. The number used to increase much on the arrival of the galleon from Manilla. Few commercial places have a more unhealthy situation. The usual heat in the day is frons 86 to $90^{\circ}$ Fahrenheit; in the night, till 3 o'clock, A. M., $78^{\circ}$; and from that time till sunrise, 64 to $62^{\circ}$. The sun's rays are reflected by the white rocks upon the city, where no creature is comfortable except the musquitoes. To procure fresh air, the Spanish government caused a passage to be cut through the rocks on the east; but neglected, what was far more necessary, to drain and dike the moruss, on the same side, situated most favourable for the culture of sugar cane. About the middle of the dry season, the water disappears, and the effluvia of putrid substances infect the air. Here the yellow fever of the West Indies, and the cholera morbus of the East Indies, sweep away mauy strangers, and especially young Europeans.' The calms under the line, which frequently continue for 
a loug time, are a natural obstacle, which renders a voyige from Cullao to Acapulco more difficulth and oftes louger, than one from Callao to Cadiz. Stenmbonts wuuld be of great adrantagc in this quarter. in onler to takc advantage of the trade-winds, it is especially necessary to keep at a distance from the line. This, however, is impracticable on a consting voragc from Acapulco to Callao. The exports hitherto, from Acapulco have been mostly silver, indigo, cochineal, Spanish cloth, and some peltry, which comes from California and the northern part of Mexicu. The imports consist of all the valuablc produotions of Asia.

Acarvavia, now called $I l$ Carnia and Il Despotato : an ancient country of Epirus, divided from Etolia by the $A$ chelous.

Acstnouct are, in general, those who do not belong to the catholic church. In certain catholic countries, protestants are distinguished by this name, which is considered less odious.

ACCEN ; the law which regulates the rising and falling of sounds or tones. Music and language, whicli are subject to this law, both originate in the feelings; and although they at last separate from each other, and music remains the language of the heart, while specch, or language, properly so called, becomes the language of the mind, yet the latter does not entirely cease to speak to the heart; and music and language thus retain certain qualities in common; these arc partly internal and partly external. Both arc adapted to the expression of emo tions; and thence arise the movements, sometimes slow and sometimes quick, which we perceive in them. They thus bccome subject to quantity or time; and we distinguish sounds, with rcference to quantity, into long and short. In order to express an emotion distinctly and plainly, there must be a suitable arrangement of the organs for the sounds intended to be produced; for, in a series of sounds measured by the relation of time, and rcgulated also by relation to some fundamental tone, there will be found a certain connexion and association which represent the emotions in their various relations and gradations; it is this also, which distinguishes correctly what is of primary importance from what is secondary, renders the unimportant subordinate to the important, and gives proper weight to that which is significant. A succession of tones thus becomes a musical conjposition, which comprehends within itself a definite meaning or sense; and, to express this, particular regard must be had to the signification and importance of single tones in connexion. The stress, which is laid on the tones, according to the gradations of meaning, constitutes what we call accent. We distinguish thc acute, or rising accent, the grave, or falling, and the circumflex. The cireumflex accent falls on those syllables or tones which are long in themselves; the grave properly denotes mercly the absence of any stress; and thus we have only the acute left, to give a designation to tones. The reasons for designating a tone by accent, and dwelling on it longer than its established quantity requires, are either mechanical, rhythmical, or emphatical. We divide accent into grammatical and rhetorical, or thc accent of words and of sentences, which last is called emphasis. The former rests on physical or mechanical causes; the latter has for its object the relations of ideas. The laws which govern both are briefly the following: $A$ syllable or tone of the natural length receives the grammatical ur verbal accent; but there are two causes, which distinguish some syllables of a word from the resttheir mechanical formation and their signification. In the word strengthen, for instance, mechanical causes compel the roice to dwell longer on the first syllable than on the second, and hence a greater stress is laid on that syllable. Rhetorical acsent, or emphasis, is desigued to give to a sentence distinctness and clearuess. In a sentence, therefore, the stress is laid on the most inportant word, and in a word on the most important syllable. Without attaching itself, in language, to the quantity of a word, or, in music, to a certain part of a bar, the accentual force dwells on the important part; and, in order that this force nay be rendered still more distinguishable, it hasteus over those parts which, though otherwise important, the context renders comparatively unimportant. It follows, from what has been said, that the accrut of worts and the accent of sentences, or empliasis, may be united or separated at pleasure. It may now be asked, whether cmphasis destroys verbal accent and quantity; and whether, for this reasou, euphony does not suffer from emplasis? In answering this question, (in which lies the secret of prosody in general, and the difference between the modern and ancient), four points come ander consideration: 1. If the accent coincides with a syllable which is long from mechanical causcs, it elevates the syllable, and imparts stress to its prosodial length. 2. The accent does not render an invariably long syllable short, but deprives it, if it immediately follow the accented syllable, of a portion of its length. The quantity, therefore, if it does not coincide with the accent, may be somewhat weakencd by it. 3. Although the accent cannot render an invariably long syllable short, it can change the relative quantity of common syllables. 4. The accent can never fall on syllables invariably short. These are the rules which are of the greatest importance, not only to the versifier, but also to the declaimer, and to the actor, so far as he is a declaimer.

The grammatical and rhetorical nomenclature of the English language is very defective and unsettled ; and hence has arisen a great degree of confision among all our writers on the subject of accent and quantity in English. We have perverted the true meaning of long and short, as applied to syllables or vowels; and, by our particular application of thosc terms, we have made ourselves quite unintelligible to foreign nations, who still use them according to their signification in the ancient languages, from which they are derived. An English writer of some celebrity, (Foster on Accent and Quantity, whose own work, however, is not free from obscurity. observes, that he has found the word accent used by the same writer in four different senses-sometimes expressing elevation, sometimes prolongation of sound, sometimes a stress of voice compounded of the other two, and sometimes the artificial accentual mark. For a long series of years, however, accent, as Johnson has remarked, in English prosody has been the same thing with quantity; and another English writer of celebrity, bishop Horsley, observes, that it is a peculiarity of the English language, that quantity and accent always go together, the longest syllable, in almost every word, being that on which the accent falls. In other languages, as Mitford justly remarks (Essay on the Harmony of Language), generally, the vowel character, representing indifferently a long or a short sound, still represents the same sound, long or short. A contrary method is peculiar to English orthography. With us, the same rowel sound, long and short, is rarely represented by the same character; but, on the contrary, according to the general rules of our orthography, each character represents the long sound of one vowel, and the short sound of another. This is eminently observable, as Dr Johnson has remarked, in the letter $i$, which likewise happens in other letters, 
that the short sound is not the long sourd contracted, but a sound wholly different. In addition to the difficulties arising from an imperfect nomenclature, as above remarked, there is an intrinsic difficulty in the extreme delicacy of the distinctions of tone, pitch, and inflections in language, and the want of an established notation, corresponding to that which we have in music; and we may add, in the words of Hermann (De Emendanda Ratione Grac. Gram.), "Quam pauci vero sunt, qui vel aliqua polieant aurium subtilitate ut vocum discrimina celeriter notare apteque exprimere possint!"-The Chinese are said to have but $\mathbf{3 3 0}$ spoken words; but these, being multiplied by the different sccents or tones which affect the vowels, furnish a language tolerably copious.

Acceptance. (Law.) An acceptance is an engagement to pay a bill of exchange according to the tenor of the acceptance, and a general acceptance is an engagement to pay according to the tenor of the bill. What constitutes an acceptance is, in many cases, a nice question of law; but the general modc is for the acceptor to write his name on some conspicuous part of the bill, accompanied by the word accepted. In France, Spain, and the other countries of Europe, where oral evidence in matters of contract is not admitted to the same extent as in England, a verbal acceptance of a bill of exchange is not valid.

ACCESSARY, or ACCESSORY; a person guilty of an offence by connivance or participation, either before or after the act committed, as by command, advice, or concealment, \&c. In high treason, all who participate are regarded as priucipals. Abettors and accomplices also come, in some measure, under this name, though the former not strictly under the legal definition of accessaries. An abettor is one who procures another to commit an offence, and in many, indeed in almost all cases, is now considered as much a principal as the actual offender. An accomplice is one of many persons equally concerned in a felony. The name is generally applied to those who are admitted to give evidence against their fellow-criminals, for the furtherance of justice.

Acclamation (acclamatio); in Roman antiquity, a shouting of certain words by way of praise or dispraise. In ages when peoplc were more accustomed to give full utterance to their feelings, acclamations were very common, wherever a mass of peoplc was intluenced by one common feeling. We find, therefore, acclamations in theatres, senates, ecclesiastical meetings, elections, at nuptials, triumphs, \&c. The senate of Rome burst into contumelious acclamations after the death of Domitian and Commodus. The theatrical acclamations were connected with music. Nero, who was as fond of music as of blood, ordered 5,000 soldiers to chant acclamations when lie played in the theatre, and the spectators were obliged to join them. In the corrupt period of the Roman empire, the children and favourites of the emperors were received with loud acclamation, as the French emperor was greeted with Vive l' empereur ! and the Erench king is with Vive le roi! The Turks have a custom somcwhat similar, at the sight of their emperor and grand viziers. The form among the Jews was Hosanua! The Greek emperors werc received with A yafn $r v x \eta$ ! (good luck), or other exclamations. Before a regular system of voting is adopted, we find its place supplied, among all nations, by acclamations. So Tacitus informs us that the Germaus showed their approbation of a measure by clashing their shiolds and swords. The bishops, in thc early times of christianity, were long elected by acclamation. In the course of time, acclamations were admitted into the churches, and the people expressed their approbation of a favourite preacher by exclaining, Orthodox! Third apostle! \&c. They seem to have been sometimes used as late as the age of $\mathrm{st}$ Bernard. The first German emperors were elected by acclaniation at a meeting of the people in the open air; and the Indians, in North America, show their approbation or disapprobation of proposed public measures by acclamations.

AccoLADE, a word derived from barbarous Latin, is composed of $a d$, to, and collum, neck, meaning, originally, an embrace. It signifies an ancient ceremony used in conferring knighthood. Antiquaries are not agreed wherein the accolade consisted. Some think it signifies the embrace or kiss, given by thic person who conferred the honour of knighthood. It is more probable that it consisted in an imitation of a blow on the neck, or on the cheek, signifying that this should be the last blow which the new-made knight should endure. The ceremony of striking the candidate with the naked sword, which afterwards took the place of the blow with the hand, harl the same meaning. The Roman master also gave a blow to his slave, at the time of his emancipation which, therefore, was called manumission; and in those parts of Germany where the ancient corporation of mechanics still continue, the apprentice receives a blow from the oldest journeyman, when his apprenticeship is at an end. The blow or stroke was in use among all christian nations of the middle ages in conferring knighthood. (See Chivalry).

Accoltr, Benedict, an Italian lawyer, born at Florence in 1415. He became secretary to the republic of Florence in 1450, and was much distillguished by the popes of his day. He wrote a treatise "De Prastantia Virorum sui Evi," and also a valuable work on the Crusades, which was serviceable to Tasso, in the composition of his Jerusalem Delivered. He died in 1549. There were other eminent men connected with the family of Accolti, in particular, Bernard Accolti, a poet, and Francis and Peter Accolti, both lawyers.

Accommodation; properly, the adaptation of one thing to another; in philosophy the application of one thing by analogy to another. It is also used in theology; thus, a prophecy of Scripture is said to be fulfilled improperly, or by way of accommodation when an event happens to any place or people similar to that prerlicted of another. Some theologians also say that Christ said many things to his disciples by way of accommodation, viz. entering in. to their views, and telling them only what they were capable of understanding. Others think this theory inconsistent with the purity of Christ. A., in law, if used for an amicable agreement or composition between two contending parties. These accommodations are frequently effected by means of compromise and arbitration.

Accompaniment, in music, (French, accompagnement; Italian, accompagnamento,) is that part of music which serves for the support of the principal melody (solo or obligato part). This can be executed either by many instruments, by a few, or even by a single one. We have, therefore, pieces of music with an accompaniment for several, or only for a single instrument. The principles on which the effect of the accompaniment rests are so little settled, that its composition is perhaps more difficult than even that of the melody, or principal part. Frequently, the same musical thought, according to the character of the accoinpaniment, produces a good ou' lad effect, without our being able to give a satisfactory reason for the difference. Hitherto, the Italians have been most distinguished for expressive accompaniments contained in a few notes, but productive of great effect. In this respect, the Italian music $\mathrm{c} \rightarrow \mathrm{D} 2$ 
generally surpasses the German and Frencl, as it uever weakens the effect of the principal part by means of the accompaniment. The French are far behind both the other nations, in respect to this part of cunposition, as they frequently estimate the efrect by the quantity of notes. The nccompaniment requires of the performer the most scrupulous study, and of the composer the greatest care and delicacy. The accompaniment of various solo instruments, $e$. $\mathrm{g}$. the violin, flute, piano, \&c. is extremely difficult, and to give it full effect requires great knowledge and skill. The Italian composers accordingly consiler a piano accompanied for a full orchestra, especially in the recitativo, (q. v.) as a great problem, which they have laboured zealously to solve. As the object of every musical accompaniment is to give cffect to the principal part, the accompanier should always aim to support, and by no means to overpower and oppress it. Of all composers, Mozart, even in respect to the accompaniments, claims the first place for the simplicity and beauty with which he amalgamates the leading and accompanying parts, through his unrivalled knowledge and excellent management of the parts for every individual instrument.

Accord; in common law, an agreement, between two or more persons, to give and accept satisfaction for an offence or trespass committed, which becomes a bar to a suit.

Accorso, Francis, an Italian lawyer, who rendered himself famous by his "Perpetual Commentary," or "Great Gloss," in illustration of the code, the institutes, and the digests. The best edition of his collection is that of Lyons, 1627, 6 vols. folio. He was born in Florence in 1182, and died in 1229. His son, also an eminent lawyer, came to England and read lectures at Oxforl, but subsequently died in Italy in 1321.

Accorso, Mariangelo, a critic who distinguished himself by the diligence with which he sought and collated ancient manuscripts, of which he published several. He was a native of Aquila in Naples, and flourished in the 16th century.

Accodchearest (French); the delivery of a woman in child-bed.

Accusation (from the Latin ad, to, and causari, to plead) ; an assertion imputing to some person a crime or a fault: in law, a formal declaration, charging some person with an act punishable by a judicial sentence. In Rorie, where there was no calumniator publicus, no attorney-general, every one was permitted to prosecute crimes of a public nature. Therefore accusations very often took place arainst innocent persons, on which account it was not considered at ail disreputable to be accused. Cato is said to have been accused 42 times, and as often absolved. Also in Prussia and Austria there exists, sccording to the codes of these countries, no public accuser. The courts accuse, try, and sentence upon information received from the police, to which private individuals apply. This is called the process by inquisition, in contradistinction to process by accusation or appeal. In the common law of Germany, the process of appeal, in which the person injured appears as the accusing party, is not general, ret not abolished (See Criminal process.) For accusation in England and France, see .Jury. At Athens, if an accuser had not the fifth part of the rotes on his side, he was obliged to pay a fine of a thousand drachmas. Eschines, who accused Ctesiphon, was condemned to pay this fine. At Rome, a false accuser was branded with the letter $K$ on his forehead, (nsed for $C$, i. e. calumnialor.) The accuser was also watched to prevent his corrupting the judges or the witnesses. The Spanish inquisition forced the suspected person to accuse limself of the crime objected to him. In France, peers are to be accused of crimes orly before the chanber of peers, and the chamber of deputies alone las the right to accuse ministers, as such, before the peers. Accusing, in these cases, is called impeaching. In the United States, any oflcer of government, the president not excepted, is impeacliable, and the constitution provides the accuser and the julges. In no monarchy can the king be brought to trial for a crime, though, in some cases his conduct nuy be such as to amonnt to a virtuil abdication of the throne. Blackstone says, "When king James II. invaded the fundanental constitution of the realm, the conveution declared an abdication, whereby the throne was rendered vacant, which induced a new settlement of the crown. And so far as this precedent leads, and no fartleer, we nuny now be allowed to lay down the law of redress against public oppression."

AcELDara, (Heb., a field of blood); the field purchased by the Jewish rulers with the 30 pieces of silver which Judas returued to them in despair, aftur betraying Clirist. This field they appropriated as it burial-place for strangers. The place is still shown to travellers. It is small, and covered with an anched roof. The bodies deposited in it are, it is said, consumed in three or four dass, or even less time.

Acepriau (headless); several sects of schismatics in the cluristian church, who rebelled against their christian head, or refused to acknowledge any ; for example, the monophysife monks and priests in Egypt, who did not acknowledge the patriarch, Peter Mongus, because he had not, at the adoption of the Henoticon, in 483, expressly condemned the council of Chalcedon. They were divided into three parties, but were soon lost among the other monophysites. The Flagellants (q. v.) were also Acephali, because, as a sect, they acknowledged no head. This term is also applied to certain nations, represented by ancient naturalists, as formed without heads, their eyes, mouths, \&c. being placed in their breasts, shoulders, \&c.

AcErra; an altar set up by the Romans, near the bed of a person deceased, on which lis friends daily offered incense till his burial.

AcEтIC ACID; the acid which, in a more diluted state, is called vinegar.

Acneass are properly the inhabitants of the district Achaia, in the Peloponnesus; but this name is very frequently, especially in Homer, given to all the Grecians. Achæus, a son of Xuthus and Creusa, went to Thessaly with a number of followers, but was soon driven out, and compelled to withdraw to the Peloponnesus, where he settled in Sparta and Argos, the inhabitants of which were called Achaens. Of the Grecian nations engaged in the siege of Troy, the Achæans were the most numerous and powerful. After the conquest of this city, being overcome by the Dorians, they retired to Ionia, on the northern coast of the Peloponnesus, gave to the country the name of Achaia, and founded a republic, which was subsequently famous for the Achæan league. This league was at first formed by a few cities, for the maintenance of their security and indepertdence ; but it afterwands included all the other cities of Achaia, together with Athens, Megara, \&c. Sparta, however, did not join the confederacy. After the destruction of Corinth, B. C. 146, the states composing this league were made a Roman province, under the name of Achaia.

Acheos, in ancient history,-1. A king of Lydia, deposed and hanged for extortion. Ovid. 2. The founder of the Achrean state in the Peloponnesus, son of Xuthus king of Thessaly. 3. A tragic poet of Eretria, who lived some time after Sophocles. 4. 
Auother poet of Syracuse. 5. A cousin-german to Selcucus Ceraunus and Antiochus the Great, kings of Syria, who enjoyed, for many years, the dominions lie had usurped from Antiochus; but at last was betrased by a Crctan to the last-mentioned king, and his limbs being cut off, his body was sewed in the skin of an ass and gibbeted.

Аснала ; properly, a narrow district of Peloponncsus, extending westward along the bay of Corinth. Early writers, particularly the poets, sometimes include all Greece under the name of Achaia. At the time of the Achran league, the Romans applied the name of Achaia to all the country beyond the isthmus, which had entered into the league ; after the dissolution of which, Greece was divided, by a decree of the Roman senate, into two provinces, viz. that of Macedonia, containing also 'Thessaly, and that of Achaia, including all the other states of Greece. (See Gibbon's Roman Hist. cliap. 1. vol. i.)

Achard, Frederic Charles, born at Berlin, April 28,1754 , an eminent naturalist and chemist, principally known by his invention, in 1800 , of a process for manufacturing sugar from beets, which, since that time, has been brought to greater perfection. lle was director of the department of physics, in the Royal A ademy of Sciences at Berlin. To enable him to extend his manufacture, the great importance of which was acknowledged by the French Institute (July, 1800), the king of Prussia presented him with an estate at Kunern, in Silesia, where his establishment, at the time of the closing of the ports of Europe, by the decree of Berlin, was attended with such success, that, in the winter of 1811 , it daily yielded 300 pounds of sirup. Achard, connected with it, in 181\%, an institution for the purpose of teaching his mode of manufacture, which attracted the attention of foreigners. He died at Kunern, April 20, 1821. Besides a number of treatises on plysics and agriculture, he published several articles on the manufacture of sugar from beets.

Acrates; the companion of Eneas, and his most fuithful friend, celebrated by Virgil.

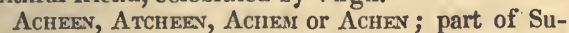
matra, of a triangular form, and containing about 26,000 square miles. The lands between its two manges of mountains are fertile. The Achanese are stouter, taller, and darker-coloured than the other people of the island, more industrious, have more general knowledge, and deal, as merchants, in a more liberal manner. They are Mahommedans; their sailors are expert and bold, and employ a multitude of vessels in trade and fishing. The government is despotic, monarchical, and hereditary; their laws extremely sevcre. The capital of the kingdom is Acheen, lon. $95^{\circ} 46^{\prime}$ E. lat. $5^{\circ} 22^{\prime} \mathrm{N}_{\text {. }}$; pop. about 36,000 . Its chief tradc is now with Hindostan, from whence it rcceives cotton goods in return for gold dust, jewels, sapan wood, betel-nut, pepper, sulphur, cimphor, and benzoin. Europeans bring their opium, iron, arms, \&c. (See Marsden's History of Sumatra.)

Acnelous, also Aspropotamus, a river munning bctween Etolia and Acaruania, has its source on mount Pindus, flows through the first settlements of the Grecians around Dodoila, and falls into the Ionian sea. The banks of this river are the only places in Enrope, which formerly afforded habitation to lions. -Hesiod calls A. the son of Oceanus and Thetis. Others say differently, He wrestled with Hercules for Dejanira, and, when thrown to the ground, assumed the sliape of a terrible serpent, then that of an ox, and after he had lost a hom, he fled, ashamcd, to his waters. From the broken horn, it is said, the nymphs made the horn of plenty. He was the father of the sircns.

Achevwall, Godfrey, born at Elljing, in Prussin,
Oct. 20, 1719, first gave a distinct character to the science of statistics. He studied in Jena, Halle, and Leipsic. In 1746, he settled at Marpurg, and lectured on history, the law of nature and of nations, and afterwards, also, on statistics. In 1748, he was appointed professor at Gottingen, where he remained until his death, May, 1772. A. travelled through Switzerland, France, Holland, and England, and published several books on the history of the European states, the law of nations, political economy, \&c. Most of them have gone through several editions. His principal endeavour, in his lectures and historical works, was to distinguish, in the long series of occurrences which are recorded in the annals of nations, every thing which might have contributed to form their character, and fix their political condition. His chief merit consists in the settled character which he has given to, and the new light which he has thrown on the science, which explains systematically the nature and amount of the active powers of a state and hence deduces the sources of its physical and moral prosperity. He gave it the name of statistics. His most distinguished pupil, who succeeded him at the university of Gottingen, was Schlcezer.

Acrieri, Luke d', a Benedictine monk of St Maur, born in 1609; died in 1685. He distinguished himself by his taste for antique research and the publication of scarce MSS., of which "The Spicelegium," a collection published in 1653-57 and 1725, forms a prominent example.

Achrenon; the name given by the ancients to a river of the infernal regions, over which Charon conducted the souls of the dead in a boat, for which he. received an obolus, placed under the tongue of the deceased. Only the shades of those who had obtained a burial in this world, or had, at least, some earth thrown upon their bodies, were carried over the river, others were obliged to wander on its banks a whole century. In ancient geography, there are five different rivers; named Acheron. The one in Epirus (now a province of Janinna) flows first through the lakc Acherusia, then, for a short distance, through the rocks of the Cassiopeian mountains, and falls, near Prevesa, into the Ionian sea. It is now called $V$ elchi. A branch of the Nile, in the neighbourhood of Memphis, is also called Acheron, and a lake, Acherusia. Over this the Egyptians ferried their dead, to bury them on an island in the lake, or on the opposite shore; or, if the judge of the dead condemincd them, to throw them into the water: hence the Greek fable. The cave of Cerberus, callel Acherusias, is found on the banks of the river Acheron, in Bithynia, near Heraclca. There is also a swamp in Campania, between Cumæe and the promontory of Misenum, called by the ancients Acherusia. At present there are salt works on this spot.

Acherosia, in ancient geography,-1. A lake in Egypt, near Memphis, over which, according to Diodorus, the bodies of the dead were conveyed for judgment. The boat was called baris, the boatman Charon. Hence came the Grecian fable of Charon and the Styx. 2. A river in Calabria. 3. A lakc in Epirus, through which runs the river Acheron. 4. A lake betwecn Cumze and the promontory of Miscnum. 5. A peninsula of Bithynia, on the Euxine, near Hcraclca.

AcurLl, an Irish island, divided from Connaught by a narrow channel. It is 30 miles in circumference, and from its situation and height is the resort of eagles, whence it is called Eagle Island.

AcrunLes ; according to the poets, soll of Peleus, king of the Myrmidons, in Thessaly, and of Thetis, daughter of Nercus, grandson of Facis. His mother dipped lim, whien an infant, in the waters of the 
heel, by which she held him. It had been foretold to Thetis that $\mathbf{\Lambda}$. would acquire inniortal glory, but, at che same time, meet an early death, if he went to the siege of Troy; while, on the other land, if he remained at home, he would eujoy a happy old age. 'lo prevent lim from taking part in the war against 'Troy, Thetis disguised lim, ilken nine years old, in a female dress, and sent lim, under the name of Pyrrha, to the court of Lycomedies, king of Scyros, with whose daughters he was ellucated. The propliet Calchas, however, announced to the Greciaus that 'Truy could not be taken without the aid of $\mathrm{A}$. He was consequently sought for every where, and finally discovered by the crafty Ulysses, who came to the contr of Lycomedes disguised as a merchant, and offered to the daughters of the king various female rrnaments, among which arms were interspersed. The princesses seized the oruaments, but $A$. took the 3mus. It was now an easy task to persuade the fiery aud ambitious hero to join the other princes of Greece in the expedition against Troy. Phœnix and the Centaur Chiron had been his instructors. The latter lad taught him medicine, music, and riding; the former, more especially his tutor, followed him to Troy, to render him an eloquent speaker, and a brave warrior. A. appears in the lliad, of which he is the hero, not ouly as the bravest, but also as the most beautiful, of the Grecians. He sailed to Troy with 50 slips filled with the Myrmidons, Achaians, and Hellenians, and destroyed 12 cities on the islands and 11 on the main laud. Juno and Minerva took him under their special protection. On account of a quarrel with $A$ gameinnon, whom the princes had chosen their leader, he withdrew from the field, and permitted Hector, at the head of the Trojans, to destroy the ranks of the Grecians. He remained implacable against the king, on account of Briseis, daugliter of Brises, and wife of Mines, king of Lyrnessus, who had fallen to his share, in the division of the booty, but whom Agamemnon lad taken from him, because he was obliged to restore to her father Chryseis, dainglter of Chryses, priest of Apollo, who lad fallen to his own share, in order to avert from the Grecians the plague sent by Apollo, in answer to the prayers of the old man his priest. Neither the defeats of the Grecians, nor the offers of Agamemnon, appeased the wrath of the liero. He, however, permitted his friend Patroclus, in his own armour, and at the head of his own warriors, to mingle again in the combat. Patroclus fell by the arm of Hector; and, to revenge his death, A. resolved to return to the ficld. Thetis herself brought him new and costly arms, made by Vulcan, amoug which the shield was particularly beantiful. He became reconciled to Agamemnon, received the presents which were offered, and, refreshed by Minerva with nectar and ambrosia, hastened to the battle. The Trojans fled, and a part of them rushed into the river Xanthus and perished. The bodies obstructed the course of the stream, and the river-god, disgusted with the carnage, commanded A. to desist. Not being obejed, lie overfowed his banks, and rushed against the hero. Encouraged by Neptune and Mineria, A. opposed Xanthus, who called to his aid the waters of simois. Juno then sent Vulcan, and the west and south winds, who drove the river-god back to his proper limits. But A. pursued the Trojans to their city, which only the interference of Apollo prevented hiun from taking. Hector alone remained before the Scaran gate, and, having fled three times round the city, pursued by $\mathrm{A}$., finally offered himself for combat. A. slew him, and, after dragging his body round the rity, resigned it, for a ransum, to Priain. Here the llarration of Homer ends. A., as represented by this sublime poet, is of a fery and impetuous character, and has little of that firmmess and rational valour which constitute the true hero. In this respect, the heroes of the Germau poem "Das Nibelumgenlied" are far greater and nobler thin those of Homer. The further listory of $\mathbf{\Lambda}$. is told as follows: Falling in love with P'olyxena, lie sought her land, and obtained it ; for which he promised to defend Troy, But Paris slew him with an arrow, which pierced his heel, in the temple of $A$ pollo, where he was celebratiug his nuptials. Others say it was $\Lambda$ pollo whio killed him, or directed the arrow of Paris. A bloody contest ensued about his body. The Greeks sacrificed Polyxena on his tomb, in obedience to his request, that he might enjoy her company in the lilysian fields, where he is also said to have marrict Medea. When Alexander saw his tomb, it is said that he placed a crown upon it, exclaiming, "tliat A. was happy in laving, during his life-time, a friend like Patroclus, and, after lis death, a poet like Homer."

Achules Tatios; a Greek novelist, or Erotic writer, so called, born at Alexandria, lived, probably, at the end of the third and the beginning of the fourth century, and taught rhetoric in his lative city. In his old age, he becaine a convert to Cliristianity, and rose to the dignity of a bishop. Besides a treatise on the sphere, which we know only from an abridgment still extant, we possess a romance of his, in 8 books, styled, The Loves of Clitophon and Leucippe, which, as regards the subject and composition, is not without merit, and in some parts shows much ability. The language; though rich in rhetorical ornaments, is not free from sophistical subtilty. The charge of obscenjty, which has occasionally been brought against the work, is very properly met by a Greek epigram, which remarks, that the scope of the work is to be considered, namely, to teach temperance, to show the punishment of uriestrained passions, and the reward of chastity. 'The best editions are the following: that published at Leyden, 1640 , one published at Leipsic, by Bode, with the notes of Salmasius, 1776, and that of Mitscherlich, 1792, (Bipont.) Achaет 1Il., a Turkisl emperor, son of Malioinet IV., reigned from 1703 to 1730 . Many remarkable events took place during lis reign, of which we shall here only mention, that Charles XII., after the battle of Pultowa, found protection at his court. Charles succeeded in involving $A$. in a war with the czar, Peter the Great, which would have had a very unfortunate issue for him, if the prudence of Catharine, his niistres;, whom he afterwards married, had not averted the impencing danger. (See Peter I.) A. established the first printing press at Constantinople, in 1727. Towards the end of his reign, the janizaries revolted against him and he was thrown into the same prison in which hits successor, Mahomet $V$., had been confined, before he took A.'s place on the throne. He died in 1736 .

Aснми or Eснми; a considerable town of Upper Egypt, on the eastern bank of the Nile, called by the ancients Chemnis and Panopolis, by the Copts Smin. Though reduced from -its former magnificence, it is still one of the finest towns of Upper Egypt. It has some manufactories. A bulfeda speaks of a superb temple here. The immense stones which composed it, scilptured with innumerable hieroglyphics, are now scattered about, and some are transferred into a mosque. A. contains also a triumphal arch, built by the emperor Nero. This place is fa. mous also for the worship of the serpent Haridi.

Acids (acida); a class of compound bodies, which have the following characteristic properties: the greater part of them a sour taste, and most of thein are very corrosire; they change the vegetable blues to red, are soluble in water, and have great affinity 
for the alkaline, earthy, and metallic oxyds, with which they form neutral salts. Some acids have no solic uaste, but their affinity for the three classes of bodies above-mentioned is always characteristic. If a few drops of sulphuric acid, nitric acid, or muriatic acid, be added to a solution of blue litmus, it becomes red. The same is the case if they be added to other vegetable colours, as violet, \&c. Hence these colours are employed as tests of acids, that is, to ascertain when they exist in any substance. We may add the infusion to the fluid in which we are trying to detect an acid, but a more convenient method is, to spread it on paper, and allow it to dry. If a strip of this be put inito a fluid in which there is an acid, it instantly becomes red. Some acids appear only in a fluid state, either gaseous, as carbonic acid, or liquid, as sulphuric acid; others appear in a solid form, or crystalized, as benzoic acid, boracic acid, \&c. All acids are compound bodies, and are sometimes divided into four classes, the three first of which are compounded with oxygen; the fourth class consists of those which, at least according to those modern chemists, have no oxygen; $e$. g. sulphuretted hydrogen, The first class consists of acids compounded with oxygen and one other body; the second class comprises the acids compounded of carbon, hydrogen and oxygen; and the thind class consists of those acids which contain nitrogen, in addition to the three substances above-mentioned. The ancient chemists were acquainted with but few of the acids now known; they divided them, according to the kingdoins of nature, into mineral, vegetable, and animal acids. This division, however, cannot now be retained, as there are some acids which appear in all the kingdoms; $e . g$. phosphoric acid. If the same radical be compounded with different proportions of the acidifying principle, forming different acids, the most powerful acid recejives a name from the radical, terninating in -ic; the weaker, a name formed in the same manner, in -ous; e. g. sulphurous acid and sulphuric acid, nitrous and nitric acid; and, where there are intermediate compounds, the tern hypo is oceasionally added to the compound next above it in point of acidity. Thus hyposulphuric acid signifies an intermediate acid between sulphurous and sulphuric acids; hypophosphorous acid, an acid containing less oxygen than the phosphorous acid. (For Prussic acid, Pyroligneous acid, \&c., see Prussic, Pyroligneous.)

Aclrs; hurricanes of snow which prevail among the Cevennes, in the south of France. Villages are sometimes so rapidly covered, that the inhabitants lave no means of communication, but by cutting passages under the snow.

Acolyth1, or Acolytrs; servants of the church, who appeared in the Lativ church as early as the $3 \mathrm{~d}$ century; but in the Greek, not till the 5th. Their office was to light the candles, thence they were called accensores; to carry the tapers to the festal processions, thence ceroferarii; to present the wine and water at the supper; and, in general, to assist the bishops and priests in the performance of the ceremonies. They biloinged to the clergy, and had it rank immediately below the subdeacons. In the Roman church, the consecration of an acolythrus is the highest of the lower kind of ordination. The person ordained receives a candlestick and chalice, in token of his ancient employment. The duties, however, formerly appertaining to this office, have been performed since the 7 th century by menials and boys taken from the laity, who are improperly called acolythi, in the books of the liturgy of the Catholic church. The modern Greek church no longer retsins eren the name.

Aconıra; a vegetable poison. recently extracted/derived from one sense into thosc derived from from aconitum napellus, or wolf's-bane, (properiy
alkaline,) by $\mathrm{Mr}$ Brande. The analysis has been made known.

Aconzio, or Acontios, James, a philosopher, mathematician, and divine of the 16th century. Hc was a native of Trent, and died about 1505. His principal works are one on the Stratagems of Satan, and another on the Métliod of Studying the Sciences, In these he displays a liberality and foresight beyond the spirit of his age.

Acosta, Uriel, a Portuguese, of the 17th century, who from Christian turned Jew, and from Jew unbeliever ; and in consequence underwent numberless persecutions. He died by his own hand in 1640 ; and his life, an interesting account of which has been often published, furnishes a notable example of intolerance and bigotry on one side, and the inutility of pursuing certain lines of inquiry without steady principles, and a calm temperament on the other.

Acoustics. One of our most important connexions with external objects is maintained through the sense of hearing ; that is, by an affection which certain actions or motions, in those objects, produce on the mind, by being communicated to it through the ear. The peculiar excitation or motion perceptible by the ear is called sound; and the consideration of this motion, its qualities and transmissions, forms the science of acoustics. Philosophers make a distinction between sound and noise: thus those actions which are confined to a single shock upon the ear, or a set of actions circumscribed within such limits as not to produce a continued sensation, are called a noise; while a succession of actions which produce a continued sensation are called a sound. It is evident from the mechanism of the ear, so far as it is understood, that it is a refined contrivance for conveying a motion from the medium which surrounds it to the auditory nerve; and that this nerve must receive every motion excited in the tympanum. Every motion thus excited, however, does not produce the sensation of sound. That motions may be audible, -it is necessary that they impress themselves upon the medium which surrounds the ear with velocities com prised within certain limits. These motions are commonly produced by disturbing the equilibrium which exists between the parts of a body. Thus, for example, if we strike a bell, the part which receives the first impulse of the blow is driven nearer to the surrounding parts; but the impulse having ceased, it is urged back by a force of repulsion which exists in the metal, and made to pass beyond its former position By the operation of another property of the metal, namely, cohesire attraction, it is then made to return in the direction of its first motion, again, beyond its position of repose. Each of these agitations influences the adjacent parts, which, in turn, infuence those beyond them, until the whole mass assumes a tremulous motion; that is, certain parts approach to and recede from each other; and it only recovers its former state of repose, after having performed a number of these sonorous vibrations. It is evident that such vilorations as are here described must result from the combined operation of attraction and repulsion, which, together, constitute the elasticity of solid bodies. When fluids, whose elasticity is eonfined to repulsion, enit sounds, a force equivalent to that of attraction in solids is supplied to them by external pressure. The sonorous vibrations of bodies are exceedingly curious, and the more difficult to be understood from our habits of measuring clianges or motions by the sight; but these motions affect very sensibly another organ, while they are almost imperceptible to the eye; and, as we are without the meaus of converting the ideas 
another, the sensation of the motion of sound does not assist us to understand its precise nature, as compared with visible mutions. 'Thus, the ear at once pexceives the differeuce betwcen a grave and an acute sound ; but it is only from attentive observation by the eye, that we discover the different rapidity of succession in the ribratious which produce them. The vibratious of a great many bodies, as strings, bells, and membranes, when enitting sounds, may, lowever, be distinclly scen, and even felt; but they may often be rendered more sensible to the cye by a little artificc, such as sprinkling the vibmting body with sand, or soine light granular substance. Sound may be produced without vibrations or alternations; thus, if we pass the mail quickly over the teeth of a comb, the rapid succession of singleshocks or noises produces all the effect of vibrations. It must be cvident that the rapid notions here describcd, whether originating in vibrations, or a succession of concussions, must be communicated from the body in which they are excited, to the shect of air, or whatever else be in contact with it, and from this again to another sheet beyond the first; thus diffusing the motion in evcry direction. The agitation of the sounding body must thus be communicated to the surrounding mediun to a great distance, and impressed upon any body situated within this distance ; if this body be the ear, the tremor cxcited in it by these agitations will be perceived by the mind. The necessity of some medium for the transmission of sound is proved by expcriment. If a bell be rung in an cxhausted receiver, the sound will be hardly pcrceptible, while the toues will become clear and distinct, on re-admitting the air. Haring thus given a general outline of the source and propagation of sound, we shall procced to consider, with as much minuteness as the limits of this work will permit, some of the more important facts connected with them,-The most olvious characteristics, by which we distinguish differeut sounds, consist of differences in their degrees of what we call loudness, and acuteness, or pitch. We can produce, at pleasure, sounds having different degrees of loudness, from the same sonorous body, by making the concussions upon it more or less violent; disturbing in a greater or less degree the arrangement of its parts. So two bodies of like substance and figure, but unlike mass, when suljected to the same shock, emit sounds unlike in loudness; and, again, bodies, of like mass and figure, but unlike substance, form sounds more or less loud, when subjected to the same shock. In this latter case, the loudness las a relation to the quantity of elasticity possessed by the bodies; and in all cases, when the disturbance of the parts is carried beyond the elastic power of the body, so as to produce a permanent change of figure, no increase of loudness is induced. From a consideration of the preceding facts, we may conclude, that loudness depends upon the quantity of motion, or sonorous vibration, in which it originates. The other principal characteristic of sound, its acutencss or pitch, depends upon the frequency with which the concussions or vibrations of the sonorons lody sncceed each other. That sounds may be audible to a common ear, it is necessary that the concussions upon the medium, which communicates them, should follow each other in such succession, that not more than 8192 , nor less than 32 , distinct concussions shall be made upon the medium during the lapse of one second. Some ears, however, can perceive sounds cmanating from vibrations a little bejond the extremes to which the perception of other ears are confined. We should be careful not to confound the frequency of vilurations with the relocity of vibratory thotion. $\Lambda$ string may vibrate with a greater or less velocity, as it passes its axis to a greater or less dis- tance; yet the times of its vibratious may be all equal. The difference of velocity, affecting the quantity of motion only, would produce 110 cliange, except in the londness of the sound. To those sounds which proceed from infrequent vibrations, we give the name of flat or grave, those from frequent vibrations we call sharp or acute. When vibrations succeer each other in equal times, their sound excitrs a pleasant seusation, and thcy are called musical. When two bodies are made to sound together, if their vilorations are perforned in equal times, the sounds sre said to be in unison. When the vibrations are performed in unequal times, so that some of those of the one are not accompanied by those of thic other, the ear perceires a degree of dissonance in 'the sonnds. If, however, the vibrations meet after short and regular intervals, the dissonance is not easily detected, and the sounds are said to accord. During the continuance of most primary sounds, however cxcited, we perceive other and more acute soumls co-existing with them. These are called their harmonics. They are supposed to originate in a series of secondary vibrations, more short and frequent than the principal vibration. Thus a sounding string, for example, may be supposed not to pass its axis in a simple curve, but to resolve itself into a tortuous line, formed by a number of smaller curves, each of which ribrates across its own axis, thus producing its larmonics. It is perhaps some combination of the harmonics with the primary sound, that characterizes the sound of different instruments, though of the same loudness and pitch, so that we can distinguish one from another. The air, being the common medium which surrounds the ear, is that by which sounds are usually transmitted. This transmission is performed with a velocity of about 1130 feet in a second. All other bodies, however, are capable of transmitting sound. It may be done perfectly, even by the solid parts of the heal. If, for example, we hold the stem of a watch between the teeth, and cover the ears with the lands, the beats are heard more distinctly than when the instrument is held at an equal distance in the air. The rubbing together of two stones under water may be heard, by an ear in the same medium, at the distance of half a mile. When the air, or any other body of indefinite extent, is disturbed, in a point sitnated within it, by a sonorous vibration, it forms a wave which passes from the disturbed point, as a centre, in erery direction. It follows that as the wave extends itself, the mass to be put in motion increases until the original motion is rendered insensible from the magnitude of the mass to which it has communicated itself. The velocity with which waves, thus former, move through any homogeneous elastic medium, is always equal to that which a heavy body would acquire by falling through half the height of the modulus of elasticity.* In applying this law to the transmission of sound by the air, it was for a long time found not to give the samc results as were ol)tained by experiment. This discrepancy, however, has been most ingeniously reconciled by a small correction for the latent heat made sensible by the zompression; the effect of this being to increase the height of the modulus of elasticily. We ought therefore, to find that liquids, and more especially some of the solids, should transmit sound mucli more rapidly than air; and this agrees most perfectly with various experiments. Cast-iron, for $1 \times$ ample, has been found to transmit sound with a velocity $10 \frac{1}{2}$ times greater than air. Sound does not readily pass from one medium to another; a sound made in the air is not easily distinguished under water, although the distance be very small. It is from

* The height of the modulus of elusticity of air is $2_{6}, 850$ feet. 
this, probably, that cork and all soft cellular bodies are bad conductors of sound, as in these the sound must, in passing through the walls of the cells and the air contained in them, change successively from one medium to another. All sounds, whatever be their loudness, or pitch, are transmitted with the same velocity; a fact most completely proved by every musical performance. Were it otherwise, indeed, this beautiful art could not exist. To make this apparent, it is only necessary to consider, that harmony is a combination of different sounds arranged with certain relations of time and pitch. Now, if one sound were transmitted with greater velocity than another, these relations would differ at different distances, or be confounded, except at a single given point. Nay, further; melody, which is a succession of single sounds, would not reach different ears with the same relations of time, if the different notes were not transmitted with equal velocities. Some observations on sound, in very high latitudes, seem to contradict the above law of transmission. The seeming dnomaly, however, is sufficiently reconciled by supposing the different strata of air, through which the sounds, in those instances, were transmitted, in very different hygrometrical or thermometrical states; which would make corresponding differences in their modulus of elasticity. When a wave of sound meets an clastic surface, it is partly transmitted and partly reflected. This reflection, when it returns back perpendicularly, is called an echo. That an echo may be distinctly heard, it is necessary that the reflecting surface be at such a distance that the original sound sliall have ceased before the reflected one returns to the ear; otherwise they will be blended, and the echo not perceived.-Hitherto we have considered the propagation of sounds in an unconfined medium, particularly the air, in which the wave of sound can diffuse itself in every direction. When this diffusion is prevented by enclosing the medium in a surface capable of reflecting the wave so that the sound shall be confined to one direction, the transmission from one point to another is much more perfect. Experiments have been made in this way, in which a hollow cylinder, about half a mile long was formed by cast-iron pipes. The sound was transmitted by the air, in this cylinder, with wonderful distinctness. The least whisper, at one end of the cylinder, was distinctly heard at the other end. So perfect, indeed, was the transmission, "that, not to hear, it was absolutely necessary. not to spcak." Captain Parry and lieutemant Foster made several experiments, during the northern expeditions, to ascertain the velocity of sound. A table of them is given in a number of the Edinburgh Philosophical Journal. These expcriments were made at Port Bowen, by means of a brass six-pounder, over a range of $12,892.89$ feet. The results given are the mean of four shots in one case, of five in another, and, in the rest, of six shots by each observer. The mean results varied from $12 \prime, 7617$ to $11^{\prime \prime}, 7387$ and $11^{\prime \prime}, 5311$ for the time in which the range of $12,892.89$ feet was traversed by the sound. At the period of the experiment which gave the first of these results, thcre was a caln; during the second, the wind was light; during the third, a strong wind was blowing. The velocity per second, in feet, was, in the first instance, 1010.28; in the second, 1098.32; in the third, 1118.10. Omitting the last of the ten results (the last above given), on account of the strong wind, the mean of the other nine gives a velocity of 1035.19 feet, at thic temperature of $17 \cdot 72$, Fahrenheit.-The mean of a table of velocities formed from observations made at lort Franklin, by lieutcnant Kendall, who accompanied captain. Franklin, in his second journey to the shore of the Polar sea, gives a velocity of $1069 \cdot 28$ feet per second, at the temperature of $9 \cdot 14$, Fahrenheit.-The science of acoustics. like the other pliysical sciences, has been in a constant state of advancement since the revival of learning. It appears that Pythagoras knew the relation between the length of strings and the musical sounds which they produce. Aristotle was not only aware of this relation, but, likewise, that the same relation subsists between the length of pipes and their notes, and that sound was transmitted by the atmosphere. This constituted the sum of ancient learning in this branch of science. These facts were taught by Gallileo, and, moreover, that the difference in the acuteness of sounds depends on the different frequency of vibrations, and that the same string, if of uniform thickness and density, must perform its vibrations in equal times. But, without attempting a history of modern discoveries in acoustics, we can only mention, that the names of 'Taylor, Moreland, Newton, Danicl Bernouilli, D'Alembert, Euler, Robison, La grange, Laplacc, Chladni, T. Young, and Biot, are all connected with it. Of these, Newton gave the law of transmission, which we have stated in this article, and the correction for heat was made by Laplace.

ACRE; a measure of land, containing four square roods, or 160 square poles or perches. The statute length of a pole or perch is $5 \frac{1}{2}$ yards, or $16 \frac{1}{2}$ feet; but the length of a pole, and, therefore, the size of the acre, varies in different counties in England. The Scottish acre contains also four squarc roorls; one square rood is 40 square falls. The English statute acre is about three roods and six falls, standard measure of Scotland; or the English acre is to the Scottish as 78,694 to 100,000 . The French acre arpent, is equal to 54,450 square English feet, of which the English contains only 43,560. The Welsh acre contains commonly two English ones, The Irish $\Lambda$. exceeds the English by two roods, $10{ }_{1}^{2}, 1$ perches. The U. S. of America use the English statute acre.

ACRE (Akka, St Jean d'Acre); in the middle ages, Ptolemais, a city and harbour on the coast of Syria, capital of a Turkish pachalic, betwcen the pachalics of Damascus and 'Tripoli, which contains 420,000 inhabitants, and 6275 sq. miles. This city, situated at the foot of mount Carmel, is the clipf emporium of Syrian cotton, and contains about 16,000 inhabitants; its liarbour, though full of sand-banks, is still one of the best on this coast. At the time of the crusades, A. was the principal landing place of the crusaders, and the seat of the order of the knights of St John as late as 1291 ; hence the French name, St .Jean d'Acrc. 'The Turks, under Djezzar, pacha of this place, who is famous for his cruelty, sustained, with the assistance of the British commodore, Sidney Smith, a siege of 61 days, by the French army under Bonaparte. After a great loss of men on all sides, the French abandoned the siege. (See Fgypt, landing of the French in.)

Acridophagi (Gr., from áxeis, a locust, and payoo, to eat); an ancient Ethiopian people, who are said to liave fed upon locusts.

ACrOCERADNIOM ; in anc. geogr. a promontory of Epirus, on which arc situated the Acroceraunia or montes Ceraunii. They run betwcen the Ionian sea and the Adriatic, where Illyria ends and Epirus begins, and arc the modern Monti della Chimera.

Acrocorintude ; a steep rock, about 2200 fect high, near the city of Corinth, of a grcy colsutr, and picturesque form, crowned with the remains of old Venetian fortifications, repaired a little by the Greeks, since the commencement of their revolution. It was famous, in ancient times, for its citadel, and on its top stood, according to Pausanias, a temple of Venus. 
At its font is a fontain, the ancient Pyrene. The anpe of the A. is that of a truncated cone. This liule fortress has been several times taken and reiaken in the war between the Greeks and Turks. The view from the top is one of the most charming in the world. It is thus described in the "Journal of Dr Lieber," before whom no Christian traveller, in modem times, had probably visited it, as the Turks did not allow Christians to asceud it while it was in their hands:-" The view from this spot amply rewarded me for my trouble. 'To the north lay the high and snowy summits of Helicon and l'arnassus, as described by Strabo, extending far under the clear blue of a southern sky. On the west was seen the lany of Crissa, mount Citharon, and the promontory of Olınize. On the east the Saronic gulf washes the islands of Salaınis and Egina. To the north-east lay the shore of Attica. There we could see Pentelicus, Hymettus, and Laurion, and even down to the cape of Sunium. 'The day was very clear, so that I could discern the acropolis of Athens. To the south I could see far into the territory of Argolis. To the west Achaia and Sicyonia lay in sight. The view comprehended the scenes of the best displays of Grecinn art, science, and valour."

Acropous (Greek); the highest part or citadel of a city, particularly that of Athens, where the treasury and public records were kept. It is situated on a rock, and has often been the subject of contest in the late war between the Greeks and the Turks.

$\Lambda$ crostic (Greek); a poem, of which the first, and sometimes the final letters of the lines or verses form some particular word or words. The middle letters, also, are sometimes used for the same purpose. An example of the three kinds united may be seen in the following Latin lexameters:

$$
\begin{aligned}
& \text { I nter cuncta micans I gniti sidera coel I, } \\
& \text { F. xpellit tenebras E toto Phobus ut orb } \mathbf{E} \text {; } \\
& \text { S ic coecas removet IESVS caliginis umbra S } \\
& \text { V ivificansque simul V ero procordia mot U } \\
& \text { S olem justitim S ese probat esse beati S }
\end{aligned}
$$

The French abbés and nobles, before the revolution, often exercised their ingenuity in the composition of thi'se poetical trifles.

Acr, in law ; an instrument in writing for declaring or justifying the truth of any thing. In this seuse, records, decrees, sentences, reports, certificates, \&c.. are called acts. The French lawyers distinguished between, 1 , private records (actes sous seing privé), which must be acknowledged by the parties, in order to have legal force; 2 , public documents (actes authentiques), which have legal force, without being acknowledged by the parties, as long as they are not proved spurious; and, 3 , executive acts (actes exécutoires), which, until their genuineness is called in question (inscription a faux), are also binding without acknowledgment by the parties subject to their operation. Of this kind are the records of the public notaries (actes notariés), and all the official documents of the French courts of justice. In England and the United States, act implies decree; hence, an act of parliament is a decree of parliament, confirmed by the king, a statute. (See Great Britain.) At the close of each annual session, the decrees or acts of parliament are collected into one body, which forms the statute of that session, the several decrees of which are contained in separate chapters. They are quoted according to the year of the king's reign, and according to the chapter; e. g. the act of habeas corpus is the second chapter of the statute of the year 1650 , the 31st year of the reign of Charles II., and is quoted, 31, Ch. II., c 2. In America, there is no uniform mode of quoting statutes : each separate act is deemed a distinct statute. Geaerally, the acts are cited by their date and year; and, if more particularity is necessary, by the chapter, when the statutes are divided into cliapters. Acts in Germany are the records and documents of any transaction, especially of a lawsuit. 'The whole process, in that country, is carried on in writing. Nothing is received as evidence, unless laid before the court on paper. When a criminal process begins, the prisoner is brouglit before a judge or assistant and a writer. The judge questions : the question is written on the left side of a folio slieet; on the right side the auswer of the prisoner is set down. The same takes place with every witness. The reader can inagine to what an immense bulk these acts often increase in the course of a single process. If there are witnesses in other places, an order to examine them is sent, and the papers containing the ininutes of their testimony are transmitted to the place of trial. The examining judge is called the judge of inquisition (inquisitionsrichter). At the close of each stage of the examinition, the prisoner subscribes the minutes made during that time with the words, "read in my hearing, approved and signed." He also signs lis name, as do likewise the judge and the writer. When the acts are completed (closed), they are delivered to the court, who appoint another judge to report on them and move for judgment, while another still acts as counsel for the prisoner. Afterwards, the whole court in pleno decides. In fact, in Germany, the whole course of administration is conducted in writing. In Saxony, such acts are almost endless. In Prussia, also, they are very numerous. All acts are preserved in archives. After sentence passed in one court, the whole pile of acts is sent to a court of appeal.

Act, in the universities, signifies a thesis maintained in public by a candidate for a degree.

ACTA ERUditordm; the first literary journal that appeared in Germany. It enjoyed a long existence and great popularity. The example set by the Joun nal des Savans, and by the Diornale de' Litterati; but, especially the increasing spirit of enterprise and activity among the German booksellers, inducel Otto Mencke, professor at Leipsic, to lay the foundation of this periodical publication, in 1680 . Having formed the necessary connexions, on his travels through Holland and England, and being assisted by the most eminent German scholars, he commenced the journal in 1682, which increased in popularity from year to year. Among the contributors were Carpzov, Leilnitz, Thomasius, \&c. Its object was, to give a faithful and particular account of books; and it was conducted on the same plan, even after a better taste in composition and greater independence were introduced into literary discussions in the French journals published in Holland. The German journal began, however, to decline gradually in value, and in the number of its subscribers, particularly after 1754; and the irregularity of its appearance became at length so great, that the last volume, for 1776 , was published in 1782, exactly a century from the time when the journal was commenced. The whole consists of 117 volumes in 4 to, including the supplementary volumes and indices. Leibnitz, in this journal, first gave to the world his notions respecting the differential calculus.

Acta Savcrordm; a name sometimes applied to all collections of accounts of ancient martyrs and saints, both of the Greek and Roman churches. It is used more particularly as the title of a voluminous work, comprising all those accounts, which was commenced at the instigation of the Jesuits, in 1613 , by John Bolland, a Jesuit of Antwerp, and after his death continued by other divines of the same order, known by the name of the Bollandists, (q. v.) to the year 1794, but not yet finished, (Antwerp, Brussels 

and Tongerlow, 1643-1794, 53 volumes in folio). their holy lives and religious constancy, during the period of the persecution of Christian believers, are found as early as the second and third centuries; particular narratives and biographies commenced with the fourth century, and were infinitely multiplied till the close of the middle ages. Since the sixth century, many works have been compiled from this imnense mass of materials. The first critical collection of óriginal legends was edited by Boninus Mombritius, in 1474. The above-mentioned collection, however, surpasses all others of the kind in extent, fidelity, and impartiality. It is likewise distinguished for sound criticism and excellent illustrations, which will make it forever a most valuable storehouse of pcclesiastical history, if truth is critically separated from fiction and superstition, by the historian who describes the manners and the spirit of those ages.

AcræoN; in fabulous history, the son of Aristæus and Autonoe ; a great hunter. He was turned into a stag, by Diana, for looking on her when she was bathing, and was torn to pieces by his own dogs. Also, a Corinthian youth, killed by Archias, one of the Heraclidæ, in an attempt to carry him off from his father's house.

Acriox (law); a term including private suits and public prosecutions. Actions are, therefore, criminal or civil; criminal, for the punishment of crime; civil, for the obtainment of right. Civil actions are divided into real, personal, and mixed. Action real is that whereby a man claims title to lands or tenenients in fee or for life. Action personal is brought upon contracts, or injury to person or estate. Action mixed lies for a thing and against the person who lias it. It seeks an object, and a penalty for its detention. 'Many personal actions die with the person. Real actions survive. In all actions merely personal, for wrongs actually committed by the defendant, as trespass, battery, slander, the action dies with the person, and never can be revived, either by or against the executors or other representatives. But in actions on contracts, where the right descends to the representatives of the plaintiff, and those of the defendant have received effects from the deceased sufficient to answer the demand, though the suits abate by the death of the parties, yet they may be revived against or by the executors. Again, actions are either local or transitory. Actions, real or mixed, for the recovery of the freehold, or for damage done to it, are to be brought in the same county where the land lies. Actions on contracts, or for personal injuries, are not limited to a particular county. Actions are likewise joint or several ; joint, wliere several persons are equally concerned, and one cannot bring the action, or be sued, without the other ; several, in case of trespass, \&c., where persons are to be severally charged. Every trespass committed by many is several.

Acriva, a promontory on the western coast of Greece, in ancient Fpirus, the northern extremity of Acarnania (now Albania), at the entrance of the Ambracian gulf, at present called capo di Figolo, or Azio, on the gulf of Arto, is memorable on account of the naval battle fought here between Antony and Octavius, Sept. 2, B. C. 31, in sight of their armies, encamped on the opposite shores of the Ambracian gulf. The forces of Octavius consisted of 80,000 Infantry, 12,000 cavalry, and 260 ships of war; those of Antony, of 100,000 infantry, 12,000 cavalry, and 2:20 ships of war. Notwithstanding the advice of his most experienced generals, to meet Octavius by land, Antony, at the instigation of Cleopatra, determined upon a naval engagement.' His vessels advanced, Leautifully ormamented, and remarkable for their size; those of Octavius, although smaller, were nore skilfully managed. Both fleets were manned with the soldiers of the Roman legions, who considered a seafight like a battle on land, and the ships as fort's which were to be stormed. Those of Antony tlirew fire-brands and missile weapons from catapults, whilst those of Octavius applied grappling-irons to the ships of the enemy, and boarded them. Soon after the beginning of the battle, before any thing decisive had taken place, the timid Cleopatra fled with 60 Egyptian ships, when she perceived the centre of Antony's fleet in an unlavourable position. Antony imprudently followed her. Octavius, perceiving his flight, proclaimed it aloud, and the deserted fleet was soon overcome, notwithstanding a brave resistance, and immediately went over to the enemy. Antony's troops, which were drawn up on the shore, and had beheld with amazement the flight of their leader, followed the example of the fleet. Antony fled with Cleopatra to Egypt, where he killed himself, to avoid falling into the hands of his enemies. Augustus enlarged the temple of Apollo at Actium, in commemoration of his victory, dedicated to Neptune and Mars the standards which he had taken, and instituted games, to be celebrated every five years, in commemoration of this battle, which made him master of the world.

Aстол, Joseph, prime minister of Naples, was born in 1737 , of Irish parents, who had settled in Besangon. After he had finished his education, he entered the French navy, which he soon quitted for the 'Tuscan, and was subsequently employed in the Spanish expedition against Barbary, in which he found an opportunity to distinguish himself. This led him to the Neapolitan navy, and then to the Neapolitan court, where he acquired the favour of queen Caroline. He was successively appointed minister of the navy, minister of war, then director of the finances, and, finally, prime minister. In this office he contracted an intimacy with the English ambassador, Sir William Hamilton, and, in concert with him, exercised a great, and by no means beneficial influence over the fortunes of Naples. His implacable hatred against France led him, during the continuance of the Italian wars, to the most extravagant measures, which always turned out disadvantageously for the royal family, and strengthened the French party, from which that of the Carbonari was afterwards formed. He accompanied the king, in 1798, on Mack's expedition against the French army. During the presence of Nelson, he had previously presided over the renowned junta, which, to satisfy its hatred against men of different political opinions, with unprecedented cruelty, sought out victims in all ranks. After the unfortunate issue of Mack's expedition, he was removed from the lielm of the Neapolitan government. He died in 1808, hated and despised by all parties.

Aсто口, in the drama, is one who represents some part or character on the stage. Among the Greeks, with whom dramatic exhibitions originated, a simple chorus only, who sung hymns in honour of Bacclus, constituted the whole entertainments. A declaimer, who recited the adventures of heroes, was introduced by Thespis, for the sake of variety. Escluylus changed the declamation into the form of a dialogue between two persons, and Sophocles added a third. To this number the actors in the Greek drama were limited; and the Romans adopted the same rule in tragedy. In comedy, the number of actors was not restricted. In modern times, the number is regulated by the nature of the piece to be performed. Actresses, in the drama, appear to have been wholly unknown to the ancients; men or eunushs always performing the female parts. Charles II. is 
said to have first encournged their public appenrance in Fingland; but there is evidence that the queen of James 1. perforned in a court theatre. Actors were long exclurded from good society, and actresses still louger, and perhaps the Finglish were the first who admittel the most distinguished into their first circles. Instances of exemplary conduct are not wanting aunongst actresses in modern times. France, England, Italy, and Germany, lave had many of unblesusili ed reputation. At Athens, actors were highly hon oured. At Rome, they were despised, and leprived of the right of suffrage. The reason of this difference is, tliat, among the Greeks, the actors were freeborm citizens, and the dramatic performances had their origin in the sacred festivals; but, among the Romans, the drama was introduced by persons of the lowest class, Etruscan players and peasants of Atella. Actors and actresses continued for a long time to be treated with little regard in France, after they liad been admitted into good society in England. Marriages of Englishmen of high rank with actresses are not rare. In some parts of Germany, actors were formerly buried like suicides, in a corner of the burying-ground, separated from the other graves. Ifow much the ancients studied the dramatic art may be seen from one fact, that Polus, a famous Greek actor, when he had to play Electra, in the tragedy of Sophocles, made use of an urn containing the ashes of his own son, to represent the funeral urn of Orestes. But here art ceased; this was again nature.

AcTs of the Apostles; one of the books of the N. Testament, written in Greek by St Luke (q. v.), the author of the Gospel which bears his name. It is acldressed to Theophilus, of whom nothing is known, and is evidently intended as a continuation of the Gospel, which the author himself calls his " first book." (Acts i. 1.) It has been universally received, and is generally allowed to have been written A. D. 63 or 64 , but in what place is doubtful ; Jerome says nt Rome; Grotius and Lardner think, in Greece ; Michaelis, in Alexandria. It embraces a period of about 30 years, beginning immediately after the resurrection, and extending to the second year of the imprisonment of St Paul in Rome. Very little information is given of any of the apostles, excepting St Peter and St Paul, and the accounts of them are partial and incomplete. Thus the history of St Peter terminates with the death of Herod, although that apostle is considered to have lived and preached 24 years longer. It describes the gathering of the infant church after the death of its founder; the fulfilment of the promise of Christ to his apostles, in the descent of the Holy Ghost; the choice of Matthias in the place of Judas, the betrayer ; the testimony of the apostles to the resurrection of Jesus in their discourses, attested by miracles and sufferings; their preaching in Jerusalem and in Judea, and atterwards to the Gentiles; the conversion of Paul, his preaching in Asia Minor, Greece, and Italy, his miracles and labours. Its place is generally at the head of the apostolicon, or before the epistles; but in some MSS. it is found after the 13 Catholic epistles. The style of this work, which was originally composed in Greek, is purer than that of the other canonical writers; and St Luke, in his quotations from the Old Testament, always makes use of the Septuagint version.

Acusa, Christopher de, a Spanish Jesuit, born at Burgos, in 1597. He is principally known as the author of a curious work, Nuevo Descubrimiento de Gran Rio de los Amazones, (A new Description of the Great river of the Amazons,) Madrid, 4 parts, 1641. Only two copies are said to exist at present. In 1692, a translation of one of them into French was published in 4 vols. $12 \mathrm{mo}$.
Acoponctore. Kampfer made known, more than 100 years ago, the Japanese and Chinese method of curing arthritic and rheumatic complaints by acupuncture; but it is only a few years since it has been carefully examined and applied in Eugland and Fmnce. (See Churchill's Treatise on Acupuncture.) In Japan and China, this mode of curing is applier much more frequently than in Europe, and even to the tenderest parts of the bocly. It cousists in driv. ing a fine needle one or two inches into the flesh on the afflicted part. The opinions of the cause of relief by acupuncture are still very different. Soune writers think a galvanic influence on the nerves takes place.

AD Limitom, used in music for a piacere, when the principal performer is at liberty to give way to lis conceptions, to change the measure from quick to slow, or the contrary, without accompaninent, and tos manifest his ability in the effusions of lis fancy. 'The term is often used in the full score, to denote those parts which are not essential, and nay be onitted.

Adagio ( Iial.) expresses a slow time. Used substautively, it expresses a slow movement. Sometimes the word is repeated to denote a still greater retardi1tion in the time of the music.

Adalbert, or Aldebert; a native of France, who preached the gospel in 744, on the banks of the Maine. He is remarkable as the first opponent to the introduction of the rights and ordinances of the catholic church into Germany. He dared to assert, that the multiplication of saints and relics, and the practico of confession, were superfluous. On this account, he was accused of heresy, by Boniface, the apostle of Germany, and condemned by two councils, at Soissons in 744, and at Rome in 745. Having finally made his escape from prison, he is said to have been murdered by some peasants, on the banks of the Fulda.

Adalbert, archbishop of Bremen and Hamburg, a descendent of a princely house of Saxouy, received his office, in 1043 , from the emperor Ileury II I., whose relation, friend, and follower he vias. He accompanied Henry to Rome, where he was a distinguished candidate for the papal chair. Pope Leo IX., in whose behalf lie had spoken at the synod of Mentz, 1049, made him his legate in the north of Europe, 1050. He superintended the churches of Denmark, Norway, and Sweden, but aspired in rain to the dignity of pope, or patriarch of the North. During the minority of Henry IV., who afterwards became emperor, he usurped, in concert with Hanno, archbishop of Cologne, the guardianship of the joung prince, and the administration of the empire, and gained an ascendency over his rival, by indulging the passions of his pupil. After Henry had become of age to rule, $A$. exercised the goverument without control, in his name. A.'s pride and arbitrary admi. nistration induced the German princes, in 1066, to remove him by force from the court; but after a short contest with the Saxon nobles, who laid waste his territory, he recovered his former power, which he held till his death at Goslar, March, 17, 1072. He excelled his contemporaries in princely qualities, in talent, and in strength of mind; and if he had possessed magnanimity, and a wise spirit of moderation, he would have deserved the name of the grcat, which has been given him. The injustice and tyranny which stained his administration were mainly instrumental in producing the confusion and calamities in which the reign of Henry IV. was involved.

Adalbert of Prague, the apostle of Prussia proper, son of a Bohemian nobleman, was educated in the cathedral of Magdeburg, between the jears 973 and 982, and appointed bishop of Prague in 983 He laboured in vain to convert the Bohemians from 
paganism, and to introduce among them the ordinances of the clurch of Rome. Discouraged by the fruitlessness of his pious zeal, he left Prague, 988, and lived in convents at Montecasino and Rome, until the Bohemians, in 993, recalled him. But after two years, he again left them, disgusted with their barbarous manners. He returned to Rome, and soon followed the emperor Otho III. to Germany; on which journey he baptized, at Gran, St Stephen, who subsequently became king of Hungary. After a visit to the monasteries of Tours and Fleury, he proceeded to Gnesen, to meet Boleslaus, duke of Poland; and being informed that the Bohemians did not wish to see him again, he resolved to convert the pagans of Prussia. But he lost his life in the attempt, being murdered by a peasant, April 23, 997, near what is now Fisclhhausen. His body was bought by Boleslaus, for its weight in gold, and became famous for its miraculous power. Its influence was greater than that of the saint himself. The Bohemians, who before had refused to receive the ordinances of the church, now suffered them to be introduced into Prague, on the sole condition, that these miraculous bones should be transferred to their city.

ADAIr (Hebrew, formed of earth), the father of the human race, was, according to Genesis, made of clay, on the sixth day of the creation. God finished the work of creation by forming man according to his own image, making him master of all created things. He gave him Ere for his companion (in Hebrew, Heva, the mother of the living), formed of his flesh, that the earth might be peopled by their union. The garden of Eden, dirersified with fruitful trees, was their abode, in which they found every thing to satisfy their wants, and to afford them pleasure. But in the centre stood the tree of the knowledge of good and evil; and of this their Creator had forbidden them to eat. Eve was beguiled by the serpent to take of this fruit, and to eat of it with her husband. This crime destroyed their felicity. The appearance of things was suddenly changed before their eyes. They perceived their nakedness, and endeavoured to conceal it. In vain did A. seek to hide himself from the sight of God; in vain did he throw the blame of his transgression upon Eve; a curse followed them and the whole creation. Driven from the state of innocence, in which he was born, $A$. saw himself condemned to earn his bread by the sweat of his brow. All the evils of life and the terrors of death came upon him. He had three sons, Cain, Abel, and Seth, and died at the age of 930 years. The history of $A$. is found, with little variation, in the traditions of nearly all ancient nations who seem to have derived their information from a common source.

ADAM (of Bremen), canon of the cathedral of Bremen, lived towards the end of the 1lth century. He wrote an Feclesiastical Ilistory in four books, which treats of the propagation of the Christian faith in the north, and which was published at Copenhagen, 1579, 4to, and Helmstadt, 1670, 8vo. Also " Chronographin Scandinaviæe," published in 1615, 8vo.

Adar. Three brothers of this name were sculptors. The eldest, Lambert Sigisbert, born in 1700 , at Nancy, where his father was also a sculptor, went, at the age of 18 , to Mctz, and thence to Paris. After four years' study in this city, he received the first prize from the academy, and soon afterwards went as a royal pensioner to Rome, where he passed 10 years. The cardinal of Polignac commissioned him to supply the parts wanting in the 12 marble statues, found in the palace of Marius, and known by the name of the family of Lycomedes, which task A. executed with great skill. When the erection of the large monuunat at Rome, known by the name of the fountain of Trevi, was contemplated, $A$. was one of the 16 statuaries appointed to furnish designs. That which he offered was accepted, but the jealousy of the Italian artists opposed its execution, and in 1733, A. returned to France. In 1737, he was chosen menber of the academy, and afterwards professor. The statue of Neptune calming the waves, with a Triton at his feet, is a fine specimen of his skill. Besides various other works, he now finished the group of Neptune and Amphitrite, to adorn the basin of Neptune at Versailles. A. was skilful in working marble; his anatomy is correct and his drapery good; but he was led astray by the bad taste of his time, which confounded the provinces of painting and sculpture. He died in 1759.-His brother, Nicholas Sebastian, born at Nancy in 1705 , studied the same art, under the care of his father, and in the academy of Paris. At the age of 18 , he was employed in a castle near Montpellier, and went, after 18 months, to Rome, in 1726. After two years, he gained the prize offered by the academy of San Luca, worked in connexion with his brother, spent nine years abroad, and was finally admitted into the academy of Paris. His Prometheus lacerated by the vulture was exhibited as a specimen of his powers, but not finished until some time after the exhibition. His masterpiece is the tomb of the queen of Poland, wife of Stanislaus. In regard to his merits, what has been said of his brother holds true of him. He died in 1778. - The third brother, Francis Gaspard, born at Nancy in 1710 , was also a pupil of his father. In 1728, he joined his brothers in Rome, and improved greatly in their company. He then returned to Paris, gained the first prize of the academy, and in 1742 , visited Rome again, where he completed his studies. He then went to Berlin, instead of his brother Nicholas Sebastian, whom Frederic II. had invited thither. He laboured there several years, and died at Paris in 1759.

ADAs, Alexander, an eminent grammarian and writer on Roman antiquities, was born in Morayshire, 1741, of humble parents, who, however, contrived to give him a good education. He removed to Edinburgh, in 1758, where, after undergoing great hardships in prosecuting his studies, he became, in 1761, assistant master of the high school of Edinburgh, and in 1771, head master of the same. In 177:2, he published his Latin Grammar, under the title of "The Principles of Latin and English Grammar." It possesses considerable merit, and is well adapted for teaching the grammars of both languages at the same time. He also compiled "Romail Antiquities," 1791 , 8vo ; "Summary of Geography and History," $1794,8 v 0$; "Classical Biography ;" and an abridged dictionary, entitled " Lexicon Linguæ Latinæ Compendiarium," Svo, all of which are popular in schools. He was a liberal in politics; and at the commencement of the first French revolution, became obnoxious for the sympathy he evinced in Gallic freedom. The weight of his character, however, bore hin up against the political prejudices with which he had to contend. He died of apoplexy, in 1809, and was honoured with a public funeral. The principal features of his character were, unshaken independence and integrity, ardour in the cause of public liberty, purity of manners and singleness of heart, and great power of application to study.

ADAM, Melchior, a German biographer of the 17th century, was a native of Silesia, Between 1615 and 1620 , he published four vols. of "Lives of Illustrious Men." "These were afterwards printed in one vol. folio, at Frankfort; and though not ably written, have been mich used by subsequent collectors.

Adam, Nicholas, a French grammarian, who published rarions popular elementary works on grau- 
mar. He was born at Paris in 1716; wis many years professor in the college of Lisieux; and died in $179 \%$.

ADAs, Robert, an eminent architect, was born in Filinburgh in 1728. He was the second son of William Adam, of Maryburgh, Fifeshire, an architect of considerable reputation. While at the university of Edinburgl, he formed intinacies and friendships with distinguished men, which smoothed the way to his future eminence. In 1754, he travelled to the continent, made a royage to Spalatro in Dalmatin, and resided three years in Italy. On his return, he was appointed architect to the king, an office which he held for six years, when he resigned it to become a member for Kinross-shire in the British parliament. In 1764, he published a work in large fulio, enriched with plates, entitled "Ruins of the Palace of the Einperor Dioclesian, at Spalatro, in Dalmatia." By this time, in conjunction with his brother, James, he carried on an extensive professional business, being much employed by the English nobility and gentry, in constructing modern and embeilishing ancient mansions. In 1773 , the brothers commenced to publish in numbers "The Works in Architecture of R. and J. Adam," which contain many elegant and splendid designs. Before this they had accomplished that noble inprovement in London, called after them the Adelphi (brothers.) As specimens of Adam's architeoture in Scotland, we may mention the register office in Edinburgh, and the royal infirmary in Glasgow. Robert Adam died in 1792, and was buried in Westminster abbey; his brother James, who was also eminent as an architect, died in 1794.

Adaмast. See Diamond.

Adamantive Spar; a stone of peculiar hardness, approaching to that of the diamond. It will cut glass casily, and mark rock crystal. It is found in China and India, and, as M. Pina alleges, in. Italy.

ADamtrs; the name of a cliristian sect, said to lave existed in the $2 \mathrm{~d}$ century ; and also of a band of heretics, which in 1421, appeared in Bohemia, during the commotions occasioned by the doctrines of IIuss. They were called $A$. because both men and women were said to appear naked in their assemblies, either to imitate Adam in the state of innocence, or to prove the control which they possessed over their passions. The tradition respecting the former sect of this name appears to have had its origin in a name of derision given to the Carpocratians of indifferent reputation. (See Gnostics.) The accounts of the latter A. are not to be relied upon with more certainty. These were also called Picards, from the founder of their sect. Picard, (perhaps also Beghards.) They appeared about the year 1421, on an island in the river Lusinicz, where Zisea surprised them, but was not able to destroy the whole sect. In the following year, they were widely spread over Bohemia and Moravia, and especially hated by the Hussites (whom they resembled in hatred towards the hierarchy), because they rejected the doctrine of transubstantiation. They subsequently formed one sect with the remaining Taborites, who have occasionally been confounded with the $A$.

Adass, John, a distinguished patriot of the American revolution, was born at Braintree, Massachusetts, October 19,1735 , being a descendent from one of the families which founded that colony. In 1761, he was admitted to the degree of barrister at law, and shortly afterwards was placed in the possession of a small landed estate by his father's decease. In 1764, he married, and, about a year afterwards, he removed to Boston, where he practised his profession on an extensive scile, and published in the Boston Cazetie serersl pieces, under the title of "An Es- say on Canon and Fendal Law," which were re printerl in london, in 1768, and (alled, "A Dissertation on Canon and Feudal I^w." It seems to havo been the priucipal object of the author of this work to extinguish, as far as possible, the reneration of his comitrmen for the institutions of England, by holding up to their ablorrence the principles of the canon and feudal law, and showing to them the conspiracy which existed between church and state, for the purpose of oppressing the people. He inculcates the sentiments of gemine liberty, as well as the necessity of correct information on the part of his fellow-citizens, in order that they inight be prepared to assert and maintain their rights by force, if force should ever become neeessary. It was indered a work eminently calculated to excite the people of America to resist, at all hazards, any infringement of their liberties. In 1769, he was appointed chairuan of the committee, chosen by the town of Boston, for the pur pose of drawing up instructions to their representa. tives, to resist the encroachments of the British government, and was elected, in 1770 , to the legislature of his state, as one of the representatives of the town of Boston. His conduct in this new situation displayed the same patriotism, courage, and hostility to the despotism of the mother country, by which lie had always been distinguished. He took a prominent part in every public measure, and served on several eommittees, who reported some of the most importaut state papers of the time. At the time that he resumed lis seat in the national eouncils, in 1776, hostilities were active between Great Britain and the colonies. But the object of the latter was as yet merely to resist the authority assumed by the parent country to inpose taxes upon them at pleasure. Few persons entertained the idea of a dissolution of connexion very few, even of the delegates in congress, secmed to desire it ; but among those few, John Adams was the foremost. Such a step was unpopular. As soon as he was suspected in Philadelphia of being an advocate of the measure, he was represented in the most odious light, and even pointed at and avoided in the streets. Still, however, he persevercd, made every day proselytes, and, May 6,1776 , moved in congress a resolution, which was, in fact, a virtual declaration of independence, recommending to the culonies " to adopt such a government as would, in the opinion of the representatives of the people, best conduce to the happiness and safety of their constituents and of America." This passed, after a hard struggle, on the 15th of the same month, and was the prelude to the glorious and daring resolution, moved by Richard Henry Lee, of Virginia, on the Tth of June following, and seconded by Mr A., "that these united colonies are, and of right ought to be, free aurl independent states; that they are absolved from all allegiance to the British crown; and that all political connexion between them and the state of Great Britain is, and of right ought to be, totally dissolverl." The debate upon this motion was of the most animated character. It continued from the 7 th to the IOth, when the further discussion of the mensure was postponed to the lst of July. A committee of five was also appointed to prepare a provisional draught of a declaration of independence. The members of it were chosen by ballot, and were Thomas Jefferson, John Adams, Benjamin Franklin, Roger Sherman, and Robert R. Livingston. Mr Jefferson and Mr A. were deputed a sub-committee to prepare the instrument, the former of whom, at the earnest solicitation of the latter, became its author. On the Ist of July, Mr Lee's resolution was again considered, and debated during that and the following day, when it was finally adopted. The draught of the deelaration was then submitted for the purpose of uudergo- 
ung an examination in detail. It was passed on the 4th of the same month, as prepared by Mr Jefferson, with only a few alterations, which were made through a prudent deference to the views of some of the states. Mr A. always preferred the draught as it originally stood. The declaration was not adopted without serious opposition from many members of the congress, including John Dickinson, one of the ablest men in that assembly. But their arguments were completely overthrown by the force and eloquence of Mr A., whose speech on the subject of independence is said to have been unrivalled. Mr Jefferson himself lias affirmed, " that the great pillar of support to the declaration of independence, and its ablest adrocate and champion on the floor of the house, was John Adams." Speaking of his general character as an orator, the same illustrious man observed, that he was " the Colossus of that congress : not graceful, not elegant, not always fluent in his public addresses, he yet came out with a power, both of thought and expression which moved his hearers from their seats." "The year following this great measure, Mr A. proceeded with Dr Franklin to the court of France, in order to negotiate a treaty of perce and alliance. He was afterwards nominated plenipotentiary to $\mathrm{Hol}$ land, and materially contributed to hasten a rupture between the United Provinces and Great Britain. After serving on two or three commissions to form treaties of amity and commerce with foreign powers, Mr A. in 1785 , was appointed the first minister to London. In 1787, whilst in London, he published his Defence of the American Constitutions, and in the same year, by his own request, he was allowed to returı to thc United States. Inımediately after his return, he was elected the first vice-president of the United States under the new constitution, and re-elected as such in 1793. He discharged the duties of his office until March 4, 1797, when he succeeded to the presidency, vacated by the resignation of general W'ashington. This great man's confidence he possessed in an eminent degree, and was consulted by him as often as any member of the cabinet. Mr A. was the founder of the American navy. Before his administration, scarcely an American ship of war was to be seen upon the ocean; but, during this period, by his strenuous exertions, mainly, a very respectable naval force was created. His administration, however, was not of long continuance, having pleased neither of the two great parties which divided the country, his measures being too strong for the democrats and too weak for the federalists. In consequence of this, after his term of four years had expired, March 4, 1801, Mr Jefferson succeeded him, and he retired from public life. At his farm in Quincy, he occupied himself with agricultural pursuits, obtaining amusement from the literature and politics of the day. He was nominated as governor of Massachusetts, but declined being a candidate, wishing only for repose. During the disputes with England, which occurred while Mr Jefferson was in office, Mr A. published a series of letters, in a Boston paper, supporting the policy of the administration. His published writings, besides those which we have already mentioned, are "Discourses on Davila," somposed in 1790, whilc he was vice-president, and printed in June and July of that year in the Gazette of the United States. In 1816, Mr A. was chosen a nicmber of the electoral college, which voted for the elevation of Mr Monroe to the presidency; and, the following year, sustained the greatest affiction that he had ever bcen called upon to endure, by the loss of his wife. On this occasion, hc rcceived a beautiful letter of condolence from Mr Jefferson, between whom and himself their former friendship, interrupted for a time by the animosities of party, had been revived. - In 1820, he was elected a member of the convention, to revise the constitution of his state, and chosen its president. This lonour he was constrained to decline, on account of his infirmities and great age, being then 85 years old; but he attended the convention as member, and fulfilled the duty incumbent upon him as such. After that, his life glided away in uninterrupted tranquillity, until the $4 \mathrm{th}$ of July, 1826, when he breathed his last. What is very remarkable, he died on the same day with the ex-president Jefferson, being the 50th yea of that American independence, which they had both so great a share in advancing.

ADAMs, Samuel, another rernarkable man con. nected with the American revolution. He was born in Boston, September 27th, 1722, was educated at Harvard college, and received its honours in 1740 . When he took the degree of master, in 1743 , he proposed the following question: "Whether it be lawful to resist the supreme magistrate, if the coinmouwealth cannot be otherwise preserved?" He maintained the affirmative and this collegiate exercise furnished a very significant index to his subsequent political career.--On leaving the university, he engaged in the study of divinity, with the intention of becoming a clergyman, but did not pursue his design. From his earliest youth, his attention was drawn to political affairs, and he occupied himself both in conversation and writing, with the political concerns of the day. He became so entirely a public man, and discovered such a jealous, watchful, and unyielding regard for popular rights, that he excited the general attention of the patriotic party, and they took the opportunity, in the year 1766, to place him in the legislature. From that period till the close of the revolutionary war, he was one of the most u1wearied, efficient, and disinterested assertors of American freedom and independence. He was one of the signers of the declaration of 1776 , which he laboured most indefatigably and unhesitatingly to bring forward. He was an active member of the convention that formed the constitution of Massachusetts ; and, after it went into effect, he was placed in the senate of the state, and for several years presided over that body. In 1789, he was elected lieiltenant-governor, and held that office till 1794, when he was chosen governor, and was annually re-electcl till 1797. He then retired from public life, and died at his house in Winter street, Boston, October 2, 1803 , in the $82 \mathrm{~d}$ year of his age.

ADAM's APPLE is a kind of orange, the citrus aurantium of Liunzus. - The same name is also given to the protuberance in the fore part of the throat, occasioned by the projection of the thyroid cartilagc of the larynx. This name originated from the tradition, that a piece of the forbidden fruit, which Adam ate, stuck in his throat, and occasioned the swelling.

ADAM's PEAK ; the lighest mountain in the island of Ceylon, called by the inhabitants Ham-al-el. It lies under $66^{\circ} 49^{\prime} \mathrm{N}$. lat $80^{\prime} 43^{\prime} \mathrm{E}$. lon., and can be seen in clcar weather, from ser, at a distance of 150 miles. It has neither been measured, nor geologically examined. The chicf river of the island, Mahavillagonga, the mouth of which forms, at Trincomalee, the best harbour in all India, has its source in this mountain. It is considered sacred by the followers of Buddha, many of whom makc pilgrimages to it. The betel-leaf is exchanged by them as a sign of peace, for the purpose of strengthening the bands of kindred, confyming friendships, and reconciling enmities. A priest then blesses them on the summit, and cnjoins them to live virtuonsly at homc. According to Davy, the road which leads to the sum. mit, is, with all its windings, eight miles long, and in 
soine places very steep. Upon the top, the priests show a fortstep which Buddha is said to have made. The place is surrounderl by venerable old trees, yarticularly rhododendra.

Adasion, Patrick, a Scottish divine and Iatin poet, was born in Perth, 15.13. After having studied at St Andrews, he visited Paris, Padun, and other places distinguished for their universities, and at Geneva imbiber the Calvinistic doctrines from the celebrated Beza. On lis return, he escaped from the uassacre of St Bartholomew by flight, and lay concenleal a long time at Bourges, where he composed his paraphrise of Job, and some other works. On his returi to Scotland, lie was appointed minister of Paisley, and afterwards, by the favour and interest of the regent Morton, was raised to the archbishopric of St Andrews. In this elevated situation, he was surrounded with dangers and difficulties, and the virulence of the presbyterians was successfilly directed against him, as the firmest pillar of episcopacy. James VI., however, patronized him, and sent him as his ambassador to England, where his eloquence nnd address gained him admirers, and raised such a tide of popularity in favour of the young king, his master, that the jealousy of Elizabeth forbade liun again to ascend the pulpit while at her court. His principal objects in England were to gain friends for his master among the nobles, and to support the cause of episcopacy in Scotland. In 1584, he was recalled, and so violent was the irritation of the presbyterians against him, that, at a provincial synod, he was accused and excominunicated; and neither appeals to the king and to the states, nor protestations of innocence, would have saved hiun from the disgraceful sentence, if he had not yielded to the storm, and inplored parion in the most abject terms. His life continued a scene of persecution; even the monarch grew deaf to lis petitions, and alienated the revenues of his see in favour of the duke of Lennox, so that $A_{\text {., }}$ in addition to the indignities offered to his office, had to endure the pangs of indigence, in the midst of a forlorn and starving fanily. He died in 1591. A 4to volume of his works has been published, containing translations of some of the books of the Bible in Latin verse, frequently composed to alleviate his griefs and disarm the terrors of persecution. He also wrote a history of his own times, and various other works, which were never published.

ADAssos, Michael, an eminent French naturalist, was born at $\mathrm{Aix}$, in Provence, of Scottish extraction, in 1727. His parents intended him for the cluurch, and had even procured him a prebend, but his thirst for natural science induced him to resign it. He made natural history his favourite study, and chose Reaumur and Bernard de Jussieu for his guides. His emulation was roused by the brilliant success of the system of Linnaus. In the prosecution of his favourite pursuits, he made several journeys to regions never yet visited by man. In 1748 , at the age of 21 , he went to the river Senegal, in the belief that the unbeal thiness of the climate would, for a long time, prevent naturalists from visiting that country. He collected, with all the zeal of an enthusiast, invaluable treasures in the three kingdoms of nature; and, perceiving the defects in the established classification of plants, endeavoured to substitute another more comprehensive. He also prepared exact maps of the countries through which he travelled, and compiled dictionaries of the languages of the different tribes, with whose manners and customs he had berome acquaintecl. After a residence of five rears in an unhealthy climate, he returned to his country, in the possession of very valuable collections, and published, in 1757, Histoire Naturelle du Sénégal. Some masterly essays of his were printed in the memoirs of the French acadeny, and procured him the honorar of being chosen a memler of the institute. These essays were only preludes to his learned and comprehensive botanical work, fiamilles des Plantes, 2 vols., 1763. 'This work, however, did not effect the olject for which it was written,-the establishment of a new system of botany, in opposition to that of Linuæus. He was preparing a new exlition, with numerous alterations and inportaut additions, when he formed the plan of jublishing a complete encyclopredia. In liopes of receiving support from Louis $\mathrm{XV}$., he began to collect inaterials, which, in a short time, increased to an immense snass; and, in 1775, he laid betore the academy a prospectus of a work, on so large a scale as to excite general astonishment. It was carefully examined, but the result did not answer the expectations of the author. $\Lambda$.'s plan was good, but he was wrong in insisting upon the immediate publication of the whole. This obstinacy prevented the appearance of the work at all. He continued, however, to increase his materials with unwearied diligence. Some valuable essays, printed in the memoirs of the academy, are all of his writings that subsequently came before the public. The illea of executing his great work continually occupiexl his mind, and he employed all his means for this purpose. But the revolution reduced him to extreme poverty, and when the national institute chose him one of its members, he declined the invitation because he had no shoes. A pension was then conferred upon him, which he enjoyed till his death, in 1806 , cortinually employed in preparing lis great work. The number of his printed books is small, in comparison with the mass of manuscripts which he has left.

Appısox, Joseph, a distinguished English essayist, was born at Milston, Wiltshire, where his father wis rector, in 1672. He received the first part of lis education in his native place: at the age of eleven, his father having been appointed dean of Litchifeld, he became a pupil of Mr Shaw. But we have no account of his early character, except that he distinguished himself in a barring ont. At the age of fifteen, he was entered at Queen's college, Oxford, where his Latin poem on the inauguration of William and Mary obtained his election into Magdalen college, on the founder's benefaction. His other Latin poems may be found with this in the Musce Angelicano, collected by himself. In 1693, having taken the degree of master of arts, he publjshed his first attempt in English, some verses inscribed to 1)ryden, with a translation of part of the fourth Georgic of Virgil, and other pieces in prose and verse. In 1695, he wrote a poem "To King William," and obtained the patronage of lord Somers, keeper of the great seal, by addressing it to him. Having declined entering into holy orders, he obtained a pension of $£ 300$ by the influence of Somers, and Montague, clancellor of the exchequer, to enable him to travel; and in 1701, he wrote the Poetical epistle from Italy, to Montague, now lord Halifax, of which Dr Johnson says, "It is the most elegant, if not the most sublime, of his poetical compositions." During his travels, he began his tragedy of Cato, and composed the Dialogues on Medals, and, after his return, which was hastened by the loss of his pension, he published his Travels. In Johnson's opinion, this work might have been written at home. In 1704, at the request of lord Godolphin, he celclsrated the victory of Hochstadt, or Blenheim, in a poem called the Campaign. Before it was finished, it procured for him the office of commissioner of appeals, in which he was the successor of Locke. About this time. he wrote also the opera of Rosmmond, which was hissed from the stage, but was fublished villı suc. 
cess. The next year he accompanied Lord Halifax to Hanover, and was soon after chosen under-secretary of state. In 1709, he went to Ireland as secretary to the Farl of Wharton, and was at the same time appointed keeper of the records in Birningham's tower, with an allowance of $£ 300$ per annum. While 4. was in Ireland, Steele, the friend of his youth, beman the publication of the Tatler, a series of essays on literature and manners: to this paper $A$. became a contributor. The first number of the Tatler appeared on the 22d April, 1\%09, and was succeeded in March, 1711, by the Spectator, which was continued daily till December, 1712. Some time afterward, the Guardian was undertaken by Steele, and to this A. contributed. His papers in the Spectator are marked by one of the letters in the name Clio, and in the Guardian, by a hand. After the publication of the Guardian, the Spectator was revived, and the eighth volume completed. In this his papers are not distinguished by any mark. The popularity of these works was very great, 20,000 copies of the Spectator being distributed at one time, and they yet stand among the classics of English literature. They may be safely said to have produced a greater effect on the mass of society than any literary productions which preceded them. By describing and criticising the manners of the times, delineating character, exposing the follies, and reproving the vices which fashion countenances, they contributed much to reform the taste of the English nation, while they furrished the noblest lessons for the heart and the understanding. Their influence on English literaturc lias been not less remarkable than on English man. ners. The character of composition which they introduced, although not absolutely English in origin, has become essentially so in tone, spirit, effect, and social adaptation, and it is still to be traced in our hest works, notwithstanding the temptation which modern bookmaking holds out to a diffusive and exaggerated style. A.'s papers in these works, may be divided into the comic, the serious, and the critical. His humour is peculiar, his-satire easy and delicate, and his wit is always on the side of truth and virtue. $\mathrm{H}$ is serious papers are distinguished by beauty, propriety, and elegance of style, not less than by their pure tone of morality and religion. They are a code of practical ethics. His critical essays contain many just remarks, conveyed in an easy and popular manner, and display the results of much study and delicate taste. In 1713, his tragedy of Cato was represented with very great success. It had a run of 35 nights, and was always received with applause. This was undoubtedly owing to party feelings; the whigs hailing whatever was favourable to liberty in the production of a whig, and the tories re-echoing the approbation, to show that they did not feel the censure it was supposed to conrey. Now, however, that it has come to be judged of apart from party feeling, its character as a dramatic composition has fallen very low, although it is admitted to contain many passages of great oratorical beauty. A. was afterwards engaged in several periodicals, principally political, particularly "The Freeholder,"-went again, as secretary of the viceroy, to Ireland, and was appointed one of the lonls of trade. In 1716, he marriod the countess of Warwick, who was won with difficulty, and whose haughty treatment of him often drove him to the tavern. The year after his marriage, he was appointed secretary of state; but his inability to speak in public, and his solicitude ahout the elegance of his expressions, rendered him unfit for the duties of the office, and he soon retired, with a pension of $£ 1500$. His principal work, after thii, was the Evidences of Christianity, a work useful at the time, as recommending the sulject by elegance and perspicuity to popular notice, but since superseded by more complete treatises. He died at Holland House, Kensington, on the 17th June, 1719. Before he expired, he sent for his pupil, lord War. wick, a young man of loose life, and addressed him in these words: "I have sent for you that you may see how a Christian can die." This scene is alluded to in the lines of Tickell on his death:

"He taught us how to live, and-oh! too high

The price of knowledge-taught ns how to die."

He was buried in Westminster abbey. He was a sincere believer in the Christian revelation; in politics earnest, but not violent, he was respected, it not beloved, by individuals of both parties. Serious and reserved in his manners, modest and even timid in society, he spoke little before strangers. "I have never," said lord Chesterfield, " seen a more modest, or a more awkward man ;" but he was easy, fluent, and familiar in the company of his friends. He studied all the morning, dined at a tavern, and spent the evening at Button's, a coffee-house fiequented by the wits of the time. As a poet, he is distinguished for taste and elegance, but is destitute of high poetic genius. His prose is remarkable for its purity, perspicuity, and simplicity, and for the higher graces of harmony and richness of metaphor. It is the sentence of the great judge of English literature, that "he who would write English with correctness and elegance must give his days and nights to the study of Addison." His chief works are the tragedy of Cato, his papers in the Tatler, the Spectator, and the Guardian, and his Evidences of the Christian Religion.

AdDress. In modern times, importance has been given to the manifestation of public opinion to the sovereign, in the form of addresses; and governments, in difficult emergencies, have in turn addressed the people. A communication from the rulers to the citizens is called a proclamation. In France only, at the time when the sovereignty of the people was acknowledged, the higher authorities sent addresses to the people. An address is essentially different from a petition, since it contains only an expression of thanks, satistaction, or dissatisfaction, communicates information, justifies measures, \&c. This practice owes its origin to the British parliament, which is accustomed to answer the king's speeches, delivered at the commencement and close of each session by a public acknowledgment of the obligations of the nation. The samc custom is adopted by the congress of the United States. The constitutions of the several German states grant this right in a very limited sense. In Wurtemberg, it has been declared unconstitutional, in reference to the army; and in Bavaria, the estates have only the right of transmitting petitions to the king, and of complaining against the ministers of state. The right of the citizens, in associations or otherwise, to present addresses, is connected with the right of complaining, convoking assemblies, and signing in a body. It is obvious, that addresses of thanks and satisfaction, like those with which Napoleon was so much pleased, are of importance only in those cases where the ex. pression of public opinion is free.

ADEx, a kingdom of Africa, lying on the eastern coast of that continent, and extending about $5(r)$ miles from east to west, and 300 from north to south. It formerly was tributary to the sovereigns of Abyssinia, but it is now an independent state. Adel and Zeila are the chief $y$ wns, from which there is a considerable trade in ivory, gold dust, and drugs.

Adrutua, John Cliristopher, a Germani scholar, distinguished for his exertions to improve the language of his country, was born August 8, 1732, at Spantekow, in Pomernia, where his father was a 
clergyman. He received his first instruction partly at Anklam, partly at Kilosterbergen, near Magleburg, ank finished his education at Halle. In 1759 , he wrs appointed professor in the protestant acarlemy at Erfurt; but, two years after, ecclesiastical disputes causerl him to remove to Leipsic, where he applied limself, with indefatigable activity, to the extensive works by which he lias been so useful to the Germau langunge and literature, particularly his Grammatisch-krit. IVorterbuch der Hochdeutschen Mundart. Leipsic, 1774-86, 4 vols. and lst half of the fifth. In 1787, he received, from the then elector of Saxony, the place of first librarian of the public library in Dresien. This office he held till his death, Sept. 10, 1806. His grammatical, critical dictionary, surpasses the Euglish lexicon of Jolnuson in the accuracy and order of the definitions, and more especially in the department of etymology, but is inferior to it in the selection of classic anthorities, bccause his predilcetion for the Upper Saxon, or Misnian authors, induced hin to neglect those writers whose country or style he disliked, and his taste was so limited, that he would not allow of any deviation from the established forns and settled laws of style. His methodical mind was struck with tcror at the irregularities and the flood of new words with which he thought the German language menaced, and could not ap. preciate its admirable flexibility and copiousness, in which it is equalled by the Grecian alonc. Of his other works, we may mention his German grammar, his Magazin fur die Deutsche Sprache, his work on German style, his .Ëlteste Geschichte der Deutschen, his Directorium, important for its exposition of the sources of the history of the south of Saxony, Meissen, 1802, 4to, and his Mithridates, in which last work he designed to store up the fruits of all his investigations, but finished only the first volume; for the three others, we are indebted to the lexicographer Vater, of Halle, who employed for this purpose, partly the papers of the deceased, partly the materials collected by $A$. and $W$. ron Humboldt, and partly the results of his own inquiries. $A$. was a man of blameless morals and amiable temper. He was never married. He daily devoted 14 hours to labour.

Adersbach Mourtaiss. These extend, with some interruptions, from Adersbach, a village of Bohemia, to the county of Glatz. Numerous clefts of various size are found amoing the rocks, which rise in strange forms more than 100 feet high, and consist of a remarkable kind of ferruginous sand-stone. Rain and snow, filling the cavities of the surface during the winter, form collections of water, which gradially filters through the rocks, and produces these clefts. The sand-stone itself has, in the course of time, become very brittle, especially on the surface. The place is a great resort for travellers.

ADHELs, or ADEcsi, a learned prelate under the Saxon Heptarchy, was born in Wiltshire, in the seventh century. He was made bishop of Shireburn, and extraordinary talcs are related of his miraculous puwers, and his voluntary chastity. He was, for the times, an eminent scholar, being acquainted with Grecian and Roman literature, a good writer, a poet of some merit, and an excellent musician. His works, which were nimerous, are mostly lost.

ADHesion, according to the latest phraseology of physics, means generally the tendency of heterogeneous bodies to stick together; but cohesion implies the attraction of homogeneous particles of bodies. Adhesion may take place between two solids, as two hermispheres of glass, or between a solid and a fluid, or between two fluids, as oil and water. Thus it is said that a fluid adheres to a solid, as water to the enger dipped into it. But there is a great difference, in this respect, in different bodies; thus small par- ticles of quicksilver do not alliere to glass, but they adhere to gold, silver, and lead. Water adheres to the greatest part of bodies, unless it is separated from their surince by oily substances, dust, flour, \&c. Fluids do not form a surface perfectly horizontal in vessels to which they adhere so as to wet them, but rise, on the contrary, around the brim of the vessels. 'This is proved by water, becr, \&c., poured into glasses, prils, pots, \&c. Fluids, on the other haud, in vessels to which they do not adhere, sink around the brim, and rise in the centre. Thus quicksilver in a glass forms a convex surface. This phenonc. non of the rising and sinking of fluids becomess stil! more remarkable in vessels of a small diameter; wherefore capillary tubes, so called, are used for performing experiments, and the singular effects produced are ascribed to capillary attraction. (See Capillary Tubes.) Water poured from a vessel $w$ which it adheres so as to wet it, runs easily down the exterior surface, unless a pcculiar direction is given to the vessel. This is never the case with quick. silver poured from a glass; but it is so if poured from a vessel of lead, \&c.

ADIAPHORA (Greek); things indifferent in themselves, and of sinall importance: 1 . objects and actions which deserve neither praise nor blamc ; 2 . in matters of church discipline, customs and rites which may be retained or rejected without injuring belicf or troubling conscience, because the loly Scriptures have neither forbidden nor ordained them. This name was originally applied to those instruments and ceremonies of the catholic church, which the protestants admitted into their forms of worship, as altars, candlesticks, images, mass-vestments, Latin hymns, vespers and orisons, private mass, \&c. On account of this admission, Flackius, a theologian of Jena, in connexion with the clergy of Lower Saxony, commenced a controversy, known by the name of the adiaphoristic controversy, with Melancthon and the divines of Wittemberg, who received the name of Adiaphorists. The same trifles bccame subse. qucntly marks, by which the strict Lutherans were externally distinguished from the Calvinists, who had retained nothing of this kind. The more enlightened theologians of the 18th century causcd the greater part of these external distinctions to be laid aside; but new importance has been attached to them in our days; and the question has again beeu discussed, "what ceremonies belong to the A."

ADIPocire, from adeps, fat, and cera, wax; a substance of a light-brown colour, formed by the soft parts of animal bodies, when kept for some time in water, or when preserved from atmospheric air. When this substance is subjected to a chemical analysis, a true ammoniacal soap is first yielded, composed of ammonia, a concrete oil, and water. The oil may be obtained pure, and this is called more strictly A. It was discovered on removing the animal matter from the burial ground of the church des Innocens, at Paris, in 1787, amongst the masses of the bodies of the poor there interred together. In this place, about 1500 bodies were thrown together into the same pit, and, being decomposed, were cunverted into this substance. (See Nicholson's Journal, vol. 4, p. 135; Phil. Trans. 1794, vols. 84, 85; Journal de Physique, tom. 38, \&ic)

ADJUTaNT; in the nilitary art, an officer whose duty is to assist the major.

ADJUTANT-GENERAL; all officer of distinction who assists the general.-Among the Jesuits, this name was given to a select number of fathers, who resilfed with the general of the order, and had each a pro. vince or country assigned to him, and their office was to inform the father-general of public occurrences in such countries. 
Adnumstratur (Latin); the person to whom the goods of a man dying intestate are committed by the proper authority, for which he is accountable when thereunto required. For matters relating to this title, see Executor.

ApMrral. ; the commander-in-chief of a squadron or fleet of ships of war, or of the entire naval force of a country. Probably this word is of Arabic origin, and signifies originally the emir, or prince, of the waters. In the time of the crusades, the office and name.were introduced into Europe. The first authentic instance that occurs of admirals in Europe is about 1284, when Philip, king of France, created Enguerrand de Coucy admiral of his fleet. In the reign of Edward I. king of England, we find a title of honour, "Admiral de la mer du roy d" Angleterre," conferred for the first time on W. de Leybourne; and about this time the jurisdiction of the English seas was committed to three or four admirals, who held the office durante bene placito. From the time of Edward II. a regular succession of admirals is to be traced; and in the 34th year of Edward III. John de Beauchamp, lord warden of the Cinque Ports, was created high admiral of England. The office underwent several changes, and persons of high rank, some of whom were entirely unacquainted with naval affairs, continued to fill this office until 1632 , when it was first put into commission, as it remained during the protectorate of Cromwell. James, duke of York, afterwards James II., exercised the functions of lord high admiral for several years of Charles II.'s reign. Many of his regulations are observed to the present time, and evince his zeal for this most important service in England. During the reign of William and Mary, the powers of the lord high admiral were committed to lords commissioners of the admiralty. Prince George of Denmark enjoyed this dignity during a short period of the reign of Anne; since which time it has always been vested in seven lords commissioners, acting under the statute of William and Mary, till the year 1827, when the first step of Mr Canning, as premier, was to prevail on the duke of Clarence to accept the office of lord high admiral ; but the duke, soon after the formation of the duke of Wellington's administration, gave up the office. The income of the first lord-commissioner is at present equal to $£ 5000$ per annum. The surplus revenue forms what are called the droits of admiralty, and is applied at the pleasure of government. To the lord high admiral, or lords commissioners of the admiralty of England, belongs the power of decision in all maritime cases, both civil and criminal ; a jurisdiction upon or beyond the sea in all parts of the world; upon the sea coasts in all ports, havens, or harbours, and upon all rivers below the bridge nearest to the spa:-according to the terms of the patent, "To preserve all public streams, ports, rivers, fresh waters, and creeks whatsoever, within his jurisdiction, as well for the preservation of the ships as of the fishes; to reform too straight nets and unlawful engines, and punish offenders; to arrest ships, mariners, pilots, masters, gunners, bombardiers, and any other persons whatsoever, able and fit for the service of ships, as often as occasion shall require, and wheresoever they shall be met with; to appoint vice-admirals, judges, and other officers durante bene placito; to remove, suspend, or expel them, and put others in their places ; to take cognizance of civil and maritime laws, and of death, murder, and maim." The lord warden of the Cinque Ports has, nevertheless, a jurisdiction exempt from the control of the admiralty within these ports, and the lord admiral "seems to have his more proper jurisdiction confined to the main sea. Between high and low water marks, the common law and the admiralty have jurisciction by turn. By the regulations of the navy, the lord high admiral grants conmissions to inferior admirals to enforce obedience in all the branches of the service; to all courts-martial for the trial of offences against the articles of war, upon which they decide by the majority of votes, a deputy judge advocate, who resides at Plymouth, presiding over those of most importance. To the office of lord high admiral are given, as perquisites, by the patent, "treasure, deodands, and relics found within his jurisdiction; all goods picked up at sea ; all fines, forteitures, ransoms, \&c.; all whales and large fishes; all ships and goods of the enemy coming into any port, \&c., by stress of weather, mistake, or ignorance of war; all ships seized at sea, salvage, \&c., together with his share of prizes. In ancient times, this officer carried a gold whistle set with precious stones. In France, the admiral ('amiral) enjoyed, until 1627. very great prerogatives; but Richelieu, deeming the influence of the office too great, abolished it. Louis XIV. re-established it in 1669 with less power. In the revolution, this office, of course, vanished with the abolition of the monarchy. Napoleon renewed the office, and invested his brother-in-law Murnt with it. The duke of Angouleme was the first admiral after the restoration of the Bourbons. The highest officers in the French navy have only the title vice-admiral; after these follow the rear-admirals (contre-amiraux).-ADMMRAL of THE FLEET; the highest naval officer under the admiralty of Great Britain, who, when he embarks, is distinguished by the hoisting of the union flag at the main-top-gallantmast head.-The powers of the lord high admiral of Scotland have been vested, since the union, in the admiralty of Great Britain, which appoints a judge, or vice-admiral, who executes its duties, and presides over an admiralty court in Scotland.-Admirals, being commanders in chief of any fleet or squadrou, carry their flags at the main-top-gallant-mast head, from which they are designated as admirals of the red, of the white, of the blue. They rank with field-marshals in the army. The vice-admiral carries his flag at the fore-top-mast head, and takes rank with the lieutenant-generals of the army. The rear-adiniral carries his flag at the mizzen-top.mast head, and ranks with major-generals. - The United States have no admirals. The board of the navy directs all the affairs of the navy. The vice-admiral is a civil offcer, appointed by the lords commissioners of the admiralty, having judges and marshals under him. From his decisions, however, there is a final appeal to the court of admiralty. The place of vice-admiral of England is now a sinecure. Ireland has four vice-admirals; Scotland one; and the governors of colonies generally hold a commission to preside over vice-admiralty courts. $A$. is alsn a name given to the most considerable ship of a fleet of merchantmen, or of the vessels employed in the cod-fishery of Newfoundland. The ship which first arrives is entitled to this appellation, and some privileges; it carries during the fishing season a flag on the main-mast. A. in natural history, a very beautiful shell of the voluta genus. It is sold at a very high price.

Admiraty Courts have cognizance of civil and criminal causes of a maritime nature, including captures in war made on the high seas, and likewise of fence committed, and many contracts made thereon. In civil suits, the judges decide unaided. In criminal cases, the judge in England is associated with three or four commissioners ; in the United States, he is assisted by a jury. In the latter country, the admiralty jurisdiction is vested in the circuit and district courts of the Union. In England, it is divided between the instance and the prize courts, the former being the ordinary admiralty court, the latter being constituted by a special commission, in time of war,

$$
E-F 2
$$


to take cognizance of prizes, though the individuals composing the court are the same in both cases.

ADNIRALTY IsLANDS; a cluster of islands to the north of New Britain, in the South Pacific ocean, in about $2^{\circ} 18^{\prime} \mathrm{S}$. lat. and $146^{\circ} 44^{\prime} \mathrm{F}$. lon. There are between 20 and 30 . The Dutch discovered them in 1616. The islanders are black, but not of a deep shade; tall and almost in a state of nudity. They evinced much kindness towards Ia Perouse. A. I. is likewise an island in George III's Archipelngo, on the north-west cast of New Norfolk, in America, between $\mathrm{N}$. lat. $57^{\circ}$ and $58^{\circ} 30^{\prime}$, and between $\mathrm{W}$. lon. $131^{\circ}$ and $135^{\circ}$. Sce Vancouver's Voyage, vol iii.

A polpios of Nassau was elected emperor of Germauy, May 1, 1292, and crowned at Aix la Chapelle, Jume 25. He was of an illustrious family, and of approved conrage; but without any patrimony, except his sword, and destitute of those great qualities which had mised his predecessor, Rodolph of Hapslurg, to the throne. A. owed his election, in part, to the arrogant conduct of Albert of Austria ; in part, to his intrigues with the electors of Cologne and Menta, who imposed on him the liardest conditions, and forced him to resign to them cities and territories, which were not his own. But, refusing to fultall, when emperor, what he had promised when count, he soon saw himself hated and deserted by his friends. Urged by want of money, he received 100,000 pounds sterling from Edward I. of England, and, in return, engaged to assist him against Philip the Fair of France; but he was by no means sorry to see the pope forbid his participation in the war. In this way he made himself contemptible in the eyes of the German princes, and became still more odious to them by taking adrantage of the hatred of Albert, landgrave of Thuringia, against his sons, and purchasing this territory from him. This purchase involved him in a five years' war, in which he attempt$\mathrm{ed}$, unsuccessfully, to subjugate the country which he had bought. Disgusted at such disgraceful conduct, and urged on by Albert of Austria, the college of electors, excepting those of Treves, Cologne, and the Palatinate, cited Adolphus to appear before it. Failing to appear, the throne was declared vacant, June 23,1298 , and Albert of Austria elected. A war already existed between the two rivals, in which Adolphus seened superior, until, deceived by the manourres of his foe, he found himself surrounded at Gellheim, and fell, after a heroic resistance, by Albert's own hand, July 2, 1298. His body was deposited by Henry VII. in the imperial vault at Spire, at the same time with that of Albert. His faults sprung mostly from the inadequateness of his abilities to his situation. One mistake followed another, and when, in the latter part of his career, he wished to adopt a better course, it was too late.

ADos, a small state or principality on the gold coast of Africa.

Adoval, one of the many Hebrew names for God. The word properly signifies my lords, in the plural number, which is called, in the Hebrew grammar, pluralis majestatis. The Jews, who, from religious reverence, do not pronounce the name Jehovah, read Adonai in all the places in which the former name occurs. This practice commenced among the latter Jews after the Babylonish captivity, at least before the time of Josephus. See Geddes's Crit. Remarks vol. i. p. 167, and Leigh's Crit. Sacr. in verb. Kevess.

Adovic. The Adonic verse consists of a dactyl and a spoudee or trochee, e. g.

$$
\text { rără jŭvēntŭs; }
$$

and, on account of its animated movement, is adapted to gay and lirely poetry. Long poems, however, would become monotonous if written entirely in a ineasure so sliort, and recurring with no variety. It is therefore rarely used by itself. Even the ancients always combined it withl other kinds of verse; thus the last verse of the Sapplic strophe is Adonic.

ADovis; son of Cinyras by his daughter Myrrlin. The wood-nymphs educated him, and he grew up so remarkably beautiful, that he beeane the fivourite of Venus, who accompanied hin to the clase', pointing out the dingers to which he was exposerl. A., disregarding her advice, engerly pursued the wild bensts of the forest, but lappening to fuil in an attack upon a wild boar, he was mortally wounderl by this ferocious animal. The goddess, liearing of his misfortune, hurried to his assistance, and in her haste her foot was wounded by a rose-bush, the flowers of which, formerly white, from that time took the colour of blood. When she reached the spot, she found him lifeless on the grass, and, to alleviate her grief and preserve his memory, she transformed him into the anemone. At her request, however, Jupiter permitted A. to spend six months with her, and the other six with Proserpine. A full explanation of this fable may be found in Creuzer's Symbolik und Mythologie der Voelker des Alterthums.

ADOPTIAN ; a religious sect which asserted tlat Christ, as to his divine nature, was properly the Son of God; but as to his human nature, only sucl by adoption, by baptism and regeneration, through which God's mercy adopts other men also as his children; for they could not comprehend how a liuman being could be called the Son of God in a literal sense. E!pandus, archbishop of Toledo, and Felix, bishop of Urgel, in Spain, avowed this doctrine in 783 , and made proselytes both in Spain and France. Clarlemagne condemned their heresy at the council of Ratisbon, and dismissed Felix from his office. This sentence was repeated three times; at Frankfort, 794 , at Rome and at Aix la Chapelle in 799, because the bishop relapsed twice into his former error. He was then placed for the remainder of his life, under the care of the bishop of Lyons. After the death of Elipandus, the whole controversy ceased. The dispute is worthy of notice, both on account of the moderation of Charlemagne, and because the opinion of the Adoptiani has often been made use of, by those who have exerted themselves, to adapt the doctrine of the divinity of Christ to the comprehension of man.

ADoption, the admission of a stranger by birth to the privileges of a child, has come down to us in the Roman law. Its purpose was the acquisition of paternal power, which could either be ceded to the person adopting by the natural parent (adoption in the strictest sense), or be obtained by the assent of a person no longer under the patria potestas, or of lis guardians. This second sort is called arrogation. According to the ancient civil law, the adopted child left the family of its parents or guardians, and became a member of the family of the person adopting it. The emperor Justinian abolished this principle in regard to adoption properly so called. Adoption was intended to supply the want of offspring in those persons who might have been parents. Eunuchs, therefore, and persons already having legitimate issuc, were excluded from this privilege. The person adopting must have been at least 18 years older than the per:son to be adopted. Guardians were not permitted to adopt their wards, nor a poor man a rich clild. Females, strictly speaking, were not permitted to adopt, but might, with the permission of the sovereign, secure to any child the right of support and inheritance. In Germany, the rules respecting adoption are derived from the civil law, but require the sanction either of the sovereign or of the judiciary. (Civil Coule 
of Austra, 1.179 ; Prussian Code, part 2, tit. 2, \$666.) The adopted child receives the name of its adopter, but does not share in his rank if he be a noblemanl, except by the special permission of the sovereign. In Prussia, a married couple must have lived many years without children, before they are allowed to adopt a child. The modern French law (Code civile, a. 343) also admits adoption, but only on certain conditions. The code establishes three kinds of adoption-l'adoption ordinaire, la rémunératoire, et la testamentoire. Those who wish to adopt must have supported the person to be adopted for six years, or the adopter's life must have been sared by the person to be adopted. Excepting in this last case, the latter must be as much as fifteen years younger than the former. Adoption (excepting as before) cannot take place until the person to be adopted is of age, and must be ratified by the district court as well as by the court of appeal. There is nothing corresponding with adoption in the law either of England or America. In Asia, adoption is a very common practice. The ceremony is frequently performed merely by the adopting person exchanging girdles with the person adopted. The Turks declare adoption often before the cadi, and a writing regularly witnessed is drawn up. The law of Mahomet prescribes still another very curious ceremony of adoption. The person adopted is required to pass through the shirt of the adopter; and hence the phrase to draw another through one's shirt is, among them, expressive of adoption. An adopted son is called akietogli, that is, the son of another life. Several writers have applied this ceremony as explanatory of many passages both of the Old and New Testaments.

Adoration; originally, the expression of the highest respect either to God or man; now used, more particularly, for the act of religious homage. The word literally signifies applying the hand to the mouth; manum ad os admovere, i. e. to kiss the liand. The word kissing is the usual idiom of the Hebrew language to signify adoration. Herodotus considers the custom of kissing the hand in adoration to have been adopted by the Greeks from the Persians. It certainly prevailed at an early period all over the East. The Roman ceremony of adoration has been thus described: the devotee, having his head covered, applied his right hand to his lips, the fore finger resting on his thumb, which was erect, and, thus bowing his head, turned himself round from left to right. The kiss given was called osculum labrutum. Sometimes, hovever, they kissed the feet or even the knees of their gods. The Grecians generally worshipped uncovered. During their prayers, their hands were raised above their heads with the palms turned towards heaven or the statues of their god, a custom still often seen, in catholic countries, accompanying fervent prayer; but generally the Christians clasp their hands during prayer, which is still the custom in Europe, both among catholics and protestants. The first Christians often turned the face towards the east when they prayed. The Mahommedans turn the face towards Mecctr. Prostration, accompanied sometimes by kissing the ground, is an ancient mode of adoring the gods, and expressing the highest respect for men. In Russia and Poland, it is still the custom for people of the lower classes to kneel down and kiss the garment of the person to whom they wish to show respect. Dioclesian offered his foot to be kissed by the courtiers, and even under Charlemagne and his son, the noblemen kissed the emperor's foot. Probably, therefore, the popes took this custom from the emperors, to whose power they laid claim in succeeding to their title of sovereign pontiff. They have an embroidered cross on the slipper of their right foot, which is kissed by the catholics. When the late king of Spain was in Rome, he prostrated himself beture the pontiff, and kissed the cross on his foot. There is no doubt that the Roman emperors borrowed this custom from the East. In the prinitive christian church, this honour is said to have been shown to every bishop, as it often is still in the Greek church. In kissing the bishop's foot, the words reorxurw os were, and still are used. The Jews, being an Asiatic tribe, often prostrated themselves in the act of worship. Taking off the shoes or slippers during adoration is an old custom in Asia. It is also practised on common occasions as an act of politeness. The Oriental takes off his shoes before he enters the temple, the mosque, or the apartment of a man of respectability. This custom was also adopted by the Roman catholic church in some cases. At the adoration of the cross on Good Friday, the Roman catholics walk barefooted; and the ceremony of humiliation, when the pope and all the cardinals approach the cross barefooted, in the Capella Sistina, makes a deep impression on the superstitious. Kneeliug was in all ages a common posture of adoration, and originates from the feeling of humility in addressing a higher and mightier being. Sitting with the thighs resting on the heels, was an ancient Egyptian attitude in the act of worship. There are many statues represented in this position. Standing with the body inclined forward, the eyes fixed on the ground, the hands probably resting on the knees, was an early eastern attitude of adoration. Dancing, screaming, rolling on the ground, and many similar acts acconlpany the worship of different savage tribes. Mr Ward, one of the Baptist missionaries at Serampore, in a work on the history and literature of the Hindoos, has given a very curious and minute account of the modes of adoration, which they call pooja. The objects of adoration have been greatly diversified. In all ages, worship has been paid to idols, but many of the worshippers have regarded the iniage merely as the representative of the Divinity. Protestants mistake when they impute to catholics, universally, the worship of images, as being in themselves objects of adoration, for they are regarded by that church, as they are by the wisest of the heathen, merely as visible signs of the invisible Deity. The ancients placed crowns of garlands on the statues of the gods ; and the catholics still offer flowers to their saints and the virgin. It was common to sleep in the ancient temples, with a view of receiving responses from the gods in dreams. The sick, in particular, slept for this purpose in the temple of Asculapius. In the Roman catholic church, a species of adoration is offered to departed saints and martyrs, and their intercession is solicited. The Phœnicians (the first navigators) adored the winds, a practice adopted by many other nations. The Persians adored the sun and fire. The Greeks and Romans adored fire under the name of Vesta. Pliny mentions the adoration of lightning by gently clapping the hands. The Egyptians adored animals, plants, and fishes ; the $A$ rabs, stones ; the Scythians, swords; the Chinese, the statues of their ancestors. The Hindoos have not only an amazing variety of gods, but they worship hiuman beings, beasts, birds, trees, rivers, fish, books, and stones. See Ward's View of the History, Literature, and Religion of the Hindoos, and Bishop Heber's Narrative of a Journey throngh the Upper Provinces of Incia, from Calcutta to Bumbay, 1824-1825, with Notes upon Ceylon, and an Account of a Journey to Madras and the Southern Provinces, 1826. It must be remembered, that all adoration originates from two different sources, either fiom love ond thankfulness, or from fear.

ADRAGANTH, in mediciue", gum elrugone. It "listily 
by incision from the trunk or roots of a plant which grows is the Levant. The gaun is of different colours, white, reut, grey, and black, and is useful in medicine. Skinners use great quantities, and prefer the red to the black. It is the astragalus tragacanthus of Linnzeus.

Aprastra; a daughter of Jupiter and Necessity, the servant of eterial Justice, the punisher of all injustice, whom no mortal escapes. A. is generally a mere epithet, given to Nemesis, (q. v.) She is represented sometimes with wings, sometimes with a rudker, and sometimes with a wheel.

Adrastos, king of Argos; son of Talaus and Eurynome. In obedience to the oracle which commanded him to give one of his daughters to a lion and the other to a wild boar, he gave Argia to Po'ynices, who came to him in a lion's skin, and Deiphyle to Tydeus, who was dressed in the skin of a wild boar. He was one of the seven heroes who encamped before Thebes, and the only one who survived the siege. Ten years after this, he made a second expedition against Thebes, accompanied by the sons of his former allies, and took the city, but lost his son in the engagement, and died himself of grief.

ADRIAN, the African, abbot of St Peter's, Canterbury, in the seventh century, accompanied Theodore, archbishop of Canterbury, to England. A. was the preceptor of Adhelm, and Bede extols the happy time when the island enjoyed his tuition, and Kent "was the fountain of knowledge to the rest of England."

Adran, or Hadrian, Publius Alius, a Roman emperor, the successor of Trajan, was born at Rome, A. D. 76. His father, Trajan's cousin, died when A. was ten years of age. A. showed very early great talents, and is said to have spoken the Greek language so perfectly in his 15 th year, that he was called the young Greek. His memory is said to have been so extraordinary, that he could commit a book to memory by once, perusing it, and that he could call all his soldiers by name. 'These stories may be exaggerated, but they prove the estimation in which his talents were held. He was an orator, poet, grammarian, mathematician, physician, painter, unusician, and astrologer. The greater developement of the sciences in modern times does not admit of distinction in so many branches. His great qualities, however, were stained by great faults, so that he never won the affections of Trajan, who was his guardian. He was indebted for his elevation to the throne to the wife of Trajan, Plotina, who concealed the deatl of her husband until she had time to forge a testamont bearing the name of the late emperor, in which he was made to adopt A. and declare him his successor. Her bribes also had in the meantime prepared the troops to espouse the cause of $\mathrm{A}$. After these preparations had been made, A. sent information of the emperor's death from Antioch to Rome, pretended that the imperial dignity had been forced upon him, promised the senate that he would discharge faithfully the duties of his station, and assured the pretorian guards that they should receive twice the usual present. A. D. 117, he ascended the imperial throne, appeared in Rome, and strove at first to win the favour of the people by the mildness of his administration. It was not long, however, before he manifested a cowardly and suspicious character, together with too great a devotion to pleasure. Among other things, he purchased peace from the Sarmatians and Roxolani, who had attacked Illyria, by the payment of a tribute. From A. D. 120 to 131, he made his famous journey on foot, and with his head uncovered, through all the provinces of his enjuire. Among other places, he visited Britain, and caused a wall to be built from the mouth of the Tyne to Solway Frith, to secure the Roman provinces from the incursions of the Caledonians. In Egypt, he lost his favourite Antinous (q. v.), whose death he lamented long aud bitterly. During his stay of two years in Atless, he established a colony of Roman soldiers on the site of the ruined Jerusalem; and on the spot where the temple of Solomon had stood, he erected a temple to Jupiter Capitolinus. Upon this, a dreadful insurrection broke out among thic Jews, which lasted two years and a half. He embellished Athens with buildings, and finished the temple of the Olympian Jupiter, begun 560 years before. A. died at Baize, $138 \Lambda$. D. in the $63 d$ year of his age, and the 21 st of his reign. He had good qualities and great faults. He promoted literature and the arts, did many good things on his jouruey, established the edictum perpetuum, enacted laws against dissipation and the cruelties of the slave trade, prohibited liuman sacrifices, forbade the indiscriminate bathing of men and women, \&c. Antoninus Pius succeeded him. It was with much difficulty that his successor could obtain a decree from the senate, granting him, according to usage, divine honours. A. wrote several books; among others a history of his own life, under the name of Phlegon, one of his freedmen, which is no longer extant. He composed, not long before he breathed his last, the following lines:

Animula, vagula, blandula,

Hospes, comesque corporis,

Qure nunc abibis in loca,

Pallidula, rigida, nudula?

Nec, ut soles, dabis jocos.

Pope has imitated them.

Adrian. There have been six popes of this name. The first, a Roman, ruled from 772 to 795 , was a contemporary and friend of Charlemagne, who, ou account of A.'s able defence of his claims to the crown of France, protected him with his army, 774. against Desiderius, king of the Lombards, confirmed the donation of Pepin to the territory of the clurch, and made further grants himself. The pope was not allowed, however, to enjoy in peace tlie gifts of Charlemagne till 787 , after the termination of the frequent campaigns of this king against the Italian princes, who claimed the territory. By confirming the decrees of the council of Nice, 786, in favour of the worship of images, A. gave offence to Charlemagne, who was opposed to the practice, and piocured a repeal of the decree at the council of Frankfort. The repeal was resisted by $\mathrm{A}$.; but he so carefully and skilfully avoided offending the king, that he remained his friend, and honoured him after his death, 795, with an inscription, yet preserved in the Vatican. Though by no means a profound theologian, A. obtained great influence by the correctness of his conduct, and his decision of character. By a prudent use of this influence, he greatly increased his power.-ADRIAN II., a Roman, was elected pope in 867 , at the age of 75 years. He was esteemed for his virtues, and famous on account of his bold opposition to the divorce of Lothaire, king of Lotharingia, from his wife Thietberga. By interfering in the dispute, which arose after the death of Lothaire, between Charles the Bald and the emperor Louis, respecting the right of succession, he made the former his enemy. He had another dispute in France, where bishop Hincmar of Laon had been dismissed against his will; he likewise excommunicated the patriarch Photius of Constantinople, on account of his spiritual jurisdiction over Bulgaria, which diminished the authority of the pope, since the Greek church maintained its independence against him, and made Bulgaria dependent on itself. He died in 872 , in the midst of his conflicts with this church.-ADRIAN JII, 
a Roman, elected 884, was pope for one year and four months only. He was opposed to the influence of the emperors on the election of the pope, and determined, if Charles the Fat should die without heir, to give Italy a new king.-ADRus IV, an Englishman, originally named Nicolas Breakspear, rose, by his great talents, from the situation of a poor monk to the rank of cardinal, and legate in the north, where he established at Drontheim the first Norwegian anchbishopric, and a second at Upsal. He waš elected pope in 1154, and waged an unsuccessful war against William, king of Sicily, who, at the peace of 1156 , claimed the privilege, still existing in the monarchice Sicilia, so called, that, in matters relating to the clurch, nothing should be donc by the pope without the consent of the king. The emperor Frederic I., who before had held his stirrup, and had been crowned by him at Rome, June 18 , 1155, was opposed to this peace with William his enemy. A. increased his resentment by the haughty language of his letters, and instigated the Lombards against him. Frederic, on the other hand, acted in ecclesiastical matters as if there liad been no pope. Before these difficulties came to a close, A. died, Sept. 1, 1159, at Anagni. He was the only Englislıman that ever sat in the papal chair. The permission which he gave to Henry II., king of England, to invade Ireland, on the condition that every family of that island should pay annually a penny to the papal chair, because all islands belong to the pope, is worthy of remark. On this grant the subsequent popes founded their claims on Ireland. - ADRIAN V., previously called Ottoboni da Fiesco, of Genoa, settled as legate of the pope, the dispute between king Henry 111. of England and lis uobles, in favour of the former; but died soon after his election to the papal chair, 1276. ADRIAN VI., son of a mechanic of Utrecht, and professor in Louvain, was, in 1507, appointed tutor of the emperor Charles V. When ambassador of the emperor Maximilian, in 1515, he persuaded Ferdinand the Catholic to nominate young Charles his successor to the Spanish throne; after which he became, in 1516, bishop of Tortosa and regent of Spain, and, in 1517, cardinal. The Spaniards were not pleased with his severe and often partial government, and expressed great joy when, at the suggestion of Charles V., he was elected to the papal chair, in 1522. He was not less hated at Rome, on account of his antipathy to classical literature, and his honest endea vours to reform the papal court, to abolish the prevailing luxury, bribery, and other abuses ; but his efforts were frustrated by the cardinals, and, if they had been successful, could not have prevented the progress of the reformation already begun in Gemuany. A. opposed the zeal of Luther with rejroaches and threats, and even attempted to cxcite Erasmus and Zuinglius against him; but his abilitics were not equal to the existing emergency. His measures against France also were unsucccssful. Notwithstanding his honest efforts and upright character, he died unlamented, in 1525 , after a reign of one year and a lialf. His reign was, according to lis own confession, the most unhappy period of his life. On lis tomb, in the cluurch of St Peter, is the following epitaph:

$$
\begin{gathered}
\text { Adrianns Papa VI, hic situs est, } \\
\text { Qui nilhil sibi infelicius } \\
\text { Ia vita, } \\
\text { Quam quod imperaret, }
\end{gathered}
$$

Idrian (de Castello), a learned Italian, who, from a low origin, raised himself to the purple, was bori at Cometta in Tuscany. He was often employed by the pope, in missions to Eugland and
Scotland; and during lis stay in the former country, he acquired the friendship of Henry VII., who conferred on him the see of Hereford, and afterwards that of Bath and Wells. He, however, had other and more ambitious views than an English bishopric, for he dwelt chiefly at Rome, where he was discovered in a plot to dethrone Leo X. and elevate himself to the vacant chair. His property was confiscated, and he fled, it is said to Riva, in the bishopric of Trent, where he died. He was not only himself a learned man, but literature lost in lim a liberal and discriminating patron.

Adriani, John Baptist, secretary to the republic of Florence, in 1511 ; died 1579. He is known chiefly by a History of his own Time, which was published at Florence, in 1583, fol. and Venice, 1587. 3 vols. 4 to.

Adrianopte, (in Turkish, Edrene), the second capital and residence of the Ottoman rulers, is situated in ancient Thrace (now Rumelia), on the banks of the navigable river Hebrus (now Maritza): On this spot a small town formerly stood, inhabited by the Bessi, a Thracian tribe. The emperor Adrian founded this city on the left bank of the Hebrus, called it after his own name, and made it the capital of the province of $\mathrm{mt}$. Hæmus. From the range of hills on which it is situated, it commands a beautiful prospect over a large and fertile plain, divided by two ranges of hills, between which the river runs. It was fortified, and resisted, in the 4th century, the violent attack of the victorious Goths, who were, however, ignorant of the mode of conducting a regular siege. To give it the appearance of a Greek origin, the writers of Byzantium called it Orestea or Orestias. According to their accounts, it is five days' journey distant from Constantinople. In 1360, it was taken by Amurath, the Turkish sultan; and from that time it continued to be the residence of the Turkish emperors for nearly a century, until the conquest of Constantinople. The number of the houses is 16,000 , and that of the inhabitants 100,000 among whom there are 30,000 Greeks, under an archbishop. It contains also an imperial palace, 40 mosques, of which that of Selim II. and of Amurath II. are the most magnificent, 22 bathing establishments, with beautiful aqueducts, important manufactures, and exports, among other articles, oil of roses, which is made in its vicinity, of the best kind.

AdRIAN's WALL; a celebrated Roman work in the north of Englaud. This work, though called by the Roman historians murus, which signifies a wall of stone, was only composed of earth covered with green turf. It was carried from the Solway frith, in as direct a line as possible, to the river Tyne, on the east, at the place where the town of Newcastle now stands; so that it must have been above 60 English and nearly 70 Roman miles in length. It consisted of four parts : 1, the principal agger, mound of earth or rampart, on the brink of the ditch; 2 , the ditch on the north side of the rampart; 2 , another rampart, on the south side of the principal onc, about five paces distant from it ; 4, a large rampart on the north side of the ditcl. For many ages, this work has been in so ruinous a condition, that it is impossible to discover its original dimensions with certainty. But from their appearance, it seems probable that the principal rampart was at least ten or twelve feet high, and the south one not mucli less; the northern one was considerably lower. The ditch taken as it passes through a lime-stone quarry near Harlow hill, appears to have becn nine feet dcep and eleven feet wide at the top. The north rampart was about twenty feet distant from the ditch. A Dratic SEA (mare Adriaticum, Adrianum),
now morc commonly called gulf of Venice, though 
in Italian, German, and French, the old name continues, is an arm of the Mediterranean, includel by the coasts of Italy, Illyria, Dalnutia, Albania, and Lipirus, about 200 lengues long and 50 broad, exteuding from sonth-east to north-west. lat. $40^{\circ}$ to $50^{\circ} 55^{\prime}$ north. It contains about 90,000 sq. miles of surfice. Different derivations of the name are given. On the Anstrian const it has a number of suall islands, and forms many bays, the most remarkable of which are these of 'Trieste, Quarnaro, and Cattaro. It is called the gulf of Venice from the city of this name, which formerly claimed exclusive dominion over this sen, and in those times annually wedded it on Asceusion Day. The cereinony was performed by the duge of Venice throwing a ring into the sea with great pomp. The entrance of the gulf is commanded by Corfu, one of the Ionian islands uncler the Britisl government. The coast of the A. sea is, in nuny places, very daigerous. The most important ports on the gulf are Venice (since 1829 a free port), 'Trieste, Ancoula. Otranto, \&c.

Adore; Adulun Marble Adule, a city in Ethiopia, mentioned by aucient authors as the most inportant conmercial place of the Troglodytes and Ethiopians, in later times the emporiun of Axum, seems to be the same with the modern $A$ rkiko. This city, now the residence of the Naib of Massual, is frequently mentioned on account of an inscription, first copiet in the Topographia Christiana, a work parily theological, partly geogrnphical, written by Cosmas Indicopleustes, in the 6th century, under the reign of the emperor Justin. The inscription, engrared on marble, is contained in part on a throne, the remainder on a stone separated from it, and there are many inconsisteucies in the several fragments, which have induced some scholars to declare the inscription spurious. 13esides the genealogy of Ptolemy Euergetes, it contains on a second part, which Salt supposes to be of Axumitic, that is of Ethiopic or $\Delta$ brssinian origin, the catalogue of nations whom some king boasts to have subdued. Buttmann (in Wolf's Museum der Alterthumscunde, vol. 2, p. 105) has removed the difficulties arising from the date on the marble, which is the 27th year of the reign of a king, whose name is unknown, probably not Ptolemy Euergetes. Several things, however, remain to be explained, and require a nore accurate knowledge than we lave at present of the country where the inseription was found.

ADULTERY. Mankind, in almost all ages, and in all cirilized countries, have regarded the violation of the marriage-bed with abhorrence. It has been punished in various ways and witlı different degrees of severity, according to the general manuers and morals of the country; sometimes with extreme and even cruel rigour; in other instances, with capricious and ridiculous penalties. By the Jewish law, it was punished with death. 'Strabo says the same was the case in Arabia Felix. Among the ancient Egyptians it was not common, but when it did occur, a thousand lashes were inflicted on the man, and the roman was deprived of her nose. In Greece, the laws against it were severe. The rich were sometimes allowed to redeem themselves by paying a fine; in which case, the woman's father returned the dower which he had received from the husband. Some suppose it was refunded by the adulterer. A frequent punishment there, was putting out the eyes. According to Homer, adulterers were stoned to death. By the laws of Draco and Solon, adulterers, when caught in the act, were at the mercy of the injured party. Adulteresses were prohibited, in Greece, from appearing in fine garments, and entering the temples. Some suppose that this offence was madc capital by a law of Romulus, and again by the twelve tables; others, that it was first nute capital by Augustus; and others, not till the reign of Constantine. The fact is, that the punishment was left to the discretion of the husband and parents of the adulteress. The most usual mode of taking reveuge was by mutilating, castrating, or cutting off the ears or nose. The punislument assigned by the lex . Julia de adulteris, instituted by Augustns, was bauishnent or a heavy fine. It was decreed by $\mathrm{An}$ toninus, that, to sustain a charge of adultery against a wife, the lnusband who brought it must be innocent hiunself. Under Macrinus, adulterers were burued at a stake. Under Constantius and Constans, they were buried or sewed in sacks and thrown into the sea." But the punishnent was mitigated under Leo and Marcian to perpetual banishment, or cutting of the nose ; and under Justinian the wife was only to be scourged, lose her dower, and be shut up in a monastery; at the expirution of two years, the husband might take her again; if he refused, she was shaven, and made a nun for life. Theodosins instituted the shocking practice of public violation, which, however, he soon abolished. In Crete, adulterers were covered with wool, as an emblem of their effeminacy, and carried in that dress to the magistrate's louse, where a fine was inposed on them, and they were deprived of all their privileges and their share in public business. The punishment in use among the Mingrelians is the forfeiture of a hog, which is usually eaten very amicably by the woman, the gallant, and the cuckold. In some parts of India, it is said, that any woman may prostitute leerself for an elephant, and it is reputed no sinall glory to have been rated so high. Adultery is stated to be extremely frequent at Ceylon, although punishable with death. Among the Japanese and some other nations, adultery is punishable only in the wonnan. Among the Abyssinians, the crime of the husband is punislied on the innocent wife. On the contrary, in the Marian islands, the woman is not punislinble, but the man is, and the wife and her relations waste his lands, burn him out of the house, \&c. Among the Chiuese, adultery is not capital ; fond parents will even make a contract with the future husbands of their daughters, to allow them the indulgence of a gallant. In Portugal, an adulteress is condemued to the flames, but the punishment is seldom executed. By the ancient laws of France, this crime was punishable with death. In Spain, the crime was punished by the deprivation of the instrument. In Poland, previously to the establishment of Christianity, the criminal was carried to the market-place, and there fastened by the testicles with a nail; a razor was laid within his reach, and he had the option to execute justice on him self, or remain where he was and die. The Saxons consigned the adulteress to the flames, and over her aslses erected a gibbet, on which her paramour was hanged. King Edmund the Saxon ordered adultery to be punished in the same manner as homicide, and Canute the Dane ordered that the offender should be banished, and the woman have her ears and nose cut off. In the time of Henry I., it was punished with the loss of the eyes and the genitals. Adultery is, in England, considered a spiritual offence, cognizable by the spiritual courts, where it is punished by fine and penance. The common law allows the party aggrieved only an action and damages. The Mahommedan code pronounces adultery a capital offence. It is one of the three crimes which the prophet directs to be expiated by the blood of a Mussulman. In France, before the revalution, an adulteress was usually condemned to a convent, where the husband could visit her duruig two years, and take her back if he saw fit. If he 
did not choose to receive her again by the expiration of this time, her hair was shaven, she took the habit of the convent, and remained there for life. Where the parties were poor, the wife might be shut up in an hospital instead of a convent. The Code Napoléon does not allow the husband to proceed against his wife for adultery, if he has been condemned for the same offence. The wife call bring an action against the husband only if he has introduced his paramour into the house where she resides. An adulteress can be imprisoned fiom three months to two years. The husband can prevent the execution of the sentence, if he sees fit to take her back. Her partuer in guilt is liable to the same punishment. In the United States, the punishment of adultery has varied materially at different times. In the state of Massachusetts, an adulterer or adulteress may be set on the gallows for one hour, be publicly whipped, be imprisoned, or fined. All or any of these punishments may be inflicted, according to the degree of the offence. Corporal punishment and exposure, however, are in that state always commuted into imprisonment and labour. Moreover, adultery is very seldom punished criminally in the United States.

ADVENT (from the Latiu adventus, $\mathrm{i}$. e. adventus Redemptoris) signifies the coming of our Saviour. The name is applied to the holy season which occupies the four or six weeks preceding Christmas. The Roman catholics spend this season in fasting, humiliation, and prayer, as if preparing for the reception of the Saviour of the world. This holy season is first mentioned by Maximus Laurinensis, a divine, in one of his homilies, written in the middle of the 5 th century, but is supposed to have been instituted by St Peter. No nuptials could be celebrated in Advent, since the council held at Lerida, in the 6th century, in order that Christians might more frequently partake in the Lord's Supper.

ADVRaruRE, bill of; in commerce, a writing signed by a merchant, to testify that the goods shipped on board a certain vessel belong to another person, who is to take the hazard, the subseriber signing only to oblige himself to account to him for the produce.

Aoventure IsLand; a small island in the $\mathrm{S}$. Pacific ocean; lon. $144^{\circ} 18^{\circ} \mathrm{W}$.; lat. $17^{\circ} 5^{\prime} \mathrm{S}$. I'lere is also an Adventure Bay, on the S. E. coast of New Ilolland; lon. $147^{\circ} 29^{\prime}$ E.; lat. $43^{\circ} 21^{\prime} \mathrm{S}$.

ADVENTURER, the society of; an ancient company of merchants, erected for the discovery of unknown regious, opening new channels of trade, \&c. It originated in Burgundy, and was established by John, duke of Brabant, in 1248, for the encouragement of Finglish and other merchants at Antwerp. It was afterwards confirmed in England by Edward III. and IV., Richard III., Henry IV., V., VI., and VII.; and by patent of the last-mentioned monarch, in 1505 , they received the title merchant adventurers. The influence of the Fnglish merchant adventurers at Antwerp was, in 1550, so great, that they were able to resist successfully the establishment of the inquisition in that city.

Advocate of the Crown; State Advocate. The institution of crown advocates or public attorneys (ministère pullic), which is found in almost all modern systems of government, has been 110 where so well regulated as in France. The separation of the office of judge from every other has been there completed, which is not only indispensable on principles of general constitutional law, but also desirable, that the people may see, in the jurliciary, judges only, and not men who, by virtue of their office, are obliged to take care of the interests of the state and the government, and who, when these interests are in question, must be necessarily, at the same time, both party and judge. It is not sufficient that the judge be personally conscious of impartiality; he should be so situated, that no particular effort should be required to attain it.. Those who appcar before the judge should have no occasion to doubt it. It must be considered as a particular defect in criminal proceedings, if the judge is obliged, by his office, to occupy the place of accuser, as he must necessarily appear to be the adversary of the accused persons. To avoid these inconveniences, the oflice of public adrocate was established in France in early times, and constituted an essential part of the establishment for the administration of justice. In France, of late, however, the state advocates are charged with being influenced too much by political differences of opinion. Some of them, in particular, have diawi upon themselves thereby very severe animadversions. It is said that, in the trials of general Barton, of Caron and Roger, at Colmar, and others, on account of political offences, they sought to implicate persons against whom nothing could be proved but a justifiable opposition to the ministry, in accordance with the charter and the nature of a representative government. It is well known how severely Benjamin Constant expressed himself on this point, with regard to the procureur général of Saumur. Certainly the dependence of the crown advocates on the government has a tendency to give a certain bias to their official conduct. But this bias is not very pernicious, because it is a notorious and natural consequence of their oflicial situation, and the judge is required, as well as empowered to resist it.-England has also her superior state advocates, the attomey general and solicitor general; but, in conformity with the English judiciary system, their sphere of action is much more limited, and is not to be compared with that of the French ministère public. In criminal causes, the prosecution is conducted, indeed, in the name and by the adrocates of the crown; but a great deal depends on the injured party, and the police magistrates that is the justices of the peace. The former have it in their power, by avoiding to appear at the trial (although liable to punishment for so doing), to defeat the whole proceeding; and, in every session of th.e courts, a large number of accused persons are set free, because, after a public summons or proclamation in court, no person appears against them. In Scotland, the king's adrocate, or lord advocate, is an officer of great power and dignity, and is empowered to commence prosecutions without complaint presented by an injured party. In crimes of a capital nature, he has also the power of restricting the sentence to an arbitrary punishment; or a punishment at the discretion of the judge, which does not extend to death.-So, in other countries, there exist officers under the names of fiscal, advocatus fisci, advocatus patria, \&c.-In the United States, the attorney general is an officer under the federal constitution, corresponding substantially to the English law officer of that name. His duty, as defined by the law of congress, is, to prosecute and conduct all suits in the supreme court of the union, in which the United States shall be concerned, and to give his advice and opinion upon questions of law, when required by the president of the United States, or when requested ly the officers at the head of any of the departments, touching any matters that may concern their departments. He is also required to examinc all letters patent for uscful inventions, and to certify to the secretary of state whether they are conformable to the law on that subject, previous to the public seal being affixed to them. The attorney general of the United States is also a member of th: president's cabinet council. In addition to this law 
officer, the government of the United States las in each of the states (which, in judicial proceedings are styled districts) a district attorney, as he is called, whose duty it is, within his particular stute, to prosecute on behalf of the United States, all delinquents for crimes and offences cognizable under the anthority of the United States' laws, and all civil actions in which the United States shall be concerned, except those which come before the supreme court, in the district in which that court slall be holden. Besides these law officers of the general government of the United States, each of the states of the union lus its attorney-general and subordinate public prosecutors, or attorneys, for its territorial subdivisions or districts; and their duties are, to prosecute and defend in all causes, criminal and civil, arising under the local laws of their respective states, and in which their own state is concerned.

Adrocatrs. This profession has played a conspicuous part in almost every civilized country. Among the Romans, the greatest statesmen and orators belonged to this class, devoting themselves especially to the defence of criminal causes of importance. Those of less consequence and of a civil character were committed to procurators. The advocates of England and France are often men of high rank, enjoying an ample income and the prospect of attrining to the highest dignities of the state. Men of the best talents, therefore, are found in their ranks. In Germany and some of the other countries of Europe, the advocates occupy a comparatively subordinate station in the courts. The profession is there considered only as a preparatory step to public employments, and these frequently of an humble description. This is the cause of the inferiority of the German lawyers in general to those of Fingland and France; and the whole administration of justice there suffers from the same cause. There are exceptions, however, in some of the German states, particularly in Prussia. In the French revolution, the lawyers acted the most important part in public affairs. Advocati ecclesiamem, superintendents of the property of the church, divided, according to their several offices, into defcnsores, causidici, actores, pastores laici, \&.c., were first appointed under the consulship of Stilicho. The pope, at the same time, issued onders, that the bishops, abbots, and churches, should have good advocates. These offices were first intrusted to canons, but afterwards were held even by monarclis; $e . g$. the German emperor, the king of France, \&c. became advocati of the Roman church. The adrocates set over single churches administered justice in secular affairs in the name of the bishops and the abbots, and had jurisdiction over their whole dioceses. In case of necessity, they defended the property of the clergy by force of arms. In the courts of justice, they pleaded the causes of the churches with which they were connected. They superintended the collection of the tithes and the other revenues of the church, and enjoyed, on the part of the convents, many benefices and considerable revenues. After a time, these advocates and their assistants becoming a burden to the clergy and the people under their charge, who began to suffer severely from their avarice, the churches attempted to get rid of them. Urban 111. laboured to deliver the church from these oppressors, but was astonished to find, A. D. 1486, the German prelates, in connexion with the emperor Frederic I., opposed to it. Under the emperor Frederic II. most of the Germain churches succeeded, however, in abolishing these offices by the grant of large sums of money and of various immunities. - In the United States, the profession of the law possesses an extensive influence upon society. It embraces, as it does in England. various classes of lawyers, such as proctors, conveyancers, solicitors, attorneys, and lastly, and above all, counscllors, or advocates. In the United States, the different branches of the profession are ofien carried on by the same person, though this practice is not universal, especially in large cities. The higher ranks of lawyers in the United States enjoy great public and private confidence. Many of them are selected for the first public employments in the state, $c_{.} g$. for the presidency, for the office of senators and representatives in the national and state legislatures, for governors, for secretaries of the great departments, nind for foreign embassies. From this class of men are also taken, almost as a matter of course, the judges of the various courts in the union. The constitutions and laws of the several states entitle every person, in civil as well as criminal cases, to the assistance of counsel, and generally two are admitted on each side. AlI trials are public, and forensic eloquence is eagerly hearl. The profession of the law is very numerous in the United States, on accomit both of its emoluments, and its free access to public favour and patronage. There is no difficulty in gaining admission to the courts, as an advocate, after three or four years of preparatory studies ; and, after admission, success is generally in proportion to talents and industry, and devotion to juridical studies. Of the seven presidents of the United States, six were bred to the law. Adrocates' Library. In 1660, the faculty of advocates in Edinburgh founded a library upon an extensive plan, suggested by Sir George $M^{\prime}$ Kenzie, of Rosehaugh, advocate to Charles II. and James II., who enriched it with many valuable books. It has been daily increasing since that time. It contains, besides law books, works onall suljects, many original manuscripts, and a great variety of coins and medals. Adrowson (from advoco); in English law, a right of presentation to a vacant benefice, or, in other words, a right of nominating a person to officiate in a vacant church. The name is derived from advocatio, because the right was first obtained by such as were founders, benefactors, or strenuous defenders (advocates) of the church. Those who have this right are styled patrons. Advowsons are of three kindspresentative, collative, and donative: presentative, when the patron presents his clerk to the bishop of the diocese to be instituted ; collative, when the bishop is the patron, and institutes or collates his clerk by a single act; donative, when a church is founded by the king, and assigned to the patron without being subject to the ordinary, so that the patron confers the benefice on his clerk without presentation, institu tion, or induction.

ADY ; the palm-tree of the island of St Thomas. Its juice supplies the place of wine among the Indians. The fruit, called abang $a$, is of the shape and size of a lemon, and is eaten roasted. An oil, prepared from this fruit, answers the purpose of butter.

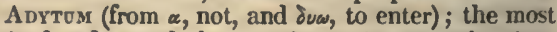
retired and sacred place in the ancient temples, into which priests only were allowed to enter. It corresponded to the Jewish holy of holies.

EAcos; son of Jupiter and the nymph Egina, daughter of the river god Asopus. He acquired the government of the island called after his mother, and became, by his uprightness, a favourite with the: gods. In compliance with his prayers, his father peopled anew the island, which had been depopulated by the plague. The new inhabitants sprang from ants, and were termed, on that account, Myrmidons. Greece, too, was delivered, at his entreaty, from a great drought and famine. The name of his wife was Endeis, and Peleus and Telamon were his children. \$\&., on account of his love of justice, was joined with Minos and Rhadamanthus in the office 
of judging the dear. His particular duty was the distribution of rewards and punishments. $\mathrm{He}$ is represented as seated upon a tribunal, bearing a crown and sceptre ; as a distinguishing mark, he carries the key of the infernal world, given to him by Pluto.

AEDILES; Ronian magistrates of secondary rank, who had the supervision of public spectacles and public edifices, and decided questions relating to the erection of buildings, and to the police of the market. At first, there were but tivo, chosen from the common people (adiles plebeii). At the end of the 4th century from the foundation of Rome, two more were added from among the patricians, to whom an ivory chair (sella curulis) was allowed, and who were thence called adiles curules. Julius Cæsar added the third class (adiles Cereales), to whose care the public granaries were intrusted.

EG son of Titan and Terra, who was fabled to have had a hundred hands, with which he threw a hundred rocks at once at Jupiter, who, when he had overcome him, bound him with a hundred chains.

EGgav SEA; the ancient name of the modern Archipelago (q. v.; see also .Egeus).

EGEUS ; king of Athens and father of Theseus. by Ethra, daughter of Pittheus, king of Trozene. He caused him to be secretly educated at Trœzene, to deceive the sons of Pallas (Pallantides), who expected to succeed him, on the supposition that he was childless. In order that he might recognize his son, he concealed a sword, and some other articles, under a stone on his departure from Troezene, and left orders that Theseus should bring them to Athens when he had reached a certain age. As soon as this young lero became acquainted with his birth, he hastened to Athens, where he was at first repulsed, and in danger of his life ; but his father fnally acknowledged him, and declared him successor to his throne. Under the erroneous idea that Theseus had been devoured by the Minotaur, As. plunged into the sea, from which circumstance the Arclipelago, between Greece and Asia, as far as the Hellespont, received the name of the Egean sea. (See Theseus).

AEgiNa, now Evgra, or EgiNa; a Grecian island in the Saronic gulf, about 30 miles in circumference. In ancient times, it constituted an independent state, and was rich and flourishing by reason of its commerce. The Greeks had a common temple in it, dedicated to Jupiter. The capital of this island was called also Eigina.

Eginetan Style and Monuments of Art. An association of English and German artists and lovers of the arts was formed in 1811 , chiefly with a view of obtaining an architectural survey of the temple of Jupiter Panhellenius, at Egina, which is one of the most beautiful remains of the Doric architecture. A sketch of this temple may be found in the English Journal of Science, and in Isis, a periodical edited by Oken, in Germany. This undertaking was amply rewarded by a fine collection of valuable sculpture, which once adorned the eastern and western fronts of that noble edifice. It was purchased by the king of Bavaria, in 1812, and the deficient parts restored by Thorwaldson. Every nember of the association received a cast of it carefully executed in plaster of Paris. These works are valuable as faithful imita tions of nature, and for the light which tliey shed over one of the darkest periods in the history of art. They showed that the Aginetan style of art was independent of the Attic. Pausanias calls Smilis the Dredalus of Einina, assures us that he was the contemporary of Dxedalus, and ascribes therefore to the Eginetan style equal antiquity and independence with the Attic. The language and manners of Egina were Doric; and its sculpture las a Doric character, as distinct from the Attic (which was originally Ionic) as Doric poetry and architecture. The characteristic peculiarity and aim of the Eginetan style is the faithful and exact imitation of nature, carried even to deception. Attic art was a daughter of the Egyptian, and a striving after the ideal is perceptible in both. To gain a clear idea of primilive art, we must distinguish between the Egyptian, ancient Attic, Eginetan, and Etrurian styles. Rudeness, stiffiness, and meagerness, belong to the first attempts in every art. In other respects, they differ from one another, although, at a later period, they exercise a mutual infuence. The perfection of art in Phidias has hitherto appeared almost a miracle ; but we now comprehend how the Eginetan school, imitating nature with almost perfectexactness, pointed out the way to the ancient Attic, teaching it to rise from the abstract to the living, from the conventional to the natural. Thus we find the long-desired link of connexion between the ancient severe and beautiful styles. Since the creations of Phidias, the traces of the proper Eginetan style have disappeared. There was subsequently, therefore, only one perfect style of art, which spread over all Greece, and Eginetan became the name for primitive sculpture. Smilis was the father and founder of the Eginetan style of art; next to him came Callon, who lived between the 60th and 70th Olympiads (540-500 B. C.). About the time of Phidias, there lired the following masters, famous in this style: Anaxagoras, who made the Jupiter which was placed in Olympia at the common expense of all the Greeks, who fought victoriously at Platzea, B.C. 379 ; Simon, the maker of the consecrated offering of a certain Phormis at Olympia ; and Glaucias and Onatas, who flourished in the 78th Olympiad. The Eginetan figures now exhibited at Munich are 17. They may be divided into 4 classes : 1 . upright, clothed, and female; 2. advancing, or fighting combatants ; 3 . kneeling, or arehers; 4. lying, or wounded. The largest of these figures is Minerva. She is a little above the human size; all the others are rather below this measure. If we consider the style of these works, there prevails in every part of the bodies, the head excepted, a minute imitation of nature, without the least traces of the ideal. Still the imitation is neither poor nor offensive to the rules of art, but a good copy of beautiful nature, with the most perfect knowledge of the bones and muscles. With respect to proportion, these figures are slender, rather small at the hips, and the legs remarkably long. There is much life in the attitudes, though they are not altogether free from a certain stiffness, such as may be observed in the paintings of Giotto, Masaccio, Perugino, \&c. The heads seem to belong to an earlier epoch of art; the eyes project, and are lengthened somewhat in the Chinese fashion; the mouth has prominent lips, with well marked edges; the corners of some are turned up; the nose is rather small ; the ears finished with the greatest care; the chin is full, and generally too large. They all look alike, and exhibit not the slightest expression of passion; between conquerors and conquered, gods and men, there is not the least difference. The appearance of the hair is not naturg!, but stiff and conventional. The arms are rather short; the hands natural to deception; not a wrinkle of the skin is forgotten. The legs are well shaped; the knees masterly ; the feet elegant; and the toes, which are rather too long, run out parallel. The drapery is close to the body, with folds artificially arranged. Though the style is hard, the execution is tasteful and elaborate. They were apparently made at the same time, but not by the same artist. No one of them has any support, and they are equally finishey on all sides. The number 
of figures originally amounted to 30 at lenst. They were symmetrically arranged on both fronts of the temple. The Minerva stoox in the mitllle, the stauling warriors next, then the archers, and the lying figures last. The temple was not intentiouslly destroyed, but was probably thrown down by an earthquake. Since Fincus erected this temple to Jupiter Panhellenius, it is probable that the figures represent the buttles of the Eacida, nnder the protection of Minerva. The two contests in which the Nacidre distinguished thenselves most gloriously were the 'Trojan war and the naval battle of Salanis: in the tatter, the images of the Facidae of Homer, $\Lambda$ jax and Telamon, were displayed, and regarded as supernatural protectors. According to another opinion, the group of the enstem front represented the contest around the body of Iaomedon, king, of Troy; and the one on the western, that aromnd the body of Patroclus. The figures should probably be assigned to a period between the 60th and 80th Olympiads. Pindar calls "Egina the "well-fortifed seat of the Facidie." probably referring to these images, for ao one of the sons of Ancus then remained in the conntry. The marble of which they are wrought is Parian, of the kind usually called Grechetto. The colours perceptible here and there on the figures are rermilion and azure. All the decorations and foliage of the temple, which are generally carved, were painted. The niches of the fronts in which these figures stood were azure, the partitions red, the foliage green and yellow, and even the marble tiles were painted with a kind of flower. We cannot call this system of painting lurbarous; we find it even on the Purthenon. Winckelmann was the first who conjectured the existence of an ancient school of art in Sgina, from the accounts of Pausanias. (See II'agner's Bericht uber die Eginetische Bildwerke herausgegeben, und mit kunstgeschichtlichen. Anmerkungen begleitet von Schelling, 1817; Wagner's Report on the Eginetan Remains of Art, \&c.) Subsequently, K. Otfr. Muller, in his learned and acute work, Ainaticomum Liber, I,eipsic, 1820, attempted to determine their relation to the other monuments still extant; and Thiersch to inrestigate their mythological signification. A gainst the idea of a peculiar Aiginetan style of art, deduced from these marbles, Henry Meyer wrote in Gathe's Kunst und Alterthum, $3 \mathrm{Bd} .1 \mathrm{Heft}$, and opposed the derivation of Grecian sculpture from the Egyptian as strenuously as Winckelmann adrocated it.

EGls; the shield of Jupiter, who is called by Homer the Egris-bearer. It derives its name from the she-goat Agis, which suckled the god in Crete, and with the skin of which the shield was covered. Also the shield of Pallas or Minerva, in the middle of which was the head of Medusa. Sometimes the cuirass of Medusa is thus called. In a figurative sense, $A$. denotes protection.

ELFRIC; archbishop of Canterbury in the 10th century. He composed a Latin Sixon vocabulary, which was printed by Somner, under the title of a Glossary, Oxon. 1659. EE. translated also most of the historical books of the Old Testament, and canons for the regulation of the clergy, which are inserted in Spelman's Councils. He frequently assisted his country in a spirited resistance of the Danish invaders, and died lighly venerated, Nov. 1005.

Eusanos, Claudius; a Greek author who lired at Praneste, about $\Lambda . D .221$. He was a learned sophist, and has left two works compiled in a pretty good styie - a collection of stories and anecdotes, and a natural history of animals. Of the first work, one of the best critical editions was puhlished by Gronovias, at Leyden, 1731, 2 rols. sto. Later editions have bee'n publislıed by liuln, Leijsic, 1780, an Coray, Paris, 1805.

Aimuvs, Panlus, surnaned Macelonicus ; a noble Roman of the ancient family of Aimilii. He conquered I'erseus, king of Macelon, and on this occision obtained a trimmpl, $\Lambda$. U. C. 586 ; B. C. 168 . During the triumpl, two of his sons died. He hore the loss like a hero, and thnuked the gods that they lnd chosen them for victims to avert bad forture from the Roman people. He was father of the renowned Scipio $\Lambda$ fricanus the younger. Ilis father, a brave general in the second Punic war, commanded and was slain at the battle of Canuae, 13. C. 216 .

A Eveas; son of Anchises and Venus, next to IIector the bravest among the heroes of Troy. He is the hero of the Aneid, in which lis life is thus described: In the night of the capture of Troy by the Greeks, Hector warned him in a dretm to fly with the innges of his gods. As. rushed, notwitllstanding this warning to the fight, but fought in vain. After Priam was slain, lie returned, at the command of his mother, to his home, and carried off his father, his child, and his houselıold gods ; but lost his wife, Creusa, in the confusion of his flight. With 20 vessels, he sailed for Thrace, where he began to build the city Finos, but, terrified by a miracle, abandoned the attempt. From thence he went to Delos to consult the oracle. Misunderstanding its reply, he went to Crete, from which he was driven by a pestilence. Thence he directed his course to the promontory of $\Lambda$ ctium, where he celebrated games in honour of Apollo. In Epirus he found Helenus and Andromache. Thence he sailed by Italy, passed the straits of Messina, and circumnavigated Sicily to cape Drepanmm, on the western coast, where Anchises died. A tempest drove him on the shore of Africa, where Dielo received him kindly in Carthage, and desired to detain and marry him. Jupiter, lowerer, mindful of the fates, sent Mercury to $\not E$. and commanded him to sail for Italy. Whilst the deserted Dido ended lier life on the funeral pile, Eneas set sail with his companions, and was cast by a storm on the shores of Sicily, in the dominions of his Trojan friend Acestes, where he celebrated funeral games in honour of his decensed father. The wives of his companions, weary of a seafaring life, and instigated by Juno, set fire to the ships on which he resolved to depart, leaving behind the women and the sick. In this resolution he was confirmed by Anchises, who admonished him in a dream to descend, by the aid of the sibyl, into the infernal regions, after his arrival in Italy. He built the city $\Lambda$ cesta, and then sailed for Italy, where lie found the sibyl, near Cumæ, who foretold lis destiny, and aided his descent into the lower world. On his return, he embarked again, and reached the eastern shore of the river Tiber, in the country of the Laurentian king Latinus. His daughter, Lavinia, was destined by an oracle to a stranger, but promised by her mother, Amata, to Turnus, king of the Rutuli. This occasioned a war, after the termination of which, A. married Lavinia. Thus Virgil relates the history of Eneas in his Eneid, deviating in many particulars from historical truth. His son by Lavinia, Aneas Sylvius, was the ancestor of the kings of Alba longa, and of Romulus and Remus, the founders of the city of Rome. By his first wife, he had a som Ascanius, who built Alba longa, from whose son, Iulus, the Romans derived the Julian family. For the different traditions respecting Eneas, and the probability of their late introduction among the Ro. mans, see Niebubr's Raman History, chapter entitled Ereas and the Trojans in Latium.

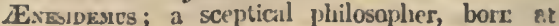


Gnossus, who flourished a little later than Cicero, it is said that the rolipile is used to remicdy smoky and taught scepticism, in Alexandria, to a greater.chimneys.

extent than liad been done bcfore. He placed truth in the general agreement of men as to the impressions produced by external objects.

Asigna ; a proposition put in obscure, ambiguous, and gencrally contradictory terms, to puzzle or exercise the wit in finding out its meaning; or an obscure discourse covering some common and well known thing under remote and uncommon terms. Many distinguished poets have written anigmas in verse. In the East, they have bcen in vogue, both in ancient and modern times. Every nation has shown a fondness for them in the infancy of its cultivation. A great part of the Egyptian learning is said to have been comprised in ænigmas. In thesc, too, the ancient oracles often spoke. But the symbols of the ancient religions should not, as is often the case, be confounded with anigmas. (See Hieroglyphics.) They were in rogue among thic Jews.

Eolian Harp, or Folus Harp$^{3}$, was introduced into England about the middle of the last century. It is generally a simple box of tin, fibrous wood (often of deal), to which are attached a number of fine catgut strings sometimes as many as 15 , of equal size and length, and consequently unisons, stretched on low bridges at each end. Its length is made to correspond with the size of the window or other aperture in which it is intended to be placed ; its width is about five or six inches, its depth two or three. It must be placed with the strings uppermost, under which is a circular opening in the centre as in the belly of the guitar. When the wind blows athwart the strings, it produces the effect of a choir of music in the air, sweetly mingling all the liarmonic notes, and swelling or diminishing the sounds according to the strength or weakness of the blast. A more recent Eolian harp, invented by Mr Crossthwaite, has no sounding-board, but consists merely of a number of strings extended between two deal boards. The invention of the Exolian harp has been generally ascribed to father Kircher, but the fact is, that it was known and used at a much earlier date in the Fast, as $\mathrm{Mr}$ Richardson has proved (Dissertation on the Manners and Customs of the East).

Eoliass; a Greek tribe in Thessaly, who took their name from Æolus, son of Hellen, and grandson of Deucalion, spread themselves there, and established scveral small states. A portion of them went to Asia Minor, and possessed themselves of the ancient Troas, giving the territory the name of EEolis. While united in a confederacy, which held its yearly meetings, with much solemnity, at Cuma, they long continued free; afterwards, they came under the dominion of the Lydians, then of the Persians. After they had thrown off the Persian yoke, with the help of Athens, they were again subdued by Darius Hystaspes, and, as the Greeks had afforded thein repeated aid, the famous Persian war arose, B. C. 500. They regaincd their liberty, but once more came under the Persian dominion, and so remained till the time of Alexander; and at length, after they had been freed by the Romans from the yoke of the Syrian kings, successors of Alexander in this portion of his vast empire, they wcre totally subdued by Sylla, because they had assisted Mithridates. Their language, the Folian dialect, was one of the three principal dialects of the Greek; their country was one of the most fertile in the world; agriculture and the raising of cattle were thcir chicf occupations.

AolipiLe; a sphirical vessel of metal, with a. pipe of small aperturc, through which the vapour of heated water in the ball passes ont with considerable noise. The ancient philosopliers thought to explain by this experiment the origin of the winds. In Itaiy,

Eolus; in Homcr, the son of Hippotas, and king of the island Lipara, to the north of Sicily. He is described as pious and just, hospitable to strangers: and the inventor of sails; having, moreover, fore told the course of the winds, with the utmost exactness, from his own observation, he was said to have the power of directing their course. His history was afterwards still more embellished with fiction; the poets made him a son of Jupiter or Neptune, and god of the winds. He is represented as an old man, with a long beard, holding a sceptre in his hand, sitting on a rock, or smiting the rock with his sceptre, at which signal the winds rush out. He is represented, also, standing in a grotto with a muscle in his mouth, and a pair of bellows under his feet.

ERA is used synonymously with epoch or epocha, (q. v.) for a fixed point of time, fiom which any computation of it is made. Erra is more correctly the range or circuit of years within certain points of time, and an epoch is one of those points itself. The word ara has been supposed to be derived from the abridgment, or initial letters, of Annus 'Eva Augusti, A.E.R.A., a mode of computing time in Spain from the year of the conquest of that country by the Romans; and Vossius favours this opinion. Various aras have been given by chronologists as aids in historical research; and it was a long time before all the Christian world agreed to compute time by the Christian æra. Mariana says that the Spanislı æra ceased in the year of Christ 1383 , under John I., king of Castile. It continued to be used somewhat longer in Portugal. We must subtract 38 from the number of a year of the Spanish mera to get that of the Christian. The Mahommedan æra begins with the flight of the prophet, 16th Jily, .622. This is called the Hegira (q. v.) The ancient Roman æra began with the building of the city, 750 before Christ. The Jewish æra begins with the creation.

Akrial Perspective; that branch of the science of perspective which treats of the relative diminution of the colours of bodies in proportion to their distance from the eye.

A frians ; the followers of Aerius, an Arian monk and schismatic, who was exiled from Sebaste, in Armenia, because he denied the difference betwecn the official power of a bisliop and a presbyter, pronounced prayers and offerings in behalf of the dead to be ineffectual and injurious, rejected the ordinance of fasting, and declared the practice, prevailing among Christians, of sacrificing a lamb on the passover, to be contrary to the spirit of their religion. Though guilty, in fact, only of opposing the abuses of the hierarcliy, and the corruptions of superstition, the Aerians wcre condemned as heretics, and soon disappeared. The protestants were accused of Aerianism by the catholics, because they maintained propositions of a similar character.

A ERODYNames; a branch of aerology, or the highicr mechanics, which treats of the powers and motion of elastic fluids. Aerodynamics are often explained in connexion with hydrodynamies, a branch of hydrology.

Arroultes, stones or masses that descend from the air. See Meteoric Stones.

ArroNautics; the art of sailing in or navigating the air. The idea of inventing a machine, which should enable us to rise into the air, appears to have occupied the luman mind even in ancient times, but was never rcalized until the last century. Henry Cavendish, having discovered, abont 1766, the great levity of inflammable air or liydrogen gas, Dr Black, of Edinburgl, was led to the idea that a thin bladder, flled with this gas, must ascend into the air. 
'avallo made the requisite experiments in 1782, and found that a bladder was too heavy, and paper not air tight. Soap liublles, on the coutrary, which he filled with infammable air, rose to the ceiling of the room, where they burst.-In the sume year, the brothers Stephen and Joseph Montgolfier constructed a machine which ascended by its own power. In Nov. 1782, the elder Montgolfier succeeded, at Avignou, in causing a large bag of fine silk, in the sline of a parallelopiped, and containing 40 cubic feet, to mount rapidly upwards to the ceiling of a chamber, and afterwards, in a garden, to the height of 36 feet, by heating it in the inside with burning paper. The two brothers soon afterwards repeated the experiment at Annonay, where the parallelopiped ascended in the open air 70 feet. A larger machine, containing 650 cubic feet, rose with equal success. - They now resolved to make the experiment on a large scale, and prepared a machine of linen, lined with pasper, which was 117 feet in circumference, weighed 430 pounds, and carried more than 400 pounds of ballast. This they sent up, June 5, 1783, at Annosury. It rose in ten minutes to a heiglit of 6000 feet, and fell 7668 feet froin the place of ascension. The method used to cause it to ascend was, to kindle a straw fire under the aperture of the machine, in whicls they threw, from time to time, chopped wool. But, though the desired effect was produced, they lad no clear nor correct idea of the cause. They did not attribute the ascension of the vessel to the rarefaction of the air inclosed in it by the operation of the heat, but to a peculiar gas, which they supposed to be developed by the burning of the straw and wool. The error of this opinion was not discovered till a later period.-These experiments roused the attention of all the philosophers of Paris. It occurred to some of them, that the same effect might be produced by inflammable air. M. Charles, professor of natural philosophy, filled a ball of lutestring, 12 feet in diameter, and coated with a varnish of gum-elastic, with such gas. It weighed 25 pounds, rose 3123 feet in two minutes, disappeared in the clouds, and descended to the earth, after three quarters of an hour, at the village of Gonesse, about 15 miles from Paris.-Thus we see two original kinds of balloons; those filled with heated air, and those filled with inflammable air.-Meantime, Montgolfier had gone to Paris, and found an assistant in Pilatre de Rozier, the superintendent of the royal museum. They completed, together, in Oct. 1783, a new machine, 74 feet in height and 48 in breadth, in which Rozier rentured for the first time to ascend, though only $\mathbf{5 0}$ feet. The balloon was from caution fastened by cords, and soon drawn down. Eventually, the machine, being suffered to move freely, took an oblique course, and at length sunk down gradually about. 100 feet from its starting place. $-B$ y this the world was convinced that a balloon might, with proper management, carry a man thirough the air; and the first aprial expedition was determined on. Nov. 21, 1783, Pilatre de Rozier and the marquis d'Arlandes as. cended from the castle la Muette, in the presence of an innumerable multitude, with a machine containing 6000 cubic feet. The balloon, after having attained a considerable height, came down in twentyfre minutes, about 9000 yards from la Muette. But the daring aeronauts had been exposed to considerable danger. The balloon was agitated very violently several times; the fire had burnt holes in it; the place on which they stood was injured, and some cords broken, They perceived that it was necessary to descend without delay; but when they were on the surface of the earth, new difficulties presented themselves. The weak coal fire no longer supported the linen balloon, the whole of which fell into the flane. Rozier, who had not set snccected in doscending, just escaped being burnt.-M. Charles, who land join d will M. Robert, soon after informed the public that they would ascend in a balloon filled with inflaunuable air. 'lo defray the necessary expense of 10,000 livres, he opencd a subscription. The balloon was spherical, 26 feet in diameter, and consisted of silk coated with a varnish of gum-elastic The car for the acronauts was attached to several cords, which were fastened to a net, drawn over the upper part of the balloon. A valve was constructed above, which could be opened from the car, by means of cords and slut by a spring. This served to afford an outlet to the inflammable air, if they wislied to descend, or found it necessiry to dinuinish it. The filling lasted several days; and, Dec. J, the voyage was commenced from the gardens of the Tuilleries. The balloon quickly rose to a height of 1800 feet, and disappeared from the eyes of the spectators. The aeronauts diligently observed the barometer, which never stood at less than $20^{\circ}$, threw out gradually the ballast they liad taken in to keep the balloon steady, and descended safely at Nesle. But as soon as Robert stepped out, and it was thus lightened of 130 pounds, it rose again with great rapidity about 9000 feet. It expanded itself with such force, tliat it must have been torn to pieces, had not Cliarles, with much presence of mind, opened the valve to accommodate the quantity of gas to the rarity of the surrounding atmosphere. After the lapse of half an hour, the balloon sunk down on a plain, about three miles from the place of its second ascent.-These successful aerial voyagers were soon followed by others. The first aerial voyage in Britain was performed by Lunardi, an Italian, who ascended from London on the 21st of Sept. 1784. In the succeeding year he ascended in Scotland, being the first person who gratified the inhabitants of Glasgow and Edinburgh with the interesting spectacle of an aerial excursion. Blanchard had already ascended several times in France, when lie determined to cross the channel between England and France, which is about 23 miles wide, in a balloon filled with inflammable air. He succeeded in this bold attempt, Jan. 7, 1785, accompanied by an American gentleman, Dr Jeffries. About one o'clock, they left the English coast, and at half past two, were on the French. Blanchard was the first who experimented with a parachute. On lis ascent from Strasburg in 1787, when he had attained an elevation of 6000 feet, he detached from the balloon the paracliute, with a dog in a basket suspended from it. Atter being a good deal driven about by the wind, the dog reached the ground in safety. M. Gamerin, whose aerial voyages were numerous and adventurous, repeatedly descended by a parachute from his balloou after it had reached a great height. Pilatre de Rozier, mentioned before as the first aeronaut, attempted June 14th, 1785, in company with Mr Romail, to pass from the French to the English side; but the attempt was unsuccessful, and the adventurers lost their lives. M. de Rozier had on this occasion united the two kinds of balloons; under one filled with inflammable air, which did not alone possess sufficient elevating power, was a second, filled by means of a coal fire under it. Rozier had chosen this combination, hoping to unite the advantages of both kinds. $\mathrm{By}$ means of the lower balloon, he intended to rise and sink at pleasure, which is not possible with inflammable air ; for a balloon filled with this, when once sunk to the eartli, cannot rise again with the same weight, without being filled anew; while, on the contrary, by increasing or diminishing the fire under a balloon filled with heated air, it can be made to rise and fall alternately. But this experiment 
carsed the death of the projectors. Probably the couls, which were only in a glowing state near the surfice of the ground, were suddenly kindled to a light flame as the balloon rose, and set it on fire. The whole machine was soon in flames, and the two acronauts were precipitated from on high. The condition of their mangled bodies confirms the conjecture that they were killed by the explosion of the gas.'This unhappy accident did not deter others; on the contrary, the experiments were by degrees repeated in other countries. However important this invention may be, it has as yet led to no considerable results. Its use has hitherto been confined to observations in the upper regions of the atmosphere. In this MM. Gay Lussac, and Biot, distinguished themselves. On one occasion, M. Gay Lussac reached a height of 23,100 feet above the surface of the earth. But should we ever learn to guide the balloon at will, it might, perhaps, be employed for purposes of which we now have hardly an idea ; possibly the plan of professor Robison might be accomplished by the construction of a gigantic balloon, which would enable us to perform an aerial circumnavigation of the eartl. During the French revolution, an aerostatic institution was founded at Meudon, not far from Paris, for the education of a corps of aeronauts, with the view of introducing balloons into armies as a means of reconnoitering the enemy. But this use of balloons was soon laid aside, for, like every other, it must be attended with great uncertainty, as long as the machine has to obey the wind. Among the French, Blanchard and Garnerin have undertaken the greatest number of aerial voyages; among the Germans, professor Jungius, in Berlin, in 1805 and 1806 , made the first. Since that time, professor Reichard and his wife have become known by their aerial excursions. Even in Constantinople, such a voyage was performed, at the wish and expense of the sultan, by two Englishmen, Barly and Devigne. In Britain, the latest aeronauts have been $\mathrm{Mr}$ Sadler and the Messrs Green. The former, after many adventurous royages, lost his life by his balloon coming in contact with a chimney gable the latter still continue to make successful ascents from various quarters of the empire. Blanchard has rendered an essential service to aeronauts by the invention of the parachute, which they can use, in case of necessity, to let themselres down without danger. Many attempts have been made to regulate the course of balloons, by means of oars, wings, \&c., but hitherto with little success.

Amrostation, or Aerostatics, is the science of weighing air, either by itself or with other substances. Since the invention of the balloon, this term has been sometimes applied to the art of managing balloons, which is more properly called aëronautics, (q. v.)

Escmines ; a famous orator of Athens; born 393, died $423, \mathrm{~B}$. C. Being the son of poor parents, he passed his youth among the lower classes, with whom he wandered about, partaking in their amusements, particularly in the festivals in honour of Bacchus. Encouraged by their applause, he became an actor, acquired the right of citizenship, engaged in politics, attended the lectures of Plato and Isocrates, and soon became the rival of Demosthenes, whom, however, he did not equal in power and energy, although he was distinguished by a happy choice of words, and by richness and perspicuity of ideas. He gradually lost the favour of the people, and fled to Rhodes and Samos, where he gave instruction in rhetoric till his death. Three orations and twelve letters of his are extant. They are to be found in the collections of Aldus, Stephanus, and Reiske, (3d and 4th vols.)

Eschises, the philosopher, a native of Athens, who, by way of distinction from the preceding, is called a Socratic, was a poor disciple of Socrates. We possess under his name three dialogues, "On Virtue," "On Riches," and "On Death," which, however, are not allowed by strict critics to be genuine. The best edition is that of I. F. Fischer, Leipsic, 1786.

Fschylos; the father of ancient Greek tragedy ; born in the $3 d$ or 4 th year of the $63 d$ Olympiad (5:5 B. C.), at Eleusis, in Attica, of a noble family. Of the circumstances of his life we have but deficient and uncertain accounts. He fought in the battles of Marathon and Salamis, witnessed the destruction of the power of Darius and Xerxes, and wrote his tragedies under the proud feeling of a successful struggle for liberty. In these he first raised the tragical art from the rude beginnings of Thespis to a dignified character, so that he may be considered as its real creator. Tragedy sprang from his head in full armour (says A. W. Schlegel), like Pallas from the head of Jupiter. He clothed it with becoming dignity, and gave it an appropriate place of exhibition; he invented scenic pomp, and not only instructed the chorus in singing and dancing, but appeared himself in the character of a player. He first perfected the dialogue, and reduced the lyrical part of the tragedy, which still, however, occupies too much space in his plays. His characters are sketched with a few bold and strong features; his plots are extremely simple, but grand. His art knew nothing of intrigues and developements. All his poetry reveals a lofty and ardent mind. Not the softer emotions, but terror is his ruling characteristic. He holds up the head of Medusa to the overawed spectators. His manner of treating fate is terrible in the extreme ; in all its gloomy majesty it hovers over mortals. The cothurnus of Eschylus is of an iron weight; none but giant figures stride in it. It appears to have required an effort in him to represent mere men. He deals commonly with gods, especially the Titans, those elder deities, the symbols of the dark primitive powers of nature, long since cast down to Tartarus. In accordance with the grandeur of his figures, he endeavours to make their language gigantic. Thence arise harsh expressions, overloaded with epithets, and frequeutly, in his chorus, intricate constructions and great obscurity. In the daring grandeur of his images and expressions, he resembles Dante and Shakspeare. We have only seven of his tragedies remaining : their whole number is stated to liave been seventy; according to some, ninety; but among these, according to the testimony of the ancients, we have some of his principal works. They are "The Prometheus Vinctus," "The Seven before Thebes," "The Persians," "Agamemnon," "The Choephoræ," "The Eumenides," and "The Suppliants." Disgusted at seeing inferior pieces preferred to his own, and particularly at the victory of the young Sophocles, or, according to the more probable account, compelled by an accusation of atheism, Eschylus left his native country, and went to Sicily, where he was received with great honours by king Hiero, and died $456 \mathrm{~B}$. C., at the age of 70 years. The best editions of his works are, London, 1663 and 1664, folio, by Stanley ; Hague, in 1745, 2 vols. quarto, by Paw; London, 1805, by Porson; and Halle, 1809 to 1821,5 vols. $3 d$ edition, by Schutz. Single plays have been published by Brunck, Herrmann, Blomfield, and others; and an English translation of him by arclideacon Potter.

EEscolapies; the god of medicine. Some writers call him a son of Apollo and Arsinoe, daughter of Leucippus; others. of Apollo and Coronis, daughter of Phlegyas. There are also different 
accounts of the wonders which befell his infiney. Acconling to some, he was exposed by his mother, snckled by a guat, found by shephents, and his divine nature recognized by a glittering lialo round his lıen; according to others, Cononis having admitted the embraces of Jschys as well as those of $A$ pollo, the latter in a fit of anger (or Diana in his stead), killed Coronis, but saved the clild from her womb. The last opinion was the most common, and was confirmed by the Pythian oracle. A pollo afterwards brought his son to Chiron, who instructed him in medicine and hunting. In the former he acquired a high degree of skill, so as to surpass even the fame of his teacher. He not only prevented the death of the living, but even recalled the dead to life. Jupiter, however, induced by the complaints of his brother Pluto, slew $\mathcal{A}$. with a thunderbolt." After his death, he received divine honours. In particular, he was worshipped at Fpidaurus in Peloponnesus, (see Argolis), where a temple with a grove was dedicated to him. From the accurate register lere kept of the most remarkable diseases and their remedies, the greatest physicians gathered experience and knowledge. Thence his worship spread over all Greece, and finally to Rome. After the plague had raged there for three years, ambassadors were sent to Aisculapius at Epidaurus by the advice of the Delphian $\Lambda$ pollo. They had handly appeared before the god, when a serpent crept from beneath lis image, and hastened directly to the Roman ship. This serpent, which was thought to be Esculapius himself, was carried with great solemnity in Rome, upon which the plague ceased. Asculapius had two sons, Machaon and Podalirius, who were called Asclepiades, and during the Trojan war made themselves famous as heroes and physicians. His daughters were Hygeia, Inso, Panacea, and Ergle; the first of whon was worshipped as the goddess of health. Esculapius is represented with a large beard, holding a knotty stafi, round which was entwined a serpent, the symbol of convalescence. Near him stands the cock, the symbol of watchfulness. He is sometimes crowned with the laurel of $A$ pollo. Sometimes his little sun Telesphorus is represented beside him, with a cap upon his head, wrapped up in a cloak. Sometimes Asculapius is represented under the image of a serpent only.

Esop ; the oldest Greek fabulist. He is said to have been a native of Phrygia, and a slave, till he was set free by his last owner. He lived about the middle of the 6 th century B. C. He inculcated rules of practical morality, drawn from the habits of the inferior creation, and this spread his fame through Greece and all the neighbouring countries. Croesus, king of Lydia, invited Esop to his court, and kept him always about his person. Indeed, he was never absent, except during his journeys to Greece, Persia, and Egypt. Croesus once sent him to Delphi to offer a sacrifice to Apollo; while engaged in this embassy, he wrote lis fable of the Floating Log, which appeared terrible at a distance, but lost its terrors when approached. The priests of Delphi, applying the fable to themselves, resolved to take vengeance on the author, and plunged him from a precipice. Planudes, who wrote a miserable romance, of which he makes Esop the hero, describes him as excessirely deformed and disagreeable in his appearance, and given to stuttering; but this account does not agree with what his contemporaries say of him. The stories related of Esop, even by the nncients, are not entitled to credit. A collection of fables made by Planudes, which are still extant, under the name of the Grecian fabulist, are ascribed to Lim with little foundation ; their origin is lost in the durkness of antiquity. Of the early editions, the most valuable are those by Henry Stephens, Paris,
1546, 4to.; sud by Hulson, Oxfonl, 1718. More lately they luwe been published from the inaum. seript, in a very different form, by De Furia, 2 vols., Florence, 1804, and Leipsic, 1810; Corray, Paris, 1810 ; and Schneider, I3reslau, 1811. The best English versions are by Croxall and Dodsley. These fables have had numberless imitators.

Esoros, Clodius, a celebrated actor, who flourished abont the 670th year of Rome. He was a contemporary of koscius. His folly in spending money on expensive dishes male him as conspicuons as his dramatic talents. He is said, at one entertainment, to have had a dish filled with singing and speaking birds, which cost $£ \delta 00$. When acting, he enterch into his part to such a degree as sometimies to be seized with a perfect eestasy. Plutarch mentions it as reported of hin, tlat, whilst he was representing Atreus, deliberating how he should revenge himself on Thyestes, he was so transported beyond hinself, that he smote with his trunclieon one of the servants who was crossing the stage, and killed him on the spot.

Estuatics (from the Greek aiverrou, perception); the science which treats of the beautiful, and of the various applications of its principles. Baungart'u, a professor in the university at Frankfort on the Oder, first used this name, and intended to designate by it a branch of philosophy, which shonld establish correct principles of criticism in relation to the beautiful. Since the time of Baumgarten, this word has been used in Germany, France, and Italy, and has lately been einployed hy some English writers. For the character of che science, aud the attention which it has received, see Philosophy.

AEtuer; an extremely fine, subtile, and clastic fluid, which philosophers have supposed to be diffused throughout the universe, and by means of which they have explained many of the great phenomena of nature. It is mentioned by Aristotle. Its existence cannot be proved. Newton believed in it, and explains by it the comexion of the parts of a body, and the laws of gravity. Fuler asserts that other is almost $39,000,000$ times thiuner, and 1,278 times more elastic, than atmospheric air.

Ftuer ; in chemistry. See Ether.

Aitriopia. See Ethiopia.

Erios; one of the most zealous defenders of Arianism, born in Syria, flourished about A.D. 336, and his followers were called Etians.

Etra (in Italian, monte Gibello); the famous volcanic mountain on the eastern coast of Sicily, not far from Catania. This mountain rises more than 10,000 feet above the surface of the sea; Buffun thinks 2000 fathoms; Saussure gives 10,963 fect. Spallanzani 11,400, and Sir G. Shucklurgh 10,954. Its circumference at the base is $\mathbf{1 8 0}$ miles. On its sides are 77 cities, towns, and villages, containing about 115,000 inhabitants. From Catania to the summit the distance is 30 miles, and the traveller must pass through three distinct climates-the hot, the temperate, and the frigid. Accordingly, the whole mountain is divided into three distinct regions, called the fertile region (regione culta), the woody region (regione selvosa), and the barren region (regione deserta). The lowest region extends through an ascent from 12 to 18 miles. 'The city of Catania and several villages are situated in the first zone, which abounds in pastures, orchards, and various kinds of fruit-trees. Its great fertility is ascribed chiefly to the decomposition of lava; it is perhaps owing, in part, to cultivation. The figs and fruits in general, in this region, are reckoned the finest in Sicily. The lava here flows from a number of small mountains, which are dispersed over the immense declivity of Aina. The woody region or temperats zone, extends from eight to ten miles in a direct line 
towards the top of the mountain; it comprehends a surface of about forty or forty-five square leagues, and forms a zone of the brightest green all round the unountain, exhibiting a pleasing contrast to its white and hoary head. It is called la regione selvosa, because it alounds in oaks, beeches, and firs. The soil is similar to that of the lower region. The air here is cool and refreshing, and every breeze is loaded with a thousand perfumes, the whole ground being covered with the richest aromatic plants. Many parts of this region are the most delightful spots upon earth, and have inspired ancient and modern poets with images of beauty and loveliness. The animal kingdom of these two regions is not equal in point of richness to the vegetable. The upper or barren region is marked out by a circle of snow and ice. Its surface is, for the most part, flat, and the approach to it is indicated by the decline of vegetation, by uncovered rocks of lava and heaps of sand, by near views of an expanse of snow and ice, and of torrents of smoke issuing from the crater of the mountain, also by the difficulty and danger of advancing amidst streams of melted snow, sheets of ice, and gusts of chilling winds. The curious traveller, however, thinks himself amply rewarded, upon gaining the summit, for the peril which he has encountered. The number of stars scems increased, and their light appears brighter than usual; the lustre of the milky way is like a pure flame that shoots across the heavens ; and with the naked eye we may observe clusters of stars totally invisible in the lower regions. The scoria, of which the mountain is composed, have the same kind of base, containing schorl and feldtspar. The first eruption of which we have any authentic account, is mentioned by Diodorus Siculus. The last eruption took place in 1819 . It appears very probable that mount Etna is exhausting its volcanic powers, as the eruptions of modern times are by no means so frequent as in former ages, nor are they so tremendous in their extent and effects. Before the Christian ara, there were nine eruptions, of which those in 477 and 121 B. C. are the most important: after Christ, the most important are those in 1160 , $1169,1329,1536,1537,1669,1693,1763,1787$, 1792, 1802, 1809, 1811, and 1819. Mount Etna supplies Sicily and a large part of Italy, and even Malta, with the luxury of snow and ice. The trade in these articles belongs to the bishop of Catania, who, as it is stated, makes from 3000 to $\mathbf{4 0 0 0}$ dollars per annum by it. The vegctation of the woody region is exceedingly luxuriant. There is one chesnut tree, under which a hundred horses may be sheltered from the sun; it therefore is called dei cento cavalli. See Denon's Voyage pittoresque en Sicile, vol. 4., and Alexander von Humboldt's Personal Narrative. Since 1824, Catania has had the Gioenian Academy (so called in honour of the cheralier Giuseppe Gioeni, author of a Litologia Vesuviana), the object of which is to investigate the topography and natural history of Etna.

AToL1A; a country in Grecce, on the northern const of the Corinthian gulf; so called from Atulus, the brother of Epeus, king of Flis, who, escaping from Elis, made himself master of this region. Ancient Etolia was separated from Acarnania by the river Achelous, and extended thence to Calydon, or to the river Evcnus. On the south lay the gulf of Corinth, and Thessaly on the north. Its extent from north to south was about forty-eight miles, and from east to west above twenty. It was subsequently enlarged by successful wars. 'The additions were comprehended under the name of Etoliu Epictetos. The borders of Atolia on the north were now mount Eta and the Athamanes in Epirus. Thermopyla, Heraclea, and a great part of Thessaly also belonged to it. On the east, Doris and thic cuast as far as Nampactus and Eupalion were added to it. The country was rough and unfruitful, but strong by rea. son of its mountains. According to Herodotus and Aristotle, lions infested $\mathbb{E}$. in the most ancient times. The original ancestors of the Etolians were Hellenes. Divided into small tribes, they had no principal city; they were occupied in hunting and robbery, and made themselves feared both on land and see In their state of independence, they preserved for a long time their ancient rudeness of manners. They very early formed the great Atolian confederacy, which assembled once a year at Therma, but first became remarkable in the time of the Achæan league. To oppose this confederacy they united with the Romans ; and afterwards deserted them, on perceiving that their freedom was in danger from their allies. They then went over to the side of the Macedonians, with whom they were obliged at last to submit to the Roman yoke. The government of $F$. was republican, controlled by the Panctolium, a general council, held as occasion required. Livy says that their cavalry was at one period esteemed superior to that of any other of the Grecian states.

AFFA; a weight on the Gold Coast of Guinea, equal to one ounce.

AfFint ; in chemistry. When two bodies are brought into contact with each other, they will often, without the sensible operation of any extraneous influences, combine by a spontaneous and reciprocal action, and form new bodies with different properties; a single body, modified by the action of the natural agents, caloric, elcctricity, \&c., sometimes produces the same results; finally, a body not apparently acted upon by other bodies, nor by the natural agents, sometimes acquires new properties, and assumes new forms. These changes in the chemical character of bodies are produced by a force, to which we give the name of affinity. Some of the laws or modes of action of this force are, that it is. exerted only at insensible distances, which distinguishes it from gravitation (see Attraction), and between heterogeneous particles, in which it differs from cohesion (q. v.) The properties of the resulting compound differ essentially from its component parts, as a salt is formed by an acid and an alkali. The forms of the elements are often changed, and the change is attended with remarkable phenomena, as the explosion of gunpowder by its conversion into gasses, the solidification of water in slaking lime, \&c. One of the most important laws of affinity is, that one body has not the same force of affinity towards all others, but attracts them very unequally, and some of them not at all. The knowledge of the affinities of different bodies is of great use to the chemist in cffecting decompositions. - Bergmann, who first, in 1775, developed the theory of affinities, distinguishes thrce cases in the reciprocal action of two bodies-when they are both free, which he calls simple affinity; when one of them is already in combination, elective, and when both are combined in different compounds, complex. Berthollet has much improved the theory of affinities. See Berthollet's Statique Chimique, and Berzelius' Theory of Chemical Proportions.

Arrinity, in law, is that degree of comnexion, which subsists between one of two marricel persons and the blood relations of the other. It is no real kindred. A person cannot, by legal succession, receivc an inlicritance from a relation by affinity; weithcr does it cxtend to the nearest relations of husband and wife, so as to create a mutual relation bctween them. The degrees of affinity are computed in the same way as those of consanguinity, or blood. By the Jewish law, narriage was prohibited within certain degrees. Nearly the same limitations aro 
silopted into the laws of Furope and Anerica. All legal impediments, arising from affinity, cerse upon the death of the husband or wife, excepting, of course, those which relate to the marriage of the survivor. The table of forbidden degrees of aftuity is, by the ecclesiastical law of Fingland, commanded to be hung ny in all churches. The Roman church speaks of spiritual affinity, which is contracted by the sacraments of buptisnı and confirmation; according to which a god-father may not marry his god-daughter without a dispensation.

Afrrmation signifies, in one sense, the solemn declarations of Quakers, and members of some other sects in confirmation of their testimony in courts of law, or of their statements on other occasions, on which the sanction of an oatl is required of other persons. The English laws did not permit affirmatious instead of oaths, in criminal cases, until 1828. No distinction las been made, in any of the United States, between testimonies in civil and criminal cases in this respect, it having been permitted to Quakers geuerally, and, for the most part, to other persons scrupulous about swearing, to give testimony .upon mere solemn affirmation. Even the president of the United States is allowed to affirm instead of taking the usual oath, when inducted into office, if he has conscientious scruples about swearing. The privilege of affirmation is allowed in Prussia only to sects recognised by government, and whose principles do not permit them to make oath. False affirInation is subjected to the same penalties as perjury in England and elsewhere.

Afrky, Lewis Augustinus Philip, count of, first magistrate of Switzerland after Napoleon. had proclaimed himself the protector of the Helvetic confederacy, was born at Freyburg, 1743. He was early destined to a military life, accompanied his father on an embassy to the Hague, soon became adjutant in the Swiss guards, and was funally elevated to the rank of lieutenant-general. At the conmencement of the revolution, he commanded the army on the Upper Rhine, till Aug. 10, 1792, when the Srriss troops having been disbanded, he returned to his country, and becarne a member of the secret council at Freyburg. Switzerland being menaced, in 1798, with a French invasion and a revolution, he resumed the command of the troops. He acknowledged the uselessness of resistance, conducted himself with undeviating prudence, and averted as much as possible from his country the evils of war and rebellion. When Freyburg was taken by the French, he became a member of the provisional government. He had an share in the insurrections of 1801 and 1802 , but accepted with pleasure the appointment of deputy to Paris, when the first consul invited the Swiss to send delegates thither, and offered them his mediation. Napoleon distinguished him above the other deputies, and intrusted to him the formation of an administration, which was to ensure the peace and happiness of the ancient allies of France. Feb. 19, $1803, A$. received from the first consul the act of mediation, was appointed first magistrate for this year, and invested with extraordinary powers, until the conrocation of a diet. He sought to promote the views of the furst consul, and acted, in every thing, with the ability, the intelligence, and the experience of a thorough statesman. He died June 16, 1810.

Afghantstan, or Afghadnistaun, the country of the Afghans, or Cabulists, also called the kingdom of the Abdallians, contains 350,000 square miles, is bounded on the north, towards Budukshan, by mount Hindoo-Koin and Paroparnisus; on the east, towards llindostan, by the Indus and mount Solomon; on the south, by the vale of Bolahn and the nountains near Sistan; on the west, towards Iran, by the great desert. The Ilindoo-Kol is a continuation of the Himalaya; many rauge's run in all directions from the Paroparnisus and monnt Solonon. The ludus is the principal river. The atmosphere is dry and healthy, and some of the valleys are very firtile. The untilled portions serve as pastures for cattle. It abounds in silver, lead, iron, sulphur, lapis lazuli, cotton, lorses, asses, dromedaries, camels, oxeri, sheep with fat tails, goats, \&c., and contains, also, several species of carnivorous animals. Of the $14,000,000$ of inlıbitants, $4,300,000$ are $\Lambda$ fghans, and $5,700,000$ are llindoos; the remaining part consists of Tadshicks (descendents of the micient Persians), with 'Tartars and Belooches. Their religion is that of Mahomet. Besides the capital, Calmul, which contains 80,000 inhabitants, there are otlier important cities; as Candahar, a fortress and commercial place, of 100,000 inhabitants ; Peslawur, or Peshour, of 100,000 inhabitants, \&c.; Bulkh, or Balk (the ancient Bactria, now inlabited by Usbecks), and Cashmere. These are almost independent cities on the frontiers. The king is of the house of Saddosei; the throne is hereditary, but limited by the power of the chiefs of the tribes. The Britisly couriers and travellers, who are going to Bagdad, generally prefer the way by Cabul. In consequence of the influence of the British over the people of $A$., the Persian court at Tehraun is subjected to an unwilling dependence on the East India compauy, which acts as protector of Persia and of $A_{\text {. }}$, and has contributed much to the preservation of peace be. tween the two nations, as far as the aristocratic character of the government of $A$. admits. Private quarrels, however, frequently happen between the Persian governors and the chiefs of $\mathrm{A}$. The great influence of the British in the Fast, over the nations of the lower Indus (Seiks), is continually exerted to prevent these powerful nations from weakening one another by wars, with a view of advancing the commercial interests of the British company, and of providing a bulwark against the progress of the Russian conquests beyond the Caucasus, in Lower Persia, in Armenia, and on the Caspian sea. But in spite of these precautions, the rajah of Lahore, Rungeet Singh, has usurped the throne of $\mathrm{Ca}$ bul, in A., and, to brave the British, has taken many Russians into his service. The Russians trade with the Afghans by way of Bucharia.

AfGhavs, or AfGhades, signifying mountaincers, is the name of a powerful nation, called also Patans, in the eastern part of Persia, in the kingdom of $\mathrm{Ca}$ bulistan. They originally lived in the mountains between Persia, Hindostan, and Bactria, and are of Median descent. The A.'s are even now wandering tribes; both those of the west, who are robbers, and live in tents, and those of the east, who have more regular settlements. During the revolution in Persia, which took place in 1747 , after the death of $\mathrm{Na}-$ dir Sliah, Amed Abdallah, chief of the A.'s in the Persian army, took possession of the provinces ot Candahar and Chorasan, made himself independent of Persia, and founded the kingdom of Afghanistan.

Arore (avant, French); all that part of a ship which lies forward, or near the stem.

Afrancesados. This title is used to denote those Spaniards who took the oath of fidelity and allegiance to the constitution of Bayonne and king Joseph, expecting, from the new order of things introduced by the French into Spain, a regeneration of their country. They were also termed.Josefinos, because they were taken into the Spanish service by Joseph. After the overthrow of the usurper (intruso), his principal partisans fled to France, to avoid the hatred of their countrymen. When king Ferdinand VII. re- 
covered his throne in 1814, he persecuted with equal cruelty, the liberales, or adherents of the cortes, who had wrought the downfall of the French system, and the .Josefinos. A gazette of Madrid, the Atalaya (Sentinel), demanded their destruction in the following terms: "Is it possible, sire, that the liberales and Josefinos still exist among us? Why have not a hundred scaffolds, a hundred pyres, been erected in every city and in every village of Spain, to do justice on the wretches?" May 30,1814 , a decree was isstied, prohibiting the return of all emigrant Afrancesados, more especially those who had received from the isvading government, any ratification of their former offices, or any new appointment, title, rank, order, \&c. In the same decree were included all generals and officers who had fought under the banners of Napoleon or Joseph, and all females who had accompanied their husbands in their emigration. The number of enigrant liberales who lived in France was estimated at 16,000 ; among whom were many distinguished literary characters, and excellent civil and military officers. They published, in London, a journal (El Espanol Constitucional), in which they laboured to convince their countrymen, that the only remedy for the misfortunes of Spain was the adoption of a liberal constitution. All others were allowed to return, but were compelled to live 50 miles from the capital, under the supervision of the police. The decree of amnesty, published Sept. 29, 1816 (suspended again in 1817), was so constructed, that it did not ameliorate the condition of the banished. Josefinos. Even the soldiers and officers, returning home after Napoleon's fall, from their captivity in France, were remanded to the frontier, through fear that they might have imbibed liberal or revolutionary principles in France. The continual attempts at rebellion in Spain were, at the same time, the consequence and the cause of the continuance of these severe regulations. When Ferdinand VII. accepted the constitution of the cortes, he proclaimel a general amnesty, Maroh 8, 1820, and afterwards allowed all Josefinos to reside in any part of Spain, Madrid excepted. The cortes, Sept. 21, 1820 , determined that they should be restored to the enjoyment of their rights and possession of their property, but not to their dignities, offices, and pensions. They proceeded on the principle, that most of them had been brought by accidental circumstances under the power of the "usurper" (intruso), but had, nevertheless, with honest intentions, prepared, in Iayonne, reforns beneficial to their country, and had pxerted themselves with spirit to promote its welfure ; and that afterwards, becoming involved in inextricable difficulties, they had remained faithful to their oath, king Joseph, and the constitution. The Afrancesados have always shown great moderation, and are, for this reason, even now, hated by the $a b$ colutists. See Mexico.

Afranios, Lucius, a Roman comic poet, flourished in the first half of the $2 \mathrm{~d}$ century $\mathrm{B}$. C. He was pre-eminently the creator of the Roman national drama, or the fabula togata; and his delineations of the life and manners of his countrymen comprehended even the lowest classes, whence arose the fabula tabernaria. From the Greeks he borrowed only the nutwand form of their comedy, and adapted it to the Roman manners, which gave rise to the saying, that the toga of $\Lambda$. perfectly fitted Menander. His coarse expressions, and licentiousness have been censured by some crities, but his wit and vivacity are acknowledged by all. Ile wrote nuch, but of his many pieces only a few fragments reniain.

Africs, one of the five divisions of the globe, mentioned in history thousends of years ago, is still to us what it was to the ancients - the land of mys- tery. Only a small extent of sen separates $\Lambda$ fri, a from Europe; its consts lie in sight of the most civilized countries; and yet we know nothing more than its outlines: into the interior the foot of a European has lately, for the first time, penetraterl. Under the same name which it now bears, the valley of the Nile was, in the earliest ages of history, the cradle of commerce, the arts and sciences. But even in the period of Egypt's greatest prosperity, deep night seems to have enveloped the surrounding countries, which were called Negroland. Subsequently, the Greeks (see the very minute accounts of Herodotis) and Romans became better acquainted with the Mediterranean coast of Africa, and penetrated into the interior perhaps as far as the river Joliba; but their knowledge never reached beyond the confines of Numidia, and they were totally ignorant of the southern part of A. How vague was the conception which Ptolemy himself formed of this portion of the earth, though it appeared to him a large peninsula! Its outlines were not determined till the 15th century. Henry, the navigator, saileo round the formidable cape Non (non plus ultra), Diaz and Vasco de Gama discorered the cape of Good Hope, and both the western and eastern coasts were examined by European navigators.-Africa is a vast peninsula, forming a triangle, with its rertex towards the south, containing $12,256,000$ (according to Gruberg, 11,031,400) square miles; situated between $18^{\circ} \mathrm{W}$. and $51^{\circ} \mathrm{E}$. lon., and from $34^{\circ} \mathrm{S}$. to $37^{\circ} 30 \mathrm{~N}$. lat. ; bounded on the north by the Mediterranean, on the east by Asia, the Red sea, and Indian ocean, and on the south and west by the Southern and Atlantic oceans. It has a great breadth, from east to west. The northern portion is much larger than the southern; the greatest breadth, from west to east, from cape Negro to cape Guardafui, is 69:. Under the equator, the breadth is $\mathbf{4 5 0 0}$ geographical miles. The internal structure of Africn is marked by many peculiarities. It possesses immense chains of mountains, extending, perhaps, from the cape of Good Hope to the Mediterranean, in many parallel ranges. Such are the Atlas mountains, the mountains of the Moon, of Kong, and Lupata; those of the Cape, 5000 feet high, and covered with continual snows; but, on the whole, it is more level than any other quarter of the globe. In none other do we find such boundless deserts; and the Cobi, in the centre of Asia, is not to be compared with the Sahara. These deserts appear like oceans of sand, by no means destitute of fertile islands. These islands are the Oases, peculiar to Africa. (See Oases.) Among the mighty streams of $\Lambda$. we can now follow the Egyptian Nile to its sources. The courses of the other great rivers have not yet been satisfactorily explored. We know, indeed, where the Congo or Zaire, Coanza, and Cuama or Zambese terminate, but not where they rise. The Joliba (the Niger of Herodotus), Mungo Park has informed us, flows from west to east. The Senegal, thie Gambia, and the Orange are also important rivers. A. contains several large lakes, such as the Dembea, Wangara, Maravi, Tschad, and Aquilunda. The climate is various, but in general extremely lot. In the lifeless atmosphere of the tropies, which lave but two seasons, the wet and the dry, the lieat of the sun is terrible; and Adanson tells of eggs being roasted in the sands of Guinea, and the naked feet of the negroes blistered. On the coasts, the heat is mitigated by the breezes from the sea and the mountains, and by incessant rains; but the atmosphere is not so healthy and pure as in the interior, which has a higher elevation. The whole tract of Barbary is warmer than the more southerly regions, and all A., compured with Europe, is a hot cunntry. Of its winds, the 
dry, parching harmattan is peculiar to $\Lambda$. ; it hás the simoom in common with $\Lambda$ sia, and the sirocco with Europe-To the maturalist, this wonderful country seems the first favourite of nature, as far as it respects the riches of tlie organic world, and the number of giant forms of animals and plants. It can enunerate five times as many species of quaIrupeds as Asia, and three times as many as all America. It excels Asia in the size of its colossal river-horse (nippopotamus), gigantic giraffe, and large antelopes and apes. That giant of birts, the ostrich, is exclusively indigenous to Africa. But the most beneficent gift of nature to the African is the camel, the constitution of which is in every respect adepted to the country and climate. Among the other animals are the eleplant and rhinoceros, the lion, panther, leopard, ounce, jackal, hyæna, wolf, fox, dog, cat, mongus, bat, rat, marmot (cavia capensis), hare, rabbit, jerbon, porcupine, hedgelıg, nole, civet-cat, ichneumon, bear, horse, ass, zebra, sheep (some with lair and large fat tails), argalis (capra ammon), goat, innumerable varieties of the gazelle, the buffalo, and fallow-leer. In Guinea are found the roe, swine, emgalos, babyroussa, and other quadrupeds, whose natural history las been as yet by no means sufficiently investigated; even the problematical unicorn is still said to exist in the interior. The varieties of birds are equally numerous; among which is the cromnbini ; the most beautiful of the feathered tribes; the flamingo, king-fisher, pelican, and many kinds of parrots ; the peacock, partridge, pheasant, widow, and cardinal-bird; the cuckoo, the cuculus indicator, turtle doves, pigeons, ducks, geese, \&c. The class of reptiles comprises the crocodile and boa-constrictor, with many other serpents, some imnoxious, some highly poisonous. The bays and rivers abound in fish, but the variety of the species is not so great as in the northern seas, and many of the most useful are entirely wanting. 'The shrubs and carth swarm with termites, ants, scolopendras, spiders, and caterpillars, while passing armies of locusts obscure the sun like clouds. The most beantiful insects abound. Still more extraordinary is the force of regetation. The earth renders back the seed to the cultivator increased a hundred fold, and produces those immense trees, among which the boabab, or monkey breadtree, whose crown of branches sometimes forms a circle 130 feet in diameter, holds the first rank; the splendid white trunk of the ceiba grows almost perpendicularly from the root to the branches, 60 feet, and, with its fine round crown, rises to a height of 120 feet. In Africa, as in America, the torrid zone produces plants and fruits, at the same time the most nutritious, the most refreshing, and most wholesome. The antiseptical quality appertains to the fruits of the palm, banana, orange, shaddock, pine-apple, tamarind, and to the juice and leaves of the boabab. The best butter (likewise an excellent medicune) may be procured from the shih or butter-tree, in the interior of the west of Africa, and the ground-nuts of Whidah ripen within six weeks from the time of sowing. The vegretable productions, used for sustenance, are principally wheat, barley, millet, poa Abyssinica, rice, the convolvulus batatas, L., yams, lotus berries, gum Senegal, dates, figs, the various kinds of spices, and especially sugar-cane; for drink, coffee is used, palm wine, from the fenale palm-tree, the milk of cocoanuts, and Cape wine; for clothing, cotton, hemp, and even flax. Here thrive the papaw, the pomegranate, five kinds of pepper, the best indigo, the dracana draco, from which is procured dragon's blood, the tallow-tree, the best wood for dyeing, and cabinet work, innumerable spices, \&c. Madngascrer is rich in the most valuable productions. Our information respecting the mineral kingdom is the most limitrl. Of gold, Africa has more than any other portion of the globe; and iron is found in most parts of this continent ; but it wants the other metals. Of other minerals, it has only saltpetre, sal ammoniac, some fuller's earth, and emery in abuudance; ambergris is found on the coasts. The want of salt, except in a few regions, is most severely felt.-The African races of men offer mauy points of interest to the inquirer. The majority of them are distinguished from the rest of the human furnily, not only by their black complexion and curly laair, but also by peculiarities in the construction of the bones of the head, and even of the nerves. This seems to imply that the negro is originally a distinct race. It is thought that traces of this primitive race may still be detected here and there; $e$. ginal Egyptians in the Copts, and of the Guanches (the original inhabitants of the Canaries) in the natives of Barbary. The population is probably leetween 100 and 110 millions. The interior of the country must be very populous, since, within two centuries and a lialf, it has contributed forty millions of vigorous men to the slave trade, and, notwitlistanding, is any thing but depopulated. Even the countries along the const are thickly peopled. Jackson computed the population of Morocco alone at seventeen millions; and the Barbary states, with Egryt, which constitute but an eighth part of the continent, contain twenty millions. The torrid Guinea has, on the whole, a numerous population; and large cities are situated on the Joliba, of which we hardly know the names. The inhabitants belong to two brancles of the human family; to the black, or Ethiopian race, which extends from the Joliba to the southern extremity, comprising, notwithstanding their tawny complexions, the Hottentots; and to the Caucasian race, which includes the natives of Barbary, the Copts, the $A$ rabs or Moors, the $A$ gaziones or $\Lambda$ byssinians, and the nations of Nubia. The Arabs are not to be regarded as aborigines of $A$ frica, but they have scatterect themselves, and become occupants of the greater part of the north and west. On the islands and some points of the sea-board, we find Portuguese, Spaniards, French, Dutch, British, and even Jews in particular spots ; but the Falaschas in Tigre, though they profess the religion of Moses, seem not to be of Hebrew descent. - The Arabic is the leading lauguage throughout all the north, and as far as the Joliba, where it is understood, in some degree at least, by those uations who revere the Koran. The Berberd and Shelluh tongues are spoken in the Barbary states, and along the Atlas mountains. The Mandingo language is used from the Senegal to the Joliba. On the western coast, a corrupt Portuguese is heard; in the regions of Abyssinia, the Tigre and Amhara tongues prevail. The languages of the blacks are as multifarious as the nations. In Sahara, alone, forty-three dialects are said to be spoken. But of all the liundred and fifty languages (this conjectural number was adopted by Seetzen) of the $A$ frican nations, we are hardly acquainted with seventy. Equally manifold are the modes of worship. Mahommedanism has diffused itself over the north to the Joliba, and most of the eastern coast ; the Christian religion is professed by the iuhahitants of Tigre and Amhara, by the Copts, the Nubians, and European strangers, though with great diversity of forms. The most disgusting Fetishism prevails among most of the negro nations, demanding, from many of its votaries, human sacrifices. - We must not look to $A$. for the triumphs of science, not even to the country which was its cradle in the infancy of man. All that the Pharaohs and Ptolemies had ever effected, was swept away by the storms which broke upon this unhappy region in the middle ages 
Schools, however, are sill maintained by the Mohammedans in the cities of Barbary, by the Maraboots, in the countries where they have settled, and, here and there, by the Copts and Monophysites in Tigre and Amhara. The arts are exercised only on the northern coasts, where the Moors manufacture much silk, cotton, leather, and linen ; an active commerce is carried on by them with the maritime nations of Europe, and, by means of caravans, a traffic, full as important, with the interior, to which they convey their own products and those of Europe. Some of the most important routes pursued by the caravans are the following:-1. From Mourzouk, the capital of Fezzan, to Cairo, thirty days' journey, by way of the market-places and encampments Siwah, Augila, and Temissa. 2. From Mourzouk to Bornou, fifty days' journey, by way of the deserts of Bilma and Tibesti; the market-ptaces and encampments are Temissa, Domboo, and Kanem. 3. From Mourzouk to Cashna or Cassina, sixty days' journey, by way of Hiatts, Ganatt, and Agadez. 4. From Fez to Timbuctoo, fifty-four days'; but a halt of some timc is made at the encampments, e.g.at Akka or Tatta, the general rendezvous, at Tegaza and Aroan, sixtyfive days ; so that this caravan is one hundred and nineteen days in reaching its place of destination. 5. Another route along the sea coast leads through Wady, cape Bodajor, and Gualata. 6 and 7. The caravans from Sennaar and Darfur to Egypt do not travel regularly every year, but once every two or three years; such a caravan comprises from 500 to 2000 camels. It goes about three miles an hour, and rarely travels more than seven or eight hours a day. - The blacks stand on the verge of absolute barbarism, even wherc they are united into states. Their wants are exceedingly simple, and every article used by them is prepared by themselves; the cloth which surrounds their loins, the hut which protects them from the weather, the bow and arrow necessary for the hunt and self-defence, as well as all their household furniture, are manufactured by themselves; the gold which they collect from the surface of the earth, is wrought by them into ornaments, and iron into arms. Commerce, however, with Europeans has taught them many wants, and increased their list of necessaries; among which may now be reckoned fire-arms, powder, brandy, tobacco, different kinds of cloth, glass, beads, coral, \&c. ; for which they barcer slaves, ivory, gold, and gums, the staples of $\Lambda$ frica. The slave trade is yet of such importance, that, although must of the European and American nations have agreed to prohibit it, nearly 50,000 negroes are yearly torn from the interior by the Mussulman, Portuguese, French, American, and even British dealers. Formerly, 105,000 slaves were annually introduced into the West Indies, besides those who were transported into $A$ sia by the Kermanians, and by the North Americans into the southern states of the Union. The exports of ivory, gold dust, and gums, are also important; those of ostrich feathers, tigers skins, hides, and other natural productions, are of less consequence. Of all the states of Africa, Barbary alone uses coin ; in the rest, not frequented by Europeans, money rarely serves as the medium of exchange; in some, on the western const, cowries are made to answer the purposes of coin; in others, pieces of salt. - The tropic of Cancer and the equator divide $A$ frica into three principal parts :-1. Northern Africa, comprising Egypt, the piratical states of Tripoli (including the coast of Barca), Tunis, and Algiers, the empire of Morosco, Fezzan, and the northern part of Soodan or the Sahara, with the Azores, Canary, and Madeira islands. 2. Ceutral Africa, comprising, on the eastern coast, Nubia, Tigre, Amhara, Efat, Adel. Ajan, the southern part of Soodan, with
Darfur and the countries of the Gallas ; and, on the western coasts, Benin, Owhere, Senegambia, and Guinea, besides the Cape Verd islands, those near Guinea, the sixteen Bissao islands, Socotora, \&c. 3. Southern Africa, with all the south-east and southwestern coasts and interior, the cape of Good Hope, and the island of Madagascar, the Comoro islands, with those of Mascareuhas, Amirante, Tristan d'Acunha, St Helena, and Ascension.-In an historical view, also, Africa is deserving of the minutest investigation, as one of the richest archives of former times and the ancient world. It guards, couched in mysterious characters, innumerable cannals of the history of man's progress from the earliest times down to the overthrow of the Roman empire in the East. In $\mathrm{A}$. the enterprising European is discovering new sources of industry and commerce. Great Britain has already flourishing colonies established on its coasts; on which the Portuguese colonies, planted four centuries since, laid the foundation of the colonial system of Europe. It is with reason, therefore, that Africa, has, in our days, engaged the attention of geographers, as in the period of Herodotus, and 400 years since, in the time of Henry the Navigator. The French expedition to Egypt (q. v.) first opened this country to modern investigition, and roused even the Turks from their sluggish apathy. British perseverance has created for the nations of the Cape new sources of prosperity, and established a colony there, to receive the superfluity of our population; while the colony previously established (1793) at Sierra Leone has been labouring, not without success, for the civilization of the negroes. At the same time, adventurous travellers, British, German, French, Italian, and American, have penetrated into A. from all sides. But we must regard as erroneous the idea that the eastern coasts of $\mathrm{A}$. were visited, in the remotest antiquity, by the Jewish and Tyrian merchants, who, according to Hebrew accounts, sailed to Tarshish and Ophir, said to be situated on those coasts, and carried thence great riches to kings David and Solomon. For a history of the voyages of discovery in Africa, since the time when the Phonicians, under Necho, king of Egypt, sailed from the Red sea, round Africa, and back through the pillars of Hercules ( 600 years before the Christian era), down to the enterprises of the latest times we refer the reader to the complete history of voyages and discoveries in Africa, from the most distant times down to the present, by Dr Leyden and Mr Hugh Murray, Edinburgh, 1817; translated from the English into ${ }^{9}$ French, with additions, Paris, 1821, 4 vols; and the N. Geogr. Ephem., 1824. Among the most important travels of our own time are the mission of Bowdich, an Englishman, to Ashantee, in 1818 , which has made us acquainted with a powerft and warlike nation near the western coast; and the journeys undertaken by Burckhardt to Nubia, which have made known to us the active conmerce of the Nubian nations. It is principally by means of the se that the "African Association," incorporated in 1787 , in London, as well as eke British consulate (e. g. Salt, in Egypt), and the British Biblc and Mission. ary societies, have been cnabled to mise the reil which hung over this continent. The bold Mungo Park, Hornemann and Rontgen, of Neuwied, had previously penetrated into the interior. 'The last was murlered on the road to Timbuctoo, not far from Mogadore. Besides these mentioned above, we ought to cite Leod's Voyage to Africa, London, 1821, becanse it gives a more minute description of the peoplc of Dahomy (q. v.), who inhabit the most fertile part of Guinea, with which we were only superficially acquainfed from the accounts of Norris, and Captain Lyon's Narrative of 'Travels, 1818-20, in Nurthiern 
Africa, Loudon, 1821, who, starting from Tripoli, visited the cares of the tribes of mount Garenn, and perietratel by wny of Mourzouk, to Tegerhy, (240 4. N. lat., the most southern city of the kinglom of Fezzn:, in company with his friend Ritchife, who dievl, lowever, in Mourzonk, Nov. 20, 1819. In September, 1821, dnctor Oulney, inajor Denlam, and captain Clapperton, proceeded on an cxpedition of a similar nature to Tripoli, in order to travel to Bornou, by way of Mourzouk, and explore the course of the Niger. Oudney died at Murmur, Jan. $12,182 \mathrm{t}$ in consequeuce of contching a cold when the frost was so violent on a plain, between lills of sand, that water froze in the lenther bags. His fellow-traveller, Clapperton, pursued his journey to Cano, the present capital of Houssa, and reached Soccatoo, the residence of the governor of Sondan. They discovered the fresl-water lake T'schad, into which two large rivers empty thenisel res, the Shary from the sonth, the Yaou from the west. (See Nirrative of Travels and Discoveries in Northern and Central Africa, by maj. Denham, capt. Clapperton, and the late Dr Oudney, in the years 1822, 23, 24, London, 1826.) In 1824, major Gordon Ising undertook to travel from Tripoli to Timbuctoo. Clapperton commenced, in 1825, a new expedition Into the interior from Benin, by way of Soccatoo, to the Tschad, in order to penetrate into Abyssinia through Timbuctoo, whence Laing was to start for Benin. He was accompanied by doctor Dickson, the naturalist, capt. Robert Pearce, and loctor Morrison. Clapperton died of a dysentery at Soccatoo, A pril 13, 1827, and Laing is now known to have been killed near Timbuctoo in the latter part of the year 1826. Clapperton's journal of his second expedition has been published at London, 1829, together with the journal of Richard Lander, from Cano to the sea-coast. To Lander the merit belongs of solving the long disputed question regarding the mouth of the Niger. Sailing down the river, he entered the sea by the outlet distinguished on maps by the name of Nun. Among the German aud French adventurers, who have explored the interior of Africa, starting from Egypt, are Minutoli (q. v.), Caillaud, and since the Jear 1822, Ed. Ruppel. lippel explored, in 1825, the great Oasis in the west of Nubia, and the unknuwn country of Kordofan ; and undertook, in 1826, a journey to the Red sea. He has imparted to the public much that is new respecting Egypt and Ethiopia, and the antiquities of the East, in von Zach's Corresp. Astron. The French Gasp. Mollien, who published a Voyage dans l'Intérieur de l'Afrique aux Sources du Sénégal et de la Gambia, Paris, 1820, 2 vols., set out from St Louis, and reacher the sources of the Senegal, the Gambia, and the Rio Grande, at no great distance from each other, lon. $7^{\circ} 15^{\prime} \mathrm{W}$., and lat. $10^{\circ} 30^{\prime} \mathrm{N}$. in the neighlourhood of Teemboo. But he was unable to reach the sources of the Niger, and also wanted instruments to give accuracy to his observations. In the connexion of those two streams by the Nerico, he has shown the route on which the caravans from the kingdoms of Oubi and Foutadiallon, in the interior, might proceed along the Senegal to fort St Louis. Much light has been shed over the south of Africa by Burchel, an Englishman, who travelled five years in the interior, setting out from the Cape. Before him, the Cape itself had been explored, by Barrow, in 1797, and by Jolin Campbell, agent of the London Missionary Society, as far as Latakoo, a scttlement of the Bushwana tribe, 900 miles north of Cape Town. In 1818, Camphell undertook a second journey, in the same direction, arrived at Latakon in 1819, and reached, in April, 1820, Old Latakoo, containing 8000 inhabitants. He here found, in a northerly direction, several populous cities, situated in a fertlle and cultivated country, where he discov. ered the tribe of the red Caffres, and reached Kurerchanee (almost $24^{\circ} \mathrm{S}$. lat.), a city of the Marootzees, near the eastern coast, said to contain 16,000 inhabitauts. Auguste Caillé, a French traveller, by his own account renclied 'Timbuctoo, $\Lambda$ pril $19,1828$. The committee of the geographical society at Paris, appointerl to examine him, report that his journey is connected, in u way very advuntagcous for science, witl those of Park, Laing, and others, whohave explored A. It may be observed, however, that considerable doubts are entertained as to the antlienticity of his stateunents. Thus the courage of Europears discoverers has penetrated $\Lambda$ frica, froun four sides, the Cape, Senegal, Tripoli, and Egspt. Nortl Africa has now been intersected aud scientifically explored, by five or six important expeditions. But there are yet wanting communication and comexion between the 20 or 25 principal lines, which mark the routes of the discovercrs. The space already explored by them in Africa is estimated at 225,000 . square miles. We have, therefore, accounts more or less antlientic respecting the 50th part of this vast continent. (Ste Jomard., Sur les Déconevertes dans l'Intérieur de l'Afrique, Rev. Enc., 1824, Dec.) Ukert las compiled the latest geography of the northem laalf of Africa (Weimar, 18\%4, the 21st vol. of the Vollst. Handb. der nuesten Erdbeschreib.) A new ancl very completc lithographic map of Africa was published in 1828, by Cotta, at Munich, containing all the late additions to African geography, price six guilders. For information respecting the American colony Liberia, and the other important settlements on this continent, see the separate articles.

African Association; a society of 95 members, who held their first neeting, June 9, 1788, in London. Its object is to explore the interior of $\Lambda$ frica, to promote the civilization of the blacks, and the commercial interests of Great Britain. The soul of this association was the famous Sir Joseph Banks. (See Banks.) Ledyard, the American traveller, aud Lucas, were the first persons sent out to explore the interior of Africa, at the expense of this association. which subsequently despatched, at different times and on different roútes, major Houghton, Mungo Park, and two Germans. Hornemann - and Burckhardt. (q. v.) See the results of these enterprises in the Proceedings of the Association for promoting the Discovery of Africa, 1790.

AFRICAN CoMPanY; a society of merchants established by Cliarles II., for the purpose of trading to Africa. Similar companies had been formed during the reigns of Elizabeth, of James I., and of Charles 1., but did not continue long. Another was incorporated in 1662, with a charter from Charles II., securing to the British a monopoly of all commerce from cape Blanco to the cape of Good Hope. The last incorporation of this kind was formed in 1672 , and conducted for some time a flourishing trade. $\Lambda t$ the time of the English revolution, the trade to Africa was thrown open. All private traders, however, were obliged to pay 10 per cent. towards maintaining the forts and factories already erected. In 1750, the original company bein completely bankrupt, its forts and various establishments on the African coast were vested, by 23 Geo. II. in the present company of merchants trading to Africa. 'This company carnot trade as a corporate body, nor possess transferable stock. Its dities are to maintain the forts and garrisons in good order; and any British subject may be admitted into it on the payment of 40 shillings.

African Institution; a society in England, the first meeting of which was held, April 14, 1807. Its principal olject is the abolition of the slave trade, 
aul the promotion of civilization among the African sations. With this view, it labours to collect the most complete accounts of the agricultural and commercial relations of the country, and of the physical, intellectual, and political condition of its inhabitants ; to form connexions with them; to introduce valuable plants; to found schools; to make the natives acquainted with the useful arts of Europe, \&c. The institution is governed by a president, vice-president, and thirty-six directors. But its funds have not been sufficient to accomplish much. It has, however, supported teachers in Sierra Leone, and exerted itself with zeal for the abolition of the slave trade, as may be seen from its excellent annual reports.

AFT; a sea term, signifying near the stern of the ship.

AGA; among the Turks, the commander of a body of infantry; likewise a title of politeness. The $A$. of the Janizaries, their commander-in-chief, had nearly as much authority as the grand vizier, and was the only person allowed to appear before the grand seignior, without his arms crossed on his breast, in the attitude of a slave. The word $a g a$ is often used as a complimentary title in Turkey, much in the same way as captain is in some parts of the United States. The clief officers under the khan of Tartary are also called $A$. The $A$. of Algiers is the president of the divan, or senate.

AGADEs (Audagost of Edrissi); a flourishing town of Central Africa. It appears to be the centre of the trade of the eastern part of the interior of Africa. It is $\mathbf{4 7}$ days' journey from Mourzouk, and many of the merchants from that quarter stop at $\mathrm{A}$. to change their commodities for those of Soudan, and the countries to the south of the Niger. Hornemann reports it to be the capital of an independent kingdom called Asben.

Agalmatolite; a soft mineral substance, capable of being cut with the knife, of a dull greenish, reddish, or yellowish-white colour, and consisting of silex and alumine, with a little potash. It is chiefly found in China, where it is wrought into figures and various ornaments. It has lately been recommended as a substitute for the bricks made of Cornish porcelain clay, to measure high heats in the pyrometer of Wedgewood; it being capable of standing a great heat, and of contracting its dimensions very considerably and equably.

AgamemenoN; king of Mycene and Argos, son of Plisthenes, nephew of Atreus, and brother of Menelaus and Anaxibia. His mother is said by some to have been Eripliyle, by others, Aerope. Common opinion, and the authority of Homer, make him the son of Atrens. At least, the two brothers are denominated Atrides by Homer. From Tantalus, the fouuder of the race, down to Agamemnon and his children, the members of this family of heroes were constantly persecuted by fate. (See Tantalus, Pelops, Atreus, and Thyestes.) The children of A. and Clytemuestra were Iphigenia, Electra, Chrysotheinis, and Orestes. When the Trojan war broke out, A. was appointed leader of the united army of Greeks, and manned alone 100 ships. The army assembled in the bay of Aulis in Boeotia. Here they were loug detained by a calm, occasioned by the anger of Diana (see Iphigeniu), but finally arrived hefore 'Troy. During the protracted siege of the city, $A$. appears superior to the other chiefs in battle aud in councils, and maintains, under all circumstances, the diguity of a commander. .His quarrel with $A$ chilles is described under Achilles. Returning home, after a ten years' siege, he was treacherously assassinated. Aigisthus, whom, at his departure; he had pardoned for the murder of Atreus, and intrusted with the care cf his wife and cl:ildren, joined with Clytennestra, and slew him at a banquet, together with Cassandra, the daughter of Priam (who had fallen to his share in the division of the captives), and their children. Thus says Homer; others say that Clytemnestra murdered him in the bath, having entangled him in a tunic. The cause of his murder is alleged by some to have been her adulterous connexion with Egisthus; by others, her jealousy of Cassandra.

Agamic Plants. See Cryptogamic.

AGANIPPE, likewise called Hippocrene; a fountain which, according to the Grecian poets, sprang out of the summit of Helicon, the seat of the muses, when struck by the hoof of Pegasus. This fountain had the property of inspiring with poetic fire whoever drank of it. Solinus distinguishes A. from Hippocrene as a different fountain.

AGAPE, in ecclesiastical history (from a $\gamma \alpha \pi n$, Gr. love) ; the love-feast, or feast of charity, in use among the primitive Christians, when a liberal contribution was made by the rich to feed the poor. St Chrysostom gives the following account of this feast, which he derives from the apostolical practice. He says, "'The first Christians had all things in common, as we read in the Acts of the Apostles; but when that equality of possession ceased, as it did even in the apostles' time, the agape or love-feast was substituted in the room of it. Upon certain days, after partaking of the Lord's supper, they met at a common feast, the rich bringing provisions, and the poor, who had nothing, being invited." These love-feasts, during the three first centuries, were held in the churches without scandal, but in after times the heathen began to tax them with impurity. This gave occasion to a reformation. The kiss of charity, with which the ceremony used to end, was no longer given between different sexes, and it was expressly forbidden to have any beds or couches for the convenience of those who wished to eat at their ease. The abuses, however, became so notorious, that the holding of the A., in churches at least, was solemnly corldemned at the council of Carthage, in the year 397. Some modern sects, as the Wesleyans, Sandemanians, Moravians, \&c. have attempted to revive this feast.

Agaric, Agaricon, Agaricos; the mushroom, a genus of the order of fungi, belonging to the class of cryptogamia, Linuæus. The generic character is is pileus, or cap, with gills underneath, which differ in substance from the rest of the plant, being composed of two laminæ; the seeds are in the gills.-Some have enumerated no less than 634 species of this fungus, others 400 . Of all these, only one species, A. campestris, common mushroom, or champignon, has been selected for cultivation in England. It is considered the most savoury of the genus, and is much in request for the table. It is eaten fresh, either stewed or boiled, and preserved either as a pickle or in powder; and it furnishes the sauce called ketchup. The field plants are better for eating, inasmuch as they are more tender than those raised on artificial beds.. The wild mushrooms are found in parks and pastures, where the turf lias not been ploughed up for many years, and the best time for gathering them is August and September.

Agate; a fossil compounded of varions substances, as chalcedony, cornelian, jasper, hornstone, quartz, \&c. These different fossils do not all occur in every A., commonly only two or three of them. There are different kinds of $\Lambda$., as the fortification, the lindscape, the riband, the moss, the tube, the clouded, the zoned, the star, the fragment, the punctuated, the petrifaction, the coral, and the jasper $\Lambda$. No country aftords finer A., or in greater abundance, than Germany. It is found in great quantities at Oberstein, in that couniry. It is also found in France, England, Scolland, Ireland, Sicily, Siberie, 
and rery benutiful in the Fast Indies, where, however, it is confounded with onyx. It is cut into vases, mortars, snufr-boxes, cups, rings, seals, handles fur knives and forks, hilts for swonds, beads, snelling-boxes, \&c. It was highly valued by the ancients, who exfcuted many fine works with it. The collections of Brunswick and Dresdeu are remarkable for beautiful specimens of this kind. Great medicinal virtues were fornerly attributed to the agate, but it is now rejected from medical practice. Agate sometimes contains figures bearing a striking resemblance to some regularly-shaped object, either natural or artificial, e. g. a man, a circle, an animal, \&c. This kind is the most prized. These figures unay, however, be produced by artificially staining the stone, so that stories of wonderful figures found on agates are not to be implicitly believed.

AGлтно ; an Athenian, distinguished both as a tragic and comic writer. We know only the names of some of his pieces. He is said to have been too partial to antithesis. As a tragic poet, le was once crowned at the Olympic games. Ite was a friend of Socrates and Furipides, and was the first who wrote on fictitious subjects. He was distinguished also for musical talent.

AGatrocLEs was one of the boldest adrenturers of antiquity. His history is principally drawn from Diodorus Siculus, books 19 and 20, and fragments of book 21, and from Justin, books 22 and 23 . They derived their accounts fron different sources, and differ, therefore, especially in the history of his youth. Agathocles was the son of Carcinus, who, having been expelled from Rhegium, resided at Therure, in Sicily. On account of a mysterious oracle, he whs exposed in his infincy, but was secretly brought up by his mother. At the age of seven years, the boy was again received by his repentaut father, and sent to Syracuse to learn the trade of a potter, where he continued to reside, being admitted by Timoleon into the number of the citizens. He was drawn from obscurity by Damas, a noble Syracusan, to whom his beauty recommended him, and was soou placed at the head of an army sent against $A$ grigentum. By a marriage with the widow of Damas, he became one of the most wealthy men of Syracuse. Under the dominion of Sosistratus, he was obliged to fiy to Tarentum, but returned after the death of the latter, usurped the sovereignty, in which he established himself by the murder of several thousands of the principal inhabitants, and conquered the greater part of Sicily, 317 B. C. He maintained his power twenty-eight years, till 289 B.C. To strengthen his authority in his native country, and to give employment to the people, he endearoured, like Dionysius, to drive the Carthaginians from $\mathrm{Si}$ cily. Having been defeated by them, and besieged in Syracuse, he boldly resolved to pass over to Africa with a portion of his army. Here he fought for four years, till 307 , generally with success. Disturbances in Sicily compelled him to leave his army twice, and, at his second return into Africa, he found it in rebellion against his son Archagathus. He appeased the commotion by promising the troops the booty they should win; but, being defeated, he did not hesitate to give up his own sons to the vengeance of the exasperated warriors, and expose these latter, without a leader, to the enemy. His sons were murdered; the army surrendered to the Carthaginians. He himself restored quiet to Sicily, and concluded a peace, 306 B. C., which secured to both parties their former possessions. He then engaged in several hostile expeditions to Italy, where he vanquished the Brutii, and sacked Crotona. His latter days were saddened by domestic strife. His intentiou was, that his youngest son, Agathocles, should
Inherit the throne. This stimulated his grandson, Archagathus, to rebellion. He murdered the intended heir, and persunded Mrenon, a favourite of the king, to poison him. This was done by means of a feather, with which the king cleaned his teeth after a meal. His mouth, and soon his whole boty, became a mass of corruption. Before he was entirely dead, he was thrown upon a fineral pile. According to some authors, he died at the age of 72 years; according to others, at that of 95 . Before his death, his wite, Texena, and two sons, were sent to Eggpt. His son-in-law, Pyrrhus, king of Epirus, inherited his infuence in Sicily and southern Italy. Agathocles possessed the talents of a general and a sovereign. He was proud of his iguoble descent. His cruelty, luxury, and insatiable ambition were the occasion of his ruin.

Agatmodesmon (Greek); a beneficent spirit, 이posed to cacodemon, an evil spirit. Ancient writers give this name to a kind of serpent revered by the Egyptians.

$A G E$, in law ; the time when the law allows persons to do acts, which, for want of years, they were prohibited from doing before. Some of the rules of the common law of England in regard to age, are as follow: fourteen years in a man, and twelve in a woman, is the age of discretion for consenting to marriage. At fourteen, a minor may choose a guardian. Trenty-one years is the full age. A person under the age of twenty-one may make a purchase, but may disagree to it, if he chooses, on reaching his full age. No one can be chosen a member of parliament under the age of twenty-one years, nor ordained a priest until the age of twenty-four years, nor made a bishop before he is thirty years old. In marriages, when either of the parties is under twentyone years, and is not a widower or widow, the consent of the parents or guardians of such minor is re. quired, if the marriage is in pursuance of a license ; or, if it be in pursuance of bans published, the parent or guardian may, at the time of the publication of the bans, declare in church his dissent to such marriage, and prevent its taking effect. The age for serving in the militia is from sixteen to forty-five years. Coke's 1 Inst. 78.-The following are some of the provisions of the Code Napoléon with regard to age : forty years are required for a member of the legislature, thirty for a judge, juror, or elector, and twenty-two to discharge any office in the courts. 'To contract marriage, it requires that the man should be at least eighteen years old, and the woman fifteen. But marriage is not valid without the consent of parents (or, in case of their death, of the other relations in the ascending line, who take their place), until the man is twenty-five, and the woman twenty-one years old, and even then it is necessary to give the parents or other relations notice. A person adopting must be as much as fifty years old, and at least fifteen years older than the person adopted, unless the latter has saved the life of the former, in which case it is only necessary that the person adopting should be of full age, and older than the person adopted. (See Adoption.) Full age is fixed at twenty-one years for both sexes. At sixteen years, a minor can make a will. Witnesses, in a strict sense, must be of full age. Under fifteen years of age, a person can only affirm, without an oath. An innocent debtor of seventy years and upwards cannot be deprived of his personal liberty. If a criminal is under sixteen years, and the jury find that he has acted without a proper sense of his guilt, he is acquitted, except that he may be confined, for a limited time, in a house of correction. These are the provisions of the French code. - In the United States of America, the rules of the English law respecting age have, in most cases, been adopted 
vinere applicable. To be chosen president of the U. S., a man must be at least thirty-five years old, a senator must be thirty, and a representative twenty-five years old. Every free white male citizen, of eighteen ycars, is obliged to serve in the militia till he reaches the age of forty-five years, unless exempted for some special reason. See age in Criminal Law.

AGE. We find the ages of the world mentioned Jy the earliest of the Greek poets. They compared the existeuce of mankind to the life of an individual, and the earliest period of the world to the tranquillity and happiness of youth. Hesiod speaks of five distinct ages : 1 . The golden or Saturnian age, when Saturn ruled the earth. The people were free from the restraint of laws; they had neither ships nor weapons, wars nor soldiers; the fertile fields needed no cultivation, and perpetual spring blessed the earth. 2. The silver age, which he describes as licentious and wicked. 3. The brazen age; violent, savage, and warlike. 4. The heroic age, which seemen an approximation to a better state of things. 5 . The iron age, when justice and honour had left the earth. The poet supposed this to be the age in which he himself lired. Ovid retained, in his Metamorphoses, the division of Hesiod, with this difference-he omitted the heroic age, and placed the four ages before the flood of Deucalion. - This idea, first used as a poetical embellishment, was also introduced into philosophy. The ages were looked upon as a part of the great year of the world, the revolution of which was to bring the heavenly bodies to their first position. Mythology was thus brought into the closest connexion with astronomy. The first, or golden age, was under the dominion of Saturn; the second, of Jupiter; the third, of Neptune ; and the fourth, of Plito, or, as sone say, of Apollo. The time of the completion of the great year of the world, or of the heavens, was fixed by some at 3000 solar years; by others, at the mysterious number 7777 solar years. Cicero estimated it at 12,954; Heraclitus, at 18,000; and Orpheus, at twelve months, consisting each of 100,000 years. The Sibylline books divided it into ten secular months, or the four seasons of the year. Spring was the golden age ; Summer, the silver; Autumn the brazen, which was interrupted by Deucalion's flood; and Winter, the iron age ; and then the cycle began with Spring again. The idea of nges of the world is so deeply fixed in the nature of man, that it is interwoven with the religious sentiments of almost every nation on the globe. We find examples of it in the millennial reign of the Apocabyse, and in the Yugs of the East Indians. The idea of four ages of the world prevailed among the Brahnins. The first, a kind of golden age, lasted, according to their tradition, 1,728,000 years; the men of this period lived 400 years, and were all ginnts; in this period, the gorl Brahma was born. In the second period, which lasted $1,296,000$ years, their rajahs were born; men lived only 300 years, and vice began to creep into the world. During the third ige, which lasted 8,064,000 years, men lived only 200 years, owing to the increase of vice. Of the last age, in which we now live, 4,02\%,213 years are already gone, and the life of man is sunk to one fourth of its original duration.

AGE. For the different ages of life, see Life; see also Longevity.

AGEDA, synod of; an assembly of Jewish doctors, held A.D. 1650, so denominated from a plain, on which they met, about thirty leagues distant from Buda in Hungary. More than 300 rabbies, and many other Jews, of different nations, attended. The object was, to debate the question whether the Messinh had appeared. The negative of the question was carried, and it was agreed that his coming was delayed on account of their sins and impenitence. They were of opinion that he would be bom of a virgin, would come as a great conqueror, would deliver the Jews from every foreign yoke, and alter nothing in the Mosaic religion. Some ecclesiastics from Rome attended this neeting, but the multitude would not hear them.

Agenoglans, or Azamograns, are children purchased from the Tartars, or raised every third year, by way of tribute, from the Christians tolerated in the Turkish empire. They are circumcised and instructed in the religion of their masters, and in military exercises. From them the janizaries were recruited. See Janizaries.

AG ENDA, among divines, sometimes signifies things which a man is bound to perform, in opposition to credenda, which he is bound to believe. It also denotes the service or offices of the church. A. is also used to signify church books compiled by public anthority, prescribing the order to be observed by the ministers and people, in the ceremonies and devotions of the church; e. g. the ritual, liturgy, missal, \&c. In Prussia, the new A. (in the last sense), arbitrarily introduced by the king, but rejected by many clergymen, and congregations, has occasioned some trouble of late years. Honours and promotions induced many of the clergy to adopt it, but others remained firm in their opposition. The city of Berlin and the famous professor Schleiermacher were very conspicuods in resisting it. In all the churches of which the king was patron, it was introduced.

Agesilaus ; a king of Sparta, 390-306, B. C. ; elevated to the throne after the death of his brother Agis, by Lysander, who afterwards formed a conspiracy to depose him; but the plan was discovered and frustrated. Called by the Ionians to their assistance against Artaxerxes, he commenced, after Lysander's death, his glorious career; defeated the Persians, but was compelled to stop in his victorious course, and turn his arms against Thebes, Corinth, \&c., which had united against Sparta, and, in a subsequent war with Thebes, to contend against Pelopidas and Epaminondas, the greatest generals of those times. His prudence, however, saved the city, without the hazard of a battle. He delivered it anew, at the age of eighty years, though it was actually in the hands of Epaminondas. On his return from his last campaign in Egypt, loaded with honours and presents, he was overtaken by a storm on the coast of Libya, and perished, being then in his 84th year. In person, he was small and insignificant. He was, nevertheless, a noble prince, and almost adored by his soldiers, though he sometimes violated the virtue of justice, in cases in which he could be useful to his country or friends.

Aggregation, in physics; a species of union, whereby several things, which have no natural dependence or connexion with one another, are collected together, so as, in some sense, to constitute one. Thus, a heap of sand, or a mass of ruins, are bodies by aggregation.

Agurus, or AUGrrm; a village in the county of Galway, in Ireland, memorable for a decisive battle fought in the neighbourhood, July 12, 1691, between the forces of William III., amounting to $20,000 \mathrm{men}$, commanded by general Ginckel, and those of James II., amounting to 28,000 men, commanded by the French general St Ruth. The forces of William were victorious.

Agincourr, or Azincounx; a village in the district Saint-Pol, in the department Pas de Calais, famous for the battle of Oct. 25, 1415, between the French and English. Henry V., king of Ergland, eager to conquer France, landed at Harfeur, took 
the place by storm, and wished to march through picanly to Calais, in onler to fix his minter-quarters ir its neighbourhood. With a powerful force, the dauphin advanced agaiust him. The nunnerical superiority of the Frenil was great, and the confidence of the leader and the nobles such, that they refused the proffered aid of the dinke of Burgundy and the city of Paris. Henry $V$. retreated to the Somme. The French followed to hariss his retreat, and to defend the passage from Abbeville to St Quentin, which he gained ouly through the inattention of the enemy. The. English, howerer, being destitute of every thing, and reduced by sickness, IYeury asked for peace on disadvantageous terns. The Freuch refused his proposals, and succeeded in throwing themselves between Calais and the Englisl. These Intter consisted of 2000 men at arms, and 12,000 archers, and were ranged in onder of battle between two hills, with the archers on tlie wings. Stakes, of which every man carried one, were fixed in front of them. The French, commanded by the constable l'Albert, numbered 100,000 troops, of whom 8000 were men at arms. They arranged themselves in two divisions, with the mell at arms, of whom 2000 were mounted, in front. The English first put themselves in motion. The French horse instantly hastened to meet them, but were receired with such a shower of arrows by the archers, that they fell back on the first division, and threw it into confusion. The light-arned archers seized their clubs and battleaxes, and broke into the ranks of the knights on foot, who could not move on account of their heary coats of mail, and the closeness of their array. The English horse flew to assist the archers; the first French division retreated; the second could not sustain the charge of the victors; and the whole French army was soon entirely scattered. The victory was complete. Henry thought that the French vould rally and renew the battle; and, being alarmed also by the report, that a party of peasants, in arms, were plundering his baggage, he ordered all the prisoners to be massacred. The command was already executed, when lie discovered the groundlessness of his fear. The victorious army, however, in the pursuit of the flying enemy, took 14,000 prisoners more, 10,000 Frenchmen lay dead on the luattlefield. Among them was the constable, with six dukes and princes. Five princes, among whom were the dukes of Orleans and Bourbon, were taken prisoners. The Fnglish lost 1600 men killed; among them the duke of York, Henry's uncle, whom the duke d'Alencon slew at his side, while pressing towards the king. He had already dashed the crown from Henry's head, and lifted his hand for a more effectual blow, when the king's attendants surrounded him, and he fell covered with wounds. After the battle, the Fnglish continued their march to Calais, and thence sailed for England, to assemble an army for a new iuvasion.

Aglo is the difference in value between bank money and coin or other currency. The term is in most frequent use in Holland and Venice. It is, however, used at Ilamburg and other places in Germany. It is synonymous with premium, when the bank money is worth more than the same nominal amount of the current coin, and with discount, when its value is less. The agio at the bank of Amsterdam was from three to four per cent: before the French invasion of Holland in 1795; that of Venice was formally fixed at 20 per cent.; the bank money of each of those places being so much more valuable than the current coin. This difference in value arises often from the circumstance, that the current coin is depreciated by wearing and clipping. The agio of the bank-money of Ilamburg was formerly fourteen per ceut. on this account. Agio is sometimes used to signify the premiun or discount on bills of exchauge.

AGIS IV., king of Lacedremon, and colleague of Leonidns in the government of Sparta, was the son of Eudanidas, and a lineal descendent of Agesilaus. Historians affirm that he was, in youth, of singular promise, and that, in unaturer age, he prepared, by the introduction of new laws, to correct the abuses which had crept into the Spartan government. This he found a mensure of peculiar difficulty, but he was supported by his naternal uncle Agesilans, though with a selfish design, and likewise by many of the citizens. They obtained a law for the equalization of property, and $\Lambda$. himself shared a valuable estate with the community. In consequence of his exertions, Leonidas was deposed and banisliel. Tlie people, however, soon becaue dissatisfied with the projected reform, and while $A$. Was leading an army to aid the Achrans, the indiscretion of lis uncle Agesilaus during his absence, occasioned a conspiracy for the restorntion of Leonidas. The conspiritors, having succeeded, forced A. to take refuge in a temple, which he never left but for the purjose of batling. On one of these occasions, he was surprised and dragged to prison. The ephori haviug there questioned him respecting his views in altering the laws, he answered that it was for the purpose of restoring those of Lycurgus. Sentence of death was passed upon him; but the ministers of the law, until forced by Deinochares, refused to conduct him to a chamber reserved for the execution of crininals. IIe was there strangled, and he submitter to his sentence with heroic firmness. The grandmother and mother of $A$. shared the same fate.

Agrtators, in English history, were persons elected by the army, in 1647 , to watch over its interests, and to control the parliament, at that time sitting at Westuninster. Two private men, or inferior officers, were appointed fron each troop or coinpany, and this body, when collected, was presumed to equal the house of commons; while the peers were represented by a council of officers of rank. Cronwell at first made use of them, but afterwards issted orders for suppressing them. These associations, so dangerous to the constitution, gave rise to the act which forbids any member to enter either house of parliament armed-a regulation enforced with jealousy to this day. Hume's Hist. cliap. lix. The term Agitator has been applied in later days to political demagogues.

AgLais; according to Hesiod, one of the three graces, daughter of Jupiter and Eurynome; accorling to others, the mother of the graces, and wife of Vulcan. (See Graccs.)

AGNAvo; a lake lying west of Naples. In its neighbourhood are the fainous grotto del Cane and the baths of St Januarius. The former is noted for the suffocating vapours of carbonic acid gas, which ascend from its bottom. The baths are beneficial in cases of gout, syphilis, \&c. Their reputation has been increased, of late years, by the way in which they have been applied by Mr Von Gimbernat to restore the weakened electricity of the sick.

Agnates (agnati), in the civil law; relations on the male side, in opposition to cognates, relations (nI the female side. In the Scottish law, $\Lambda$. are understood to be those persons nearest related by the father, though females intervene.

AGNEs, St ; a saint who suffered martyriom at the time of the persecution of the Christians, in the reign of the emperor Diocletian. Her festival is celebrat ed on the 29th of January. Domenichino has painted her at the moment of her execution. Two churches of this saint, one in Rome, the other near tlue city, are remarkable buildings. In front of the latter, the 
feast of the saint is celebrated with much observance. Many cattle, horses, \&c. are brought there and blessed by the priest. This ceremony is thought to protect them against sickness during the following year.

Agnrs, St; one of the Cassiterides, or Scilly isles. (q. v.) This island is commonly called Lightkouse island, because it has a light-house. W. Ion. $6^{\circ} 20^{\prime}$; N. lat. $49^{\circ} 53^{\prime}$.

AgNes SOREL, the mistress of Charles VII., king of France, was born 1409, of a noble family, and was one of the most beautiful and accomplished women of her time. As lady of honour to Isabella of Lorraine, duchess of Anjou, she accompanied that princess, in 1431, to the French court. Her beauty attracted the farour of the young king, and he appointed her one of the queen's ladies of honour. A fter some resistance, A. yielded to the passion of the monarch. The English then had possession of half of France; and Charles VII., though naturally bold, became depressed and inactive under the weight of his misfortunes. A. alone was able to rouse him from his apathy, and make him feel what he owed to himself and his people. The eventual success of his arms increased his passion for his mistress, who did not, however, abuse her power over him. She retired, in 1445, to Loches, where Charles had built her a castle. He afterwards conferred on her the county of Penthievre, in Bretagne, the seigniories of Roche-Serviere and Issodune, in Berri, and the chateau de Beauté, on the banks of the Marne; whence she received the name of dame de beauté. She had lived here about five years, frequently visited by the king, when the queen invited her again to court, in 1449. A. consented, and to be nearer the king, proceeded to the castle of Masnal-la-Belle, where she died, in 1450, so suddenly as to afford ground for the suspicion of poison. She was buried in the collegiate church of Loches where her monument was to be seen in 1792. She left the king three daughters, who were acknowledged by him, and portioned at the expense of the crown.

Agnes, Maria Gaetana, a learned Italian lady, was born at Milan, in 1718. In her ninth year, she spoke Latin with correctness, and also delivered an oration in this language, in which she maintained that the study of the ancient languages was proper for females. This oration was printed at Milan, in 1727. In her eleventh year, she is said to have spoken Greek as fluently as her mother tongue. She now proceeded to perfect herself in the oriental languages, so that she was usually called a living polyglot. She next studied geometry and speculative philosopliy. Her father fostered her love of learning by assembling at his house, at certain times, learned societies, in which Maria proposed and defended philosophical theses. The president de Brosses asserts, in his Letters on Italy, that nothing can be inagined more delightful than these conversations with one of the prettiest and most learned females of the time. In her twentieth year, she appears to hare become tired of these erudite disputations, the substance of which was afterward published by her father. They fill a quarto volume. Mathematics now attracted her attention, and she composed a treatise on conic sections; besides which, in her thirtieth year, she published a treatise on the rudiments of analysis, which has been considered as the best introluction to Euler's works, and was translated into English, in 1801, by the reverend John Colson, professor of mathematics at Cambridge. It gained her so much reputation, that she was appointed, in her thirty-second year professor of mathematics at the university of Bologna. IIer deep study of this science seems to have cast a gloom over her spirits. She secluded herself altogether from society, retired to the strict order of blue nuns, and died in her eighty-first year, 1799. Her sister, Maria Theresa, set to music several cantatas, and the three operas, Sophonisba, Ciro in Armenia, and Nitocri, with applause.

Agnonev, in ancient Rome; a name or epithet given to a person by way of praise or dispraise, $\omega^{\circ}$ from some remarkable event in his history. Such names remained peculiar to the person, and not descendible to his issue. Thus one of the scipios obtained the A. of Africanus, and the other of Asiaticus, from their achievements in Asia and Africa. The Romans often had three names besides the $A$.; the pronomen, corresponding to our Christian name, distinguishing the individual from others of the same family ; the second, or nomen, marked his clan ; and the third, or cognomen, expressed his family; to these the A., e. g. Atticus, Cunctator, Germanicus, \&c. was added.

Agnos DeI (Latin; the Lamb of God). 1. A prayer of the Romish liturgy, beginning with the words Agnus Dei, generally sung before the communion, and according to the regulation of pope Sergius I., in 688, at the close of the mass. 2. A round piece of wax, on which is impressed the figure of the sacred Lamb, with the banner of the cross, or of St John, with the year and name of the pope: The pope consecrates and distributes a great number of them. It was originally customary, in the churches of Rome, to distribute the remains of the Paschal taper, consecrated on Easter eve, in small pieces, among the people, who burned them at home, as an antidote against all kinds of misfortune. But when the number of candidates became too large to be all satisfied, the above expedient was adopted. A. D. is also the name of that portion of the mass, which is introduced, in Roman catholic churches, at the distribution of the host.

$\Lambda$ cows, in geography; the inhabitants of a province of Abyssinia. They are, in their manners, ferocious, and in their religion, superstitious. They are heathens, and adore the spirit residing in the Nile. (See Abyssinia.) Bruce's Travels, vol. i. 401. vol. iii. 527 .

AgRA; a province of Hindostan Proper, situated between $25^{\circ}$ and $28^{\circ} \mathrm{N}$. lat. ; the capital of which, of the same name, is in the possession of the British. Several rajahs, allies of the British, possess the western and north-western district. The part of the province south of the Cliumbul is under the dominion of the Mahrattas. No part of Hindostan affords a richer soil ; grain of all kinds, sugar, indigo, and cotton, are yielded with little labour in all the British districts. Formerly the province was also famous for its silks. It furnishes superior horses. It contains six millions of inllabitants. A., the city, N. lat. $27^{\circ} 12^{\prime}$, and E. lon. $77^{\circ} 56^{\prime}$, is connected with the whole of the modern history of India. The Mahommedans call it Akbarabad. It is ornanented with splendid edifices, of which the Taje Mahal, or Crowi of Edifices, an unrivalled tomb to the memory of the empress of Shah Jehau, who died 1632, is the inost famous. This is wholly built of the finest white marble. General lord Lake took A. in 1803 , from the Mahrattas. A. is 137 miles fiom Delhi, ani 830 from Calcutta.

Agrariav Laws; laws enacted in ancient Rome for the division of public lands. In the valuable work on Roman history by $\mathrm{Mr}$ Niebulir, it is satisfactorily shown, tlat these laws, which have so long been considered in the light of unjust attacks on private property, had for their object only the distribution of lands which were the property of the state, and that the troubles to which they gave rise 
were occasioned by the opposition of persons who liad settled on these lands without having acquired any title to them. These laws of the Romans were so intimately connected with their system of establishing colonies in the different parts of their territories, that, to attain a proper understanding of them, it is necessary to bestow a moment's consideration on that system.-According to Dionysius of Halicarnassus, their plan of sending out colonists, or settlers, began as early as the time of Romulus, who generally placed colonists from the city of Rome on the lands taken in war. 'The same policy was pursued by the kings who succeeded him ; and, when the kings were expelled, it was adopted by the senate and the people, and then by the dictators. There were several reasons inducing the Roman government to pursue this policy, which was continued for a long period without any intermission ; first, to have a check upon the conquered people; secondly, to have a protection against the incursions of an enemy ; thirdly, to augment their population; fourthly, to free the city of Rome from an excess of inhabitants; fifthly, to quiet seditions; and, sixthly, to reward their retern soldiers. These reasons abundantly appear in all the best ancient authorities. In the later periods of the republic, a principal motive for establishing colonies was to have the means of disposing of soldiers, and rewarding them with donations of lands; and such colonies were, on this account, denominated military colonies. Now, for whicherer of these causes a colony was to be established, it was necessary that some law respecting it should be passed, either by the senate or people; which law, in either case, was called lex agraria, an agrarian law, which will now be explnined. $-\Lambda$ n agrarian law contained various provisions; it described the land which was to be divided, and the classes of people among whom, and their numbers, and by whom, and in what manner, and by what bounds, the territory was to be parcelled out. The mode of dividing the lands, as far as we now understand it, was twofold; either a Roman population was distributed over the particular territory, witlout any formal erection of a colony, or general grants of lands were made to such citizens as were willing to form a colony there. The lands which were thus distributed were of different descriptions; which we must keep in mind, in order to have a just conception of the operation of the agrarian laws. They were either lands taken from an enemy, and not actually treated by the government as public property, or lands which were regarded and occupied by the Roman people as public property; or public lands which had been artfully and clandestinely taken possession of by rich and powerful individuals; $\mathrm{or}$, lastly, lands which were bought with money from the public treasury, for the purpese of being distributed. Now, all such agrarian laws as comprehended either lands of the enemy, or those which were treated and occupied as public property, or those which had been buught with the public money, were carried into effect withont any public commotions; but those which operated to disturb the opulent and powerful citizens in the possession of the lands which they unjustly occupied, and to place colonists (or settlers) on them, were never promulgated without creating great disturbances. The first law of this kind was proposed by Spurius Cassius; and the same measure was afterwards attempted by the tribunes of the people almost every year, but was as constantly defeated by various artifices of the nobles; it was, however, at length passed. It appears, both from Dionysius and Varro (de Re Rustica, lib. 1), that, at first, Romulus allotted two jugera (about one and a fourth acre) of the public lands to each man: ther.
Numa divided the lands which Rommius had taken in war, and also a portion of the other public lands; aftervards Tullus divided those lands which Romulus and Numn had appropriated to the private expenses of the regal establishment ; then Servius distributed anoug those who had recently become citizens, certain fands which liad been takén from the Veientes, the Carites, and Tarquinii; and, upon the expulsion of the kings, it appears that the lands of Tarquin the Proud, with the exception of the Campus Martius, were, by a decree of the senate, granted to the people. After this period, as the republic, by means of its continual wars, received continual accessions of conquered lands, those lands were either occupied by colonists or re:mained public property, until the period when Spurins Cassius, twenty-four years after the expulsion of the kings, proposed a law (already mentioned), by which one part of the land taken from the IIernici was allotted to the Latins, and the other part to the Romau people; but, as this law comprehended certain lands which he accused private persons of having taken from the public, and as the senate also opyosed him, he could not accomplish the passage of it. This, according to Livy, was the first proposal of an agrarian law; of which he adds, no one was ever proposed, down to the period of his remembiance, without very great public conmotions. Dionysins informs is, further, that this public land, by the negligence of the magistrates, had been suffered to fall into the possession of rich men; but that, notwithstanding this, a division of the lands would have taken place under this law, if Cassius had not included among the receivers of the bounty the Latins and Hernici, whom he had but a little while before made citizens. After much debate in the senate upon this subject, a decree was passed to the following effect : that commissiomers, called decemvirs, appointed from among the persons of consular rank, should mark out, by boundaries; the public lands, and sloonld designate how much should be let out, and how much should be distributed among the common people; that, if any land had been acquired by joint services in war, it should be divided, according to treaty, with those allies who had been admitted to citizenship; and that the cloice of the commissioners, the apportionment of the lands, and all other things relating to this subject, should be committed to the care of the succeeding consuls. Seventeen years after this, there was a vehement contest about the division, which the tribunes proposed to make of lands then unjustly occupied by the rich men; and, three years after that, a similar attempt on the part of the tribunes would, according to Livy, have produced a ferocious controversy, had it not been for the address of Quintus Fabius. Some years after this, the tribunes proposed another law of the same kind, by which the estates of a great part of the nobles would have been seized to the public use; bnt it was stopped in its progress. Appian says, that the nobles and rich men, partly by getting possession of the public lands, partly by buying out the shares of indigent owners, had made themselves owners of all the lands in Italy, and had thus, by degrees, accomplished the removal of the common people from their possessions. This abuse stimulated Tiberius Gracchus to revire the Licinian law, which prohibited any individual from holding more than 500 jugera, or about 350 acres, of land; and would, consequently, compel the owners to relinquish all the surplus to the use of the public; but Gracchus proposed that the owners should be paid the value of the lands relinquished. The law, however, did not operate to any great extent, and, after having cost the Gracchi their lives, was by degrees rendered wholly inoperative. After this period, 
various other agrarian laws were attempted, and with various success, according to the nature of their provisions and the temper of the times in which they were proposed. One of the most remarkable was that of Rullus, which gave occasion to the cele. brated oration against him by Cicero, who prevailed upon the people to reject the law.-From a careful consideration of these laws, and the others of the saine kind on which we have not commented, it is apparent, that the whule object of the Roman agrarian laws was, the lands belonging to the state, the public lands or national domains, which, as already observed, were acquired by conquest or treaty, and, we may add also, by confiscations or direct seizures of private estates by different factions, either for lawful or unlawful causes; of the last of which we have a wellknown example in the time of Sylla's proscriptions. The lands thus claimed by the public became naturally a subject of extensive speculation with the wealthy capitalists, both among the nobles and other classes. In our own times, we have seen, during the revolution in France, the confiscation of the lands belonging to the clergy, the nobility, and emigrants, lead to similar results. The sales and purchases of lands, by virtue of the agrarian laws of Rome, under the various complicated circumstances which must ever exist in such cases, and the attempts by the goverument to resume or re-grant such as liad been sold, whether by right or by wrong, especially after a purchaser had been long in possession, under a title which he supposed the existing laws gave him, naturally occasioned great heat and agitation; the subject itself being intrinsically one of great difficulty, even when the passions and interests of the parties concerned would permit a calm and deliberate examination of their respective rights.-From the commotions which usually attended the proposal of agrariau laws, and from a want of exact attention to their true object, there has long been a general impression, among readers of the Roman history, that those laws were always a direct and violent infringement of the rights of private property. Eren such men, it has been observed, as Machiavelli, Montesquieu, and Adam Smith, have shared in this misconception of them. This erroneous opinion, however, has lately been exposed by the genius and learning of Niebuhr, in lis Roman history, above mentioned, a work which may be said to make an era in that department of learning, and in which he has clearly shown, that the original and professed object of the agrarian laws was the distribution of the public lands only, and not those of private citizens. Of the Licinian law, enacted about 376 B. C., on which all subsequent agrarian laws were modelled, Niebuhr enumerates the following as among the chief provisions: 1 . The limits of the public land shall be accurately defined. Portions of it, which have been encroached on by individuals, slall be restored to the state. 2. Every estate in the public land, not greater than this law allows, which has not been acquired by violence or fraud, and which is not on lease, shall be good against any third person. 3. Every" Roman citizen shall be competent to occupy. a portion of newly acquired public land, within the limits prescribed by this law, provided this land be not divided by law among the citizens, nor granted to a colony. 4. No one shall occupy of the public land more than five hundred jugera, nor pasture on the public commons more than a lundred head of large, nor more than five hundred head of small stock. 5. Those whio occupy the public land shall pay to the state the tithe of the produce of the field, the fifth of the produce of the fruit-tree and the vineyard, and for every head of large stock, and for every head of sinall stock, - yearly. 6. The public lands shall be farmed by the censors to those willing to take them on these terms. The funds hence arising are to be applied to pay the army.The furegoing were the most important permanent provisions of the Licinian law, and, for its immediate effect, it provided that all the public land occupied by individuals, over five hundred juger $a$, should be divided by lot in portions of seven jugera to the plebeians. - But we must not hastily infer, as some readers of Niebuhr's work have done, that these agrarian laws did not in any manner violate private rights. This would be quite as far from the truth as the prevailing opinion already mentioned, which is now ex. ploded. Besides the argument we might derive from the very nature of the case, we have the direct testimony of ancient writers to the injustice of such laws, and their violation of private rights. It will suffice to refer to that of Cicero alone, who says, in his Offices (lib. 2, c. 21), "Those men who wish to make themselves popular, and who, for that purpose, either attempt agrarian laws, in order to drive people from their possessions, or who maintain that creditors ought to forgive debtors what they owe, undermine the foundations of the state; they destroy all concord, which cannot exist when money is taken from one man to be gireir to another; and they set aside justice, which is always violated when every man is not suffered to retain what is his own"-which reffections would not have been called forth, unless the laws in question had directly and plainly violated private rights. The various modes in which those rights might be violated would require a longer discussion, and one which would partake more of legal investigation, than might be admissible in the present work. But as the republic of the United States, like that of Rome, has also been much occupied in legislating upon the subject of its public lands, and as laws have been made, in some of the states, bearing a considerable resemblance, in their operation, to the Roman agrarian laws, which will afford room for a useful and interesting comparison between the laws of the two republics, we sliall make some further remarks upon this subject under the head of Public Lands. See Lands, Public.

Agricola, Cneius Julius; a Roman consul under the emperor Vespasian, and governor in Britain, the yreater part of which he reduced to the dominion of Rome, about 70 A.D.; distinguished as a statesman and general. His life has been exeellently written by his son-in-law, the fanous Tacitus, who holds him up as an example of virtue. This life of $A$., in addition to its excellence as a piece of biography, contains information interesting to the British antiquarian.

Agricola, John, properly Schnitter, the son of a tailor at Eisleben, was born in 1492, and called, in his native city, master of Eisleben (magister Isleb.), also John Eisleben. He was one of the most active among the theologians who propagated the doctrines of Luther. He studied at Wit mberg and Leipsic; was afterwards rector and preacher in his native city, and, in 15\%6, at the diet of Spire, chaplain of the elector John of Saxony. He subsequently becanie chaplain to count Albert, of Mansfield, and took a part in the delivery of the confession of Augsburg, and in the signing of the articles of Smalcald. When professor in Wittemberg, whither he went in 1537 , he stirred up the Antinomian controversy with Luther and Melancthon. (See Antinomianism.) He afterwards lived at Berlin, where he died in 1566, after a life of controversy. Besides his theological works, he published a work explaining the common German proverbs. Its patriotic spirit, its strict morality, and pithy style, place it among the first German prose compositions of the time, at the side of Luther's translation of the Bible. In conjunction with Julius 
l'flug and Michacl Heldingus, he composed the finmous Interim.

AGricoltuge is the art of cultivating the earth in such a manner as to cause it to profnce, in the grentest plenty and perfection, those vegetables which are useful to man, and to the animals which he las suljected to his dominion. This art is the basis of ull other arts, and in all countries coeval with the first dawn of civilization. Withont agriculture, mankind would be savages, thinly scattered throngh interminable forests, with no other liabitations than caverus, hollow trees or huts, more rule und inconvenient than the most orkinary hovel or cattle shed of the modern cultivator. It is the most univcrsal as well as the most ancient of thic arts, and requires the greatest number of operators. It employs sevenrigliths of the popnlation of almost every civilized community.-Agriculture is not only indispensable to national prosperity, but is eminently conducive to the welfare of those who are engaged in it. It gives luealtls to the body, cnergy to the mind, is farourable to virtuous and temperate habits, and to knowledgc und purity of inoral character, which are the pillars of good government and the true support of national independence. - With regard to the history of agriculture, we must confine ourselves to slight skctclies. The first mention of agriculture is found in the writings of Moses. From them we learn that Cain was a " tiller of the ground," that $\Lambda$ bel sacrificed the "firstlings of his flock," and that Noah "began to be a huslandınan, and planted a vineyand." The Chinese, Japarese, Chuldeans, Egyptians, and Phonicians, appear to lave held husbandry in high estimation. The Egyptians were so sensible of its blessings, that they ascribed its invention to supcrhuman agency, aud even carried their gratitude to such an absurd excess as to worship the ux, for his services as a labourer. The Cartlaginians carried the art of agriculture to a higher degree than other nations, their contemporaries. Mago, one of their most famous generals, wrote no less than twenty-eight books on agricultural topies, which, according to Columclla, were translated into Latin by an express decree of the Roman senate.-Hesiod, a Greek writer, supposed to be contemporary with Homer, wrotc a poem on agriculture, entitled IVeeks and Duys, which was so denominated because husbandry requires an cxact observance of times and seasons. Other Greek writers wrote on rural teconomy, and Xenophon among the number, but their works have been lost in the lapse of ages.-The implements of Grecian agricul. ture were very few and simple. Hesiod ncntions a plough, consisting of tlirec parts-the sliare-beam, the draught-pole, and the plongh-tail ; but antiquarians are not agreed as to its exact form; also a cart with low wheels, and ten spans (seren feet six inclies) ill width; likewise the rake, sickle, and ox-goad; but no description is given of the mode in which they were constructed. The operations of Grecian culture, according to Hesiod, were neither numerous nor complicated. 'The ground received three ploughings-one in autumn, another iu spring, and a third immediately before sowing the seed. Manures were applied, and Iliny ascribes their invention to the frecin king Angeas. Theophrastus mentions six different species of manures, and adds, that a mixture of soils produces tie sanie effects as manures. Clay, lie observes, should be mixed with sand, and sand with clay. Seed wns sown by liand, and corered with a rake. Grain was reaped with a sickle, bound iu sheaves, threshed, then winnowed by wind, laid in chests, bins, or grnnaries, and takell out as wanted by the family, to be pounded in mortars or queru nills into meal.-The ancient Romans venerated the plough, and, in the earliest and purest times of the republic, the grentest praise which could be given te an illustrions character was to say that he was an industrions anul judicions huslanulman. M. Cato, the ceusor, who was celebrated as a statesman, orator, and general, laving conquered uations and governcd provinces, derived lis hilghest and most durable honours from having written a voluminons work on agriculture. In the Georgies of V'irgil, thic majesty of verse and the harmony of numbers add clignity and grace to thic most usefinl of all topics. The celebrated Columella flourished in the reign of the emperor Claudius, and wrote twelve books on hushandry, which constituted a complete trentise on rural aflairs. Varro, Pliny, and Palladius, were likewise among the distinguished Romans who wrote on agriculturil subjects.-With regard to the Roman implements of agriculture, we leuru that they used a great many, but their particular forms and uses arc very imperfectly described. From what we can ascirtain respecting them, they appear more wortliy of the notice of thic curious antiquarian, than of the practical cultivator. The plough is represented by Cato as of two kinds-one for strong, the other for light soils, Varro mentions onc with two monld-boands, with which he says, "when they plongh, after sowing the seed, they are said to rilge." Pliny mentions a plough with one mould-board, and others with a coulter, of which he says there were many kinds.-Fallowing was a practice rarely deviated from by the Romans. In most cases, a fallow and $\varepsilon$ year's crop succeeded eaclı other. Manure was collected from nearly, or quite as many sources as have bcen rcsorted to by the moderns. Pigeons' duig was esteemed of the greatest value, and, next to that, a mixture of night soil, scrapings of the streets, and urine, which werc applied to the roots of the vine and olive.-The Romans did not bind their corn into sheaves. When cut, it was sent directly to the urea to be threshed, and was separated from the chaff hy throwing it from one part of the floor to thic otlier. Feeding down grain, when too luxuriant, wis prac. tised. Virgil says, "What commendation shall I give to him, who, lest his corn should lodge, pastures it, while young, ns soon as the llade equals the firrrow!" (Geor., lib. i. 1. 111.) Watering on a large scale was applied botlı to arable and grass lands. Virgil advises to " bring down the water's of a river upon the sown corn, and, when the field is parclied and the plants drying, convey it from the brow of a hill in channels." (Geor., lib. i. 1. 106.)-The fam management most approved of by the scientific husbandmen of Rome was, in general, such as would mcet the approbation of modern cultivators. The importance of thorough tillage is illustrated by the following apologue : $\boldsymbol{\Lambda}$ vine-dresser had two dainglters and a vineyard; when his oldest daughter was married, he gave her a third of his vineyand for a portion, notwithstanding which lie had the same quantity of fruit as formerly. When his youngest daughter was married, he gave her half of what remained; still the produce of his vineyard was undiminished. This result wns the consequence of lis bestowing as much labour on the third part left afier his daughters had received their portions, as he had been accustomed to give to the whole vineyard.The Romans, unlike many conquerors, iustead of desolating, improved the countries which they subdued. They seldom or never burned or laid waste conquered countries, but laboured to civilize the inhabitants, and introduce the arts necessary for promoting their confort and happiness. To facilitate communications from one district or town to another, seems to have been a primary object with them, and their works of this kind are still discernible in numerous places. By employing their troops in tlis 
way, when not engaged in active service, their commanders seen to liave had greatly the advantage ever our modern generals. The Roman soldiers, inctead of loitering in camps, or rioting in towns, enerrating their strength, and corrupting their morals, were kept regularly at work, on objects highly beneficial to the interests of those whom they sibjugated. In the ages of anarchy and barbarism which succeeded the fall of the Roman empire, agriculture was almost wholly abandoned. Pasturage was preferred to tillage, because of the facility with which sheep, oxen, Xc., can be driven away or concealed on the approach of an enemy.-The conquest of England by the Normans contributed to the improvement of agriculture in Great Britain. Owing to that event, many thousands of husbandmen, from the fertile and well-cultivated plains of Flanders and Normandy, settled in Great Britain, obtained farms, and employed the same methods in cultivating them, which they had been accustomed to use in their native countries. Some of the Norman barons were great improvers of their lands, and were celebrated in history for their skill in agriculture. The Norman clergy, and especially the monks, did still morc in this way than the nobility. The monks of every monastery retained such of their lands as they could most conveniently take charge of, and these they cultivated with great care under their own inspection, and frequently with their own hands. The famous Thomas à Becket, after he was archbishop of Canterbury, used to go out into the field with the monks of the monastery where he happened to reside, and join with them in reaping their com and making their hay. The implements of agriculture, at this period, were similar to those in most common use in modern times. The various operations of husbandry, such as manuring, ploughing, sowing, harrowing, reaping, threshing, winiowing, \&c., are incidentally mentioned by the writers of those dars, but it is impossible to collect from them a definite account of the manner in which those operations were performed.- The first English treatise on husbandry was published in the reign of Henry VIII., by Sir A. Fitzherbert, judge of the common pleas. It is entitled the Book of Husbandry, and contains directions for draining, clearing, and enclosing a farm, for euriching the soil, and rendering it fit for tillage. Lime, marl, and fallowing are strongly recommended. "The author of the Book of Husbandry," says Mr Loudon, "writes from his owi experience of more than forty years, and, if we except his biblical allusions, and some vestiges of the superstition of the Roman writers about the influence of the moon, there is very little of his work which should be omitted, and not a great deal that need be added, in so far as respects the culture of corn, in a snanual of husbandry adapted to the present time." Agriculture attained some eminence during the reign of Flizabeth. The principal writers of that period were Tusser, Googe, and Sir Hugh Platt. Tusser's Five Hundred Points of Husbandry was pubiished in 1562 , and conveys much useful instruction in metre. The treatise of Barnaby Googe, entitled Whole Art of Husbandry, was printed in 1558. Sir Hugh Platt's work was entitled .Jewel Houses of Art and Nature, and was printed in 1594. In the former work, says I.oudon, are many valuable hints on the progress of liusbandry in thic early part of the reign of Elizabeth. Among other curious things, he asserts that the Spanish or Merino sheep were originally derived from England.-Several writers on agriculture appeared in England during the commonwealth, whose names, and notices of their works, may be seen in Loudon's Encyclopædia of agriculture. From the restoration down to the middle of the eighteenth century, agriculture remained almost stationary. Immediately after that period, considerable improvement in the process of culture was introduced by Jethro Tull, a gentleman of Berkshire, who began to drill wheat and other crops about the year 1701, and whose Horsehoeing Husbandry was published in 1731 . Though this writer's theories were in some respects erroneous, yet even his errors were of service, by exciting inquiry, and calling the attention of husbandmen to important objects. His hostility to manures, and attempting, in all cases, to substitute additional tillage in their place, were prominent defects in his system.-After the time of Tull's publication, no great alteration in British agriculture took place, till Robert Bakewell and others effected some important improvements in the breed of cattle, sheep, and swine. By skilful selection at first, and constant care afterwards to breed from the best animals, Bakewell at last obtained a variety of sheep, which, for early maturity, and the property of returning a great quantity of mutton for the food which they consume, as well as for the small proportion which the weight of the offall bears to the four quarters, were without precedent. Cully, Cline, lord Somerville, Sir J. S. Sebright, Darwin, Hunt, Hunter, Young, \&c., have all contributed to the improvement of domestic animals, and have left little to be desired in that branch of rural economy.-Among other works on agriculture, of distinguished merit, may be mentioned the Farmer's Letters, Tour in France, Annals of Agriculture, \&c., by the cele brated Arthur Young; Marshall's numerous and excellent works, commencing with Minutes of Agriculture, published in 1787, and ending with his Review of the A gricultural Reports in 1816; Practical Agriculture, by Dr R. W. Dickson, \&c. The writings of Kaimes, Anderson, and Sinclair, exhibit a union of philosophical sagacity and patient experiment, which have produced results of great importance to the British nation and to the world. To these we shall only add the name of John Loudon, F. L. S. H. S., whose elaborate Encyclopædia of Gardening and Encyclopadia of Agriculture have probably never been surpassed by any similar works in any language.-The establishment of a national board of agriculture was of very great service to British husbandry. Hartlib, a century before, and lord Kaimes, in his Gentleman Farmer, had pointed out the utility of such an institution, but it was left to Sir John Sinclair to carry their ideas into execution. To the indefatigable exertions of that worthy and eminent man, the British public are indebted for an institution, whose services cannot be too highly appreciated. "It made farmers, residing in different parts of the kingdom, acquainted with one another, and caused a rapid dissemination of knowledge amongst the whole profession. The art of agricul. ture was brought into fashion, old practices were amended, new ones introduced, and a degree of exertion called forth heretofore unexanpled among agriculturists in this island."-We shall now make a few remarks on the agriculture of different countries of Europe and of the United States. - FrevCr AGRiculTURE began to flourish early in the 17th century, under Henry IV., and a work on that subject was fublished by Olivier de Serres. In 1761, there were 13 agricultural societies in France, and 19 auxiliary socicties. Those of Paris, Amiens, and Bourdeaux, have distinguished themsclves by their memoirs. Du Hamel and Buffon made the study of rural economy fashionable, and other writers contributed to the advancement of husbandry. . M. de Trudaine introduced the Merino brecd of sheep in 1776 , and count Lasteyrie has written a valuable work on sheep-husbandry.. The celebrated Arthur Young made an agricultural survey of France in 1787-89. 
Since that time, several French and English writers have given the statistics of different districts, and the mode of cultiration there in use, and the abbe IRosier and professor Thonin have published general views of the whole kingdom. Bonaparte established mairy new agricultural societies and professorships, botanical and econonical gardens, for the exhibition of different moles of culture, and the dissemination of plants. Ife also greatlyenlarged and eurichel that extensive institution, the Natioual Garlen, whose professor of culture, the chevalier Thoun, is one of the most scientific agriculturists in liurope.-The lands in France are not generally enclusel and subdivided by hedges or other fences. Sonne fences ocrur near towns, but, in general, the whole country is open, the boundaries of estates being marked by slight ditches or ridges, witl occasional stones or herps of earth, trees in rows, or thinly scattered. Depredations from passengers on the highways are prevented by gardes champetres, which are established throughout all France,-Since the time of Colbert, the French have paid attention to sheep, and there are considerable flocks of Merinos owned by individuals, besides the national flocks. That of Rambouillet, established in 1786, is, or lately was, mauraged by M. Tessier, an eminent vrriter on agriculture. Sheep are generally housed, or kept in folds and little yards or enclosures. Mr Birkbeck considers the practice of housing or confining sheep as the cause of foot-rot, a disease very common among them in France. Where flocks remain out all night, the shepherd sleeps in a small thatched lut, or portable house, placed on wheels. He guides the flock by walking before them, and his $d \circ g$ guards them from wolves, which still abound in some parts of the country. In the south part of France, the ass and the mule are of frequent use in husbandry. A royal stud of Arabian horses lias been kept up at Aurillac, in Limousin, for more than a century, and another has been more recently established uear Nismes. Poultry is an important article in Freuch husbandry. Mr Birkbeck thinks that the consumption of poultry in towns may be equal to that of mutton. The breed of swine is in general bad; but fine hams are made in Bretagne from hogs reared on acurns, and fattened with Indian corn.-The French implements of agriculture are generally rude and unwieldy, and the operations of husbandry unskilfully performerl.-The vine is cultivated in France in fields and on terraced hills, in a way different from that which prevails elsewhere. It is planted in hills, like Indian corn, kept low, and managed like a plantation of raspberries. The white mulberry tree is very extensively cultivated for feeding the silk-worm. It is not placed in regular plantations, but in comers, in rows by the sides of roads, \&c. The trees are raised from the seed in nurseries, and sold, generally, at five years' growth, when they liave strong stems. They are planted, staked, and treated as pollards. The eggs of the silk-worm are hatched in rooms heated by means of stoves to $18^{\circ}$ of Reaumur ( $72 \frac{1}{2} \mathrm{Fah}$.) One ounce of eggs requires one hundred weight of leaves, and will produce from seven to nine pounds of raw silk. The hatching commences about the end of April, and, with the feeding, is over in about a month. second broods are procured in some places. The silk is wound off the cocoons, in little balls, by women and children. The olive, the fig, the almond, and rarious other fruits are also extensirely cultivated in France.-Agricolture iv Gramavy. The earliest German writer on husbandry was Conradus Heresbachius, who lived and died in the 16th celltury. His work, De Re Rustica, was an arowed compilation from all the authors who had preceded liinn. No other books on agriculture, of any note, appearerl previous to the 17 th century. With regard to the present state of agriculture in Germany, we would remark, that the country is very extensive, and presents a great variety of soils, surface, climate, and culture. Its agricultural produce is, for the most part, consumed within its limits; but excellent wines are exported from IIungary aud the Rhine, together with finx, hauns, geese, silk, \&c. 'The culture of the mulberry and the rearing of the silkworm are carried on as far north as 13erlin. The theoretical agriculturists are well acquainterl with all the improved implements of freat 13ritain, and some of them have been introluced, especiully in IIolstein, Hanover, and Westplolia ; but, generally speaking, the ploughs, waggons, \&c. are unwieldy and inefficient. Fish are carefully bred and fat tened in some places, especially in P'russia, and poultry is everywhere attended to, particularly in the neighbunrhool of Vienna. The culture of forests likewise receives particular attention in that country, as well as in France. The common agriculture of Germany is everywhere improving. Government, as well as individuals, have formed institutions for the instruction of youth in its prin. ciples. The Imperial Society of Vienna, the Georgical Institution at Presburg, and that of professor Thaer, in l'russia, may be numbered among recent institutions of this description.-AGRICOLTORE IN Italy. The climate, soil, and surface of Italy are so various as to have given rise to a greater diversity of culture than is to be found in the whole of Europe besides. Corn, grass, butcher meat, cheese, butter, rice, silk, cotton, wine, oil, and fruits of all kinds are fonnd in perfection in this fertile country. Loudon asserts that only one-fifth of the surface of Italy is considered sterile, while only a fifth of the surface of France is considered fertile. The population of Italy is greater, in proportion to its surface, than that of either France or Great Britain. Among the writers on the rural economy of Italy are, Arthur Young, in 1788, Sigismondi, in 1801, and Chateauvieux, in 1812. - In Lombarly, the lands are generally farmed by metayer's (from metà, laalf.) The landlord pays the taxes and repairs the buildings. The tenant provides cattle, implements, and seeds, and the produce is divided. The irrigation of lands, in Lounbardy, is a remarkable feature of Italian husbandry. All canals taken from rivers are the property of the state, and may be carried through any man's land, provided they do not pass through a garden, or within a certain distance of a mansion, on paying the value of the ground occupied. Water is not only employed for grass-lands (which, when fully watered, are mowed four and sometimes five times a-year, and, in some cases, as early as March); but is conducted between the narrow ridges of corn-lands, in the loollaws between drilled crops, among vines, or to flood lands, to the depth of a foot or more, which are sown with rice. Water is also used for depositing a surface of mud, in some places where it is charged with that material. The details of watering, for these and other purposes, are given in various works, and collected in those of professor Re. In general, watered lands let at one-third higher price than those not irrigated.-The implements and operations of agriculture in Lombardy are both imperfect. The plough is a rude contrivance, with a handle 13 or 14 feet long. But the cattle are fed with extraordinary care. They are tied up in stalls, bled once or twice, cleaned and rubbed with oil, afterwards combed and brushed twice a day. Their food in summer is clover or other green lerbage; in winter, a mixture of elm-leaves, clover-hay, and pulverized 
waluut-cake, over which boiling water is poured, and bran and salt added. In a short time, the cattle cast their hair, grow smooth, round, and fat, and so improved as to double their value to the butcher. The tomato or loveapple (solanum lycopersicum), so extensively used in Italian cookery, forms an article of field-culture near Pompeii, and especially in Sicily, from whence it is sent to Naples, Rome, and several towns on the Mediterranean sea.-AGRIculture of the UNited States of AMrrica. The territory of the United States is very extensive, and presexits almost every variety of soil and climate. The agriculture of this wide-suread country embraces all the products of European cultivation, together with some (such as sugar and indigo) which are rarely made objects of tillage in any part of Europe. A full description of the agriculture of these states would require a large volume. We shall confine ourselves to such sketches as we may deem of most practical importance to those who are or intend to become cultivators of North American soil.-The farms of the Eastern, Northern, and Middle States consist, generally, of from 50 to 200 acres, seldom rising to more than 300 , and generally falling short of 200 acres. These farms are enclosed, astd divided either by stone walls, or rail fences made of timber, hedges not being common. The building first erected on a "new lot," or ou a tract of land not yet cleared from its native growth of timber, is what is called a log-house. 'This is a hut or cabin made of round, straight logs, about a foot in diameter, lying on each other, and notched in at the corners. The intervals between the logs are filled with slips of wood, and the crevices generally stopped with mortar made of clay. The fire-place commonly consists of rough stones, so placed as to form a hearth, on which wood may be burned. Sometimes these stones are made to assume the form of a chimney, and are carried up through the roof; and sometimes a hole in the roof is the only substitute for a chimney. The roof is made of rafters, forming an acute angle at the summit of the erection, and is covered with shingles, commonly split from pine-trees, or with bark, peeled from the hemlock (pintus Canadensis). - When the occupant or "first settler" of this "new land" finds himself in " $\mathrm{com}$ fortable circumstances," he builds what is styled a " frame house," composed of timber, held together by tenons, mortises, and pins, and boarded, shingled, and clap-boarded on the outside, and often painted white, sometimes red. Houses of this kind generally zontain a dining room and kitchen and three or four bed-rooms on the same floor. They are rarely destitute of good cellars, which the nature of the climate renders almost indispensable. The farmbuildings consist of a barn, proportioned to the size of the farm, with stalls for horses and cows on each side, and a threshing-floor in the middle; and the more wealthy farmers add a cellar under the barn, a part of which receires the manure from the stalls, and another part serves as a store-room for roots, \&c. for feeding stock. What is called a corn-barn is likewise very common, which is built exclusively for storing the ears of Indian com. The sleepers of this building are generally set up four or five feet from the ground, on smooth stone posts or pillars, which rats, mice, or other vermin cannot ascend.With regard to the best manner of clearing forestland from its natural growth of timber, the following observations may be of use to a "first settler." In those parts of the country where wood is of but little value, the trees are felled in one of the summer months, the earlier in the season the better, as the stumps will be less apt to sprout, and the trees will have a longer time to $\mathrm{dry}$. The trees lie till the following spring, when such limbs as are not very near the ground should be cut off, that they may burn the better. Fire must be put to them in the driest part of the month of May, or, if the whole of that month prove wet, it may be applied in the beginning of June. Only the bodies of the trees will remain after burning, and some of them will be burned into pieces. Those which require to be made shorter are cut in pieces nearly of a length, drawn together by oxen, piled in close heaps, and burned, such trees and logs being reserved as may be needed for fencing the lot. The heating of the soil so, destroys the green roots; and the ashes nade by the burning are so beneficial as manure to the land, that it will produce a good crop of wheat or Indian corn without ploughing, hoeing, or manuring. -If new land lie in such a situation that its natural growth may turn to better account, whether for timber or fre-wood, it will be an unpardonable waste to burn the wood on the ground. But if the trees be taken off, the land must be ploughed after clearing, or it will not produce a crop of any kind.The following remarks on this subject are extracted from some observations by Samuel Preston, of Stockport, Pennsylvania, a very observing cultivator. They were first published in the New England Farmer, Boston, Massacluusetts, and may prove serviceable to settlers on uncleared lands. Previous to undertaking to clear lands, $\mathrm{Mr}$ Preston advises, "1st. Take a view of all large trees, and see which way they may be felled for the greatest number of small trees to be felled along-side or on them. After felling the large trees, only lop down their limbs ; but all such as are felled near them should be cut in suitable lengths for two men to roll and pile about the large trees, by which means they may be nearly all burned up, without cutting into lengths, or the expense of a strong team, to draw them together. 2d. Fell all the other trees parallel, and cut them into suitable lengths, that they may be readily rolled together without a team, always cutting the largest trees first, that the smallest may be loose on the top, to feed the fires. 3d. On hill-sides, fell the timber in a level direction; then the logs will roll together; but if the trees are felled down-hill, all the logs must be turned round before they can be rolled, and there will be stumps in the way. 4th. By following these directions, two men may readily heap and burn most of the timber, without requiring any team; and perliaps the brands and the remains of the $\log$-heaps may all be wanted to burn up the old, fallen trees. After proceeding as directed, the ground will be clear for a team and sled to draw the remains of the heaps where they may be wanted round the old logs. Never attempt either to chop or draw a large log, until the size and weight are reduced by fire. The more fire-heaps there are made on the clearing, the better, particularly about the old logs, where there is rotten wood. The best time of the year to fell the timber in a great measure depends on the season's being wet or dry. Most people prefer having it felled in the month of June, when the leaves are of full size. Then, by spreading the leaves and brush over the ground (for they should not be heaped), if there should be a very dry time the next May, fire may be turned through it, and will burn the leaves, limbs, and top of the ground, so that a very good crop of Indian corn and pumpkins may be raised among the logs by hoeing. After these crops come off, the land may be cleared and sowed late with rye and timothy grass, or with oats and timothy in the spring. If what is called a good burn cannot be had in May, keep the fire out until some very dry time in July or August; then clear off the land and sow wheat or rye and timothy, harrowing seve. 
ral times, both before and after suwing; for, after the fire has been over the ground, the sol of timothy should be introduced as soun as the other crops will sudnit, to prevent briers, alders, fire-cherries, \&x. froun springing up from such seeds as were not consumed by the fire. The timothy should stand four or five years, either for mowing or pasture, until the small roots of the forest-trees are rotter; then it may be ploughed; and the best mode which I liave observer is, to plough it very shallow in the antumn; in the spring, cross-plough it deeper, harrow it well, and it will produce a first-rate crop of Indian corn, and potatoes, and, the next senson, the largest and best crop of flax that I have ever seen, and be in onder to cultivate with any kinds of grain, or to lay down again with grass. - These directions are $t \omega$ be understood as applying to what are generally called leech lands, and the chopping may be done any time in the winter, when the snow is not too deep to cut Jow stumps, as the leaves are then on the ground. By leaving the brush spread abroad, I lave known such winter choppings to burs as well in a dry time in August as that which had been cut the summer before." - The agricultural implements and farming operations of the United States are, in most particulars, very similar to those of Great Britain. Circumstances, however, require variations, which the sagacity of the American cultivator will lead him to adopt, often in contradiction to the opinions of those who understand the science better than the practice of husbandry. In Eumpe, land is dear and labour cheap; but in the United States, the reverse is the case. The European cultivator is led, by a regard to his own interest, to endenrour to make the most of his land; the American cultivator has the same inducement to make the most of his labour. Perhaps, however, this principle, in America, is generally carried to an unprofitable extrene, and the farmers would derive more benefit from their land, if they were to limit their operations to such parts of their possessions as they can afford to till thoroughly and to manure abundantly. A man may possess a large landed estate, without beiug called on by good husbandry to hack and scratch over the whole, as evidence of his title. He may cultivate well those parts which are naturally most fertile, and suffer the rest to remain woodland, or, having cleared a part, lay it down to permanent pasture, which will yield him an annual profit, without requiring much labour. -The climate and soil of the United States are adapted to the cultivation of Indian corn, a very valuable vegetable, which, it has been supposed, could not be raiser to advantage in this country.* This entirely and very advantageously supersedes the field culture of the horse-bean (vicia faba), one of the most common fallow crops with us. The root husbandry, or the raising of roots for the purpose of feeding cattle, is likewise of less importance in the United States than in Great Britain. The winters are so severe in the northern section of the Union, that turnips can rarely be fed on the ground, and all sorts of roots are with more difficulty preserved and dealt out to stock, in that country, than in those which possess a milder climate. Besides, hay is more easily made from grass in the United States than in Great Britain, owing to the season for hay-making being generally more dry, and the sun more powerful. There are many other circumstances which favour the American farmer, and render his situation more eligible than that of the European. He is

- Mr Cobhett has lately attempted to raise Indian corn in Euglasd. In a book which he publinhed in Loudon, 1828, A Trealive on Cobbett's Corn, he profeases to have met with wuch success in the culture of it. generally the owner as well as the accupier of the soil which he cultuvates; is not burdened with tithes; lis taxes are light; and the product of his labours will command more of the necessaries, comforts, and imocent luxiries of life.-The American public seem, at present, fully aware of the importance of spirited and scientific agriculture. The state of Massachusetts has appropriatel considerable suns to add to the funds of the agricultural societie's in that commonwealth. Institutions for the promotion of husbandry, cattle shows, and exhibitions of manufactures are common in every jart of the Union. A periodical publication, entitled the American Farmer, is established at Baltinore, and another, called the New England Farmer, is published in Buston. Men of talents, wealth, and enterprise have distinguished themselves by their laborions ant liberal efforts for the improvement of Ainerican husbandry. Merino sheep have been imported ly general Humplireys, chancellor Livingston, and others, and are now common in the United States. The most celebrated breeds of British cattle have bee'i: imported by colonel Powel of Powelton, near Philadelphia; and there prevails a general disposition, among men of intelligence and ligh standing in the community, to promote the prosperity of Anerican agriculture.-We shall conclude with a few brief notices of some of the most prominent benefits and improvements which modern science has contributed to the art of agriculture. The husbandmen of antiquity, as well as those of the middle ages, were destitute of many advantages enjoyed by the modern cultirutor. Neither the practical nor the theoretical agriculturists of those periods liad any correct knowledge of geology, mineralogy, chemistry, botany, vegetable physiology, or natural philusophy; but these sciences have given the modern husbandman the command of important agents, elements, and principles, of which the ancients lad no idea. The precepts of their writers were conformable to their experience; but the rationale of the practices they prescribed they could not, and rarely attempted to explain. Nature's most simple modes of operation were to them inexplicable, and their ignorance of causes often led to erroweous calculations with regard to effects. We are indebted to modern science for the following among other improvements: viz. 1. A correct knowledge of the nature and properties of manures, mineral, animal, and regetable; the best modes of applying them, and the particular crops for which particular sorts of manures are best suited. 2. The method of using all manures of ani$\mathrm{mal}$ and vegetable origin while fresh, before the sun, air, and rain, or other moisture, has robbed them of their most valuable properties. It was formerly the practice to place barn-yard manure in layers or masses for the purpose of rotting, and turn it over frequently with the plough or spade, till the whole had become a mere caput mortuum, destitute of almost all its original fertilizing substances, and deteriorated in quality almost as much as it was reduced in quantity. 3. The knowledge and means of cliemically analyzing soils, by which we can ascertain their constituent parts, and thus learn what substances are wanted to increase their fertility. 4. The introduction of the root husbandry, or the raising of potatoes, turnips, mangel-wurzel, \&ic. extensively, by field husbandry, for feeding cattle, by which a given quantity of land may be made to produce much more nutritive matter than if it were occupied by grain or geass crops, and the health as well as the thriving of the animals in the winter season greatly promoted. 5. Laying down lands to grass, either for pasture or mowing, with a greater variety of grasses, and with kinds adapted to a greater variety of soils; such as 
orcharl-grass (ductylis glomeratu), for dry land, foulmeadow-grass (agrostis stricfin), for very wet land; herds-grass or timothy (phleum pratense), for stiff, clayey soils, \&c. $\quad 6$. The substitution of fallow crops (or such crops as require cultivation and stirring of the ground while the plants are growing), in the place of naked fallows, in which the land is allowed to remain without yielding any profitable product, in order to renew its fertility. Fields may be so foul with weeds as to require a fallow. "In England, when a farmer is compelled to fallow a field, he lets the weeds grow into blossom, and then turns them down; in America, in fallow means a field where the produce is a crop of weeds ruming to seed, instead of a crop of grain." 7. The art of breeding the best animals and the best vegetables, by a judicious selection of individuals to propagate from. - These improvements, with others too numerous to be here specified, have rendered the agriculture of the present period very different from that of the middle ages, when it had sunk far below the degree of perfection which it had reached anong the Romans.

Agricultoral Inplements. Under this head we shall notice the more essential implements used for the cultivation of the ground, with the modern improvements that lave been made on them. The first in importance is THE PLOUGH. The plough was originally contrived to do the work of a spade, and was probably invented after the introduction of til. lage, properly so called. In some wann climates, the plough is not used, the fertility of the earth being so exuberant, that merely scratching the surface is a sufficient preparation for crops. Of ploughs, there are many varieties of form, suited to different soils, and modes of culture. The most obvious general distinction among ploughs is, their being constructed with or without wheels: and each of these kinds may be again distinguished by other circumstances-such as the form of the mould-board and share ; their operation in making one or more furrows at a time; their size; and the depth at which they are calculated to work, as in trench-ploughing. It is not very satisfactorily known what sort of ploughs the ancients used; they were probably of various kinds, suited to different countries, and altered with different ages. The following cut represents an ancient Roman plough, taken from a brass figure in the Jesuits' college at Rome, and answering in the principal part of it (the shaft) to Virgil's description, (Georgics, i. 163-175) of the "heavytimbered plnugh." It affords some proof that early ploughs were constructed to tear up the soil, but were not adapted to turn it over.

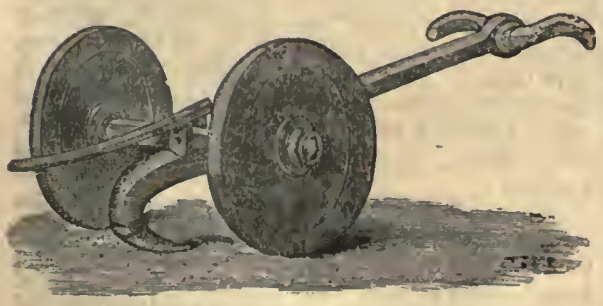

In plate II. representations will be found of the Rotherain or Swing-Plough, the Wheel or. Norfolk Plough, and Finlayson's Improved Plough. The swing-plough, with a feathered sock or share, and a curved monld-board, is almost the only one used in Scotland, and throughout a considerable part of England. 'The old Scottish plough, with a spear- sock, has been laid aside, except in a few of the least improved counties, where it is still found useful whe'n the soil is encumbered by roots and stones. The swing-plough is drawn with less power than wheelploughs, the friction not being so great; and it pro bably admits of greater variations in regard to the breadth and depth of the furrow-slice. 'This plougl: is sometimes made in such a manner that the mould. board may be shifted from one side to the other when working on hilly grounds; and it is then called a turn-avrest plough. The present improved swing. plough was little known in Scotland till about the year 1764, when Sinall's method of constructing it began to excite attention. This ingenious mechanic formed the mould-board upon distinct and intelligible principles, and afterwards made it of cast-iron. His appendage of a chain for strengthening the beam has since been laid aside. It has been dis. puted whether he took the Rotheram or the old Scottish plough for the basis of his improvements. The swing-plough has been since varied a little from Small's form, for the purpose of adapting it more completely to particular situations and circumstances. Of late, it has been made entirely of iron. The Argyleshire plough is a simple swing-plough, which acts without a coulter; instead of the coulter, a large flat plate is fixed to the share, in a vertical plane, corresponding with the land-side of the plongh ; and the advanced edge of this is sharpened to cut the ground. The object of this clange is to remove the resistance necessary to make the vertical incision farther back from the point of draft than if a coulter were used; and also to aroid the choking of the plough by weeds and rubbish, which sometimes lodge before the coulter, beneath the beam. The Argyleshire plough has a rod of iron in place of the chain of the chain-plough, to strengthen the beam ; it is attached at one end to the middle of the beam, and connected at the other with the rack from which the horses draw. In some ploughs two iron rods are used, and they extend quite to the end of the beam, and are attached to a hook near the handles. Wheel-ploughs, in a great variety of forms, are used in many parts of England. They require less skill in the ploughman to manage, but they are more expensive, more heavy in the draught, and more liable to be put out of order than the swing-ploughs. In plate II. will be found a representation of the Wheel or Improved Norfolk Plough. The share is united to the beam by a plate of castiron; and the coulter is wedged into an iron socket at the side of the beam, without weakening the beam by a mortise. At the top of the uprights of the carriage are eyes to conduct the reins by which the ploughman guides the horses. In the same plate will be found a representation of Finlayson's Patent Self-cleaning plough. This is the construction of Mr John Finlayson, farmer at Muirkirk, and is found well adapted to coarse old swards. It clears itself from obstructions without often requiring the aid of the ploughman, and it turns over the furrow in a complete and workman-like manner, in situations where the common plough fails. It does not, however, seem to possess any advantages over the common plough upon land under a regular course of cultivation. Tuo-furrou ploughs are used in a few places, but are not likely ever to become general. They are: constructed either with or without whecls. A plough of this kind was strongly recommended by lord Sonerville, and used by his lordship and others apparently with some advantage. Various other implements have been used for stirring the soil-such as the Miner, for following in the furrow of a common. plough, and loosening the ground to a greater deptls, without hringing up the subsoil; the Paring Plaugh,

$$
1-\mathrm{K} 2
$$


the Sole, and other sorts of plonghs for draining.Many implements are in use for stirring and pnlverizing the soll without turning it over. Sone of them are used in preparing it for the seed, and others, as horse-hoes, between drilled crops. One of them, called a Grobskr, from its efticiency in bringing weed roots to the surfice, differs froin the harrow, by laving the iron teeth male with sharp edges, and bent forward like so many coulters. It is heavier than the harrow, but covers less surface. It is constructed with triangular sharp-edged dipping feet four cast-iron wheels, two handles, \&c. Sir John Sinclair strongly recommends it, as being useful in working fallow, or in stirring land on which potatoes or turnips have grown, so that a crop may be sown in spring without use of the plough. It is made of different sizes, and worked by four or two horses. - The Harrow. Common harrows are of an oblong shape, each containing twenty tiues five or six inches long beneatl the bulls or bars in which they are inserted. Most harrows are drawn cornerwise, by which contrirance their teeth do not follow each other in rows, but scratch the surface more effectually. The brake, as usually constructed, is nothing more than a heavier harrow, sometimes in one piece, and sometimes in two pieces joined together. 'Two harrows have been lately invented, which are found to be very efficient, especially in soils where weed-roots abound. They will be found represented in Plate II. The one is by Mr Finlayson, the inventor of the self-cleaning plough already mentioned, and the other by Mr Samuel Morton, agricultural implement maker, Edinburgh. The latter is called the Revolving Brake Harrow, and is excellently adapted for bringing roots to the surface, and pulverizing the land when under fallow, so as tu save one or two ploughings. -DriLL-Machixss. These are used in depositing the seed in equi-distant rows on a flat surface; on the top of a narrow ridge ; in the interval between two ridges; or in the bottom of a common furrow. Corn when drilled is usually sown in the first of these ways, turnips in the second, and pease and beans in the third or fourth. One of the best for sowing all kinds of corn was inrented by $\mathrm{Mr}$ Bailey of Chillingham, but the practice of drilling corn does not seem to be gaining ground. The drill-machine is universally used in Scotland for sowing turnips, on ridges about 30 inches broad. In some cases, the machine is made to sow two of these ridges at once, and two rollers are attached to it, one for smoothing the tops of the ridges before the seed is deposited, and the other for compressing the soil and covering the seed. The front roller is now made concave, which leaves the ridges in a better form for receiving the seed. The machine is drawn by one horse, walking between the ridges. A representation of it will be seen in Plate II.-Reaping Machines, Many endeavours have been made to introduce reaping machines, but hitherto without success. This is to be regretted, as whatever tends to abridge manual labour, although possibly injurious to individuals for a time, tends in the end to elevate humanity. Despatch in reaping, besides, is a matter of great importance in a climate so variable as that of Britain. The most promising reaping machines of which we have heard, are those of Mr Smith, of the Deanston Cotton Works, Perthshire, and of the Rev. Patrick Bell, Forfarshire. Mr Smith made the first trial of his on a small scale in 1811 , and continued to prosecute his experiments for several years with satisfactory results, but has latterly, we understand, been induced to suspend or aluandon his speculation. Mr Bell's machine is of more recent construction, and promises every success. It was tried at Gowrie in Forfarshire in 1829, in cutting down grnin on gromud of uneven surface. It is about 5 feet broad, unl embraces with its knife that breadth of corn. The cut conu was deposited 's the machine advanced in a very regular manner. It accomplished about an imperial acre in the hour. It was driven by one horse, and may cost alout £30. Those present at the trial considered this machine perfectly triunghlant, and that it would speedily come into general use. A representation of it will be seen in Plate II.

AGragvroM, in ancient geogr.; now Girgenti or Agrigenti; a town in Sicily, in the valley of Mazara, about three iniles from the coast. The nodern tow: is near the ruins of the ancient one, is a bishop's see, and lies on the river St Blaize, 47 miles S. Palerno; long. $13^{\circ} 33^{\prime} \mathrm{E}$; lat. $37^{\circ} 22^{\prime}$, N.; pop. 11,876. -A. was much renowned among the ancients. Different stories are told of its foundation, among which is the fabulous tale, that Dredalus, who fled to Sicily from the resentment of Minos, erected it. Its situation was peculiarly strong and imposing, standing as it did on a bare and precipitous rock, 1100 feet above the level of the sea. To this military advantage, the city added those of a commercial nature, being near to the sea, which afforded the means of an easy intercourse with the ports of Africa and the south of Europe. The soil of $\mathrm{A}$. was very fertile. By ineans of these advantages, the wealth of $\Lambda$. became very great. It was therefore considered the second city in Sicily, and Polybius says (l. ix.) that it surpassed in grandeur of appearance, on account of its many temples and splendid public buildings, most of its contemporaries. $\Lambda$ mong the most magnificent of these buildings were the temples of Minerva, of Jupiter Atabyris, of Hercules, and of Jupiter Olympius; the latter, which vied in size and grandeur of design with the finest buildings of Greece, is said hy Diodorus (Sic. 1. xiii.) to have been 340 feet long, 60 broad, and 120 high, the foundation not being included, which was itself remarkable for the immense arches upon which it stood. The temple was ornamented with admirable sculpture. But a war prevented the completion of it, when the roof only remained unfinished. Near the city was an artificial lake, cut out of the solid rock, about a unile in circuit, and thirty feet deep; from which fish were obtained in abundance for the public feasts. Swans and other water-fowl frequented it. Afterwards, the mud having been suffered to accumulate in this basin, it was turned into a remarkably fruitful vineyard. Both the temple of Jupiter Olympius and the lake were the work of a number of Carthaginian captives. The people of Agrigentum were noted for their luxurious and extravagant habits. Their horses were also famous. (Virgil, En. l. iii. v. 705.) After the expulsion of the Carthaginians from Sicily, it fell, with little resistance, under the power of the Romans. Diodorus states the population, in its best days, to have been not less than 120,000 persons. Many of the modern writers describe minutely this interesting spot. Christian churches have there, as in many other places, been erected out of the remains of temples.

Agrionis ; a Grecian festival, solemnized at night in honour of Bacchus. He was supposed to have fled, and the females assembled to seek him. At length, tired of their vain search, they exclaimed, that he had taken refuge with the Muses, and concealed himself among them. These mysteries have been thought to signify that learning and the muses should accompany good cheer. This solemnity was followed by a banquet, at the close of which it was customary to propose to each other riddles, whence A. is used to denote a collection of riddles, charades, \&c. 


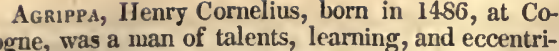
city. In his youth, he was secretary to the emperor Maximilian, subsequently served seven years in Italy, and was knighted. He says that he was acquainted with eight languages. On quitting the army, he devoted himself to science, and made pretensions to an acquaintance with magic. In certain lectures, he advanced opinions which involved him in contests with the monks for the remainder of his life. In 1530 , he wrote a treatise "On the Vanity of the Sciences," which was a caustic satire upon the inefficiency of the common modes of instruction, and upon the monks, theologians, and members of the universities. At a subsequent period, he produced another treatise at Antwerp, "On the Occult Philosopher." This was a sketch of mystical theology, explaining, on the principles of the emanative system, the harmony of the elementary, celestial, and intellectual worlds. His pretensions to skill in occult science, particularly alchymy, led to his receiving numerous invitations from royal personages and others of high rank, and his inability to answer their absurd expectations produced their subsequent neghect of him. After an active, varied, and eventful life, he died at Grenoble, in 1539.

Agrippa, Marcus Vipsanius; a Roman, the sonin-law of Augustus, with whom he was twice consul. Although not of high birth, his talents soon raised him to honour. He distinguished himself as a general, and commanded the fleet of Augustus in the battle of Actium. As the minister and friend of the emperor, he rendered many services to him and the Roman state. He was impartial and upright; and $a$ friend of the arts. To him Rome is indebted for three of her principal aqueducts, and several other works of public use and ornament. (See $A u$ gustus.)

Agrippina. 1. The wife of the emperor Tiberius, who very reluctantly divorced her, when obliged to marry Julia, the daughter of Augustus, after the death of her first husband, Agrippa. A. was subsequently married to Asinius Gallus, whom Tiberius, still retaining his love for his former wife, condemned to perpetual imprisonment, in the spirit of a jealous rival. -2. The daughter of Marcus Vipsanius A grippa, by Julia, daughter of Augustus; wife of C. Germanicus; an heroic woman, adorned with great virtues. She accompanied her husband in all his campaigns, and accused Tiberius, before the senate, of compassing his death. The tyrant, who hated her for her virtues and popularity, banished her to the island of Pandataria, where she starved herself to death. The cabinet of antiquities at Dresden possesses four famous busts of this A.-3. A daughter of the last mentioned A., and sister of Caligula, born at Cologne, which she enlarged, and called Colonia Agrippina. She had the misfortune to become the mother of Nero, by Domitius Ahenobarbus. Her third husband was the emperor Claudius, brother of her father, who married her after he had divorced Messalina. She was distinguished for ability and political experience, but her ambition was boundless, and her disposition cunning and dissolute. She was mundered by Nero, her son, to whom she was troublesome after he had become emperor. It is said, that she begged the assassins to stab her first in the womb, that had brought forth such a monster.

AGVE, in medicine; a disorder belonging to the class of intermittent fevers (febres intermittentes). It may be followed by serious consequences, but, generally, it is more troublesome than dangerous, and is sometimes even considered salutary. According to the length of the apyrexia, or intermission between one febrile paroxysm and another, agues are deno- minated quotidians, tertians, quartans; which latter are much the most obstinate, being generally attended with a greater degree of visceral obstruction thail those, the attacks of which return at shorter intervals. The quartan ague is apt to terminate in dropsy. An ague paroxysm has been divided into the cold, the hot, and the sweating stages. The feeling of extreme cold, in the first stage, cannot be prevented by fire or the heat of summer. Generally, after the sweating stage, in which there is a profuse exhalation from the pores of the skin, with a flow of urine, depositing a copious sediment, of a lateritious or brickdust' appearance, the patient falls into a refreshing sleep, from which he awakes without any remains of indisposition, except a slight degree of languor and debility. Agues occur chiefly in situations where there are shallow, stagnant waters. Hence their frequency in Holland, in the East and West Indies, in the flat, marshy parts of England, and the thinly settled parts of the United States, where they diminish with the clearing of the woods and the draining of the lands. The neighbourhood of rivers or marshes, therefore, is carefully to be avoided by persons afflicted with agues. They are cured by medicines, which, at the same time that they exert a tonic influence, produce and keep up an impression upon the system greater than that communicated by the causes of the disease ; such as Peruvian bark, various bitter and astringent drugs, certain metallic salts, \&.c.

AGUE-CAKE; a name sometimes given to a hard tumour on the left side of the belly, lower than the false ribs, said to be the effect of intermittent fever.

Aguesseau, Henry Francis d', a man distinguish ed in the annals of French eloquence and jurispru dence, was born at Limoges in 1668, and early evinced distinguished talents. His father, intendant of Languedoc, was his first instructor. The intercourse of d'A. with Racine and Boileau formed his taste for poetry. He was, in 1691, avocat général at Paris, and at the age of thirty-two years procureur général of the parliament. In this office, he effected many improvements in the laws and the administration of justice, and took particular care of the government of hospitals. During a famine in the winter of 1709 , he employed all his power to relieve the suffering. As a steady defender of the privileges of the nation and the Gallican church, he procured the rejection of the decrees of Louis XIV., and the chancellor Voisin, in farour of the papal bull Unigenitus. Under the government of the duke of Orleans, he was made cliancellor in 1717, but fell, in 1718 , into disgrace, on account of his opposition to Law's destructive system of finance, and retired to his country seat at Fresnes. He there passed, according to his own words, the happiest days of his life, employed in reading the Bible, projecting a code, and instructing his children. Mathematics, agriculture, and the arts and sciences occupied his leisure hours. In 1720, loud clamours against Law were raised throughout France, and it was thought that a man like d'A., who possessed the love of the nation, was necessary to allay the general discontent. He was, therefore, replaced in his former dignity. This period of his life did not add to his renown; for he accepted his office from Law, and gave his consent to certain weak and injurious plaris, which the parliament rejected; he finally suffered the same parliament to be exiled to Pontoise. In 1722, he was banished a second time, for opposing the cardinal Dubois, but was recalled in 1727 by the cardinal Fleury, and in 1737 restored to his former office. Ho formed the design of introducing uniformity into the execution of the ancient laws, and of adding what was wanting. But this work surpassed the abisity of 
a single man. If divl in 1751, after resigning, in 1750, the oftice of chancellor. Ilis work's, which have passed throngh several editions, are said, by Bouterwek, to be molels of their kind; fuil of spirith julicions, elegant, yet powerful, and rich in valua')le instruction for statesmen and laryers. II is discunrses, with which he opened the sittings of the parliane'ut, are excellent. - I is nephew. the narquis $d$ '. Iguesseau (Heury Cardin Jean lBaptiste), peer of Frince, and member of the academy of sciences, linel ut l'aris, Jamiary 22, 18:6. He was a lawyer, member of the first national assembly, and senator ulaler Napoleon; afterwands, a faithful adherent of the king.

Aguirad, Joseph Saenz de, a Benedictine, and learned main, was born in 1630. He was censor and secretary of the suprenc council of the inquisition in Spail, and professor in the university of Salamanca. He published commentaries on Aristotle's Ethics, and died at Rome in 1699.

Acostisı, in mineralogy; a term by which professor Tromsdorff has desiguated a supposed new earth, discorered by him in 1808. It bears a great resemblance to alumina.-Annales de Chimie, xxxiv. p. 133.

AGOTI, the cavia aguti of Linnacus; an Aurerican animal, much resembling the Guinea pig. Therc arc three varieties, all indigenous to Soutli America and the West Indies. They live on vegetables, inhabit hollow trees, and burrow in the ground. They eat like the squirrels, grow fat, and are used as food in South Anrerica. They propagate very fast.

Aнarta ; a kingdom on the Gold Coast of Africa, extending from the Alucobra to the Chamah; bounded on the west by Apollonia, and on the east by the Fantee territories. It is the richest, and in crery respect the most improved district upon this coast. The principal towns arc Axim, Dixcore, and Succondee.

Anssogrus, in Scripture history; a king of Persia, the husband of Fsther, to whom the Scriptures ascribe a singular deliverance of the Jews from extirpation, which they commemoratc to this day, by an aumual feast, that of Purim, preceded by what is called the fast of Esther. Different opinions have been entertained by Scaliger, Prideaux, and others as to which of the kings of Persia mentioned in other historical books may be the A. of the Bible.-Ahasuerus is also a Scripture name for Cambyses, the son of Cyrus, Ezra iv. 6., and for Astyages, king of the Mcdes, Dan. ix. 1.

AuттPнEL; one of king David's counsellors, and highly esteemed for his political sagacity. He was certainly one of the first men of his age, both for wisdom and wickedness. His advice to Absalom, who followed the wicked part of it, but left the wise part unaccomplished, together with the tragical end of the politician, the first suicide recorded in history, are well known.

A-HoLL; the situation of a ship when all her sails are furled on account of the violence of a storm, when, having lashed her helm on the lee-side, she lies nearly with her side to the wind and sea, her head being somewhat inclined to the direction of the wind.

AID ; a subsidy paid, in ancient feudal times, by rassals to their lords on certain occasions.

Algsas, Stephen, a poet and author, born in 1773, at Beaugency, on the river Loire, and since 1814 a member of the French academy, has distinguished himself by successful translations of the Iliad, and of Pope's Essay on Criticism, into verse. The translation of the lliad is the best in the French language. He also translated the Odyssey, but we finow not whether the version has been published.
He translated, likewise, some Euglish tales, $e$. g. the Vicar of Wakefield. His original writings consist of a tragedy, Brunehuut; 111 opera, Nephthali, with music by Blangini; aud sone excellent political essays, Sur le jury; De l' état des protestants en France, depuis le XV sieclc, jusqu' a nos jours, ¿'c. 2d ed. Paris, 1818, and Sur les coups d' état; as well as various contributions of merit to the Minerv Francaisc. II was libernl in his riews, wrote weh! and independently, but with moderation. He showed remarkable courage in publishing his tragedly, $L n$ Mort de Louis XYI., his first poem, a few werks after the execution of the king. He held severnl public offices during the reigu of terror, ant opposed, in some cases successlully, the tyramy of the administration. He died at Paris, Junc $23,1824$.

Algothos, duke d'; peer of l'rance, and minister of foreign aftairs moler Louis $\mathrm{XV}$.; distingnished, as a courtier, by his ready wit, but destitute of almost all the qualities that constitutc the statesman. During his ministry the partition of Poland took place; and till it was actually accomplished, d'A. knew nothing of this proftigate project. Even Louls XV. cxclaimed, when it came to his knowledge, "Had Choiseul been here, this partition would nerer have taken place." D'A. was bom in 1720 . When he first appeared at the court of Louis, hic struck the fancy of the duchess of Chatcauroux, mistress of the king. She obtained him an appointment in the army in Italy. After experiencing many alteruations of favour and disgrace, he was admittech, through the influence of the comntess du Barry, into the ministry with the abbé 'Terrai and the chancellor Maupeou, after Choisenl's downfall. His administration of the department of foreign affairs was disgraceful to France, which, under him, degenerated from the high diplomatic character she had hitherto sustained. He bonsted of having brought about the revolution of Sweden in 1772, which now is made a inatter of reproach to him. At the accession of Louis XVI. he was removed from the ministry. His place was supplied by the count of Vergennes, in 1774. D' $A$. was hated by the queen, was exiled in 1775 , and died in banishment in his 80th year.

AIKEN, John, M. D., an English miscellaneous writer, born in Leicestershire, 1747 ; died at his residence in Stoke Newington, 1822. He practised as physician at Chester, Warrington, and latterly at Yarmouth ; and published various works 'of a miscellaneous description, some in conjunction with his sister, Mrs Barbauld (q. .). . His most elaborate work is his "General Biographical Dictionary," begun in 1799 , and fuished in 1815. He was cditor of the Monthly Magazine from 1796 till 1806, in which capacity he distinguished himself as a very sensible and entertaining essayist.

Arksıs, William, an eminent portrait painter of the last century, was born in Scotland, and (arly enjoyed the patronage of John duke of Argyle, and the earl of Burlington. He also cnjoyed the friend. ship of most of the wits of queen Anne's time, especially Swift, Pope, Gay, Somerville, and his countrymen, Arbuthnot, Thomson, Smollett, and Allan Ramsay. His best portraits are those of the Buckinghamshire family and the Royal family. He died in 1731, aged 49 .

Ailsa Craig, a rocky island in the Frith of Clyde, between the coasts of Ayr and Cantyre, of a conical form. It is a conspicuous object, 940 feet high, seven miles from the shore, about two miles in circumference; lon. $508^{\prime} \mathrm{W}$., lat. $55^{\circ} 18^{\prime} \mathrm{N}$. Innumerable sea-fowl, many of which are good for the table, or valuable on account of their fcathers, frequent it; a few rabbits and goats live on its sterile surface. A ruinous castle stands on its summit, and 
is useful as a sea-mark. Excellent banks, well stocked with fish, surround it. Ailsa Craig is celebrated in Scottish song, and has commanded the admiration of several poets. Annong the latest tributes to it is the following splendid somnet, by John Keats:

Hearken, thou craggy ocean pyramid 1

Give answer from thy voice, the sea-fowls' screams, When were thy thunders mantled in liuge streanss? When from the sun was thy broad forehead hid?

How long is't since the mighty Power bid

Thee heave to airy sleep from fathom dreams?-

Sleep on the lap of thunder or sumbeams-

Or when grey clouds are thy cold coverlid ?-

Thou answerest not, for thou art dead asleep;

Thy life is but two dread eternities ;

The last in air, the former in the deep,-

First with the whales, last with the eagle skies :

Jrown'd wast thou till an earthquake made thee steep Another cannot bow thy giant size

Ainos, or Aivus; the aborigines of Jesso and Saghalin, commonly called wild Kuriles, and supposed to be corered with hair in unnatural profusion. 'They are nearly black, and resemble the Kamtschadales, but have more regular features. The Clinese and Japanese say that they have inmense beards; captain Broughtou, who ancliored at Endermo harbour, in Jesso, in 1797 , remarks, that the bodies of the men are corered with long black hair; and lirusenstern, the Russian navigator, mentions that a child of this description was seen in 1805, but that the parents had no such characteristics, and he denies that it is general, Other testimony, e. g. that of the early missionaries at Japan, seems to confirm this peculiarity of the $A$. The women are very ugly. The A. are of a mild, liberal disposition; their manners, however, are very little known. Polygamy is practised among them. Agriculture they know very little of. They fatten bears for winter provision. The A. were formerly independent, but are now in subjection to the Japanese.

Aissworth, Dr Henry, an Englishman, who distinguished himself, about 1590, among the Brownists. His knowledge of Hebrew, and his annotations on the Holy Scriptures, gained him much reputation. He died about 1629, in Amsterdam. He is said to have restored to a Jew a valuable diamond which he had lost. The only compensation which he asked was a conference with some Jewish rabbies on the prophecies of the Old Testament relating to the Messiah. The Jew promised to bring it about, but failing of success, is said to have poisoned $\mathrm{A}$. through slame and vexation.

Aissworth, Robert, born at Wood-yale, in I ancashire, 1660, was master of a boarding-school at Bethnal-Green, whence he remored to Hackmey and other places in the neighbourhood of London. After acquiring a moderate fortune, he lived privately till 1743, when he died. He compiled the wellknown Latin and English Dictionary, published in 1736 ; and in 1752, the fourth edition, under the care of Dr Ward and William Younge, was enlarged to 2 vols. folio. Many editions with inprovements have followed.

A 100 ; a group of 15 islands in the eastern seas, off the N. coast of Waggiou, and surrounded by a reef $\mathbf{5 0}$ miles in compass, which is penetrated by a deeu channel on the north-west side. Aiou Baba is the largest, about 5 miles in circuit, 500 feet high, long. $128^{\circ} 25^{\prime} \mathrm{F}$, lat. $0^{\circ} 32^{\prime} \mathrm{N}$. Fish, turtle, and tropical fruits abound in these islands. They have some trade with the Chinese.

Aı, (Greek, ane; Latin, wër), in natural philosopliy, is that fluid, "transparent substance which surrounds our globe, reaching to a considerable height above its surface, perhaps $\mathbf{4 0}$ miles; and this ocean of air is the great laboratory in which most of the actions of life go on, and on the composition of which they depend. Though invisible, except in large masses, withont smell or taste, yet it is a substance possessing all the principal attributes of matter; it is iupenetrable, ponderable, compressible, dilatable, perfectly elastic, and its particles are operated on like those of other bodies, by chemical action. To prove the impenetrability of the air, a very simple experiment is sufficient. Plunge a gla ss receiver perpendicularly into water, after having put under the receiver a piece of cork. However deep you may plinge the vessel, the water never reaches the top of it, though it diminishes the volume of the air ; the liquid, therefore, cannot penetrate the air. The cork serves to show how high the water rises. In fact, the most commor occurrences give constant proofs of the impenetrability of the air, and the theory of sailing, of windmills, \&c. is based on that property of this fluid. (See $W_{i n d}$.) To prove that the air is ponderable, it is only necessary to weigh a large balloon, first empty, and afterwards filled with air. It has been found, that 100 cubic inches of air, rery dry, taken at the temperature of $60^{\circ}$, und under the barometrical pressure of 30 inches, weighs 30.5 grains ; and this weight is to that of water as 1 to 770. Galileo first discovered that air is ponderable, though severai preceding philosophers seem to have had some suspicion of the fact.' (See Galileo, Torricelli, Barometer.) In consequence of this quality of air, the atmosphere which surrounds us exerts a pressure on all points of the globe proportionate to its weight ; this is the cause of the rise of liquids in sucking-pumps, siphons, and the barometer. To show this pressure, plunge the orifice of an exhausted tube, closed at the other end, into a liquid. The liquid, yielding to the pressure of the external air, rises in the tube till the weight of its column is equal to that of the atmospheric column. In this experiment, water will rise 33 feet, and nercury 29 inches, provided the place where the experiment is tried is nearly on a level with the sea ; for the height varies with the weight of the column of air, which diminishes in proportion as we ascend above the level of the sea. The height of the colunin of mercury in the barometer, therefore, affords a good means of determining the eleration of any given place. The weight of the column of air, which presses constantly on a man of middle stature, is equal to $32,343 \frac{1}{4}$ pounds. But this weight does no injury, because it is counterbalanced by the reaction of the fluids, which fill the interior cavities of the body. (See fir.pump.) That air is compressible, and that the space which it occupies corresponds always to the pressure on it, has been shown by Mariotte. He took a bent glass tube, wixh legs of unequal length, exactly graduated; after having sealed the orifice of the shorter leg, he introduced a small quantity of mercury, sufficient to rise to an equal height in both legs. The air enclosed in the shorter leg then courterbalanced the atmospheric column. By raising the mercury in the longer leg to the height of 29 inches, the air in the shorter leg was compressed into half the space which it occupied at first. In other words, the veiglit of two atmospheres (the column of mercury being equal to one) compressed the air to this degree. Mariotte con. tinued to pour mercury into the long leg, and found that the weight of $z, 3,4, \& c$. atmospheres reduced the air confined in the shorter leg to $\frac{1}{2}, \frac{1}{3}, \frac{1}{4}$, \&c. of its primitive volume. In repeating this experiment, it is necessary to give time to the caloric which is disengaged to pass off. It seems as if the compres. sion of air would be indefinite, if we had sufficiently powerful means; but as yet we have only been able to reduce its volume to one-eighth. (See Compres. sion, Air-gun. The dilatability of air consists in 
the tendency of a volume of confuied air to ocaupy a greater space. In consequence, it presses equally in all directions on the sides of the vessel containing it, and this pressure increases or diminishes in proportion as the enclosed air is condensed or rarefied, provided the temperature remains the same. The dilatability of air has, according to the preceding experiment, no limits. $\Lambda$ bladder, almost empty, will become intlated if placed in an exhausted re. ceiver. Elasticity being the property of a body to resume its original form as soon as the force which changes it ceases, it is eviclent, from what we have said, that it is a property of air. The different applications made of air in the different branches of art ure so various and unnerous, that we caunot possibly enumerate them. Of the chemical properties of air, it will be sufficient to meution the following: the ancients believed it a simple body, one of the four -lements; molem chemists have discovered that it is coinposed of two bodies, apparently elementary, oxygen and azote. The most accurate experiments have shown that this fluid, taken from different parts of the globe, and even at a great height, is comjoserl of 21 parts of oxygen, 78 of azote, one part of carbonic acid, and some atoms of hydrogen. The air refracts the mys of light, and its power of refraction is in the ratio of its density. (See Refraction.) It is capable of acquiring electricity, and it refuses, when very dry, a free passage to the electricity which tends to escape from electrified bodies. (See Electricity.) When subjected to great heat or cold, it is dilated or condenied, but undergoes no charıge of properties. If it is suddenly compressed, much heat is disengaged, vith a bright light. It enters bodics through the most minute pores, and adheres to them strongly; coal, particularly, absorbs a great quantity of air. (See Carbon.) Water and all liquids always contain it, and it can only be expelled by a strong heat. Almost all combustible borlies decompose it at a high temperature, which varies with the different substances. They absorb its oxygen with the disengagenent of more or less caloric and light, and form acids or oxydes: phosphorys, however, combines at a low tempernture with the oxygen and azote of the air, and produces, with the former, phosphorous acid ; with the latter, phosphureted nitrogen; the moisture of the air and the melting of the phosphorus favour these combinations. When the air is brought into contact with animal and vegetable substances, it changes them immediately, particularly if it is moist, and gives to some of them acid properties; it bleaches flax, hemp, silk, and increases the brilliancy of many colours. It is indispensable to the life of all organic beings; an imals respire it incessantly, and decompose it; a part of its oxygen is transformed into carbonic acid, and this combination produces caloric, which contributes principally to the preservation of animal heat. (See Respiration.) Vegetables imbibe the carbon, which the carbonic acid, diffused through the air, contains. The air is the agent of combustion; the particles of bodies combine with its oxygen, and evol ve heat and light. (See Combustion.) Finally, the air is the principal medium of sound. (See Acoustics.) For further information, see the articles Atmosphere, Gas, and Contagion.

$A_{I R}$, in painting, deserves the most accurate study of the artist, particularly of the landscape painter, as it is the medium through which all objects are seen, and its density or transparency determines their appearance, both in respect to size and colour. It softens the local colours, and renders them more or less decided or characterized, producing what is technically called tone. The appearances produced by the interposition of the air differ with the climate, the sensun, and the tine of the day; and landscape painters, who, in other respects, are not masters, have given the grentest charm to their pictures by a happy imitation of these appearances, even where the objects painted possess in thennselves very little attraction. Hackert, a German, who was a loug time painter to the late king of Naples, excels, perlaps, in this branch of art, all modern painters. His views on this subject are given in lis life by Guethe.

Aır, fixed. See Gas.

$A ı r$, in music (in Italian, aria), at the present day, unenns a continnous melody, in which some lyric subject or passion is expressed. It was originally opposed to the irregular declamation of recitative, or the more staid action of choral music. Saumaise regands the term as derived from the Latin aëru. The air appertained, consequently, to measured music, and, whether constituted of one or of more voices, this measured style (if not choral) was denominated air. But in modern times, by way of dis. tinction, the lyric melody of a single voice, accompanied by instruments, is its proper form of composition. Thus we find it in the higher order of nusical works; as in cantatas, oratorios, operas, and also, independently, in concertos. It should be constituted of euphonic simple lyric strains. An air formerly supposed as its ground-work a particular state of fecling or emotion, of a certain duration, expression, and interest, to which the recitative is generally preparatory. Formerly, too, as essential to an air, a symphony, expressing the burden of the stanzas or couplets of the song (ritornello, or refrain), was introduced as tributary to the leading melody, which was followed by another and less claborate part, forming the antithesis, to which was subsequently added a repetition of the first part. Since the days of Gluck and Mozart, these have declined, and other forms have been adopted, particularly by Mozart, more conformable to poetry, and more expressive of the sentiments and situation of the singer. Still Mozart could not entirely withstand the prevailing taste, with reference to which he produced numerous bravura airs, not always in character, yet not wanting in expression and effect. Another form of airs are the cavatinos (or single strains), lately introduced by the Italians, and calculated to add grace and embellishment to the song. At the present day, the Germans either adopt this or make use of other forms, as the subject may require.-Arietta signifies a short, less elaborate air, designed to express a more simple and transient emotion.-Ariosn is also applied to music resembling the aria, and is inserted in sirigle lyrical passages to vary the recitative.

ArR-GUv; an instrument for the projection of bullets by means of condensed air. The ancients were acquainted with the principles of its construction, and an instrument of this description was invented by Ctesibius of Alexandria, who flourished about 120 B.C. The first modern account of an air-gun, which we meet with, is in the Eléments d'Artillerie of David Rivaut, preceptor to Louis XIII. of France.

AlR-PIPES; a recent invention for the ventilation of ships by means of the rarefying power of heat. Mr Sutton, a brewer of London, is the inventor. If the usual aperture to any fire be closed up in front, and another be introduced by the side of the firepiace, it will attract the current of air into that direction; and the coppers, or boiling-places of ships, are well known to be placed over two holes, separated by a grate, the one for the fire, the other for the ashes; there is also a flue from the tops for the discharge of smoke. Mr Sutton's pipes, now, are introduced into the ash-place, and carried throngh the hold to any part of the ressel. The two holes 
before alluded to are closed up by strong iron doors; a continued draught of air supplies the fire, and creates a salutary circulation through any part of the vessel into which the pipes may be directed. They are made either of copper or lead.

A1R-PUNP; a machine for the purpose of withdrawing the air from some vessel or cavity, and thereby making what is called a vacuum. It is one of the most curious and useful of philosophical instruments. By experiments with it, the weight, elasticity, and many other properties of air inay be shown in a very simple and satisfactory manner.I cet $R$ be the section of a glass bell, closed at the top T, but open at the bottom, and having its lower edge ground smooth, so as to rest in close contact with a smooth brass plate, of which SS is a section. This glass is called a receiver, because it receives and holds substances on which experiments are to be made. If a little unctuous matter be rubbed upon the edge of the receiver $R$, and it be pressed with a slight circular motion upon the plate SS, it will be brought into such close contact as to be air-tight. In the middle is an opening $A$, which communicates by a tube $\mathrm{AB}$ with a hollow cylinder or barrel, in which a solid piston $\mathrm{P}$ is moved. The piston-rod $\mathrm{C}$ moves in an air-tight collar D, and at the bottom of the cylinder a valve $\mathrm{V}$ is placed, opening freely outward, but immediately closed by any pressure from without. There is thus a free communication between the receiver $R$, the tube $A B$, and the exhausting barrel BV. This communication extends in the same manner to a second similar barrel $\mathrm{XV}$. When the piston CP is pressed down, and has passed the opening at $\mathrm{B}$, the air in the barrel $\mathrm{BV}$ will be enclosed, and will be compressed by the piston. As it will thus be made to occupy a smaller space than before, its density, and consequently its elasticity, will be increased. It will therefore press downwards upon the valve $V$ with a greater force than that by which the valve is pressed upwards by the external air. This superior elastic force will open the valve, through which, as the piston descends, the air in the

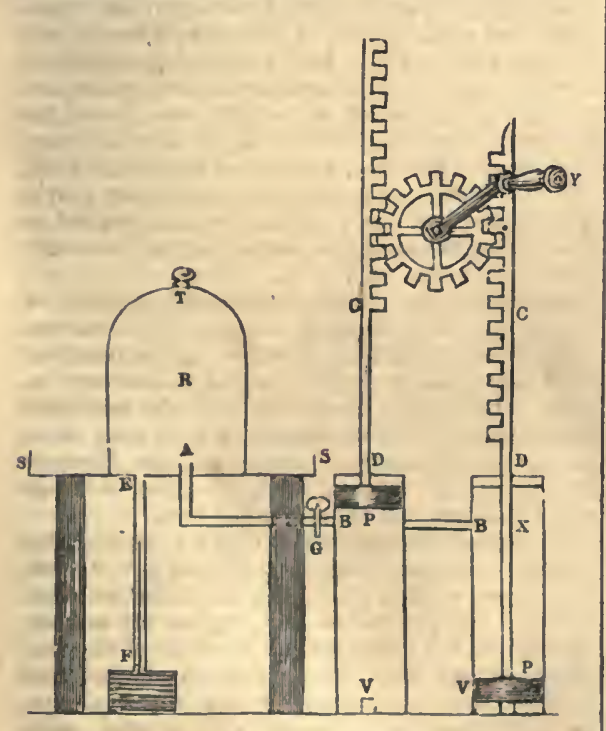

harrel will be driven into the atmosphere. If the piston be pushed quite to the bottom, the whole air in the barrel will, be thus expelled. The moment the piston begins to ascend, the pressure of the air from without closes the valve completely. Nune of the external air can enter; and, as the piston ascends, a vacuum is left beneath it ; but, when it rises beyond the opening $B$, the air in the receiver $R$ and the tube $A B$ expands, by its elasticity, so as to fill the barrel BV. A second depression of the piston will expel the air contained in the barrel, and the process may be continued at pleasure. The communication between the barrels and the receiver may be closed by a stop-cock at G. It is evidently only in consequence of the elasticity of the air that it ex. pands and fills the barrel, diffusing itself equally throughout the cavity in which it is contained. The operation of the machine depends, therefore, on the elasticity of the air, and it is obvious that a perfect vacuum cannot be formed by it in the receiver, as only a part of the air is each time expelled, and a portion must always remain after each depression of the piston. The degree of rarefaction produced by the machine may, however, be easily calculated. Suppose that the barrel contains one third as much as the receiver and tube together, and, therefore, that it contains one-fourth of the whole air within the valve V. Upon one depression of the piston, this fourth part will be expelled, and three-fourths of the original quantity will remain. One-fourth of this remaining quantity will in like mannerbe expelled by the second depression of the piston, which is equal to three-sixteenths of the original quantity. By calculating in this way, it will be found that after thirty depressions of the piston, only one 3096th part of the original quantity will be left in the receiver. The rarefaction may thus be carried so far that the elasticity of the air pressed down by the piston shall not be sufficient to force open the valve. To show how far the exhaustion has been carried at any particular point of the process, a barometer-gauge is connected with the machine. This is a glass tube, opening at $\mathrm{E}$ into the receiver, and at $\mathrm{F}$ immersed in a cistern of mercury. As the rarefaction proceeds, the mercury rises from the pressure of the external air, and indicates how far this pressure exceeds that from within the receiver, that is, the degree of exhaustion. Both pistons are worked by the wheel $H$ and winch $\mathbf{Y}$, by means of the rack or tooth-work on the pistonrods. When one piston is raised, the other is depressed. The winch is then turned in the opposite direction, and the piston which had been raised is depressed, and the other raised. When the rarefaction of the air within the barrels is considerable, the pressure of the atmosphere upon each piston is not resisted from within, and therefore opposes its ascent. But this pressure is not felt by the operator, as the pressure upon one piston counterbalances that uron the other. The elasticity of the air is proved by the action of the machine. Its pressure is proved by the great firmness with which the receiver is pressed upon the plate SS during the rarefaction of the air within. If any animal is placed beneath the receiver, and the air exhausted, he dies almost immediately; a lighted candle under the exhausted receiver immediately goes out. Air is thus shown to be necessary to animal life and to combustion. A bell, suspended from a silken thread beneath the exhausted receiver, on being struck, cannot be heard. If the bell be in one receiver, from which the air is not exhausted, but which is within an exhausted receiver, it still cannot be heard. Air is therefore necessary to the production and to the propagation of sound. A shrivelled apple or cranberry, placed beneath an exhausted receiver, becomes as plump as if quite fresh. They are thus shown to be full of elastic air. A great variety of experiments may be made, which are very interesting, but too numerous to be described.-The air-pump was invented by Otto de Guericke, burgo- 
master of Magleburg, about the jenr 1651. Modifications and improvements were afterwants male by I3oyle, Hawksbee, Morton, and many others. It is made in various forms, one of the simplest of which is that already describerd. - The following cut represents the air pump as it is usunliy coustricted.

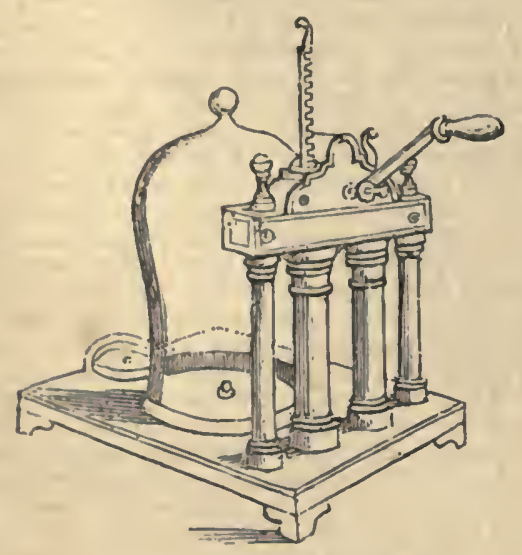

AIR-TRUNB; a contrivance by Dr Halcs to prevent the stagnation of putrid effiuvia in jails, or any apartments where many people are collected. It consists of a long, squarc trunk, open at both cuds, one of which is inserted into the ceiling of the room, and the other extends a considerable distance berond the roof. Through this trunk a continued circulation is carried on, because the putrid efllnvia are much Jighter than the pure atmosphere. Dr Keil estimates these effluvia arising from onc man in twenty-four liours at not less than thirty-nine ounces. These trumks were first tried in the English house of commons, where they were nine inches wide within, and over the court of king's bench, where they were six inches wide.

Aissí (Dcmois.), a lady well known for her roInantic adventures and unliappy fate, was born in Circassia, 1689, and was purchiased by the connt de Ferriol, the French ambassador at Constantinople, when a child of four years, for 1500 livres. 'The seller declared her to be a Circassian princess. She was of great beanty. The count took her with him to France, and gave her an education, in which nothing was neglected but the inculcation of virtuous principles. Her disposition was good, but her life immoral. She sacrificed her innocence to the solicitations of her benefactor. On the other hand, she resisted the splendid offers of the duke of Orleans. Of lier numerous suitors, she favoured only the chevalier Aidy. This love decided her fate. Aidy had taken the rows at Malta; he wished to disengage himself from them; but lis mistress herself opposed the attempt. The fruit of her love was a daughter, born in England. She was subsequently a prey to the bitterest remorse; she resisted her passion in vain, and lived in a continual struggle with herself, which her weak health was unable long to sustain. She died in 1727, aged thirty-eight. Her letters are written in a pleasant and fuent strain, and exhibit a lively picture of the author's feelings. They contain many aneodotes of the prominent personages of her times. They first appeared with notes by Voltaire, subsequently with the letters of Messlames de Villars, Lafagette, and de Tencin, 1806,3 vols.
Aırox, William, au eminent botanist and gardener. was bom in Lautarkshire, Scotland, in 1731. In 1754, he went to Fngland, and was employed as an assistant in the physic garden at Chelsea, under Plilip Miller. In 1759, he obtained the situation of head gardener of the royal gardens at Kew, and becane a great favourite with George H1. In 1789, he published a catalogue of the plants cultivated in this garden, under the title of Hortus Kewensis. It was in 3 vols. $8 \mathrm{vo}$, and contained an (enumeration of between 5000 and 6000 species. Mr Aiton died in 1793.

Aix (among the Romaus, Aqua Sextice), in the Freuch department of the mouthis of the Rhione, on the river Arc, contains 21,960 inlabitants, is the seat of an archibishop, a royal court of appeals and channber of commerse, a school of theology and jurisprudence, a college, a considerable library, a learned society, and a museum. Several mamnfactures ure carried on in the city, principally of cotton; they ure, however, on the decline. 'The warm batlis, too, are less visited than formerly. In the cluurch of the Minorites, Frederic the Great erected a nonument to the marquis d' Argens. This city las the largest limits of any city in France. The numerous fausilies residing on the grcat gardens around thic eity are counted among the population, as is cistomary in France and Italy. This is the reason that the accounts of the population of the southern cities of Europe seem so frequently exaggerated to strangers, unacquainted with the circumstance. Aix derives its principal support from the culture and nanufacture of silk, in its extensive district, which contains marsliy, saudy, calcareous, and stony soils, together with the cultivation of the olive, and of the fruits of the south, which are well paid for by the luxury of northern France. Lon. $5^{\circ} 97^{\prime} \mathrm{E}$. ; lat. $43^{\circ} 32^{\prime} \mathrm{N}$.

Aix un Chaprole (in German, Aachcu); capilal of the district of the same name, in the Prussian grand duchy of the Lower Rline; $51^{\circ} 55^{\prime} \mathrm{N}$. lat. ; $5^{\prime \prime} 54^{\prime} \mathrm{E}$. long. The district contained, in the year $18: 5$, upon 1550 square miles, 336,025 inlabitants, anong which were 324,453 Catholics, 9686 Protestants, and 1891 Jews. The city itself contains 2732 houses, and in 1822, had 34,584 inhabitants. It lies between the Rhine and the Meuse, at a distance of about thirty-seven miles from the former, and eighteen from the latter. It is very pleasantly situated in a fine vale, surrounded by benutiful hills. There are traces of its existence under the gorernment of the Romaus, to whom it was known as early as the time of Cresar and Drusus; Pliny mentions it under the name of Vetera. Here, according to some writers, the emperor Charlemagne was bortu, A. D. 742 ; here he died, A. D. 814 . The extensive privileges which he and other emperors conferred on this imperial city, gave rise to the saying, that "the very air of A. unade free even the outlaws of the empire." Fifty-five emperors have been crowued in this city, and the imperial insignia werc preserved here till the year 1795 , when they were carried to Vienna, and are now in the imperial treasury. Its citizens, throughout the empire, were exempt from feudal service, both in peace and in war; from attachment of their goods and imprisonment ; from tolls and taxes levied on the property of travelling merchants, \&c. By the peace of Luneville, concluded Feb. 9, 1801, which separated the left lank of the Rhine from Germany, the city was transferred to France, and remained, till the overthrow of Napoleon, the chief town of the department of the Roer. To its French name, Aix, the term la Chapelle has been added in order to distinguish it fiom other towns of the sume name. The inarket-plact:

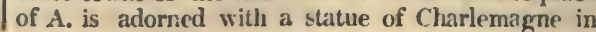


hronze. On the spot where, in ancient times, a Roman castle stood, the kings of the Franks built a royal castle, in German Pfalz. This was destroyed, A. D. 88:, by the Normans, restored by the emperor Otho I1I., 993, and used in the 14th century as the town-house. This building contains many relics of old German art, the liall where the emperors were crowned, the bust of Napoleon and his first empress, painted by David, a tower of Roman origin, \&c. The minster was - erected between the years 796 and 804 , by the emperor Charlemagne, and was ornamented with great splen dour. In the middle rises the monument of Charlemagne, with the simple inscription, Carolo Magno. Above it hangs, suspended by a chain, a colossal crown of silver and gilt copper, a donation of Frederic I., which serves as a chandelier for forty-eight candles. Here is to be seen the chair of white marble, on which several emperors have sat at the time of their coronation. It was formerly overlaid with gold. The church of the Franciscans is distinguished by a beautiful picture of Rubens, the Descent from the Cross, which was carried to Paris, but has been brought back. The inhabitants are for the most part catholics, many of whom are actively engaged in manufactures. The cloths of $\mathrm{A}$. are famous on the continent of Europe. A manufacture of needles, established about the middle of the 16th century, by Gauthier Wolmar, formerly employed more than 15,000 workmen, but in the year 1808 only 8000 . A. contains fifteen charitable institutions; it has seven inineral springs, six of them warm. The most famous is the imperial spring, the vapour of which, if confined, deposites sulphur. The rooms for bathing are excellent, with baths from four to five feet deep, in massive stone, after the old Roman fushion; the greater part have bed-chambers with chimneys. At a distance of 500 paces from $A$. lies the village of Burtscheid, which also contains hot springs. The upper springs are in the village itself, the lower in the valley, in the open air. The water is useful for washing and dyeing clotlis. The upper springs contain no hepatic gas, and deposit no sulphur; in this respect they differ from the lower, and those of $\mathbf{A}$. There are also in Burtscheid manufactures of broadcloth, cassimere, and needles. The coal-mines and pyrites in the surrounding country account for the hot-wells of $A$. and $B$. The names of several streets, Alexander, Francis, Wellington street, remind us of the congress of $A$. in 1818 . (See the following article.) 'The history and description of $A$. with B. and Spa, by Aloys Schreiber, Heidelberg, 1824, is the best guide-book for travellers on the Rhine.

AIX LA CHAPELLF, congress at. In modern politics, the congress at A. in Oct. and Nov. 1818, is of high importance. The principal measures determined on at this meeting of the great powers which had conquered Napoleon, were the following: 1. The nimy of the allies, consisting of 150,000 British, Russian, Austrian, Prussian, and other troops, which, since the second peace at Paris, had remained in France, to watch over its tranquillity, was withdrawn after France had paid the contribution imposed at the peace of 1815. The king of France was then admitted into the holy alliance. 'Thus the congress of A. restored independence to France. 2. The five allies, the emperors of Austria and Russia, and the kings of Great Britain. France, and Prussia, issued at this time the famous declaration of Nov. 15,1818 , a document of very dangerous tendency, too inde? finite to settle any of the important political questions then pending, but full of the personal views and feelings of the monarchs, and the legitimate offspring of the holy alliance concluded Sept. 26,1815 , at
Paris. The friends of absolute government in Europe, who confound the idea of the reigning family with that of the state and the government, admired the paternal professions of the sovereigns in this instrument, which is principally of a religious character; but sagacious politicians and the friends of justice foresaw all the evils which it afterwards produced. Its vagueness admitted of a great latitude of construction, and it was soon followed by a breach of the law of nations in the invasion of Italy and Spain under the newly-declared droit $d$ ' intervention armée, pronulgated at Laybach, a direct consequence of the doctrines advanced at $\mathbf{A}$. The holy alliance, with all the declarations of the succeeding congresses at Troppau, Laybach, and Verona, affords the first instance of an avowedly personal alliance between many monarchs to maintain certain principles of government, and attack every nation within their reach which adopts a different political creed. After the termination of the struggle against Napoleon, in which princes and people were firmly united, the former anxiously separated their interests from those of the latter, and at the congress at $\mathbf{A}$. they openly manifested the designs which every succeeding congress has developed more clearly. (See Holy Alliance.) The king of France, at this congress, became a member of the holy alliance only in his personal chancter, not as the constitutional chief of the French government, following the example of George IV. then prince regent of Great Britain. In fact, the accession of these two sovereigns was only to avoid appearing directly opposed to the alliance. 3. From the congress of $A$. are to be dated all the decisive measures of the German governments against the liberal spirit which had spread among their subjects since the wars of Napoleon. In A. it was first seen how unwilling the king of Prussia was to fulfil his promises of liberal institutions, and how anxiously Austria desired to suppress whatever tended to give force to public opinion, to secure the rights of the people, or promote the cause of representative government. At A. Mr Stourdza, a Russian subject, published his influential work, Mémoire sur l' Etat actuel de l' Allemagne. The congress at Carlsbad (q. v.) was an immediate consequence of the congress at $\mathrm{A}$. It had reference, however, only to Germany. History will point out the period of these congresses as the era of violent political bigotry, corresponding to the former ages of religious bigotry in its principles as in its measures. (See M. des Pradt's L' Europe après le Congrès d' Aix la Chapelle, 8vo. Paris, 1819, and Mr Scholl's Histoire des Traités de Paix, with his Archives Politiques, 181819.) For the congress at $A$. in 1748 , see the following article.

Aix la Chapelize, treaties of peace concluded at. The first, May 2d, 1668, put an end to the war carried on against Spain by Louis XIV., in 1667, after the death of his father-in-law, Philip IV., in support of his claims to a great part of the Spanish Nether. lands, which he urged in the name of his quien, the infanta Maria Theresa, pleading the jus devolutionis, prevailing among private persons in Brabant and Namur. Conde had already conquered FrancheComté, and Turenne had taken ten fortresses, wheis the triple alliance, concluded by de Witt and Sir Williain 'Temple (see $\boldsymbol{V}$ itt and Temple), determined France to make peace with Spain, on conditions which were agreed upon at St Germain with the allies, and ratified at $\Lambda$. Spain had the option to surrender either the Franche-Comte or the fortificd places in the Netherlands. She chose to give up the latter. Thus France obtained a part of the ancient Burgundy, the Spanish fortresses Lilie, Charleroi, Binch, Douai, Tournai, Oudenardo, and 
six others, together with their appendages. (See
Sicholl, Hist. des Tratés, \&c. 1. 331.) Tile scholl, Hist. des Traites, \&c. 1. 331.) The second war of succession (see Austriu), in which the parties were at first Louis $X V$. of Frnece and the enipress Maria Theresa, and, in the sequel, Spain on one side, and Great Britain, Maria Theresa, ancl Charles Esasanuel, king of Sardinia, on the other. In this war, the united Netherlands were engaged as allies of Great Britain and Austria, Modena and Genoa as allies of Spain. Maria Theresn surrenlered to Philip, infant of Spain, Parma, Piacenza, and Gunstalla. Thus the fourth sovereign line of the house of Bourbon, that of Parma (since 1817 established in Lucca), took its origin. On the whole, the state of possession before the war was restored, the pragmatic sauction and the succession of the house of Hamover in Great Britain guaranteed, and Silesir and Glatz sccured to the king of Prussia. A Russian auxiliary army of 37,000 men, under prince Repnin, in the pay of the naval powers, approaching, in the spring of 1748, from Bolnevilia to the Rhine, accelerated the conclusion of the peace. The plenipotentiaries of France, Grent Britain, and the States General, in a secret session, April 30, 1748, signed the prelinninaries, four copies of which were presented to the otlier powers engaged in the war, and signed by them separately. Charles Stuart, the eldest son of the pretender, protested, at Paris, July 16 , against the exclusion of his father, who called himself James III. from the British throne. The above-named tliree powers first signed, in like manner, the definitive peace, whereupon Spain, Genos, and Modena, July 20, and Austria, July 23, (by lier plenipotentiary, count, afterwards prince Kaunitz), did the same. (See Scholl, i. 411, et seq.)

Asaccio, or Asazzo, the capital of Corsica, colltains 6570 inhabitants. It has a harbour, protected by a citadel, lying to the north of the gulf of the same name, on the western coast of the island, at the confluence of the rivers Terignano and Restonico. The entrance into the liarbour is rendered unsafe by projecting rocks. A. is the birth-place of Napoleon, his brothers, and sisters. It is the handsomest city of Corsica, and the seat of a bishop. In the commercial world, it is famous for its coral and anchory fisheries; less so, in the learned world, for its academy. Lon. $8^{\circ} 44^{\prime}$ E.; lat. $41^{\circ} 59^{\prime} \mathrm{N}$.

Asswos; a town rendered memorable by Joshua's victory over the five Canaanitish kings, and still more so by the extraordinary circumstance of the miraculously lengthened day.

AJAs; a coast and country of Africa, which has the river Quilmanci on the south, the mountains from which that river springs on the west, Abyssinia and the straits of Babelmandel on the vorth, and the Indian ocean on the east. The coast abounds with all the necessaries of life, and has plenty of very good horses.

Ajassaluck; the Turkish name for a village on or near the site of the ancient Ephesus. The whote place seems to have been built from the ruins of Ephesian grandeur. Tamerlane encamped here, after having subdued Smyrna, in 1402.

Ajax (Greek, Aras). Among the Grecian chiefs who fought against Troy were Ajax Oileus and Ajax Telamonius. The former, the son of Oileus and Ftiopis, a Locrian, was called the less. He accompanied the expedition to Troy, because he had been one of the suitors of Helen. In the combat, his courage sometimes degenerated into inconsiderate fury. Examples of this are given by the poets who succeeded Homer. When the Greeks, they say, had entered Troy, Cassandra fled to the temple of Pallas, from whence she was forced, and dragged along, bound as a captive. Some aciounts add, that she canghit hold of the statue of the goxldess, and that $\mathrm{A}$. thragged her away by the Lair; others, that he violated the prophetess in the temple of the gockless. Ulysses accused him of this crime, when he exculpated hinself with an onth. But the anger of the goddess at last overtook hin, und he perished in the waves of the ser. The other $A$. was the son of 'Telamon, from Salauis, and a grandson of Alacus. He, also, was a suitor of Helen, and sailed witl 12 ships to Troy, where he is represented by Homer as the boldest and handsomest of the Greeks, after Achilles. He understool not how to speak, but how to act. Ile was frank, and full of noble pride. After the death of Achille's, whe's his arms, which Ajax clained on account of his courage aud relationship, were awarded to Ulysses; he was filled with rage, and, driven by despair, threw lrimself on his sword.

Aкваn; a celebrated Samcen conqueror in the first century of the IIegira, who overran Africa from Cairo to the Atlantic ocean. A general revolt among the Greeks and Africans recalled him from the west, and occasioned his destruction. He founded Cairoan, in the interior of Africa, to check the barbarians and secure a place of refuge to the families of the Saracens.

AKBAR, or AKBER, Moliammed, sovereign of India; the greatest $A$ siatic prince of modern limes. He was born at Amerket, in the year of the Hegir. 949 (1542 of the Christian era), and, after the death of his father, ascended the throne, at the age of thirteen, and governed India under the guardianship of his minister, Beyram. His great talents were early developed. He fought with distinguished valour against his foreign foes and rebellions subjects, among whom was Beyram hinself. His government was remarkable for its mildness and the greatest tolerance towards all sects. Though compellet by continued commotions, to visit the different provinces of his empire at the head of his armiy, he lored the sciences, especially listory, and was indefatigable in his attention to the interual administration of his empire. He instituted inquiries into the population, the nature and productions of each province. The result of his statistical labours were collected by his minister, Abul Fazl, in a work, entitled Ayeen Akberi, printed in English, at Calcutta, 1783-86, 3 vols, and reprinted in London. A. died after a reign of 49 years, in $1017(1604, A$. D.) His splendid sepulchral monument still exists near Agra, with the simple inscription, Akbar the Admirable. He was succeeded by his son Selim, under the name Djihangir.

Axesside, Mark, a poet and physician, was born in 1721, at Newcastle-upon-Tyne. His father, a butcher, of the presbyterian sect, intended him for a clergyman, and placed him, at the age of 18 , in the university of Edinburgh, to qualify him for that office. The taste of A. was not inclined to that profession, and he abandoned the study of theology for that of physic. Having received some assistunce from the funds employed by the Dissenters in the education of soung men intended for the ministry, he very honourably refunded the amount when he relinquished his theological studies. After three jears' residence at Edinburgh, he went to Leyden, and in 1744 became doctor of physic. In a thesis, which he published on receiving his degree, De Ortu et $\mathrm{In}$. cremento Foetus Humani, he proposed a new theory, which has been since confirmed and received. In the same year, he published the Pleasures of Imagination, which, however, he is said to have written during his residence at Edinburgh. In the following year, he published a collection of oles, 
and the epistle to Curio, a satire on Pulteney. After having unsuccessfully attempted the practice of his profession at Northampton and Hampstead, he was invited to London by his friend Mr Dyson, from whom he received a pension of $£ 300$ a-year. Here he became a fellow of the royal society, was admitted into the college of physicians, and read the Gulstonian lectures in anatomy, but never obtained a very extensive practice. He was, however, nominated physician to the queen. While at London, he wrote little poetry, but published several medical essars and observations. His discourse on the dysentery (1764) has been much admired for the elegance of its Latinity. He died in 1770 , in the 49 th year of his age, of a putrid fever. A. was a man of religion and strict morals; a philosopher, a scholar, and a fine poet. His conversation is described to have been of the most delightful kind, learned and instructive, without any affectation of wit, cheerful and entertaining. Yet his pride, insolence, and irascibility involved him in frequent disputes, and prevented his success in the practice of his profession. His favourite authors were Plato and Cicero among the ancients, and Shaftesbury and Hutchinson among the moderns. The ridicule cast.upon him by Smollett, 'ii the novel of Peregrine Pickle, where he figures as the giver of a feast after the manner of the ancients, is well known. The odes of $\mathrm{A}$. do not entitle him to a very high rank in lyric poetry; his epistle to Curio is written in a tone of vigorous and poignant satire. He is particularly distinguished as a didactic poet, and has left in his Pleasures of Imagination one of the most pleasing didactic poems in our language. The periods are harmonious, the cadence graceful, and the measure dignified. It is replete with elevated sentiments, with images of poetic beauty and high philosophy. The sentences are sometimes extended to ton great length, splendid imagery too nuch accumulated, and the thought sometimes too thickly overlaid with words. These faults he endeavoured to correct in the new edition, in which nuany other changes are introduced; but the original will always be more read and admired.

Arerblad, John David; by birth a Swede. When very young, he accompanied the Swedish embassy to Constantinople in the capacity of secretary. The leisure which his station afforded, he employed in iravelling through the East. He visited Jerusalem and the Troad in 1792 and 1797 ; and has offered some suggestions respecting the situation of the city of 'Troy, in the German translation of Le Chevalier's travels, which display both the classical scholar and the learned orientalist. For some time, about the year 1800 , he lived in Gottingen, and then went to Paris, as Swedish chargé d'affaires., Discontent at the changes in his native country is said to have induced him to throw off all connexion with Sweden, and retire to Rome, where he received from the duchess of Deronshire, and other friends of litera. ture, the means of living in literary leisure. He died at Rome, Feb. 8, 1819. His writings display a great knowledge of the oriental and western languages, which he could speak as well as interpret. Among them are his Lettre à M. Silvestre de Sacy, sur l'Ecriture cursive Copte (Mag. Encyc., 1801, tom. v.), the Lettre à M. de Sacy, sur l'Inscription Emyptienne de Rosette (id. 1802, tom. iii.), his famous explanation of the inscriptions on the lions at Venice, Notice sur deux Inscriptions en Caractères Runiques, trouvées à Venise et sur les Varanges, avec les Remarques de M. d'Ausse de Villoison. Equally important, both for the knowledge of ancient writings and of inscriptions, is the Inscrizione Greca sopra una Lamina di piombo Trovato in un Sepolcro nelle Vicinanze d'Atene (Rome, 1813. 4to), in improving wlich he was employed when surprised by death. The last of his works, that appeared in print, was a Lettre sur une Inscription Phenicienne trouvée à Athènes (Rome, 1814, 4to.), addressed to count Italinsky. The national institute at Paris chose him a corresponding member of their society. He lies buried near the pyramid of Cestius, at Rome.

Akermav, or Ackermav (the ancient Julia Allua and Hermonoclis); a town in Bessarabia, a province of Russia, on the coast of the Black sea, at the mouth of the Dniester, 65 miles S.E. of Bender, 68 S.W. of Otchakow ; lon. $30^{\circ} 44^{\prime}$ E. ; iat. $46^{\circ} 12 \mathrm{~N}$.; pop. stated very differently; formerly at 20,000 , more recently at 8000 . It contains a number of mosques, one Catholic and one Armenian church, and has some trade. A. has recently acquired some celebrity by the treaty between Russia and Turkey, there concluded, Oct. 6, 1826, in which the latter power agreed to the 82 points of the Russian ultimatum. This treaty is a supplement to the peace of Bucharest. The porte ceded to the emperor Nicholas all the fortresses in Asia of which it had previously demanded the restoration, and acknowledged the political organization (if we dare use this expression for so rude a state of politics) which Russia had determined on for Servia, Moldavia, and Walachia. But the treaty was not executed till 1827 , and then not to the satisfaction of Russia. This furnished the ostensible reason of the late war between the two great eastern powers.

Alabalia, one of the United States of America; bounded N: by Tennessee, E. by Georgia, S. by Florida and the gulf of Mexico, and W. by Mississippi ; lon. $85^{\circ}$ to $88^{\circ} 30 \mathrm{~W}$.; lat. $30^{\circ} 10^{\circ}$ to $35^{\circ} \mathrm{N}$. ; 330 miles long, from $N$. to $S$., and 174 from $E$. to W.; square miles, about 51,000 ; pop. in 1810 , less than 10,000 ; in 1816. 29,683 ; in 1818, 70,544; in 1820 , by the imperfect census at first returned, 127,901; by the census as subsequently completed, 144,317 ; in 1827,$244 ; 041$, of whom 152,178 were whites, 93,303 slaves, and 555 free persons of colour. The last estimate of the number of Indians within the territory of the United States, by the war department, in 1829, states that there are 19,200 Indians in the state of A.-The number of counties into which this state was divided in 1820 , was 24 ; and in 1828,36 . Tuscaloosa is the present seat of government. Cahawba was formerly the capital. Mobile is the principal port, (q. v.) - The principal rivers are the Alabama, Tombeckbee, Mobile, Black-Warrior, Coosa, Tallapoosa, Tennessee, Chatahoochee, Perdido, Cahawba, and Conecuh.-The southern part of the state, which borders on the gulf of Mexico and Florida, throughout a space fifty or sixty miles wide, is low and level, covered with pine, cypress, and loblolly; in the middle it is hilly, with some tracts of open land or prairies; in the northern part it is somewhat broken and mountainous. The Alleghany mountains terminate in the north-east part. Tlie forest-trees in the middle and northern divisions are post, black, and white oak, lickory, poplar, cedar, chesnut, pine, mulberry, \&c.-The soil is various, but a large part of it is excellent. In the south it is generally sandy and barren; and a part of the high lands are unfit for cultivation. A large portion of the country which lies between the Alabama and Tombeckbee, of that part watered by the Coosa and Tallapoosa, and of that on the Tennessee, consists of very excellent land. On the margin of the rivers there is a quantity of cane bottomland of great fertility, generally from one-half to three-fourths of a mile wide. On the outside of this is a space which is low, wet, and intersected by stagnant water. Next to this river swamp, and elevated ten 
or ffteen feet above it, suceeds an extensive borly of level land, of a black, rielı soil, will a growth of hickory, blaek onk, post onk, poplar, dogwood, \&c. After this come the prairies, which are wide spreading plains, or gently-waving land, without timber, clothed with grass, herbage, and flowers, txhibiting in the month of May, the most enchanting seenery. Cotton is the staple production, and is raiserl in great quantities. Other proluctions are maize, rice, wieat, rye, onts, \&c. Irou ore is found in several places, and cual abounds on the Black-Warrior and Cahawbu.-The clinate in the sonthern part of the bottomland bordering on the rivers, and of the country bordering on the Muscle shouls, is unhealthy. In the elevated country, the climate is very fine; the winters are mild, and the summers pleasant, being tempered by breezes from the gulf of Mexico.-The population of this state, frona the time when the first settlement was commeneed, has increased with remarkable rapidity. Occupying the valley of the Mobile and its tributary streams, the Alabama and Tombeckbee, its position, in an agrienltural and commercial point of view, is highly advantageous; and from the fertility of its soil, and the value of its productions, it may be expected to becone an importaut member of the Union.-The Cherokee Indians occupy the N. E. corner of the state, the Creeks the castern part, and the Chiekasaws and Choctaws some portions of the westert. - Alabama originally belonged to the state of Georgia; in 1800, the eountry ineluding the present state's of Mississippi and Alabama was formed into a territory; the part of Florida between Pearl and Pendido rivers, being taken possession of by the United States in 1812, and annexed to this territory, enigration into it immediately eommericed. During the years 1813 and 1814 , it was harassed-hy the attaeks of the savages, who were rcfluced to submission by general Jackson. In 1817, the western portion of the territory became the state of Mississippi, and the eastern the territory of Alabama, which by an act of congress, Mareh, 1819, was udmitted into the Union as an independent state. By its constitution, adopted July, 1819, the legislative power is vested in two houses, ehosen by universal suffrage.-Many of the settlers in this state are rieh planters. Some of the lands were sold for 50 dollars an acre in a state of nature. The fertility of the soil, the general salubrity and mildness of the elimate, the great facilities for internal navigation and foreign cominerce, sufficiently aeeount for the rapid inerease of its population.

Alabama; a river which gives its name to the state so called; (see the preceding article). It is formed by the junetion of the Coosa and Tallapoosa, and, flowing S. S. W., unites with the Tombeckbee, forty-five miles above Mobile bay, to form the river Mobile. From the junetion to Clairborne, sixty miles, it is navigable at all seasons for vessels drawing six feet. From Clairborne to the month of the Cahawba, about 150 miles, the river has four or five feet of water. From the mouth of the Cahawba to the junetion of the Coosa and Tallapoosa, the navigation generally continues good, the river affording three feet of water in the shallowest plaees. The river is subject to great variation by rising and falling.

Alabasta; a tribe of Indians so called, which formerly inhabited the eastern side of the Mobile river.

A laAaster (in Greek, a $\lambda \alpha \beta \alpha \sigma \tau \rho o s ;$ in Latin, alabaster), in mineralogy; (see Gypsum.) In seulpture; the common name, among ancient and modern artists, for gypsum and the calc-sinter of modern mineralogy. A. has a greater or less degree of transparency, aecording to its goodness; has a granular texture, is softer than mable, does not take so finc a joulish, and is usually of a pure white eolour. In Enirope, it is found near Coblentz in Germany; in the neighlonrlood of Cluny, in Franee; in Italy, near Rome. Some of the $\Lambda$. near this eity is particularly celebrated for its whiteness ond the size of its blocks, which are large enongh for a statue of the size of life. There are, also, many quarrie's of the granular gypsum, which is used for the mannfacture of plaster of Paris, in Nottinghanshire and Derhyshire. 'Io prepare the plaster, the gypsum is bumed and ground. Moulds and easts from statues and other seulptures are formed froin this valuable material, and also a very strong cement for the use of the sculptor and mason, to form the close joints of marble; plasterers also use it inueh, partienlarly for monldings and foliage. 'The ancients obtained large blocks of A. from Thebes (where was a town from which it received this name), and used it for statues and columns. The various museums contain many vases and similar artieles of A., for which the Romans often employed this naterial. They imported nuch from Cyprus, Spain, and even A frica. 'They liked] particularly to put their lanps in vases of transparent $\Lambda$., which gave an agreeable softuess to the light. In the inuseums, several figures of aneient seulpture are preserved, the bodies of whieh are of $\Lambda$. and the heads of some other substanee. A box, vase, or other vessel, to hold perfiumes, formed of $\Lambda$. was called by the aneients alabastrum; Horace calls the'm onychites. The alabastrun is always among the attributes of the Buthing Venus. Oricntal A. was the most sought after for the purpose of making tliese vessels.

Alacranas ; a range of hidden rocks, shoals, and banks, in the gulf of Mexieo, near the coast of Yucatan. Loll. $90^{\circ} \mathrm{W}$.; lat. $22^{\circ} 36^{\prime} \mathrm{N}$.

Aladan, Alada, or Aladise Islands; a elustir of small islands in the bay of Bengal, belonging to what is sometimes called the Mergui Archipelugo, near the coast of Siam. They run from $9^{0} 5^{\prime}$ to $9 \circ 40^{\prime}$, N. Iat., and are in $97^{\circ} 5 \varkappa^{\prime \prime}, \mathrm{E}$. Ion.

Alamans, Luigi; a famous Italian poet, born at Florenee, in 1495, of one of the noblest and most distinguished families of the republic. His father was zealously deroted to the party of the Mediei, and he himself stood in high favour with the cardinal Giulio, who governed in the name of pope L'o X.; but, conceiving himself to have been injured, he joined a eonspiracy formed against the lite of the cardinal. The plan was discovered; $A$. fled to Venice, and, when the cardinal ascended the papal chair, under the name of Clement VII., he took refuge in France. . But the misfortunes which befell this pope giving Florence an opportunity to become free, in $1527 \mathrm{~A}$. returned thithier. His country sent him on an embassy to Genoa. Here he became the friend of Andrew Doria, with whose flect he went to Spain. Charles V. soon after sailed in the same flect from Spain to Italy, to arrange the affairs of Florenee, and subject it to the Mediei. After this new revolution, A., proseribed by the duke Alessar dro, went to France, where the favours of Francis I. retained him. Here he eompnsed the greater part of his works. The king esteened him so highly; that, after the peace of Crespy, in 1544 , he sent him us ambassador to the emperor Charles V. A. diseharged his office with great skill. Ile was held in like estimation by Henry II., who also employed him in several negotiations. He followed the court, and was with it at $\Lambda$ inboise, when he was attaeked with the dysentery, whieh terminated his life. His prineipal works are a colleetion of poeins, eelogues, psalms, satires, elegies, fables, \&c., part in blank verse, the invention of whieh is contested with him 
by Trissino; Opere Toseane, a didactic poem; La Coltivazione, to which he is mostly indebted for his tame ; Girone il Cortese, a heroic poen, in 24 cuntos, from an old French poem of the same name; La Avarchide, an cpic, in which he describes, in a few happy imitations of Homer, the siege of the city of Bourges (Avaricum,) likewise in 24 cantos; Flora, a comedy in versi sdruccioii (see Rhyme); and a number of epigrams. The writings of $\mathrm{A}$. are recoinmended by ease, perspicuity, and purity of style, but otien want strength and poetic eleration.

$A-L \bar{A}-M I-2 E$, in music; an Italian method to determine the key of $\mathrm{A}$, by its dominant, and subdominant A E D. In the Guidonian scale of music, ala-mi-re is the octave above a-re, or $\mathrm{A}$ in the first space in the base.

Alav, or Allev, William, was born in Lancashirc, in 1532. Being warmly attached to the Roman catholic religion, he left England on the accession of Elizabeth; and, though he soon after returned, he lived in the greatest privacy, and finally fled to Flanders. He was, both during this concealment in England and his residence abroad, actively engaged in writing and distributing polemical tracts, and was ore of the ablest advocates of Rome. He asserted the necessity of deposing Elizabeth, maintained that heresy absolved subjects from their allegiance, and recommended the invasion of England by the Spaniarls. For these services he was created a cardinal, and continued to reside at Rome till his deat! 1 , in 1594.

Alaxd ; a cluster of islands in the gulf of Bothnia; $59^{\circ}-47^{\prime}$ to $60^{\circ} 32^{\prime} \mathrm{N}$. lat., and $18^{\prime \prime} 47^{\prime}$ to $21^{\circ}$ $37^{\prime}$ E. long. They contain 13,340 inhabitants, of whom more than 9000 belong to the principal island of the same naine, which is forty miles long, and thirty broad. Above eighty of these islands and rocks are inhabited. They contain some good harbours. In 1809, this cluster of islands, together with Finland, was made over by Sweden to Russia. The government founded a city there, and fortified some spots. The ground is so stony, and the soil so thin, that the crops sometimes wither in hot summers. Several circumstances conspire to make the Aland isles the principal rendezvous of the Russian fleets, which ride there secure in fortified harbours. These circumstances are, the early breaking of the ice in spring ; the lateness of the period till which the harbours and roadsteads remain open and free from ice, on account of the strong currents which cross there from the gulfs of Bothnia and Finland; the facility of observing the ships entering lake Maler, and of watching the Swedish consting trade along the right coast of the gulf of Bothnia, as well as of protecting the Russian coasting trade on the left shore of the same gulf.

Alasi, or Alans; one of the warlike tribes which migrated from Asia westward at the time of the decline of the Roman empire. They appear to have lived near mount Caucasus. A part of the tribe (about 375 A. D.) was conquered by the Huns; another part turned their steps towards the west, probably drove the Vandals and Suevi from their abodes, and passed with them over the Rhine into France and Spain (about 407). The Visigotlis drove them from hence or reduced them to subjection, and, since $41 \%$, they are lost among the Vandals. (q. v.)

Alsaric, king of the Visigoths; the least barlarous of all the conquerors who ravaged the Ronian empire. History first mentions him about $A . D$. 395 , when the Gotlis were united with the armies of Theodosius the Great, in order to repel the Huns, who menaced the western empire. This alliance disclosed to $A$. the weakness of the Roman empire, and inspired him with the resolution of attacking it himself. The dissensions between the two sons and successors of Theodosius, Arcadius, and Honorius, and their ministers, Rufinus and Stilicho, facilitated the execution of his purpose; and, though the brave Stilicho was successful in averting his first attack, in the years $400-403$, by routing him on the Addis and at Verona, yet A. found in 404 , an opportunity of returning to Italy with his army. By the mediation of Stilicho, he concluded a compact with Honorius, conformably to which he was to advance to Epirus, and from thence to attack Arcadius, in conjunction with the troops of Stilicho. This war did not take place ; but $A$. demanded an indemnification for having undertaken the expedition, and Honorius, at the advice of Stilicho, promised him $\mathbf{4 0 0 0}$ pounds of gold (see Stilicho); but, after the execution of the latter, he failed to fulfill his promise. A. advanced with an army to Italy, and invested Rome; but was persuaded to spare the city on receiving a ransom of 5000 pounds of gold, 30,000 pounds of silver, 4000 silk garments, 3000 pieces of fine scarlet cloth, and 3000 pounds of pepper. Negotiations took place between Honorius, in Ravenna, and $A$., with a view of putting an end to the war ; but, the parties could not agree, and $\mathbf{A}$. besieged Rome a second time. By cutting off the supplies of the city, he soon compelled a capitulation, by virtue of which the senate declared the prefect of the city, Attalus; emperor instead of Honorius. But Attalus evinced so little prudence, that A. obliged him publicly to resign the empty dignity. Negotiations again took place with Honorius, but were as unsuccessful as the former, and $\mathrm{A}$. besieged Rome for the third time. The Goths penetrated into the city in 410 , sacked it, burned a part of it, and destroyed a great quantity of ancient works of art. But the moderation of $\mathrm{A}$. is praised, because he gave orders to spare the churches, and those who had fled to them for shelter. The once proud mistress of the world now experienced a severe retribution for the sufferings which she had caused to so many cities, countries, and nations in the days of her former splendour and power. The treasures collected during a thousand years, from all quarters, became the prey of barbarians. A. left Rome after a residence of six days, with the view of reducing Sicily and Africa. He lad already laid waste Campania, Apulia, and Calabria, when death overtook him at Cosenza, a Calabrian town, A. D. 410. He was buried in the channel of the Busento, that his remains might not be found by the Romans; and the captives employed in the work were murdered. Rome and Italy celebrated public festivals on the occasion; Sicily and Africa saw themselves freed from imminent danger; and the world enjoyed a moment of peace. But the march of desolation was soon renewed; the barbarians had learned the way to Rome; $A$. had taught them the weakness of the former queen of the world.

Alatamaila, or Altanaha; the largest river of the state of Georgia, formed by the junction of the Oakmulgee and Oconee, botli of which rise in the spurs of the Alleghany mountains. After the junction, the $A$. becomes a large river, flowing with a gentle current, through forests and plains, 120 miles, and runs into St Simon's sound by sereral mouths, sixty miles S.W. of Savannah. Its average breadth is about 600 yards, its depth eight feet, and thie bar at the mouth of the river has fourteen feet of water at low tide. Large steam-boats have ascended the Oconee branch to Milledgeville, and the Oakmulgee to Macon, about 300 miles from the ocean by the windings of the rivers.

Alay, or Triumph; the name of a ceremony practised by the Turks at the commencement of war. 
We are informed by laron Tott, who saw the ceremoury which accompanied the breaking out of a war between Russia and the porte, that the $\Lambda$. consists of a kind of masquende, in which the different tradesmen exhibit the implements of their respective arts, and their mole of operations. (A similar exhibition of various trades was seen in the procession furmed to celebrate the commencement of the railroad at Baltimore, July 4, 1828; and in the more recent reform processions which have taken place in Scotland.) The mechanics are followed by the standind of the prophet Mahoinet, brought from the seraglio, to be carried to the Ottoman arny. This sacred banner is viewed with fanatical reverence. None but emirs are allowed to touch it; and the very look of an infudel is said to be sufficient to profane it. The $A$. having been almost forgotten, from the long peace which preceded the war above-mentioned, the Christians imprudently crowded to witness the exhibition; the emir, who preceded the holy standard, cried with a loud roice, "Let no infidel profane with his presence the banner of the prophet; and let every Mussulman, who perceives an unbeliever, make it known under pain of reprobation." At these words, the fanaticism of the Turks wras roused, and a horrid massacre of the Christians began, in which no age and neither sex was spared.

A LBA LoNGA; a considerable city of Latium; according to tradition, built by Ascanius, the son of Eneas; governed, after the death of its founder, by Aineas Sylvins, the second son of Fneas. It was the birth-place of Romulus and Renus, the parent of Rome, under whose dominion it fell, in consequence of the victory of the Romans in the contest between the Horatii and Curiatii. The beautiful lake of Albano, with its caul, and the castle of Gondolfo, still remind us of A. (See Niebuhr's Roman Hist.) - There was also a city of Alba near the Laeus Fucinus, a town of the Marsi ; an A. Poinpein in Liguria, and an A. Julia, now Weissemburg, in Transylvania.

Alsas, St, lived in the $3 \mathrm{~d}$ century, and is said to have been the first person who suffered martyrdom for Christianity in Great Britain. He was born near the town which now bears his name, in Hertfordshire. In his youth, he served seven years as a soldier, under the emperor Diocletian. Returning to Britain, he embraced Christianity, and suffered martyrdom in the great persecution which took place in the time of the above emperor. A number of miracles are attributed to this saint. The celebrated monastery of St Alban's was founded between four and five centuries after his death, by Offa, king of Mercia.

Alвaxт; a rich and powerful family of Rome, which fled before the Turks in the 16th century, from Albania to Italy. Here it was divided into two branches; the one constituting the family of Bergamo; the other, that of Urbino. The Roman branch of the A. owes its splendour to a fortunate circumstance. It was an A. who announced to Urban VIII. the acquisition of Urbino; and riches and posts of honour were the reward of his tidings. The influence of the family was very great when Clement $X I$. ascended the papal chair, in 1700 . Of the nephews of this pope, Annibale A., Alessandro A., and Giovanni Francesco A., Annibale has distinguished himself by his writings and collections of books and works of art, which have been incorporated with the treasures of the Vatican. Alessandro A., his younger brother, born at Urbino in 1692, took orders at the express desire of pope Clement XI. He was raised to the dignity of cardinal, in 1721, by Innocént XIII. As a member of the sacred col- lege, as protector of Sardinia, and, under Benedict XIV., as associate protector of the imperial states, he took an active part in all the contests in which the papal court was then engaged, particularly on aecount of his great friendship for the Jesnits, of which many proofs exist, especially in the journals of father Condara. In the charms of a quiet, literary life, of agrecable society, and a well-filled table, the carlinal found greater enjosment than in the turmoil of business. One of his greatest plensures was in a collection of works of art, which he was assisted in arranging by Winckelmanu, whose collections he inherited. It is known low sincerely Winckelmann was devoted to the cardinal, whose knowledge could appreciate and second the genius of the archarologist. of this, his splendid villa before Porta Salara, at Rome, notwithstanding many losses, affords striking proof. Morcelli, Marini, Fea, and Zoega combined to make it known, and owe a portion of their own reputation to its treasures. It contains the richest modern private collection, and does honour to the taste of its founder. It was said in Rome, soon after the death of the cardinal, as a proof of his acquaintance with ancient coins, that he could distinguish the genuine from the counterfeit by the mere touch, without the aid of his eyes. Indefatiga bly active, yet nerer an author, the cardinal died, Dec. 11, 1779. Dionigio Strocchi las written his life.

AlBan, Francesco, a famous painter, born al Bologna, in 1578, entered the school of Dionysius Calvert, a Flemish painter, who liad a great reputation in Bologua. A. was one of his most distinguished seholars. He laboured here several years, in comexion with Domenichino, to whom he was closely attached by friendship and love of art; and some resemblance is perceptible in their manner of colouring. But in invention he surpasses his friend, and, indeed, all his rivals of the school of Calvert. His female forms Mengs places above those of all other painters; an opinion wlich we cannot assent to uneonditionally. Those of his compositions that are most frequently met with are, the sleeping Venus; Diana in the bath; Danae reclining; Galatea on the sea; Europa on the bull. Scriptural subjects he has less frequently selected; when he has, the paintings are principally distinguished for the beauty of the heads of the angels. In general, he was most successful in paintings of a limitet character. He had a numerous school in Rome ant Bologna. The scholars of Guido, with whom he vied, accused him of effemivacy and weakness of style, and maintained that he knew not how to give any dignity to male figures. For that reason he avoided subjects which demand fire and spirit, and has been called, not without reason, the Anacreon of painters. The narrowness of his sphere of excellence was eventually injurious to him. He ontlived his fame, and died in 1660 , in the $82 \mathrm{~d}$ year of his age. He left behind him several writings, which Malvasia has preserved.

Alabania (in the Turkish language, Arnaut; in the Albanian, Skiperi); (Epirus and Illyria); a Turkish province in Arnaut-Wilajeti, extended from the Drino to the Acroceraunian mountains, along the coast of the Adriatic and Ionian seas. It has a delicious climate, and produces in abundanee wine, grain, oil, tobacco, cotton, wood, mineral salt, and horned cattle. The principal mountains are the Montenegro and the Chimera; the principal rivers the Drino, Bojana, Somini, \&e. The 300,000 inhabitants are composed of Turks, Greeks, Jews, and Amauts; the last of which constitute the boldest soldiers in the Turkish armies. The country is divided into the pashalies of Janina, Ilbessan, and 
Scutari, and the sangiacats of Anlona and Delvino. The principal cities are Janinn, Delvino, Scutari, Durazzo, Argyro-Castro, Valona, \&c. The authority of the porte in this region is very uncertain, being more or less relaxed in proportion as the independent communities and beys enlarge or contract their possessions, in opposition to the pashas whom it appoints. The vast mountainous coast of $\Lambda$. is very little known. The Venetian government, while the republic of Venice existed, defended it against any permanent conquest by the Turkish pashas. Here Greek and catholic Christians, and Mahommetans likewise, live in a half savage state, and under the most various forms of government. At the time of the revolt of the Greeks, the most southern part of Albania took the ancient name of Epirus. (See Epirus.) From the lake of Janina arise the rivers Acheron (q. v.) and Cocytus, not far from the mouth of which lies Parga. Epirus, especially in the neighbourhood of the sea, is a fertile country; it produces wine, corn, and fruit. In ancient times, its horses were famed for swiftness, its cows for size, and its dogs for strength and courage. These races seem now to be extinct. Before the Greek revolution, Ali Pasha (q. v.) ruled in Janina. In Scutari, there are yet independent communities, the inhabitants of mount Montenegro, the Suliots, and others in the neighbourhood of the former $\mathrm{Ve}$ netian, now Austrian, territory. These small free tribes enjoyed, as long as the republic of Venicc existed, the secret protection of that government; to which is to be attributed their success in maintaining themselves against the Turkish force, and the violence of private feuds. The same policy was pursued likewise by the French Illyrian government. In the country itself, the Arnauts are.called Skypetar3. They are bold and indefatigable, but mercenary and perfidions warriors. They once constituted the flower of the Turkish army. Every one who has no landed property seeks to acquire the means of obtaining it, by incursions into the neighbouring territory, or military service in foreign countries. The sons of influential families, or distinguished soldiers, collect a troop, and, like the former condottievi of Italy, sell their aid to any one who will pay them well. This migration of armed hordes, caused by the want of landed property sufficient to support them, is a national instinct, common to the Greek, catholic, and Mahommetan Arnauts. For this reason, the communities in the most fertilc valleys rarely increase, and there is a great disproportion of unmarried females. But in case of attack, the woinen defend their homes and property with masculine courage. The political infuence of the clergy is great amolig the Christian Arnauts.

Albavo. Roman tradition represents Alba Longa as the parent city of Rome. It gives us a catalogue of the kings of Alba, who lived before the foundation of the latter city; but this is now universally believed to be fabulous. Tullus Hostilius is faid to have destroyed the city, and transplanted the inhabitants to Rome. Its site was afterwards occupied by a village, surrounded by the splendid villas of the Roman nobility. Tiberius and Domitian indulged in their palaces at $\mathrm{A}$. their appetite for pleasurc and for cruelty. The present $\Lambda$. still glories in its old renown. On the mountain of $\hat{\Lambda}$. the amuiversary of the alliance of thic Romans and Latins, concluded under Tarquin the Proud, was celebrated with peculiar solemnities. The lake of A. is a wonder of nature and ancient art. During the war with Veii, 395 B. C., this lake is said to lave risen in a hot summer, without any visible cause, to an unusual height. Etruscan soothsayers spread the report, that the fate of Veii depended on the drawing off of this water; and the Romans, confirmed in this belief by a Delphic oracle, errected a remarkable structure for this purpose. (Liv. v. 15 -19.) Iuring the labour, they probably learned from the architectural Etruscans, the art of excavating subterranean canals, which they sonn applied to undermining the fortifications of Veii, and thereby gained possession of the city. The canal of the lake of $A$. is 3700 paces in length, six feet higl, and three and a half broad, Niebulır, in his Romische Geschichte (Roman History), part 2, page 234, regards this admirable work as an ancient labour of all Latium; or, if belonging particularly to Rome, to be referred to the age of the kings. The Albanian stone is also famous. It is of a darkgrey colour, and is excavated in large quantities near A. It is of two kinds; the one of which is called Sperone, the other Peperino. Of this, says Winckelmann, was made the foundation of the capitol at Rome, built in the year of the city $38 \%$, of which five layers of large stones are still to be seen above ground. The cloaca maxima, a work of the Tarquins, as well as the most ancient of the Roman funeral monuments at $A$., and another of their oldest works, constructed about the 358th year of the city, the outlet of the lake of $A$., at present Lago di Castello, are built of this stone.

A LBANY; the name given to a British agricultural colony, established about 1824 , in Sonthern $\Lambda$ frica. The fertility of the soil rendered the situation promising, and several thousand emigrants were located upon it. The experience, however, of three disastrous seasons proved the district unfit for tillage, and suited only to pasturage. The distress of the emigrants became extreme, and partial relief was aftorded by a subscription of $\mathfrak{£} 3,000$, raised at the, Cape of Good Hope.

Aleany, or Albanl, countess of, princess louisa Maria Caroline, or Aloysia, born in 1753 , cousin of the last reigning prince of Stolberg-Gedern, who died in 1804, married, in 1772, the English pretender, Charles Stuart. After this marriage, she bore the title of countess of A. Her marriage was unfruitful and unhappy. To escape from the barbarity of her husband, who lived in a continual state of intoxication, she retired, in 1780 , to a cloister. $\Lambda$ fter his death, in 1788, the French court conferred on her an annuity of 60,000 livres. She survived the house of Stuart, which became extinct at the deatl of her brother-in-law, the cardinal of York, in 1807. (See Stuart.) She died at Florence, lier usual place of residence, Jan. 29, 1824, in her $72 \mathrm{~d}$ year: Her name and her misfortunes have bcen transmitted to posterity in the works and the autobiography of count Victor Alfieri. This famous poet called lier mia donna, and confessed that to her he owed his inspiration. Without the friendship of the countess of $\boldsymbol{\Lambda}$., he has said that he never should have achieved any thing excellent: "senza laquella non aurei mai fatto nulla di buono." The sketch of his first meeting with the countess, quella gentilissima e bella signor $\alpha$, as he calls her, is full of sentiment and genuine poetry. (See Alfieri.) Her ashes and those of Alfieri now repose under a common monument, in the church of Santa Croce, at Florence, between the tombs of Machiavelli and Michael Angelo.

ALBAYY, a mountainous district in Scotland, comprising those of Glenorchy, shirc of Argyle; Athol and Breadalbane, shire of Perth; and a part of Lochaber, shire of Inverness. It anciently gave the title of Dnke to a prince of the blond-royal of Scotland, and latterly to the late duke of York.

Albany, a city of New York, the seat of the government of the state, is situated on the west bank of the Hudson, 144 miles $N$. of the city of New York; lat. $42^{\circ} 39^{\prime}$ N.; lon. $73^{\circ} 13^{\prime} \mathrm{W}$.; nop. is 
$1810,9,356$; in 1820, 12,613; and in 1825, 15,97t. lonk. Fislı squwn, gelatinous moluscre, and various Allony lies near the lieal of ticle-water, on one of the funest rivers in the world, which is navgahle as fur as the city for sloops of 80 tons; ind, except when the river is obstrncted by ice, stean-boats run daily between this place and the city of New York. The Erie and Clamplain canals form a junction at Watervliet, about elght miles north of thic city, and their united climuel is conuerted at $\mathbf{A}$. with a large basin, which covers a surfice of 32 acres, on the west side of the river. 'These advantages, logether with many stage-conches in various directions, render A. one of the greatcst thoronghifares in the United States. The city carries on an extensirc trade by means of sloops, chiefly with the city of New York; and also, to a considerablc amount, with Boston, Plitadelplia, and other places. The exports consist of wheat, and various other kinds of produce.A. was settled by the Dutch about the year 1614, and is, next to Jamcstown in Virginia, the oldest town in the United States. The sitc on which it is built is very uneren, and it was originally laid out with little regard to clegance. The oldcr houses are in the Dutch style, with the gable ends to the streets; but within the last twenty years, the city has been greatly improved, and it now contains many clegant public and privatc buildings. The principal public edifices are thic capitol or state-house, a large structure of stone, the Albruy academy, a spacious and elegant edifice, the state-hall for the public offices, a state arsenal, and twclre houses of public worship.

Almaxy ; the molern district of the colony of the cape of Good Hope. Sec Good Hope.

Almatross (diomedea, L.) ; a genus of reb-footerl birks, having the following generic characters: a very long bill, which is sutured, robust, thick, straight, and laterally compressed, terminating in a large look, apparently articulated therewith. Thic upper inandible is laterally grooved, and the. short, tnlnilar nostrils are situated in these grooves; the lower mandible is truncated. The toes are very long, and are webbed with an cntire membrane; the lateral toes are externally edged by a narrow nembrane. There is no hind toe or nail; the nails are short and blunt. The tail is rounded, and com. posed of fourteen feathers. The A. most generally known is the diomedea exulans of naturalists, the frigate bird, man-of-war bird, and cape sheep of sailors. It is the largest of marine birds, as its wings, when extended, measure from ten to twelve feet from tip to tip. These long wings are vcry narrow, but the $A$. being extremely strong, is able to fy with ease over a vast space. Except during high winds, when it ascends to the superior regions of the air, the $\Lambda$. sails gently over the surface of the billows, rising and sinking in graceful undulation, and seizing with avidity every linckless creature that approaches the surface. Pursuing its prey in this manner, it urges its flight far from land, and, by ocasionally alighting upon vessels, deceives the inexperienced voyager into an idea that the shore cannot be very distant. At night, this bird settles down upon the waves, and sleeps securely until hunger again commands a renewal of its efforts. The A. might be assumed as a perfect emblem of gluttony, as it is scarcely possible, in description, to do justice to its excessive voracity. Whenever food is abundant, it gorges to such a degree as to bccome unable either to fly or swim; frequently it is seen in this state, with a fish partly swallowed and partly hanging from its mouth. The gulls then attack and worry it until it disgorges its prey, upon which they are ready to seize. When caught by hand, it makes violent struggles with its wings, and strikes with its small marine animals constitute its ordinary food. Flying-fish are also particularly cxposed to this thevourer, whose swiftness of wing is far superior to theirs. The voice of the $\Lambda$. is a harsh, disugreeable cry, somewhat resembling that of a pelican; it has nlso been compared to the braying of an ass.-Towards the midtle of Jume, vast numbers of these birds flock towaris thic coast of Kamtsclatka, the sen of Ochotsk, the shores of the Kurile islands and Bchring's straits. They arrive there, extremely lean, a short time preceding the fish, which coine annully to spawn in the fresh water of the rivers; but, soon after, the birls become very fat from the abundance of food. They begin to retire from these: coasts about the end of July, and by thic 15th of August the whole have diseppeared. During their sojourn, the Kantschadales catch numbers of thiem by baiting hooks with fish, or by knocking them on thic hicad when orergorged. They are not taken for their flesh, which is coarse, rank, and disgusting; but their large, hollow wing-bones furnish the untives with various useful implements, while certain parts of their intestines are inflated and employed as floits for fishing-nets. - About the middle of September, they seek the southern shores of America, for the purpose of brccling; there they build nests of earth two fect or more high, and lay numerous eggs, which are larger than those of a goose, being about four and a half inclies long, generally white, cxcept towards the larger extremity, where they are speckled with black. These eggs are edible, and it is stated, by those who have used them, that the white is not rendered hard by boiling. While the female sits upon the nest, the male is industriously cmployed in supplying her witl food. This scems to be urore especially necessary, as hawks are constantly on the watch for an opportunity of pouncing upon the eggs the moment the nest is left cxposed. As sooll as the $\mathrm{A}$. finally relinquishes the nest, it is taken possession of by a species of penguin.-The common $A$. (diomedea exulans) is from three to four feet long, of a greyish-brown or whitish colour, with lines of b!ack upon the lack and wings. The inferior part of the body and rump are white; the end of the tail and a great part of the wirigs are black. The shafts of the quills are yellow. The feet, toes, and web membrane are of a reddish brown colour; the beak is blackish. The female is similar to the male; the young differ much from the adult. The $\Lambda$. moults twice a-year without changing its colours.-Thrce other species arc considered as laving been established by naturalists: diomedea chlororhyncos, black and yellow-beaked $A$., of the size of a domestic goose; diomedea spadicen, dark brown or chocolatecoloured A., larger than the common goose; diomedea fuliginosa, souty or quaker A., smaller than the common A. It is highly probable tuat futurc inve'stigation will reduce the number of species which have becn proposed. - This bird is most commonly found within the tropics, about the cape of Gool Hope, and even amid the ice of the Austral seas. It is sometimes, though rarely, seen on the coasts of thic Middle States of the Union.-Except what has been already mentioned relative to the use made of them by the Kamtschadales, we know of no 'conomic purpose for which they are employed. Possibly their large quills might be found useful, if obtained in sufficient numbers.-The importance of the $A$. in the economy of nature may be readily collected from what we have stated relative to its food, and the vast extent of surface over which it can protract its flight. It serves as one of the numerous restrainers of the superabundant increase of animal life, and, in its turn, becomes the prey of creatures stronger or more 
sauguinary thau itself. Among others, a species of lestris is a dreadful enemy, and beats it, while on the wing, until the A. disgorges its food, which the other immediately seizes, or the blows are continued until the liuge bird expires, a victim to the ravenous uppetite of its adversary. This fierce bird is cominonly called the skua gull; but it is improperly termed gull, being more closely allied to the petrels and $A$. in appearance; in habits, it has some analogy with the eagles. When the $A$. is attacked by a flock of gulls or other birds, while on the wing, it has no other resource but that of suddenly dropping upon the water. Under all circumstances, however, the cowardice of this gigantic bird is equal to its voracious gluttony.

Albemarle Sound; an inlet of the sea on the east coast of N. Carolina. It extends into the country sixty miles, and is from four to fifteen wide. It may be considered as an estuary of the Roanoke and Clowan rivers. It communicates with the Atlantic ocean and Pamlico sound by small inlets, and with Chesapeake bay by a canal cut through Dismal swamp.

ALiseron, Giulio, cardinal, and minister of the king of Spain, was the son of a gardener. He was born in 1664, at Firenzuola, a village of Parma, and educated for the church. His first office was that of bell-ringer in the cathedral of Piacenza. Possessed of uncommon talents, he soon became canon, chaplain, and favourite of the count Roncovieri, and bishop of St Donnin. The duke of Parma sent him as his minister to Madrid, where he gained the affection of Philip V. He rose, by cunning and intrigue, to the station of prime minister; became a cardinal; was all-powerfil in Spain after the year 1715, and endeavoured to restore it to its ancient splendour. He reformed abuses, created a naval force, organized the Spanish army on the model of the French, and rendered the kingdom of Spain more powerful than it had been since the time of Philip Il. He formed the great project of restoring to Spain lier lost possessions in Italy, and he began with Sardinia and Sicily. Even when the duke of Orlears, regent of France, renounced the Spanish alliance to form a comnexion with England, the proud prelate did not alter his system; on the contrary, he threw off his mask, attacked the emperor, and took Sardinia and Sicily. After the Spanish fleet was destroyed by the English in the Mediterranean, he entertained the idea of stirring up a general war in Europe ; of forming an alliance for this purpose witl Peter the Great and Charles XII. ; of involving Austria in a war with Turkey, exciting an insurrection in Hungary, and causing the duke of Orleans to be arrested by a court faction. But the scheme was discovered. The duke, in connexion with England, declared war against Spain, and explained, in a manifesto, the intrigues of the Italian cardinal. $A$ French army invaded Spain, and, although Alberoni endeavoured to cripple the power of France by fomenting disturbances within that kingdom, the Spanish monarch became despondent, and concluded a peace, the chief condition of which was the dismissal of the cardinal. He received, Dec. 1720, orders to quit Madrid within twenty-four hours, and the kingdom within five days. Ile was now exposed to the vengeance of the powers of Europe, by all of whom he was liated, and saw no country where he could abide. He did not even dare to go to Rome, because he liad dereived the pope, Clement XI., in order to obtain the rank of cardinal. While crossing the. Pyrenees, his carriage was attacked, onc of his servants killed, and he himself obliged to continue his journey on foot and in disguise. He wandered about a long time under false names. He was arrested in the territory of Genoa, at the request of the pope and the king of Spain; the Genoese, however, soon dismissed him. The death of Clement put an end to this persecution, and his successor, Innocent XIII., restored him, in 1723 , to all the rights and honours of a cardinal. He died in 1752 , at the age of eighty seren years. He left behind him the character of a bold and versatile intriguer, rather than of a great politician, although he certainly created a strong temporary impulse in the Spanish monarchy, and established many regulations which were favourable to arts, agriculture, and commerce. The publication called his "Testament Politique," is of no authority.

AlBert I., duke of Austria, and afterwards emperor of Germany, was born in 1248 , son of Rodolph of Hapsburg (q. v.), who had, a short time before his death, attempted to place the crown on the head of his son. But the electors, tired of his power, and emboldened by his age and infirmities, refused his request, and indefinitely postponed the election of a king of the Romans (this was the title of the designated successor of the emperor). After the death of Rodolph, A., who inherited only the military qualities of his father, saw lis hereditary possessions, Austria and Stiria, rise up in rebellion against him. He quelled by force this revolt, which his avarice and severity had excited; but success increased his presumption. He wished to succeed Rodolph in all his dignities, and, without waiting for the decision of the diet, seized the insignia of the empire. This act of violeuce induced the elector's to choose Adolphus of Nassau emperor. The disturbances which had broken out against him in Switzerland, and a disease which deprived him of an eye, made him more humble. He delivered up the insignia, and took the oath of allegiance to the new emperor. As soon as he had quelled the insurrection in Switzerland, he was involved in new quarrels with his subjects in Austria and Stiria, especially with the bishop of Salzburg, who, upon the report of his death, had made an incursion into his dominions. In the meantime, Adolphus, after a reign of six years, had lost the regard of all the princes of the empire. A. endeavoured to arail himself of this change of feeling, and succeeded so far, by assumed milduess, in deceiving the princes, that they chose him emperor, after deposing Adolphus at the diet in 1298. Adolphus, however, would not resign his high dignity, and force was found necessary to remove him. The rivals met, with their armies, near Gellheim, between Worms and Spire. A. enticed $\Lambda$ dolphus, by a feigned retreat, to follow him with his cavalry only. The leaders engaged hand to hand, and Adolphus exclaimed to his adversary, "Thou shalt lose at once thy crown and life." "Heaven will decide," was the auswer of $A$., striking him with lis lance in the face. Adolphus fell from his horse, and was despatched by the companions of his antagonist. The last barrier had fallen between $\boldsymbol{A}$. and the supreme power, but he was conscious of liaving now an opportunity of displaying his magnanimity. He voluutarily resigned the crown conferred on him by the last election, and, as he had anticipated, was reelected. His coronation took place at Aix la Chapelle, in August, 1298; and he held his first diet at Nuremberg, with the utmost splendour. But a new storm was gathering over lim. The pope, Boniface VIII., denied the right of the electors to dispose of the imperial dignity, declaring limself the real emperor, and legitimate king of the Romaus. He accordingly summoned $\Lambda$. before him, to ask pardon, and submit to such penance as he should dictatc; he forbade the princes to acknowledge 
hinn, sund released them from their onth of nllegiance. 'The archbishop of Mentz from a friend became the enemy of $\mathrm{A}$., and joined the party of the pope. On the other land, $\lambda$. formed an alliance with Philip le Bel of France, secured the nentrality of Sixony and Jrandenburg, and, by a sudden irruption into the electornte of Mentz, forced the archbishop not only to renounce his alliance with the pope, but to form one with hin for the five ensuing yenrs. Disinayed by this rapid success; Boniface entered into negotintious with $\boldsymbol{A}$., in which the Latter again showerl the duplicity of his character. He liroke his alliauce with Philip, ncknowledged that the western enpire was a grant from the popes to the emperors, that the electors derived their right of choosing from the see of Rome, and promised to defend with arms the rights of the pope, whenever he should demand it, against any one. As a reward, Boniface excommunicated Philip, proclained him to have forfeited his crown, and gave the kinglom of France to $A$. Philip, however, chastised the pope. A. was engaged in unsuccessful wars with Holland, Zealand, Friesland, I ungary, Bohemia, and Thuringia. While preparing to revenge a defeat which he had suffered in Thuringia, he received the news of the revolt of the Swiss, and saw himself obliged to direct his forces thither. The revolt of Underwalden, Schweitz, and Uri had broken out Jan. 1, 1308. A. had not only foreseen this consequence of his oppression, but desired it, in onder to lave a pretence for subjecting Switzerland entirely to himself. A new act of injustice, however, put an end to his ambition and life. Suabia was the inheritance of John, the son of his younger brother, Rodolph. John had repeatedly asserted his right to it, but in vain. When $A$. set out for Switzerland, John renewed his demand, which was contemptuously rejected by A., who scoffingly offered him a garland of flowers, siying, "This becomes your age ; leave the cares of government to me." $\mathrm{John}$, in revenge, conspired with his govemor, Walter of "Eschenbach, and three friends, against the life of A. The conspirators improved the moment when the emperor, on his way to Rheinfelden, was separated from his train by the river Reuss, and assassinated him. A. breathed his last, May, 1, 1308 , in the arms of a poor woman, who was sitting on the road. He was a prince regardless of right and equity, tyrannical, avaricious, ambitious, and able. How cruelly Agnes, queen of Hungary, rerenged her father's death, will be related under John the Parricide.

Albert the Great, or Albertus Magues, bishop of Ratisbon; a distinguished scholar of the 13th century. Besides his theological learning, he was well versed, for his time, in mechanics, natural history, and natural philosophy. He was born in 1193 (acconding to some accounts, in 1205), at Lauingen in Suabia, of the noble family of Bollstadt; studied at Padua; became a monk of the Dominican order; in 1254, was made provincial of his order; and in 1260 received from pope Alexander IV. the bishopric of Ratisbon. Two years later, he returned to his convent, devoted himself to sclence, and produced many learned works on arithmitic, geometry, optics, music, astrology, and astronomy. "He died in 1280.

A LBERTI. There were two painters of this name, Cherubino and Giovanni, brothers, natives of the Florentine territory, who flourished about the close of the 16th century. Cherubino, who was also an engraver, died in 1615, surviving his brother about fourteen years.

AlBErT, Leon Baptista, an eminent Italian architect, was born at Venice in the beginning of the 15th century; died nbout 1475. His principal erections are at Florence, Mantu, and Rimini. He was author of various works, particularly one, " De Re Adtificatoria," which was published in Italian and kinglish, London, 1726, 3 vols. folio. The invention of the Cumcra Obscura las been attributed to Alberti.

Albertisl, Francis, an ecclesinstic of Florence, and an able nutiquary, flourished in the beginning of the 16th century. Some of his works are still esteemed.

Almigases (Albigeois); a name common to several lieretical sects, particularly the Cathari and Waldenses, who agreed in opposing the doninion of the Roinish hierarchy, and eudeavouring to restore the simplicity of prinitive Christianity. They had increased very much towards the close of the 12th century, in the south of France, about 'Ioulonse and Albi, and were denominated by the crusalers A., from the district Albigeois (territory of $\Lambda l b i$, where the army of the cross, called together by pope Innocent III., attacked them in 1209. The assassination of the papal legate and inquisitor, Petur of Castelnau, while occupied in extirpating these: heretics in the territory of the count lRaymond of Toulouse, occasioned this war, which is inportant as the first which the Romish church waged agninst heretics within her own dominions. It was carricul on with a degree of cruelty which cast a deep sliade over the Romish clergy, as their real ubject appeared to be to deprive the count of Toulouse of his possessions, on account of his tolerating the lieretics. It was in vain that this powerful prince liad suffered a disgraceful penance and flagellation from the legate Milo, and obtained the papal alsolution by great sacrifices. The legates, Arnold, abbot of Citeaux, and Nilo, took Beziers, the capital of lis nepliew Roger, by storm, and put all the inhabitants (about 60,000 ), without any distinction of creed, to the sword. Simeon de Mont fort, the military leader of the crusade under the legates, was equally severe towards other places in the territory of Raymond and his allies, of whom Roger died in a prison, and Peter I., king of Arragon, in battle. The lands taken were presented by the clurch, as a reward for his services, to.the count of Mlontfort, who, however, on account of the clianging fortupe of war, never obtained the quict possession of then ; he was killed by a stone, at the siege of 'Toulouse, in 1218. The legates prevailed on his son, Amalric, to cede his claims to the king of France. The papal indulgences attracted from all provinces of France new crusaders, who continued the war. and, even after the death of Raymond VI., in 12:2, under excorrmunication, his son, Raymond VII., was obliged, notwithstanding his readiness to do penance, to defend his inheritance, till 1229, against the legates, and Louis VIII. of France, who fell, in 1226, in a campaign against the heretics. After hundreds of thousands had fallen on both sides, and the most beautiful parts of Provence and Upper Languedoc had been laid waste, a peace was made, by the terms of which Raymond was obliged to purchase his absolution with a large sum of money, to cede Narbonne, with several estates, to Louis IX., and make his son-in-law, a brother of Louis, heir of his other lanils. The pope suffered these provinces to come into the possession of the king of France, in order to bind him more firmly to his interests, and force him to receive his inquisitors. The heretics were now delivered up to the proselytizing zeal of the Dominicans, and to the courts of the inquisition; and these new auxiliaries, which priestcraft had acquired during the war (see Dominic de Guzman, and Inquisition), employed their whole 
power to bring the remainder of the $A_{\text {. }}$ to the stake, and male even the converts feel the irreconcilable anger of the church, by heary fines and personal phinishments. 'The name of the A. disappeared after the middle of the 13th century; but fugitives of their party formed, in the nountains of Piedmont and in Lombarly, what is called the French church, which was continued, through the Waldenses, to the times of the Hussites and the reformation.

Al.rivos (white Negroes, Blafards, Lencrethiops, Dondos), who were formerly found on the isthmus of Panama and at the mouths of the Ganges, and have been described as a distinct race of men, have been likewise discovered, by modern naturalists, in various countries of Europe, e. g. in Switzerland, -sinong the Savoyards in the valley of Chamouni, in France, in the tract of the Rhine, in Tyrol, \&c. The characteristics of the $A$. are now said to be owing to a disease which may attack men in every climate, and to which eren animals are subject, such as white mice, rabbits, \&c. The $A$. have a milky or cadaverous look, and are distinguished from the genuine whites, not only by their wrinkled skin, but also by their red eyes, which want the black mucus, and cannot, therefore, endure the bright light of day. By moon-light, and in the dark, they can see pretty well, for which reason they are accustomed to go abroad only in the night, and, by Linnæus and other naturalists, are termed nocturnal men. Their hair is woolly when they are descended from actual negroes, and somewhat less curly when they are the children of East Indians; but it is always of an unpleasing milk-colonr, like their skin. They are weak in body and mind, and very rarely attain the common size of the nations to which they belong. They are generally incapable of begetting children, but when the case is otherwise, the offspring resemble the parents. There are instances of A. possessed of the common faculties of mind, and capable of literary accomplishments. (See, likewise, Cretin.) The Germans use the word Albino for all individuals afflicted with this disease of the skin, but Kakerlake for varieties, whose skin is only sprinkled with white spots. - The East Indians give the name of albino to a species of beetle (blatla), especially the blatta gigantea of the Indian forests, which grows three inches long, and forms an ornament of entomological collections. It is dark-brown and shining; the feathers of its wings are fox-coloured and yellow. After this beetle the Indians have named the Albinos.Blumenbach, Saussure, Buzzi, surgeon to the hospital at Milan, Soemmering, and many others, have made interesting observations on Albinos, and the causes which produce their peculiar colour.

Albivus, Bernard Siegfried, whose true name was Weiss (White), a distinguished anatomist, born Feb. 24, 1696, at Frankfort on the Oder, died, Sept. 9, 1770, at Leyden, where he was fifty years professor of anatomy. Instructed by lis father, Bernard, who enjoyed a good reputation as a professor of medicine, and by the fumous professors of the Leyden school, Rau, Bidloo, Boerhaave, he went to France in 1718 , where he formed an intinacy with Winslow and Seuac, with whom he afterwards carried on a correspondence highly advantageous to anatomy, their favourite science. He entered upon his office as lecturer, in Leyden, 1719, with an oration De Anatomice Compuruta. The medical faculty there conferred on him the degree of doctor, without either examination or disputation. A few weeks after, professor Ran died, and, in 1720, A. succeeded him in the professorship of anatomy and surgery. He was one of the first who felt the impulse which Boerhaave gave to anatomy, by explaining the phenomena of the animal economy, not chenically, but mecha- nically, - a system which renderen a more accurate stndy of the single parts of the body, and of their formation, necessary ; for the least deviation in the form of any part, according to him, necessarily produces differences in its action. This system rendered it necessary to describe with more accuracy what Vesalius, Fallopius, and Eustachius had explained only in a general manner. A. laboured in this spirit; we are indebted to him for the most exact anatomical descriptions and prints, especially of the muscles and bones. While he held the office of professor, at Leyden, he wrote Index Supellectilis. Auatomica Raviana, likewise De Ossibus Corporis Humani, also Historia Musculonun Hominis, and other works, which fill an honourable place in the history of science. He edited, also, several writings of Harvey, Vesalius, Fabricius al) Aquapendente, and Eustachius. His brother, Cluristian Bernard, professor at Utrecht, distinguished hiniself in the same science, and was likewise an esteemed anatomical writer; he died May 23, $17 \% 8$.

A Lpos; the former name of the island of Great Britain, called by the Romans Britannia Afajor, from which they distinguished Britamia Minor, the French province of Bretagne. Agathenterus (lib. xi. c. 4), speaking of the British islands, uses the names Hibernia and Albion for the two largest; Ptolemy (lib. ii. c. 3 ), calls $A$. a British island; and Pliny (H. N. lib. iv. c. 16), says, that the island of Great Britain was formeriy called Albion, the name of Britain being common to all the islands around it. In poetry, A. is still used for Great Britain. The etymology of the name is uncertain. Some writers derive it from the Greek a $\lambda$ cov (white), in reference to the chalky cliffs on the coasts; others, from a giant, the son of Neptune, mentioned by several ancient writers; some, from the Hebrew alben (white); others, from the Phœenician alp or alpin, (high, and high mountain), from the height of the coast. Sprengel, in his Universal History of Great Britain, thinks it of Gallic origin, the same with Albyn, the name of the Scottish Highlands. It appears to him the plural of alp or ailp, which signifies rocky mountains, and to have been given to the island, because the shore, which looks towards France, appears like a long row of rocks. The ancient British poets call Britain Inis $W e n, \mathrm{i}$. e. the white island.

Albios, New. This name is given to an extensive tract of land on the N. W. coast of America. It was originally applied by Sir Francis Drake, in 1578, to the whole of California, but is now, by recent geographers, e. $x$. Humboldt, confined to that part of the coast which extends between $43^{\circ}$ and $48^{\circ} \mathrm{N}$. lat. Cook discovered it, March 7, 1778. In 1792, Vancouver visited this cuast, made a very diligent inspection of all its parts, and gave a most interesting account of them. The country is described as very fertile; the quadrupeds seem not to be very numerous. The inhabitants are not numerous, and resemble the other sarages of the nurth-west coast of N.A. Vancourer's chart of this region is still the best. The most authentic account of a part of New $A$. is to be found in Lewis and Clark's Expedition to the Sources of the Missouri, 2 vols., Phila delphia, 1814. The citizens of the United States, and others who have frequented the north-western const of Anerica for commercial purposes, have lad but little, if any, intercourse with the natives, who inhabit that part of the coast which lies between the entrance of Colunbia river, in lat. $46^{\circ} 15^{\circ}$, and the Russian settiement at Port Bodega, in lat. $38^{\circ} 21$, because no harbour, capable of admitting such vessels as are usually employed in the north-west trade, lias yet been discorered within these limits. It has been affirmed by the Russians, that they have dis- 
(wovered several small rivers, but they are not probably of sufficient importance to give ans value to the coumtry, until the settlements of civilized nations have become much inore extensive than at present. The appearance of the country, as seen froin the ocean, is by 10 means inviting; but some hunters, who have penetrated into the interior, give n favoumble representation of it, particularly of that portion which lies near the Multnomal, a branch of the Columbia river, that runs from the south.

ALBos, king of the Lombards, succeeded his father, Audoin, in 561. He reigned in Noricum and Pamonia, while Cunimund, king of the Gepidx, ruled in Dacia nnd Sirmia, nud Baian or Chagan, king of the $\Lambda$ vara, was completing the conquest of Moldavia and Walachia. Narses, the general of Justinian, sought his alliance, and received his aid, in the war against Totila. A., in connexion with the $A$ vars, made war against the Gepidx, and slew their king, Cunimund, with his orn hand, in a great trattle fought in 566 . This victory established his fame. After the death of his wife, Clodoswinda, he married Rosamond, the daughter of Cunimund, who was among the captives. He afterwards undertook the conquest of ltaly, where Narses, who had subjected this country to Justinian, offended by an ungrateful court, sought an avenger in A., and offered him his co-operation. Every year witnessed the increase of A.'s power in Italy, in reducing which he'met with no resistance, except the brave defence of single cities. Pavia fell into his lands after a siege of three yens. After reigning three and a half years in Italy, he was slain at Verona, in 574, by an assassin, instigated by his wife, Rosamond. Ife had incurred her latred by sending her, during one of his fits of intoxication, a cup, wrought from the skull of her father, filled with wine, and forcing her, according to his owi words, to drink with her father. This incident has been introduced by Ruccellai and Alfieri, into their tragedies, called Rosamunda, in a very pathetic manner.

Alborak; amongst the Mahommetan writers, the beast on which Mahomet rode on lis journeys to lieaven. The Arab commentators report many fables concerning this extraordinary animal. It is represented as of an intermediate shape and size between an ass and a mule. A place, it seems, was secured for it in paradise, at the intercession of Mahomet, which, however, was in some measure extorted from the prophet by Alborak refusing to carry lim upon any other terms, when the angel Gabriel was come to conduct him to heaven.

Albufras; a considerable salt-water lake, lying north of the city of Valencia, in Spain, near the sea, with which it is connected by sluices, It abounds in fish, but dries in summer so much as, in some parts, to become a mere marsh. The French general Suchet, received the title of duke of Albufera on account of the blockade and capture of the Spanish general Blake, in Valencia. 'The water-birds and eels which are taken here yield 12,000 dollars annually.

Albohera; a village in Estremadura, on the Albuhera, twelve miles S.S.E. of Badajoz, $A$ battle was fought here, May 16, 1811, between the army of marshal Beresford, consisting of about 30,000 British, Spanish, and Portuguese, and that of the French marshal Soult, amounting to about 25,000 men, but considerably superior in artillery. The object of the French was to raise the siege of Badajoz, which was invested by the English. Soult was obliged to retreat to Seville, with a loss stated at 8000 men. The allies lost about $7000 \mathrm{men}$, and gained the rictory by a cool, well-directed, and opportune fire on the columns of French infantry. allies.

A Luг ; umong the Romans, a white board for official publications. These boards received their appellations frum the various magistrates; the album pontificum served as a state clironicle - Allum is also used to denote a kind of table or pocket-book, wherein the men of letters, with whom a person has conversed, inscribe their names, with some sentence or motto. The fanous Algernon Sydney, being in Denmark, was presented by the university of Copeu hagen with their album, whereupon he wrote these words :

\section{Manus hec inimica tyrannis}

Ense petit placidam sub libertate quieten.

Albums are at present in fashion among ludies. I Germany, where the fashion is said to lave originated, they are now almost cut of use, excepting such as are kept on interesting spots, high towers, mountains, fields of battle, \&c. Gnethe, being once asked by a tedious visitor to write something in his album, wrote $G$, the initial of his name. The uame of this letter, in German, signifies go.

Albomazer, an Arabian philosopher of the ninth century, who combined the study of physic with that of judicial astrology and astronomy, a work upon which latter science was printed under his name at Venice, in 1489. A treatise on the revolution of years, Venice, $1526,8 \mathrm{ro}$. is atso ascribed to him.

Alduses, in physiology, exists nearly pure in the white of eggs. As thus procured, it is a glareous fluid, with very little taste. When kept for some time exposed to the air, it putrefies, but when spreal in thin layers and dried, it does not undergo my change. When lieated to about $165^{\prime \prime}$ Fahr., it cotgulates, and its properties are entirely changed. It is soluble in cold water, and is separated, in its coagulated state, by liot water, if the quantity of fluid be not great, but if the water be about ten times as much in amount as the albumen, there is no coagulation. Hence we cannot dissolve it in warm water, for, when put into it (as when a little of the white of eggs is thrown into a glass of boiling water), it is instantly coagulated. It is also coagulated by acids. A. exists in different parts of animals, as cartilage, bones, horns, hoofs, flesh, the membranous parts, and in considerable quantity in blood, from which it is usually procured, when required in the arts. From the property which it possesses of being coagulated by heat, it is employed for clarifying fuids, as in the refining of sugar, and in many other processe's. When required in a large quantity, bullock's blood is used. When this or the white of eggs is put into a warm fluid, its $A$. is coagulated, and entangles the impurities, and, as the scum rises, it is remored. $\Lambda$. acts in the same way, also, in clarifying spirituous fluids. When, for instance, the white of an egg is added to wine, or to any cordial, the alcohol coagulates it, and the coagulum entangles the impurities, and carries them to the bottom. Both gelatin and A. exist in flesh, and, as the former is solnble in warm water hence the difference in the nutritions quality of butcher's meat, according to the mode of cooking it ; when, for instance, meat is boiled, the greater part of the gelatin is extracted, and retained by the soup; when, on the coutrary, it is roasted, the gelatinous matter is not removed; so that roasted meat contains both gelatin and A., and should, therefore, be more nutritious than the other. By the analysis of Gay Lussac and Thenard, 100 parts of $A$. are formed of 52.883 carbon, 23.872 oxygen, 7.540 hydrogen, 15.705 nitrogen. The negative pole of a voltaic pile in high activity cragulates A. Orfila has found the white of eggs to be the best antidote to the 
poisonous effects of corrosive sublimate on the human stomach. See $\mathbf{E g g}$.

AlBuguerque, Alfonso de, viceroy of India, surnamed the Great, and the Portuguese Mars, was born at Lisbon, 1452, of a family that derived its origin from kings. An heroic and enterprising spirit at that time distinguished his nation. They had become acquainted with, and had subjected to their power, a large part of the western coast of Africa, and began to extend their sway over the seas and nations of-India. A. was appointed viceroy of their acquisitions in this quarter, and arrived, Sept. 26, 1503 , with a fleet and some troops, on the coast of Malabar; took possession of Goa, which he made the centre of the Portuguese power and commerce in Asia; subdued the whole of Malabar, Ceylon, the Surda islands, and the peninsula of Malacca. In 1507, he made himself master of the island of Ormus, at the entrance of the Persian gulf. When the king of Persia demanded the tribute which the princes of this island lad formerly paid him, $\boldsymbol{\Lambda}$. laid before the ambassadors a bullet and a sword, saying, "This is the coin in which Portugal pays her tribute." He made the Portuguese name highly respected by all the nations and princes of India, and several, as the kings of Siam and Pegu, courted his friendship and protection. All his enterprises were extraordinary. His discipline was strict; he was active, cautious, wise, humane, and just ; respected and feared by his neighbours, beloved by his inferiors. His virtues made such an impression on the Indians, that they, for a long time after his death, made pilgrimages to his tomb, and besought him to protect them against the tyrany of his succrssors. Notwithstanding his great merits, he did not escape the envy of the courtiers, and the suspicions of king Emanuel, who sent Lopez Soarez, the versonal enemy of $\Lambda$., to fill his place. The ingratitude of his sovereign severely afflicted him, and he died, a few days after receiving the intelligence, at Goa, in 1515, having recommended his only son to the king's favour, in a letter written a short time before his death. Emanuel honoured his memory by a long repentance, and raised his son to the highest dignities of the kingdom.

Alborsos ; the soft, white substance which, in trees, is found between the liber, or inner bark, and the wood, and, in progress of time acquiring solidity, lecomes itself the wood. A new layer of wood, or rather of $\mathbf{A}$., is added annually to the tree in every part, just under the bark.

ALC.EOS, one of the greatest Grecian lyric poets, was born at Mitylcne, in Lesbos, and flourished there at the close of the 7th and beginning of the 6th centuries B.C. Somewhat older than Sappho, he paid homage to the charms of his renowned countrywoman, but, as it seems, unsuccessfully. Being of a fiery temperament, he sought at the same time the laurel of war and of the muses. H is misfortune in losing his shield, in a war between Mitylene and Athers, has been falscly attributed to cowardice. He engaged in the civil war which convulsed his country at the time of the expulsion of the tyrants, and used both the lyre and the sword in the cause of liberty. In the beginning, he took part with Pittacus; subsequently against lim, when he took the reins of governmeut into his owi hands, after the overthrow of the petty tyrants, in order to unite and quiet the divided people. A., expelled from Mitylene by the change of circum. stances, wandered about for a loug time, and at last fell into the hands of Pittacus, in an attempt to force his way into his native city, at the head of a body of exiles. The latter magnanimously restored him to liberty. His songs breathe the same spirit with his life. $\Lambda$ strong, manly enthusiasm for freedom ami justice pervades even those in which he sings the pleasures of love and wine. But the sublinnity of his nature shines brightest when he praises valour, chastises tyrants, describes the blessings of liberty and the misery of exile. His lyric muse was versed in all the forms and subjects of poetry, and antiquity attributes to him hymns, odes, and songs. - A few fragments only are left of all of them, and a distant eclio of his poetry reaches us in some odes of Horace. He wrote in the Eolic dialect, and was the inventor of the metre that bears his name, one of the most beautiful and melodious of all the Lyric metres. Horace has employed it in many of his odes. German poets, too, have imitated it, as Klopstock. Jani has collected the fragments of his works. Some of them are in the Analecta of Brunck, and in the $A n$ thologia of Jacobs. There were two other poets of the same name, but of less reputation.

alcala de Hevarez; a beautiful and extensive city of Spain, in New Castile, seated upon the river Henarez, eleven iniles S. W. of Guadalaxara, and fifteen E. N. E. of Madrid. The ancient name was Complutum, when it was a Roman colony, and here was printed the celebrated Biblia Complutensia, or Complutensian Polyglot, at an expense of 250,000 ducats to cardinal Ximenes. It was the first polyglot Bible ever printed. 600 copies were struck off, three on vellum. One of these three was deposited in the royal library at Madrid, a second in the royal library at Turin ; a third, supposed to have belonged to the cardiual himself, after passing through varions hands, was purchased at the sale of signor Pinelli's library in 1739 , for the late count $M^{\circ}$ Carthy, of Toulouse, for $£ 483$. On the sale of his library at Paris, 1817, it was sold for above $£ 676$ sterling.

Alcalde (Spanish), or Alcadde (Portuguese); the name of a magistrate in the Spanish and Portuguese towns, to whom the administration of justice and the regulation of the police is committed. His office nearly corresponds to that of justice of the yeace. The name and the office are of Moorish origin.

Alcavtara; an ancient town and frontier fortress in the Spanish province Estremadura, with 3000 inhabitants, built by the Moors, on the Tagus, over which is a splendid bridge, erected by the Romans. One of the three ancient Spanish orders of knighthood, which derives its origin from the bre. thren of St Julian del Parero (of the pear-tree), in the 12th century, and fought bravely against the Moors, received, in 1207, from the order of Calatrava, the town of Alcantara, of which it took the name, and was united with the Spanish crown, after the grand master, don Juan de Zuniga, had delivered up the town to Ferdinand the Catholic, in 1494. The knights, since 1540, have been allowed to marry. The order was very rich. The badge is a gold and green cross, fieur de lis ; the coat of arms, a peartree, with two chevrons.

Alcavala is the name of a tax or excise imposed in Spain and the Spanish colonies upon sales of property, whether movable or immovable. The rate of this tax has varied, heretofore, in Spain, from fourteen to six per cent. It differs from the ordinary excise in this, that an excise is most generally intended to be levied upon consumption, so that each one shall pay in proportion to the goods he may consume ; and it is, therefore, founded upon one of the legitimate principles of taxation. But the alcarala, being levied upon all sales, is, in fact, a tax upon internal cumnerce; it is a forfeit paid by the vender for selling a thing to be used or consumed by another, instead of using or consuming it himself, which he night do free of any such tax. It is, accordingly. 
one of the most unequal and pernicions taxes that could possibly be levied, since its amount is not governed by the amount of property which the party paying it is worth, nor by the amount that he consumes. It is, to all intents and purposes, an arbitrary tax, and Ultaritz attributes to it the ruin of the Spanish manufactures. The alcavala was introducel under Alphonso XI., and was borrowed from the Arabians. It was imposed at first in 1342, only for a specifed periol. In 1349 , it was made perpetual, and fixed at ten per cent.

Alceste; the daughter of Pelins, and wife of Admetus, king of Thessaly. Her husband was sick, and, according to an oracle, would die, unless some one else made a row to meet deatl in his stend. This was secretly done by $A$. She became sick, and Admetus recovered. $\Lambda$ fter her decease, Hereules visited Admetus, with whom he was connected by the ties of hospitality, and promised his friend to bring back his wife from the infernal regions. He made good lis word, coinpelling Plnto to restore $\Lambda$. to her husband. Enripides has made this story the subject of a tragedy.

Alcuysr; the art of clinuging, by means of a secret chemical process, base metals into precious. Probably the ancient nations, in their first attempts to melt metals, observing that the composition of different metals produced masses of a colour unlike either,-for instance, that a mixture like gold resulted from the melting together of copper and zinc,-arrired at the conclusion, that one inetal could be changed into another. At an early periou, the desire of gold and silver grew strong, as luxury increased, and men indulged the liope of oblaining these rarer metals from the more common. At thic same time, the love of life led to the idea of finding a remedy against all diseases, a means of tessening the infirmities of age, of renewing youth, and repelling death. The hope of realizing these ideas prompted the efforts of several men, wlio taught their loctrines through mystical images and symbols. To transmute metals, they thought it necessary to find a substance, which, containing the original principle of all matter, should possess the power of dissolving all into its elements. This general solvent, or menstruxum universale, which, at the same time, was to possess the power of removing all the seeds of disease out of the human body, and renewing life, was called the philosopher's stone, lapis philosophorum, and its pretended possessors adepts. The more obscure the iileas which the alchymists themselres had of the appearances occurring in their experiments, the more they endea voured to express themsel ves in symbolical language. Afterwards, they retained this phraseo$\operatorname{logy}$, to concesl their secrets from the uninitiated. In Egspt, in the earliest times, Hermes, the son of $\Lambda$ nubis, was ranked anong the heroes, and many books of chemical, magical, and alchymical learning are said to have been left by him. These, however, are of a later date. (See Hermes Trismegistus.) For this reason, chemistry and alchymy received the name of the Hermetic art. It is certain that the ancient Egyptians possessed particular chemical and metallurgical knowledge, although the origin of alchymy cannot, with certainty, be attributed to them. Several Grecians became acquainted with the writings of the Egyptians, and initiated in their chemical knowledge. 'The fondness for magic, and for alchyiny more particularly, spread afterwards among the Romans also. When true science was persecuted unler the Roman trrants, superstition and false philosophy flourished the more. The prodigality of the Romans excited the desire for gold, and led them to pursue the art which promised it instantaneously and abundantly. Caligula made experiments with a view of obtaining gold from orpiment. On the other hand, Diocletian onlered all bouks to be burned that taught to manufacture gold and silver by alchyny. At that time, many bouks on alchymy were written, and falsely inseribed with the names of renowned men of antiquity. Thus a number of writings were ascribed to Democritus, and more to Hermes, which were written by Eggptinn mouks and hermits, and which, as the Fabula Smaragdina, taught, in allegores, with mystical and symbolical figures, the way to discover the plilosopher's stone. At a later period, chemistry aud alcliymy were cultirated anong the Arabians. In the eighth century, the first chemist, cornmouly called Geber, flourished among thein, in whose works rules are given for preparing quicksilver and other metals. In the iniddle ages, the monks deroted themselves to alchymy, afthough they were afterwards prohibited from studying it by the popes. But there was one, even annong these, John XXII. who was fond of alchymy. Raymond Lully, or Lullius, was one of the most famous alchymists in the thirteenth and fourteenth centuries. $\boldsymbol{A}$ story is told of him, that, during his stay in London, he changed for king Edward 1. a mass of 50,000 pounds of quicksilver into gold, of which the first rose-nobles were coined. The study of alchymy was prolibited at Venice in 1488. Paracelsus, who was highly celebrated about 1525, belongs to the renowned alchymists, as do Roger Bacon, Basilins Valentinus, and many others. When, however, more rational principles of cliemistry and philosophy began to be diffused, and to shed light on chemical phenomena, the rage for alchymy gradually decreased, though many persons, includiug some no bles, still remained devoted to it. Alchymy lias, however, afforded some service to chemistry, and even medicine. Chemistry was first carefully studied by the alchymists, to whose labour and patience we are indebted for several useful discoveries; e. g. various preparations of quicksilver, mineral kernes, of porcelain, \&c. - Nothing can be asserted with certainty about the transmutation of metals. Moderu chemistry, indeed, places metals in the class of elements, and denies the possibility of changing an inferior metal into gold. Most of the accounts of such transmutation rests on fraud or delusion, although some of them are accompanied with circumstances and testimony which render them probable. By means of the gal ranic battery, even the alkalies have been discorered to have a metallic base. The pos. sibility of obtaining metal from other sulstances which contain the ingredients composing it, and of changing one metal into another, or rather of refining it, must, therefore, be left undecided. Nor are all alchymists to be considered impostors. Many have laboured, under the conviction of the possibility of obtaining their olject, with indefatigable patience and purity of heart (which is earnestly recommended by sound alchymists as the principal requisite for the success of their labours). Designing men have often used alchymy as a mask for their covetousness, and as a means of dofrauding silly people of their money. Many persons, even in our days, destitnte of sonnd chemical knowledge, have been led by old books on alchyms, which they did not understand, into long, expensive, and fruitless labours. Hitherto chemistry has not succeeded in unfolding the principles by which metals are formed, the laws of their production, their growth and refinement, and in aiding or imitating this process of nature; consequently the labour of the alchymists, in search of the philosopher's stone, is but a groping in the dark.

AlCirindes. This famous Greek, son of Clinias 
and Dinomache, was born at Athens, in the $82 \mathrm{~d}$ Olympiad, about 450 B. C. He lost his father in the battle of Charonea, and was afterwards educated in the house of Pericles, his grandfather by his mother's side. Pericles was too much engaged in affairs of state to bestow that care upon him, which the impetuosity of his disposition required. In his childhood, $A$. showed the germ of his future character. One day, when he was playing at dice with some companions in the street, a waggon came up; he requested the driver to stop, and the latter refusing, A. threw himself before the wheel, exclaiming, "Drive on, if thou darest." He excelled alike in mental and bodily exercises. His beauty and birth, and the high station of Pericles, procured him a multitude of friends and admirers, and his reputation was affected by the dissipation in which he became in volved. He was fortunate in acquiring the friendship of Socrates, who endeavoured to lead him to virtue, and undoubtedly obtained a great ascendency over him, so that $A$. often quitted his gay associates for the company of the philosopher. He bore arms, for the first time, in the expedition against Potidæa, and was wounded. Socrates, who fought at his side, defended him, and led him out of danger. In the battle of Delium, he was among the cavalry who were victorious, but, the infantry being beaten, he was obliged to flee, as well as the rest. He overtook Socrates, who was retreating on foot, accompanied lim, and protected him. As long as the demagogue Cleon lived, A. was principally distinguished for luxury and prodigality, and did not miugle in the affairs of state. On the death of Cleon, 422 B. C., Nicias succeeded in making a peace for fifty years between the Athenians and Lacedrmonians. A., jealous of the influence of Nicias, and offended because the Lacedæmonians, with whom he was connected by the ties of hospitality, had not applied to lim, fomented some disagreement between the two nations into an occasion for breaking the peace. The Lacedæmonians sent ambassadors to Athens; A. received them with apparent good will, and advised them to conceal their credentials, lest the Athenians should prescribe conditions to them. They suffered themselves to be duped, and, when called into the assembly, declared that they were without credentials. A. rose immediately, aceused them of ill faith, and induced the Athenians to form an alliance with the Argives. A breach with the Lacedæmonians was the consequence. A. commanded several times the Athenian fleets, which devastated the Peloponnesus; but even then he did not refrain from luxury and dissipation, to which he gave himself up entirely after his return. On one occasion, after leaving a nocturnal revel, in the company of some friends, he laid a wager that he would give the rich Hipponicus a box on the ear, and so he did. This act made a great noise in the city, but $\Lambda$. went to the injured party, threw off his garment, and called upon him to revenge himself by whipping him with rods. This open repentancc reconciled Hipponicus; he not only pardoned him, but gave him afterwards his daughter, Hipparete, in marriage, with a portion of ten talents (10,500 dollars.) $\Lambda_{\text {., howcrer, still continued his }}$ levity and prodigality. His extravagance was conspicuous at the Olympic games, where he entered the stadium, not like other rich mell, with one chariot, but with seven at a time, and gained the three first prizes. He seems to have been victor, also, in the Pythian and Nemaan games. All this together drew upon him the hatred of many of his fellow citizens, and he would have fallen a sacrifice to the nstracism (q. v.), if he had not, in connexion with Nicias and Phrax, who fearred a sinnilar fate, artfully contrivel to procure the banishment of his most formidable enemy. Soon afterwards, the Athenians, at the instance of $A$., resolved on an expedition against Sicily, and elected him commander-in-chief, together with Nicias and Lamachus. But, during the preparations, it happened one night that all the statues of Mercury were broken. The enemies of A. clarged him with the act, but postponed a public accusation till he had set sail, when they stirred up the people against him to such a degree, that he was recalled, in order to be tried. $A$. had been very successful in Sicily, when he received the order to return. He obeyed, and embarked, but, on reaching Thurium, disembarked, and concealed himself. Some one asking him, "How is this, Alcibiades? have you no confidence in your country ?" he answered, ". I would not trust my mother, when my life is concerned; for she might, by mistake, take a black stone instead of a white one." He was condemned to death in Athens, and said, when the news reached him, "I shall show the Athenians that I am yet alive." He now went to Argos, thence to Sparta, where hc made himself a favourite, by conforming closely to the prevailing strictness of manners. Here he succeeded in inducing the Lacedæmonians to form an alliance with the Persian king, and, after the unfortunate issue of the Athenian expedition against Sicily, he prevailed on them to assist the inhabitants of Clios in throwing of the yoke of Athens. He went himself thither, and, on his arrival in Asia Minor, roused the whole of Ionia to insurrection against the Athenians, and did them considerable injury. But Agis and the principal leaders of the Spartans becanie jealous of him, on account of his success, and ordered their commanders in Asia to cause him to be assassinated. A. suspected their plan, and went to Tissaphernes, a Persian satrap, who was ordered to act in concert with the Lacedæmonians. Here he changed his manners once more, adopted the luxurious liabits of Asia, and understood how to make himself indispensable to the satrap. As he could no longer trust the Lacedæmonians, he undertook to serve his country, and showed Tissaphermes that it was against the interest of the Persian king to depress the Athenians entirely; but that Sparta and Athens ouglit to be preserved for their mutual injury. Tissaphernes followed this advice, and afforded the Athenians some relief. The latter had, at that time, considerable forces at Samos. A. sent word to their commanders, that, if the licentiousness of the people was suppressed, and the government put into the hands of the nobles, he would procure for them the friendship of Tissaphernes, and prevent the junction of the Phœnician and Lacedremonian fleets. This demand was granted, and Pisander sent to Athens; by whose means the government of the city was put into the hands of a council consisting of 400 persons. As, however, the council showed no intention to recall $A$., the army of Samos chose him their commander, and exhorted him to go directly to Athens, and overthrow thc power of the tyrants. He wished, however, not to return to his country before he had done it some services, and therefore attacked and totally defeated the flect of the Lacedremonians. When he returned to Tissaphernes, the latter, in order not to appear a participator in the act, caused lim to be arrested in Sardis. But A. found means to escape; placed himself at the head of the Athenian amy; conquered the Lacedæmonians and Persians, at Cyzicus, by sea and land ; took Cyzicus, Chalcedon, and Byzantium; restored thicısovereignty of the sea to the Athenians, and rcturned to his comntry. whither he had been recalled, on the motion of Critias. Hc was received with general enthusiasul; 
for the Athenians considered his exile the cause of all their misfortunes. But this triumpln was of short churation. He was sent with 100 ghips to Asia; but, not being supplied with money to pay his soldiers, he saw himself under the necessity of seeking help in Caria, and committed the command to Antiochus, who was drawn into a snare by Lysander, and lost his life, and a part of his ships. The ene mies of $\Lambda$. improved this opportmity to accuse him, and procure his remoral from office. $\Lambda$. went to P'acte in Thrace, collected troops, and waged war agaiust tie Thracians. He obtained considerable livoty, and secured the quiet of the neighbouring Greek cities. The Athenian fleet was, at that time, lying at Egos Potanos. He pointed out to the generals the danger which threatened them, advised them to go to Sestos, and offered his assistance to force the Lacedremonian general, Lysander, either to fight, or to make peace. But they did not listen to him, and soon after were totally defeated. A., fearing the power of the Iacedsemonians, betook himself to Bithynia, and was about to go to Artaxerxes to procure his assistance for his country. In the meantime, the thirty tyrants, whom Lysander, after the capture of $\Lambda$ thens, had set up there, requested the latter to cause $A$. to be assassinated. But Lysander declined, until he received an onder to the same effect from lis own goverument. He then charged Phamabazus with the execution of it. A. was at that time with Timandra, his mistress, in a castle in Phrygia. The assistants of Pharnabazus set fire to his house, and killed him witl their arrows, when he had already escaped the conflagration. Timandra buried the body with due honour. Thus $\Lambda$. ended his life, 404 13.C., about forty-fice years old. He was endowed by nature with distinguished qualities, a rare talent to captivate and rule men, and uncommon eloquence, although he could not pronounce $r$, and stuttered; but he had no fixed principles, and was governed only by external circumstances. He was withont that elevation of soul, which steadily pursues the path of virtue; on the other hand, he possessed that coldness which arises from consciousness of superiority, and which shrinks from no difficulty, becruse always confident of success. Plutarch and Cornelius Nepos, among the ancients, lave written his life.

Alctos ; a surname of Hercules, usually derived from the name of his grandfather, Alcaus, the father of Ainphitryon.

Aucjoons; said to kare been a king of the Phracians, in the island now called Corfu. His gardens have immortalized his memory. The passages in which Homer describes his lospitality towand Ulysses, and the ardent desire of the latter to reach his home, are most beautiful. He was a grandson of Neptune.

Alcipirox; the most distinguished of the Grecian epistolary writers. Nothing is known of his iife, and even his age is uncertain. It is probable that he belongs to the second century after Christ. We'hare 116 fictitious letters by him; the object of which seems to be, to represent the manners, thoughts, and feelings of certain strongly-marked classes in the free communication of epistolary intercourse. These letters are distinguishel by purity, clearness, and simplicity of language and style. Principal editions, Geneva, 1606; Leipsic, 1715, and one in 1798 , at the same place, by T. A. Wagner.

Alcrzox; the son of Amphiaraus and Eriphyle (१. v.) of Argos; chosen chief of the seven Epigoni, il which capacity he took and destroyed Thebes. IIiz father, going to war, charged A. to put to death
Eriphyle, who hal betrayed him. He dicl so, sunl was pursued by the furies. An oracle inforn. 'd him, that, to escape their veugeance, he must reside in a land which was not in existence when he was cursed by his mother. He at last fonnd rest, for a short time, on an island in the river $A$ chelous, where he married Callirrhoe, the dimghter of the god of the river, after repudiating his former wife, Arsinoe. But he did not long ('njoy pence. At the request of his wife, he atteinpled to recover the fatal necklace of Hernione from his former fatherin-law, the priest Phlegeus, who caused him to be murdered by his sons.

Alcuas ; a Grecian poct, son of a Spartan slave, born at Sardis, in Lyelia, abont 670 years B. C. He seems to have lived, for the most part, in Sparta, where he obtained the rights of citizenship. He sang hymns, paeans, and other lyrical poems, in the Doric dialect, aukl gave their polished forn to these higher kinds of poetry. II remaining works were collected by F. 'Th. Welcker (Giessen, 1815, 4to).

A ICMENa; the daughter of Electryon, and wife of Amphityron. Jupiter loved her, and deceived her by assuming the form of her husland. Froin this connexion, which continued for tliree nights, sprang Hercules.

Arcocr, John, bishop of Ely, and founder of Jesus College, Cambridge, and of the Gramunar School at Kingston-upon-Hull, was a prelate of the 15 th century, distinguished as a patron of learning. He died in 1500. Among his works are "Galli Cantus ad Confratres suas Curatus in Syuodo apud Barnwell," 1480, 4to. "Mons l'erfectionis," Lond., 1501, 4to. "Abbatia Spiritns," \&c.

Alconol; the purely spirituous part of all liquors that have undergone the vinous fermentation, and derived from none but such as are susceptible of it. As a chemical agent, it is of the highest importance, involving in its various combinations all the graml principles of chemistry. - It has been found that spirit of wine, of sp. gr. 867 , when enclosed in a bladder, and exposed for some time in the air, is converted into alcohol of sp. gr. $\cdot 817$, the water only escaping through the coats of the bladder. Alcohol, obtained by slow and careful distillation, is a limpid, colourless liquid, of an agreeable smell, and a strong, pungent flavour. Its specific gravity varies with its purity, the purest obtained by rectification over chloride of calcium being $\cdot 791$; as it usually occurs, it is 820 at $60^{\circ}$. If rendered as pure as possible by simple distillation, it can scarcely be obtained of a lower specific gravity than 825 at $60^{\circ}$ - $-\mathrm{Mr}$. Hutton is said to have succeeded in freczing alcohol, but the fact is regarded as doubtful, as the means by which he effected its congelation were never disclosed. Mr Walker exposed it to a temperature of $91^{\circ}$, but no congelation took place; it has, therefore, been much used in the construction of thermometers. Even when diluted with an equal weight of water, it requires a cold of $6^{\circ}$ below 0 to congeal it. When of a specific gravity of $\cdot 825$, it boils at the temperature of $176^{\circ}$, the baronetrical pressure being 30 inches. In the vacuum of an airpump it boils at common temperatures. The specific gravity of the vapour of alcohol, compared with atmospheric air, is $4 \cdot 613$. - Alcohol may be mixed in all proportions with water, and the specific gravity of the mixture is greater than the mean of the two liquids, in consequence of a diminution of bulk that occurs on mixture. - The strength of such spirituons liquors as consist of little else than water and alcohol, is of course ascertained by their specific gravity; and, for the purpose of levying duties upon them, this is ascertained by the hydroneter. But the only correct mode of ascertaining the specific gravity 
of liquids, is by weighing them in a delicate balance against an equal volume of pure water, of a similar teinperature. - $A$ lcohol is extremely inflammable, and burns with a pale-blue flame, scarcely visible in bright day light. It occasions no fuliginous deposition upon substances held over it, and the products of its combustion are carbonic acid and water, the weight of the water considerably exceeding that of the alcohol consumed. According to Saussure, jun. 100 parts of alcohol afford, when burned, 136 parts of water. The steady and uniform heat, which it gives during combustion, unakes it a valuable material for lamps. - The action between alcohol and some of the metals, particularly platinum, is remarkable. When a small piece of thin platinum leaf, suspended hy a wire, is heated by a spirit lamp, and then quickly put into a glass, in which there is a little alcohol, so that it shall remain just over the surface, and of course in the vapour arising from the alcohol, it continues red-hot, as long as there is any fluid in the jar; which is owing to the vapour undergoing a sort of combustion, and generating heat sufficient to keep the metal in that state. This action affords the means of making a lamp without flame.-There are some substances which communicate colour to the flame of alcohol ; from boracic acid, it acquires a greenish-yellow tint; nitre and the soluble salts of baryta cause it to burn yellow, and those of strontia give it a beautiful rose colour; cupreous salts impart a fine green tinge.-Alcohol dissolres pure soda and potassa, but it does not act upon their carbonates ; consequently, if the latter be inixed with alcohol containing water, the liquor separates into two portions, the upper being alcohol deprived, to a considerable extent, of water, and the lower the aqueous solution of the carbonate. The alcoholic solution of caustic potassa was known in old pharmacy under the name of $V$ an Helmont's tincture of tartar. It is used for purifying potassa.-Alcohol dissolves the greater number of the acids. It absorbs many gaseous bodies. It dissolves the regetable acids, the volatile oils, the resins, tan, and extractive matter, and many of the soaps; the greater number of the fixed oils are taken up by it in small quantities only, but some are dissolved largely.-The composition of alcohol was investigated by Saussure, and Gay Lussac. The result was, that 100 parts of pure alcohol consist of

$$
\begin{aligned}
& \text { Hydrogen . . . 13.70 } \\
& \left.\begin{array}{l}
\text { Carbon1 . . . } 51 \cdot 98 \\
\text { Oxygen . . } 34 \cdot 32
\end{array}\right\}
\end{aligned}
$$$$
100 \cdot 00 \text {. }
$$

These numbers approach to 3 proportionals of hydrogen, $=3 ; 2$ of carbon, $=12 ;$ and 1 of oxygen, $=8$. Or it may be regarded as composed of 1 volume carbureted hydrogen, and 1 volume of the $\checkmark$ apour of water; the 2 volumes being condensed into 1 , the specific gravity of the vapour of alcohol, compared with common air, will be $1 \cdot 599$, or, according to Gay Lussac, 1.613. When alcohol is submitted to distillation with certain acids, a peculiar compound is formed, called ether (q. r.), the different ethers being distinguished by the names of the acids employed in their preparation.

Alcoran. See Koran.

Aucuivos, or Albinos, Flaccus; an Englishman, renowned, in his age, for learning; the confidant, instructor, and adviser of Charlemagne. He was born in York (according to some, near London) ill 732, was educated under the care of the venerable Bede and bishop Egbert, and was made abbot of Canterbury. Charlemagne became acquainted with hin in Parna, on his return from Rome, whence he land brought the pallium for a friend; invited him, in 782 , to his court, and made use of his services in his endea rours to civilize his subjects. In the royal academy, he was called Flaccus Albinus. To secure the benefit of his instructions, Charlemagne established at his court a school, called Palatina, and intrusted him with the superintendence of several monasteries, in which A. exerted himself to diffuse a knowledge of the sciences. Most of the schools in France were either founded or improved by him; thus he founded the school in thite abbey of St Martin of Tours, in 796, after the plan of the school in York. He himself instructed a large number of scholars in this scliool, who afterwards spread the light of learning through the empire of the Franks. A. took his leave of the court in 801 , and retired to the abbey of St Martin of Tours, but kept up a constant correspondence with Clarles to the time of his death, in 804. He left, besides many theological writings, several elementary works in the branches of philosophy, rhetoric, and philology; also poems, and a large number of letters, the style of which, however, is not pleasing, and plainly betrays the uncultivated character of the age ; nevertheless, he is acknowledged as the most learned and polished man of his time. He understood Latin, Greek, and Hebrew. His works appeared in Paris, 1617, folio, and in a more complete form in Ratisbon, 1777, 2 vols. folio.

Aldebaran, or the bull's eye, in astronomy; a star of the first magnitude in the southern eye of the constellation Tauris.

Aldegonde, St Philip, of Marnix, lord of mount St Aldegonde, was bom in Brussels, 1538, and studied in Geneva. He drew up, in the begiming of Dec. 1565, the act of compromise for the preservation of the privileges of the Netherlands, whicl was signed by count Louis of Nassau, Henry of Brederode, and himself. The act was directed chiefly against the introduction of the inquisition into the Netherlands, and the members promised to assist each other with their persons and property. It was rejected, however, by the regent Margaret. In 1566, Alva arrived. St A. fled, with the friends of the prince of Orange, to Germany, and returned with them as their leading counsellor. In 1573, lie fell into the hands of tlie Spaniards, at Maesluys, was afterwards exchanged, and conducted many diplomatic negotiations of the young republic abroad. He defended Antwerp a long time, though not successfully. He assisted in establishing the university of Leyden, and died there, professor of theology, in 1598.

Aldenhovea, battle at, March I, 1793. The engagement near this town, situated between Juliers and Aix la Chapelle, opened the campaign of 1793. The year previous, the Austrians had been obliged, after the battle of Jemappe, to evacuate Belgium, and retire behind the Roer. Dumouriez, at the beginuing of the year 1793, threatened Holland with an invasion. To prevent this, and to raise the siege of Maestricht, the prince of Coburg drew together his army, consisting of 40,000 men, behind the Roer, and forded this river, March 1 , in two columns, at Duren and Juliers. In the engagement which ensued, the French lost about 6000 men killed and wounded, and 4000 prisoners. On the following day, Aix la Chapelle and Liege were occupied, the siege of Maestricht raised, ani the French actively pursued. At Neerwinden the French halted, and receired a re-enforcement, consisting of the corps destined to invade IIolland, but were beaten here, March 18, a second time.

Aldfr. The alder or owler (betula alnus) is a tree which grows in wet situations, and is distinguisled by its flower-stalks being branched, its leaves being roundish, waved, serrated, and downy at the branching of the veins beneath. It is common in 
linrope ard Asia, and the United States of Ameria. There are few means of better employing suranpy and morassy grounds, than by planting thein with alders; for, although the growth of these trees is not rapid, the uses to which they are applicable are such as anply to compensate for the slowness with which they come to perfection. The wood of the alder, which is in great denand for machinery, is frequently wrought into cogs for mill-wheels, as it is peculiarly adapted for all kinds of work which are to be kept constantly in water. It is consequently used for pumps, sluices, pipes, drains, and conduits of differ'ut descriptions, and for the foundation of buildings situated in swamps. For these purposes, it has been much cultivated in Flanders and Holland. It is commonly used for bobbins, women's slioelieels, ploughnien's clogs, and numerous articles of turnery wate. This wood also serves for many clomestic and rural uses, for spinning-wheels, troughs, the handles of tools, ladders, cartwheels, \&c. The roots and knots furnish a beautifully-reined wood, nearly of the colour of maliogany, and well adapted for cabinet-work. The bark mny be advantageously used in the operations of tanning and leather-dressing, and by fishermen for staining their nets. This and the young twigs are sometimes employed in dyeing, and yield different sluades of yellow and red. The Laplanders chew the bark of the alder, and dye their leather garments red with the saliva thus produced. IV ith the addition of copperas, it yields a black dye, used to a cousiderable extent in colouring cotton. In the Highlands of Scotland, we are informed that joung branches of the alder, cut down in the sumwer, spread over the fields, and left during the winter to decay, are found to answer the purpose of manure. The fresli-gathered leaves, being covered with a glutinous inoisture, are said to be sometimes strewed upon floors to destroy fleas, which become entangled in it, as birds are with bird-lime.

ALDERMAN (aldor, elder, and man); among the ancient Saxons, the second order of nobility. It was synonymous with the Iatin comes, the eorla or jarl of the Danes (which after the Danish times superseded it), and the scnior and major of the Franks. The aldermen were at first governors of counties, and were admitted into the wittenagemot, or great council of the nation; gave their consent to the public statutes; kept order among the freeholders at the county courts; in times of war, appeared at the head of the military forces of their shires, and were called dukes, or heretogen, (the Germ. herzog). They were at first appointed by the king, and were afterwards elected by the freeholders of the shire; at first the office was during good behaviour, but finally became liereditary. Aldermen, at present, are officers associated with the mayor of a city, for the administration of the municipal government, hoth in England and the United States. In some places, they act as judges in certain civil and crimimal cases. In London, there are twenty-six aldermen, who preside over the twenty-six wards of the city, and from whose number the mayor is elected annually.

Aldhels. See Adhelm.

Aldersey ; an island on the coast of Normandy, about eight miles in circumference. Though within seven miles of cape la Hogue, it is subject to the crown of Great Britain. With Guemsey, Jersey, and Sark, it forms the only part of the possessions of William the Conqueror that now remain under the gorernment of England. A. is about thirty miles from the nearest part of the English coast, and about eighteen from Guernsey. The race of $A$. is a name given to the strait running between the coast of France and this island. The town of this name. about two zniles from the harbour, is but poorly built, and contains about 1000 inhabitants. In stormy weatlier, the whole const is dangerous, particularly from a ridge of rocks, called the Cuskets, which form numerous eldies that have often proved fatal to mariners. The air is salubrious, the soil fertile and inuch cultivated; but the custoin of gavelkind dividiug the lands into suall parts, keeps the people in a strite of poverty. They send grain to England. In 1119 , Henry, dike of Normandy, son of king Henry 1., with many nobles, was lost near this island; and in 1714, the Victory, of 116 guns, admiral Sir Jolm Ialchen, with 1100 marints and sailors, was lost near the coast of $A$.

Aldive EDitioss; the name given to the works which proceeded from the press of the family of Aldus Manutius. (See Manutius.) Recommended by their intrinsic value, as well as by a splendicl exterior, they lave gained the respect of scliolars, and the attention of book-collectors. Many of them are the first editions of Greek and Roman classics, and some have not been printed again; as Rhetores Graci, Alexander Aphrodisiensis. The text of the modern classical authors printed by them, as Petrarca, Dante, Boccaccio, and otlers, was critically revised from manuscripts. Generally speaking, their editions are distinguished for correctness, thougl their Greek classics are inferior, in this respect, to their Latin and Italian. These editions, especially those of Aldus Manutius, the father, are of importance in the listory of printing. Aldus deserves much credit for lis beautiful types. He had nine kinds of Greek types, and no one before him printed so much and so beautifully in this language. Of the Latin character he procured fourteen kinds of type. Among the latter is the antigna, with which Bembus de Etna, 1495, tto, is printed; a very beautiful character. The Italic cliaracters, invented and cut by Francesco of Bologna, and brought into use by Aldus, who emplosed them for the collection of editions of ancient and modern classics, in $8 \mathrm{vo}$, (the first of which, Virgil, appeared in 1501,) are less handsome; they are too stiff and angular, and faulty in a technical respect, on account of the many letters connected together. He had even three kinds of Hebrew types. He was no friend to ornaments of the capitals, roses, vignettes, and the like. The Hypnerotomachia Poliphili, 1499, fol., is his only work furnished with ornaments of that kind, and wood-cuts. His paper is invariably strong and white. He introduced the custom of striking off some copies of an edition on better, finer, and whiter paper than the rest; first, in the Epistolce Gracce, 1499. He also first published single copies on large paper, in the edition of Plilostratus, 1501. He printed alsu the first impressions on blue paper, beginning with some copies of the Libri de Re Rustica and Quintilian, both in 1514. His impressions on parchment were eminently beautiful. His ink is of excellent quality. At the same time, his prices were fair. His Aristotle, five rols. fol., cost only eleven ducats. The press sank in reputation under the care of his son Paul, and his grandson Aldus. When it was broken up, in $\mathbf{1 5 9 7}$, after a duration of 100 years, and after proulucing 908 editions, it was distinguished in nothing from otler presses in the country. The Aldine editions, especially those of the father, were early sought for. The printers in Lyons, and the Giunti in Florence, in 1502, found it advantageous to publish inferior and spurious reprints. In modern times, they have been highly prized by scientific collectors. The Horce b. Mar. $V$ irg., of 1497 (lately sold for 100 ducats), the Virgil of 1501 , and the Rhetores Graci, not to mention the vory rare editions between 149 i and 1497 , are par- 
ticularly scarce and valuable. The bookseller and bibliographer Renouard, in Paris, and the grand duke of 'Tuscany, possess the most complete collections. Of the former's excellent work on the press of Aldus, a supplementary volume appeared in 1812. A list of all genuine Aldine editions is given in the appendix to the 1st vol. of Ebert's Bibliographical Lexicon.-See, also, Annales de l'Imprimerie des Aldes, ou Histoire des trois Manuce, et de leurs editions; par Ant. Aug. Renouard; second edit., Paris, 1825, 3 vols. 8vo.; and Repertorium Bibliographicum, in quo Libri omnes ab Arte Typographica inventa usque ad Annum M.D. typis expressi, ordine Alphabetico enumerantur vel adcuratius recludentur ; Opera L. Hain; Stuttgard. The second part of the first vol. of this work has been published quite recently.

AldorRandisı ; the name of a princely family at Rome, celebrated in the history of art on account of an antique fresco, in their villa, representing a wedding, and called by the name of the Aldubrandine scedding. It was discovered in the time of Clement VIII., not far from the churcli Santa Maria Mag. giore, in the district where, formerly, were the gardens of Mrecenas, and carried thence into that villa. Winckelmann supposed it to be the wedding of Peleus and Thetis; the count Bondy, that of Manlius and Julia,-Several scholars, also, of this name have distinguished themselves, especially Sylvester A., famous for his knowledge of law, and his brother Thomas, both in the 16th century.

ALDRED; ablot of Tavistock, and afterwards bishop of Worcester, 1046. He was the first English bishop who visited Jerusalem, and after his return was raised to the see of York, an elevation which, when he appeared at Rome, the pope refused to ratify, on account of his ignorance and simony. A.'s solicitations, however, prevailed, and he received the pallium from the pontiff. On the death of Edward the Confessor, he crowned Harold, and afterwards the Conqueror, whose esteem he enjoyed, and whose power he made subservient to the views of the church. When he had received some indignities from a governor of York, he flew to London, and, with all the indignation and haughtiness of an offended prelate, demanded vengeance, and pronounced a curse on the head of William. His wrath was with difficulty pacified by the entreaties of the sorereign and his nobles, and the curse was recalled, and changed into a blessing. It is said that he died with grief, on seeing the 110 rth of Fingland desolated by the ravages of Harold and Canute, sons of Sweyn, Sept. 11, 1068.

AldRicr, Henry, dean of Christ Church, Oxford, 1689 , and distinguished for lis love and knowledge of music. He adapted many of the works of the older masters to the liturgy of the cliurch of England, and composed, besides, many original services and anthems. He was also author of several esteemed polemical works. At his death, which took place in 1710, lie bequeathed to the college, over which lie had presided upwards of twenty years, a large and valuable collection of music, of which Dr Burney speaks higlily.

Aldrovandus, Ulysses, a traveller and naturalist, born in 1522 at Bologna, where he was professor of philosophy and plysic; and died in 1605. After his death, the result of his travels was publislied in six vols. folio, wherein he describes a great variety of birds and insects.

Aldos. See Manutius.

ALE and BEER; well known and extensirely used fermented liquors, the principal of which is extracted from several sorts of grain, but most commonly from barley, after it has undergone the process termed malting. The distinction between ale and beer, or porter, has bcen ably elucidated by Dr Thomas Thomson, in his very valuable article on brewing, in the Supplement to the Encyclopædia Britannica: - "Both ale and beer are in Great Britain obtained by fermentation from the malt of barley; but they differ from each other in several particulars. Ale is light-coloured, brisk, and sweetish, or at least free from bitter; while beer is dark-coloured, bitter, and much less brisk. What is called porter in England is a species of beer; and the term "porter" at present signifies what was formerly called strong beer. The original difference between ale and beer was owing to the malt from which they were prepared. Ale malt was dried at a very low heat, and consequently was of a pale colour; while beer or porter malt was dried at a higher temperature, and had of consequence acquired a brown colour. This incipient charring had developed a peculiar and agreeablc bitter taste, which was communicated to the beer along with the dark colour. This bitter' taste rendered beer more agreeable to the palate, and less injurious to the constitution than ale. It was consequently manufactured in greater quantities, and soon became the common drink of the lower ranks in England. When malt became high priced, in consequence of the heavy taxes laid upon it, and the great increase in the price of barley which took place during the war of the French revolution, the brewers found out that a greater quantity of wort of a given strength could be prepared from pale malt than from brown malt. The consequence was, that pale malt was substituted for brown malt in the brewing of porter and beer. We do not mean that the whole malt employed was pale, but a considerable proportion of it. The wort, of course, was much paler than before; and it wanted that agreeable bitter flavour which claracterized porter, and made it so much relished by most palates. The porter brewers endeavoured to remedy these defects by several artificial additions. At the same time various substitutes were tried to supply the place of the agreeable bitter communicated to porter by the use of brown malt. Quassia, coculus indicus, and we believe even opium, were employed in succession ; but none of them were found to answer the purpose sufficiently. Whether the use of thesc substances be still persevered in, we do not know; but we rather believe that they are not, at least by the London porter brewers."-The manufacture of ale or beer is of very high antiquity. Herodotus tells us, that owing to the want of wine, the Egyptians drank a liquor fermented from barley (lib. ii. cap. 77). The use of it was also very anciently introduced into Greece and Italy, though it does not appear to have ever been very extensively used in these countries. Mead, or metheglin, was probably the earliest intoxicating liquor known in the north of Europe. Ale or beer was, however, in conımon use in Germany in the time of Tacitus (Morib. Germ. cap. 23). "All the nations," says Pliny, "who inhabit the west of Europe have a liquor with which they intoxicate themselves, made of corn and water (fruge madila). The manner of making this liquor is somewliat different in Gaul, Spain, and other countries, and it is called by many various names; but its nature and properties are every where the same. The people of Spain, in particular, brew this liquor so well that it will keep good for a long time. So exquisite is the ingenuity of mankind in gratifying their vicious appetites, that they liave thus invented a method to make water itself intoxicate." (Hist. Nat. lib. xiv. cap. 22.) - The Saxons and Danes were passionately fond of beer; and the drinking of it was supposed to form one of the prisl- 
cipal enjoyments of the lieroe's admitted to the lall of Odin. (.Ma!let's Northern Antiquities, cap. 6, \&.c.) -The manufacture of ale was early introduced into Fngland. It is mentioned in the laws of Ina, king of W'essex; and is particularly specified among the liquors provided for a royal banquet in the reign of Filward the Confessor. It was customary in the reigns of the Norman princes to regulate the price of ale; and it was enactrd, by a statute passed in 1272, that a brewer should be allowed to sell two gallons of ale for a penuy in cities, and three or four gallons for the same price in the country. The use of hops in the manuficture of ale and beer seems to liave been a German invention. They were used in the breweries of the Netherlands in the beginning of the fourteenth century ; but they do not seem to have been introluced into England till two hundred years afterwards, or in the beginning of the sixteenth century. In 1530, Henry VIII. enjoined brewers not to put hops into their ale. It would, however, apfear, that but little attention was paid to this order; for in 1552 hop plantations had begun to be formed. (Bechmann's Hist. Invent. vol. iv. pp. 336-341. Eng. (cl.) - The addition of hops renders ale more palatable, by giving it an agreeable bitter taste, while, at the same time it fits it for being kept much longer without injury. Generally speaking, the English brewers employ a much larger quantity of lops than the Scottish. The latter are in the habit of using, in brewing the fine Edinburgh ale, from a pound to a pound and a half of hops for every bushel of malt. Previously to 18:3 there were only two sorts of beer allowed to be brewed in England, viz. strong beer, that is, beer of the value of 16 s. and upwards, the barrel, exclusive of the duty; and small beer, or beer of the value of $16 s$. a barrel, exclusive of the duty. In 1823, howerer, an act was passed ( 4 Geo. IV. c. 51.) authorizing the brewing, under certain conditions, of an intermediate betr. But this sort of beer was either not suited to the public taste, or, which is more probable, the restrictions laid on the brewers deterred them from engaging extensively in its manufacture. This limitation and classification of the different sorts of ale and beer, according to their strength, originated in the duties laid upon them; and now that these duties have been repealed, ale and beer may be brewed of any degree of strength. Since the abolition of the beer duties, the regulations, as to the manufacture of ale and beer, are very few and simple; and consist only in taking out a license, entering the premises, and abstaining from the use of any article, other than malt, in the preparation of the beer. $A$ brewer using any place, or mash-tm, for the purpose of brewing, without having made an entry thereof at the nearest excise office, forfeits for every such offence $\mathrm{f}_{200}$; and all the worts, beer, and materials for making the same, together with the mash-tun, are forfeited, and may be seized by any officer.-Brewers obstructing officers shall, for every such offence, forfeit $£ 100 .-(1$ Will. IV. c. 51 . $\$ 15,16$.) The duties on ale and beer in Scotland have been for a lengthened period the same as in England. At the union in 1707, the English duties oil ale and beer were introduced into Scotland. But, besides strong and small beer, the Scots had an intermediate species, which they called two-penny, ard which was their favourite beverage. The duty on this descripticn of beer was fixed, at the union, at $2 s .1 \frac{1}{4} d$. a barrel. For thirty years after its imposition the quantity of two-penny that paid duty was always above 400,000 , and sometimes exceeded 500,000 barrels a year. But in 1760 the duty on two-penny was increased to $3 s .4 t d$. and the consumption immediately fell off to between 100,000 and 200,000 burrels : The quantity that paid duty in 1800 amounted to 149,803 barrels. The manufacture of this species of beer ceased entirely in 1802 .

$A$-LEE ; the situntion of the helin when it is push. ed down to the lee side of the ship, in order to $p$ it the ship about, or to lay her head to the vindward.

A lnosane, Philip; an author whose writings afford a great amount of information respecting the order of the Jesuits. He was a Jesuit, born at Brussels, 1592. His Bibliotheque des auteurs Jesuites was published at Antwerp, 1643; Vita P. Joannls Cardin. Lusitani ex Societ. Jesu, $12 \mathrm{~m}$ (), Rome, 1649; Heroes et Victime Caritatis Societ. Je:u, 4to, Rome, 1658; Mortes illustres et gersta corum de Societ. Jesu, qui iu Odium Fidei ab IJareticis rel aliis occisi sunt, folio, Rome, 1657. A. died at Rome, 1652. He was fir some time cunfessor of the emperor Ferdinand, and afterwards retained at Rome by the general of lis order as secretary, to prepare the Latin despatclies to Germany. The Bibliotheque, his chief work, was also published in Latin, Rome, 1675.

Alesax, Matthew, the author of the once ponillar history of "Guzman d'Alfarache, the Spanish Rogue." It was born near Seville, and during the reign of Philip II. was mucls about court. II s work has been translated into almost every Europea 1 language.

Alesusus ; that is, all men, or various sorts of men; the name of a military confederacy of siveral German triles, which, at the commencement of the $3 \mathrm{~d}$ century, approached the Roman terr:tory. Their settlements exteuded, on the east side of the Rhine, from lake Constance, the Elbe and the Danube, to the Maine and the Lahn. Their neighbours on the east were the Suevi, and, farther on, the Burgundians. The principal tribes composing the Alcunannic league were the Teucteri. Usipetes, Clatti, and Vangiones. Caracalla first fought with them, on the southern part of the Rhine, in 211, but did not conquer them; Severus was likewise unsuccessful. Maximin was the first who conquered and drove them beyond the Rhine, in 236. Aftrr his death, they again invaded Gaul; but Posthunius defiratel them, pursued them into Germany, and fortified the boundary with ramparts and ditches; of which tlie mounds near Phoring, on the Darube, the rampar extending througit Hohenlohe to Jaxthausen, and the ditch with palisadoes on the north side of the Maine, are remnants. (See Devil's Wall.) But the A. did not desist from their incursions, and were successively repulsed by Lollianus, the successor of Posthumius, by the emperor Probus, in 282, and ifterwards by Constantius Chlorus. Nevertheless, during the disturbances in the empire, and until Constantine became its sole master, they occupied the tract from Mentz to Strasburg. At last, Julian was sent, when Casar, to Gaul, in 357. He again repulsed the $\Lambda$., and forced their princes, of wiom there were then eight, to sue for peace. Their whole force, in the chief battle against Julian, amounted to 35,000 men. When the migration of the northern tribes began, the $A$. were among the? hordes that over-ran Gaul. They spread along the whole westerr side of the Rhine, and, in the lattr half of the 5th century, orer all Helvetin. At last, Clovis broke their power in 496 , subulued them, and deprived them of a large portion of their possessions. Many of them fled to Theodoric, king of the Ostrogoths, into Italy and the Alps; the greater part, however, returned to thieir own country.

Alessiert, Jean le Rond d', one of the most dis. tinguished mathematicians and literary characters of the 18th century, was born in Paris, in 1717, but was exposed by his parents, madame de Tencin am\} 
the poet Destonches, provincial commissary of artiltery. The child appeared so weak, that the police officer, instead of carrying it to the foundling hospital, corrmitted it to the care of the wife of a poor glazier. Perhaps he had secret instructions to do so; for, althoigh his parents never publicly acknowledged him, they did not withdraw their care from him; en the contrary, his father afterwards settled upon him an income of 1200 livres, a sum which was thien sufficient to procure the necessaries of life. - He showed much facility in learning, and it the age of four years, was sent to a boardingschool. He was but ten years old, when the principal, a man of merit, declared that he could teach him no more. He e'ntered the college Mazarin at the age of twelve. His talents surprised his instructors, who thought they had found in him a second Pascal to support the cause of the Jansenists, with whom they were closely connected. He wrote, in the first years of his philosophical studies, a comnentary on the epistle of Paul to the Romans. But, when he began to study mathematics, this science captivated him so much, that he renounced all theological disputes. He left college, studied law, became an advocate, but did not cease to occupy himself with mathematics, though he was almost entirely destitute of property. A pamphlet on the motion of solid bodies in a fluid, and another on the integral calculus, which lie laid before the acadeny of sciences in 1739 and 1740 , sliowed him in so favourable a light, that the academy received lim, in 1741, into the number of its members. He soon after published his famous works on dynamics, Traté de dynamique, and on fluids, Traité des fuides. In 1746 , his 'Theory of the Winds obtained the prize offered by the academy of Berlin, of which he was chosen a member. Among his communications to this academy, two are highly distinguished-that on pure analysis, and the one which treats of the vibrations of strings. He also took a part in the investigations which completed the discoveries of Newton respecting the motion of the heavenly bodies. Whilst Euler and Clairaut were engaged in these, he delivered, in 1747 , to the academy of sciences, a solution of the problem proposed to determine what disturbances are occasioned by the mutual attraction of the planets, in their elliptical revolntions round the sun, and what their motion would be, if they were acted on only by the attractive power of the sun. He continued these labours for several years, and published, at intervals, various important astronomical treatises, including one on the precession of the equiuoxes; also his experiment on the resistance of fluid bolies, and a number of dissertations on other subjects; works, of the value of which there is but one opinion among scholars, but which produced a coldue'ss on the part of Euler and others. - In the first fervour of his fondness for mathematics, he had, for a time, become indifferent to belles lettres; but lis carly love of them soon revived, after lis most important discoveries, when mathematical investigations ceased to afford him so rich a liarvest of new truths, or he felt the necessity of relaxation. He entered on this new career, with his introduction to the Encyclopédie, and it will always be a pattern of style in treating of scientific subjects, uniting, as it does, elegance and precision. D'A. comprised, in his introduction, the essence of all his knowledge of mathematics, philosophy, and literature, acquired in at study of twenty years, and this was all that was known at that time, in France, on these subjects. He undertook to prepare the nathematical part of the Encyclopédie, and wrote a great number of excellent articles. His name being prefixed to tnis work he shared its fate, and exposed himself to numberless quarrels. D'A. soon after entered the French academy, and continued to cultivate the belles lettres, together with mathematics. His literary works, on account of their profoundness and accuracy, met with the approbation of all sound minds ; they are distinguished by purity of language, cleamess of style, and force of thought. Althoughi he experienced much persecution on account of his connexion with the Encyclopédie, and was neglected by the government of lis country, he would not accept the invitations of Frederic II. to settle in Berlin, nor the offers of the Russian empress, who desired him to take charge of the education of her son, with a pension of 100,000 livres. His country learned his worth from foreigners; and the king of Prussia gave him a pension, when the academy of sciences, at Paris, refused him the salary to which he was justly entitled. Though his income was always moderate, his beneficence was great. He lived above thirty years, in the plainest manner, in the house of the woman who had brought him up, and left these lodgings only when his health compelled him. His long attachment to Mlle de l'Espinasse shows that he was not destitute of a feeling heart. Valuing independence more than any thing else, he avoided the society of the great, and sought only that into which he could enter with cheerfulness and frankness. The reputation which he enjoyed, the intimate friendship between him and Voltaire, and his great merits, procured him many enemies. He had a literary contest with J. J. Rousseau, on account of an aricle on Geneva, intended for the $E n$ cyclopédie. His religious character seems to have been that of a sober deist. He died of the stone, being unwilling to submit to an operation, in 1783, in the 66th year of his age. Frederic II., who had, in 1763 , become personally acquainted with D'A., inaintained a correspondence with him, which was published after the death of both, and is very interesting. The enemies of D'A., with a view of depre. ciating his merits, called him a good geometrician among the literati, and a good belles lettres scholar among the geometricians. The truth is, that his rank is somewhat higher in geometry than in belles lettres; but, owing to the influence of style upon the fate of writings, his works in the department of belles lettres will continue to interest longer than his mathematical treatises. The former are collected in the Euvres philosophiques, historiques, et litteraires de D'Alembert, 18 rols. Paris, 1809. Condorcet has drawn his character in his Eloge.

Alnsgon, capital of the French department of the Orie, on the Sarthe, contains 1528 houses, and 13,500 inhabitants, a college, a société d'émulation, a library, arul considerable manufactories of bone-lace, etainine, woollen stockings, leather, \&c. The dillmonds of A., so called, are found in the neighbouring quarries. 3000 women are employed here in manntacturing point-lace. Also a kind of linen, toile d'Alencion, enjoys much reputation. 'The neighbouring country lias become richer by the division of the large estates, and the town itself more industrious.

Alevio, Jnlius ; a Jesuit, born at Brescia, in the territory of Venice. He was a missionary in China, arrived, in 1610, at Macao, and left sereral works in the Chinese language. He died 1649.

AlEPPo, or HALEP ; capital of the Asiatic pashalic of the same name, which is the second in the Turkish empire, and comprises the northern part of Syria, including mount Lebanon. It contains 9,800 square miles, and 450,000 inhabitants. The Orontes, abounding in fish, is the only river of the pashalic; which, under any other government, would long since have been connected, by a canal running through a level plain, with the Euphrates. The country 
proluces chiefly wheat, barley, cotton, indigo, sestmun, \&.c., and, in the mountains, nulberry, olive, and fig-trees. Halep, a seat of a pasha of three tails, a Greek patrinrch, an Arneninu, a Jacobite, and a Maronite bishop, is, within the walls, about three aud a laalf miles in circumference; including the suburbs, however, about seven or eight. It contains 14,137 louses, 200,000 inlıbitants (24,000 of whom are Christians), 100 mosques, three Catholic churches, oue Protestant cluurch, a symagogue, many manufactories of silk, cotton, \&.c. It carries on cousiderable trade, forming the centre of the intercourse between the Persian gulf and the Mediterranean sea. Most of the inhabitants are Mahommedans, the rest Jews, oriental Cliristians, and Europeaus. The city lost two-thirds of its loouses, and 8000 inlıabitants, by the earthquakes in 1822 and 1823. Lon. $37^{\circ} 10^{\prime} \mathrm{F}$. ; lat. $36^{\circ} 1 \mathrm{l}^{\prime} \mathrm{N}$.

A LER, Paul, a French Jesuit, known as the author of the "Gradus ad Parnassum," which las been so long in established use in the schools of Europe. He was a native of Luxemburg, and died in 1727.

AlEs, or AlEsse, Alexander, a theologian of the sixteenth century, born at Edinburgh, 1500 . He was first cauon in the cathedral of St Andrews, but, becomiug sceptical of the Catholic creed, was obliged to retire to Germany, and eventually he became professor of divinity at Frankfort, and afterwards at Leipsic. He died in 1565. The most esteemed of his works is one entitled, "De Sancta Trinitate, cum confutatione erroris Valentini."

Alasis, the capital of the Mandubii, a Gallic people, who dwelt in what is now Burgundy, was an important fortress, the siege and taking of which was, undoubtedly, the greatest military exploit of Casar. All Gaul had risen against the Romans, even the Adui, the old allies of the oppressors; but Cresar conquered them under Vercingetorix, and besieged them in Alesia. 80,000 men were shut up in the town; Casar, with 60,000 troops, lay before it. He erected immediately a line of contravallation, extending four leagues, in order to reduce the place by famine, since its situation on a hill, 1500 feet high, and on all sides abrupt, between the rivers Ope and Operain, rendered an attack impossible. Vercingetorix, after making several furious but unsuccessful sallies, called all the Gauls to arms, and in a short time, 250,000 men appeared before the place. Ciesar had, in the meantime, completed his line of circumvallation, protecting himself against any attack from without by a breast-work, a ditch with palisadoes, and several rows of pit-falls. These defences enabled him to repel the desperate attack of 330,000 Gauls against the 60,000 Romans under his command, though he was assailed both in front and rear. The Gauls were unable to force his lines at any point. Vencingetorix, reduced to extremity by hunger, was compelled to surrender, without having carried into execution his design of murdering all the persons in the town who were unqualified for battle. But the whole tribe of the Mandubii, which had been expelled from the city by the Gauls, and were not allowed by the Romans to pass into the open country, died of famine between the two camps. Afterwards, A. rose again to a flourishing condition, until it was destroyed, in 861 , by the Normans. Vestiges of wells, aqueducts, broken tiles, coins, and the like, found in the fields where A. once stood, prove the former existence of the city. At the foot of the ancient citadel (now mount Auxois), is a village called Alise (depart. Coté d' Or), with several hundred inhabitants.

Aleotian Islands; a group belonging to Russia, and separating the sea of Kamtschatka from the .wrthern part of the Pacific ocean, extending nearly
700 uniles from $\mathrm{F} . \mathrm{tu} \mathrm{W}_{\text {. }}$ from lou. $169^{\circ}$ to $183^{\circ} \mathrm{E}$.; lat. $53^{\circ} \mathrm{N}$. They form a chain comecting $\Lambda$ sia and Americn, and inclnde what liave generally been called, in Euglish geographical works, the Fo. islands, Behring's and Copper islands, and the group formerly clivided into the Aleutian and Andrenovian isles, altogether above 100 , comprising about 10,000 square miles, all rocky, some containiug volcanoes and hot springs. The most known and largest are the Oonalashka, Behring's islaml, and Kodiak. The principal place is Alexandria, the seat of the governor, and the chief emporium. No tree grows on these islands, and no domestic animal thrives there; but they afford an abundance of valunble fir and of fish. The iuhabitants belong to the same stock with the natives of Kamtscluatka; they are a harınless race of hunters and fishers. Their numbers has been reduced by the small-pox and the venereal disense to 1000. The Russinns to whom they pay tribute, visit these inhospitable islands only for the sake of fur. The officers of the Russian-American company treat the inlabitants so cruelly, that Krusenstem made a report about it to the Russian government.Muller's Sammlung Russischer Geschichte, rol. iii. ; Coxe's Account of the Russian Discoveries; Tooke's View of the Russian Fmpire; Krusensteru's Voyage round the world; Cooke, \&c.

Alexander the Great, son of Philip of Macedon, was born in Pella, B. C. 356. His mother was Olympias, the daughter of Neoptolemus of Epirus. In his early youth, he showed the marks of a great character. When he heard of the victories of Plilip, he exclaimed, "My father will not leave any thing tor me to do." Philip confided the cliarge of his education first to Leonidas, a relation of lis mother, and to Lysimachus; afterwards to Aristotle. At a distance from the court, this great philosopher instructed him in all the branches of human knowledge, especially those necessary for a ruler, and wrote for his benefit a work on the art of government, which is unfortunately lost. As Macedon was surrounded by dangerous neighbours, Aristotie songht to cultivate in lis pupil the talents and virtues of a nilitary commander. With this view he recommended to lim the reading of the Ilind, and revised this poen himself. The copy revised by Aristotle was the farourite book of $A$., who never lay down without having read some pages in it. At the same time he former his body by gymnastic exercises. When very young, as every body knows, he tamed the horse Bucephalus, which no one else dared to mount. When he was sixteen years old, Philip, setting out on au expedition against Byzantium, delegated the government to lim during his absence. He performed prodigies of valour, two years later (338), in the lattle at Charonea, where he obtained great reputation by conquering the sacred band of the Thebans. "My son," said Philip, after the battle, embracing him, "seek another empire, for that which I shall leare you is not worthy of you." The father and son, however, quarrelled when Philip repudiated Olympias. A., who took the part of his mother, was obliged to flee to Epirus, to escape the vengeance of his father; but he soon obtained pardon, and returned. He afterwards accompanied Philip on an expedition against the Triballi, and saved his life in a battle. Philip, having been elected clief commander of the Greeks, was preparing for a war against Persia, when he was assassinated, B. C. 326. A., not yet twenty years of age, ascended the throne, punished the murderer, went into the Peloponnesus, and received, in the general assembly of the Greeks, the chief command in the war against Persia. After his return, he found the Illyri and Triballi in arms, went to meet them, forced a passage through Thrace, 
and was every where successful. But the Thebans, having heard a rumour of his deatl, had taken up arms, and the Athenians, urged by Demosthenes, were about to join them. A. liastened to prevent this junction, appeared before Thebes, and, having suminoned it in vain to surrender, took and destroyed the city. 6000 of the inliabitants were put to the sword, and 30,000 carried into captivity. The house and family of the poet Pindar alone were spared. This severity terrified all Greece. The Athenians suffered less. A. demanded only the banishiment of Charmides, who lad spoken most bitterly against him. Leaving Antipater to govern in his stead in Furope, and being confirmed as commander-in-chief of the Greek forces, in the general assembly of the Greeks, he crossed over into Asia, in the spring of 334 , with 30,000 foot and 5,000 horse. To secure the protection of Minerva, he sacrificed to her, on the fields of Ilium, crowned the tomb of Achilles, and congratulated this hero, from whom he was descended through his mother, on his good fortune in having had such a friend as Patroclus, and such a poet as Homer. When he approached the Granicus, he learned that several Persian satraps, with 20,000 foot, and as many horse, awaited him on the other side. A., without delay, led his army through the river, and obtained a complete victory; having overthrown, with his lance, Mithridates, the son-in-law of Darius, and exposed himself to every danger. The Macedonians, encouraged by his example, bore down every thing before them, and the whole army crossed the river. The Greek auxiliaries of the Persians, who were formed in phalanxes, resisted longer, and were all destroyed, except 2000 , who were taken prisoners. A. performed splendid funeral ceremonies in honour of those of his army who had fallen, and granted privileges to their fathers and children. Most of the cities of Asia Minor, even Sardis, openerl their gates to the victor. Miletus and Halicarnassus resisted longer. A. restored demccracy in all the Greek cities. In passing through Gordium, he cut the Gordian knot, and conquered Lycia, Ionia, Caria, Pamphylia, and Cappadocia. But a dangerous sickness, brought on by bathing in the Cydnus, checked his course. On this occasion he slowed the elevation of his character. He received a letter from Parmenio, saying that Philip, his physician, had been bribed by Darius to poison him. A. gave the letter to the physician, and at the same time drank the potion which he had prepared for him. Scarcely was he restored to health, when he advanced towards the defiles of Cilicia, whither Darius had imprudently betaken himself, with an immense army, instead of awaiting $h$ is adversary on the plains of Assyria. The second battle took place near Issus, between the sea and the mountains. The disorderly masses of the Persians were broken by the charge of the Macedonians, and fled in wild confusion. On the left wing, 30,000 Greeks, in the pay of the Persian king, resisted longer; but they also were obliged to yield. The treasures and family of Darius tell into the hands of the conqueror. The latter were treated most magnanimously. A. did not pursue Darius, who fled towards the Euplirates, but, in order to cut him off from the sea, turned towards Coelosyria and Phonicia. Here he received a letter from Darius, proposing peace. A. answered, that, if he would come to him, he would restore to him not only his mother, wife, and children without ransom, but also his empire. This answer produced no effect. The victory at Issus had opened the whole country to the Macedonians. A. took possession of Damascus, which contained a large portion of the royal treasures, and secured all the towns along the Mediterranean sea. Tyre, emboldened by the strength of its situation, re- sisted; but wastaken, after seven months of incredibl exertions, and destroyed. A. continued his victori. ous march through Palestine, where all the towns surrendered, except Gaza, which shared the fate of Tyre. Egypt, weary of the Persian yoke, received him as a deliverer. In order to confirm his power, he restored the former customs and religious rites, and founded Alexandria, which became one of the first cities of ancient times. Hence he went through the desert of Libya, to consult the oracle of Jupiter Ammoll. Some historians assert that the god recognised him as his son, but others reject all that las been related respecting this journey. At the return of spring, A. marched against Darius, who, in the meantime, had collected an army in Assyria, and rejected the proposals of $A$. for peace. A batthe was fought at Gaugamela, not far from Arbela, in 331. Justin estimates the forces of Darius at 500,000 men; Diodorus, Arrian, and Plutarcl at more than double that number. Notwithstanding the immense numerical superiority of his enemy, $A$. was not a moment doubtful of victory. At the head of his cavalry, he attacked the Persians, and routed them immediately; he then hastened to the aid of his left wing, which had been, in the meantime, severely pressed. His wish was to take, or kill, the king of Persia. The latter was on an elevated chariot, in the midst of his body-guards. These, when they saw how $A$. overthrew every thing, fled. Darius then mounted a horse, and fled likewise, leaving his army, baggage, and immense treasures to the victor. Babylon and Susa, where the riches of the East lay accumulated, opened their gates to A., who directed his march towards Persepolis, the capital of Persia. The only passage thither, Pylæ Persidis, was defended by 40,000 men under Ariobarzanes. A. attacked them in the rear, routed them, and entered Persepolis triumphant. From this time the glory of A. began to decline. Master of the greatest empire in the world, he became a slave to his own passions; gave himself up to arrogance and dissipation; showed himself ungrateful and cruel, and, in the arms of pleasure, shed the blood of his bravest generals. Hitherto sober and moderate, this hero, who strove to equal the gods, and called himself a god, sank to the level of vulgar men. Persepolis, the wonder of the world, he burned in a fit of intoxication. Ashamed of this act, he set out with his cavalry to pursue Darius. Learning that Bessus, satrap of Bactriana, kept the king prisoner, he hastened his march with the hope of saving him. But Bessus, when he saw himself closely pursued, caused Darius to be assassinated (B. C. 330 ), because he was an impediment to his flight. $\mathrm{A}$. belield, on the frontiers of Bactriana, a dying man, covered with wounds, lying in a chariot. It was Darius. The Macedonian hero could not restrain his tears. After interring him with all the honours usual among the Persians, he took possession of Hyrcania, the land of the Marsi, and Bactriana, and caused himself to be proclaimed king of Asia. He was forming still more gigantic plans, when a conspiracy broke out in his own camp Philotas, the son of Parmenio, was implicated. A., not satisfied with the blood of the son, caused the father also to be secretly murdered. This act of injustice excited general displeasure. At the same time, his power in Greece was threatened. Agis, king of Sparta, had collected 30,000 men to shake off the Macedonian yoke; but Antipater, at the head of a numerous army, overcame the Spartans, and dissolved the league of the Grceks. In the meantime A. marched, in the winter, through the north of Asia, as far as it was then known, checked neither by mount Caucnsus nor the Oxus, and reaclied the 
Caspian sm, hitherto muknown to the Greeks. Insatiable of glory, and thisting for conquest, lie sparml not even the hondes of the Scythians. Returning to Bactriana, he hoped to gain the affections of the Persians, by assuming their dress and manners, but this hope was not realized. The discontent of the army gave vccasion to the scene which erded in the deatli of Clitus. A., whose pride he had offended, killed hin with his own hand at a banquet. Clitus had been one of his most faithful friends and bravest generals, and $\Lambda$. was afterwards a prey to the keenest remorse. In the following year, he subdued the whole of Sogdiana. Oxyantes, one of the leaders of the enemy, had secured his family in a castle built on lofty rocks. The Macedonians stormed it. Roxana, the daughter of Oxyantes, oure of the most beautiful virgins of Asia, wns among the prisoners. A. fell in love with and married her. Upon the news of this, Oxyantes thought it best to submit, and came to Bactra, where $A$. received hin with distuction. Here a new conspiracy was discovered, at the head of which was Hermolaus, and, among the accomplices, Callisthenes. All the conspirntors were condemned to death, except Callisthenes, who was mutilated, and carried about with the army in an iron cage, until he terminated his torments by poison. A. now formed the idea of conquering ludia, the name of which was scarcely known. He passed the Indus, and formed an alliance with Taxilus, the ruler of the region beyond this river, who assisted him with troops, and 130 elephants. Conducted by Taxilus, lie marched to wands the river Hydaspes, the passage of which, Porus, another king, defended at the head of his army. A. conquered him in a bloody battle, took him prisoner, but restored him to his kingdom. He then marched victoriously through India, established Greek colonies, and built, accorling to Plutarch, serenty towns, one of which he called Bucephala, after his lorse, which had been killed on the Hydaspes. Intoricated by success, he intended to advance as far as the Ganges, when the murmurs of his army compelled him to return, in doing which he was exposed to great dangers. When he had reached the Hydaspes, he built a fleet, in which he sent a part of his army down the river, while the rest proceeded along the banks. On his march, he encountered several Indian princes, and, during the siege of a town belonging to the Mallii, was severely wounded. Ilaving recovered, he continued his march, sailed down the Indus, and thus reached the sea. Nearchus, lis admiral, sailed hence to the Persian gulf, while A. directed his march by land to Babylon. He had to wander through immense deserts, in which the greater part of his army, destitute of water and food, perished in the sand. Only the fourth part of the troops, with which he had set out, returned to Persia. On his route, he quelled several mutinies, and placed governors over various provinces. In Susa, he married two Persian princesses, and rewarded those of his Macedonians who had married Persian women, because it was his intention to unite the two nations as closely as possible. He distributed rich rewands among his troops. At Opis, on the Tigris, he declared his intention of sending the invalids home with presents. The rest of the army mutinied; but he persisted, and effected his purpose. Soon after, his favourite, Hephæstion, died. His grief was unbounded, and he buried his body with royal splendour. On his return from Fcbatana to Babylon, the magicians are said to have predicted that this city would be fatal to him. The representations of his friends induced him to despise these wrrniugs. He went to Babylon, where many foreign amlussadors waited for him, and was engag- el in extensive plans for the future, when lif be. cane suldenly sick, after a banquet, and died in a few days, 323 B. C. Such was the end of this conqueror, in his 32 d year, after a reign of twelve years and eight months. He left behind him an imnense empire, which became the scene of continual wars. He had designated no heir, and, being asked by lis friends to whoin he left the empire, answered, "To the worthiest." After many disturbances, the generals ackıowlenlged A ridous, a man of a very wenk mind, the son of Philip and the dancer Philinua, and Alexander, the posthumous son of $\Lambda$. and Roxana, as kings, and divided the provinces amoug themselves, under the name of satrapies. They appointed Perdiccas, to whom 1 . on his death-bed had given his ring, prime ininister of the infant kings. The body of $\mathrm{A}$. was interred, by Ptolemy, in Alexandria, in a golden coffiu, and divine honours were paid to him, not only in Egypt, but also ir other countries. His sarcophagus, since 1802, ha. been in the British museum. Arrian, Diodorus, Plutarch, and Curtius are the sources from whence the history of A. is drawn. (See also St Croix, Exam. critique des Historiens $d^{\prime}$ Alex., 4to, Paris, 1804.) Secunder is the oriental name of $A$.

Alkxasder Balas, king of Syria, was, accord. ing to some, the natural son of Antiochus Epiphanes, but, according to others, a young man of mean extraction at Rhodes, suborned by Heraclides, at the instigation of Ptolemy, Attalus, and Ariarathes, to personate the son of Antiochus, and under that title to lay claim to the crown of Syria, in opposition to Demetrius. In a war between the two competitors, A. was slain, B. C. 145.

Alexavder J ANsaeds, king of the Jews, suc. ceeded to the throne, B. C. 106. His fourth bro. ther endeavoured to deprive him of the crown, and was put to death. A. began his reign by leading an army against Ptolemais, but was obliged to return to defend his own dominions against Ptolemy Iathyrus, and was defeated on the banks of the Jordan. He subsequently conquered Gaza, made war on the Arabians, and was engaged in quarrels with his own subjects. After reducing them to order, he extended his conquest through Syria, Idumæa, Arabia, and Phoenicia. On returning to Jerusalem, he devoted himself to drinking and debauchery, and died, B. C. 79 .

Alexander Severds, a Roman emperor, was born at Acre, in Phonicia, in the year 205. He was the son of Genesius Marcianus and of Mammaa, niece to the emperor Severus. He was admirably educated by his mother, and was adopted and made Casar by his cousin Heliogabalus, then but a few years older than himself, at the prudent instigation of their common grandmother, Mrasa. That contemptible emperor, howerer, soon grew jealous of his cousin, and would have destroyed him, but for the interference of the prætorian guards, who soon after put Heliogabalus himself to death, and raised Alexander to the imperial dignity in his 17 th year. Alexander adopted the noble model of Trajan and the Antonines; and the mode in which he administered the affairs of the empire, and otherwise occupied himself in poetry, philosophy, and literature, is eloquently described by Gibbon. On the whole, he gorerned ably both in peace and war; but, whatever he might owe to the good education given him by his mother, he allowed her a degree of influence in the government, which threw a cloud over the latter part of his reign, as is usually the case with the indirect exercise of female political influence. A. behaved with great magnanimity in one of the frequent insurrections of the protorian guards; but, either from fear or necessity, he allowed many of their se- 
ditious muinies to pass unpunished, although, in one of then, they murdered their prefect, the learned lawyer Ulpian, and, in another, compelled Dion Cassius, the historian, then consul, to retire into Bithynia. At length, undertaking an expedition into Gaul, to repress an incursion of the Germans, he was murdered, with his mother, in an insurrection of his Gallio troops, headed by the brutal and gigantic 'Thracian, Maximin, who took advantage of their discontent at the emperor's attempts to restore discipline. This event happened in the year 235, after it reign of twelve years. A. was favourable to Christianity, following the predilections of his nother, Mammæa ; and he is said to have placed the statue of Jeisus Christ in his private temple, in company with those of Orpheus and Apollonius Tyancus. In return, the Christian writers all speak very favourably of him. Herodian, on the contrary, accuses him of great timidity, weakness, and undue subjection to his mother; but exhibits a disposition to detract from his good character on all occasions, in a way that renders his cvidence very.suspicious. He was thrice married, but left no children. Ailius Lampridius tells the following singular story of A. :-Ovinius Camillus, a Roman senator, conspired against him. A., learning the fact, sent for Ovinius, thanked him for his willingness to relieve him from the burden of government, and then proclaimed him his colleague. A. now gave him so much to do, that he narl hardly time to breathe, and, on the breaking out of a war with Artaxerxes, the fatigues to which A. exposed himself, and which Ovinius was compelled to share, so overwhelmed the latter, that, at last, he besought $A$. to permit him to return to a private station. He was accordingly allowed to resign the impcrial dignity.

ALEXANDER; the name of several popes.-Alexander I. reigned from 109 to 119 , and is known only as having introduced the use of holy water.-A. II., Anselm of Milan, previously bishop of Lucca, was, in 1061, raised to the papal throne by the party of Hildebrand, afterward Gregory VII., while the adherents of the German king, and of the nobility of Rome, chose Honorius II. at Basle. This antipope expelled A. from Rome, but Hildebrand, then the soul of the papal government supported him ; a synod at Cologne acknowledged him in 1062, and the Romans themselves revolted, in 1063, from Honorins. 'Thus A. attained quiet possession of 'Rome, and of the papal powcr, which, however, Hildebrand administered in his name. The papal bulls, therefore, against lay investiture, against the marriage of priests, and the divorce of Henry IV., and the haughty summons of this king to appear before the papal chair, must be ascribed to the influence of Hildebrand, who used the weak A. II. as his tool. A. died in 1073. (See Gregory VII.)-A. III. reigned from 1159 to 1181 , and struggled with various fortune, but undaunted courage, against the party of the emperor Frederick I., and the antipopes Victor III., Paschal III., and Calixtus III., who rose, one after the other, against him. He was obliged to flee to France in 1161 , where he lived in Sens, until the dissatistaction of the Lombards with the government of Fredcrick, the assistance of the German ecclcsiastical princes, and the desire of the Romans, opened a way for his rcturn, in 1165 . He now strengthened his power by a league with the cities of Lombardy, but was obliged to retire, in 1167 , before the imperial army, and resided in Benercnto, Anagni, and Venice, until after the victory of the Lombards over the emperor at Legnano, followed by the peace of Venice (so humiliating to the pride of the emperor Frederick, who was compelled to kiss the feet and hold the stirrup of A., in 1177), the abdication of the third antipope, and the return of the victor to Rome. A. humbled, also, Henry II., king of England, who had exposed himself to the papal vengeance by the assassination of Becket. The terms on which the German and English sovereigus were restored to ta. vour, were such as to increase the power of the pope in both countries. He placed Alfonso II. on the throne of Portugal, and laid Scotland under an in terdict on account of the disobedience of the king. 'The rest of his labours to augment the papal power, and his persevering efforts, in the spirit of Gregory VII., till the period of his death, are related in the article Popery.-A. IV., count of Segni and bishop of Ostia, ascended the papal throne in 1254, at a very unfavourable time. Conquered by Manfred of Sicily, implicated in the quarrels of the Guelphs and Glibellines, despised in Italy, 'this pope, with good intentions, and a peaceable disposition, was not able to prevent, either by his prayers or his excommunications (which were only laughed at), the disturbances prevailing over the whole country. At lis death, in 1261 , he left the papal power in a state of great weakness. - A. V., a Greek from Candia, under the name of Peter Philargi, a mendicant friar, rose to the dignity of cardinal, and was chosen pope in 1409 , at the same time with the antipopes Gregory XII. and Benedict XIII. He was considered by the greater part of Christendom legitimate pope, but carried his prodigality and luxury in Bologna, where he constantly resided, to an extent injurious to the interests of the church. At the council of Pisa, he promised to reform the abuses prevailing in the church, but took no steps towards it. While occupied in the condemnation of the doctrines of Wickliffe, and in preparations for the trial of the Bohemian reformer, Huss, he died in 1410 , probably by poison.-A. VI. See the following article.-A. VII., who was employed, when cardinal Chigi, as papal nuncio, in negotiations of peace at Munster and Osnabruck, and was revercd on account of his pious zeal for the church and holy life, laid aside the mask of sanctity after his elevation to the papal throne, April 8, 1655, and gave himself openly up to luxury and voluptuousness. He surrounded himself with show and splendour, and appeared in the character of an intriguing politician. For an account of his condemnation of the five points of Jansen's Augustinus, and the quarrels in which he was consequently involved in France, see.Jansen. He quarrelled not only with the Sorbonne, and the parliament, but even witl l king J,ouis XIV.; so that the latter declared war against him, took Avignon and Venaissin, and forced him, in 1663, to make a disgraceful peace at Pisa. His improvements in the city of Rome, his attempts at poetry, and encouragement of learued men, could not indemnify the Roman court for the loss of authority in France, and he died without glory, May 22, 1667.-A. VIII., an Ottoboni from Venice, became pope in 1689 . By artful negotiations, hc induced Louis XIV. tu deliver up Avignon and Venaissin, and to renounce the privileges belonging to the quarter of his ambassador in Rome. Ie supplied the Venetians with men, money, and ships to carry on a war against the 'Turks.' Less intent upon the weal of the church than on euriching his own family, he delayed the condemnation of the four articles of the Gallican church, in order to gain advantages for his relatious. He was hostile towards the Jesuits, and condemned their doctrine of the philosophical sin; at the same time, however, thirty-one theses of the Jansenists. (See Jansen.) The library of the Vatican is indebted to him for the purchase of the excellent library of the qucen Christina of Sweden. He died in 1691, eightity-one years old. 
Alex.sider V1., a pope uotorious for his profligacy, wns born at Valeucia, in Spenin, in 1430, and ascended the papal throne in 1492. His name was loadrigo Lenzuoli; but he took the ancient aud th renowned name of lis mother's family, Borgia. In lis youth he was noted for dissipation, thongh not descitute of talent. He had five children, by a woman famous for her beauty, Rosa Vanozza. Cresar Borgia and Lucretin are the most known; the latter was fonr times married, and was suspected of incestuous intercourse with her father and brothers. $\Lambda$. was made a cardinal by pope Calixtus III., his uncle. By bribing the cardinals Sforza, Riario, and Cibo, he prepared his way to the papal throne, after the denth of Innocent VIII. The long residence of the popes in Avignon, at a distance from their dominions in Italy, lad diminished both their authority and revenues. To make up for this loss, A. VI. endearoured to impair the power of the Italian princes, and seize upon their possessions, for the benefit of his own family. To effect this end, he employed the most execrable means. His policy, foreign as well as domestic, was faithless and base, particularly in the case of France, whose king, Charles VIII., was lis enemy. He understood how to extract immense sums of money from all Christian countries. He decided the dispute between the kings of Portugal and Castile concerning $\Lambda$ merica, dividing their conquests, in 1492 , by a line running from pole to pole, 370 miles west of the Azores. A. died, 74 years old, in 1503. Machiavelli abhorred this detestable miscreant, and says of him,

\section{Mald valenza, e per aver riposo Portato fu fra lanime beate \\ Lo spirito d' Alesaandro glorioso; \\ Del qual seguiro le sante pedate \\ Tre sue familiari e care ancelle, \\ Lussuria, simonia crudeltade.}

ALECANDER, Three kings of Scotland were so named.-A. I., son of Malcolm III., succeeded his brother Edgar in 1107. He was called the Fierce, from his vigour and impetuosity. A conspiracy was formed against his life, and the traitors obtained admission into his bed-chamber at night. A., having killed six of them, made his escape. He died in the 17 th sear of his reign.-A. II. succeeded his father, William the Lion, 1214, in his 16th year, and died in his 51 st year. - His son, A. III., succeeded him in 1249. He married Margaret, daughter of Henry III. of England. In 1263, he defeated, at Largs, Haquin, or Haco, king of Norway, who had landed an army in his kingdom. He was killed by his horse falling down a precipice between Bruntisland and Kinghorn. He was a prince of an excellent character, introduced many good regulations of government, and greatis contributed to diminish the burdens of the feudal system, and to restrain the license and oppressions of the nobility. His death makes an era in Scottish history.

Alexander ab Alexandro, a Neapolitan lawyer of the sixteenth century, who distinguished himself in polite literature. An edition of his principal work, "Dies Geniales," was published in 1587, with notes by his commentator Tiraqueau.

AlEXANDER, John, a Scottish painter of some eminence during the earlier half of the eighteenth century. He studied his art chiefly at Florence, and on returning to his native country he resided at Gordon castle, and painted sereral subjects, consisting chiefly of poetical, allegorical, and ornamental pieces. He also painted portraits and historical landscapes. Many of the portraits of Queen Mary are by him.

Alexander Newskol, a Russian hero and saint, the son of the grand-duke Jaroslav, was born in
1219. In onter to defend the emuire, which was attackel on all sides, but especially loy the Mongols, Jaroslar quitted Norgorod, and left the charge of the government to his sons, Fedor and Alexanier. the former of whom soon afterwards died. A. repulsed the assailants. Russia, nevertheless, came under the Mongolian dominion, in 1238. A., when prince of Norgorod, defended the western frontier against the Ianes, Swedes, and knights of the Teutonic order. He gained, in 1240, a splendid victory, on the Neva, over the Swedes, and thence received his surnane. He overcane, in 1242 , the knights of the swond, on the ice of lake Peipus, After the death of his father, in $1245, \mathrm{~A}$. became grand-duke of Wladimir. He died in 1263. The gratitude of his countrymen has commemornted the liero in popular songs, and raised him to the dignity of a saint. Peter the Great honoured his memory by the erection of a splendid monastery in Peters burg, on the spot where $A$. gained his victory, and by establishing the order of Alexander Newskoi.

Alexander, Noel, a French dominican of the 17 th century, who died in 1724 . He wrote various works, the most important of which is an Ecclesiastical History of the Bible, in Latin, 8 vols. folio.

Alexander I., Padlowitsch (that is, the son of Paul), emperor and autocrat of all the Russias, and king of Poland, was born Dec. 23, 1777 ; ascended the throne March 24, 1801; was crowned 27th Sept. of the same year, in Moscow; married, 9 th Oct., 1793, Elizabeth (previously called Louisn Maria Augusta), third daughter of Charles Louis, hereditary prince of Baden; and died 1st Dec., 1825. A. was one of the most important men of modern times. He was a great benefactor of his own country, and did some good and a great deal of evil to Europe. Nature had endowed him with great talents, which were judiciously cultivated by his mother and his instructors. He recognised the spirit of the age; frequently acted in accordance with liberal principles; had sense enough to know that a monarch, to play an important part, must have respect to the wishes of the people, whatever his ultimate object may be; loved justice, if it dul not militate with his love of power, which was indeed of a higher order than that of a common tyrant; and sought to rnake himself, like Napoleon, master of Europe, though with different means. In many respects he resembled the great pope Gregory VII. He was; whether from policy or convietion of its necessity, in a religious point of view, the principal contriver and the chief support of the "Holy Alliance" (q. v.), -a league which history will denounce as the origin of infinite evil. His father did not. take any part in his education, which was directed by the empress Catharine II. and colonel Laharpe, (q. v.) His mother, Maria, the daughter of the duke Eugene of Wirtemberg, always possessed his love and confidence, and retained a great infuence over him throughout his reign. She died in the year 1828. Laharpe educated him in the principles of an enlightened age. His first gorernor, count Nich. Soltikoff, received orders from Catharine not to give the young prince any instructions in poetry and music, as requiring ton much time for the attainment of proficiency. Professor Kraft instructed him in natural philosophy, and Pallas, a short time, in botany.- He took part, it is probable, in the conspiracy against his father, though it is not likely that he had the most distant thought against his life. He wished to save himself and many nobles of the empire from the mad persecution of the emperor, and nothing short of dethroning him could afford them safety. He is often said, therefore, to have acted in self-defence.-The history of his government may 
be divided into three periods: The first was peaceful and entirely devoted to the execution of the schemes of Peter the Great and Catharine 1I., respecting the internal administration. The second, extending from 1805 to 1814 , was a time of war with France, Sweden, the Porte, and Persia, and developed the resources and the national feeling of the people. In the third period, he used the experience acquired in the two preceding, to carry into effect the declaration of Peter the Great, made 100 years before, in 1714 , after a victory over the Swedish fleet, near the Aland islands:-" Nature has but one Russia, and it shall have no rival." $-A$. was distinguished for moderation, activity, and attention to business, personally superintending the multiplied concerns of his vast empire, while his simple and amiable manners gairied him the love and confidence of his subjects. He understood and was zealous in promoting the welfare of his people. Greal attention was paid, during his reign, to education and intellectual culture, and many improvements were introduced into the internal administration of the empire; e. $g$. the establishment of the senate by the ukase of 1802, of the imperial council and the ministry of eight divisions by the ukase of 1810 , of the provincial administration in the governments, \&c. The shackles which hung on the industry of the nation were removed, and its commerce. increased. $-A$. has likewise advanced the military establislıments of Russia to a high degree of perfection; he has developed in lis people the sentiments of union, courage, and patriotism; and, lastly, he has raised Russia to a high rank in the political system of Europe, and has made its importance felt even in Asia. It must be also acknowledged that, during lis reign, taste and intelligence began to be diffused among the higher classes, as well as eminent and even liberal statesmen to be formed, though it is in this, as in so many other things, difficult to distinguish what is owing to the prince, and what to the spirit of the age.-Among the most intimate associates of the emperor were general Jermoloff, afterwards Wolclionsky, Araktschejeff, and Diebitsch. In the earlier part of his reign, some Greeks stood high in his favour, as did the French ambassador, count Caulaincourt, from 1807 to 1812.-Among the merits of $A$. are to be reckoned his exertions for the improvement of the Sclavonian nations, and the cultivation of their language and literature. He founded or new-modelled seven universities, at Dorpat, Kazan, Charkow, Moscow, Wilna, Warsaw, and St Petersburg; 204 academies, many seminaries for the education of instructors, and above 2000 common scliools, partly after the system of Lancaster. He did mucl for the distribution of the Bible, by the aid which he rendered to the Bible societies (abolished in 1826). He granted important privileges, by a ukase of 1817 , to Jews beconning Christians. He appropriated large sums for the printing of important works, as the Voyage of Krusenstern, the History of Russia by Karamsin, \&c. He esteemed and rewarded literary merit, both in and out of Russia. He purchased rare and valuable collections. In 1818, he invited two orientalists, Demange and Cliarmoy, from Paris to Petersburg, to advance the study of the Arabic, Armenian, Persian, and Turkish languages. He attended particularly to the education of young men of talent, whom he sent to travel through foreign countries. He endeavoured, at the same time, by moderate measures, to relieve his subjects from the tyranny of their lords, the nobles, the boyars, starosts, \&c. Servitude was abolished in 1816, in Esthonia, Livonia, and Courland; and A. declared, that he would no longer transfer with the crown-lands the boors who culti- vated them. He forbade the advertising of human beings for sale, and gave leave to a number of boors, a part of the bondmen of the late chancellor Romanzoff, to ransom themselves from their master. He endeavoured, with much earnestness, to give to his people a good system of law, but the civil code of Russia still requires many improvements. The law. school, opened in 1807, ceased in 1810.-The custom of slitting the nose and branding, litherto connected with whipping with the knout, was abolished by $A$. in 1817. He likewise abolished, in 1801, the secret court, as it was called, before which politic : criminals, chiefly, were brought, and compelled, by liunger and thirst (not, however, by instruments of torture), to confess. He cliecked the abuse of power in the hands of governors, by preventive laws. The privilege of the nobles, that their estates could not be confiscated as a punishment for their crimes, was extended by $A$. to all his subjects. He also rendered efficient aid to manufactures and com. merce in his empire, by the introduction of a better tariff, the improvement of the finances and currency of the country, after the establishment of a sinking fund; the erection of the bank of the imperial chamber, May 19, 1817 ; by providing continually for the construction of roads and canals; by making Odessa a free port, and granting it other privileges, in 1817. The condition of manufactures in Russia has greatly improved since 1804, when it became known from the report of the minister of the interior. The greatest progress has been made in manufactures in wool. The whole foreign policy of Russia; the voyages round the world, under the patronage of her government; the embassy to Persia, in 1817 , to which was attached a Frenchman, Gardanne, who was acquainted with all the plans of Napoleon respecting India and Persia; the mission to Cochin China and Khiwa; the relations of Russia with the United States, Brazil, and Spain; the treaties of commerce and navigation with the Porte; the set. tlements on the western coast of North America, all prove the enlightened commercial policy. of the Russian cabinet. The travels of $\mathrm{A}$. in foreign countries, even his short stay in England, his intercourse with well-informed and seusible men, but principally, his frequent journeys through the provinces of his empire, afforded the materials of lis numerous projects for the benefit of his country. On this his attention was continually fixed.-The peace of Tilsit, in 1807, makes an epoch in the Russian military system. It not only opened the way to the conquest of Finland, in 1809, and of two of the moutlis of the Danube, in 1812, but afforded A. time to remove the defects of the military system hitherto in use. The armies of Russia, during the war with Napoleon, were remarkable for their equipment and discipline. The active interest which A. took in the proper ordering of all the branches of the administration, is the reason wly the nation was attaclied to him with full confidence, which he experienced in time of danger. A. never showed a timid, unenterprising spirit. $H$ is decision frustrated the plans of Napoleon at Moscow. He gave his word to his people, that he would never negoliato with Napoleon, as long as an armed eneny was in the country. The activity which prevailed in the military department of the Russian administration is proved by the army which appeared, in 1813, in Germany, and that which was. kept ready, in 1815 , to marclı against France, conprising $\$ 00,000$ me'll and 2,000 pieces of cannon. The peaceful character of $A$.'s policy is remarkable. His personal friendship for the king of Prussia, Frederick IVilliam III. which was confirmed at the tomb of liederick 1I., in 1805 , led to important consequences. 'The queen. 
Louis?, was the living tie of this union. Admimtion for the dazzling qualities of Napoleon drew him over to his side. He believed, too, that he might, in comexion with the emperor of France, decide the fate of Europe. This was the purpose of his farmous mecting with Napoleon at Erfurt, in Sept., 1808. But when he saw that the ambitious conqueror wished to involve lim in political contradictions, and prescribe laws to him injurious to the welfare of his empire, he resolutely maintained his independence. He succeeded, at an interview with the prince-royal of Sweden, at Alx), Aug., 1812, in iorming an allinnce with that country, after laving induced the Porte, in May of the same year, to conclude the peace of Bucharest. After 1812, a kind of religions chancter appears in the policy of $A$., and he gave limself up, more and more, to religions influence. This character is remarkably munifest in the proclamation which he addressed from Warsaw, on the loth (22d) Feb. 1813, to the nations of Europe, and the proclamation of Kalitz, 25th March, 1813, directed to the Germans, in which lie promised a great improvement in their condition, by meaus of a proper constitution, the object of which sliould lee, to promote their liberty, security, and prosperity. The inemorable manifesto of 27 th Jan. 1816, contained an exposition of the political principles of the emperor. In the war of 18t3-14, A. exposed hinself to danger, in order to inflame the courage of his troops. He undoubtedly exercised a great influence upon the course of the war in France. \& His openness gained the confidence of the French, and it is said that he was secretly applied to from Paris. He also principally directed the march of Schwartzenberg, on the 29th March, 1814, to this capital, which put a glorious termination to the war. The magnanimity with which he treated Paris and all the French, the strict discipline of lis troops, and the assurances which the allies, at his instance, tendered to the nation, facilitated the settlement of peace; and it is asserted that he acted from the belief that he was complying with the wishes of the French, and not from adherence to the principles of legitimacy, in recalling the Bourbons. He did not treat the conquered and dethroned emperor meanly, but respected in him the former sovereign and distributor of crowns, regandless of his birth. He called upon the empress Josephine, and dined with her at Malmaison; he interceded in favour of the prince Eugene Beauharnois; he visited Ney. The enthusiasm of the Parisians for him was unlimited. Juue 1, 1814, he went to England, whcre he was joyfully received. Several things, however, seem to have made an unfavourable impression upon him. He was not at ease among free Britons. He rose from his seat, however, at tlie banquet in Guildhall, in honour of the national song, Rule Britannia. He left Fingland 2sth June, and reached Petersburg 25th Jily, where he declined the name of the Blessed, offered to lim by the senate. A later nkase, of 27 th Nov., 1817, forbade the praises which the clergy were accustomed to bestow on him from the pulpit. Itis presence in Vienna, during the congress, liad a great infuence upon the policy of Furope, occasioned the admission of some liberal riews into the acts of the assembly, and arded the kingdom of Poland to the gigantic power of Russia. The draft of the Polish constitution, prepared at the instance of A., was the first symptom of a disposition in the Furopean rulers to perform the promises made to their subjects during the wars with Napoleon. A. again visited Paris, July, 1815, and from that period the great infurnce of Russia upon the French cabinet, in opposition to the infuence of England, vas apparnt; especially when Richelieu, who liad formerly been in the Russian service, was placed at the lueal of the ministry of Louis XVIIf. In Spain, also, the same influence manifested itself. Even the conrt of Rio Janciro showed a derire ct allying itself with Russia; ant the kingdon of the Netherlands, as well as Prussia, Wirtemlerg, and other states, entered into a closer union with the Russian court. A., together with the powers that liad concluded the treaty of Cliammont, took an active part in the general concerns of Europe ; for instance, the revolt of the Spanish colonies, and the dispute: of Spain with Portugal, on account of Monte Video. He took measures against the piracy of the African states. Very soon, nothing occurred, of impertance to the political affairs of the Furopean continent, in which this ambitious monarch did not appear as leader, mediator, or partaker. From the formation of the holy alliance (q. v.), in I'aris, 26th S.pt., 1815 , to his death, $A$. was actively engaged in jolitics, and kept his emissaries all over Europte, who reported to him every important occurrence. Ainoug these was Kotzebue, the German anthor, who was assassinated by the student Sand. The nemoir, directed to all the Russian ambassators, cuncerning the affairs of Spain, the answer of the Russian citbinet to the Spanish minister, the chevalier Zea Bermudez, and the declaration of the congress of Aix-la-Chapelle, 15th Nov., 1818, are interesting documents in the listory of A. He took part, in $18 \% 0$, in the congresses held at Troppau aul Iaybach, to settle the affairs of Italy, and ordercd his army to advance towards this country, to suppress the revolt of the Carbonari. As its presence was found to be unnecessary, it returned to Russia, when the affairs of Greece (q. v.) occupied the attention of the Russian cabinet, in 1821. A. publicly expressed his disapprobation of the enterprise of prince $\mathrm{Al}$ exander Y psilanti (q. v.), but interceded, however. with the Porte, for the cause of lummanity and Cliristianity. (See Stroganoff.) It is possible, that, from a sincere love of peace, he suffered the best opportumity to escape of liberating Greece, and increasing lis empire. His letter to the viceroy of Poland, prince Zajonczeck [Aix-la-Chapelle, 7 (l(s) Oct., I818], is a proof that lie was not a stranger to liberal sentiments. He spoke in the same spirit, March 5, 1819, to a deputation of the Livonian 110 bility, requesting lis ratification of the new constitntion, which had been made for the benefit of the $\mathrm{Li}$ vonian peasantry, when he used the memorable words, - "You liave acted in the spirit of our age, in which liberal ideas afford the true basis of the liappiness of nations." His remark to madame de Stucl, several years before, was characteristic: "Yon will be offended with the sight of servitude in this land. It is not my fault; I lave set the example of cuan. cipation, but I cannot employ force; I must respect the rights of others as much as if they were protected by a constitution, which, unlappily, does not exist.' Madame de Stael answered- "Sire, votre caractive est une constitution," (Sire, your character is a constitution). He lad, at the beginning of his reign, abolished the secret police of state and thie censor ship of books, (the latter of which, however, lie intro. duced again at a later period), and declared, A pril 7, 1801 " "I acknowledge no power to be lawfill whicl does not emanate from the laws." In the same spirit he banished the Jesuits, Ist Jan., 1816, frum Petersburg and Moscow, and at last, 25th March, $18: 0$, from the empire, because they dared to interfere with the affairs of the government, aud disturl the peace of families. Ile had prohibitel prosely. tism, and promoted the instruction of the Je'ws. A. developed, in the same spirit, the internal resources and the exterral power of his immense cnpire. The 
ardition of Georgia, Bialystock, Finland, Warsaw, Schirvan, and Bessarabia, has rendered its frontiers almost every where impenetrable, and increased the number of its inhabitants from thirty-six millions to more than forty-three, for the most part Europeans. The speedy rebuilding of Moscow, the progress of cultivation in Siberia and the Crimea, the number of inhabitants in the governments of Tobolsk, Tomsk, and Irkutsk increased by 800,000 , and similar proofs of the advancing prosperity of the empire, have immortalized the reign of $\mathbf{A}$. Whether the gigantic plan of uniting the supporters of the political power of Russia, the classes of peasants and soldiers, will prove to be good, experience must decide. (See Military Colonies of Russia.) A., by the edict of 28 th Dec., 1818, granted to all peasants in his empire the right of establishing manufactories, - a right confined, hitherto, to the nobility and the merchants of the first and second classes. A better disposition of the national debt, and a sinking fund, permitted an alleviation of taxes. A ukase of Ist Jan., 1810, therefore, abolished the tax upon income from landed property, establislied 11th Feb., 1812, but the expenses attending the support of a numerous army prevented any farther remission.-The population of soutliern Russia has been greatly increased by the admission of German emigrants; and the same plan was extendec to Poland, where, by a decree of $A$., Warsaw, 10th Aug., 1816, the new settlers received deserted loouses and lands, belonging to the national domains, or assistance of some other kind. Schools and universities have been established; the system of Bell and Lancaster introduced; the ecclesiastical affairs of the Protestants and the Catholics arranged ; the conversion of the Jews, or Christian Israelites, as they are called, encouraged; the activity of all public institutions for instruction increased, and the seventeen scientific institutions in Petersburg and Moscow much improved. The expulsion of the Jesuits, indeed, disturbed a little the relations of the emperor with the see of Rome, but satisfactory explanations were made by $A$. to the pope at Laybach. Lastly, the emperor nominated a bishop, and established a general consistory for the Lutheran church throughout the empire, in 1820 , which was to maintain, in their purity, the doctrines of the Protestant church. A. showed great respect for all Christian sects, and protected them equally. His endearours to clevate the condition of the boors, and the general tendency of his policy to introduce the principles and manners of western Europe, offended the old Moscavite nobility, and, towards the conclusion of his reign, in spite of the vigilance of the police, a fearful and widely spread conspiracy was formed against him, the discovery and punishment of which was reserved for his successor. Perhaps A. was aware of the existence of treasonable projects when he followed his sick wife to the Crimea. I is intention may have been to clioose a place of retirement from the cares of govermment; but he fell sick at Taganrock (q. v.) of a bilious fever, and died, Ist Dec., 1825, in the arins of his wife. The news of his death had scarcely reached Petersburg, 8th Dec., O.S., when his eldest brother, Constantine, then in Warsaw, was proclaimed emperor; and all the civil officers and the guards took the oath of allegiance, 9tl Dec. O.S. But the grand-duke declined accepting the crown, having resigned his right of succession, during the life-time of A. in a letter addressed to the emperor, Peterslurg, 14 th Jun., 1822, to which an answer was sent, Feh. 2,1822 , by $A$. expressing his approbation, and that of the empress mother. Before the arrival at Petersburg of the letter of Constantine, dated Nov. 26 th, O. S. in which he announced to his mother and brother, the grand duke Nicholas, tliat he recognised the latter as emperor, the senate had upened the testament of $A$., and found in it the document containing the resignation of Constantine, together with a manifesto of the emperor (dated Zarskojeselo, 16th Aug., 1823), declaring his second brother, Nicholas, his successor. This prince, therefore, ascended the throne, made known these documents in his proclamation of the 12th Dec., O.S. 1825, and declared, at the same time, that the day of the deatlı of $A$. was the beginning of his reign (1st Dec., N.S., 19th Nov., U.S.) Then the oath of allegiance to the emperor Nicholas I. was taken, 13th Dec., O.S. 25th, N.S., in Petersburg. The death of $A$. wats a fortunate event for Europe ; for the influence of Russia was growing continually stronger in all the cabinets of the European continent, and even England could not keep entirely exempt from it. No other empire has united, on so great a scale, the power of masses, yet rude and vigorous, with experience and the advantages of culture, $-\mathrm{a}$ union the mure dangerous, as it was under the control of one absolute master. With A., moreover, perished the principal support of the holy alliance,-a sufficient reason for Europe to rejoice at his decease. Russia, however, laments in him a great benefactor. He had the good fortune to ascend the throne at a time when the empire was prepared for the greatest improvements, and his ambition was of a kind to be gratified by promoting the welfare of his people.

Alexander Trallanus, a physician of Tralles, in Lydia, in the 6th century. He is esteemed as the best Grecian physician after Hippocrates. His works have been published in the original Greek and Latin. Haller gave a Latin version of them in 1772 .

Alexander, William, earl of Stirling, an eminent Scottish statesman and poet, in the reigns of James I. and Charles I. He was born about 1580 and early in life commenced to celebrate an unsuccessful passion, by composing a century of sonnets. These were published in London in 1604, under the title of "Aurora, containing the first Fancies of the Author's youth." He followed his monarch, James I., to the English court; and in 1607 published some dramas, entitled "Monarchick Tragedies," which he dedicated to the king. He had previously published a tragedy at Edinburgh, founded on the story of Darius. In 1613, he became gentleman usher to prince Charles, and receiver the honour of knight'lood, his origin being merely that of an untitled landed proprietor. In 1614, he published at Edinburgh his largest work, entitled, "Doomsday or the Great Day of Judgment," which has been several times reprinted. In 1621 , the king made a grant to him of Nova Scotia, with a view to colonization; and he was afterwards appointed lordlieutenant of that colony, and founded the order of Nova Scotia baronets; but the speculation failed. Sir William was subsequently made secretary of state for Scotland (salary $£ 100$ per annum), and created viscount Canada and earl of Stirling. He died in $164 n$, leaving three sons and two dainghters, whnse posterity was supposed to have been extinct, until a claimant appeared in 1830 , as descended from oue of the younger branches of the family, and who has assumed the titles of Stirling and Dovon. From the following article the reader will see that a supposed descendent distinguished himself in America during the last century. The poems of the earl of Stirling form one volume folio, and are chicfly cliaracterized by a pervading moral and religious spirit.

ALExaNDER, William, a mojor-general in the service of the United States during the revolutionary war, was born in the city of New York, 'nt passed a portion of his life in New Jersey. He was gene- 
rully styled, through courtesy, lord Stirling, in consequence of being considered by many as the rightfisl heir to the ticle and estates of an earldom in Scotland, from which country his father came, though the government refused to acknowledge the son's claim, when he repaired to Great Britain in pursuit of this inheritance. He was earty remarkable for his fondness for mathenatics and astronomy, in which sciences he made considerable progress. - Thronghout the revolution, he acted an important part, and distinguished himself particularly in the battles of Long Island, Germantown, and Monmouth. In the first, he was taken prisoner, after having, by a bold attack upon a corps commanded by Cornwallis, effected the escape of a large part of his detacliment. In the second, his division, with the brigades of generals Nash and Maxwell, formed the corps de reserve; and, in the last, he commanded the left wing of the American army. He was always warmly attached to general Washington, and the cause which he liad espoused. He died at Albany, Jan. 15, 1783, aged fifty-seven years, leaving behind him the reputation of a brave, discerning, and intrepid officer, and an honest and learned man.

Alexandria (in Turkish, Scanderia); the capital of Lower Egypt, and the ancient residence of the Ptolemies, built 332 B. C., by Alexander the Great, who destined it to be the capital of his empire, and the centre of the commerce of the world. Its natural situation is strong, and it has five harbours. The Ptolemies, especially P. Soter, or Lagus, and $P$. Philadelphus, improved it much, and made it the sent of learning. (See Alexandrian School.)-The first inhabitants of Alexandria were a mixture of Egyptians and Greeks, to whom must be added numerous colonies of Jews, transplanted thither in 336, 320 and 312 B. C., to increase the population of the city and country, who, becoming familiar with the Greek language and learning, were called Hellenists. (q. v.) It was they who made the well-known Greek translation of the Old Testament, under the name of the Septuaginta. (q. v.)-The most beautiful part of the city, near the great harbour, where stood the royal palaces, magnificently built, was called Briction. There was the large and splendid edifice, belonging to the academy and museum, where the greater portion of the royal library ( 400,000 volumes) was placed; the rest, amounting to 300,000 , was in the Serapion, the temple of Jupiter Serapis. The larger portion was burned during the siege of Alexandria by. Julius Cæsar, but was afterwards replaced by the library of Pergamus, which Antony presented to Cleopatra. The museum, where nuany scholars lived and were supported, eat ingether, studied and instructed others, remained unhurt till the reign of Aurelian, when it was destroyed in a period of civil commotion. The library in the Serapion was preserved to the time of Theodosius the Great. Ife caused all the heathen temples, throughout the Roman empire to be destroyed; and even the splendid temple of Jupiter Serapis was not sparex. A crowd of fanatic Christians, headed by their arch bishop, Theodosius, stormed and destroyed it. At that time, the library, it is said, was partly burnel, partly dispersed; and the historian Orosius, towards the close of the 4 th century, saw only the "m pty shelves. Christian barbarians, therefore, and not Arabs under Omar, as is usually asserted, were the cause of this irreparable loss to science. The Alexandrian library, called, by Livy, Elegantice regum eurceque egregium opus, embraced the whole Greek and Latin literature, of which we possess but single fragments. - In the division of the Roman dominions, Alexandria, with the rest of Egypt, was compreheruled in the Eastern Empire. The Arabs pos- sessed themselves of it in 640 ; the caliph Motawa$\mathrm{kel}$, in 845 , restored the library and acadeiny ; but the Turks took the city in 868 , and it declined nore and more, retaining, however, a flourishing com merce, until the Portuguese, at the end of the 15th century, discovered a way to the Fast Indies by sea -The modern $\Lambda$., situated N. lat. 310 11', F. lon. $30^{\circ} 16^{\prime}$, does not occupy the place of the old town, of which nothing remains except a portico in the vicinity of the gite leading to Irosetta, the southwestern amphitheatre, the obelisk, or needle of Cleopatra (presented to the king of England by the pacha-but a mass of 400,000 posunds is too heavy to be transported), and Pompey's pillar, eighty-eiglit feet six inches high, which, according to an English traveller (Memoirs rclating to Europe and Asiatic Turkey, by Robert Walpole, 1817), was erected by a governor of Egspt, named Pompey, in lionour of the emperor Diocletian. The equestrinn statue on the top is no longer standing. - The town las now two citadels and harbours, of which the western, which is the best, is closed against Christian ships. Before both harbours are the peniusula Farillon and the island Pharos, with the ruins of the lighthouse of Ptolemy. (See Pharos.)-The population, formerly amounting to 300,000 , is now 12,600 ; the houses, 3132. A. is the seat of a patriarch. The canal of Ramanieh, from Cairo to Alexandria, forty miles, was restored by the viceroy, Mohammed Ali Pacha, and first navigated 26th Jan., 1820. In consequence of this, the commerce of Alexandria has been much improred. In the year 1824, 1290 ships, among them 606 Austrian, arrived, and 1199 departed.-A peculiarity of modern A. is the great number of dogs, which here, as well as in Cairo and Constantinople, run about in a very wild state:-According to the latest accounts, the trading pacha of Egypt has appointed an Italian renegade, to collect all the remains of ancient art, which are capable of transportation, in his dominions, in order to sell them, in a bazar to be built for this purpose in A., to the Europeans.

Alfxandris, with the surname della Paglia; a considerable town and fortress in Piedmont, situated in a marshy country, near the junction of the Bormida and the Tanaro. It was built in 1178 , by the Cremonese and Milanese, and at first called Casarea; afterwards, in honour of the pope Alexander III., who established there a bishopric, Alessandria. Its magnitude and opulence increased from century to century ; it now contains 30,000 inhabitants, and may be considered fourishing, since it is the capital of the province of the same name, and has two fairs annually, which are much frequented. Intended, originally, for a fortress to guard the passage over the Tanaro and Bormida, and constantly kept in good order, as the point where several roads meet, Alexandria has frequently been the object of long contention. It was taken and plundered, in 1522; by duke Sforza; besieged, without success, by the French, under prince Conti, in 1657; and taken, after an obstinate defence, by prince Eugene, in 1707. On the 16 th of June, I800, after the battle of Marengo, the Austrian general, Melas, agreed upon an armistice with Bonaparte, at Alexandria, by which he ceded to the latter Upper Italy, as far as the Mincisy and twelve fortresses. The fortifications of A. consist now of a surrounding wall and bastions, a strong citadel, formed by six bastions and many out-works, on the left bank of the Tanaro, and a redoubt, protecting the bridge on the right bank of the Bormida. A bridge of stone connects the town and citadel.- For an accoint of the revolt of the garrison of A., see Piedmont, Revolution of.

Alexandria; a city and port of entry, in the 
district of Columbia, and county of Alexandria, on the S. bank of the Potomac, six miles S. of Washingtoll, 115 N. of Richmond ; lon. $77^{\circ} 4^{\prime} \mathrm{W}$.; lat. $38^{\circ} 49^{\prime}$

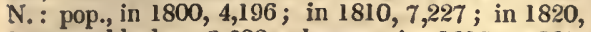
8,218 ; blacks, 2,603: houses, in 1817, 1,385. Among the public buildings are a court-house, a jail, an alms-house, a theatre, a market-house, and eight houses of public worship. -The situation of Alexandria is considerably elevated, with easy and gradual descents to the river, which is neatly wharfed for about half the length of the city, with water sufficient for the largest merchant ships. The streets intersect each other at right angles, and a great part of them are neatly paved. The city is farourably situated for commerce, nearly at the head of the tide-water of the Potomac, having an extensive and fertile back country, and carries on a considerable trade, chiefly in flour. A. expects to derive nuch benefit from the intended canal from Ohio to Washington.

Alexandria, the name of a thriving village in Scotland, situated in Dumbartonshire, on the west bank of the river Leven.

Alexandrian Copy, or Codex Alexandrinos : a manuscript, now in the British museum, of great importance in biblical criticism. It is on parchment, with uncial letters, without breathings and accents, written, probably, in the latter half of the sixth century, and contains, in four vols. folio the whole Greek Bible (the Old Testament according to the Septuagint), together with the letters of the bishop Clement, of Rome. A large part of the Gospel of St Matthew and of the Second Epistle to the Corinthians, as well as a portion of the Gospel of St John, are wanting. The text of the Gospels is different from that of the other books. The patriarch of Constantinople, Cyrillus Lucaris, who, in 1628, sent this manuscript as a present to Charles $\mathbf{I}$., said he had received it from Egypt; and it is evident, from other circumstances, that it was written there. But it cannot be decided, with certainty, whether it came from Alexandria (whence its name). John Emest Grabe follows it in his edition of the Septuagint (Oxford, 1707-20, fol., four vols.) Dr Woide published the New Testament from this copy, (London, fol., 1786), with types cast for the purpose, line for line, with intervals between the words, as in the manuscript itself. The copy is so perfect a resemblance of the original, that it may supply its place. Henry Hervey Baber undertook a similar edition of the Old Testament, London, 1816, fol. This famous manuscript belonged, in 1098, to the library of the patriarch of Alexandria. The text of this manuscript is of the greatest importance in the criticism of the Epistles of the New 'Testament ; in the Gospels it is evidently worse. The three first divisions contain the Alexandrian translation of the Oid Testament; the fourth, the New Testament in the original language.

Alexandrian School. When the flourishing period of Greek poetry was past, study was called in to supply what nature no longer fiurnished. Alexandria in Egypt was made the seat of learning, by the Ptolemies, admirers of the arts, from whence this age of literature took the name of the Alexandrian. Ptolemy Philadelphus founded the famous library of Alexandria, the largest and most valuable one of antiquity, which attracted many scholars from all countries; and also the museum, which may justly be considered the first academy of sciences and arts. (See Alexandria.) The grammarians and poets are the most important among the scholars of Alexandria. These grammarians were philologists and literati, who explained things as well as words, and may be considered a kind of encyclopedists.
Such were Zenodotus the Ephesian, who estabiislied the first grammar-school in Alexandria, Eratosthenes of Cyrene, Aristophanes of Byzantium, Aristarchus of Samothrace, Crates of Mallus, Dionysius the Thracian, Apollonius the sophist, and Zoilus. Their merit is to have collected, examined, reviewed, an.t preserved the existing monuments of intellectual culture.-To the poets belong Apollonius the Rhodian, Lycophron, Aratus, Nicander, Euphorion, Callimachus, Theocritus, Philetas, Phanocles, Timon the Phliasian, Scymnus, Dionysius, and seven tragic poets, who were called the $A$. Pleiads. The A. age of literature differed entirely, in spirit and character, from the preceding. Great attention was pail to the study of languages; correctness, purity, and elegance were cultivated; and several writers of this period excel in these respects. But that which no study can give, the spirit which filled the earlier poetry of the Greeks, is not to be found in nost of their works. Greater art in composition took its place; criticism was now to perform what genius had accomplished before. But this was impossible. Genius was the gift of only a few, and they soared far above their contemporaries. The rest did what may be done by criticism and study; but their works are tame, without soul and life, and those of their disciples, of course, still more so. Perceiving the want of originality, but appreciating its value, and striving after it, they arrived the sooner at the point where poetry is lost. Their criticism degenerated into a disposition to find fault, and their art into subtilty. They seized on what was strange and new, and endeavoured to adorn it by learning. The larger part of the Alexandrians, commonly grammarians and poets at the same time, are stiff and laborious versifiers, without genius.-Besides the $A$. school of poetry, one of philosophy is also spoken of, but the expression is not to be understood too strictly. Their distinguishing character arises from this circumstance, that, in Alexandria, the eastern and western philosophy met, and an effort took place to unite the two systems, for which reason the A. philosophers have often been called Eclectics. This name, however, is not applicable to all. The new Platonists form a distinguished series of philosophers, who, renouncing the scepticism of the new academy, endeavoured to reconcile the philosophy of Plato with that of the East. The Jew Philo of Alexandria (q. v.) belongs to the earlier new Platonists. Plato and Aristotle were diligently interpreted and compared in the first and second centuries after Christ. Ammonius the Peripatetic belongs here, the teacher of Plutarch of Chæronea. But the real new Platonic school of Alexandria was established at the close of the second century after Christ, by Ammonius of Alexandria (about 193 A. D.), whose disciples were Plotinus and Origen. (See Platonists, New.) Being, for the most part, Orientals, formed by the study of Greek learning, their writings are strikingly cluaracterized, e. $g$. those of Ammonius Saccas, Plotinus, Iamblicus, Porphyrius, by a strange mixture of Asiatic and European elements, which had become annalgamated in Alexandria, owing to the mingling of the eastern and western races in its population, as well as to its situation and commercial intercourse. 'Their philosophy had a great influence on the nanner in which Christianity was received and taught in Egypt. The principal Gnostic systems had their origin in $\Lambda$ l' $x$ andria. (See Gnosis.) The principal teachers of the Christian catechetical schools (q. v.), which had risen and flourished together with the eclectic philosophy, had imbibed the spirit of this philosophy. The most violent religious controversies disturbed the $A$. church, until the orthodox tenets wre established in it by Athanasius, in the controversy with the Ariars. 
-A mong the scholars of Alexandria are to be found grent mathematicians, as Enclid, the father of scienstific geometry; Apollonins of Perga in Panphylia, whose work on conic sections still exists ; Nicomnchus, the first scientific arithmeticinn;-nstronomers, who enployed the Egyptian hieroglyphics for marking the northern hemisphere, and fixerl the images and names (still in use) of the constellations, who left astronomical writings (e.g. the Phanomena of Aratus, a didactic poem, the Spharica of Menelaus, the astronomical works of Fratosthenes, and especially the Magna Syntaxis of the geographer Ptolemy). nud made improvements in the theory of the calendar, which were afterwards adopted into the Julian calendar ; natural philosophers, anatomists, as Herophilus aud Erasistratus ; - physicians und surgenus, as Demosthenes Philabethes, who wrote the first work on the disenses of the eye; Zopyrus and Cratevas, who improved the art of pharmacy and invented nutidotes; instructors in the art of medicine, to whom Asclepiades, Soranus, nud Galen, owed their education;-nedical theorists and empiries, of the sect fonnded by Plilinus. All these belonged to the numerous association of scholars contiuning under the Roman douninion, and favoured by the Roman emperors, which rendered Alexandria one of the most renowned and influential seats of science in antiquity. - The best work on the learning of Alexandria is the prize-essay of Jacob Matter; Essai Historique sur l'Ecole d'Alexandrie, Paris, 1819, 2 vols.

Alfacisdrixe, or Alexundrian; the name of a verse, which consists of six feet, or of six and a half, equal to twelve or thirteen syllables, the pause being always on the sixth syllable; e.g. the second of the following verses:

A needless Alexandrine ends the song,

Which, like wounded snake, drags its slow length along.

It corresponds, in our language, to the hexameters in the Greek and Latin; though, accorling to some writers, it rather answers to the senarii of the ancient tragic poets. Chapman's translation of Homer, nind Drayton's Polyolbiun are written in this measure. The concluding line of the Spenserian stanza is also an $A$. This verse becomes fatiguing from monotony, unless the writer las a very delicate ear. The French, in their epics and drama, are confined to this verse, which, for this reason, is called by them the heroic. The $A$. derives its name from an old French poem, belonging to the middle of the 12th or the beginning of the 13th century, the subject of which is Alexander the Great, and in which this verse was first made use of. See French Poetry.

Alexis, a Greek comic poet, who flourished in the time of Alexander, 13. C. 323. Only a few fragments of his works remain, which may be found in collections of the ancient Greek poets.

Alexis Connesos. See Comnenus.

Alexis Michaelovitsch, czar of Russia, born in 1630 ; succeeded his father Michael in 1646; died 1677. He was father to Peter the Great, and the first Russian monarch who acted on the policy of a more intimate connexion with the other states and nations of Europe.

Alexis Petrovitsch, the eldest son of the czar Peter the Great and Eudoxia Lapuchin, was born in Moscow, 1690, and opposed the innorations introduced by his father, who, on this account, determined to disinherit him. A. renounced the crown, and declared that he would become a monk; but, when Peter set out on his second journey, he made his escape, in 1717, to Viennat and thence to Naples, under the pretext of going to his father, who liad sent for him. At the command of Peter, he roturned; but the enraged car, regarding his fight as an nct of treason, disinherited him, by a ukase of 211 Feb., 1718; and when he discorered that $A$. was paving the way to succeed to the crown he not only cansed all the participators in his project to be punished capitally or otherwise, but had A nlso condemied to denth, and the sentence read to him, as pronounced unnimously by 144 judges. Althongh he was soon afterwarls pardoned, yet the fright and anxiety which he lond experienced, affected hin so much, that he died in the course of four days, June 26, O.S. 1718. Ile left a daughtir, and a son, afterwards the emperor Peter II. The account of Busching, that general Weide decropitated A. in prison, is without any authority.

A LEXIS-BATI ; a watering-place in Anlult-Berenburg, of all the German nineral springs the mosi strongly impregnated with iron. It is charmingly situated at the foot of the Harz.

ALFARABI, an emineut Arabian philosopher of the 10th century, was a native of Farab, in $\Lambda$ sia Minor; lied at Damascus in 950. His works consist of treatises our different parts of the Aristotelian plilosophy. These were printed at Paris in 1638.

AlFier, Vittorio, count, was born at Asti, in Piedmont, in 1749, of a rich and distinguished family. His early education was very defective, like tliat of most men of his rank and country at that time. His uncle and guardian sent him to Turiu, whose academy he left as ignorant and uninformund as when he entered it. He then joined a provincial regiment, which was unly called together for a few days during the year. He afterwards travelled over Italy, France, England, and Holland; returned and commenced the study of history, lut, soon disgusted with this pursuit, commenced his travels anew, and wandered for nearly three years, continually restless and unsatisfied. He left the military service, and led, for a long time, an innctive life, until ennui drove him to write dramatic poetry. His first attempt was crowned with undeserved success; and he determined, at the age of twenty-seven years, to derote all his efforts to the single object of becoming a tragic poet. Sensible of lis deficiencies, he went to work zealously to acquire the rudiments of knowledge. He first studied Latin and Tuscan, for which purpose he went to Tuscany. In this journey he became acquainted with the countess of Albany (q. v.), the consort of the English pretender, and a daughter of the noble family of Stolberg, to whom he soon became deeply attached. From this time, he strove with restless zeal to acquire distinction as a poet, in order to be worthy of leer, whose esteem and love had such value in lis eses. In order to continue his labours wholly free nnd independent, he broke the last tie which bound him to his country. He bestowed lis fortune on his sister, reserving only a moderate income for himself, and henceforth lived alternately at Florence and Roine. Here he composed fourteen tragedies, to which he afterwards added some others, although contrary to lis own inclination. The unforiunate situation of his belored friend often disturbed him, but the death of her husband at length put an end to her troubles, and enabled lier to marry $A$. Henceforth $\Lambda$. lived with her alternately in Alsace and in Paris, imceas. ingly busied with composition, and the arrangenent and publication of his works (by Didot and Beau. unarcluais). When the disturbances in France begau, he: quitted the country, and went to England. Jimbarrussed by the constant fall of assignats, he went back to Paris, angry at secing the cause of freculom dishonoured by unworthy hands, and unable, from the state of his feelings, to continue his intellectual labours. This torture of misd he endured till the 
end of Aug. 1792, when he fled from Paris, and escaped thic horrors of the ensuing September. He lost his books, and the greatest part of the complete edition of his tragedies, published by Didot, in five vols. Afterwarus he lived with his inseparable companion at Florence, resumed his usual labours, wrote his satires, and six comedies, and, in his last years, studied the Greek language. With the Greek poetry he did not become acquainted till his conrse was nearly finished. He died in the midst of these labours, Oct. 8, 1803. He was buried in the church of Santa Croce, at Florence, between Machiavelli and Michael Angelo, where a beautiful monument by Canova covers his remains. - A. has distinguished himself as a dramatic poet in thrce different departments. He has written six comedies, twenty-one tragedies, and a tramelogedia, so called. All these works are to be looked upon as the efforts of a great spirit employed out of its proper sphere of action. Disgusted with idleness, and desirous to distinguish himself, $\mathrm{A}$. became a poct. It was wholly impcssible, for one who seldom contented himself with performing half of any design, to propose to limself a moderate degree of excellence in that which he had made the business of his life. He expressed his hope that his high exertions would associate his name with those of all the great poets that Italy had possessed. His noble efforts disarm the severity of criticism. He was worthy to attain what he could not attain. Above the degeneracy of his coutemporaries, cherishing, too, a deep abhorrence of despotism, and possessed of a proud, free, and passionate heart, $\Lambda$. was animated with a political rather than a poetical spirit. In the midst of a debased people, he wished to inspire the spiritless with strength, courage, and freedom of thought; but he disdained the arts of persuasion. He purposely threw aside all omament, and wished to attain his end by loftiness of thought, strong brevity, and manly earnestness; but he forgot that, in doing this, he must throw off the peculiar characteristics of a poet. His tragedies are abrupt and stiff; the plots simple, even to barrenness; the verse liard and unpleasing; and the language devoid of that attractive splendour, by which the poet stirs the inmost soul of man. Nevertheless, he is the first tragic writer of Italy, and has served as a model for those who have followed him.-If, in his youth, the genius of A. was ton stiff for tragedy, he must, of necessity, fail when he attempted comedy in his old age, Jong after the sweet deceptions of life had vanished. His comedies, like his former works, had a serions, and, generally, a political aim; they are barren of invention; their plots are without interest ; the characters, as in his tragedies, only general sketches, without individuality. They are, therefore, far inferior to his tragedies, and, indeed, are not worthy of his lofty spirit. We consider A.'s Abel the most successful of all his dramatic works. This he called a tramelogedia, $-\mathbf{a}$ name as novel as the work itself. He invented this species of drama intermediate between the tragedy and opera, and intended to have written six pieces in this form. His genius, which was the most successful when least restrained, liere found its proper spliere, and if the species can stand bcfore the critic, then the inrention and execution of $A$ bel make it, without doubt, a fine poetic work. Besides his dramas, $\Lambda$. has written an epio poem in four cantos, several Iyrical pieces, sixteen satires, and poctical translations from Terence, Virgil, and some portions of Aischylıs, Sophocles, Euripides, and Aristophanes. $\Lambda$ fter his death appeared the Misogallo, a momment of his hatred towards the French; and his autobiography, a striking cxhibition of his characier. His complete works appeared at Padua and Brescin in 1809 and 1810,37 vols.

Alfred the Great, king of England, one of the most illustrious rulers on record, was born at Wantage, in Berkshire, A. D. 849. He ascenáed the throne of England in 872, at a time when the Danes, or Normans, who were formidable to the Saxons as early as the year 787 , had extended their conquests and devastations very widely over the country. A.'s efforts against them were at first unsuccessful, and he concluded some treaties which were not kept on their side. He was obliged to fy in disguise, and remained, for more than a year, in the service of a shepherd. In this situation, lie formed the design of freeing his country. He ordered his subjects to hold themselves in readines. against the enemy, gave them intelligence of his retreat, and informed himself of the condition of the Danes. He went, disguised as a harper, into the camp of king Guthrum, and, having ascertained that the Danes felt themselves secure, hastened back to his troops, led them against the enemy, and gained such a decided victory, that the Danes begged for peace. Those who were already in the country he allowed to remain there, on the condition that they and their king should embrace Christianity. A. now built forts, and exercised a part of his people in arms, while the rest cultivatcd the ground. He soon after divided the kingdom into counties, or shires, whereby he secured the public tranquillity. He made London the capital city of his dominions, and held there, twice a year, a general assembly of the estates. From time to time, new swarms of Danes sought entrance into the land, but the fleets of $A$. drove them from the coast. He collected the laws of his predecessors, and endeavoured to improve the condition of his subjects by an impartial administration of justice. He translated the Psalms, the fables of Æsop, and other writings, into AngloSaxon, and founded a school at Oxford. His familiar acquaintance with the most learned men of his time improved his own mind, and enabled him to do much for the good of his people. He laid the foundation of the English navy by causing ships, or rather galleys, of sixty oars to be built, which were as strong as any ships at that time in use. He also made discoveries in the north, and in the Baltic sea, the results of which he has madc known in his translation of Orosius. After reigning twenty-eight years and a half, and acquiring and meriting the love, gratitude, and reneration of his subjects, this illustrious prince died, A. D. 900. His history, considering the times in which he lived, presents one of the most perfect examples on record of the able and patriotic monarch united with the virtuous man.

AlFRED, an Englishman of the thirteenth ceutury, sumamed "the Philosopher." He is author of five books on the Consolations of Boethius, and others, upon portions of the Pliysics of Aristotle. He died in 1170. He is to be distinguished from another Alfred, an English bishop, of the tenth century, who wrote a History of the A bbey of Malmsbury.

ALGE, in botany; one of the seven families of plants, into which Linnæus distributed the whole vegetable kingdom. They are defined to be plants, of which the roots, leaf, and stem are all one. Under this description are comprehended all the seaweeds, and some other aquatic plants. A. are also one of the Linusean orders of the class cryptogamia.

Algarm, Alexander, a sculptor, who derived his origin from a fanily of high standing in Bologna. He was educated in the academy of Lodovico Carucci, and went, when twenty years old, to Mantua. The attempt to imitate, in sculpture, the famous pictures of Giulio $R$ Jmano, in the palace del $T$, was sufficient 
to give his genius a wrong directlon, since the excellencies of these pictures are directly opposed to those of sculpture. In 1625, he went to Venice, and thence to Rome. The duke of Mantia had reconmented hún to cardinal Ludorisi, nephew of pope Gregory $\mathbf{X V}$., who was intent on renewing the magnificence of the gandens of Sallust. Here A. was employed in restoring mutilated antiques (e. g. a Mercury), and in preparing original works. Ilere he becane acquainted with his countryman Domenichino. The statue of St Magdalen, for the church of St Silvestre, on the Quirinal, was his first great work. Cardinals and princes now arailed themselves of his talents, and the French court wished him to come to Paris; but the prince Pamfili succeeded in retaining him in Rome, where he died,

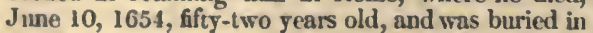
the church St Giovanni di Bolognesi. His Flight of Atrila, a basso relievo in marble with figures of the size of life, orer the altar of St Leo, in St Peter's church, is his most renowned work. But, with all the excellencies of this work, an inclination to give to sculpture the effect of painting is observable. This was owing to the influence of the school of Caracci on him. His God of sleep, of nero antico, in the villa Borghese, has often been taken for an antique. The basso-relievo of the Flight of Attila has often been engraved. It may be seen in Cicognara's Storia della Scoltura.

Algarotri, Francesco, count; born at Venice, 1712 ; an Italian writer, who united the study of the sciences with a cultivated taste for the fine arts. He studied at Rome, Venice, and Bologna. He was a distinguished connoisseur in the fine arts, and excelled in mathematics, astronomy, and natural philosophy. He lad a predilection for this last science, as well as for anatomy, and deroted himself to them. He was acquainted with the Latin and Greek tongues. And paid great attention to the Tuscan style and language. He risited France, England, Russia, Germany, Switzerland, and all the important towns of Italy. The last ten years of his life he spent in his own country. When twenty-one years old, he wrote at Paris, the greater part of his $\boldsymbol{N}^{\prime}$ en tonianismo per le Dame, 1737, after the model of Fontenelle's Plurality of Worlds, and thereby laid the foundation of his fame. Until 1739, A. lived alternately in Paris, at Cirey, with the marchioness du Chatelet, and in London. At that time he made a journey to Petersburg with lord Baltimore. On his return, he visited Frederic II., then crown-prince, and residing at Rheinsburg. The prince was so much fleased with him, that, after his ascension to the throne, he invited him to live with him, and raised him to the rank of count. He was not less esteemed by Augustus III., king of Poland, who conferred on him the office of privy-councillor. A. now lived alternately at Berlin and Dresden, but particularly in the former place, after receiving from Frederic, in 1747, the order of merit and the office of chamberlain. In 1754, he returned to his own country, where he resided first at Venice, afterwards at Bologna, and, after 1762 , at Pisa. Here he died of a consumption, 1764, after suffering long from hypochondria. He himself formed the design of the monument which Frederic II. caused to be erected over his grave, in the court of the campo santo, at Pisa. He was called, in the inscription, with reference to his Congresso di Citera, and his Neutonia nismo, a rival of Orid, and a scholar of Newton. A.'s knowledge was extensive and thorough in many departments. In painting and architecture, he was one of the best critics in Europe. Many artists were formed under his direction. He drew and etched with much skill. In his works, which embrace a great variety of subjects, he shows much wit and acuteness. Ilis poems, though not of a very high order, are plensing, and his letters are considered among the funest in the Italian language. The latest collection of his works appeared at Venice, from 1791 to 1794,17 vols.

AlokBRs is a general method of resolving wathematical problems by means of equations, or it is a method of performing the calculations of all sorts of quantities by means of general signs or claracters. Some authors define algebra as the art of resolving mathematical problems; but this is the iden of analysis, or the analytic art in general, mether tlan of algebra, which is only one species of it. In the application of algebra to the resolution of problems, we must first translate the problem out of common into algebraic language, by expressing all the conditions and quantities, both known and unkuown, by their proper characters, arranged in an equation, or several equations, if necessary, and treating the unknown quantity as if it were a known one; lhis forms the composition. Then the resolution or analytic part is the disentangling the unknown quantity from the sereral others with which it is connected, so as to retain it alone on one side of the equation, while all the known quantities are collected on the other side, thus obtaining the value of the unknown. This process is called analysis or resolution; and hence algebra is a species of the analytic art, and is called the modern analysis, in contradistinction to the ancient analysis, which chiefly regarded geometry and its application. The mode of applying algebra to the resolution of problems may be seen in the following example :-If we wish, from the given difference of two numbers, and the difference of their squares, to find the numbers themselves, then the algebraist represents, in his language, the first of these differences by $a$, the second by $b$, the unknown numbers to be found by $x$ and $y$, and marks the relation between the things given and those sought by the $x$ pressions $x-y=a$, and $x^{3}-y^{8}=b$. Then $x^{2}-$ $y^{*}$, he continues to say in his language, $=(x+y)$ $(x-y)$; thus is $x+y=\frac{b}{a}$; and hence, by addition and subtraction, $x=\frac{b+a a}{2 a}$, and $y=\frac{b-a a}{2 a}$, which is then the general expression of this proposition. For particular cases, we have only to substitute the respective numbers instead of $a$ and $b$, in order to have immediately the corresponding values of $x$ and $y$-The oldest known work on algebra, that we possess, is by Diophantus of Alexandria. (The best edition of the works of this geometrician, who is commonly supposed to have lived in the fourth century, is that of Toulouse, 1670 , folio, with a commentary by Bachet, and notes by Fermat.) Europe, however, owes its first acquaintance with this science, not to the Alexandrian writer, but (as is the case with much of its knowledge) to the Arabians, as, indeed, the name itself shows. The Arabians brought their algebra to Spain, whence it found its way to Italy. The state of this science at that time may be learned from the work of Lucas de Burgo sancti sepulchri, Summa Arithmetica et Geometria, Proportionumque et Proportionalitatum, Venice, 1494. Tartaglia of Brescia, Gardanus of Milan, and Ferrari of Bologna, are highly distinguished names among the Italian al gebraists of this early period. In Germany, also, the study of al gebra was prosecuted in the first half of the sixteenth century, of which the work of Mich. Stifel, professor of mathematics at Jena, Arithmetica Integra cum praf. Melanchthonis, Nuremb. 1544, 4to, gives the most decisive proof. In England, Recorde, in France, Peletarius, were dis 
tiuguished algebraists abont the same time; but the science was afterwards greatly enriched by Vieta, master of requests of queen Margaret of France, who died in 1603, and by the Englishman Harriot, who died in 1621, to whose labours the Flemish mathematician Albert Girard, who died about 1630 , added his own with splendid success. Next appeared, Descartes (q.v.) and Fermat, counsellor of the parliament of 'Toulouse, who died in 1664; and the great Newton (q. v.) published in 1707 his Arithmetica Universalis. At the same time with him, Leibnitz acquired credit by some algebraical propositions. After him, Maclaurin and Euler distinguished themselves in the most eminent manner by their additions to this part of mathematical knowledge. In later times, there have been constant efforts to raise algebra to a higher degree of perfection. We may name Lambert, d'Alembert, Lagrange, Ozanam, Saunderson, Clairaut, Cousin, Tempelhof, Kæstner, Bézout, Gauss, \&c.-Algebra enables us to survey remote and highly complicated relations. It is distinguished by this, that each of its expressions contains exactly the idea intended to be conveyed, while all other languages, as those of words, of the arts, of symbols, only approximate more or less to the proposed idea. On this account an exact lexicon of two languages ran never be made, because every word in one is connected with.ideas and associations different from those belonging to the corresponding word in the other. An algebraical formula, on the contrary, can be understood equally well by the Frenchman and the Hindoo, if they are both acquainted with the signs. In Rosenthal's Encyc. of Mathem. Sciences, i. 44, there is a list of the principal works on algebra. The most important are, Wiedeburg on the Study of Algebra, Jena, 1775, Euler's Algebra, translated by Bernouilli into French, with notes by Lagrange. A new and good edition of this translation appeared at Lyons in 1795, in two vols. Kaussler translated Lagrange's additions separately (Frankfort on the Maine, 1796). The profound Maclaurin's Treatise on Algebra (2d ed. London, 1756) is distinguished among the old elementary books for solidity and clearness. We find examples and explanations in Saunderson's Elements of Algebra, Cambridge, 1740 , two vols., 4to, translated into French by Janconrt, Amsterdam, 1756. Claimut's Algebra, which was first published in 1746 , has been several times reprinted, lately in two vols., by Lacroix, with notes by Lagrange and Laplace. Bezout's Algebra, in the second part of his excellent work, Cours des Mathématiques à l'Usage de la Marine et de l'Artillerie, second ed. by Peyard, Paris, 1800 , is well written. The French have the most excellent elementary works in this as in every other branch of mathematics. The first vol. of Vega's Lectures on Mathematics, 3 d ed., Vienna, 180\%, contains a thorough introduction to common arithmetic and algebra. An excellent collection of problems in algebra und other branches of mathematics, is that of Meier Ilirsch, a German, 2d ed., Berlin, 1811, which well lleserves to be translated into other languages, because it contains the greatest variety of interesting examples arranged in the best order.

Algiers. See Barbary.

AlgOA or ZWARTKOP's BAY, on the S. coast of Africa, where ships may lie in five fathoms water, a mile from the general landing-place. The bay abounds in black whales and a variety of other fish. 500 miles $\mathrm{E}$. from the Cape. Lon. of the landingplace, $26^{\circ} 35^{\prime} \mathrm{E}$. ; lat. $33^{\circ} 56^{\prime} \mathrm{S}$. A small river of the same name flows into it. Mr Barrow describes the adjacent country as very fertile, and abounding in useful animals. Fort Frederic is a recent establishment on the shore of the bay, but as yet very small.
Algonguins; North American Indians on the As. siniboill or Rainy Lake, and Prairie de Portage; formerly more numerous than at present ; their number amounts only to 600 . This tribe was once closely connected with the Iroquois Indians, and considered as their protectors; but their allies und protegees soon began to rival their former masters in the arts of hunting and of war, and quarrels arose, which proved almost fatal to the existence of the A., although they were assisted by the French. There is a church devoted to the Romish religion in their territory, but the exertions of the clergy have hitherto had little effect on their morals. They are in the general practice of polygamy, and much given to the use of intoxicating liquors. The country around them is cultivated in miserable and detached patches, and this solely by their women, the men being engrossed with fishing and hunting. They are, like most of the other Indians, declining, and in a miserable state. See Indians.

AlgoszlL; in Spain, an officer whose business it is to execute the decrees of a judge.

Alhama ; the ancient Artigis Julia; a town of Spain, in Granada ; lon. $2^{\circ} 46^{\prime}$ W.; lat. $36^{\circ} 57^{\prime} \mathrm{N}$. ; on the Motril, twenty-five miles from Granada; population, 4,500. This place is celebrated for its warm nıedicinal baths and drinking waters, its romantic situation between craggy mountains, and the gallant defence of the Moors against the Spaniards, 1481, when the town was taken and sacked. The kings of Spain have erected a grand building for the use of invalids, with baths of free-stone, regulated to different degrees of heat. On the surrounding mountains the Rio Frio rises, and forms several cascades. Washington Irving, in his Chronicle of Granada, gives a spirited account of the taking of A., "the key of Granada." Byron's translation of the Romance Muy Doloroso, on the taking of A., is familiar to every reader.

Alhamra, Medinat Alhamra, or Almambra, i. e. the Red City; a splendid portion or suburb of ancient Granada, when it was one of the principal seats of the empire of the Moors in Spain. It was the Alcazar, or royal palace of the kings of Granada, but grew, by numerous additions, at last, into another city. Ib-nu-l Khatib, or Alkatib, describes it in his account of this kingdom and capital (which is preserved in Casiri's Bibliotheca Arabico-Escurialensis) as a most splendid place, where art and na. ture rival each other in magnificence. Seated on the northern brow of a lofty eminence, which consmands a full view of the city of Granada on the one side, and of a charming country on the other, $A$. encloses in its ruined walls many monuments of ancient art, and traces of its former splendour. Our limited room does not allow us to give a description of the Arabian palace, commenced by Moliammed Abu Abdillah Ben Nasr, the second of the Moorish kings of Granada, and completed under Abu- $1 \mathrm{Haj}$ jaj, in the year of the Hegira 749, or A.D. 1348; nor of the Spanish palace commenced by Charles $V$. on a portion of the ruins of the Moorish edifices. It is a place equally interesting for the artist, the antiquarian, and the historian. Mr Murphy's splendid work on the Arabinn Antiquities of Spain contains many views of these ruins. - See also History of the Mahometan Empire in Spain, 4to, London, 1816, with the supplement; a Collection of Historical Notices and Poems on the Alhamra of Granada ; Swinburne's 'Travels through Spain; and Washington Irving's recent work, entitled, 'The Alhambra.'

AL; the son of Abu Taleb, who was uncle of Mahomet. When the latter assembled his kinsmen, and declared his prophetic mission, he asked which among them would be his vizicr, "I am the man," 
exclaimed Ali, then but fourteen rears old. "Whoever rises against thee, I will dash out his teeth, thar ont his eyes, break his legs, rip up his belly. $O$ prophet, I will be tlyy vizier." Ali kept his word; tistinguished both by eloquence and valour, he becane one of the unain pillars of the new faith, and obtained the name of the Lion of God, always victorious. He also received Fatima, the danghter of the prophet, in marringe. After the death of Othman, he became caliph, and finally lost his life by assassunation, at Cufa, in the sixty-third year of his age. There was something of grandeur in the primitive simplicity and fanatical heroism of the first followers of Mahomet, and Ali formed one of the most cunspicuous examples of the conjunction. The Maliommedan schism caused by the murder of $\mathrm{Ali}$, is well known, and his sect is called Shiites, or heretics, by the Sonnites, or orthodox. The Persians, a part of the Ushec Tartars, and some of the princes of India, remain followers of Ali to this day. His posterity are numerous, and are allowed to wear green turbans, in lonour of their descent from the prophet. There is extant, anong various writings atuributed to Ali, a collection of a hundred maxims or sentences, which have been translated by Golius and Ockley.

Au; pacha of Yanina (Tepeleni), generally called Ali Pacha; a bold and crafty rebel against the Porte; an intelligent and active governor of his province; as a warrior, decided and able; as a man, a very fiend. His life is a curious exemplification of the state of the Turkish empire. He was born at Tepeleni, in 1744, of a noble family, which stood at the head of an independent tribe, the Toczides; and was the grandson of a bey named by the Porte. His early life was unfortunate, but his extraordinary strength of mind, which shrank from no danger nor crime, united with great address, raised him to princely independence. The neighbouring pacha lad stripped his father of all his possessions. After his death, his mother, a warlike and cruel Albanian, placed her son, then sixteen years old, at the head of her dependents. He was defeated, and taken prisoner; but the Curd pacha was so much struck with his beauty and viracity, that he set him at liberty, after chastising him. A. then commenced robber, but was so unfortunate that he fled into the mountains, where, to keep himself from starving, he jawned his sabre. In this situation, his mother scornfully advised him to put on a woman's garment, and serve in the haram. In a second attempt at plunder he was wholly defeated, and concealed himself in a ruined building, where, brooding over his fate, he sat, unconsciously pushing up the ground with a stick. He struck something hard, and found a chest containing gold. With this treasure he raised 2000 men, gained his first victory, and returned in triumph to Tepeleni. From this time he was continually fortunate, but, at the same time, false and cruel. On the day of his return, he murdered his own brother, whom he thought guilty of treachery, and confined his mother to the baram, under pretence of her laving poisoned the deceased, where she soon after died from grief and rage. A. now continued his robberies, regained the favour of the Porte by assisting in the subjugation of the rebellious vizier of Scutari, and possessed himself of the estates which had been taken from his father, as well as of some Grecian cities. He then attacked the pacha Selim of Delvino, who was obnoxious to the Porte, and caused him to be beheaded, by which ineans he became his successor. At length the divan, in which he had obtained great infuence by bribery, named him lieutenant of the dervender pacha, whose duty it was to preserve the highways secure; but, instead of attending to the duties of his office, A. sold commissions, in the name of the grand signior, to the richest lands of robbers, and thereby gave them legal authority to plunder. The dervendgi pacha snd his lieutenant were now deposed, but A. purchased anew the favour of the prime minister. He rendered such inportant services to the Porte with his bold Albnuians, in the war with Russia and Austria (begun 1787), althongh he carried on a secret correspondenee with prince Potemkin, that the Porte named him pachia of Tricala in Thessaly. He immediately possessed himself of the city of Yanina, by showing a forged firman, which gave him the city and the citadel, and then compelled the inhabitants to sigu a petition to the sultan, requesting hin to give them $\Lambda$. for a governor. He likewise compelled them to pay hin a large sum of money, with which he bribed the divan, who granted the request. Ile afterwards entered into an alliance with Bonaparte, who sent him eugineers to build him fortifications; but when Napolion was defeated in Egypt, those place's on the coast of Albania, which land belonged to the Venetins, and were now under the dominion of the French, were seized by A. Parga (q. v.) alone made a successful resistance. But lie contrived that, in the treaty between Russia and the Porte. in 1800 , all the Venetian places on the main land (and, therefore, Parga) sliould be surrendered to the latter power. He tlien attacked the lrave Suliotes (q. v.), and conquered them in 1803 , after a three years' war. The Porte now made him governor of Romania, where he continued his system of oppression still more openly than before. He then revenged on the inhabitants of Gardiki an injury whicli they lad done to his mother, forty years before, by putting to death 739 of the descendents of the perpetrators, they themselves being all dead. Security and quiet now reigned in his dominions; the roads were well constructed; commerce flourisled; so that European travellers, with whom A. was glad to converse (see Hughes' 'Travels in Greece), acknowledged in him an active and intelligent governor. In 1807, he entered again into an alliance with Bonaparte, who sent him M. Pouqueville, as consul general, and from this time his dependence on the Porte was merely nominal. His object in this alliance was, to have Parga and the Ionian islands included in the peace of 'Tilsit. Failing to attain this end, he made an alliance with the English, and gave them many advantages; whereupon Parga was restored nominally to the Porte, but in reality to $\mathrm{A}$. He afterwards caused it to be inserted in his gazette, that Maitland, who was the British lord high commissioner of the Ionian islands, had received from the Porte, at his recommendation, the order of the crescent. When $A$. thought himself strongly fixed in his power, he caused some of the capitani (q. v.) of the Greek Armatolics, who had hitherto rendered him assistance, to be murdered (among them, the father of Ulysses, the famous chief, and had the murderers also put to death, that he might not be known as the author of the crime. At length, in 1820, the Porte determined to crush him. Ismail Pascho Bey, with 5000 Turks, and supported by the capitani, who brought 10,000 soldiers to his standard, advanced against lim. The Greeks surrounded his positions in the passes of the mountains, so that he was compelled to throw himself, with all his troops, into the citadel of Yanina, well prorided with every thing. From hence he set Yanina on fire. Pascho Bey had no orduance fit for besieging the city, and was suspected by the Porte, because he had called the Christians to his assistance. The Porte therefor gave the clicef 
command to Kavanos Oglu. This commander dismissed the capitani and their bands, with cruel threats, compelling them to make restitution to the Turks for the loss which they had before occasioned them. Hereupon they went over to A., especially after they beheld the insurrection of the Hetaria, and aided him in the field against the Turks before Yanina. Kavanos Oglu eould then do nothing against the rebels. The valiant Beba Paclia, his quccessor, died suddenly, after the capture of Arta, which Veli, A.'s son, had defended. The savage Khurschid, Pacha of the Morea, who was hated by all the Greeks, now advanced against the city with 12,000 men. But every attack was repulsed by A.'s brave troops, and the capitani, strengthened by the Suliotes, suddenly attacked the Turkish camp. Immediately the Hetaria (q. v.) called all Greece to arms. The Turks were now compelled to throw Uiemselves into the strong piaces, and Khurschid retreated, Aug. 1821, with the remains of his army, out of Epirus into Macedonia. The Albanians alone, whom A. had beguiled with empty promises, left the tyrant. Khurschid Pacha attacked Yanina with a new army. The Greeks gave up A.'s cause for lost. He then determined, persuaded, perhaps, by his wife, Wasilika, who was a Greek, to treat w ith Khurschid. On receiving assurances, confirmed by an oath, that his property and his life should be spared, he surrendered his fortress to the pacha, Feb. 1, 1822, and retired to his summer-palace in the lake of Yanina. Here Khurschid's lieutenant, Mehmet Pacha, made known to him the sentence of death pronouneed against him by the sultan. A. put himself on his defence, but was cut down, with six companions. This happened Feb. 5, 1822. The head of the rebel was sent to Constantinople. The Porte took possession of A.'s treasures. His sons, $V$ eli and Muchtar Pacha, had come into the power of the Turks, in 1820, when the strong places of A. were taken, and lived afterwards in exile, in Asia Minor. But attempting, by means of a Greek disguised as a dervise, to form a connexion with the party of their father, they were executed in Aug., 1821. A.'s grandson obtained from the Porte, in 1824, permission to retire to Larissa with A.'s widow, Wasilika. Pouqueville, in his Histoire de la Regeneration de la Grece, rol. i., paints a dreadful picture of A's barbarity, falsehood, and love of revenge. He says that $A$. caused a Greek lady Fuphrosyne, and fifteen other women, to be thrown into the sea, because they appeared to have too mueh influence over his son Veli. Since his mother was an Albanese, and his father a Turk, from this double relationship, he seized on all property left by persons dying, on pretence that the testator was his relation, by the mother's side, if he happened to be a Greek, or on his father's side, if a Turk. In this way $\mathbf{A}$. amassed vast quantities of furniture and utensils, and occasionally held a market for the sale of these effects. A Jew was his treasurer. If he saw a beautiful maiden whom he wished to possess, his executioner, who was always at his side, went to the parents, and said, "Your daughter has pleased Ali ;" whereupon the daughter was sent to him, or the whole family were obliged to fly. The writer of this knows two families who were compelled to fly in this way. He took possession, in the same summary mode, of every thing which struck his fancy. - This favourite of fortune liad great endowments from nature. He united a reniarkably enterprising spirit with equal penetration; an extraordinary knowledge of men and things with determination and courage; great firmness with great adroitness. But he was false, suspicious, implacable, and bloodthirsty from ambition and avarice; every means pleased him alike, provided that it led him to his object with quickness and safety. The dissensions of his enemies, the eorruption of the divan, and the political weakness of the Porte, were the comerstones on which this modern Jugurtha built up his ephemeral greatness.

Auns (Latin), otherwise; often used in the trial of criminals, after one name and before another, to signify that they have more than one appellation; as, John, alias Thomas.

ALibl (Latin), elsewhere, in law, denotes the absence of the accused, at the time of the crime coumitted, from the place where he is charged with having committed it.

Alicant, or Alicante (ancient Lucentum); a city and port on the Mediterranean sea, lon. $0^{\circ} 29^{\circ}$ W., lat. $38^{\prime \prime} 21^{\prime}$ N., with 17,300 inhabitants, situated in the Spanish kingdom of Valencia, with a castle whieh was formerly strong, but has fallen to decay since the war of the Spanish succession. It is the see of a bishop. The liarbour is good. The maritime nations of Europe have all of them consuls here. The principal artiele of export is sweet wine, called Alicant, and also, from its dark colour, vino. tinto, which is, for the most part, sent to England. Charles V. first planted the vines, bringing shoots from the Rbine. $A$. is important as the emporium of Valencian produce, and the centrai point of the eommeree between Spain and Italy.

AucoNDA; an African tree, of an imineuse bulk, a native of Congo. Of the bark a coarse thread is made; the shell or rind of the fruit may be made into a nourishing pap, serves for vessels of various kinds, and gives an aromatic taste to water preserved in it. The small leaves are used as food in time of scarcity, the large ones to cover huts, and, being burned, make good soap.

Aulevs. The legislation of a uation in regard to aliens is a criterion of its civilization. All uncivilized nations treat the alien as an enemy, as out of the protection of law. Some difference, however, is universally made between aliens and natives ; e. g.s some states require the alien to give sureties when he institutes a criminal prosecution against a citizen. In some, he cannot become a guardiall, or a witness of a will; the protection of the law may be deniect him, and he himself be banished from the eountry. The alien, also, has no right to enjoy certain advantages, granted by the state to the citizen, in addition to the general protection of the laws; for instance, the benefit of institutions of education, poor-houses, \&c. Some countries treat alieus with unreasonable severity, by throwing obstacles in the way of their admission, by rendering naturalization difficult, and by depriving them of personal security. Although the right of a state to forbid the entrance of aliens, even under pain of death, as in China and Japan, may be abstractly defended, the policy of exercisin 9 such a right can be justified only to a very limited extent. A high degree of civilization can be atta ined only by a free and aetive intellectual interco urse among nations, in like manner as their true prosperity is best promoted by a free and active com. merce. All the progress made by one nation, whether in the production of raw materials, or in the art of preparing then, or in scientific discovery, is advantageous to every other nation, if they only pernut perfect freedon of intercourse. In our days, civilized states rarely oppose the personal entrance of aliens; but the liberty of commercial interccurse is still imperfectly understood.-In respect to naturalization, several states have had peeuliar causes of caution; such, for instance, as the exeessire influence of a foreign power, or the occupation of a throne by a foreign dynasty. - The following are the principal 
points in the laws of Fnglaud and the United States of America respecting alieus:-In regard to each country, an alien may be defined to be a person born ont of the jurisliction of the country, and not having acquired the rights of a citizen by naturalization. 'This, however, is not strictly true; for children, born out of the dominions of the British king, whose grandfathers by the father's side, or whose fathers were untural-born subjects, are entitled to the rights of native citizens, unless, at the time of their birth, their fathers were in the service of an enemy. In the United States, this same right is given by the act of April, 1802, "to the children (boril out of the iurisdiction of the United States) of persons who now are or have been citizens of the United States." "This clause," as chancellor Kent observes, (Commentaries on American Law, vol. ii.)," applies only to the children of persons who then were, or liad been, citizens, and consequently the benefit of this provision narrows rapidly by the lapse of time ; and the time will soon arrive, when the children of American parents, born abroad, will be obliged to resort for aid to the dormant and doubtful principles of the English law." Minor children of naturalized persons are also admitted to the privileges of citizens in the United States. Aliens cannot acquire a title to real property by descent or other mere operation of law. They may purcliase it or receive it by devise, but the state has a right to take possession of it as forfeited, whatever it is ascertained, by a proper examination, to be the property of an alien. (In point of fact, aliens often do own real property in the Inited States, holding it in the name of a friend.) They can acquire, hold, and transmit movable property in the same manner as citizens, and they can bring suits for the recovery and protection of such property. They owe a local allegiance, and are bound equally with natives to obey all general rules for the preservation of order, which do not relate specially to citizens. Even alien enemies may sue and be sued, as in time of peace. Aliens may dispose of their personal property by will, and, in case of their dying intestate, their personal property is distributed according to the law of distribution of the place of their domicile at the time of their death. The unjust and inhospitable rule of the most polished states of antiquity prevailed, in many parts of Europe, down to the middle of the last century. The law, which claimed for the benefit of the state the effects of deceased foreigners, who left no heirs who were natives existed in France till 1791, when it was abolished by the first constituent assembly. Chancellor Kent, in the second volume of his very valuable Commentaries on American Law, observes, that " the Napoleon Code seems to have revived the harsh doctrine of the droit d'aubaine, with the single exception, that aliens should be entitled to enjoy in France the same civil rights as were secured to Frenchmen, by treaty, in the country to which the alien belongs. The law in France at present, is, that a stranger cannot, ezcept by special favour, dispose of his property by will; and, when he dies, the sovereign succeeds, by right of inheritance, to his estate." The remark on the revival of the droit d'aubaine by the Code Napoleon, we suppose to be correct; but we believe that this " inhospitable rule," as the learned judge justly terms it, has been since abolished. The article Aliens, in the German Conversations-Lexicon, states, that the droit d'aubaine, in France, was wholly abolished, July 4, 1819, and the Encyclopédie Moderne, in the article Etranger, printed in 1828, says, that "aliens have been placed again under the protection of the common law of the country. They can now acquire and enjoy property, sell it, transmit it to their heirs, and dispose of it, by testament or donation, like the other inbiahitants of the kimglom. 'They canmot, however, exercise political rights, or be appointed to public offices, previous to naturalization." - $\mathrm{Au}$ alien may, by letters-patent ex donatione regis, be made an English subject, and is then called a denizen, being in a mid. dle state between a natural-horn subject and an alien. He may now purchase lands, or possess them by devise, but cannot take them liy inheritance, although his heirs may inherit from lim; the parent of the denizen being held to have no inheritable blood, which the denizen possesses after becoming such. 'The full rights of a natural-born subject can be conferred only by an act of parliament. Even after naturalization, an alien cannot becone a menber of the house of commons or privy coumcil, or hold offices or grauts under the crown. If the partiament wisl to confer these privileges, as is sometimes the case when a foreign prince becomes connected, by marriage, with the royal family, a double act of legislation is necessary. In the United States of America, naturalization confers all the privileges of a native citizen, except that of being a candidate for the office of president of the Union. Previous to becoming a citizen of the United States, an alien must have resided in the country five years, and, two years before the ceremony of naturalization takes place, he must have abjured all allegiance to every other power. Fngland is the only country where an act of the legislature is required for naturalization. In the countries of Europe generally, with the above-mentioned exception of England, the right of naturalization, in each particular case, belongs to the executive branch of government. It is so in France, in Bavaria, and in all the German states. In France, a residence of ten years gives to the alien all the rights of a citizen, even that of becoming a member of the chamber of deputies (e. g. Benjamin Constant). In the states of the German confederacy, no German can be treated as an alien; e. g. the Prussian laws grant the full rights of a citizen to every one who takes up his residence in that state. The unjust distinctions formerly made between aliens and natires, in cases where the intercsts of the two came in collision, are going continually out of use. As to the right of aliens to own real estate, the laws of different countries are very different. We have already said, that this is not permitted in England and the United States of Aınerica. France allows it without limitation, like most of the German states. This right is a fundamental principle of the German con. federation. By the law of July 4, 1819 (which contains a total abolition of the droit d'aubaine), every alien lias an equal right of inheritance with native Frenchmen in respect to all real and personal goods in France; only, when Frenchmen have to divide an inheritance with foreign heirs, and the laws of the foreign country do not allow them a proportionate share of the property abroad, they receire in advance, from the property in France, as much as is necessary to the restoration of equality. - In addition to what we have already said on the laws of England and the United States of America respecting aliens, we will add a short account of certain acts passed by the legislative bodies of these countries, with a view of guarding against the hostile attempts of aliens. In Fingland, certain alien acts of recent date $(33 \mathrm{Geo}$. III. c. 4. and $34 \mathrm{Geo}$. III. c. 43,67 ) arose out of the influx of strangers into that country from the continent during the French revolution. They compelled the masters of ships arriving from foreign ports, under certain penalties, to give an account at every port of the number and names of the foreigners on board to the custom-house officers, appointing justices and others to grant passports to such aliens, and 
giving the king power to restrain them, and to send them out of the kingdom, on pain of transportation, and, on their returil, of deatl. The same acts also direct an account to be given in of the arms of aliens, which, if required, are to be delivered up ; and aliens are not to go from one place to another in the kingdoin without passports. These acts have been, froin time to time, amended and continued, as in $43 \mathrm{Geo}$. III. c. $155, \&$ c. Of late, all restrictions of this kind on aliens have been abolished, and they are only obliged to inform the secretary of the home departinent, from time to time, of their places of residence. The only restrictions of this kind, on aliens, in the United States of America, are, that, in case of war between the United States and any other nation, the president is authorized, if he sees fit, to order the subjects of the hostile country to be apprehended and removed, or to prescribe the conditions on which they shall be allowed to remain in the United States. If such aliẹns are not chargeable with actual hostility, or with any other crime against the public safety, they are to be allowed a reasonable time to remove with their effects. During the late wars in Europe, serere restraints were imposed on Englishmen in France, in retaliation, as Bonaparte alleged, of the strict enforcement of the British alien-acts in regard to French subjects. In the states of Europe, generally, aliens canıot travel without passports. In Britain and the United States of America, none are required.

AuмEx; a term which includes every thing serving as nutriment for organized beings. In animals and regetables we can observe the phenomena of decomposition and reproduction, and analyse the sulustances that administer to their growth and repair distinctly. Generally, however, the word A. is used for what serves as nutriment to animal life. It is, in this respect, a subject of great interest for the zoologist. In the present article we shall confine ourselves to the aliment of mankind.-Man, it is well known, derives nourishment both from animal and vegetable substances. He eats fruits, both ripe and unripe, roots, leaves, flowers, and even the pith and the bark of different plants, many different parts of animals, and the whole of some. Climate, custom, religion, the different degrees of wanteand of civilization, give rise to an innumerable diversity of food and driik, from the repast of the cannibal sarage of New Zealand to that of the Parisian epicure at the table of Very; from the diet of the carnivorous native of the north to that of the Brahmin, whose appetite is satisfied with regetables; from the oak-bark bread of the Norwegian peasant to the luxuriously-served table of a Hungarian magnate at Vienna. Some nations abhor what others relish, and great want often renders acceptable what, under other circumstances, would have excited the greatest disgust. The flesh of dogs is commonly eaten in China, and in Africa that of snakes, particularly of the rattle-snake and boa-constrictor. Locusts are, eaten both in $\Lambda$ sia and $\Lambda$ frica, and the Negroes on the coast of Guinea relish lizards, mice, rats, snakes, caterpillars, and other reptiles and worms. The Otomaes, a tribe of American Indians, are said by Humboldt to collect a kind of clay to eat in the rainy season. It is an interesting subject, by no means sufficiently investigated as yet, how far the different aliment of various cutuntries is connected with the climate, \&c., and what influence it exerts on the different races, as well as the consequences of introducing new species of aliments. Some excellent remarks on the national dishes of different nations were published by baron Rumor, a German, in 182:, in a work which he called Kochkunst ( $\mathrm{Art}$ of Cookery). All kinds of aliment must contain nutritions substance, which, being extracted by the act of digestion (q. v.), enters the blood, and effects by assimilation (q. v.) the repair of the body. (Sce Nutrition.) Alimentary matter, therefore, must be similar to animal substance, or transmutable into such. In this respect alimentary substances differ from medicines, because the latter retain their peculiar qualities in spite of the orgaus of digestion, and will not assimilate with the animal substance, but act as foreign substances, serving to excite the activity of particular organs or systems of the body. All alimentary substances must, therefore, be composer, in a greater or less degree, of soluble parts, which easily lose their peculiar qualities in the process of digestion, and correspond to the elements of the body. These substances, in their simple state, are mucilage, gelatin, gluten, albumen, farina, fibrin, and saccharine matter. Of these, regetables contain chiefly of mucilage, saccharine matter, and farina, which latter substance, particularly in connexion with the regetalule gluten, by which both become fit for fermentation, and thus for dissolution and digestion, is the basis of very nutritious food. The nutritive part of fruits consists of their saccharine matter, and a little nucilage. In animal fool, gelatin is particularly abundant. The nutritiousness of the different species of food and drink depends. therefore, upon the proportion which they contain of those substances, and the mode in which they are connected, favouring or obstructing their dissolution. Organs of digestion in a healthy state dissolve alimentary substances more easily, and take up the nutritious portions more abundantly, than those of which the strength has been impaired so, that they cannot resist the tendency of each substance to its peculiar chemical decomposition. The wholesome or unwholesome character of any aliment depends, therefore, in a great measure, on the state of the digestive organs, in any given case. Sometimes a particular kind of food is called wholesome, because it produced a beneficial effect of a particular character on the system of an individual. In this case, however, it is to be considered as a medicine, and can be called wholesome only for those whose systems are in the same condition. Very often a simple aliment is made indigestible by artificial cookery. Aliments abounding in fat are unwhole some, because fat resists the operation of the gastric juice. The addition of too much spice makes many an innocent $\mathbf{A}$. injurious, because spices resist the action of the digestive organs, and produce an irritation of particular parts of the system. They were introduced as artificial stimulants of appetite. In any given case, the digestive power of the individual is to be considered, in order to deternine whether a particular aliment is wholesome or not. In general, therefore, we can only say, that that $\boldsymbol{\Lambda}$. is healthy, which is easily soluble, and is suited to the power of digestion of the individual ; and, in order to render the $\Lambda$. perfect, the nutritious parts must be mixed up with a certain quantity of innocent substance affording no nourishment, to fill the stomach, because there is no doult, that many people injure their health by taking too much nutritious food. In this case, the nutritious parts which camnot be dissolved act precisely like food which is in itself indigestible. (See Digestion.) In Prussia and Austria, where, as in many despotic governments, the nuedical police is very good (this being a thing much more easily regulated in an absolute government than in a free one), the public officers pay much attention to aliment, and are careful that provisions exposed to sale shall be of a good quality, particularly that no decayed or adulterated things are solil to the poor. Such regulations exist. 
to a certain extent, in Fingland, France, the United State's of America, and in fact, in every civilized country. The kind of $\Lambda$. used influences the health and even the chancter of man. He is fitted to derive nourishment both from aninal and vegetable A., but can live exclusively on either. Experience pmves that animal food nost readily augments the solit parts of the blood, the fibrin, and, therefore, the strength of the muscular system, but disposes the body, at the sane time, to inflammatory, putrid, and scorbutic diseases, and the character to violence and coarseness. On the contrary, vegetable fool renders the blood lighter and more liquid, but fonns wrak fibres, disposes the system to the diseases which spring from feebleness, and tends to produce a gentle character. Something of the same difference of moral effect results from the nse of strong or light wines. But the reader must not infer that meat is indispensable for the support of the bodily strength. The peasants of some parts of Switzerland, who hardly ever taste any thing but bread, cheese, and butter, are vigorous people. The nations of the north incline generally more to animal $\mathbf{A}$.; those of the south, and the Orientals, more to vegetable. These latter are generally simpler in their diet than the former, wheu their taste has not been corrupted by luxurious indulgence. Some tribes in the East, and the caste of Brahnins in India, live entirely on regetable food. The inhabitants of the most northeri regions live almost entirely upon aninal food, scarcely ever partaking of any vegetable substance, at least during the greater part of the year. Some nations feed chiefly on terrestrial animals, others on aquatic ones.

Asmovy, in law; the allowance to which a woman is entitled on a legal separation from her husband, not occasioned by adultery or elopement on her part.

Allgonat Part, in arithmetic; a part of a givell quantity which will not divide it exactly, or without remainder.

Alegot Part is such part of a number as will divide and measure it exactly, without any remainder. For instance, 2 is an aliquot part of 4,3 of 9 , and 4 of 16. To find all the aliquot parts of a number, divide it by its least divisor, and the quotient by its least divisor, until rou get a quotient not further divisible, and you will have all the prime divisors or aliquot parts of that number. By multiplying any 2 or 3 of these together, you will find the compound aliquot parts. Aliquot parts must not be confounded with commensurable ones; for though the former are all commensurable, yet the latter are not always ali. quot parts : thus 4 is commensurable with 6 , but not ant aliquot part of it.

ALKAL, in ehemistry; from the Arabian kali, the name of a plant from the ashes of which one species of alkali can be extracted. The substances that are met with under the denomination of alkaline are possessed of certain peculiar properties; they are mainly characterized, however, by a power of combining with acids in such a mauner as to impair the activity of the latter, so that alkalies, as chemical agents, are distinguished by properties the reverse of acids; acids and alkalies are, therefore, generally considered as antagonist substances. Besides the power of neutralizing acids, and thereby forming certain saline substances, the alkalies are further distinguished by the following properties:-1, they have an acrid taste and corrosive power whell applied to some substances, thus proving caustic to the skin and tongue; 2 , they change vegetable-blue to green, red to purple, and zellow to a reddish-brown (if the purple be reddened by an atid, an alkali will restore the original colour); 3 , they are almost indefinitely soluble in water; that is, they combine with it in every proportion; 4, they mite with oils and fats, and form by this mion the wetl-known componnd callesl soop. There is another class of substances which have a strong analogy with alkalies, especially in the particular of op position to acids, viz. the earths. Some of these, indeel, have been classed by Fourcroy among the alkalies, but they have been kept separate by others, on the gromd that the analogy between them is far from anomuting to an identity of properties. The true alkalies have been arrangei by a modern chemist in three classes:-1, those which consist of a metallic basis, combined with oxygeu ; these are three in number-potish, soli, and fithia ; 2, that which contains no oxygen, viz. ammonia ; 3 , those containing oxygen, hydroge $n$, anu carbon; in this class are placed aconiti, atropia, brucir, cicuta, datura, delphia, hyoscyania, morphia, strychina. And it is supposed that the regetable alkalies may be found to be as numerous as the regetable acils. The original distribution. of alkaline substances was into volatile and fixel, the volatile alkali being knotwn under the name of ammonic ; while of the two fixed kinds, one was called potash, or vegetable, because procured from the ashes of vegetables generally; the other soda or mineral, on account of its having been principally olstained from the incineration of marine plants.

AlKaNer is a dyeing drug, the bark of a root which produces a rough plant (anchusa tinctoria), with downy and spear-shaped leaves, and clusters of small, purple, or reddish flowers, the stamens of which are shorter than the corolla. This plant is sometimes cultivated in Britain, but by far the greater portion of the A. here used is imported either from the Levant, or from the neighbourhood of Montpellier in France. A. imparts a fine deep-red colour to all unctuous substances and to spirit of wine; but it tinges water with a dull, brownish hue. Its chicf use is for the colouring of oils, plasters, lip-salve, and other similar articles. It is likewise euploged in compositions for rubbing and giving colour to mahogany furniture, Wax, tinged with $\Lambda$., and applied to the surface of warm marble, stains it fleshcolour, and sinks deep into the stone.

Alkman, Henry von. See Reynard the Fox.

A LKorax. See Koran.

All-rours; a game played by two persons with an entire pack of cards. The name is derived from the four chances of which it consists, viz. High, Low, Jack, and Game.-Laws of the game. 1. If, in dealing, the dealer discovers any of the adversary's cards, a new deal may be demanded. 2. If the dealer, in dealing, discovers any of his own cards, he must abide by the same. If it is discovered, previous to playing, that the dealer has given his adversary too many cards, there must be a new deal ; or, if both parties agree, the extra cards may be drawn by the dealer from his opponent's hand; and the same if the dealer gives himself too many cards. But, in either case, if a single card has been playcd, then there must be another deal. 4. No person can beg more than once in a hand, unless both parties agree. 5. In playing, you must either follow suit or trump, on penaity of your adversary's adcling one: point to his game. 6. If either player sets up his game erroneously, it must not only be taken dowr1, but the antagonist is entitled to score four points, or one, as shall have been agreed upon. 7. It is allowable for the person who lays down a high or a low trump to inquire whether the same be figh or low.

AlL Hasdos HoAy, in sea language; the order by which the ship's company is summoned on deck by the boatswain. All hands to quarters hoay, is thes order to the crew for preparation for battle. This 
sommand is nore generally given by the boatswain piping down the hatchway.

ALL IN THE WIND; the state of a ship's sails when parallel to the direction of the wind, so as to shake and shiver by turning the ship's head to windward, either by design or neglect of the helmsman.

All Salyts' Bay, or Bahia da Todos Santos; a bay on the coast of Brazil, province of Bahia. It is secure and large enough for a great number of ships. Lon. $38^{\circ} 50^{\prime} \mathrm{W}$.; lat. $13^{\circ} 10 \mathrm{~s}$.

Au. Saints, Feast of. After the persecution, in the 4th century, against the Christians in the Roman empire, had ceased, the Sunday after Whitsuntide was appointed to commemorate the holy martyrs. Chrysostom's 74th homily was delivered -on such an occasion and shows how far they were from being objects of adoration, A. D. 380. This feast was introduced into the western church, in 610 , by Boniface IV. The emperor Phocas had presented the Pantheon, in Rome, to this pope, who made a church of it, and dedicated it as such, March 4, to the honour of the virgin and all the martyrs. This church still exists under the nnme of Rotunda, or Maria de Martiri. Gregory IV., in 835 , appointed Nov. 1st for the celebration of this feast, and consecrated it to all the saints and angels. In order that it might be generally celebrated, Gregory solicited the emperor I Luis le Débonnaire to confirm it. About the year 840, we find this feast in the calendiur of the monk Wandelbert. About 870 , it was introduced into England.

ALL Soors; a ferst celebrated on the $2 \mathrm{~d}$ of November, in commemoration of all the faithful deceased. It was instituted in the 11th century.

ALLA BREVE is the proper designation of the time of a piece of music, in which the breve is equal to a semibreve in 2 time; and is to be played in a morement of twice the usual rapidity; so that a breve is played as fast as a semibreve, a semibreve as fast as a minim, and so on. It is usual, in this mode of time, to prefix to the piece a designation, that resembles a $\mathrm{C}$ with a perpendicular line through it, but is intended to represent a circle bisected; sometimes also $\mathrm{a}^{2}$, or large 2 , or ${ }_{1}^{2}$. It is, however, distinct from two-minim time, which is also often called alla breve time, and may be designated by 2 , and $C$ with a perpendicular. line through it; but the value of the note corresponds with the designation. Besides, the expression alla capella is sometimes used; by which phrase is meant, that though the notes in their proportional magnitide are the sane as in the ancient psalm tune, yet they are not to be giveu in the choral style as sung by the congregation, but more lively, as is usual in the chapel style.

Allasi, or Alla, in Arabic; the name of God, the Creator of all nature, of whom Mohamined says, he is the ouly being who derives his existence from himself, and has no equal. All creatures are made by him. He is lord of the material and spiritual unirerse; and Molnmmerl inculcates obedience to him as the one true God, the Author of his religion. The word is compounded of the article $a l$, and the word Elali; which signifies the Adored, and the Adosable, and is synonymous with the singular of the IIebrew word Elohim.

Allas, David, a Scottislı historical painter, was born at Alloa in 1744. Some early cfforts of his genius laving attracted attention, he was sent to the Messrs Foulis's academy of painting and cngraving, in Glasgow, where he remained seven years. He afterwards visited Italy, where lie passed sixteen years in pursuing his studies, and copying the remains of antiquity, and the old masters. While at Rome, in 1773 , he received a geld medal, for the best speci- men of historical composition: On his retum, he established himself at Edinburgh, where hedied, in 1796. His illustrations of the Gentle Shepherd, the Cotter's Saturday Night, and other sketches of rustic life and manners in Scotland, in aquatinta, obtained for him the name of the Scottish Hogarth. His principal painting is the Return of the Prodigal Son. The subject of his prize composition, which is much admired, is thc Origin of Painting.

Allatios, or Allaccl, Leo, a Greek physician, librarian of the Vatican at Rome, and a professor is! the Greek college there. He was a native of the island of Scio, and died in 1669, aged eighty-three. He published a variety of works, chiefly on church listory. It is told of him, that he used but one pen for upwards of forty years, and shed tears when it became entirely unserviceable.

Allay. See Alloy.

Allegliany, or Appalachian Modvtains ; A range of mountains in the United-States. 'They commence in the northern part of Georgia and Alabama, and run nortli-east to the state of New York, nearly parallel with the sea-coast, about 900 miles in lengtl, and from 50 to 200 in breadth. They divide the rivers and strenms of water, which flow into the Atlantic on the E., from those which flow into the lakes and the Mississippi on the W. These nountains are not confusedly scattered and broken, but stretch along in uniform ridges, for the most part searcely lialf a mile high. The several ridges are known by different names, as Blue ridge, Alleghany ridge, north mountain, Jackson's monntain, Laurel mountain, Cumberland mountains, \&c. - For the geological structure of these mountains, see North America.

AlLFGHANY; a river which rises in Lycoming county, Pennsylvania, winds through the south part of New York, turns again into Pennsylvania, ruus S. W., and unites with the Monongahela at Pittsburg, to form the Ohio. It is navigable for keel boats of ten tons to Hanilton, in New York, 260 miles above Pittsburg. Its most important branches are the Kiskimenetas, and Toby's and French creeks.

Alleglance (from alligare, to bind); the obedience which every subject or citizen owes to the government of his country; in England and the United States, obedience to its lawful commands. It is the doctrine of the English law, that naturalborn subjects owe an allegiance which is intrinsic and perpetual, and which cannot be divested by any act of their owu. It has been a question frequently and gravely argued, both by theoretical writers and in forensic discussions, whether the English doctrine of perpetual allegiance applies in its full extent to the citizens of the United States of America. From an historical review of the principal discussions in the federal court of the United States on this interesting subject in American jurisprudence, the better opinion would seem to be, that a citizen call. not renounce his allegiance to the United States without the permission of government, to be declared by law; and that, as there is no existing legislative regulation on the subject, the rule of the Finglish common law remains unaltered. (See Kent's Commenturies, vol. ii.) If an alien wishes to become a citizen of the United States, lie must renounce his allegiance to the gorernunent wlose subject he has been, as long as two years before lie? can be admitted to take the oatlo of allegiance to the government of the United States.

AlLEGORY (from the Greek a $\lambda \lambda$ o, something else, and ayoous, to speak); a figurative representation, in which the signs (words or forms) siguify something besides their literal or direct meaning. Irony is distinguished from allegory by conveying a meaning 
directly contrary to the literal signifiention of the wonls, while in allegory there is an agreenent between the literal and the figurative sense, each of which is complete in itself. "The allegery should be so constructed as to express its meaning clearly and strikingly; and the more clear and striking the menuing is, the better is the allegory. All of the fue arts have, to a certain degree, an allegorical character, because, in all, the visible signs generally represent sonething higher, - the ideal; but in the narrower sense of allegory, its object is to convey a neaning of a particular cliaracter by means of signs of an analogous import. The allegory, noreover, ought to represent an ensemble, by which it is distinguished from the trope or metaphor and the conrentional symbol. The last differs from the allegory, also, in this particular, that its claracter could not be understood, if it lad not been previously agreed upon. For instance, the olive-branch would not convey the idea of peace if it lad not been adopted as its sign. From all which has been said, it is clear, that the allegory can take place in rhetoric, poetry, sculpture, painting, and pantomime, but never in inusic or architecture, because these two. arts are not capalule of conveying a double meaning in their representations. As an instance of allegory in poetry, Prior's verses from Henry and Emma may serve:

"Did I but purpase to embark with thee On the smooth surface of a summer sea, While gentle zephyrs play with prosperous gales, And fortune's favour flls the swelling sails,

But would forsake the ship, and make the shore,

When the winds whistle, and the tempests roar ?"

or the often quoted ode $i ., 14$ of Horace. An instance of allegory in painting or sculpture is the representation of peace by two turtle-doves sitting on their nest in a helmet or a piece of ordnance ; or Guido's representation of Fortuna. The representation of an allegory ought always to lead directly to its figurative meaning; thus a warrior throwing the dores out of a helmet would be a bad allegory of war; a good one would be a husbandman making a weapon out of his scythe. In rhetoric, allegory is often but a continued metaphor. The symbolic and allegoric representation of ten come very near to each other, and sometimes it is hard to say to which a piece of art most inclines. This is the case, for instance, with the beautiful representations of Justice, Poetry, \&c., by Raphael, in the Vatican. Parables and fables are a species of allegory; e. g. the beautiful parable in one of the tales in the Arabian Nights, in which the three religions, the Mahommedan, Jewish, and Christian, are compared to three similar rings, bequeathed to three brothers by their father. This allegory has been repeated by Boccaccio in a tale of his Decameron, and by Lessing, in his Nathan the Wise. Allegory in rheloric was used by the most ancient nations, because it is well fitted to express an elevated state of feeling, and, at the same time, to gire somewhat of the charm of novelty to ideas at once common and important. Addison truly says, "Allegories, when well chosen, are like so many tpacts of light in a discourse, that make every thing about them clear and beautiful. In painting and sculpture, however, the ancients made by no means so much use of allegory as the modern artists, partly owing to their greater facility of expressing certain ideas by means of the stories and the innges of their different gods, who all more or less represented a single idea. The moderns have no such copious stores of illustration, the protestants particulariy, who are not familiar with the multitude of catholic saints and legends; thus they are often obliged to express single ideas by allegory. Another cause of the greater prevalence of allegory in modern times is to be found in the circunistance, that allegory is always more cultivated in the period of the decline of the arts, when the want of great and pure and simple conceptions of the beatiful is supplied by studied and ingenious inventions, as well as in the fact, that the ancients were more exclusively conversant with simple ideas than the moderns, among whou the relations of society are much more complicated, and every brancls of science, art, and social life more fully developed. Sometimes whole poems are allegorical, as spenser's Fairy Queeu; but, in these cases, the poct uust take gruat care not to fall into trifling. J3ungan's Pilgrim's Progress is a faunous instance of a work wholly allegorical. There was a time when every poem was taken as an allegory; even such works as those of $\Lambda$ riosto and Tasso were tortured from their true meaning, and made to pass for allegorical pictures. There exist many editions of these poets, in which, at the loginning of each canto, the allegory of it is given. With equally little reason, the Song of Solonon las lung been considered an allegory of Clurist's love to his church. The uiost productive period of allegory in painting and sculpture was that of Louis XV., which may be styled, in regard to the arts, the age of fattery. During this period, inmumerable bad, and some good ones were produced. They are now much less in vogue. Rubens painted several fine allegorical pictures, in the Luxemburg gallery. Lessing, Herder, and Winckelmam have iurestigated the subject of this article, perhaps, more thoroughly than any other modern writers. No poet, in our opinion, has made use of allegory in a more powerful and truly poetical manuer than the great Dante; yet the opinion that the whole of his Divina Commedia is allegorical, is quite erroneous.

AlLEgR1, Gregorio, a singer in the papal chapel, and considered to this day, in Italy, one of the most excellent composers of his time, was born at Rome, in 1590, and died there in 1652. He was a scholar of Nanini. His Miserere, one of the most sublime and delightful works of human art, has particularly distinguished him. It is even now sung yearly, during passion-week, in the Sistine chapel at lione. This composition was once esteemed so holy, that whoever ventured to transcribe it was liable to $\mathrm{ex}$ comnunication. Mozart disregarded this prohibition and, after two hearings, marle a correct copy of the original. In 1771, it appeared at London, engraved, and in 1810, at Paris, in the Collection des Classiques. In 1773, the king of England obtained a copy, as a present from the pope himself." According to the opinion of Baini, at present the leader of the choir (maestro della cappella), in the pope's chapel, the Miserere of Allegri was not composed for all the voices, but only the bass of the eighteen or twenty first parts; all the rest is the addition of sl:ccessive singers. But in the beginning of the 18th century, the existing manner of singing it was established as a standard at Rome, by the orders of the pope. A full score of it has never existed.-A. is also the name of an Italian satirical poet, a native of Florence, who flourished towards the end of the $10 \mathrm{th}$ century. His Christian name was Alexander.

Allfgro, in music; a word denoting one of the six distinctions of time. It expresses a sprightly motion, the quickest of all, and originally means gay. The usual distinctions succerd each other in the following order-grave, adagio, largo, vivace, allegro, presio. Allegro time may be heightened, as allegro assai and allegrissimo, very lively, or lessened, as allegretto or poco allegro, a little lively. Più allegro is a direction to play or sing a little quicker. A LLear, Joseph, the author of a popular religions 
book, entitled "An $\Lambda$ larm to Unconverted Sinners," was born at Devizes in Wiltshire in 1623; edıcated at Oxford; became minister of Taunton in Somersetshire, from which benefice he was ejected for nonconfornity; died in 1688, at the early age of thirtysix.

Alleldia, See Halleluia.

Allevand ; 1, a well-known dance, originally German, distinguished for its sprightliness ; 2, a very lively dancing tune, in two-four time, which las much resemblance to the French tambourine.

Alukv, Ethan, a brigadier-general in the American revolutionary army; was born in Salisbury, Connecticut, but was educated principally in Vermont, to which state his parents emigrated whilst he was yet young. His education was of a limited character. In the disturbances which agitated Vermont, he took an active part against the royal authority, in farour of the Green mountain boys, the name by which the settlers in that territory were designated. -In 1775, soon after the battle of Lexington, in compliance with the request of the legislature of Connecticut, A. collected a body of about 230 Green mountain boys, and marched against the fortresses of Ticonderoga and Crown Point, for the purpose of taking them by assault. At Castleton, he was joined by colonel Amold, who had received directions from the Massachusetts committee of safety to raise a corps of men for the same purpose, but, failing to accomplish that object, he determined to proceed with the small force of colonel A. They arrived at the lake opposite to Ticonderoga, on the zvening of May 9, and, having with great difficulty procured boats, landed eighty-three men on the opposite shore during the night. The day beginning, lowever, to dawn, A. was obliged to attack the fort before his rear could cross the lake, having previously animated his soldiers, by a harangue, which he concluded with saying, "I now propose to adrance before you, and in person to conduct you through the wicket-gate; but, inasmuch as it is a desperate attempt, I do not urge on any one contrary to his will. You that will undertake voluntarily, poise your firelocks." They all immediately poised their firelocks. He then advanced at the head of the centre file to the wicket-gate, where a sentry snapped his fusee at him, and retreated through the covered way, followed by A., who formed his men upon the parade. The apartments of the commanding officer having been pointed ont to him by a centry who asked quarter, he instantly repaired thither, and, holding his sword over captain de Laplace, whom he found undressed, demanded the surrender of the fort. The latter asking him by what authority, "I demand it," said A., " in the name of the great Jehoval, and of the continental congress." De Laplace was constrained to comply with the summons, and the fort, with its stores and garrison, was given up. On the same day, also, A. obtained possession of Crown l'oint, and soon after captured a sloop of war, the only armed vessel on lake Champlain, and thus acquired the entire command of that lake.-In the following autumn, he was twice despatched into Canada, to engage the inhabitants to lend their support to the $\Lambda$ merican cause. In the last of these expeditions, he formed a plan, in concert with colonel Brown, to reduce Montreal. September $10,1775, \Lambda$. accordingly crossed the river, at the head of 110 men, but was attacked, before Brown could join hin, by the 3ritish troops, consisting of 500 men, and, after a most obstinate resistance, was taken prisoner. The events of his captivity he himself las recorded in a narrative conpiled by him after his release, in the most singular style, but apparently with s'eat fulclity.-For some time he waskept in irons, and treated with much severity. He was sent to England as a prisoner, with an assurance, that, on his arrival there, he would ineet with the halter. During the passage, extreme cruelty was exercised towards him and his fellow prisoners. They were all, to the number of thirty four, thrust, hand-cuffed, into a small place in the vessel, enclosed with white-oak plank, not more than twenty feet wide by twenty-two long:- -After about a month's confinement in Pendennis castle, near $\mathrm{Fal}$ mouth, he was put on board a frigate, January 8 , 1776, and carried to Halifax. Thence, after an imprisonment of five months, he was removed to New York. On the passage from Halifax to the latter place, $\mathbf{A}$. was treated with great kindness by captain Smith, the commander of the vessel, and evinced his gratitude by refusing to join in a conspiracy to kill the British captain and seize the frigate. His refusal prevented the execution of the plan. He remained at New York for a year and a half, sometimes in confinement, and sometimes at large, on parole.-On May 6, 1778, A. was exchanged for colonel Campbell, and immediately afterwards repaired to the liead-quarters of general Washington, by whom he was received with much respect. As his health was impaired, he returned to Vermont, after having made an offer of his services to the commander-in-chief, in case of his recovery. His arrival in Vermont was celebrated by the discharge of cannon; and he was soon appointed to the command of the state militia, as a mark of esteem for lis patriotism and military talents. $\Lambda$ fruitless attempt was made by the British to bribe him to lend his support to a union of Vermont with Canada. He died suddenly at his estate in Colchester, February 13, 1789.-General Allen was a man of a strong and enterprising, but haughty and restless mind. Although his education had been circum. scribed, he was daring in his pretensions to knowledge, and bold and peremptory in his assertions. Besides the narrative of his captivity, which we have noticed, and a number of pamphlets in the controversy with New York, he published a "Vindication of the Opposition of the inhabitants of Vermont to the Government of New York, and their Right to form an independent State," 1779, and a work, entitled "Allen's Theology, or the Oracles of Reason," the first formal publication, in the United States, openly directed against the Christian religion. $\Lambda$. was a confirmed infidel. He adopted some of the most fantastical and absurd notions imaginable, believing, with Pythagoras, that the soul of man, after death, would live again in beasts, birds, fishes, \&c. He often told his friends, that he himself would live again under the appearance of a large white horse However, there is an anecdote extant, which proves that he professed to entertain those ideas more from an affectation of singularity, than from conviction. Whilst sitting in his library, conversing with a physician of the name of Elliot, $A$. was informed that his daughter was dying, and desired to speak with him. He immediately repaired to her chamber, followed by doctor Elliot. Ifis wife was distinguish ed for piety, and had instructed her danghter in the principles of Christianity. As soon as her fatlur stood at her bedside, she said to him, "I am about to die; shall I believe in the principles you have taught me, or shall $I$ believe in what my mother las taught me?" He became greatly agitated; his chin quivered; his whole fiame shook; and, after waiting a few moments, he replied, "Beliere what your mother has tanght you."

AlLEx, Thomas, an eminent mathematician of the reign of Elizabeth, was a native of Staffordshire ;
died in 1632. He is author of several astronomical 
treatises, written in Latin. His skill in science made hin, in his own diny, to be generally reputed a dealer in the blacks art.

ALLErs, Fdwarl; a celebrated actor in the reigns of lilizabeth and James I., better known as the founder of Dulwicl college. Ile was bon 1566, in London, in the parish of St Botolph, Bishopsgate. Acconling to the testimony of Ben Jonson and the ether dramatists of the age, he was the first actor of the day, and of course plnyed leading characters in the plays of Shakspeare and Jonson; although, in consequence of the names not being set against the parts in the old editions of those authors, his partieulur share in them is uot ascertained. He was keejer, of the myal bear-garden. Ilaving become wealthy, he founded Dulwich college, for the maintenance of one master, one warden, and four unmarried fellows of the name of Alleu, three whereof were wo be clergymen, and the fourth a skilful organist; also six puor men and as many women; and twelve poor boys, to be educated until of the age of fourteen or sixteen, and then put out to some trade or calling. Aubrey tells a ridiculous story of the origin of this donation, in a fright endured by $\Lambda$., who saw a real devil on the stage, while himself performing a fictitious one in a drane by Shakspenre. After the college was built, he met with some difficulty in ubthining a charter, owing to the opposition of the lord chancellor Bacon. The very mational letter of this great man to the marquis of Buckinglam on this sulject, is extant. $\Lambda$. was the first master of his own college, and, dying in 1626, was buried in the new elapel belonging to it. Within these few ycars, it has been brought into great additional notice by the ahnirable collection of pictures of the best masters, bequeathed by Sir Francis Bourgeois.

Allgemanf Zatong, i. e. General Gazette; a German political daily paper, published at $\Lambda$ ugshurg in Bavarin, for which reason it is sometimes called loy foreigners the Augsburg Gazetle. The A. Z. is by far the best German newspaper, and particularly rich in information respecting the affairs of the East and of Italy. The summary of new publications which it contains semi-annually after the book-fair in Leipsic is excellent. Baron Cotta, the owner of the $\Lambda . Z$. has regular correspondents in Constantinople, in almost all the capitals of Europe, and in the United States of America. He has recently established another daily pajer, Das Ausland, at Munich, which contains accounts of foreign countries nuly. The $A$. Z. has existed now forty years or lunger. It is, like all the German newspapers, sinall in comparison with the British or American, and is ufforded at a very low price.-For a general view of newspapers, see Neuspapers.

Alliance; a league between two or more powers. Alliances are divided into offensive and detensive. The former are for the purpose of attacking a common enemy, and the latter for mutual defence. An alliance often unites both of these conditions. Offensive alliances, of course, are usually directed against some particular enemy; defensive alliances against auy one from whom an attack may come. Âs regards the obligations and rights of the contracting parties, alliances are divided into three chief classes: -1. Those in which the allied parties agree to prosicute the war with their whole force (societé de guerre; alliance pour faire la guerre en commun). In this case, all the parties are principals. 2. Auxiliary alliances, if the allies pledge themselves mutually to furnish assistance to a fixed amount, in which case only one of the contracting powers appears as princip̧al. 3. Mere treaties, by which one power uromises, in consideration of certain subsidies, to furmish troops, or to place its troops in the pay of ano. ther power, withont directly taking part in the war: or to make ouly advances of money. Triple alliance is an alliance between three, quadruple alliance, quintuple alliance, letween four and five powers. See Coalition, Quadruple Alliance, and Holy Alti ance.

Allance, Holy. See Holy Alliance.

Alugation is, in aritlunetic, of two kinds, alternate and medial. Alligation ullernute is the methol of finding the quantities of ingredients of different values, necessary to form a compound of al given value, and it is the converse of alligntion mediul, which teaches low to find tlie menn rate of a mix ture, when the prartieular quantities conposing the mixture, and their respective mean rates are givon.

Alligator; the name of a large reptile, of the saurian or lizard order, derived, according to Cuvier, from a corruption of the l'ortuguese wort lagarto, equiralent to the Latin lacerta. 'Ihe alligators or cainans form the second sul,-genus of Cuvier's crocodile family, and belong to the soutliern parts of the Anerican continent. 'I'wo species, very mumerous in these regions, are well known; the spectuclerl caiman, crocodilus sclerops, most common in Guiana and Brazil ; and the pike-nosed $\mathrm{A}$. (C. lucius), frequenting the southern rivers and ligoons of the United States. - In the water, the full grown $A$. is a terrible animal, on account of its great size and strength. It grows to the length of fifteen or twenty feet, is covered by a dense hardness of horny scales, impenetrable to a musket ball, exeept about the head and shoulders, and has a liuge mouth, armed witl a fearful row of strong, unequal, conical teeth, some of which shut into cavities of the upper jaw-bone. They 'swinn or dart along through the water with wonderful celerity, inpelled by their long, laterilly. compressed, and powerful tails, which serve as very efficient oars. On land, their motions are proportionally slow and embarrassed, because of the length and unwieldiness of their bodies, the shortness of their linus, and the sort of snall, false ribs which reach from joint to joint of their necks, and render lateral motion very difficult. In addition to the usual number of ribs and false ribs, they are furnished with otlıers, for the protection of the belly, which do not rise up to the spine. The lower jaw extends farther back than the skull, so that the neck must be somewhat bent when it is opened; the appearance thus produced has led to the very universal error of believing that the $\Lambda$. moves its upper jaw, which is incapable of motion, except with the rest of the body. Under the throat of this animal are two openings or pores, the excretory ducts from glands, which pour out a strong, musky fluid, that gives the $A$. its peculiarly unpleasant smell.-In the spring of the year, when the males are under the excitement of the sexual propensity, they frequently utter a roar which is a rery alarming sound, from its harshness and reverberation, resembling distant thunder, espocially where numbers are at the same time engaged. $\Lambda$ t this period, frequent and terrible battles take place between the males, which terminate in the discomfiture and retreat of one of the parties. At this season, also, an old champion is seen to dart forth un the surface of the waters, in a straight line, at first as swiftly as lightning, gradually moving slower as he reaches the centre of a lake; there lie stops, infates himself by inhaling air and water, which makes a loud rattling in his thrnat for a moment, until he ejects it with vast force from lis mouth and nostrils, making a loud noise, and vibrating his tail vigoronsly in the air. Sometimes after thus inflating linnself, with head and tail raised above the water, lie whirls round until the waves are worked to foam, and at length retires, leaving to others an opjor- 
tunity of repeating similar exploits, which have been compared to an Indian warrior rehearsing his acts of bravery, and exhibiting his strength by gesticulation. -The fentales make their nests in a curious manner, upon the banks of rivers or lagoons, generally in the marshes, along which, at a short distance from the water, the nests are arranged somewhat like an encampment. They are obtuse cones, four feet high, and about four feet in diameter at the base, built of mud and grass. A floor of such mortar is first spread upon the ground, on which a layer of eggs, having hard shells, and larger than those of a common hen, tre spread. Upon these another layer of mortar seven or eight inches in thickness, is deposited, and then another bed of eggs; and this is repeated nearly to the top. From 100 to 200 eggs are found in one nest. It is not ascertained whether each female watches her own nest exclusively, or attends to morc than her own brood. It is unquestionable, however, that the females keep near the nests, and take the young under their vigilant care as soon as they are liatclied, defending them with great perseverance and courage. The young are seen following the mother through the water like a brood of chickens following a hell. When basking in the sun on shore, the young are heard whining and yelping about the mother, not unlike young puppies. In situations where alligators are not exposed to much disturbance, the nesting-places appear to be very much frequented, as the grass and reeds are beaten down for several acres around. The young, when first hatched, are very feeble and helpless, and are devoured by birds of prey, soft-shelled turtles, \&c., as well as by the male alligators, until they grow old enough to defend themselves. As the eggs are also eagerly sought by vultures and other animals, the race would become speedily extinct, but for the great fecundity of the females. - The A. is generally considered as disposed to retire from man, but this is only to be understood of alligators frequenting rivers or waters where they are frequently disturbed, or have learned to dread the injuries which man inflicts. In situations where they are seldom or never interrupted, they have shown a ferocity and perseverance in attacking individuals in boats, of the most alarming character; endeavouring to overturn them, or rearing their heads from the water, and snapping their jaws in a fearful manner. Bartram, who has made more interesting and valuable observations on the $A$. thau any other naturalist, gives numerous instances of their daring and ferocious disposition, and himself very narrowly escaped with his life on several occasions. At present, alligators, though still numerous in Florida and Lollisiana, are no longer regarded as rery dangerous. Their numbers annually decrease, as their haunts are intruded upon by man, and at no distant periol they must be nearly, if not quite, exterminated.-In the winter, thic alligators spend great part of their time in deep holes, which they make in the marshy banks of rivers, \&c. They feed upon fish, various reptiles, or carrion flesh which is thrown into the streams, and, though very voracious, are capable of existing a long time without food. The barking of a dog, it is said, will at any time cause them to forsake their holes, and come on shore, as they prey upon any small quadruped or donestic aninal which comes within their reach. They lave a very snall brain, and live a long time even after it is destroyed. Titian Peale, a naturalist distinguished for practical acquaintance with the works of nature, informed thic writer that he destroyed the whole superior part of the head and brain of a large $A$. by a ball from his gun, iil the morning of a long day, and, on passing the same place in the evening, he found thc animal had crawled off. Following his trail through the marsh for a considerable distance, he found him still alive, and, though dreadfully mangled about the head, ready to give battle.- In the economy of nature, alligators are of very considerable importance. They abound most wliere fish and other creatures are found in the greatest numbers. Their voracity tends to repress exuberant increase in the beings upon which they feed; while themselves are exposed to very numerous enemies in early life, and gradually pass away, as man usurps the sway over their peculiar dominions. The peculiarities of construction, \&c. will be given under the title Crocodile, which see.

Aluosi, Charles, an esteemed physician and professor of botany at Turin, was born in 1725, and died in 1804. He published various works, which tended to the advancement of medical and botanical science.

ALutrRation; a figure or embellisliment of specch, which consists in the repetition of the same consonants, or of syllables of the same sound, in one sentence. Such alliteration. sometimes happens witlout the intention of the writer or speaker, and may be disagreeable to the ear, in the same way as a rhyme occurring involuntarily. Alliteration is pleasing when skilfully managed, so as to produce what the French have called harmonie imitative; but by too frequent use, it becomes trivial and ridiculons. An excellent instance of imitative harmony and happy alliteration is afforded by the line of Virgil, describing the measured gallop of the horse-

Quadrupedante pedum sonitu quatit ungula campum; or another verse of the same poet-

Luctantes ventos tempestatesque sonoras-

in which the continual recurrence of the $t$ reminds us of the uninterrupted noise of the winds. Greek literature affords many instances of this imitative harmony. English poetry furnishes many beautiful specimens of alliteration, but instances of an unhappy use of this figure are not wanting even in good writers. Gray has many alliterations, e. g.

Weave the warp and weave the woof, or,

Ruin seize thee, ruthless king!

Among the Frencl, a line of Racine-

Poux qui sont ces serpens qui sifflent sur vos tetes?-

is thought to represent very happily the hissing of the serpent. In German literature, Burger, perliaps, lias made the most use of alliteration; but he often carries it too far. A sonnet of A. W. Schlegel finishes with the following:

Wo Liebe lebt und labt ist lieb das Leben.

Among modern languages, alliteration is altogether more used in those belonging to the Teutonic stock, than in those of Latin origin. So far has A. sometimes been carried, that whole treatises have been composed, each word of which coumenced with the same letter. Not the least successful specimen of burlesque $\Lambda$. arc the lines on Cardinal Wolsey-

Begot by butchers, but by bishops bred,

How high his honour holds bis haughty head !

$\Lambda$ LLOA, a sea-port town, situated pleasantly on the north side of the Forth, five miles from Stirling, and in the county of Clackmaunan, Scotland. It las been long a place of some note, and contains within its vicinity a massy tower, which was erected in the 13th century, and at one period occupied as a royal residence. It has an excellent harbour, from which it exports great quantities of coal, the chief 
imports being grain, linestone, ironstone, and wood aul iron from the Baltic. Several large distilleries, breweries, glass and brick works, \&ic. are in the neiglibourlivol of $A$. The population of the parish is 6:377. General Sir Ralph Abercronby, and David Allan, the painter, were natives of Alloa.

Alcodion; land held by a man in his own right, without any feudal obligation. It is opposed to fee, or feubun. All landed property unust be either fendal or allodial. In Eingland, accorling to the theory of the British constitution, all land is held in fex. The worl allodial is, therefore, never applied to landed property there. Such as is really allodial bears the naine of feesimple. The same word is ised in the United States of America, though land is not held there, in fact, by any fendal tenure. In ancient France, the feudal claracter of landed property was taken for granted, (nulle terre sans seigneur,) until the contriry was proved. In Germany, the contrary rule prevails. As the vassal is under many restrictions in respect to the disposal of the feud, and as the principles of inheritance with respect to the $A$. are, in some particulars, different from those which govern the feud, the distinction is of importance. If a feud falls back to the lord, of course the $A$, is separated from it; the same takes place when the heir of the A. and that of the feud are different persons. In Germany, the word allodificiren signifies to make an estate allodial, which is faroured by many governments. In such allodification, a part of the value must be paid as a compensation to the former lord, or a fixed annual tax (canon) is imposed on the estate. The great, ant generally successful efforts, which the Prussian government has made for about seventeen years, to absolve the estates of the peasants from all feudal obligations, on the payment of a certain part of their value to the lond, must be considered as one of the consequences of the enlightened spirit of the age, even in countries not favoured with a representative government. - The immense change whieh took place in France, during the revolution, by the extinction of all feudal tenures, and the endeavours to bring about the same change wherever governments in the French spirit were established, e. g. in the kingdom of Westphalia, are well known. The etymology of the word A. is uncertain; most probably it is of German origin.

AlLo:var, an ancient parish in the district of Kiyle, situated on the river Doon, between Marbole and $\mathbf{A y r}$. It is now united to the parish of Ayr, and its cluurch has fallen into ruins; nor would it have been considered of sufficient importance to be noticed here, had the place not given birth to Robert Burns, who has rendered it for ever sacred ground, and lighted up "Allowry's auld haunted kirk" with an unfarling lustre.

ALLoY; a composition, the result of a mutual combination of two or more metals. To alloy generally means to mix $₫$ metal of less with one of more value. Various processes are adopted in the formation of alloys, depending upon the nature of the metals. Many are prepared by simply fusing the two metals in a covered crucible. It has been a question whether alloys are to be considered as compounds, or as mere mixtures. Mr Dalton considers alloys to be chemical compounds, one striking instance of which is in the alloy of tin and copper, called speculum metal; the smallest deviations from the true proportions will spoil the alloy as a reflector. In some cases, the metals are found to unite in definite proportions only; and it is probable that all the alloys contain a definite compound of the two metals. - The principal characters of the alloys are the following:-1. We ubserve a change in the duetility, malleability, hardness, and colour. Malleability and ductility are usually impairen, aut often in a remarkable degree; thiss gold and lenl, and gold and tiu, fonn a brittle alloy. The alloy of copper and gold is havder than either of its compom nent parts; und a mimute quantity of arsenic added to eopper renders it white. 2. The specific gravity of an alloy is marly the mean of its component parts; in some cases an incrense, in others a diminution of density laving taken place. 3. The fusibility of au alloy is generally greuter than that of its components. Thus platinum, which is infusible in our conmon furnaees, forms, when combined witl arsenic, a very fusible alloy; nud an alloy of certuin proportions of lead, tin, and bismuth is fusible at $212^{\circ}$, a temperature several demrees below the melting point of its most fusible constituent. 4. Alloys are generally more oxydizable than tlieir constituents taken singly; a property which is, perhaps, partly referable to the formation of al electrical combination. From early times, the laser metals have been used to alloy gold and silver coins, to prevent loss by wear. In Fngland, the legal proportion of base metal for gold coin is onte part in twelve, and for silver eoin three parts in forty. In France, the legal proportions of the different coins are as follows: silver coin, nine parts silver, one copper; copper money, four parts copper, one silver; gold coin, nine parts gold, one copper. For silver plate, the French proportions are nine and a half parts silver, one-half copper; for trinkets, eight parts silver, two copper. For gold plate they liave three different standards; ninetytwo parts gold, eight copper; also, eighty-four gold, sixteen copper, and seventy-five gold, twentytre copper. Gold and silver are alloyed partly that they may wear better, partly to diminish the priee of articles made of them.

Allspice, or Pinasta, is the dried berry of a West Indian species of myrtle (myrtus pimenta), which grows to the height of twenty feet and upwards, and has somewhat oval leaves about four inches long, of a deep shining, green colour, and numerous branches of white flowers, each with four small petals. In the whole vegetable creation there is scarcely any tree more beautiful or more fragrant than a young pimenta-tree about the month of July. Branched on all sides, richly clad with deepgreen leares, which are relieved by an exuberance of white and richly aromatic floirers, it attraets the notice of all who approach it. Pimenta-trees grow spontaneously, and in great abundance, in many parts of Jamaica; but they cannot be propagater witliont great difficulty. The usual method if making a new pimenta walk, or plantation, is to appropriate for this purpose a piece of woody ground in the neighbourhood of an already existing walk, or in a part of the country where the scattered trees are found in a native state. The other trees are cut down; and, in a year or two, young pimenta plants are found to spring up in all parts, supposerl to have been produced from berries dropped there by birds, which eagerly devour them. Abont the month of September, and not long after the blnssoms have fallen, the berries are in a fit state to bu gathered. At this time, though not quite ripe, they are full grown, and about the size of pepper-corns. They are gathered by the hand; and one labourer on a tree will strip them off so quickly, as to employ three below in picking them up; and an industrious picker will fill a bag of seventy pounds' weiglit in a day. The berries are then spread on a terrace, in the sun, to be dried, but this is an operation which requires great care, from the necessity of kepping them entirely free from moisture. By the drying 
they lose their green colour, and become of a reddisli brown; the process is known to be completed by their change of colour, and by the rattling of the seeds within the berries. They are then packed into bags or hogsheads for the market. When the berries are quite ripe, they are of a dark-purple colour, and filled with a sweet pulp. Pimenta is thought to resemble, in flavour, a mixture of cillnamon, nutmegs, and cloves, whence it has obtained the name of all-spice. It is much employed in cookery, and is chiefly used in whole grains. It is also employed in medicine, as an agreeable aromatic, and forms the basis of a distilled water, a spirit, and an essential oil. 'The leaves of the pimenta-trees yield, in distillation, an odoriferous oil, which is not unfiequently used, in medical preparations, instead of the oil of cloves.

Allon. See Alum.

Alluvion, (from the Latin alluvio, or adluvio, rising or swelling of a river, flood, deluge) now signifies a gradual increase of land along the seaslore or the banks of large rivers, or at their nouths. Great alterations in the limits of countries are produced by A. ; e. g. New Orleans and Messalonghi stand on land formed by A. Holland, too, constantly experiences the effeets of $A$. Whole islands are often formed by this cause. In most of the countries on the European continent, the sovereigns have declared themselves owners of all alluvial formations. In Germany, $A$., which is there called by the much more proper name Anlandung, takes place constantly on the coast of the North sea, owing, probably, to the great extent of flats along the shore, on which every tide deposits some mud. This alluvial land is at first without vegetation; then the salicornia maritima appears, which affords a rich salad. Next.follows' poa maritima, and, on very rich A., aster tripoleum, $-\mathrm{a}$ plant from one to six feet ligh. In this state, the $A$. receives the uame of Vorland, and geese begin to resort to it. Afterwards it is diked, and used as pasture for sheep, horses, and cattle. It is supposed that this kind of land will increase much, in consequence of the many flats along the sea-shore of Germany.

Alma. The Latin word almus belongs to those words which canuot be rendered precisely in other languages, and of which every idiom possesses some. It means cherishing, nourishing, fustering, bountiful, dear. This epithet, therefore, was applied to gods, men, qualities, and things-Alma Ceres, A. Venus, A. lux, A. parcus, \&c. In modern times, it is particularly used in Italy, alma cittu, for Rome, and in Britain, alma mater, for Oxford, Cambridge, \&c., by those who have received their education at these universities. This custom has been transplanted into the United States of America. Sometimes A. is used as the Christian name for individuals of the female sex.

A llasgest; a celebrated book, composed by Ptolemy; being a collection of the observations and problems of the ancients relating to geometry and astronomy. The original Greek name was

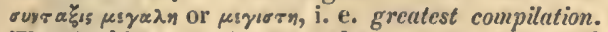
The Arabians, at the time when science flourished among them, translated it, about 827 , and added their article $a$ l to the word megiste; thus the word almagest originated. (See Ptolemy.) In 1230, the emperor, Frederick Il., caused this work to be translated from the Arabic into Latin.

Almagro, Diego; a Spaniard of low birth, one of the adventurers who accompanied Francis Pizarro. He showed himself brave, profligate, and cruel. In 1525 , he took Cusco, the ancient capital of the incas, by storm, when he exhibited the greatest barbarity towards the uufortunate $\Lambda$ tahualpa, or Alaba. lipa, as he is sometimes called, the last monarch of the race of Manco Capac, and put him to a horrid death. Quarrelling with Pizarro about the division of their spoil and power, a schism ensued; and both factions taking arms, Almagro was defeated, made a prisoner by his rival, and strangled in 1538 , at the age, it is said, of 75. His son, however, succeeded in avenging him: the friends of his father, rallying round him, assassinated Pizarro in his turn, after an obstinate resistance, in his own palace, July 26,1541 . This outrage excited the attention of de Castro, viceroy of Peru; and young Alinagro, fall. ing into his power, was, with a considerable number of his party, executed by his orders in the following year. See Pizarro.

Alaramon, or ABdallah, caliph of Bagdad, was the son of Haroun al Raschid, and succeeded his brother, Al Amin, in 813. He was a great patron of learning, and founded a celebrated academy at Bagdad. He died in 833.

Almanac; a table or calendar, in which are set down the revolutions of the seasons, the rising and setting of the sun, the phases of the moon, the most remarkable conjunctions, positions, and phenomens of the hearenly bodies, for every month and day of the year; also the several fasts and feasts to be ol)served in the church and state, \&c. The history of $\Lambda$., and even the etymology of the word, are involved in considerable obscurity. By some, it is derived from the Arabic al manach, to count. Verstegan, who has written on the antiquities of Great Britain, under the title of "Restitution of decayed Intelligence concerning Britnine," makes the word of German origin, almonat, and says that the Saxons were in the habit of carving the annual courses of the monn upon a square piece of wood, which they called alnonaught. The modern almanac answers to the fasti of the ancient Romans. There are several very splendid English almanacs of the 14th century existing in MS., particularly in the British museum. A very curious specimen is in the library of Corpus Christi college, Cambridge. Almanacs became generally used in Europe within a short time after the invention of printing; and they were very early renarkable, as some are now in England, for the mixture of truth and falsehood which they contained. In 1579, their effects in France were found so mischicvous, from the pretended prophecies which they published, that an edict was promulgated by Henry III., forbidding any predictions to be inserted in them relating to civil affairs, whether those of the state or of private persons. No. such law was ever enacted in England. It is singular, that the earliest English a!manacs were printed in Holland, on small folio slieets; and these have occasionally been preserved, from having been pasted within the covers of old books. In the reign of James I., letters patent were granted to the two universities and the Stationers' Company for an exclusive right of printing almanacs. These, in 1775 , were dectared to be illegal. During the civil wars of Charles I., and thence onward to our,own times, English almanacs became conspicuous for the unblushing boldness of their astrological predictious, and their determined perpetuation of popular errors. This, however, has recently received a check, by the society for the diffusion of usefill knowledge issuing a British almanac, free from deceits and absurdities, and having more to recommend it as a statistical work than former ones, which were all monopolized by the stationers' company of London, and which, much to the discredit of that company, too often abounded in silly doggrels and prophetical ravings. At the present day, the almanacs of the continental states are generally free from mislcading matters of this malure; 
anl the alınanacs most similar to some of those $\mathrm{ex}$ teusively circulated amongst the Fuglish are produced in Persin. $\Lambda$ molem Persian almanac is thus described in the Encyclopadia Metropolituna: " The first page contains a list of fortunate days for certain purposes; as, for example, to buy, to sell, to take medicine, to marry, Rc.; then follow predictions of events, as earthquakes, storıns, political af filirs, \&c., after the mamer of Moore's $\Lambda$ manac, except being apparently inore concise." This resemblance between the productions of a highly-cultivated nation, and one which is noted for its general imorince, is a remarkable instance of the permanency of vulgar errors. The first ahnanac at Constantinople is said to have been printed in 1716, under the direction of Abdounhaun. Regionnontanns was the first person in Europe who prepared almanncs in their present form, with the exception of their preclictions, which were, in all probability, introduced into Europe from the Persians. - Some of the almanacs in the United States still contain predictions respecting the weather. There is, perlaps, no class of books, which bear so obviously the stamp of the age, and of the spirit of different countries, as almanacs. At present, they become every year more full of statistical natter. Once they were almost entirely filled with subjects of a religious character. At another time they overflowed with astrological calculations and predictions. In the time of Napoleon, an almanac was published in Frnnce, in which, to every day, an achievement of the emperor, or something else relating to him, was added. Almanacs, in the petty principalities of Germany, exhibit the endless genealogical tables of the princes. Some almannes in modern Greek, printed at Venice, where, formerly, all books in this language were published, we found full of astrological superstition, and matters relating to the Greek churcl. One of the most curious almanacs which we have seen is an Italian one for 18:2, exhibiting, in a striking manner, the Italian viracity. To the 30th of July is added, Sudano ancora le ossa! to the eleventh of August, Oh! che noja; to July 12, Cascano le lraccia; to Jamury 2, Stivali $e$ Onebrello! In Germany, atsanuch is the name given to anmuls like those which appear in England, and the United States of America, under the nanes of Souvenir, Forget-me-not, \&c. In France, a work appears annually under the title of Almanach des Gourmands, which is conducted with much spirit, and is in high repute among epicures.

ALuANac, Nautical. An important work of this kind is published in England annually, but two or three jears in advance, bearing the name of Nautical Almanac, in which (besides most things essential so general use, that are to be found in other alma.acs) are contained many interesting particulars; more especially, the distances of the moon from the sun, and from certain fixed stars, for every three hours of apparent time, adapted to the meridian of the royal observatory, Greenwich. By comparing these with the distances carefully observed at sea, the mariner may, with comparative ease and certainty, infer his longitude to a degree of accuracy unattainable in any other way, and sufficient for most nautical purposes. This almanac was commenced, in 1767 , by I)r Maskelyne, astronomer royal, and has been continued ever since. During forty-eight years Dr Maskelyne deroted the most sedulous attention to it, and it was distinguished for accuracy. Since his death, it has not been so well conducted, and the board of longitude, under whose auspices it was published, has been lately dissolved. The French Connaissance des Tems is published with the same views as the English Nautical Almanac, aud nearly on the same plan. It commenerd in 1698 , and las been, in one or two instances, discontinuer for short intervals. For mauy years, however, it lias been published with grent regularity, and in a manner lighly creditable to the bureau de longitude. 'The most valuable of the nntical almmacs now existing, is that published at Berlin, under the smper. intendence of professor Encke, who has, within a short time past, taken charge of it. It is called $A s$. tronomisches. Jahrbuch, and is the sane which was conducted for fifty years by professor Boxle, with great credit to hinself. It is distinguished for com. pleteness and accuracy.

ALME, or AlMa; girls in Hindostan and Egypt, whose profession is to tell stories, dance, sing, play, and appear as improvisatrici. Tlie latter accom plishment is not of very difficult acquisition, as the extempore poetry of the Fast deals inuch in repetition, and is little constrained by rule. 'These arts are taught to fenale slaves, with a view to euhance their price in the market. 'The art of telling sturies, of whicls the $\Lambda$ siatics are so fond, is undoubtedly carried to much greater perfoction in the Fast, than with us. The Alnes, in their dances, imitate the occurrences and actions of life, and often overstep the bounds of decency. 'Their singing, like Asintic singing in general, is extremely poor; but in their dances, they slow the greatest skill. They often amuse rich people at dinner. There are also Almes for the lower classes.

Almedd, Fraucisco and Iorenzo; father and son. Francisco was the first viceroy of India, in 1505. After mvaging the coast of $A$ frica in the course of his expedition, he subjected to the P'ortuguese dominion Quiloa, Onor, Cananor, with other petty states, and, in a desperate struggle, carried by storm and burned the strong fortress of Panama, though defended by a resolute garrison of 4000 men, while his own force scarcely exceeded 700 . His son, who accompanied him, being now detached on a separate expedition, subdued the island of Ceylon, carried off 250,000 lbs. weight of cimmanon as the first fruits of his success, and imposed on the country an annual tribute to the same anount. In a subsequent expedition against the combined flects of the Arabians and Egyptians, he was slain. His father revenged his son in a bloody battle at Dabul. He then resigned his command to the famous $\mathrm{Al}$ buquerque, and sailed for Portugal, but was killed on the African coast, near the cape of Good Hope. -A Portuguese bishop, a Jesuit, member of the same family, called Apolinarius, suffered martyrdon in Ethiopia, whither he went as a missionary, in 1568.

ALMmDA, one of the strongest fortresses in Poitugal, is situated in the province of Beira, near the Spanish border, on the Coa, and contains 2750 in. habitants. In 1762, it was taken by the Spaniards, after great loss, but was restored at the peace. When Ney, 24th July, 1810, attempted to pass over the Coa into Portugal, the British defended the fortress of $A$. against marshal Massena, till 27 th August, when they were obliged to capitulate. In his retreat from Portugal, Mareh 1811, the evacuation of A. cost marshal Massena a bloody battle of two days with Wellington, the $3 \mathrm{~d}$ and 4 th of May, near Fuentes d'Onoro, when the French commander, general Brenier, blew up the fortress on the night of the IIth, and made his way through the milst of the besiegers. The British have restored the works.

Alsmer ; a weight of two pouncis, used to weigh saffron in several parts of the Fast Indies.

Almonedes; the name of an African dynasty which succeeded that of the Almoravides, in Barbary, in the commencement of the 12th century. 
Alson, John, a political writer and pamphleteer of the last century, was born at Liverpool about 1738 ; and weut to Loudon in 1758, where he became bookseller, and published various panphlets for the day, chiefly in support of John Wilkes, of whom he was a violent partisan. He also compiled several large works, the best knowu of whicl are his Anecdotes of Eminent Persons. He retired from business in 178\%, but subsequently injured lis fortune in a newspaper speculation, and died in depressed circumstances in Hertfordshire, in 1805 .

Alasond. The common or sweet almond is a soft and pleasantly-flavoured kemel, contained in a nut, which is of flattish shape, and has a tender shell, with numerous small holes on the outside. The almond tree (amygdalus communis) is usually twelve or fourteen feet high. Its beautiful pi ik flowers, of five petals, grow in pairs, and appear very early in spring. The leaves are oval, pointed, and delicately sernited at the edges. Its flowers are remarkably benutiful, and form a great omament of the Englisli shrubberies, particularly as they appear in Marclı and $A$ pril, - a season when fow otlier parts of the vegetable creation have recovered from their wintry state. Though kiown to the ancients from the most remote period of antiquity, the almond tree has been cultivated in England only since 1562, and this almost wholly on account of the beautiful appearance of its flowers, since the climate of Great Britain is not sufficiently warm for the fruit to be perfected. The almonds which are consumed in this country and the United States, are inported, sometimes in the shell, and often without, from France, Spain, Italy, and the Levant; and they are packed in casks, boxes, or bales. The Jordan almonis, which rome from Malaga, are the best sweet almonds brought to Britain. The province of Valencia vas formerly much celebrated for its almonds, but the cultivation of the trees in that part of Spain has for several years been much neglected. Almonds are very highly taxed in Britain. The duty on Jor-

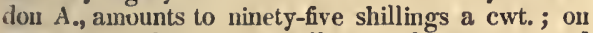
sweet $\Lambda$., to forty-seven shilliugs and sixpence; and on bitter A., to thirty-one shillings and eightpence. Notwitlıstanding tlie enormity of these imposts, whicls might almost exclude almoirds altogether from the country, they yield a revenue of about $£ 18,000$ a year. 'The chief uses of sweet almonds are in confectionary and cooking. They are also eaten with raisins in desserts after dinner; but they should be well chew$\mathrm{el}$, since every piece that is swallowed entire is illdigestible. By pressure, they yield a considerable proportion, sometimes nearly half their weight, of oil. Some preparations of almonds are used in uredicine, particularly that called milk of almonds, which is formed of pounded almonds, loaf sugar, and water, well mixed together. In some parts of the East Indies, it is said that almonds supply the place of small money.-Bitter almonds resemble, in all respects, the sweet almonds, both in the appearance of the kernels themselves, and of the trees which produce them, excepting a slighit difference in the size of the flowers and fruit. Like the sweet al. monds, they yield a large portion of oil. This has no bitterness, but the substance that remains after the pressure is intensely bitter. If these almonds be eaten freely, they occasiou sickness and vomiting; and, to many quadrupeds and birds, they are fital poison. There was formerly a notion, but it is quite erroneous, that the eating of them would prevent the intoxicating effects of wine. They are frequently used instead of apricot kernels in ratifia, and-sometimes are employed in making a counterfeit clierrybrandy. The oil and emulsions of bitter almonds are used in medicince, and a yowder and paste for washing the hands is made both from them and from sweet almonds. By confectioners, they are mucls nsed to give flavour to biscuits and other articles, The substance which gives their peculiar flavour to bitter almonds, and to the kernels of peaches, apricots, \&c., as also to the leaves of all the species of cherry and peach, is the prussic acid, so well known as a powerful medicine and poison. It is this which renders a large drauglit of noyau, or other cordial of a similar kind, so often injurious, or even fatal. The Prussian medical police, therefore, which is remarkably vigilant, is in the liabit of examining liquors of this sort exposed for sale.-For a further account of this substance, see Cherry Laurel and Prussic Acid.

$\Lambda$ LxONER, in its primitive sense, denoted an officer of any religious establishment, to whom belonged the distribution of alms. By thie ancient canons, all monasteries were to spend at least a tenth part of their income in alms, - a rule which is still followed by several convents. Every bishop, also, was required to keep an almoner. The great almoner (grand aumonier) of France was the highest ecclesiastical dignitary in that kingdom before the revolution. Napoleon restored this office, and it has beeI kept up by the Bourbons, but we do not know its rank at present. To the almoner bolonged the superintendence of all hospitals and houses of cliarity. The king received the sacrament from him, and he said mass at all grand solemnities. He still officiates at the performance of the mass called Veni spiritus, before the chamber of deputies. The lord almoncr, or lord high almoner of England, is an ecclesiastical officer, generally a bishop, who formerly received all deodands and the goods of every felo de se, which he was to distribute among the poor. He had, also, the power of giving the first dish from the king's table to whatever pour person he pleased. The emperors of Gernany, too, and most of the European monarchs, had their almoners. The almoner of the pope is one of the highest officers of his state.-The name $a l$ moner has been given, by some writers, to the chap. laus of ships, regiments, \&c.

Alvos, in botany. See Alder.

Auwwick, the county town of Northumberland, is situated partly in the southern division of Banborough ward, and partly in the eastern division of $\mathrm{Co}$ quetdale ward, 84 miles soutl from Edinburgh, and 310 north from London. It is built irregularly on the declivities of a hill, near the river Alne, over which a handsome stone bridge was built by the late Duke of Northumberland. This town has a spacious market place, and a considerable town hall, in which the sessions and county courts are held, and the members of parliament for the county elected. It is paved, watched, and lighted under an act passed in 1821. Although the county towir, the assizes are held at Newcastle. The town is governed by a bailiff and four chamberlains, who are chosen every jear out of a common council of twenty-four. The bailiff is nominated by the Duke of Northumberland, by virtue of his ancient office of Constable of Alrwick castle. The latter, for many centuries a fortress of great strength, and the family mansion of the Percys, stands on an eminence on the south side of the Alne, opposite to the town, and commands a beautiful view of the country. The walls are flanked with sixteen Gothic towers, the battlements of which are ornaneuted witlı figures of ancient wertiors. It is very celebrated in border history, and peculiarly fatal to the kings of Scotland, of whom Malcolm 11 . and his son Edward fell before it, and Willian, suruamed the Lion, was takelı prisoner. The mansion has lately undergone a complete revair, great attention having becen paid to the restoration of the Gothic ornaments in their original style. The 
chapel has been reulerel extrinely benutiful by the intruluction of a cciling, in initation of the celebrated one of King's College, Caunbridge. 'There is also a Inandsome window', on the molel of one at York minster, and the walls are painted in the imaner of those of the cathedral at Milan. The custom of making freeneu at $A$., which is very ludicrous, is attributed to a piece of limmurous revenge on the part of king John, for laving endared considerable personal inconvenience from the miry state of the ronds. Those who are to be made free, assemble in the market-place on St Mark's day, each man dressed in white, with a white cap, and a sword by his side. From this place they proceed on horseback, headed by the four chamberlains, attirch in the same manner, to the 'lown unoor, where they alight, and all rush through a muddy pool; which ceremony perforned, they change their soiled habiliments, and return to the town. 'The living is a perpetual curacy in the archeleacoury of Northumberland, and diocese of Durham. The church is dedicated to St Mary and St Michael; patron, the duke of Northumberland. Here is a free-scliool, supported by a revenue arising out of the tolls, and various minor charities. Here are also several congregations of dissenters. The population is about 6000 .

Alondis; prince of the Assassins, or Arsacides ; commonly called the Old Man of the Mountains. Ife was the sheik of a Srriaus tribe professing the Mohanmedan religion, but blindly deroted to the will of their chicf, with whose temporal superiority was also ningled a sort of ecclesiastical character. Uniting, as it were, in his own person the pretensions of friuce and proplet, the slightest of his commands is said to have been always executed, though at the expense of certain loss of life to the emissary. Many falulous stories are related of this prince, from whose followers the word assassin has its derivation.

Alofs are an extensive tribe of plants, some of which are not more than a few inches, whilst others are thirty feet and upwards, in height. All the leaves are fleshy, thick, and more or less spinous at the edges, or extremity. These plants, which are chicfly iuhabitants of hot climates, have flowers of a single petal, the mouth expanded, the base nechariferous, and the filaments of the stamens inserted into the receptacle. Some of the larger kinds of aloes are of great importance to the inhabitants of countries in which thicy grow. Beset as the leaves are with strong spines, they form an impenetrable fence. The negroes of the western coast of Africa make lopes and weave nets of the filurous parts of these leares. The Ilottentots hollow out the stems of one of the kinds into quirers for their arrows. In Jamaica, there is a species of aloe, which supplies the inlıbitants with bow-strings, fishing-lines, and materials from which they are able to weave stockings and hanimocks. An aloe which grows in the kingdom of Mexico is applied by the inlubitants to almost every purpose of life. It serves to make hedges for inclosures; its trunk supplies beans for the roofs of louses, and its leaves are used instead of tiles. From this plant they make their thread, needles, and various articles of clothing and cordage ; whilst from its juices they manufacture wine, sugar, and vinegar. Some parts of it they eat, and others they apply in medicine. The juice of aloes was formerly used in Fastern countries, in embalming, to preserve dead bodies from putrefaction, and, as the resinous part of this juice is not soluble in water, it is sometimes adopted, in hot climates, as a preservative to ships' bottoms against the attacks of marine worms. One ounce of il, mixed with turpentine, tallow, and white lead, is considered sufficient for covering about two superficial feet of plank; and about twelve pounds as sufficient for a vessei of fifty tons burlen. In proof of the efficacy of this menthod, two planks of erual thickness, and cut from the sane irce, wrie plucel under water, one of them in its natural state, and the other smeared with this composition. They were suffered to con. tinue in the water eight montlis, and when, at the end of that tine, they were taken out, the former was perfornted in every part, ancl in a state of absolute decay, whilst the latter was as perfect as at first. In the East Indies, the juice of these plants is used as a varuish to preserve wool from the attacks of destructive insects ; and skius, and even living animals, are sometines smeared with it for the same purpose. There is a tract of mountains about fifty miles nortl of the cape of Gond Hope, which is wholly covered with aloes. Among the Moliammedans, and particularly in Egypt, the aloe is a kind of symbolic plant; it is declicated to the offices of religion, and pilgrims, on their retum from Mecca, suspend it over their loors, to show that they have performed that loly joumey. The inspissated juice of several species of aloes is userl in medicine, under the name of aloes. The medicinal properties of aloes have been long known and established, and their extensive application in medicine is, perhaps, the best proof that cau be adducrel of their utility. In the arts, aloes are in several respects useful. Particularly, a beautiful violet colour is aflorded by the leaves of the Socotrine aloe, which does not require the aid of any mordant to fix it ; the same also is capable of being formed into a fine transparent colour for painting in miniature.

AloE, the great or American (agave Americana), is a large plant, the leaves of which are thick, fleshy, and. spinous at the edge, and the sten brauched, and of great height. The flowers have the tube of the corolla narrowed in the middle, the stamens longer than the corolla, and the style longer than the stanens. This Inagnificent native of North America is by no means an uncommon plant in English gardens, but is seldom seen there in flower. There is, indeed, a notion, but an erroneous one, that the American aloe does not bloom until it is 100 years old. The fact is, that the time of flowering depends almost wholly on the rapidity of its growth. In hot countries, it will flower in a few years; but in colder climates, the growth being slower, it is necessarily longer in arriving at maturity. The stem, which bears the blossoms, rises from the centre of the leaves, and, when the plant is in a vigorous state, it frequently exceeds the height of twenty feet. An American aloe, in the garden of the king of Prussia, was forty feet high. Branches issue from every side, and in such a manner as to form a kind of pyramid, composed of greenish-yellow flowers, which stand erect, and are seen in thick clusters at every joint. When in full flower, its appearance is extremely splendid; and, if the stason be farourable, and the plant be sheltered from the cold in autumn, a succession of blossoms will sometines be produced for near three mouths. In the warmer parts of Europe, the American aloe is cultivated as an object of considerable utility. They are frequently set out in rows, as fences for enclosures, particularly in Spain, Portugal, and Italy. In Algarva, the leaves are employed for scouring pewter, kitchen utensils, and floors, and, being cut into slices, are nsed for the feeding of cattle. The juice of these leaves is made into cakes, which are used for washing, and will make lather with salt water as well as with, fresh. Tle fibres of the leares, when yroperly prepared, may be separated into threads, which are useful in rarious 
ways. This is sometimes done by bruising and stecping them in water, and afterwards beating them. The process in some parts of Portugal is, after plncking the largest and best leares, to place them on a square board, which a person presses obliquely between his breast and the ground, and then scrapes with a square iron bar, held in both hands. By this operation, all the juices are pressed out, and only the fibres and some of the membranous parts of the leaves remain, which are easily detached. The fibres are employed for all the purposes to which thread can be applied; but they are neither strong nor durable, and, if exposed to moisture, soon decay:

A LO1DES (so called from their supposed father, Aloeus). Otus and Ephialtes, sons of Iphimedia and Neptune, were enormous giants. They attempted to storm lieaven with the other giants, but were killed by Apollo. $\Lambda$ s a punishment, they were bound to a stake in Tartarus, and gnawed by snakes, while an owl, on the top of the stake, disturbed them with its cries. (See Giants.) This fable which is also differently related, originated with the Boeotians, who maintained that the Aloides introduced the worship of the Muses.

ALPHA and OMBEA, the first and last letters of the Greek alphabet, in the Holy Scriptures, signify the beginning and the end, or the first and the last; i. e. before and after all things. These two letters are, therefore, used as a symbol of the Divine Being. They were also formerly the symbol of Christianity, and engraved accordingly on the tombs of the ancient Christians, to distinguish them from those of idolators.

Alphabet (from $\alpha \lambda \phi \alpha$ and $\beta \eta \tau \alpha$, the two first letters of the Greek alphabet); the ordinary series of the letters or syllables (in syllabic alphabets) of a language. (For the lypotheses respecting their origin, the relation between the different alphabets, and the different systems on which they are based, see the article Writing, Art of.)-The number of letters and their meanings varies in the different tongues very much. The English alphabet (including $j$ and $v$ ) contains twenty-six letters; the French, twenty-three; the Italian, twenty; the Spanish, twenty-seven; the German, twenty-six, or twentyfour, if some compound letters are not reckoned; the Dutch, twenty-six; the Bohemian, or that of the Czechian Slavonic dialect, forty-two; the Russian, forty-one ; the Ethiopic, Abyssinian, or Tartarian, two hundred and two, as has been asserted, but this subject needs further investigation; the Turkish, thirty-three; the Georgian, thirty-six; the Bengalese, twenty-one; the Baramese, nineteen; the Coptic, thirty-two; the Persic, thirty-two; the Arabic, twenty-eight; the Armenian, thirty-eiglt ; the Sanscrit, fifty; the Japanese, fifty; the Hebrew, Chaldee, Syriac, and Samaritan, twenty-two each; the ancient and modern Greek, twenty-four; the Latin, twenty-two; the Cherokee, eighty-two syllables. Almost all alphabets begin with $A$. (See article $A$.) - For further information, see the articles on the different languages and letters.

A LpHevs; one of the largest rivers of Grecce, which rises near the source of the Eurotas, in Arcadia, flows by Olympia, and falls into the Ionian sea. -In mythology, a son of Oceanus and his sister Thetis. Whell a river-god, he fell in love with Diana, who, in order to escape him, disfigured with mire her own face, and the faces of her nymphs. He was enamoured of and pursued the nymph Are. thessa, but Diana concealed her in a cloud, and changed her intu a fountain. Upon this, Alpheus resumed his own form of a river, and mingled lis waters with hers. This fablc probably arosc from the circumstance, that the river Alpheís, at a certain place, is lost in the earth; the fable makes it come to light again in Sicily, where it unites with the fountain Arethusa.

ALPhosso III., king of Leon and Asturias, called the Great, succeeded his father, Ordogno, in 866, at the age of eighteen years; according to some, in 862 , when fourteen years old. After having subdued by force the powerful nobles of his kingdom, who saw with jealousy the royal dignity remain hereditary in a family, he turned his arms against his foreign enemies, and distinguished his reign by more than thirty campaigns, and numerous victories obtained over the Moors. He crossed the Duero, overthrew the walls of Coimbra, passed the Tajo into Estremadura, added to his dominions a part of Portugal and Old Castile, and peopled Burgos anew. But all these successes did not conciliate his subjects, and he had the grief of seeing his own son, don Garcia, at the head of the malcoitents, endeavouring to tear the crown from his head. A. defeated the rebels, took his son prisoner, and kept him in close confinement at the castle of Gauson. The queen, donna Ximena. then formed a dangerous conspiracy in Garcia's favour, and armed both her other sons ngainst the king. A bloody war desolated the kingdom, until A., defeated by lis own son, abdicated the crown, and placed it on don Garcia's head. He afterwards commanded an army, as the general of his son, against the Moors, collquered them, and returned enriched with booty. After this expedition, he died at Zamora, 912, sixıyfour years old.

Alpuosso X., king of Lenn and Castile, surnamed the Astronomer or the Philosopher, succeeded his father, Ferdinand the Holy, in 1252. His love of the sciences and of law, and his surname of Sabio (the wise) gave his subjects hopes of a happy reign ; but the event did not answer their expectations. A. was neither loved by his family, his subjects, nor his neighbours; but his learning and eloquence had given him such a reputation in Europe, that many German princes favoured his claim to the imperial throne. Instead of employing himself in expelling the Moors, and humbling his own nobility, he ex. hausted the strength of his kingdom by endeavouring to secure his election to the imperial throne (1257). But it was vain for him to aspire to this dignity in opposition to Rodolph of Hapsburg ; and pope Gregory $\mathbf{X}$. not only refused to acknowledge him as emperor, but even to allow his right to Suabia, which he clained through his mother, Beatrice, daughter of Philip I., archduke of Suabia. In the meantime, his throne was endangered at home by the conspiracies of the nobles and the attacks of the Moors. He finally conquered them, in a bloody hattle, in 1263, took from then? Xeres, Medina-Sidonia, San-Lucar, and a part of Algarra, and united Murcia with Castile. But these victories were interrupted by new troubles, excited by his son, the infante Philip, which he succeeded in quieting only after three years' war. But the mildness witli which he treated the rebels was considered only a proof of weakness, and, when he at last determined to act with rigour against his own family, his son Sanchn again rebelled, and, in 1282, deprived him of his crown. A. sought support in an alliance with the Moors, and died in 1284, after unsuccessful efforts to regain the throne. $\Lambda$. was the most learned prince of his age, and has gained a lasting fame by lis collection of laws, called Las Partidus. There is in this book a very remarkable sentiment, considering the age in which it was produced: "The despot roots up the tree; the wise master only piunes off the superfuities." Enrope is indebted to A. for the 
astmonuical tables which go under his name. Un- 1 cler is jutronage, the first general listory of Spain was composed, in the Castilian tongue, and the Bible translater. He contriluted much to the reviral of science, and, with this view, strove to increase the privileges and the professorships of the university of salamanca; but without firmuess and prudence, learuing is useless to a muler.

A.risı, Prospero, an eminent pliysician and naturalist, was a native of the Venetian republic, and Lom in 1553. He stndierl merlicine at the university of Padua, and afterwarls accompanied the Venetian consul to Egspt, where a residence of three years enabled lim to extend his knowledge of plants, and of vegetable economy. From observations he made on the management of date palm-trees in that country, it appears that he deduced the doctrine of the sexual difference of plants, which was assumed as the foumdation of the Linnzean system. He returncl to Venice in 1586, practised at Genoa, and eventually filled the botanical chair in Padua, where lie died in 1617, leaving various works on medicine in general, on the practice of merlicine among the Egyptians, on the Plants of Egypt, on Exotic Plants, \&c.

ALIs; the lighest ridge of mountains in Furope, lying between $5^{\circ}$ and $17^{\circ} \mathrm{E}$. lon., ant $45^{\circ}$ and $48^{\circ}$ N. lat.; consequently extending through $11^{\circ}-12^{\circ}$ of lon., and $2^{\circ}-4^{\circ}$ lat, or 120,000 square miles. Their branches connect them with alinost all the other monntains of Europe. The highest points are in Savoy and Switzerland, and thence bianches diverge in all directions. The Alps are commonly divided into High, Micldle, and Jow $A$ lps. The first rise from 8000 to 15,000 feet aloove the level of the sea, and are covered with perpetual ice and snow. Jord Byron has beautifully charncterized them, as

"The palaces of nature, whose rast walls Have piunacled in clonds their snowy scaips, And throned Eternity in icy lialls

Of cold sublimity, where forms and falls

The avalanche-the thunderbolt of snow!

All that expands the spirit, yet appals.

Gather around these summits, as to slinw

How earth may pierce to heaven, yet leave vain man below !"

The Middle Alps begin at abont 5500 feet alove the sea, and rise to the line of perpetual congelation. The Jower Alps commence with an elevation of about 2000 feet, and extend to the Middle Alps. The more scientific division, of the Alps are the following:-1. The Maritime Alps, between Nice and Provence, extending from mount Viso to the Mediterranean, and connecting the Apennines, in Italy, with the Alps, in Prosence. Their princijal summits are the mount $A$ rdente, di Tenda and Camelon. -2. 'The Cottian Alps, from monnt Viso, by mount Generre, to mount Cenis. They separate Piedmont and Dauphiné. The Pelvoux de ValIouise is 13,836 fcet high, the Olan, 11,206 , and the Viso, 13,820 teet. -3 . 'The Grey or Grecian $A$ lys, from mount Eenis to the Col de bon Honme, traversing the department of Isere. They separate Piedmont from Savoy, but do not equal the height of the Cottian Alps. Their highest summit, mount Cenis, is 11,460 feet high. -4. 'The Pennine Alps, from Col de bon Homme, by mount Blanc and the Great St Bernard, to mount Rosa. 'They separate P'iedmont from Saroy and the Valais, and contain the lighest summits and most dreadful glaciers of the whole ridge. Mount Blanc, the ligighest momtain of Furope, which was first ascended in the last part of the 18th century, rises 2,468 French toises, or 15,814 Finglish feet; mount Rosa, 15,205 English feet ; mount Vilan, the lighest point of the Great St Beruarl, 11,027; aut the pass of the Simplon, 6,579 fert. - 5. The Iepoutine or Ilelvetian $A l p s$, which cover Western Switzerland, extending from momit Rosa, on both sides of the Rhone, throngh the Valais, by St Fothard, to the Mnschellown and Beruardino in the Grisons, and dividing Lombardy from Switzerland. It is the must visited of ull the chaius of the Alps, and is ventarkable for its sublime scenery, and as giving rise to several of the largest rivers of Europe. Its most elevated smumits are the Finsteranhorn, 14,116; the Jungfran, 13,730; the Selireckliorn, 13,404; the Furka, 14,040; the Grimsel, 9,704; and the St Gothand, 9,964 fiet high. The Iurten mountain and the Jura run out from this claain. -6 . The Rlıetian $A$ lps, from Burnardino, through the Grisons anul Tronl, to the Dreilierruspitz, on the borders of Saltahurg and Car rinthia, and sonthwards to the Pellegrino. 'They soparate Lombarly from Gemany and the Grisons, and are comnected, hy means of the Arlberg, with the Rauhe-Alb or Suabiau $\Lambda / p s$, ant through them with the principal momtains of Germany. The: Orteles rises 12,859 feet; the Wetterhorn, 12,470 ; the 1)oedi, 11,818; the Riegleberg, 9,775; and the Pilates, 7,496 feet. -7 . 'The Noric $\Lambda$ lys, which I'un from the Dreilerruspitz, through all Carinthia, Saltzbuter, Anstria, and Styria, anid lose lhemselve's in the plains of Cedenburg. 'The Cetian numutains unite them with the Bohemian forest and the. IImgarian mountains. They lave very high sumuits, above which projects the Great fluckner, 12,98: feet high -8. The Carnic Alps, firom Pellegrino, bedween the Save and the J)rne, to the Terglon. One of their lighest peaks, the Obis, is 7,038 feet high.-9. The Julian Alps reach from the Terglou, between the right bank of the Save, the Kinlpa, ani the Adriatic, to the rock called Kleck, near Segna, and separate Jombardy from Illyria. The Terglon rises to the height of 9,906 feet ; the Loibl, 4,266 'To these belong the Karst, the Crontian, and Sclavonian mountains. -10 . The J)inn rian $A \mathrm{p} p \mathrm{~s}$, from the Kleck to the vicinity of Soplia, where they unite with the Balkan, and form, by different spurs, the Hellenic and Rumelian mountaius.-The jopulation of all the different bianches of the $\Lambda$ lps amounts to at least $7,000,000$, of which the greater part is of German origin; the rest are Italiaus and Sclaronians. More than 2,000,000 are herdsmen, who live by breeding cattle. The declivities of the Noric, Carnic, and Rhretian Alps, are rich in motals, particularly in iron, copper, lead, and many kinds of scmi-metals. The bouquetin grazes on their summits. It is now, however, becone very rare. Half-way up their sides are fonnd chamois, marmots, dornice, eagles, and vultures. Here also are fonul the beantiful Alpine fowers, which disappear tuwards the summits. (See Alps, Rouds over thc.)As to the geological structure of the Alps, it is, in general, very regular. To the north and sonth muns a steep and almost perpendicular wall; a chain of sindstone hills extend along it, reaching, loweser, but l, an unimportant height, and not belonging, in a geognostical respect, to the proper Alpine formation. This mass of steep mountains is formed by a centra? chain and two rilges of line-rocks, which extend from S.S. W. to E. N. E., and near Turin and Genera cease to accompany the central ridge. 'This consists of the oldest motutain formations. Fineiss and granite occupy the whole middle tract of the Alps, and form, in particular, the loxly of the upper range, which is covered with an infinite number of peak's and glaciers, and can be crosserl with tolerable convenience only at a few points. This range forms the disision of the Mlpine streams, and here are 
situated the highest of the above-mentioned mountains. This formation is particularly rich in beautiful minerals, of which line-stone, mueiss, mica slate, and granite are the chief. To this succeeds, as well upon the northern as upon the southern side, the slate formation, which rises also to a considerable height, without reaching, however, the highest points. It consists principally of table-slate, whetslate, silicious slate, graywacke, and cont ins, also, a kind of lime-stone. In it there are fo nd, also, layers - of ore, particularly the famous masses of sparry iron in Styria. The porphyry formation appears only on the south side of the Alps, particularly in Tyrol, where it forms a wide, low p'ateau. The latest formation of the central chain is the elder or red sand-stone, consisting of a coarse stone, often a conglomerate, or of a finer red or gray stone. The ridges of lime-stone Alps rise northwards and southwards, at the foot of the central chain, steep, and highly picturesque, constituted by Alpine or elder Floetz lime-stone, marl, plaster, clay, fossil salt, trap, porphyry, also amygdaloid, and conglomerate. It is distinguished by beds of calamine, galena, and clay iron-stone. On the lime-stone chain lean the younger formations of the Jura (q. v.), of the Suabian Alps, \&c.-See the article Alps, Suabian; also Ebel, uber den Bau der Erde in dem Alpengebirge, On the Structure of the Alps, 2 vols., Zurich, 1808.

ALPS, Roads over. One of the most lasting monuments of the power and policy of Napoleon are the artificial mountain-roads, which connect Savoy with France, and Valais with Italy. The first leads over mount Cenis (a mountain 5,879 feet high) by Lansleburg to Susa, froin Savoy to Piedinont. Formerly, travellers were obliged to pass over the steepest height on mules, or in chairs ; but, in 1805 , Napoleon ordered a winding road for carriages to be laid out here, thirty miles long and eighteen feet wide, which is passable even in winter. In 1815 , 16,000 carriages, and 34,900 mules passed this road. - The second leads over the Simplon (Sempione), which is 10,327 feet in height, from Valais to Piedmont, from the village Glus to Domo d'Ossola. This road, constructed between 1801 and 1806, is the only one from Switzerland, over the Alps, passable by wheel carriages. It is about thirty-six miles long, and twenty-five feet wide throughout, and is nowhere too steep to be passed by the heaviest waggons. It is carried over steep precipices, and through six galleries hewn in the rocks. Some of these passages are sereral hundred paces in length, and are lighted by openings. From them you step into lovely valleys, adorned with cottages, and see above them dark forests of pine, glaciers, and peaks covered with snow shining in the blue sky. Bridges are thrown over tremendous precipices, from one mountain to the other. The Italian side offers a more brautiful spectacle than the Swiss, because the rocks are steeper. The grande galerie is 683 feet 1.ng, entirely excarated in granite, called the gallery of Frissinone, from the rivulet, which forms a splendid cascade near it. The road commences a. mile westward from Brieg, and leads over the Saltina-bridge; abore the village of Ried, it goes through a beautiful grove of larch-trees, to the first gallery, and then over the Canter-bridge, eighty paces in length, to Persal. Here begin precipices and avalanches, on which account the road has many windings. At the galerie des glaciers the growth of trees ceases, and the road rises 1,033 toises above the lago Maggiore, or almost 6,000 feet above the sea. At the top stands a hospitium for travellers, a turnpike, and, lower down on the right, the old hospital. Four miles further on lies the village of Simplon, 4,548 feet above the sea. The road goes along the river Veriola, till near Uomo d'Ossola. At Gunt is a tavern; a inile further, the territory of Valais terminates near a chapel; the first Itiliau village is S. Marco. Avalanches, and masses of earth, brought down by the rain, often damage this road, so that the annual repair requires a considerable expense, which, however, neither the Swiss nor the Sardinian government have, as yet. been willing to take upon themselves. Osterwald has given fine sketches of the picturesque views on the road over the Simplon. (q. v.) - A third road leads over mount Genevre (about 6000 feet high), on the frontiers of France and Piedmont. There is a village on the level summit of the mountain, with a monastery, where travellers are received.-The fourth road (la corniche) goes from Nice, by Monaco, to Genoa, through the rocky ground at the foot of the Maritime Alps.-Among the other roads over the Alps are to be mentioned, 1, that over $\mathrm{Mt}$ St Gothard (q. v.), from the canton Uri to the canton Tessino; but, as this is very toilsome, and, in some places, dangerous, particularly near the Devil's bridge, in the Urnerloch, and at the descent to Airolo, in the Val Livino, goods can be transported from Switzerland to Italy only on pack-horses. The road ascends to a height of $8: 64$ feet, and at an elevation of 6367 feet there is a hospitium of the Capuchius. 2. The road over the Great St Bernard (q. v.), from the lake of Geneva to Italy (the nearest of all to Turin and Genoa), is unfit for carriages, and can only be passed on foot and by packhorses. In order to shorten the way, it has been proposed to make a passage, for the transport of wares, from the Valais to Genoa. 3. The main road from Innspruck to Italy, over the Brenner, a mountain of Tyrol, 6063 feet in height. At this place the road is about ten miles long, and ascends to a height of 4367 feet. With this is connected, 4. the new road built by Austria since 1821, the highest in Europe, from Bormio, in Valtellina, over the Braglio, and the yoke of Stilfs, 8400 feet high. 5 and 6 . The road from Bellinzona to Coire, over the Bernardin, and that over the Splugen, passable for wheel-carriages suce 1823 ; the former leading to the lake of Lugano, the latter to the lake of Como. The canton Tessino, in 1818, enterea into a compact with the government of Lombardy, by which, on condition of being aliowed the importation of salt and fruits from Lombardy, it promised to prevent the building of a new road from Bellinzona to Coire, over the Bernardiu, and only to keep the old road in its present condition. The validity of this treaty, however, so contrary to the interest of the Grisons and the other cantons, was disputed, and the building was finally commenced. The roads over the yoke of Stilfs, and that over mount Simplon, are among the greatest productions of human energy and art in modern times.

ALPS, the Suabian. The northern continuation of the Schwarz-wald, or Black Forest, is a regular, calcareous mountain, serenty miles long, and from nine to twenty broad, on the southern frontier of Wirtemberg, of which the highest and most barren part is the Rough Alps (Rauhe Alp). The highest point is not quite 3000 feet above the level of the sea. In the village of Sirchingen, the eaves of a house shed the rain, on one side, into the Rhine, through the Neckar, and on the other, into the Dannbe. As the mountain abounds in lime, it is rich in caverns containing stalactites. The higher the quarries of limestone are situated, the finer is the grain of the stone, and the greater the mass of petrifactions ; among which are particularly to be noticed large specimns of the cornu ammonis. These Alps large specimens of
are poor in metals. 
Aluuxaras, los (anclent montes Solis); a range of mountains in Granada, abont fifty-one miles in

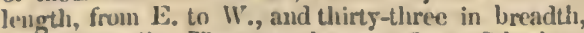
froil N. to S. They can be seen from Gibraltar, and even from the coast of Africa. Here the descendants of the Moors, Moriscoes (now Clristinns), live, and cultivate the land extremely well. No part of Spain is su well peopled.

Alsace (Germ., Lilsass; French, Alsace); before the French revolution, a yrovince of France, on the Rhine, now constitnting the departunents of the Lower and the Upper Rhine (the former of which rontains 1760 square miles, with 370,660 inhabitints; the latter, 2140 square miles, with 501,600 julıbitants); a fertile country, formerly dipided into Lower and Upper Alsace. In ancient tines, it was a German duchy, but, in 1268, the line of its dukes becoming extinct, it was parceled ont to several members of the Gernan empire. By the peace of Munster, in 1618, the part of $A$. belonging to Austrin, and to ten free cities of the empire, was ceded to France. The possessions of the other German states in $A$. still preserved their comnexion with the German empire. By the peace of Ryswick, in 1697, the city of Strasburg, and all the territory nccupied by the French troops on the left bank of the Rhine, were celled to F rance. Several states of the empire had still inportant possessions in it, which, at the beginning of the revolution, the first national assembly declared to be a conquest pointed out by nature itself; because, they said, foreign pewers conld not be allowed to retain possessions witlin the territory of France without danger; compensation was promised for the losses sustained by the German owners; few of them, however, were willing to accept it, and this affair was one of the clief carses of the war which took place soon after between France and Germany. By the peace of Paris, Nov. 20, 1815, a part of A., viz. Landau, was again separated from France, and reunited with Germany.-(See Resume de l'Histoire d' Alsace, par M. V., Paris, 1825; and Nouv. Descript. Histor. et Typogr. des deux Depart. du Rhin, par J. F. Aufschlager, I number; Strasburg, 18:5.) The inhabitants of A. contime to speak German. Strasburg is the chief city. The two departments produce wine, copper, iron, hemp, flax, tobacco, madder, \&c. Severnl of the most distinmished liberals in the French chamber have lately been sent from these departments, and, on the whole, they were much attached to the French emperor.

At SEgno (Italian; to the mark or sign). This expression is usually accompanied with this character, $\mathbf{S}$. and signifies that the performer is to return to a similar nark in the composition, and end with the first part of the strain.

Al-Srrat; the bridge, of breadth less than the thread of a famished spider, orer which the Mussulmans must skate into paradise, to which it is the only entrance. But this is not the worst ; the river beneath being hell itself, into which, as may be expected, the unskilful and tender of foot contrive to tumble, with a facilis descensies Averni, not very pleasing in prospect to the next passenger. There is a shorter cut downwards, for the Jews and Christians. - Lord Byron.

A Lsor, Richard, a man of letters, born in Middletown, Connecticut, published a number of fingitive pieces in verse and prose, which had considerable success, besides several translations from the Italian and French. The principal one is the Natural and Civil History of Clili, from the Italian of the abb. Molina, in 2 vols., 8ro, reprinted in London. In 1815, he prepared the Narrative of the Captivity and Adventures of J. R. Jewett among the Savinges of Nootkr Somul. He died Ang. 20, 1815, in tho 57 th yenr of his age.

Ar.srow, Charl's, a Scoltish plissician and lotanist, was born in Ianarkslire in 1683, commenced his studies at the miversity of Glasgow, ant, under the Intronage of the duchess of Hamilon, attaclied himsclf to unedicine, in the prosecution of which, in his 33 year, he nccompanied the first Dr Mouro 20 Leyden, where he continued three years, under the instruction of the celebrated Boerlnave. On his return to his native comutry, in conjunction with Dis Monro, Rutherforl, Sinclair, and Plumner, lie projected the revival of inclical lectures in Eilinburgh, and laid the fomslation of that high claaceter, which Edinburghl, as a medical school, las in long enjoyed. Jr A.'s tlepartment was botany and the materia medica, which he continued to teach until his death, in-1760. His pricipal botanical work is entitlel "Tirocininm Botanicun Elinburgense," 1753. In one of his japers in the Edinburgh Physical and Literary Essays, he euleavoured io combat the Linnaen doctrine of the sexunl system of plants. His Lectures on the Materin Medica were published in 2 vols. 4 to, ten years after his death.

Alstone, or ALDSTone-Moon, a parish and market-town in the county of Cunberlaul and the borlers of Northumberland, containing a popmlation of 5700 , who are chiefly employed in the leal mines in the vicinity, which lave been long celebuated for the abundance of that metal.

Alstroemer, Jonas, the reviver of industry and commerce in Sweden, was born of poor parents, in the province of West Gothland, in 1685 . After visiting I,ondon, where he paid particular attention to the commercial and manufacturing sources of British prosperity, he obtained a license, in 17\%3, to establish manufactures in his native town, and it soon became the seat of industry and activity, which afforded an example to the whole kingdoun. In order to collect further informatiou, he visited Germany, Holland, and Flanders. He also established a sugar-house at Gottenburg, and traded to the Indies and the Levant. He improvel rural ceonomy, the breed of sheep, \&c., cultivated plants propet" for dyeing, and extended the culture of the potatoe, then a novelty in Sweden. His country was not baekward in acknowledging his services. He received various honours, among which was a patrut of nobility. He died in $176 \mathbf{i}$, lesving a name and character honourable for patriotism, activity, and talent.

ALT; a term applied to that part of the grcat scale of sounds which lies between $F$ abore the treble-cliff note, and $\mathrm{G}$ in altissimo.

Altai or Altaic Mountains; a vast clain of mountains in Asia, extending from lon. $68^{\circ}$ to $170^{\circ}$ L., terminating at East Cape, and forming, for a great distance, the southern boundary of Siberin. Their length is about 5000 miles. They assume different names, and are supposed to be connectel with the Uralian chain. A large part of the A. cliain is sometimes called the Kolhyvan mountains, because situated in the government of that name. The highest summits are computed at 10,730 feet above the sea.

Altar; an elevated place intended for sacrifice. At first, altars were made of earth or ashes, but afterwards, when men began to build temples, they were made of stone or metal, and much adorned. They stood in the eastern part of the edifice, before the statue of the gool, but lower. Very different from these are the altars in Christian churchu's. In these, the altar is not a place of sacrifice, but was, at frst, a table at which the love-feast (ngape) was held. 
When this was cliangea into a church ceremony, the altar yet remained a table, placesl in the choir of the church, used for the distribution of the Lord's supper, and for various other purposes. Altars of inason-work were, probably, first used among Christians in the reign of Constantine the Great. The regulation of placing them always towards the east originated with.Sextus II. Since the time of Gregory VI., Roman Catholic churches frequently contain several altars. The high altar, the most important, is in the chancel of the church, somewhat elevated; the other smaller ones are near the pillars, or the side walls, or in the chapel. In the larger Protestant churches, also, there is usually a great and small altar.

Altenburg; a Saxon duchy, which is divided into two parts by the principality of Gera. At present, it belongs to the houses of Gotha and Saalfeld. The division belonging to the former house contains about 525 square miles, with 109,557 inhabitants, famous for their attention to agriculture and to the breeding of cattle. It is one of the most beautiful and best cultivated parts of Germany. The division of Saalfeld contains about 212 square miles, with 30,500 inhabitants (according to some, about 170 square miles and 21,400 inhabitants); has four cities, one market-town, and 100 villages. Each line possesses full sovereignty. The city of A., well built on the Pleisse, contains 1279 houses, 10,100 inhabitants, and, till 1308, was a free city of the empire.

Alter, Francis Charles, a German Jesuit and laborious scholastic critic, was Greek teacher at Vieuna, where he died in 1804. He was author of no less than 250 volumes of dissertations, one of the principal of which is "Norum Testamentum ad codicem Vindobonensem Grace expressum," 2 vols. Sro.

Alter Ego (Latin; the other I); a law term, used particularly in the official style of the kingdom of the Two Sicilies, by which the king gives to a substitute, appointed to manage the affairs of the kingdom, the full exercise of royal power. This happened in Naples after the insurrection of Monteforte, where the present king, when crown-prince, Jily 6,1820 , was appointed by his father vicargeneral of the kingdom. In France, the phrase used to express this is lieutenant-général du royaume.

AlTitude denotes the perpendicular height of the rertex of any plane, or solid body, abore the line or plane of its base; thus the altitude of a triangle is measured by a perpendicular let fall from any one of its angles upon the base, or upon the base produced; therefore the same triangle may have different altitudes, accordingly as we assume one side or another for its base. Again, the altitude of a cone or pyramid, whether right or oblique, is measured by a perpendicular let fall from the vertex to the plane of its base. Similar remarks apply to other solids. - In astronomy, altitudes are measured or estimated by the angles subtended between the object and the plane of the horizon; and this altitude may be either true or apparent. The apparent altitude is that which is obtained immediately from olservation; and the true altitude that which results from correcting the apparent altitude, by making allowance for parallax, refraction, \&c. The altitude of a terrestrial object is the height of its vertex above some horizontal plane assumed as a base. The altitude of mountains is measured, generally, from the level of the ocean ; that is, the altitude of a mountain is the difference between the mean terrestrial raclius, and the distance of the vertex of the mountain from the centre of the earth. If the altitude of a mountain is given without any explanation, the altitude above the ocean is always understorid. This altitude can be measured trigonometrically, by barometrical observations, or by actually measuring the nearest distance between the level at the base and that at the vertex of an object; and, if very great accuracy is not required, by optical reflection, by the length of shadows, by moveable staves, the geometrical square, \&c.; and, generally, by any method in whieh the calculation depends upon the similarity of plane rectilinear triangles.

Alto, or Alto Tenore. Alto is the term applied to that part of the great vocal scale which lies between the mezzo soprano and the tenor, and which is assigned to the highest natural adult male voice. In scores it always signifies the counter-tenor part.

Altona ; the largest city of Denmark, after $\mathrm{Co}_{0}$ penhagen, in the duchy of Holstein ; $53^{\circ} 54^{\prime} 25^{\prime \prime} \mathrm{N}$. lat.; $9^{\circ} 55^{\prime} \mathrm{E}$. lon.; two miles from Hamburg on the Elbe. The city contains upwards of 23,000 inhabitants; among whom are 2400 German and Portugnese Jews, under the direction of a rabbin. The remainder are Lutherans, Calvinists, Catholics, and Anabaptists. The number of houses is about 2230 . There are also 520 habitable cellars. The city is built on the side of a sfeep hill, which gives it the appearance of an amphitheatre, when viewed from the side of the Elbe. The commerce of A., both inland and foreign, is considerable. The Danish government has conferred many privileges on the eity. Here is a board of commerce, a mint, an exchange, a royal bank, and, since 1739 , a royal school. In 1713, A. was almost totally bumed by the Sivedish general Steenbock. It has been since beautifully rebuilt.

Altranstadt ; a town in Saxony, famous for the treaty concluded between Charles XII., king of Sweden, and Augustus, elector of Saxony, Sept. 24,1706 , by which the latter resigned the crown of Poland. After the defeat of Charles, at Pultawa, Augustus, Aug. 8, 1709, declared the peace of Altranstadt void, because his commissioners, von Imhof and Pfingsten, had exceeded their powers in signing the conditions. The former was condenned to be imprisoned for life, the latter to be put to death. Augustus, at the invitation of some Polish nobles, returned to Poland, took possession of the throne, and renewed his alliance with the czar.

Alum, artificial. Common alum is a triple salt, consisting of sulphuric acid, alumine, potash, and water, or of sulphate of alumine and sulphate of potash, united together, with a certain quantity of water of crystallization. It crystallizes in regular octahedrons, which are generally truncated on their edges and solid angles. Alum may also be formed by substituting either soda, ammonia, or magnesia for the potash, without at all altering its crystalline form or its taste. It dissolves in five parts of water, at $60^{\circ}$, and the solution reddens vegetable blues, indicating the excess of acid which this salt contains. Exposed to heat, it undergoes a watery fusion, and becomes light and spongy, in which condition it possesses slightly corrosive properties, and is used as a caustic, under the name of alumen exsiccatum.The simplest process by which alum is prepared is, perhaps, that adopted at the Solfatara near Naples, which is covered with a white clayey soil, through which sulphureous vapours are eoustantly emitted. This soil is always hot, and nothing more is requisite than to immerse it into cisterns, and subject the earthy matter to lixiviation; nfter which, the saline solntion is evaporated by means of the subterranean heat, and placed in a situation to $\mathrm{cool}$, when the alum is deposited in crystals. As nothing is added during the process, it is obvious that the alun must exist ready formed in the soil. From the pre- 
sence of a small portion of irom, the Solfatam alum is not so valuahle, for many purposes, as that produced elsewhere ; and, accordingly, its use is mostly confined to the Neapolitan states. - The inanufacture of alum directly from its component parts, has, of late years, furnished a large proportion of this substance found in commerce. The process is conducted in the following manner:-Sulphur and nitrate of potash (nitre) are mixed together, in the proportions for forming sulplutic acid, and brought into combustion in large leaden chambers, or rooms lined with a thick coating of plaster. The sulphur is thus acidifed, and converted into vapour, and, the foor of the apartment being covered with clay of the purest kind, previously calcined, the acid gradually combines with it, and forms sulphate of alumine, which, after a few days, is dissolved out and considerably reduced by evaporation, when a solution of sulphate of potash (being the residue of the combustion of the nitre and sulphur) is poured in, and the perfect crystals of alum are deposited. (See Alum-slate and Alum-stone.)-The importance of alum in the arts, is very meat, and its annual consumption is immense. It is emplojed to increase the liardness of tnllow, to remove greasiness from printers' cushions and blocks in calico manufactories, and to render turbid waters limpid. In dyeing, it is used to cleanse and open the pores on the surface of the substance to be dyed, and, by the attraction of the colouring matter for the alumine it contains, to render it fit for receiving the colouring particles. Wood and paper are dipped into a solution of it to render them less combustible. Paper impregnated with alum is useful in whitening silver, and in silvering brass without hest. It is also largely used in the composition of crayons, in tannery, and in medicine.

Alom, native, is found in most countries, in the state of an efflorescence or mould upon the surface of certain slate clays and lavas, and, in the United States, in mica-slate rocks; also, in delicate hairshaped fibres, occupring clefts in a bituminous shale, principally found in Italy. It may always be easily recognised by its sweetish, astringent taste, in which it resembles the artificial alum. It exists only in very limited quantities, and contains too many impurities to be of any practical use. - A native alum has of late been found near the foot of the Andes, in South America, in which soda is substituted for potash. Am. Lyceum, Nat. Hist. New York, vol. iii. p. 19.

Alox-Slate; a slaty rock, of different degrees of hardness; colour, greyish, bluish, or iron-black, and often possessed of a glossy or shining lustre. It is chiefly composed of silex and alumine, with variable proportious of sulphuret of iron (iron pyrites), lime, bitumen, and magnesia. It is found abundantly in most European countries, and from it is obtained the largest part of the alum of commerce. As the alum-slate contains only the remote principles of this salt, the process for obtaining it is somewhat complicated. In the first place, it is requisite to acidify the sulphur of the pyrites, and combine it with the alumine. This is effected by roasting the ore in contact with the air, and then lixiviating it ; after which, potash is added, and the crystallized alum obtained by evaporation.

ALUM-STONE; a mineral of a greyish or yellowish-white colour, fine-grained, and approaching to earthy in its composition, and flled with numerous small cavities. It may be scratclied with the kuife, and easily reduced to fragments. When strongly heated, it emits a sulphureous gas. It is composed of alumine, 43.92; siłex, 24.00 ; sulphuric acid, 25.00 ; potash, 3.08 ; water, 4.00 . It is found at Tolfa, in Italy, in secondary rocks, and from it is obtained a very pure alum, by simply suhjecting it to rousting and lixiviation.

Alumise, or Alomsa; one of the earths entering most lurgely into the combination of all rocks, clays, and lonms. From its forming the plastic principle in clays, it was fornerly called argil, or the argillaccous eurth; but since it has been ascertained that it constitutes the base of the salt alum, it is styled alumine. Like the other earths, it was rom garded as an elementary substance in chemistry, until the researches of Sir H. Dnvy led to the belief that it was a compound of a peculiar metallic bise with oxygen.-It exists in the state of a liydrate, or in combiution with water, in the Gibbsite, a mineral found in Richmond, Massachusetts, and nenrly pure in the corundum gems. 'The porcelain class and kaolins contain about half their weight of this earth, to which they owe their most valuable properties. Alumine may be obtained pure by addfing, in the first place, to a solution of alum in twenty parts of water, a small quantity of a solution of carbonate of soda, to precipitate any iron that may be present, and afterwanls a little water of ammonia (uqua ammonia) to the supernatant liquid, separated from its precipitate, which, uniting with the sulpluric acid of the alum, liberates the alumine. On being washed, and thoroughly dried, it is of a white colour, and without taste or smell. It is soluble in liquid soda and potash, from which it may be separated, unaltered, by the acids. It is infusible, except in the heat of the compound blonpipe. Alumine is the basis of porcelain, pottery, bricks, and crucibles. It has a strong affinity for oil aucl colouring matter, which causes it to be employed, in the state of clays, as a cleansing powder, and, in a state of purity, in the preparation of lakes, in dyeing and calico-printing. It combines with the acids, and forms numerous salts; the most important of which are the sulphate of alunine and potash (see Alum), and the acetate of alumine. This salt is formed by digesting strong acetic acid (vinegar) upon the newly-precipitated earth; but, for the use of the manufacturer, by decomposing alun with acetate of lead, (sugar of lead), or, more economically, with acetate of lime, a gallon of which, of the specific gravity $1 \cdot 050$, is employed for every two and three-quarters pounds of alum. The sulphate of lime formed falls to the bottom, and the acetate of alumine remains in solution with an excess of alum, which is necessary to prevent its decomposition. It is of extensive use in calico-printing and dyeing, as a mordant, and is employed in the place of alum, to which it is generally preferred.

AldRED, an ancient English annalist, who floulished in the beginning of the 12th century, was a canon and treasurer of the church of St John of Beverley, his native town. His annals come down to his own times in the year 1129 , and are valuable both on account of the matter and the manner in which they are written. He is also supposed to be anthor of "The History of St John of Beverley;" a MS. preserved in the Cottonian library.

Alva, Ferd. Alvarez, of Toledo, duke of, minister of state, and general of the imperial armies, was born in 1508, of one of the most illustrions families of Spain. He was educated under the eyes of his grandfather, Frederic of Toledo, who instructed him in military and political science. Ile carriel arms, when very young, at the battle of Pavia; commanded under Charles $V$. in Hungary; also at the siege of Tunis, and in the expedition against Algiers. He defended Perpignan againsi the dauphin, and distinguished himself in Navarre and Catalonia. His cautious character, and lus inclinstion for politics, at first, led men to believe that be 
hard but little military talent; and Charles V. himself, whom he advised, in Hungary, to build a bridge of gold for the Turks, rather than risk a decisive battle, deemed him unqualified for ligh commands, and intrusted him with important offices rather from personal farour than respect for his ability. His pride was offended at the low estimation in which he was held, and his genius roused to the perfornance of exploits deserving of a permanent remembrance. His able generalship gained, in 1517, the battle of Muhlberg, against John Frederic, elector of Saxony. The elector was taken prisoner, and the duke, who presided in the council of war, adjudged him to death, and strongly urged the emperor to execute the sentence. In 1555, he was commissioned to attack the French in Italy, and pope Paul IV., the irreconcilable enemy of the emperor. He gained sereral victories, relieved Milan, advanced to Naples, where the intrigues of the pope had stirred up a rebellion, and confirmed there the Spanish influence. When Charles V. resigned the goverument to his son, Philip II., A. received the supreme command of the army. He conquered the States of the Church, and frustrated the efforts of the French. Philip, however, compelled him to contract an honourable peace with the jope, whom A. wished to humble. Recalled from Italy, he appeared, in 1559, at the French court, in order to marry Elizabeth, the daughter of Henry II., by proxy, for his sovereign; she was, at first, destined for the crown-prince, don Carlos. About this time, the Netherlands revolted, and $A$. advised the king to suppress the insurrection by severity and force. The king intrusted him with a considerable arny and unlimited power, to reduce the rebellious provinces. Scarcely lad A. reached Flanders, when he established the council of blood, at the head of which stood his confidant, Juan de Vargas. This tribunal condemned, without discrimination, all whose opinions were suspected, and whose riches excited their avarice. The present and absent, the living and the dead, were subjected to trial, and their property confiscated. Many merchants and mechanics emigrated to England; more than 100,000 men alsandoned their country; others resorted to the standard of the proseribed prince of Orange. The cruelty of $\mathrm{A}$. was increased by the defeat of his lieutemant, the duke of Aremberg, and he causer the counts of Egmont and Horn to be executed on the scaffoll. He afterwards defeated the count of Nassau, on the plains of Gemmingen. Soon after, the prince of Orange advanced with a powerful army. The young Frederic of Toledo sent to his father, asking permission to attack the prince. The duke, who demanded blind obedience from his inferiors, answered, that he pardoned him on account of his inexperience, but bade lim beware of pressing nim further, for it would cost the life of any one who slould renture on a similar message. The prince of Orange was forced to withdraw to Germany. The duke stained his reputation, as a general, by new cruelties; his executioners shed more blood than his soldiers: The pope presented him with a consecrated hat and sword, $-\mathrm{a}$ distinction previously conferred only on princes. Holland and Zealand, however, resisted his arns. A fleet, which was fitted out at his command, was annihilated; and he was every where met with insuperable courge. This, and perhaps the fear of losing the favour of the king, induced him to request his recall. Plinip willingly granted it, as he perceired that the resistance of the Netherlands was rendered nore obstimate by these cruelties, and was desirous of trying milder measures. In Dec. 1573, A. proclaimed an amnesty; resigned the command of the troops to
Louis de Requesens, and left the land, in which he had executed 18,000 men, as he himself boasted, and kindled a war, that burned for sixty-eight years, cost Spain 800 millions of dollars, its finest troops, and seven of its richest provinces in the Low Countries. Duke A. was receired with distinction in Madrid, but did not long enjoy his former credit. One of his sons had seduced one of the queen's ladies of honour, under a promise of marriage, and was, for that reason, arrested ; his father assisted him to escape, and married him to one of his relations, contrary to the will of the king. A. was banished, in consequence, from the court, to his castle Uzeda. Here he lived two years, when the troubles stirred up by don Antonio, prior of Crato, who had been crowned king of Portugal, forced Philip to have recourse to $A$., as one in whose talents and fidelity he placed great reliance. A. led an army to Portugal, gained two battles in three weeks, drove out don Autonio, and reduced all Portugal, in 1581, to subjection to his sovereign. He made himself master of the treasures of the capital, and permitted his soldiers to plunder the suburbs and surrounding country, with their usual rapacity and cruelty. Thilip was displeased at this, and desirons of instituting an investigation into the conduct of his general, who was, moreover, charged with having applied the wealth of the conquered to his own purposes. But a liaughty answer from the duke, and the fear of rebellion, caused him to desist. The duke died, January 21, 1582, aged seventyfour years. A. had a proud mien, a noble aspect, and a strong frame; he slept little, laboured, and wrote much. It is said of him, that, during sixty years of warfare against different enemies, he nevr.r lost a battle, and was never taken by surprise. But pride, severity, and cruelty tarnished his r. nown.

Alves, Robert, a Scottish minor poet, born at Elgin, in 1745, studied at Aberdeen under Dr Beattie, became schoolmaster first at Deskford, afterwards at Banff, whence he migrated to Edinburgh, where he subsisted himself by private teaching. In 1782, he published a volume of poems, and in 1789 another, with the title of " Edinburgh, a poem, in two parts, and the Weeping Bard, in sixteen cantos." These are said to contain striking traits of genius, but have been little attended to. He died in 1794, leaving a laborious work in the press, entitled, "Sketches of a History of Litera. ture," which was afterwards published.

\section{AMadeIsts. See Franciscans.}

AMADEUS ; the name of sereral counts of Savoy. -A. V., surnamed the Great, succeeded to the sovereignty in 1282. He gained distinguished honour in defending Rhodes against the Turks. He died, after a reign of thirty-eight years, in 1323 , at Avignon, where he was soliciting pope Joln II. to publish a crusade in farour of Andronicus, emperor of the East, who had married lis danghter. He was much loved and honoured by all the sovereigns of Europe, and was frequently the mediator in their differences.-A. VIII. succeeded his father, A. V II., in 1391, and acquired the titles of the Pacific, and the Solomon of his age. In 1416, Savoy was made a duchy; but, after this elevation, $A$. retired from his throne and family, into a religious house, at a place called Ripaille. In this retreat, he deroted himself to pleasure, so that faire ripailles became proverbial to siguify a life of indulgence and exquisite gratification. Here he aspired to the papacy, and employed large sums of money, at the council of Basil, to secure his election. Accordingly, this courcil, in 1439, having deposed Eugenius IV., chose A. in his place, under the name of Felix T:, 
though he had never taken looly onlers. Eugenins exconmunicated him. On the death of his rival, A. was persuaded to abdicate. He died at the age of sixty-nine, in 1451.-A. IX., suruaned the Huppy, on account of his virtue and piety. Being once asked by a courtier whether he kept hounds, he pointed to a great number of poor people seated at tables, eating and drinking, and replied, "These are my lounds, with whom I go in chase of heaven." He died in 1742, aged thirty-seven years.

Asapis; a name very celebrated in the romances of chivalry. -1. A. of Gaul, called, from the bearings on his shield, the knight of the lion, but in the wilderness, Beltenebros; a son of king Perion of France, and Eilesena, daughter of king Gavinter of Hretagne.-2. A. of Greece, a great-grandson of the Gallic A., and son of Lisuarte and Onoleria, daughter of the emperor of Trebisond.-3. A. of the Star, a great-grandson of the Grecian A., son of A gesilaus, king of Colchis, who was descended from Alastraxerea, a natural child of the Grecian A., by the queen Zahara of Caucasus. The mother of this third A. was Diana, a natural child of Sidonia, queen of Guindaga, by Florisel, the knight of the beautiful shepherdess, a lawful son of the Grecian A.-4. A. of Trebisond, descended from Roger of Greece, the Much-beloved, a son of Florisel and Helen, princess of Apollonia. This A. was a great-grandson of Florisel, and son of Polixana and Liscaron, prince of Cathay. The history of this hero, who was nearly the same to Spain as Charlemagne with his twelve peers to France, and king Arthur with his knights of the round table to England, is continued through uine generations; but the question concerning its origin and mixture of truth with fable, is involved in so much darkness, that it is even doubtful whether it originated with the Spanish, the Portuguese, or the French. In the Spanish original, this romance is contained in thirteen books, of which Cervantes, in the well-known exumination of the library of Don Quixote, caused the four first to be preserved, because they were not only the first, but also the best and only books of this kind which Spain had proluced; but the others were committed to the flames. These four contain only the history of $A$. de Gaul. Some say, that Vasco Lobeira, a Portuguese, who lived at the beginning of the fourteenth century, was their author; some, that they were written by an unknown Portuguese lady; and others ascribe them to the infante don Pedro, son of John I. of Portugal. On the contrary, the count Tressan has endeavoured to render it probable, that the honour of their authorship belongs to a French troubadour of the school of Rusticien de Puice, the author of nearly all the romances of the round table till the time of Philip Augustus (1180-1223). We shall be ready to acknowledge this, if it is established by a critical comparison of the most ancient manuscripts. Garcias Ordonnez de Montalbo, the corrector of the old edition, is said to have been the author of the fifth book, which contains the history of Esplandian, the eldest son of $\boldsymbol{A}$. The sixth book, by Pelag. de Ribera, contains the adventures of the knight Florisando; the serenth, those of an unknown knight; and the eighth, by J. Diaz, contains the deeds of Jisuarte; the ninth and tenth, those of Florisel, of A. of Greece, and of the knight Anaxante; the elerenth and twelfth, the adventures of Rogel and Agesilaus; and the thirteenth, those of Silvio de la Silva. The Spanish original goes no farther. Next follow the French translations, which have been increased to twenty-four books, since the translation of Nicholas d'Herberay, lord of Essars, in 1540. The books from the fourteenth to the serenteenth contain the exploits of Spharamont and A. of the Star; those from the seventeenth to the twenty-fourth, the adrentures of the remuining posterity of $\mathrm{A}$. of Gaul, including the deerls of A. of Trebisond. The separate parts of this work, which are seldom found altogether, are of very various merit. The additions are by no means equal to the four first books. There is not one of the new German modifications of this romance, or, rather, this string of romances, which deserves the name. The New $A$. of Wieland, a licentious book, has nothing in cominon with the old A., except its title and profusion of adventures. A late French poet, Crenzé de I.esser, las undertaken to give the adventures of Arthur and his knights of the round table, Charlennagne and his Paladins, and Amadis, in a new dress. His version of the first of these contains twenty cantos. A secourl edition of it appeared in 1812. His Amadis, containing, like. wise, twenty cantos, appeared in 1813.

Asratfr, a seaport town in Italy, situated in the gulf of Salemo, about thirty miles south from $\mathrm{Na}$ ples. In the ninth century, it rose to grcat splendour; assumed the form of a commonwealth; and, for its zealous exertions against the Saracens, was distinguished by the title of Defender of the Fnith. After enjoying its republican constitution and commercial rank for 300 years, it fell into decliue, aut now presents a sad contrast to its former graudeur.

Amalgam; a name applied to the combinations of mercury with the other metals. See. Mercury.

Amalia, Anma, duchess of Saxe-Weimar, born October 24, 1739, daughter of Charles, duke of Brunswick-Wolfenbuttel, died in 1806 . During the latter half of the eighteenth century, this princess was the centre of a court, which, in more than one respect, resembled that of the duke of Ferrara, which was adorned by the preserice of Tasso and A riosto. She gave to learned men the support which they looked for in vain from the great princes of Germany, while she afforded them a point of union and an agreeable residence. She assembled round her Wieland, Gœthe, Scliller, and many of the finest minds of Germany; and goverued witl wisdom after the death of her liusband.

Astalthea ; the name of a goat in Crete, which suckled Jupiter when his mother concealed him there through fear of Saturn. From this goat came the horn of plenty, which Jupiter gave to the daughters of Melissus, who assisted Rhea, with the power of obtaining from it every thing necessary for their subsistence; called cornu Amalthace (the same as cornu copia, the horn of plenty). According to some, A. was the name of the nymph who watched this goat. The Cumrean sybil also bore this name.

AMaranth; a kind of fower which preserves its bloom after it is plucked and dried. On this account, poets make it an emblem of immortality.

Amathus ; formerly a city in Cyprus, renowned for the worship of Venus, who is called, fron this place, Amathusia.

Asuri; a fanily of Cremona, who manufactured violins, in the sixteenth and seventeenth centuries, which, on account of their full tones, are yet held to be the best in use, and have become very dear. They are called Amati violins, and also Cremonas.

Amazon, Amazons, Maranon, ur Orbllana; a river of South America, the largest in the world. It is formed by a great number of sources which rise in the Andes; but the two head branches are the Tunguragua and Ucayale, both rising in Peru, the former from lake Lauricocha, in lat. $10^{\circ} 29^{\prime} \mathrm{S}$., the latter formed by the Apurimac and Beni, the head waters of which are between lat. $60^{\circ}$ and $18^{\circ} \mathrm{S}$. The general course of the rirer is $\mathbf{N}$. of $\mathbf{E}$.. and, including its windings, is upwards of 4000 miles in length. It flows into the Atlantic under the equa- 
tor ; the width of the mouth is stated by some writers at 150 , by others at 180 miles. Boat navigation commences at Jaen de Bracomoros, in Quito; and it is said that vessels of 400 or 500 tons may sail from the mouth throughout almost the whole extent. The depth is stated at from thirty to forty fathoms, 1500 miles from the ocean, and the tide is perceptible 600 miles. Its descent, in a straight course of 1860 miles, was found by Condamine to be 1020 feet (about six and a quarter inches in a mile); but the place where the tide is first perceived is only ninety feet above the sea. Its current is very rapid and violent.-It drains an extent of country about 1600 or 1700 miles from $N$. to $S_{\text {, }}$ receiving the waters of about 200 rivers, some of them as large as the Danube. From the $\mathbf{N}$. it receives the Santiago, Morona, Pastaza, Tigre, Napo, Negro, Putumayo, Yupura, Yaguapiri, Curupatuba, Yari, \&c. ; from the S., the Guallaga, Ucayale, Cuchivara, Yahuari, Cayari, Madeira, Topayos, Xingu, Guanapu, Muju, \&c.-The banks are clothed with immense and inpenetrable woods, which afford a haunt to tigers, bears, leopards, wild boars, and a great variety of venomous serpents; they also abound in birds of the most beautiful plumage, and apes of the most fantastic appearance. The waters swarm with alligators, turtles, and a great variety of fish. The vegetable productions, that grow wild, are cacao, cinnamon, vanilla, pincs, \&c. The country is adapted to cofiee, sugar-canes, rice, maize, plantains, lemons, limes, and oranges. Here are also precious woods, as cedar, red-wood, holly-wood, pine, \&c. In the rainy season, the river overflows its banks, and waters and fertilizes the adjacent country. The shores and islands were formerly peopled by numerous tribes of Indians, who have either become extinct or liave retired to the mountains. The first Euro. pean that visited this river was Francis d'Orellana, who, having met with some armed women on its banks, from this circumstance gave it the name of the river of the Amazons.

Amazons. An old tradition, which appears to be founded, in some measure, on historical truth, gives an account of a community of women, who permitted no men to reside among them, fought under the conduct of a queen, and long constituted a formidable state. They had commerce with the men of the neighbouring nations merely for the sake of preserving their community. The male children they sent back to their fathers, but they brought up the females to war, and burned off the right breast, that this part of the body might not impede them in the use of the bow. From this circumstance, they were called Amazons, i.e. wanting a breast. The ancients enumerate three nations of A.-1. The Africall, who made great conquests under their queen, Myrena, but were afterwards extirpated by Hercules. -2. The Asiatic, the most famous of all, who dwclt in Pontus, on the river 'Thermodon. 'These once made war on all Asia, and built Ephesus. Their queen, Hippolyta, was vanquished by Hercules. They attacked Attica in the time of Theseus. They came to the assistance of Troy under their quecn, Penthesilea, daughter of Mars and Otrere. About 330 years before Christ, their queen, Thalestris, madc a visit to Alexander of Macedon, soon after which they disappcar from history.-3. The Scythian A., a branch of the Asiatic. They attacked the neighbouring Scythians, but afterwards contracted marriages with them, and went farther into Sarmatia, where they hunted and made war in cumpany with their husbands. - The old geographers gave the namc of Amazonia to a large tract of country in the interior of South America, becausc the first discoverers of the cointry said that they found there a nation of Amazons. Later writers have correctel this error, and Amazonia has disappeared. It is laid down on the old maps as a part of what is at present Brazil and Peru. The river Amazon, (q. v.), or Maranon, which inundates and fertilizes this country as the Nile does Egypt, is the largest river in the world. (See South America.) Orellana, the first discovercr of the country, relates, that, as he sailed up the river, he found on its banks a nation of armed women, who made war on the neighbouring people; and this circumstance gave the name to thc river and country.

AMBassador (French, ambassadeur); the highest degree of foreign ministers. They represent the pcrson of their sovereign, or the people, if they are sent by a republic. They enjoy great privileges. Ambassadors, in this strict sense of the word, are sent at present only by a few of the most important governments of Europe, e.g. England, France, Spain, Austria, Russia: Prussia never sends them. The old republic of Venice was accustomed to send ambassadors, and was always considered equal in rank to a king. - For further information, see Minister, foreign.

AMBER. This well-known substance usually presents some shade of yellow in its colour, from which it sometimes passes to reddish-brown. It is brittle; yields easily to the knife; is translucent, and possessed of a resinous lustre. Specific gravity, 1.065. It burns with a yellow flame, emitting a pungent, aromatic smoke, and leaving a light, carbonaceous residue, which is employed as the basis of the finest black varnishes. By friction it becomes strongly electric; from which property originated the name and science of electricity, $\dot{\lambda} \lambda \varepsilon x$ roy being the Greek word for amber; and with this substance Thales, one of the Greek philosophers, performed the first electrical experiment. - It is found in masses, from the size of coarse sand to that of a man's head, and occurs in beds of bituminous wood situated upon the shores of the Baltic and Adriatic seas; also in Poland, France, Italy, and Denmark. Sometimes it is found on the east coast of Britain, and in gravel pits round London. More recently, it has been found in the United States, at cape Sable, in Maryland. The largest mass ever found was got in Lithuania, and weighed eighteen pounds. From its occurring very frequently attached to pieces of bitumenized wood, and containing insects, it is inferred, with great probability, that amber originated from vegetable juices, and has undergone its present modification, possibly, from sulphuric acid, derived from the iron pyrites which always abounds in the deposits where it occurs. - It is susceptible of a good polish, and has, at diffcrent times, been much esteemed as a personal ornament; but its want of hardness and lustre, together with the ease with which imitations arc made of it, have brought it into comparative disuse.-By distillation, it affords an oil, and a peculiar acid, the former of which is denominatcd oil of amber, and the latter succinic acid, from succinum, the Latin name for amber. The succinic acid, when purified, exists in whitc, trans. parent, prismatic crystals. It is soluble in water and alcohol; has strong acid properties; it forms salts with the alkalies and several of the carths. The succinate of potash is useful in analysis for the separation of oxyde of iron. 'The oil of amber is used in medicine.

A siberg; formerly the capital city of the Upper Palatiuate, on the Vils, in the Bavarian dominions, in the midst of numerous iron-works. Lon. $11{ }^{\circ} 50$ E.; lat. $49^{\circ} 25^{\prime} \mathrm{N}$. It contains 7680 inhabitants, and 712 houses. The manufactory of arms yields yearly from 10,000 to 20,000 muskets of the best 
quality. The old fortifications serve for a public walk. At A. the archduke Charles, Ang. 24, 1796, tefeated the French general Jourdain, and compelled him, Sepit. 3, by the battle of Wurtzburg, to retreat to the Rhine.

A MBERger, Christoph.; a German painter of the with century, born in Nureuberg. He resided in Augsburg, where he paintel, in 1530 , a portrait of the emperor Charles V., who rewanded him richly, und honoured him highly. This painting is now at

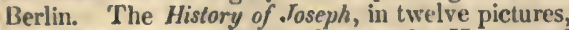
is said by Sandrart to be his best work. He painted in the powerful style of the elder Holbein, who was !iving in his time; he copied, also, many portraits of this inaster, and cut in wood. A. died between $\mathbf{5 5 0}$ and 1560 .

AMBERGRIs is found floating in the sea near the consts of various tropical countries, and has also lxen taken from the intestines of the speruaceti whale, where it is supposed to originate, owing to lisease. It is met with in masses of various sizes, sometimes weighing nearly 200 pounds. Its colour is a yellowish or blackish white; it is generally brittle, and may be compressed with the teeth or nails. It melts at $140^{\circ}$, and is entirely dissipated on red-hot coals. It is soluble in xther, volatile oils, and alcohol, and is chiefly composed of a peculiar nuimal substance called adipocire. Its odour is very agreeable, and hence arises its only use. In the state of an alcoholic solution, it is added to lavender-mater, tooth-powder, hair-powder, washlalls, \&c., to which it communicates its fragrance. Its retail price in London is a guiner per ounce.

Asiвоrna ; one of the largest and most valuable of the Molucca islands, in the Indian ocean, the scat of their government, and the centre of the commerce in nutmegs and cloves. It lies in E. lon. $128.15^{\prime}$, and S. lat. $3^{\circ} 42^{\prime}$, and is between fifty and sixty miles long. Its general aspect is benutiful, and its climate generally salubrious. It has been occasionally visited by earthquakes. It affords a great varicty of benutiful wood for inlaying and other ornamental work. Rumphius reckons the species at 400 . The clove-tree is the staple production of A. The island affords annually about '350,000 pounds of its firuit. The Dutch, during the Jong period of their possession of $A$., made every effort to monopolize this valuable spice. The number of trees was regularly registered by the governor, all the plantations of them visited, and particular districts devoted to their cultivation. They bonght from the neighbouring islands all the cloves that other nations were likely to import, and, in some cases, compelled the chiefs to destroy the rest, and even the trees that bore them. They are said to hare prohibited the culture of many edible roots on the island, to withhold the neans of subsistence from settlers and conquerors. Sugar and coffee are plentiful in A. Sago is the principal article of food. The few fruits cultivated are delicious. The natives, like other Malays, are rude and savage, and, when intoxicated with opium, capable of any crime. There are many Chinese and European cettlers on the island, and mixed races, from intermarringes, nearly as fair as Europeans. The Chinese are industrious, and live much together. Some of the aborigines in the woods are said to be as barbarous as ever, and to offer human sacrifices. When the English took A., in 1796, it contained about 45,252 inlabitants, of whom no less than 17,813 were Protestants; the rest were Mohammedans and Chinese. Thie houses of the natives are made of bamboo-canes and sago-trees. They sleep upon mats. Their weapons are bows, darts, cimeters, and tarcets. The's are said to be indolent, effeminate, and pusil. lanimous, and their women to be licentious.--In 1605, A. was conquered by the Dutch, and taken from the Portuguese, its former masters. They did not, however, get possessiou of the whole island, till after the lapse of some years. During this perioxl, the English had erected some factories in A., and the dispute between the settlers of the two nations led to the event callnd lise massacre of Amboyna. The Dutch accuserl the English inhabitants of being engaged in a couspiracy against the Dutcl possessions. They were inmediately seized, loaded with irons, thrown into prison, put to the torture to extort a confession, and those who survived this treatment were executed. The number of persons who perished were twenty-two; ten Englishmen, cleren Japanese, and one Portuguese. The linglish factory was, in cousequence, withdrawn from the island, and the effects of the English merchants seized to the amount of $£ 400,000$. The English factories in the adjacent islands were also seized. James I. and Charles I. obtained no satisfiction for this outrage, but Cromwell compelled the United Provinces to pay $£ 300,000$ as a small compensation. A. Lins been twice taken by the English, in 1790 and 1810 , but, after each capture, restored to the Dutch, in whose possession it is at preseut. The capital city of the island is called by the same name.

Ambras, or Amras; a castle in Tyrol, near Inspruck, formerly distinguished for its museum, containing armour, paintings, \&c., and a librury, which is now at Inspruck. The museum is at present in Vienna, and has been described by Alois Primisser (Vienna, 1819). Sixty-nine MSS. belong to this museum, one of which is a copy of the famous Heldenbuch.

Ambrosia, in the mythology of the Greeks and Romans; a sweet and balsamic juice flowing frem the soil of the happy island of Oceanus. It wits the nutriment of the gods, and preserved their immortality. Generally it was taken as food, sometimes as drunk, but must not be confounded with nectar. (q. v.) It was used also as an ointment. Mell who were allowed to partake of $A$. received an increase of beauty, strength, and swiftness; and became, in some measure, assimilated to the gods.

AMBrose, Saint; a celebrated father of the church; born in 340 , probably at Treves, where his father resided as governor of Gaul. Hapry omens attended him, even in the cradle. A swarn. of bees covered the eyes of the boy, while slumbering in the court of his father's castle, and, when tlie nurse hastened to him, slie was astonished to perceive the bees going in and out of his mouth, without doing him any injury. His father, recollecting perlaaps, a similar wonder mentioned of Plato hoped, from this circumstance, that he was destiued for greatness. His education was suitable to his rank; the best teachers at Rome, where the family had gone after the death of his father, formed his mind and his heart. After finishing their studies, A. and his brother, Satyrus, went to Milan, where they commenced the study of the law. Here $A$. distinguished himself so much that Valentinian appointed him governor of the provinces between the Alps, the Mediterranean, Tuscany, the Adige, and the Adriatic sea. His kindness and wisdom gainc? him the esteem and love of the people; but their prosperity was interrupted by the disturbances growing out of the doctrines of Arius, and he was called to the bishopric of Milan, by the unanimous voices of Arians and Catholics. A. long refused tc accept this dignily, but in vain. He fled by night, and thougl:t himself on the way to Pavia, but unexpectedly found himself again before the gates of 
Milan. At length he yicided, received baptism, for he had hitherto been only a catcchumen, and, eight days after, was consecrated a priest. The 7 th of December is still celebrated by the church on this account. A. obtained great honour by his conduct as bishop. He died in 397. Amiable, affable, mild, and modest, he used his authority only to promote the happiness of those around him, and the good of the Catholic church. His writings (the best edition is by the Benedictines, 2 vols. folio, $1686-90$ ) bear the stamp of his character. The Ambrosian Chant, or I'e Deum Laudamus, has been ascribed to him. Later critics, however, have shown that he should not be considered its author. A. improved the singing in the western churches. A Latin commentary on the thirteen epistles of the apostle Paul, called Ambrosiaster, or Pseudo-Ambrosius, has been falsely ascribed to him.

Auвrose, Isaac, a learned and pious presbyterian clergyman, was born about the year 1591, educated at $0 x$ ford, and appointed minister first at Preston, and afterwards at Garstang in Lancashire, from which latter place he was ejected, in 1662 , for 110 conformity. He died in 1664 , leaving several religious works, among which the most popular is the one entitled " Looking unto Jesus."

Ambrosian Library. This collection of books at Milan, famous, in modern times, on account of the discoveries made by Angelo Maio, was opened to the public, in 1609 , by cardinal Frederic Borromeo, a relation of $\mathrm{St}$ Charles Borromeo. The cardinal, archbishop of Milan, a lover of knowledge, caused the books to be purchased by learned men whom he sent through Europe, and even through Asia. At the opening of the library, it contained about 35,000 printed books, and 15,000 manuscripts in all languages. It now contains 60,000 printed books (according to Millin, 140,000). It was called the Ambrosian Library, in honour of St Ambrose, the patron saint of Milan. Angelo Maio, in his preface to the fragments of the Iliad, which he obtained from the treasures of this library, has shown how the collection has been improved, particularly by the addition of the Pinellian manuscripts. Its learned founder wished to connect with it a college of learned men, who should take charge of the different departments of the library, and make known its treasures, particularly to foreigners, who wished for information. The want of funds reduced this college from sixteen members to two, who jet bear the title Doctores Bibli. Ambros., with a gold medal, having Singuli singula inscribed on it. Besides the palimpsests discovered by Maio, this library contains a Virgil, in which is the account of Petrarch's first meeting with Laura, written by his own hand. At a little distance from the library is a gallery of works of art, containing, besides casts in plaster, several pictures of eminent masters, particularly the cartoon of Raphael's School of Athens, and the studies of Leonardo da Vinci, as well as the marly copies of this great painter's Last Supper ( La Cona). Of the twelve volumes, containing manuscripts in the hand of Leonardo da Vinci, which were formerly preserved as a treasure in the A. L., only one volume, more interesting than the others on account of the drawings in it, is to be found there at present; all the others having been carried to Paris.

AMEN, a Hebrew word, originally signifying verily, truly, has been transferred from the religious lauguage of the Jews to that of the Christians. He who pronounced the blessing, at the close of the service in the Jewish synagogues, was answered by the Jewish audience with the word amen. Also, in the religious assemblies of the first Cluristians, the prayer made by the eldest of the worshippers, or by a teacher, was concluded by the people with an anen. Public prayers are still often coucluded with this word. By the amen of a composer of music, we understand this word set to music to enable the choir to respond to the prayer or blessing chanted by the priest before the altar. Some amens are famous.

AMENDE HoNOURABLe was an infamous kind of punishment formerly inflicted, in France, upon traitors, parricides, and sacrilegious persons. The offender being delivered into the hands of a hangman, his shirt was stripped off, a rope put about his neck, and a taper into his hand; then he was led into court, where he was obliged to ask pardon of Gort, the king, the court, and his country. Sometimes the punishment ended here; but sometimes it was only a prelude to banishment to the galleys, to imprisonment in the Bastile, death, or torture.Amende honourable is also a term used for making recantation in open court, or in presence of the person injured.

AMENDMrNT, in law; the correction of any error committed in a process. An error in judgment cannot be amended, but an error after judgment may be. A writ of error must. be brought by the party aggrieved by an error in judgment. Any error after judgment, in plea or otherwise, may always be amended, by leave of the court.-Amendment, in parliament or congress, denotes an alteration made in the original draught of a bill, whilst it is passing through the houses. Amendments may be made so as totally to alter the nature of the proposition; and it is a way of getting rid of a proposition, by making it bear a sense different from what was intended by the movers, so that they vote against it themselves. A member who has spoken to the main question may speak again to the amendment. See, for this and other points respecting amendments, both in England and the United States, Jefferson's Manual of Parliamentary Practice, sect. 35.

America. Eastward of Asia, westward of Europe and Africa, between the Atlantic and Pacific oceans, lies the continent of America. It extends from lat. $56^{\circ} \mathrm{S}$. to an unknown northern latitude, and consists of two great divisions, North and South America (q. v.), which are connected by the isthmus of Darien or Panama. The whole continent is upwards of 9,000 miles in length, and from 1,500 to 1,800 in average breadth. The number of square miles which it contains is stated differently by different authorities. Templemann gires 14,323,000; Balbi, 14,622,000; Graberg, 15,737,000; Hassel, $17,303,000$. Between the two great divisions lie the West India islands ( $ๆ . v$.$) , extending from the$ gulf of Mexico and the Caribbean sea into the Atlantic. North America includes Greenland, belonging to Denmark; British America, which comprises New Britain, Upper Canada, Lower Canada. New Brunswick, and Nova Scotia; the Russian possessions in the north-west; the United States : Mexico, and Guatimala. The principal ranges of mountains are, the Alleghany mountaiss, the Rocky mountains, and the Cordilleras of Mexico. Some of the largest rivers are, the St Lawrence, Missis . sippi, Missouri, Rio del Norte, Colorado, Arkansas, Red river, and Ohio. North America contains the largest fresh-water lakes on the globe; some of the most extensive are, lakes Superior, Huron, Michigan, Erie, Ontario, Winnipeg, Slave lake, Athapescow, Champlain, and Nicaragua. The principal bays and gulfs are, Baffin's bay, Hudsou's bay, James's Bay, the gulf of St Lawrence, Delawaice bay, Chesapeake bay, the gulfs of Mexico and California, and the bays of Honduras and Cant- 
reachy. The most important islauds are, Newfoundland, Cape Breton, St Johu's, Rhode Island, Loug Island, and the Berundas, on the casteri cusst; queen Charlotte's islands, Quadra and Vancouver's island, king George III.'s island, and the Fox islauds, on the western const. Sonth America comprises Columbia, Guinua, 13razil, Peru, Bolivia, Clili, Buenos Ayres, or the United Provinces of Ia Plata, and Patagonia. The principal range of mountains is the Audes. The largest rivers are, the Amazon, Ia Plata, Orinoco, l'arana, Paraguay, Madeira, Tocantins, St Francisco, and Magdalena. There are few large lakes; some of the most considerable are, Maracaybo and Titicaca. The principal islands are, the Falklond islands, 'Terra del Fuego, Chiloe, Juan Feruandez, and the Gallapagos.-The coast of $\Lambda$. was explored to $72^{\circ} \mathrm{N}$. lat. by Hearne, in 1770 ; to $69^{\circ} \mathrm{N}$. by Mackcuzie, in 1789 ; to $78^{\circ} \mathrm{N}$. along the shore of Bafliu's bay, by captain Ross, in 1818; but its northern boundary is lost in the arctic circle. Near the southern extremity of Amcrica, in the latitude of $54^{\circ}$, lie the straits named, from the first circumnavigator of the world, Magellan (q. v.), and beyond, the southern promontory of the Terra del Fuego, cape Horn.The continent of $\Lambda$. has been cxamined by Europeans principally on the seaboarl. Expeditions, however, have becn made through its interior, in several directions; e. g. through North America, by captains Lcwis and Clarke, in 1804; major Pike, in 1805 ; through Brazil, by Langsdorf, Grant, Mawe, Koste, Eschwege, the prince of Neuwied, Spix, Martius, and others, especially by Alex. von Humboldt. For the history of its aboriginal population, and its condition before the arrival of the Europeaus, only a small portion of the existing materials have, as yet, been collected. Traditions, monuments, and other circumstances, seem to indicate a double emigration from the Fast, -one across the Aleutian islands, another farther sonth, over the tract which occupied the present place of the Atlantic ocean, if such a tract ever cxisted, as many writers have imagined. Or are the earliest inlubitants of America, the Toltecas, in Mexico, descended from that branch of the Huns, who migrated to the northeast, A. D. 100, and the nations of South America from a tribe of the Mexicans, driven southward by the plague, about the year 1050? More light, we hope, will be shed on this subject, especially on what respects North America, by the American antiquarian societies. From the first volume of the transactions of the one established at Worcester, in Massachusetts, it may be seen that those antiquities which pertain, in reality, to the North American Indians, consist, for the most part, of rude liatchets and knives of stone, of mortars for bruising maize, of arrow-heads, and similar articles. A secoud class consists of articles which the natives received from the earliest settlers. They are frequently found in the graves of the Indians. There is a thind and more interesting class, derived from the nation that built the forts or tumuli (graves, walls, artificial eminences, hcarths, \&c.) in North America. To judge from these works, this nation must have been far mure civilized, and much better acquainted with the useful arts, than the present Indians. From the lofty trees with which they are overgrown, it is concluded that a long period must hare elapsed-perhaps 1000 years-since the desertion of these fabrics, and the extinction of the people by whom they were constructed. They are found in the vicinity of each other, spread over the great plains, from the southern shore of lake Erie to the gulf of Mexico, generally in the neighbourhood of the great rivers. Thcir structure is regular, and they have been supposed to warrant the opinion of the existence, in ancient times, of great cities along the Mississippi. The mummies, as they are called, or dried bodies, enveloped with coarse elotlı, aul found in some of the saltpetre caves of lientucky, are worthy of attention. As we proceed further sonth, these works increase in number and naguitude. Their traces may be followed, through the provinces of Texas and New Mexico, into South America.-Alihough the accounts of the carliest generations of this quarter of the world are scinty and obscure, its later listory is rich in occurrences. The Jcelanders made a voyage, in 982 , to Windlaud (the name giren to the tract cxtending from Grecinland to Labrador); and the Venetians gave some information respecting the West Indian islands (in maps of 1424); but Ainerica still remained a sealed book for Europe till the period of its discovery by Columbus (q. v.), in 1492. Besides several voyages which he made subsequently to this continent, it was visited by Amerigo Vespucci (from whom it takes its name), in 1497; by Cabot, likewise, in 1499 by Cabral, in 1500, and by Balboa, in 1507. Shortly after, followed the expeditions of Cortez, Pizarro, \&c. It is probable that the new world has not becn inhabited more than twelve centuries. 'This circumstance, together with the oppression which the aborigines have suffered since the settlcurnt of the whites in their country, will account for the smallness of their number. Equally obscure with the origin of the Americans are their various rantifications. Their different languages, stated by Franc. Lopez at 1500, have bcen resolved, by Alex. ron Humboldt, into two original tougues,-the Toltecan and the Apalachian. (See Indirns.)Nature has cast the surface of the new world in larger forms, and cndowed it with fresher vitality, at least in the warmer regions, than she has bestowed on the soil of the old world. A. lias every variety of climate ; but the climate generally differs from that of the castem hemisphere, by a greater predominance of cold. It is calculated that tie heat is at least ten degrees less, than in the same parallels in the eastern continent. A. abuunds in almost all the varieties of the animal, vegetable, and mineral productions. It contains a great variety of wild animals; and, since its discovery, the various domestic animals of Europe have been introducel, and are now found in great abundance. In comparing animals of the same species, in the two continents, it has been found, in a majority of instances, where a difference in size has been ascertained, that the American animal is larger than that of the east. ern continent. The birds are exceediugly numerous, and are said to be more beautiful in thcir plumage than those of Asia and Africa, but in their notes less melodious. The condor, which frequents the Andes of South America, holds, on account of its size, strength, and rapacity, the pre-eminence over all the feathered creation. Reptiles are numerous, and many of then venomous. Insects abound, and, in many parts, are very oftensive. The American waters are remarkable for the variety and abundance of their fish. A. produces every kind of grain, fruit, pulse, herbs, plants, and flowers native to Europe, besides a great variety of others, as cacao, cinnamon, 'pepper, sarsaparilla, vanilla, scarlet dye, a great variety of balsams, mahogany, logwood, Brazil-wood, sassafras, aloes, barks, gmuns, resius, and medicinal herbs. This continent, particularly South America and Mexico, abounds in gold and silver. Since the discovery of the American mines, such ample supplies of these precious metals have been carried to Europe, that their value has become much diminished. A. also produces au 
abundance of copper, quicksilver, iron, antimony, sulphur, nitre, lead, londstone, and marbles of every sort. It has various kinds of precious stones, as diamonds, rubies, emeralds, amethysts, alabaster, \&c. The inhabitants may be divided into three classes, Whites, Negroes, and Indians. The whites are descendants of Europeans, who have migrated to A. sirce its discovery. The Negroes are mostly lield in sluvery, and are descendents of Africans, forced from their native country. The Indians are the aborigines, and generally savages. They are of copper complexion, fierce aspect, tall, straight, athletic, and capable of enduring great fatigue. They are hospitable and generous, faithful in their friendships, but inplacable in their resentments. Their common occupations are hunting, fishing, and war. At the time of the discovery of America, the natives, in some parts, particularly Mexico and Peru, were considerably advanced in civilization. For the most part, they continue a distinct people, and retain their savage customs; but, in some instances, they have mingled with the white population. The Indians still occupy the greater part of America. In North America, they possess almost all the country, except the southem and eastern parts; that is, the northern part of Spanish America, most of the territory of the United States which lies west of the Mississippi, and nearly all the vast regions which lie north of the United States' territory, and west of the St Lawrence. In South America, they possess Patagonia, and most of the interior of the continent.-The whites, who are descended from Spanish, Portuguese, British, French, Dutch, Danish, German, and Russian colonists, are estimated, by Humboldt, at . . 13,500,000 Indians

Negroes

$8,600,000$

$6,500,000$

Mixed races

$6,500,000$

The whole amount is over thirty-five millions; some think there are forty millions of inhabitants; but there is yet space and fertile soil for more than 500 millions. A great part of the Indians are subdued, and are included in the population of Mexico, Guatimala, and the states of South America. The numbers of those who speak the different languages made use of in A., are thus distributed :

English language

Spanish

Portuguese

Indian languages

French language

Dutch, Danish, Russian

$11,647,000$

$10,174,000$

$3,740,000$

$7,593,000$

$1,242,000$

216,000

See Carey and Lea's Historical, Chronological, and Geograplical American Atlas, \&c., Philadelphia, $18 \% 5$, fol.- Sce also the different names mentioned in this article.

Asrarica, Geology of. The great leading features in the structure of the new world are,-1st. The continuous belt of high mountains and plateaus traversing its westem border, from Behring's straits to Terra del Fuego, forming the most uninterrupted extent of primitive mountains known. Their northeril portion, consisting of the Rocky mountains, appears to be cliefly granitic, while, in the Cordilleras of Mexico, and the Andes of South America, the primitive strata are, for the most part, covered with inmense accumulations of transition porplyries, tracliytes, and laras, forming numerous rolcanoes, many of which are in constant activity. 2dly. The wide expanse of low and generally plain country, that succeeds immediately on the west to the abovementioned zone of mountaus, and tlirough which, in both hemispheres, flow some of the most magnificent streams in the world. This region consists of immense deposits of newer rocks, orer which is strewed every where, as with a mantle, the alluvial formation, or a covering of sand and gravel, witl I which are intermingled rolled masses of rocks. 3 dly. The chain of mountains of lower elevation and inferior continuity, which forms the eastern boundary to the low country, and iwhose principal masses and highest points are composed of granite. 4thly. The clusters of islands occupying the seas between North and South America, which are, almost without exception, of a volcanic origin.-The geological character of A. partakes of the simplicity observable in her great mountain ranges, which obey highly uniform laws of arrangement, and are, in a measure, free from those interruptions which occur in Europe arising out of its numerous chains, whose irregular and often contradictory structure it is frequently difficult to reconcile or explain. The two continents agree in the prevailing primitive clraracter of their northern extremities, and in the prevalence of rolcanoes about their equatorial and southern regions; and an investigation of their geological relations affords no grounds for the common opinion, that the new world is of a more recent origin than the old.For a more minute account of the geology of America, see North America, Mexico, and South America.

American Company, the Russian. In 1785, two Russian mercantile houses, Schelikoff and Golikoff, projected the formation of a regular company, to encourage the fur-trade of the north-westen shore of North America. They erected forts for the protection of a chain of factories on most of the islands, and induced several respectable merchants to join in their extensive and lucrative adventures. Many cruelties against the natives were charged upon the company, and the emperor Paul was upon the eve of suppressing it altogether, when the company pledged itself to more regular proceedings. In 1799, it was formally established with considerable privileges. The emperor Alexander took it under his particular patronage at his accession. The condition of the fur-collectors of the company is said, however, to be still wretched in the extreme, and only to be exceeded by that of the oppressed Aleutians, who are, in turn, their slaves.

Americanrss; an idiom, or use of the English language, peculiar to the inluabitants of the United States. The deviations of the Americans from the English usage, in their common language, were occasionally noticed, many years ago, by some of their own writers, as well as by the critics of the mother country. Among the American authors, who have animadverted upon them, the most conspicuous was doctor Franklin, who was himself a writer of great purity and correctness of style, and who censured, in strong language, the popular errors several of the states were continually falling into, both with respect to "expression and pronumciation." This remark was made forty years ago, when he himself noted a few words, which, at that time, he pronounced to be objectionable innorations. in their parliamentary language; as the verbs to notice, to advocate, and to progress, the last of which he condemned as "the most awkward and abominable of the three. The word opposed," he adds, " though not a new word, is used in a new manner; as, "the gentlemen who are opposed to this measure, to which I have myself been opposed." Several other American writers have remarked upon particular words and expressions. The British reviewers and other writers have also, until very lately, indulged themselves in serere animadversions upon American writers, for their occasional deviations from the English standard; though, in some instances, they 
lave themselves alopted the very woris which they formerly condemined. (Of the words thus sanctioned by them, the verb to advocate was, no longer ago thu in the year 1793, denonnced as one of the words which the Anericans lad " invented, without any apparent reason," and which the Euglish luul " altogether declined to countenance." But this ill-fated wond, which was then proscribed as an Anerican intruder into the language, has more recently been discovered to have been used so long ago as the age of Milton, the excellence of whose jrose writings had, until molern days, been entirely lust sight of in the splendour and inajesty of lis poetic diction. We have still, however, some doubt whether Milton used this wond in the sense now nfixed to it both in Britain and America; it was certainly userl in a different sense by his contemporaries, and the present meaning of it had not been sauctioned, as we strongly believe, by any subsequent writers (if we except a single instance in Burke's works), until it was brought into general use in America, by the writers of that country, and, more recently, by the authority of Milton's uame, snıong English writers, some of whom now claim it as their own, with as inuch zeal as it was once condeuned. (See 'Todd's edition of Johnson's Dict.) Some other words, which were either newly-coined, ur old ones newly brought into use in America, have been admitted into good writing in England. The particulars in which Americans have departed from Einglish usage, may be reduced to the following classes :-1. Words entirely new, of which the number is extremely small; e. g. caucus, boatable. 2. Words to which is aftixed a meaning different from that of the English; e.g. clever, to girdle. 3. Words whose original meaning has been preserved by Americans, while the English have given them a new signification. 4. Provincialisms, origirially tuken from difierent counties in England, by the first emigrants, to America, and still used there, just as they are in the mother country at this day. This class of wonds may be said to be wholly confined to the language of conversation. 5. Words which have become obsolete in England, but are still in use in A merica ; as, to tarry. It may be further remarked, that, in all these classes, a great proportion of the rords are of local use, technical, mere vulparisms, or used only by individual writers, whose caprice and affectation of style are not followed by the nation at large.-We have observed, that single words and expressions had been occasionally mentioned by American writers many sears ago. The first attempt to make a general collection of all such words as liad been supposed to be American peculiarities, was that of Mr John Pickering, who published a Vocabulary of them in the Memoirs of the American Academy (vol. 3, p. 439), in the rear 1809. This valuable collection was afterwards reprinted, with large additions by the author, under the title of A Vocabulary, or Collection of Words and Phrases, which hare been supposed to be veculiar to the United States of America (8ro., 2p. 206, Boston, 1816), and was accompanied with a Memoir on the present State of the English Language in the United States. It contains a list of about 500 words and phrases, which are all carefully examined, and traced, in almost every instance, to an English origin. This Vocabulary has been freely used in the late valuable American edition of Jolunson, by $\mathrm{M}_{\mathrm{r}}$ Worcester, who observes that it " has had a salutary influence on our literature, by calling the attention of our scholars to the occasional deviam tions of American writers from pure English." Mr Webster's new Dictionary of the English Language (1ublished 1320, New-York) contains many words with their Anerican significations; but this work is not so complete in Americauisus as the Vocabulary of Mr P'ickering, alove-meutioned. We slall recur to this subject under the article English Language.-We cannot couclude these renarks, without directing the realer's attention to the circunstance, that Britain and the United States of America afford the first iustance in history of two great, independent, and active nations daily developing new and characteristic fentures, situated at a great distance from eacl other, and having a common language and literature. These relations must, sooner or later, exert a decisive influence ujon the common dialect; for no langunge is so settled as not to undergo continual changes, if spoken by $\varepsilon$ nation in the full vigour of social and political life. Authority, in regard to language, will go far, but never can withstand for a long time the energies and wants of a free, industrious, and thinking people. Spain and Portugal, inded, with the independent nations of South America, present an instance in many respects parallel ; but the contest of language will be more languid, in proportion as there is less energy and activity in the mother countries, and less progress in the arts and sciences, as well as less political advancement, in the states which have lately shaken off the yoke.

Amemcus Vespucius; properly Amerigo Fespucci; born March 9, 1451, at Florence, of an ancient family. He early made great progress in uatural philosphy, astronomy, and geography, at that time the three principal branches of science studied at Florence, on account of their importance in relation to commerce. In 1490, he went to Spain for the purpose of trading, and was at Seville when Columbus was making preparations for his second voyage. The success of Columbus's undertaking excited Vespucci to give up trade, and explore these newly-discovered countries. According to his own account, in one of his letters, he entercil on his first voyage, under the command of aduiral Ojeda, May 20,1497 , who left tlie harbour of Cacliz with four ships, and, after a voyage of thirty-seren days, reached the main land of America, explored the bay of Yaria, and the coast for several huudred miles, and, after eighteen montlıs, returned to Spain, and was received with distinction by the conrt at Seville. In Mas, 1499, he began his second voy age, the fruit of which was the discovery of a multitude of small islands. This is his own account. But it is fully proved, that no such royage as the one first mentioned was made, and that his first expedition to the new continent was in 1499, under the command of Ojeda, a year after the discovery and examination of that part of the coast by Colunbus. Other accounts of Vespucci are, also, inconsistent with the statement above given. (See Irving's Columbus.) After this, he entered the service of king Emanuel of Portugal, and made two voyages in Portuguese ships; the first, May 10,1501; the second, May 10, 1503. The object of this last royage was to find a westerly passage to Malacca. A. arrived at Brazil, and discovered the bay of All Saints. In 1505, he again entered the service of the king of Spain, but made no more voyages, as appears from memoranda, showing that he was at Serille till 1508, at which time he was appointed principal pilot. His duties were to prepare charts, and prescribe routes for vessels in their voyages $w$ the new world, which soon received his name. This honour certainly belonged to Columbus rather than to A., for the prior discovery of the continent by the former is not to be questioned. We lave a chart of America laid down by $A . ;$ a journal of four of his yoyages, printed at Yaris, 1532 , in the Latin lan. 
gwage, in twenty-two pages, 4to ; and Amerigo's I.etters, which appeared at Florence after his death, published by John Stephen di Carlo da Pavia. Vespucci died at S'eville, in 1512. Emanuel, king of Portugal, caused the remains of the ship Victoria, in which he had made his last voyage to America, to be hung up in the cathedial at Lisbon, and Florence conferred marks of distinction on his family. The accounts of his life are full of contradictions and perplexities. See Irving's Life of Columbus, 3u vol., Appendix, No. ix.

Amss, Fisher, one of the most eloquent of American statesmen and writers, was bom at Dedham, in Massachusetts, April 19, 1758, of very respectable parents. Soon after the completion of his 12 th year, he was admitted to Harvard college, with the reputation of uncommon talents and attainments. Diligence, regularity, and success marked his collegiate course of four years. After receiving his degree, in $\mathbf{1 7 7 4}$, the narrow circumstances of his widowed mother compelled hin to y ustpone, for several years, the accomplishment of his original purpose of studying the law. In the interval, he acted as an assistant teacher in a public school, and continued to cultivate classical literature, to the signal improvement of his taste and fancy. At length, in 1781, he commenced the practice of the law, with the stock of knowledge which he had acquired in the office of a member of the profession, in Boston. Opportunity soon occurred for the display of his superior qualifications, both as a speaker and essay writer. The fame which followed his early efforts conduced to place him in the Massachusetts convention for ratifying the constitution, in 1788. From this sphere, in which he made a deep impression by some of his specches, particularly that on biennial elections, he passed to the house of representatives in the state legislature. Here, he soon became so eminent as an orator and man of business, that the voters of the Suffolk district elected him their first representative in the congress of the United States. He had not been long in that assembly before his firiends and admirers were satisfied that they had not overrated his abilities. He won there the palm of eloquence, besides proving himself equal to the discussion of the deepest subjects of politics and finance, and the execution of the most arduous committee labours. He remained in congress during eight years, the whole of Washington's administration, which he coustantly and zealously defended. " His speech on the British treaty," says"his distinguished liographer, doctor Kirkland, "was the era of his political life. For many months, he had been sinking under weakness, and, though he had attended the long and interesting debate on the question which involved the constitution and the perce of the United States, it was feared he would be umable to speak. But when the time came for taking a vote so big with consequences, his emotions would not suffer him to be silent. His appearance, his situation, the magnitude of his subject, the force and the pathos of his eloquence, gave this speech an extraordinary power over the feelings of the dignified and mumerous assembly who heard it. When he had finished, a member in opposition mored to pustpone the decision of the question, that they might not rote under the influence of a sensibility which their calm judgment might condemn."-On the retirement of Washington, Mr A. returned to his residence at Dedham, where he occupied himself with the management of his farm, and the practice of the law. The latter he relinquished in a few years, owing to the decline of his health; but he felt too deep an interest in the welfare of his country to withdraw his mind and pen from polities. He published a considerable number of essays, relating chiefly to the contest between Great Britain and revolutionary Fiance, as it might affect American liberty and prosperity. No writer evinced more ardour for the success of Britain, or more horror of the character and tendencies of the French despotism. In 1804, Mr A. was chosen president of Harvard college,-an honour which he declined. When Washington died, $\mathrm{Mr} \mathrm{A}$., then a member of the council of the commonwealth, was appointed to pronounce his funeral eulogy before the legislature of Massachusetts.-The injury which his constitution sustained in 1795 was never fully repaired. From that period his health declined, until, at length, after an extreme debility for two years, death ended his sufferings. He expired July 4, 1808; and, when the intelligence of this event was received, a public meeting of citizens was held, in order to testify the general respect for his character. His remains were carried to Boston, where they were interred with honour's such as had not been before paid to those of any private citizen.- In 1809, his works were issued in a large octavo volume, with prefatory notices of his life and cliaracter, from the pen of the reverend doctor Kirkland, president of Harvard college, who had enjoyed his personal friendship and intimacy. The volume is fraught with profound remarks, various historical lore, and eloquent declamation. Although the political interest of most of the topics is gone, there remains much to captivate and reward attention in the richness of fancy, warmth of feeling, beauty of language, and felicity of copious illustration, which distinguish almost every page.-Fisher Ames left seven children and a wife, to whom he was tenderly attached. In person, he exceeded a little the middle stature, was well-proportioned, and perfectly erect. His features and countenance were fine, and his manners easy and affable. Of his delivery as an orator, his biographer states, that he did not systematically study the exterior graces of speaking but his attitude was firm, his gesticulation natural and forcible, his voice clear and varied, and his whole manner earnest and expressive. According to the same authority, all the other eftorts of his mind were probably surpassed by his powers of conversation.

Ames, Joseph, the historian of British typography, was born at Yarmouth, 1688-9. He published, in one rol., 4to, 1749, "Typographical Antiquities, being an historical Account of Printing in England, with some Memoirs of its ancient Printers, and a Register of the Books printed by them from 1471 to 1600 ; with an Appendix concerning Printing in Scotland and Ireland to the same time." Mr A. died in 1739. Besides his great work, he wrote a Catalogue of English Printers from 1471 to 1700 , 4to, and several other works. An enlarged edition of the Typographical Antiquities was published by the late Mr W. Herbert, vol. 1, 1785, vol. 2, 1786, and vol. 3, 1790 . A new and splendid edition of Ames and Herbert has since been presented to the world by the Rev.

T. F. Dibdin.

A METHYST. See Quartz.

AMHERs ; a pleasant and flourishing post-town of America. It is situated in the province of Massachusetts, county of Hampshire; eight miles N. E. of Northampton, $90 \mathrm{~W}$. of Boston; pop., in 1820, 1917. It is noted cliefly for its literary institntions, which consist of a college, an academy, and a seminary styled the Mount Plcasant Classical Institution. Amherst college was opened in 1821, and incorporated in 1825. It is a flourishing institution, and has three 
rdifices or halls for the accommotation of students. In 1828 , the college was under the direction of a president, five professors, one tutor, and two assistant teachers, and had 211 students.

Aswerst, Jeffrey, lond, a distinguished British general officer, was descended from an ancient Kentish family, and born in 1717. He early levoted himself to the profession of arms, receiving an ensign's commission when only fourteen years of age. Ai the age of trenty-five, he acted as aid-de-camp to lord Ligonier, in the battles of Dettingen and Fontenoy, and afterwards served on the staft of the luke of Cumberland, at those of Laffeld and Hastenbeck. In 1756, he received the colonelcy of a regiment, and was appointed mnjor-general, and, in the summer of 1758 , commanded the expedition against Louisburg, which, together with the whole island of Cape Breton, surrendered to his arms. The capture of fort du Quesne, Niagara and Ticonderoga in due time followed; and, in 1760 , the whole of Canada being reduced, general Anlierst received, for his share in these exploits, the thanks of the house of commons, and the order of the Bath. In 1763, he was made governor of Virginia; in 1770, governor of the isle of Jersey, and, in 1772, lieutenant-general of the ordnance aul officiating commander-in-chief of the British forces. Besides these, and several other military honours, he was, in 1776 , created a peer by the title of baron Amherst of Holmesdale, in the county of Kent. On the breaking up of the North administrition, lord Amherst was removed from the commandership-in-chief, and the lieutenancy of the orinance, and, in 1787, received another patent of peerage as baron Amherst of Montreal, with remainder to his nephew, William Pitt Amherst; and, on the staff being re-appointed in 1793, he was once more called upon to act as commander-inchlief. In 1795, he resimned the commandership-inchief to the duke of York, and, in 1796, received the rank of field-marshal. He died in 1797, in the eighty-first year of his age. A. was twice married, but left no issue, being succeeded by his nephew as afuresaid. Lord Amlierst was regarded as a inan of a collected and temperate mind, without brillincy or parade; a strict officer, yet the soldier's friend. He had two brothers, one an admiral of the blue, the other a lieutenant-general; it is the son of the latter who has succeeded him.

Amintrus; a kind of flexible asbestos. (q. v.)

A siosurps; the middle of a ship, either with regand to her length or breadth.

Amrens, in Picandy; a fortified city in the French department of the Somme, situated on the river Somme ; lon. $2018^{\prime}$ E.; lat. $49053^{\prime} \mathrm{N}$. It contains 5950 houses, 41,000 inhabitants, is the residence of a bishop, and has possessed, since the year 1750, a Société d' Emulation, an academy of arts and sciences, of literature, commerce, and agriculture, a lyceum, a school at St Acheul, under the direction of the Jesuits, a convent of the order of la Trappe, in the abbey du Gard, many considerable manutactories of woollen cloth, tapestry, damask, and kerseymere (of which 130,000 pieces are sold annually), leather, soap, as well as eighty cotton factories. The pastry of A., also, often goes across the channel, and is very celebrated.

AMress, peace of ; concluded March 27, 1802, hy Joseph Bonaparte, the marquis Cornwallis, d'Azzara, and ron Schimmelpenninck. In 1800 , Britain saw herself deprived of all her continental alliances; the Russian emperor, Paul, was dissatisfind that Malta was not restored to the order of which he was grand master, and Pitt had laid an cubargo on the ships of Prussia, Desmiark, and
Sweten, because, at the instigntion of Paul, they deternined to revive the armed neutrality of the north. Oll the other liand, the ports of the continent were closed against the British ships, and this circumstance gave the opposition in parliament a majority against the ministry. At the same time, the minister could not obtain the consent of the king to the emanciuation of the catholics. So the Pitt ministry was dissolved, and the speaker, Addington, took l'itt's place, as first lord of the treasury. The new ninistry, of which lord Hawkesbury was secretary of foreigm afiairs, commenced negotiations for peace, and the prelininaries were signed at I.ondon, Oct. 1, 1801. A defuitive treaty was concluded at A. between Great Britain, France, Spain, and the Batavian republic, March 27, 1802. Britain retained, of her conquests, the islands of Ceylon and Trinidad; the harbour of the cape of Good Hope remained open to her ships. France regained her colonies, and the Arowari was made the boundary of her possessions in Guiana on the side towards Brazil. The republic of the Seve'n Islands was acknowledged, and Malta was restorel to the order of the same name. Spain and the Batavian republic, also, regained their colonial possessions, with the exception of Ceylon and Trinidad. The French were to evacuate Rome and Naples, together with Elba. The house of Orange was to be indemnified; the status quo ante bellum guaranteed to the Porte; and, on these conditions, the sultan Selim formally acceded to the treaty of A., May 13, 1802. But this peace soon became gener. ally unpopular in Britain; for the first consul fitted out a great expedition against St Domingo, and wished to place French consuls in all the ports of Ireland. On the other hand, Great Britain declined evacuating Egypt and Malta, maintaining that France had first threatened; in which assertion they were confirmed by Sebastiani's inconsiderate report of his mission to Egspt. May 10, 1803, the British court declared the conditions on which, alone, all new differences could be reconciled; demanded indemnification for the king of Sardinia, who had been expelled from the continent ; restitution of the island of Lampedosa, and the evacuation of the Batavian and Helvetian republics by the French troops. These conditions the French refused, and the court of St James's declared war, May 18, 1803.

Aurlcar, or Hamicar ; the name of several Carthaginian generals. A. Barcas, the father of Hannibal, is the most celebrated of them. The Roman fleet defeated his, near Trapani, $242 \mathrm{~B}$. C., and thus put an end to the first Punic war. $A$. began the second, landed in Spain, and subdued its most warlike nations; but, as he was preparing for an expedition against Italy, he was killed in battle A. U. C. 526, B. C. 228 . He left three sons, and is said to have made Hannibal swear an etenual hatred against the Romans.

Amor, father; a French Jesuit, born in 1718 , at Toulon ; a missionary to Pekin, who las contributed much to our knowledge of China. We owe to him the most elaborate account of the antiquities, the history, the language, and the arts of this kingdom. In 1750, he went to Macro, and, in the following year, by the invitation of the emperor of China, to Pekin, where he remained till his death, in 1794. Uninterrupted study gave him a knowledge of the Chinese and Tartar languages, by means of which he became acquainted with China through the best sources. Mlost of his valuable works, which treat of the writing, the art of war, the music, \&c. of the Chinese, together with a biography of Confucius, and a grammar, \&c. of the 
Tartar-Mantcheou language, are to be found in Memoires concernant l'Histoire, les Sciences et les Arts des Chinois, the tenth part of which sets forth, in fourteen columns, his contributions to the first ten volumes. He wrote, also, Eloges de Moukden, published by Guignes, and the Dictionnaire Tatarmantcheou-Francais, published by Langles.

Amman. There were three eminent physiologists of this name. The first, JoHN CoNRAD, a native of Schaffhausen, distinguished himsclf by his success in teaching persons born deaf and dumb to speak, upon which subject he published two treatises. He was born in 1669, and died in 1724 . His soll, JoHs, was an eminent botanist, and lectured on botany at Petersburg. He died in 1740. The third, PAul, was a native of Breslau, who settled in 1674 at Leipsic, where he gave lectures on pliysiology, natural history, and botany, and published sercral treatises on these subjects. He died in 1691, aged fifty-seren.

Ammanus, Marcellinus; a Roman historian, of the fourth century after Christ, born at Antioch, in Syria. His work, in thirty-one books (of which only twenty-four are extant), includes the history of the Casars, from Nerva to Valens. It may be considered a continuation of 'Tacitus and Suetonius, and is very interesting and instructive. There is an old and good edition by Gronovius (Leyden, 1693), a later one by Ernesti (1773), and the latest by Wagner (Erfurt and Leipsic, 1808, 3 rols.).

AmMrato, Scipio; a distinguished Italian historian, born at Lecce, in Naples, 1531. After having travelled through Italy, he was employed by the grand duke of Tuscany to write the history of Florence; for which he was presented to a canonry in the cathedral there. Some of his works, while in this station, are, 1. Arguments, in Italian verse, 4to. Venice, 1548. 2. II Decalione Dialogo del Poeta, 8vo. Naples, 1560. 3. Istorie Florentine, dopo la Fondatione di Firenze insino all' anno, 1574. He died in 1601 .

AMmon; a Libyan deity. Some writers make him a son of Triton; others say, that he was found in a wood, where, with the exception of a sheep, no living thing was to be seen; and affim, therefore, that he was the son of this sheep and Jupiter. Others say, that when a boy, he was found by some herdsmen, playing in the sand, between Carthage and Cyrene; and that, as long as he remained on the sand, he continued uttering predictions, but, as soon as they removed him, he became dumb. Finally, it is related, that Bacchus, on his journey through India, being exhausted by heat and thirst, called upon Jupiter for hclp, not far fiom Xerolibya; thereupon a ram appeared, and, stamping with his foot, opened a spring in the sand, and then vanished. 'This ram he acknowledged as Jupiter himself, paid him divine honours, and built a tcmple to him. According to Diodorus Siculus, A. was a king in Libya, whose wife was Rhea, sister to Saturn, and whose mistress was Amalthea, by wliom he had Bacchus. The lattcr built that celebrated temple to $A$., where he delivered oracles, not by words, but by signs made by his priests, and where he was exhibited under the form of a ram, or, according to some, of a man with a ram's head or horns. Alexander visited this temple, and was declared, by the priests, a son of the deity. For an account of this old temple of $A$., in the Oasis of Siwah, see, also, Oasis and Meroe.-A.'s horn is a species of fossil, in the form of a ram's horn.-A., in Hebrew history, the son of Lot, by his youngest daughter. He was the father of the Ammonites.

AMmonia; an alkaline substance, differing from the other alkalies by its volatility, not being obtain- ed pure, except in its gaseous form, and hence called the volatile alkali. It is obtained by mixing together equal weights of dry quick-lime and muriate of ammonia (sal ammoniac), separately powdered, and introducing them into a retort or iron bottle, and applying heat. It is a transparent, colourless gas, of little more than half the weight of common air, and has an exceedingly pungent smell, well known under the old name of spirits of hartshorn. It extinguishes flame, and is fatal to life. It is decomposable, by a strong heat, into three parts, by measure, of hydrogen, and one of nitrogen gas. It is rapidly absorbed by water, which dissolves one third of its weight of this gas, or 460 times its bulk, and forms the aqueous ammonia, or aqua ammonia, as it is commonly termed in commerce. The process for procuring this is merely to connect a retort, or iron bottle, containing the muriate of ammonia and quick-lime (generally slacked), with a common still and refrigeratory, and apply a moderate heat. It is very accurately valued by its specific gravity; that used in medicine is about 0,950 . It is also soluble in alcohol, and is used in medicine under the name of spirits of hartshorn.-Ammonia combines with the acids, and forms a numerous class of salts : with carbonic acid, it forms the carbonate of ammonia (volatile sal ammoniac), which was formerly prepared from the destructive distillation of animal substances, but is now fabricated, in part, by mixing one proportion of muriate of ammonia with two of carbonate of lime, in a state of dryness, and subliming in an earthen pot; and, more largely, from purified sulphate of ammonia, sixed with one quarter of its weight of chalk, finely ground, and previously calcined, introduced into cast-iron retorts, and subjected to a red heat : the carbonate of ammonia, as it is formed, is conveyed by a tube into a leaden or cast-iron receiver, where it is condensed. It is used as a stimulant, usually in the form of smelling-bottles, and also by bakers, to raise their bread lighter and quicker than by yeast alone. With muriatic acid, ammonia forms muriate of ammonia (sal ammoniac). It is found native in fibrous masses and crusts, sublimed into the cracks of lava, among other volcauic matters, about the craters of volcanoes. The muriate of ammonia of commerce, however, is prepared, by a tedious process, from an impure carbonate of ammonia, obtained by the distillation of bones and other animal mattcrs: the carbonate is decomposed by sulphate of lime, and the sulphate of ammonia again by muriate of soda ; and the muriate of ammonia is separated from the sulphate of soda by crystallization, after which it undergoes the process of sublimation two or thrce times; and, this being done in rounded vessels, it assumes the form in which we are familiar with it in commerce. The sulphate of ammonia, obtained in procuring gas-lights for illumination from coal, is also made use of in the manufacture of sal ammoniac. It has lately been discovered, that muriate of ammonia exists in the water of the ocean, and that it may be obtained, by sublimation, fiom the uncrystallizable part called bittern. (Phil. Trans, 1822 , p. 454.) This salt was formerly imported from Egypt, but is now manufactured in Europe. Great quantities are annually carried from Buch. arian Tartary to Russia and Siberia.-Sal am. moniac is applied to many useful purposes. Occa. sionally, it is used in mcdicine. A considerable portion of it is consumed by dyers, to give brightness to some of their colours. It is also employed in the assay of metals, to discover the prescnce of iron; and, having the propcrty of rendering lead brittle, is sometimes used in the manufacture of shot. By coppersmiths and tinners, it is used for 
cicansing the surface of the metals which they are about to cover with tin. It is said that twonty tons of sal ammoniac, for the purpose of soldering, are searly used in Birminghain.

A smosis, nitrate of, is formed by saturating diluted nitric acid with carbonate of ammonia. From it is obtained the nitrous oxyde, or exhilarating gas.

Aммомл, sulphate of, in the form of stalactites, is found in the fissures of the earth surrounding certain small lakes in Tuscany, also in the lavas of Etna and Vesurius, and, dissolved in a spring, in Dauphine. It is, of late, obtained in large quantities, as a secondary product in the distillation of coal for gas-lights. $\Lambda$ chaldron of Newcastle coal affords 200 pounds of ammonincal liquor, which consists chiefly of sulphate of ammonin and carbonate of ammonia. It is used for the manufacture of sal ammoniac and volatile salt.

Amsosits. There trere many learned men and philosophers in $\Lambda$ lexandria of this name :-1. A Peripatetic or rather Eclectic philosopher, who was the instructor of Plutarch in the first century after Christ. 2. A., surnamed Saccas, who was a founder of the new Platonic school in Alexandria, 193. (See Alexandrians.) 3. A disciple of this school, in the fifth and sixth centuries, son of Hermias, scholar of Proclus, and master of Simplicius.

A s.ronition, a term expressive of the various articles used in war. No ammunition can be imported into Britain by way of merchandise, except by license from his majesty; and such license is to be granted for fumishing his majesty's stores only, miter penalty of forfeiture, 6 Geo. 4, c. 107 . His majesty may forbid, by orier in council, the exportation of any saltpetre, gunpowder, or any sort of A., under a forfeit of $£ 100$. (29 Geo. 2, c. 16.)

Aswestr, (Greck, from a priv. and pyaopal, to remember), in law; an act of oblivion; the entire freedoun from penalty, granted to those who have been guilty of any neglect or crime, usually on condition tlat they return to their duty within a certain period. An amnesty is often declared in case of the rebcllion of whole districts or countries, because it is not possible to exercise on them the severity of the law, and it is often considered sufficient to punish the leaders. In domestic disturbances and ciril wars, oblivion of the past is a necessary prelude to peace. But amnesties are often only deceitful assurances, of which modern history affords many instances. The amnesty, or the religious peace, of 1570 , in France, was followed, in 157\%, by the shocking spectacle of a government causing a part of its subjects to be murdered. (See St Bartholomew, massacre of.) The terms of the religious peace concluded at Passau, 1552, contain an amnesty, in which the campaign of the elector, Maurice, of Saxony, against the emperor Charles V. is mildly termed an excursion for the sake of military exercise, and full forgiveness is promised to all who lad taken part in the war. Also in the peace of Westphalia (art. 2.), after much dificulty, a full and general amuesty, from the beginning of the disturbances in Bohemia, was granted. A general amnesty was proclaimed in England, 1660, at the restoration of Charles II., from which the king excepted no one, and the parliament only the judges of Clarles I. The French revolution is rich in amnesties; the victorious party promising them to their opponents, or securing themselves in this way from punislument. At the restoration, a formal amnesty was not thought experient; but in the ('harte Constitutionelle, (art. II), all prosecutions on account of political offences are forbidden. Notwithstanding his abdication, Napoleon Bonaparte considered those who had conspired, in 1814, to ovcrtum his throne, as state traitors, and, Marcls 12,1815 , granted them an amnesty nt Lyons, from which only thirte' enne, the cluke of Dalberg, \&.c.) were excluded. $\Lambda t$ the second restorition, Jan. 1\%, 1816, all who had taken an immediate part in the usurpation of Bonaparte were pardoned, with the exception of only nineteen persons, who were prosecuted under the decree of July 24, 1815 (Ney, Labedorere, Lavalette, Bertrand, Rovigo, \&.c.), besides thirty. eight others, whom the king was to lave the right of banishing any time within two months, (Soult, Jassano, Vandaıne, Carıtot, Ifullin, Merlin, \&c.), and, in fine, all those who liad roted for the drath of Louis XVI. (régicides), and such as had takcil office during the "lhumdred days." These, as well as all the nembers of the Bonaparte family, wre banished from France. Many of them liave been permitted to return. Also, in the Italian and l'ortuguese revolutions and connter-rerolutions, such political amnesties have beeit proclaimed, with inore or fewer restrictions. $\Lambda \mathrm{n}$ article of this nature is to be found in the peace signed at Viema betwee'n Prussia and Saxony.-For amnesties in Spain, see Spain.-Of all the instances of annesties which listory affords, there have been few in which the promise of forgiv'ness has been strictly kept by the ruling party, when seated in secure possession of power. Generally, governments have found means to punish their opponents without openly violating their promise of pardon.

Asor, with the Romans; with the Greeks, Egws; the god of love. According to the later mytholog5, $\Lambda$. is the son of Venus and Mars, the most beautiful of all the gods; a winged boy, with bow and arrows, sometimes represented blind-foldert. His arrows inflict the wounds of love, and his pow(r is formidable to gods and men. He is not always a playful child in the arms of his mother, but appears sometimes in the bloom of youth, e. g., as the lover of Psyche. He is brother to Ilymen, the goll of marriage, wliom he troubles much by his thoughtlessness. (See Hymen and Cupid.) According to the earlier inythology (that of Hesiod and Orpheus), he is the eldest of all the gods, and existed befor'e any created being. $13 y$ his means the sterile Chaos brought forth Nox, from whom issued Day ant Light. This eldest $A$. is the lofty idea of the allexciting and all-fructifying love. To him, according to some writers, Hate is opposed. In English, the god of lore is less frequently called A. than Cupid; yet, with the ancients, Cupido denoted, properly, only the animal desire, which the Greeks expressed by the word natos.

A moretrl, $\Lambda$ bbate Carlo; a great mineralogist, and, since the year $179 \%$, one of the conservatori of the $\Lambda$ mbrosian library, was born at Oneglia, March 13,1741 ; died at Milan, in 1816. Till 1772, he was professor of canon law at Parma. Being well versed in modern languages, he endeavoured to make known to his countrymen the progress of other nations in the arts and sciences. $\Lambda$. was a member of many learned societies in Italy. Between 1775 and 17SS, he published, at Milan, twenty-seren rols. in quarto, with engravings. Nuova scelta d'Opuscoli Interessanti sulle Scienze e sulle Arti, in connexion with several friends. His knowledge of the art of mining obtained lim a seat, in 1808, in the Consiglio delle Miniere. He first encouraged a careful examination of the treasures of the Ambrosian library, in which Maio has since exerted himself so successfully. By his means, the following works werc printed:-the first royage round the workl of Pigafetta of Vicenza, from isig 
-1522, and a treatise on navigation, by the same; also, the north-eastern voyage through the Atlantic and the Pacific oceans, by captain Maldonado (this appeared in 1811); and, in 1804, Leonardo da Vinci's Trattato della Pittura, with plates; also a biography of this renowned painter, in 1806 ; and, finally, in 1808, Codice Diplomatico Sant' Ambrosiano, a supplement to the collection of Italian documents, of the eighth and ninth centuries, by Pater Fumigalli. Of his great work, Della Rabdomanzia Ossia-Elettrometria Animale Ricerche Fisiche $e$ Storiche, Milan, 1808, he published, in 1816, an abridgment, Elementi di Elettrometria Animale.

Amortization; the right of transferring lands in mortmain, i. e. to some community which is never to cease. This word is used in France and Germany to signify the redeeming of public debts. Anortissement, from amortir, is the French word for sinking fund.

Asory, Thomas, a dissenting minister of eminence, was born at Taunton in 1701. His opinions were those of the celebrated Dr Samuel Clarke, and, in 1770, he became the colleague of Dr Price, at Newington Greel. He was an efficient member of the committee for procuring an enlargement of the Toleration Act. He died in 1774, leaving behind him some volumes of sermons, and some minor pnetry.

Asiory, Thomas, the author of "John Buncle," was the son of an Irish councillor, and born in 1692. It is conjectured that he was brought up a physician, but it does not appear that he followed any profession. In 1755 , he published a singular heterogeneous work, entitled, "Memoirs," which treated of various matters, particularly the lives of ladies, in a peculiar and racy manner. In 1756 , he published the first volume of the Jife of John Buncle, and, in 1766, the second. This is, in some sort, a continuation of the Memoirs. Both works have been reprinted, and the latter las received the valuable commendation of $\mathrm{Mr}$ Hazlitt. John Buncle is remarkable chiefly for the number of excellent ladies whom he falls in with and marries, and for his great enjoyment of the tea-table. From the character of his writings, Mr Amory has been thought insane by some; but it would be uncharitable to characterize him further than a man of eccentricity. He was married, and resided chiefly at Westminster in a retired manner, where he died in 1789 .

A sos, the prophet; a herdsinan who appeared in the vicinity of Jerusalem, under the kings Josins of Judah, and Jeroboam II. of Israel, B. C. 850, and presched with zeal against the idolatry then prevailing in Israel. His prophetical book, contained in the Old Testament, is made up of descriptions of the moral profligacy and idolatiy of this people, and of threatenings and promises, similar to those which the other Jewish prophets have delivered. II pecnliarities are the use of certain rural images, a rounded style, clearness in the construction of his sentences, and distinctness in his descriptions. He is amongst the best of the Hebrew writers.

Astpellites, or CaNdele-Coal, or Canal-Coal. See Coal.

Asipularaus ; son of Oiclens (accorling to some, of Apollo) and Hypermuestra; endowed by the gods with prophetical powers. Foreseeing that he should perish before Thebes, he hid himself; but, being betrayed by his wife, Friphyle (q. $v$.), he joined Polynices in his expedition against this city, and was one of his most valiant warriors. The besiegers having been repulsed in one of their attacks, the earth opened under him in lis flight, and swallowed him, with his horses. On the spot where this event is snid to have taken place, at Oropus, feast was celebrated in honour of him (Amphiarca! and, not far from this city, a temple was dedicated to him, where oracles were delivered. His death was revenged by his son, Alcmaon.

A мrнibia; animals of the third class, in the Linnæan system, most of which, by their peculiar anatomy, are able to live either upon land or in the water. Since Cuvier's exertions to introduce a better classification in zoology, this term has been superseded by the term reptilia. See Reptiles.

A Mrutbology, in grammar; a loose manner of expression, whereby the sense may be construed into a double meaning. It has a similar application to phrases or sentences with the word equivocal in respect to words.

\section{AMPHIBRACHYs. See Rhythm.}

Amphictyons, court of the; an assembly composed of deputies from the different states of Greece, according to most authors, established by kinis Amphictyon, son of Deucalion and Pyrrha, according to Strabo, by Acrisius, king of Argos, as a point of union for the several Grecian states. At first, they assembled at Delphi ; in later times, at Thermopyla, or rather at the neighbouring village, Anthela. Twelve Grecian states sent two deputies each, who assembled with great solemnity; cosnposed the public dissensions, and the quarrels of individual cities, by force or persuasion; punished civil and criminal offences, and, particularly, transgressions of the law of nations, and violations of the temple of Delphi. After the decision was published, a fine was infticted on the guilty state, which, if not paid in due time, was doubled. If the state dicl not then submit, the whole confederacy took arms to reduce it to obedience. The assembly had also the right of excluding it from the confederation. An instance of the exercise of this right gave rise to the Phocian war, which continued ten years.

Amphinackr. See Rhythm.

Ampunon; son of Jupiter and Antiope; the eldest of the Grecian musicians. In Lydia, where he married Niobe, the danghter of king Tantalus, he leamed music, and brought it thence into Greece. He reigned in Thebes, which was before called Cadmea. A. joined the lower and upper city by walls, built the seven gates, and gave it the name of Thebes. To express the power of his music, and, perhaps, of his eloquence, the poets said, that, at the sound of his lyre, the stones voluntarily formed themselves into walls; that wild beasts, and even trees, rocks, and streams, followed the musician, With the aid of his brother, Zethus, he is said to have revenged Antiope, who was driven into banislıment by his father, and to have bound Dirce to the tail of a wild bull; which incident is supposed to be represented by the famous piece of sculpture, the Farnese bull.

A mpinsbana; a genus of serpents, so called on account of the shape of its body, which is of equal thickness from head to tail ; which are, consequently, difficult to distinguish. This occasioned the notion of its having two heads. Different naturalists establish different numbers of species. Doctor Sliaw mentions two, viz. the alba and the fuliginosa. 'T'he alba is about eighteen or twenty inches long, and totally white. It is a native of South America, and a harmless animal. The fuliginose is white, with black or deep-brown spots. The head is withont spots. It is found iu many parts of South $A$ merica, and in Libya. It is innoxious. All the other species are also found in America.

Ampntheatre, with the Romans; a building without a roof, of a round or oval form, destiner for the combats of gladiators, or of wild beasts. In 
the midhlle was the arena, a large place covered with sund, on which the fights were exhibited. Round alwout were the vaults or caves, in which the animals were kept; above these was the gallery, from which ascended successive rows of seats, each of greater height and circiunference than the precerling. The fourteen first were for the senators and judges, the others for the common people. In the year 709 from the building of the city, Julius (Tesar erected the firs: large amphithentre at Rome, for his gladiatorial exhibitions. It was of wood, and was pulled down after it lad been used. Statilins Taurus, twenty years later, built the first stoue one. The Coliseun (ף. v), at Rome, is the largest of all the ancient anphithentres. In Verona there is one, the interior of which still shows the whole ancient architecture, and is carefully preservol; it is called there arena. Of all the Roman antiquities, none has withstood the effects of time so well as this renarkable building. The form is oval, and the architecture is in the taste of the Coliseum at Roune. There is another at Pola.

AминттRाтs; daughter of Oceanus and Tethys, or of Nertus and Doris. Neptune wished to make leer his wife, and, as she hid herself from him, he sent a dolphin to find her, which brought lier to him, and received as a reward a place among the stars. As a goddess and queen of the sea, she is represented as drawn in a clariot of shells by l'ritons, or riding on a dolphin, with the trident of Neptune in her lhand.

Aмарнiтrion; king of Thebes, son of Alcæus, and hushand of Alcmena. Plautus, after hin Moliere, and, still later, Falk and Kleist, have made the trick played upon hin by Jupiter (see Alcmena) the subject of amusing comedies, in which the return of the true $A$., and his meeting with the false one, occasion several humorous scenes at the palace and in the city. The French give this name to a courteous host.

AspLIFICATION, in rhetoric; the part of a speech wherein circumstances are enumerated and dwelt upon to excite the minds of the auditors. Some writers on rhetoric understand by amplification only the explanation of a subject by examples. The Greek and Roman rhetorical writers meant by it a mode of adding to or detracting from the dignity of a subject by an accumulation of words or ideas. Longinus defines amplification the collection of all the circumstances connected with a suljject, in order to give force to that which is already proved. The amplification generally embraces both these objects. Cicero and other ancient orators make the amplificatio and cnumeratio (recapitulation) essential to a speech. In this case, amplification, also called exaggeratio, embraces only the conclinding strokes by which the orator sought to heighten the effect of what he had said. Every one, who makes use of this rhetorical figure, ought to remember the simple and just remark of Boileau :

Teut ce qu'on dit de trop est fade et rebutant.

Astrlitude, in astronomy; the distance of any celestial body, or other object (whel referred by a secundary circle to the horizon), from the east or west points; the comp'ement to the amplitude, or the distance froin the north or south poine, is called the aximuth.-Amplitude denotes, also, with reference to the direction of the magnetic needle, or compass, the arc of the horizon contained between the sun or a star, at its rising or setting, and the magnetical east or west points of the horizon; or it is the difference of the rising or axting of the sun or star from the east or west poiats of the compass. -
In gunnery, amplitude is sometimes used for the range of a shell, or other projectile, fiom its departure out of the mouth of the piece to the place where it falls. 'Thus the French engineers speak of the amplitude de parabole, \&c.

AspoLLA, in antiquity; a vessel bellying out like a jug, that contained unctions for the bath; also a vessel for drinking at table. In ecclesiastical ritu's, the ampulla was employed for several purposes, suel as loolding the oil for clirismation, consceration, \&.c., also for auointing monarchs at the ir coronation. In Englaud aud France, a vessel of this kind is still in use for the last mentioned purpose. The French ampulla was at Rheins, the archbishop of which performs the cornnation of the French kings. A dove, it was said, brought this ampulla from licaren for the baptismal unction of the crafty Clovis I., in 496 . In the revolution, this ampulla was lost; and it is said that a soldier oiled his boots with the nirnculous liquid. On the late coronation of Charles X., the public papers stated that a phial containing some ot this unction had survived the catastroplee. The anpulla of the English kings, now in use, is an eagle weighing about ten ounces, of the purest chased gold. Having passerl through various hands to the Black Prince; it was by lim deposited in the tower. Henry IV. is the first king who was anvinted froin it. See Anointing.

Aspotatios, in surgery ; that operation by which a member is sevarated from the body according to the rules of the science. Though the medical art endeavours to prevent the necessity of amputation, yet many cases arise in which it is absolutely necessary, in order to save the life of the patient. It may be considered as one of the greatest victories which science and skill have gained over barbarism. There is no decisive proof tlat Hippocrates ever performed this operation. A. C. Celsus, wlio lived under 'Tiberius, has left a short description, in lis book $D e$ Re Medica, of the mode of amputating gangrenous linbs. Paulus Aigineta, about eight centuries afterwards, suggests little improvement. The Arabiaus seem to have made little progress in the art of suppressing the bleeding after the amputation, which was still the most important desideratum. 'The rreatest improvements were introduced by Pari, a French surgeon, in the 16 th century, since whose: time amputation has been performed with much skill among all cirilized nations, and, in the latest times, with a boldness at which former ages would have shuddered, and with great precision and success. The late wars in Europe have adianced this branch of the surgical art, perhaps, more than any former period, by the number and variety of the cases re. quiring amputation, which they lave presented. Increasing knowledge of antatomy has continually increased the boldness of the operator.

A MRETSIR, i. e. the pool of immortality; formerly called Chak, a town of Hindostan, in the province of Lahore, the principal place of the religious worship of the Seiks. It is, on account of its farourable situation, between Cabul and Delhi, Cashmere and the Deccan, a place of great trade; but its chicf importance is derived from the sacred pond, constructed by Ram Dass (one of the earlier pontiffs of the Seik faith), in which the Seiks and other Hindoo tribes immerse themselves, that they may be purified from all sin. This holy basin is 135 paces square, built of brick, having in its centre a temple dedicated to the Hindoo saint G00roo Govind Singh. Under a silken canopy, in this temple, is deposited the sairit's book of religion and laws, called Grant'h. The voluntary contributions of pilgrims and devotees support this place, to which 600 priests are at tached. 
A msterdam; the chief city of Holland; lon. 4o $40^{\prime}$ E.; lat. $52025^{\prime}$ N. ; situated at the mouth of the Amstel, where it falls into an arm of the sea, called $Y$ or $W y y e, 65$ miles from Antwerp, 240 miles north-east of Paris. This famous commercial city, before the late separation of Holland and Belgium, the capital of the Netherlands, though not the usual residence of the king, was, at the beginning of the 13th century, a fishing village in the possession of the lords of Amstel. About the niddle" of that century, it became a small town, and obtained a municipal government. In 1296, it was suddenly attacked and plundered by the neighbour. ing Kennemers, on account of the participation of Gysbert of Amstel in the murier of the count Floris of Holland, and Gysbert himself was expelled. In this way Amsterdam, together with Amstelland came under the rule of the counts of Holland, who granted the city many privileges. Amsterdam soon acquired an important commerce in the Baltic sea, and, in the 16th century, was a place of considerable commerce. The transition from the bondage of its lords to the state of suljects of the counts of $\mathrm{Hol}-$ land was the origin of its prosperity. A second cause was its deliverance from the Spanish dominion. It became, in a short time, the first commercial city in the United Provinces. In 1585, after Antwerp liad fallen a second time under the dominion of Spain, its extensive commerce was transferred to Amsterdam, and the western or new part of the city was built. The city receired new accessions in 1593, 1612,1658 . In 1622, it contained 100,000 inhabi tants. Its increasing importance awakened the envy of its neighbours. In 1587, Leicester attempted to take it by treachery, and prince William II., in 1650 , by surprise. Both attempts were frustrated by the prudence of the two burgo-masters, Hooft and Bicker. The burgo-masters of Amsterdam then acquired so much weight in the assembly of the states-general, that their authority, during the first 94 years of the 18th century, rivalled that of the hereditary stadt-liolder. During this period of prosperity, A. acquired so great wealth, that it surpassed every other city in Europe. It was the great market of all the productions of the East and West, and its harbour was always full of ships. The fame of Dutch honesty and frugality increased the flourishing trade of the city. This was obstructed, however, by the sand bank before the Pampus, on account of which large ressels could not enter without unloading part of their cargoes into lighters. Vessels, moreover, could not sail from the Zuyderzee, near the Texel, except with certain winds. Finally, A. has often experienced great depression during the continuance of wars. Fven in the glorious period of the 17 th century, in 1653 , the war with England did such injury to its commerce, that four thousand houses in the city were left unoccu. pied, and, it is said, the exchange was overgrown with grass. Commerce, however, afterwards revived, and continued, with little diminution, even Juring the unquiet period from 1790 to 1794 , with the exception of the time of the English war, from 1781 to 1782. But after the change of Government in 1795 , the trade and wealth of $A$. continually diminished. The forced alliance of Holland with France, which obliged her to follow the French policy, against the powers at war with France, operated to the great disadvantage of A. Iouis Bonaparte endeavoured to restore the trade of Holland by means of grants and privileges, and even transferred his residence and the seat of government to A. in 1808; but the first measure only irritated Napolcon against Holland, and the other, though it opened some new sources of traile, was followed by various disadvantages. The complete incorporation of Holland, with France, in 1810, entirely annihilated the foreign trade of $A_{\text {. }}$; and many other measures, as, for instance, the introduction of the monopoly of tobacco and of the droits réunis, as they were called, were very injurious to the domestic trade of the city. The revolution of 1813 restored the business of A. Since that time, its commerce has increased very considerably. Many of the longestablished houses are very rich, but, nevertheless, for several reasons, less actively engaged in trade than the merchants of Antwerp. Besides the public buildings, Amsterdam contained, in 1732, 26,385 dwelling-houses, besides a great number of shipyards, manufactories of ropes, cordage, tobacco, \&c. The number of inhabitants was, in $1796,217,000$; in $1808,208,000$, among whom were 20,000 Jews. In 1820 , however, there were but 180,000 , of wlom 90,000 were Calvinists, 38,000 Catholics, and 30,000 Lutherans. From comparing the censuses, it appears that the proportion of the male to the fe. male sex is about four to five. In 1817, the number of the poor of all degrees amounted to 39,000 . On account of the lowness of the site of the city, the greater part of it is built on piles. A. affords a splendid prospect from the harbour, by reason of its numerous steeples; the view from the Amstel bridge is also very fine. In earlier times, A. was a strolig fortress. Its twenty-six bastions, and its means of inundating the country, made even Louis XIV. cautious of attacking it; but, in 1787, when threatened by a Prussian army of only moderate size, it was obliged to surrender, after the cápture of the fortified villages in the vicinity. In consequence of the changes which have taken place in the mode of conducting sieges, $A$. can be defended only by the inundation of the surrounding country. Y $Y$ et it is said, that, in the last years of the reign of the exking Louis, a plan was formed for the regular fortification of $A$. On the side towards Haarlem, the city is, at present, protected by the sluice of Halfwegen, and on the eastern side by the fortress of Naarden. Within the semicircle which the borders of the city describe on the land side, several canals form many smaller semicircles, which all open into the Amstel river, or into the $\mathbf{Y}$, or Wye. A mong the public buildings, the old stadt-house is particularly famous. The building began under the superintendence of the architect Jacob van Kampen, after the peace of Westphalia, in 1648 , which fixed the independence of the Dutch republic, and it was finished in 1655. In the vaults under the stadt-house are deposited the treasures of the bank of Ansterdam. This splendid building stands upon 13,659 piles, is 282 feet long, 235 feet wide, and 116 feet high, without reckoning the high tower. The interior of this magnificent building was decorated by the Dutch painters ánd sculptors of the 17th century with their master-pieces. The patriotic Dutcli were therefore highly offended, when Louis Bonaparte, in 1808, close the stadt-house for his residence, and his attendants and courtiers occupied the councilrooms of the fathers of the city. The hall prepared for the reception of the throne on this occasion is probably the finest in Europe. The magnificent museum of Dutch paintings, which were exhibited in the stadt-house, is now transferred to the Trippenhouse. The present king, also, resides in this palace (the former stadhuijs), when he is at Amsterdam. The public weigh-house, which was oplosite to it, was pulled down under kiıg Louis, in ordes to lave an open space before the palace, and was transferred to the western market. The magistrates of the city now assemble in the forner royal hall. 'The exchange of Amsterdam, which was built be- 
tween 1603 and 1613 , rests upon five vanlted arches, under which the Amstel flows into the Dannack water; it is 250 feet long and 140 feet wide. The East India house, of which a whole wing, used for granaries, lately tumbled down, the national shipranl, and the magazine upon the Katenburg, at the $\boldsymbol{Y}$, are at present used for other purposes of commerce and navigation 'The benutiful 'Trippenhouse, where the academy of arts and sciences assembles, is now a temple of the arts and sciences. The society felix meritis (established by the merchants), which promotes the stindy of every thing that can occupy sud ennoble the mind; the society Doctrina et amicitia; the Tot nut van't algemeen, deroted to the liberal arts and sciences; the excellent reading-room ; several musical societies; the Dutch, French, and German theatres; the hortus medicus, belonging to the Athenaum illustre; the famous Latin schools; the many excellent national poetsprove the taste of the citizens of $A$. for science and learning. Their regard for religion, charity, and order, is manifested by the numerous churches, by the hospital for the aged, the poor-house and orphan asylum, the houses of correction, the navigation school, the many societies for humane objects, and the work-houses of different descriptions. The churches are numerous: annong them, the Dutch Reformed lave ten, the French one, the English one, the Roman Catholics eighteen, and even the Greeks and Armenians have a church. The most splendid is the new church upon the Damm, in which the pulpit and organs are master-pieces; heme you see the monuments of the admiral de Ruyter, of the valiant von Galen, and of the great poet Vondel; here, also, after so many storms, the fabric of the state was strengthened by the adoption of the constitution, and by the allegiance sworn to the present sovereign, March 29 and 30,1814 . In the Oude Kerk monuments are erected by the naval Heemskerk, van der 'Zaan, Zweerts, and van der Hultz. The Western Kerk has a handsone steeple. With so much that is beautiful and great, and witl a trade wlich affords the means of support to every industrious man, A. has, indeed, the disadvantage of a very damp air, and an offensive, mephitic smell, which often rises, in summer, from the canals. It suffers, also, from the want of good spring-water, and from the inconvenience of very high and narrow dwelling-houses, occasioned by its crowded population. The new canal, extending from its liarbour to the extreme point of North Holland, 26 feet in depth, is of great advantage to $\mathrm{A}$. It removes some of the chief impediments to the commerce of the city, viz. the necessity which existed of unloading large ressels, before they eould enter the harhour, and of encountering the passage through the Zuyder-zee, which was peculiarly difficult with contrary winds. The shipping of goods to and from Amsterdam will, therefore, be effected in fiture more promptly and cheaply. This canal extends from A. to Niewe Diep. The distance between the extreme points is 41 English miles; but the canal is about 50 miles and a half long. The breadth at the surface is $124 \frac{1}{2}$ English feet; the breadth at the bottom 36 feet; the depth, 20 feet and nine inches. It passes through a somewhat marshy country, and touches, besides several villares, the cities of Purmerend and Alkmaar. Like the Dutch canals generally, its level is that of the high tides of the sea, from which it receives its snpply of water. The only locks which it requires, of course, are two tide-locks at its extremities; but there are, also, two sluices with flood.gates in the intermediate space. The locks and sluices are double, that is to say, there are two in the breadch of the canal. The canal is wide enongh to odmit of one frigate passing anotler. The tinn spent in trncking vessels from the Helder to A. is 18 honts. - There is an excellent acconnt of this city, in a medical point of view, by D. C. I. Nienwenhnijs : Proeve tcner geneeskundige plaaesbeschrijeing der Stad Ansterdam, Ainst. 1820 , 4 vols. For more particular details respecting the commerce of Austertam, see Holland.

Amsterdan; an island of the South Pacific ocean, in lon. $76 \circ 54^{\prime} \mathrm{E}$., and lat. $380^{\circ} 42^{\prime} \mathrm{S}$., first visited by van Vlaming, a Dutch nuvigator, in 1697. and explored, in 1793, by the gentleinen attached to loni Macartney's embassy to Chinn. 'The length of the island, from N. to $S$. is upwards of four miles; its breadth, from E. to W., abont two and a lialf miles. A fertile, but very soft and spongy soil covers the island, which bears every where unquestionable marks of a volcanic origin. Several springs of lot water were visited by the travellers, of which the average heat is about $2120 \mathrm{Fahr}$. The soil is evidently a decomposition of lava, which is continually spreading a rich mould over all parts of the island, for the thll, rank grass that abounds in it. The putrefaction of vegetable matters mixes with this lara and with the mouldering ashes, while the long roots of the grass form the principal tie of the wliole. The soil is so light, that the foot breaks in at every step. Sea-birds abound on the island. Near the centre is an area of about 200 yards square, where the heat of the soil is so great, as to admit of no regetation. During the winter months, violent storms prevail in A. On the shores of the island, immense numbers of seals were formerly taken, of the phocourzina species. The people of the U. $\mathrm{S}$. have taken more of these useful animals here than any other nation. They are altogether the most active seal-hunters in the South sea. The number of seals on the island is now very much less than when it was first visited, as is always the case in places where the animal is actively hunted. At first it was immense, as it usu. ally is in undisturbed resorts of this creature. The American vessels, at present, generally leave a number of men on the islands freqtiented by the seal, and return to take them after they have had time to collect a snfficient number of skins. The neighbourhood of $A$. abounds in fish.

A usterdan; a sinall, uninhabited island in the Nortl sea, near the N.W. coast of Spitzbergen. Dntch ressels resort thither towards the end of their whale-fishery. Lon. $9 \circ 40^{\prime}$ E. ; lat. $79 \circ 46^{\prime} \mathrm{N}$.

AMsterdas; an island in the South sea. See Tongataboo.

Austrapan Island; a small island on the N. W. coast of Ceylon, five miles long and two in breadth; lon. $8^{\circ} \mathrm{I}^{\prime} \mathrm{E}$. ; lat. $9050^{\circ} \mathrm{N}$.

Amsterdau, New; a town in Dutch Guiana, situated between the rivers Berbice and Canje; lon. $57^{\circ} 15^{\prime} \mathrm{W}$.; lat. $6 \circ 20^{\prime} \mathrm{N}$. It is the seat of the government of Berbice.

A моск, or Амок; an Indian term for slaughter, and an exclamation of certain Batavian slaves, who, when irritated, intoxicate themselves with opium, and run frantic abont the streets. This is called running $a$-muck, or $\alpha$-mock.

Asulet ; a piece of stone, metal, or other substance, marked with certain figures or characters, which people wear about them as a protection against diseases and enchantments. The name, as well as the thing itself, is derived from the East. The word comes from the Arabic hamail (locket, any thing hung round the neck). The derivation from the Latin amollire has less probability. Amulets serre as a convenient substitute for the talismans of stone or metal, and must be thought of more recent origin. Among the Turks, and many people of 
Central Asia, every individual thinks an amulet necessary to secure him from harm. 'They were introduced into Christian Europe by the Jews. With the ancients, e. g., the Egyptians, Greeks, Romans, they were frequently found. From the pagans they were introduced among the Basilidians. Their amulets were stones with the word Abraxas (q. v.) ellgraved on them. The Jews had many superstitious notions about amulets. Many Christians of the first century wore amulets, which were marked with a fish, as a symbol of the Redeemer. To the Cliristian divines, the use of amulets was interdicted, by the council of Laodicea, under penalty of dismission from office. With the spread of Arabian science and astrology, the astrological amulets of the A rabians, the talismans (q. v.), came into use in the West. The sulall images of saints, which the Neapolitan seamen, and almost all the Greeks, wear about them, are nothing but amulets. The 'Turks, the Chinese, the people of Thibet, and many other nations, liave yet great confidenice in them.

AJUSETTE ; a small one-pound caunon, employ. ed in war, in mountainous regions. Lightness and a great facility of movement are its advantages. Marshal Saxe recommends the A. strongly. The count of Lippe Buckeburg improved it essentially and introduced it among the Portuguese infantry. Each platoon had an A. drawn and served by five men. The duke of Weimar, also, in 1798, gave his riflemen amusettes. At present they are out of use in all armies.

Amigdalus. See, Almond.

Амуот, James; an old French writer; was born at Melun, in 1514; died in 1593. He was bishop of Auxerre, and grand Almoner of France; and is known even in foreign countries, by his much esteemed translations of Plutareh and Diodorus.

A mrraut, Moses, a learned French theologian, borv in Touraine, in 1596 ; died in 1664. His works are chiefly theological, and very voluminous. The rigid Calvinists accuse him of Arianism, but Mosheim calls him rather Arminian, or Semi-pelagian. He was professor of divinity at Saumur, and was much respected for his abilities, and the extent of his charity, allowing the whole of his salary to flow to the poor of every denomination.

Avs. This termination, derived from the Latin, when connected with a proper name, is used to denote collections of the sayings of distinguished men, or of anecdotes relating to them. These collections are numerous ; and compilations of the same character were known even among the Greeks. The Mfemorabilia of Xenophon, and the Lives of the Philosophers by Diogenes Laertius, are full of anecdotes and sayings. The Attic Nights of Aulus Gellius contain many observations and repartees of distinguished persons in Rome. Thus, according to Quiuctilian, a freed man of Cicero left a whole book of his master's jests, and another freed man of Macenas the table-talk and witticisms of this distinguished friend of the muses. At the time of the restoration of learning, the sayings of famous men began to be collected? The Scaligeriana were the first compilation which appeared under that name, Since that time they have become common, particularly among the Frencl, who have ofien used them merely as a vehicle for disseminating certain opinions under some famous name. Among the French collections are the Huetiana, Menagiana, Voltariana, Bonapartiana, Bièvriana, Brunetiana, Pradtiana, \&ic. Among the English, such collections are also very common, e. Walpoliana, Baconiana, Parriana, \&c. Selden's 'Table-talk and Boswell's Life of Johnson are of a very similar character, though they have not a similar title. The Germans make not so much use of the syllable $a n \alpha$, as their literature is extremely poor in memoirs and works of the sort above-mentioned, when compared with the English or French. In some instances, however they employed it, e. g., Taubmanniana. The most famous German work of this kind is Luther's 'Table, talk (Tischreden). Collections of a different kind, likewise, bear a title terminating in ana, e. g. Parisiana, Revolutiana, Polissoniana, Ivrogniana. There even exists a work entitled Encyclopédiana, ou Dictionnaire Encyclopédique des ana, by lia Combe, Paris, 1791, 4to. M. Peignot has published a Bibliographie raisonnée des ana. (See his Répertoire de Bibliographies speciales, curieuses et instructives, Paris, Renouard, 1810, 8vo.)-If it is allowable to add the syllable ana to proper nouns, still such words as Encyclopcdiana, Literariana, \&c., will always be barbarous and offensive to a cultivated ear.

ANa Santa; the name of three desert islands in the Atlantic ocean, W. Ion. $43^{\circ} 44^{\prime}$, S. lat. $2^{\circ} 30^{\prime}$ near the coast of Brazil, in the bay of San Luis de Masanasis; also of an island on the coast of the province of Maranham, called Dos Macomes by the Portnguese, and of another in the straits of Magellan, on the northeri coast, near the entrance of the South sea. Also the name of several points.

Anabaipists (from the Greek $\alpha v \alpha$ and $\beta \alpha \pi \tau \%$ \% a name given to a Christian sect by their adversaries, because they objected to infant baptism ; they baptized again those who joined their sect, and hence their name. Anabaptists say that infant baptism was not customary in the earliest period of the Christian church. (See Baptism.) In the middle ages, it was declared invalid by many dissenting parties, as the Petrobrusians, Catharists, Picards, \&c.; but in the prevailing church, for important reasons, it was retained. In 1521, when the progress of the reformation had opened the way to new opinions, some enemies of infant baptism appeared at Zwickau, in Saxony, united partially witl the rebels in the peasants' war, and were completely separated, by their lawless fanaticism, from the Protestant cause. (See Munster.) With the baptism of adults, performed even by lavmen, they comnected principles subversive of all religious and civil order. They acknowledged neither ecclesiastical nor civil autliority; and attempted to bring about a perfect equality of all Christians. 'The vast increase of th. eir adherents from the year 1524, especially among the common people on the Rhine, in Westphalia, Holstein, Switzerland, and the Netherlands, was soon met by severe measures on the part of the magistrates, After 1525, imperial and ecclesiastical decrees were issued against the Anabaptists in Germai $y$, and many were put to deatl, after being urged to recant. The same happened in Sivitzerland and in the Netherlands. Still, new associations of this sect were perpetually formed by itinerant p.ophets and teachers; and their doctrines collsisted of the following propositions: "Impiety prevails every where. It is therefore necessary that a new family of looly persons should be founded, entjoying, without distinction of sex, the gift of propliecy and skill to interpret divine revelations. Hence they need no learning; for the internal word is more than the outward expression. No Christiar must be suffered to engage in a legal process, to hold a civil office, to take an oatl, or to lold any private property; but all thiugs must be in commou." With suclı sentiments, John Bockhold, or Bockelsnn, a tailor of Leyden, aged twenty-six, and John Matthins, or Mathiesen, a baker of Haarlem, came, in 1533, to Munster, in Westphaiia a eity which had alopted the doctrines of the refor. 
mation. Here they soon gained over a portion of the cxciterl populace, and, among the rest, Rothnum, a Protestant clergyınau, aul the comsellor finipperdolling. The magistrates in vain exclnded thiem from the churches. They obtained possession of the council house by violence. Their numbers dhily increased, and, townds the end of the year, they extorted a.treaty, securing the religious liberty of both parties. Being strengthenel by the accession of the restless spirits of the adjacent cities, they s) on made themselves masters of the town by force, and expelled their adversaries. Matthiescn cane forwand as thicir prophet, and persunded the people to derote their gold and silver, and movable property, to the common use, and to burn all their books but the Bible. But in a sally against the bishop of Munster, who liad laid siege to the city, he lost his life. He was succeeded in the prophetic office by Bockhold and Kinperdolling. The churches were destroyed, and twelve judges were set over the tribes, as in Israel ; but even this form of government was soou abolished, and Bockhold, under the name of .Tohn of Leyden, raised himself to the dignity of king of Nero Zion (so the Anabaptists of Munster styled their kinglom), and caused himself to be formally crowned. From this period (1534), Munster was a theatre of all the excesses of fanaticism, lust, and cruelty. The introduction of polsgamy, and the neglect of civil order, concealed froin the infintunted people the avarice and madness of the young tyrant, and the daily increase of danger from abroad. Bockhold lived in princely luxury and maguificence; he sent out seditious proclamations against neighbouring rulers, against the pope and Luther; he threatencd to destroy with his mob all who differed in opinion from him, made himself an object of tcror to his subjects by frequent executions, and, while famiue and pestilence raged in the city, persiuded the wretched, deluded inhabbitants to a stubborn resistance of their besiegers. The city was at last taken, June 24,1535 , by treachery, though not without a brave defence, in which Rothmann and others were killed, and the kingdom of the Anabaptists destroyed by the execution of the chief men. Hockhold and two of his most active companions, Knipperdolling and Krechting, were tortured to denth with red-hot pincers, and then hung up in iron cages on St Lambert's steeple at Munster, as a terror to all rebels.-In the mean time, some of the twenty-six apostles, who were sent out iny Bockhold to extend the limits of his kingdom, had been successful in various places, and many indepcndent teachers, who preached the same doctrines, continued active in the work of founding a new cmpire of pure Christians, and propagating their risions and revelations in the countries abovementioned. It is true that they rejected the practice of polygamy, community of goods, and intolerance towards those of different opinions, which had prevailed in Munster; but they enjoined upon their adherents the other doctrines of the early Anabaptists, and certain heretical opinions in rcgard to the humanity of Christ, occasioned by the controversies of that day about the sacrament. 'The most celebrated of these Anabaptist prophets were Melchior Hoffmaun, and David Joris. The former, a furrier from Swabia, first appeared as a teacher in Kiel, in 1527 ; afterwards, in 1529, in Emden ; and finally, in Strasburg, where, in 1540 , he died in prison. He formed, chiefly by his magnificent promises of a future eleratiou of himself and his disciples, a peculiar sect, whose scattered members retained the name of Ho/mannists, in Germany, till their remains were lost among the Anabaptists. Thes liave never orned that Hoffmann recanted before his death.
Davil Joris, or George, a glass-painter of Delft, born 1501, and re-baptized in 1534, showed more depth of mind and warmth of imagination in his various works. Amidst the confusion of ideas, which prevails in them, they dazale by their elevation and fervour. In his endegvours to unite the discorlant parties of the Auabaptists, he collecterl a party of quiet adherents in the country, who studied his works (as the Gichtelians did those of Bohne), ispecially lis book of miracles, which appeared at Deventer in 1542, and revered him as a kind of new Messiah. Unsettlel in his opinions, he travelled a long time from place to place, till, at last, to aroid persecution, in 1554, he berame a citizen of Balc, under the name of John of Isruges. In 1556, after an honourable life, he died there, among the Calvinists. In 1559, his long-concenled heresy was first made public. He was accused, though without much rcason, of profligate doctrines and conduct, and the council of Bale condemued him, and ordered lis body to be burnt. A friend of Joris was Nicholas, the founder of the Familists, who do not belong, however, to the Anabaptists. After the disturbances at Munster, an opinion slowly gained ground among the Protestants, that no heretic could be punished with death unless he was guilty of exciting disturly ances; hence these and similar parties of separatists were permitted to remain unmolested, provided they continued quiet. But, till after the midallc of the 16th century, prophets were constantly rising $\Perp p$ among the Anabaptists, and subverting civil order. Of the heretics executed by Alva in the Spanish Netherlands, a large proportion were Anabaptists. In fact, they wcre never worthy of toleration, till quiet and good order were introduced among them. The institutions of Menno were the first occasion of this change. This judicious man, about the iniddle of the 16 th century, united them in regular societies, which formed an independent church, under the name of Mennonites, Mennists, or Anabaptists, as they are still called in the north of Germany and in Holland, imitating strictly the peculiarities of the primitive apostolical church. But he could not prevent the division, which took place amoug them as early as 1554, in regard to the degree of severity necessary in case of excommunication. The stricter party punished every individual transgression against morality and church order with excommunication, and carried their screrity so far that near relations, even husbands and wives, were obliged to renounce all connexion with one another, in case of such punishment. The more moderate party resorted to excommunication only in case of long-continued disobedience to the commands of the Holy Scripture'. Moreover, they never inflicted this punishment till after variotis kiuds of warnings and reproofs (gradus admonitionis), and even then it did not extend beyond the relation of the individual excommunicated with the cluurch. As neither party would yield, aud the strict often excluded the moderate from their communion, the Anabaptists have continued, to this day, divided into two parties. The moderate party were called Waterlanders, because their enrliest congregations lived in the Waterland, on the Pampus in the north of Holland, and in Franeker. By the strict party they were styled the Gross, and even the Dung-carts, as a designation of their inferior purity. This latter party, who consisted of the Frieslanders in and about Emden, Flemish refugees (Flemingians), and Germans, called themselyes the Pure (Die Feinen), i. e. the Blessed, the Strict. Menno did not wholly adopt the excessive rigour of the Pure, nor yet would he abandon the Frieslanders, among whom he taught. Immediately after his death, in 1565, a contest broke out among the l'ure, 
and they divided into three parties. Of these, the Flemingians were more severe and fanatical than the rest, and maintained the utmost severity in regard to cxcommunication; the Frieslanders did not indeed exercise this discipline on whole congregations, nor extend the curse, in the case of individuals, to the destruction of their family relations; the Germans were distinguished from the Frieslanders only by more carefully avoiding all luxury. 'To the party of these Germans belonged those who were settled in Holstein, Prussia, Dantric, the Palatinate of the Rhine, Juliers, Alsace, and Switzerland, and the numerous Anabaptists, who inhabited Moravia till the thirty years' war. In 1591, they were united again with the Frieslanders by means of the concept of Cologne, so called, or articles of faith, chiefly because their separation was injurious to commerce, in which the Anabaptists soon became much engaged. With these two sects, thus connected, after many attempts towards reconciliation and friendship, the stricte'st Anabaptists at length joined theinselves, and certain articles of faith were adopted by the whole body. But these arrangements were insufficient to clieck the bitterness with which they persecuted one another. Soon after the union of the Frieslanders with the Germans, a large number of malcontents left the former, because they were displeased with this connexion, and the laxuess of the church discipline. Under Jan Jacob, their teacher, they constituted a separate church on the most rigid principles. 'They were not numerous. During the negotiations of the Flemingians with the Frieslanders, there appeared amoug the former a Friesland peasant, Uke Wallis, who held the opinion that Judas and the high-priests were blessed, because in the murder of Jesus they had executed the designs of God. In 1637, he collected a party of individuals, who adopted this opinion, but still remained distinct from the other Anabaptists, on account of their aversion to the excessive strictness of the ancient Flemiugians. The Uke-Wallists, or Groningenists, so called because the sect arose in the territory of Groningen, received the malcontents of the united parties, and therefore called themselves emphatically the ancicnt Flemingians, or the ancient Frieslanders; but, by their adversaries, they were denominated the Dompelers, i. e. Dippers, because some of their churches used, in baptism, the three-fold immersion of the whole body. The other Anabaptists, on the contrary, regarded the sprinkling of the head as sufficient. Beyond Friesland, though not numerous, they spread to Lithuania and Dantzic. The Anabaptists in Gallicia, a part of the ancient Moravia, who were divided, on account of their dress, into Buttoners (those who buttoned their clothes) and Pinners (those who used wire pins instead of buttons, and wore long beards), and comprchended about twenty-four families of the simple country people, agreed with the Uke-Wallists in maintaining the ancient doctrines and strict excrcise of excommunication, and were distinguished for purity of morals. The ancient Flemingians, or the strictest sect of Anabaptists, persevere firmly in the aucicnt doctrines and practices of the sect. They reject the worl person, in the doctrine of the 'Trinity, and explain the purity of the human nature in Christ, according to Menno, by saying, that he was created out of nothing by (God, in the womb of Mary, al. though he was nourished by the blood of the mother. They view the baptism of their own party as alone valic, and practise the washing of feet, as an act commanded by Clirist, not only towards travellers of their own party, like the Pure, but even in religious assemblies. Like Anabaptists in general, they view as inproper, oaths, the discharge of civil offices, and all defence of property, liberty, or life, which re. quires violence against their fellow men. Hence they were formerly called, without distinction, the unarmed Christians. Only in this particular, and in church-discipline, are the ancient Flemingians more strict than the other Anabaptists. Immorality, the bearing of arms, marriage with a person out of their church, extravagance in dress or furniture, they punish by excommunication, without gradus admonitionis, and extend their discipline to domestic life. Those of Dantzic excluded persons who had their portraits painted, as a punishment for their vanity. In general, they strive to imitate, with the utmost exactness, the simplicity and purity, and the democratic government, of the earliest apostolic church, the restoration of which was originally the olject of every Anabaptist. Hence they appoint their teachers by a vote of the whole church, forbid them to enjoy any political office, and place but little value on learning. In modern times, it is true, they have gradually remitted their severity, and given up, in particular, the rebaptism of proselytes from other Anabaptist sects; while Christians, who have only been baptized in infancy, are admitted into any sect of the Anabaptists only after rebaptism. The Flemingians, Frieslanders, and Germans, who had united, 1649, and at first belonged also to the Pure, gradually sided with the moderate party, with which they are now reckoned. $-\Lambda$ division took place in the general church of the united Waterlanders, Flemingians, Frieslanders, and Germans, in 1664, on account of the farour with which a part of them regarded the doctrines of the Remonstrants. Galenus Abrahamssolun, of Haen, a learried physiciau, and teacher of the Anabaptists, of a gentle disposition and distinguished talents, was the leader of this new party, which was called, after him, the sect of the Galenists. He maintained that sound doctrine is less decisive of Christian worth than a pious life; and, therefore, church-communion should be refused to no virtuous person, believing in the Scriptures. But he betrayed, by these opinions, his Socinian views of Christ and the Holy Ghost. Samuel Apostool (also a physician and teacher of the churcli) and the orthodox party in it, declared themselves opposed to such imovations, and determined to maintain their ancient faith and discipline.-Besides the branclies of the ancient Flemingians, or the proper Pure, described above, there are now two leading parties of Anabaptists,-the Apostoolians, who, from their attachment to the ancient confessions, founded on the doctrines of Menno, are called Mennonites, in a more limited use of that word; and the Galenists, who are likewise styled Remonstrants and Arminiun Baptists, after Armuius, the founder of the Remonstrants. The Mennonites, as they belong to the moderate party, no louger maintain Menno's doctrine of the creation of Christ in the womb of Mary; they rebaptize no proselyte, and punish none but gross crimes with cxcommunication, and that not without previous warning. They do not require church-members utterly to aroid the excommunicated. 'Tley carefully prohibit onths, military service, and the lolding of civil offices. The confession of fiith of the true Mennonites, composed by Cornelius Riss, one of their teachers, and published in Gcrnian, at Hamburg, in 1776, corresponds, in aluost every point, with the doctrines of the Calvinist church.- The Remoustrants have departed the most widely from the faith and order of the ancient $A$ nabaptists. They reject all symbolical books, and permit the most unrestrained reading; hence they liave amoug them many Socinians. They tolerate, in the bosom of the church, those of a different faith, and receive Cluristians of all creeds, but 
enly in a few congregations without rebaptism. They consider the J'ure and Mennonites as brethrent; seldom exclude members, except from the sacrament, and this not so frequently as the latter porties; permit military service, and the discharge of civil offices, and even an oath of testimony, and prohibit only the onth of promise. They allow of learning, and lave erected a seminary at Ansterdam for the elucation of ministers, to which young mell of the Mennonite party are also aduitterl. In Holland, the Anabaptists obtained toleration under William I., and conuplete religious liberty in 1626. There are now in that country 131 churches, and is3 teachers of all the parties of Anabaptists, of whom the majority belong to the Remonstrants, alout oure-third to the Mennonites, and a few small congregations to the Pure. The Anabaptists in Ciermuny, where they are most inmerous, on the banks of the Rhinc, in East Prussia, Switzerland, Alsace, and Lorraine, consider thenselves proper Mennonites. In the religions worship of all these larties, there is but a trifling difference from the forms of the Protestant service; but they more netrly resemble the Calvinists than the Iutherans. 'The Pure have elders or bishops who administer the sacraments, ministers who preach, and deacons or almoners. All these officers are chusen by the vote of the churches. The Mennonites have ministers or deacons, of whom the former arc the proper pastors, and the latter only cxhorters or preachers; but both are chosen by the ecclesiastical council or presbytery. The Remonstrants pursue a similar course. In general, the Amabaptists still teserve the praise fermerly bestuwed upon them, of diligence, industry, orier, and purity of morals. Many of them, however, have become so accustomed to the manners of the world, that the peculiarities of this sect have gradually worn away, and the seet itself seems hasteung to decay. The Baptists (q. v.) in England form a distinct sect, without any connexion with the successors of the ancient Anabaptists here described.

Avacharsis tHe Younger, a Seythian, and brother of the king Saulus, was a lorer of wisdom and of thc sciences, and esteemcd one of the seven wise men of Greece. The love of knowledge induced him to leave his barbarous country, and travel among the more cirilized nations. In the time of Solou, he visited Athens, from whence he proceeded to other countries: After his retum, the king put him to death, in order to prevent the introduction of the effeminate manners and worship of the Greeks, which was attempted by A. See Foyage du jeune Anacharsis, par Barthélémi; see also the translation, Travels of Anacharsis the Youngcr.

ANAchorets, or Axchorets, in ecclesiastical history, were a celebrated class of religious persons, who generally passed their lives in cells, from which they never removed. - Their habitations were, in many instances, entircly separated from the abodes of other men, sometimes in the depth of wildernesses, in pits or cavems; at other times, several of these individuals fixed their habitations in the vicinity cf each other, when their cells were called by the collective name of laura; but they always lived personally separate. Thus the laura was distinguished from the conolium or convent, where the monks lived in snciety on a common stock; and the anachoret differed from a hermit, although his abode was frequently called a hermituge, inasmuch as the latter ranged at liberty, while the furmer rarely, and, in many instances, never, quitted his cell. But a convent was sometimes surroinded by a laura, to which the more devout or the more idle of the monks. would-ultimately retire. Paul the Hermit is said to lave been the first person who deroted himself to this kiul of solitude. In all ages and in all countries, retirement from the world lias been considered us ficilitating thc attninment of a virtıous life, os Radiug strength to strong chamcters, and enabling the inind to follow ont great idcas without interruption. The prophets prepared themselves in solitude for their tasks ; the Pythagoreans, Stoics, Cynics, and Platonists recommend the self-denial and the quiet happiness of the solitary sage. Vasari cails solitude the detight and scliool of great minds. In many parts of the East, where a sombre religion throws over life á melancholy shade, it has been thought, from time immenorial, a religions act to quit for ever the busy world, and esen to add bodily pain to the melancholy of solitnde. This spirit, which still prevails in the Fast, passed over, with nany other Oriental ideas, doctrines, and customs, to thic early Christians, and thic state of the world, in the beginning of the Cluristian era, was peculiarly fitted to favour its growth. The continual prevalence of bloody wars and civil commotions, at this period, must have made retirement anil religions meditation agrieable to men of quiet and contemplative minds. Accordingly, we find, in the first conturies of our era, very eminent and virtuous men among the anichorets, e. g. St Augastin. This spirit, however, as might have becn expected, soon led to fanatical excesses. All the horrid penances of the East were introduced among Christian hermits; and we find, at the close of the 4th century, Simeon Stylites passing thirty. years on the top of a column, withont ever descending from it, and finally dying there. 'Though we must needs pity such unhappy delusion, such a moral insanity, we caunot help acknowledging the strong power of will exhibited in this and many other instances of a similar kind. In fact, the spirit of retirement and self-torment raged likcan epiclemic among the early Christians ip the East. In Egypt and Syria, where Christianity became blended with the Grecian philosophy, and strongly tinged with the peculiar notions of the East, the anachorets were most numerous; and from those who lived in cells, in the vicinity of a church, such as Moore descrilses in the Epicurean, the convents of a later period sprung, which were filled with inmates anxious to escape from the tumult and bloodshed, which marked the beginning of the midulle ages. Farly in the seventh century, the councils began to lay down rules for the order of anacliorets. The Trullan canons say-"Those who affect to be anachorets shall first, for three years, be confined to a cell in a monastery; and if, after this, they profess that they persist, let them be examined by the bishop or abbot, let them live one year at large, and, if they still approve of their first choice, let them be confined to their cell, and not be permitted to go out of it but by the consent and after the benediction of the bishop, in casc of great necessity." Frequently, at this period, the monks of various abbeys wonld select from among them a brother, who was thought to be most exemplary in his profession, and devote him to entire seclusion, as an honour, and to give him the greater opportunity of indulging his religions contemplations. In Fosbrook's Monachism, 4to, 1817 , the ceremony by which an anachoret was consecrated to seclusion from the world is described at length. The cells in which the anachorets lived were, according to some rules, only twelve feet square, of stone, with three windows. The door was locked upon the anachoret, and often walled up. The cell which is said to have been occupied by St Dunstan, at Glastonbury, was, according to Osborn, in his life of that monk, not more than five feet long, two and a half feet broad, and barely the height of a man. Here the recluse passce this time 
in ingenious self-torture; e.g. in eterual silence, ? rising from the sea. Apelles painted her rising heavy chains, severe flagellations, singing psalms in from the waves, and, according to some writers, cold water during winter nights, \&.c. Tantum reli- Campaspe, the mistress of Alexander, according to gio potuit suadere malorum! This species of devotion; originally introduced, as we have said, from the warm climate of the East; found inany more adherents in the south of Europe than in the north. With the reviral of science, and the consequent diffusion of nore liberal views, the strictest kind of anachorets have almost entirely disappearéd. Few men now retire to any seclusion more strict than that of a convent. 'Some persons, who pass a solitary life in the neighbourhood of Rome, call themselves anchorites; but in India, the proctice still prevails in all its severity.

ANacletus; there were two popes of this name. The first is said to have suffered death as a martyr, A.D. 91. All the other stories respecting him, e. g. that he divided Rome into twenty-five parishes; are uncertain. - The second, the grandson of a baptized Jew, at first called Peter de Leon, was a monk in Clugny, a cardinal and papal legate in France and England, and, in 1130, competitor for the papal chair, against Innocent II. Rome, Milan, and Sicily were on his side, and Roger of Sicily received from him the royal title. He also maintained himself against Lothaire II., and died 1138.

ANacoluthos, in grammar and rhetoric ; a want of coherency. This often arises from want of attention on the part of an orator or author. Such an omission may proceed from passionate feeling, and the anacoluthon may then become a beauty. Many anacolutha are peculiar to certain languages.

Anacreon, whom the Greeks esteem one of their nine greatest lyric poets, was born st-Teos, in Ionia, and fluurished about $500 \mathrm{~B}$. C. Polycrates, king of Samos; invited him to his court, and bestowed on him his friendship.. Here A. composed his songs, inspired by wine and love. After the death of his protector, he went to Athens, where he met with the most distinguished reception from Hipparchus. The fall of the latter drove him from Athens, and, probably, he returned to Téos. But when Ionia revolted from Darius, he fled to Abdera, where he passed a gay and happy old age, and died in his 85th year. According to tradition, he was choked by a grapestone. The city of Teos put his likeness upon its coins; his statue was placed on the Acropolis, in Atliens, and he was held in honour throughout Greece. Only a small part of his works has come down to us. Of five books; there are sixty-eight poems remaining, under the name of $\Lambda$. . A mong these, criticism acknowledges but few as genuine. Those generally believed to be A.'s are models of delicate grace, simplicity, and ease. The difficulty of attaining these excellencies is proved by numberless unsuccessful imitations, unworthy of the name of Anacreontics. The measure in which A. composed his poens, and which is called after him, is commonly divided into three iamluses, with a casura. But, accorling to Hermann, it consists of the Ionie a majore, with the anacrusis:

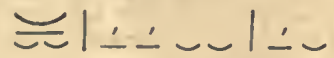

Among the best editions are that of Spoletti, Rome, 1781, 4to ; that of Fischer, Leipsic, 1793; and that of Brunck, Strasburg, 1786, last edition. The latest are that of Moebins, 1810, and that of Mehlhorn, 1825. 'The best Fnglish translations of A11acreon are those of Cowley, Fawkes, and Thomas Moore.

ANanYomane (Grcck; she who comes forth); a name given to Venus, when she was represented as others, the famous courtesan Phryne, served him as a model. Of the latter it is related, that she threw off her clothes, at a feast in honour of Neptume at Eleusis, in presence of many spèctators, loosened her hair, and bathed in the sea, in order to give the painter a lively idea of the Venus Anadyomene. In the reign of Augustus, this picture was brought to Rome. Antipater of Sidon, in the Anthology, and also other poets, have celebrated its beauty.

Anagnosta, or Anagnostre, in antiquity; a kind read to his master during meals. They are first mentioned by Cicero. Atticus, according to Corn. Nepos, always had an anagnostes to read to him at supper. In many convents, one of the monks still reads aloud, while the others take their meal. Charlemagne, too, heard reading during dinner and supper, generally on historical subjects. .

ANAGOGY (from the Greek $\alpha y \alpha$ and $\alpha \gamma \omega$ ); one of the various modes of interpreting the text of the Bible.-To explain anagogically, means to apply the literal sense of the text. to heavenly things; for instance, to treat the Sabbath as a symbol of the rest in heaven. Of such explanations, frequent use was made in earlier times, particularly in sermons and religions books. The bride and the bridegroom, in Solomon's Song, were and are often. still referred to Christ.as the bridegroom, and to his churchias the bride; and the application of this figure was frequently carried to an indelicate sxtreme. Even now, such extravagancies of a disordered imagination seem to be favoured, in many places, by the spirit of mysticism.-Anagogy, in medicine, signifies the return of humours, or the rejection of blood from the lungs by the mouth.

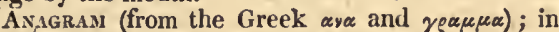
its proper sense, the letters of..one or several words read backwards; thus, evil is an anagram of live. In a wider sense, it means a transposition of -letters, to form a new word or phrase ; for instance, tone and note. An anagram is called impure, if, in their transposition, all the letters of the given words are not used. In former times, such plays of ingenuity were popular, and we frequently find, in old inscriptions, the year and date indicated by means of an anagram. An anagram of Berolinum is Lumen orbi. Calvin, in the title of his Institutions, called himself Alcuinus, by ananagiram of his name, C'alvinus. In a similar way, the words Revolution Francaise include the words Un Corse la finira, and the significant $V$ cto. . The question of Pilate to Christ Quid est veritas? 'gives the anagram-Est vir qui adest. Dr Burney's anagram of Horatio Nelson is of William Noy, attorney-general to Charles I., a laborious lawyer, affords the anagram, I moyl (toil) in law. A very curicus work respecting the subject of this article is, Z. Celspirï (Christ. Serpuliii) de Anagrammatismo Libri ii. quorum prior Theoriam, posterior Anagrammátographos celebriores, c:tm Appendice selectorum Anagrammatum exhibet; Ratisbonæe, 1713 , in 8 ro.

Avalncta (from the Greek avadsyw, I gather); losophy, of history, and of literature. A perioxlical of the famous philologist, Wolf, was called Analecta. - With the ancients, analccta signified a servant, whose business it was to gather up what fell from the tables, at meals, as the pavements of the Roman floors sometimes were too finely inlaid to admit of sweeping.

ANALGY originaliy denotes a relation, similarity, of literary servant, whose chief business it was to one of the happiest;-Honor est a Nilo. The name extracts froin different works; e.g. analecta of phi- 
or agreenuent of things in certain respects. The knowledge which rests merely on this relation is callerl a nalogical. The conclusion deduced frum the similarity of things in certain respects, that they are similar, also, in other respects, is called, in logic, an analogical conclusion, and amounts ouly to a probability. This reasouing is applied to the explanation of authors (analogia interpretationis), and particularly to the interpretation of the Holy Scriptures, in which cousistency of doctrine is taken for granted (analogia fidei). It is also used in the application of the laws, to form a juilgment, in any particular case, by a comparison of former decisions in similar cases. In practical medicice, it is used in the application of reunedies. $-\Lambda$ great part of the principles of experiuneutal plilosophy are established by inferring a further uniformity from that which has been already settled. - In grammar, by aualogy is meant a couformity in the organization of words.-In mathematics, it is the similitude of certain proportions.-Newton grives analogy the second place amongst his laws of philosophizing, and may be said to liave established some of the most characteristic parts of his system, as arising out of the doctrine of gravitation, on its sober and patient use. In fact, analogical reasoning is essential in inductive philosophy, though it must be used with caution. The history of philosophy shows innumerable instances of the wildest errors, as well as of the sublimest discoveries arising from its application. The modern philosoplyy of Germany has suffered inuch in point of correctness and clearness, from several bold speculators, led away by fancied analogies between the moral and pliysical world; though it cannot be denied, that much of the progress of that nation in philosophical investigations is due to the use of the same instrument.

ANacrsis, in philosophy; the mode of resolving a compound idea into its simple parts, in order to consiler them more distinctly, and arrive at a more precise knowledge of the whole. It is opposed to symthesis, by which we combine and class our perceptions, and contrive expressions for our thoughts, so as to represent their several divisions, classes, and relations. Analysis is regressive, searching into principles; synthesis is progressive, carrying forward acknowledged truths to their application. - $A$ nalysis, in mathematics, is, in the widest sense, the expression and developement of the functions of quantities by calculation. There are two ways of representing the relations between quantities, to wit, by construction, and by calculation. Pure geometry determines all magnitudes by construction, i. e. by the mental drawing of lines, whose intersections give the proposed quantities; analysis, on the contrary, makes use of symbolical formula, called equations, to express relations. In this widest extent of the idea of analysis, algebra, assisted by literal arithmetic, appears as the first part of the system. Analysis, in a narrower sense, is distinguished from algebra, inasmuch as it considers quantities in a different point of view. While algebra speaks of the known and unknown, analysis treats of the unchanging or constant, and of the changing or variable. 'The algebraic equation, $x^{2}+a x-b=0$, for example, seeks an expression for the unknown $x$ by means of the known $a$ and $b$; but the analytical equation, $y^{2}=$ $a x$, expresses the law of the formation of the variable $y$, by means of the variable $x$, together with the constant a.-In its application to geometry, analysis seeks by calculation the geometrical magnitudes for an assumed or undetermined unit. The analysis of the ancients was exhibited only in geometry, and made use ouly of geometrical assistance, whereby it is distinguished from the analysis of the moderns, which, as before said, extends to all measnrable ob- jects, and expresses in equations the mutual dependence of magnitules. But aualysis and algebra resemble encli other in this, tlat both, as is shown more fully in the article on algelora, reason in \& language, iuto the expressions of which certain conditions are translated, and then, according to the rules of the lauguage, are treated more fully, i1 order to arrive at the result. Analysis, when con. sidered in this light, appears to be the widest extent of the province of this language. Analysis, in the more limited seuse, is divided into lower and higher, the bounds of which run very mucl into one another, because many branches of learning are accessible in both ways. While we comprise in lower analysis, besides arithmetic and algebm, the doctrines of functions, of series, combinations, logarithms, an curves, we comprehend in the higher the differentin! and integral calculus, which are also included in the name infinitesimal calculus; the first of which the French consider as belonging, in a wicler sense, to the théorie des fonctions anulytigues. $-\Lambda$ good aceount of the ancient analysis is given by Pappus of $\Lambda$ lexandria, a mathematician of the 4 th century, in his Collection of Geometrical Problems, * in which there is also a list of the analytical writings of the ancients. What progress was made after the destruction of the Roman empire, particularly by the Arabians, in algebraical, and, as interwoven with them, in analytical inquiries, has been related in the articte on algebra. Newton and Leibnitz (q. v.) iuvented the above-mentioned infinitesimal calculus. After them, Euler and the brothers Bernouilli (q. v.) Iaboured with splendid success for the further improvement of mathematical analysis ; wand, in later times, d's.embert, Laplace, Lagrange, \&c. have raised it still ligher. Hindenburg $(q . v$.$) is the inventor of the$ analysis of combinations. We have not room here to go into detail with respect to the other analytical doctrines.-Euler's Introductio in Analysin Infinitorum, $\nmid$ Lausanne, 1748, 2 vols. (new ed., Leydell, 1797) still contiuues one of the most important works, in regard to the analysis of finite quantities. In closit connexion with this stands the same author's Institutiones Calculi differentialis, Petersburg, 1755, 4 to. Lagrange's Théorie des Fonctions Analytiques (new ed., Paris, I813, 4to.) is, on account of the depth of its views and its many valuable applications to geo. metry and mechanics, a valuable work for the study of the connexion between the analysis of finite quantities, and the so named (though, indeed, here considered in a very different light) calculation of infinities. As this work cannot be understood without a good acquaintance with general and very abstract calculations, we would connect with it the same author's Leçons sur le Calcul des Fonctions (new ed., Paris, 1806). Arbogast's Calcul des Derivations, Strasburg, 1800, 4to, is new in its views of the analysis of finite quantities. The most excellent of the old works on the integral calculus is Fuler's Institutiones Calculi Integralis,' Petersburg, 17681770,3 vols., 4 to. The present state of the integral calculus, after the improvements of the Irench analysts, may be learned from Lacroix's Traité du Calcul différentiel et du Calcul intégral, Paris, 1797 and seq., 3 vols., 4to. (There has since appeared is new edition.) - For begiuners, we recommend Pasquich's Mathematical Analysis, Leipsic, 1791, and, for more advancel sturlents, the same author's EleThere is a Latin translation of it by Commandinus:-
Mathemat. Collutiones, Commentaris illustrata, Bonu, 1659 , folio. The freek text is not published.

+ It has this title on account of the application which is here made of the idea of the infinite, and its courexion with the higher analysis. 
menta Analyseos sublimioris, Leipsic, 1799, 4to. Nurnberger's Exposition of the Formation of all derived Functions, Hamburg, 1821, treats this subject in a new point of view. For $A$. in chemistry, see Chemistry.

ANaMlokruosiss; a perspective projection of any thing, so that it shall appear at one point of view deformed; at another, an exact representation.

Avavas, in botany; a species of "bromelia, commonly called pine-apple (q. v.), from the similarity of its shape to the cones of firs and pines.

Anapdest. See Rhythm.

ANAPHORA (Greek, ava بog $\alpha$, repetition); a rhetorical figure, which consists in the repetition of the same word or phrase at the beginning of several successive sentences. A similar repetition at the end of -sentences is called epiphora, or homoioteleuton. Anaphora is sometimes used as the general name for both figures; the former is then called epanaphora. The anaphora aims to increase the energy of the phrase, but is often rendered ineffectual by too frequelit repetition.

Avastasius I., emperor of the East, succeeded Zeno, A.D. 491. He distinguished himself: by his moderation towards different Christian sects, whose quarrels at that time disturbed the peace and safety of the Byzantine empire. Moreover, he repealed a very heavy tax, called chrysargyrun, and prohibited the fighting with wild beasts. He died A.D. 518, after a reign of twenty-seven years.-A. II. was another emperor of the East, dethroned by Theodosius, in 719 , and afterwards put to death.-A., sur- uamed Bibliothecarius, a Roman abbot, keeper of the Vatican library, and one of the most learned men in the 9th century, assisted, in 829, at the fourth general council, the acts and canons of which he translated from the Greek into Latin. He also composed the lives of several popes, and other works, the best edition of which is that of the Vatican, 4 vols. fol. 1718.

Avathesa (cursed by God) is the form of excommunication from the church. Hence, to pronounce the anathema, or to anathematize, means, in the Roman Catholic church, to excommunicate the living from the church, and the dead from salvation. How important an instrument of spiritual power the anathema was, in the hands of the popes, in the middle ages, how much disorder they gave rise to, and how little they have been reganded in modern times, is matter of history. - Napoleon died in excommunication, and yet a priest attended him, and the circumstance is hardly mentioned. - Originally, the word was applied to various persons and things separated from ordinary life or uses to the will of a real or supposed deity, a gift hung up in a temple, and dedicated to some god, a votive offering; but as the

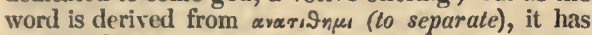
been, in later ages, used for expulsion, curse. The Greek and Romai Catholic churches both make use of the anathema. In the latter it can be pronounced only by a pope, council, or some of the superior clergy. The subject of the anathema is declared an outcast from the Catholic church, all Catholics are forbidden to associate with him, and utter destruction is denounced against him, both body and soul. The curse is terrible. Mere excomnunication is less severe. The heretic has also to anathematize lis errors. Once in every year, the pope publicly repeats the anathema against all heretics, amongst whom the Protestants, Luther, \&c., are mentioned. When councils declare any belief heretical, the declaration is couched in the following form: Si quis dixerit, \&c., anathema sil, which often occurs in the decisions of the councils. See Excommunication.

Avatonucal Prepabations. Dead bodies and parts of bodies, notwithstanding their tendency to decomposition, can be preserved by art. It is important to the physician, for the determination of the medical treatment proper in similar cases, to preserve the organs, which have been attacked by diseases, in their diseased state, and, as a counterpart, the same organ in its sound condition. The anatomical preparations of liealthy parts may serve for instruction in anatomy. Preparations of this sort can be preserved either by drying them, as is done with skeletons, or by putting them into liquids, e. g., alcohol, spirits of turpentine, $\& c$., as is done with the intestines and the other soft parts of the body, or by injection. The injection is used with vessels, the course and distribution of which are to be made sensible, and the shape of which is to be retained. The beginning of the ressel, e. g., the-aorta among the arteries, is filled, by means of a syringe, with a soft, coloured mass, which penetrates into all, even the smallest branches of the vessels, dries them and makes them visible. The finest capillary vessels may be thus made perfectly distinguishable. The infusion usually consists of a mixture of soap, pitch, oil, and turpentine, to which is added a colouring substance ; for instance, red for the arteries, green or blue for the veins, white for the lymphatic vessels. For very fine vessels, e. g. for the alosorbing lymphatic vessels, quick-silver is preferred on account of its extreme divisibility. Dried preparations are the bones, cleared of all the soft parts by boiling, and bleached, or any of the soft parts, covered witli a protecting but transparent varnish; e. g., muscles, intestines, \&c. The quicker the drying of the organs destined for preparation can be effected, the better they will be preserved. For. the purpose of preserving them, alcohol is used; the more colourless, the better. Spirits of wine, distilled with pepper, or very strong pimenta, are also used, together with some muriatic acid. Washing with acids (lately, pyro-ligneous acid has been used) gives to the preparation sometimes firmness, an sometimes whiteness. Washing is particularly necessary with bones which are in a state of putrefaction. Muscles are usually tanned; and all that is in danger of being eaten by worms, or injured by a damp atmosphere, is corered with a suitable varnish. The preparations treated thus are fixed upon a solid body, or in a frame. Preparations preserved in liquids are usually kept in transparent glasses, hermetically sealed, to secure them from the destroying infliences of dust, air, humidity, heat, cold, the sun, insects, \&c. Damaged preparations can seldom be perfectly restored.

ANatomy (Greek, avarspvsu, to dissect); the art of dissection; that of brutes is frequently called zootomy. Anatomy is a part of natural history, and is one of the most important branches of the science of medicine. The dissection of the human budy was but little practised by the ancients. The old Egyptians held it in great abhorrence, and even pursued with stones those men, who, in embalming the dead, were obliged to cut open their bodies. The Greeks were prevented by the principles of their religion from studying anatomy, since these required them to bury the bodies of the deceased as soon as possible. Even in the time of Hippocrates, anatomical knowledge was imperfect, and was probably derived from the dissection of animals ; the skeleton, however, was better known. When, in later times, under the Ptolemies, Alexandria in Egypt became the seat of the arts and sciences, auatomy was also brought to a high degree of perfection, by Herophilus of Chalcedon, 300 B. C., and by Erasistratus of Chios. According to the testimony of Celsus, the former obtained permission to open living criminals. He enriched anatomy with many important discoveries; 
e. g. respecting the Irain, the functions of the nerves, the blood-ressels of the inesentery, which go to the liver, \&c. Erasistratus determined many fincts in the construction of the brain with greater distinctuess, and, amoug other improvements, gave to the valres in the cena cava the unnes which are yet used. In later times, the study of anatomy was again neglected, particularly by the empirics. Galen, -qucated in Alexandria, bori A. 1). 131, collected all the anatomical knowledge of his contemporaries, and of earlier pliysicians, but seens not to have much euriched human auatomy himself, as he was principally occupied with the dissection of animals, and vuly applied his observations on them to the structure of the humau boly. Among the Arabiaus, anatomy was not practised; it was forbidden by their religion. 'Their physicians, therefore, took their anatomical information merely from the writiugs of the Greeks, particularly from those of Galen. Thus anatony was checker in its progress for several centuries. Finally, in the fourteenth century, individuals arose, who, not satisfed with the anatomical instruction of the age, ventured to make investimations of their own. The superstitious fear of the dissection of human corpses, which had hitherto prevailed, appeared to subside by degrees, when a philosophical spirit gave birth to more liberty of thought. Moudini di Luzzi, professor at Bologna, first publicly dissected two corpses, in 1315, and soon afterwards published a description of the human body, which for a long time was the common compendinm of anatomy, though many errors were contained in it. From this time it became customary, in all universities, to make public dissections once or twice a yenr. Anatomy, however, made but slow progress, since the dissections were intended only as illustrations of the writings of Galen and the compendium of Mondini. Montagnana alone, professor at Padua in the 15th century, could boast of having performed fourteen dis:ections, which was then a great number. In the 16 th century, there were many celebrated anatomists by whose influence the study of anatomy became more general. Fallopia, Eustachia, Vesal, Varol, sud many others enriched anatomy with new discoveries. In the 17 th century, there were likewise many fanous anatomists, and many discoveries were made; thus Harrey discorered the circulation of the blood, Wirsung the pancreatic duct, Schneider the mucous membrane, \&c. In the 18 th century, Pacchioni, Valsalva, Keil, Lancisi, Ruish, Haller, Boerhare, Vicq-d'Azir, the two Hunters, and others, distinguished themselves by their skill in anatomy. Meckel, Sommering, Loder, Reil, Bichat, Rosenmuller, are worthy to be mentioned as renowned anatomists of later times. According to the parts of the body described, the different divisions of anatomy receive different names; as, osteology, the description of the bones; myology, of the muscles; desmology, of the ligaments and sinews, \&c.; splanchnology, of the viscera or bowels, in which are reckoned the lungs, stomach, and intestines, the liver, spleen, kidneys, blatder, pancreas, \&c. Angiology describes the vessels through which the liquids in the human body are conducted, including the blood-vessels, which are divided into arteries and veins, and the lymphatic ressels, part of which absorb the chyle from the bowels, while others are distributed through the whole body, absorbing the secreted humours, and carrying them back into the blood. Neurology describes the system of the nerves and of the brain; dermology, of the skin.-Comparative anatomy is the science which compares the anatomy of different classes or species of animals ; e. $g$. that of man with quadrupeds, or that of fish with quadrupeds. It is a science which has greatly increased our knowledge of nature, and affords one of the most interesting subjects of study. Among anatounical labours are particularly to be mentioned the making and preserving of anatomical prepamtions. (q.v.) By jureparing, we mean the scparnting of any organ, or of an entire system, or of single parts, from all the other parts of the body. Thus, for instance, the whole system of bones, cleared from all the adherent muscles, tendons, and other parts, is prepared, and called the skeleton; so, too, the muscles, nerves, intestines, their vessels and distributions are laiel open in order to examine their veculiar constrnction. These labours require considerable anatomical knowledge. - Explanation of the anatomical plate (No. III.) Fig. 1.-1. Os Frontis. 2. Sutum coronalis. 3. Os Verticis. 4. Sutura squamosa. 5. Os Temporis. 6. Processus mamillaris. 7. Os Malae. 8. Ossa Nasi. 9. Ossa Maxillaris superiora. 10. Os Maxilla inferioris. 11. Vertebre Colli. 12. Vertebra Lumborum. 13. Os Sacrun. 14. Stemum. 15. Scapula. 16. Costre veræe. 17. Costxe notha. 18. Claviculse, 19. Processus coracoideus. 20. Os Humeri. 21. Ulna. 22. Radius. 23. Os Ilium. 24. Crista Ossis 1lii. 25. Ischium. 26. Os Pubis. 27. Foramen magnum. 28. Os Femoris. 29. Trochanter major 30. Trochanter minor. 31. Patella. 32. Tibia. 33. Fibula. 34. Talus. 35. Os Calcaneum. 36. Ossa Tarsi.-Fig. 2.-1. Os parietale. 2. Sutura sagittalis. 3. Sutura lambdoidalis. 4. Os occipitis. 5. Sutura squamosa. 6. Maxilla inferior. 7. Vertebræ Colli. 8. Vertebra Dorsi. 9. Vertebræ Lumborum. 10. Os Sacrun. 11. Os Coccygis. 12. Clavicula. 13. Scapula. 14. Spina Scapulæ. 15. Acromion. 16. Os Humeri. 17. Ulna. 18. Radius, 19. Ossa Carpi. 20. Ossa Metacarpi. 21. Ossa Digitorum. 22. Ilium. 23. Ischium. 24. Os lemoris. 25. Collum Ossis Femoris. 26. Trochantes major. 27. Trochanter minor. 28. Condylus exterior Ossis Femoris. 29. Condylus interior Ossis Femoris. 30. Tibia. 31. Fibula. 32. Os Calcaueun. 33. Ossa Tarsi. 31. Ossa Metatarsi.-Fig. 3.-1. Frontales. 2. Orbicularis Palpebre. 3. Zygomaticus major. 4. Nasales Labri superioris. 5. Depressor Labri inferioris. 6. Depressor anguli Oris. 7. Platisma myoides. 8. Pectoralis. 9. Latissimus Dorsi. 10. Serratus magnus. 11. Externus obliquus abduminis. 12. Rectus abdominis. 13. Pyramidales. 14. Linea alba. 15. Gracilis. 16. Adductor longus tricipitis Femoris. 17. Pectineus. 18. Psoas magnus. 19. Iliacus internus. 20. Sartorius. 21. Glutrus medius. 22. Fascialis. 23. Vastus externus. 24. Rectus Femoris. 25. Vastus internus. 26. Pars bicipitis. 27. Pars Gastrocnemii. 28. Soleus. 29. Peroneus longus. 30. Extensor longus digiti Pedis. 31. Tibialis anticus. 32. Deltoides. 33. Triceps. 34. Biceps. 35. Brach iæus externus. 36. Supinator longus. 37. Pronator rotundi Radii. 38. Radialis internus. 39. Palmaris longus. 40. Sublimis. 41. Ulnaris internus. 42. Abductor longus Pollicis. 43. Radialis externus longus.-Fig. 4. -1. Occipitalis. 2. Attoliens Auricularis. 3. Orbiculares Palpebrarum. 4. Latissimus Colli. 5. Mastoidæus. 6. Trapezius. 7. Deltoides. 8. Biceps. 9. Brachial is internus. 10. Triceps. 11. Supinator longus. 12. Radial is internus. 13. Radialis externus longior. 14. Radialis externus brevior. 15. Ulnaris externus. 16. Abductor Pollicis longus Manus, 17. Infraspinatus. 18. Teres minor. 19. Teres major. 20. Latissimus Dorsi. 21. Pectoralis. 22. Serratus magnus. 23. Obliquus externus Abdominis. 24. Tensor vaginæ Femoris. 25. Glutæus medius. 26. Glutæus magnus. 27. Semitendinosus. 28. Biceps Cruris. 29. Vastus externus, 30. Rectus Cruris. 31. Gastrocnemius. 32 Soleus. 33. Tendo Achillis. 34. Peroneus longus. 
35. Peroneus hrevis. 36. Extensor longus digiti Pedis. 37. Tibialis anticus. 38. Ligamentum a patella ad libram pertinens. 39. Vastus internus. 40. Sartorius. 41. Triceps pars quæ longus vocatur. 42. Triceps pars qua brachialis vocatur. 43. Brachialis externus. 44. Biceps Brachii. 45. Pronator teres. 46. Palmaris longus. 47. Sublimis. 48. Ulnaris internus. 49. Ulnaris externus. - Fig. 5.1. Temporalis. 2. Mastoidzeus. 3. Trapezius. 4. Deltoides. 5. Brachiæus. 6. Gemellus. 7. Palmaris longus. 8. Sublimis. 9. Ulnaris externus. 10. Radialis externus longior. 11. Extensor communis digitorum. 12. Infraspinatus. 13. Latissimus Dorsi, 14. Obliquus externus Abdominis. 15. Glutæus medius. 16. Glutæus major. 17. Gracilis. 18. Adductor inagnus Femoris. 19. Semitendinosus. 20. Biceps Cruris. 21. Vastus externus. 22. Gastrocnemins. 23. Soleus. 24. Tendo Achillis.

Asatron; the scum which swims upon the molten glass in the furnace, sometimes called sal vitrei, which, when taken off, melts in the air, and coagulates into common salt. It is also that salt which gathers upon the walls of vaults; likewise the same with natron (q. v.). Anatron is also a componnd salt, made of quick-lime, alum, vitriol, common salt, and nitre, used as a flux to promote the fusion and purification of metals. It is also used for the terra Saracenica.

Avaxagoras, one of the principal Ionic plilosophers, born at Clazomenæ, in Ionia, in the first year of the 70th Olympiad (500 B. C.), of rich and respectable parents, devoted himself to the study of philosophy, under Anaximenes of Miletus, or, according to some, under Hermotimus, his countryman. At the age of twenty years, he set out on his travels, visited Egypt, and all the countries where the sciences flourished, and finally settled at Athens. There he formed an intimacy with Pericles, and numbered among his disciples the most respectable citizens; e. g. Archelaus, the natural son of Perdic. cas, king of Macedonia, who himself reigned nine years, and Euripides. A profound study of the natural sciences enabled him to explain the eclipses of the sun and moon, earthquakes, and similar phenomena; but, by the intrigues of his enemies, he became suspected of blasphemy, and, in consequence of this accusation, was obliged to leave Athens, in 431. He went to Lampsacus, where he died after three years, seventy-two years old. The principle of A. was, "froin nothing comes nothing." He adopted, therefore, the idea of a chaos, and, as the primary clement of all bodies, a kind of atoms, of the same nature as the bodies which they formed. These atoms, in themselves motionless, were, in the beginning, put in motion by another equally eternal, immaterial, spiritual, elementary being, which he called Nous (Intelligence). By this motion, and by the separation of the dissimilar particles, and the combination of those of the same nature, the world was formed; the earthy bodies sank down, whilst the ether or fire rose and spread in the upper regions. The stars, however, were, according to him, of earthy materials, and the sun a glowing mass of stone, about as large as the Peloponnesus. The milky way he thought to be, like the rainbow, the reflection of light. The earth was, according to him, flat; the mooll, a dark, inhabitable body, receiving its light from the sun; the comets, wandering stars. He contended that the real existence of things, perceived by our senses, conld not be demonstrably proved, and considered reason as the source of truth. On acconnt of this principle, many have regarded lim as the first theist among the philosophers. $\mathrm{Ar}$ chelaus of $A$ thens was his disciple.

- Avaximanderr, son of Praxiades, a disciple of
Thales, and an original thinker was born at Miletus in the $42 \mathrm{~d}$ Olympiad (610 B. C.) His chief study was mathematics. He discovered, or taught, at least, the inclination of the ecliptic, and determined the solstices and equinoxes, by meaus of a dial (gnomon). He first used figures, to illustrate the propositions of geometry. He was also the first who attempted to sketch the outlines of lands and seas on a globe, and made a celestial globe, for the explanation of his system of the universe. Yet his statements are not to be entirely relied upon. His ideas concerning the first principle of things are so obscurely stated, that they cannot well be ascertained. His system seems to have been that infinity, ro arsıoo, is the origin of all existence, from which all emanates, and to which every thing returns. He has not, however, defined the nature of this eternal, incorruptible, original matter, the parts of which are variable, the whole unchangeable. The number of worlds is, according to him, infinite. The firmament is composed of heat and cold, the stars of air and fire. The sun occupies the highest place in the hearens, has a circumference 28 times larger, than the earth, and resembles a cylinder, from which streams of fire issue. When its opening is obstructed, it appears eclipsed. The moon is, according to him, likewise a cylinder, 19 times larger than the earth; its inclination produces the phases, its entire revolution the eclipses. Thunder and lightning are productions of the wind, compressed within the clouds. The earth has the shape of a cylinder, and is placed in the midst of the universe, where it remains suspended.- He died in the 58th Olympiad (546 B. C.), 64 years of age.

ANaxinness of Miletus flourished about the 56th Olympiad (556 B. C.) He was a disciple of Anaxim mander, from whose doctrines he, however, deviated. According to him, the air (ane) is the infinite, divine, perpetually active, first principle of all things. He taught that the exterior circumference of the heavens consisted of earth; that the stars were solid bodies, surrounded by fire; that the sun, by whose course alone the seasons are determined, was flat, as well as the earth, which rests upon the air. Diogenes of Apotlonia carried his doctrine still further.

Avaxisievs, of Lampsacus, was one of the preceptors of Alexander the Great. He accompanied his pupil through most of his campaigns, and afterwards wrote the history of his reign and that of his father Philip. He was also the author of a history of Grece. ANBERT KEND (the cistern of the waters of life); a celebrated book of the Brahmins, wherein the Indian religion and philosophy are contained. It is divided into 50 beths or discourses, each consisting of 10 chapters. It has been translated into Arabic, under the title of Morat al Maani; i. e. the marrow of intelligence.

ANCEstors. All nations, in any way civilized, have paid respect to the memory of their ancestors. Some have gone so far as to offer them religious homage. All the Asiatic nations are proud of a long line of aucestors. The Bible abounds in genealogies, and modern travellers state, that the same pride of descent prevails among the Arabians, Persians, \&c. Men of rank in the Fast are frequently entertained with songs in praise of their ancestors, - a custom which prevail ed in Greece and Rome, and throughout Europe in the middle ages. Esteem for parents and ancestors is so natural to all mankind, that low people, throughout the world, if they liappen to quarrel, as the readiest menns of insulting the opposite party, attack the honour of his mother, the honesty of his father, or the general character of the family from which he is descended, as the writer has had occasion to remark in very different conntries. There is hardly any age which does not furnish many instances, some even in 
the shape of political institutions, of an erroneons transfer to a man's posterity, of the honour belonging w himself, by which a natural and laudable feeling has been made the source of much injustice, and moml and political confusion. Another rery conmuis fault, into which mankind constantly fall, is that of suffering reverence felt for the persons of ancestors to produce an untue respect for their knowleclge and wisdom, -an error which arises, perlaps, urity from the ilea of age and experience attached to that of ancestors. The age and experience of living ancestors demand our respect, and the same feeling is transferred to the lead and to former ages, which, in point of fact, were jounger and less experienced than we. It is therefore ridiculous to see a numerous party, c. g., in France, constantly recommend the example of their ancestors (even of those who lived in ages when luardly any thing in politics was settled), as the only model to be imitated. Individuals and whole nations act as if wisdom belonged only to the dead. The true feeling of respect to ancestors is that expressed by a contemporary orator, on the 200th anniversary of the settlement of his native city: "let us not act as they did, but as they would have actel to-day." - The Egsptians are known to have paid particular attention to the bodies of their deceased relations; but no nation ever revered their ancestors in such degree as the Chinese, whoin Confucius directed to offer them sacrifice. lilial love, in fact, is one of the essential elements of the Chinese religion, politics and domestic life. Sir George Staunton (see his Embassy to China, 3 vols. 8 ro.) gives several instances which support this opinion. The inhabitants of New Fngland are noted for the esteem in which they hold their ancestors, without, however, being blind to their faults.

Avcuises, son of Capys, and great-grandson of Tros. Venus, captivated by his beauty, appeared to liun on mount Ida (according to some, near the river Simois), in the shape of a Phrygian shepherdess, and bore him Eneas. Itis son carried him off on his shoulders at the burning of 'Troy, and made him the companion of his voyage to Italy. He died during the royage, in Sicily. According to other accounts, Jupiter killed $A$. with a thunderbolt, because, when excited with wine, he betrayed the secret of his intimacy with Venus.

Avcuor, in navigation, is an important, strong, and heary instrument of iron, consisting of a shank having at one end a ring, to which the cable is fastened, and, at the other end, two arms or flukes, with barbs, or edges on each side, intended to be dropped from a ship into the bottom of the water, to retain her in a convenieut station in a larbour, road, or river. The most ancient anchors are said to have been of stone, and sometimes of wood, to which a great quantity of lead was usually fixed. In some places, baskets full of stones, and sacks filled with sand, were employed for the same use. All these were let down by cords into the sea, and, by their weight, stayed the course of the ship. Afterwards, they were composed of iron, and furnished with teeth, which, being fastened to the bottom of the sea, preserved the vessel immovable; whence osovrs and dentes are frequently taken for anchors in the Greek and Latin poets. At first, there was only one tooth, whence anchors were called irsporropos; but, in a short time, the second was added by Eupalamus, or Anacharsis, the Scythian philosopher. The anchors with two

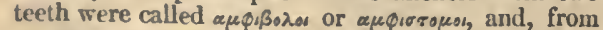
ancient monuments, appear to have been much the same with those used at present, only the transverse piece of wood upon the handles (the stocks) is wanting in all of them. Every ship had several anchors, one of which, surpassing all the rest in bigness and strength, was peculiarly termed ispa, or sacra, and was jever used but in extreme danger; whence sacram anchoram solvere is proverbially applied to such as are forced to their last refuge.-Iarge ships, at the present day, carry several anchors, with twn flukes each. 1. The sheet anchor is the largest, and is only used in case of violent storms. 2. 'Iwo bower anchors, viz. the best bower and small bower, so called from their situntion at the bows. 3. 'The stream anchor, the kedge, and grappling, or grapnel. The three last are often used for moving the ship from place to place, in a harbour or river.-The anchor is said to be $a-p c a k$, when the cable is perpendicular between the liawse and the anchor; it is snid to come home, when it does not hold the ship; it is said to be foul, when the cable gets hitched about the flukes. To shoe an anchor, is to fix boards upon the flukes, so that it may hold better in soft bottom. - Killing at anchor is the state of the vessel when moored or fixed by the anclior. Dropping or casting anchor is letting it down into the sea. Weighing anchor is raising it from the bottom.-The anchor, as every body knows, is the symbol of hope.

Axcnorets. See Anachorets.

Ascrovy ; a small fish of the clupea or herring genus, constituting, in Cuvier's classification, a subgenus, under the title of ingraulis. The common anchovy (clupea encrasicholus, L.) is about a span long, brownish on the back, with argentine belly and flanks. It differs from the other herrings in having the xthmoid and nasal bones prolonged to a point, beneath which their very small intermaxillaries are attached; their maxillaries are very straight and long; the mouth and throat rery wide; both jaws well furnished with teeth, and the gills more open than in other species. The anchory is found in the greatest abundance in the Mediterranean, on the coasts of France, England, and Holland, whither they come in immense shoals, like the larger lierrings, for the purpose of spawning. Nets of 40 fathoms long, and from 25 to 30 feet wide, are $\mathrm{em}$ ployed to take them; these nets differ in nothing from those commonly used, except in having very small meshes. - The anchovy fishery, in the Mediterranean, is begun in the spring, and continues until the commencement of summer, and is especially carried on, in dark nights, by the aid of fires. 'The fishermen provide themselves with floats, upon which a fire of pine-knots is made, and these are placed, at different distances, over a very consi derable extent of sea. The anchovies approach these lights, and collect near them in vast multitudes, when the fishermen silently surround them with their nets, extinguish the fire, and begin to beat upon the water. The frightened fish immediately endeavour to make their escape, and, rushing against the net, are caught by the meshes, which, passing over their gills, neither allow them to advance nor retreat. The fishermen, as soon as the net appears sufficiently full, raise it, and remove the fish, and go to repeat their operations at the next light. The Dutch, on their coasts, make use of a sort of funnel-shaped trap of reeds, with a net attached to the bottom. This is fastened to a stake, at low-water, and, at every change of tide, is visited for the purpose of removing the anchovies, which generally fill the net. Nearly all the anchovies caught are immediately salted, because othervise they spoil with great rapidity. The scales separate from the surface with so much ease, that it is a common notion these fish are not possessed of this integument. The heads of the anchovies must be taken off, on account of their bitterness, $-\mathrm{a}$ quality which has obtained for this species the name of encrasicholus, from a strange idea, that the gall-bladder was in the 
head. The intestines are removed, and the fish, after being washed, are packed in barrels like ordinary herrihıs, with layers of salt and fish alternately. A considerible difference is produced in the quality of anchovies by thersort of salt used, and the state of the pickle in which they are kept. The fishermen of Provence believe that the salt ought to be of a red colour, which is generally caused by rust of iron, where salt has been prepared in iron vessels, but, for their- use, is mostly caused by mixing a small quantity of ochre with the salt. They are very careful, also, not to change the pickle, merely supplying the loss, from leakage or evaporation, by adding water. Thesc anchovies have a peculiar acrimony of tastc, which is prized by epicures. They do not keep, however, so well as those packed by the northern fishermen, which are cured with grey salt, and have the pickle changed as often as tliree times.-As an article of diet, anchovies recently caught are eaten dressed in a great variety of modes. Salted anchovies ought to be recent, white above and reddish below, and free from taint. The books of cookery exhibit numerous salads, sauces, and relishes, of which anchovies form a part. A very favourite mode of using them is in anchovy-toast, made by spreading the flesh of the pickled anchovy over bread toasted brown. This is eaten as a provocative of thirst, by topers, or as a stimulant to a languid appetite, by persons whose stomachs are enfeebled or dyspeptic from excesses. Like all other stimulants, however, they soon lose their efficacy in such cases, and become positively injurious. - The ancient Romans made use of a sauce celebrated under the name of gamım, which is thought, by some writers; to have been prepared from the anchovy. We have made some investigations on this subject, and are led to the conclusion, that this sauce was prepared from the intestines, \&c. of fish, but by no means of any one species. According to Pliny, lib. 31, cap. 3, it was originally prepared from the shrimp called gamu. Subsequently, the sauce was made by macerating the intestines of fish in salt and water, until they becamc slightly putrescent, to which vinegar and parsley, chopped fine, or pounded, were added. As the anchovy was caught in such abundance in the Mediterranean, this fish was doubtless sometimes used for the preparation of the luxurious garum. Martial speaks of it as made from the scombrus, or mackerel, in the following words:-

Exspirantis adhuc scombri de sanguine primo,

Accipe fastosum, munera cara, garum.

$$
\text { Lib. xiii. Ep. cii. }
$$

How well it deserved the epithet fastosum, may be gathered from the statement of Pliny, lib. 31, cap. 8, in which he says, that two gallons of this garum sold for singulis millibus nummorum, or some thousands of sesterces.

Ascry Losis ; a stiffness or immobility of the joints. The existence of the disease is obvious to the eye. It is often connected with deformities of the limbs, and, in the anchylosis of the little bones of the ear, with deanfness; in that of the joint of the lower jaw, with inability of chewing. The anchylosis may occasion the decaying of a limb, bleedings, aneurisms, \&.c., and may even become fatal. In the beginning of these diseases, the patient usually suffers pain in the limbs, a more or less audible rustling in moving the joint affected, a feeling of weakness awd inability of directing the limb as it could be done in a state of health. An anchylosis usually arises from several causes, and afflicts somctimes the whole body, at other times one limb only. The anchylosis is sometimes constitutional; old people are more subject to it than young, and the male sex than the female.
The real anchylosis is incurable. Excessive indul. gence in animal love mny contribute to this disease; but it is, for the most part, the result of inflammation in the membrane lining the joints.

Ancrlion, David, a learned Protestant minister, born at Metz, in 1617. After the revocation of the edict of Nantz, he fled from France, and died at Berlin in 1692. He was author of several polemical treatises of merit; and his son, Charles, who was historiographer to the king of Prussia, and died at Berlin in 1715, published his "Conversations," in two rols., besides other works.

Ancona, capital of the delegation, and of the former marquisate of Ancona, Ion. $13^{0} 29^{\prime} \mathrm{E}$., lat. $43^{\circ} 38^{\prime} \mathrm{N}$, on the gulf of Venice, the seat of a bishop, has 17,330 inliabitants, among whom are 5000 Jews. The city and its finc harbour are praised by the most ancient writers. This harbour was inproved and beautified by Trajan; and the grateful citizens erected to him, in return, a triumphal arch of white marble, which is yet standing on the oldest mole. In 1732, A. was declared a free port, and, notwithstanding thc frequent obstruction of the haven by mud, it is visited every sear by more than 1100 vessels, and the commerce and manufactures of the city are considerable. $\lambda$. has also a quarantine establishment. It was always a famous fortress; was conquered and destroyed repeatedly by the Romans, Goths, Lombards, and Saracens ; rose by its own resources from its ruins, and becamc a republic. It was, howerer, in 1532, taken by the pope, by surprise, and annexed, together with its territory, to the papal dominions. The siege of this place by the Russians, Turks, and Austrians, in 1799, was remarkable, because the Russian colours, first planted on the walls of A., were pulled down by the Austrian soldiers, which gave occasion to the unfortunate dissensions of the emperor Paul with the allies. Since 1815 , the citadel only has remained fortified.

Ancourt, Florent Carton d', a French actor and dramatic writer, born at Fontainbleau in 1661. After going through a course of education, he was admitted an advocatc at the age of seventeen, but falling in love with an actress, he married her and went upon the stage, where he soon distinguished himself, and began to write for the theatres. He composed fifty-two dramatic pieces, of which many still keep the stage. They were published in 1710 , and 1750,9 vols. 12mo. Long before his death, which occurred in 1726, he had retired from the stage, and deroted himself to a life of almost ascetic derotion.

Ancus Martus, the fourth king of Rome, succeeded Tullus Hostilius, 640 B. C. (114 A. U.) and died 618 B. C. (136 A. U.) Hc bnilt the harbour at Ostia, the mouth of the Tiber. Rome, therefore, must have hat, as early as that period, some navigation, even if it did not amount to more than a coasting trade. He rcvived the neglected observance of religion, and inscribed the laws respecting religious ceremonies on tables set up in the inarketplace. Ennius and Lucretius call him the Good. Virgil reproaches him with undue regard for popular favour, because he distributed the conquered lands among the citizens.

ANDA; a tree of Brazil, the wood of which is spongy and light, the fower yellow and large, and the fruit a grey nut, which encloses two kernels, of the taste of chestnuts, in a double rind. The fruit is said to bc purgative.- Oil is pressed from these kernels, with which thc natives anoint their limbs. The rinds of the fruit, thrown into ponds, kill the fish.

Andalusia (nncient Batica); a province of Spain, divided into Upper and Lower. Upper $\Lambda$. compre. 
hends Grensda; Isower A. compreliends Jaen, Cordova, and Seville. A. is the most western province of Spain, and is lounded $\mathbf{N}$. by Fstremadura and La Mancha; E. by Mnrcia; S. by the sea and the straits of Gibraltar ; and W' by Portugal ; 170 miles long, and 180 wide. It is, withont tloubt, one of the finest, the richest, and most fertile parts of Spain, producing nbundance of oil and grain, also honey, sugar, silk, and wine. Its herds of cattle are numerous, and its horses are esteemed the best in the kingdon. The iuhabitants are descended, in part, from the Saracens, and dirler nuch from the natives of Castile, and the other parts of Spain, in their physiogionny and cliaracter. Yop., in $1787,788,153$. Its chitef cities are Seville and Cadiz. See Grenada.

Avdavte (music) denotes a tine somewliat slow, and a performance distinct and exact, gentle and sootling. Andnutino stands betreen andante and allegretto, at least according to the conmon notion; some assert that andantino implies a little slower motion than andante. The andante requires a delicate performance.

Andaman lsces, a cluster of isles in the Bay of Bengal, opposite to the coast of Malacca, two of which are distinguished by the names of Great and Little Andaman. The inhabitants of these islands are estimated at between two and three thousand, and are still in a state of extreme barbarity.

Axderab, a populous city of independent Tartary, situated on a river of the same name, and at the foot of the mountains which divide India and Persia from Great Buckharia. The only route to India is through this place.

Avdersos, Adan, author of the largest British compilation upan commercial history, was born in Scothand, about the year 1692. Having removed to London, he was for forty years a clerk in the South Sea house, and at length was appointed chief clerk of the Stuck and New Annuities in that establishment, in which situation lie continued till his death. He was also one of the court of assistants of the Scots corporation in London. In 1764, he published his work, entitled, "An Historical and Chronological Deduction of the Origin of Commerce, from the earliest accounts to the present time; containing a history of the large commercial interests of the British Empire, \&c.", Lond. 2 vols. folio. This elaborate work was subsequently improved in a new edition by Mr David Macpherson, 4 vols. quarto; and a manual abridgment of the work may still be considered a desideratum in our literature. Mr Anderson died soon after he had given it to the world, January 10th, 1765.

Avdersos, Alexander, an eminent mathematician, born at Aberdeen, near the close of the sixteentl century. How or where he acquired his mathematical education is not known; he probably studied belles lettres and philosophy in his native university. He comes into notice at Paris, early in the serenteenth century, as a private teacher or professor of mathematics. In that city, between the years 1612 and 1619 , he published or edited various geometrical and algebraical tracts, which are conspicuous for their ingenuity and elegance. It is doubtful whether he was ever acquainted with the famous Vieta, Master of Requests at Paris, who died in 1603 ; but his pure taste and skill in mathematical investigation pointed him out to the executors of that illustrious man, who had found leisure, in the intervals of a laborious profession, to cultivate and extend the ancient geometry, and by adopting a system of general symbols, to lay the foundation, and begin the superstructure, of algebraical science, as the person most proper for revising and publishing his valuable manuscripts. Arderson, however, did not confine liniself to the duty of a mere editor, he enriched the text witl learned comments, and gave neat demonstrations of those propositions which had been left imperfect. He afterwards produced a specimen of the application of geometrical analysis, which is listinguisheal by its clearuess and classic elegance. The works of $\Lambda$. amount to six thiu quarto volumes, now very scarce. These are, -1 . Supplementum Apollonii Redivivi : sive analysis problematis lacte-

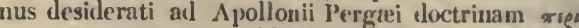
nuosan a Marino Gheuldo Patricio Ragusino hujus. que non ita pridem institutan, \&c. I'aris, 1612, 410. This tract refers to the problem of inclinations, by which, in certain cases, the application of the curve? called the conchoid is superseded.-2. Airsonoyos: Pro Zetetico Apolloniani problematis a se jam pri. dem edito in supplemento $\Lambda$ pollonii Redivivi. Being alı addition to the former work. Paris, 1615,4 to.3. The edition of the works of Vietal. P'aris, 1615 4to.-4. Ad Angularun Sectioneu Analytica Theoremata xabodsxwrsea, \&c. Paris, 1615, 4to.-5. Vindiciæ Archimedis, \&c. Paris, 1616, 4to.-6. Alexandri Andersoni Scoti Exercitatiounm Mathe naticarum Decas Prima, \&c. Paris, 1619, 4to.

Asderson, Sir Edmund, lord chief justice of the Common Pleas under Queen Elizabeth, was a nativ: of Lincolnshire ; died 1651. "Anderson's Reports," 1644, fol., is still a book of authority; and his judgments in the Westminster Courts, were publislıed in 1653 .

ANDERsox, George, accomptant-general of the Board of Control, was originally a Buckinglamshire peasant, and born in 1760 ; died 1796 . He published "A General View of the Aflairs of the East India Company," 1784, 4to.; and translated from the Greek of Archimedes, "Arenarius, or a Treatise on numbering the Sand."

Axdersos, James, an eminent Scottish antiquary, was born in 1662, and, after finisling a scholastie education at Fdinburgh, obtained the degree of Master of $\Lambda \mathrm{rts}$, on the 27th of May, 1680 . He chose the law for his profession, and was admitted a member of the society of writers to the signet in 1691. In this branch of the legal profession, the study of written antiquities in some measure forces itself upon the practitioner; and it appears that Anderson, though a diligent and able man of business, became in time too fond of the accessory employment to care much for the principal. A circumstance which occurred in 1704, decided his fate by tempting him into the field of antiquarian controversy. The question of the union of the two countries was then very keenly agitated; on the one side with much jealons assertion of the national independency, and on the other, with not only a contempt for the boasts of the Scots, but a revival of the old claims of England for a superiority or paramouncy over their country. A lawyer named Attwood, in 1704, published a pamphlet, in which all the exploded pretensions of Fdward I. were brought prominently into view, and a direct dominion in the crown of England asserterl over that of Scotland. For this work, Mr Auderson, thougl altogether unknown to $\mathrm{Mr}$ Attwood, was cited as an evidence and eye-witness, to voucl some of the most important original charters and grants by the kings of Scotland, which $\Lambda$ ttwood maintained were in favour of the point he laboured to establish. Mr Anderson, in consequence of such an appeal, thought himself bound in duty to his country, to publish what he knew of the matter, and to vindicate some of the best of the Scottish kings, who were accused by Attwood of a base and voluntary surrender of their sovereignty. Accordingly, in 1705, he published "An Essay, showing that the crown of Scotland is imperial and independent," Edinburgh. 
ovo, which was so acceptable to his country, that, besid's a reward, thanks were voted to him by parliament, to be delivered by the lord-chancellor, in presence of her majesty's high-commissioner and the estates. Mr Anderson's publication is now of little value, except for the charters attached to it in the shape of an appendix.-Under these circumstances, Anderson found it easy to secure the patronage of the Scottish estates towards a design for engraving and publishing a series of fac-similes of the royal charters, previous to the reign of James I., and of seals, medals, and coins, from the earliest to the present time. In November, 1766, he had a parliamentary grant of three hundred pounds towards this object. He then proceeded vigorously with the work, and in March, 1707, had not ouly expended the three lundred pounds granted by parliament, but five hundred and ninety pounds besides, which he had drawn from his own funds. A committee reported the facts; and the estates, while they approved of his conduct, recommended to the queen to bestow upon him an additional contribution of one thousand and fifty pounds sterling. Intoxicated with this success, A. now gave up his profession, and, resolving to devote himself entirely to the national service as an antiquary, removed to London, in order to superintend the progress of his work. The event only added another proof to what is already abundantly clear, that scarcely any prospects in the precarious fields of literature, ought to tempt a man altogether to resign a professional means of subsistence. The money voted by the expiring parliament is said to have never been paid; but, in lieu of money, he was favoured, in 1715, with the appointment of post-master general for Scotland; but of this he was deprived in little more than two years. What progress he now made with his great work is not very clearly known. He is found, in 1718, advertising that those who might wish to encourage it " could see specimens at his house, above the postoffice in Edinburgh." As the expense of engraving must have borne hard upon his diminished resources, he would appear to have digressed for some years into au employment of a kindred nature, atterided with greater facilities of publication. In 1727, he published the two first volumes of his well-known "Collections relating to the History of Mary, Queen of Scotland," Edinburgh, 4to, which was speedily completed by the addition of two other volumes. A. died in 1728, of a stroke of apoplexy, leaving his great work unfinished. The plates were sold, in 1729 , by auction, at $£ 530$, and it was not till 1737 that the work appeared, under the title of "Selectus Diplomatum et Numismatum Scotire Thesturus," the whole being under the care of the celebrated 'Thomas Ruddiman, who added a most elaborate preface.

Anderson, James, D. D., author of a large and useful work, entitled, "Royal Genealories," was the brother of Adam Anderson, author of the Commercial IIistory. He was for many years minister of the Scots presbyterian church in Swallow-street, Picradilly, and was well known among the people of that persuasion.in London, by the nick-name of Bishop Anderson. He was a learned but imprudent man, and lost a considerable part of his property from too deep dabbling in the South.sea sclieme. His mag$n u m$ opus as an author was, "Royal Genealogies, or the Genealogical Tables of Emperors, Kings, and Princes, from Adam (!) to these Times," London, folio, 173:. The compilation of this liuge work, in which he was aided by many eminent personages, whose families entered into its plan, cost lim, according to his own account, the labour of seven years. It is certainly the completest work of the kind in existence, though with no pretensions to discrimina- tion. Dr A. also wrote "The Coustitutiuns of the Free Masons," being the chaplain of that body in Loudon. The dates of his birth and death are not ascertained.

AxDERson, James, an agricultural and miscellaneous writer of great merit, was the sou of a farmer at Hermiston, in the county of Midlothian, Scotland, where he was born in the year 1739. His father dying when he was young, he was educated by his guardian to occupy the farm, which, accordingly, he began to manage at the early age of fifteen. At the saine time, he attended the chemical lectures given in the university of Ediuburgh by Dr Cullen, who, although surprised that one so young should liave formed this resolution, had soon reason to admire his pupil's laudable curiosity and good sense, and liberally afforded him every encouragement in his power. To chemistry lie added the study of certain collateral branches of science ; so that, when he entered upon his farm, lie was not ouly able to keep up with his more aged and experienced neighbours, but adopted a number of improvements, suggested by scientific knowledge and native good sense, which were speedily found to be of a most profitable nature. Among his improvements was the introduction of the small two-horse plough, which, since then, lias so completely banished the lumbering engine formerly drawn by a string of cattle. Nor did the necessary business of his farm preclude all advancement in knowledge. He still prosecuted his studies with great eagerness, and soon contrived to amass an immense stock of information upon almost all subjects. His first attempts in literature appeared in the shape of Essays on Planting; in Ruddiman's Weekly Magazine for 1771. In 1777, having previously removed to a large farm in Aberdeenshire, he publislıed these essays in a separate volume. In 1776, appeared his Essay on Chimneys, in which the principle afterwards acted on in the patent Bath stove was first explained. In the same year with his volume on planting, appeared various pamphlets connected with rural economy, all of which were more or less calculated to gratify the increasing desire of his countrymen for scientific knowledge upon such familiar subjects. The fame of these works procured him a very extensive acquaintance with persons of eminence, who wished to profit by the remarks of so able a practical farmer; and in 1780, the university of Aberdeen acknowledged his merit by conferring upon him the degree of LL. D. $-\Lambda$. had been married in 1768; and a desire of educating a very numerous family, together with certain considerations as to the enjoyment of literary society, induced him, in 1783, to remove to Edinburgh, leaving the management of his farm to persons properly qualified. A tract which he had written on the subject of the Fislieries, though not printed, attracted the attention of the government, and he was requested, in $\mathbf{1 7 8 4}$, to undertake a tour of the western coast of Scotland, for the purpose of obtaining information on this important subject. He readily acquiesced, and performed the task to the high satisfaction of his employers, who, however, never offered him any remuneration. The result of his labours appeared in 1785, as " An Account of the present state of the Hebrides and Western Coasts of Scotland; being the substance of a report to the Lords of the Treasury." - Passing over some minor works of $\mathrm{Dr} A$., we must make honourable niention of a literary and scientific miscellany which he commenced in 1791, under the title of "The Bee." This work was published in weekly numbers at sixpence, and, by its delightful intermixture of useful information with lighter inatters of the belles lettres, was eminently calculated for the improvement of the young. 'The work ran from the 
22d of December, 1790, to the 21st of Jamunry, 1794. The numbers published, foru eightcen volunes duolecimo, and throughout the whole of that space, we believe there doe's not oreur one line which can be considered reprehensible for its moral effect.-About the year 1797 , Dr $A$. removed with his family to London, where he undertook varions works comected with his favourite study of agriculture. For several years he wrote the articles of this nature in the Monthly Review; and from 1799 to 180:, he conducted a separate miscellany, under the tille of "Recrentions in $\Lambda$ griculture," which was only discontinued on account of some obstructions incident to such a mode of publication. From the last mentioned date, he devoted himself almost entirely to the relaxation which advanced years and severe studies laad rendered necessary, and particularly to the cultivation of his garlen, which became a mininture of all his past labours. In 1801, he married a stcond wife, who survived lim. He died on the 15th of Uctober, 1808, at the nge of sixty-nine.-In his younger days, Dr A. was remarkably handsome in his person, of midllle stature, and robust make. -Extremely inoderate in his living, the country exercise animated his cheek with the glow of health; but the overstrained exertion of lis mental powers afterwards shook his constitution, and liurried hin into old age. He was a man of independent mind; and in the relative duties of husband and father, exlibited a prudential care, mixed with affection, which commanded the admiration of his friends. Of $\mathrm{Dr}$ A.'s abilities, his werks exhibit so many proofs, that they may be appealed to with perfect confidence. Although a voluminous writer, there is no subject connected with his favourite pursuit, on which he lins not thrown new light. $\Lambda$ minute specification of nis works is to be found in the Scots Magazine for 1809.

Axprasox, Joln, M. $\Lambda$. , an eminent presbyterian clergyman of the last century, was at first minister at Dumbarton, and afterwands at Glasgow, where he died about 17:3. The earliest of his productions is entitled, "A Dialogue between a Curat and a Countreyman concerning the English Service, or Common-Prayer Book of England," which was printed in quarto at Glasgow, abont 1710. Soon afterwards, A. published a "Second Dialogue," dated 1711, " in which," says he, "there is lardly my thing of importance which is not said in the rery worts" of the writers of the other side," and in which South, Beveridge, Hammond, and Burnet are the curates whose sentiments are opposed, "A Letter from a Countreyman to a Curat," followed the dialogues, and received several answers, of which we slall only mention one, written by Robert Calder, an episcopalian clergyman. To this attack A. replied in a pamphlet entitled "Curat Calder Whipt." He soon after published, "A Sermon preached in the church of $\Lambda \mathrm{yr}$ at the opening of the Synod, on Tuesday the first of April, 1712," printed at the desire of the synod of Glasgow and Ayr; and in 1714, the work by which he is best known appenred, entitled,

. "A Defence of the Church-Government, Faith, Worship, and Spirit of the Presbyterians, in answer to a book entitled ' An Apology for Mr THomas Rhind," \&c. 4to. In the same year (1720) in which he was appointed one of the ministers of Glasgow, " Mr Anderson's Letters upon the Overtures concerning Kirk Sessions and Presbyteries," appeared in $12 \mathrm{mo}$. These letters extend to six, and although now little known, as they rofer merely to an epliemeral subject, contain some curious historical infornuation, and not a little satire. Mr A. did not long survive his call to Glasgow; the date of his death has not been ascertained, but his successor was ap- pointed hu 1723. His controversial writings aue full of valuable historical information, and slow him to have been thoroughly versed in theological literature, lout it cannot be too much regretted that he so far indulgel in iutemperate language.

Andenson, John, F.R.S., jrofessor of natural philosophy in the universily of Glasgow, and fomuler of the eminently useful institution bearing lis name in that city, was born in the parish of Roseneath, in Dumbartoushire, in the year 1726. He was the eldest son of the Rev. James Auderson, minister of Roseneath, who was, in his turn, the eldest son of the Rev. Joln Anderson, whose memoir is given in the preceding article. The sulject of this memoir, having the misfortune to lose his father in early life, was euncated by his aunt, Mrs Turuct, widlow of one of the uninisters of the High church of Stirling. Ile received the more advanced part of his edncention at the college of Glasgow, where, in 1756, he was appointed to be professor of oriental languages, being then in the thirtietl year of his age. In 1760, he was appointed to the cliair of natural philosoplyy, anl entered upon the business of that elass with enthusiasm. Not contented with the ordinary duty of delivering a course of lectures, though he performed that duty in a manner alone sufficient to obtain distinction, he was indefatigable in studying and exemplifying the application of science to mechanical practice ; visiting, for this purpose, the workshops of artisans in the town, and receiving, in return for the scientific doctrine which he had to communicate, a full equivalent of experimental knowledge. The most estimable characteristic of professor $\Lambda$., was a liberal and diffusive benevolence in regard to the instruction of his race. Under the inspiration of this feeling, he instituted, in addition to his usual class, which was strictly mathematical, one for the working classes, and others whose pursuits did not enable them to conform to the prescribed routine of acadenical study, illustrating lis precepts by experiments, so as to render it in the lighest degree attractive. He continued to teach this anti-toga class, as he called it, twice every week, during the session, to the cud of his life ; and it would not be easy to estimate the aggregate of good which he thus rendered to lis fellow crentures. As a lecturer, his style was ensy and graceful, his command of language unlimited, and the skill and success with which his manifold experiments were performed, could not be surpassed. He excited the interest, and attracted the attention of his pupils, by the numerous and appropriate anecdotes with which he illustrated and enlivened his lectures. Enthusiastic in his profession, his whole ambition and happiness consisted in making himself useful to mankind, by the dissemination of useful knowledge ; ant nothing afforded him purer pleasure than liearing that any of his pupils had distinguished themselves in the world. 'The only distinct work which he published in connexion with his favourite science, was a valuable one, entitled "Institutes of Pliysies," which ap. peared in 1786, and went throngh fre editions during the next ten years. On the conmencement of those political changes in France, which ended in such unhappy results, Mr A., as might have been predicated from his ardently liberal and enlightened clin. racter, was among those who sympathized most warmly with the proceedings of the emancipated people. Previous to that period, he had prosecuted a taste for the military art, and invented a species of gun, the recoil of which was stopped by the condensation of common air, within the body of the carriage. Haring in vain endeavoured to attract the attention of the British government to this invention, he went to Paris, in 1791 , carrying with him a model, which he presented to the national Convention. The governing 
party in France at once perceived the benefit which would be derived from this invention, and ordered Mr A.'s model to be hung up in their hall, with the following inscription over "it- "THE GIFT or SCIENCE to LiBerty." Whilst he was in France, he got a six-pounder made from his model, with which he made numerous experiments in the neighbourhood of Paris, at which the famous Paul Jones, amongst others, was present; and who gave his decided approbation of the gun, as likely to prove highly useful in landing troops from boats, or firing from the roind tops or poops of ships of war. Mr A. at this period, took a keen interest in the transactions which passed hefore his eyes. He was present when Louis XVI. was brought back from Varennes; and on the 14th of July, on the top of the altar of liberty, and in the presence of half a million of Frenchmen, he sung Te Deum with the bishop of Paris, when the king took the oath to the Constitution, amen being said to the ceremony by the discharge of five hundred pieces of artillery. As the Emperor of Germany had drawn a military cordon around the frontiers of France, to prevent the introduction of French newspapers into Germany, he suggested the expedient of making small balloons of paper, varnished with boiled oil, and filled with inflammable air, to which newspapers and manifestoes might be tied. This was accordingly practised, and when the wind was farourable for Germany, they were sent off, and descending in that country, were, with their appendages, picked up by the people.

O'er hills and dales, and lines of hostile troops, I float majestic,

Bearing the laws of God and Nature to oppressed men, And bidding them with arms their rights maintain.

A posthumous work of professor A., entitled "Observations on Roman Antiquities between the Forth and Clyde," appeared in 1804. Mr A. died, January 13th, 1796, in the 70th year of his age and the 4 lst year of his professorship, directing, by his will, dated May 7th, 1795, that the whole of his effects, of every kind, should be devoted to the establishment of an educational institution in Glasgow, to be denominated, Anderson's University, for the use of the unacademical classes. His will was carried into effect on the 9th of June following, by the magistrates granting a charter of incorporation to the proposed institution. According to the design of the founder, there were to be four colleges,-for arts, medicine, law, and theology,-besides an initiatory school. Each college was to consist of nine professors, the senior professor being the president or dean. $\Lambda$ s the funds, however, were inadequate to the plan, it was at first commenced with only a single course of lectures on natural philosophy and chemistry, by $\mathrm{Dr}$ Thomas Garnett. This course was attended for the first year by nearly a thousand persons of both sexes. In 1798, a professor of mathematics and geography was appointed. The splendid apparatus and library of the founder, which were valued at $£ 3000$, added greatly to the advantages of the infant institution. In 1799, 10r Garnett was succeeded by Dr Birbeck, who, in addition to the branches taught by his predecessor, introduced a familiar system of philosophical and mechanical information to five hundred operative mechanics, free of all expense. The institution was placed by the will of the founder under the inspection and control of the lord provost, and many other honourable persons, as ordinary visitors, and under the more immediate superintendence of eighty-one trustees, who are elected by ballot, and remain in oflice for life. Since the first establishment of $\mathbf{A n}$ derson's University, it has gradually been extended nearer and nearer to the original design of the founder, and it may be considered as the parent of the various Mechanics' Institutions which have of late years arisen throughout the country.

Avperson, Robert, M.D. the biographer of Smollett and Johnson, was born in 1749, the son of a fenar in the rural village of Carnwath in Lanarkshire. After studying medicine, he entered into praetice, as surgeon to the Dispensary of Bamborough Castle in Northumberland; but in 1784 removed to Edinburgh, where he ever afterwards resided. About the year 1793 he began to prepare his edition of the British Poets, which appeared in a succession of volumes, in large octavo, between the years 1795:and 1807. To the works of each poet is prefixed a biographical memoir by $\mathrm{Dr} A$.; and the work was deemed to be very respectably executed. A collection of the works of Smollett, by Dr A., with a memoir prefixed, has gone chrough eight editions. To the last edition is affixed a highly characteristic likeness of the editor. The memoir has been published repeatedly in a distinct shape, and is a very respectable production. Dr A. also published a "Life of Dr Samuel Johnson, with critical observations on his works " which has reached a third edition. For several years before the end of the eighteenth century, Dr $\Lambda$. was editor of the Edinburgh Magazine, a rival of the Scots Magazine, and more varied and lively in its details, which afforded him an opportunity of bringing forward the productions of his young friends. Tliis work commenced in the year 1784 , and at the end of 1803 , was incorporated with the Scots Magazine: it was much indebted to its proprietor, James Sibbald, editor of the Chronicles of Scottish poetry, to Lord Hailes, and other eminent literary characters. Dr A. was greatly instrumental in bringing before the public, Campbell's celebrated "Pleasures of Hope," and to him that work is dedicated. As a literary critic, Dr A. was distinguished by a warm and honest sensibility to the beauties of poetry, and by extreme candour. His character as a man was marked by perfect probity in all its dealings, and unshaken constancy in friendship. His manner was lively and bustling; and from his long-continued acquaintance with the literary world, he possessed an unrivalled fund of gossip and anecdote. He died in 1829 .

ANDERSon, Walter, D.D., a Scottish clergyman of the last century, who died in 1800 at the manse of Chirnside, of which place he had been minister for fifty years. He wrote the History of France during the reigns of ${ }^{-F r a n c i s}$ 1I. and Charles IX. 1769, 2 vols. 4to, a work which he continued in three subsequent volumes, down to the peace of Munster. He also produced an Essay, in 4to, on the Philosophy of Ancient Greece, and a life of Croesus, king of Lydia, in $12 \mathrm{mo}$. His works are of no repute, and his character seems to have been that of a laborious fool, led astray by the ambition of authorship. His last mentioned publication (which was his first.) is said to have arisen from a conversation he had with the celebrated David Hume, with whom he was familiar. One day, Anderson said, "Mr David, I dare say other people might write books too; but you clever fellows have taken up all the good subjects. When I look about me, I cannot find one unoccupied." Hume, who liked a joke upon an unsuspecting clergyman, said, "what would you think, Mr Anderson, of a history of Croesus, king of Lydia? - that has never yet been written." Mr $\Lambda$ nderson was delighted with the idea, and, in short, "11pon that hint he wrote." In 1755 was published accordingly, "The History of Croesus, king of Lydia, in four parts ; coutaining observations on the ancient notion of destiny, or dreams, on the origin and credit of the oracles, and the principles upon which the oracles were defended against any attack." The work was honoured with a serio-burlesque notice in the 
old Finburgh Review, then just started by Hume, Sinith, Carfyle, and other wits-the article being written probably by the very man who incited the unhappy author to his task.

$\Lambda$ wons, called by the Spaniards Cordilleras de los Andes, an immense chain of momtains, extending throughout South America from north to sonth, genernlly at the distance of about 150 miles from the western const. They extend from cape lilares, in the straits of Magellan, northwrurds to the isthunus of Dari ell. A mountainous ridge passes through the isthmus of Darien, dividing farther north unto various branches, styled the Cordilleras of Mexico. 'To the north of Mexico, the principal range takes the uame of the liocky montains, and reaches to the Frozen ocean, the northern limits of the American continent. These are by many considered as parts of one continued range, but the term Ancles is usually limited to the monutains in South America. - The Andes differ greatly in their general aspect and chiracter, being in some parts blended together into an entire mass, and in others, divided into two or three distinct ridges. In Chili, they are about 120 miles in brendth, presenting numerous summits of prodigious height. "To the north, they diverge in a straggling manner; and in l'eru, they are formed into three irregular ridges, which continue to about lat. $6^{\circ} \mathrm{S}$., where they are formed into a single chain. They divide again, in Quito, into two chains; and farther north, between lat. 20 and $5^{\circ} \mathrm{N}$., they are formed into three parallel ridges, whicl are again blended together between lat. $6^{\circ}$ and $7^{\circ} \mathrm{N}$. - Between the two ridges in Qnito, there is a plain from 5 to:6 leagues in breadth, of great fertility, well cultivated, and thickly settleal, having populous towns, and though under the equator, yet, owing to its great elevation, which is about 9000 feet above the sea, it possesses a temperate and delightful climate.-The Andes are the highest mountains in America, and, next to the Himmaleh nountains, the most elevated in the known world. They are composed, in a great part, of porphyry, and abound in the precious metals. Many of them are volcanic, and there are numerous.summits which are covered with perpetual snow. The medium height of the range, under the equator, may be estimated at about 14,000 feet above the level of the sea, while that of the Alps laardly exceeds 8000 . - The following table exhibits some of the highest summits, with their elevation gbove the level of the sea.

Chimborazo,

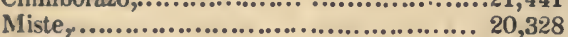

Disca Casada,.................................. 19,570

Cayamba Curco,............................ 19,388

Antisana,.................................... 19,149

Cotopaxi,.................................. 18,891

Altair,..................................... 17,256

Ilinissa,................................... 17,238

Sangai, ................................... 17,136

Tunguragin,............................ 16,500

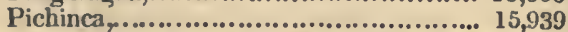

Mr Pentland has recently asserted, that mount Nerado de Sorato is the lighest mountain of America. He estimates its height at 25,200 feet. Its situation is in $15^{\circ} 30^{\prime} \mathrm{S}$. lat. The second in altitude he considers mount Illimani (Nevados de Illimani), in $\mathrm{Paz}$, in Bolivia, or Upper Peru, 22 marine leagues S. E. of the city $\mathrm{Paz}$, between $15^{\circ} 35^{\prime}$ and $16^{\circ} 40 \mathrm{~S}$. lat., and between $67^{\circ}$ and $68^{\circ} \mathrm{W}$. long. The most northern peak of it he gives as 24,200 feet high. (See $A n$ rales des Sciences, xiv. 290.) - A lively idea of the character and grand features of the Andes may be formed from the accounts given in the celebrated Alexander von Humbollt's Journey into the Equiuoctial Countries of the New Continent; which, at the same time, afforls much scientific information on these remarkable mountains. - Gool roads have been cut with great labour in the neighbourhood of Chimborazo, one of which is 1000 miles in length; and similar labours of the ancient incas of Peru may be found Uhroughout the province. Over the Rio Desagualero, in Buenos Ayres, is a singular bridge, formed of ropes and rushes, attributed to Caune Yupanqui, the 5th inca.- The approach to the Andes fioin the western coasts has always been achnired. The rond leads through the most beautiful forests, the foliage of which exhibits the most varions and lovely colours. As the traveller advances, an awful sublinity pervades the mind, and the wide interstices and tremendous clasms, together with the cataracts that roll down the mountrins from an amazing nltitude, filling the distant view, overwheln him with admiration. 'The highest deserts of the Andes are in the north calle't Paramos, and in Peru, Punas; but so acute and peculiar is the cold air in these places, as rather to pierce the vitals than affect the exterior feclings. It is no uncommon circumstance to meet with the borlies of travellers who lave perished in the cold, whose faces have the horrid appearance of laughter, owing to the contraction of the muscles at the period of dissolution. The pine lingers last of the more statcly tribes of vegetables, accompanied by a low species of moss. It is found 13,000 feet in altitude above the level of the sea. Numerous orders of the larger trees appear progressively in the space between the lieights of 10,000 and 9000 feet. At the height of 9200 feet, is found the oak, which, in the equatorial regions, never descends below that of 5500 . It is, however, said to be found in the neighbourhood of Mexico, at the height of only 2620 feet. European grains flourish best between the altitude of 6000 and 9000 feet. Wheat under the equator will seldom spring up below the elevation of 4500 feet, or ripen above that of 10,800 . IIumboldt says there are very fine harvests of wheat near Victoria, in the Caraceas wrovince, at 1640 and 1900 feet above the level of the sea. In Cuba, wheat crops will flourish and ripen at a small eleration. Rye and barley, from their constitution, are capable of resisting cold better than wheat, and, consequently, of ripening in a superior altitude. Maize is cultirated in the same climate as the banana, but will flourish 9000 feet high. Orange's, pine-apples, and every variety of delicious fruits and vegetables, are found in the lower grounds of the Andes, within the tropics. Cassava, maize, cacal, coffee, sugar, cotton, and indigo are cultivated with success. Indigo and cacao, liowever, require great heat to ripen them. Cotton and coffee require a more temperate clime. Sugar arrives at a superior degree of perfection in the more temperate regions of the province of Quito.-For further information, see Humboldt, and the Journal de Physique, vol. liii. for 1801. For the different mountains of the Andes, see their respective articles. See, also, America.

ANDover, a borough, market-town, and parish in Hampshire, situated on the river Anton, near the borders of the Downs. It is supposed to have been the Andareon of the Romans. It is distant from London sixty-three miles. The population of the borough and parish is 4843 .

AsDover ; a post-township of Massachusetts, in the. county of Essex, twenty miles $\mathbf{N}$. of Boston ; pop. in 1820, 3889. It is situated on the S. F. side of the Merrimack, and is also watered by the Shawshee'n, is pleasant and flourishing, and contains three parishes, in each of which there is a congregational meeting house. A. has some manufacture's, but it is chicfly celebrated for its literary institutions, particnlarly its theological seninary.

ANDRÉ, major J. ; an adjutant-general in the Bri- 
tish army in North America during the revolutionary war. He was originally a mercliant's clerk. Employed to negotiate the defection of the American general Arnold, and the delivery of the works at West Point, he was apprehended in disguise, Sept. 23, 1780, within the American lines, and sent prisoner to general Washington, who submitted his case to the examination and decision of a board of general officers, consisting of major-general Greene, William Alexander (lord Stirling), the maryuis de la Fayette, \&c. "The board declared him a spy from the enemy, and, agreeably to the law and usage of nations, he was hanged at Tappan, in New York, Oct. 2, 1780. A monument is erected to his memory in Westminster abbey. He is the author of a poem entitled The Cow Chase. See Arnold.

ANdRea del Sarto. See Sarto.

Axpreas, Onuphrius, a Neapolitan poet of the 17 th century, who died in 1647. His works consist of an epic poem entitled "Italia Liberata," several Iyric effusions, and two dramatic pieces, besides some prose essays on moral and philosophical subjects.

Andreas, Valerius, professor of civil law and Hebrew at Louvain, was born at Desschel, in the Netherlands, in 1584; died 1656 . He was author of various works in biography, topogzaphy, philology, and antiquity.

AxDreivl, Francis, an Italian comedian, who, besides his histrionic talents, was distinguished for his knowledge of languages. He wrote several pieces for the stage. His wife, Isabelis, a native of $\mathrm{Pa}$ dua, was the finest performer of her day, and published several poetical works, which were much admired. She died in 1604 , in the $42 \mathrm{~d}$ year of her age. Her husband survived her nearly sixteen years. They left a son, Giovanni Battista, who inherited the talents of his parents, both in acting and composition.

AxDREw, St; brother of St Peter, and the first disciple whorr. Christ chose. Both brothers were fishermen, but left their business and followed the Redeemer. The fate of A., after Christ's death, is uncertain; the common opinion is, that he was erucified. The Russians revere him as the apostle who brought the gospel to them; the Scots, as the patron saint of their country. In the early ages of the church, a pretended Gospel of his was in circulation. The Acta, also, which bear his name, are not genuine. The order of St A., is one of the highest orders of the empire of Russia, instituted by Peter the Great, in.1697.-For the Scottish knights of St A., spe Thistle.

Andrew, St, cross of; a cross of the form X, be cause, according to tradition, St $A$. was executed on a cross which had this shape, Nov. $30, A . D .83$, at Patras, in Achaia.

ANDREws, St, an ancient borough and seaport town of Fifeshire, in Scotland, and the seat of the oldest of the four Scottish universities, stands on a rocky promontory at the bottom of a bay of the same name, and on the south side of the firth of Tay, thirty-nine miles north by east from Edinburgh. It was erected into a royal burgh by David I., in 1140, and has been the scene of nany memorable transactions in the civil and ecclesiastical history of Scotland. About the same time, it was rendered archiepiscopal, and was the resort of many religious orders. The revenmes of the see in $\mathbf{1 5 6 1}$ have been estimated ot $£ 10,000$ of our present money, and an Augustine monastery, founded in 1120 , was still richer. The cathedral church, begur in 1159, was not finally coinpleted till 157 years had elapsed, and was de. molished at the Reformation by the populace. The castle, of which little now remains, was built in the 12th century, on a rock projecting into the sea, and has been rendered famous as the scene of several events in Scottish history, particularly of the assassination of cardinal Beaton. The university of St Andrews was founded by bishop Wardlaw, in 1411; it formerly consisted of three colleges; that of St Salvador, founded in 1455 ; that of St Leonard's, founded in 1512 ; and that of St Mary's, completed in 1561. St Salvador's and St Leonard's were colljoined in 1747, under the name of the United College, in which, besides the ancient languages, the usual academical courses of philosophy are delivered. In St Mary's, divinity, church history, and the oriental languages, are taught. The burgh of St Andrews consists at present of three principal streets and a few lanes, but its old ruins give an exalted notion of its former magnificence. It once had an extensive foreign trade, but now very few vessels belong to it. Its manufactures principally consist of Osnaburgs', canvass, and linen. The making of golf-balls also employs a portion of the inhabitants. The parish of St Andrews, which is about ten miles in length and three broad, is generally fertile, and in a high state of cultivation.

ANDrews, James Pettit, an English miscellaneous writer, was born in Berks in 1737, and attached himself to literature until his deatll, which took place in 1797. His principal works are, "Aneodotes, Ancient and Modern, 1789 ;" "Continuation of Henry's History of Britain, 4to and 8vo ;" and "The History of Great Britain connected with the Chronology of Europe, \&c., 1794-5."

ANDrews, Lancelot, bishop of Winchester, in the reigns of James $I_{\text {. }}$ and Charles $I_{*}^{*}$, was born in London, 1565. He is particularly known by one of his works, Torturi Torti (1609), which he wrote against a publication of cardinal Bellarmine, under the fictitious name of Matthew Tortus, in which the cardinal had attacked James' Defence of the Rights of Kings. His works best known at present are, a volume of Sermons, 1628-31, fol. 1642; the Moral Law Expounded, or Lectures on the Ten Commandments, 1642, fol.; Collection of Posthumous and Orphan Lectures, delivered at St Paul's and St Giles', London, 1657 , fol.

Androclus, or ANprodus; a Dacian slave, who being exposed to a lion in the circus, the animal forbore to hurt him, because he had formerly taken a thorn out of its foot. He was, in consequence, liberated, and led the lion about the streets of Rome. -Aul. Gel. l. v. c. 14. El. Hist. An. l. vii. c. 48. ANDroldes (from ayne, a man, and woos, form); a figure of human shape, which, by certain machinery, is made to perform some of the natural motions of a living man.

ANDRosuche; daughter of Eetion, king of Thebes in Cilicia, and wife of Hector. (q.v.) After the con. quest of Troy, she became the prize of Pyrrhus, son of Achilles, who carried her to Epirus, and had three sons by lier, but afterwards left her to Helenus, brother of Hector, to whom she bore a son. Euripides has made her the chief cliaracter of a tragedy.

ANDROMEDA ; daughter of the Ethiopian king Cepheus, and of Cassiopeia. The mother and daughter were very beautiful. The former having boasted that her daughter surpassed the Nereides, if not Juno herself, in beauty, the offended goddesses called on their father to revenge the insult. He not only inundated the territory of Cepheus, but also sent a lorrid sea-monster, which threatened universal destruction. The oracle declared that the wrath of Neptune could not be appeased, unless Cepliens delivered his daughter to the monster. In this exiremity, Perseus belield her, when, with the head of the Gorgon in his hand, and mounted on Pegasus, he was returning from his victory over Medusa. 'Touched by compassion and love, the hero promised

$$
x-x^{2}
$$


to kill the monster 'on condition that the virgin should be given him in marriage. The father jronised it, and kept his word. In memory of the exploits of Perseus (q. ง.), A., by the firvour of Pallas, was placed among the stars.

ANDronicos of Cyresthes; a Greek architect, celebrated for having constructed, at Athens, the tower of the winds, an octngonal building, on each side of which was a figure representing one of the winds. On the top of the tower was a small pyramid of marble supporting a brazen Triton, which turned on a pirot, and pointed with its rod to the side of the tower on which was represented the wind that was then blowiug. As each of the sides had a sort of dial, it is conjectured that it formerly contained a clepsydra or water-clock.

Androsicos of Rhodes; a follower of Aristotle, who lived B. C. 63, and wrote commentaries on that author. He also restored and published the works of that philosopher, which Sylla had brought from Greece.

ANDros ; islands of the Holy Ghost (isles del Espiritu Santo); a group of isles extending in the form of a crescent, for upwards of fifty leagues in the neighbourhood of the Great Bahama bank, and amongst the Bahamas; in N. lat. $24^{\circ}$ to $25^{\circ} 30^{\prime}$, and W. Ion. $77^{\circ}$ to $78^{\circ} 20^{\prime}$. The passages through them are dangerous. Attempts have been made to colo. nize the principal Andros island. In 1788, 200 inhabitants, including slaves, were settled there. It has the privilege of sending one member to the house of assembly of the Bahamas. The approach to it is very difficult, for various reasons.

Androscoggiv, or $\Lambda$ sirruscoggiv; a river which forms the outlet of Umbagog lake, and has the first part of its course in the eastern part of New Hampshire. After entering the state of Maine, it flows first in an easterly, and afterwards in a southerly direction, and joins the Kennebec at Merry-meeting bay, six miles above Bath, and eighteen miles above the entrance of the river into the ocean. Its whole course is about 150 miles in length.

Avprooer du Cerceau, James, an eminent French architect of the 16th century, who wrote several works of merit connected with his profession. The dates of his birth and death are uncertain.

ArDRY, Nicholas, a physician of Lyons, and afterwards dean of the faculty of medicine in the rosal college of Paris, was the author of several medical works of some repute. He died in 1742, aged 84.

Aszur, Thonias. See Masaniello.

ANEMaveTER ; an instrument contrived to measure the strerigth and velocity of the wind.

AvEsose, wind-flower, in botany ; a genus of the polygamia order, and polyandria class, ranking, in the natural method, under the 26th order, multisiliqua. It has its name from the Greek arreos, (the wind), because it is supposed not to open unless the wind blows. Linnæus enumerates twenty-one species: those valuable on account of their beauty are the following: 1, anemone Apennina, a native of Britain, growing in the woods; 2, anemone coronaria ; 3 , anemone hortensis ; both natives of the Le vant, particularly of the Archipelago islands, where the borders of the fields are covered with them; 4 , anemone nemorosa, growing wild in the woods, in many parts of Britain, where it flowers in April and May. Prof. Candole, De Cand. Syst. vol. i. 188, enumerates forty-five species of anemone.

ANzasoscops; every contrivance which indicates the direction of the wind. The vane upon towers and roofs is the simplest of all anemoscopes. There are also some, where the vane turns a movable spindle, which descends through the roof to the chamber where the observation is to be made. On the ceiling of this apartment a compass-card is fixed, and, whilst the wind turns the vane together with the spindle, an index, fixerl below, points out the direction of the wind on the card. Some are so made as, even in the absence of the observer, to note down the changes of the wind. Annong the most perfect of this kind, is that of prof. Moscati, and of the cav. Marsilio Landriani.

ANEORISM; the swelling of an artery, or the dilatation and expausion of soine part of an artery. This is the true aneurism. There is also a spurious kiml of aneurism, when the rupture or puncture of au artery is followed by an extravasation of bluol in the cellular membrane. If the exterual membrane of the artery is injured, and the internal meubrane protrudes through, and forms a sac, it is called mixed aneurism. Lastly, there is the varicose aneurism, the tumor of the artery, when, in bleeding, the visi has been entirely cut through, and at the same time the upper side of an artery beneath has been perforated, so that its blood is pressed into the vein. The genuine aneurisms arise partly from the tos violent motion of the blood, partly from a preteruatural debility of the membranes of the artery, which is sometimes constitutional. They are, therefore, more frequent in the great branches of the arteries; in particular, in the vicinity of the heart, in the arch of the aorta, and in the extremities, for instance, in the ham and at the rilos, where the arteries are exposed to frequent injuries by stretching, violent bodily exertions, thrusts, falls, and contusions. 'They may, however, be occasioned also, especially the in. ternal ones, by diseases, violent ebullitions of the blood, by the use of ardent spirits, by vehement passions and emotions, particularly by anger; in such cases, the arteries may be ruptured, and sudden death produced. The external aneurisms are either healed by continued pressure on thie swelling, or by an operation, in which the artery is laid bare, and tied above the swelling, so as to prevent the flow of the blood into the sac of the aneurism, which contracts by degrees. Sometimes the ligature is applied both above and below the aneurism.

Asfossi, Pasquale, was born at Naples, in 1729, played on the violin in the music schools of Naples, and studied composition under Sacchini and Picciri. The latter had a great friendship for him, and pro. cured him, in 1771, his first employment, in the theatre delle dame at Rome. Though he met with no success, Piccini procured him, in the following year, a second engagement, in which he was also unsuccessful. In a third engagement, the year afterwards, A. was more fortunate. The Persecuted Unknown was performed, in 1773 , with great applause, as were also La Finta Giardiniera and Il Geloso d. Cimento some time afterwards. On the other hand, the Olimpiade, in 1776, entirely failed, and the nortification of the author, on this occasion, induced him to leave Rome. He travelled through Italy, and, about 1780, went to France. He performed in the royal academy the Persecuted Unknown; but this lovely and delicate music did not meet with the reception which it deserved. From France A. went to London, where, in 1783, he was director of music at the Italian theatre. In 1787 , he returned to Rome, where he brought out sereral pieces, the success of which made him forget his disappointments, and gained him a reputation which he enjoyed until his death, in 1795 . A. frequently reminds us of Sacchini and Piccini, after whoin he formed lis style; but his taste, expression, and style of progression and resolution are extraordinary. Several of his finales are models in their kind. His fertility proves that he conposed with ease. Of his works, we may also mention the.Avaro, Il Curioso Indiscreto and $I$ Viaggiatori Felici, wlyich rank among the best comic 
operas. He has also composed several oratorios and jualms, written mostly by Metastasio.

AxGEL (from the Greek $a \gamma \gamma \varepsilon \lambda$ os, a messenger). Under the articles Demon and Demonology is shown in what way the idea of angels was introduced into Clıris. tianity; here we slall only explain how this idea was further developed. Under the name of angels is understood a kind of good spirits, having a near connexion and communication with men. In the Jewish theolo$g y$, they were divided into different classes and ranks. These have been most accurately described by the author of the Heavenly Hierarchy, ascribed to Dionysius the Areopagite. He forms them into three classes, each containing as many subdivisions. According to the majority of writers, they were created long vefore the visible world; according to others, at the same time as the heaven and earth, when God commanded the light to be, and his spirit moved over the waters. Their office is to serve the Deity, whese agents they are in effecting his good purposes, as the tutelary spirits of whole nations and kingdoms, as the heralds of his commands, as the guardians of particular individuals, and the directors of particular events. They were supposed to be spirits with ethereal bodies. This conception of them was established as a doctrine of the church by the council of Nice (in 787), but is at variance with the decision of the Lateran council of 1215 , which makes them inmaterial beings. Those who regard the body merely as an incumbrance, or prison of the soul, and conceive a very exalted idea of pure spirits, hold angels to be such spirits, and explain their visible appearance by supposing that they have the power of assuming at will bodily forms and a human shape. Those who consider it no imperfection for a spirit to exist in a body, maintain that angels have bodies. As finite beings, they must have some place where they reside. The ancients easily found a habitation for them in their heaven, which was conceived to be a vast azure hall, where God dwelt with his angels; but we, who have very different ideas of heaven and the universe, can only suppose that, if they still operate on human things, they dwell invisibly with and about us. As to their names, the Catholic church receives only three as sanctioned by the Scriptures,-Michael, Galoriel and Raphael. Among the heresies of Aldebert, condemned by a Catholic council, at Rome, under pope Zachary, 704, he was accused of invoking angels by unknown names, such as Uriel, Raguel, Simiel, \&c. It was expressly declared that these were not names of angels, but of evil spirits. The later Catholies, however, have now changed their views in this respect, and the Catholic Somnenberg has, after the example of Milton and Klopstock, not only mentioned other angels, but invented names for them. Swedenborg gives in his works a classification and detailed description of the angels. It is known that his followers believe in the constant influence of angels and the spirits of the deceased.

ANGEL; a gold coin formerly current in England, so named from having the representation of an angel upon it. It weighed four pennyweights, and was twenty-three carats and a half fiue. It had different values in different reigns; but is now only an imaginary sum, or money of account, implying ten shillings.

Avgen, Peter, professor of belles lettres at Pisa, in the sixteenth century, was born in Tuscany, in 151\%; died 1596. He published various works, but chiefly distinguished himself as a Latin poet. His Syrias, a Latin poem in 12 books, is on the same sulject as Iasso's Jerusalem Delivered.

Avgro Buonarott, Michael; of the ancient family of the counts of Canosa; born, 1474, at Caprese or Clinsi ; one of the most distinguished names in the history of modern art, eminent alike in painting, sculpture, and architecture, and; withal, no mean poet. He was also an expert fencer. A. was one of those favourites of nature, who combine in their single persons the excellences of many highly-gifted men. Domenico Ghirlandaio was his first master in the art of drawing. Before he had been with him two years, in the academy of arts established by Lorenzo de" Medici, he studied statuary under Bertoldo, and, in his 16th year, copied the head of a satyr in marble, to the admiration of all connoisseurs. He attracted no less attention as a painter, and received the honourable commission (together with the great Leonardo da Vinci) of decorating the senate-hall at Florence with historical designs. For this purpose, he sketched that renowned, though not completely preserved cartoon, which represents a scene from the Pisan war, and is praised by critics as one of his most perfect creations. Meanwhile, pope Julius II. had invited him to Rome, and entrusted him with the charge of erecting his sepulchral monument. Twice this labour was interrupted-once by the offended pride of $A$., and then by the envy of contemporary artists. Bramante and Juliano da San Gallo, in particular, persuaded the pope to have the dome of the Sistine chapel painted by Michael A. Knowing that he had not yet attempted any thing in fresco, they hoped that the imperfect execution of this task would alienate the farour of the pope from him. A. declined the commission, but the pope would not be refused; and, in the short space of 20 months, the artist finished the work, which was admired by all connoisseurs, and of which Fernow says rightly, that it displays, perhaps, more than any other of his productions, all the sublimity of his original genius. The cappella Sistina is certainly the grandest ensemble of art. Its perfection is owing chiefly to Michael Angelo's divine paintings. (See Sistine Chapel.) A. was about to proceed with the monument of Julius, when this pope died. His successor, Leo, sent A. to Florence to erect the front of the Laurentian library. Leo, however, shortly after died, and his successor, Adrian VI., employed A. to make the statues for the monument of Julius; particularly the renowned statue of Moses, and the Christ, which was afterwards placed at Rome, in the church della Minerva. Clement VII., who next ascended the pontifical chair, recalled A. to Rome, and cliarged him with the finishing of the new sacristy and the Laurentian library at Florence. In the first, the monuments of the Medici are by him; e. g., the figures of Day and Night. Tu. multuous times followed, after the lapse of which, he was employed to paint the Last.Judgment in the Sistine chapel. The artist, now 60 years old, unwillingly commenced a work which might endanger his fame. Naturally inclined to deep and eaniest thought; preferring the sublime conceptions of Dante to all other poetry; having, by a constaut study of anatomy, investigated the most secret meclianism of the muscles, and conscious of his own power, - he endeavoured, in this work, to strike out a new patl, and to surpass his predecessors, particu. larly Luca Signeretti, by a display of terrible power. The picture is grand, nay, gigantic, like the mind which created it. It represents Christ in the act of judging, or, rather, at the moment of condemuing. Martyrs are seen, who show to the Judge of the living and dead the instruments of their torture; souls ascend to the choirs of angels hovering above; the condemned strive to break loose from the grasp of the devils; there the evil spirits burst into shouts of triumph at the sight of their prey ; the lost, who are dragged down, endeavour to cling to the good, who remain in Christ's kingdom ; the gulf of eternal damnation is seen opening; Jesus Christ and his mother are seen surrounded by the apostles, who place a 
crown on his hend, and by a multitude of srints, 1 while angels ahove carry in triunuph the symbols of his passion; and, lower down, another company of angels somind the trumpets intended to awaken the dead from their tombs, nnd call then to juigneut. All this, and a vast deal more, is executed in the awfinl style of Dante. With these scenes of fear and despair, of judgment and of heavenly beatitude, a wall of great height and breadth is filled, and every where is displayed the inost profound study, the richest experience, and the lofty spirit of a master. The effect of this picture resembles that of the s11. blimest passages of Dante, particularly in connexion with the large innages of the prophets, who, like warning and stern heralds of tlee last judgment, look down from the ceiling upon the spectator, resembling beiugs of another world, rather than images made by the hand of man. Whilst this picture of the Last Judgment shows the human figure in all its attitudes and foreshortenings, and gives us the expression of nstonishment, of pain, of despair, through all their degrees, it may be considered as an inexhnustible treasure for the study of the arts. A.'s last considerable works in paintings were two large pictures - the Conversion of St Paul, and the Crucifixion of St Pcter, in the Pauline chapel. In sculpture, he executed the Descent of Christ from the Cross, four figures of one piece of marble. It is reported of his Cupid in marble, that it was a more perfect copy of another Cupid, which he had buried in the ground, after having broken off one of its arms, in order that it might pass for an antique. This perfect Cupid is as large as life. A.'s statue of Bacchus was thought, by Rapliael, to possess equal perfection with the masterpieces of Phidias and Praxiteles. As late as 1546. A. was obliged to undertake the continuation of the building of St Peter's. He corrected its plan, for which he chose the form of the Grecian cross, and reduced to onder the confusion occasioned by 'the various plans which had been successirely pursued in the course of its construction. But he did not live long enough to see his plan executed, in which many alterations were made after his death. Besides this, he undertook the building of the Campidoglio (Capitol) of the Farnese palace, and of many other edifices. His style in architecture is distinguished by grandeur and boldness, and, in his ornaments, the untamed character of his imagination frequently appears, preferring the uncommon to the simple and elegant.-His poems, which he considered merely as pastimes, contain, likewise, convincing proofs of his great genius. They are published in several collections, but have also appeared singly.-One of the greatest historians of our time has suggested, that a king of Italy, such as Machiavelli wished him, and every reflecting Italian must wish him, in order to unite that unhappy country, ought to be a man like Michael Angelo-andent, severe, firm, and bold. Michael A., though of a lofty spirit, was not haughty; he is said to have been in the habit of giving models for the images of saints to the engravers in wood, and the dealers in pictures and casts. His prose works, consisting of lectures, speeches, ciccolate, that is, humorous academical discourses, are to be found in the collection of the Prose fiorentine, and his letters in Bottari's Lettere pittoriche. (See the Vita di Michelangelo B., scritta da Ascanio Condivi, suo Discepolo; Rome, 1553, 4 ; Florence, 1746 , fol., with addit.; the last edition, Pisa, 1823, with comments by the cav. de Rossi.)

ANG ERSTEN, John, Julius, a distinguished patron of the fine arts, was born at St Petersburg in 1735 , and went to England under the patronage of the late Andrew Thompson, with whom he continued in partpership upwands of 50 years, A. first proposed a re- wanl of $£ 2000$ from the fund at Ilosd's to the in ventor of the life-bonts. His celebrited collection of paintiugs has beeu purchased siuce his death by the British goverument, nt the expeuse of $£ 60,000$, as the nucleus of a national gallery. Mr A. died at Woodlank, Blackhenth, January 22, 182\%.

Angerstian Gallery. See National Gallery.

AvGLe; the inclination of two lines: 1 , or two straight lines. Augles are ineasured by arcs of a circle, the centre of which is the point where both the sides of the angle meet, the vertex, $n$ it is called in geometry. Every circle, large or small, is divides] into 360 degrees, each degree imto 60 minutes, each minute into 60 seconds. It is, therefore, clear, that the size of the angle has nothing to do with the length of the lines, becanse ouly their inclination is measured. An augle of 6 degrees, 2 nimutes aud 3 seconds is written thus: $6^{\circ} 2^{\prime} 3^{\prime \prime}$. Angles are divided into right angles, equal to $90^{\circ}$, four of whicl are equal to the whole circle; obtuse angles, those greater than $90^{\circ}$; and acute angles, those which are less. 2. There are, also, spherical angle's and solid au:gles; the former formed by arcs, the latter by planes Whole sciences are based on the theory of angles, e.g., trigonometry. The calculations of the astrono mer, and the measuring of distant objects, depend on the science of triangles, which, in fact, is nothing else but the science of angles. The ancients writ: acquainted with the theory of angles. In fact, geometry, and, one might almost say, mathematics began with the science of angles.

ANGLEs; a German nation, which resided in what is now the dukedom of Magdeburg, in Prussia, near the Elbe, and, probably, succeeded to the former seat of the Lombards, when these latter had driven the Cherusci from the northern half of their country. As they never approached the Rhine and the Romai frontiers, we do not find their name mentioned by the Roman authors, who comprehended them, with many others, under the general name of Chauci and Saxons, until the conquest of Britain made them better known as a separate sation. In the 5th celltury, they joined their powerful northern neighbours. the Saxons, and, under the name of Anglo-Saxons, conquered the country now called England. (See Great Britain.) A part of them remained near the Danish peninsula, where, to the present day, a small tract of land, on the eastern coast of the duchy o Sleswic, bears the name Angeln.

Avglesea, or Axglesey (ancient Mona); an island and county of North Wales, in the Irish sea, sefrirated from the main land of Britain by a narrow strait called Menai, over which there has been lately erected a magnificent suspension bridge. (Se'e Ifenai.) The island is 24 miles long and 17 broad, containing 4 market-towns and 74 parishes. Sq. miles, $40 \%$; population, 37,045 . The soil is fertile, the chief products are grain and cattle. Of the for mer, about 100,000 bushels are exported in favourable seasons. It returns two members to parliament. AsGLING; the art of ensnaring fish with a look, which has been previously baited with small fish, worms, flies, \&c. Among no people has this art attracted so much attention, and nowhere have so many persons of all classes, both clerical and secular, resorted to angling as an amusement, as in England, whose literature is richer than that of any other country in works relating to this sport, both in prose and verse. A similar fondness for angling exists in the United States. In both countries, in England and North America, angling is followed by many sports. men with a kind of passion. In England, it has been thought of sufficient importance to be protected by statute; and a series of acts, from the reign of Edward I. to George III., exists, relating to angling" 
anl fisling. In the United States of America, angl- them well, that the hair at every link may be of equal ing, like all other kinds of sport, is free to every body. In a rude state of society, angling was resorted to from necessity. This occupation soon became an amusement for those who had leisure enough to spend time in it, as it affords to most people uuch pleasure. We find occasional allusions to this pursuit among the Greek writers, and throughout the most ancient books of the Bible. Plutarch mentions an amusing anecdote of Antony's unsuccessful angling in the presence of Cleopatra, and a fine trick which she played him. It is said that angling came into repute in England ahout the period of the refomnation, when both the secular and regular clergy, being prohibited by the common law from the amusements of lunting, hawking, and fowling, directed their attention to this recreation. The invention of printing aided in drawing attention to this subject, and made known its importance " to cause the helthe of your body, and specyally of your soul," as the first treatise concludes. W ynkin de Worde gave the world, in 1496, a small folio republication of the celebrated Book of St Albans. It contained, for the first time, a curious tract, entitled the Treatyse of Fyshinge wyth an Angle, embellished with a wood-cut of the angler. This treatise is ascribed to dame Juliana Berners or Barnes, prioress of a nunuery near St Alban's. "The Angler," she observes, "atte the leest, hath his holsom walke and mery at his ease, a swete ayre of the swete sauoure of the meede floures that makyth him hungry; he hereth the melodyous armony of the fowlls, he seeth the yonge swannes, heerons, duckes, cotes and many other fowles, with their brodes, whych me seemyth better than alle the noyse of houndys, the blastes of hornys, and the scrye of fowles, that hunters, fawkeners and foulers can make. And if angler take fysshe, surely thenne is there noo man merier than he is in his spyryte." Walton's inimitable discourse on angling was first printed in 1653, in an elegant duodecimo, with plates of the most considerable fish cut in steel. This edition and three subsequent ones consisted wholly of what is now called part the first of the Complete Angler, being Walton's individual portion of the work. For the benefit of young sportsmen, we shall here lay before him, 1. A short general description of the tackle he will require; 2 . A detailed list or account of the fish usually taken by anglers in Great Britain; and, 3. A table, which forms a summary of the art, and in which various baits are included, not mentioned in the list.-Tackle for Angling.- In the choice of his rod the angler will generally be directed by local circumstances. The cane rods are lightest; and where fishing-tackle are sold, they most commonly have the preference; but in retired country places, the rod is often of the angler's own manufacture, and he should, at any rate, be capable of supplying himself with one upon an emergency. No wood, as a whole, is better adapted for this purpose than the common hazel ; and if to this he can add a sound ash stock, or bitt-end, and a whalebone top, he is as well furnished with materials as he need desire to be. Salmon rods are sometimes wholly made of ash, with a whalebone top. Other rods may be formed thus:-a yellow deal joint of seven feet; a straight hazel joint of six feet ; a piece of fine grained yew, tapered to a whalebone top, and measuring together about two feet. Always carry a jointed rod, when not in use, tightly looped up. The line, like the rod, should gradually diminish toward the further extremity ; and no materials exceed strong clear horse hair. If yon make it yourself, the hairs from the middle of the tail are best, and those of a young, and healthy, grey, or white stallion; sort size with each other; and if you wash them, do not dry them too rapidly. For ground fishing, lorown or dark hairs are best, as resembling the colour of the bottom. Silk lines are more showy than useful. They soon rot and catch weeds. Your hook shonld readily bend without breaking, and yet retain a sharp point, which may be occasionally renewed by a whetstone. It should be long in the shank and deep in the bed; the point straight, and true to the level of the shank; and the barb long. From the difficulty of tempering and making them, few anglers ever undertake tlie task. Be careful to provide, yourself with a variety accordingly. Their sizes and sorts must, of course, entirely depend on the kind of fish for which you mean to angle. Floats are formed of cork, porcupine quills, goose and swan quills, \&c. For heavy fish, or strong streams, use a cork float; in slow water, and for lighter fish, quill floats. To make the former, take a sound common cork, and bore it with a small red hot iron through the centre, length ways; then taper it down across the grain, about two-thirds of the length, and round the top, forming it, as a whole, into the shape of a pear. Load your floats so as just to sink them short of the top.Fish usually taken by anglers in Great Britain.-The Barbel, so called from its four barbs, two of which are at the corners of its mouth, and the others at the end of its snout, is a heavy, dull, fish, and gives very inferior sport to the angler, in proportion to his size and strength. They begin to shed their spawn about the middle of April, and come in season about a month or six weeks after. In their usual haunts, among weeds, \&c., they are fond of rooting with their nose like the pig. In summer, they frequent the most powerful and rapid currents, and settle among logs of wood, piles, and weeds, where they remain for a long time apparently immovable ; during the winter time, they return to deep bottoms. The most killing baits for the barbel are the spawn of trout, salmon, or indeed of any other fish, especially if it be fresh, respecting which, the barbel is very cunning ; the pastes that imitate it must, therefore, be well made, and of fresh flavour. It is also an advisable plan to bait the water over night, by spawn or a quantity of cut worms. The barbel will also bite well at the cobworm, gentles, and cheese, soaked in honey. The rod and line, with which you fish for barbel, must both be extremely long, with a running plummet attached to the latter, as they swim very close to the bottom. By a gentle inclination of the rod, you may easily ascertain when there is a bite; immediately upon which the fish should be struck, and seldom escapes, unless he break the line. The Bleak, or Blay, is a common river fish, so called from its bleak or white appearance, that spawns in March ; and is fond of many of the baits for trout. It is usually caught with a small artificial fly of a brown colour ; and the hook should be suited in size to the fly. The bleak seldom exceeds six inches in length; its flesh is highly valued by epicures, and beads are made of its scales. Bream shed their spawn about midsummer, and although they are occasionally niet with in slow running rivers, are reckoned a pond fish, where they will thrive in the greatest perfection; and have been known to weigh from 8 to $101 \mathrm{bs}$. In fishing for them, the angler should be very silent, and take all possible care to keep concealed from the fish, which are angled for near the bottom. His tackle also must be strong. This fish, according to Dr Shaw, is a native of many parts of Europe, inhabiting the still lakes and rivers, and sometimes found even in the Caspian sea. Bull head, or Miller's thumb, is a small ugly fish, which hides itself in brooks and rivers under a gravelly bottom. They 
spath in April, and their average length is from four to five inches. When their gill funs are cut off they serve as good baits for pike and trout, and, like the cray fosh, when boiled, their flesh turns red. Carp is a fish, that by its frequency of spawning, and quickness of growth, is grently used to stock ponds, where it thrives better, and lives longer than in rivers. Gesner spenks of one who lived to 100 years old; there is much donbt about its general age, but it is supposed to be a very long lived fish. 'They spawn thiree or four times a year, but the carliest time is about the coinmencement of May. They are observ(1) to live uncommonly long out of water, and in Holland are frequently kept alive for three weeks, or a month, in a cool place, by being liung with wet noss in a net, and fed with breal, steepea in milk. In angling for carp, it is necessary to make use of strong tackle, with a fire gut next the hook, and a float formed of the quill of a goose. They bite alinost close to the bottom, and are marely caught if angled for in a boat. From its subtlety, it has been sometimes called the water fox. The river carp is accustomed to haunt in the winter, the most quiet and broad parts of the stream. In summer they live in deep holes, reaches, and nooks, under the roots of trees, and among great banks of weeds, turtil they are in a rotten condition. The pond carp loves a rich and fat soil, and will seldom or never thrive in cold liungry waters. The carp pouds of Germany yield a considerable income to the gentry. The $C h u b$, or Chevin, is, like the perch, a very bold biter, and will rise eagerly at a natural or artificial fy. They spawn in June, or at the latter end of May, at which time they are easily caught by a fly, a beetle with his legs and wings cut off, or still more successfully by a large suail. When they are fished for at mid-water, or at bottom, a float should be made use of ; when at top, it is customary to dip for them, or to use a fly, as if a trout were the angler's object. Strong tackle is also requisite, as they are a heavy fish, and usually require a landing net to pull them out. 'Their average length is from ten to fourteen inches. Dace, Dart, or Dare, are a rery active and cautious fish and rise to a fly, either real or artificial. It is necessary, in angling for them, to remain in concealment as much as possible. They spawn in February and March, and their flesh is but inferior in point of flarour. They frequent gravelly, clayey, and sandy bottoms, leaves of the water lily, and deep holes, if well shad$\mathrm{ml}$ In sultry weather they are frequently caught in the shallows; and during that period, are best taken with grasshoppers or gentles. In fishing at bottom for roach and dace, whio are similar in their haunts and disposition, bread soaked in water, and kneaded to a good consistency, and then made up together with bran into round balls, and thrown into the place where it is proposed to angle, will be found very serviceable, but must always be thrown up the stream. There is a mode of intoxicating dace, and by this means rendering them an easy prey; but this is no part of the real angler's sport. The Thames is wel] known to abound in dace, and the graining of the Mersey is thought to be a rariety of the same species. The Eel is rarely angled for, but it is usually caught by the process of suiggling or bobbing, with night lines, \&:c. Being fond of quiet in the day time, all who expect much sport in eel fishing must derote their evenings and even whole nights to the pursuit. The method for sniggling for eels is as follows:Take a common needle, attached in the middle by fine waxed twine a packthread line, or a strong small hook fixed to this kind of line; place a large lobworm, by the head end, on your needle or hook, and draw him on to his middle; affix another needle to the ead of a long stick, and guide your bait with it into any of the known haunts of the fish, between inill boards, or into clefis of banks or holes, holding the line in your hand; now give the cel time to gorge the bait, and the'n by a sharp twiteh fx the needle across his throat, or the hook into his body; tire him well, and your triumph is certain. Althongh this is not strictly a methad of angling, the lovers of that sport will find it so successtul a mode of diversifying their pursuits, where eels are commou, that the pre sent appeared the most convenient place to insert it. Hobbing is a rough species of angling. The best method is to provide yourself with a cunsiderable number of gook-sized worms, and string them from heal to tail, by a needle, on fine strong twine, viz. to the amount of a pound, or a pound and a half in weight. Wind them round a card into a dozen or fifteen links, and secure the two ends of each link by threads. Now tie a strong cord to the bundle of strung worms, about a foot from which put on a bored pluminet, and angle with a line from two to three feet long, attached to a stout tapering pole. Erls, and perhinps pike, are found in no part of Great Britain in such numbers or variety as in the marsliy parts of the counties of Cambridge and Lincoln. The silver eel is the finest, and is very common in Scotland. The manner in which this fish is propagated, lus long been a matter of dispute. They liave neither spawn nor melt, as known organs of generation. W'alton gravely argues for their being bred of corruption, " as some kind of bees and wasps are ;" others strongly contend for their being viviparous. It is a subject, indeed, upon which naturalists liave no certain iuformation. The lamprey, "a lambendo petras, from licking the rocks," says the quaint author of the Worthies of England, is a species of eel variously esteemed. In Worcestershire and Gloucestershire, the Severn lamprey is regarded as a luxury ; and, by the city of Gloncester, a pie made of this fisl is annually presented to the king. In the north of Grent Britain it is much disliked. Eels bite in a shower, and in windy, gloomy weather, at the lob aud garden worm, designed for other fish, particularly trout. Unlike other fish, they are never out of season. They are a very greedy fish, and if you wish to angle for them in the ordinary way, they will take a lamprey, wasp grubs, ninnows, \&c., but particularly the first. The Pinnock, or Hirling, is a species of sea trout which usually attains the length of from 9 to 14 inches, and is principally known in Scotland; the whitling, another species, is from 16 to 24 inches long. They will both rise equally at an artificial fly, but require generally a more showy one than the common trout. The Grayling, or Umber, spawns in May, and is in the best condition in November. They will greedily take all the baits that a trout does, and frequent the same streams. They are said to have the fragrant smell of the plant Thymallus. Their average length is from 16 to 18 inches; and they must be angled for with very fine tackle, as they are a remarkably timid fish. When hooked, they must also be cautiously worked, as the hold in their mouth easily gives way; but they will speedily return to the bait. It is fine eating, unknown to Scotlaud or Ireland. The Gudgeon is a fish in some request, both for its flavour and the sport it affords to the inexperienced angler. It is very simple, and is allured with almost any kind of bait. It spawns two or three times during the year; is generally from 5 to 6 inches long, and fond of gentle streams with a gravelly bottom. In angling for gudgeon, the bottom should be previously stirred up, as this rouses them from a state of inactivity, and collects them in shoals together. Some anglers use two or three hooks in gudgeon fishing A float is always used, but the fish should not be struck on the first motion of it; as they are acous- 
tomed to nibble the bait before they swallow it. It frequently happens, that in angling for gudgeons, perch are caught. The Loach, or Groundling, sheds its spawn in April, and remains in the gravel; where the'y are usually caught with a small red worm. They are principally found in the north of Great Britain, and in the streams of the mountainous parts. They are about three inches in length ; and their flesh is pleaoant and wholesome. The Minnow or Minim, one of the smallest river fish, seldom exceeds two inches in length. They spawn generally about ouce in two or three years, and swim together in shoals, in shallow waters, where they are very free, and bold in biting. 'They serve also as excellent baits for pike, trout, chub, perch, and many other fish which prey upon and devour them greedily. Mullet take almost the same haits as the trout, and will rery eagerly rise to an artificial fly ; they are considered free bitcrs, and come and go with the tide. If artificial flies are made use of, their size should be larger than those generally used to insuare the trout. They are found in their greatest perfection, in the river $\Lambda$ run, Sussex ; but are seldon or never seen in Scotland. The Par, or Sumlet, is a fish that is known by different names in different parts of Great Britain. On the river Wye it is usually called a skirling, in Yorkshire, a brandling, in Northumberland, a rack-rider ; and in some parts of England, a fingering, from the resemblance of its spotted streaks to the human fingers. Par, or Samlet, is its Scottish name, and in that part of Britain it is best known. Some have affirmed, that it is the bleuded spawn of the trout and salmon. This opinion is strengthened by the circumstance of their usually frequenting the same haunts with the salmon and sea trout, and their being forked in their tail like the former. The Perch is a very bold biting fish, and affords excellent amusement to the angler. He is distingnished by the beauty of his colours, and by a large erection on his back, strongly armed with stiff and sharp bristles, which he can raise or depress at pleasure. Defended by this natural excrescence, he bids defiance to the attacks of the ravenous and enormous pike, and will even dare to attack one of his own species. Perch spawn about the beginning of March, and measure from cight to fourteen inches. In fishing for perch with a minnow, or brandling, the look should be run through the back fin of the bait, which must hang about six inches from the ground. A large cork float should be attached to the line, which should be leaded about ninc inches from the hook. It must be observed, that they invariably refusc a fly. The Pike, Luce, or Jack, is a fish of enormous size, and the greatest voracity; indeed, so notorious is he for the latter quality, as to have gained the appellation of the fresh water shark. They are also great breeders. Their usual time of shedding their spawn is about March, in extremely shallow waters. The finest pike are those which feed in clear rivers; those of fens or meres, being of very inferior quality. They grow to a vast size in these last mentioned places, where they feed principally on frogs, and such like nutriment. They are reckoned to be the most remarkable for longevity of all fresh water fish; are solitary and melancholy in their habits, generally swimming by themselves, and remaining alone in their haunts, until compelled by hunger to roain in quest of food. There are three modes of catching pike : by the ledger, the trolling, or walking bait, and the trinmer. The Pope, or Ruff, is a fish very similar in its nature and appearance to the perch, and is frequently caught when fishing for the latter. They spawn in March and April, and arc taken witn a brandling, gentles, or caddis. They are extremely vorncious in their disposition, and will devour a min- now, which is almost as big as themselves. In their favourite haunts of gentle deep streams, overhung by trees, they swim in shoals together; and you may fish for them either at the top or the bottom of the water, as thcy are known to bite in alnost any weather, and in any situation. Their average length is from six to seren inches. Roach are frequently taken with flies under water. They will bite at all the baits which are prepared for club or dace, and are considered a simple and fool ish fish. They spawı in May, and turn red when boiled. The compactness of their flesh gave rise to the proverb, "Sound as a roach." The roach haunts sliallow and gentle streams, and the mouths of small streams which rum into larger ones. In angling for roach, the tackle must be strong, and the float large and well leaded. The Rud, or Finscale, is a very scarce fish, found only in the river Charwell, in Oxfordshire, and a few of the lakes of Lincolnshire and Yorkshire. It sheds its spawn in April, will take all kinds of worms, and will rise at an artificial fly. Its colour is a kind of yellowish brown, and its average length from nine to fifteen inches. Salmon are accustomed to quit the fresh waters, and retire into the sea at the approach of winter, which, at the commencement of April, they usually leave for rivers; but the Wye and Usk in Monmouthshire, and the Exe in Deronshire, have them in season during the six wintry montls. The finest species are canght in the Exe, Thames, and Tamar, but not so abundantly as in many other places. Salmon prefer more chilly streams, and arc consequently found in greater numbers northward, in the rivers of Scotland, particularly in the Tiveed, the Tyne, the Clyde, and the Tay. In the latter, they occasionally occur at the immense weight of seventy pounds; and in the 'Tweed, and Clyde, at about fifty or sixty pounds weight. They are also found in all the great streams of Europe $\mathrm{N}$, of $51^{\circ}$, and in the United States of America N. of $41^{\circ}$. Some recent accounts of the N. W. coast of America, describe them also as abounding there. In the American rivers, they seldom exceed from fifteen to twenty pounds weight. They appear some time in the rivers before they are in a healthy state; and the best season for thc angler to commence his operations, is in the close of the month of May, or the early part of June. The usual time for the salmon to deposit their spawn, is from the first of September to the latter end of October, when they grow very sickly both in appearance and flavour. Previous to this, they generally retire to brooks which branch out irregularly from the main river, or remain in shallows, where they sometimes are scarcely covered with water. During their residence in fresh water, it is a well authenticated circumstance, that they always lie with their heads pointing up the river; and never swim down the stream, unless during the period of their emigration to the sea, or when their position is molested. Tlie length of the rod for catching salmon should be frum about seventeen to twenty feet, which, however, cus be regulated according to the breadth and general size of the river in which the angler pursues his ope. rations. The rcel, which on these occasions, forms the most material appendage to the rod, is made of brass ; it should be constructed with the utmost nicety, and capable of the swiftest circumvolutions. The line, which is fastened to the reel, may be composed either of strong silk or twisted horse liair, gradually diminishing at the top, and having a loop at the end of the wheel, and another at the cast lines, to faste'n them to each other. I et this last line be very carefilly twisted with the fingers, and shorter than the rod, so that none of the knots may come within the top ring; sixteen to twenty horse hairs may be used in the upper links, but they must be diminished to- 
wand the hook, where they are best made of three small round twisted silk worn guts, or a fow strong horse hairs. Of fies, the natural ones reconmended in the tables have been used with great success. The urtificial ones should the generally of large dimensions, and of a gaudy and glittering colour. 'The materials that compose them are hairs, furs, and wools, of every variety that can be collected, mingled with the tailfeathers of cocks and game, and secured together by plated wire, or gold and silver thrend, marking silk, shoe'makers' wax, bees' wax, \&c. Their wings may be made of the feathers of domestic fowls, or any others of a showy colour. Initate principally the natural fies recommended; but you may safely indulge your fancy, rather than depart without a bite; for many anglers succeed with the most monstrous and capricious baits of this kind. $\Lambda$ raw cockle, or muscle, taken ont of the shell, prawns, and minnows, have also been recommended as salinon baits. The mode of angling with these is to drop the line, which must be totally unincumbered with shot, into some shallow which approximates to the edge of a hole of considerable depth, and in this situation to suffer it to be carried in by the current. The noviciate in angling will, at first, experience considerable diffculty in throwing his line to any great extent. For this we can give no recipe, but a most inflexible determination to proceed, and the most consummate patience in disappointment. It should always be thrumn across the river, and on the off side from the spot where you expect the fish to rise. When you imagine that the salmon has been struck, be cautious in giving him time sufficient to enable him to poach his bait, that is, to swallow it fairly and securely. After this, fix the hook firmly in him, by a gentle twitch. On the first sensation of this pain, the salmon will plunge and spring with great violence, and use every endeavour of strength and cunning to effec his escape. He will then, perhaps, rum away with a considerable length of line, which is to be kept in a gently relaxed situation, so that it may always yield with facility to his obstinate resistance : nor can you give him too much line, if you do but clear it of weeds and encumbrances. If he now becoine sullen and and quiet in the water, rouse him gently, by flinging in a few stones; and when he once more commences resistance, do not be too eager in checking his career, but let him gradually exhaust himself of his strength; follow him down the stream, or allow him to cross it; while, at every opportunity, you keep winding up your line until you approach him in this wearied state, and take him softly by the gills out of the water. The salmon peal may be caught in the same manner; he is smaller than the salmon, and seldom exceeds fourteen or fifteen inches in length. Tench, like the carp, are generally considered pond fish, although they have been frequently caught in the river Stour. They shed their spawn about the commencement of $\mathrm{July}$, and are in season from September to the latter end of May. They will bite very freely during the sultry months. Their haunts are similar to those of the carp; except that they frequent the foulest and muddiest bottoms, where they may shelter themselves among an infinite quantity of reeds; hence you must angle for them very near the bottom, and allow them sufficient time to gorge the bait. Trout are considered as one of the finest river fish that this country can produce. Its co. lours are beautifully varied at different seasons of the year, and according to the rivers it frequents. They abound in the generality of our streams, rivers, and lakes, and are usually angled for with an artificial fiy. Their weight also differs from half a pound to three some few have been caught which weighed upwards of four pounds. Trout are extremely voracious; and, by their activity and eagerness, afforl famous diversion to the angler. Previons to their spawiling, they are observed to force a passage through weirs and flood-gates against the strean; ant how they are enibled to overcome some of these impediments, is a subject of much conjecture. Their general time of shedding their spawn is about October or November; in some rivers, liowever, it is much sooner, in others later. They are also met with in eddies, where they remain concenled from observation behind a stone, or log, or a bank that projects into the stream; during the latter part of the summer, they are frequently caught in a mill-tail, and sometimes under the hollow of a bank, or the roots of a tree. In angling for trout, there are many things worthy of particular observation : 1st. That the day on which the sport is undertaken, be a little windy, or partially overcast, and the south wind is superior to all others, if it do not too much disturb your tackle. 2d. The sportsman should remain as far as possible from the stream, fish it downwards, the line never tonching the water, as the agitation proceeding from the fall might disturb the fish, and preclude all possibility of capturing them. 3d. Clear streams are famous for sport, and in fishing in them, a small fly with slender wings must be attached to the hook. When the water is thick, and the sight more imperfect from this disadvantage, a larger species of bait must of necessity be used. 4th. The line should, on an average, bo about twice as long as the rod, unless in cases of emergency, when the number and variety of trees exclude the probability of a successful throw, if at any distance. 5th. Let the fly be made to suit the season. After a shower, when the water becomes of a brown appearance, the most killing bait is the orange fy ; in a clear day, the light coloured fy; and on is gloomy day, in overshadowed streams, a dark fly. Very large trout have been killed in Ullswater, in Cumberland, and still larger in Loch $\Lambda$ we in Argyleshire. The late Mr Morrison of Glasgow claimed the merit of discovering these fish in the last-named locality, about 40 years ago, and the largest recorder to have been killed there weighing 25 pounds. Mr Lascelles, a Liverpool gentlemain, has also of late years been equally assiduous and successful in their capture; and it appears that any persevering sportsman is almost certain, with the proper tackle, to obtain specimens in Loch Awe of this great fish, weighing from ten to twenty pounds. The largest we have lately heard of weighed $19 \frac{1}{4}$ pounds. It is said to be by far the most powerful of our fresh-water fishes, exceeding the salmon in actual strength, though not in activity. The most general size caught by trolling, ranges from three to fifteen pounds; beyond that weight they are of uncommon occurrence. If hooked upon tackle of moderate strength, they afford excellent sport; but the general method of fishing for them is almost as well adapted for catching sharks as trout; the angler being apparently more anxious to have it in his power to state that he had caught a fish of sucli a size, than to enjoy the pleasure of the sport itself. Ilowever, to the credit of both parties, it may be stated, that the very strongest tackle is sometimes snapped in two by its first tremendous springs. The ordinary method of fishing for this king of trouts is with a powerful rod, from a boat rowing at the rate of from three to four miles an hour; the lure, a commun trout, from tliree to ten inches in length, baited upon six or eight salmon hooks, tied back to back upoir strong gimp, assisted by two swivels, and the wheelline strong whip cord. Yet all this, in the first impetuous efforts of the fish to regain its liberty, is frequently carried away for ever into the crystal depths of Loch Awe! 


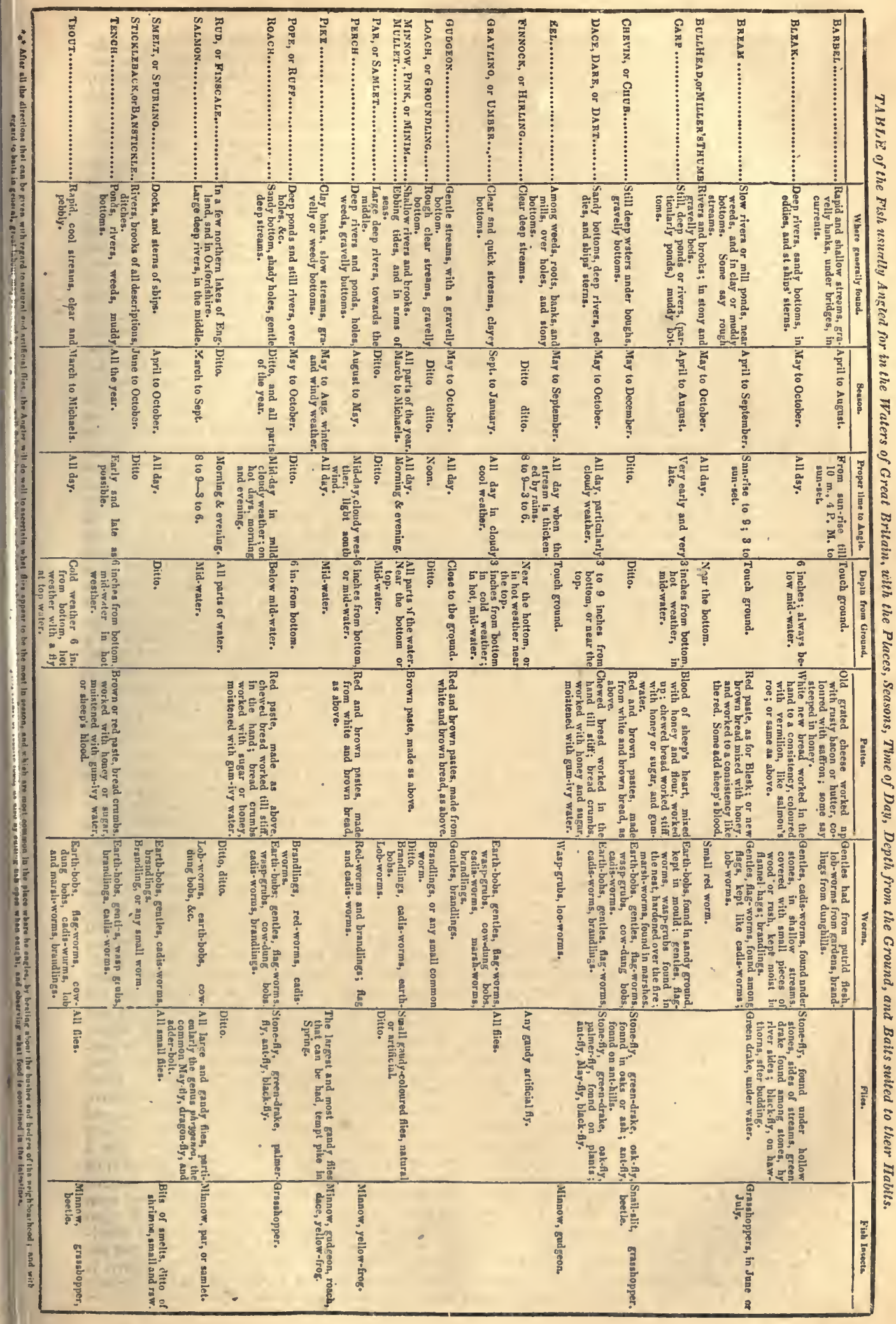


Asgro-Saxon History. (See the article England, suul, for further information, Tumer's History of the Anglo-Saxons, London, 1807 ; ulso the urticle AngloSrax in the American exlition of the New lislinburgh Fncycloparlia) - Anglo-Saxon Language; that lumguage which, in the middle of the sth century, was transplanted by the Angles, Saxous, and some other German tribes, into Fingland, and continues, though much altered, to form the basis of the modem English dialect. 'The German language was early divided into two principal dialects, the Upper and Lower German, both derivel from the Gothic, as we find it in Ulphilas' translation of the Gospels. To the Lower German belouged the idiom which was spoken by the Saxons, a numerous and valiant German tribe, who inlabited almost all the north of Germany, where this idiom prevailed, and branched outh at a later period than the migration of the AigloSaxons and Goths or Jutes, into various dialects, of which the Frisian was the earlier, the Dutch the more recent, formation. It remained the prevailing language, even after the subjugation of the Saxous in Germany by Charlemagne, and continued, down to the period of the reformation, not only the dialect of conversation, but also of several valuable literary works, in prose and verse, many of which, from the period of the middle ages, are still preserved. At the reformation, it gave way to the High German, for the purposes of literary composition and the conversation of the ligher classes; though, to this day, it eontinues to be the dialect of the people, and is known by the name of the Low German. There is no doubt that any one, who intends to investigate the Funglish language scientifically and thoroughly, trac. ing the worls, as well as the structure of the language, as far towards their origin as possible, cannot lispense with studying Low German, which has been too mucli neglected even by those eminent scholars whose investigations have done so much service to the English linguage. Few readers, probably, are aware of the striking resemblance between Low German and English, even as it is now spoken, and we feel induced to quote some lines of the famous poem Reynard the Fox (q. v.) in Low German, first published in 1498, with a literal interlineary translation into English. The poem begins thus :

\section{It shag up enex Pinkste-dag,}

It chanced upon a Pentecost-day,

Dat man de wolde un felde sag

That men the woods and fields saw

Grone stan mid lóv un grass, \&c.

Green stand with leaf and grass, \&.c.

The difference between the Low and the High German is, in many respects, striking. It is found in the words, the grammar, the promunciation, and in the whole style of expression; and it is very interesting to see how many of these deviations from the High German are common to the Low German with the English : for instance, it has not the augment ge of the participle; it often cuts off the ends of words which do not belong to the radix; and has.many more monosyllables than the High German; it makes 110 distinction between the accusative and dative ; the masculine, feminine, and neuter articles are the same; the pronunciation of $\alpha$ is, in many cases, mixed with the sound of $o$, as in the English all, and often inclines strongly to the English sound $a$ in case ; it has often an s, where the High German has sch (pronounced $s h$ ), preceding a consonant; in some parts of Low Germany, sch (pronounced, generally, sh), before a vowel, takes the sound of the English $s k$; instead of $c h$ at the end of words, it takes a $k$ or $c ;$ in an which particulars it is nearer to the English than to the High German. A deeper investigation would show the close connexion even of the Saso:s, as it now forms a part of English, with the Luw German; to say nothing of the immmerable worls which ure almost the sime in both languages. (Among other works on this subject, see $A$ Letter from Germany to the P'rincess Royal of England on the English and German Languages ; by Herbert Croft; Loudon and Leipsie, 1797.). The remarkable English pronmeiation of the $i$ is less comnon in the dialects we lave just spoken of, than in the German dialect spoken in Dantzic and Prussia l'roper. In this dialeet, the German ei (pronomeed i) and the German $i$ (pronounced ee) are uttered more in the English way than in the other German dialects. Probably this pronumciation, when the Saxon eonquerors left Germany, was common to all the dialects of the north of Germany.-After the eminuest of England by the Angles and Saxons, the Sixon became the prevalent tongue of that country, borrowing words, indeed, from the aborigines, and from the IRoman conquerors, but these were only single and detached parts, and did not constitute an integral portion of the language. From this time to the conquest of the Normans, the Saxon idiom made very considerable advances, as appears from the relics of the Saxon literature. The Saxon language of that time, moreover, seems to have been more sonorous and finer sounding than its remains in the present English tongue, in the same manner as the moderi! German is of a less open sound, and is poorer in rowels, than the ancient was. Who does not think the worls noma, eortho, urna, willa, finer than their successors, name, earth, our, will? It is strange to see how both the German and English languages have lost many of their vowels and finer sounds, whilst, at the same time, the Italian language has always had a decided tendency to soften and euplionize all the materials left from the Latin. After the conquest by the Normans, the Finglish langunge exhibits the peculiar case, where languages of two different stocks are blended into one idiou, which, by the cultivation of a free and active nation and highlygifted minds has grown to a powerful, organized whole. It cannot be doubted, on the one haid, that the English language has derived great advantages from the addition of the Freneh stock, and the closer connexion with Latin, and all the lauguages of Latin origin, thus effected; but, on the other hand, this addition could not fail to prove injurious in some respects, of which we will here mention only two, -1 , that the power of formation, of composition and decomposition, in which all the German idioms nearly resemble the Greek, has been, in a considerable degree, lost, so that we now very often find a word common to both languages, German and English, but in the former putting forth many branches, and giving birth to a whole tamily of words for the different shades of one idea or many connected ideas, whilst in the latter it has remained like a stump with no foliage; and, 2, that the English language has acquired too great a readiness to receive foreign words, without seeking, in its own store, the means of supplying the new want. In no period, perlaps, has this disadvantage appeared more strikingly than at the present, when a greater intercourse between England and France exists .than ever, and fashionable works appear full of Freneh intruders. If we consider the Saxnn stock in the present English idiom, the following cireumstances appear the most striking:-1. By far the greater part of the language is of Saxon or (to include the Danish) of Teutonic origin; almost all the verbs, particles, and other words, which form the frame of our speech, being of Teutonic descent. Mr Turner has shown this very strikingly at the end of his History of the Anglo- 
Saxons, where he gives many passages of the most eminent writers, both in poetry and prose, of different ages, with the words of Saxon origin printed in italics. Mr Duponceau, in the article Anglo-Saxon, in the American edition of the Edinburgli Encyclopædia, says, "So far as we are able to judge from a superficial investigation of the subject, we are apt to believe that the English words of northern derivation are to those derived from the ancient, as well as the modern languages of southern Europe, in the proportion of something more than three, but not quite as much as four, to one." 2. The structure of the verb and the greater part of the grammar is, fundamentally, Saxon. 3. A large quantity of Saxon words have disappeared, which were used before the Norman conquest. Mr Turter, in the work already imentioned, says, - "I found, in three pages of Alfred's Orosius, 78 words which have become obsolete, out of 548 , or about one-seventh. In three pages of his Bede, I found 230 obsolete, out of 969 , or about one-fifth." 4. In many cases, the Saxon word denotes the raw material, or the thing before it is changed by human art; e. g., ox, swine, sheep : the English word of Latin or French origin signifies the same thing after changes have been made in it by human labour; e. g., beef, pork, mutton. 5. If there exist two synonymous words, one of Saxon, the other of Latin origin, the former, on account of its grenter antiquity (as far as regards the English language), is, generally, more expressive and poetical, though the latter is frequently considered more elegant; e. g., fatherly and paternal, motherly and maternal, happiness and felicity, faithfulness and fidelity, kindred and relations, bereave and deprive, to dwell and to lodge, \&c. If the reader will take any fine passage of Shakspeare or the Bible, and change all the Saxon words for which he finds synonymes of French origin, the thoughts will appear deprived of their proper dress. This is also the reason why passages of German writers on common subjects often soind to Englishmen, who begin the study of this kindred language, as if poetically expressed, because the German words correspond to the Saxon and more poetical words of -their own language. 6 . In the English Bible, the Saxon stock prevails more than in any other English work, not only in respect to the words (many a long passage being wliolly composed $0=$ Saxon words), but also in respect to the constriction. - We may be allowed to close this article with the remarks of $\mathrm{Mr}$ Duponceau in the Encyclopredia above mentioned. "The peculiar structure of the English language," he says, "is far from having been investigated as yet with that degree of attention and accuracy that it deserves. Among other things, we do not find that any grammarian has been at the pains to take a full comparative view of its two great component parts; by wlich we mean, on the one liand, those words that are derived from the Saxon, Danish, and other northern languages, and, on the hand, those from the Greek, Latin, French, Spanish, and other idioms of the south of Europe. These two sets of vocables are so dissimilar from each other, that they, appear at first view incapable of being ainalgamated together, so as to form an harmonious whole; yet who is there that can read, feel, and understand, and does not admire the sublime harmony which Milton; Dryden, Pope, Shakspeare, Bolingbroke, and the other immortal poets and prose writers of Great Britain, have produced out of those discordant elements? To analyze, therefore, those elements, from which have resulted such inconceivable effects, is well worth the trouble of the grammarian and philologer; and the interesting discoveries, to which such an inquiry will lead, will amply repay their learned labours." We will only add, that not only would such an inquiry lead to interesting and beneficial results, but the trouble of the student would be well repaid, if he would investigate the tendency of the language at different periods, and observe how, in some, an inclination to the Saxon stock. in others, to the Latin and its derivative languages. is apparent. At present, the Saxon stock is undoubtedly most in favour, as may be seen by any one who will look into the writings of Byron; Sir Walter Scott, and other eminent writers of our time, although a disposition to make free use of French and Italian words is very observable in the intercourse of society and among secondary writers in the departments of light literature. See Low German.

Angola (formerly called Abonda, or Dongo); a country of W estern Africa, S. of Congo. In mercantile language, it includes all the coast from cape Lopez Gonsalvo to St Phelipe de Benguela, from about lat. $1^{\circ}$ to $12^{\circ} \mathrm{S}$. The principal object for which this coast is visited is the trade in slaves, of which the number annually obtained is estimated, at least, at 40,000. Loanda, or St Paul de Loanda, is the principal Portuguese establishment for obtaining negroes. The Portuguese settled there in the middle ages. A remarkable range of mountains commences at the southern limits of Angola, now cape Negro, and runs up the interior in a N. E. direction. Large herds of wild cattle and mules adorn the plains, whilst lions, tigers, elephants, \&c., infest the surrounding country. Vegetation is extremely luxuriant in $\mathbf{A}$.

Angostura (S. Tomas de Angostura); a town of South America, in the republic of Colombia, 700 miles E. of Santa Fe de Bogota, on the Oronoco river ; known by the congress held here.-The second congress' of Venezuela, commonly called the congress of Angostura, was installed in the city of St Tomas de A., Feb. 15, 1819, and the 9th year of the independence of Venezuela. 'Twenty-six deputies assembled at that time, being four short of the number of which it was intended to consist, but sufficient to constitute a quorum. There were five from the province of Caraccas; four from the province of Varinas; five from the province of Barcelona; four from the province of Guiana; four from the province of Cumana; and four from the province of Margarita. The session of this congress was opened with an elaborate address from the supreme chief, Bolivar; afier which, the deputy Francisco Antonio Zea was elected president. 'This congress had the honour, eventually, of proposing and effecting the union of New Grenada and Venezuela into one government, under the name of Colombia, by the fundamental law of the republic, dated Dec. 17, 1819. Its sessions terminated Jan. 15, 1820, arrangements being previonsly made for assembling the first general congress of Colombia at Rosario de Cucuta, on the Ist of Jan., 1821. (See Colombia, Rosario de Cucuta.)

ANGodleme; a city of France, the capital of the department of Charente, 60 miles from Bordeaux. The irihabitants are about 14,000 , and carry on a considerable trade in paper. Lon. $9^{\circ} 14^{\prime} \mathrm{E}$. ; lat $45^{\circ}$ $39^{\prime} \mathrm{N}$. Before the revolution, it was the capital of Angoumois. Balzac and Ravaillac were born here. Angora, Angyra, or Angovra; a populous city of Natolia, 212 miles from Constantinople, and one of the neatest and most polished towns of Asia Minor. The inhabitants, the number of whom is not ascertained, are composed of Turks and Christians. It formerly was much more extensive, and its population, perhaps, double that of recent times, having been reckolled at 80,000 souls. The town stands oil an eminence, and is surrounded by hills covered with fine garden's. It is fortified, but the walls of the city are suffered to go to decay. A. was, at one time, 
a place of great trade, and the inhabitants still maintain a considerable maunfacture of yaru, Angorn stuffs and shawls. It is supposed that not less than 15,000 picees of these latter articles are searly made in the city. The shawls are peculiarly fine, rivalling even those of Cashmere, and fabricated from the hair of the $A$ ugorn goat. The surrounding country is chiefly devoted to the raising of wheat. Opium, however, is cultirated in the clistrict, and large quantities of honey and wax are obtained from the extensive beehives in and near the city. A. stands on the very site of the ancient Ancyra, in E. lon. $33^{\circ} 18^{\prime}, \mathrm{N}$. lat. $40^{\circ} 4^{\prime}$. Numerous caravans continually pass through this city.

ArGRA; \& seaport on the S. side of Terceira, one of the Azores, of which $A$. is the capital ; lon. $27^{\circ} 14^{\prime \prime}$ W. ; lat. $38^{\circ} 38^{\prime} \mathbf{N}$.; pop. 11,000 . 'The town is well built, and has five parislses, a cathedral, four monasteries, and as mauy nunneries. It is defended by a strong castle and deep ditch. King Alplionso VI. was inprisoned in this castle by lis brother, Peter II. in 1668. 'The town derives its mame from angra, a creek, Iay, or station for shipping; this bay beiug the only convenient $h$ urbour in all the Azores. The English, French, and Dutch have consuls residing here.

Angoilla; the most northerly of the Caribbee islands, so named from its form. It was discovered in $\mathbf{1 6 5 0}$, by the English. In 1745, the militia defendol it against the French. Some sugar is raised here. Lon. $63 \circ 10^{\prime} \mathrm{W}$.; lat. $18^{\circ} 15^{\prime} \mathrm{N}$. - There is a rocky island of the same name, one of the smaller Bahama or Incayos islands; twenty miles long, five broad; lon. $78^{\circ} 50 \mathrm{~W}$.; lat. $23^{\circ} 36^{\prime} \mathrm{N}$. - Anguilla bay lies on the north side of the island of St John's, in the gulf of St Iawrence, opposite the Magdalen isles.Anguilla cape; a promontory on the west side of Newfoundiand, in the gulf of St Lawrence.

Asceisum Ovos, the adder-stone; a fabulous kind of egg, said to be produced by the saliva of a cluster of serpents, and possessed of certain magical virtnes. The superstition in respect to these was rery prevalent among the ancient Britons, and there still reInains a tradition of it in Wales. This wondrous egg seems to have been nothing more than a bead of glass, used by the Druids as a charm to impose on the people, whom they taught to believe that the possessor of it wonld be fortunate in all attempts. The unethod of ascertaining its genuineness was no less extraordinary than the powers attributed to it. It was to be enchased in gold, and thrown into a river; and, if it was genuine, it would swim against the stream. Pliny gives a similar account of it, lib. xix. c.3.

AxHalt ; under this name, the possessions of three different dukes-those of Anhalt-Bernburg, AnhaltCotlien and Anhalt-Dessau - are compreliended. Before the right of primogeniture was introduced, in the succession of the German princes, this little country was divided into four hereditary sovereignties, lout was afterwards reduced to the above-mentioned three. In April, 1807, the princes of A. took the title of duke. 'The house has, at present, joined the German confederation, and, together with Oldenberg and Schwarburg, has the fifteenth vote in the diet; in the general assembly (plenum), however, each of the three houses has a separate vote. Each enjoys sovereign power in its own division, fet the three together form a confederation, by the terms of which the right of mutual succession is secured to the lines respectively, and the assembly of the states, as well as the public debt of the family, put under the direction of the senior member of the house for the time being, at present the duke of Bernburg. 'The ducal house bears a common title and arnis, and professes the Cal vinistic faith. 'The greater part of the inhabitauts, also are of the same persuasion. Towards the close of 1825, however, the duke and duchess of Cothen went over to the Catholic chnrch at l'aris. There are also anoug the inluabitants many I utheraus and a few Jews. The lands of the house of A., comprising abont 1030 square miles, with 128,100 inhabitants, are mostly situated betreen the Hartz and the river Flbe, and are surrounded by the Prussian province of Saxouy; they are fertile. The inhabitants are wealthy, and live partly by agriculture and grazing; but, in the vicinity of Bernburg, also by mining. The manufactures are unimportânt.

ANHYDRITE; a dry sulplate of lime, found in the salt-mines of Austria and Salzburg, and in limestone at Lockport, New York. It presents several varicties of structure and colour. The vulpinite of Italy is the only one used in the arts. This possesses a granular structure, resembling a coarse-grainet marble. Its colour is greyish-white intermingled with blue. It is cut and polished for various oruamental purposes, under the name of marmo barliglio di Bergamo.

Asıch, Peter ; a 'Tyrolese peasanit, astronomer and geographer; born in 1723, at Oberporfess, near Inspruck; died in 1766. 'Till twenty-right yenrs old, lie was, like his father, a farmer, but very early became an admirer of the sciences. The Jesuits in Inspruck perceived his talents, and gave him instruction in mechanies and mathematics. This was sufficient to induce the young inan to undertake the making of a celestial globe, of a terrestrial globe, and of many mathematical instruments. When his teacher, a Jesuit, observed the success of his labours, he recommended him to the empress Maria Theresa, who ordered lim to draw a map of the northern Tyrol. Tlie superstition of lis countrymen made his labours difficult, and even endangered lis life. Finally, the map was finished; but it was fomd, in Vienna, that it had been executed on too large a scale, and lie was commanded to reduce it to nine sheets. This reduction cost hin much labour, and lie died before completing it, Sept. 1, 1766. In 1774, the map finally appeared, under the title Tyrolis geographice delineala a Petro Anich et Blasio Huever, curante Ign. Weinhart.

Anchusi, Luigi; a famous seal-engraver, in the time of Michael Angelo. He was a native of Ferrara. His Interview of Alexander the Great vith the High-priest at Jerusalem, was declared by Michacl Angelo to be the perfection of his art.

Anısa MUNDi; the soul of the world or universe; a certain pure, etherial substance or spirit, which was said, by some ancient philosophers, to be diffused throngliout all nature-the living principle of the world, the god of the Pantheists. Plato treats at large of the yuxn rou norpou, the soul of the world, in his 'Timaus. He is considered, by some, the originator of this idea, but this is not at all probable; on the contrary, it is an ancient idea, prevailing in the systems of certain Eastern plilosophers. The Egyptians also adopted it. Many plilosophical aud philosophico-religious sects entertaincd the same no. tion, under a considerable diversity of forms. Many of the first Christian sects believed in the anima mundi; and at all times there have existed estimable and religious men and philosophers, who could not believe in a God who exists without the material world but pervades it every where. Of the most recent philosophers, Schelling has dwelt most on this idea, and incorporated it into his whole system. He calls it Die Weltseele. (Sce Philosophy.)

Antanl, Animal Life. Life, in the earlier periods of natural history, was attributed only to animals. With the progress of science, howerer, it was extended to plants; and man, who had been hitherto regarded as a distinct order of being, was now considered as but a higher animal, intimately connected 
with the whole chain of the organized world. The great discoveries in chemistry, magnetism, electrieity, and galvanism, have shown that those elements and principles on which rest the laws of life, prevade nature in the most various forms and combinations ; that there is no harsh and abrupt distinction between the animate world and the inanimate, but, on the contrary, an intimate connexion between the energy which makes the crystallizing mineral follow the law of the strictest regularity, or the stone fall fiom the height, and that which makes the heart of man beat.-The difficulty of defining animal life has, therefore, been greatly increased. What is animal life? What constitutes an animal? Since mankind began to cultivate philosophy, they have sought in vain for a definition of life. It would require much more metaphysical discussion, to enter at all satisfactorily into this subject, than the character of the present work allows ; and we are constrained to offer the reader only the following remarks on this most interesting subject. - Linnæus defines an animal an organized, living, and sentient being. An animal is indeed organized; but are not vegetables organized also? Animals are endowed with sensation; but are all, without exception? and do not some plants possess this faculty? Locomotion is not a more certain characteristic of animals than life or irritability, for many animals are destitute of this power, and vegetate like plants, the images of torpidity and inseusibility. Neither are the chemical characters of animal substances more distinct; animals are chiefly composed of azote, and vegetables of carbon; but, among the latter, some are, like the former, composed principally of azote. In whatever point of view we cousider these two kingdoms of nature, we find them blended in so many ways, and separated from each other by such imperceptible gradations, that it is impossible to draw a line, at which we can affirm that animal life ends and the vegetable begins. We cannot, therefore, give a rigorous definition of the animal kingdom, but we may point out certain general characteristics, which clearly distinguish this fiom the other kingdoms of nature. There are two kinds of motion in animals, one of which is voluntary, and the other mechanical. The latter is involuntary, and belongs to the regetative life of the aninal. By this the vital actions are carried on independently of volition. By this the heart beats, the blood circulates, the food is assimilated. The former is voluntary, and is peculiar to animal life ; it cannot exist without a nervous system, or something equivalent, by which the animal perceives and wills. However feeble the manifestations of this will may be, it nevertheless exists in proportion to the simplicity or complexity of the organization of the creature which perceives and wills. Thus the vibrio and the monas, although apparently destitute of viscera, organs, and locomotive apparatus, when they avoid or pursue surrounding objects, act by virtue of the will as completely as the lighest orders of organized creatures. One sense is sufficient to produce voluntary motion, and, therefore, to constitute animal life; the vibrio and the monas have at least one sense analogous to that of touch. 'This kind of motion may exist without locomotion, as in the oyster. 'There is no one organ which characterizes the animal kingdom; there is none which is found in all animals. The liead, the stomach, the system of circulation, in a word, all the complicated apparatus of the mammalia, for example, disappears iil other classes, or undergoes a thousand rarious combinations of form and proportion. The organ, of which the slightest injury in one animal produces iustant death, may be wounded or even extracted from another withont fatal consequences: whilst some are killed by the loss of some parts of the body, others may be cut in pieces, and each fragment becomes a perfect animal. - M. de Lamarck lays down the nine following characteristics, as common to all animals, and peculiar to them, and constituting, therefore, the distinction between theanimal and vegetable kingdoms : 1 , that they have parts susceptible of contraction of themselves, and thus the power of moving them:selves suddenly and repeatedly; 2 , that they have the power of changing place, and of acting at will, if not completely, at least to a great extent ; 3 , that they perform no motion, total or partial, unless in consequence of certain motives, and that they are able to repeat the motion as often as the exciting cause operates; 4 , that they betray no perceptible relation between the motions they perform and the exciting cause; 5 , that their solid as well as fluid parts partake of the vital motions ; 6 , that they nourish themselves with compound substances of a different nature from themselves, and that they digest these substances in order to assimilate them; 7 , that they differ from each other in their organization, and in the faculties resulting from this organization, from the most simple to the most complicated, so that their parts cannot be mutually transformed into each other; 8, that they are able to act for their own preservation; 9 , that they have no predominant tendency in the derelopement of their bodies to grow perpendicularly to the plane of the horizon, or to preserve a parallel direction in the vessels which contain their fluids. Linnæus was the first who ventured to include man in the systematic classification of animals; and though he was vielently assailed for thus degrading the dignity of the human race, he has been followed, in this arrangement, by succeeding philosophers. Cuvier has, however, assigned him a distinct order, bimana, by which means he is separated from monkeys, with whom Linnæus had classed him. Linnæus divided the animal kingdom into six classes, as follow:-*. Such as hare the blood warm and red; the heart with two auricles and two ventricles. - I. Mammalia; viviparous; suckle their young. -II.Aves, birds ; oviparous ; have neither teats nor milk. - **. Such as have the blood red and cold; single heart, with one auricle.-III. Amphilia; oviparous ; without teats, milk, hair, or feathers.-IV. Pisces, fishes; breathe by gills, a sort of external lungs; oviparous; their organs of locomotion, fins ; their covering, scales ; they emit no sound, and inhabit the water._***. Such as have a single heart, without auricles; blood cold and white, consisting of a sort of transparent lymph. (These characters liave since been found to be incorrect; for some of these animals have red blood, and some lave no heart at all.) - V. Insects; provided with antenna; breathe by lateral stigmata; all have feet, most have wings, and undergo transformations.-VI. Vermes, worms; provided with tentacula; no feet or fins. The progress of natural history has revealed some defects in the system of Linnaus. Cuvier has corrected its errors and supplied its deficiencies. His system is as follows :-*. Vertebral animals. They have an internal skeleton, composed of a series of bones attached to each other, and called the vertebral column. It is perforated by a canal containing the substance from which the nerves, or organs of sensation, take their rise. This column is terminated at one end by the head, (which is, perhaps, only a vertebra fully developed), and at the other by the os coccygis, or tail. Two cavities, the chest and the abdomen, contain the principal organs of life. The sexes are two, male and female; testicles belong to the former, ovaries to the latter; a spleen, liver, pancreas, jaws incumbent, transversal, and provided with teeth (which are imperfectly developed in the beak of birds), not more than four 
limbs, constitute the character of this class. The organization of the vertebral animals presents a striking analogy throughont.-I. Mfammalia; producing their young alive, which they suckle by teats; having warm blood; a heart with two rentricles; lungs; a convolutel brain, with a corpus callosum; five senses; a muscular eliaphragu between the chest and the abdominal cavity; seven cervical vertebre (one species excepted, which has ninc). The mammalia, anong which man is included, are gencrally the most intelligent of animals : they are divided into orders, according to the structure of their teeth and their feet, which organs determine the habits and manner of life in animals.-II. Birds, aves; oviparous; the eggs coverel with a calcareous shell ; without milk or teats; heart and blood like those of the mammalia ; lungs; no diaphragm ; no teeth apparent on the jaws, which are called the beak; feathers and wings; projecting sternum, which completes the apparatus for flying; a gizzard for a stomach; no external ear. The'se animals are the only ones which sleep standing ; they are divided into orders, accordling to the structure of the beak and fect.-III. lieptiles; oviparons; the eggs without shells, and sometimes fccundated without coition; single heart; bloor almost cold, and red. The reptiles indisputa. bly form a separate class, but they have few common characters peculiar to them; some are inclosed in a bony shell; others are raked; and others are corered with plates, scales, or rings. There are some which lave limbs; others, without the least trace of them; and others, in which the number and structure of the linbs rary. Some undergo transformations, like insects, and are, at one period of their life, real fish, and for the rest of their days, little quadrupeds.-IV. P'isces, fish; oviparous; eggs without shell or albuminous envelope, and fecundatel without coition; single lieart; blood cold and rerl; no real limbs, their place being supplied by vertical fins: this vertical disposition of the fins is sufficient to distinguish, at the first glance, fshes from the cetaceous animals, which have horizontal fins; the borly is naked, when not covered with scales; the skeleton is destitute of solidity, and, in the lower species, is reduced to a inere cartilaginous vertebral column._**. Mollusca; no skeleton; the muscles attached to a soft skin, which is sometimes naked, and sometimes covered with shells of very various forms. The nervous system, in these animals, is confounded with the other parts; none of the organs is protected by a bony case ; the nervous system is composed of several ganglia, a sort of little brain, connected by sensitive flaments. 'The organs of nutrition and generation are very complicated in some; they appear to have but two senses, touch and taste, but some have also sight; they breathe by gills, and have sometimes tliree liearts. Cuvier divides the mollusca into six orders: the cephalopoda, pteropoda, gasteropoda, acephala, branchiopoda, and cirrhopoda._***. Articulated. Their nervous system is composed of tro long cords, running the whole length of the body, interrupted, at interrals, by knots, or ganglia, the first of which is always the largest ; the blood is cold, generally a white lymph, except in the first order, the annelides, in which it is red. The body and limbs, when they have any, are composed of rings. This great division will probably undergo some modifications hereafter.-I. Annelides; heart fleshy, visible; blool red; breathe by gills, the position of which is various ; body composed of articulated rings; no feet, sometimes threadlike members in their stead. The annelides are hermaphirodites, and probably oviparous.-II. C'rustaceons; heart composed of one fleshy ventricle; blood white, circulates; breathe by gills; provided with antenne, commonly with four, and several transverse jaws; they are oviparons, and the sexes are distinct.-III. Arachnides, spiders; hend and thorax united; no antenne, nor gills; breathing by tracliex, or by pulmonary bars ; distinct sexes ; ' 'ggs; the young undergo no complete transformation after they are hatched, number of eyes and fret variable.IV. Insects; 110 heart; lymph instead of blook; breathe by trachea; body divided into three injortant parts,-the hend, which supports the antenure, and compound eges, consisting of numerons facets; the thorax, to which are attaclied the feet, to the number of slx, and the wings, to the number of four or two; finally, the abdomen, containing the principal viscera : sexes distinct; oviparous ; generate by copulation; the young undergo wonderful transformations. Insects propagate but once during their life. They are divided into orlers, according to the structure of the moutl, of the tarsis or foot, of the antenmæ, and of the wings.-****. Racliated. 'This class is distinguished from the three preceding almost entirely by negative characters, the animals incluled in it having few claracters in common. Alourtions of nature, provided only with the incipient forms of organization, they show no traces of cliculation, no organs of sense, no distinct nervous system: the organs of respiration are indistinct; those of digestion sometimes complicated, sometines consisting only of a sack without an outlet; sometines exhibiting organs, of whicl the action is visible, but the functions unknown; some of them manifest a tendency to the radiated formation, and many arc composed of rays, that is, of tentacula diverging $\mathrm{re}$ gularly from the centre to the circumference; but this character is fur from being universal, since many of this class are perfectly spherical or membranous, without the least tendency to the radiated structure. They all inhabit the water.-I. Echinodermala ; distinct organs of respiration and circulation; the viscera contained in an interior cavity formed by the spines disposed in rays, and sometimes star-formed ; they inliabit the sen.-II. Intestini, intestinal worms ; long body, without lizuls ; no distinct viscers, except a long digestive canal ; parasites of other animals, in whos bodies they are found; it is not known how they enter them, nor is any thing known of their manner of respiration arid generation. - III. Acalephe, sen-netthes; body orb cular or radiated, containing a digestive sack ; no organs of circulation, respiration, or generation distinguislable; some of them, however, emit a substance, which might be taken for eggs, and which, when touched, excites a tingling sensation in the skin, similar to that produced by nettles; the: mouth serves as an anus; they inhabit the sea.IV. Polypi; bedy soft, contractible, forming an intestinal sack, which presents the appearance of an orifice surrounded by tentacula; no appearance of organization which would lead us to suppose them endowed with any sense except that of touch; they are found only in the water, but inhabit both salc and fresh.-V. Infusoria; bodies transparent, contractible, microscopic; no organ discernible.-For the mental powers of animals, see the article Understanding.

AvimaL HeAT is that property of all animals, by means of which they preserve a certain temperature, which is quite independent of that of the medium by which they are surrounded, and appears rather to be in proportion to the degree of sensibility and irritnbility possessed by them. It is greatest in birds. The more free and independent the animal is, the more uniform is its temperature. On this account, the human species preserves a temperature nearly equal, about $96-100^{\circ}$ Fahr., in the frozen regions at the pole, and beneath the equator; and on this 
account, too, the heat of the human body remains the same when exposed to the most extreme degrees of temperature ; in fact, cold at first rather elevates, and extreme heat rather depresses the temperature of the human body. Fordyce and Blagden endured the temperature of an oven heated almost to redness, and two girls in France entered a baker's oren heated to $269^{\circ}$ Fahr., in which fruits were soon dried up, and water boiled. A Spaniard, Francisco Martinez by name, exhibited himself, a short time since, at Paris, in a stove heated to $279^{\circ}$ of Fahr., and threw himself, immediately after into cold water. Blagden was exposed in an oven to a heat of $257 \%$, in which water boiled, though covered with oil. There is also a remarkable instance of a similar endurance of heat, by the convulsionnaires, as they were called, upon the grave of St Medardus, in France. A certificate signed by sereral eye-wituesses, among whom were Armand, Arouet, the brother of Voltaire, and a Protestant nobleman from Perth, states that a woman named la Sonet, surnamed the salamander, lay upon a fire nine minutes at a time, which was repeated four times within two hours, making, in all, thirty-six minutes, during which time fifteen sticks of wood were consumed The carrectness of the fact stated is allowed even by those opposed to the abuses in which it originated. The flames sometimes united over the woman, who seemed to sleep; and the whole miracle is to be attributed to the insensibility of the skin and nerres, occasioned by a fit of religious insanity. Tliese facts are the results of a law of all living substances, viz., that the temperature of the living body cannot be raised above certain limits, which unture has fixed. There is also an increased flow of perspiration, by means of which the heat of the body is carried off. The cxtreme degrees of cold which are constantly endured by the human frame without injury are well known, and are to be explained only by this power in the living body to generate and preserve its own heat. The greater the irritability of individuals, whether from age, sex, or peculiarity of constitution, the greater the warmth of the body: it seems also to depend, in part, upon the quickness of the circulation of the blood: thus children and small animals, whose circulation is lively, feel the cold least. The heat and the power of preserving it differ also in the different parts of the body; those appearing to be warmest in which there is the most copious supply of blood, as the brain, the head and neck, the lungs and central parts of the body. We see, also, that when the irritability of the body, or of any part of it, is particularly increased, the heat of the part undergoes a similar change. Incrensed activity and motion of the hody, as in walking, running, \&c. and disenses of increased excitement, as fever and inflammation, produce a similar increase in the temperature of the body. All this justifies the conclusion, that animal heat alepends chiefly upon the irritability of the body, and is thus most intimately coninected with the state of the nervous system. This view is confirmed by the late experiments of Brodie, who ascribed this power of the living body to the influence of the brain. He destroyed the brain of a rabbit, and kept up thc respiration by artificial means; but the lieat of the animal regularly diminished.

Animal Magnetism See Magnetism.

ANImAL MATTER is the protection, the residence, and the visible form of animal life. The simple elementary substances are combined by the powers of life, according to the objects for which it was destined, into various animal substances, falling แกturally under certain divisions, which all, lowerer, in some respects, comprehend each other. These divi- sions are as follow : $-a$. FLund. These have no distiuct form or organization, and yet possess properties, by means of which, when acted upon by the vital powers, they are capable of forming all the various organs of the body; and it is surely a most unnatural view of them to regard them as destitute of life. In the following list of animal fluids, which, in the processes of life, pass constantly the one into the other, we find all the fluid parts or kinds of animal matter: they are chyme, chyle, lymph, venous and arterial blood, and the various secreted and excreted fluids. b. Soluus. These comprehend all the solid parts of the animal frame, both hard and soft, and are of nearly the same essential structure in all auimals, although variously arranged, according to their species. A minute description of all these belongs to anatomy; we shall merely enumerate them. They appear in the form of, 1, bones, constituting the basis - the frame of the animal, and found in all animals till we come to shell-fish (whose shells may be even regarded as external bones), and to still in. ferior animals, possessing no substitute for bones; 2, ligaments and fibrous membranes, connecting and covering them ; 3 , muscles, which move then, and place the body and its limbs at the command of the animal ; 4, fat and marrow, which soften and lubricatc all the various parts of the body; 5 , nervous or medullary matter, constituting the brain and nerves in which the vital power seems more particularly to reside; 6, the cellular substance, or membrane, which pervades all parts of the frame, and serves to connect them, and to furnish with the fat, which fills its cells, a soft bed for the vessels, nerves, \&c ; 7, the mucous membranes, lining the whole body, from the nose and mouth to the parts at which all evacuations take place, and thus coating the mouth, throat, lungs, stomach, and bowels, in which the important functions of digestion and respiration are performed; 8, the serous membranes, which line all the large cavities, and which, by the soft fluid that always moise tens their surface, render easy the motion of all the internal organs upon each other; 9, the vascular system, or vessels of all descriptions, conveying the blood to all the organs of the body, and returning it from them to the heart and lungs; and, 10, the glandular system, by means of which various fluids important to life are separated from the blood, or rather formed from it by a new composition of its original elements. These vaxious classes of animal matter comprehend all the various forms, in which it appears in all animals of all kinds ; the heart of a frog and of a philosopher being composed of similar muscular fibres, and their brains of sinilar nerrous natter. Theso obvious component parts of animals are, however. separable by the art of the cliemist into morc simple and uitimate elements. The following are all that are at present known to exist, and of these some are peculiar to animals, while others enter, more or less, into the composition of all parts of the creation. They are, 1, iron, which is found chiefly in the blood, in the state of an oxyde; 2, lime, which enters largely into the composition of bones, shells, \&c. ; 3, silex, in the enamel of the teeth; 4 , water, which gives their liquid character to all the animal fluids; 5 , air is found, mixed with watery vapour, in the various cavities of the body; 6 , soda, united with various acids, in all the various fluids of the body; 7 , aminonia, in the sweet urine, \&c. ; 8 , sulphur ; 9 , phosphorus, in the bones, \&c. ; 10 , carbon ; 11 , various acids, as the phosphoric, muriatic, uric, lactic, formic, \&c., which are found, variously combined, in most of the solid and fluid parts of the body; 12 , gelatin, or glue; 13 , albumen, constituting the chief part of the transparent and colourless membranes, and the fluids which moisten them; 14, fibrine, con- 
stituting the basis of all the muscles, ligaments, \&c., and the most important ingredieut in the composition of the blood. Most of these substances are again susceptible of still farther analysis, by which they may be resolved into the simple gases, as azote, hydrogen, oxygeu, \&.c. ; so that it appears, that the ultinate elements of all parts of the visible world are nearly the same in their essential character.

Avimalcola, in a general sense, demotes small animals. It is here used to denote one so minute that its form and parts camnot be distinguished without the aid of the microscope. Microscopical animals may be described as more or less translucid, destitute of members, and in which no vestiges of eyes have yet been discovered. They are contractile in whole or in part, possessed of the sense of touch, and nourish themselves exclusively by absorption. If particles of animal or vegetable matter are a few days infused in the most limpid water, on applying the smallest portion of it to the microscope, innumerable such animals of various shapes are discovered. These lave been tenominated infusory animalcules. They are also found in the mud of ditches, the scum of stagnant waters, \&c. The origin of animalcules is a point of extrene difficulty, beeause their existence seems solely dependent on the adventitious union of animal or regetable substances, and a sinple fluid. There is great reason to conclude that their germs exist, not only in the air, but also in the macerating substances, or even in the fluid itself, and are gradually unfolded according to circumstances. Among these, heat and putrescence seem the most indispensable. The degree of heat to which infusions may be exposed, and still produce animalcules, is very different. The smaller species still originate after infusions have been suljected to $212^{\circ} \mathrm{Fahr}$. in close vessels. These appear to be capable of withstanding a much greater degree of heat than the larger animalcules. Milk, blond, urine, and other animal fluids, abound with animalcules after standing a certain time, though in their natural state they do not contain them. There is no certain law with regard to the particular species produced by any particular infusion. In general, several different species will he exhibited, which disappear, and are succeeded by others; and sometimes where there are myriads of one kind, a solitary animalcule of a remote genus is found among them. Vinegar is full of minute eels, which are also found in paste. Muller conceives that the sea abounds in animaleules peculiar to itself, and Spallanzani observes, that vegetable substances dissolving in sea water, produce swarms of animalcules. The minuteness of animalcules surpasses the conception of the human mind. Leeuwenhok calculates that the size of some is to that of a mite, as the size of a bee to that of a horse; a hundred others will not exceed the thickness of a single hair; and ten thousand of a different species may be contained in the space occupied by a grain of sand. The most powerful microscopes can only discover points in motion in the fluid, gradually decreasing until they become imperceptible to the view. The shape of animalcules is infinitely diversified: one is a long slender line; another is coiled up like an eel or a serpent; some are circular, elliptical, or globular; others resemble a triangle or a cylinder. Some resemble thin, flat plates, and some may be compareal to a number of thin articulated seeds. One is like a funnel; another like a bell; others cannot be compared to any object familiar to our senses. Certain animalcules, such as the protens diffuens, can change their figure at pleasure, being somelimes extended to an immoderate length, at other times contracted to a point. One moment they are inflated to a sphere, the next completely flaccid; and then various eminences will project from the surface, altering them, apparently, into animals entirely different. Their peculiar notion is not less remarkable. In several species in consists of incessant gyration on the head as a centre, or round a particular point, ns if one of the foci of an ellipse. 'The progression of others is by means of leaps or undulations; some swin with the velocity of an arrow; the eye can hardly follow them; some drag their bodies along as if with painful exertion, an? others seem to remain in perpetual rest. Their food is not yet iudisputably ascertained. Probably it consists both of animal and vegetable mattur; and they also prey on each other. The'y propagnte by eggs, by living foctuses, and by a portion of the borly being detrched. Whetler they have any union of sexes, like the larger animals, is keenly contested. The mode of the multiplication of animalcules, hy division into two or more parts, was first oluserved by M. de Saussure. If one of the kinds of asimalcules propagating in this manner is isolated in a watch glass, the traces of a contraction around the midkle of the body becomes visible, which marks incipient division. The stricture soon increases insensibly, and the animal then somewhat resembles a blown bladder tied tight across. The contraction gradually augments, and the animalcule is at length changed into two spherules, connected by a single point. At last they separate, and two perfect animals are produced. Other kinds divide in different manners, which we have not room to describe. We will inention only the volvox globator, a globular animalcule of a greenish colour, visible by the naked eye. It is frequently found in the water of ditches and marshes abounding with growing regetables, as well as those in a decomposing state. Its mode of progression is by revolving on itself like a spliere; whence its name. This animalcule consists of extremely transparent membranaceous substances, containing minute globules irregularly dispersed within it. On examination with a very powerful magnifier, the glolules appear to be so many young volvoxes, each provided with its diaphanous membrane, and within that again is involved another race of descendants. Some olservers have discovered even down to the fifth geuera. tion in the parent; others lave not been able to se' farther than the third. When the volvoxes liave attained a certain maturity, the included young begin to move; they detach themselves from the parcut, and successively escaping from the investing mem brane, swim about. When all have left it, the common envelope, or mother, becomes motionless, bursts, and disappears. Then the new volvoxes rapidly increase in size; their included globules likewise grow, they begin to move, the parent bursts, and the young swim at large. By isolating these animals in watch glasses, the thirteenth successive generation from a single parent has been obtained. The dangers to which animalcules are exposed, infinitely exceed those attendent on the larger animals, not only from the noxious qualities imparted to infusions, but from evaporation. According to Muller, several of the larger species are destroyed, and totally dissolved, by simple contact with the air. Some he has seen decomposed on approaching the edge of a drop; and otliers, amidst the rapidity of their conrse, have been dissolved in a moment. Too much heat and cold are alike fatal to them; the anguilla of vinegar, however, can endure a great degree of cold. Doctor Power remarks that the vinegar may be frozen and thawed several times over, and they will still remain as lively as ever. Some animalcules can be revived afler the vital functions have been suspended for a long, perhaps an unlimited, time. This is the case, for instance, with the wheel animal, a singular animalcule. When the water containing this animol 
eraporates, it becomes languicl, the slape alters, and / loss of a suit aggrarated his animosity against the the animal to appearance dies. Its figure is now so king. In 1783, he received his dismission, narried duminished and distorted as to have little resemblance to the living animal. It grows dry and hard; yet the animal may still be revived, on being moistened, after days, months, and even years. It has been said, that those which have been dead for years, revive as soon as those that have been dry only a few hours. Fortana revived them after being dry for two years, The presence of sand with the water is absolutely necessary for their revival. . Animalcules are found in the seminal fluid, but in none of the other fluids of the animal body, if recent.

A.vime; a resin exuding from the trunk of a large American tree, called by Piso jetaiba, by the Indians, courbaril, a species of hymenad. 'The tree is found particularly in New Spain and the Brazils. A superior kind is sometimes imported from the Fast.

ANISE-SEEDS are the production of all umbelliferous plant (pimpinella anesum), which grows wild in Egypt, Syria, and other eastern countries. They are roundish and striated, flatted on one side, and pointed at one end; and of a pale colour, inclining to green. -Attempts were made, more than 200 years ago, to cnltivate anise in England, but the summers are seldom warm enough to bring the plant to perfection. It has, consequently, been found necessary to inport the seed from Malta and Spain, where it is cultivated to a considerable extent. Anise-seeds have an aromatic sinell, and pleasant, warm taste, accompanied with some degree of sweetness. They have long been employed in medicine, and have beei considered useful in diseases of the lungs and complaints of the stomach. They give out all their virtue to rectified spirit; and a spirituous water is kept in the shops as a cordial, which is prepared from a mixture of equal parts of anise-seed and angelica.

Axsoo; an ancient province of France, 75 miles in length and 60 in breadth, now forming, with some of the late provinces in its neighbourhood, several departments, viz., that of the two Sevres, of the Indre and Loire, the Sarthe, the Loire, but chiefly that of Mayenne and Loire, in which also the old capital is situated. The noble river Loire divided the old province. The entire district contains about 256 French square miles, and is watered by upwards of 40 rivers. A. is very fertile, producing all sorts of grain; fruits, hemp, and flax; it contains excellent pastures and rich vineyards. Much brandy is sent from hence to Nantes and Paris. A. contains, also, coal, lead, and tin. It manufactures much. The clief town is Angers, and the population was estimated, prior to the first revolution, at upwards of 90,000 families. St Louis bestowed this province on his brother Charles, in 1246; but, in 1328, it again fell to the crown with Philip IV. John I., raised it to the rauk of a ducal peerage, and gave it to his son, Louis I; but, in 1488, it reverted once uore to the crown. Different princes of the blood bore, subsequently, the title of Anjon, till Lontis XV. conferred it, together with that of Provence, on his grandsol1, Louis Stanislans, count of Provence, afterwards Louis XVIII. (See the history of France in the article France.)

Avkre, a liquid mensure at Amsterdam, forming about $10 \frac{1}{4}$ gallons Fnglish wine measure.

Ank frstres, Jolın Jacob, the murlerer of Gustaviis 11I., was, at first, a page in the Swedish court, afterwards an inferior officer in the regiment of bodyguards, and later, an ensign in the royal guards. His father was lieutenant-colonel, and knight of the rimler of the sworl. He was of a passionate and gloomy character, and maintained a continual oppo-
sition to the measures of the king, particularly those for limiting the power of the senate and nobles. The and retired to the country; but, in 1790 , returned to Stockholm. Hehere united himself with several of the nobility, particularly the counts Horn and Ribbing, barons Bidke and Pechlin, lieutenantcolonel Liljehorn and others, and they decided upon the death of the king. $A$. entreated that the nurder might be left to him; but Ribbing and Horn putting in their claims, they cast lots, and it fell to A. The king had just assembled a diet in Gefle, 1792, and the conspirators went there. Here, however, they found no opportunity to execute their plan. The ineasures of the diet exasperated them still more. The king returned to Stockholm, and it was known that he would be present at a masquerade, March 15. Here A. discharged a pistol at him, and wonnded him mortally. (See Gustavus III.) He was discovered, arrested, and confessed his crime, but refused to betray his accomplices. April 29,1792 , he was condemned to death, scourged during several days, and dragged upon a cart to the scaffold. Through the whole of his sufferings lie showed the greate'st calmness, boasted of his deed, and ended his life at the age of 31 years. The counts Horn and Ribbing, and colonel Liljehorn, were banished for life.

Avl_ACE; a falcluon or sword, shaped like a scythe.

Anva Comena, daughter of Alexius Comnenus I., emperor of the East. After his death she endeavoured to secure the succession to ler husband, Nicephorus Briennius, but was baffled by his want of energy and ambition. She wrote a life of her futher, Alexius, which, in the midst of mich fulsome panegyric,-contains some curious facts. An edition of this life was printed at the Louvre, 1651, folio. The time of her death is unknown. She forms a character in one of Sir Walter Scott's latest romances, "Count Robert of Paris," and this will preserve her memory from oblivion longer than her own work.

Anva Ivanowna, empress of Russia; born in 1693, the daughter of Ivan, the elder brother of Peter the Great. She was married to the duke of Courland, was left a widow, and, in 1730 , ascended the throne of the czars, under singular circumstances. Peter II., son of the unfortunate Alexis, died in his 16th year, and the young princess, Ivan and Basil Dolgorucky, administered the government, under the direction of the old chancellor Ostermann. As the latter flattered himself that he should retain his authority under a princess to wlom he had given the first instruction in reading, he used his whole influence to procure the crown for the dinchess of Courland. He gained over the synod, and the nobles assembled at Moscow, and thus $\Lambda$. was preferred to both the daughters of Peter the Great, and the prince Basil Dolgorucky was appointed to inform her of the choice of the nation. When he entered her apart. ment, he found a poorly-dressed man in the rooin, to whoun he inade a.sign to withdraw. The other showed no inclination to obey, and, when Dolgorucky took his arm to turn him out of the door, he was prevented by A.; it was Ernestus Jolun von Biren, the favourite of his sovereign, whose influence was soon all-powerful m Russia. A., at tirst, promised to remove her farourite, and to limit the unrestrained powers of the czars, but had scarcely ascended the throne, when she refused to do either, and proclaim. ed herself autoerat of all the Russias. Biren now put no limits to his ambition. The Dolgoruckys were his first victims. Their friends experienced a similar fate, notwithstanding A.'s earnest remoustrances. (See Biren.) In 1737, she forced the Courlanders to choose him duke, and nominated him, at her death, regent of the empire during the minority of prince Ivan (ot Brunswick). She died in 1740.

$$
z-2 \times 2
$$


Asvaberg; one of the most important manufacturiug towns of the Erzgebirg. Mining is also carried on here, though to a less exteut. The unnber of inlabitants is abont 5000 . It was, ut first, ouly a mining place. Afterwards, manufuctures were introduced, particularly those of various kinds of lace, of which a great part is exported to America. The miues are nearly exhausted. The population of the town was grently increased by the addition of the Belgians who fled from the persecutions of duke Alva.

Asxass ; an listorical account of the affiers of a state, digested in the orler of time. The name comes from the first annual records of the Ronians, which were enlled annales pontificum, or annales maximi, and the conpilation of which was the business of the pontifex maximus.

Anvamaboe; a town of Africa, on the Gold Coast, formerly a very considerable market for slaves. It is $n$ strongly-fortified place, having a port, where, in 1808 , a British garrison of ' 30 men withstood the attacks of 20,000 Ashantees, who were compelled to raise the siege and retire. It is said to eontain 10,000 inhabitants. The fortifications are maintained by the African company at an expense of about $£ 1900$ per aumum.

Avnamooka, or Rotrerpas; one of the Friendly islands in the Polynesian group of the South sea. Round the island, which is of a trinngular form, and about 10 or 12 miles in circuit, lie scattered a number of small isles, sand-banks, and breakers. These, together with Middleburg, or Eroowee, and Pylstart, inake a group occupying about 3 degrees of lat. and 2 of lon., named, by captain Cook, the Friendly isl. ands or archipelago, as a firn allianee and friendship seemed to subsist among their inhabitants, whose courteuus behaviour entilled them to that appellation. Lolı. $174^{\circ} \mathrm{W}$.; lat. $20^{\circ} \mathrm{S}$. The island was discovered by Tasman, a Dutch navigator, in 1643. Cook visited it in 1777 .

Axsapols; a city and port of entry, in the county of Ann Arundel, Maryland, United States. Lon. $76^{\circ} 43^{\prime} \mathrm{W}$.; lat. $39^{\circ} \mathrm{N}$. Population, 2260. It is the seat of the state government, is a pleasant and healthy town, and coutains a spacious and elegant state-house, a market-house, a theatre, and two houses of public worship. The streets converge to the state-house and to the Episcopal church, as two centres. The shipping owned here, in 1816, amounted to 2,553 tons.-There is another Annapolis, A. Royal, a city of Nova Scotia, on the bay of Fundy; lon. $65^{\circ} 50 \mathrm{~W}$.; lat. $44^{\circ} 47^{\prime} \mathrm{N}$. The harbour is large and safe.

Axvises; a year's income due to the pope, on the leath of any bishop, abbot, or parish-priest, to be paid by his successor. The concordata Germania, in 1448 , restored to the pope the right of raising the aunates, which had been forbidden by the council of Bale, in 1434. They were made perpetual, by Boniface IX., in 1399. In France, they were finally abolished in 1789. In England, they were at first paid to the archbishop of Canterbury, but afterwards appropriated by the popes. In 1532, the parliament gave them to the crown; but queen Anne restored them to the church, by applying them to the augmentation of poor livings.

Axse, the last member of the family of Stuart (now extinct) who was seated upon the throne of Great Britain, was born at Twiekenham, near London, 1664, four years after her uncle, Charles II., ascender the throne. She was the second daughter of James II., then duke of York, and Anue, his wife, daughter of the renowned Clarendon. Her father had not then gone over to the Catholic church; A., was, therefore, educated accord- ing to the principles of the Euglish church, and, in 1683, marriel $\omega$ prince (irorge, brother to king Cluristian $V$. of Demmark. When in 16s8, the party which invited the prince of Orange to dethrone his father-in-law prevailed, $A$., the favourite daughter of Jumes, wished to remain with her fatlier. But she was, in some measnre, foreed by Cliurchill, afterwarls duke of Marlborough, to joil the triumphant party. After the death of her sister, Mary, in 1694, and that of William 111., in 170\%, without children, and after she lierself, in 1699, had lost her only son, the young duke of Gloucester, she aseended the Einglish throne. Hor capacity was but moderate, and she was goveruct by Marlborough and his wife. The tories were satisfied to know that the sceptre was in the hands of a daughter of James Il., and hoped to see the old royal house revivel in her male descendauts. 'The whigs rejoiced, at leust, that the queen, faithfil to the triple alliance, opposed the domineering spirit of Louis XIV., in order to defend the liberty of Europe, and to prevent the union of the French and Spanish crowns in one liouse. Slie, therefore, took part in the war of the Spanish succession, in which Eugland captured Gibraltar, the only important acquisition of this eleven yenrs' war. During the reigu of queen A., Fngland and Scotlind were united nnder the name of Great Britain, and, notwithstanding the wishes of the queen for the restoration of her own loouse to the line of suecession, it was settled in the house of Hanover. James in vain attemnted a landing in Scotland, and the queen was obliged to sign a proclamation setting a priee on his liead. Of her seventeen children, all died young; and, when left a widow, she would not listen to the entreaties of the parliament (altliough but forty-four years old at the time) to conclude a new marriage, which might tlirow new obstaeles in the way of the restoration of her owi fanily. She now intended to put all power into the hands of the tories, who were then the majority in the three kingdoms, The duchess of Mariborough lost her influence; Godolphin, Sunderland, Somers, Devonshire, Walpole, Cowper, were superseded by Ilarley, earl of Oxford, Bolingbroke, Rochester, Buckinghain, George Grenville, and Sir Simon Harcourt, and the parliament was dissolved. Peace was resolved ıpon. Marlborough was accused, suspended, and banished. Meanwhile A., notwithstanding the measure's which she publicly took against her brother, seems not to have given up the hope of securing to him the suecession, but the irreconcilable enmity of Oxford and Bolingbroke, the former of whom accused the latter of favouring the Pretender, was an insurmonntable obstacle. Grieved at the disappointment of her secret wishes, she fell into a state of weakness and lethargy, and died July 20, 1714. The words " 0 , my dear brother, how I pity thee !" which she pronounced on her death-bed, unveiled the secret of lier whole life. The reign of $\mathrm{A}$. was distinguished not only by the brilliant successes of the British arms, but also as the golden age of English literature, on account of the number of admirable and excellent writers who flourished at this time, among whom were Pope and Addison. It may be eorsidered the triumph of the English high-church party, owing to her strong predilection for the prineiples by whieh it has always been actuated. Her private eharacter was amiable, but her good sense was rendered inefieetinal by want of energy. The goodness of her disposition obtained for her the title of the good queen Anne. She was an exeellent wile and muther, and a kind mistress.

ANve of Austria, queen of France, was the daughter of Philip 11I., king of Spain, and, in 1615, married Louis XIII. On her cousin's death, his son being 
under age, she became sole regent of France during the minurity. She, however, brought upon herself the hatred of the nation, by her boundless confidence in cardinal Mazarin, and was forced to flee from Paris. In a little time, matters were accommodated; and, when her son took the reins of government into his own hands, in 1661, she gave up all concern with public affairs, and spent the remainder of her life in retirement. She died in 1666.

AxSE of Cleves, the wife of Henry VIII., king of England, was the daughter of John III., duke of Cleres. The king asked her in marriage after having seen a portrait of her, drawn by Holbein; but it was not long before he was disgusted with the Flanders mare, as lie called her, and a divorce ensued; when Anne, without appearing disconcerted, returned to her own country, where she died in 1557.

Anvesuing, or Nescivg, as it is called by the workmen, is a process particularly employed in the glasshouses, and consists in putting the glass vessels, as soon as they are formed, and while they are yet hot, into a furnace or oven, not so hot as to remelt them, in which they are suffered to cool gradually. This is found to prevent their breaking so easily as they otherwise would, particularly on exposure to heat. Unaniealed glass, when broken, often flies into powder, with great violence, and, in general, it is in more danger of breaking from a very slight stroke than from one of considerable force. An unannealed glass vessel will often resist the effect of a pistol bullet dropped into it ; yet a grain of sand, falling into it, will make it burst into small fragments, and, which is very curious, it will often not burst until several minutes after being struck. The same phenomena are still more strikingly seen in glass-drops or tears : they are globular at one end, and taper to a small tail at the other: they are the drops which fall from the melted mass of glass on the rods, on which the bottles are made, into the tubs of water, which are used in the work. Those which remain entire, after having fallen into the water, show the properties of unannealed glass in the highest degree. They will bear a smart stroke on the thick end, but, if the snall tail is broken, they bursi into powder, with a loud explosion. The reason of this singular fact is differently given. A similar process is used for renderiug cast-iron vessels less brittle.

Axvides of Viterbo, or Jom Naxsi, a Dominican friar, was born at Viterbo, in 1432. He was distinguished for his learning, and was made master of the sacred palace by pope Alexander VI. He died, as was suspected, of poison, administered at the instigation of Cresar Jorgai, in 1502. He employed his leisure in the construction of fragments, which he palmed on the world as the remains of several ancient writers, in "Seventeen Books of Antiquities." The first edition of this work, dedicated to Ferdinand and Isabella, was printed at Rome, in 1498, and, in 1552 , republished in $8 \mathrm{ro}$. at $\Lambda$ ntwerp. The imposition passed for sometine; and, when discovered, the Dos miuicans, auxious to save the credit of their order, pretended tlat $\Delta$ nuius copied his inventions from a unanuscript which lie found in the Colbertiue library; but, as this manuscript was never produced, the dislionour was ineffaceable. The success and magnitude of the forgery rendered it exceedingly remarkable, as an instance of great but unprincipled ability.

Axvo, archbishop of Cologue, died in 1075. The Hymn which celebrates his praises was composed not long after his death. The last edition of it was publisled by Dr Goldınann, Leipsic, 1816. The political importance of St A., as chancellor of the emperor Henry III., and afterwards as administrator of the empire during the minority of Hellry IV.; his bold spirit of government, as well as the dignity of his holy life ; his paternal care for his archbishopric ; the zeal with which he laboured for the reformation of the monasteries, and established new ones, as well as clurches,-gained him the character of a saint. The liymn of St Anno begins with the popular traditions of Germany, goes over to the history of the archiepiscopal seat at Cologne, of its thirty-three bishops before $\Lambda$., among whom were seven saints, and of their residence in the city of Cologne, on the Rhine. The poet then describes the secular and spiritual government of the saints, and his grief on account of the madness of his countrymen, continually at war, and nutually destroying each other by internal discord. In despair at not being able to change this state of things, the German patriot becomes weary of life, and dies of grief at the ingratitude of his con. temporaries, whom he had zealously striven to benefit. This Hymn is the only poetical monument, of importance, of the German national literature of the 11th century.

Assuities are periodical payments of money, amounting to a certain annual sum, and continuing either a certain number of years, as tenl, twenty, or a hundred, or for an uncertain period, to be determined by a particular event, as the death of the annuitant, or that of the party liable to pay the annuity, or of some other person, or indefinitely ; and these last are called perpetual annuities. The payments are made at the end of each year, or semi-annually, or at the end of every quarter, or at other periods, according to the agreement upon which the annuity arises ; and, where it is liable to cease upon the happening of an event, at the time of the occurrence of which is uncertain (e. g., the death of a person), and such event happens after the expiration of a part of the time between one payment and another, neither the annuitant nor his heirs will be entitled to any proportional part of a payment for such time, unless some express provision is made for this purpose in the contract. The probability of the loss of such fractional part is to be taken into consideration in estimating the present value of the annuity ; $e . g$., if the life in question is, according to the tables of longevity, good for $5 \frac{1}{2}$ years, an annuity for such life is worth more than if it were good for only just five years, since the probability of its continuing six years is greater. As an annuity is usually raised by the present payment of a certain sum, as a consideration whereby the party making the payment, or some other person named by him, becomes entitled to an annual, semiannual, quarterly, or other periodical payment of a certain sum, for a stipulated number of years, or for a period to be determined by the happening of a certain event; the rules and principles by which this present value is to be computed have been the subjects of much scientific investigation. The present value of a perpetual annuity is evidently a sum of money that will yield an interest equal to the annuity, and payable at the same periods; and an annuity of this description, payable quarterly, will evidently be of greater value than one of the same amount payable annually, since the anmuitant has the additional adrantage of the interest on three of the quarterly payments, until the expiration of the year; or, in other words, it requires a greater present capital to be put at interest, to yield a givell sum per annum, payable quarterly, than to yield the same annual sum, payable at the end of each year.-The pre. sent value of an annuity, for a limited period, is a sum which, if put at interest, will, at the end of tliat interest give an amount equal to the sum of all the payments of the annuity and interest; and, accordingly, if it be proposed to invest a certain sum of money in the purclase of an annuity, for a given number of years, the comparative value of the two may be precisely esti- 
nated, the mite of interest being given. 13ut annulties for uncertain periorls, and particularly lifo annuities, are more frequent, and the value of the nnnuity is computed acconling to the probahle duration of the lite by which it is limited. Many such amuities are grunted for pullic services; and, as these do not arise from a specific contract, and are not usually suljects of purchase, their precise value is not often a subject of investigation. But life annuities are often created by contract, whereby the goverument or a private annuity office, agrees, for a certain sum adraiced by the purchaser, to pay a certain sum annually, in searly, quarterly, or other periodical payments, to the person advancing the money, or some other anuuitants named by hin, during the life of the ammitant; or the alunuity is granted to the an. nuitant, his heirs, and assigns, during the life of some other person, or during two or more joint lives, or during the life of the longest liver or survivor among a number of persous named in the act or agreement whereby the annuity is raised. Snch anuities are usually made transferable, and are sold and purchased in the market as a species of public stocks. When granted by a government, they ure generally one mode of mising loans; when created by a contract with a private corporation or company, their object usually is, to give the amuitant the use, during his life, not only of the income of his capital, but of the capital itself.-If a person, having a certain capital, and intending to spend this capital and the income of it during his own life, and leave no part to his heirs, could know precisely how long he should live, he might loan this capital at a certain rate during his life, and, by taking every year, besides the interest, a certain amount of the capital, he might secure the same annual amount for his support during his life, in such manner that he should have the same sum to spend every year, and consume precisely his whole capital during his life. But, since he does not know how long he is to live, he agrees with the government, or an annuity office, to take the risk of the duration of his life, and agree to pay him a certain annuity during his life, in exchange for the capital which he proposes to invest in this way. The probable duration of his life, therefore, becomes a subject of computation ; and, for the purpose of making this calculation, tables of longevity are made, by noting the proportions of deaths, at certain ages, in the same country or district.The celebrated mathematician, Dr Halley, was the furst who calculated a talle of mortality, which he deduced from olservations made at Breslaw, in Silesia. In 1724, Mr De Moivre published the first edition of his tract on Annuities an Lives. In order to facilitate the calculation of their values, Mr De Moivre assumeit the annual decrements of life to be equal; that is, he supposed that out of 86 (the utmost limit of life on his hypothesis) persans born together, one would die every year till the whole were extinct. This assumption agreed pretty well with the true values between thirty and seveaty years of age, as given in Dr Halley's table; but was very remote froin the truth in the curlier and later periods. Mr Thomas Simson, in his work on Annuities and Reversions, originally published in $174 \%$, gave a table of mortality deduced from the London bills, and tables founded upon it of the values of annuities. But at the period when this table was calculated, the mortality in London was so much higher than in the rest of the country, that the values of the aunuities given in it were far too small for general use. In 1746, M. Deparcieux published, in lis Issni sur les Probabilités de la Durée de la I. ie Humaine - a work distinguished by its perspicuity and neatuess-tables of mortality deduced from observations made on the mortunry registers of severa' religions houses, and on lists or the nominees in several tontines. In this work, separate tables were first constructed for males and fenales, and the greater longevity of the latter rcudered apparent. $M$. De parcieux's tables were a very great aequisition to the science; and are decidedly superior to some that are still extensively used. Ir P'rice's famons work on Annities, the first edition of which was published in 1770 , contributed powerfilly to direct the public attention to inquiries of this sort ; and was, in this respect, of very great utility. Of the more recent works, the best are those of Mr Baily, and Mr Milne, which, indeed, are both excellent. The latter, besilles all that was previously known as to the history, theory, or praclice of the science, contains nuctr new and valuable matter; and to it we beg to refer snch of our readers as wish to enter fully into the subject. The table on which Dr Price laid the greatest stress, was calculated from the burial registers kept at Northampton and some adjoining parishes. There cau be no doubt, however, as well from original defects in the construction of the table, as from the improvement that has since taken place in the healthimess of the public, that the mortality represented in the Northampton table is, and has long been, decidedly above the average rate of mortality in England. Mr Morgan, indeel, the learned actuary of the Equitable Society, contends that this is not the case, and that the Society's experience shows that the Northampton table is still remarkably accurate. But the facts $\mathrm{Mr}$ Morgan has disclosed in lis Vicw of the Rise und Progress of the Equitable Society (p. 42), published in 1828 , are quite at variance with this opinion: for he there states, that the deaths of persons insured in the Equitable Society, from fifty to sixty years of age, during the twelve years previously to 1828 , were 339 ; whereas, according to the Northampton table, they should have been 545! And Mr Milne has en. deavoured to show (Art. Annuities new edition of Ency. Brit.) that the discrepancy is really much greater. The only other table used to any extent in England for the calculation of life anmuities, is that framed by Mr Milne from observations made by $\mathrm{Dr}$ Heysham on the rate of mortality at Carlisle.-It gives a decidedly lower rate of mortality than the Northampton table; and there are good grounds for thinking that the mortality which it represents is not very different from the actual rate throughout most parts of England; though it cannot be supposed that a tahle founded on so narrow a basis should give a perfectly fair view of the average mortality of the entire kingdom. In order to exhibit the foundations on which tables of life annuities and insurance have been founded in this and other countries, we give in the following table, the rate of mortality that has been observed to take place among 1,000 children born together, or the numbers alive at the end of each year, till the whole become extinct, in England, France, Sweden, \&c., according to the most celebrated authorities. The rate of mortality at Carlisle, represented in this table, is less than that observed any where else : the rates which approach nearest to it are those deduced from the observations already referred to, of $M$. Deparcieux, and those of M. Kerseboom, on the holders of life annuities in Holland:- 
TABLE of the Probable Duration of Human Life; shour. ing the Number of Persons allive at the end of every Year, from 1 to 100 Years of Age, out of 1000 born together, in the different Places, and according to the Authorities undermentioned.

\begin{tabular}{|c|c|c|c|c|c|c|c|c|c|c|c|c|}
\hline & & Englan & & & France & & $\begin{array}{l}\text { Swe- } \\
\text { den. }\end{array}$ & $\begin{array}{l}\text { Vien- } \\
\text { pa. }\end{array}$ & $\begin{array}{l}\text { Ber- } \\
\text { lin. }\end{array}$ & $\mid \begin{array}{l}\text { Swit- } \\
\text { zer- } \\
\text { land. }\end{array}$ & $\begin{array}{l}\text { Sile- } \\
\text { sia. }\end{array}$ & $\begin{array}{l}\text { Hol- } \\
\text { land. }\end{array}$ \\
\hline 4 & 步 & 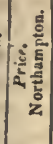 & 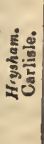 & 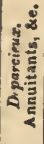 & 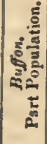 & 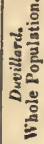 & 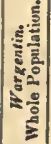 & है & हूँ हैं & $\mid$ & चै & 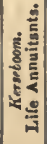 \\
\hline
\end{tabular}

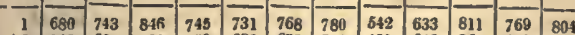

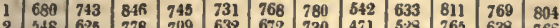

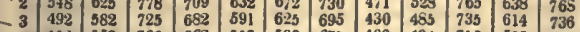
\begin{tabular}{ll|l|l|l|l|l|l|l|l|l|l|l|}
3 & 492 & 582 & 725 & 682 & 593 & 625 & 690 & 430 & 435 & 735 & 614 & 736 \\
4 & 453 & 553 & 700 & 662 & 537 & 599 & 671 & 400 & 434 & 715 & 585 & 709
\end{tabular} \begin{tabular}{ll|l|l|l|l|l|l|l|l|l|l|l|}
5 & 426 & 536 & 680 & 647 & 540 & 583 & 656 & 377 & 403 & 701 & 563 & 689 \\
& 410 & 521 & 668 & 634 & 523 & 573 & 644 & 357 & 387 & 688 & 546 & 676
\end{tabular}

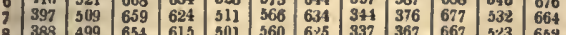
\begin{tabular}{l|l|l|l|l|l|l|l|l|l|l|l|l|}
8 & 388 & 499 & 654 & 615 & 501 & 560 & 625 & 337 & 367 & 667 & 523 & 652 \\
9 & 880 & 492 & 649 & 607 & 494 & 556 & 618 & 331 & 361 & 659 & 515 & 646 \\
\hline
\end{tabular} \begin{tabular}{r|r|r|r|r|r|r|r|r|r|r|r|r|}
9 & 880 & 492 & 649 & 607 & 494 & 556 & 618 & 331 & 361 & 659 & 515 & 646 \\
10 & 373 & 487 & 648 & 600 & 489 & 551 & 611 & 327 & 356 & 653 & 508 & 639
\end{tabular}

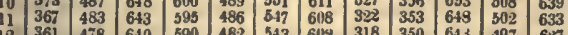

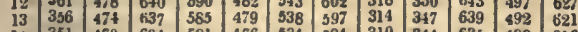
\begin{tabular}{l|l|l|l|l|l|l|l|l|l|l|l|l|}
14 & 351 & 470 & 634 & 581 & 476 & 531 & 594 & 310 & 314 & 633 & 488 & 816 \\
\hline & 337 & 46 & 69 & 578 & 479 & 329 & 590 & 306 & 341 & 631 & 483 & 511
\end{tabular} \begin{tabular}{l|l|l|l|l|l|l|l|l|l|l|l|l|}
15 & 347 & 4655 & 630 & 578 & 472 & 329 & 590 & 306 & 341 & 631 & 483 & 611 \\
\hline & 343 & 461 & 626 & 574 & 468 & 524 & 586 & 302 & 338 & 626 & 499 & 600
\end{tabular} \begin{tabular}{llllllll|l|l|l|l|l|l|}
17 & 338 & 457 & 6282 & 570 & 464 & 319 & 582 & 299 & 335 & 828 & 474 & 601
\end{tabular}

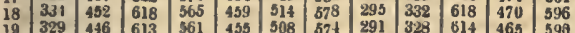
\begin{tabular}{l|l|l|l|l|l|l|l|l|l|l|l|l|}
19 & 329 & 446 & 613 & 561 & 455 & 508 & 574 & 291 & 323 & 614 & 465 & 590 \\
20 & 325 & 441 & 619 & 550 & 449 & 302 & 570 & 283 & 324 & 610 & 461 & 584
\end{tabular}

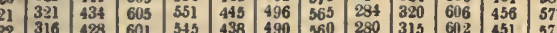

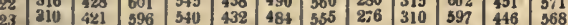

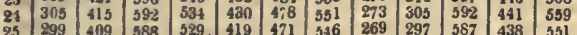
\begin{tabular}{ll|l|l|l|l|l|l|l|l|l|l|l|}
25 & 299 & 409 & 588 & 529 & 419 & 471 & 546 & 269 & 297 & 587 & 438 & 531 \\
26 & 294 & 402 & 584 & $523 i$ & 114 & 465 & 541 & 265 & 293 & 582 & 431 & 543
\end{tabular}

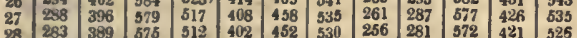
\begin{tabular}{ll|l|l|l|l|l|l|l|l|l|l|l}
29 & 278 & 389 & 575 & 512 & 402 & $\mathbf{4 5 2}$ & $\mathbf{5 3 0}$ & 256 & 281 & $\mathbf{5 7 2}$ & $\mathbf{4 2 1}$ & $\mathbf{5 2 5}$ \\
29 & 270 & 3706 & $\mathbf{5 7 0}$ & $\mathbf{5 0 6}$ & $\mathbf{3 9 8}$ & $\mathbf{4 4 5}$ & $\mathbf{5 2 5}$ & $\mathbf{2 5 1}$ & $\mathbf{2 7 5}$ & $\mathbf{5 6 7}$ & $\mathbf{4 1 5}$ & $\mathbf{5 1 7}$
\end{tabular}

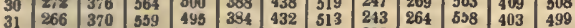
\begin{tabular}{lll|l|l|l|l|l|l|l|l|l|l|l|l|l|}
32 & 260 & 364 & 553 & 490 & 377 & 423 & 507 & 239 & 259 & 553 & 397 & 490
\end{tabular} \begin{tabular}{ll|lll|lll|l|l|l|l|l|}
93 & 254 & 357 & 547 & 484 & 371 & 418 & 501 & 235 & 254 & 548 & 391 & 482 \\
\hline
\end{tabular} \begin{tabular}{lllll|l|l|l|l|l|l|l|l}
34 & 248 & 351 & 542 & 479 & 366 & 411 & 495 & 231 & 249 & 544 & 384 & 474 \\
35 & 242 & 344 & 536 & $474^{\prime}$ & 355 & 404 & 489 & 226 & 243 & 539 & 377 & 967
\end{tabular}

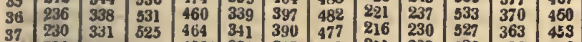
\begin{tabular}{lllllllll|l|l|l|l|l|l|l}
38 & 227 & 325 & 519 & 459 & 334 & 383 & 171 & 211 & 223 & 520 & 363 & 440 \\
\hline
\end{tabular} \begin{tabular}{lllll|l|l|l|l|l|l|l|l|}
40 & 212 & 312 & 508 & 449 & 314 & 369 & 459 & 199 & 209 & 506 & 349 & 439 \\
\hline
\end{tabular}

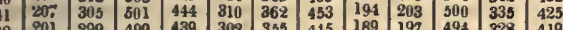
\begin{tabular}{ll|l|l|l|l|l|l|l|l|l|l|l|l|}
43 & 194 & 292 & 487 & 434 & 297 & 348 & 437 & 185 & 192 & 488 & 321 & 413
\end{tabular} \begin{tabular}{lll|l|l|l|l|l|l|l|l|l|l}
4 & 187 & 285 & 480 & 429 & 292 & 341 & 430 & 181 & 187 & 482 & 314 & 407 \\
180 & 279 & 473 & 424 & 279 & 334 & 422 & 176 & 182 & 476 & $30 \%$ & 400
\end{tabular} \begin{tabular}{|l|l|l|l|l|l|l|l|l|l|l|l|l}
174 & 272 & 466 & 419 & 273 & 327 & 414 & 171 & 177 & 469 & 290 & 393 \\
167 & 265 & 459 & 413 & 269 & 320 & 407 & 165 & 172 & 461 & 291 & 396
\end{tabular}

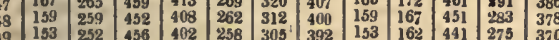

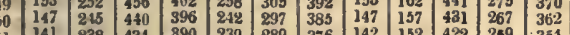

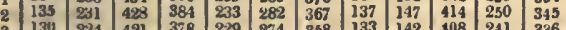
\begin{tabular}{llllllll|l|l|l|l|l|l}
53 & 1311 & 224 & 421 & 378 & 229 & 274 & 358 & 133 & 142 & 108 & 241 & 336 \\
54 & 125 & 217 & 414 & 371 & 224 & 263 & 349 & 128 & 137 & 397 & 232 & 327
\end{tabular}

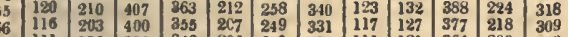

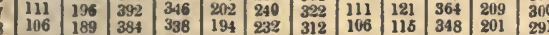

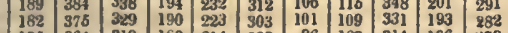

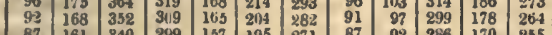

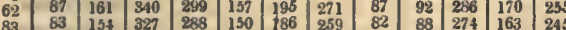

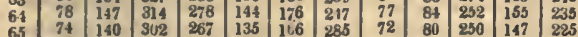
\begin{tabular}{llllllllllll|l|l|l|}
66 & 70 & 133 & 289 & 256 & 126 & 157 & 224 & $8 \%$ & 75 & 236 & 140 & 215 \\
67 & 65 & 126 & 277 & 245 & 117 & 147 & 212 & 62 & 70 & 220 & 132 & 205 \\
\end{tabular}

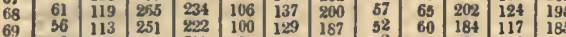
\begin{tabular}{lllll|l|l|l|l|l|l|l|l|}
70 & 52 & 106 & 240 & 211 & 90 & 118 & 175 & 45 & 55 & 168 & 109 & 175 \\
\hline
\end{tabular}

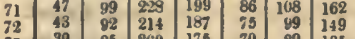
$\begin{array}{lllllllllllllll}73 & 39 & 85 & 200 & 175 & 70 & 89 & 135 & 36 & 43 & 129 & 85 & 145 \\ 7 & 35 & 78 & 104 & 169 & 63 & 50 & 121 & 33 & 99 & 119 & 77 & 135\end{array}$ \begin{tabular}{rrr|r|r|r|r|rr|r|r|r|r|}
75 & 32 & 71 & 168 & 118 & 52 & 72 & 108 & 30 & 35 & 109 & 69 & 125 \\
76 & 28 & 65 & 152 & 134 & 47 & 63 & 96 & 27 & 32 & 98 & 61 & 114 \\
\end{tabular} \begin{tabular}{l|llllllllllllll}
77 & 25 & 58 & 136 & 120 & 42 & 56 & 84 & 24 & 29 & 85 & 53 & 103 \\
78 & 22 & 52 & 121 & 106 & 36 & 48 & 75 & 21 & 26 & 71 & 55 & 92
\end{tabular} \begin{tabular}{ll|r|r|r|r|r|r|r|r|r|r|}
79 & 19 & 48 & 108 & 94 & 34 & 41 & 65 & 18 & 23 & 71 & 55 \\
80 & 17 & 40 & 95 & 81 & 23 & 33 & 56 & 18 & 20 & 46 & 38 \\
\hline
\end{tabular}

In order to calculate from this table the chance which a person of any given age has of attaining to any higher age, we have only to divide the number of persons alive at such higher age, given in that column of the table selected to decide the question, by the number of persons alive at the given age, and the fraction resulting is the chance. We add, by way of supplement to this table, Mr Finlaison's table of the rate of mortality among 1,000 children born together, according to the decrement of life observed to take place among the nominees in government tontines and life annuities in this country, distinguishing males from females. The rate of mortality which this table exhibits is decidedly less than that given in the Carlisle table; but the lives in the latter are the average of the population, while those in the former. are all picked. Still, however, the table is very curious; and it sets the superiority of female life in a very striking point of view.

TABLE of the Progressive Decrement of Life amon 1000 Infants of each Sex, born together, accurding to Mr Finlaison's Observations on the Mortality of the Nominees in the Government Tontines and Lije Annui-

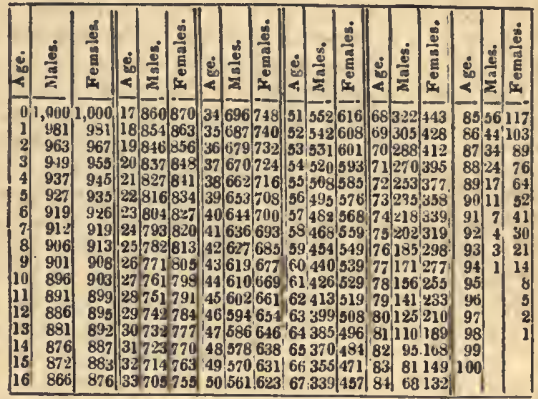

The next table, extracted from the Second Report of the Committee of the House of Commons on Friendly Societies, gives a comparative view of the results of some of the most celebrated tables of moltality, in relation to the rate of mortality, the expectation of life, the value of an anurity, \&c.

TABLE giving a Comparative View of the Results of variou T'ables of AIortality, in relation to the following Particulas.

\begin{tabular}{|c|c|c|c|c|c|c|c|}
\hline 1 & 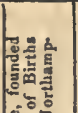 & 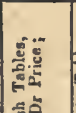 & 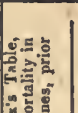 & 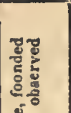 & 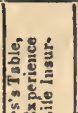 & $\begin{array}{c}\text { By Mrr F } \\
\text { Tables, } \\
\text { on the E } \\
\text { of the } \\
\text { ment Lit } \\
\text { tie }\end{array}$ & $\begin{array}{l}\text { Iiilaison's } \\
\text { founded } \\
\text { xperience } \\
\text { Govern- } \\
\text { ife Annui- } \\
\text { ies. }\end{array}$ \\
\hline$(1$ & 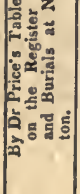 & 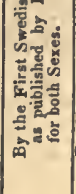 & 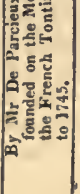 & 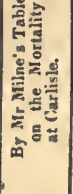 & 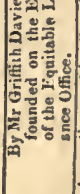 & 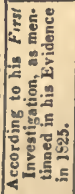 & 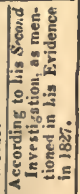 \\
\hline$O f 1000$ & & & & & & $\begin{array}{l}\text { Mfean } \\
\text { of both } \\
\text { Sexes. }\end{array}$ & $\begin{array}{l}\text { Mlean } \\
\text { of hoth } \\
\text { Sexes. }\end{array}$ \\
\hline 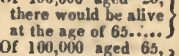 & 34,286 & 43,137 & 51,033 & 51,235 & 40,330 & 53,470 & 53,950 \\
\hline $\begin{array}{l}\text { there would be alive } \\
\text { at the age of } 80 \ldots . . .\end{array}$ & 28,738 & 23,704 & 29,873 & 81,577 & 37.267 & 38,655 & 37,355 \\
\hline $\begin{array}{l}\text { Fxpectation of life at } \\
\text { the age of } 25 \text { yrars.. }\end{array}$ & $30-65$ & $34 \cdot 38$ & $37 \cdot 17$ & $37 \cdot 86$ & $37 \cdot 45$ & $38 * 35$ & 38.52 \\
\hline $\begin{array}{l}\text { Expectation of life at } \\
\text { the age of } 65 \text { years... }\end{array}$ & 10.88 & $10 \cdot 10$ & $11-25$ & $11 \cdot 79$ & $12 \cdot 25$ & $12 \cdot 81$ & $12-50$ \\
\hline $\begin{array}{l}\text { Value of annuity } \\
\text { life aged } 25 \text {, Inte } \\
\text { being at } 4 \text { per er }\end{array}$ & $£ 15 \cdot 438$ & $<16 \cdot 839$ & 217.420 & 7.615 & ×17.491 & $\{17 \cdot 534$ & 217.634 \\
\hline $\begin{array}{l}\text { Value of annuity on a } \\
\text { life aged } 65 \text {, interent } \\
\text { heing at } 4 \text { per cent.. }\end{array}$ & 87.761 & $\mathbf{8 7 \cdot 3 2 8}$ & 28.039 & $\angle 8-307$ & $\angle 8.635$ & $28-896$ & $f 8751$ \\
\hline $\left.\begin{array}{l}\text { Value of a deferred } \\
\text { annuity commencing } \\
\text { at } 6.5, \text { to a life now } \\
\text { aged } 25 \text {, interest at } \\
\text { \& per cent_......... }\end{array}\right\}$ & $.55 \div 24$ & 0.65812 & $\leq 0 \cdot 85452$ & 8882 & 60.8872 & $00-99078$ & f0-98334 \\
\hline
\end{tabular}


Anvoxci.ı rios; the declaration of the angel Gabriel | to the virgin Mary of the intarnation of Christ in her woub.-Lute i. 26-38.

Axvoxcl.stion DAY ; a fenst of the cluurch, in honour of the anumnciation, celebraterl in the western churches, March 25. The institution of this festival is generally assigned to the 7th century.

Axodves (from the Greek odun, prain, and the privative $a$ ) ; uneans for soothing pain. As the pain may urise fron different causes, the means for counteracting it must be very diflerent. Thus, for instance, a pain may be proluced by inflammntion; aud, iu this case, cooling means, luke wamn poultices, sometines even bleeding or purging, will be the proper anodyues. At other times they should be of an inflammatory kind; for instance, in debility of the nerves, cramps, or spasms. In the stricter sense, we understand by anodynes such remedies as lessen the susceptibility to painful impressions, by diminishing the sensibility of the nerres. In early times, when the doctrine of poisons and antidotes was more attended to than any other part of medicine, the soothing quality of many simples was also more closely observed, und a particular class was formed in this way. As this property existed to a high degree in opium, then already in use, it not only obtained the first place in this class of simples, but the name anodyne was given to all mixtures containing it. The use of anodynes is proper only when the cause of pain cannot be reunoved, or not so soon as its violence requires, or where the pain itself is more injurious than the cause which produces it; e. g., when it prevents a favourable crisis, by rendering the patient unable to sleep.

Avorvrivg. From lime immemorial, the nations of the Fast have been in the habit of anointing theinselves for the sake of liealth and beauty; and to anoint a guest, was to show him one of the highest unarks of respeet. In the Mosaic law, and several ancient religions, a sacred character was attacled to the anointing of the garments of the priests, and things belonging to the ceremouial of worship. This could be done only with oil made for the purpose, and siguified a consecration of the articles to the service of religion. The Jewish priests and kings were anointed when inducted into office, and were called the anointed of the Lorl, to show that their persuns were sacred, and their office from God. In the Old Testament, also, the prophecies respecting the Redeemer style him, oli account of his royal descent and his rlignity, Messias, that is, the Anointed. The custom of anointing priests still exist in the Ronan Catholic church, and that of anointing kings in Christian morarchies. In the Catholic church, the ordaining bishop anoints with the holy oil called chrism (q. ..) the palm of both hands, the thumb, and the forefinger (by which the priests hold the host), of the person to be orlained; and thus, according to the expression of the ritual of ordination, the hands receive power tc bless, to consecrate, and to make holy. If a clergyman is excommunicated, these spots are rubbed off. (For the ceremony of anointing kings, see Coronation.) The frecks and Romans, particularly. the former, anointed themselves after the bath, and thus gave a yellow colour to the body. Perliaps in order to imitate this colour, perhaps to make the figure look softer, and to deprive it of the harsh white colour, they often oiled their statutes. The remains of the oily matter used are still sometimes to be seen. Athletax anointed themselves in order to render it more difficult for their antagonists to get hold of them.

Axомaly; the deviation from a rule. That which deviates is called anomalous. We use this expression in this signification in grammar, where it is opposed to analogy. It is also user in astronomy, to denote the deviation of the planets fron the aphelion for, rather, acconling to the untem usige, from the perihelion), which is owing to their nuequal velocity.

Asom(knss ; the mane by which the stricter Arians were called in the 4 th century, in contradistinction to the Semi-Ariuns.

Asoxymots (from the Greek); literally without nanke; also, a person whose name is unknown, or who keeps his name a secret, e. g., the author of an avonymous writing. P'seulo is an epithet applicrl to all assumed name. Writers often conceal themselves under a pspulo or false unme, which they retain as anthors, even when their true name las long been known. It was some time since decided by a legal tribunal at Stuttgarl in Gernnany, that it was not lawful for a third person to put the psendo name of another known writer before his own work. The knowledge of the anonymous and pseudonyı:ous authors is indispensable to the bibliographer. (see Barbier's Dictionnaire des Ourmges Alionynes et l'seudonymes, composes, traduits ou publies t'n l'rancais et en Latin, with historical and critical notes, second edition, Paris, 1822-1824, 3 vols.) Authors often keep their names secret from political motives, e. g., Junius. (q. v.) - In history we call psenulo, impostors who act a political part under a feigned name; for.instance, the psendo Sebastians in Portugal, the pseudu Demetri in Russia, pseudo Woldmar in Brandenburg, the psendo Smerdis in Persia.

Anguetil do Pzrron, Abraham Hyacintlie; one of the most distingushed Orientalists of the 18th century, born in Paris, Dec. 6, 1731; studied theology at the. university there, and afterwards at Auxerre and Amersfort; devoted himself with ardour to the Hebrew, Arabian, and Persian languages, and retumied to Paris in order to study them with more advantage. Here his assiduous attendance at the library exciterl the attention of the abbe Sallier, keeper of the manuscripts, who introduced lim to some of lis friends, by whose means the young A. obtained a sinall salary, under the title of a student of the Oriental languages. Having accidentally laid his hands on some fragments of a manuscript of the Zenu-Avesta, India became the object of lis thoughts, and he cherished the hope of discovering there the holy books of the Parsees. In the harbour of l'Orient, an expedition was preparing for the East Indies, but the endeavours of his protectors to procure a passage for him were fruitless. A. immediately went to the recruiting captain, enlisted as a private soldier, and set out from Paris, with his knapsack on his back, in 1754. Struck with such extraordinary zeal for science, the government allowed him a fiee passage and a salary. $\mathrm{Ar}$. rived at Pondicherry, he learned the modern Persian, and then went to Chandernagore, where he hoped to study the Sanserit. But sickness and the war hetween France and England frustrated his hopes. Chandernagore was captured, and A, not to lose the whole object of his rogage, returnel on foot to Fondicherry, and embarked for Surat. But in order to explore the interior, as well as the coast of Coromandel, he landed at Mahe, and journeyed on foot to Surat. Here he succeeded, by perseverance and address, in orercoming the scruples of some priests of the Parsees (Destour). They instructed him so far in the Zent and Pehlwi, that he was able to translate the Dictionary and some other works from this language. He then resolved to go to Benares, to study the languages, the antiquities, and the sacred laws of the Hindoos, when the capture of Pondicherry forced him to return to Europe. He visited London and Oxforl, and returnet to Paris in 1762 , with 180 manuscripts, and other curiosities. The ablse Barthelemy and his other friends obtained for him a salary, with the office of interpreter of the Oriental languages, at the royal 
library. In 1763, he was made member of the academy of belles-lettres. $A$. then commenced the arrangement of the materials which he had collected with so much toil ; he published in succession, the Zent-Avesta, the Spirit of Oriental Legislation, his historical and geographical researches in India, and his work on commerce. "Afterwards, the revolution disturbed his literary labours. To withdraw himself from its horrors, he broke off all connexion with society, and sliut himself up in lis chamber, with no friend but his books, no recreation but the recollec. tion of his dear Brahmins and Parsees. The fruits of this retirement were his work, l'Inde en Rupport avec l'Europe, and the Unrevealable Mysteries (Oupnekhat), 2 vols., 4to, 1804 ; the latter, a translation into Latin of a Persian extract from the Vedas. When the national institute had taken the place of the former academies, $\boldsymbol{\Lambda}$. was elected a member. Exhausted by continued labours, and a very abstemious diet, he died at Paris, Jan. 17, 1805. Immense learning, acquaintance with almost all the European languages, and a restless activity, were united, in :A., with the purest love of truth, with sound philosophy, rare disinterestedıess, and an excellent heart.

ANSELs, archbishop of Canterbury, was born at Aosta, in Piedmont, 1034; became a monk in 1060 ; some years later, a prior; and, in 1078, abbot of the monastery of Bec, in Normandy, whether the fame of the renowned Lanfranc had attracted him. In 1093, he succeeded Lanfranc as archbishop of Canterbury, in Fugland, which place he held till his death. Intelligence and piety distinguish his writings. He endeavoured to discover some conclusive proofs of the existence of God, which he thought he had finally effected in the ontological method, as it is called, of which he is falsely styled the inventor. He inferred the existence of a supreme and perfect Being by arguments drawn fiom the abstract idea of sich a Being. Notwithstanding the insufficiency of this proof, which found an early opponent in Gamilo, a monk at Marmontier, the labours of $\Lambda$. werc of great inportance. Though the influence of the church, and the fathers of St Augustin in particular, is obvious, he deserves the praise of having dcveloped the principles of his system of philosophical religion in a decidedly logical form, with acuteness and energy, and of having laid, at the same time, the foundation of the scholastic philosophy. He died in 1099, and will be remembered by his writings, $D e$ I'erilate, De Libertate Arbitrii, by his Monologium and Prologium; in the latter of which his argument in proof of the cxistence of a Supreme Being is set forth.

ANSGAR, or ANSHAR; called the apostle of the North, because he introduced Christianity into Denmark and Swelen. Born in 800 , in Picardy, and educated in the monastery of Corvey, he became, in 813, a Benedictine. At the instigation of the emperor, Louis le Debonnaire, he went to Denmark in the suitc of some baptized Danish princes, in 826, and, after many disappointments and persecutions, converted the king, and the greater part of thic nation, in 830. After lis return, 831, he founded a metropolitan church at Hamburg, and became first archbishop in that place. In 847 , he transferred his residence to Bremen. At this time, he undertook a new mission into Demmark, in orler to convert king kiric I., and went, with recommendations from him, to Sweden, wherc hic baptized many converts, with the permission of king Olaus. He also baptized the successor of Eric, in 858. He died 865 , with the reputation of having undertaken, if not the first, the most. successful attempts for the propagation of Cluristianity in the North. His prudence, the purity and warmth of his religious zeal, and the integrity of his life, arc equally praised by all his contemporaries. 'The Catholic church has placed him aunong the saints.

Anson, George, lord, whose name shines in the annals of British navigation, was born in 1697, at Shugborough manor, in Staffordshire, and entered early into the navy. In 1716 , he served, as second lieutenant, under Sir John Norris, in the Baltic, and in 1717 and 1718, under Sir George Byng, against the Spaniards. In his 27 th year, he was raised to the rank of post-captain, and was, for a long time, on the South Carolina station. When, in 1739, the ministry considered a rupture with Spain as unavoidable, he was made cominander of a fleet in the South sea, directed against the trade and the colonies of that nation. The expedition consisted of five men-of-war, and three smaller vessels, which carried 1400 men. A. left England, with this squadron, Sept. 18, 1740, and was attacked, on leaving the straits of le Maire, by terrible storms, which prevented him from doubling cape Horn for three months. Separated from the rest of his squadron, he reached the island of Juan Fernandez, where three of his vessels rejoined him in a very miserable condition. After his men had rested, he proceeded to the coast of Pern, without waiting for the missing ships, made several prizes, and captured and burned the city of Paita. After a fruitless attempt to intercept the annual Manilla galleon, he found himself obliged to burn, not only a great part of his booty, but all except one of his vessels, in order to equip that one, the Centurion, with which he made his retreat to Tinian, one of the Ladrones. Here the Centurion was blown out to sed while the commander was on shore. Upon this, much exertion was made to enlarge and fit out a sinall vessel, found in the island. The return of his ship relieved him from this difficulty, and, after some weeks of rest, he sailed for Macao, where he formed a bold plan for taking the galleon of Acapulco. For this purpose, he spread the report of his having returned to Europe, but, in fact, directed his course to the Philippines, and cruised near the promontory Spiritu Santo. After a month, the expected galleon appeared, which, trusting to its superiority, commenced the fight. But the valour of the British prevailed, and the galleon, worth $£ 400,000$ was taken; the booty gained on the former occasion amounted to more than $£ 600,000$. With these acquisitions, A. returued to Macao, sold his prize, and maintained with energy the rights of his flag against the Chinese government at Canton. From this place he sailed for England, and, passing undiscovered through the French fleet in the channel, arrived at Spithead, having circumnavigated the globe, June 15, 1744, after an absence of three years and nine months. This perilous voyage through unexplorcd scas added much to geography and navigation. His adventures and discoveries are described in Anson's Voyage. A few days after his return, he was made rear-adiniral of the blue, and, not long after, rear-admiral of the white ; he was also elected momber of parliament. His victory over the French admiral Jonquicre, near cape Finisterre, in 1747, raised lim to the peerage, with the title of Lord Anson, baron of Soberton. Two of the prizes taken on this occasion were called l'Invincible and la Gloire, which induced the captain of the former to say, on giving up his sword, "Mfonsieur, vous avez vaincu l'Invincible, et la Gloire vous suit." "Sir, you have vanquished the Iuvincible, and Glory follows you." Four years afterwards, he was made first lord of the admiralty. In 1758, he commanded the fleet before Brest, protected the landing of the British at St Malo, Cherbourg, $8 \mathrm{c}$, and received the repulsed troops into his vessels. Finally, in 1761, he was appointed to convey the queen of Gcorge III. to England. He died in 1762. on his estate at Moor Tark, leaving no children. 
Anspaci (Onolzbach); formerly the residence of the margraves of Anspach Baireuth, now the chief Wwn of the Bavarian district of the lezat; contains 1016 louses, and 16,370 inlabitants, with a fue palace, a royal school, und some manufictures. In the garden of the palace stands the monument of the poet $\mathrm{Uz}$, who was born at $\Lambda$., and died there in 1796. The last margrave ceded the marquisate or principality of A. to Frederic Willian 1I., king of Prussin, Dcc. 2, 1791. Ilis wife was lady Craven. Frederic William III. cedel $\Lambda_{0}$, in 1806 , to France, and she exclinged it with Iavaria for Juliers and Berg. P'russiu gave up, also, Baireuth, in 1807, at the pence of 'Tilsit, to France, and France transferred it to Bavaria. In the time when $A$ uspach and Baireuth were unler the French goremment, lBernadotte, the present king of Sweden, was their governor, and gained the love of all the inlıabitants, by lis strict justice, even where French soldiers were concerned, and by his endeavours to alleviate, as much as possible, the evils of war. His conduct presented a striking contrast to that of several other French governors of conquered yrorinces under Napoleon.

Anstey, Christopher, an ingenious poet of the 18th century, was the son of the reverend Christopher Anstey, 1. D., and born in 1724. He was educated at Bury St Edmond's, whence he remored to Eton. In 1754, he succeeded to his patrimonial property, when he inarried Aun, daugliter of Felix Calvert, Esq., of Albury Hall, Herts, by whom he had thirteen children, eight of whom survived hin. He then resided, for the most part, at Bath. He had long cultivated poetry, but most of his early productions were Latin translations of English popular poems, one of which was Gray's Elegy. It was not until 1766, that his humorous production, the New Bath Guide, was published, which at once became highly popular for its pointed and original humour, and, as usual, led.to numerous imitations. He also wrote several other pieces, which are incorporated in an edition of his entire works, edited by his son. He died in 1805 , in his 81 st year.

Ast (formica, L.), a genus of hymenopterous or membranouswinged insects, belongs to Cuvier's second section, aculeata; family, hcterogyna.-This race of insects, celebrated from all antiquity for singular instincts, industry, and foresight, would require a volume for the enumeration of all the curious and interesting circumstances observed by various naturalists, who have devoted themselves to their investigation. But as such amplitude and minuteness of detail are inconsistent with the present work, our remarks will be confined to essentials. To the works of Swammerdam, Reaumur, and, most especially, Huber, we must refer those who desire to be particularly informed on the subject: the last-named author has, in his work on ants, rivalled his father's justly celebrated treatise on bees, and bestowed upon lovers of natural science a gift as precious as it is rare.Most of the species live in large companies or societies, composed of three sorts of individuals, -males, females, and neuters. The males and females lave long wings, not so much veined as in other insects of the same section, which are rery temporary; the neuters, which are actually females with imperfect ovaries, are destitute of wings. The males and females are found in the vicinity of their habitation but a short time, as they speedily mount into the air, where their sexual connexion is consummated, after which the males perish, and return no more to their former dwelling; while the impregnated females, aligliting on the ground, detach their wings by the aid of their feet, and commence the great work of their existence,-the deposition of their eggs for the contimuace of the species. Some of the females, which couple in the vicinity of the ant hill, are fre quently seized upon by the numerous neuters, curried back into the galleries of their dwelling, and detained until they destroy their vings, and lay their eggs; after which they cease to be of consequence, and are driven forth. The males are much smaller tham the females, and have larger eyes, though the head and mandibles are proportionally snaller. The neuters have neither wings nor smooth eyes; their heads are large, their jaws strong, und their corselet compressed, or even knotty ; their feet proportional. These neuters perform all the labours of the ant hill; they excavate the galleries, procure food, and wait upon the larves until they are fit to leave their cells, appearing always industrious and solicitous. They are apparently endowed with the power of communicating to each other the result of their searches after food, and thus obtain the co-operation of several, where the strength of an individual would be insufficient. They feed the larves, or young ants, which are destitute of organs of motion, with materials which they disgorge from their own mouths, and which seem to have undergone some preparation in their stomachs. In fine weather, they carefully convey tliem to the surface for the benefit of the sun's heat, and as attentively carry them to a place of safety, either when bad weather is threatened, or the ant hill is disturled. In like manuer they watch orer the safety of the nymphs or larves about to acquire their perfect growth, some of which are in cocoons, and soine urcovered. When the time arrives at which the former are to undergo the final change, they tea. open the coccons to permit them to escape. If the weather be unfarourable, they detain those which have acquired their wings till a suitable opportunity offers, and then aid them to gain their liberty by the easiest route.-There is a very considerable variety in the ant hills, or nests, according to the peculiar nature or instinct of the species. The greater number make their nests in the earth, under buildings, \&.c., where they excavate extensive galleries for the reception of their young ; and of these the dwelling is almost entirely concealed. But others build their hills or nests of various substances, and form cones or domes of considerable size above ground. Some, again, prefer the trunks of old trees, in which they form the most singular labyrinths, leading to the cells where the progeny are to be reared. These nests, whether above or under ground, have commonly a strong and sour odour, which arises from the acid secreted by some of them from glands placed near the anus. This acid, once supposed to be of peculiar character, but now considered as acetic acid, is known by the name of formic, or acid of ants. One among the most curions circumstances connected with the general history of ants, is the exception to the general rule relative to the occupants of nests being individuals of the same species. Huber first observed, and his observations have since been ankply confirmed, that the reddish, Amazon or sanguineous ant resorts to violence to obtain working ants, of other species, for their own use, thus actually making slaves of those they carry off to their nests. The neuters of these Amazons, regularly abont the same hour, when the heat of the day begiris to diminish, and for several successive days, advance in a dense mass towards the ant hill they design to plunder ; there, in spite of all the opposition made, they enter, seize on the larves and nymphs peculiar to this species, and carry them off to their own nest, where other neuters of the same species, lout of full growth, take care of these kidnapped individuals, as well as of the offspring of their vas- 
qุuishers. Another exceedingly curious fact, in relation to ants, is the subserviency of the little insects, called aphides or vine-fretters, to their necessities. The aplides are remarkable for ejecting from little prominences on the posterior part of their bodies, a small drop of limpid and sweet-tasted fluid. Not unly do the ants profit by this when it is found un the leaves, but they know how to obtain it from the aphides at will. An ant approaches the aphis, and begins very gently to touch it with his antenna over the sides and back, as if caressing it. In a very short time, the aplis raises its hinder limbs slightly, and from the orifices on its back a small, clear drop exules, which is greedily drunk up by the ant, who repeats the same treatment to several, until his hunger is entirely sated. These aphides have been appropriately called the cows of the ants, which, in fact, seem to regard them as their peculiar property, not only taking great care of them, but fighting tor their possession. So fully sensible are they of their great value, that they carry the egrs of the aphides into their nests, where they take care of them till they are hatched. Some species of ants keep their aphides altogether under ground, or at least during bad seasons, where they feed on the roots of plants; others build with clay small galleries from the antliills up trees, and even to the branches, upon which the aphides abound. - Male and female ants survive, at most, fill autumn, or to the commencement of cool weather, though a very large proportion of them cease to exist long previous to that time. The neuters pass the winter in a state of torpor, and of course require no food. This well-ascertained fact proves that their remarkable foresight has no other object than the continuance of the species by perfecting and securing their habitations. The only time when they require food is during the season of activity, when they have a vast number of young to feed. It would be well for mankind if ants derived all their nourishinent from the aphides, or from the dead bodies of other insects, small birds, \&c. Unfortunately, they are but too celebrated, in most countries, for their lestructive operations among the grain, in gardens, pantries, and conservatories. Their larves and nymphs are, in some parts of the world, collected for the purpose of feeding pheasants and young turkeys, but we know of no other economic use, to which they are particularly applicable. The bodies of small aninals, skinned, and secured near an ant-hill, are soon converted into very neatly-cleaned skeletons; hat care must be taken to prevent them from being carried off by larger animals, or from remaining too long exposed to the weather after laving been stripped by the ants of their flesh.

ANT-E.ATER (myrmeeophaga, I.) ; a genus of mammiferons quadrupeds, of the order edentata, C. - This peculiar race of animals is only found in the southern part of the American continent, where they aid in diminishing the numbers of immense hordes of ants, which desolate the country in the vicinity of their dwellings. Fvery particular of their construction renders the ant-eaters especially fit for the duty they perform. The whole head is remarkably elongated, and destitute of teeth, but furnished with a very narrow, long, smooth tongue, by the aid of which they gather their prey. Their limbs, especially the anterior, are very robust, and furnished witlı long, rompressed, acute nails, admirably adapted for breakfing into the hillocks containing their appropriate food. The most remarkable of the species, whose habits are best known, is the myrmecophaga jubrita, or great ant-eater, sometimes called ant-bear.-The great ant-eater is four or five feet long, exclusive of the tail, which is about tliree. The head and anterior extremities are covered with a brownish lıair, whlch is mixed with white on the trunk and tail, though the predominant colour is brown. On each side of the shoulders there is a black band between two white ones, which ascend towards the middle of the back, where the hair is elongated to a sort of mane, which increases in length and thickness towards the base of the tail. The hair is flat at the end, and round for the rest of its length, somewhat resembling the hair of the deer. The fore feet have five digits, with very strong claws; the hind feet, four: there are two pectoral mammix. The great ant-eater leads a harmless and solitary life, but is not so incapable of self-defence as might be inferred from its exceedingly small moutl and ertire want of teeth. When irritated, it erects its long, brush-like tail, and waves it in the air, and, when attacked by a dog or other small quadruped, either seizes and compresses it to suffocation between its powerful fore legs, or, sitting on its hinder limbs, strikes destructive blows with its strong, sharp claws. To man, however, they offer very little resistance, being easily killed by blows on the head. In feeding, the great ant-eater either thrusts his long, narrow tongue, covered with a glutinous fluid, into the ant-heap, whence he withdraws it covered with the insects; or else, having partially demolished the lill by means of his fore limbs, he, with wonderful celerity, transfers the alarmed inhabitants to his stomach, by repeated extensions and retractions of his tongue, which operation the animal is stated, by observers, to effect twice in a second. The sarages and negro slaves hunt the great ant-eater for the sake of its skin and flesh, which the negroes esteem highly. This species may be domesticated, and then feeds upon small pieces of bread or ment, and various insects. Two other species have been long known, both of which have naked, scaly and prehensile tails. These are the three-toed ant-eater, mymneeophaga tamandua, C.; tridactyla; L.; and the two-toed ant-eater, myrmecophaga didactyla, L. These, as might be inferred from their size (the first twentyfive inches, with a tail sixteen inches long; the second seven or eight inches long, with a tail of eight or nine inches), and the prehensile character of their tails, are adapted for climbing trees and preying upon ants which make their nests in such situations. The two-toed ant-eater brings forth but a single young one at a birth, on a bed of leaves prepared in a hollow tree. Krusenstern, in the narrative of his voyage, describes a species which grunted somewliat like a hog, had a tail shorter than the body, was of a white colour, with twelve blackish bands. The name of myrmecophaga annulatus has been given to this by Desmarest. All the ant eaters are slow in their movements, and the two smaller species are especially helpless when on the ground, though they defend themselves bravely when attacked. In order to use their defensive fore claws to greater advantage, they sit upon their hinder limbs like the bear, and strike with great force.

Ant.eus; the giant son of Neptune and of the Earth, who lived in a cave in Lybia, and forced every stranger who arrived to fight with him. Whenever he was thrown to the earth, his strength was restored by his mother. By this means, he succeeded in killing his antagonists, and planted their skulls round his dwelling. But Hercules, whom he challenged to combat, perceiving the secret of his strength, grasped him in lis arms, and stifled him suspended in the air.

Antagonist Muscles; those muscles which have opposite functions, as flexors and extensors, abductors and adductors.

Antanaclasis (Greek; from avravariaw, I drive back); the repetition of a word in a differcnt mean 
ing, or as a different part of speech, which attracts atcoution, mind gives expressiveness to the plirase; e. g., "I set the deal bury their lead;" or, "Live while you live." The retnruing to a subject after a long parenthesis is also called antanaclasis.

ANTAR, or ANDAR; a fimous Arubian prince in the middle of the 6th century, and one of the seren poets, whose successful verses, embroidered with gold upon silk, were hung up at the door of the Caaba. (See Arabian Literurure, and Moallakut.) He describes in his Moallaka his warlike deeds and his love for Abla. The most complete edition is that of Menil (Leyden, 1816, 4to.) Hartmam's German translation, from the English translation by Sir W. Jones, was published in the Hellstrathlenden Plejaden, an Arab. poet. Himmel. (Muuster, 1802.) In the Arabian romance Antar, the author, Asmai, a renowned gramınarian and theologian at the court of llarom $A l$ Raschid, in the beginning of the 9th century, who first collecterl the old A rabian traditions, lias added to the name, and the heroic adventures of Antar, the other most famous chivalrous deels of the Arabians. Sir W. Jones first made us well acquainted with this remarkable and attractive romance ; after him, v. Hammer, in his Fundgruben des Oricntes (1812,) described the complete copy of it in the imperial library at Vienna; besides which, there are six others in Furope. This romance gives the most complete idea of the manners and life, of the way of thinking, of the opinions and the superstitions, of the early Arabians before the time of the proplict, and the fidelity of the picture is eren now to be recognized in many features of the modern Bedouins. It is written in the purest Arabic, and rauked among the classics of Arabian literature. It is so attracting, that critics prefer it to the Arabian Nights. Hamilton, secretary of the British embassy in Constantinople, lus translated it into English (Antar, a Bedoueen Romasice, translated from the Arabic, by Terrik Hamilton; London, 1819 , 4.vols.)

A French translation has since appeared at Paris.

A.rtarctic Circle (of avit, opposite, and aexros, a bear) is one of the smaller circles of the sphere, parallel to the equator, and distant from the south pole $23^{\circ} 30^{\prime}$. Antarctic pole, being opposite to the arctic pole, denotes the opposite end of the earth's axis, or the south pole. 'Till lately, no land was known to exist beyond the 60th degree of south lat. Cook (q. v.) reached this degree, but masses of ice and storms drove him back. In 1820, a whaleman discovered an island south of cape Horn, in lat. $61^{\circ}$ about 200 miles in length, which he called New Shetland. Since this time, British and Russian ships have penetrated still farther towards the south pole. (See Southern Polar Islands.) Probably not the cold, but the great number of islands, with shallow currents between them, and the late melting of the ice on the sand-banks, in narrow gulfs, would form the chief obstruction to ever reaching the south pole. As, in this region of cold, the whales have been pursued but a few years, they are very numerous, and chance will no doubt, lead some seaman, while engaged in the whale fishery in the antarctic region, to new discoveries.

- Antenllovias; any thing or being which existed before the deluge. See Deluge, and Fossil Remains.

AvTrLops; a genus of mammiferous, ruminant quadrupeds, intermerliate to the deer and goat, first established by the Russian naturalist Pallas, and subsequently divided into numerous sections by Blainville, founded on characters furnished by the shape and curvature of the horns, \&c. The characteristics of the genus are the following :-horns per. sistent, hollow, resting on a solid, bony nucleus of the os frontis ; straight, spiral, lyre shaped, annulated ? at base; marked with transverse bands, n salient spiral line, or bifurcatrul in different species: gall bladder unifornly present, which is not possessed by deer. In other churacters, the antelopes bear a very marked resemblance to the deer, except that some species of antelope have tufts of hair pendent from the carpus. Numeruus as ure the species of antelope, but two are found in lurope, and only one in America-the chanois and saiga in the former, the pronghom (q. v.) in the latter. All the rest are natives of the hottest parts of Asia and Africa. They are genemally remarkable for the symuetry und delicacy of their forms, and surpassing celerity of inovement. 'Their eyes are proverbial for largeness and lustre. Possessing less of muscular vigour and conpactness of frame than the deer, they do not advance by siccessive bounds, but by a regular mee, the swiftness of which in some species, almost excecls imagination. They are generally jellow on the back, anl white beneath, liaving a lrown band separating these colours at the flank. The ears are long, straight, pointed, and somewhat dilated in the midule. Great varieties of appearance and habits are exhibited in the different species : sone are monogamous and sulitary; some prefer arid deserts, where but a scanty subsistence is to be obtained, of aromatic, acriel, or salt tasted plants; others delight exclusively in the fresh lerbage growing in the vicinity of rivers and marshes. One species, the cliamois, delights to browse on the almost inaccessible summits of the icy $A l p s$ : almost all the others prefer the sultry plains of the torrid zone. In form, some of the species resemble a slender deer or goat; while a few others approximate considerably to the appearance of the ox. With a solitary exception, that of the gnu, they are gentle, timid, harmless, and easily tamed. The gnu is fierce and warlike, exhibiting through life a vicious and indomitable disposition. Many of the species are gregarious, living in herds or families, cunsisting of twenty or thirty individuals. They feed exclusively on regetable food, and their flesh is regarded as a luxury when obtained in the proper season. A gainst their muneruus enemies, they have no resort but in fight, and swift as this is, it cannot save them from the unremitted pursuit of the jackal, or the insidious prowling of the tiger. Lions. leopards, ounces, and other carnivorous tyrants lie in ambush for them at their drinking-places; and man, aided by dogs and falcons, contributes his share to their destruction. In the great system of balances established by uature, they seem peculiarly adapted for their situation, which is generally in countries where a luxuriant vegetation requires constant efforts to repress its superabun. dance; while they, at the same time, furnish large supplies of food to numerous carnirorous animals, as well as to the human race. The following are the names of the subgenera proposed by Blainville, \&c. and now generally adopted by naturalists:-1. $A n$. tilope. 2. Gazella. 3. Cervicapra. 4. Alcelaphus. 5. Tragelaphus. 6. Oreas, Desm. 7. Boselaphus. 8. Oryx. 9. Egocerus, Desm. 10. Bupicapra. 11. Antilocapra.

Avtrusat (a Latin word, signifying born before); the subjects of Scotland born befure the accession of James I., to the English crown are thus callerl; those who were born after the accession being denominated postnati. The A. were considered aliens in England; so, too, persons born in Britain before the separation of the present United States from the mother country have been held to be aliens in the United States.

ANTENSE, in entomology; slender bodies, with which nature has furnished the heads of insects, being the same with what are called horns or feelers. ANTENor : a noble Trojan. In Homer, he is repre- 
sented as a prudent old man. He received Ulysses and Menelaus as guests, during their embassy to 'Troy, accompanied Priam to the field of battle, to ratify the treaty, and after the single combat between Ajax and Hector, proposed, though in vain, the restoration of Helen. This was probably the foundation of the story that he was friendly to the Greeks, and treacherous to the Trojans. He is said to have delivered the Palladium to the Greeks, to have given the signal for their entrance by a light from the wall, and to have himself opened the famous horse. His house remained safe in the sack of the city, which may, however, he explained by the former hospitality of A. to Menelaus. He himself escaped in the same manner as Eneas, and became like him, the founder of a new dynasty. Traditions differ concenning it. The most common is the story told by Virgil, that he removed with his sons to Thrace, and thence, with the Heneti, to Italy, where he founded Patavium, now Padua.

Axteros, in mythology; the god of mutual love. The later mythology says, that as soon as Eros, the god of love, was grown up, his mother borc Anteros to Mars, a fiction which indicates that love must be mutual. According to some modern interpreters, however, Anteros is the cnemy of love, or the god of antipathy.

Aงtrej. See Antiphony.

Anthing, Frederic; known by his biograplyy of the famous field-marshal Suwaroff, whose companion in arms he had been. He was born in Gotha, travelled through Europe, and went to Petersburg, where he lived. by taking silhouettes (profiles cut in paper), which just then had come into fashion. The likenesses of this sort, which he took of the imperial family, made him known. He was for a long time on the most intimate terms with Suwaroff, till this general fell into disgrace with the emperor Paul. A. died, in 1805, in Pctersburg.

ANTnoLogy (Greek; a collection of flowers) is the name given to several collections of short poems, mostly epigrams, which have come down from antiquity. The first compiler of this kind was Meleager, a Syrian, who, albont sixty B. C., made a collection of his own poems, and those of others. In later times, the same was done by Philip of Thessalonica, probably in the time of Trajan; Diogenianus of Heraclea, Strato of Sardis, both under Adrian; and Agathias, in the 6th century. But all these ancient collections are lost. We now possess two of a later period, the one by Constantinc Cephalas, in the 10th century, who, in his Florilegium, made much use of the earlier ones, particularly that of Agathias; the other by Maxinus Planudes, in the 14th century, a monk of Constantinople, who, however, by his tasteless extracts from the Anthology of Cephalas, rather injured than inproved the existing stock. The latter is the most common. It contains seven books, which, with the exception of the 5th and 7th, are subdivided in alphabetical order. It agrees only in part with the Anthology of Cephalas, which has been preserved in a single copy. This copy was carried from Heid. elberg to Roine, and thence to Paris, but has been again restored to the Ileidelberg library. The last and most complete edition of this original text is that of Jacobs, Leips. 1813, fonr vols. The editions of Brunck (Analecta), Sirasb. 1772, three vols. which appearcd accompanied with the commentary of Jacubs, Leips. 1794, thirteen vols., are compiled from the Anthology of Planudes and Constantinus. In Germany, the Greek Anthology has been often translated, and the rich poetical vigour, the delicacy of feeling, the sportive gayety, the noble and elevated thonghts, displayed in thesc little picces, have secured for them a deserved admiration. A simi- lar Iatin Anthology has been collected by Joseph Scaliger, Lindenbruch, and several others; the best cation is that of Peter Burmann, junior, Amsterdam, 1759-73, two vols. 4to. Orieital literzture, particularly the Arabian, is very rich in anthologies. The Arabian name for them is Hamasah.

Avтнovy, St, the Great ; first institutor of monastic life ; born A. D. 251, at Coma, in Heraclea, a town of Upper Egypt ; went into retirement from a propensity to devotion, A.D. 285, when he had never known the pleasures of knowledge, and, probably never learned to read. A.D. 305, several hermits united with him, and formed the first community of monks. A. D. 311 , he went to Alexandria, to seek the honour of inartyrdom, amid thc persecutions then raging against the Christians; but, as his life was spared, he returned to the cottages of his monks. He afterwards left this institution to the care of his scholar Pacomius (see Monastery), and retired with two friends to a more remote desert, where he died, A.D. 356. That he used no garments but a shirt inade of hair and a sheep-skin, and never washed his body, is more credible than the strange stories of his contests with devils, and the wonders which he has himself made known, as rclated in his life by St Athanasius. All his conduct indicates a fervent and melancholy imagination. Seven letters, and some other ascetic writings were formerly attributed to him, but it is not probable that he was their author. There is, also, but little proof that he instituted laws for the monks ; and the opinion is wholly unfounded that he established a particular order. Yet the monks of the heretical churches in the East, 'e. g., the Maronites, Armenians, Jacobites, Copts and Abyssinians, pretend to belong to the order of St A., but they only follow the rules of St Basil. As a saint of the Catholic church, A. is much esteemed. Prayer for his intercession was intended, particularly, to preserve from the St Anthony's fire, so called from him,-a violent and terrible disense of the middle ages, which dried up and blackened every limb which it attacked, as if it were burnt. Gaston, a rich nobleman in Dauphiny, whose son had been cured (as he supposed) by the pretended bones of St $A$., at St Didicr-la-Mothe, in token of his gratitude, established, A.D. 1095, the hospitable fratemity of St Anthony, for the care of the sick, and the assistance of pilgrims, of which he was the first chief. 'This order received, from the churches assembled at Clermont, A. D. 1096, the papal confirmation; took the monastic vows, A. D. 1218 ; and were declared by Boniface VII., A. D. 1298, a fratcrnity of regular canons, according to the rules of St Augustin; their clief was to be termed abbot, have his seat at St Didierla-Mothe, and be the general of all the houses of that order. The priors of these houses called themselves comthure, afterwards preceptors, and werc subject to the abbot. The dress of these Anthonians was black, marked on the breast with a blue cross, nearly in the form of a T. They afterwards altered the rules of their institution, and deroted themselves to a silent, contemplative life of devotion. This society became very rich by reason of the many pilgrimages to the grave of St A., and the presents which they received. Their order now became widely extended. Fven in the 18 th century, they numbered 30 convents, mostly in France; but not one of them has continued to the 19th.

ANruony, St; a cape on the coast of Buenos Ayres. It forms the southern point of the entrance into the La Plata.-There are threc other capes of the same name, one of which forms the western extremity of the island of Cuba ; another on the coast of 'Todos Samtos in Brazil; another on the coast of the straits of Magellan. 
Avтuoxy, 8t, fulls of, on the Mississippi ; lon. $93^{\circ}$ $40 \mathrm{~W}$.; lat. $44^{\circ} 15^{\prime} \mathrm{N}$. 'The river is 627 yards hroad above the falls, and immediately below it is contracted within a chamel of 209 yaris. An island divides the falls into two parts. The perpendicular height of the cataract is 16 t feet, besides 58 feet more of a rapid below; so that, when viewed from a distance, it appears to be much higher than it really is. When the river is high, the appearance of these falls is very sublime, as the spray then formed reflects all the colours of the rainbow. The surrounding country is extremely beautiful, exhibiting many gentle ascents, with enninences covered with the finest vendure. The portage around the falls is 260 rods long.

Astrosy, St, island of ; the most northern of the cape Verd islands. Topazes are found in one of its mountains, and it is said to contain mines of gold and silver. The iuthabitants, chiefly negroes, are about 580 in number.

Avtnoss of Padıa, St; born August 15, A. D. 1195, of a noble family in Lisbon; one of the most renowned disciples of St Francis of Assisi, and a powerful advecate of the Franciscan onder, which he entered A. D. 12:0 ; was shipwrecked on the const of traly, in a voyage to Africa, which he had undertaken with a view of becoming a martyr to the Christian faith, and preached, with great applause at Montpellier, Toulouse, Bologna, and Padua, where he died, June 13, A.D. 1231. His legends are full of prodigies; but all agree in extolling his talents as a preacher. According to tradition, the very fishes were affected by his eloquence. The Catholic church, particularly in Portugal and Italy, honoured him as one of its most eminent saints, anong whom pope Gregory IX. assigned him a place, A.D. 1232. At Padua, a church, coutaining his sepulchre, is consecrated to him, which is a master-piece of architecture.

ANtiracite (from aneper, coal) is the name of one of the most valuable kinds of coal used in the arts and domestic economy. Its mineralugical character is as follows: colour, greyish-black, or ironblack ; lustre, imperfectly metallic ; opaque; specific gravity, from 1.4 to 1.6 ; fracture, conchoidal. Some varieties abound in fissures, in consequence of which they possess an irregular columnar structure, and a lower degree of lustre, and occasionally highly compact, of a black colour, with a shining lustre, and occasionally highly tarnished with irridescent colours. Anthracite consists wholly of carbon, mixed with a slight and variable proportion of oxyde of iron, silex, and alumine. It is inflammable with some difficulty, and burns without smell or smoke, leaving a more or less earthy residue. It is less widely distributed than the bituminous coal, and belongs exclusively to transition rocks. It has been found in several European countries, where owing to its limited extent and other causes, its use appears to be but little known. In the United States, on the contrary, it occurs in the greatest abundance, and, within the last ten years, has acquired a high degree of importance. Its difficult combustibility wns, for a time, an obstacle to its introduction; this, however, was obviated by the invention of peculiar furnaces and grates. It is now very largely used in all the maritime parts of the United States, not only for manufacturing purposes, in which its utility is immense, but in the warming of apartments, both private and public; and its cheapness, the intensity and equability of heat it produces, together with its perfect safety, and freedom from all disagreeable smoke and smell, gire it a decided preference over every other species of fuel. In Pennsylvania, the anthracite coal formation is known to cover a tract of country many miles in width, extending across the two entire coluties of
Luzerne and Schuylkill. Mauch Cluunk, upon the Lehigh, Fottsville, at the head of the Schmylkill cama, and Wilkesharre, upon the Susquehanna, hav. ing afforded the chief supply of coal from this region, as well as the grentest proportion consumed in the United States. At Mauch Chunk, 800 men were emplosed in digging coal, in 1825, in which year 750,000 bushels were sent to Philadelphia. 'The anthracite, throughont this region, is explored with very little labour, being situated in hills from 300 to 600 feet above the level of neighbouring rivers and canals, and existing in nenrly horizontal beds, from 15 to 40 feet in thickness, covered only by a few feet of gravelly loam. At l'ortsuouth, in Rhoxle Island, an extensive bed of this conl has been worked, with some interruption, for 20 years; and, more recently, a nine of antliracite has been opened at Worcester, in Massachusetts, at the head of the I3lackstone camal.

ANTuropolites ; petrifactions of human borlie's or parts of the body. (See Petrifications.) 'I'huse of animals are called zoolites.

ANTHRopology (fiom avfewers, man, and royos, a discourse) signifies the science which trents of luman nature, either in a physical or an intellectual point of view. It is frequently used to denote the science of anatomy. In theology, it denotes a way of speaking of God after the manner of men, by attributing to him human passions and affections. (See Philosophy.)

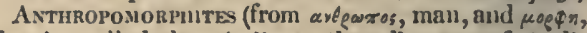
form); called also Audians; the adherents of Audius, or Audaus, a teacher in Syria, who was banished to Scythia, introduced Christianity among the Goths, and died about 370 after Christ. They were excommunicated by the orthodox church, rather on account of their persevering in the old way of celebrating Easter, at the same time with the Jewish Passover, their deviation from the usual penances, and their zeal against unworthy priests, than on account of their representation of God in a human shape. Towards the close of the fourth century, they still existed, as schismatics of severe morals, in small bodies in Syria; in the fifth century they were extinct. - The Italian divines at Vicenza, about the year 938, who were called Anthropomorphists on account of similar representations of God, formed no sect.

Axtriropopiagl (from avfowros, man, and payo, I eat); man-eaters, cannibals. The practice of eating luman flesh, unnatural as it may seem to us, is found to prevail among some nations. In some cases, lounger, in others, revenge, in others superstition, is the motive; at least, it is reported that the Mexicans used to eat the flesh of the victims whom they had sacrificed to their idols. In some instances, a horrid desire for human flesh appears to have been occasioned by disease, like other perversions of the appetite. Thus a cowherd, named Goldschmidt. who had committed a murder, and in order to prevent discovery, had cut the body in pieces, is said to lave felt a craving for human flesh arise within hin, and, after devouring the body of the murdered man, to have killed an infant expressly for the purpose of gratifying his unnatural longing. (See Gruner's Almanac for Physicians, Almanach fur Aerzte, 1782. page 312.) Boethius reports, in his history of Scotland, an instance in which this disease seized a whole. family. A robber, his wife and children, were burnt, because they had killed and eaten several persuns whom they had enticed into their dwelling. Only one daughter, who was very young, was left alive; but scarcely had she reached her 12 th year, when she was executed for the same crime. That there are nations who eat the flesh of enemies slain in battle, e. g., the New Zealanders, is well knowu; but there are none who make human flesh their. nsul 
foot, except, perhaps, the Battos in Sumatra, according to the report of Anderson (London, 1826). The cruelty of the first conquerors of America, the Spaniards, inflamed the gentle natives to a barbarous revenge; and they were calumniated as cannibals, to afford a better pretext for their destruction. Under this pretence, the Caribs were extirpated. Modern navigators have not confirmed those sweeping accusations of barbarism and eannibalism; and even where they have met with nations who ate human flesh (that of slaughtered enemies), they have found them mild and kind-hearted people. In Germany, during the reign of Joseph II., it was pretended that gipsies had been known to murder travellers, cut them in pieces, salt and eat them! Camilaalism prevailed among the savage Scythians and Sarmatians, also among the ancient inhabitants of Canaan.

Antibacchos. See R/ythmus.

Antizes ; an old town of Provence, in the department of the Var, on the Mediterranean, with a commodious harbour and a strong citadel. It was founded by the Massilians, $340 \mathrm{~B}$. C. and named Antipolis. A. now contains 500 houses, with 5270 inhabitants. It is an important barrier fortress on the side of ltaly, and was, in 1747, besieged without effect by the Austrians and British. A. is remarkable for being the only place where the French soldiers refused to join Napoleon on his landing from Elba, in 1815. Lon. $7^{\circ} 11^{\prime}$ E. ; lat. $43^{\circ} 35^{\prime} \mathrm{N}$.

Avticagla, See Antique.

Antichmst. In the last centuries before Christ, the Jew's connected with their idea of the Messiah the notion of an Anti-Messiah, or an enemy to the attempts of the Messiah to promote the good of their ration, who would cause great sufferings before the advent of the latter. The books of the New Testament mention the Antichrist as one or several false prophets, who would pretend to be the true Christ, and would deceive the world. In the Apocalypse alone, he is represented as a powerfill ruler, opposed to Christianity. The Christians, in the first centuries, retained the idea of such a powerfil enemy of the church, whose appearance, announced by their own persecutions, would precede the re-appearance of Christ, which was then commonly expected. With the belief of the millenniun, which was to succeed the vexations of the church by the Antichrist, the idea of such a being continued under various forms, and heightened by the most lively descriptions on the part of the Christian fathers, until the year 1000 had elapsed without the fulfilment of these prophecies, and the millennial enthusiasm itself was cooled. The interpretation of the A pocalypse constantly occasioned new calculations on the appearance of the Antichrist. In the middle ages, the opponents of the Roman hierarchy eagerly applied this character to the pope, in whom not only the Waldenses, Wiekliffites, and Hussites, but even Luther and his friends, recognized the true Antichrist, as having placed himself against and above Clurist. On the other hand, the Catholics bestowed this title on Luther and other reformers. 'Thus the idea of the Antichrist, as a dangerous enemy to the true church, remained under a variety of forms, without ever regaining universal acknowledgment. The fathers have generally agreed, that the Anticlirist will appear, at the approach of the last day, in a bodily shape; ; but as to nis origin, and time and place of appearing, their nuinions differ. Some believe that he will be a mere man - "the man of sin, the son of perdition," spoken of by St Paul; and. others, that he will be an incarmation of the devil. Malvenda, in a large work, consisting of thirteen books, has given the most minute account of the birth, childhood, education, character, power, wars, peusecutions, and death of Anti christ. The church of Rome has never pronounced any decision with regard to the varions notions its members have entertained on this subject. Napoleon was styled Antichrist by some persons, and several passages of the Apocalypse were referred to him. At present, the great party of fanatics, political and religious, perceive the Antichrist in human reason, or, rather, in the free use of it against the views and pretensions of fanaticism. Among the Jews, too, since the destruction of Jerusalem by Titus, the wonderfinl prophecy of a contest is preserved, in which an Antichrist, by name Armillus, will be vanquished by the true Messiah, after a severe oppression of the Jews.

ANticyra ; a town of Phocis, in Greece, famous for the hellebore which it produced. This plant was of great service in curing diseases, particularly insanity, and $\mathrm{A}$. was therefore much resorted to by the ancients; hence the expression of Horace, Naviget Anticyrans.

ANTigone, the fruit of the incestuous marriage of Edipus and Jocasta, though innocent, bore the curse of her father's house. For her listory, see the articles Eteocles and Edipus. Sophocles has immortalized her in a tragedy.

Antigonus; one of the generals of Alexander, to whom, after his first conquests in Asia, he intrusted the government of Lycia and Phrygia. A. not only defended his provinces with very small forces, but also subdued Lycaonia. When, after the deatlı of Alexander, his generals divided his conquests among thenselves, he obtained the Greater Phrygia, Lycia, and Pamphylia. Perdiccas, who strove to unite all the states of Alexander under his own dominion, and who feared the energy of Autigonus, accused him of disobedience to the commands of the king. A. saw through his intentions, embarked secretly for Europe, and connected himself with Craterus and Antipater. 'These three, then, together with Ptolemy, declared war against Perdiccas. The latter was killed by his own soldiers. Eumenes, the general of Perdiccas, was still, however, very powerful in Asia. A. continued the war against him alone, got him into his power, and put him to death. Thus, in a short time, he became master of almost all Asia ; for Seleucus, who reigned in Syria, and had endearoured to oppose his usurpations, was likewise overpowered by him, and sought shelter with Ptolemy. A. possessed himself, also, of the greater part of the treasures of Alexander at Ecbatana and Susa, but would not render an account of them to Ptolemy, Cassander, and Lysimachus, and even declared war against Cassander, in order to revenge, as he said, the death of Olympias, and to deliver the young Alexander, who lived with his mother, Roxana, at Amphipolis. Disgusted by his ambition, all the generals united themselves against him; and, whilst Cassander attacked Asia Minor, Ptolemy and Seleucus invaded Syria, where they defeated Demetrius, the son of A. Seleucus retook Babylon. As soon as A. was apprized of these events, he returned, and obliged Ptolemy to retreat. Demetrius recovered Babylon from the hands of Seleucus. Antigoms, Ptolemy, Lysinachus, and Cassander, concluded a treaty of peace, by which they were to retain, till the. majority of the young Alexauder, who bore the title of $\mathrm{king}$, the territories in their possession. But, after the murder of the young king, with his mother, by Cassander, the war was rekindled among the competitors. A. took the royal title, but was obliged to give up his plan of conquering Egypt, as part of his fleet was lost at sea in a storm, and Ptolemy frustrated every attempt at invasion by land. Soon afterwards, young Demetrins drove Cassander from Greece. He applied for aid to Iy- 
s!machus, who went with a powerful army to Asia ; licre Setencus also joined him. Near Ipsus, in phrygin, 301 13. C., a battle was fought by the three allie's against $\mathbf{A}$. and his son, in which $\Lambda$. fell, aged 84 rears. There are several other persons of the name of Antigonus mentioned in history. A. king of Juden, son of Aristobulus. He besieged Jernsalem, was taken prisoner by IJerod, and sent to Mark Antony, who put him to deatio, 13. C. 36.-A. fonatus son of Demetrius Poliorcetes He was distinguished by his mill and humane disposition. At lis father's death, he succeeded him in the kingdom of Macelon, and all his other European dominions. Ile died, nfter a peaceful reign of 34 years, B. C. 243. Demetrius II., succeded hin. Antigonus Il., surnamed Doson, king of Macedonia, the son of Antigonus I., succeederl his brother, Dennetrius 11., 13. C. 225, and was soon after chosen commander-in-chief of the Achan forces by sen and land. A. defeated Cleomenes, king of Sparta, at Sellasia. Ile was succeeded by his nephew, Philip VI., B. C. 220 .

ANTicos; an island in the West Indies, one of the Caribbees, 21 miles long, and nearly the same in breadth, upwards of 50 miles in circunference. It contains 59,838 acres of ground, of which 31,000 are appropriated to the growth of sugar and to pasturage; its other principal commolities are cotton, wool, and tobacco. Population, in 1817, 2,102 whites, exclusive of troops; 1,747 free people of colour, and 31,452 slaves. Official value of exports,

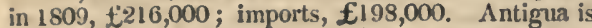
divided into six parishes, and eleven districts. The name of the capital is St Jolm's. No island in this part of the West Indies can boast of so many excellent harbours. Of these the principal are Englisi harbonr and St John's, hoth well fortifiet ; and at the former the British government has established a royal uavy-yard and arsenal, and conveniences for careening ships of war. Lon. $61^{\circ} 48^{\prime} \mathrm{W}:$; lat. $17^{\circ} 5^{\prime} \mathbf{N}$. Antigua constitutes, along with St Christopher, Nevis, Montserrat, and those of the Virgin islands which belong to the British, a separate government. The governor, who is styled captaingeneral of the Leeward and Caribbean islands, generally resides at $A$. and occasionally visits the other islands. Antigur was discovered by Columbus in 1493. The first settlement was made, in 1632 , by a few Fnglish families. In 1663, Charles II. granted it to lord Willoughby. In 1666, a French expedition, uniting with the Caribs, invaded the island, laid waste the settlements, and committed great cruclties. The island was re-settled a few jears afterwards, through the enterprise of colonel Codrington, of Barbadoes, who was appointed commander-in-chief of the Leeward islands. In 1706, and during the three succeeding years, Antigua was cursed by the government of a ferocious and unprincipled tyrant, whose varied crimes and tragical end will not soon be forgotten in the West Indies. The administration of governur Park seems to have resembled more closely the barbarous despotism of Nero or Caracalla than the governments of modern times. Ample rengeance was taken by the people, who, driven to madness by oppression, rose in a body, overpowered the regular troops, tore the living body of the oppressor limb froin limb, and gave the fragments to beasts of prey. So well was this punishment thought to be deserved, that the British government ratified the act by granting a general pardon to all concerned in it, and shortly afterwaris promoted two of the principal actors to public offices. No event of importance has nccurred in the recent history of $A$. which still remains under the British government.

Ainlegoneva : a word in Scripture criticism de- moting those books the authority of which has bern disputerl.

Antules ; a cluster of islauds in the West Indies, extending in the forn of a crescent from the coast of Floricla to the month of the Orinoco, in Colombia. They are distinguished into N'indward and Leeward islands, and into lireater and Less. The Greater comprehended Cuba, Ilayti or St Domingo, Jamaica and Porto Rico. The Less embrace Antigua, IBarbadoes, St Cliristoplere, Guadaloupe, Murtuico, Grenada, Trinidad, St 'Thomas, Santa Cruz, Dominica, St Vincent, Tobago, St Incia, \&c. Sec W'

Axtrlocinos; son of Nestor, it is sail, hy Amaxibia or Eurydice; the youngest soldier in the army of the Greeks before'Troy ; valiant and courageons, beautiful and of great strength and activity; on this account the inost favoured, after Patroclus, hy Achilles. Ile was, for this reason, according to Jlomer, chosen to announce to Achilles the denth of Patroclus. He was called from the battle, flew to his friend, reported, with tears, the monrnful tidings, and soothingly held the hands of the despairing $\Lambda$ chilles. In the ganes in lonour of the dead, he received the third prize in running, the vahe of which was enhanced by the praises of $\Lambda$ chilles. IJ slew many of the Trojan chicfs in hattle, and was once saved from the perils of fight by Neptune hinself. He finally fell in the defence of his grey-lıaired father, who, when hard pressed by the Fithiopian Memnon, had called him to his aid (Pindar Pyth. VI.), on which account the name Philopator has been given to him. His fall is represented in the llian Table, No. 48. United with his friends Patrochus and $A$ chilles, he appears among the shades in the lower world. The other traditions respectiug lim are of later origin.

Avmsacuos; a poet, a native of Colophon, who is supposed to have lived in the 5th century 3. C. Adrian, who placed Ennius before Virgil, preferred $\Lambda$. to Homer, - a circumstance which renders the loss of his compositions a subject of great regret. The names of two of his works, the Thebaid and the Lrdian, are preserved, and a fragment of $A$. is to be found in the Analecta of Brunck. The rest of his remains were published, in 1786, by Schellenburg, under the title of Antimachi Colophonii Reliquia.

Astusosy is a bluish-white, brittle metal, of a scaly or foliated texture; it has a brilliant lustre, but becomes tamished by exposure to the air ; its specific gravity is 6.7 . In this state, it is called the regulus of antimony, and is used as an ingredient in the manufacture of the best pewter, in some type-metal, and in casting leaden medallions. By exposure to heat it melts, and, becoming oxydized, rises in dense white fumes, formerly called argentine flowers of antimony.-Antimony forms with oxygen several oxydes, with which the acids unite and give rise to numerous salts, the most important of which is the triple one, called tartrate of potash and antimony. It is manufactured in the large way by mixing one pound of glass of antimony with a pound of cream of tartar, and boiling the mixture in a gallon of water for an lour or two: it is then filtered, evaporated, and set by to crystalize. Tartar emetic is the most generally used antimonial inedicine; and it may be so managed as to produce either sweating, purging, or romiting. $-\Lambda$ ntimony is found in its metallic state in minute quantities in sereral countries, and in occasional mixture with ores of silver, lead, and copper; but it is from its combination with sulpluur, in which state it occurs abundantly in Auvergne, Scotland, and Hungary, that the antimony of commerce is furnished. 'This mineral, the sulphuret of antimony, is found in compact, foliated, and radiated masses. as 
well as in distinct rhombic prisms. Its colour is a light lead-grey; it is dull, and often iridescent. Specific gravity, $4 \cdot 3$. It melts in the flame of a candle; and before the blowpipe, on charcoal, is wholly evaporated, with a sulphureous odour. It is composed of antimony $72 \cdot 86$, and sulphur $27 \cdot 14$, and in its composition exactly resembles the artificial zompound which possesses the same properties.-To obtain the crude antimony of commerce, the above ore is reduced to fragments, and put into large earthen pots, with holes in their bottoms, and these are inserted into other similar vessels; heat is applied to the upper ones, which causes the sulphuret of antimony to separate from its stony gangue, and flow into the lower vessels, which are kept cold; here it concretes into fibrous, crystalline masses, without laving undergone any change in its nature during the process. In this condition, it constitutes the crude antimony of commerce.-From this substance the regulus of antinnony is prepared, by roasting the sulphuret of antimony in a reverberatory furnace, until it forms a grey oxide, 100 weight of which is afterwards mixed with eight or ten pounds of argal, or crude tartar, and smelted in large melting pots in a vind-furnace. It also affords, by calcination and subsequent fusion in earthen crucibles, the glass of antimony, which is of so much importance in the preparation of tartar emetic. The kermes mineral, a popular medicine, is likewise prepared from the sulphuret of antimony, by boiling crude antimony and pearl ashes; the kermes mineral is deposited in the form of a purplish-brown powder. The supernatant liquid, on the addition of any acid, yields an orange sediment, called golden sulphur of antimony, which is used by the calico-printers as a yellow colour.

Axtuxomianisu (opposition to the law); the name givell, by the reformers of Wittenberg, to the disparagement of the moral law, particularly the law of Moses, by certain Protestants, who aimed thereby to exalt the efficacy of faith in the salvation of man. John Agricola was the most conspicuous member of this party, and, in 1537, violently attacked Luther and Melancthon on this ground, in a public dissertation, in Wittenberg. But, in 1539, he recanted, and published a renunciation of his errors, in 1540, at Berlin.--Antinomians is the name given to those who adhere to his doctrine, which lad its origin in an erroneous apprehension of the grace of God and the necessity of good works.

Antivous ; a young Bithynian, whom the extravagant love of Adrian has immortalized. Whether he threw himself into the Nile, with the intention of preserving the life of $\Lambda d$ rian, whom he accompanied ou his travels, or because weary of his own life, is not to be decided. Adrian sets no bounds to his grief for lis loss. Not satisfied with giving the name of his favourite to a newly-discovered star in the galaxy, which appellation is still preserved, he erected temples in his honour, called cities after him, and caused him to be adored as a god throughout the empire. His image was, therefore, represented by the arts in every way. Several of these figures belong to the finest remains of antiquity, particularly the statue called the $A$ ntinous of Belvidere, in the Vatican, found in the bath of Adrian; and the $\Lambda$. of the Capitol, found in the virta of Adrian at Tiroli. $\Lambda$ ntiquaries, however, differ much in opinion concerning these statues, and many will not allow them to be inages of $\Lambda$., but recognise in them the characteristics of certain heroes or gods. This dispute is dificult to be decided, because the artists, who represented $\Lambda$. as a god, chose divine ideals, to which they gave his features. The Vatican st atue, which goes under his name, is probably a Her es, the Capitoline probably a Hermes-Antinous. "In all the figures of
A." says Winckelmann, "his countenance has snme. thing melancholy; his eyes are always large, with mood outlines ; his profile gently descending; and in his mouth and chin there is something expressed which is truly beautiful." (See Levezow on $A$., re presented in the Monuments of Ancient Art; Lerlin, 1803.)

Antroch, or Antakia (anciently, Antiochia, and Antigonia, and Theopolis, and Selerecis, and Epiphane, and Rcblata), in Syria, fifty miles W. of Aleppo, lon. $36^{\circ} 18^{\prime} \mathrm{E}$., lat. $36^{\circ} 6^{\prime} \mathrm{N}$., once greater and richer than Rome itself, but often ruined by earthquakes, and finally razed by the Mamelukes, in 1269, is now only a small town. It was founded by Antigonus, and captured by Seleucus, who changed its situation, and called it Antioch, from his father, Antiochus. Long celebrated as one of the first cities of the Fast, it was the residence of the Macedonian kings of Syria, and of the Roman governors. It is frequently mentioned in the New Testament, and the name Christians was first given to the disciples of Christ in this city (Acts xi. 26). In the 7th century, it was taken by the Saracens, and, in the 11th, by the crisaders, who established a principality under the name of $A$. Boemond was the first ruler. $A$. is situated on the Orontes, about twenty-one miles from the sea. The "Queen of the East" now exhibits hardly any relies of lier former splendour; even the ruins are constantly thrown down by earthquakes. The population is less than 20,000 ; the houses are low, witl only one story above ground; the streets narrow; and the whole appearance of the city is dull and melancholy. The banks of the Orontes are covered with mulberries, figs, and olives, but the plain of $\mathrm{A}$. is uncultivated. The governor here is called mohassel, and is dependent on the pacha of Aleppo, but appointed by the Porte. A. is also the residence of a Greek patriarch.-There was also another Antiochia (in Pisidia) in the Greater Phrygia, where the Romans settled a colony. It was famous for a tenple of Luna.

ANTiochus ; a name of several Syrian kings, which makes an epoch in Roman history. The first wlio was known by this name, a Macedonian, and general of king Philip, was father of the famous Seleucus (q. v.), by his wife Laodice. The son of the latter, A. Soter, carried on many unsuccessful wars, and is chiefly known for his love of his step-mother, Stratonice. Though he endeavoured to subdue his passion, it threw him into a lingering sickness, which continued till the king's physician, Erasistratus, perceived the cause, and disclosed it to his father, who, thereupon, from love to his only son, gave him his young and beautiful bride in marriage. One of his descendants was $\Lambda$. the Great, who succeeded his brother, Selellcus Ceraunus, as king of Syria, 244 years B.C. He chastised Molo, governor of Media, and conquered Ptolemy Philopator, who was obliged to surrender all Syria. He was no less successful against the Parthians, and at length engaged in a contest with the Romans. This is the famous war of $A$, for which, with the aid of Hannibal, he made great preparations. He did not, however, enter fully into the plans of this general, and sent only one army to Greece, which remained inactive, and was defeated, first at Thermopylae, and several times by sea, till, at length, he became so disheartencd, that he did not even contest with the Romans the passage into Asia Minor, where they gained a victory at Magnesia, and obliged him to contract a disgraceful peace. $\Lambda$ fterwards, attempting to take away the treasures from the temple of Jupiter Elymæus, he was slain, with all his followers. His second son, Epiphanes, who is represented, in the history of the Mnccabees, as a most cruel oppressor of the Jews, attacked the Egyp. 
tinn king, Ptolemy Philonator, and laid singe to Alexandria. But he afterwards alandoued it, as well as all Egspt, when the Roinaus took the part of Ptolemy. - Many other Syrian kings, under the name of A., with various surnames, succerded, till at last, $\Lambda$. Asiaticus, was expelled from his dominions by Pompey, and Syria (sec Syria) became a Roman province.

Avrope; daughter of Nycteus, king of Thebes (according to Hoiner, of the river Asopus), renowned through all Greece for her uncommon benuty. Epopeus, king of Sicyon, carriel her off, and married her; but Lycus, the successor of Nycteus, who had promised him to punish his daughter, slew Epopeus, and carried A. prisoner to Thebes, where he delivered her to his wife, Dirce, by whom she was treated with the greatest cruelty. A., however, was happy enough to escape, and to see herself arenged by her own sons, Zethus and Amphion, whom she boasted to have conceived in the embraces of Jupiter. The rest of her story is told in a varicty of ways.

\section{Avtiparos. See Paros.}

ANTIPAscina, among ecclesiastical writers, denotes the first Sunday after Faster. It is also called domirica in albis.

A.TIPATER; a general, and a confidential friend, of Philip of Macedon. Alexander left him governor of Macedonia when he went to Asia. Although he filled this post with honour, reducing to obedience Memnon, a seditious governor of Thrace, and, after a hard-fought battle, overcoming the Spartans, who were struggling for independence, yet Olympias, the mother of Alexamier, with whom he was constantly at variance, succeeded in making him an object of her sou's suspicion; so that he summoned him to his presence in Asia, and appointed Craterus governor of Macedonia. But Alexander died before this change was accomplished. A. receired Macedonia and Greece in the well known division of the empire, and was appointed guardian of the child with which Roxana, Alexander's widow, was then pregnant. Soon after, he was involved in a war with all the powers of Greece. At first, he was unsuccessful; but, when Leonatus and Craterus came to his assistance, the Greeks again submitted. This war was followed by another with Perdiccas, which terminated as happily. A. died 317 years B. C., at an advanced age, having confided to Polysperclion the gururdianship of the young king. The assertion that he caused Alexander to be poisoned, is wholly urlfounded.

ANTIPATHY ; a natural enmity or aversion of one thing towands another. In a more restricted sense, antipathy denotes the natural aversion which an animated and sensitive being feels towards some object presented to it, either in reality or imagination, the cause of which is often mysterious and inexplicable. Such is the aversion of which some persons are conscious under the apprehension or at the sight of particular objects, as cats, mice, spiders, serpents, eels, \&.c. Many instances of antipathies are no better than fables, and a severe examination would reduce them to the class of vulgar errors. There are also fictitious aversions, having their source in affectation, and a pretended delicacy of nerves. The greater part of antipathies arise from prejudice; many from terrors inspired in infancy ; and, in most cases, reflection and a gradual accustoming of ourselves to the objects of our dislike, will weaken or remove the feelung of aversion; yet there are instances of incurable $A$., which seems to have its seat in the nerrous system.

A.rtiphlogistic Chrustry. See Chemistry.

A.rriphory (alternate song); applied particularly, in the Catholic church to the verse which is first sung by a single voice, aud then repented by the whole choir, afier the psalin has been sung by the two parts of the choir alteruately. - Also, a song of the priest, to which the choir or the congregation responds. Hence Antiphonarium, or Antiphonale, a large volume of Latin songs, from which the cunous and other ecclesiastics sing antiphonies, hymus, collects, \&c. 'The 87 th psalm, 7 th verse, proves that this mode of alternate singing formed a part of the old Jewish worship. Its introduction into the Christinu clurel is ascribed to Ignatius, a father of the cluurch, in the Ist century after Christ. The Westeru church is said to have received it more particularly from Ambrose. (q. v.) At the end of the 6 th century, Gregory the (ireat composed an Antiphonary in honour of the virgin Mary, and the other saints. In the Protestant cliurch, two sorts of antiphouy are known. They consist either of whole psalms, as the litany, or of ouly a few words of scripture. The latter sort includes the introductory chant of the preacher, and the mutuil response of the choir and the cougregation. $-\Lambda$ species of English cathedral music is called an anthem, or antiphony. Handel has composed several allthems.

Axtiphrasis. This may be defined a form of speech, in which we affirm a thing by denying it to be the contrary; as, $\mathrm{He}$ is no fool. It is also userl, though less correctly, to signify a figure of speech, by which the name of any thing is derived trom a

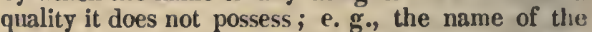
Fates, Parca, from parcere, to spare, though to spare is foreign to their nature. So also the name of the Furies, Eumenides. Such appellations are usually ironical.

ANTIPODEs; the name given to those inhabitants of the earth who are diametrically opposite to each other, and, of course, turn their feet towards each other. The name comes from the Greek avrt, against, and zous, a foot. The zenitl of the one is the nadir of the other. The antipodes live in similar but opposite latitudes, and their longitudes differ 180 degrees. Hence the difference in their days is about 12 hours, and their seasons are reversed. The spherical form of the earth naturally leads us to the idea of the antipodes, of whose existence some idea was entertained even before the age of Cicerv. The fathers of the church, however, found in this theory a contradiction of the Bible, and, in the 8th century, Virgilins, archbishop of Saltzburg, was excommunicated for maintaining it. Circuminavigators of the globe first put the question beyond all doubt, and the opposition to the doctrine of the sphericity of the earth, and the existence of the antipodes, is now donc away.

ANTIPOPE; thus are called all those who, at different periods, have produced a schism in the Roman catholic church, by opposing the authority of the frope, under the pretence that they were themselves mpes. This is the catholic explanation, because it is evident that the Roman church cannot admit that there ever existed two popes; but the fact is, that, in inany cases, both competitors for the papal chair (sometimes there were even three) were equally an tipopes; that is to say, the claims of all were equally good. Each was frequently supported by whole nations, and the schism was nothing but the struggle of political interests, whicl induced particular gorernments to support a pope against the pope sur ported by other governments. Those were the most unhappy periods of the Roman clurch, when to mauy other evils were added violent contests between rival candidates for the papal chair, and the consciences of the honest believers were offended and perplexed by the excommunications which the adversaries thundered against each other. These quarrels, of course, 
lessened much the belief in the pope's sanctity and istallibility, shook the whole fabric of the church, and contributed much to prepare the way for the great reformation; but it would be unjust to throw an the popes alone the blame of these unhappy conflicts. They were natural consequences of thie dimiaution of the dependence of the different governments on the papal see, resulting, in a great measure, from the increase and diffusion of knowledge. Another cause of these schisms was the diminished authority of the clergy, whose corruption and profligacy, in many countries, had given the greatest offence throlighout Christendom. Of this the most melanilioly proof may be found in almost any work of the 14 th and 15 th centuries, as well as in the proceedIngs of the councils. Those, for instance, of the rouncils of Constance and Basle, and some of the writings of Petrarca, who lived at Avignon when it was the seat of the papal court, are full of such facts ind complaints of thein. Only one antipope is recorded to have existed at an earlier period-Novatianus, a Roman priest and heretic, the rival of Cornelius, in 251. Amadeus VIII. duke of Savoy, was the last antipope. He was elected by the council of Basle, in 1439, in opposition to Eugene IV. and Nicholas V. But he renounced his title in favour of the latter, in 1449. Similar scenes had taken place in the latter ages of the Roman empire. When that gigantic structure was fast verging to ruin, enperors rose against emperors, elected and supported by their soldiers in different quarters of the world. In fact, suclı divisions must always take place whenever a vast empire, spiritual or temporal, declines, and loses that energy which had conducted it. to greatness. Thus we find in the Mohammedan history, at one period, many anticaliphs.

Avtrouaris ; men who employ themselves in the study or collection of antiquities. In Italy, the ciceroni are often antiquaries. In England, and particularly in Scotland, there are important associations of antiquaries. In Germany, those booksellers who deal pxclusirely in old books, are called by this name, and the custom has extended beyond this country. In France, these dealers are ironically called bouquinists, from bouquin, a book of little value. In London, the most valuable collections may be found at Iougman's and Bohu's; in Paris, at Renouard's; in Madrid, at Sancha's ; in Rome, at de Romani's ; in Florence, at Molini's ; in Utrecht, at Wild's and Altheer's; and in Leyden, at Luchtmans's. In Germany, Weigel in Leipsic, Meusel in Coburg, Hæssler and Nestler in Hamburg, and Sommerbrod in Berlin, are among the best known, and often have very vaInable editions.

ANTique. After the convulsions which attended the settlement of the tribes of the North and the Fast, on the ruins of the Roman empire, had, in some degree, subsided, and the nations of Europe began to enjoy, to a certain degree, the blessings of peace, a regard for science and the arts grew up anong the. rude conquerors, and revired in the minds of the vanquished. In the midst of barbarism, the remains of Grecian and Roman civilization, literature, and art, appeared like the productions of a better and nobler world; and the word antiguus, applied to literature, science, or art, becane almost synonyunors with excellent. By degrees, the relics of ancient literature were collected in libraries, and those of art in muselums. It was not, however, till the 14th and 15 th centuries, that the effects of the admiration and suidy of the numerous and continually increasing collections of antiques began to be perceptille, and first of all in Italy. What is termed moderm art, in contradistinction to antient, then had its origin. This was based, incleed, on different principles from the ancient, inasmuch as it was infuenced by the spirit of Christianity, of clivalry, and the prevailing character of the Teutonic nativns. Still the noble impulse, which it received at this time, was derived almost entirely from the study of the remains of antiquity, to which the greatest masters of modern times deroted themselves most intensely; though their own works bear distinctly the stamp of their own characters, and of the age in which they lived. The great question then arises,-In what does the difference between ancient and modern art consist? To explain this, it would be necessary to go deeply into the nature of the fine arts ; and, moreover, it cal never be correctly understood without personal acquaintance with the great works of both. Some of the most striking diversities are, that the ancient art attaches more importance to the form; ancient art, also, aims particularly to express general ideas, and to give something of a general character even to individual representations; while the modern confines itself more to individual characteristics. To explain the reasons of the existing differences, would require a closer investigation of the religion and government, the science and social life of the ancients, as distinguished from those of the moderns. One of the principal causes is to be found in the different light in which man and outward nature are regarded, in the popular belief of antiquity, from that in which Christianity considers them. The ancient creeds gave a divine character to the outward creation, and represented the gods in the figures of men; while the Christian religion has been generally understood as inculcating contempt for all things earthly, and the scriptures themselves continually connect the idea of sin with that of the world. - We shall pursue these ideas farther, under the articles Classical and $R_{0}$ mantic, also in the article Philosophy.-When we consider the remains of Greek and Roman art, we find the former far superior; in fact, the Roman might be considered an after-blossom of the Greek, sprung from the immensely rich collections of antiques in Rome. Greek art was so pure and chaste, so truly based on nature, and yet strove so zealously after ideal beauty, that the study of its remains is, and must continue, indispensable to the artist and the connoisseur. Among the circumstances which contributed to produce its excellence, we may mention, in addition to the influence of the prevailing religion (which saw in the gods ideal men, raised men to the rank of gods, and personified every quality in its multitude of gods and demigods), the number of small states, and also the joint celebration of the Olympic games by all of them, the inventive and finely-tempered spirit of the people, their happy views of life, the mildness and beauty of the climate, and the fine marble which the country afforded in abundance. In painting, as we have already said, the moderns are superior, although the ancients had many excellent artists in this branch of art. In poetry, we cannot attribute to either the superiority. In architecture, both have reached a high degree of excellence. The Gothic architecture is esteemed, by many persons, as perfect as the ancient, though resting on very different principles; others, however, regard it as decidedly inferior. However much the remains of ancient art and literature deserve our admiration and study, there was a tine when they were overrated, at the expense of the best productions of modern times. This was particularly tlie case when the real spirit of art had fled, and the power of invention was lost. It was reserved to the present age to value both according to their merits, which can never be impartially estimated, while one is made the standard of the other. Fach must be studied and judged on its own principles. 
Armgorr. The word antiquity, old time, in opposition to nero, is in itself indeterminte, but is, in general, applied to the time which elapsed between the crention of the world and the irruption of the barbarians into the Roman empire, which, in connection with the wide spread of Christinnity, makes a great epoch in the history of the human race. In a narrower sense, it is applied to the two principal nations of former times, Greece and Rome, or to the early age of any nation. The name antiquities is given to the remains of ancient art. The phrase is used in a wider sense, to signify all which belongs to a knowledge of the politics, manners, religion, literature, and arts of the nations of antiquity, or of the modern mations, until the existing order of things commenced. We lave no single work giving such a general picture of nations and states, but only separate treatises on the antiquities of the Hebrews, Greeks, Romans, Etrurians, Gauls, Germans, Britons, \&.c. The want of a knowledge of antiquities was first felt in the 15th century, when the zeal for classical learning began to revive. In the earlier works on this subject, one finds extensive learning, but no fixed plan, no critical division of the time and subjects. In the 18th century, the rich collections of materials, which had formerly been made, were critically examined and systematically distributed. The Bibliographia Antiquaria of Fabricius (Hamburg, 1713-1716) contains valuable information, especially the new edition by Schaffshausen (1740), to which it is desirable that some additions should be made. Among the principal works treating of Grecian and Roman antiquities are, Thesaurus Antiquitatum Gracarum, by Gronovius (Leyden, 1697-1703, 13 rols.); Thesaurus Antiguitatum Romanarum, by Grevius (Utrecht, 1694-99, 12 vols.); Novis Thesaurus Antigu. Roman. by Sallengre (Hague, 1716 $-19,3$ vols.); and Poleni Utriusque Thes. nova Supplem. (Venice, 1737, 5 vols. fol.) Burmann has left a Catalogus Librorum qui in Thes. Rom., Grac., Italico et Siculo continentur (Leyden, 1725). The information collected by these antiquaries has been revised and arranged by later scholars. A very useful work on Roman antiquities is Sam. Pitisci Lexicon Antiquit. Roman. (Leyden, 1713; Venice, 1719, 3 vols.; Hague, 1737, 3 vols.), an edition of which appeared at Berlin, 1793. The assistance which these works afforded to the scholar, desirous of obtaining a just idea of Grecian and Roman literature and history, stimulated the students of the oriental langrages to similar labours. Their attention was directed to Hebrew antiquities, on account of the connexion between Hebrew literature and customs and the evidences of Christianity. On the subject of Hebrew antiquities, Iken, Faber, Warnekros, Bellermann, Jahn, and others, have given us books as useful as they are interesting. On the antiquities of the other nations of the Fast, the Asiatic Researches, and the labours of Goguet, furnish valuable information. Sir William Jones, Anquetil du Perron, A. W. ron Schlegel, and others, have thrown light on the antiquities of India; Zoega, Denon, and others, on those of Egypt; von Hammer, Rhode, Gorres, on those of Persia. Many collections exist, which treat of the antiquities of the modern nations of Europe. The Italians hare very rich ones by Muratori, Donati, Maffei, and others; the French, those of Montfaucon, Millin; and the English, the Archaologio Brilannica. They are found also among the Germans and other northern nations. Since the beginning of the 18th century, the arts have been made a serarate branch of antiyuarian research.

ANTISABBataruans; a modern religious sect, who deny the necessity of observing the Sabbath. Their chief argument is, that the Sabbath was a Jewish institution; and that, in the New Testament, no commandiment for keeping it is to be found. 'Tlue Quakers do not object to the observance of the Salbath, yet they attach importance neither to this nor to any form or ceremony, and believe that there is no difference, in a religions point of view, between Sabbath and any other day.

AvTISEPTICs; remedies against putrefaction. The ancients thought it possible, by certain preparations, to resist a general tendency to putrefaction, which they supposed to exist in the system. The moderus have only attempted to prevent the affection of the sound by the mortified parts, by means of extermal applications, which farour their separation. We are. indebted to chemistry for most of these remedies, which generally operate by absorbing the liquids and gases of the gangrenous parts. Among antiseptical substances, charcoal-powder has hitherto he''n one of the most esteemed, but the chloride of lime lias been recently discovered to be much more effcacious in arresting the progress of putrefaction. Placed in contact with the affected parts, it destroys the offensive odour which they exhale, and prevents the extension of the corruption. The practitioner must adapt the treatment to particular circumstances : to inflammation he opposes bleeding, emollients, \& : ; to weakness, nourishing food, tonics, \&:c. ; at the same time with the local application of the antiseptic. Anti-Slavery Society. See Abolition of Stuvery.

Avtispasmodic (Greek, avrs, against, oracpos, the cramp); that which has the power of relieving the cramp. Antispasmodics are more accurately defined, medicines proper for the cure of spasms and convulsions. Opium, balsam of Peru, and the essential oils of many regetables, are the most useful of this class of medicines.

Antistuens; founder of the sect of the Crnies ; born at Athens, in the 89th Olympiad, $424-421$ years B. C. He enjoyed the iustructions of the sophist Gorgias, and followed the prufession of a rhetorician; but, after he had heard Socrates, he renounced the vain ornaments of eloquence, in order to derote himself entirely to philosophy. From the doctrines of Socrates he acquired that zeal for virtue, and that unexampled hatred to vice, by which the school that he founded is distinguished. He made virtue to consist in voluntary abstimence, and independence of exterior circumstances ; and he despised wealth, honours, sensual pleasure, and even knowledge. He aimed to reduce body and mind to the ferrest possible wants; nor did he hesitate to appear publicly as a beggar, with a wallet on his back, and a staff in his liand. Plato perceived the true design of this strange behaviour. "I see tliy vanity," said he to him, "through the holes of thy coat." The eccentricity of his behaviour induced many to imitate him. His most distinguished scholar was Diogenes. (q. v.) The latter is celebrated for the firmness and viracity of his mind, and the originality of his remarks; but the conduct of $\mathrm{A}$. was more dignified. He was unalterably a virtuous citizen. He first attacked the accusers of Socrates, procured the banishment of one of them, and the death of another. This, however, Barthelemy doubts. His conversation was agreeable, and is praised in the Symposium of Xenophon. After the death of Socrates, he took up 3 is abode in the Cynosarges, a school of Athens; from which circumstance some suppose the school derived its name. The opinions of $\mathrm{A}$. are well known. His numerous works are all lost; for the letters published under his name are considered spurious. The time of his death is unknown.

Axtisyphutic; a term applied to remedies used in cases of syphilis. They are almost numberless; and there exists, perhaps, not one substance in the 
three kingdoms of nature, to which an antisyphilitic power has not been ascribed. The most efficacious are preparations of mercury, which is administered in a great variety of ways; sudorific vegetables, the combinations of which are also extremely nmmerous and preparations of gold, particularly of the muriatc of this metal.

A.vrithesis (opposition); a figure of speech, by which two things are attempted to be made more striking, by being set in opposition to each other. This figure often produces a great effect, yet, by too frequent use, becomes disgusting. Lessing affords an instance of a liappy antithesis, when, in the review of a book, he says, "This book contains much that is good, and much that is new; only it is a pity that the good is not new, and the new is not good." The following is an example in poetical composition.

"Though deep, yet clear; though gentle, yet not dull; Strong, without rage; without o'erflowing, full."

Some use antithesis only to express the connexion of things exactly opposite.

ANTITRinitarians; all who do not receive the doctrine of the divine Trinity, as it is represented by the Nicene and Athanasian creeds, and either put the Son and the Holy Spirit in the Godhead below the Father, or consider Christ merely a man, and the Holy Spirit an arbitrary personification of the divine mind. In the early period of the Christian church, parties maintaining these sentiments were very numerous ; especially the Arians, Sabellians, and Pneuniatonachists. The name Antitrinitarian first arose in the 16tl century, and was applied to Socinians, or Unitarians, who remonstrated against the system of Episcopius, who died in 1643 , and to a great number of theologians, who ventured, in their writings, to maintain the preceding opinion. Many were unwill. ing to acknowledge Antitrinitarians as Christians, esteeming them enemies to the fundamental doctrines of Christianity, or even to tolerate them in Christian states. The Spanish Protestant, Michael Servetus, was burnt at Geneva, in 1553, at the instigation of Calvin, on account of this heresy, and the severest edicts were once issued against them in England. An English clergyman, however, Theophilus Lindsey, at London, in 1774, and a merchant, Wm. Christie, at Montrose, in Scotland, formed Unitarian congregations, who separated themselves from the established church, since which time they have become InImerous, both in Britain and America. See Unitarians.

AxTiou ; an ancient city of the Volsci, situated on the Tuscan sea. In the neighbourhood, the Romans gained their first naval reputation, in an engagement with the Antiates. It was entirely destroyed by the Saracens; but vestiges of it still remain in Capo d" Anzo, or Autio.

ANTolvetre (Marie Antoinette Josephc Jeanne) ot Lorraine, archduchess of Austria and queen of France, boru at Vieuna, Nov. 2, 1755, was daughter of the emperor Francis I., and Maria Theresa. She received a careful education, and obtained an acquaintance with various branches of knowledge. Nature had bestowed upon her an uncommon share of grace and beauty. In a letter of Maria Theresa to her futurc husband, she says, among other things, "Your bride, dcar dauphin, is separated from mc. As she has ever been my delight, so will she be your happiness. For this purpose have I cducated her; for I havc loug been awarc that she was to be the companion of your life. I have enjoined upon her, as among her highest duties, the most tender attachment to your person, the greatest attention to every thing that can please or make you happy. Above all, I liave recommended to her humility towards God, because I ain convinced that it is impossible for us to contribute to the lappiness of the subjects confided to us, without love to Him who breaks the sceptres and crushes the thrones of kings according to his own will." The departure of Marie Antoinette from Vienna filled the capital with sorrow. Her arrival at Strasburg, and her journey to Compeigne, where Louis.XV., and the dauphin received her, and to Versailles, where her marriage took place, May 16 , 1770 , had the appearance of a triumph. It was subsequently remarked, that, immediately after the marriage ceremony, a fearful thunder-storm, such as had scarcely ever before been witnessed, threw Versailles and all the surrounding country into the greatest terror. Anxious minds indulged in yet more fearful forebodings, when, at the festivity which the city of Paris prepared, May 30, for the celebration of the dauphin's marriage, tlirough the want of judicious arrangements, a great number of people, in the rue Royale, were pressed or trodden to death in the crowd, fifty-three persons were found dead, and about three-hundred dangerously wounded. When Marie Antoinette, after the death of Louis XV., became queen, she imitated the example of Louis XII. An officer of the gardes du corps, who had formerly displeased her, and now was about to resign, she ordered to remain at his post, and forget the past-" Heaven forbid that the queen should avenge the injuries of the dauphiness!" Thus she continued to win the hearts of the people by mildness and generosity; in particular, she took the most energetic measures to relieve the sufferers in the dreadful winter of 1788 . But, auout this time, she drew upon herself the liatred of the court party, who used every means to make her odious to the nation. She was accused, in pamphlets, of continually con. triving plots, and though none of the accusations could be proved, and many of them were wholly improbable, yet it must be confessed that the young and inexperienced queen gave cause for then. Her lively imagination often gave her the appearance of levity, and sometimes of dissimulation. A natural restlessness led her to change, to new fashions, to a continual varying of her diversions. Great sums of money were, by this means, taken from more important oljects. It was still more to her disadrantage, that she injured her dignity by neglecting the strict formality of court manners. Besides, she expressed herself with pettishness, in reply to the censures that were passed upon her. Her enemies now spread abroad a report that she was still an Austrian at heart, and a natural enemy to the French, to whose happiness she could no longer contribute. An extraordinary occurrence added fuel to the flame of calumny, while it subjected the name of the queen to a disgraceful law-suit. Two jewellers demanded the payment of an immense pricc for a necklace, which had been purcliased in the name of the queen. At the examination which she demanded, it was proved that she had never ordered the purchase. A lady of her size and complcxion had impudently passed her. self off for the queen, and at midnight had a meeting with a cardinal in the park of Versailles. (See $L a$ mothe and Rohan.) Notwithstanding this, the encmies of the queen succeeded in throwing a dark shadc over her conduct. When Calonne had reported a great deficieucy in the finances, the cause was blindly attributed to the queen's extravagance. At length it became necessary to summon a meeting of the states-gcueral. The queen was present at the opening of the first session; but from that moment her tranquillity was gone. Events soon followed, which put her courage to the test. Shc appeared with her husband at the banquet, which the gardes du corps gave at Versailles, October 1, to the officers of the troops of the line, where, soon after the de- 
parture of the court, the national cocknde was trampled on. This excited the Parisians still more against the queen. They regarded her as the soul of the party which, at that time, was collecting an army against Paris, and against the national assembly. On the 5th, the Parisians rushed violently to Versailles. Farly on the $6 \mathrm{th}$, they broke into the castle, nurdered sereral of the body-guands, und uttered against the queen the most furious threats. In the midale of the night, a clergy man wrote to her, "Take measures for your preservation; early in the morning, at 6 o'clock, you are to be murdered." She remained tranquil, and concealed the letter. The infuriated mob rushed into her chamber; she fled to the king. To put a stop to the scene of murder, the king and queen showed themselves, with both their children, in the balcony. This spectacle made a momentary impression upon the enraged people; but soon the cry resounded from every mouth, "No children! the queen-the queen alone! She instantly put her son and daughter into the arms of the king, and returned to the balcony. This unexpected courage disarmed the mob; their threats were followed by shouts of approbation. The same day she was obliged to view a most fearful spectacle, for six liours, on her way to Paris. Before her carriage were borne, on pikes, the heads of two guards; intoxicated furies surrounded her, with the most horrid imprecations. When she was asked about the scene that had just ended, by the officers of justice, who desired to punish the guilty, she replied, "Never will I accuse one of the king's subjects; and when the question was repeated, "I have seen all, I have heard all, I have forgotten all," was her answer. The first month after her arriral in Paris, she expended 300,000 livres in redeeming clothes pledged by the poor to the pawnbrokers; but all her benefits were insufficient to appease their exasperated minds. In 1791, when Iouis XVI, determined to flee, she followed her husband, though she saw the attempt was fruitless. From Varennes, she was brought back to the Tuileries, and when the committee of the constituent assembly demanded an explanation, she answered, "As the king wished to depart with his children, nothing in the world could hinder me from accompanying him. I have given sufficient proof; for these two years, that I would nerer desert him. What made me more decided on that point was, the firm conriction that the king would never leave France; if he liad wished to do so, I should have employed every effort to restrain him." This tempest was followed by a momentary calm. In the meantime came on the 20th of June and the 10th of August, 1792. Prepared for whatever might happen on the latter of these days, the queen exerted all her power to excite her husband to meet death sword in hand. Led with him into the legislative assembly, she heard his deposition announced, together with the appointment of his judges; and then went with him to the temple. None of her female attendants were suffered to accompany her. Here she occupied the only comfortable chamber with her daughter and the princess Elizabeth. Close bars of iron secured the window, admitting only a glimmering light. She now exhibited the full strength of her character. Invariably calm in the circle of her friends, she urged them to disregard sickness and suffering. When Louis XVI. informed her of his condemnation, she congratulated him on the approaching termination of an existence so painful, and the unperishing reward that should crown it. After her husband's death, she asked nothing of the convention but a mourning-dress, which she wore the remainder of her days. July 4, 1793, she was separated from her son. She felt that this separation was for erer, jet her firmness. was unchanged. August
5 , at midnight, sle was removed to the keeper's house. A dark and damp dungeon here was her last abode. Oct. 3, the convention ondered her to be brought before the revolutionary tribunal. She was charged with having dissipated the finances, exhausted the public treasury, giren large sums out of it to the emperor, with having corresponded with foreign enemies, and faroured donestic tumults. But, notwithstanding the inultitude of witnesses who were examined, no evidence could be brouglit against her : and her defender, Clauvenu-Lagarde, exclaimed justly, "I am embarrassed not to find answers, but plausible accusations." Bailly, then mayor of I'aris, who was summoned as a witness, had the courage te take the queen into his protection, without hesitation, and to censure, with the greatest severity, her bloodthirsty accuser, Fouquier-Tinville, for his testimony, which all might see to be false. The queen herself replied to all inquiries with finnness and decision. When Hébert shamefully accused her of having seduced her own son, she answered, with the decpest indignation, "I appeal to every mother here, whether such a crime be possible." She heard hir sentence of death with perfect calmness, and soon gently fell asleep, when she was carried back to her prisun, nftcr sitting 18 hours. The next day, at 11 o'clock, she ascended the cart which conveyed her to the scaffuld. Great efforts were made to induce the people to insult her on the way, but a deep silence reigned. 'The charms for which she was once so celebrated were gone. Grief had distorted her features, and, in the damp, unhealthy prison, she had almost lost one of her cres. Her look seemed to fill the fierce people with awe. At 12 o'clock, the cart arrired at the place of Louis XV. She cast back a long look at the Tuileries, and then ascended the scaffold. When she came to the top, she threw herself on her knees, and exclaimed, "O God, enlighten and affect my" executioner! Farewell, my children, for ever; I go to your father!" Thus died the queen of Franci, Oct. 16,1793, towards the close of the 38th year of her age. (See Marie Antoinette, i la Conciergerie; Fragm. Hist. Publ. par le Comte de Robiano, I'aris, 1824 ; and Mém. sur la Vie privée de Marie Antoinette, Reine de France, \&c., by madame Campan (her reader), 5th edition, 4 vols., Paris, 1823.)

Antornzlo of Messenia, See Oil Painting.

Antonisus (Annius Verus), the Philosopher, best known by the name of Marcus Aurelius, born A. D. 121 , ascended the throne $A . D .161$, after the death of Antoninus Pius, who had adopted him. Ile voluntarily divided the empire with Lucius Verus (see the succeeding article), whom he made emperor, and united in marriage with his daughter Lucilla, Brought up and instructed by Plutarch's nephew Sextus, the orator Herodes Atticus, and the famous jurist $\mathrm{L}$. Volusius Mecianus, he had become acquainted with learned men, and formed a particular love for the Stoic philosophy. While his generals, Statius Priscis, Avidius Cassius, Marcius Verus and Fronto, overcane the Parthians, conquered Armenia, Babylon, and Media, and destroyed the great city Seleucia on the Tigris, he devoted his attention to Rome and G(rmany. The former was laid waste by pestilence, famine, and inumdations, the consequences of whicls he endearoured to mitigate; the latter kept the Roman territory in continual alarm, by frequent in. vasions, which, however, were always repulsed. At the same time, he undertook to improve the morals of the people, and the administration of justice. After the ternination of the Parthian war, both emperors celebrated a triumph, and assumed the title Parthicus. But a fearful pestilence soon broke out, with which the eastern army infected all the countries they passfd through. In additian to this, there were earthquakes, 
inundations, and a universal insurrection on the confines of the empire, from Gaul to the Black sea. Both emperors went to Aquileia, in order to attack the Marcomanni, early in the spring. A part of the enemy submitted for a time, but soon took up arms again. For eight years, they fought with various success. Verus died, A. D. 169, in the first year of the war. A. D. 174, the enemy invaded Italy, and, as the treasury was exhausted, the emperor saw himself reduced to the necessity of selling the most valuable furniture of the palace. In the following campaigns, the Romans came off conquerors. A. D. 178, when the emperor, in the city of Gran, in the war against the Quadi, was surronnded on every side by his enemies, he was reduced to extremity from want of water. A fearful tempest arose, a sudden shower refreshed the army, and the Quadi were vanquished. Afterwards, the Marcomanni, the Quadi, as well as the rest of the barbarians, sued for peace. The sedition of the Syrian governor, Avidius Cassius, who had brought Egypt and the region within mount Taurus to own his authority, called off the emperor from his conquests; but, before he reached Asia, the rebel was slain by his own party. Aurelius pardoned all who were engaged in the revolt, marched in triumph to Rome, and busied himself about the internal concerns of the empire, till new incursions of the Marcomanni compelled him once more to take the field. He conquered the enemy several times, but was taken sick at Sirmium, and died, according to Aurelius Victor, at Vindobona, in the 59th year of his age, and 19th of his reign.-The best editions of the Meditations, which he wrote in Greek, and in which he "acknowledges himself ta follower of the Stoics, are by Cassaubon, London, 1643 ; Morus, Leipsic, 1775; and Schulz, 1802, translated by Schulz and Kuhn, with annotations.-Aurelius was one of the best emperors who ever governed Rome, although his philosophy and the natural magnanimity of his character did not restrain him from ordering the persecution of the Cliristians in Gaul.

Astonivos Pios (Titus A urelius Fulvius), of a family originally from Nismes, in Gaul, was born at Lavinium, in the neighbourhood of Rome, A.D. 86. His father, Aurelius Fulvius, had enjoyed the consulship, and, A. D. 120 , he succeeded to the same dignity. He was one of the four persons of consular rank, among whom Adrian divided the supreme administration of Italy. He then went, as proconsul, to Asia, and after his return to Rome, became more and more the object of Adrian's confidence. By his wife, laustina, the daughter of Annins Verus, whose licentious conduct he wisely endeavoured to conceal from the view of the world, he had four children. They all died but Faustina, who afterwards became the wife of Marcus Aurelius. A. D. 138, he was adopted by Adrian, for which reason he, in his turn, adopted L. Verus and M. Annius Verus (Marcus Aurelius). The same year, he ascended the throne, and under him the empire enjoyed tranquillity and happiness. Temperate and simple in his private life, ever ready to assist the necessitous, an admirer of virtue and wisdom, he was truly the father of his people. He often repeated those beautiful words of Scipio, "I had rather preserve the life of a citizen than destroy a thousand enemies." His wise frugality enabled him to diminish the taxes. The persecutions of the Christians he speedily abolished. He carried on but a fow wars, viz. in Britain, where he extended the Roman dominion, and, by raising a new wall, put a stop to the desolating invasions of the Picts and Scots. The senate gave him the surname Pius, i, e, remarkable for filial affection, because, in gratitude to the memory of Adrian, his second father, he had built a semple in honour of him. Conflagrations, floods, and earthquakes, spread desolation in many places during his reign, but his generosity did much to mitigate the consequences of these unhappy events. He died, $A$ D. 161, 74 years old, having reigned 23 years. His remains were deposited in the tomb of Adrian. The senate built a pillar to his memory, which is yet standing, under the name of the Antonine column. The whole kingdom lamented him, and the following emperors assumed his name as an honour. It has been said of him, "He is almost the only monarch that has lived without spilling the blood of his countrymen or his enemies."

ANTonisos, the wall of; a barrier erected by the Romans across the isthmus between the Forth and the Clyde. The whole length of it exceeded 36 miles. It was constructed A. D: 140, and consisted, when entire, of a ditch 40 feet wide and 20 feet deep, and a wall on the south side 24 feet thick and 20 feet in height, the wall being formed of the earth that was thrown up. This wall is now nearly demolished by the plonghshare. General Roy, in his 35 th plate, has traced its course, and given plans of the stations belonging to it. This wall was the third rampart built by the Romans against the incursions of the North Britons. It is called, by the people in the neighbourhood, Graham's dyke.

Antonio, St; a Dutch fort of Axim, on the Gold Coast of Africa. It belongs to the West India conspany.-This is also a name of one. of the cape de Verd islands, separated from St Vincent by a narrow, navigable channel, 15 miles broad. The inhabitants, mostly negroes,; about 500 in sumber, live, notwithstanding all the plenty of the island, in wretched poverty. Lon. $0^{\circ} 26^{\prime}$ E. ; lat. $18^{\circ} 4^{\prime} \mathrm{N}$.

Antono, Nicholas; a native of Seville, in Spain ; born in the year 1617. After 22 years spent at Rome, in the capacity of agent-general for Spain, he returned to Madrid, and obtained a seat at the council board. His works are, Bibliotheca Hispana Vetus, in two folio volurnes; De Exilio, Lib. iii., folio, published in 1659 ; Bibliotheca Hispana Nova, two rols. folio, 1672, reprinted in 1783; and Censura de Historicis Fabulis, folio, 1742. His library was of great value. He died, 1684 .

ANTonius, Marcus, the triumvir, son of the prator, and grandson of the orator of the same name, born 86 years B. C., was connected with the family of Cæsar by his mother Julia, a lady of distinguished excellence. Debauchery and prodigality marked his youth. To study eloquence and the art of war, he went to Greece, and from thence followed the consul Gabinius on a campaign in Syria. He showed much activity and courage here, as well as in Egypt, where he aided in the establishment of Ptolemy Auletes. The soldiers, whom he treated with extreme generosity, indulgence, and confidence, conceived a strong affection for hin. In Rome, he united with Curio, and, like him, supported the party of Casar. He became augur and tribune of the people; but some of his projects excited such odiun against him, that, with Curio and Cassius Longinus, he fled for refuge to the camp of Casar. This became one of the pretences for civil war. At the breaking out of this war between Cresar and Pompey, A. was appointed by Caesar commander-in-chief in Italy: he afterwards led a considerable force to Epirus, to his assistance. In the battle of Pharsalia, he commanded the left wing, and afterwards returned to Rome with the appointment of "master of the horse and governor of Italy. He degraded himself so deeply by acts of excess and violence, that, on his return, Cæsar treated him with great coldness. About this time, he married Fulvia, the widow of Clodius, who long ruled him. When Cæesar returned from Spain, A. regained his favour by the basest 
dattery, anu, 13.C. 44, became his collengue in the consulship. At the Lupercalia, he threw hinself publicly at Cresar's feet, and thrice offered him a iliadem, which he exhibited amid the shouts of the people. Soon after, Casar was assassinated, and $A$. would have shared tho same fate, had not Brutus, who hoped to gain him over for the republic, stood II) in his defence. A. delivered, over the body of Ciesnr, a funeral oration, in the course of which he epread ont his garment stained with blood, and thus excited the people to anger and revenge. The murderers were obliged to tlee, and $A$. long ruled with unlinited power. After haring many times quarrelled with young Octavius, the heir of Cesar, who aspired to the supreme power, and, from political motives, took the side of the senate, he was reconciled to him, and went with an army to Cisalpine Gaul, the government of which fell to his share, and laid siege to Mutina, which Decimus Brutus valiantly defended. In the meantime, Cicen delirered his famous orations against him. The senate declared him a public enemy, and both consuls, Hirtius and Pansa, accompanied by Octavius, met him in the field. $\Lambda$ t first, $\Lambda$. vanquished Pansa in a bloody Inttle, but Hirtius hastened to his aid, and $A$. was subdued. Both consuls, however, fell, and Octavius took the head of the republican army. $\Lambda$. fled with his troops over the Alps, amid great difficulties and privations. Lepidus then commanded in Gaul, and A. fled to his camp in mourning garments, and soon gained the affections of the army, so that Lepidus was ubliged to resign the command to him. Plancus, also, and Pollio, strengthened his party with their forces; so that A., who, a short time before, liad fled from Italy, returned now at the head of 23 legions and 10,000 horse. Octavius, who had hitherto appeared to be a supporter of the senate, and a defender of republican freedom, now suffered the mask to fall off. He marched against $\Lambda$. and Lepidus, and, on the small island of Reno, not far from Bologna, or, accorling to some, on the island of Panaro, near Modena, had that memorable meeting with them, in which they divided among themselves the whole Roman world. Here they decided upon the proscription of their mutual enemies : each gave up his friends to the other. Upon this, the triumviri marched to Rome, and their steps were marked with muirder and rapiue throughout Italy. A. caused Cicero's head and right hand to be fixed up, as a spectacle, on that same rostrum from which his eloquence had so often been victorious. 300 senators and 2000 knights perished in this proscription. When the sum of money necessary for the war was procured, viz. $200,000,000$ sesterces (above a million and a half sterling), and the triumviri had appointed magistrates for several sears, B. C. 42, A. and Octavius departed for Macedonia, where the united forces of their enemies, Brutus and Cassius, formed a powerful army. At Philippi, A. commanded in an engagement against Cassius, who, when he perceived the event of the fatal battle, ordered one of his slaves to stab him. After the second battle, Brutus, also destroyed himself. At the sight of his body, $\boldsymbol{A}$. discovered the deepest emotion, covered it with his cloak, and gave orders that it should be interred with the highest honours. He then wrent to Greece, visited the public schools at Athens, and manifested his admiration of this city, splendid even in its ruins. Thence he proceeded to Asia. In Cilicia, he ordered Cleopatra, queen of Egypt, to apologize for her insolent behavour to the triumviri. She appeared in person, and her charms fettere-t him forever. He followed her to Alexandria, where, in a constant course of dissipation, he bestowed not even a thought upon the affairs of the world, till he was aroused by a report that hostilities had commenced in Italy, between his wite, Fulvia, and Octavius. A short war followed, which was decicled in finvour of Octavius, before the arrival of $A$. in Italy. The death of Fulvia facilitated a reconciliation, which was sealed by the marriage of A. with Oetavin the sister of Octavius. The two armies made a new division of the Ronan dominions. A. obtained the East, Octavius the West. For mere form, Africa was consigued to the feeble Lepidus. With Sextus Pompey, who ruled the Mediterranean, a treaty was made. Upon this, A. went to Athens, made a campaign against the Parthians, which brought him but little honour, and then returned to Italy. By the interposition of Octavia, there appeared to be perfect harmony between the triumviri; but, after his return to $\boldsymbol{A}$ sia, $\boldsymbol{A}$. gave himself up to a nost abandoned course of life; lavished upon Cleopatra, without regard to the interests of the state, whole kingdoms and provinces; and exercised the most opell injustice. After a second disgraceful camlaign against the Parthians, he took Artavasdes, king of Armenie, prisoner, by treachery, accising him of want of fidelity, and carried him in triumph to Alexandria. Octavius excited against $A$. the displeasure of the Romans, by a relation of his conduct. War betweers the two rivals was inevitable, and buth began to prepare for it. Amid a round of pleasures, A. neglected his most important affairs, and filled the island of Samos, the rendezvous of his troops, with musicians and revellers, and, at the same time, divorced Octavia. These measures were followed by disapprobation as universal as the knowledge of Octavia's magnanimity and the hatred of Cleopatra's arrogauce. At length, war was declared at Romeagainst the queen of Egypt, and $\mathrm{A}$. was deprived of his consulship and government. Each party assembled its forces, and $\mathrm{A}$. lost, in the naval battle at Actium (q. v.), B. C. 31, the dominion of the world. He disgracefully followed Cleopatra in her flight. The army on land waited in vain for his arrival, and at last surrendered to the conqueror. Upon this, he went to Libya, where a considerable host, which he had left there, was his last hope. On his arrival, he perceived that it had embraced the party of Cctavius, and his grief on the discovery was so great, that he was, with much difficulty, prevented from committing suicide. He returned to Egypt, and lived in obscilrity, till Cleopatra succeeded in bringing him back to her palace and to his former mode of life. Her festivals were interrupted by the arrival of Octavius. who refused all proposals of submission. At his appearance before Alexandria, A. seemed to recover all his former courage. He marched out at the head of his cavalry, and repulsed the hostile forces; but. afterwards, deserted by the Egyptian fleet and his ar ny, and suspecting that he was betrayed by Cleo: patra, he again lost his courage. He retired to th.e palace of the queen, in order to take vengeance upon her; she fled, however, and deceived hin by a false report of her death. Resolved to die with her, he fell upon his own sword, B. C. 30 . Plutarch relates, that A. commanded his slave Eros to slay him; the slave, pretending to be ready to obey, requested him to turn away his face, and then, stabbing himself, fell dead at his feet. Moved by this exhibition of heroic affection, $A$. threw himself upon the same swurd. On being told that Cleopatra was still alive. he caused himself to be carried into her presence, that he might die in her arms. See Augustus, and Cleopatra.

Avrony, Mark. See Antonius, Marcus.

Antraigues (Emanuel Louis Henry Launey), comte d'. This man, who became distinguished as a statesman during the revolution, was born in Bivarais. His tutor, the famous able Maury, early cultivated his 
talents for a splendid and captivating, though unsubstantial eloquence. He made the first public display of his talents in the renowned Memoire sur les Etats Généraux, leurs Droits et la Mfanière de les convoguer, A. D. 1788, in which his love of liberty, extending to the entire condemnation of all despotic governjnents, and the justification of resistance, was expressed with such force, that, in the excitement of the age, the work was honoured with the greatest applause, and may justly be regarded as one of the first sparks, that lighted the flame of the French revolut.oll. But when he was appointed deputy to the states general, in 1789 , he defended the privileges of hereditary nobility, was among those who most violently opposed the intended union of the three estates, and voted for a constitution fixing the rights of man, or rather of citizens, in which he declared the reto of the king an indispensable support of monarchy. In 1790 , lie left the assembly, renounced his oath of citizenship, with certain limitations, was accused of disturbing the public peace, openly defended himself, and then went to Petersburg and Vienna, engaged, continually, in diplomatic business. He was now the most zealous defender of monarchy and the Bourbons. Having been sent from Russia to Italy, in 1798, he was imprisoned, by order of Bonaparte, at Milan. His wife, the renowned opera singer St Huberti, pro. cured for him the means of escape. He returned to Vienna, and then to Russia, where, in 1803 , he was made counsellor of state by Alexander I., and sent on public business to Dresden. He wrote here a remarkable work against Napoleon-Fragment du $18 \mathrm{me}$ Livre de Polybe, trouvé sur le Mont Athos. After his return to Russia, he found means to become acquainted with the secret articles of the peace of 'Tilsit, weut to England, and communicated them to the ministry, by which means his influence became so great, that Canning did nothing in relation to France without his advice. He maintained his diplomatic connexions, especially in France, and was every where esteemed one of the first politicians of the age. In spite of his attachment to the Bourbons, and his nunerous struggles in their behalf, he did not succeed in gaining, entirely, the confidence of Louis XVIII. In 1812, he was murdered, in a village near London, together with his wife, by his servant Lorenzo, an Italian, who immediately after, shot himself also.

ANTRIM, a county in the province of Ulster, in Ireland, bounded on the east by the Irish channel; on the west by the counties of Londonderry and Tyrone; on the north by the northern ocean; and on the south by Lough Neagh and the county of Down. It extends from north to south 54 miles, and from east to west 35 miles, embracing 420,999 acres. Its population is estimated at 262,860 . The mountainous tistricts of this county are towards the east and north, but no part of the elevated land rises to a great height. Knoll Lade (1820 feet above the sea) in the north, Slenish in the middle of the county, and Davis, near Belfast, are the principal mountains. The general soil of the plains and valleys is strongloam, interspersed with patches of gravel and sand; but the mountainous parts are basalt or limestone rock, or covered with heath and bog. Gypsum is dug out, for exportation, near Beltast; coals have been long wrought at Ballycastle, on the northern coast; the shores of Lough Neagh furnish masses of petrified wood; and pearl stone, a rare mineral production in the British islands, is found at Sandybrae, twenty miles from Belfast. But the stupendous range of basaltic strata, exhibiting, in many places, magnificent colonnades, particnlarly at the celebrated Giant's Causey, and stretching almost the whole length of the northern coast, forms the most striking object to the geologist. The extent of sea-coast produces great scientific va- riety, and there is much picturesque beauty in the more fertile parts of the interior, particnlarly in the vale of Lagan, between Belfast and Lisburn. The Lagan and the Bann, which in different airections form the boundaries of the county, are its chief rivers. The other rivers are, the Ravil, the Braid, the Gleir wherry, the Main, the Six-Mile-Water, the Crumlin, the Glenevy, the Carey, and the Glenshesh, all of which, except the last two, fall into Lough Neagh. The staple manufactures of the county are linen and cotton. Flax, potatoes, barley, and oats, are the principal agricultural produce. The cattle are of small size ; the mountainous pastures feed numerous herds of goats; and the rearing of swine is extensive and profitable. Salmon fisheries are also successfully prosecuted. No county of Ireland includes a larger proportion of presbyterian protestants than Antrim, many of whom are descended from natives of Scotland. The principal towns of the county are Belfast, Carrickfergus, Antrim, Lisburn, and Randalstown. The assizes, elections, \&c., are held at Carrickfergus, and the quarter sessions at Antrim.-The town of Antrin is pleasantly situated on the north end of Lough Neagh, or the Six-Mile-Water, over which there is a bridge. The inhabitants are chiefly engaged in the linen manufacture. The population of the town is 2485 , and that of the parish 5129.

AnTwerp, (Anvers, French ; Amberes, Spanish ; Antwerpen, German and Dutch); a large, well-built capital of a province of the same name in the Netherlands, which, in 1814, was formed out of the former marquisate of $\mathbf{A}$. and the lordship of Mechlin, which, under the French government, had composed the department of the two Nethes. The province contains 1017 square miles, and 287,347 inhabitants. The city lies on the Scheldt; E. lon. $4^{0} 22^{\prime}$; N. lat. $51^{\circ} 14^{\prime}$ The largest vessels can ascend the river to the wharfs of $A$. on eight chief canals and three basins, built by the French. The city contains 60,000 inhabitants, is strongly fortified, has a citadel, more than 10,000 houses, among which is the magnificent exchange, the oldest in Europe ; also the council-house, the catheiral, in which Rubens (whose family was from A.) lies buried, the ample house of the Ostrelins (the former warehouse of the Hanseatic league), \&c. A. is the see of a bishop, contains an academy of sciences, an academy of painting and sculpture, a medico-surgical school, and a marine arsenal. Its manufactures of laces, sugar, white lead, litmus, cotton cloth, and fine thread, are very important. Its sewing silk, black silk stuff, and printers' ink, are known throughout Europe. Its commerce has greatly increased since the Scheldt was once more opened; and, in 1828, 955 vessels, anongst which were 73 from America, entered this port. Before the war of the Netherlands with Spain, A. was even more inportant than Amsterdam, which increased very much by the decline of A., in the l6th century. At that time, the Scheldt was covered with vessels belonging to all nations, of which, at one tine, 2500 lay in the harbour. An animated description of the commerce and activity of A., at that period, is given in Schiller's introduction to his Thirty Years' War. It then had 200,000 inhabitants, and the Fiansa, the famous league of the Hanse towns, had numerous warehouses here. The first blow was given to its prosperity by the memorable siege under the prince of Parma, in 1585 , and it was entirely ruined by the closing of its harbour after the peace of Westphalia. Joseph II. attempted in vain to open the Scheldt. .This was not done till after the conquest of the $\Lambda$ ustrian Netherlands by the French. The Scheldt was then declared free, and commerce would soon have revived, had not Napoleon made the place a military depot. In 1814 , it was besieged by the English and Saxons uncer. 
Graham, and defended by Carnot, who did not surrender it till the 5th of May, atter the armistice with Monsieur had been concluded. Carnot's conduct was such, that he gained the admiration of all soldiers nud military connoi-seurs, and the love of the people of $A$. though they hated the French, and suffered unch from the siege. The latest siege of Antwerp occurred in 1832, und originated thus:-Belgium was given to Holland by thie Holy Alliance, at their settlement of Europe, grievously against the will of the Belgians. In 1830, the Belgians endeavoured to throw off the Dutch soke; a fierce war ensued, which was stopped by the interference of the five great powers of Europe. Both Holland and Belgium agreed to abide by the decision of these powers. Belgium proinptly adhered to the terms of the award, which Holland, on the contrary, refused to do. After two years spent in protocols, Holland persisted in stopping the navigation of the Scheldt, and in retaining possession of the citadel of Antwerp. France and Britain, the only two of the five powers who considered their honour compromised by this violation of the imposed treaty, resolred to drive the Dutch out of Antwerp. With this view a combined fleet proceeded to blockade, or rather cruise off the Dutcli coast; andorders were given to the French army of the north, to besiege the citadel, which was under the command of baron Chassé. A force, accordingly, consisting of about 55,000 , under the command of marshal Gerard, sat down before it, and hostilities commenced towards the close of November. The precise position of the garrison and defences of the citadel on the 29th of November, 1832, may be summed up in a few woris. At the moment operations commenced, the Dutch held the citadel, including the lunettes Kiel and St Laurent, with a garrison of abrut $\mathbf{4 5 0 0}$ men. They had an ample supply of pro. visions, ammunition, and 130 pieces of artillery of different calibre. The Tete de Flandre, the forts Burcht, Zuyndrecht, and St Hilaire, were armed and garrisoned by about 500 men, whilst eleven gun-boats and a steamer were anchored in the river. The whole of the Polders, included within the bend of the Scheldt irom near the village of Burcht to the Pipe de Tabac, wre laid under water to the depth of seren to nine feet, and thus completely secured the forts, flotilla, and citadel from all molestation from the left bank. These inundations were fed by a rupture in the dykes of the Scheldt, nearly opposite the citadel, and another in the ricinity of the Pipe de Tabac. By this means it was intended to liare secured a free communication andpassage for the gun-boats between the Upper and Lower Scheldt, without the necessity of their passing under the fire of the Belgian batteries; but the operations of the French army neutralized the tffect of this measure. After a spirited defence of four weeks, the citadel surrendered, and was delivered over to the Belgians on the first of January, 1833, By all accounts, the French conducted the siege in a masterly manner; and when the garrison surrendered, treated their opponents with the characteristic courtesy of the nation. Of the besieging army, the number killed was 108, the wounded, 695. Of the besieged, the number killed was 122 ; the wounded, 369 .

Asobis; one of the most distinguished deities of the Egyptians. At first, he was worshipped under the form of a dog; afterwards under that of a man with a dog's head; hence he was termed Cynocephalus. Tradition calls him a son of Osiris by Nephthys, whom he mistook for Isis. When Isis was cun rinced of this by the lotus wreath left with Nephthys by Osiris, she sought out the child, exposed by his mother for fear of $T$ sphon, discovered him, with the help of a dog, educated hian, and found in him a faithiful guard and attendant. $\Lambda$. guards the gods as the tog guards men. So says Plutarch. According to Diodorns, Osiris was accompanied on his expeditions by $\Lambda$., and Macedon, another of his sons. $A$. carried a helmet corered with a dog's skin, and was therefore worshipped in the form of a dog. According to the astronomical theology of the Egyptians, he was the seventh amoug the eight gods of the first class, and designated the planet Mercury, as did also Piernies, the more common name of the planet. He was, consequently, lord of the ascendant for an hour of the day, and genius of wisdom. It is original form was derived, probably, from the worship of the dog among the Egyptians, who regarded him as the gorl of hunting; then he became, according to Zoega, a guardian spirit in general, a protector of the gools. The Greeks recognised in him their Hermes, with whom, therefore, he became confounded.

Axvin, in smithery, and other manufartures of the malleable metals, is an instrument on which substances are laid for the purpose of being hammered. For some purposes anvils are made of cast iron ; but when the face of the anvil is required to possess great hardness, or a bright surface, it is made of wrought iron and faced with steel. The core or body of wrought iron anvils is prepared at the forge, where malleable iron is first formed into bars, or into masses for any particular purpose. The body of the anvil is formed by welding a number of smaller masses together under the forge-hammer. These are rude blocks of different sizes, according to the size of the anvil. Smaller masses are also furnished in this way, which the anvil-maker occasionally welds to the large blocks, for giving to the anvil any particular form. The fire-place or hearth of the anvil-maker's forge is similar to the common smith's forge. His bellows are not double, like the latter. His fuel is cork, which produces a great heat without much flame. Adjacent to the hearth is a crane, which, turning upon a pivot, brings the heated masses of iron froni the fire to the anvil. The latter is a large mass of cast metal, about eighteen inches square on the face, and about a foot from the ground. When the core of the anvil to be formed is heated, the first thing is to make three square holes, one in the bottom, and one at each end of the anvil. These holes are about one and a fourth inch long, one inch broad, and about two inches deep. They are for the purpose of receiving a bar of iron, which is connected with the crane by which the anvil is held in the fire, and by which it is turned and guided while forming with the hammers. The common smith's anril is generally made of seven pieces, namely, the core or body; the four corners, for the purpose of enlarging its base; the projecting end, which contains a square hole, for the reception of a set, or chisel, to cut off pieces of iron; and the serenth piece is the beak, or conical end, used for turning pieces of iron into a circular form, welding hoops, \&c. These pieces are each separately welded to the core, and hammered so as to form a regular surface with the whole. When large pieces are required to be welded to the core one fire is not sufficient to lieat both at the same time. In this case two hearths are emplosed. The core and the piece are both raised to a welding heat. The piece being put into its place, is hammered by a quick succession of blows till it adheres. The whole is again heated and hammered till the due form is obtained. The hammering is perforned by a number' of men at the same time, each using a large swing-hammer. The blows follow each other in regular succession, great experience and care being required to prevent the hammers from coning in contact with each other. When the anvil has received its due form, it now reanires in he farrol with 
steel. This is performed by first preparing the steel face to the size of the anvil. The anvil is then heated to a strong welding heat in one fire, while the steel facing is heated in another, but not so hot as the iron. The anvil is now brought out and plaeed it: a proper position, and the facing is brought to it. The surfaces. which are to be brought together are brushed, and the facing is then laid on and hammered as rapidly as possible, till it is closely united. The whole is finished by repeated heating and hammering. The next process is that of hardening the anvil. This consists in henting the face, in particular, to a full red heat, and quenching it in cold water. When a stream of water can be employed it is better. IVhere this cannot be had, the mass of water should be great, and the anvil moved about as quick as possible. The facing should be laid on as thin as it can be firmly welded; when it is ton thick it is apt to crack in the hardening. "After hardening, the face is ground till it is perfectly even, and the edges made sharp or round, as may be required. When the anvil is required for planishing metals, it is polished with emery, and afterwards with crocus. The smith's anvil is generally placed loose upon a wooden block, the root-end of an oak-tree being preferred. The anvils used in cutlery and for files are fastened into a large block of stone, which is doubtless better than laving the anvil loose upon a small block. The more firmly the anvil is connected with the earth and the substance it stands upon, the greater will be the effect of the blow of the hammer.

ANVILLE, Jean Baptiste Bourguignon d' ; first geographer of the king, pensionnaire of the academy of inseriptions and fine arts, \&c., was born at Paris, in 1697. A map, which ehance put into his hands, awakened his love for geography at the age of 12 . Ile began to sketch regions mentioned in the Roman historians, and directed all his studies to geography. He read the ancients only to ascertain the position of cities, and to fix the limits of the remote kingdoms, of which we find traces in history. Thus he early acquired an extensive knowledge of geography, became acquainted with the learned, and, at the age of 22 , receired the office of geographer to the king. He now began to examine and set in order the mass of lis knowledge, and acquired a nice tact, resembling instinct, which was the result of ingenious and careful comparison. Almost everywhere, his accuracy was rewarled by the discovery of truth. The highest estimation is due to him as a eritic, and most of his opinions and conjectures have been verified by later inquiries on the spot. He has published 211 maps and plans, and 78 treatises. His atlas of ancient Egypt is the most deserving. His Orbis Veteribus notus, and his Orbis Romanus, ought to be in the hands of all who read ancient history. So, also, his maps of Gaul, Italy, and Greece. His naps of the owme conntries for the middle ages are of equal value. His maps of modern times are as good as could be formed of the materials in his possession. He was ınodest and unassuming, although too irritable when censured. The natural delicacy of his constitution flid not hinder him from labouring fifteen hours daily. Two years before his death, his mental powers sank beneath the infirmities of age. He died in 1782 . His valuable collection of maps was purchased by the government in 1779.

Aosian Mooxt ; Parnassus (q. v.); the residence of the Muses. The nane Aonia was sometimes given to a part of Boeotia.-Aonidcs; one of the many names given to the Muses.-Annes (Aovs) were a chain of mountains, of whieh Helicon was one.

Aorasia (Greek, coparia, from $\approx$ priv. and iona, to see), the invisibility of the gods. The ancient opinion with regard to the appearance of the gods to men was, that they never showed themselves face to face, but were known from their baeks as they withdrew.

AORTA; the great artery, which rises immediately out of the left ventricle of the heart. It is distinguished into two grand divisions by the epithets ascending and descending. See Artery.

APaNage; an allowance which the younger princes of a reigning house (in which the right of primogeniture prevails, as is now generally the case) receive from the revenues of the country, that they may be enabled to live in a manner becoming their rank. It consists mostly in money, with the use of a prineely castle and hunting grounds, attended, frequently, with the right of jurisdiction over these domains. When it is once fixed, it passes to the descendants of the apanaged princes, sprung from a lawful marriage, of a suitable rank, and, in their default, commonly falls into the hands of the reigning sovereign. Sometimes it is added to the possessions of the surviving apanaged princes. A tract of land with the right of ruling it, set aside for an apanage, is called peragium.

APE. This designation, often indiscriminately applied to the members of the monkey tribe, was first properly restricted by Ray, the precursor of Linnæus, to those quadrumanous animals which, in structure, most closely approximate to the human configuration. In speaking of apes as distinguished from monkeys, we have reference to those genera of the great family quadmemana, which have neither tails nor cheek pouches, attain nearly to human height, and present a facial angle, varying from $65^{\circ}$ to $30^{\circ}$. 'The apes at present known are classed differently by different naturalists: Cuvier considers them all as species of one genus; Desmarest, whose arrangement in this instance we prefer, places them under the three gencra, troglodytes, pithecus, and pongo, the second of which he divides into two sub-genera, orangs proper, having no gluteal callosities; and gib. bons, or long-armed apes, having callosities. The species are troglodytes niger, the chimpanzee or orangotang, which is a native of Africa, especially of the coasts of Angola and Congo, pithecus satyrus, the red orang, found in the most eastern parts of Southern Asia, particularly in Cochin China, Borneo, and Malacca ; pithecus lar, the great gibbon, a native of the Molucca islands, Coromandel, \&c. ; pithecus leuciscus, the wou-wou (so called on account of its cry), found in the same countries; pithecus syndactylus or siamang, and the pithccus agilis or aetive gibbon, both from Sumatra. As to the pongo, Cuvier has given excellent reasons for believing it to be nothing but the first-mentioned species in a state of maturity.Like all the four-handed animals, the apes are destined to live among the branches of trees, and are especially adapted, from their size and strength, to occupy large forests. All of them have the power of assuming a nearly erect position, though on the ground this is by no means convenient, as they stand upon the outer edges, being unable to apply the paluns of the posterior hands fairly against the soil, and require a staff, or other support, to maintain this attitude, except when they have been taught to stand crect by man.- They generally live in troops, anc. some of the species are said to construct a sort of hut of leaves, as a defence against the weather. They defend themselves with clubs, and employ these weapons with considerable effect, cren against the human race. They are frugivorous in a state of nature, but, from the resemblance of their teeth to those of the human species, it is very evident that their diet may be almost as various as that of man. Some of them, the gibbons, are very remarkable, from the cxceeding length of their superior extremities, the arm being so long that the lands hang near the ground when the animal is in the erect position. 'This 
singular conformation serves to adapt these crentures to their situations, in a manner which would scarcely be imagined, without having been witnessed. They spend their days chiefly upon the tops and branches of lofty trees, canes, and banbons, and, in passing from one to the other, are forced to make great leaps. The advantage of their vast length of limb is then rendered evident, as the gibbons would be umble to cling with their hinder hands to a long, flexile branch, swayed in various directions by the breeze, were it not that they can maintain their position by balancing themselves with their long arms. On the loftiest branches of the gigantic enstern forest trees, troops of these animals are seen sitting balanced in perfect security, and some of the species at sunrise and sunset scream forth discorlant cries from such positions. If any circumstance occur to disturb these orisons, the apes disappear with amazing celerity into the deptlis of the forest, springing from tree to tree, swinging themselves to great distances by their long arms, and catching as readily at the next object with the posterior laands. The orangs of Borneo attain to the greatest size, growing to be five or six feet high ; and travellers speak of apes of a still larger size. They are represented, with justice, as terrible animals, and are endowed with unexampled strength of limb, one adult ape being more than a match for several umarmed men. They cause much terror to the natives residing near their haunts, and commit great ravages among the plantations of fruit, \&.c.-The orang most frequently exhibited and closely observed in captivity is the chimpanzee, joco or wild man of the woods, commonly called orang-otang ( $S$. troglodyfes, L.) This species is an inlabitant of Africa, and especially of the coasts of Congo and Angola. In the proportions of its nembers, and form of the head, it most closely resembles the human kind. It is a very amusing, though, at the same time, an unproductive employinent, to read the monstrous exiggerations and ridiculous fables, which have been written of this animal by various learned authors. As they are always obtained when very young, they are trained to the performance of actions, which their exhibitors afterwards are careful to say have been acquired by voluntary imitation. It is, however, only after long and painful discipline that this education is effected; and, this once terminated, they advance no farther. They never exhibit as much sigacity as is shown by a good dog, nor are they capable of an equal degree of improvement. As they adrance in life, they become untractable and savage, and, if Cuvier's opinion be confirmed, that the pongo of Africa is this orang-otang in a state of maturity, they become, with age, the most terrible and indomitable of their whole race. Lascivious, filthy, gluttomous, and ferocious, they offer to man a perfect picture of what he would be, were he, like them, destitute of the divine faculty of reason, which controls the brute impulses of his organization. In their native haunts, these animals manifest differences sufficiently striking, in their habits and modes of life, to render them interesting objects of contemplation. Some of the species are remarkable for great activity ; others are sluggish, indolent, and inert. The females manifest an ardent attachment to their offspring, and make vigorous efforts to save them from injury. All show various degrees of that restless mobility, which indicates how much they are under the exclusive influence of sensation, without appearing to form conclusions from their repeated experience. An ape, in captivity, on seeing his image in a mirror, will look behind it to discover the animal reflected; and will as eagerly perform this action after the thousandth repetition as the first.-Our limits will not permit us to enter more particularly into this subject; but the curious rewler will find in the works of F. Curier details suffi:iently ample to satisfy the most inquisitive spirit.

A-prak (d pique, $\mathbf{F r}$ ) ; perpendicular to the anchor. A ship is said to be in this situation, when the cables is drawn so tight into the bow as to bring her directly over the anchor, so that the cable bears right down from the ship's stem.

APECLIs, the most famous of the ancient portrait painters, was the son of l'ythias; probably born at Colophon. At Ephesus, he received the rights of citizenship, and therefore is called, sometimes, the Ephesian. Ephorus of Eyhesus was lis first tencher, but, attracted by the renown of the Sicyonian school, which distinguished itself by exact study, le becane the disciple of Pamphilus, in Sicyon, though already himself an artist of reputation. Here he executed, with some other pupils, of the same master, different paintings, which, for a long time, enjoyed great fane. In the time of Philip, $\Lambda$. went to Macedonia, and there, probably, the friendship and familiar inter course between him and the king were established, which have given origin to so many anealotes. But many of these may relate to a meeting with Alexander in Ephesus, where $\Lambda$. liad gone, after a short stay at Rhodes, Cos, and Alexandria. While staying at Rhodes, being in the study of Protogenes, during the absence of the latter, he drew a sketch, in which Protogenes, on his return, recognised the masterly stroke of $\Lambda$. and undertook to excel him. A. re turned and drew a third sketch, superior to both, se that the Rhodian painter declared himself conquered. The table containing the figures was afterwarls brought to Rome, and ornamented the palace of the Casars, till destroyed in a conflagration. The unost celebrated painting of this artist-Alexander holding the lightning, from which the chief light of the picture proceeds-stood in the temple of Ephesus. $13 y$ a happy npplication of perspective and chiaro-oscuro, the hand with the lightning seemed to project from the picture. The talent and renown of $\mathrm{A}$. were at their height in the 112th Olympiad. Yet, after the death of Alexander, he several times painted king Antiochus. This must have happened in the 118 th Olympiad. Death seems to have surprised the artist in Cos, where an unfinished Venus was shown as lis work, which nobody dared to complete. But the story that A., at the court of Ptolemy, at Alexandria, was accused, by the painter Antiphilus, of being engaged in a conspiracy, and that, his innocence being proved, he took revenge on the king and his rival, by a picture of Calumny, must refer to another artist of the same name. Tolken, professor at the university of Berlin, in his lecture, Apelles and Antiphilus, in vol. iii. of Amalthea, has proved that this Apelles lived between the Olympiads 139 and 144, consequently 100 years later than the contemporary of Alexander. The greatest merit of $\mathbf{\Lambda}$. was inimitable grace ; his works were full of life, grace, and poetry, and his art, therefore, was justly called ars Apellea. According to Pliny, A. generally painted with four colours only, which he made to harmonize by means of the varnish, which he himself had invented.

Apenatiss, or Appexisines; a chain of mountains beginning near the Maritime Alps, not far from Genoa, there forming the pass of Bocchetta, extending through all Itaiy to the shores of Otranto and the straits of Sicily, and dividing it into two nearly equa! parts, eastern and western. The Apennines are covered to the top with trees, especially chcsnut trees, the fruit of which, in some countries, is the principal food of the inhabitants. Lower than the Alps, the Apennines present only a few elerated summits; e. g., the Gran Sasso, at Aquila, in the province of Abruzzo, 8255 feet high, and the Velino. 7872 feet 
bigh. The Apennines are corered with snow in winter, which sometimes melts late, and, congealing, forms ice, indispensable in a warm climate like Italy. In the Apennines are some large valleys, a few lakes and rivers, and many marshes at the foot of the hills. The internal construction of the chain shows great uniformity, the prevailing mineral, a thick, white limestone, being found in the same position in many places. The northern part deviates from this formation where it unites with the Alps, as well as the extreme south : both exhibit a great variety of elder formations. The lower elevations between the plain and the central chain display considerable diversity of construction. Primitive formations are wasting "ntirely in the next range of heights. . In the highest of all, they are not abundant. Yet, in the southern part, granite, gneiss, and mica slate are considerably diffused. The transition rocks, however, are widely spread, and abundant in various parts of the chain; e. g., grey wacke, clay slate, limestone (e. g., the Carrara marble) and gabbro. Very widely diffused, also, is the compact floetz limestone, known under the name of Apennine limestone, which probably belongs to the limestone formation of the Jura. These mountuins also are rich in recent formations, and in the vulcanic tufa, which is an aggregate of volcanic substances transported and deposited by water. Proper volcanic and trapp formations, as they are called, are foreign to the principal chain of the Apennines. These are confined to the south eastern part of Italy. Only Vesurius, the extinct volcanoes of Nemi and Albano, and the lava stream of Borghetto, approach the borders of the chain.

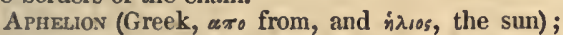
that part of the orbit of the earth, or any other planet, in which it is at the point remotest from the sun. This also applies to a satellite; for the moon has her aphelion as well as the planets.

APHronite; the goddess of love among the Greeks; synonymous with Aphrogeneia, that is, born of the foam of the sea:-Aphrodisia; a festival sacred to Venus, which was celebrated in various parts of Greece, but with the greatest solemnity in the island of Cyprus. See Venus.

Aplos, M. Gabius; an epicure in the time of Augustus and Tiberius. He had the most delicate table in Rome, proved his genius for cookery by the invention of new dishes, and at last, when he had exhausted his vast fortune, he poisoned himself, that he might not die with hunger.-There were two other notorious epicures of the same name at Rome. The hook of cookery, however, De Arte Coguinaria, published under the name of Apicius, was written by one Cælius, who assumed the proverbial nickname Apicius. The latest edition was by Bernhold, Anspach, 1806.

Aprs; a bull to which divine honours were paid by the Egyptians, chiefly at Memphis. According to the belief of the people, a cow became pregtant of lim by a beam of light from heaven, coming particularly from the moon. It was necessary that he should be black, with a triangle of white on the forehead, a white spot, in the forn of a crescent, on the right side, and a sort of knot, like a beetle under his tongue. When a bull of this description was found, he was fed four months in a building facing the east. At the new moon, he was led to a splendid ship, with great solemnity, and conveyed to Heliopolis, where he was fed 40 days more by priests and women, who performed before him various indecent ceremonies. After this, no one was suffered to approach him. From Heliopolis the priests carried him to Memphis, where he had a temple, two chapels to dwell in, and a large court for exercise. He had the gift of prophecy, which he imparted to the children about him. The omen is good or bad, according as he goes into one chapel or the other. His birth-day was celebrated every year, when the Nile began to rise; the festival continued for 7 days ; a golden sliell was thrown into the Nile, and the crocodile was always tame as long as the feast continued. Notwithstanding all this veneration, the bull was not suffered to live beyond 25 years; the reason of which is probably to be found in the astronomical theology of the Egyptians. He was buried in a fountain. Belzoni thought he had discovered a tomb of Apis in one of the stone sepulchres anong the mountains of $\mathrm{Up}$ per Egypt, which enclose the valley of tombs, or the gates of the kings. In the same place, he found a colossal sarcophagus of alabaster, transparent and sonorous (now in the British museum), ornamented within and without by carved hieroglyphics and figures. In the interior of the apartment was found the body of a bull, embalmed with asphaltum. The death of A pis excited universal mourning, which colltinued till the priests had found a successor to him. As it was extremely difficult to find one with all the above distinctions, fraud was often practised by the priests.

A POCALYPSE (Greek; from $\alpha \pi \circ$ ox $\alpha u \pi \tau \omega, I$ reveal); the name of the last book of the New Testament, containing an account of the visions of St John the evangelist. It is generally believed, that the Apocalypse was written by John, in his old age, at the end of the first century, in the isle of Patmos, whither he had been banished by the Roman emperor Domitian. Though the book was commonly regarded as genuine in the first centuries of Christianity, critics have not been wanting, who have doubted the evidence of its being the work of St John. Its genuineness seems to have been first questioned in the $3 d$ century; but archdeacon Woodhouse, in his Dissertation on the divine origin of this book, in answer to the objections of Michaelis, las, we think, set this question pretty well at rest. The Apocalypse, on account of its metaphorical language, has been explained differently by almost every writer who has ventured to interpret it; and, for the same reason, it is one of those parts of the Bible which has furnished all sorts of sects and fanatics with quotations to support their creeds or pretensions. Even at the present time, people who have no clear and simple views of religion, but make it a mere matter of feeling and passion, refer more to this mysterious book, and to some parts of the Old Testament, than to the Gospels, and the other comparatively intelligible portions of the Scriptures. In the metaphors and symbolical expressions with which the Apocalypse abounds, the author seems to have had in view, the then existing state of the church of Christ, and its future prospects. The Apocalypse contains 22 chapters, which may be divided into two principal parts. 'The first, after the title of the book, (ch. i. 1-3.), comprises "the things which are," that is, the then present state of the Christian church, including the epistolary instructions and admonitions to the angels or bishops of the seven churches of Ephesus, Sinyrna, Pergamos, Thyatira, Sardis, Philadelphia, and Laodicea, situated in Asia Minor. The second part comprehends a prediction of "the things which shall be hereafter," referring either to the future state of the church through succeeding ages, from the time when the apostle beheld the apocalyptic visions, to the grand consummation of all things, or the state of the souls of men after the great resurrection of the dead. The millennium, which is spoken of in the Apocalypse, has, at different times, seduced people into the strangest expectations respecting the end of the world, particularly in the earlier times of Cliristlanity ; nay, the expectation of a speedy destruction 
of the worll appears to have been an idea of the apostles themselres, based on a misinterpretation of the assurance of Christ, that he would som return, connected with the idea, that the only object of lis returu must be to judge the living and the dead.

A rocry pIIAL (Greek; concealed); an evithet generally applied to certain books not admitted into the conon of the Old Testament; being either spurious, or not acknowledged as of divine origin. 'They are opposed to the canonical writings, i. e. those which are considered as affording rules of faith and conduct, beause a divinc origin is attributed to them. Besides the apocryphal books of the Old Testament which usually stand after the canonical books in our elitions, therc are numerous spurious books, composed in the early days of Christianity, and publisher under the names of Jesus Clirist and his apostles, their companions, \&c. These bear the names of Acts, Epistles, Revelations, \&c. 'They are entirely tlestitute of evidence to justify their admission into the sacred canon, and, on this account, are omitted entirely. 'They may be found in the Cod. Apocryph. by Fabricius, (Hamburg, 1719, 2 vols.)

$\triangle A O G E$ (Greek; from $\alpha \pi s$, from, and $\gamma n$, the earth); that point in the orbit of the sun, or of a planet, which is at the grentest distance possible from the earth. The point of greatest nearness is called the perigee. The ancient astronomers, regarding the earth as the centre of the system, paid particular attention to these points, which the moderns, making the sun the centre, change for the aphelion and perihelion.

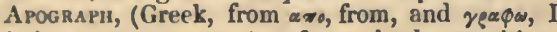
write), a copy or transcript of some book, or writing. In this sense, apograph stands opposed to autograph; as a copy to an original.

A pollinariav Games; games at Rome, celebrated searly in honour of Apollo, on the fifth day of July, under the direction of the prator, in the circus Maximus. They were instituted in the year of Rome 542 ; and were merely scenical, no chariot races, or other exercises, being performed at them.

A pollunariass, in ecclesiastical history; a sect which maintained the doctrine that the Logos (the Word of God) holds in Christ the place of the rational soul, and consequently that God was united in him with the human body and the sensitive soul. Apoltinaris, the author of this opinion, was, from A. D. 362 till at least A. 1). 352, bishop of Laodicea, in Syria, and a zealous opposer of the Arians. As a man and a scholar, he was highly esteemed, and was among the most popular authors of his time. According to the old historians of the church, when the emperor Julian forbade Christians the use of schools and the study of the Greek classics, Apollinaris, with his father, of the same name, a teacher of languages, and a presbyter, composed imitations of them, for the use of the Christians; for instance, heroic poems and tragedies, fiom the historical matter of the Old Testament, and dialogues in imitation of Plato's, from portions of the New. None of these works are now extant. His doctrine above-mentioned was first made known A. D. 371 , and has been condemned as heretical, since A. D. 375 , by various councils; among others, by the ecumenical council at Constantinople, A. D. 381 . Apollinaris, however, formed, a congregation of his adherents at Antioch, and made Vitalis their bishop. The Apollinarians, or Vitalians, as the followers of Apollinaris and Vitalis were called, soon spread their sentiments in Syria and the neighbouring countries, established sereral societies, with their own bishops, and one even in Constantinople; but, after the death of their leader, between A. D. 382 and A. D. 392, they separated into two varties-one, the Valentinians, who adhered to the doctrine of Apollinaris; the other, the Polemians, who assert that Goul and the boly of Chrlst became onc substance, and who, conseruently, pay divine honours to the flesh; tor which reason they were, called Sarcolatra, Anthropolatre, and, because they admit the union of both natures in Christ, Synusians. lmperial edicts, A. J. 388 and 397 , forbade them to hold religious assemblies; and, A. $\mathbf{1}$. 428 , they were wholly forbidden to have ecclesiastics, or to dwell in cities. 'This sect, never numerous, now disappeared, being partly included among the orthodox, und partly, afterwards, amoug the Monoplyysites. The doctrine of transubstantiation, and divine honour to the consecrated host, arises from the sume view, which the Catholics deemed a crime in the Poleminns.

Apolio; son of Jupiter and Latona, who being persecuted by thic jealousy of Juno, after tedions wanderings and nine days' labour, was delivered of him and his twin sister, Artemis (Diana), on the island of Delos. (q. v.) A. appears in mythology as the god of poctry, music, and prophecy, the patron of physicians, shepherds, and the founders of cities. Skilled in the use of the bow, he slew the serpent Python on the ffth day after his birth; afterwards, with his sister Diana, he killed the children of Niobe, \&c. He aicled Jupiter in the war with the Titans and the giants. He destroyed the Cyclops, becansc they forged the thunderbolts with which Jupiter killed his SCn and favourite, Esculapius. All of the malc sex who were snatched from the world by a sudden and easy death, without previous sickness, were supposed to be smitten by the arrows of $A$. In the oldest poems, $A$. is exhibited as the god of song. In the festivals of the gods on Olympus, and those of men in which they took part, lie plays and sings, while the Muses dance around him. He invented the harp or lyre. Marsyas, who ventured to contend with him on the flute, was conquered and flayed alive by the god. A. had another contest with Pan, in which the former played on the lyre, the latter on the pipe. Tmolus had already decided in favor of A., when Midas opposed the sentence, and was decorated with a pair of ass's ears for his insolence. That $\mathbf{A}$. lrad the gift of prophecy, appears from the Iliad, where lie is said to have bestowed it upon Calchas; and, in the Odyss $\cdot y$. mention is made of an oracular response, delivered by him in Delphi. (q. v.) The oracle of A. at this place became very famous. He also revealed futurc events at Didyma, Claros, Tenedos, and Patara. As medical advice was sought chiefly from oracles and soothsayers, A., in later times, came to be regarded as the god of physic. He was called the father of Esculapius, and poets feigned that he taught the Asclepiades the art of healing. Fables about the pastoral life of A. were not unknown in Honer's time, and Callimachus mentions him among the gods of shephcrds. He is reported to have taken clarge, for a long time of the herds of Admetus, according to some authorities, voluntarily, according to otliers, compelled by Jupiter, on account of the murder of the Cyclops, or the serpent Python. As a builder of cities, the founding of Cyzicum, Cyrene, and Naxos in Sicily, is ascribed to him. Homer relates that he built the walls of Troy together with Neptune, and afficted the city afterwards with a pestilence, because. Laomedon defrauded him of his pay. According to Pausanias, he assisted in building the walls of Megara; at which time he laid down his lute upon it stone, which ever after sent forth the music of the lute, as often as it was touched. According to the descriptions of poets, and the representations of sculptors, A. with Mars, Mercury, and Bacchus, belongs to the beardless gods, in whom the dawnings of early manhood appear. His attributes are a bow, a quiver and plectrum, a serpent, a shepherd's crook, a griftin and a swan, a tripod, a laurel, an olive-trec, \&c. My- 
thology relates many of his amours. (See Daphne.) In later times, he was confounded with Helios, among the Romans, Sol, the sun. Besides many temples, the island Delos, the city Delphi, mount Helicon, Leucadia, and Parnassus were sacred to him.-The Apollinaria were games, celebrated in honour of him at Rome, which consisted of bull-fights, theatrical shows, and athletic exercises. He is often called Phoebus, both by Greeks and Romans. Among the ancient statues of $\mathrm{A}$. that have come down to us, the most remarkable, and, in the judgment of the learne'd and acute Winckelmann, the best and most perfect that art has produced, is the one called the Apol10 Belvidere, from the pavilion of Belvidere in the Vatican, at Rome; also called the Pythian Apollo, because it is supposed that the artist has represented the god as the conqueror of the serpent Python. This statue was found in the ruins of Antium, at the end of the 15th century. On the peace of Tolentino, 1797 , it was carried to Paris, with other treasures of art, whence it was restored to Rome in 1815 .

A pollo (BeLviderE), an ancient marble statue of the most exquisite funish and workmanship, so called from being placed in the Belvidere gallery of the Vatican palace at IRome. It represents the god of day holding a fragment of a bow in his left hand, from which he appears to have just discharged an arrow, and he seems in an attitude of suspense, awaiting its descent upon the object of his wrath. It has been always considered, by the best judges, as one of the most beautiful of the remnants of ancient art, now extant in Italy. Wincklemann, lord Byron, and other writers, have expressed themselves in raptures as to its exquisite beauty, high finish, fine proportions, and great expression. The learned Visconti, in his Dissertation on its merits, attributes it to the chisel of the Greek sculptor Calamis, and thinks that it is a representation of the Apollo Alexicacos,-or the deliverer from evil-the Apollo destroying the Python or great serpent-and thinks that it has been described both by Pliny and Pausanias. The history of its discovery and removal is to be found in the Museum Pio-Clementinum, and in the works of several modem travellers. It is noticed as rather a remarkable fact, that only one small antique repetition of this statue is to be found, whereas the statue of the Venus de Medicis, now at Florence, seems to have been so great a favourite with the ancient Greeks and Romans, that not fewer than one hundred ancient copies or repetitions of it have been noticed by travellers, and the reason why this Apollo seems to have been so anjustly depreciated in ancient times, is thought by $V$ isconti to arise from the fact that the transcendent Phidias, that prince of sculptors, had produced a statue similarly occupied, but of which the attitude was more energetic and daring, and that the applause bestowed on the work of Phidias, joined to his great reputation, had caused this work of Calamis to be overlooked in a great degree. Of this work of Phidias, which has been lost in the ruin of ages, nothing remains but a description by Maximus Tyrius. See Wincklemann, Histoire des Arts, Byron's Childe Harold, Visconti, Forsyth, Eustace, \&c.

Apollodoros; son of Asclepiades; an Athenian grammarian, who flourished about 140 B. C.; studied philosophy under Panzetius, and grammar, in the ancient sense of the word, under Aristarclius. He wrote a work on the gods, a cummentary on Homer's catalogue of ships, and a history in verse. The mythological work entitled Bibliotheca, which bears his name is probably a later extract from the larger work of A. It is very closely connected, however, with his history of the gods and heroes. The best editious are Heyue's, $2 d$ edition, Gottingen, 1803, 2 vols., and Clavier's, Paris, 1805, 2 vols., with a
French translation. $-\Lambda$, is also the name of a distinguished architect, who built the forum Trajani.

A pollodoros of Athens; a distinguished painter, about 408 B. C. See Painting.

Apollonikos; a large hand-organ, completed, in 1817 , by Flight and Robson, organ-builders, which, however, may be played by the aid of keys, of which there are five rows arranged together in such manner that several musicians may perform at the same time. It is said to resemble the panharmonicon of Maelzel, and is calculated to produce a powerful effect, which is greatly enhanced by the variety of its stops. Prior to this, Roeller, an instrument-maker, born in Hesse-Darmstadt, lad invented an instrument with two rows of keys, which might be played as a piano-forte and as a chamber organ, combined at the same time with a musical automaton. It is described in the $2 \mathrm{~d}$ vol. of the Leipsic Musical Journal. This instrument was called the apollonion.

Apollonios of Perga, in Pamphylia; one of four authors (Euclid, Archimedes, Apollonius, and Diopliantes) whom we must regard as the founders of mathenatical science. He lived about 240 B. C., and studied mathematics at Alexandria, among the scholars of Euclid. The most renowned of his uumerous mathematical works is a book on Conic Sections (Oxford ed., 1710, fol.) a branch of the science to. which he added much by new inventions and liappy explanations. -A. of Rhodes, according to some authorities, was born' at Alexandria, according to others, at Naucratis, about 230 B. C. As the jealousy of other learned men incessavitly persecuted him in his own country, he retired to Rhodes where he taught rhetoric with so much reputation, and obtained, by his writings, so much fame, that the Rhodians bestowed upon him the rights of citizenship. He returned to Alexandria to succeed Eratosthenes, as superintendent of the library of that city. Of his various works, we have only the Argonautica, a poem of moderate merit, though written with much care and labour. There are some passages, however, of great beauty, especially the episode on the love of Medea. The best editions are those of Brunck, Strasb. 1780, Leipsic, 1810, and that of 1813 , with notes, \&c.; the latter is not yet completed. (See Weichert On the Life and Poetry of Apollonius, Meissen, 1821.)-A. of Tyana in Cappadocia, was born in the beginning of the Christian era, and became a follower of the Pythagorean philosophy. Euthy. demus, the Phœnician, instructed him in granmar, rhetoric, and the various philosophical systems, and Euxenus of Heraclea taught him the Pytlıagorean philosophy. A. felt an irresistible desire to become a disciple of Pythagoras, according to the rigid rules of his sect. At Egae, there was a temple consecrated to Esculapius, where this god wrought miracles for the cure of the sick. To this temple A. repaired. In obedience to the precepts of Pythagoras he abstained from all animal food, and lived only on fruits and herbs, drank no wine, dressed in a stuff prepared from plants, went larefooted, and suffered his hair to grow. The priests of the temple instructed him, and initiated him into their mysteries. It is said that Essculapius himself made him a witness of his cures; yet we have never been told that he liad then attempted to perform miracles. He established a philosoplical school, and enjoined silence upon himself for five years. During this time he visited Pamplyylia and Cilicia, and afterwards, Antioch, Ephlesus, and other cities. He then determined to pass beyond Babylon, to. India, in order to become acquainted with the doctrines of the Bramins ; and, as his scholars refused to follow him, he began his journey alone. A certain Damis, who met him and regarded him as a deity, was his coniparion, 
and the narmator of his travels. At Babylon, he conversed with the Magi, and departerl thence, with rich presents, on his way to Taxella, where l'hraortes, king of India, had his seat of goverument, who gave him letters of introluction to the first among the Branins. After four months, $\Lambda$. retnrned to Babylon, from whence he proceeded to Ionia, and visited several cities. His fame every where preceded him, and the people came forth eagerly to meet him. He publicly reproached thein for their indolence, and recommended community of gools, according to the doctrines of Pythagoras. He prophesied pestilence and earthquakes at Ephesus, which afterwards really came to pass. He spent one night in solitude at the grave of Achilles, and pretended to have had a conversation with the shade of that hero. At Leshos, he conversed with the priests of Orpliens, who at first refused to initiate him into the sacred mysteries, regarding him as a sorcerer; but they received him some years later. At Athens, he recommended to the people sacrifices, prayers, and reformation of their morals. In every place which he visited, he maintained that he could prophesy and perform miracles. $\Lambda$ t last he came to Rome. Nero had, just before, banished all the magicians from the city. A. felt that he might be arrested in consequence of this edict; this reflection, however, did not prevent him from entering the city, with eight of his companions; but his stay was short. He raised a young lady from the dead, says an historian, and was expelled from the city. He then visited Spain, returned through Italy to Greece, and thence to Egypt, where Vespasian made use of him for the support of his authority, and asked advice of him as of an oracle. 'Thence he journeyed to Ethiopia, and, after his return, was received as favourably by Titus, who nsked his advice in all the affairs of government. When Domitian ascended the throne, $\Lambda$. was accused of having excited an insurrection in Egypt, in favour of Nerva. He readily submitted to a trial, and was ac. quitted. After this, he went once more to Greece, and passed over to Ephesus, where he opened a Pythagorean school, and died, almost 100 years old. Among the many miracles related of him, he is said to have announced the murder of Domitian, at the very moment when it happened. The heathens compare him to Christ, as a worker of miracles. Flavius Philustratus wrote a history of his life, very favourable to him, in eight parts.

A rolog हтісs. A great number of apologies were written in defence of Christianity, in the early ages of the church, by Justin and others, but apologetics did not form a separate branch of theological science till the 18 th century. We understand by them a philosophical exhibition of the arguments for the divine origin of Chrislianity. 'They are to be carefully distinguished from polemical writings, which have for their object only to maintain the peculiarities of one religious sect or party against another. Hugo Grotius is one of the most eminent among the writers of these works. The Génie du Christianisme of Chateaubriand is a superficial declamation, with little merit but that of elegance. One of the principal apologetic works of modern times is in Dauish - Kristelig A pologetik, eller $V$ idenskabelig Udvikling af Grundene for Kristendommens Guddommelighed, ved P. E. Muller (Christian Apologetics, or philosophical Arguments for the divine Origin of Christianity), Copenhagen, 1810.

Apologue. See Fable.

A poLoGy ; defence of one who is accused. Judicial trials, among the ancients, were public, as they are in Britain and America, and consisted of speeches for and against a person or cause, and of the examination of witnesses. From judicial defences, which were cften written down during the trial, and frequently composed accurately, and cominitted to paper by the spenkers themselves, nud afterwards made public, nrose apologies. Of this nature are the apologies of Socrates, attributed to l'lato and Xenophon. The former is a laboured speech, in which Socrates is introduced speaking himself; the latter, rather a narration of the last hours and words of the wise man, with an explanation of the reasons why he preferred death, by which he seemed elevated above his accusers inore than he would have been by a formal defence, which he scorned to make. Later rhotoricians wrote upon the use of apologies, and caused them to be composed by their scholars. Of this sort are the Apologies of Libanius (in four parts, the Reiske edition). Thus the name passed over to Christian mithors, who, having before been orators or philosophers, borrowed a great part of their teclmical terms from the public courts of justice. They gave the name of apologics to the writings which were designed to defend Chiristianity against the attacks and accusations of its enemies, particularly the pagan philosophers, and to justify its professors before the emperors. Of this sort were those by Justin Martyr, Athenagoras, Tertullian, Tatian ; and others, which are lost, written by Quadratus, Aristides, Melito, Miltiades, and Theoplilus. To these might be added several works of Origen, Clement of Alexandria, Eusebius; and, among the Latins, those of Lactantius, Arnobius, Minucius Felix, and Augustin, though they are published undrr another title. We must not expect in them strict philosophical connexion, nor the accurate interpretation of the sacred writings. It must be remembered, that most of the authors, part of whom had belongel to the profession of advocates, made use of all the arts of eloquence that were permilted in public courts. After the secure establishment of Christianity, such apologies, in a great measure, ceased to appear, till, in later times, several writers have again attackel it, either directly or by indirect insinuation. In collsequence, new apologies have been written, and, among many weak ones, some exhibit great power and eloquence. There are, also, apologies for the doctrines of particular sects ; e. g., Robert Barclay's Apology for the People in Scom called Quakers.

Aposo, Peter, one of the most celelorated physicians of the 13th century, was born at Apono, or Abano, a village near Padua, in 1250 . He studied at the university of Paris. His reputation as a physician became so great, that his rivals, envious of his celebrity, gave out that he was aided in his cures by evil spirits, and brought him under the notice of the inquisition, but he died before his process was finisherl. His body would have been consigned to the flames, but for the attachment of a female domestic, who harl it privately disinterred, and secretly re-buried. His memory received honours more than equal to this attempted disgrace, for the duke of Urbino and the. senate of Padua afterwards erected statues to him. Besides the work, Conciliutor Differentiamem Philosvphorum, et pracipue Medicorum, which he composed in Paris, and which was published at Padua, in 1490 , and reprinted at Florence and at Venice, this autlor wrote De Venenis eomumque Remediis, Marpurg, 1517, and Venice, 1550; De Medicina Omnimoda; Qucestiones de Felribus; and various other works.

A Pophtheg (from the Greek $\alpha$ ro $\phi \theta \delta \mu \alpha$ ); a short. pithy sentence, or maxim, as, for example, the sayings of the seven wise men, so called. Julius Caesar wrote a collection of them, but history has not handed them down to us. Sereral modern writers have written such apophthegms, in prose and rerse. Some parts of the Bible are entirely composed of apophthegms.

A POPLEXY is the name applied to a disease which occurs very suddenly, as if a blow had been inflicted upon the head, and deprives the person of conscious- 
ness and voluntary motion, while the respiration and action of the heart continue, although much oppressed. In a complete apoplexy, the person falls suddenly, is unable to more his limbs or to speak, gives no proof of seeing, hearing, or feeling, and the breathing is stertorous or snoring, like that of a person in deep sleep. In a case of less violence, the symptoms are more moderate. Consciousness sometines remains in part; some power of motion is' retained, upon one side, or in some parts, at least; the speech is not entirely lost, but is only an unintelligible nuttering of incoherent words. The imnediate cause of this disease is some affection or injury of the brain, or of some portion of it; and it is most commonly produced by a fulness of blood in the head, either remaining in the blood vessels, or poured out, in, or upon the brain, from the rupture in some part, and in sufficient quantity to exert considerable pressure upon that organ. As the state of the whole body clepends much upon the sound condition of the brain and nerves, it is evident that such an unnatural state of these organs cannot continue long without danger to life. 'The termination and effects of the disease vary with the violence of the attack; and it is either fatal in a few hours, or after a few days, during which a degree of fever is often observed, or the patient recovers, entirely or with a weakuess or lameness of oue or more limbs: The immediate cause of the symptoms first occurring, and of those remotely subsequent, is not knowil with absolute certainty; but from the examination of the bodies of those who have died with this disease, or in whom death has been produced by mechanical injuries to the head, which have been attended by similar appearances; and from the entire similarity of the symptoms in persons whose brains are injured by the pressure of bones, or blood, or in whom the brain exposed by some wound is purposely compressed, \&c., to the symptoms presented by apoplexy; there is scarcely room to doubt, that genuiue, coniplete apoplexy is produced by the pressure of blood (whether extravasated or not) upon the brain. This arises from the destruction of the equilibrium or balance of the circulation by various causes, by which an unuatural quantity of blood is forced into an otherwise healthy brain, or the brain and its ressels so weakened, that they are unable to sustain the pressure of the usual quantity of blood. Some of these causes operate directly upon the brain, as strong passions, hard stndy, exhaustion from fatigue, \&c. ; others, indirectly, through the medium of the stomach, as when this disease is produced by indigestible food, \&. The disposition to it is sometimes hereditary and is most usually found to accompany a short, full, person, a short neck, and a system disposed to a too copious sanguification. It sometimes, also, occurs in people who are exhausted by old age, excessive labonr or anxiety, and, in these cases, the brain seems to be too weak to perform its common functions, and the efforts required of it produce an injurious or destructive flow of blood to it. It will be readily conjectured, from what has been said, that the cure of this disease is by no means easy, as the treatment must be accommodated to the various causes which may liave produced it. It is at all times a disease of great danger, but by no means always fatal; and those affected by it sometimes recover as entirely ns from any other complaint, although some lameness or defect of motion is apt to remain, either in the limbs, the organs of speech, the eyes or mouth, or some other part. A fatal result is to be anticipated, when the consciousness and feeling are entirely lost; when the eye is insensible tolight, and the pupil does not conlract ; when the patient caunot swallow, the respiration grows more laborions, and froth or lolool appears at the month or nuse. But if, on the contrary, the remedies used appear to afford relief, and produce a gradnal diminution of the symptoms above described, a favourable result may be expected. Although an attact of apoplexy comes on, for the most part, sudden$l y$, and unexpectedly, yet it is often preceded by ap. pearances, which give waruing of. its approach. These are a high colonr of the whole face, giddiness or vertigo, sparks, or flashes of light before the eyes, noises in the ears, bleeding at the nose, and pain in the head. The danger, in such cases, may nost commonly be averted by bleeding and abstemious diet, to be continued till these symptoms are removed. When a person is unfortunately attacked by apoplexy, the first step should be to open the cravat and collar, so as to leave the neck free : if it be a short time after a meal, or if the last meal has been of an indigestible character, the stomach shonld be emptied hy an emetic, or by tickling the throat with the finger, without waitiug for a physician, and, at the same time, a vein or two should be opened, so as to produce a free flow of blood, which should be continued, if the face is fushed and red, till relief is obtained. Subsequent treatment will of course be directed by a medical attendant. Great care should be taken, in such eases, that no attempt is made to arouse the person by rubbing, or any sort of stimulation, internal or external, as these can only do harm. Palsy is sometimes a consequence of apoplexy, but it is more commonly produced by causes of a different character, and constitutes a different disease. See Palsy.

APOSTASY (from Greek $\alpha \pi 0$ irsapat, I stand off); a renunciation of opinions or practices, and the adoption of contrary ones, usually applied to one wlio has forsaken his religiou. It is always an expression of reproach. What one party calls apostasy, is termed by the other conversion. History mentions three eminent apostates-Julian the Apostate, who had never been a Christian, except nominally, and by compulsion; Hemry IV., king of France, who thought that Paris vaut bien une messe, and that, of course, all France was worth the whole Catholic faith ; and William of Nassau, the stadtholder, who separated himself from the Catholic church, and became a Protestant, according to the faith of his father, which, in fact, had always been secretly his own. One day, Henry IV., standing with the marshal Joyeuse on a balcony, seeing many people looking at him, said, Mon cousin, ces gens-la me paraissent fort aises de voir ensemble un apostat et un renégat. General Bonneval, a Frenchman, was a famous apostate. He became a Turkish pacha. Generally, apostates, religious or political, are violent partisans. Catholics, also, call those persons apostates, who forsake a religions order, or renounce their religious vows withont a lawful dispensation. The apostasy of a Christian to Judaism or paganism was punislied, by the emperors Constantius and Julian, with confiscation of goods; to which the emperors Theodosius and Valentinian added capital punishment in case of the apostate's perrerting others. Also, in ancient England, it is said, that apostasy was punishable by burning, and tearing to pieces by horses. Statutes 9 and 10 of William III, c. 32 , also provide thut, if any person, edicated in, or having made pro fession of the Christian religion, shall deny it to be true, he shall be rendered incapable of loolding any office for the first offence, and, for the second, shall be made incapable of bringing any action, of being guardian, executor, legatee or purchaser of lands, and shall suffer three years' inprisonment without bail. The punishment of the first offence, however, will be remitted in case the delinquent, within four months after convietion, publicly renoumces his error in open court. Penal laws of this sort, relating to religion, have generally laiu dormant in Erigland. 
A mosten:ori. See A priori.

A postles; such as are sent; (from the Greek arorrinsu, to send); in the Christian church, the 12 men whom Jesus selecterl from his disciples as the best instructed in his doctrines, and the fittest instruments for the promulgation of his religion. Hence they were regarded as the ambassadors of Jesus to the rest of the world, (Matt. ch. xxviii. ver. 19.) Their uames were as follows :-Simon Peter (Greek for Caiaphas, the rock), and Andrew his brother; James the greater, and Joln his brother, who were sons of Zebedee; Philip of Bethsaida, Bartholomew, Thomas, Matthew ; James the son of Alpheus, commonly called James the less; Lebbeus, his brother, who was surnamed Thaddeus, and was called Judas or Irode; Simon the Caunanite, and Judas Iscariot. Of this number, Simon Peter, John, James the greater, and Andrew were fishermen; and Matthew, a publican or tax-gatherer. When the apostles were reduced to 11 by the suicide of Judas, who had betrayed Christ, they chose Matthias by lot, on the proposition of St Peter. Soon after, their number became 13, by the miraculons vocation of Saul, who, under the name of Paul, became one of the most zealous propagators of the Christian faith. The Bible gives the name of apostle to Baruabas also, who accompanied Paul on his missions (Acts of the Ap. cl. xiv. ver. 13), and Paul bestows it also on Andronicus and $J$ unia, lis relations, and companions in prison. Generally, however, the name is used, in a narrower sense, to designate those whom Christ selected himself while on earth, and Paul, whom he afterwards called. In a wider sense, those preachers who first taught Christianity in heathen countries, are sometimes termed apostles; e. g., St Denis, the A. of the Gauls; St Boniface, the A. of Germany; the monk Augustin, the A. of England; the Jesuit Francis Xavier, the $\mathbf{A}$. of the Indies; Adalbert of Prague, A. of Prussia Proper. Paul was the only A. who had received a scientific education; the others were mechanics. Peter, Andrew, and Jolın are called in the scripture (Acts, ch. iv, ver. 13), homines sine litteris, idiota. Questions have often been started respecting the domestic circumstances of the apostles. Were they very poor? Were they married? \&c. Our information on these points is very limited. Some eminent theologians have thought that Christ was not poor, and that the apostles had a common fund sufficient to meet many expenses, of which some indications exist. Tradition reports that several of the apostles were married. The wife of St Peter is said to have accompanied him on his journeys, and died a martyr. The tradition further states, that Peter lind a daughter, Petronilla, who was also a martyr ; thus, at least, say St Augustin, St Epiphanius and St Clement of A lexandria. St Philip, also, is said to lıve been married, and to have had several daughters, among whom was St Hermione. Hegesippus speaks of $t$ wo martyrs, grandsons of Jude. His wife was called Mary. St Bartholomew is also said to have been ma rried. But tradition affords almost our only auth ority respecting their private lives. During the life of the Saviour, the apostles more than once showed a misunderstanding of the object of his mission, and, during lis sufferings, evinced little courage and firmness of friendship for their great and benevolent Teacher. After his death, they received the Holy Ghost on the day of Pentecost, that they might be enabled to fulfill the important dities for which they land been chosen. Their subsequent lives the Catholic church represents as follows, partly on the authority of the book of Acts, mostly on that of tradition :-St John made some excursions into Asis, and preached among the Parthians, and in India. In the reign of Domitian, he was carried to Rome, tortured, and exiled to Patmos, where he wrote the A pocalyose. He dicl in Fiphesus. St Bartholomew travelled through India, Persia, Abyssinia, Arabia Felix, and finished his course in Amuenia. St Philip preached in Plırygia; St Thomas in Media, Caramania, Bactria, in India, and even in China; hut this last fact is not positively asserted. St Matthew preached in Fithiopia. St Simon, say the Greeks, after having baptized in Fgypt, CFrenaica, Libya, and Manritania, went to England, and thence to l'ersia, where he diel. St Jude preached in Syria, Mesupotamia, Persia, Armenia, and Libya. St Peter, afterwards bishop of Antioch, and then of Rome, visited Asia Minor, and also Babylon, as one of his letters slsows, provided Babylon, does not signify in that passage, liome, as some critics lave thought. St Paul visited $\mathbf{A}$ sia Minor, Greece, and Rome. The two Jameses seem not to have gone far from Jerusalem ; yet the body of James the greater is snid to be buried at Compostella in Spain. According to Matthew (ch. xvi. ver. 18), Christ considered St Peter the first in rank of the apostles ; and it is known, that the pope derives his authority over the living and the dead from the power which Christ gave to St Peter, of whom all the popes, according to the Catholic dogma, are successors in an uninterrupted line.-In Venice, the 12 first families were called apostles, as are likewise 12 islands in the straits of Magellan.

Apostles' Islands; in the strait of Magellan, at its entrance into the Pacific, near cape Deseado. They are 12 in number, which circumstance gave then their name. All are small, barren, and desert. Their shores abound with shell-fish. Lon. $75^{\circ} 6^{\prime} \mathrm{W}$.; lat. $52^{\prime \prime} 34^{\prime} \mathrm{S}$.

Apostolical; all that comes from the apostles, or has relation to them. Thus the apostolical writings are writings composed by the apostles. The earlier Christian clurch was called the apostolical church, because the apostles at first conducted it, and, after their death, their spirit remained in it. So, also, the papal see is called the apostolical see, because it is supposed to have been founded by the apostle P'eter. The apostolical office, at Rome, is the name of the office which manages the - apal revenues. -The apostolical blessing is the blessing bestowed by the pope, as successor of Peter.-The king of Hungary is styled apostolical king, apostolical majesty. Pope Sylvester II. bestowed this title on Stephen I., duke of Hungary, A. D. 1000 , because he not only greatly promoted the Christian religion in Hungary, but also in imitation of the apostles, preached himself. Clement XIII. renewed the memory of this occurrence, by giving the empress-queen Maria Theresa the title of apostolical queen, in 1758. - The apostolical symbol is a short summary of the Christian faith, and bears this name because it contains, in three articles, the doctrines of the apostles. This apos. tolical symbol is found even in the writings of Ambrose, who lived in the beginning of the 4 th century. Peter Gnapheus, in the 5th century, ordered the constant repetition of the same in the church service.

Apostolics, or Apostolici; the rame of three sects who professed to imitate the manners and practice of the apostles. The first flourished at the close of the second century. They had all things in com. mon. Little else is known of their peculiar tenets. The second sect of this name existed in the twelfth century. It was composed of people of the lotier class. 'They were numerous, and their lives, as Bernard admits, were exemplary. 'Their peculiarities were as,follows:-They held it to be unlawful tc take oaths; they suffered their hair and beards to grow to an enormous length; they preferred celibacy to wedlock, calling themselves the chaste brethrev 
and sisters; each mal, however, had a spiritual sister, with whom he lived in a domestic relation.The third sect of $\Lambda$. was founded, about 1260 , by Gerhard Sagarelli. They went barefooted, begging, preaching, and singing throughout Italy, Switzerland, and France; announced the coming of the kingdom of heaven, and of purer times; had females in their retinue, as the apostles had their female companions, and were suspected of unlawful intimacy with these sisters, This society never received the papal confirmation; on the contrary, it was abolished, A. D. 1286, by Honorius IV. Though they were persecuted by the inquisition, they continued in existence, perpetually wandering about; and, when Sagarelli was burnt as a heretic, A. D. 1300, another chief apostle appeared,-Dolcino, a learned man of Milan, - who eneouraged the sect, now increased to 1400 men, with his prophetic promises. To defend themselves against persecution, they rere compelled, about the year 1304, to station themselves in fortified places, whence they might resist attacks. In the plundering habits which they were forced to adopt, they wholly lost the original design of their institution, and, after having devastated a large tract of country belonging to Milan, they were subdued, $A$. D. 1307 , by the troops of bishop Raynerius, in their fortress Zebello, in Vercelli, and almost all destroyed. Dolcino was burnt. 'The survivors afterwards appeared in Lombardy, and in the south of France, as late as A. D. 1368. Their heresy consisted in reviling the pope and the elergy.

A postool; a Mennonite minister at Amsterdam, who established, in 1664, a sect called Apostoolians, a branch of the Mennonites.

A postrophe; a figure of speech which received this name from the ancients, because the orator, in using it, turned from the judge to the accuser, or the accused, and spoke to him. In a more limited sense, we understand by it, an address to one absent as if he were present, or to things without life and sense, as if they had life and sense. The apostrophe, according to its nature, is spoken in an elevated tone. The same term is also used to signify the contraction of a word by the use of a comma.

A poth macy, or preparing and vending medicines for the use of the sick. Previously to the reign of James §., the Apothecaries were confounded with the druggists and grocers, and retailed syrups, Venice treacle, and wine; but upon tle joint solicitation of his physicians, Dr Mayerne and Dr Aikin, that monarch was pleased to grant thenı a separate charter, whereby they were withdrawn from their spicy. associates, in order to enable them to make up the Physicians' preseriptions with greater nicety and accuracy-and during the reign of George I., they were exempted from serving on juries, or in parish offices. They are obliged to prepare all their medicines according to the rules laid down from time to time in the Pharmacopoeia of the College of Physicians, and are liable to the dumiciliary visits of the four censors of that Indy, who can enter their shops, examine all their drugs, and burn, destroy, and throw into the kennel all such articles as are not properly prepared or in good preservation. The company of apothecaries of London, are governed by a warden and masters, and have a large laboratory and hall in Blackfriars, where they retail drugs to the public, and from which all the rnedicines required for the liospitals of the British navy are sent. ILegally speaking, apothecaries have no right, by the laws of England, to visit the sick in their own louses, or prescribe for them; for they are not allowed to make any charge for medical attendance or visits; and in making out their bills, they can onlv charge for their potions, draughts, powders, electuaries, pills, boluses, \&c. To account for this absurdity, which is the source of a great deal of folly, it should be known, that before the last great plague in London, the sick were always attended by physicians only, who wrote prescriptions, which were sent to the apothecary or grocer's shop, and there prepared, and the medicine sent back to the sick persons' houses. But during that dreadful visitation, a great majority of the regular physicians having died, and many of the survivors fled into the country, the friends of the sick were forced to implore the aid of the apothecaries, who thus left their counters and shops and came, for the first time, to the bedsides of the sick. Having become the attendants of the infirm, on the return of order, the pliysicians abandoned the poorer classes to their care, and obtained for them a royal charter; and since that period, the increasing demands of a large and industrious population have fostered the increase of apothecaries, who are now generally called in by the rich on all slight occasions, and have, conjointly with the surgeons, rendered their former patrons, the pliysicians, dependent on their bounty; for it is it general maxim with an apothecary, never to permit a physician to be called in, as long as his patient will swallow his medicines wholesale, without disputing their necessity, or unless his victim is absolutely in the agonies of death, and then a physician is called, mierely for decency's sake, and to sign the deathwarrant. It is agreed on all lands, that the state of the medical profession in England requires a thorough investigation and legal reform; but no person seems inclined to meddle with such a nesst of hornets, and in the meantime, the race are permitted to prey on the livers of the Promethean public as it best pleases them so to do.

A poth вosis (deification); a solemnity among the ancients, by which a man was raised to the rank of the gods. The custom of placing mortals, who had rendered their countrymen important services, among the gods, was very ancient among the Greeks, who generally followed, in so doing, the advice of an oracle. On their coins, most of the founders of cities and colonies are immortalized as gods; and, in subsequent times, living princes assumed this title. The Romans, for several centuries, deified none but Romulus, and first imitated the Greeks, in the fashion of frequent apotheosis, after the time of Augustus Cæsar. From this period, apotheosis was regulated by the decrees of the senate, and accompanied with great solemnities. There are still many monuments extant exhibiting the Roman apotheosis. It became, at last, so common, as to be an object of contempt. Vespasian, in an attack of sickness, said, by way of joke "I am a god, or, at least, not far from it."-According to Eusebius, Tertullian, and Chrysostom, Tiberius proposed to the senate the apotheosis of Jesus Christ, which, however, was refused by this body. Juvenal, satirizing the frequent practice of A., introduces poor Atlas, complaining that he could not any longer bear the immense and daily increasing mass of gods. That virtuous persons, after their death, were raised to the rank of demigods, was a doctrine of Pythagoras, who probably derived this idea from the East. It corresponds with the notions of many Christians, who believe that virtuous men become angels after their death. The period of the Roman emperors, so rich in crime and folly, offers the most infamous instances of apotheosis. After Casar, the greater part of the Roman emperors were deified. The same hand which had murdered a predecessor often placed him among the gods. The savage Nero deified the beautiful Popprea, his wife, after lıving killed her by a kick when she was pregnant; and Caracalla, having murdered his brother, Geta, with his own hands, in lis $2 n-\pi 2$ 
mother's arms, gmnted him divine honours, accompanied with the infamous remark-Sit divus, dum non sit vivus. The first emperors were not adored in their life time; but, with the progress of insanity, temples were built to the living tyrant. Caligula was not satisfied with being a gool; he wished to be a priest too, and, taking his horse as a companion in the office. offered sacrifice to himself, and, immedintely after wards, appeared as Jupiter or as Cythera, \&c. Constantinus had the clouble advantage of being deified by the religion which he had persecuted, and canonized by that which he supported. It was quite customary for the Christian emperors to have altars, and be adored by their pagnn subjects. Critics are not wanting, who see, in the canonization of the Catholic church, nothing but a continuance of this Romas: fushion of deifying men, with this difference only,that saints were never canonized during their lifetime. This deification of the living, the Romans derived, perlaps, from the Greeks, whose lively and poetical imaginations led them sometimes to build altars to their mistresses, and offer sacrifices to them. The apotheosis never degenerated to such a criminal excess among the Greeks as among the Romans. The ceremonies of the Roman apotheosis were very curious, but are too long to be repeated here. tains.

Appalachan Moontanss. See Alleghany Moun-

Appalacmicola; a river of the United States, formed by the Chatahoochee and Flint rivers, which unite near the northern border of Florida. The A., after a course of about 70 miles, flows into St George's sound, in the gulf of Mexico, and is navigable throughout for schioners of considerable size. 'The Chatahoochee, the western and largest tributary of the $A$., rises in the Appalachian or Alleghiany mountains, on the confines of Georgia and Tennessee, and is navigable for bosts nearly 400 miles from the gulf of Mlexico.

A PPANAGE, See Apanage.

APPAREvT, among mathematicians and astronomers, denotes things as they appear to the eye, in distinetion from what they really are. Thus they speak of apparent motion, magnitude, distance, height, \&c. So important is this difference between reality and appenrance, particularly in regard to the heavenly bodies, that we find all early astronomers, who were igtorant of this fact, running continuallyinto errors; and a great advancement in science was required, before mankind were able to establish systems opposed to appearances. Every one knows that a body may appear to move while it is, in fact, at rest, and the motion is in the spectator, or the place on which he stands, as is the case with the sun, irr relation to the iuhabitants of this earth.-The phrase apparent heir, or heir apparent, signifies one whose right of inheritance is indefeasible, provided he survives his ancestors; as the eldest son or his issne, who must, by the course of the common law, be heirs to the father. Heirs presumptive are such who, if the ancestor should die immediately, would, in the present state of things, be his heirs.

ApPARItion; a spectral illusion, involuntarily generated, by means of which figur's or forms, not present to the actual sense, are nerertheless depicfured with a vividness and intensitysufficient to create a temporary belief of their reality. It is the result of the re-action of an excited imaginstion, renovating past feeling or impressions, with an energy proportioned to the degree of excitement; arranging them often in new and fantastical groups; and thus surrounding us with a phantasmagoria of the bodiless creation of the brain, so distinct both in outline and lineamerit, that, while the existing cause continues to operate, the illusion of reality pieduminates over the mind with an Intensity genemlly equal to, sometimes greater thum, that of the impressions proclucer by actual perceptions. But although the illusion thus generated is necessarily co-existent with the state of excitement in which it las its origin; or, in other words, ceases to be active when the spectral phenomeua vanish; it does not therefore follow that the mind, when it regains its orlinary condition, becones inmediately sensible of the hallucination under which it has for a time been labouring, or capable of distinguishing between the perceptionis of sense and the phantasms of inagination. On the contrary, observation proves, what theory equally sanctionis, that the conviction of reality generally outlasts the inpressions which originally produced it; and that, so far from any suspicion of ilhsion being entertained, or any power of discriminating the actual from the imaginary being evinced, this conviction takes entire possession of the mind, and, in many instances, maintains its hold with a furmness which all the force of argument and reason is insufficient to overcome. Hence the tenacity, and, we may add, the universality, of the belief in apparitions; and hence also the prodigious diversity of forms under which these spectral illusions are presented in the popular legends and superstitions of different ages and countries ; - a diversity, in fact, which seems commensurate with the incredible variety of influences, whether morbific or other, by which the imagination may be excited, and past feelings or impressions vividly renovated in consequence of its re-action on the orgaus of seise. -Dr Brewster has remarked, as a physical fact, that "when the eye is not exposed to the impressions of external objects, or when it is insensible to these objects in consequence of being engrossed with its own operations, any object of mental contemplation, which has either been called up by the memory or created by the imagination, will be scen as distinctly as if it had been formed from the vision of a real object. In examining these mental impressions," he ackls, "I have found that they follow the motions of the eyeball exactly like the spectral impressions of luminous objects, and that they resemble them also in their apparent immobility when the eye-ball is displaced by an external force. If this result shall be found generally true by others, it will follow that the objects of mental contemplation may be seen as distinctly as external objects, and will occupy the same local position in the axis of vision as if they had been formed by the agency of light." This goes to the very root of the theory of apparitions; all the phenomena of which seem to depend upon the relative intensities of the two classes of impressions, and upon the manmer of their accidental combination. In perfect health, the mind not only possesses a control over its powers, but the impressions of external objects alone occupy its attention, and the play of imagination is consequently cliccked, except in slerp, when its operations are relatively more feeble and faint. But in the unhealthy state of the mind, when its attention is partly withdrawn from the contemplation of external objects, the impressions of its own creation, or rather reproduction, will either overpower or combine themselves with the impressions of external objects, and thas generate illusions which in the one case appear alone, while in the other they are seen projected among those external objects to which the eye-ball is directed, in the manner explained by Dr Brewster. We may add, that the same reasoning which applies to the impressions derived from the sense of sight, is equally applicable to those received through the medium of any other sense, - as the ear, for instance, an organ which ninisters abundantly to the production of spectral illusions.

Appeal (law) signifies the removal of a cause from 
gn inferior tribunal to a superior; from the Frencl appeller, of the same signification. In England, appeals lie from the ordinary courts of justice, and also from the equity courts to the parliament. Appeals irom courts of equity differ from writs of error, which impugn the judgments of the ordinary courts, in these respects, - that the former may be brought upon inter ocutory matters, that is, questions occurring in the course of the trial ; the latter, upon definitive judg. ments only. On writs of error, the house of lords pronounces judgment; in appeals, it directs the court to rectify its judgment. In Germany, originally, appeals could be brought only when the feudal lord refused to administer justice. The cause might then be carried before the king's court; and, if magistrates decided wrongly, their decisions might be called in question (Fr. fausser le jugement), and thus the appellant became at issue with his former judges, and the dispute, according to law, was to be decided by mortal combat. Subsequently, all judgments were examined by a superior court. This change had been already introduced in France by king Louis IX., but was first firmly settled in Germany, by the establishnient of the court of the imperial chamber, A. D. 1495. Appeal was made from the tribunals of the lords of manors to the courts of the princes, and from these latter to the tribunals of the empire, the court of the imperial chamber, and the aulic council. The states of the empire endearoured, as far as possible, to shake off this subordination of their tribunals to the supreme judicature of the kingdom. Austria, from the very first, kept herself perfectly free from this dependence. The electors were entitled to the same liberty, by virtue of their ancient privileges; but it had now becoine a fundamental law, that there should be three degrees of courts, and those who would not establish tribunals of the third or highest degree (high courts of appeal), were obliged to allow the right of appeal to the supreme courts of the empire, and could obtain exemption therefrom only by particular imperial privileges (privilegia de non appellando). The same privilege was granted also to other states, who might establish their own supreme tribunals (as Sweden at Wismar, Hanover at Celle, Hesse-Cassel, \&c.), or else send the documents, belonging to questions at issue, to foreign colleges, which had the right of final judgment. The tedious forms in the supreme courts of the empire, and other defects in the judicial administration, gave popularity to these establishments, on the part of the separate states; aftlough the maxim, that three consecutive decrees ire requisite for the entire settlement of a controversy at law, infinitely delayed the process; and the want of a supreme court, extending its authority throughout Germany, was lighly prejudicial to the improvement of the German code. The dissolution of the German empire increased the difficulties attending the administration of justice in the small states; and it is one of the most salutary resolves of the German compact (while recognizing the necessity of three consecutive judgments as a fundamental law of the empire), that the smaller states shall be cumpelled to erect, in conımon, high courts of appeal, and not confine themselves to petty, local jurisdictions. These supreme courts, common to several states, have all, within a few years past, been reduced to a regular order. The great limitation, almost anounting to exclusion of criminal cases, is a remarkable circumstance in the constitution of these courts. The di. versity in the amounts of property in question, for which appeal is allowed from the different states, is also interesting. Saxe-Hildburghausen alone suffers all causes, without reference to the amount in dispute, to go to the high court of appeal at Jena. In the rest of the states, the limitation varies between 100 and 500 Saxon dollars. With a few differences in names and forms, all the judicial administration of Germany is now uniform, and the rule of the three gradations of tribunals is universal. The smaller states, we have already said, have joint courts of appeal. Austria has such courts of her own, at Vienua, and many other places, besides a supreme court of justice at Vienna. Hungary and Transylvania lave a judicial constitution peculiar to themselves. In old Prussia, the courts of the first or lowest degree are those of cities, districts, \&c.; of the second degree there are fifteen, in as many important places; of the third degree, there is properly but one, the superior tribunal at Berlin; but the efficacy of this court in maintaining unity in the administration of justice is much interrupted by many revisions of each other's decrees, which take place between the various courts of the second degree. The Prussian lands on the Rhine still have the French judicial constitution ; and, for this, a court of revision was established at Berlin, by the decree of July 20, 1819, in the room of the French court of cassation. Bavaria has eight tribunals, with appellate jurisdiction, and a supreme court of appeal, at Munich. The high courts of appeal of individual states, according to the chaice of the parties in every case, stand in the place of a joint tribunal, for the settlement of the contests of the states with one another. In France, only two gradations are permitted-the tribunals of the first instance (district and county courts), and the courts of appeal (cours royales), which have taken the place. of the old parliament. For the whole kingdom, however, there is the royal court of cassation, which has to decide only in cases where the competency of a tribunal, or the formality of a process, is called in question. This court does much towards the preservation of harmony in the administration of justice.

APPEAL, in the.judicial language of England, be. sides the common meaning in other countries, had, till lately, another also, denoting an accusation by one private subject against another, for some heinous crime, demanding punishment on account of the particular injury suffered, rather than for the offence against the public. The usual English criminal process is a process of accusation by indictment of a grand jury, in which the accuser is obliged to prove lis charges, and the accused is not bound to give answer or reply with regard to his actions. The German criminal process, on the contrary, seeks especially to investigate the truth from the statements of the accused himself. In the English system, the prosecution is conducted by the goremment, at the request of the injured party, who has nothing further to do, but to furnish means of proof to the advocates of the crown. But the process of appeal, of which we are now to speak, was another sort of prosecution or suit, in which the defendant, or one of his relations, summoned the plaintiff before the proper tribunal of justice (the king's benclt), in order to obtain satisfac. tion for the offence, and to have the proper puishment inflicted. The accuser, here, is called appellor, or appellant, and the accused, appellee. This kind of appeal took place when the supposed criminal liad been acquitted on an indictment, but not if he liad been sentenced and punished for a less crime than that of which lie was accused ; for instance, of $\mathrm{mall}$ slaughter instead of murder. If lie was pardoned, this did not protect him from this private accusation, and, if found guilty on these charges, he was obliged to suffer the punishment established by law, and the king could not pardon lim. This right of private accisation continued for a year. If, therefore, the judge, the public, or the relatives, were not satisfied with the sentence of acquittal passed by the jury, such an appeal might be:made, and the person acquitted 
tetainer in prison till the end of the year, unless bail whs given for his appearance to answer to the appeal. The jury on the appeal was usually different from that on the indictunent, and examples are not wanting where a man has been brought in guilty by the second jury, on the same gronnds upon which he was acquitted by the first. Thus, A. D. 1708, John loung was murdered, and suspicion fastened upon Ephraim Slaughterford, his friend, with whom he was last scen. He was acquitted at the assizes, but the public were so convinced of his guilt, that a subscription was opened to pay the expenses of a private accusation. Slaughterford was found guilty by a second trial, and executed. A similar event happened, A. D. 1818 . A young lady, Mary Ashford, was found inurdered under circumstances which fixed the strongest suspicions upon one Abraham Thornton. He lad waited upon her home from a ball, and had been with her, as he himself confessed, a short time before the discovery of her body, not far from the pit, full of water, in which it lay. Notwithstanding this, he was acquitted, and the brother of the deceased now prosecuted him by an appeal of murder. Upon this, Thornton made use of a right, the existence of which had been almost forgotten. He summoned the accuser to a wager of bacile, i. e. a trial by combat, instead of submitting to a trial by jury. The validity of this right could not be questioned, and the adrocate of the accuser received a severe reproof from the court, because he suffered himself to call it unreasonable and barbarous. The accuser, a weak young man, twenty years old, did not venture to engage in a contest, with clubs, with the athletic Thornton: he was obliged to recall his accusation, and the suspected murderer was once more acruitted. The public feeling, howerer, was so strong against him, that he emigrated to America, where he soon after died. This erent occasioned the abolition, not only of the wager of hattle, but also of the right of appeal, as experienced lawyers were of opinion that the accused could not be deprived of the choice between a second trial by jury and a wager of battle. This was done, A. D. 1819, by the act of parliament 59 George III., c. 46. Some may think that this abolition has occasioned an essential defect in the English laws; but it is merely applying to such cases a just and proper principle of criminal law, which is now generally adopted both in England and America, that no person shall be twice tried for the same offence, $\rightarrow$ principle that gives great security against oppressive and successive prosecutions. The process of appeal and the trial by combat were never introduced into the American law.

Apperlasts; a religious party. See Unigenitus.

APPEAZEL; a canton of the Swiss confederation, surrounded on all sides by the canton St Gall. It is divided into two parts, called Inner-rood, or rhode, and Outer-rood, each having, since 1597, a separate government, independent of the other. In respect to the others cantons of the confederacy, both are considered as forming one canton. The form of government is entirely democratic. Every man, above the age of 16 years, annually appears, with his sword, in the general assembly, when the officers are chosen. A. contains, on 222 square miles, 55,000 inhabitants. The canton is actire in manufactures of different kinds, and in raising cattle. The chief place is the market-town, Appenzel, in the Inner-rood; lon. $9 \circ 3 \mathbf{I}^{\prime}$ E. ; lat. $47^{\circ} 20^{\prime}$ N. ; pop. 3,000. See Swiss Confederation.

APPIAX of Alexandria ; governor and manager of the imperial revenues, uniler Adrian, Trajan, and Antoninus Pius, in Rome. He wrote a Roman history, from the earliest times to those of Augustus, in 24 books, of which only half have come down to us, an unetgual work, according to the sources from which the anthor drew his materinle. The best lato edition is that of Schweighauser, Leipsic and Strasburg, 1785,3 rols.

Appian WAY, leading from Rome to Capua; the oldest and most renowied Roman road. It was sunde: by Appins Claudius Crassus Curcus, when he was censor, 313 years 13. C. ; and afterwards extended to 13rundusium. It consisted of hard, hexagonal stones, exactly fitted to one another; and there may still be seen, particularly at Terracina, impartant remains, which prove its excellent workmanship.

Appiasi, Andrew; a painter, born at Milan, May 23,1754 , of an old and noble, but poor family. He was obliged to work with scene-painters for his support, and to go with his masters from town to town. In Yarma, Bologna, and Florence, he land an opportunity to see and study the master-works of his art, and to form his style. He visited Rome three times, in order to penetrate the secret of Raphael's style of fresco-painting, and suon excelled in this art every living painter in Italy. He displayed his skill particularly in the cupola of Santa Maria di S. Celso, at Milan, and in the paintings which he prepared for the walls and ceiling of the villa of the archuluke Ferdinand, at Monza (1795). Napoleon appuinted him royal court painter, gave him the order of the legion of honour, and that of the iron crown, and mate him member of the Italian institute of sciences and arts. A. painted afterwards almost the whole of the imperial family. His best works are the fresco-paintings, on the ceiling of the royal palace at Milan, allegories relating to Napoleon's life, and his Apollo with the Muses, in the villa Bonaparte. Almost all the palaces of Milan have fresco-paintings by him. Napoleon's fall affected A.'s fortune severely. He dieu in 1817, in straitened circumstances.

Appios Craddios Crassinds, a member of the patrician family of the Claudii, though cruel and arrogant like his ancestors, was hardly appointed consul, B. C. 401 , when, to gain the favour of the people, he supported the law proposed by the tribune Terentillius, or Terentius, which had for its object a change in the form of government. Instead of the usual nagistrates, decemvirs (ten men) were appointed to compose a code of laws for Rome (afterwards called the law's of the twelve tables), and to possess sovereign power for a year. He was himself chosen decennvir, and when, after the first year, this office was prolonged for a year more, lie was the only one who succeeded, by his influence over the chief men among the people, in being re-chosen. He was resolved never again to give up his power, and conspired with his colleagues for the accomplishment of this plan. The sane year, the Aqui and Sabines laid waste a portion of the Roman territory. The decemviri collected an army, and marched against the enemy. Only A. and Oppius remained in Rome, with two legions, to support the authority of the decem viri, already prolonged beyond the lawful term, when an unexpected event overthrew them. A. was passionately in love with the daughter of Virginius, a respectable plebeian, absent with the army. When A., as a husband and a patrician, could not lawfully marry Virginia, who was betrothed to Icilius, formerly a tribune of the people, and had sought in vain to seduce her, he persuaded M. Clandius, his client, with several associates, to carry her off by violence from the public school where she was, under the pretence that she was the daughter of one of his slaves. The people compelled him to set her at liberty; but Claudius summoned her immediately before the tribunal of A., who decided that the pretended slave should be given up, for the present, to her master. Upon this, Numitorius, her uncle, and lcilius, her lover, made known the criminal designs of $\Lambda$. $A$ 
fearful disturbance arose, and the decemvir was compelled to leave Virginia in the liands of her family; but le declared that he would pronounce his decision the next day. Virginius, summoned by his brother and Icilius, appeared in the forum, with his daughter in a mourning dress. He brought the most indubitable proofs of the groundlessuess of the claim; but A., trusting to the number of his guards, still commanded Claudius to take her as his slave. When Virginius asked permission of the decemvir to speak to her nurse, in Virginia's presence, that he might, for his own satisfaction, be convinced of his error, A. consented. Upon this, the unhappy father tenderly einbraced his daughter, suddenly seized the knife of a butcher who was standing by, and plunged it into her bosom, with these woids: "Go, free and pure Virginia, to thy mother and thy ancestors." A. commanded Virginius to be seized; but he fled to the camp. The senators Valerius and Horatius, who hated the decemvirate, inflamed a spirit of vengeance in the people, already excited by the sight of Virginia's body, and A. could silence the disturbance only by summoning a meeting of the senate. In the meantime, Virginius had related the affair to the army, which marched to Rome, demanding revenge. The decemvirs, seeing they could no longer maintain their authority, resigned their offices. The senate, without delay, resolved to restore the tribunes and consuls, A. U. 305. A. died in prison, Livy says, by his own hand; according to Dionysius of Halicarnassus, the tribunes caused him to be strangled. Oppius, also, who was accused of being his companion in crime, killed himself. The abject Claudius, as he had only been the tool of a tyrant, was banished to Tibur, then a desert. Various tragedies have been written on the subject of Virginia, the latest as well as the most successful of which is by Mr Knowles.

A pPLAdSE (from Latin plaudere); to express approbation by any movement of the hands. No nation has systematized applause like the Romans, who, according to Suetonius, had three kinds-bombus, the noise of which was like the humming of bees; imbrices, which sounded like rain falling on the tiles; and teste, a sound like the breaking of pots. The two latter were produced by instruments placed in the theatre, and persons were instructed to give applause with skill. The plausores, or applauders, were divided into chori, and disposed in theatres opposite each other, like the choristers in cathedrals. In France, Britaill, and America, applause is often given by making a noise with the feet, which, in Germany, always signifies a high degree of dissatisfaction. For further information, see the article Acclamation.

APpLE. The apple, in all its innumerable varieties, is said to have been derived entirely from the crabapple (pyrus malus), which grows wild in every part of Britain. The uses of the apple are very various; even the bitter crab-apple is not without value; for its fermented juice, known by the name of verjuice, is employed both in cookery and medicine, and also for the purifying of wax. Hogs and deer are fond of them. The wood is hard and durable, and makes good wheel-cogs, \&c. All good apples, and many of the common kinds, are produced by the process termed grafting. This is performed by inserting young twigs or shoots from trees bearing fine fruit into stocks of inferior kinds, raised upon every farm, from the pomace of the cider-mill. The branches formed by the twig inserted are found to bear fruit corresponding in quality to the tree from which it was cut. The same process is pursued with all other kinds of fruit-trees; for inoculated or ingrafted fruit is always found to be the best. The kinds of apples most ligh ly prized in all countries are the varicties of pippin. The conmon family uses of the apple are too fami- liar to need specification ; but its most important application is to the manufacture of cider. The process for making the best cider is simple; perhaps quite as much so as any mode of spoiling it. The apples should be sorted according to their degrees of ripeness. \&c., and left a few days in heaps to ripen, if necessary. They should then be ground in a mill, till they are entirely bruised. They are afterwards allowed to stand a day or two in open vessels or troughis, and then pressed between hair-cloths or layers of clean straw ; the last is not so good, from ab. sorbing and wasting a portion of the juice. The liquor running from the press is then received into a vat, or large casks, till it has fermented, when it is drawn off, and placed in clean, tight barrels or casks, to stand till it is fine and clear; it is then racked off from the lees, and kept in casks or bottled for use. A portion of brandy and a little flowers of sulphur render it more pure, and less likely to grow hard and sour. Cider is a very wholesome drink during the heat of summer, although more apt to derange the stomach, produce colic, \&c. than beer. A liquor is obtained by distillation from cider, termed ciderbrandy, of which great quantities are made in the United States; while a very strong liquid may be obtained by allowing cider to be frozen, and then drawing off the portion which remains fluid, and thus retains its heat. But a far more wholesome liquor than either is the pomona wine, which is prepared by adding one gallon of brandy, to six of new cider, after it is racked off. This, when eight or twelve months old, is a very good substitute for wine, for the use of the poor or the sick, and is, beyond all comparison, more wholesome than the wretched mixtures sold so cheap under the name of Lisbon wine, \&c.

Appogglato denotes, in music, and particularly in song, a blended and not abrupt utterance of the tones ; so that they insensibly glide and melt into each other without any perceptible break. It is from appoggiare, to lean on. Hence, also,

Appoggiatura; a small additional note of embellishment preceding the note to which it is attached, and taking away from the principal note a portion of

\section{its time. It is expressed thus :}

A PPRENTICE; a young person of either sex, bound by indenture to serve some particular individual, or company of individuals, for a specified time, in order to be instructed in some art, science, or trade. Accorling to the common law of England, every one has a right to employ limself at pleasure in every lawful trade. But this principle was almost entirely subverted by a statute passed in the 5th year of the reign of Elizabeth, which enacted, that no person should for the future exercise any trade, craft, or mystery in England, unless he had previously served to it an apprenticeship of seven years at least; so that what had formerly been a bye-law of a few corporations, became the general and statute law of the kingdom. Though the impolicy of this enactinent was long apparent, it was not till 1814 that it was repealed by the $54 \mathrm{Geo}$. 1II. c. 90. The repeal did not interfere with any of the existing rights, privileges, or bye-laws of the different corporations; but wherever these do not interpose, the formation of apprenticeships and their duration is left to be adjusted by the parties themselves. The ancients had nothing similar to our apprenticeslips, not even a term of corresponding signification. The mechanical arts were carried on, anong the Greeks and Romans, by slaves. Apprenticeships in these and the liberal arts and professions grew up in the middle ages, when the members of a particular trade or profession formed a corporation. These cor- 
porations belong to those niany Institutions recorded in history, which were oncc necessary, and had useful effects, but which a change of circumstances, and revolutions in thic social condition, as well as many abuses to which they becanc subject, lave rendered, in most cases, inexprolient. They have generally been abolished. Onc of these abuses, in relation to trades, was the long periol of service required in the apprenticeships, as it was evidently for thic interest of the masters, who were already adinitted to the practice of a trade, or inade free of a corporation, to nake thic time of service as long, or the consideration for admission into the company as high, as they coukl. In some countries, another abusc crept in, viz., a very great latitude of discretion and authority allowed to masters in the treatment of their apprentices, many of whom were accordingly treated witlı great larshness and severity. The usual time of service was seven years, and the custom of apprenticeships was extendel to almost every trade and profession. The time of technical apprenticeship, among barristers in England, was 16 years, for which period the candidates were apprenticin ad legem; after which they might take the degree of serjeants, servientes ad legem. Adam Smith, in his Wealth of Nations, b. i, c. 10, maintains that apprenticeships are entirely unnecesary. He says, " Arts which are much superior to common trades, such as those of making clocks and watches, contain no sucl mystery as to require a long course of instruction. The first invention of those beautiful and useful machines, indeed, must, no doubt, lave been the work of deep thought and long time; but, when both have been fairly invented, and are well understood, to explain to any young man, in the completest manuer, how to construct the machines, cannot well require more than the lessons of a few weeks; perhaps those of a few days might be suffcient. In the common mechanical trades, those of a few days might certainly be sufficient. Dexterity of hand, indeed, even in common trades, canuot be acquired without much practice, and experience." He thinks, however, that it would be much better for the leamer to acquire this dexterity in the clraracter of a journegman, than in that of an apprentice. But this view of the subject does not seem to be very practical. The change of the name of the novitinte, from that of apprentice to that journeyman, would effect no material alteration in the relation between the employer and the employed, except in respect to the authority of the former over the latter. Adam Smith, probably, would not recommend that a boy, going to learn a trade, should, from that time, be free; and, if not, it is much better that his master should stand to him, in some respects, in thc relation of a parent. This is what is intended in the ordinary articles of apprenticeship; and the advantage to the parties, mutually arising from this relation, is so great, and its beneficial infuence in the coumunity is so apparent, that there seems to be hardly any ground forquestioning the expediency of continuing it. For information respecting the correctional and disclipinary authority formerly exercised by these corporations, in relation to apprentices, see Corporation.

ApProaches. See Trenches.

Approximation; a term used in mathematics to signify a continual approach to a quantity required, when no process is known for arriving at it exactly. Although, by such an approximation, the exact value of a quantity cannot be discovered, yet, in practice, it may be found sufficiently correct ; thus the diagonal of a square, whose sides are represented by unity, is $\sqrt{ } \mathcal{Z}$, the exact value of which quantity crnot be obtained; but its approximate value may be substituted in the nicest calculations. This proces is the. basis of many calculations in pure and applied nathe- inatics, and is of frequent use and great immortance in all practical operutions.

APRicot (prunus Armeniaca) is a fruit of the plum tribe, which grows wild in several parts of Armenia, and was introdnced into lingland about the middle of the 16th century. Some consider the apricot the most delicate of all our handy fruits. For pastry, certaiuly none is more excellent. It is used for tarts, both green and ripc; it is also preserved witlı sugar in both these states, and is sometimes dried as a sweetmeat. Care should be taken to gather it before it becones soft and mealy. The kernels of apricots have a pleasantly bitter flavour, and auswer much better, for several purposes in confectionary, than bitt'r almonds, which are commouly used. They likewise contain a street oil, which, like that of almoukls, was formerly used in emulsions. 'The gum that issur's from the apricot-tree is similar to that of the cherry. 'The wood is coarsely-grained and soft, and is consequently seldoin used in carpentry. A pricot-tree's are chiefly raised agaiust walls, and arc propagated by grafting upon plum-tree stocks. .

APRIE; the name of a month; either from aperire to open, because, at this timc, the earth seens to be opening and preparing to eurich us with its gifts; or according to Varro, from Aphrodite, because April is consecrated especially to this goddess. -The first derivation appears the best, for April is truly the spring and opening of the year, in which the earth is nourished by alternate rains and sunshine. Something similar to April fools' day, about the origin of which there are ditferent opinions, is said, by Mr Hammer, to exist in the East Indies, at the time of the Huli feast. This strangc custom of April fools' day prevails throughout Europe. One of the explanations of the custom is as follows: In the middle ages, scenes from biblical history were often represented by way of diversion, without any fecling of impropriety. The scene in the life of Jesus, where he is sent from Pilate to Herod, and back again from Herol to Pilate, was represented in April, and may have given occasion to the custom of sending our fruitless erranils and other tricks practised at this season. The phrase of 'sending a man from Pilate to Herod' is common in Germany, to signify sending about unnecessarily. The reason of choosing the first of A pril for the exlibition of this scene was, that the feast of Faster frequently falls in this month, and the events connected with this period of the life of Jesus would naturally afford subjects for the spectacles of the season. The tricks of the first of April may, however, be the remains of some Roman custom, derived from the East, and spread over Europe, like so many other customs, by these conquerors. In France, the unlucky party who may be fooled is called un poisson or poison (mischicf) d'Avril. In Scotland, he is called a gouk, which signifies, in the Scottish dialect, a cuckoo. - One of the best tricks of this description is that of Rabelais, who, being at Marseilles without money, and desirous of going to Paris, filled some phials with brick-dust or ashes labelled them as containing poison for the royal family of France, and put them where he knew they would be discovered. The bait took, and he was conveyed as a traitor to the cipital where the discovery of the jest occasioned universal mirth.

A PRIORI; the opposite of $a$ postcriori. To judge or prove any thing a priori, means to do it on grounds or reasons preceding actual knowledge, or indepen dent of it. Mathematical pronfs, e. g., are a priori. On the contrary, judgments or pronfs a posteriori are founded on knowledge before acquired, like the conclusions of natural history, and all experimental science.

AProv, in ship-building; a piece of curved timber fixed behind the lower part of the stem, inmediately above the foremost end of the keel. 
A psidis. The orbits of the planets and comets are ellipses, in one of the foci of which is the sun. In the same way the satellites move round their planets. The nearest point of the ellipse from that focus, or the lower apsis (Greek, $\alpha \psi(s)$, is called, in the orbits of the planets and comets, perihelion; the farthest point, or the higher apsis, is called aphelion. In the orbit of our moon, the corresponding terms are perigee and apogee. The straight line which joins the apsides, or the transverse axis of the ellipse, is called the line of the apsides. It moves slowly forward in the direction of the planct's course. Therefore, if the earth sets out from the apogee, it must make more than a whole revolution in its orbit before it returns to the same point. The time which it employs in so doing is called an anomalistical year. It is, therefore, longer than a tropical one. See Year.

Apuleios, $\Lambda$. Lucius, born at Madaura, in Africa, towards the end of the reign of Adrian, descended from respectable ancestors, and flourished about the middle, and in the latter half, of the second century. He studied at Carthage, became acquainted with Greek literature at Athens, particularly with the Platonic philosophy, and thence went to Rome, where, he himself says, he learned the Latin language without a teacher, by great exertions, - a circumstance not to be overlooked, in judging his stylc. To satisfy his thirst for knowledge, he performed tedious journeys, in which he was initiated into various mysteries; again lived some time at Rome; studied law ; returned, finally, to his own country; married a rich widow, and was much respected. $-\Lambda$. was of an ardent and active ipirit, with an uncommon share of wit, though much devoted to religious mysticism and magic. His Golden Ass, a romance in cleven books, contains wit, humour, powerful satire, and much poetical merit. He drew the materials from Lucian. The finest part of this work is the cpisode of Psyche, called by Herder, the most tender and diversified of all romances. It is sufficient to render him immortal, even if he be, as some liave supposed, only the narrator, and not the inventor, of the story. A. was also the author of many works on philosopliy and rhetoric, some of which are still extant. His style is not pure. He is tond of numerous epithets and unusual constructions, and sometimes falls into a flowery and bombastic manner. The best edition of the Golden 'Ass, or the Metamorphosis (" golden" was a subseruent addition, to express the value of the book), is by Oudendorp, Ruhnken and Bosclia ; Leyden, $1786-1823$; 3 vols. 4to. Elmenhorst published the Metamorphosis, with a large part of the rest of $\Lambda$.'s philosophical writings, Frankfort, 1621.

Arouls. Iapygia, so called from Iapyx, son of Dxerlalus, comprehending the soutl-eastern parts of Italy, from the river Siris to mount Garganus, contains $\Lambda$. within its limits. In the most ancient times three distinct nations dwelt here-the Messapians, or Sallentines, the Peucetians, and the Dauni, or $\Lambda \mathrm{pu}$ lians. (Sec Niebulur's Inquiry concerning the oldest historical Acconts of this Conentry, in his Roman History, part i. sect. 99, compared with Wachsmuth's older History of Rome, sect. 61.) The Peucetians were in the southern part as far as the Aufidus; the Dauni in the northern, as far as mount Garganus. The old Latin traditions speak of Daunus, a king of the Apulians, who was expelled from Illyria, and retired to this part of Italy. According to the tradition which conducts the wandering lieroes of the Trojan war to Italy, Dionicd settled in $\Lambda$., was supported by Daunus in a war witl the Messapians, whom he subdued, and was afterwards treacherously killed by his ally, who desired to monopolize the fruits of the victory. Roman history informs us of no other Apulian kings, but mentions $\Lambda \mathrm{rpi}$, Luceria, and Canusinm, as important cities. Aufidus, a river of A., has been celebrated by Horace, who was born at Venusia, in this territory. The second Punic war was carried on for years in $\Lambda$. Cannæ, famous for the defeat of the Romans, is in this region. Puglia, the modern name, is only a melancholy relic of the ancient splendour which poets and historians have celebrated. It now supports more sheep than men.

A PORE; a river of south America, which rises in the Andes, near Pamplona, in Colomibia, and, after an easterly course of about 500 miles, runs into the Orinoco, of which it is onc of the most important tributaries. Lon. $66^{\circ} 36^{\prime} \mathrm{W}$.; lat. $7^{\circ} 36^{\prime} \mathrm{N}$.

ApURisiac; a river of Peru, which rises from a lake N. of Arequipa, and afterwards, joining the Ene, with several other rivers, forms the Ucayale. Lon. $73^{\circ} 40^{\prime}$ W. ; lat. $10^{\circ} 50^{\prime} \mathrm{S}$.

AQda Forts ; nitric acid in a diluted state. See Nitric Acid.

Agoa Marina. See Beryl.

AOOA REGIA; the name given by alchymists to what is now called nitromuriatic acid,-a mixture of nitric and muriatic acid, yellow, and possessing the power of readily dissolving gold, which ncither possessed separately. 'Sce Nitric Acid.

Agoa Tinta ; the art of engraving on copper, aftcr the mamer of Indian ink, by which liappy imitations are made of figures that have been drawn with the pencil in Indian ink, bistre, sepia, \&c., particularly those which are on a large scale. There are several sorts of it. In the-first, after the outlines of the figure have been etched, fuely powdered mastic (colophonium) is sifted over the plate, which is then warmed over coals, that the mastic may be melted. In this way, insensible spaces are formed between the particles of mastic, upon which the nitric acid is afterwards to act. :The work then goes on as in the mezzo-tinto, only that the scraper is used in this, and the pencil in that; and all the places where there is to be no work or sliade, are covered with a thick black varnish, on which the acid does not act. The nitric acid is now poured on, and left to stand as long as is necessary for the lightest shade-about five minutes. The light shades are now stopped out with varnish, and the acid allowed to act a second time, and this stopping out is continued till we come to the deepest shades, which are bit in last. This method is best for historical and architectural subjects; but in landscapes, in which the trees rcquire more freedom of the pencil, the second is used. In this, a good etching ground is spread over the plate; and covered by means of a hair-pencil, with oil of lavender or oil of turpentine, to which lamp-black is sometimes added. The oil softens the ground, which may be wiped off with a fine linen cloth, leaving all the marks made with the pencil apparent on the copper. Then, as in the first process, fine mastic is sifted over the plate, melted in and etched. This operation may be repeated many times, according as there are more or fewer tints in the original. By a happy union of both sorts, this style of engraving is carried to a ligh degree of perfection, and is particularly adapted to express the colouring of the air, wherc large surfaces are often represented of one tiut. In Francc and Switzerland, the roulette is used-a little wheel or roller of stcel, with a rougl surface and several prominences, which, when it is rolled back and forth on the plate, deepens the cxcavations made by tlie acid. They lave roulettes of all degrees of size and fineness, to make deeper or more shallow impressions on the plate. From time to timc, the particles separated by this process are removed with a scraper.-The aqua tinta mode was first introduced a sloort time since into I3ritain and Germany; and the British, particularly since Gilpiu brought the art into notice, have adonicd their lite:- 
mry works in this manner. For the technica. details of the art, seo The Complete Aquatinter, by J. H. Green; Sil edit. Lond. 1810.

Agoa Torasa; a poisonous liquid, which excited extraordinary attention at Naples, at the end of the 17 th and beginning of the 18 th centuries, the history of which, however, is obscure. Tofana, a Sicilian woman, seems to have invented it. According to Lolatt, after she had murdered many hundred men, she was strangled, althougl on the discovery of her guilt, she fled to a convent. lieyssler, on the contrary, affirms that she was still alive in prison, 1730.-The drink is described as transparent, tasteless water, of which five or six drops are fatal, prochucing death slowly, without pain, inflammation, convulsious, or fever. Gradual decay of strength, disgust of life, want of appetite, and constant thirst, were the effects, which soon changed to un entire consumption. That the exact day of death can be predicted, is a mere fable. The strangest stories, with regaril to its composition, have gone abroad. A solution of crystallized arsenic seems to have been the chief ingredient to which something else was added, probably to conceal the presence of it.

A gos VIT , (water of life) is a name familiarly applied to native distilled spirits. It answers to the whisky of the Scottish and Irish, the eau de vie or brandy of the French, and the geneva of the Dutch.

AQUA 1 Bов; one of the grcatest kingdoms on the const of Guinea, in Africa, stretching 20 miles in breadth, and ten times that space in length from $\mathrm{E}$. to $\mathrm{W}$. The inhabitants are very warlike, and infest their neighbours much.

Agoarans. 1. Christians in the primitive church, who consecrated water instead of wine, for the celebration of the Lord's supper; some for the sake of abstinence, others because they thought it unlawful to eat flesls or drink wine. 2. Those Christians, also, were denominated Aquarians, who used water instead of wine at the celebration of the eucharist, for fear the smell of wine should discover them to the heathens.

AQdarios is the name of the eleventh sign of the zodiac, emblematical of the rainy season. The constel. lation of the same name contains 108 stars in the Britamic catalogue, and 119 in that published at Berlin.

AQOAlirs, Claude, son of the duke of Atri, was born in 1542. He became general of the Jesuits in 1581 , and died about 1607. (See .Jesuits.)-There is another A., with the baptismal name of Ottavio, cardinal and papal legate at Avignon. He was renowned for moderation, wisdom, and patronage of the sciences and arts. He was the particular friend of the learned Peiresc, and lived under Clement VIII.

AgoвDост, (Latin, agueductus); a conveyance of any kind made for conducting water. The Greeks diu very little towards the construction of aqueducts and roads. The Romans, on the contrary, who were more persevering, and had abundant resources of men and money, made prodigious structures of both kinds. Some of the immense aqueducts of the Romans are still in use; some, in the state of ruins, are among the greatest ornaments of Italy. Iu other ancient countries, also, large aqueducts were built ; e. g. under Sesostris, in Egypt; under Semiramis, in Babylonia; under Solomon and Hezekiah, among the Israelites. The consul Sextus Julius Frontinus, who had, under the emperor Nerra, the direction of the aqueducts, has written a treatise on this subject, $-D e$ Agraductibus ITrbis Roma,-and is of opinion, that they are the most distinguishing proofs of the grandeur of the empire. He mentions nine aqueducts, which had 1594 pipes of an inch and upwards in dianeter.-Aqueducts were either formed by erecting one or several rows of arcades across a valley, and making these arcades support onc or more level caunls; or by piercing through mountains, which would have interrupted the water-course. When the aqueduct was conveyed under the grouml, there were openings at abont every 240 feet. Somic of the Roman aquelucts bronghtt water from the distance of upwards of sixty miles, throngh rocks and mountains, and over valleys in places more thau 190 feet high. 'The declivity of the aqueduct, according to Pliny, was one inch, and according to Vitruvius, half a foot, in a hundred. - The censor Appius Claudius Crassus Carcus, the builder of the great road which was called after him, caused the first aqueduct to be built at Rome, the Appia agua. Frontinus, as we stated, mentions nine, I'rocopius fourteen, and $P$. Victor twenty-four aqueducts; some of which were one, some two, some eren three stories high, and many miles long. In almost all countries whiere the Romans extended their conquests, aqueducts were built; thus we find the remains of them in France, Spain, and Asia. The principal Roman aqueducts now remaining are the aqua Virginia, repaired by pope Paul IV., and the agrua Felice, constructed by Sextus V. In modern times, that of Stgovia may be compared with the most admired works of antiquity. At a recent period, there remained 159 arcades, wholly consisting of enormous stones joined without mortar. Louis XIV. began an aquetluct, in J684, near Maintenon, to carry water from the river Fure to Versailles; but the works were alsandoned in 1688. This would have been, perhaps, the largest aqueduct in the world; the whole length being 60,000 fathoms, the bridge being 2070 fathoms in length, 220 feet high, and consisting of 632 arches. Though the system of pipes has superseded the use of stone channels all raised to a level in the conveyance of water, there are still cases, such as those of canals, where the water inust be kept on a perfect level, and where, therefore, aqueduct bridges are still necessary in conveying it orer the lalleys; and of these we have loug had examples in France, on the Ianguedoc canal. The first aqueduct briclges for canals in this country were those made by the duke of Bridgewater, under the direction of the celebrated Brindley, and which, being quits new liere, excited no small degree of astonishment. The first and largest was the aqueduct at Barton Bridge, for conveying the canal across the Irwell, 39 feet above the surface of the water. It consisted of three arches, the middle one 63 feet span, and admitting under it the largest barges navigating the Irwell with sails set. It was commenced in September, 1760; and in July of the following year the spectacle was first presented in this country, of vessels floating and sailing across the course of the river, while others in the river itsclf were passing under them. Since that period canal aqueducts have become more common; and many excellent examples are to be found both in England and Scotland. Of these are the aqueducts over the river Lune, on the Lancaster canal, designed by Rennie, a very excellent and splendid work of five arches, each 72 feet span, and rising 65 feet above the level of the river : and the Kelvin aqueduct, near Glasgow, which conveys the Forth and Clyde canal over the valley of Kelvin, consisting of four arches, each 70 feet span, and rising 70 feet above the level of the river. In Plate IV. we have given views of several aqueducts. Of these the Pont Cysylte by Mr Telford is justly celebrated for its magnitude, for the simplicity of the design, and the skilful dispositions of the parts, eombining lightuess with strength in a degree, seldom attempted. This aqueduct serves to convey the waters of the Ellesmere canal across the Dee and the vale of Llangollen, which it traverses. The channel for the water is made of cast iron, supported on cast iron 
ribs or arches, and these resting, on pillars of stone: | unless every rise greater than one in fifteen or one in The iron being much lighter than stone arches, this is one reason why the pillars have been reduced apparently to such slender dimensions. They are quite strong enough, however, as experience has proved. The whole length of the aqueduct is about 1000 feet, and consists of 19 arches, each 45 feet span. The breadth of the pillars at the top is eight feet, and the height of the four middle ones is 115 feet to the springing. 'The pillars have a slight taper, the breadth of the middle ones at the base being 15 feet. The height from the surface of the water in the Dee to that in the canal was to be 126 feet eight inches. The channel for the water consists of cast iron plates, cast with flanches, and these screwed together with bolts; they are represented in the drawing, between the arched ribs and the railing. The lines there show the joinings of the different plates. In order to preserve as much water-way as possible, the channel is made the full width of the canal and towing path, and the latter projected over one side, and supported inside by posts resting on the bottom of the canal. The aqueduct of Chirk was designed by the same able engineer, and serves also to convey across a valley the waters of the same canal. This aqueduct was the first in which any iron was employed. Hitherto the channel for the waters had been constructed of stone, or partly of stone and partly of clay puddle, which it was generally found very difficult to keep water-tight for a length of time. It was determined, therefore, by Mr Telford to try the effect of cast iron, and to lay it at first only in the bottom. The plates were accordingly laid directly over the sprandrel walls, which they served to bind together, and united by flanches and screws. The sides of the chanuel were built with stone facings and brick hearting laid in water-lime mortar. This plan has succeeded completely, and the quantity of masonry in the aqueduct was thereby greatiy reduced. The aqueluct itself is 600 feet long, and 65 feet high above the river, consisting of ten arches, each 42 feet span. The piers are ten feet thick. The aqueduct of Slateford serves for conveying the waters of the Edinburgh and Glasgow Union Canal across the valley of the Water of Leith at Slateford. It is an elegant structure, and very similar in the plan to that of Chirk, only that the water channel is composed entirely, the sides as well as the bottom, of cast iron, which is moreover built in with masonry. It is about 500 feet in length, and consists of eight arches, each 45 feet span; and the height of the canal is about 70 feet abore the level of the river. On this canal another aqueduct of the very same construction occurs in crossing the valley of the Almond, and having several more arches. There are, in different parts of the country, various other aqueducts, which might be described; but our limits preclude our enlarging upon them ; and it is the less necessary, as, excepting the formation of the water-way, these structures differ nothing in their design or the principle of their construction from ordinary bridges, particularly those that are undertaken not so much with the view of crossing rivers as of raising up the level of the road itself entirely out of the valley, -an object now become of great importance, froun the improvements which have taken place within the last half century on all our roads, and the refined notions which have in consequence begun to prevail as to the rates of travelling, and, what conduces most essentially to this object, the levels of the road. Formerly people were content to traverse slowly all the inequalities of the country through which the road might pass, descending into the valleys, and mounting the steepest acclivities. Now, however, a rond is thought imperfect, and quite behind the standard of improvement, twenty feet be cut down. In crussing the valleys, therefore, it is not enough now that we build a bridge in all respects sufficient for crossing the stream itself; we must raise it nearly to a level with the ground or: each side of the valley; and this circunstance gives rise to new and very extensive works of this kind; which formerly never. would have béen thought of. Of these we may, just instance the splendid bridge of one arch of 140 feet span, built over the Den Burn at Aberdeen, to form a new access into that town; also the beautiful bridge of Cartland Craigs, built by $\mathbf{M r}$ Telford, orer the little stream of the Mouse, on the new road from Glasgow to Carlisle, consisting of three arches 50 feet span, and elevated 130 feet above the bed of the stream. More recently the introduction of railways opens a new and still wider field for the skill and talents of the engineer in the erection of such works.-Aqueduct, in anatomy, is a bony canal or passage, in the os petrosum, supposed to contribute to the purposes of hearing.

Aquila ; the chief city of Abruzzo Ulteriore II., on the chain of the Apennines, with a population of 7500. It is the ancient Amiternum, and the birthplace of Sallust. It is of military importance as the point where several roads meet, and contains a citadel which capitulated, 1815 and 1821 , on the first appearance of the Austrians. (See Abruzzo.) In 1703, it suffered most. severely by an earthquake. Lon. $13^{\circ} 25^{\prime} \mathrm{E}$. ; lat. $42^{\prime} 19^{\prime} \mathrm{N}$.

AQulleia, also Aglar; in the time of the Roman emperors, a flourishing commercial city on the Adriatic sea, and the Timavus, in Upper Italy. Marcus A urelius made it, A.D. 168, the principal fortress of the empire. It was the key of Italy against the barbarians, and, on account of its wealth, was sometimes called the second Rome. It was also the seat of a patriarch, whose diocese, in 1750, was divided into the archbishoprics Udine and Gorz, afterwards Laybach. In 452, it was destroyed by Attila. The inhabitants fled to the islands, on which Venice was afterwards built. An inconsiderable city afterwards arose here, which now belongs to the Austrian kingdom Illyria (circles Trieste and Friuli). The inhabitants (1500) support themsel ves, chiefly, by a trifling fishery, and foreiguers visit the place on account of the Roman antiquities to be found there.

AQuinas, St Thomas, a celebrated scholastic divine, descended from the counts of Aquino, in Calabria, in the kingdom of Naples, was born in the year 1224 . He acquired the rudiments of education at the school of Monte Cassino, and was thence removed to the university of Naples. At the age of seventeen, he entered a convent of Dominicans, much against the wishes of his mother, who persevering in her wishes to recover him, the monks, anxious to secure so honourable an addition to their frateruity, determined to send him out of the kingdom to Paris. He was, however, arrested by his two brothers on his way, and, refusing to give up his intention, was shut up in a castle belonging to his father for two years. He at last, however, found means to escape to Naples, and, in the year 1244, was conducted by John, master of the Teutonic order, to Paris, whence he soon after departed to Cologne. At Cologne, he studied under Albert, an eminent teacher of philosophy, who foresaw his future celebrity. In 1246, he visited Paris, in company with Albert, and, at the age of twenty-four, became a preceptor, at the university of that capital, in dialectics, plilosophy, and theology, and acquired the highest reputation. Princes and popes held him in the greatest estimation, and he was invited by St Louis, then reigning in France, to his court and table. On a visit to Rome, Aquinas distinguished himself by a neat repartee: being in a 
closet with Inuocent IV., when an offcer brought in a large sum of money produced by the sale of alsolutions and indulgencies, "You see, young man," said the pope, "the age of the church is past, in which she said, "Silver and gold lave I none." "True; holy father," replied the angelic doctor; "but the age is also past, when slic cululd say to a paralytic, "Rise up, and walk." In 1:263, lic returned to Italy, wlien pope Clement IV. offered him the archbishopric of Naples, which he refused. A general council being summoned at Lyons, in 1274, for the purpose of uniting the Greek and Latin churches, $\Lambda$ quinas was called thither, to present the council with a book, which he had written on the subject, but died on the way, near 'T'erracina. After his death, the lonours paid to his memory were prodigious: besides the title of angelic doctor, bestowed on him after the fashion of the times, he was called the angel of the schools, thic eagle of divines, and the fifth loctor of the church; and, at the request of the Dominicans, he was canonized by Jolın XXII., his tomb supplying the necessary testinony of miracles. His writings, which were held in the highest estimation in the next century, gave rise to a sect, called, after hin, Thomists. The'y are exceedingly voluminous, amounting to seventeen volumes folio. His principal work, Summa Theologia, bears a high reputation in the Roman Catholic church, and the second section on morals is universally esteemed. The latest edition of his works at large is that of Antwerp, 1612; but his Summa Theologia has passed separately through various editions. The resemblance, in thinking and writing, between Augustin and Aquinas is so marked, that it has been fancifully said, that the soul of the onc had passed into the body of the other.-Another A., properly called Philip d' Aquino, a baptized Jew, acquired much reputation by his knowledge of Hebrew, which he taught at Paris, in the reign of Louis XIII., as well as by his Dictionarium Ifebreo-Chaldao-Thalmudico-Rabbinicum.

Acortanis; the name of a Roman province in Gaul, which comprehended the countries on the coast from the Garonne to the Pyrenees, and from the sea to Toulouse. Augustus extended it to the Loire. Those who dwelt near this western coast were called, by the Celts, Amnoricans, and were probably of Spanish origin, driven towards the west by the incursions of the Celts. They were actively engaged in commerce. In Aquitania the Visigoths established a kingdom, A. D. 412. Since that time, it has been sometimes a kingdom, sometimes a duchy; and, more lately, it has passed under the name of Guienne. At present, the ci-devant Guienne forms the two departments of Gironde, and of Lot and Garonne.

Arabelud Stoart; commonly called the lady Arabella. This unhappy and innocent victim of jealousy and state policy was the only child of Charles Stuart, earl of Lennox, younger brother to Henry lord Darnley, the husband of Mary queen of Scots. She was therefore cousin-german to James I. to whom, previously to his having issue, she was next in the line of succession to the crown of England, being the grand-daughter of Henry VII., by the second marriage of his eldest daughter, Margaret. She received an excellent education. Her proximity to the throne was the source of her mistortunes. Elizabeth, for some time before her decease, held the lady Arabella under restraint, and refused the request of the king of Scotland to give her in marriage to the duke of Lennox, his kinsman, with a view to remove her from England. The pope had likewise formed the design of raising her to the English throne, by espousing her to the duke of Savoy; which project is said to have been listened to by Henry IV. of France, from a wish to prevent the union of Eugland and Scolland. The detection of s plot of some Finglish nobles to set aside James in favour of $\mathrm{A}$., of which she was altogether inuocent, ultimately proved lier destruction; for, although le.tit at liberty for the present, when it was some time after discovered that she was secretly married to the grandson of the earl of Ilertford, both husband and wife were conmitted to the tower. After a year's imprisonwent, they contrived to escroe, but the unhappy lacly was retaken. Remanded to the tower, the remainder of her life was spent in close confinement, which finally deprived her of her reason. She died on the 27th September, 1615, aged thirty-eight years. She possessed talents of a superior order, and a very pleasing person.

Arabesque, or Moresque, in painting or sculpture, is a term applied to a particular specie's of oruanental fireze or border, first introdncel into Europe, as has been asserted, by the Moors, when they conquered Spain. This assertion, lowever, is not altogether well founded, since some indications of this style of omanent may be observed on the friezes of the ancient buildings in Rome. The Moors being prohibited by the Alcoran from representing the figures of men and beasts, have endeavoured to evale this law by inventing a series of monsters, griffius, dragons, strange birds, and chimeras, passing hy wild gradations from one class of beings into another; affixing the head, wings, and talons of birds to the bodies of lions, horses, and other quadrupeds; and making the upper parts of children, men, and beasts spring out from amidst luxuriant clusters of foliage, \&.c. This strange and incongruous admixture of parts is, howcver, capable of being formed into beautiful arrangements ; since, in some of the chanbers of the palace of the Vatican, there are orumental paintings, executed from the drawings of Raffaelle, in this style, which are deservedly nuch admired. Most of the ormanents around the capitols of Gothic columus in our cathedrals, belong to this species of oruanent; as, for instance, in York-minster, Roslin chapel cathedral, in Jcolmikill, and many others. In the old Moorish palaces in Spain are superb specimens of this sort of ornament, as in the Alhambra at Grenada ; and the cathedrals of Coria, Salamanca, Cuidad Rodrigo, Valladolid, \&ic. abound with it. In the painted chambers of Pompeia, also, it has been detected, and in some of the mausoleums of ancient Rome, particularly in that called the Sepulchro Nasoni, as well as in the baths of Titus.

ARABLA ; a peninsula containing about $1,000,000$ square miles, and $12,000,000$ inluabitants; the most westerly portion of southern Asia, extending from $33^{\circ} 30^{\prime}$ to $59^{\circ} 30^{\prime}$ E. lon., and from $12^{\circ}$ to $30^{\circ} \mathrm{N}$. lat. By the inhabitants, it is sometimes called Arabia, sometimes Dschesira al Arab ; by Turks and Persians, Arabistan. It lies between the Red sea and Persian gulf; bounded on the north by the great deserts Irak and Dschesira, on the south by the Arabian sea, and connected with Africa on the north-west by the isthmus of Suez. Instead of the old divisions of Ptolemy, -A. Deserta, A. the Stony, or A. Petraa (fiom an ancient fortified place, used for merchandise, called Petra), and A. the Happy, - the more natural division is that which distinguishes the coast, covered with aloes, manna, myrrh, frankincense, indigo, nutmegs, and especially coffee, from the interior, cousisting of a desert of moving sand with thorns and saline herbs. The civil divisions are five provinces : -1 . The country of Yemen, containing about 68,700 sq. miles, and $3,000,000$ inhabitants, is governed by the hereditary caliph or imam of Yenien, who recognises the supremacy of the Turkish caliphate, and resides at Sana. In 1818, the viceroy of Egypt subjected Yemen, which contains Mocha, cu the straits of Babelmandel. The 
tribute which he obtains from it Is 2000 hundred/depot of the Phonician land trade : at present, the weight of coffee. Aden, the chief gum market, lies III ruins. 2. The province Oman, under the imam of Mascat, a seaport, containing 60,000 inhabitants, to which belongs, also, the island Socrota (which furnishes the best aloes, ) on the coast of Africa. 3. The province Lachsa, or Hadsjar, whose harbours, in the Persian gulf, are infested with pirates, has also rich pearl fisheries.e 4. The provinces Nedsched and Jemama, the original and principal country of the Walıbees (q. v.), or Wehabites, with their chief city, Derrejeh. This country, or central Arabia, has become very familiar by Mengin's Hist. d' Egypte sous Mohammed Ali, and a map of Jomard, 1823. 5. The province Hedsjas, on the upper shore of the Red sea. Here is the Holy Land of the Molianumedans, containing Mecca, Mediua, \&c. Not far from the valley of Moses are the remarkable antiquities of Petra and Jerrasch. The seaport, Jidda, population 5000, is indeed the residence of a Turkish pacha, but the sheriff of Mecca conducts the government himself. In the Syrian deserts lie the ruins of Palmyra. (q.v.) On the western coast of Arabia there are high chains of mountains, which unite on the north with the mountains of Syria, and are connected with the primitive mountains of Asia; annong them are Sinai and Horeb. Df the rivers, which appear only after great rains, and seldom reach the sea, the Aftan, on the sea coast is the most considerable : the Euphrates lies on the northern boundary.-The climate is very various. Countries where it rains half the year alternate with others, where dew supplies the place of rain for the whole season. The greatest cold prevails on high places, and the most oppressive lieat in the plains. Damp winds succeed to the dry simoom, which is as dangerous to life as the liarmattan and khamseen in Africa. The soil consists of sandy deserts and the most fruitful fields. Wheat, millet, rice, kitchen vegetables, coffee (which grows on trees in Arabia, its home, and on bushes in America, the plants being kept low for the sake of gathering the truit more easily), manna, sugar-cane, cotton, tropical fruits, senna leaves, gums, aloes, myrrh, tobacco, indigo, odorous woods, balsam, \&c., are the rich products of Arabia. There are, also, precious stones,
iron and other metals (gold excepted, which the ancients, however, seem to have found pure in rivers and in the earth). The animais are, mules, asses, camels, buffaloes, horncd cattle, goats, noble horses, lions, liyænas, antelopes, foxes, apes, jerboas ; birds of all sorts, pclicans, ostriches, \&c.; esculent locusts, scorpions, \&c.-The inhabitants are principally genuine Arabs, who speak a peculiar language, and profess the Mohammedan religiou. The Arabians are still, as in the most ancient times, Nomades, of patriarchal simplicity. They are herdsmen and husbandmen. A passionate love of liberty, independence, and justice keeps them in a condition in many respects liappy. The old " Peace be with thee" is still their common salutation. "Welcome! what do you wish?" is the address to a stranger, whose entertainment costs only a "God reward you." They practise robbcry, though never at the expense of the laws of hospitality. This warlike people have much activity and skill in bodily exercises; a good physical conformation ; in warm plains, a skin of a brownishsellow: their hardy education, cleanliness, and temperance secure them from sickuess. They call thcmselves Bedouins (Bedevi, sons of the desert, the Arabes Sienita among the ancients), and are distinguished by their made of life from the Moors, who dwell in houses, and carry on, exclusively, agriculture, trade, and commerce. Besides the original inhabitants, Clıristians, Jews, Turks, and Banians dwell trade by land and sea is wholly in foreign hands. That by land is conducted by caravans. In the high schools of the Arabians, instruction is given in as. tronomy (rather astrology), pharinacology, and philosophy, so called : attention is also paid to history and poetry. The Bedouins remain in the deepest ignorance. Their government is very simple: the chiefs are named the great emir, the emir, and sheikh, and the judges are called cadi. The T'urkish sultan is, indeed, nominal master of the country, but the free Arabian scorns his imbecile rule, and only obeys when he pleases.-The history of the Arabians, before Moliainmed, is obscure, and, on account of its slight connexion with the rest of the world, of little interest. The original inhabitants of the country are called by the present Arabs Bajadites (the lost). The present Arabs derive their origin from Joktan or Kahtan in part, and in part from lshmael. The descendants of the former call themselves, emphatically, Arabs; those of the latter, Mostarabs. The name Arab signifies an inhabitant of the West (for they are in that direction from the Asiatics): in Europe and Africa, they were called Saracens (inhabitants of the East). The older Arabian historians understand by Arabia only Yemen. Hedsjaz (the rocky) they regard as belonging partly to Egypt, partly to Syria ; and the rest of the country they call the Syrian desert. The princes (tobbai) of this land were, ancient. $1 y$, entirely of the race of Kahtan, to which belonged the family of the Homeyrites, who ruled over Yemen two tlioisand years. The Arabians of Yemen and a part of the desert of Arabia lived in cities, and practised agriculture : they had commerce, also, with the East Indies, Persia, Syria, and Abyssinia ; and to the latter of these countries they sent many colonies, so that it was probably peopled by them. The rest of the population then, as now, led a wandering life in the deserts. - The Arab is courteous in his mallner, temperate, and sprightly. Reared to continual wandering, he possesses great bodily activity, and power of enduring fatigue. The attachment of the Arab to his horse, is as well known as the swiftness of the animal itself. The following cut represents an A rab on horseback in the ordinarydress of the country.

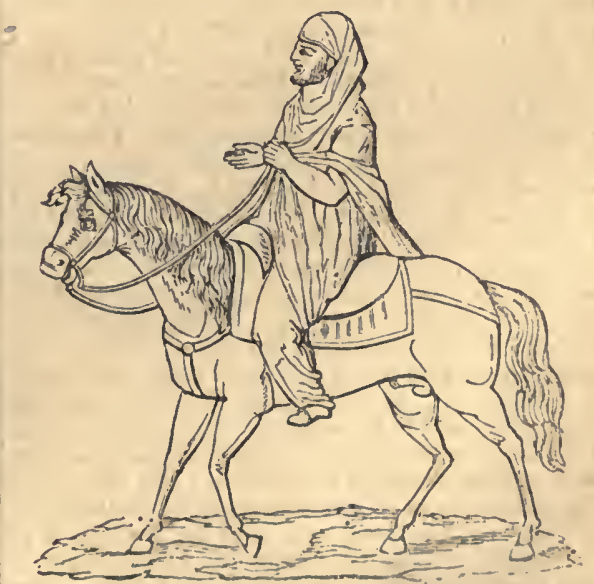

The costume of the Arabian women is not weli fitted to display the graces of person, yet, thicy are generally clegantly formed, and would be considered attractive in the eyes of Europeans, did they not abuse their skin by paints. The following cut represents an A rabian woman, in the common rank of life, with her in the country. Formerly, Arabia was the grcat Icathern pitcher for carrying water over her slouller. 
The religion of the Ambiuns, in the time of their ignorunce (as they call the: period before Mohammed), was, in general, alomtion of the stars; varying much, however, in the different tribes, each of whom selected a different constellation asthe highest object of worship. For a thousand years, the Arabians manfully dofended the-freedom, faith, and manners of their fisthers against all the attacks of the Eastern conquerors, protected by deserts and seas, as well as by their own arms. Neither the Babylonian and Assyrian, nor the Egyptian and Persian kings, could bring them under their yoke. $\Lambda t$ last they were overcome by Alexander the Great; but, immediately after his death, they took adrantage of the disunion of his generals and successors to recover their independence. At this period, the northern princes of the country were bold enough to extend their dominion beyond the limits of Arabia. The Arabian Nomades, especially in winter, made deep inroads into the fertile Irak or Chaldses. They finally conquered a portion of it, which is hence still called Irak Araby. Thence the tribe of Hareth advanced into Syria, and settled in the country of Gassin, whence they received the appellation of Gassanides. Three renturies after Alexander, the Romans approached these limits. The divided Arabians could not resist the Roman arms every where successfully ; their country, however, was not completely reduced to a province; the northern princes, at least, maintained a virtual independence of the emperors, and were regarded as their governors. The old Homeyrites in Yemen, against whom an unsuccessful war was carried on in the time of Augustus, preserved their liberty. Their chief city, Saba, was destroyed by a flood. With the weakness of the Roman government, the struggle for absolute independence increased, which a union of all the Arabian tribes would have easily gained; but, weakened and scattered as they were, they spent several centuries in this contest, during which the mountainous country of the interior (Nedschid) became the theatre of those chivalrous deeds so often sung by Arabian poets, till a man of extraordinary energy united them by communicating to them his own ardour, and union was.followed by augmented force.-Christianity early found many adherents here, and there were even several bishops, who acknowledged as their metropolis Bosro in Palestine, on the borders of Arabia. Yet the original worship of the stars could not be entirely abolished. The former opposition of the Arabians to the despotism of Rome drew to them a multitude of heretics, who had been persecuted in the orthodox empire of the Fast, especially the Monoplyysites, and the Nestorians, who were scattered through all the Fast; and the religious enthusiasm of those exiles rekindled the flame of opposition. The Jews, also, after the destruction of Jerusalem, became very numerous in this country, and made proselytes, particularly in Yemen. The last king of the Homeyrites (Hamjarites) was of the Jewish faith, and his persecutions of the Christians, A. D. 502, involved him in a war with the king of Ethiopia, which cost him his life and his throne. To the indifference excited by so great a variety of sects is to be referred the quick success of Mohammed in establishing a new religion. He raised the Arabians to inportance in the hislory of the world, and with hine begins a new eproch in the history of this people. See Moors, and Caliph, Caliphate.

Araban Gulf. See Red Sca.

Arabian Iatratatore and Ioangoagr. Of the first cultivation and literature of this commtry, we have but few accounts. 'That poetry early flourished in Arabia, may be inferrel from the clumeter of the inhabitants, who are known to be bold, valiant, adventurous, proud, and excessively fond of honour. The tribes who wandered, under the government of their.sheiks, through the beantiful region of $A$ rabia the Ilappy, had every thing favourable to the growth of poetry, $-\Omega$ delightful country, lively feelings, and warm fancy. If it were beyond doubt, that the poem of Job was of Arabian origin, this would slow, not only that Arabia l'etroea liad its poets, but also the character of their productions. We find in it bold images, noble metaphors, comparisons and descriptions, mingled with enigmas. The antiqnity of philosophy among the Arabians might also be shown from Job, - a poem comprehending, at the same time, physical and astronomical knowledge, which is, however, very imperfect. Even before the time of Mohammed, the genius of the people was very conspicuous, particularly in poetry. In the fairs at Mecea and at Okadh, A. D. 500, poetical contests were held, and the poems to which the prize was awarded, were written on byssus, in letters of gold, whence they were called Modabahath (gilt), and hung up in the caaba, at Mecca, therefore called $\mathrm{Mo}$ allakath (lung up). The collection of the Moallakath contains seven poems by seven authors- $\Lambda$ mralkeis, Tharasah, Zoheir, Lebid, Anthara, Amru Ben Kalthun, and Hareth. They are distinguished by deep feeling, high imagination, riclness of imagery anul sentiment, national pride and liberal spirit, violent breathings of revenge and lore.-The brightest period of the Arabian history commenced with Mohammed, and was soon followed by the golden age of their literature. Mohammed announced himself to the people as a prophet sent from God, and laid dowin rules of faith and life, which were collected by $A$ bubekr, first caliph after his death, corrected and published by Othman, the third caliph, and constitute the Koran. (q. v.) By this, the Arabian language of literature was fixed, the first literary dircetion given to the people, and their national character determined. The Arabians seem to be favourably situated for commerce, but less so for conquest, particularly as a large part of the population consists of tribes wandering through the desert, and living alternately by keeping cattle and by plunder. But $\mathrm{Mo}$ hammed succeeded in subduing the whole country, gare it a constitution at once religious and military, and inflamed the native valour of the people by an enthusiastic zeal fồ religion. When he died, A. D. 632 , without a male heir, his adherents chose a caliph (successor) in his room, under whom the spirit of conquest first took possession of the Arabians, and urged them onward like a rapid stream. Only 80 years after the death of Mohammed, their power extended from Egypt to the Indies, from Lisbon to Samarcand. During this period, the nation was only animated with warlike enthusiasm, under the dominion of which the tender blossoms of genitus seldom thrive. Time, and intercourse with cultivated nations, by degrees overcame their rudeness. With the government of the caliph of the family of the Abassides, A. D. 750, began their progress in the arts and sciences. In the splendid court of $\mathrm{Al}$ Mansur, at Bagdad, these first found support ; but it was Haroum al Raschid, (786-808) who infused into his people an enduring love for them. He invited learned men from all countries to his kingdom, and paid them 
princely salaries. He caused the works of the most famous Grecian authors to be translated into Arabic, and spread abroad by numerous copies. Al Mamum; who ruled soon after him, offered the Grecian emperor 10,000 pounds of gold and a perpetual peace, if he would send him the philosopher Leo, for a time, to instruct him. Under his goverument, excellent schools were established at Bagdad, Bassora, Bocha$\mathrm{ra}, \mathrm{Cufa}$, and large libraries at Alexandria, Bagdad, and Cairo. The caliph Motasem, who died A. D. 841, was of the sane disposition, and a high degree of literary rivalry existed between the dynasty of the Abassides in Bagdad, and that of the Ommaiades in Spain. What Bagdad was to Asia, the high school at Cordova was to Europe, where, particularly in the - 10th century, the Arabians were the chief pillars of literature. At a time when learning found scarcely any where else a place of rest and encouragement, the Arabians employed themselves in collecting and diffusing it in the three great divisions of the world. Soon after the beginning of the 10th century, students travelled from France, and other European countries, to the Arabian schools in Spain, particularly with the view of learning mathematics and medicine. Besides the academy of Cordova, the Arabians had established 14 others in Spain, without mentioning the higher and the elementary schools. They had five public libraries, and Casiri mentions 17 Arabians, in Spain, who undertook scientific journeys. Such rapid advances did this nation make (which, scarcely half a century before, was limited to the Koran, poetry, and eloquence), when they had formed an acquaintance with the Greeks. In geography, history, philosophy, medicine, physics, mathematics, and especially in arithmetic, geometry, and astronomy, their efforts have been crowned with great success, as is proved from the various terms of Arabian origin, still in use; for example, almanuc, algebra, alcohol, azimuth, zenith, nadir, and many others. The invention of the common ciphers, also, has been generally ascribed to them; but professor Seyffarth, who has been lately engaged in examining the precious collection of papyra and other Egyptian antiquities in the royal museum of Turin, among other important discoveries, asserts, that the Arabic figures are found among those of the Egyptians, which renders it probable that the Arabians did not invent; but merely borrowed, their ciphers. The Egyptians wrote, as we do, 1, 2, 3, \&c. Even their fractions resemble ours, their fractional figures being written above and below a small liorizontal line. He has also discovered that they employed the decimal system. Most of the geography in the middle ages is the work of the A rabians. They extended, in Africa and Asia especially, the limits of the known world. In the north of Africa, threy penetrated as far as the Niger; in the west, to the Senegal ; in the east, to cape Corientes. When they first commenced their conquests, the generals were ordered, by the caliphs, to give a geographical description of the conquered countries. The countries, nations, and wealth of Asia were, in a great degree, known to them. They extended the knowledge of Arabia, their own country, of Syria and Persia, and gained some acquaintance, at least, with Great Tartary, the south of Russia, China, and Hindostan. Al Marun, Abu Ischak, Scherif Edrisi, Nassir Eddin, Ebn Haukal, wlio wrote between A. D. 15 and 21, Abulfeda, and Ulugh Begh Abdollatif, distinguished themselves as geographers; and much that the most renowned among them, Abulfeda and Edrisi, have written, is still useful and important in regard to historical geography. The Arabian historians, since the 8th century, have been very numerous, though they lave not yet been long enough known to European scholars to enable tliem to derive much advantage therefrom. The oldest and best known historian is Hestram Ibn Muhamed Ibn Schoaib Alkhekebi, A. D. 818. Praise is due, also, to Abu Abdallah Mohammed Ibn Achmed, Abulpharagius, George Almakin, Abulfeda (who wrote a universal history of the world till A. D. 1315), Macrizi, Arabschah, and others. The Iater historical works are in a calmer and more simple style. The philosophy of the Arabians was of Greek origin, and de. rived principally from that of Aristotle, which was studied first by those in Spain, and thence in all the west of Europe, having been translated from Arabic into Latin. Hence the origin of the scholastic philosophy may be traced to the Arabians. To dialectics and metaphysics they paid particular attention. Of their philosophical authors, Alfarabi must be mentioned, who wrote on the principles of nature, 954; A vicenna, who died A. D. 1036, and, besides other philosophical writings, was the author of a treatise on logic, physics, and metaphysics, and of a commentary on the works of Aristotle. Ibn Bajah distinguished himself as an original thinker. Algazel wrote a work, attacking all philosophical systems, to which Happalath Hahappalah published an answer. The commentary on Aristotle, by Averroes, was particularly esteemed, and his paraphrase of Plato's Republic, which appears formerly to have been little read, even among his countrymen, deserves much praise. Many famous phílosophers were, at the same time, physicians; for the physical sciences, including medicine, were not then separated from philosophy. Next to geography, the Arabians, without doubt, lave contributed most to these sciences. At Dschondisabur, Bagdad, Ispahan, Firuzabad, Bukharia, Cufa, Bassora, Alexandria, and Cordova, from the 8 th to the 11 th century, medical schools were instituted, and, with the devoted study bestowed on this branch of science, the nation could not fail of making important advances in it, though, in reality, they were here also dependent on the Greeks. Anatomy made no progress among them, because the Koran expressly prohibited dissections. Yet they had an extensive knowledge of medicine, zealously studied botany, and might be regarded as the inventors of chemistry; at least, they have made many discoveries in it, and Dscheber is regarded as the inventor of a panacea. In the science of diseases (nosology) they made much progress, and learned how to treat judiciously various kinds of sickness. To their famous writers on medicine belong Aharum (who first described the small-pox), Jahiah Ibn Serapion, Jacob Ibn Islak Alkendi, John Mesve, Rhazes, Almansor, Ali Ibn Abbas, Aviceına (who published the Canon of Medicine, for a long time the best work of the kind), Ishak Ben Soleiman, Abulcasis, Abeir Zohar, Averroes (the author of a compendium of physic). It cannot be denied, that honour is due to the Arabians for having maintained the scientific knowledge of medicine during the middle ages, and revived the study of it in Europe. If physics made less progress among them, the cause lies in the method of study. This science was treated metaphysically, in order to reconcile the principles of Aristotle with the doctrine of fatality taught in the Koran. Mathematics the Arabians enriched, simplified, and extended. In arithmetic, they introduced the use of the ciphers which go under their name, and of decimals, into Furope, and, in trigonometry, sines instead of chords. They simplified the trigonometrical operations of the Greeks, and extended the general and useful applications of algebra. Mohanmed Ben Musa and Thibet Ben Corrah particularly distinguished themselves in this department. Alhazen wrote on optics. Nassireddin translated the elements of Euclid. Dscheber Ben Afla wrote a com- 
mentary on the trigonometry of Ptolemy. Astronony they especially culcivated, for which famous schools amd observaturies were erected at Bagdal and Corlova. As early as $\Lambda .1) .812$, Allazen and Sergius had translated into Arabic the Alungest of Ptolemy, the first regular treatise on astronony, of which, in \$33, Alfargani, and, still later, Averroes, published editions. Albaten, in the loth centur, observed the motion of the aphelion. Moliammed Ben Dscheber noticed the obliquity of the ecliptie, and completed a theory of the sun. Almansor tormed astronomical tables, in which appear some observations on the obliquity of the ecliptic. Alpetrngius wrote a theory of the planets. Geography was brought into counexion with mathematics and astronomy, and treated scientifically, particularly by Abulfeda. The division of the earth into seven climates, various geographical measures, and the like, belong to the Arabians. Much as the severer sciences were cultivated, the genius of the people for poetry was not fettered. A bu Temam, in 830, collected the greater Hamasah, an anthology in ten books, and Bochteri, in 880 , the lesser Hamasah, as a supplement to the other. 'These contain the seven prize poems of the Moallakith. After this periol, the oriental peculiarities of A rabian poetry became more and more strong, the tone grew mystical and extravagant, and the langunge lost its purity. Motemabbi deserves to be noticed for his teniler elegies in a classic style; (see Proben der AraUischen Dichtkust, - Specimens of Arabic Poetry,by Reiske, Leipsic, 1765; and Motenabbi, translated [into German] completely, for the first time, by Joseph Hammer, Viemua, I823 ;) Abu Ismael Tograi, vizier of Bagdad, for his elegies and poems (see Nero German Mercury, 1800, No.1. sect. 8); Ithiel Hariri, for his history of a knight errant, entitled Makamat, in fifty chapters (see Rosenmuller On an Arabic Romance of Hariri, Leipsic, 1801, translated, 1826, by Ruckert); Abu Dschafar Ibn Tophail, for his interestiug philosophical romance, the Natural Man, transIated by Eichhorn, Berlin, 1783. Admai's great heroic romance, Antar's Life (see Antar), is still said to produce amusement in the coffee-houses of Aleppo. It is written in 35 parts. - The dramatic excepted, there is no sort of poetry which the Arabians lave left unattempted. The ballad, a production of the bold and adventurous spirit of the nation, was invented by them. There is no doubt that they had, by this means, a powerful effect on modern European poetry ; for no small share of the romantic poetry of the middle ages belonged to the Arabians. The adventurous, chivalrous spirit, the tales of fairies and sorcerers, and perhaps, also, rliyme, passed from the Arabians to our western poetry. Thus this nation, in the period of the middle ages, contributed, in various ways, to the literature and the refinement of Europe, and left behind many traces of its former superiority. Hence the importance of their language to learned inquirers must appear evident to all. No one can do without it, who would take an accurate view of knowledge and human character. It belongs to the Semitic dialects, so called, among which it is distinguished for its antiquity, richness, and softness. By tlie Koran it was fixed as a written language, and, a short time after Mohammed, and still more since the 10th century, among the Arabian authors, who established the principles of the language, its beauties were explored, and its wealth collected in dictionaries. By the entrance of the Arabians into Sicily and Spain, their dialect became known in Furope. But, notwithstanding it has left many traces in the languages of those countries, the knowledge of it has been mostly lost since the expulsion of the Moors from Europe. Postel again introduced the scientific study of it into France, and Spey into Ger- many. In the 17th century, it flourished in the Netlerlands, and was afterwards zealously pursued in Germany, Holland, and England. We lave valuable granmars by Eimeu, Michnelis, Richarison, Jahn, Rosenuuller, de sacy; good dictionaries liy Frpen, Colius, Giggeji, Custel, Meniuski, Wilmet, Scheid; collections of extracts by Reiske, Hirt, Rosenunller, Jahn, de Sacy, Savary, and others. Kirsten,Schultens, Jones, Eichlıorn, Tychsen, Schnurrer, Hasse, Kosegarten, Hezel, Wahl, Paulus, Rosenmuller, Vater, $\Lambda$ ugusti, and others lave done the world important services, by their great cultivation, investigation, and illustration of the language. Grumer and Sprengel have shown how inportant the knowledge of it is to physicians. In fine, the remains of Arabian architecture, in Spain and $\Lambda$ frica, eleserve the attention of travellers. The French architect $P$. Coste, in 1818, studied this style, particularly in Cairo and Alexandria. Thence arose his work, $A r-$ chitecture Arabe, ou Monuments du Caire, dessinés ct mesurés, with seventy-four engravings, fol., Paris, 1823.

Arabian Niguts, or the Thousand and one Niguts; a celebrated collection of Eastern tales. The Jist is the ancient and native country of fabulous listuries. The ever active fancy of the people, their love of adventures, their belief in spirits, and their fondhe'ss for lively stories, are attested by uumerous traveller: This character appears in the amusements of their coffee-houses and caravansaries. It gave rise (perhaps first in India and Persia) to tloose thousand fables which, contrary to Mohammed's express command, found in Arabia a second home, and were spreal, with alterations and improvements, first separately, aud afterwards in large collections, through all Elirope. Many of them found their way thither in the time of the crusades or sooner. They were the inexhaustible fountains which supplied the writers of the French fabliaux, and the story-tellers and fabulists of Germany. In the beginning of the 18th century (1704), the collection which had long existed in the East, under the above title, was introduced to the literary men of Europe, and, in a short time, to the public generally, by means of the translation of $\Lambda$ ut. Galland, a distinguished French Orientalist. Its appearance was hailed with universal delight, and it became one of the nost popular works in all Europe. The manuscript of Galland, now in the royal library at Paris, was incomplete. The interest inspired by the work led to more careful investigation; and, in the year 1788, appeared at Paris the New Thousand and one Nights, by Chaois and Cazotte, from a manuscript deposited in the royal library by the former, who was a native Arab. The genuineness of the book was, at first, suspected, on account of the freedom which the editors used with the original; but the suspicion was afterwards proved to be without foundation. Much is due, however, to Caussin de Perceval, the successor of Galland in the chair of the Arabic professorship, who made a new version, in 1806, from the original text, and to the improved copy of Gatland added the conclusion of the whole. But many defects still remained, and many lost passages were yet to be found. The work, however, was not rentered complete by the improred translation of Jouathau Scots, in 1811, nor by the last edition of Galland's Mille et une Nituts, prepared by Gautiers, aided by Langles, and published in 1822. It was reserved for the German literati to put a finishing stroke to this rich collection, by the use of manuscripts. before unknown. In 1823-4, appeared a German translation, superintended by Zinserling, of a splendid collection of new tales, which had been found at Rosetti, in Egypt, and a French translation of which liad been unaccountably lust. The German translation 
was ushered into the world by $\mathrm{Mr}$ von Hammer. Still more valuable was a Tunisian manuscript in the possession of professor Habicht, of Breslau, by the assistance of which every defect was corrected, and, with the advice of two other learned men, a German translation was made, far excelling every previous one-Tausend und eine Nacht, vollstandig ubersetat, con Max. Habicht, $v$. der Hagen und $K$. Schall, (the Thousand and one Nights, translated in full, by Max. Habicht, v. der Hagen and K. Schall), 15 vols. $12 \mathrm{mo}$. Breslau, 1825; also the original Arabic was publisled by doctor Habicht, with a glossary, in one vol., Breslau, 1825. A Danish translation of the Arabic text, printed in Culcuttr, in 1814, has been published by Rasmussen, professor of Oriental languages at Copenhagen (1st vol., Copenhagen, 1824). With these exertions to restore to its original beauty and valne one of the most remarkable monuments of Fastern manners, inquiries into the origin of the Arabian Nights were also prosecuted with success. It was easy to show that the position maintained by Caussin, that the work was a production of the 16 th century, was untenable, and every other hypothesis which considers them as all composed at the same time. Von Hammer certainly took a more correct view of the subject. It was his opinion, that these fables sprang up in the soil of India, were afterwards transplanted to Persia, and finally made Arabian property by a translation into that language, in the time of the caliph Al Mansur, about thirty years before the time of Haroun al Raschid, the contemporary of Charlemagne. After a time, new branches, native and exotic, were grafted upon this original stock, which soon sent forth new shoots, like the parent tree. And no one can doubt the reasonableness of this opinion, who knows that stories of this sort allow of the introduction of every circumstance and every event in any way connected with the subject of the tale; and in fact it is plain, that many of these fables have a later origin and another home. Acconling to Jonathan Scutt, no two manuscripts in different countries agree; the copies found in every nation are corrupted by the traditions of the people. The story which forns the point of union anong the Thousand and one Night is as follows:-The sultan Schahriar, exasperated by the faithlessness of his bride, made a law, that every one of his future wives should be put to death the morning after marriage. At length one of them, named Sheherazade, the generous daughter of the grand vizier, succeeded in abolishing the cruel custom. By the charm of her stories, the fair narrator induced the sultan to defer her execution every day till the dawn of another, by breaking off in the middle of an interesting tale which she had begun to relate. Thus passed a thousand and one nights, - -two years and nine months, - and, in the course of this period, Sheherazade became the mother of three children. These she led before the throne of her husband. The stern monarch was melted by her tears; he clasped his wife and children to his bosom, gave Sheherazade her life, and required of her no return, but the frequent relation of some of those tales, which liad often kept him fuscinated with delight at her side. Only a part of this story was known to the first French trunslator of the rork ; the conclusion was unknown till von Hammer discovered the circumstances just related, and laid thrm before the world. The delight felt by Schahriar has been felt by thousands more of his own faith, and still continues in the greatest part of Asia, in Egypt, and aloug the southern shores of the Mediterranean. It has been spread by the translations through the countries of Christian Europe, and will continue as long as men delight in the phenomena of a mysterions world, summoned up by the magic of an innocent and playful imaginatioil. Most of the Arabinn tales aim merely to delight the fancy, yet many of them contain much knowledge of mankind, and sometimes acute delineations of the hidden passions and vices of man's heart, and much practical wisdom. They are doubly interesting to the European reader, because they place before us, in a far more striking light than travellers can do it, all the peculiarities of the Eastern nations. The fearless courage of the Arab knight, his propensity to bold adventures, his dexterity and skill, his love and his revenge, the cunning of the women, the hypocrisy of the priests, the venality of the judges,-all stand before us in full relief. Golden palaces, beautiful women, splendid gardens, and rich banquets captirate our senses, and fetter us to a soil in which we delight to view the shadowy forms of a foreign world of fancy. Besides this, the poetical language of many passages, and the great naivete of the whole, cannot but interest the reader. If we were to give an idea of the Arabian Nights by pointing out its very antipode in literature, we would mention Dante's Divina Commedia. Both are creations of the boldest fancy ; but the latter is grave, sometimes harsh, reflective, and speaks design throughout; the former, playfil, natf, sometimes childish, exhibiting the natural fluw of a lively imagination. There are, however, some truly and deeply tragical tales among them; we only mention that of Ali Ebn Becar and Schemselnihar.-The pleasure inspired by the Arabian Nights soon gave rise to numerous imitations and changes. We ought to mention, among the first, the Thousand and one Days ; an imitation, in Persian, of the Thousaud and one Nights. It is less artless than the pattern, and executed with more apparent design. It attempts to remove the prejudice of a king's daughter against men, by recounting numerous examples of honour and faithfulness in that sex. Of the ancient French and German paraphrases, we have already spoken incidentally. Among modern paraphrases, we will mention only Oehlenschlager's Aladdin, which is founded on one of the Arabian tales.

Arabian Sea; a part of the Fastern ocean, on thie southern coast of Arabia.

ARABICI; a sect of Christian teachers who arose in Arabia, in the first half of the third century. Their distinguishing doctrine was, that the human soul dies, cecays, and rises again, at the same time with the body. Origen refuted and converted them, A. D. 246. Their error took its rise from the opinion, at that time prevalent, of the materiality of the soul.

ARACATSCHA ; a plant; a native of the chain of the Andes, and first discovered in Santa Fe de Bogota (New Grenada, in Spanish South America). It is more nourishing and prolific than the potatoe (solanum tuberosum), which grows wild in that country, in the woods of Santa Fe de Bogota, and in Peru aud Chile. In tasteand solidity, the aracatscha rescmbles the Spauish walnut. The soil requires no greater degree of warmth or moisture than is afforded by Europe. In Germany, it was first cultivated successfully in Banberg or Wurzburg. In the 19th page of the Quarterly Journal of Science, Literature, and the Arts (Oct. 1820), Mr Lambert gives an account of the aracatscha (heracleum tuberosum Molina), and its cultivation in England. Mr Jackson, in the 20th page of the same journal, asserts that this plant grows also in the country of Sus, on the south side of the Atlas, and is called, by the Arabians, aracatscha, or atschu, i. e. dry root. How did it find its way to America, and maintain its original name there? Had the old Arabians more knowledge of navigation than is commonly supposed? Or shall we believe that a former continent, by name Atlantis, lias sunk below the ocean, which, before its destruction, formed a connexion between $A$ frica and Sonth America? 
ARACuXE, in mythology, diughter of Idmon, a dyer of purple, at Colophon, in lonia, laul leurned from Pallus the art of weaving, and ventured to challenge her teacher to a trial of skill. In vain did the gorldess, in the form of an old wonan, forewarn her of the consequences of her folly. The contest began, and $A$. prepared, with much skill, a web which represented the amours of Jupiter. This irritated Pallas, who tore the web in pieces, and struck $\boldsymbol{\Lambda}$. on the head with the shuttle. A. hanged lierself in despair. The goddess restored her to life, but changed her into a spider.

Aracinology, or Araneology; the art of deciding on the changes of the weather from the motious and and works of spiders. Intinations of it appear even in Pliny (HI. N., book xi., sect. 2S). It is also treated of in the Eiciguahrenden Practica (Things of everlasting Value), which appeared at Gorlitz in 1588. In Is.ter times, Quatremere Disjonval, once member of the academy of sciences at Paris, during an eight months' imprisonment, in which some spiders were his only companions, made various olsservations on the subject, and, in 1797, at Paris, made known hisdiscovery of the close connexion existing between the appearance or disappearance, the linbour or rest, the greater or less circumference of the webs and fibres, of spiders of different sorts, and the atmospherical changes from fair weather to rain, from dry to wet, and particularly from hot to cold, and from frost to a milder temperature.

ARAcK, or RACK ; a strong spirituous liquor, distilled from rice, stgar-cane, or the juice of the cocoanut. The last, which is the best, comes from Batavia ; the others from Goa. At Goa, there are three kinds -single, double, and treble distilled. The double is most sought, although weaker than the Batavian.

Arafat, or Gibel fl, Orphat (the mountain of knowledge or of gratitude), in Arabia, near Mecca. The Mohammedans say that it was the place where Adam first received his wife, Eve, after they had been expelled from Paradise, and separated from each other 120 years. On the summit is a chapel ascribed to Adam, rifled, in 1007, by the Wahabees. The mountain not being large enough to contain all the devotees that come annually on pilgrimage to Mecca, stones are set up round it, to show how far the sacred limits extend. The latest description of a celebration is by the indefatigable traveller Burckhardt (q. .), who visited the place in July, 1814. He estimates the number present at 70,000 . The camp covered a space of between three and four miles long, and from one to two broad, containing 300 tents and 25,000 camels. In this Babel, he reckoned about forty languages, and had no doubt there were many more. The sermon delivered on the mount constitutes the main ceremony of the Hadj, and entitles the hearer to the name and privileges of a Hadjy. The hill is about 200 feet high, with stone steps reaching to the summit. After concluding the ceremonies at A., the pilgrims set out for Mecca, passing through the valley of Muna, on their return, in which they spend some time in stoning the devil. This ceremony consists in throwing stones against small pillars set up at each end of the valley. Each completes 63 jaculations. 6 or 8000 sheep and goats are then sacrificed. The third day brings them back to Mecca, where some further ceremonies finish the festival.

Aragos, Tullia d', a poetess of the 16th century, descended from an illegitimate branch of the royal family of Spain. Her father, Pietro Tagliava, cardinal d'Aragon, whose natural daughter she was, placed her first at Ferrara, and afterwards at Rome, where her fine talents received the highest degree of cultivation. Her works which remain are, "Rime" in one 8 ro vol. printed in 1547 ; Dialogo dell infinito
d'Amore, which appenrol in the same year; and $l l$ Meschino o il Guerino, 4to, in 1560 . Her beauty and accompl ishments were the theme of several poets. She died, near Florence, nt the end of the 16th century.

Aragon, kingdom of. See Arragon.

Aral; next to the Caspian sea, the largest inland collection of water in Asia. It was unknown to the ancients. It lies amid the plnins of the Turconans and Kirghises. Its leugth is estimated at 250 niles, and its greatest breaclth at 120 . Its water is salt, like all standing collections without an outlet. It receives the Oxus and the Jaxartes, and contuins a multitude of sturgeons and seals. It is encirclenl by desert, soudy heatlis, and its sandy shores are without harbours. Evaporation, as there is no outlet, seems to draw off its water. It lies very low, and is surrounded by many small lakes and morasses, but no hills. It was once, probably, united with the Caspian sea, the enstern coast of which is separated from the western coast of the $A$. only by eighty miles of low, samly, and marshy lands. Both ends of these seas, where they approach each other, are very shallow. The A. is full of islands, which, like its banks, are without inlıabitants.

Aray, Fugene, a man of considerable learning, and remarkable for his unhappy fate, was born in Yorkshire, 1704. His education consisted in learning to read; but, being of a studious disposition, le made great progress in mathematical studies and polite literature, by his own unaided exertions. He acquired the Latin and Greek languages, reading all of the Roman and most of the Greek classics, and also became acquainted with the oriental and Celtic tongues. In 1734, he set up a school at Knaresborough, where he married. About 1745, a shoemaker of that place, named Daniel Clarke, was suddenly missing under suspicious circumstances; and 110 light was thrown on the matter till fill thirteen years afterwards, when an expression dropped by one Richard Houseman respecting a skeleton then discovered in a cave, caused lim to be taken into custody as one concerned in the murder of Clarke. From his confession, an order was issued for the apprehension of Aram, who had long since quitted Yorkshire, having been usher, first in a school in London, and afterwards at another at Hayes, in Middlesex, and in 1757 at the grammar-school at Lynn, in all which places he had acquitted himself with credit, and prosecuted his studies with great diligence. He was arrested in the latter end of 1758, and brought to trial on the 3d of Augusb 1759, at York, where, notwithstanding an able and eloquent defence which he read to the court, he was satisfactorily conricted of the murder of Clarke, and sentenced to be executed. After his conviction, he confessed the justice of his sentence, and alleged his suspicion of an unlawful interconrse between Clarke and his wife, as his motive for the commission of the murder. He attempted to end his life, while in prison, by bleeding, but was revived and executed. His case produced at the time a great sensation, and has of late been pressed into the service of fiction.

Arasda (don Pedro Pablo, Abarca de Bolea) count of; born 1719, of a distincuished family in Arrag: 11. He devoted himself to military pursuits; but, as he discovered a remarkably penetrating spirit, Charles III. appointed him his minister at the court of Augustus III. king of Poland, an office which he held seven rears. After his return, he became governor. general of Valencia. In 1765 , the king recalled him, in consequence of an insurrection that broke out in Madrid, and appointed him president of the council of Castile. A. not only restored order, but also effected the expulsion of the Jesuits from the kingdom. The influence of Rome and the priests, how- 
ever, succeeded in inducing the king to send him on all embassy to France. In Paris $A$. lived nine years; then returned to Madrid, as counsellor of state, and lired in a sort of disgrace, till the queen, not contented with the count Florido Blanca, in 1792, gave his place to A. Some months after, he was succeed ed, greatly to the displeasure of the court and nation, by don Manuel Godoy (q. v.) A. continued president of the council of state till he declared his opinion respecting the war against France, when he was banished to Arragon. He died here, A. D. 1794, leaving a young widow, and no children. Madrid was obliged to him, in a great degree, for its security, good order, and the abolition of many abuses.

Aransogz; a village and palace, with splendid gardens, beautiful walks shaded with elms, and a park for hunting, in the Spanish province of Toledo, in a charming shady vale of the Tagus, which receives here the waters of the Xarama; thirty miles from Madrid, to which a Roman road, built by Ferdinand VI., leads; every mile of which cost $3,000,000$ reals, about 147,000 dollars. A. lies in lon. $3^{\circ} 36^{\prime}$ $W$., lat. $41^{\circ} 5^{\prime} \mathrm{N}$. The court usually resides here from easter till the close of June, when the number of people increases from 2600 to about 8000 . Charles $V$. marked out this vale as the seat of a royal residence. Philip II. founded the palace and garden. His successors, particularly Ferdinand VI., Charles III., and Charles IV., improved and greatly enlarged it. The village is built in the Dutch style, and has broad and straight streets, which cut each other at right angles. The palace has marble stairs, superb mirrors from the manufactory of St Ildefonso, rich works of art; and both the ehurch and the monastery are adorned with many fine paintings by Spanish and Italian masters. The casa del labrador was designed by Charles IV. with great richness and splendour. The palace of A. has been often celehrated by Spanish poets, and is renowned for its gardens, shaded walks, and water-works. The gardens are in the form of a star. The chief walk, overshadowed by elms, is 600 or 700 paces long, twelve feet wide, and is. bordered by a quick-set hedge. Every seventy or eighty paces, there are resting-places, in the form of a hexagon, cooled with fountains. Twelve passages, shaded by elm-trees. unite in forming a large, round area. The royal stud, the herds of nules and buffaloes, the grounds under tillage, the orchards and gurdens here, were formerly in a good condition. Tllere is a fountain in the neighbourhood, from which a sort of Glauber's salts is obtained. $\Lambda$. has become cclebrated, of late years, by the revolution of March 18, 1803. See Spain.

Ararat ; a mountain in Armenia, in the pachalic of Erzerum. It stands on an extensive plain, and is counected by low hills with mount '́aurus. Its summit, covered with perpetual snow, in the form of a sugar-loaf cut into two peaks, presents a formidable appearance with its craggy cliffs and deep precipices. Its highest peak, Mazis, is in the Persian province of Irall, rising to the height of about 9500 feet. It is the greatest elevation in the whole region, and sacred history affirms that Noah's ark settled upon it.

Ararat, or Pilot Modntain; a mountain of Nortl Carolina, on the N. side of the Yadkin about sixteen miles N. of Salem. It is about a mile in height, and rises in the form of a pyramid, with an area of an acre at top, on which is a stupendous rock 300 feet high. From the summit of this rock there is an extensive, variegated, and delightful prospect. It is seen at the distance of seventy miles, and served is a beacon or pilot to the Indians in their routes.

Aratus; a Greek poet, born at Soli (Pompeiopolii), in Cilicia. He flourished abont 270 B. C., was a tavourite of Ptolemy Philadelphus, and a firm friend to
Antigonus Gonatas, son of Demetrius Poliorcetes. We know him only from his poem Phanomeng, in which he has given us, in correct and elegant verse, all that was then known of the heavens, with their signs and appearances, although there is reason to believe that he was not himself an astronomer. The esteem which the ancients had for this work, appears from the fact that it was translated by Cicero, Cæsar German cus, and Avienus. Eratosthenes, with many other great astronomers, wrote commentaries on it. The best editions are by Fell, Oxford, 1672; by Buhle, Leipsic, 1793-1801, 2 vols.; and by Matthiae, Frankfort, 1817-18. It has been translated into German by J. H. Voss, Heidelb, 1824, and published with the Greek text and illustrations.

Aratos of Sicyon, son of Clinias, was born 273 B. C. His father fell in a tumult excited by Abantidas, and A. fled, without knowing it, into the house of the tyrant's sister, who, struck with the circumstance, saved the life of the boy, then seven years old. Afterwards he was sent to Argos, and the exiles from Sicyon expected in him their future restorer. When he had scarcely reached his twentieth year, he delivered Sicyon from the tyrant Nicocles. He would not stain the liberty of his native city with the blood of any citizen, but met with much difficulty in the administration of its affairs, as, besides a large party in the city, the king of Macedon also espoused the cause of the deposed Nicocles. Under these circumstances, he deemed it best to join Sicyon to the Achxan leagne, - the only remaining support of freedom in Greece. By his influence with Ptolemy, king of Egypt, he obtained a sum of money sufficient to settle the various claims of the returned citizens, and, being vested with the supreme constitutional power in Sicyon, he governed with justice and moderation. In due time, being made general of the Achran league, he recovered the almost inaccessible fortress of Corinth from the king of Macedon, by a plan which is one of the most admired instances of ancient military stratagem. In the end, however, owing to a hostile league against the Achrans between the Ætolians and Spartans, A., in opposition to his own principles, was obliged to call in the assistance of Antigonus, king of Macedon. This turned the tide of affairs for a while, but, on the death of Antigonus, similar difficulties occurring, his successor, Philip, was in the same manner called to the aid of the Achrans. At first, Philip highly esteemed A., but was gradually estranged from him, and it was thought that he had caused a slow poison to be administered to him, for A., spitting blood in the presence of a friend, exclaimed, "Behold the friendship of kings!" He died in his fifty-seventh year, 216 B. C., and was interred with the highest honours. A. was one of the most virtuous and noble-minded men that shed lustre on the declining days of Greece. Polybius speaks in high terms of Commentaries, written by $A$. on his own actions and the affairs of the Aclizans, which, it is much to be regretted, have not reached posterity. The chief materials for his his. tory are to be found in Polybius and Plutarch.

Aradcanians. This is a South American nation, of 400,000 inhabitants, in the southern part of Chile. They occupy a territory containing 64,000 square miles, and stretching from $33^{\circ} 44^{\prime}$ to $39^{\circ} 50^{\prime}$ of $\mathrm{S}$. lat. They have maintained their independence against the Spaniards to the present time. Bounded on the $\mathrm{N}$. by the river Bio-Bio, on the S. by the river Gal lacally, on the F. by the Andes, and W. by the Pacific ocean, they live under a free, though aristocratical form of government, agreeably to common laws and customs. They dwell in villages, and enploy themselves in agriculture and raising cattle. The woollen dress of the men is a shirt and a dark-

$$
\text { 2F-G } 2
$$


blue mantle; the women wear a unatlc aul a loug petticout. The freenn'n live in huts. Vegetables form their principal food. Polygamy prevails amoug them, yet the domestic aflairs are inanaged by the women. Their language is allied to the Pratagonian. One of the four toquis (high hereditary nobility) conducts the public affairs. If he does not, however, enjoy universal respect, the ulmenes, or hereditary uobleınen of an inferior class, displace him, aud substitute one of their own number. Distinguished knowledge and boldness unst be shown by the nobility, to excite respect. 'The general appoints his own lieutenant, who, in his turn, appoints auther for himself. Thus every inferior rank is dependent upon the one above it, yet not on the suprome power. In establishing laws and determining in military operations, every $A$. has a voice. The executive power, however, is not bound by expression of the popular opinion. Till 1551, the A. fought only on foot, and then, for the first time, they learned the value of cavalry. Now they lave many horses, and, on their marches, each rider carries a foot soldier behind him, so as to advance with more speed. In battles, the cavalry are posted on both wings. The lieutenantgelleral, vice-toqui, commands one of the wings. In the middle stand the infantry, armed with clubs or spers. They are, likewise, wcll skilled in the use of fire-arnns. In their battles, a portion of the warriors usually remain behind as a corps-de-reserve. The A. advance to an attack with a hideous noise. In the revolutionary struggles of the South American states, the toqui of the $\hat{A}$. resolved upon neutrality, which he honourably maintained.

Aнвеца ; now Ërbil; a small place in Eastern Assyria, renowned for a decisive battle fought by Alexander the freat against Darius, at Gaugamela, in its neighbourhood, B. C. 331 .

Arsitra; a name applied among the Romans, 1. to a judge, whom the pretor had commissioned to decide a controversy pending before him, according to the principles of equity (ex aquo et bono); 2 . to a persoll to whom the contending parties had committed the decision of their dispute, without the interference of a magistrate, by an agreement partly with one another (compromissum), partly with him (receptum) ; finally, 3. one whom the contending parties had only consulted, witl the design of his drawing up terms of settlement, without binding themselves to assent to them. To an arbiter, in the first signification, decisions were committed by the prator ouly in affairs of trust and confidence (in negotiis lona fider), not in cascs of strict right (in negotiis stricti juris). In the latcer cases, the prætor appointed a judge (judex peduneus) who was to decide according to a strict rule (formula) which was given to him. In this threefold signification, the arbiters (১เаเтทrai) annong the Athenians are comprehended. From the arbiter comes the arbitrator, i. e. one to whom the deciding judge proposes questions depending on scientific or technical knowledge, which affect the decision of the dispute. From the opinions of such a man, the parties may appeal to the opinion of a third (to a reductio ad arbitrium boni viri). But as soon as they have committed the decision to a third by an agreement (compromissum), and the commission (receptum) has been receired by him, they must submit to his decision. His sentence (arbitrium, or laudum) can only be assailed when something fraudulent, e.g. bribery, can be proved against him. In the opinion of many learned jurists, however, it may be called in question in case of a great though unintentional violation of justice (propier lesionem enomissimam). Justinian established a distinction between the decision to which the parties subscribe, or which they approve by a silence of ten days, and that against which they have protested within ten days. The forner is called arlitrium homologatum; the latter, non homologatum. 'The latter, acconting to him, ought to have no legal force.

Armitration. Partie's may submit a dispute to arbitration either orally or in writing, and, in either case, the awarl, when r roperly made, will be binding upon the parties. The subunission is in the nature of a commission by both parties to the arbitrators to deternnine the subject in disputc. If either revokes this authority before the award is made, the award will not be binding upon the party so provoking. But if the submission were by boul or covenant, or in writing, and, in some cases, if it were merely oral, the other party will be entitled to daunages against the party so revoking, for the breach of his agrcement to submit the matter in dispute to arbitration. General agreements to submit disputes that may arise, such as those contained in policies of insurance, are not binding by the laws of England. Similar agreeinents, are, however, binding in Germany, and some other parts of the continent, where articles of copvartnership frequently contain a clause to submit disputes between the partners to arbitration; and wills often contain a provision that disputes among the lcgatees and devisees shall be so settled. In submitting disputes under these stipulations, the parties sometimes take an oath to comply with the award, or they agree upon a penalty for not complying. Each is binding. One reason for not giving effect to such general agreements in England is, that it substitutes other tribunals in the place of those established by the laws of the country, which may be done in case of a dispute that las actually arisen, but not by a general and prospective agreement. The laws of mosi countrics, however, favour the settlement of disputes by arbitration. The parties may agree in court to refer their case to arbitration, and the judges will recognisc the agreement. Crimes caunot be made the subjects of adjustment and composition by arbitration, for the public is here one party; but the personal injuries and pecuniary damage resulting from crimes or breaches of the peace may be made subjects of reference. As to the persons who may agree upon a submission, any one may do so who is capable of making a disposition of his property, or a release of his right ; but one under a natural or civil incapacity cannot, as a married woman or minor. The arbitrators chosen by the parties are often authorized to choose an umpire, in case they disagree; but in some of the general stipulations for reference in Germany, the umpire is agreed or beforehand by the parties. As an arbitrator is a judge who receives a commission from the contending parties, it must be left to them to decide on his qualifications, and the laws do not generally make any specific provisions on this subject. If, however, it appears that the arbitrator was interested, and his interest was unknown to one of the parties, or that he was bribed, or that any other strong objection lay against his acting as arbitrator, exception may be made to the award on that account. The provisions of various statutes for carrying awards into execution, and the exceptions that may be made to them on the ground of interest, circumvention, mistake, or informality, arc too numerous to be stated particularly.

ARBRoAtH, or ABERBrothick, a rojal burgh and sea-port town in the county of Forfar, Scotland, situated near the confluence of the small river Brothic, with the German ocean, 56 miles N. F. from Edin? burgh. The early history of Arbroath is chiefly connected with its abbey, the ruins of which afford striking proofs of its former magnificence. King William the Lion granted the privileges of a royal burgh to Arbroath about the middle of the 12th century, and founded the abbey in 1178 , which was dedicated to 
the memory of Thomas à Becket. The monks were of the Tyronensian order, and enjoyed great privileges. Its last abbot was Cardinal Beaton, after whose death it fell a prey to the religious zeal of the reformers. The town declined with the abbey until 1736, when commerce began to revive, and the manufacture was tuidertaken of Osnaburgs, brown linens, and sail cloth, which has eminently succeeded, and forms the principal employment of the inhabitants. The harbour of Arbroath is artificial, but well sheltered by a long pier, and defended by a small battery. About 50 vessels of from 60 to 160 tons burthen belong to the port, which are chiefly employed in the Baltic and coasting trades. Population of Arbroath, 897\%.

Arвothxoт, Alexander, a Scottish divine, in the reign of James VI., and zealous promoter of the reformation, was born in the year 1538. He was much employed by the cluurch of Scotland in its tedious disputes with the regency during the minority of James VI.; and displeased the king so much by the part he took in these affairs, as well as by editing the publication of Buchanan's History, that he was ordered to confine limself within his college of Abcrdeen, of which he was principal. This is supposed to have hastened his death, which took place in 1583. His only existing work is an elegant treatise, entitled "Orationes de originc et dignitate Juris," Edin. 1572, 4to.

Arвotunot, John, an eminent physician and distinguished wit, was born at Arbuthnot, ncar Montrose, in Scotland, soon after the restoration, but in what year is uncertain. He received the degree of doctor of physic at the university of Aberdeen, and engaged in the business of teaching mathematics in Loudon, where he soon distinguished himself by his writings and by his skill in the practice of his profession. In 1704, he was chosen fellow of the royal society, in consequence of his communicating to that body a curious and instructive treatise " on the regularity of the births of the sexes;" and soos after he was appointed physician extraordinary, and then physician in ordinary, to queen Anne. About this time he became intimate with Swift and Pope, and this brilliant triunvirate formed the plan of a satire on the abuses of human learning. But the completion of this design was interrupted by the death of the queen, and we have only an imperfect essay, under the title of Memoirs of Martinus Scriblemis: The death of queen Anne made such an impression on doctor Arbutlınot, that, to divert his melancholy, he visited Paris, and, on his return, was deprived of his place at St James's. He continued, however, the practice of his profession, and, in 1723, was chosen second censor of the royal college of physicians, and afterwards an elect of the same college. Being afflicted with an asthma, which, having increased with his years, was at last become incurable, he retired to Hampstead for relief; but, being sensible that his disease was mortal, he returned to Lolldon, where he died in 1735.-The principal works of doctor Arbuthnot are, an Examination of Doctor Woodward's Account of the Deluge, 1697, and an Essay on the Usefuluess of Mathematical Learning, which were the foundation of his literary reputation; the Table of Ancient Coins, Weights and Measures, cxplained and excmplified, in several Dissertations, which appeared in 1727; the treatise of the Nature and Choice of Aliments, 1732 ; and that of the Effects of Air on Human Bodies, 1733. In these he displays his solid and extensive learning. His trcatise on the Altercation or Scolding of the Ancients, his History of John Bnll, his contributions to Martinus Scriblerus, his Art of Political Lying, and other pieces usually published in Swift's works, are equally distinguished for ingenuity, wit, and exquisite satire, His epitaph or: Charteris is a masterly composition in its kind.
His miscellaneous works have been published in 2 vols. $12 \mathrm{mo}$., with a memoir of his life prefixed, but some of the pieces there given, are now known not to be his. Arbuthnot was greatly beloved by his literary friends. Pope has addressed to lim the "Prologue to the Satires," and Swift affectionately adverts to him in more than one of his poems. "Arbuthnot," he says in one place, "has more wit than we all have, and more humanity than wit." The following sketch of his character, from Dr Johnson's life of Pope, is justified by the testimony of his contemporaries and of his works :- " $\Lambda$ rbuthnot was a man of great comprehension ; skilful in his practice, versed in the sciences, acquainted with ancient literature, and able to animate his mass of knowledge by a bright and active imagination; a scholar, with great brilliance of wit ; a wit, who, in the crowd of life, retained and discovered a noble ardour of religious zcal ; a man estimable for his learning, amiable for his life, and renerable for his piety."

Arc, Jeanne d'. See .Toan of Arc.

ArcaDE, any opening in a building formed by an arch. Of late, there have been erected in some of our principal cities, elegant ranges of shops and warehouses, so constructed as to form a covered lane, to which the term arcade is applied.

Ancadia ; the middle and highest part of the Peloponnesus ; the Greek Switzerland; bounded on the north by Achaia and Sicyon, on the east by Argolis, on the south by Messenia, and on the west by Elis. it is rich in rivers, springs, and pastures, and is watered by the Eurotas and Alpheus. The principal mountains were called Cyllene, Erymanthus, Stym. phalus, and Menalus. From its first inhabitants, the Pelasgi, the land derived the name Pelasgia. In later times, it was divided among the fifty sons of Lycaon, and received from his grandson, Arcas, the name Arcadia. In the course of time, the smali kingdoms made themselves free, and formed a confederacy. The principal were, Mantinea, where Epaminondas obtained a victory and a tomb (now the village of Mondi), Tegea (now Tripolizza), Orchomenus, Pheneus, Psophis, and Megalopolis. The shepherds and hunters of the rugged mountain country remained for a long time in a savage state. By degrees, they acquired the rudiments of civilization, bcgan to cultivate their fields, and to amuse themselves with dancing and music. Their chief deity was Pan, and the occupation of the people alnost entirely pastoral. This, together with the romantic character of the country, occasioned the pastoral poets to select Arcadia for the theatre of their fables.

Arcadiass, Academy of the ; a society of Italian poets in Rome, established in the latter half of the 17th century, for the improvement of taste and the cultivation of Italian poetry. The whole constitution of the society had as its olject the imitation of the pastoral life of the Arcadians. Hence their meetin gs are held in gardens, and every member adopts the name of a Greek shepherd, by which he is called in the society. Under these names the poems of the members are usually published. The laws of the society are drawn up after the model of the twel re Roman tables: the most important are, that the so. ciety shall have no patron, and that no poems are to be read which are contrary to religion and good morals. 'The device of the society is the syrinx (the ancicnt shephord's pipe), entwined with pines and laurels. Only poets (without distinction of sex, however) can be nembers of it. Formerly, the society. enjoyed much respect, and it was an object of ambition to obtain admission to it; but this is no longer the case. In imitation of the chief socicty in Rome, societies for the same purpose were instituted in several Italian cities. Crescimbeni (q.v.) has pub. 
lished collections of the poems of this association, and biographies of several of its members. In 18\%4, Leo XII., under the name of Leo Pistate Cecropio, was admitterl a member.

Arcavon; a secret; especially a secret remedy, or a medicine of which the ingredients and preparation are kept secret. Such medicines, on acconnt of numerous ahuses, lave been made, in some conntries, nn object of nedical police. In the time of alchymy, there were many celehrated arcana.

Arcesilade, a Greek plilosopher, the fornder of the second or mildle acadeny, was horn at Pitane, in Eolia, in the first year of the 116th Olympiad, B. C. 316 , and sent to Athens to study rhetoric, but plrilosopliy attracted him more. Ile enjosed the instructions of the Peripatetic Theoplirastus, then of l'olemon, and, after the death of Crates, stood at the head of the academy, but made important innovations in its doctrines. Plato and lis successors had distinguished two kinds of objects-material, which act upon the seuses, and those that are only comprelieuded by the mind. Onr notions of the former, they say, compose opinion ; of the latter, knowledge. Arcesilaus, who approached to scepticism, or rather went beyond it, denied that a man knows any thing -ereut the fact that he knows notling. He rejected as false and delusire the testimony of the senses, and accordingly maintained, that the truly wise man can maintain notlring. In this way he was able to combat all opinions. As he was obliged, however, to reconcile these strange maxims with the necessities of life, inposed alike on every being, he said their strict application was admitted only in science, and that a man may even adhere to what is only probable in the present life. Moreover, he was kind to the distressed, and a friend to pleasure. A rival of Aristippns; he divided his time between Venus, Bacchus, and the Muses, without ever filling a public office. He died, from an intemperate indulgence in wine, seventy-fire years old, in the fourth jear of the 134th Olympiad.

ARCH, in building. See Architecture.

ARCH (from the Greek prefix $\alpha e x i$ ); a syllable which is placed before some words, in order to denote the highest degree of their kind, whether good or bad, e. g. archangel, archiuke, archchancellor, archbishop, archspirit of evil, archfiend, archflatterer, archfelon, \&c. Many of the highest officers in different empires have this syllable prefixed to their titles, and, in the German empire, the arch-offices (erzamter), as they were called, were of high importance. They were established in France, by the same constitution which conferred the imperial diguity on Napoleon.

Arcilalsar ; an antiquated word or phrase. In general, the use of archaisms is objectionable, bnt in certain kinds of writing, and particularly in poetry, they may even be an oruament, as they are often peculiarly forcible.

Archasger; the chief city in a Russian district of the same name, which contains $356,400 \mathrm{sq}$. miles, with 263,100 inhabitants, among whom are $7000 \mathrm{Sa}$ moyedes. The city lies between twenty and thirty miles from the mouth of the Dwina, on the White sea ; long. $38^{\circ} 59^{\prime} \mathrm{E}$; ; lat. $64^{\circ} 34^{\prime} \mathrm{N}$. It contains 1900 houses and 15,100 inhabitants. The monastery of Michael the archangel, founded there in 1584, gave the city its name. The English first discovered a passage thither through the Frozen ocean, A.D. 1553, and, until the building of Petersburg, A. was the only port whence the productions of Russia were exported. When Petersburg became a place of export, and Riga also was used as a Russian port, the trade of A. sunk till 1762, when queen Elizabeth granted to it all the privileges of Petersburg. The trade on the Dwina has since increased more and more with the growing population of Russia; and $\mathbf{A}$. las become the clief mart of all imports and exports for Siberia, heing connected by canals with Moscow and Astraclinu. In June or July, foreign vessels arrive, which snil again in the last of September or October. In these summer months, there is a perpetual market for fish, fisli-oil, tallow, grain, various sorts of fur, skins, ship-timber, wax, iron, coarse linen, logs" bristles, china and japanned wares, caviare, sturgeon, \&c. More than 200 foreign vessels arrive annuully; in 1823, 230 sailed. The trade is seriously obstructed by a sand-bank, affording only twelve and a half feet of water, at the entrance of the harbour, which is in other respects good. The fortification of Nova-1 wwiesk protects the entrance. Tlipre are now dockyards here for slrips of war, which are built by the Russian government in $\mathbf{A}$. as cheap or cheaper than they can build them in suy other place; nlso an excellent warehouse for foreign nerchandise subject to a duty. In A pril, the ice breaks up at the moutl of the Dwina, on the banks of which, $65^{\circ} \mathrm{N}$. lat,, the vegetation of grain and fruit entirely ceases. Severrteen versts from the city is the anchoring place of ships, witl three docks. A civil and military governor, and an archbishop, reside at $A$. The house of the admiralty and the barracks of the soldiers are situated on the island Solombol, formed by the river Cuschenida. In 1816, the value of imported goors subject to duties was $1,138,000$ rubles, and of the exports, $8,600,000$ rubles. The paper ruble fluctuates in value witl the exchange; in 1829 , it was estimated at about 11d. sterling; while the silver ruble is worth $3 s .23 d$. The shortness of the nights, during the time the luarbour is navigable, presents a natural obstacle to smuggling. The shortest day is three hours and twelve minutes long. Many expeditions, every year, for fishing and lunting, go from this place to Spitzbergen and Nova Zembla, by water in summer, and by sledges in winter, to the mouth of the Lena, and perhaps farther.

ARchBishop (from the Greek ; in Latin, archiepiscopus); a metropolitan prelate, having several suffiragan bishops under him. In Catholic countries, the archiepiscopal chapters elect the archbishop, who is confirmed by the pope. The establishment of this dignity is to be traced up to the earliest times of Christianily, when the bishops and inferior clergy met in the capitals to deliberate on spiritual affairs, and the bishop of the city where the meeting was held presided. Certain honours were allowed him, the title of metropolitan particularly, on account of his residence. The synod of Antioch gave the archbishops, in the year 341 , the superintendence over several dioceses, which were called their province, and a rank above the elergy of the sane, who were obliged to ssk their advice in some cases. By degrees, their privileges increased; but of these the pope has retained many since the 9 th century, so that only the following were left to the archbishops: - jurisdiction, in the first instance, over their sufiragan bishops, in cases not of a criminal nature, and appellative jurisdiction from the bishops' courts ; the right of convoking a provincial synod, which they were required to do at least once in every three years, and the right of presiding in the same; the care of enforcing the observance of the rules of the church, of remedying abuses, of distributing indulgences; the right of devolution (q. v.), of having the cross carried before them in all parts of the province (if the pope himself or a legatus a latere is not present), and of wearing the archiepiscopal pallium (q. v.) In Fngland thiere are two (Protestant) archbishops-those of Canterbury and York; the former styled prinate of all England, the latter, primate of England; but with regard to the exact distinctions between these appes- 
lations, there is no little obscurity in the books of such as treat upon this subject. In ancient times, the primacy of the archbishop of Canterbury extended to Ireland, as well as England. Hence he was styled a patriarch, had the titles of orbis Britannici pontifex, and of papa alterius orbis. He is the first peer of the realm, having precedency before all dukes not of royal birth. He crowns the sovereign, whether king or queen, and when he is invested with his archbishopric, he is said to be enthroned. The first prelates in England are his oflicers. He is addressed by the titles of your grace, and most reverend father in God, and writes himself by divine providence, while the bishop only writes by divine permission. His jurisdiction extends over twenty-one dioceses. The first archbishop of Canterbury was Austin, appointed A. D. 598, by Ethelbert, when he was converted to Cluristianity. Next in dignity is the archbishop of York. He takes place of all dukes not of the blood royal, and all the great officers of the crown, except the lord high chancellor of England. He crowns the queen consort. The first archibishop of York was Paulinus, appointed in 622. The income of these iwo highest prelates of England has often been misrepresented, one party stating it too high, the other too low. It is certainly very great, though the amount cannot be exactly ascertained. Scotland had two archbishops-those of St Andrews and Glasgow; now she has none. In Ireland, there are fourthose of Dublin, Armagh, Tuam, and Cashel. In the United States, there is an archbishop of the Roman Catholic church, whose see is at Baltimore, and whose spiritual jurisdiction extends over all the United States. There is, as yet, no archbishop of the Protestant Episcopal church, though there are several bishops. In the year 1828, pope Leo XII. appointed, after much delay, an archbishop in Colombia, whom Bolivar had proposed. Perhaps the two most important archbishops in history were those of Cologne and Mentz. These archbishops were sovereigns of a considerable country, electors of the German empire, and the two highest officers under the emperor. Till Napoleon dissolved the German empire, they played a conspicuous part in the history of the continent. In France, there are now nine archbishops; in Spain, eight; in Portugal, two; in Hungary, three ; in Italy, thirty-eight.

Archderacos. This ecclesiastical officer, who was at first only the chief among the deacons in a cathedral or metropolitan church, in the 5th century, acquired an importance, which raised him above the rank of presbyters, and placed lim nearly on an equality with the bishops. The archdeacons have since been not mere assistants, but representatives of the bishops in the dioceses and councils. By degrees, the affairs of the bishop's jurisdiction, the superintendence of the clergy, the churches, convents, and ecclesiastical possessions, the right of visitation, the trial of heresies in the western bishoprjes, came to be exercised by the archdeacons. Until thie 9 th century, they were only delegates of the bishops, but they afterwards became independent officers of the church, with almost episcopal power, partly through the weakness anä ignorance of their yrincipals, partly tlurough the division of the dioceses, which tonk place in the 8 th century, into several smaller districts or archdeaconates, over which the archdeacons presided. In the 11 th and 12 th centuries, they were acknowledged as the most iufuential prelales of the church, and at the summit of their power. On the establisliment of the general episcopal tribunals under particular officers or general vi(ars, in the 13th century, the dignity of the archdercons diminished, anil their jurisdiction in nustdioceses, in the 15th and 16th centuries, yassed to the new courts. In the 18th century, they were still regarded as dignitaries in some chapters ; but now this office, principally on account of the contention about rank with the deans and other officers, is almost wholly abolished in the Catholic church. In the chapters established again since the downfall of Napoleun, it has not been revived. In the Greek clurch, since the 7 th century, there have been no archdeacons, except one in the Greek imperial court at Constantinople. The episcopal church in England, on the contrary, still has archdeacons, who are the deputies of the bishops, to superintend the districts. The archdeacons in the evangelical Lutheran church enjoy no particular privileges, except precedence over the other deacons. In Hamburg, they are the second ecclesiastics in the principal churches.

Archerlads.-1. A Greek philosopher, a disciple of Anaxagoras. He flourished about 440 years B. C. Like his predecessor, he chiefiy devoted his attention to the origin of things. He first taught at Lampsacus, and subsequently removed to Athens, where Socrates became his disciple and successor.-2. A. king of Macedon, natural son of Perdiccas II., and his successor. He entertained at his court Euripides, and employed Zeuxis' pencil. He died about 398 B. C. - 3. The son of Herod the Great. His reign is described as most tyranuical and bloody. The people at length accused him before Augustus (Judea being' then dependent upon Rome). The emperor, after hearing his defence, banished him to Vienne, in Gaul, where he died. To avoid the fury of this monster, Joseph and Mary retired to Nazareth.-4. The son of Apollunius, a sculptor. He was a native of Ionia, and is thought to have lived under Claudius. He executed in marble the apotheosis of Homer, which was found, in I768, at a place called Fratocchia belonging to the house of Colonna.

ARcheNholz, Joln William von; a very voluminous German author; born 1743, died 1812. He is known in foreign countries by his England and Italy, translated into almost all the living languages of Europe. He also wrote Annals of British History, from 1788, in twenty vols. 1789-98. Perlaps lis most important work is his History of the Seven Years' War (in Germau), two vols. Berlin, 1793.

Archery ; the art of shooting with a bow and arrow. This art, eitler as a means of offence in war, or of subsistence and amusement in time of peace, may be traced in the history of almost every nation. The first notice of archery in the sacred writings occurs in the twenty-first cliapter of Genesis, wliere it is said, that Ishmael, the illegitimate son of Abraham, "dwelt in the wilderness, and became an archer." It appears that the Jews did not excel so much in this art as some of the neighbouring nations, by whom they were infested with perpetual lostilities. When David succeeded to the throne, lie found it necessary to issue an order, that Judah, the most warlike of all the tribes, should be taught the use of the bow. Jonatlan, the son of Sanl, appears to have been so expert in the practice of archery, that he never drew his bow in battle, without drenching his arrows in the blood of the inighty; but in that fatal encounter, in which he and lis father fell, the Philistines manifested a great superiority over the men of Israel, in the use of that nilitary weapon. From different passages of the Old 'Testament, and from other ancient books, we learn, that archery was used not only in war, and as a pastime, but also as one of the means of divination. From the accounts transmitted to us by Herodotus, it would appear that the Scytlians were superior to all other nations in the practice of archery; and that the Ethiopians and Egyptians also greatly excelled the Persians. Among the Greeks, the bow and arrow appear to have hee'il 
empluyed frum the earliest times. If the descriptions of buttles given by Homer, are to be admitted as ge-nuine representations of the mole of fighting in the heroic ages, we must conclude that the archers were interspersed among the other troops; and that, sheltering themselves behind the slirelds of their companions, they tonk their aim deliberately and securely. In later times, the archers formed part of the $\psi, \lambda_{0}$, or light armerl troops, who were not held in such estimation as the dzגıras. The Athenians, however, were indebted for some of their grcatest victories to the feats of the archers; and particularly for the success of the bloody engagenent with the Lacedamonians, nenr Pylos. The guards of the city of Athens were archers. There is no early account of bows having been used in the Roman armies. In the time of Scipio Africanus, they were applied with great effect against the Numantines in Spain. Tiberius owed his success in the war with Arminius and Inguiomerus chiefly to the great cxecution done by the archers, some of whom fought on foot, and others were mounted on horseback. After his time, the practice of archery was not discontinued; but it would require a great share of credulity to admit the narratives of Suetonius and Herodian, concerning the surprising expertness of Domitian and Commodus, to be faithful reports of facts given by eye-witnesses. The Roman Sagittarii were part of the Velites, composed of pauperes et juvenes, often also of auxiliaries. Their service was peculiarly tangerous; they were sometimes placed in front, sometimes in the wings, sometimes in the rear; aul the chief purpose for which they were employed was to harass the enemy, by attacking the weakest parts of their lines, before the general attack coms. menced. The subjoined cut represents the costume of a Roman archer. - In the middle ages, the Goths, Vandals, and Huus, gained their victories chiefly by the use of the same destructive weapons. The Swiss were famous arch. ers. The English claim to be considered the best of modern archers, and their claims have scarcely been disputed. Edward III. was at great pains to provide bows and arrows. In

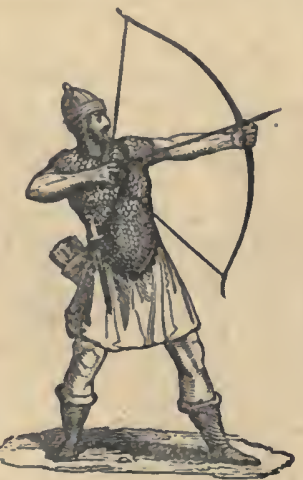

the nattle of Cressy, his archers cut off the fower of the French nobility. The French had as many archers in the field as the English; but the former are understood to have used the cross bow, which is not easily protected from the rain; and, it is said, their bows or their strings were so completely soaked as to be altogether unfit for use. The victory gained by the Black Prince at Poictiers, when the French king and the dauphin, and almost all the pecrs of France, werc taken prisoners, was also ascribed to the archers, very few of whom fell, though the slaughter of the French was enormous. The battle of Agincourt, still more fatal to the French, and more glorious to the English, was gained by the same mode of fighting. The advantages from time to time obtained over the Scots were chiefly orving to the strength and skill of the English archers. The great example which Robert the Bruce set at the hattle of Bannockburn, of dispersing the archers with lis cavalry at the commencement of the conflict, was, unfortunately for Scotland, too seldom followed. Notwithstanding the encomiums which ancient and modern writers have lavished on archery, it must be admitted, that, in many respects, it was not worthy of being compared with the use of fire-arms. In some states of the at nosphere it could not beapplicd with any effect; moisture not ouly impairs the elasticity of the bow, but relaxes the strings, and soon renders them unfit for use. The direction and intensity of the winds must often lave bcen still more disconcerting ; except in a calm, or hin a very molerate wind, the best marksinan camot shoot straight, and when the wind is very boisterous, especially if it either be opposite or a side wind, it is impracticable to shoot far. Another disadvantage under which the archers must have laboured, was being attacked in the niglit, or in a fog, in either of which cases they might have been cut off before they found time to bend their bows. In modern times, this weapon is used by the Asintic nations, by the tribes of Africa, by the Indians, \&c. In 1813 and 1814 , irregular troops, belonging to the Russian army, particularly the Bushkeers, appeared in Paris, armed with bows and arrows, and made surprising shots.-Concerning archery as a pastine, or a healthful cxercise, it lias the sanction of Galen, as being sufficiently active and not too violent; in addition to this salutary and moderate exertion of the muscles, it possesses two other advantages. It leads to pure air, and it is also abundantly inter-? esting to the mind, especially when it is attended by competition. For more than two hundred years after fire-arms were introduced, attempts were made by the English government from time to time to encourage the practice of archery. Charles I., in the fourth year of his reign, granted a commission under the great seal for enforcing the use of the long bow : and though this was revoked a few years afterwards, another was granted in the year 1633 , to two persons of the name of Meade, authorizing them to teach an invention for uniting the use of the bow and the pike. Ten years afterwards a precept was issued by the earl of Essex, calling upon all well-affected persons to assist in raising a company of archers for the service of the king. Since that time, and, indeed, long before, archery can claim only to be considered as a recreation. In Great Britain, a number of societies have contributed to preserve the exercise from falling into total disuse. The archers of Finsbury are now extinet, but their society is incorporated with the archers' division of the Artillery Company of London, founded by royal charter in the twenty-ninth year of the reign of Henry VIII.; who were permitted to shoot not only at marks, but birds, except pheasants or herons, and to wear dresses of any colour, except purple, or scarlet. The only other companies still subsisting in England, are the Kentish Bowmen, the Woodmen of Arden, and the Toxophilites. The Royal Company of Archers in Scotland is said to have arisen in the time of James I. The commissioners appointed by that prince to superintend the exercise of archery in different districts, selected the most expert archers, and formed them into a company, to act in the capacity of the king's principal body guards; a distinction which the Royal Company still claim within seven miles of Edinburgh. In 1677 , we find them recognised by an act of the privy council, as his Majesty's Company of Archers; and at the same time a king's prize, consisting of a piece of plate valued at $£ 20$ sterling, was ordered to bc given annually to be shot for at their weapon shawings. Their attachment to the unfortunate family of Stuart subjected them, at different periods, to fuctuations of bad fortune, and occasionally threatened their entire dissolution. In the year 1703 , they obtained a royal charter from queen Anne, confirming and multiplying their privileges. The royal prize, which had been withdrawn by king William soon after the revolution, 
was restored about twenty years ago by George III. This company, which includes a great proportion of the Scottish nobility and gentry, as well as many respectable citizens of Edinburgh, contains above 100 members. A president and six counsellors, chosen annually from the body of the members, manage their concerns; many of the members who reside in Edinburgh meet weekly during the summer in the Meadows, and shoot at butts or rovers. Their uniform is tartan lined with white, and trimmed with green and white fringes; a white sash, with green tassels, and a blue bonnet, with a St Andrew's cross and feathers. The only prize shot for at butts, or point-blank distance, is called the goose : originally it was shot for thus : a living goose was inclosed in a butt made of turf, having nothing but the head left visible, and he who first pierced the head with his arrow, received the goose as his reward. A practice so barbarous has long been discontinued; a mark, an inch in diameter, is now placed on the butt, and the archer who first hits it is captain of the butt shooters for the succeeding year. The other prizes annually given are shot for at rovers, the marks being 185 yards distant. The king's prize already mentioned, becomes the property of the winner; all the others are retained by the victors for a year, and are restored, each with a medal affixed, having a motto and device engraven on it. The first is a silver arrow given by the town of Musselburgh, 1603, or earlier. The second is a silver arrow given by the royal borough of Peebles, 1626 . The third, a silver arrow given by the city of Edinburgh, 1709. The fourth, a punch bowl, value $£ 50$, made of Scottish silver, at the expense of the company, 1720, which is now surrounded with rows of gold medals, and always used at the convivial meetings of the company in the $\Lambda$ rchers' Hall, a neat building adjoining to the Meadows, where all their business is transacted.

Arches Codrt (curia de arcubus); the chief and most ancient consistory court, belonging to the archbishop of Canterbury, for the debating of spiritual causes. It is so called from the church in London, commonly called St Mary le Bow (de arcubus), where it was fornerly held, which church is named Bow church, from the steeple, which is supporterl by pillars built archwise, like so many bent bows. The jurisdiction of this court extends over the province of Canterbury. An appeal, however, lies to the king.

ARchil, or Arcimlla, called, also, rocella and orsielle; a whitish moss, which grows upon rocks, in the Canary and cape Verd islands, and yields a rich purple tincture, fugitive, indeed, bint extremely beautiful. When it is prepared for dyeing, it is called lacmus, or litmus (q. v.)

Archilochus ; a Greek poet, born on the island of Paros. He flourished about 700 B. C. His ardent spirit hurried lim into the whirlpool of political party, and he was cbliged to leave his country. He retired to Tarsus, where he fought against the Thracians, and lost his shield, more by accident than cowardice. He afterwards visited Greece, but the Spartans banished him from their state. He gained the laurel crown, however, at the Olympic games, for a hymn to Hercules. Some say he was killed in battle; others, that he was assassinated. A. was no less formidable with the pen than with the sword. Lycambes, who had promised him his daughter, and faithlessly riolated his agreement, hanged himself in despair on account of the satires in which the offended poet wreaked on him his revenge. Witl the same severity, he persecuted all his fellow citizens, who were unfortunate enough to displease him. His memory was honoured in all Greece so highly, that he was placed beside Homer. His iambic poems were renowned for the force of the style, the liveliness of the metapliors, a sententious conciseness, elevated feeling, and a powerful, but bitter spirit of satire. In other lyric poems of a higher character, he was also considered as a model. All his works are lost but a few fragments, collected by Liebel, Leipsic, 1812-17. He used the half-pentameter verse in his poems, whence this verse is called, from him, Archilochian verse : $\smile \smile-\smile \smile-$ ARCHIMANDRITE; in the Greek church, abbots or general-abbots, who have the superintendence of many abbots, and convents; because in the ancient Greek clurch, the abbots were called mandra, and archi is the Greek prefix (see $A r c h$ ). In Sicily, the abbots are called thus because their convents were originally of Greek institution, and conform to the rules of St Basil. The general-abbots of the united Greeks in Poland, Galicia, Transylvania, Hungary, Sclavonia, and Venice bear this title.

Archimedes, the most celebrated among the ancient geometricians, born at Syracuse, about $287 \mathrm{~B}$. C. a relation of king Hiero, appears to have borne no public office, but to have devoted himself entirely to science. We cannot fully estimate his services to mathematics, for want of an acquaintance with the previous state of science; still we know that he enriched it with discoveries of the highest importance, npon which the moderns have founded their admeasurements of curvilinear surfaces and solids., Euclid, -in his elements, considers only the relation of some of these magnitudes to each other, but does not compare them with surfaces and solids bounded by straight lines. $\mathrm{A}$. has developed the propositions necessary for effecting this comparison, in his treatises on the sphere and cylinder, the spheroid and conoid, and in his work on the measure of the circle. He rose to still more abstruse considerations, in his treatise on the spiral; which, however, even those acquainted with the subject can with difficulty comprehend. A. is the only one among the ancients, who has left us any thing satisfactory on the theory of mechanics, and on liydrostatics. He first taught the principle, "that a body, immersed in a fluid, loses as much in weight as the weight of an equal volume of the fluid," and determined, by means of it, how much alloy an artist had fraudulently added to a crown, which king Hiero had ordered to be made of pure 'gold. He discovered the solution of this problem while bathing; and it is said to have caused him so much joy, that he hastened lome from the bath undressed, and crying out, "I have found it, I have found it!" Practical meclianics, also, appears to have been a new science at the time of $\mathrm{A}$. ; for his exclamation that he could move the earth, if lie had a point without it to stand upon, shows the enthusiasm with which the extraordinary performances of his machines had inspired lim. He is the inventor of the compound pulley, probably of the endless screw, \&c. During the siege of Syracuse, he devoted all his talents to the defence of his native country. Polybius, Livy, and Plutarch speak in detail, and with admiration, of the machines with which he repelled the attacks of the Romans. They make no mention of his having set on fire the enemy's fleet by burning-glasses, - a thing which is, in itself, very improbable, and related only in the later writings of Galen and Lucian. $\Lambda$ t the moment when the Ronuans, under Marcellus, gained possession of the city by assault, tradition relates that $\Lambda$. was sitting in the market-place, absorbed in thought, and contemplating some figures which he lad drawn in the sand. To a Roman soldier, who addressed him, he is related to have cried out, "Disturb not my circle!" but the rough warrior little heeded his request, and struck him down. As the conquest of Syracuse is placed in the year 212 B. C., Archimedes must have bees 
seventy-five years old when he lost his life. On his tombstonc mas placed a cyliuler, witls a sphere inscribed in it, thereby to immortalize his discovery of their mutual relation, on which he set particular value. Cicero, who was appointed questor over Sicily, found this monument in a thicket which cuncealed it. 'The works of Archimedes, as arranged by Torelli, are, 1. De Planorum Equilibriis, cum Comment. Eutoc. Ascalonita. 2. Qualratura Paraboles. 3. De I'lanornem Equilibriis, cum Conm. Entoc. Ascalon. 4. De Sphar. et Cylindro, lib. prim. cum Comm. Eutoc. Ascalou. 5. De Sphar. et Cylindro. lib. sec. cum. Comn. Futoc. Ascalon. 6. Circuli Dimensio, cum Comm. Eutoc. Ascalon. 7. De Helicibus. 8. De Conoidibus et Sphcroidibus, cum Torelli Comment in Prop. 12. 9. Arenarius. 10. De ï qua in IIumido Vehuntur, lib prim. 11. De iis que in Humido Fehuntur, lib sec. 12. Ismmata. 13. Opera Mechanica, ut cujusquc mentio ab antiquis scriptoribus facta est. After the taking of Constantinople, in the midule of the 15th century, the works of A rchimedes were brought, by the Greek refugees, from that city to Italy, wherc they were found by the celebrated Regiomontanus, who carried them into Germany. In 1544, they were published at Basil, in Greek and Latin, by Hervagius, and were accompanied with the Commentaries of Futocius. 'They have since passed through many editions, and liave been illustrated by the annotations of some of the most eminent mathematicians of modern times. A very complete and splendid edition of the works of Archimedes issued from the Clarendon press, at Oxford, in 1792. This edition was prepared by Joseph Torelli of Verona. The Latin translation is new; and there is a large collection of the various readings that occur in the manuscripts of Archimedes's works which are preserved at Paris and Flo. rence. This edition was printed under the direction of the learued and reverend Abram Robertson, of Christ's Church College, Oxford; who has added a commentary of his own, on the treatise of Archimedes relative to floating bodies. In the large work, entitled, "Mathematici Veteres," which contains a collection of the works of the Greek mathematicians, and which appeared at Paris in 1693, the writings of Archimedes hold a principal place.

ARChIpelago; a corruption of .Eigeopelago, the modern Greek pronunciation of Asyosov $\Pi_{s} \lambda \alpha$ yos, the Aigean sea. 'The term, however, is applied to any tract of sea abounding in small islands, and to the clusters of islands situated therein. The group to which the name is most generally given is that lying in the Egean sea, between the coasts of ancient Greece and Asia Minor. According to their situation, they are divided into the islands belonging to Europe and to Asia. The former lie together, almost in a circle, and for this reason have been called, by the Greeks, the Cyclades (q. v.); the latter, lyeing farther from one another, the Sporades (q. v.) All these islands are in the government of the capudan pacha, to which, however, Candia, with the little islands lying about it, does not belong. Compare with this article Hydra, Negropont, Scio, Samos, Rhodes, Cyprus, \&.c.-Archipelago, Northern, extends between the coasts of Kamschatka and the west coast of America, and comprehends four clusters : 1, Sasignan, containing five islands; 2 , Khoa, including eight islands; botls these groups together are called the Aleutian islands (q. v.); 3, the Andreanoffki Ostrova, comprising sixteen islands; $\mathbf{4}$, the Lyssil or Fox islands, including, also, sixteen islands. - Archipelago of Lazarus, near the coast of Malabar and Malacca.-Archipelago of the Great $C_{y}$ cindes; a cluster of islands in the South Pacific ocean, so named by Bongainville, and afterwards called the
New Hebridcs by Cook. - Archipelago of the Philippines, containing the Philippines, Moluccas, Celebes, ¿.c. Some call it, also, thic Grcat A.-Archipelago of the Recherche; several groups of islands, rocks, and slioals, on the south coast of New Holland, ex. tending from between $34^{\circ}$ to $34^{\circ} 30^{\prime} \mathrm{S}$. lat., and $121^{\circ}$ $30^{\prime}$ to $123^{\circ} 20^{\prime} \mathrm{F}$. lon. The largest islands were named, by the French, Mondrain and Middle island. - Many other $A$. might be mentioned.

ARсHiтвстURE, in the general sense of the word, is the art of erecting durable, commodious, healtliful, and handsome buildings of all kinds, adapted to the purposes of the builder. According to the objects to which it is applied, architecture is commonly divided into civil architecturc, military architccture (see For tification), and naval architcclure. For the sakc of convenience, further divisions are sometimes introduced, such as hydraulic, mining, \&:c., architecture. Upon the continent of Europe, architecture is often divided into privatc and public. The latter includes all structures commonly undertaken or particularly superintended by government. In Germany aud France, therc is a building police, which oversees both public and privatc edifices, and takes care that security and health arc prorided for in both.- There is sumething divine in man, which prompts him to look bcyond the mere supply of lis necessities, and to aim continually at higher objects. He therefore soon expected from his habitation and his temples more than merc utility. He aimed at elegance, and architecture became, by degrees, a fine art, differing essentially, howerer, from the other fine arts in these respects; 1 , that it is based on utility; 2 , that it elevates mathematical laws to rules of beauty. Painting and sculpture are only the expression of the feeling of the beautiful. On the contrary, every creation of architecture nust appear to lave utility in view. A column or an architravc, which supports nothing, appears ridiculous, and cvery part of a building ought to show the purpose for which it is dcsigned.-Architecture appears to have been among the earlicst inventions, and its works have been commonly regulated by some principle of hereditary imitation. Whatever rude structure the climate and materials of any country have obliged its early inhiabitants to adopt for thcir temporary shelter, the same structure, with all its prominent features, has been afterwards kept up by their refined and opulent posterity. Thus the Egyptian style of building has its origin in the cavern and mound;* the Chinese architecture is modelled from the tent; the Grecian is derived from the wooden cabin, and the Gothic from the boner of trees.-The essential elementary parts of a building are those which contribute to its support, enclosure, and covering. Of these, the most important are the foundation, the column, the wall, the lintel, the arch, the vault, the dome, and the roof.-In laying the foundation of any building, it is necessary to dig to a certain depth in the earth, to secure a solid basis, below the reach of frost and common accidents. The most solid basis is rock, or gravel which has not been moved. Next to these are clay and sand, provided no other excarations have been made in the immediatc neighbourliood. From this basis a stone wall is carried up to the surface of the ground, and constitutes the foundation. Where it is intended that the superstructure shall press unequally, as at its peers, chimneys, or columns, it is sometimes of use to occupy the space between the points of pressure by an inverted arch. This distributes the pressure equally, and prevents the foundation from springing between the different points. In loose or muddy situations, it is always 
nnsafe to build, unless we can reach the solid bottom below. In salt marshes and flats, this is done by depositing timbers, or driving wooden piles into the earth, and raising walls upon them. The preservative quality of the salt will keep these timbers unimpaired for a great length of time, and makes the foundation equally secure with one of brick or stone. -The simplest member in any building, though by no means an essential one to all, is the column or pillar. - This is a perpendicular part, often of equal breadth and thickness, not intended for the purpose of enclosure, but simply for the support of some part of the superstructure. The principal force which a column has to resist, is that of perpendicular pressure. In its shape, the shaft of a column should not be exactly cylindrical, but, since the lower part nurst support the weight of the superior part, in addition to the weight which presses equally on the whole column, the thickness should gradually decrease froin bottom to top. The ontline of columns should be a little curved, so as to represent a portion of a very long spheroid, or paraboloid, rather than of a cone. This figure is the jount result of two calculations, independent of beauty of appearance. One of these is, that the form best adapted for stability of base is that of a cone; the other is, that the figure, which would be of equal strength throughout for supporting a superincumbent weight, would be generated by the revolution of two parabolas round the axis of the column, the vertices of the curres being at its extrenities.*-The swell of the sliafts of columns was called the entasis by the ancients. It has been lately found, that the columns of the Parthenon, at Athens, which have been commonly supposed straight, deviate about an inch from a straight line, and that their greatest swell is at about onethird of their height. Columns in the antique orders are usually made to dininish one-sixth or one-seventh of their diameter, and sometimes even one-fourth. The Gothic pillar is commonly of equal thickness throughout. - The wall, another elementary part of a building, may be considered as the lateral continuation of a column, answering the purpose both of enclosure and support. A wall must diminish as it rises, for the same reasons, and in the same proportion, as the column. It must diminish still more rapidly if it extends throngh several stories, supporting weights at different heights. A wall, to possess the greatest strength, must also consist of pieces, the upper and lower surfaces of which are horizontal and regular, not rounded nor obliqne. The walls of nost of the ancient structures, which have stood to thie present time, are constructed in this manner, and frequently have their stones bound together with bolts and cramps of iron. The same metliod is adopted in such modern structures as are intended to possess great strength and durahility, and, in some cases, the stones are even dovetailed together, as in the lighthouses at Eddystone and Bell Rock. But many of our modern stone walls, for the sake of cheapness, liare only one face of the stones squared, the inner half of the wall being completed with brick; so that they can, in reality, be considered only as brick walls faced with stone. Such 1 walls are said to be liable to become convex outwardly, from the difference in the slırinking of the cement. Rubble walls are made of rough, irregular stones, laid in mortar. The stones should be broken, if possible, so as to produce horizontal surfaces. The eoffer walls of the ancient Romans were made by enclosing successive portions of the intended wall in a box, and filling it with

- See Tredgold's Principles of Carpentry, p. $5 \mathrm{n}$.

+ By Messrs Allason aud Cockerell. See Branite's Jour. nal, rol $x$. p. 204 . stones, sand, and mortar, promiscuously. This kind of structure must have been extremely insecure. The Pantheon, and various other Roman buildings, are surrounded with a double brick wall, having its vacancy filled up with loose bricks and cement. The whole has gradually consolidated into a mass of great firnness. The reticulated walls of the Romans, hav ing bricks with oblique surfaces, would, at the present day, be thought highly unphilosophical. Indeed, they could not loing have stood, had it not been for the great strength of their cement. Modern brick walls are laid with great precision, and depend for firmness more upon their position than upon the strength of their cement. 'The bricks being laid in horizontal courses, and continually overlaying each other, or breaking joints, the whole mass is strongly interwoven, and bound together. Wooden walls, composed of timbers covered with boards, are a common, but more perishable kind. They require to be constantly corered with a coating of a foreign substance, as paint or plaster, to preserve them fiom spontaneons decomposition. In some parts of France, and elsewhere, a kind of wall is made of earth, rendered compact by ramming it in unoulds or cases. This method is called building in pisé, and is much more durable than the nature of the material would lead us to suppose. Walls of all kinds are greatly strengthened by angles and curves, also by projections, such as pilasters, chimneys, and buttresses. These projections serve to increase the breadth of the foundation, and are always to be made use of in large buildings, and in walls of considerable length. The lintel, or beam, extends in a right line over a vacant space, from one column or wall to another. The strength of the lintel will be greater in proportion as its transverse, vertical diameter exceeds the horizontal, the strength being always as the square of the depth. The floor is the lateral continuation or connexion of beams by means of a covering of boards. The arch is a transverse member of a building, answering the same purpose as the lintel, but vastly exceeding it in strength. The arch, unlike the lintel, may consist of any number of constituent pieces, without impairing its strength. It is, howerer, necessary, that all the pieces should possess a uniform shape,-the shape of a portion of a wedge,-and that the joints, formed by the contact of their surfaces, should point towards a common centre. In this case, no one portion of the arch can be displaced or forced inward ; and the arch cannot be broken by any force which is not sufficient to crush the materials of which it is made. In arches made of common bricks, the sides of which are parallel, any one of the bricks might be forced inward, were it not for the adhesion of the cement. Any tuo of the bricks, however, constitute a wedge, by the disposition of their mortar, and cannot collectirely be forced inward. An arch of the proper form, when complete, is rendered stronger, instead of weaker, by the pressure of a considerable weight, provided this pressure be uniform. While building, however, it requires to be supported by a centring of the shape of its internal surface, until it is complete. The upper stone of an arch is called the key-stone, but is not more essential than any other. In regard to the shape of the arch, its most simple form is that of the semi-circle. It is, however, very frequently a smaller arc of a circle, and, still more frequently, a portion of an ellipse. The simplest theory of a arch supporting itself only, is that of Dr Hook. The arch, when it has only its own weight to bear, niay be considered as the inversion of a chain, suspended at each end. The chain hangs in such a form, that the weight of each link or portion is held in equilibrium by the result of two forces act ing at its extremities; and these forces, or tensions, 
are produced, the one by the weight of the portion of the chain below the link, the other by the same weight increased by that of the link itself, both of thein acting originally in a vertical direction. Now, supposing the chain inverterl, so as to constitnte an urch of the same form and weight, the relative situations of the forces will be the same, only they will act in contrary directions, so that they are compounded in a similar manner, and balance ench other on the same conditions. The arch thus formed is kenomimated a catenary arch. In common cases, it differs but little from a circular arch of the extent of about one thinl of a whole circle, and rising from the abut ments with an obliquity of about 30 elegrees from a perpendicnlar. But though the catenary arch is the be'st form for supporting its own weight, and also all additional weight which presses in a vertical direction, it is not the best form to resist lateral pressure, or pressure like that of fuids, acting equally in all directions. Thus the arches of bridges and similar structures, when covered with loose stones and earth, are pressed sideways, as well as vertically, in the same manner as if they supported a weight of fluid. In this case, it is necessary that the arch should arise more perpendicularly froin the abutment, and that its general figure should be that of the longitudinal segment of an ellipse. In small arches, in common buildings, where the disturbing force is not great, it is of litule consequence what is the shape of the curve. The ontlines may even be perfectly straight, as in the tier of hricks which we frequently see over a window. This is, strictly speakirg, a real arch, provided the surfaces of the bricls tend towards a common centre. It is the weakest kind of arch, and a part of it is necessarily superfluous, since no greater portion can nct in supporting a weight above it, that can be included between two curved or arched lines. Besides the arches already mentioned, varions others are in use. The acute or lancet arch, much used in Gothic archirecture, is described usually from two centres outside the arch. It is a strong arch for supporting vertical pressure. The rampant arch is one in which the two ends spring from unequal heights. The horse shoe or Moorish arch is described from one or more centres placed above the base line. In this arch, the lower parts are in danger of being forced inward. The ogee arch is concavo-convex, and therefore fit only for ornament. In describing arches, the apper surface is called the cxtrados, and the inner, the intrados. The springing lines are those where the intrados meets the abutments, or supporting walls. The span is the distance from one springing line to the other. The wedge-shaped stones, which form an arch, are sometimes called voussoirs, the uppermost being the key-stone. The part of a pier from which an arch springs is called the impost, and the curve formed by the upper side of the voussoirs, the archivolt. It is necessary that the walls, abutments, and piers, on which arches are supported, should be so firm as to resist the lateral thrust, as well as vertical pressure, of the arch. It will at once be seen, that the lateral or sideway pressure of an arch is very considerable, when we recollect that every stone, or portion of the arch, is a wedge, a part whose force acts to separate the abutments. For want of attention to this circumstance, important mistakes have been committed, the strength of buildings materially impaired, and their ruin accelerated. In some cases, the want of lateral firmness in the walls is compensated by a bar of iron stretched across the span of the arch, and connecting the abutments, like the tie-beam of a rowf. This is the case in the cathedral of Milan, and sou e other Gothic buildings." - In an arcade, or continuts-

- Cadell's Jour, tbrough Carniola und Italy, vol. ii. p. 77. tion of arches, it Is only necessary that the outer supports of the teruninal arches should be strong enough to resist horizontal pressure. In the intermediats. arches, the lateral force of each arch is counteracted by the opposing lateral force of the one contiguous to it. In bridges, however, where individual arches are liable to be destroyed by accident, it is elesirable tluat each of the piers should possess sufficient horizontal strength to resist the lateral pressure of the atjoining arches.-The vanlt is the lateral continuation of an arch, serving to cover an area or passage, and hearing the same relation to the urch that the walls do to the column. A simple vault is constructed on the principles of the arch, and distributes its pressure equally aloug the walls or abutments. A complex or groined vault is made by two vaults intersecting each other, in which case the pressure is thrown upon springing points, and is greatly increased at those points. The groined vault is common in Gothic architecture.- The dome, sometime's called cupola, is a concave covering to a building, or part of it, and may be either a segment of a sphere, of a spheroid, or of any similar figure. When built of stoue, it is a very strong kind of structure, even more so than the arch, since the tendency of each part to fall is counteracted, not only by those above and below it, but also by those on each side. It is only necessary that the constituent pieces should have a common form, and that this form should be somewhat like the frustum of a pyramid, so that, when placed in its situation, its four angles may point toward the centre, or axis, of the dome. During the erection of a dome, it is not necessary that it should be supported by a centring, until complete, as is done in the arch. Each circle of stones, when laid, is capable of supporting itself without aid from those above it. It follows that the dome may be left open at top, withont a ker-stone, and ret be perfectly secure in this respect, being the reverse of the arch. The dome of the Pantheon, at Rome, has been always open at top, and ret has stood unimpaired for nearly 2000 years. The upper circle of stones, though apparently the weakest, is nevertheless often inade to support the additional weight of a lantern or tower above it. In several of the largest cathedrals, there are two dome's, one within the other, which contribute their joint support to the lantern, which rests upon the top. III these buildings, the dome rests upon a circular wall, which is supported, in its turn, by arches upon massive pillars or piers. This construction is called build ing upon pendentives, and gives open space and ronin for passage beneath the dome. The remarks which have been made in regard to the abutments of the arch, apply equally to the walls immediately supporting a dome. They must be of sufficient thickness and solidity to resist the lateral pressure of the dome, which is very great. The walls of the Roman Puntheon are of great depth and solidity. In order that a dome in itself should be perfectly secure, its lower parts must not be too nearly vertical, since in this case, they partake of the nature of perpendicular walls, and are acted upon by the spreading force of the parts above them. The dome of St Panl's clurch, in London, and some others of similar construction, are bound with chains or hoops of iron, to prevent them from spreading at bottom. Domes which are nade or wood depend, in part, for their strength, on their internal carpentry. The Halle du Bled, in I'aris, had, originally, a wooden dome more than 200 fret in diameter, and only one foot in thickness. This has since been replaced by a dome of iron.- The roof is the most common and cheap method of covering buildings, to protect them from rain and other effects of the weather. It is sometimes flat, but more frequently oblique, in its shape. The fat or platform 
roof is the least advantageous for shedding rain, and is seldom used in northem countries. The pent roof, consisting of two oblique sides meeting at top, is the most common form. These roofs are made steepest in cold climates, where they are liable to be loaded with snow. Where the four sides of the roof are all oblique, it is denominated a hipped roof, and where there are two portions to the roof, of different obliquity, it is a curb, or mansard roof. In modern times, roofs are made almost exclusively of wood, though frequently covered with incombustible materials. The internal structure or carpentry of roofs is a subject of considerable mechanical contrivance. The roof is supported by rafters, which abut on the walls on each side, like the extremities of an arch. If no other timbers existed, except the rafters, they would exert a strong lateral pressure on the walls, tending to separate and overthrow them." To counteract this lateral force, a tie-beam, as it is called, extends across, receiving the ends of the rafters, and protecting the wall fiom the horizontal thrust. To prevent the tiebeam from sagging, or bending downward with its own weight, a king-post is erected from this beam, to the upper angle of the rafters, serving to connect the whole, and to suspend the weight of the bean. This is called trussing. Queen-posts are sometimes added, parallel to the king-post, in large roofs ; also various other connecting timbers. In Gothic buildings, where the vaults do not admit of the use of a tie-beam, the rafters are prevented from spreading, as in an arch, by the strength of the buttresses. In comparing the lateral pressure of a high roof with that of a low one, the length of the tie-beam being the same, it will be seen that a high roof, from its containing most materials, may produce the greatest pressure, as far as weight is concerned. On the other hand, if the weight of both be equal, then the low roof will exert the greater pressure ; and this will increase in proportion to the distance of the point at which perpendiculars, drawn from the end of each rafter, would meet. In roofs, as well as in wooden domes and bridges, the materials are subjected to an internal strain, to resist which, the cohesive strength of the material is relied on. On this account, beans should, when possible, be of one piece. Where this cannot be effected, two or more beams are connected together by splicing. Spliced beams are never so strong as whole ones, yet they may be made to approach the same strength, by affixing lateral pieces, or by making the ends overlay each other, and connecting them with bolts and straps of iron. The tendency to separate is also resisted, by letting the two pices into each other, by the process called scarfing. Mortises, intended to truss or suspend one piece by another, should be formed upon similar principles. Roofs in many instances, after being boarded, receive a secondary covering of shingles. When intended to be incombustible, they are covered with slates or earthen tiles, or with sheets of lead, copper, or tinned iron. Slates are preferable to tiles, being lighter, and absorbing less moisture. Metallic sheets are chiefly used for flat roofs, wooden domes, and curved and angular surfaces, which require a flexible material to cover them, or have not a sufficient pitch to shed the rain from slates or shing1es. Various artificial com. positions are occasionally used to cover roofs, the most

* The largest roof that has hitherto been built is suppos. ed to have been that of the riding-house at Moscow. It span was 235 feet, and the slope of the roof about 19 degrees. The principal support of this immense truss consisted in an arch of timber in three thicknesses, indented togetler, and atrapped and bolted with iron. The principal rafters and tie-beams were supported by several vertical pieces, notched to this arch, and the whole stiffened by diagonal braces. Tredgold's Corpentry common of which are mixtures of tar with lime, and sometimes with sand and gravel.-Styles of build. ing. 'The architecture of different counitries has been characterized by peculiarities in external form, and in modes of construction. These peculiarities, among ancient nations, were so distinct, that their structures may be identified even in the state of ruins; and the origin and era of each may be conjectured with tolerable accuracy. Before we proceed to describe architectural objects, it is necessary to explain certain terms, which are used to denote their different constituent portions. The architectural orders will be spoken or under the head of the Grecian and Roman styles, but their component parts ought previously to be understood. - The front or faćade of a building, made after the ancient models, or any portion of it, may present three parts, occupying different heights. The pedestal is the lower part, usually supporting a column. The single pedestal is wanting in most antique structures, and its place supplied by a stylobate. This stylobate is either a platform with steps, or a continuous pedestal, supporting a row of columns. . The lower part of a finished pedestal is called the plinth ;* the middle part is the die, and the upper part the cornice of the pedestal, or surbase.-The column is the middle part, situated upon the pedestal or stylobate. It is commonly detached from the wall, but is sometimes buried in it for half its diameter, and is then said to be engaged. Pilasters are square or flat columns, attached to walls. The lower part of a column, when distinct, is called the base; the middle, or longest part, is the shaft; and the upper, or ornamented part, is the capital. The height of columns is measured in diameters of the column itself, taken always at the base.-The entablature is the horizontal, continuous portion, which rests upon the top of a row of columns. The lower part of the entablature is called the architrave, or epistylium. The middle part is the frieze, which, from its usually containing sculpture, was called zophorus by the ancients. The upper, or projecting part, is the cornice. -A pediment is the triangular face, produced by the extremity of a roof. The middle, or flat portion, enclosed by the cornice of the pediment, is called the tympanum. Pedestals for statues, erected on the summit and extremities of a pediment, are called acroteria. An attic is an upper part of a building, terminated at top by a horizontal line, instead of a pediment. - The different mouldings in architecture are described from their sections, or from the profile which they present, when cut across. Of these, the torus is a convex moulding, the section of which is a semi-circle, or nearly so. The astragal is like the torus, but smaller. The ovolo is convex, but its outline is only the quarter of a circle. The echinus resembles the orolo, but its outline is spiral, not circular. The scotia is a deep, concave moulding. The cavetto is also concave, and occupying but a quarter of a circle. 'The cymatium is an undulated moulding, of which the upper part is concave, and the lower convex. The ogee or talon is an inverted cymatiun. The fillet is a small, square, or flat moulding. + - In architectural measurement, a diameter means the width of a column at the base. A module is half a diameter. A minute is a sixtieth part of a diameter. In representing edifices by drawings, architects make use of the plan, elevation, section, and pcrspective. The plan is a map, or design, of a horizontal surface, showing the iclunographic projection, or ground-work,

* The name plinth, in its general sense, is applied to any square, projecting basis, such as those at the bottom of walls, and under the base of columns.

+ By a singular mixture of derivations, the Greek, Latin, Italian, French, and English languages aro laid under contrilution for the teclnical terms of architecture. 
with the relative position of walls, colunns, doors, Sc. The elevation is the orthographic projection of a frout, or vertical surface; this being represented, not as it is actually seen in perspective, but as it would appear if seen from an infinite distance. 'The section slows the interior of a building, supposing the part in front of an intersecting plane to be removed. 'The perspective shows the building as it actually appears to the eye, subject to the law's of scenographic perspective. The tliree former are used by architects for purposes of admeasurennent; the latter is used also by painters, and is capnble of bringing more than one side into the same view, as the eye actually perceires them.-As the inost approved features in modern architecture are derived from buildings which are more or less ancient, and as many of these buildings are now in too dilapidated a state to be easily copied, recourse is had to such imitative restorations, in drawings and models, as can be made out from the fragments and ruins which remain. In consequence of the known simplicity and regularity of most antique edifices, the task of restoration is less difficult than might be supposed. The ground-work, which is comnonly extant, sliows the length and breadth of the building, with the position of its walls, doors, and columns. A single column, whether standing or fallen, and a fragment of the entablature, furnish data from which the remainder of the colonnade, and the lieight of the main body, can be made out. A single stone from the cornice of the pediment is often sufficient to give the angle of inclination, and, consequently, the height of the roof. In this way, beautiful restorations are obtained of structures, when in so ruinous a state as scarcely to have left ene stone upon another. - We come now to the different styles of architecture.-I. Egyptian style. In ancient Egrpt, a style of building prevailed, more massire and substantial than any which has succeeded it. The elementary features of Egyptian architecture were chiefly as follows: 1. Their walls were of great thickness, and sloping on the outside. This feature is supposed to have been derived from the mud walls, mounds, and carems of their ancestors. 2. The rcofs and covered ways were flat, or without pediments, and composed of blocks of stone, reaching fiom one wall or column to another. The principle of the arch, although known to them, was seldom, if ever, employed by them. 3. Their columns were 1. umerous, close, short, and very large, being some$t$ mes ten or twelve feet in diameter. They were cenerally without bases, and had a great variety of capitals, from a simple square block, ornamented with hieroglyphics, or faces, to an elaborate composition of palm-leaves, not unlike the Corinthian capital. See this illustrated in the view of the Portico of the Great Temple at Tentyra, given in Plate VI.) 4. They used a sort of concare entablature, or cornice, composed of vertical flutings, or leaves, and a winged globe in the centre. 5. Pyramids, well known for their prodigious size, and obelisks, composed of a single stone, often exceeding seventy feet in lieight, are structures peculiarly Egsptian. (See examples of obelisks in the view of the entrance to Luxor, given in Plate VI.) 6. Statues of enormous size, sphinxes carved in stone, and sculptures in outline of fabulous deities and animals, with innumerable hieroglyphies, are the decorative objects which belong to this style of architecture. The architecture of the ancient Hindoos appears to have been derived from the same original ideas as the Egyptian. The most remarkable relics of this people are their subterraneous temples, of vast size and elaborate, workmanship, carved out of the solid rock, at Elephanta, Ellora, and Salsette. (See Plate VI.)- wandering shepherds of Asia, appear to have lirel from time immemorial in tents, a kind of habitation adapted to their erratic life. The Chinese have unade the tent the elementary feature of their architecture; and of their style any one may form an idea, by inspecting the figures which are depicten upon common China ware. Chinese roofs are concave on the upper side, as if made of canvass, instead of wood. A Chinese portico is not unlike the awnings spread over shop windows in summer time. The verandah, sometimes copied in dwelling-houses, is a structure of this sort. 'The Chinese towers and pagados have concave roofs, like awnings, projecting over their several stories. (See Plate V I. for illustration of a Chinese Pagoda.) 'The lightness of the style used by the Chinese leads them to build with wood, some. times with brick, and seldom with stone.-111. The Grecian style. Grecian arclitecture, from which have. been derived the most splendid structures of later ages, had its origin in the wooden lint or cabin, formed of posts set in the earth, and covered with transverse poles and rafters. Its beginnings were very simple, being little more than imitations in stone of the original posts and beams. By degrees, these were modified and decorated, so as to give rise to the distinction of what are now called the orders of architecture.-By the architectural orders are understood certain modes of proportioning and decorating the column and its entablature. They were in use during the best days of Greece and Rome, for a period of six or seven centuries. They were lost sight of in the dark ages, and again revired by the Italians, at the time of the restoration of letters. The Greeks had three orders, called the Doric, Ionic, and Corinthian. These were adopted and molified by the Romans, who also added two others, called the Tuscan and Composite. (See Plate V.)-The Doric is the earliest and most massive order of the Greeks. It is known by its large columns with plain capitals; its triglyphs resembling the ends of beans, and its mutules corresponding to those of rafters. The column, in the examples at $A$ thens, is about six diameters in height. In the older examples, as those at Prostum, it is but four or fire. The shaft had no base, but stood directly on the stylobate. It had twenty flutings, which were superficial, and separated by angular edges. The perpendicular outline was nearly straight. The Doric capital was plain, being formed of a few annulets or rings, a large echinus, and a flat stone at top called the abacus. The architrave was plain; the frieze was intersected by oblong projections called triglyphs, divided into three parts by vertical furrows, and ornamented beneath by gutta, or drops. Thie spaces between the triglyphs were called metopes, and commonly contained sculptures. The sculptures representing Ceutaurs and Lapithæ, carried by lord Elgin to London, were metopes of the l'arthenon, or temple of Minerva, at Athens. The cornice of the Doric order consisted of a few large mouldings, having on their under side a series of square, sloping projectioes, resembling the ends of rafters, and called mutules. These were placed orer both triglyphs and metopes, and were ornamented, on their under side, with circular guttce. The best specimens of the Doric order are found in the Parthenon (see Plate VI.), the Propylæa, and the temple of Theseus, at Atliens. The Ionic is a lighter order than the Doric, its column being eight or nine diameters in height. It had a base often composed of a torus, a scotia, and a second torus, with intervening fillets. This, is called the Attic base. Others were used in different parts of Greece. The shaft had twenty-four, or more, flutings, which were narrow, as deep as a semicircle, an separated by a fillet or square edge. The capital of 
called volutes, occupying opposite sides, and supporting an abacus, which was nearly square, but moulded at its edges. These volutes have been considered as copied from ringlets of hair, or perhaps from the horns of Jupiter Ammon. When a column made the angle of an edifice, its volutes were placed, not upon opposite, but on contiguous sides, each fronting outward. In this case, the volutes interfered with each other at the corner, and were obliged to assume a diagonal-direction. The Ionic entablature consisted of an architrave and frieze, which were continuous or unbroken, and a cornice of various successive mouldings, at the lower part of which was often a row of dentels, or square teeth. The examples at Athens, of the Ionic order, are the temple of Erectheus (see Plate VI.), and the temple on the Ilissus, which was standing in Stuart's time, seventy years since, but is now extinct. - The Corinthian was the lightest and most decorated of the Grecian orders. Its base resembled that of the Ionic, but was more complicated. 'The shaft was often ten diameters in height, and was fluted like the Ionic. The capital was shaped like an inverted bell, and covered on the outside with two rows of leaves of the plant acanthus, ${ }^{*}$ above which were eight pairs of small volutes. Its abacus was moulded and concave on its sides, and truncated at the corners, with a flower on the centre of each side. The entablature of the Corinthian order resembled that of the Ionic, but was more coinplicated and ornamented, and had, under the cornice, a row of large, oblong projections, bearing a leaf or scroll on their under side, and called modillions. No vestiges of this order are now found in the remains of Corinth, and the most legitimate example at Atlens is in the choragic monument of Lysicrates (see Plate VI.) The Corinthian order was much employed in the subsequent structures of Rome and its colonies._Caryatides. The Greeks sometimes departed so far from the strict use of the orders, as to introduce statues, in the place of columns, to support the entablature. Statues of slaves, heroes, and gods appear to have been employed, occasionally, for this purpose. The principal specimen of this kind of architecture, which remains, is in a portico called Pandroseum, attached to the temple of Erectheus, at Athens, in which statues of Carian fenales, called Caryatides, are substituted for columns (see Plate V I.) One of these statues has been carried to London.-Grecian temple. The most remarkable public edifices of the Greeks were their temples. These beirig intended as places of resort for the priests, rather than for the convening of assemblies within, were, in general, obscurely lighted. Their form was commonly that of an oblong square, having a colonnade without, and a walled cell within. The cell was usually without windows, receiving its light only from a door at the end, and sometimes from an opening in the roof. The part of the colonnade which formed the front portico, was called the pronaos, and that which formed the back part, the posticus. The colonnade was subjcct to great variety in the number and disposition of its columns, from which Vitruvius has described seven different species of temples. These were, 1 . The temple with ante. In this, the front was composed of pilasters, called anta, on the sides, and two columns in the middle. 2. The prostyle. This had a row of columns at one end only. 3. The amphiprostyle, having a row of columns at each end. 4. The peripteral temple. This was surrounded by a single row of columns, having six in front and in rear, and elcven, counting

- The origin of the Corinthian capital has been ascribed to the sculptor Callimachus, who is said to have copied it from a basket accidentally enveloped in leaves of acanthus, A more probable supposition traces its origin to some of the Egyptian capitals, which it certainly resembles. the angular columns, on each side. 5. The diptercel, with a double row of columns all round the cell, the front consisting of eight. 6. The psendo dipteral differs from the dipteral, in having a single row of columns on the sides, at the same distance from the cell as if the temple had been dipteral. 7. The hypathral temple had the centre of its roof open to the sky. It was colonnaded without, like the dipteral, but had ten columns in front. It had also an internal colonnade, called peristyle, on both sides of the open space, and composed of two stories or colonnades, one above the other.-Temples, especially small ones, were sometimes made of a circular form. When these were wholly open, or without a cell, they were called monopteral temples. When there was a circular cell within the colonnade, they were called peripteral.* (Ground plans of the above temples will be found in Plate VI., Figs. 1 to 9.)The theatre of the Greeks, which ivas afterwards copied by the Romans, was built in the form of a horse-shoe, being semicircular on one side, and square on the other. The semicircular part, which contained the audience, was filled with concentric seats, ascending from the centre to the outside. In the middle, or bottom, was a semicircular floor, called the orchestra. The opposite, or square part, contained the actors. Within this was erecterl, in front of the audience, a wall, ornamented with columns and sculpture, called the scena. The stage, or floor, between this part and the orchestra, was called the proscenium. Upon this floor was often erected a movable wooden stage, called, by the Romans, pulpitum. The ancient theatre was open to the sky, but a temporary awning was erected to shelter the audience from the sun and rain.-Grecian architecture is considered to have been in its greatest perfection in the age of Pericles and Phidias. The sculpture of this period is admitted to have been superior to that of any other age; and although architecture is a more arbitrary art than sculpture, yet it is natural to conclude, that the state of things, which gave birth to excellence in the one, must have produced a corresponding power of conceiving sublimity and beauty in the other. Grecian architecture was, in general, distinguished by simplicity of structure, fewness of parts, absence of arches, lowness of pediments and roofs, and by decorative curves, the outline of which was a spiral line, or conic section, and not a circular arc, as afterwards adopted by the Romans. -IV. Roman style. Roman architccture had its origin in copies of the Greek models. All the Grecian orders were introduced into Rome, and variously modified. Their number was augmented by the addition of two new orders-The Tuscan and the Composite.-Theorder derived from the ancient Etruscans is not unlike the Doric deprived of its triglyplrs and mutules. It liad a simple base, containing one torus. Its column was seven diameters in lieiglit, with an astragal below the capital. Its entablature, somewhat like the Ionic, colssisted of plain, running surfaces. There is no vestige of this order among ancient ruins, and the modern examples of it are taken from the descriptions of Vitruvius. - The Romans modified the Doric order by increasing the lıeight of its column to eight diameters. Instead of the echinus, which formed the Grecian capital, they employed the ovolo, with an astragal and neck below it. They placed triglyphs over the centre of columns,

* The intercolumniation, or distance between the columns, according to Vitruvius, was differently arranged under the following names:-In the pycnostyle, the coJumns were a diameter and a half apart; in the systyle, they were two diameters apart; in the diastyle, three; in the arcostyle, more than three; in the eustyle, two and a quarter. 
not at the corners, and used horizontal mutules, or introluced foreign ormaments in their stead. The theatre of Marcellus lias examples of the Roman Doric.-The Romans diminished the size of the volutes in the Ionic orler. They also introducerl a kint of Ionic capital, in which there were four pairs of dingonal volutes, instend of two pairs of parallel ones. This they usually adderl to parts of some other capital; but, at the preseut day, it is often used alone, under the name of modern Ionic. -The Composite order was made by the Romans out of the Corinthian, simply by combining its capital with that of the dingonal, or modern Ionic. Its best example is found in the arch of 'Titus (see Plate VI.) The fuvourite order, however, in Rome and its colonies, was the Corinthian, and it is this order which prevails among the ruins, not only of liome, but of Nisines, Pola, PaImyra and I3albec.-The temples of the Romans sometimes resembled those of the Greeks, but of ten lifferel from them. The Puntheon, which is the most perfectly preserved temple of the Augustan age, is a circular building, lighted only from an aperture in the dome, and having a Corinthian portico in front. The amphitheatre differed from the theatre, in being a completely circular, or mather elliptical building, filled on all sides with ascending seats for spectators, and leaving only the central suace, called the arena, for the combatants and public shows. The Coliseum is a stupendous structure of this kind. The aqueducts were stone canals, supported on massive arcades, and conveying large streams of water, for the supply of cities. The triumphal arches were commonly solid, oblong structures, ornamented with sculptures, and open with lofty arches for passengers below. The basilica of the Romans was a hall of justice, used also as an exchange, or place of meeting for merchants. It was lined on the inside with colonnades of two stories, or with two tiers of columns, one over the other. The earliest Christian churches at Rome were sometimes called basilica, from their possessing an internal colonnade. The monumental pillars were towers in the shape of a column on a pedestal, bearing a statue on the sunmit, which was approached by a spiral staircase within. Sometimes, however, the column was solid. The therma, or baths, were vast structures in which multitudes of people could hathe at once. They were supplied with warm and cold water, and fitted up with numerous rooms for purposes of exercise and recreation.-In several particulars, the Roman copies differed from the Greek models on which they were founded. The stylobate or substructure, among the Greeks, was ustully a plain succession of platforms, coustituting an equal access of steps to all sides of the building. Among the Romans, it became an elevated structure, like a continued pedestal, accessible by steps only at one end. The spiral curve of the Greeks was exchanged for the geometrical circular arc, as exemplified in the substitution of the ovolo for the echinus in the Doric capital. The changes in the orders have been already mentioned. After the period of Adrian, Roman architecture is considered to have been on the decline. Among the marks of a deteriorated style, introduced in the later periods, were columns with pedestals, columns supporting arches, convex friezes, entablatures squared so as to represent the continuation of the columns, pedestals for statues projecting from the sides of columns, niches covered with little pediments, \&c.-V. Grcco-Gothic style. After the dismemberment of the Roman empire, the arts degenerated so far, that a custom became prevalent of erecting new buildings with the fragments of old ones, which were dilapidated and torn down for the pur. pase. This gave rise to an irregular style of building, which continued to be imitated, especially in Italy, during the dark ages. It consisted of ficcian and Roman details, combined under new forms, and piled up into structures wholly unlike the antique originals. Hence the uames Greco.Giothic and Romanesque architecture have been given to it. It frequently contained arches upon colunms, forming successive arcades, which were aecumnlated above each other to a great height. The effect was sometimes imposing. The cathedral (sce l'late VII.) and leaning tower, at Pisa, and the church of St Mark, at Venice, are cited as the best specimens of this style. 'The Saxon architecture, used anciently in Eugrand, has some things in common with this style. Two examples of this will be found in the doorways given in Plate VII.-VI. Saracenic, or Moorish stylc. The edifices erected by the Moors and Saracens in Spain, Egspt, and Turkey are distinguished, anong oth'r things, by a peculiar form of the arch. This is a curve, conslituting more than half of a circle or ellipse. This construction of the arch is unphilosophical, and comparatively insecure. A similar peculiarity exists in the domes of the Oriental mosques, which are sometimes large segments of a sphere, appearing as if inflated, and, at other times, concavo-convex in their ontline, as in the mosque of Achmet. The minarct is a tall, slender tower, peculiar to Turkish architecture. A peculiar flowery decoration, called arabesque, is common in the Moorish buildings of Europe and $\Lambda$ frica. Some distinguish the Arabian style, formed after the Greek, and the Moorish, formed after the remains of the Roman buildings in Spain, which seems a good division. With regard to the latter, nobody can behold the remains of the Moorish buildings at Grenada, Seville, and Cordova, without admiration. (See Plate VII.) The Arabian style is particularly distingnished by light decorations and splendour.-VII. Gothic style. By this style is generally understood what is strictly called the modern Gothic, which flourished after the destruction of the Gothic kingdom by the Arabians and Moors. The old Gothic style, which probably originated under Theodoric, king of the Ostrogoths, during whose reign in Italy the Romans, with little sense of beauty, imitated the ancient Roman style, is coarse and heavy. The style now called Gothic exhibits a wonderful grandeur and splendour, and, at the same time, the most accurate execution; yet it is only in modern times that its great master-pieces, as the minster of Strasburg, the cathedral of Cologne, the minster at York, \&ic., have begun to be justly appreciated. (See Plate VII.) Very great attention is, at present, paid to the study of this style. Its principle scems to have originated in the imitation of groves and bowers, under which the Druicls performed their sacred rites. Its striking characteristics are, its pointed arches, its pinnacles and spires, its large buttresses, clustered pillars, vaulted roofs, profusion of ornaments, the general predominance of the perpendicular over the horizontal, and, in the whole, its lofty, bold spirit. As the common place for the display of Gothic architecture has been in ccclesiastical edifices, it is necessary to understand the usual plan and construction of these buildings. A church or cathedral, is commonly built in the form of a cross, having a tower, lantern, or spire, erected at the place of intersection. The part of the cross situated toward the west, is called the nave. The opposite, or eastern part, is called the choir, and within this is the chancel. The transverse portion, forming the arms of the cross, is called the transept. Any high building erected above the roof is called a steeple; if square-topped, it is a tower ; if long an! acute, a spire; and, if short and light, a lantern. Towers of great height in proportion to their diameter are called turrets. The walls of Gothic churches are 
supported, on the outside, by lateral projections, extending from top to bottom, at the corners, and between the windows. These are called buttresses, and they are rendered necessary to prevent the walls from spreading under the enormous weight of the roofs. On the tops of the buttresses, and elsewhere, are slender pyramidal structures, or spires, called pinnacles. These are ornamented on their sides with rows of projections, appearing like leaves or buds, which are named crockets. The summit, or upper edge of a wall, if straight, is called a parapet; if indented, a battlement. Gothic windows were commonly crowned with an acute arch. They were long and narrow, or, if wide, were divided into perpendicular lights by mullions. The lateral spaces on the upper and outer side of the arch, are calted spandrills; and the ornaments in the top, collectively taken, are the tracery. An oriel, or bay window, is a projecting window. A wheel, or rose window, is large and circular. A corbel is a bracket, or short projection from a wall, serving to sustain a statue, or the springing of an arch. Gothic pillars or columns are usually clustered, appearing as if a number were bound together. The single shafts, thus connected, are called boltels. They are confined chiefly to the inside of buildings, and never support any thing, like an entablature. Their use is to aid in sustaining the vaults under the roof, which rest upon them at springing points. Gothic vaults intersect each other, forming angles, called groins. The parts which are thrown out of the perpendicular, to assist in forming them, are the pendentives. The ornamented edge of the groined vault, extending diagonally, like an arch, from one support to another, is called the ogyve. The Gothic tern gable indicates the erect end of a roof, and answers to the Grecian pediment, but is more acute. The Gothic style of building is more imposing, admits of richer ornaments, and is more difficult to execute, than the Grecian. This is because the weight of ite vaults and roofs is upheld, at a great height, by supporters acting at single points, and apparently but barely sufficient to effect their object. Great mechanical skill is necessary in balancing and sustaining the pressures; and architects, at the present day, find it often difficult to accomplish what was achieved by the builders of the middle ages.-In edifices erected at the present day, the Grecian and Gothic outlines are commonly employed to the exclusion of the rest. In choosing between them, the fancy of the builder, more than any positive rule of fitness, must direct the decision. Modern dwelling houses have necessarily a style of their own, as far as stories and apartments, and windows and chimneys, can give them one. No more of the styles of former ages can be applied to them, than what may be called the unessential and decorative parts. In general, the Grecian style, from its right angles and straight entablatures, is more convenient, and fits better with the distribution of our common edifices, than the pointed and irregular Gothic. The expense, also, is generally less, especially if any thing like thorough and genuine Gothic is attempted. But the occasional introduction of the Gothic outline, and the partial employment of its ornamients, has undoubtedly an agreeable effect, both in public and private edifices; and we are indebted to it, among other things, for the spire, a structure exclusively Gothic, which, though often misplaced, has become an object of general approbation, and a pleasing landmark to cities and villages. (For further information, see, among other works, Bigelow's Technology, Boston, 1829, p. 112-152, from which the above article is chiefly extracted. The illustrative plates we have gathered from various sources.)

Architecture, history of.' The first habitations of men were such as nature afforded, with but little labour on the part of the occupant, and sufficient to satisfy his simple wants, -huts, grottos, and tents. But as soon as men rose above the state of rude nature, formed societies, and cultivated the soil, they began to build more durable and more commodious habitations. They wrought the materials with more care, fitted the parts together more closely and neatly, prepared bricks of clay and earth, which they first dried in the air, and afterwards baked by the fire; they smoothed stones, and joined them, at first, without cement. After they had learned to build houses, they began to erect temples for their gods, who first dwelt with them in caverns, huts, and tents. These temples were larger and more splendid than the habitations of men. Thus architecture became a fine art, which was first displayed on the temples ; afterwards, on the habitations of princes, and public buildings, and, at last, with the progress of wealth and refinement, became a universal want of society: 'The haughty palace appeared in the place of the wretched hut of reeds and clay; the rough trunk was transformed into a lofiy column, and the natural vault of a cavern into the splendid Pantheon, Colonnades, halls, courts, and various ornaments now appeared. Stieglitz contends that the fundamental forms of the ancient Egyptian and Grecian architecture probably originated in structures of stone, and not from those of wood, as Hirt maintains in his History of the Architecture of the Ancients. 'The earliest buildings of the Indians were modelled on the structure of caverns. To the most ancient nations known to us, among whom architecture had made some progress, belongthe Babylonians, whose most celebrated buildings were the temple of Belus, the palace and the hanging gardens of Semiramis ; - the Assyrians, whose capital, Nineveh, was rich in splendid buildings ; - the Phœnicians, whose cities, Sidon, Tyre, Aradus, and Sarepta, were adorned with equal magnificence ;-the Israelites, whose temple was considered as a wonder of architecture; -and the Syrians and the Philistines. No architectural monument of these nations has, however, been transmitted to us. But we find subterraneous temples of the Hindoos, hewn out of the solid rock, upon the islands Elephanta and Salsetta. Of the Persian architecture, the ruins of Persepolis still remain; of the Egyptian, obelisks, pyramids, temples, palaces, sepulclires; of the Etruscan, some sepulchres and portions of city walls. - The character of this elder architecture was immovable firmness, gigantic height, prodigal splendour, which excited admiration and astonishment, but comparatively little pleasure. The Greeks were the first who passed from the rough and gigantic to a noble simplicity and dignity. 'The Doric order of columns characterizes this first period. The greatest masters, Phidias, Ictinus, Callicrates, and others, encouraged and supported by Pericles, emulated each other, as soon as peace at home and abroad was restored. The beautiful temple of Minerra was erected upon the Acropolis of Athens, also the Propylæum, the Odeum, and other splendid buildings. An equal taste for the arts arose in the Peloponnesus, and in Asia Minor, A high degree of simplicity was united with majestic grandeur and elegance of form. The beauties of architecture were displaged not only in temples, but also in theatres, odeums, colonnades, market-places, and gymnasia. The Ionic and Corinthian columns were added to the Doric. At the end of the Peloponnesian war, the perfection of architecture was gone. A noble simplicity had given place to excess of ornament. This was the claracter of the art at the time of Alexander, who founded a number of new cities. But a strict regularity hitherto prevailed in the midst of this overcharged decoration. Afit $r$ the death of Alexander, $323 \mathrm{~B}$. C., the increasing lote of gaudy splendour hastened the decline of the art 
more and more. In Greece, it was afterwanls but little cultivated, and, in the edifices of the Selencidar. in $A$ sia, and of the Ptolemies in Figrot, an impure taste prevailed. The Romans liad no temples, or similar public edifices, equal to the (irecinn masterpieces, although they had early applierl their industry to other ohjects of architecture, viz, to aqueducts anil sewers. The crpitol and the temple of the capitoline Jupiter were erecterl by Etruscan architects. But. stous after the second Punic war, 200 B. C., they became acquainted with the Greeks. Sylla was the first who introduced the Grecian architecture to Rome; and lie, as also Marins and Cresar, erecterl large temples in this and in other cities. Hut under Augustus thewart first rose to the perfection of which it was capable at that time. He encouraged the Greek artists, who had exchanged their country for Rome, and erected, partly froin policy, many splendid works of architecture. A grippa built temples (the Pantheon), aqueducts, and theatres. Private habitations were adorned with colunins and marble. Splendid villas were built, of which the rich Romans often possessed several. The interior was adorned with works of art, obtained from Greece. The walls were covered with thin marble plates, or were painted, and divided into panes, in the middle of which were represented mythological or historical subjects. They were also surrounderl with the most elegant borders. These borders were what we call grotesgues. Almost all the successors of Augustus embellished the city more or less, crected splendid palaces and temples, and adornel, like Atrian, even the conquered countries with them. Constantine the Great trunsferred the imperial residence from Rome to Constantivople, so that notliing more was done for the embellishment of Rome. - But, at the time when the Romans receivel the art from the Greeks, it had already lost, anong the latter, its perfection and purity. In Rome, it rose, indeed, in a short time, to its former height, but soon degenerated, with the continsally increasing magnificence of the emperors, into extravagance of ornament. About this time, the Roman or Composite column originated, which was employed in temples and splendid buildings. In the time of Nero, whose golden palace is celebrated, the exterior and interior of the buildings were profusely adorned. Adrian, who encouraged artists as much as possible, was not able to restore a noble and simple taste in architecture. Instead of imitating the beautiful models already existing, the endeavour, in his time, was to invent new styles, and to embellish the beautiful more and more. Now originated the many curved and twisted ornaments, the high pedestal under the columns, the numerous bass reliefs on the exterior of buildings, the flutings of the columns, the reduction of the same according to a curred line, the coupled columns, the reduced pilasters behind the columns, the small columns between larger ones, the round and cut pediments, and the concave friezes. Thus the art was practised from the time of Vespasian to the reign of the Antonines. Works were producer, in this period, which may still be considered as master pieces, but which want the great and noble style of the Greeks. In the provin. ces, taste became still more corrupt. Architecture declined continually after the Antonines; more ornaments were continually added, which is proved partirularly by the arch of the goldsmiths, so called, in l?une. Alexander Severus, indeed, himself a connoisseur, dit something for its improvement, but it rapidly declined under his successors. The buildings of this time are either overcharged with mean and trifling orraments, as those of Palmyra, erected about $260 \mathrm{~A}$ : D., or they border on the rude, like those of Rome, ericted under Constantine. Little was dóne, unkler the following emperum, for the embellishment of the cities, un accomnt of the continually disturbed - state of the empire. Justinian, lowever, buit mucli. His principal edifice was the church of St Sophia, at Constantinople. The beautiful works of ancient arclitecture vere almost entirely destroycyl by the Gotlıs, Vandals, nut other barbarians, in Italy, Spain, Gruece, Asia, and Africa; and whatever escaped de. struction remained in neglect. 'Theodoric, king of the Ostrogoths, a frieud of the arts, endeavoured to preserve and restore the ancient buildings, and even cructed several new ones, the ruius of which are still to be seen in Ravenua and Verona. We may consider this perial as the era of the origin of molern art. We see a new style taking place of the ancient classical architecture, and eventually extending as far as the conquests of the Goths, through Italy, France, Spain, Portugal, a part of Germany, and even to Fingland, whither, however, the Goths did not penetrate. Wliether this inodern architecture, which is called Gothic, originated from the Germans, is not decided. We find, in the buijdings erected under 'Theodoric, notling attempted but simplicity, strength, and the display of nitional taste in their exterior (the interior is unknown to us). But the buildings erected during the Lombard dominion in Italy (from 568), and all the monastic architecture of that time, have been erroneously called Gothic. Since the error was perceived, it has been distinguished, by the name of the old Gothic, from the proper Gotlic, which is called the modern Gothic. "Tlue Lombards entertained no respect for antiquities, anc] neither spared nor preserved them. Whatever they built was tasteless and faulty. On the exterior of their churches they placed small semicircular columns; and small pillars in a row along the cornice of the pediments; in the interior, coarse pillars united by semicircular arches; the small windows and doors were fnished with senicircles; the columns, capitals and arches were often overlaid with incongruous sculpture; the roofs of the naves covered with beams and boards, which were afterwards changed into arches, and, on this account, often required arclied buttresses on the outside. This Lombard style is architecture clearly proves the decline of scierce and art. It was employed, in the 17th century, in Pavia, the chief city of the Lombard kingdom, in the erection of the churclies of St John and Si Michael ; at Parma, in the church of St John; at Bergamo, in the church of St Julia ; in the chapel of Alteriotting, in Bavaria ; in the castle of Nuremberg, in the Scottish church at Ratisbon, \&c. The architects driven from Constantinople (Byzantium) were the first who combined with it the use of the lonic pedestals and columns, provided with capitals formed according to their own taste, among which were twisted ones. In this Lombard-Brzantine style were erected the cathedrals of Bamberg, Worms and Mentz, also the church Miniato al Monte, near Florence, and the most ancient part of the minster of Strasburg. Cupolas were afterwa rds added, as used in the East, and these, as well as thr tasteless capitals, and the many slender pillars ant minarets, of which we often see two rows, one on another, indicate the proper Brzantine or Oriental style of architecture. In this style were erected, besides the church of St Sophia in Constantinople, ant others, the church of St Mark, in Verice, the Baptisterium and the cathedral of Pisa, and the church of St Vitalis, in Rarenna. The Normans, who hat settled in Sicily, built the cathedral of Messina upon the foundation of an old temple, - a huge but tastel ess edifice, in which, by means of the changes made in different centuries, we may observe, at the sane time. the rise and fall of the art. The Vandals, Alaus, Suevi and Visigoths had penetrated into Spain ani Portugal : the Arabs and Moors expelled them in 
the 8th ceutury, and destroyed the kingdon of the they gave to the wirdows an extraordinary height, Goths. The Mussulman conquerors had, at that and adorned the building itself with statues. This time, almost exclusive possession of the arts and style, in which many churches, convents, and abbers stiences. Saracen architects rose in Greece, Italy, Sicily, and other countries: after some time, many Christians, particularly Greeks, joined them, and formed together a fratemity, who kept secret the rules of their art, and whose members recognised one another by particular signs. (See Freemasons.) At this period, three different styles of architecture prevailed-the Arabian, a peculiar stylc, formed after Greek models; the Moorish, which originated in Spain, out of the remains of Roman edifices; and the modern Gothic, which originated in the kingdom of the Visigoths, in Spain, through the mixture of the A rabianand Moorish architecture, and flourished from the 11th until the 15th century. The two first styles differ but little from each other : the Moorish style is principally distinguished from the Arabian by arches in the form of a horse-shoe. But the Gothic, or old German, is very different. Swinburne mentions the following marks of distinction: The Gothic arches are pointed, the Arabian, circular : the Gothic churches have pcinted and straight towers; the mosques terminate in globes, and have here and there minarets, covered with a ball or a cone: the Arabian walls are adorned with Mosaic and stucco, which we find in no ancient church in the Gothic style. The Gothic columns often stand united in groups, over which is placed a very low entablature, upon which arches are erected; or the arches stand immediately upon the cupitals of the columns. The Arabian and Moorish columis are single, and if, by chance, they are placed close together, in order to support a very heavy part of the building, they never touch one another; but the arches are supported by a stout and thick arch below. If, in an Arabian building, four columns are united, it is by a low, square wall at the bottom, between the columns. The Gothic churches are extremely light buildings : they have large windows, often with variegated panes. In the Arabian mosques, the ceiling is mostly low ; their windows are of less height, and often covered with carvings; so that the light is received less through them than through the cupola and the opened doors. The entrance of a Gothic clurch is a deep arch, diminishing towards the interior of the huilding, and adorned on the side-walls - witl statues, columns, niches, and other ornaments; but those of the mosques, and of other Arabian, and even Moorish buildings, are shallow, and made in the same manner as doors are at present. Besides, Swinburne observes, that, among the different Arabian capitals which he saw, he found none resembling, in design and arrangement, those which we fiud in the Gothic churches of England and France. The Moorish architecture appears in all its splendour in the ancient palace of the Mohammedan monarchs at Grenada, which is called the Alhambra, or red-house, and which resembles more a fairy palace than a work of human hands. The character of the Arabian architecture was lightness and splendour. Rich ormaments, and lightness in the single parts, render it agreeable to the eye. The modern Gothic architecture, which originated in the attempts of Byzantine artists to cover the coarseness and heaviness of the old Gothic by an appearance of lightness, excites the imagination by its richly adomed arches, its distant perspective, and its religious dimness, produced by its painted windows. It retained, from the old Gothic architecture, the ligh, bold arches, the firm and strong walls; but it disguised them under rolutes, flowers, niches, little pierced towers, so that they appear to be light and weak. Afterwards, the archilects went still farther, and pierced the large, high towers, so that the stairs appear hanging in the air; were erected, was formed in Spain, and thence ex Germans were unacquairited with architecture until the time of Charlemagne. He introduced from Italy to Germany the Byzantine style, then common. Afterwards, the Arabian architecture had some influence upon that of the western nations; for the German art shows its characteristics in the pointed arches, and the buttresses, \&c. This was united with the Byzantine style, to which, in general, they still adhered, and thus originated a mixed style, which maintained itself until the middle of the 13th century. Then began the modern Gothic or German style, which we may also call the romantic, since it was formed by the romantic spirit of the middle ages. Growing up in Germany, it obtained its perfection in the towers of the minster of Strasburg (see Minster). in the cathedral of Cologne, in the church of St Stephen in Vienna, the cathedral of Erfurt, the church of St Sebaldus in Nuremberg, the church of St Elizabeth in Marburg, \&c., and extended itself from thence to France, Britain, Spain, and Italy. The German architecture shows also the influences of climate and religion, particularly in the churches. The slender columus, always united in groups, rise to a lofty height, resembling the giants of the grove, in whose dark shade the ancient Teuton used to build his altar. In the chiaro oscuro of the dome, the soul, divested of earthly thoughts, must collect itself, and rise, like the dome, to its Maker. The decorations of the ancient Christian churches are by no means an accidental ornament. They speak a figurative, religious language; and at the tabernacle, or ciborium, over the altar, where the pyx is kept, the whole temple is presented, in miniature, to the view of the beholder. In these edifices, every one must admire the accurate proportions, the bold yet regular construction, the unwearied industry, the grandeur of the bold masses on the exterior, and the severe dignity in the interior, which excites feelings of devotion in every spectator. We must, therefore, ascribe to the German architecture more symbolical than hieroglyphic eloquence and dignity. (See Constenoble "On old German Architecture and its Origin," Halle, 1812 ; Rumohr's "Fragments of a History of Architecture," in Schlegel's German Museum, 1813, March number, \&c.)-The Italians disengaged themselres, by little and little, from the Byzantine taste. Even in the 11 th century, Byzantine architects built the cathedral of Pisa and the church of St Mark in Venice. But, in the 12th century, a German architect, named William (Guglielmo), and, in the 13th, Jacob, with the surname: Capo, who died in 1262, and his pupil or son, Arnolf, are mentioned as having built churches and convents in Florence. The modern Gothic style passed from the churches and abbeys to the castles, palaces, bridges, and city gates, many of which were built in this manner; e. g., in Milan, sixteen city gates of marble, and several new palaces; in Padua, seven bridges, and three new palaces; in Genoa, two docks and a splendid aqueduct; and the town of Asti, in 1280, almost entirely. Architecture was continually inproving in Italy, particularly in the 14th century. Galeazzo Visconti finished the great bridge at Pavia, and built a palace which had not then its cqual. About the same timc, the famous cathedral of Milan was erected. The inarquises of Este erected handsome edifices at Ferrara, and Albert the splendid palace at Belsiore. In Bologna, the great church of St Petronius was begun, and, in Florence, the famous tower of the cathedral. The 15th century, in which the stuly of ancient architecture was revived, was

$$
2 \text { II-I } 2
$$


greatly distinguished. The dukes of Ferram, Borso, and Ercole of Este, were active patrons of architecture. Duke Francesco embellished Mitan with the ducal palace, the castle Porta di Giove, the hospital and other edifices. Ludovico Sforza erected the buildings of the university at Pavia and the lrospital of Milnn. The popes adurned Rome, and Lorenzo de' Medici, Florence, with splendid buildings. The artists returued to the monuments of antiquity, and studied their beautiful forms and just proportions. The most illustrious architects of this time were Filippo Brunelleschi, who built, at Florence, the dome of the cathedral, the church S. Spirito, and the palace Pitti, besides many edifices at Milan, Pisa, Pesaro, and Mantur; Battista Alberti, who wrote, at the same time, on architecture; Michelozzi Bramante, who commenced the building of St Peter's; Michael Angelo Buonaotti, who erected its magnificent dome; and Giocondo, who built much in France, and afterwards directed, with Raphael, the building of the church of St Peter's. These were followed by others, who proceeded in their spirit-Palladio, Scamozzi, Serlio, Barozzio, known by the name of Vignola. They are the founders of the existing taste in architecture. That, however, they studied their art in those works of antiquity which had already deviated from the early purity and elevated grandeur, is evident in their buildings, from the many curved and twisted ornaments, the circular, irregular, and cut pediments, the coupled columns, high pedestals, and other things, which were unknown to architecture at the time of Pericles. Thns a new period in architecture had begun in Italy. Italian masters, and young artists sent to Italy, introduced the Roman taste into foreign countries, which gradually supplanted the Gothic.-Since that time, architecture has experienced different destinies in different countries. It has risen and declined at different -periods; yet laudable attempts have been made, in recent times, to advance it to its true perfection, though we cannot affirm that they have succeeded every where.-In America, the pure Grecian architecture is gradually prevailing, either because this style is founded on plainer principles than the others, or because the Grecian really deserves to be called a republican style, since it is better adapted than the Gothic to snall buildings, and does not require large and splendid edifices (a great number of which can never exist in a democracy), in order to display all its beauty. (For an account of modern architecture in different countries, see the respective articles.)

Arcurves ; a collection of written documents, containing the rights, privileges, claims, treaties, constitutions, \& c., of a family, corporation, community, city, or kingdom; also, the place where such documents are kept. There are, accordingly, private and public or state archives. Archives were known among thie most ancient people. The Israelites, Greeks, and Romans had them in their temples, and the Christians, at first, preserved important manuscripts with the sacred ressels and relics, till proper places were assigned to them. Those gorernments which transact every thing by writing have, of course, much larger archives than others; thus the archives in every branch of government in Prussia and Austria are immense.-According to Wageinselius, the archives of the German empire contain very few documents before the time of the emperor Rodolph of Hapsburg (who was elected in 1273), or even of the subsequent century. At the end of the 15 th century, and at the beginning of the $16 \mathrm{th}$, under Maximilian $\mathrm{I}$, the archives of the empire received a new form, and have been preserved with great care. Some historians, (e. g., Schmidt, in his History of the Germans), have made the most diligent and praiseworthy use of them. The modern archives of I'russia are excellently arranged; probably none are so com. plete in respect to statistical matters. In Britain, great care has been taken of archives, insomuch that continental mations often have recourse to this country for documents. In France, the archives were dispersed all over the country till the revolution, when, by law of Sept. 7, 1790, they were put in a common place of deposit, after a very large quantity of documents had been destroyed. This inmense collection of public acts is now in the ancient hotel Soubise, au Marais, in Paris. The laws of Oct. 10, 1792, and Feb. 20, 1793, put the whole management of the archires on a systematic footing. In 1814 , June 6 , the archives of the navy and the war departments were organized, in order to preserve the. historical documents, military memoirs, plaus, maps, \&c.

Archoss ; the highest magistrates in Athens. (Ser Attica.) The Jews, also, had archons in their captivity.

Arcuytas of Tarentum; a famons Pythagorean, renowned as a truly wise man, a great mathematicisu, statesman, and general. He devoted limself, at Metapontum, to the study of the Pythagorean philosophy. Being the contemporary of Plato (Olynuiad $96 ; 400 \mathrm{~B}$. C.), he must have lived a century later than Pythagoras, and was still alive when Plato travelled to Sicily. Hence he cannot be regarded as the instructure of Philolaus, who was older ; and still less as the immediate scholar of Pythagoras. The invention of the analytic inethod in mathematics is ascribed to him, as well as the solution of many geometrical and mechanical problems. He also constructed an automaton (a flying pigeon). Perhaps he was also the inventor of the categories in philosophy. It is, however, still undecided whether Aristotle's work on the ten categories is drawn from his work or forged. Horace mentions him, in one of his poems, as laving been drowned on the coast of Apulia.

Arck knnolz, John, the listorian, was born, 1695 , in Swedish Finland, and died 1777, at Stockholm. He wrote Mémoires concernant Christine, Reine de la Suède, Amsterdam, $1751-60,4$ vols. 4 to.

Arcos, Jean Claude Eleonore d', inventor of the floating batteries, for the attack of Gibraltar, borı 1732, at Pontarlier, was designed for the churcli, but his father, a lawyer, yielded to the decided inclination of his son for military science. He was received into the military school at Mezieres, 1754, and, the following year, into the corps of engineers. In the seven years' war, he highly distinguished himself, particularly at the defence of Cassel, in 1761. 1774, he was employed in drawing a map of the Jurn and the Vosges, and, to expedite the labour, he invented a new mode of shading, much superior to the common one. He was gifted with an inventive imagination and an unwearied activity. He wrote much, and in all his writings, which are read with pleasure, in spite of their incorrect style, we find a richness of ideas, and traces of a splendid genius. In 1780 , he invented the floating batteries. The jealousy and disunion of the French and Spanish generals tended to prevent the result from anstwering his expectation. Elliot, wl:o directed the defence of Gibraltar, did full justice to the inventor.-At the invasion of Holland, under Dumouriez, he took several places, including Breda. He then went into retirement, where he wrote his last and best work, the result of all the rest,-Considérations Militaires et Politiones sur les Fortifications, (Military and Political Considerations on Fortifications). The first consul placed him in the senate in 1799, and he died July 1, 180 ?.

Ancosi; the most northern point of Germeny (it Prussia Proper is not included therein); the north- 
eastern promontory of the island Rugen, in the parish Altenkirchen, upon the peninsula Wittow, consisting of chalk, flint, and petrifactions. Here was formerly situated the old Vandal castle, with the chief temple of the god Swantewit, who was highly venerated by all the Sclavonians in North Germany, and whose worship king Woldemar I. of Denmark put an end to, by capturing the castle, in 1168 . The country is delightful and fertile. The shores are precipitous and abrupt, and very picturesque. In the vicinity of the old Herthasburg, in the holy grove of Hertha, may yet be seen the deep lake which served for ablutions and secret sacrifices. Travellers frequently visit the island, which, on account of its seclusion, abounds with old and marvellous tales. (See Rugen.) Lately, a light house has been erected on the promontory of A. by the Prussian government.

Arcot ; a large district of Hindostan. It was formerly independent, but since 1802 , it has been under the British dominion. The exports consist chiefly of arrack, pepper, palmirahs, received from Ceylon, Travancore, and Prince of Wales's island.

Arcor (anciently Arcati, Regıe Sora, and Soromandala); a city of Hindostan, formerly capital of the Caruatic, on the Peliar, or Palar, 57 miles W. S. W. of Madras ; lon. $79^{\circ} 29^{\prime}$ E. ; lat. $12^{\circ} 52^{\prime} \mathrm{N}$. The fort is a mile in circumference. The city is extensive, and manufactures coarse cotton cloth. Hyder Ali gained possession of it Sept. 30, 1780, after having defeated the English, who had possessed it since 1760 .

ARCTIC; an epithet given to the north pole, or the pole raised above our horizon. It is called the arctic pole, on account of the constellation of the Little Bear, in Greek called agxzos, the last star in the tail whereof points out the north pole.-Arctic circle is a lesser circle of the sphere, parallel to the equator, and $23^{\circ}$ $28^{\prime}$ distant from the north pole, from whence its name. This and its opposite, the antarctic (q. v.). are called the two polar circles, and may be conceived to be described by the motion of the poles of the ecliptic round the poles of the equator, or of the world.

Arcturus; a fixed star of the first magnitude, in the constellation of Arctophylax or Bootes.

Arctus (Greek apxros) ; a name given by the Greeks to two constellations, called, by the Latins, Ursa ( $m a$ jor and minor), and by us, the Bear (great and little).

Arcuation; the method of raising, by layers, such trees as cannot be raised from seed. The process consists in bending to the ground the branches which spring from the offisets or stools, after they are planted. Arcuation is based on this principle in vegetable life, that the plant depends chiefly upon external influences, and that a part, which now has become a branch by the influence of air, may be easily turned into a root by the influence of the earth. In fact, alleys of trees have been made, which, after growing to a considerable size, have had the branches turned into the ground, and the roots towards the sky. The former, yfter a while, became roots, and the latter put forth foliage. In the animal kingdom, such great changes do not appear to take place; yet some parts may be turned into others.

Ardícue, department de l'; a department in the south of France, on the right bank of the Rhone. It contains 1836 square miles, and had, in 1828, a population of 328,419 .

ARDENAEs; a chain of mountains covered with woods, between the Meuse and the Moselle, in the grand.duchy of Luxemburg. In the time of the Romans, the wood of A. comprehended a large part of Gallia Belgica, and, according to Caesar, extended irom the Rhine, through the country of 'Treves, to the territory of the Remii. More than twenty rivers and brooks take their rise in it. The mines are no longer worked for iron, copper, and the precious metals.
Sheep are raise'd here in considerable numbers, and the country affords much ganne.-The name $A$. is derived from the Celtic ar, in, and drianna, well of God. - In a wider sense, the mountains extending from the former French Hainault to the Moselle are called A.; whence, also, a department in the north-eastern part of France, containing about 2100 square miles and 281,624 inhabitants, the chief city of which is Mezieres, has the same name.

ARDEY ; the chain of mountains extending along the Ruhr, in the county of Mark, from Frodesiberg to Volmarstein. It consists of rough sandstone, above which are masses of coal. This mineral is very important in this populous manufacturing region. The ruins of a castle, where the counts of Ardey dwelt in the 7 th century, are still to be seen in this mountain.

Ardrossan, a parish and village in Ayrshire, Scotland, situated on the firth of Clyde. Ardrossan is chiefly remarkable for the extensive harbour erected there under the auspices of the earl of Eglinton. The object of this harbour was to open a direct communication between Paisley, Glasgow, and the west cuast, instead of the present circuitous passage by the firth of Clyde. A canal was therefore to be cut from Glasgow to Ardrossan, a distance of fully thirty-one miles, at the estimated expense of $£ 125,000$. Of this, a third has been executed, viz. from Glasgow to Johnstone, and this part, it is said, cost nearly the whole of the above sum. No further extension of the canal las been made for many years, but in 1830 a railway was opened between Johnstone and Ardrossan, chiefly for the conveyance of coal for shipment. The harbour of Ardrossan is one of the safest, most capacious, and most accessible on the west coast of Britain. It consists of a pier of 900 feet in length, constructed at an enormous expense. The village attached to it is of modern erection, and has become a favourite resort in the sea-bathing season. Population of the parish, 3494 .

ARE; a superficial square measure in France, substituted for the former square rod. It consists of 1076.44 English square feet. The 10th part of an are is called a deciare, and the 100th a centiare. Decare is ' $\mathrm{s}$ 'surface of ten ares.

ArEa (from the Latin, in which it signified, first, a threshing-floor; later, a vacant place bounded on all sides, or before a public building); in geometry, the superficial contents of any figure; in geography, the contents of any surface. Balbi estimates the surface of the earth at 198,020,000 British miles, of which almost three-fourths, or 147.790,000 miles, are covered by the ocean, and its branches which form the inland seas; the remaining $50,230,000$ miles form the five parts of the world, with the numerous islands regarded as their geographical dependencies. The same excellent authority estimates Europe to contain an area of $3,724,000$ square miles; Asia 16,156,000 square miles; Africa 11,354,000 square miles; America 14,860,000 square miles; and the Maritime World or Oceana, $4,130,000$ square miles. There are, of course, corisiderable differences in the estimates of different geographers. The following tables of the areas of the zones, seas, and countries are taken from Mr Iarby's View of the United States (Philadelphia, 1828), and will be found to differ materially from Balbi. According to Mr Darby

\section{The torrid zone contains land in}

Asia

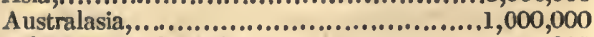

Polynesia, or Oceanica,......................... 100,000

Africa, ............................................5,000,000

South and North America,......................4,500,000

Total,................................., $13,600,000$ 
Land urea of the southern tompernte zone.

\&.ustralnsia,.....................................1,400,00n

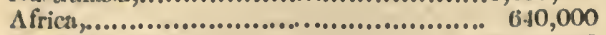

Suth America1,................................1,520,000

Total,.....................................3,560,000

Land area of the northern tomperate zone.

A sin, ..........................................7,600,000

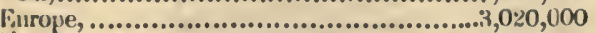

North America, Greenland, \&c...............5,000,000

1 frica $, . . . . \ldots \ldots \ldots \ldots \ldots \ldots \ldots \ldots \ldots \ldots \ldots \ldots \ldots . . .2,360,000$

Total, ................................17,980,000

Land area in the northern polar circle.

Asin,

$900,0 \% 0$

Europe,..........................................20,000

North America, Greenland, \&c...............2,600,000

Total,.......................................3,520,000

Land area in the southern polar circle,........200,000

Int it is doubtful whether there are, in reality, 200,000 square miles of land within the antaretic circle.

Arelas, or Arelatom; the present Arles; in ancieut geography, a town of Gallia Narbonensis, situated on the Rhone. It was a favourite place of the Romans, and hence called Gallula Roma. A. was the chief city of the kingdom of Arelat or Arles, which consisted of the duchy of Burgundy, with Provence, and existed for a short time in the 9th century. See Burgundy.

Aremberg; a place with 490 inhabilants, in the mountains of the Fifpl, near Cologne, now belouging to the Prussian grand-duchy of the Lower Rhine. The dukes of A. Jerive their name from this place.

Areva. See Amphitheatre.

Armint, Martin Frederic. This learned man, renowned for his scientific travels through a large part of Europe, was born at Altona, 1769, and died of the palsy, in the neighbourhood of Venice, 1824. Being recommended by count de Rerentlow, in 1797, he was appointed an éléve in the botanic garden at Copenlagen. But his predilection for the study of anttiquities led him to the library of the university, where, in the most piercing cold, he spent whole hours in examining the collections of Arnomagne. He travelled, in 1798, to Finmark, under the royal patronage. He made accurate observations in Norway and other countries, which had been visited by no stranger before him. He was to have collected living plants and seeds, but he brought back little or nothing, and was therefore discharged. He began his antiquarian collections in Norway, 1799 and 1800. He then resided again in Swedell, in Rostock, in Paris, and in Venice. A part of his papers, drawings, and treatises, all containing researches respecting northern antiquities, he deposited in the library at Copenhagen. He has also published some separate treatises in Paris, and in rarious cities of Sweden, Germany, and Denmark. Afterwards, he travelled through Switzerland, Spain, Italy, and Hungary. He lived on the charity of strangers, and slept often in the open air, without suffering any inconvenience. He carried all his papers with him. The persecutions which he endured at Naples, on a suspicion of Car bonarism, contributed much to hasten his death.

ARENs, or ARENSHADE; a district of Denmark, in the duchy of Sleswick, through which runs the famous wall called Danneuske, which Gottric, king of Denmark, built, in the 9th century, across the country from Hollingsted to the Sley (an extent of forty.six miles), as a defrnce against the iumads of the Eaxuns and Slavi. The native's of $\Lambda$. were the first in the country who professed Christianity, and their church, built in 826, was demolished several times by the iitolaters.

Arropages ; the oldest of the Atlienian courts of justice, and, at the same time, the most famous for its respectability, purity, and love of justice. It ob. tained its name from its place of meeting, on the hill of Mars, near the citadel. The establishment of this conrt is ascribed, by some, to Cecrops, by others, to Solon; from the latter, however, it seems to lave only received a better constitution and nore important privileges. Of how many members it consisterl, is not now known. A seat in it was held for life. 'The niembers were men who had formerly been archons, lad rendered themselves worthy of this houour by tlie honest and diligent execution of their office, und whose character and conduct had been subjected to a jarticular examination. Aristides called the areopagns the most sacred tribunal of Greece; and Demosthenes assures us, that they never passed a sentence in which both parties did not concur. The crimes tried before this tribunal were wilful murder, poison, robbery, arson, dissoluteness of morals, and innovations in the state and in religion; at the same time, they took care of helpless orphans. The other states of Greece also, submitted their disputes to the judgment of the areopagus. Its meetings were held in the open air, and in the night time. After the investigation of a case, the votes were collected. Till the government of Pericles, this court of justice retained its purity inviolate; it was first encroached upon by his causing himself to be made a member, without having been archon. It retained its respectability, however, for a long time, but sunk, gradually, with the decline of Athens.

Arroutra ; a city of Peru, and capital of a province of the same name; 180 miles S. of Cuzco, $340 \mathrm{~N} . \mathrm{W}$. of La Plata; lon. $71^{\circ} 48^{\prime} \mathrm{W}$.; lat. $16^{\circ} 30^{\prime} \mathrm{S}$.; pop. stated from 24,000 to 40,000 . It is situated in a fertile valley, and is elerated 7775 feet above the level of the sea. Behind the city rises three lofty mountains, nue of which is called the volcano of Arequipa, or peak of Misté, and is one of the nost elevated summits of the Andes. The houses are well built of stone, are vaulted, and are much decorated on the outside. It contains a cathedral, a college, an hospital, three unnneries, six convents, \&c. It is subject to frequent earthquakes; but this evil seems to be overbalanced by the mildness of the climate, and the beauty and fertility of the country rounel about. Aranta is the: port of $\mathrm{A}$.

Ares. See Mars.

AREskoUl, or AREOUskl ; the god of war among some of the American Indians.

ARETHUSA. 1. One of the Hesperides. -2. $\Lambda$ daughter of Nereus and Doris, first a nymph of Diana, then a famous fountain of the island Ortygia, which comprises a fourth part of the city of Syracuse. (Respecting her metamorphosis into a fountain, see Alpheus.) As Theocritus composed his idyls on her banks, she is often made the muse of pastorals.

A RETIN (Christopher), baron of ; born at Ingolstadt, December 2,1772 . He early entered into the public service. In 1799 and 1800 , he nuged the abolish. ment of the feudal estates, and the assembling of the diet. In the contest of the Bavarian states with the government, in 1800 and 1801 , he was very active as a writer. In 1803 after the abolition of the monas. teries, he was appointed commissioner, by the government, to examine their libraries; in 1804, he was made vice-president of the academy of sciences; in 1806 , chief director of the library of Munich, and, in 1807 , secretary to the first class of the academy of 
sciences. He now published, with some other persons, from 1801 to 1806 , a daily paper, the Aurora, and afcerwards, as a continuation of the well known Leipziger Allgem. Liter. Anzeiger (Leipsic Universal Literary Informer), the Neuer Lit. Anzeiger (Nesv Litcrary Informer); also, Decisions of the Courts of Love, and a History of the Jews in Bavaria, 1803; ()ldest Traditions respecting the Birth of Charlemagne, 1803; Memoir on the History of the Divining Rod, 1807 ; the Earliest Consequences of the Art of Printing, exhibited in the History of the World, 1809; Historical and Literary Memoirs (Beitrage), particularly from the Treasures of the Library at Munich, 7 rols. ; Introduction to the Theory and Practice of Mnemonics, 1810 ; Historical Literature of Bavaria, 1810; Information on the History of Bavaria, frum hitherto unused, and mostly foreign Sources, 1811 ; Annals of the Administration of Justice in Bavaria, 1813 and 1818; History of the 13th Article of the Act of the German Confederation; and many other works on the politics and literature of Bavaria. One of his works excited a long and violent contest between the learned men of Munich, at the end of

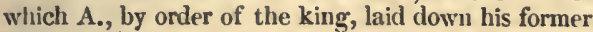
offices, and, in 1811, went to Neuburg, as first director of the court of appeal ; in 1813, he became vicepresident. II is pamphlet, Saxony and Prussia (in favour of Saxony), excited uncommon attention, and drew upon him much persecution. In 1819 , he was chosen member of the chamber of deputies in the Bavarian diet, and was one of the most influential men in the assembly. In the same year he became a member of the society for collecting the ancient history of Gerinany. He died, Dec. 24, 1824, at Munich, in the office of president of the court of appeal in the circle of Regen.-- His brother, Adan, has also held high offices inder the government, and has published several works, but not under his name. Most of these relate to the fine arts.

Areriso, Guido, or Gui ; a Benedictine monk of the 1 ith century, born at Arezzo. He is said to have first reduced the science of music to a fixed system, and to have been the inventor of the monosyllables of the solfcggo, -ut, re, mi, fa, so, la, -drawn from the words of a Latin hymn. It is far from improbable, that Aretino was merely the restorer of the true principle of the ancient Greek music, with which, in the course of his studies, he became acquainted, tlirough sources which have escaped modern research. It is unnecessary to add, that the monosyllable si, whence the modern scales of the two modes, major and minor, is a later invention.-The syllables $u t, r e, m i, \& c$., wre taken from a liymn of St John, composed by Paul, in 770 :-

$U l$ queant lax is $R e$ sonare fibris $M / l$ ra gestorum Fa muli tuorum, So Ive pollutis $L a$ biis reatum.

Aretivo, Leonarl; a very learned Italian historian, born at Arezzo, in Tuscany, in 1370. At the period of the revival of learning, he was a very distinguished scliolar, and, being chosen secretary to the republic of Florence, amassed a large fortune. He died in that capital, highly respected, in the year 1443 . He translated Aristotle's Fthics and Politics, and Plu. I arch's Lives, into elegant Latin. His original works are: also in Latin, anongst which a History of Florence (tolio, 1476), On Studies and Letters (1642), Epistles (republished in 1741, 8ro, with his life by Melius, are particularly esteemed.

Aretino, Pietro, one of the most famous Italian authors of the 16th century, who was indebted for the greater part of his fame to the licentionsness of his pen. He was born at Arezzo, 1492, the natural son of a nobleman, whose name he never bore for the name $A$. is expressive of his birth place), and, fiom a book- binder's apprentice, became an autlior, whio soon gained the favour of kiugs. He was, indeed, called their scourge, but he was profuse in his adulation to them. He had, warm admirers, notwithstanding the malignity and severity of his satires. Although he was so licentious a writer, that his very name is expressive of indecency and profligacy, he wrote many works of devotion, and gave the preference to the latter, if lis own interest required it. His reputation gained for him the name of divire, by which even Michael Angelo addressed him; and his ostentation led him to adopt the name as his title. He cansed medals, therefore, to be struck for him, witl the inscription, Divus Petrus Aretinus, flagellum principum, and presented them to several princes. Being banished from Arezzo, on account of a sonnet against indul. gences, he went to Perugia, and thence to Rome, where lie entered into the service of Leo X., and afterwards of Adrian VI. On account of the sixteen indecent sonnets, which lie coinposed as illustrations of as many designs of Giulio Romano, he was obliget to leave Rome. Giovanni. de' Medici invited him to his court, and took him to Milan, where he found an opportunity to insinuate himself into the favour of Francis I. After having again visited Rone, he returned to his protector, Giovanni de' Medici, wlio grew more and more attached to him, and died in his arms of his wounds. In $1528, A$. went to Venice, where he acquired powerful friends, among whom was the bishop of Vicenza, who reconciled the pope to lim, and recommended him to Charles $V$. so strongly, that he was presented by lim with a golden chain. Francis I., wishing to be equally generous, gave him a similar chain. But when Charles afterwards settled on him a pension of 200 dollars, which liberality Francis did not equal, the former alone received all the encomiums which he had formerly divided between them both. 'The duke of Leve also gave him a considerable pension. He gained besides, according to his own assertion, 1000 dollars in gold, every year, by his writings, together with a ream of papei and a flask of ink. Nicolo Franco, as licentious an author, though not so learned, aided him in his labours. A.'s fame was extended to such a degree, that he received letters from all parts of Italy, and his company was much sought. By his devotional writings, he regained the farour of the Roman court, and Julius III., who was also from Arezzo, was so pleased with a sonnet addressed to him by his countryman, that he sent him 1000 crowns of gold, and made him knight of St Peter. Three years afterwards, he was introduced, by the duke of Urbino, to the pope, who received him not only with honour, but even with tenderness. Yet he could not obtain the dignity of cardinal, for which he made very great exertions. The nature of his death corresponded to his life. He liad some sisters at Venice, who equalled their brother in licentiousness. As a person was one day relating to lim one of their adrentures, he was so amused that he burst into $h$ fit of laughter, and, losing lis balance, fell to the ground, and died soon after, in 1556 , aged sixty-fire. He had received from nature a happy constitution. He was born with a taste for the arts, and practised several with success. But, above every thing else, he loved money, a good table, and handsome women.His works consist of several religious compositions ; five comedies and a tragedy, the former full of wit and genuine comic liumour, the latter not without merit; the licentious Ragionamenti, and Puttana errante; sixteen profligate Sonetti lussuriosi; several pieces in rhyme, stanze, capitoli, partly laudatory, and partly licentious and satirical : some unfinished epics complete the list. The academicians of la Crusca counted A. among the classic authors of the 
nation. He deserved this honour less, however, for the purity than for the boidness, skill, and originality of his style.

Arszzo (anciently Aretium); a city in Tuscauy, sented on the declivity of a mountain, in the middle of a fruitful plain, seventeen miles from Citta di Castrllo, and lying between it and Florence. It had gone almost entirely to decay before Cosmo de' Mledici took it under his protection. A. is the birthplace of Maccenas, Petrarch, and Pietro $\Lambda$ retino. It contains now about 8000 inhabitants.

ARGAL, or ARGOL, or TARTAR, a hani crust formed on the sides of ressels in which wine has been kept, ret or white, accorling to the colour of the wine. On being purified, it is termed cream, or crystals of tarur. It consists of a peculiar acid, combined with potash. White argal is preferable to red, as containing less drossy or earthy matter. The marks of gool nrgal of either kind are, its being thick, brittle, hard, brilliant, and little earthy. That brought from Germany is the best, on account of its being taken out of those great tuns wherein the salt has time to crystallize. Argal is of considerable use among dyers, as serving to dispose the stuffis to take their colours the better. When pure, or creaun of tartar, it is extensirely used in nedicine.

Argall (ovis ammon); mountain, or wild sheep. This animal is regarded with propriety as the savage stock whence the endless varieties of domestic sheep are descended ; though it is difficult, from an inspection of the $\Lambda$., to conceive how so wild and energetic an animal could, by any management, be converted into the imbecile and helpless creatures of which our flocks are composed. - In size, the $\Lambda$. equals the common deer, and in port and bearing resembles the wild goat, though his huge, laterally-twisted horns give his head a very marked similarity to that of the connmon ram. These horns are very large, arise near the eyes, curve first backwards and then forwands, and have the points directed forwards and outwards; from their base, they are transversely waved or wrinkled for half their length, the remainder being nearly smooth. The horns of the female are more like those of the common goat, rising directly upwards, and curving gently backwards, especially towards the extremity. In summer, the $A$. is covered with harsh and rather short hair, genewally of a greyish-yellow, having a blackish or reddish stripe along the back, and a large spot of the same colour on the rump. The inferior parts of the body, and inside of the thighs, are of a pale redlish. white; in winter, the colour is a deeper red, with a greater whiteness about the muzzle, throat, and belly. - The mountain sheep is found in considerable numbers on the elevated ranges of northern $A$ sia, in the deserts or steppes of Siberia, the mountains of California, and the Rocky mountain range of America. They live in herds or families, consisting of a male with the females and young, and seek their food on the lofty elevations, corered only with lichens or small shrubs. They are shy and fearful, and, when disturbed, retreat with a swiftness and agility which renders pursuit hopeless, as they bound from rock to rock with security, and are soon lost to sight. It is by stealing upon them against the wind, or lying in ambush near where they must yass, that the hunter is enabled to make them his prey. In the spring of the year, when under the influence of sexual excitement, the males acquire a warlike disposition, which induces serere and obstinate combats for the possession of the females. - The A. was first satisfactorily made known as an inhabitant of America by the expedition of Lewis and Clarke, who brought the skins of a male and female from the Rocky mountains, which are still presrred in the Philadelphin inuseum. The $\Lambda$. had been previously indicated as an inhabitaut of Califoruia by Veregas. The species is called bighorn by the Indians and traders. The Indians make various domestic utensils of these large horns, and apply their skins to the sume purpose as those of the deer. - The domestication of the sheep is coeval with the infancy of the human family; and it is not, therefore, surprising, that the donesticated breeds should differ so macerially from the parent stock, when we know what can be accomplished by cross-breeding, even during the life of a single man. When domesticated soft fleeced sheep are cake'n to warm climates, this fleece is sueedily sher, as wr have repeatedly witnessed, and a coarse, reduish hair takes its place. In this condition, the resemblance of the animal to the $A$. becomes very striking.

Argand Lamr. See Lamp.

Argens (Jean Baptiste), marquis d'; born, 1704, at Aix. He was designed for the law, hut, following his inclination, entered into the military service at the age of fifteen. His passion for Sylvia, an actress, induced him to leave the service, and France also, to be with her in Spain. But he was arrested, brought back to Provence, and sent to Constantinople with the French ambassador. His residence in 'Turkey was marked with adventures. After his return, he entered the army again. In 1734, at the siege of $\mathrm{Kehl}$, he was wounded, and afterwards, . before Philipsburg, rendered incapable of further service by a fall from his horse. Disinherited by his father, he became an author, and went to Holland, that he might write with more freedom. Here he published his Lettres Juives, Lettres Chinoises, and Lettres $\mathrm{Ca}$. balistiques. Frederic II., then crowu-prince, wished to become acquainted with the author, and riceive a visit from him. He replied, that he should be it. danger from Frederic William I., with his six feet six (this king being in the habit of compelling tall men to join his regiment of grenadiers.) After the death of the king, Frederic again invited him. D'A. appeared in Potsdam, received the place of clianberlain, and that of director of the fine arts, in the academy, and became the king's daily companion, who loved him for his frankness, but ridiculed his melancholy humour. When almost sixty years old, he fell in love with the actress Cochois, and married her without the knowledge of Frederic, who never wholly pardoned him for this act of rashness. He died in 1771. Frederic II. caused a monument to be erected to him, in the church of the Minorites, in Aix.-His numerous writings, the fruits of an unrestrained freedom of thought, once had some reputation, but now, though instructive, are no longer esteemed, because they are deficient in purity, taste, critical discemment, and sound views.

Argent (French for silver, from the Latin argentum); a word used in heraldry, and in several terms of art employed by the goldsmiths.

Argentros Codex; a MS. copy of the four Gospels, so named from its silver letters. It is preserved in the university of Upsal, and is a copy from the Gothic version of bishop Ulphilus, who lived in the 4th century. It is in quarto, written on vellum, stained with a violet colour. On this ground the letters, all uncial, or capitals, are painted in silver, except the initial letters, which are in gold. 'This MS. was discovered, in 1597 , in the Benedictine abbey of Werden, in Westphalia, and, after several changes of owners, was sent, as a present, to Christina, queen of Sweden. Vossius, a Dutchman, either received it from her, or stole it. Count Magnus Gabriel de la Gardie bought it, at Vossius' death, for $£ 250$, and sent it to Upsal. Three editions of it have been given to the public; at Dort, 1655; Stockliolm, 1672; the Clarendon press,1750.-Some 
fiagments of the Gothic version of St Paul's Epistle to the Romans were discovered by linittel, in 1756 , in a codex rescriptus, in the ducal library of Wolfenbuttel. It secuns to have been written in the 6 th century; and Angelo Maio (q. v.) lately discovered firaments of the Maso-Gothic translation of the Epistles of St Paul, inade by Ulphilas; also a corlex rescriptus. These discuveries are interesting additions to the above-mentioned colex.

Argextikra, or Kimou (the ancient Cimolus); a sinall island in the Archipelago, which belonged to the government of the capudan pacha. It is rocky and sterile. The inhabitants (Greeks) live in one village, and are very poor. Formerly, silver mines were worked here, whence its name. The whole island is covered with a sort of chalk, called Cimotian curth, which is used in the washing and bleaching of linen. Lon. $24^{\circ} 42^{\prime}$ E. ; lat. $36^{\circ} 47^{\prime} \mathrm{N}$.

ARglihovres. See Argus.

Argives. See Argolis and Argos.

Argo. See Argonauts.

Argol. See Argal.

Argolss; the eastern region of Pelopnnnesus ; bounded N. by Achaia and Corinth; N. E. by the Saronic gulf; W. by Arcadia; S. by Laconia, and S. W. by the Argolic gulf. The Greeks inhabiting it were often calfed, by the ancient authors, Argives and Argians. Hills and momitains alternate witl fruitful plains and valleys. According to the monuments of Greek mythology, A. was peculiarly rich, and early cultivated. Inachus, about 1800, and 1)anaus, about $1500 \mathrm{~B}$. C., came hither with colonists fion Egypt. Here reigned Pelops, an emigrant from Asia Minor, from whom the peninsula derives its name. Here, too, was afterwards the seat of government of Atreus and Agamemnon, Adrastus, Eurystheus, Diomedes. Here Hercules was born. In the morass of $\mathrm{A}$. he slew the Lernzean hydra, and, in the cave of Nemea, subdurd the ferocious lion. In the earliest times, it was divided into the sunall kingdoms of Argos, Mycenæ, Tirintlus, Troezene, Hermione, and Epidaurus, which afterwards formed free states. The chief city, Argos, has retained its name since 1800 B.C. Its inhabitants were renowned for their love of the fine arts, particularly of music. Here, and in Delphi, statues were erected to the brothers Biton and Cleabis, who fell victims to their filial piety. In 1825, a high school and a monitorial school were established at Argos. Near this city lies Napoli di Romania (q. v.), the ancient Nauplia, with an excellent harbour, and the inost important fortress of the peninsula. On the site of the present village Castri, on the Egean sea, formerly lay the city Hermione, with a grove dedicated to the Graces ; opposite is the island of Hydra (q. v.) Near the city of Epidaurus, the wateringplace of ancient Greece, on the Ægean sea, Esculapins (q. $v_{\text {. }}$ ) had his temple. At Træezene, now the village Dumala, Theseus was born.

Argonauts; in fabulous history, those heroes of ancient Greece who performed a hazardous voyage ta Colchis, in quest of the golden fleece. Asson, king of Iolcos, in Thessaly, enfeebled by age, had abdicated the throne in favour of his son, Jason, and appointed his brother-in-law, Pelias, to administer the government during his son's minority. At the time fixed, Jason appeared to demand his father's kiıgdom. Pelias, apparently ready to resign the throne, required of him first to bring from Colchis the golden fleece of the ram, on which Pliryxus and Helle (q. v., under Athamas) had escaped the persecutions of their step-mother, Ino; for Phryxus, having sacrificed the ram, had hung up the fieece in a consecrated grove at Colchis. The ambitious youth, unconscious of the treacherous nature of the proposal, engaged to accomplish the adventure; and the most valiant heroes of Greece took part with him. Hercules, Castor and Pollux, Peleus, Admetus, Neleus, Meleager, Orpheus, Telamon, Theseus and his friend Pirithous, Hylas, and many others. They sailed with favourable winds, from the promontory of Magnesia, in a vessel called the Argo, built at the foot of mount Pelion, in Thessaly, superior to all ships previously built in size and equipment. Tiphys, skilled in navigation, nıanaged the rudder, and the shar'psighted Lynceus explored the seas for the place of their destination. Orpheus elevated the courage of his companions, when danger threatened, by music and songs. When a tempest broke upon them, as he was initiated into the mysteries, he made vows, with the rest of his companions, to the Samotluracian deities, upon which the storm was allayed; and, to show the interposition of the gods by a niracle, two stars appeared over the heads of the Dioscuri. (See Castor.) They happily reached the harbour of Lem. nos, where they remained two years. The women of Lemnos, instigated by the angry Venus, offended with their husbands, and oppressed by their Thracian concubines, avenged themselves by the nurder of their husbands, and detained among them the welcome strangers. At length they sailed to Samothrace, where, according to their vows, they caused themselves to be initiated into the mysteries there. Then they landed at Troas. Here Hylas rambled, and lost his way, and Hercules, who went in search of him, remaining too long on shore, the ressel sailed without them. Telamon, also, left them hereThence they went to the city of Cyzicus, where the king received them hospitably. But at night, being forced back by a storm, they were taken for enemies; a contest followed, in which Jason slew the king, in consequence of which Rhea, the guardian goddess of the island, detained the Argo by magic. Having appeased the angry deity, they sailed to the east, and landed at Bebrycia. Driven by a storm to the shores of Thrace, the Argonauts sailed thence to Salmydessa, where the blind soothsayer, Phineus, was king. Phineus gave the strangers directions, and a guide to conduct them through the Cyanean rocks, which, driven furiously a gainst each other by the winds, dashed in pieces vessels passing through them. Having arrived at the rucks, in compliance with the advice of Phineus, they caused a dove to $\mathrm{fly}$ through before them, and followed, rowing with all their strength, while Orpheus played on his lyre. The rocks stood firm, and the danger was escaped. The last adventure awaited them at the island of Aretias (or Dia.) Here they found the Stymphalides, birds which shot their feathers like arrows, and from which the heroes could only protect themselves by a violent clashing of weapons. Having driven away these dangerous monsters, they met with the sons of Phryxus, who, having been sent by Æetes to Orchomenus, to take possession of their father's inheritance, had been forced hither by storms. They relieved these sufferers, and received from them much useful information. At last, the shore of Colchis appeared in view ; they landed, at night, at the moutlı of the Phasis. King Eletes, previously informed of the design of the strangers, and fearing their power, did not refuse, alssolutely, to deliver the golden fleece, on which his life depended, but cliarged Jason with three labours, by which he hoped to destroy him. Jason was to yoke the two fire-breathing bulls of Vulcan to a plaughshare of adamant, and to plough with them four acres of land consecrated to Mars, never before turned up. He was then to sow in the furrows the remaining serpents' teeth of Cadmus, in the possession of Eetes, and to kill the armed heroes which they produced; at last, to fight with and slay the.dragon that guardct the 
molden fleece. All three lalours he was to accoinplish in a single day. To rescue the hero, Jumo and Minerva, who had instructed Midea, the daughter of Hetes, in magic, infused into her an ardent love for Jason, and, in return for a pronise to conduct her tume as his bride, she gave him a mixture to amoint limuself with, a stone to throw among the formidable heroe's sprung from the serpent's teeth. and herbs and a drink to linll to sleep the dragon. Thus equipped, in the sight of the king and assembled people, Jason roked the formidable bulls, and plougled with them the futal field, sowed the serpents' teeth, and threw amoug the armed host that arose the stone given him by Meder; upon which they turned their weapons agaiust one another, and, in a furious conflict, all perished. Fetes, terrified, commanded him to delay the last adrenture. Contriving another plan, he resolved to murder Jason and his companions, and to burn the sacred Argo. Being informed, by Meles, of the king's design, Jason, hastened, by night, to the consecrated grove, lulled to sleep the drigon, by a magic potion, and took the golden fieece from the oak on which it liung; thence he retired in liaste, with Medea and his companions, to his ship. The next day, Eetes, perceiving the robbery of the grove, and the flight of the straingers, embarked on board a ressel to pursue them. At the mouth of the Danube, they were within sight of one another. Here, also, Meden averted the threatening danger, by killing her brother, Absyrtus, and strewing on the shore his mangled limbs. The melancholy sight detained the unhappy father, who quitted the pursuit to collect the bloody limbs of his beloved son. As Plhineus had advised the $\Lambda$ rgonauts to return another way, they now sailed up the Danube, carried the lightly-built $\Lambda$ rgo many miles over mountains and villess, to the shore of the Adriatic sea, and here again embarked. Then the roice of an oracle soundei from the Dodonean mast of the Argo-"You shall not kiss the shores of your country, till Jason and Medea have atoned for the murder of Absyrtus, and appeased the goddesses of rengeance." Upon this, they directed their course to the port of Eea, to Circe, sister of Fetes. She, however, refused them expiation, but directed them to the promontory of Malea, where they might obtain it. On their voyage, they encountered the frightful Scylla and Charybdis, the alluring Sirens, and a fearful storm not far from the coast of Libyr. Then they came to Crete, where the giant Talos, who guarded the island, opposed their landing. A single vein ran from his head to his heel, and was closed below by a brass nail. Medea gave him an intoxicating potion, and opened the vein, that he might bleed to death. At last, they reached the long-wished for promontory of Malea; their crime was expiated, and, without further misfortune, the Argo arrived at the port of Jolcos. On the isthmus of Corinth, Jason consecrated his ship to Neptune, and it afterwards shone as a constellation in the southern part of the heavens. Thus the expedition terminated gloriously. But, before the heroes parted, they agreed to aid one another in war, and resolved, at certain times, to celebrate public games in honour of $\mathrm{J}_{\text {upiter. The }}$ There the beginning of the Olympic games. The further fortunes of Medea and Jason are mentioned under those articles. The tales describing the return of the Argonauts differ very essentially. Several poets of antiquity have celebrated this adventurous undertaking, which is placed in the middle of the 13th century B.C. We still have, under the name of Orphers, a poem on this subject; another by Apollonius of Rhodes, and one by Valerius Flaccus.

A RGONNE; a former province of France, between the rivers Metuse, Marne and Aisne. St Menelold was the capital.-Argonnc, wood of, runs through Upper Champagne and Iower Bar, and is mostly mountainous. It was so desert, that the prince of Condé, who received it, in 1657, as an apanage, nul his successors, used it only as a humting. ground, and place for felling wood, and it became a resort of the snugglers of salt. In order to expel them from the place, the crown purchased the wood, in 1784, for 650,000 livres. This wool hecame ton) well known in the unlappy campaign of Prussia, in 179\%.

Argos. See Argolis.

ARGUIs, or ARGUIN; an island on the coast of Africa, not far from cape Blanco, scarcely two miles long. Notwithstanding its insignificance, the possession of it was violently disputed, for vights-seven years, between the Portuguese, Dutch, Eniglish, ans] French. After a variety of fortume, it has been at last totally abandoned.

ARGUMENTUM. AD HoMneM; an argument which presses a man with consequences drawn from his owu principles and concessious, or his own conduct.

ARGOS, in fabulous history, was the son of Arestor, or Agenor, or Inachus and Ismene, and had a hundred eyes. According to some, his whole borly was covered with eyes (hence lie was called Panoptes), half of which were always awake, while the rest were closed in sleep. The jealous Juno made hin keeper of the unlappy Io (q. v.) ; but Mercury lulled him to sleep with the sound of his flute, and cut off his head; hence Mercury is called Argiphonles. - Juno afterwards took his eyes to adorn the tail of the peacock.

ARGYLE, an extensive county in the south-western extremity of the Highlands of Scotland, partly conposed of a number of peuinsulas on the mainland, aut partly of an archipelago of small islands scattered along its margin, and in the bosom of its lakes, with others of larger dimensious divided from it by straits and sounds. The mainland is situated between $55^{\circ}$ $21^{\prime}$ and $57^{\circ}$ north latitude, and between $1^{\circ} 22$, aud $5^{\circ} 25^{\prime}$ of longitude west from Edinburgh. The greatest length of Argyleshire is 115 miles, its breadth above 68 ; and from the windings of the numerous bars and creaks with which the land is every where indented, it is supposed to lave mor than 600 miles of sea-coast. The population of the county amounts to 101,425. Argyle is popularly divided into five great districts, viz. Cowal, Lon or Argyle proper, Cantire or Kintyre, Morven, and Sinart. Of these there are varions subdivisions, such as Appin, Glenorcliy, Ardnamurchan, and Knapdale. A number of isles are included in the shire, viz. Tyrie, Coll, Mull, Isla, Jura, Staffa, Icolmkill, \&c. the more important of which will be found noticed in their proper places. The chief towns of Argyleshire are Inverary, Campbelton (two royal burghis), Ohau, Bowmore, Lochgilphead, Tobermory, and Ballahulish. For a long time this shire scarcely formed part of the kingdoin of Scotland, haring become subject to the Macdonalds of the Isles, who assumed regal and independent authority, until mastered by king Robert Bruce. On the depression of the Macdonalds, their estates and titles were bestowed on the Campbells, who have ever since retained them. The duke of Argyle, whose seat is at Inverary, is the proprictor or feuar of a large portion of the territory. He is the chief of the numerous family of Camplell. The general features of the county are variel and striking, consisting of lofty mountains, deep glens, and inlets of the sea entering far into the land. Towards the northern parts, it assumes the wild and savage grandeur so peculiarly characteristic of the Highlands of Scotland, exhibiting monntains piled upon mountains, in great but picturesque irrtgularity. The mountain of Ben Cruachan is one of the highest 
in Scotland, being 3.390 feet ahove the level of the sera ; and about Ben Lomond there are several which ure little inferior to it. The hills and forests abound with fallow deer, stags, roes, and almost every sort ,f wild game. The coast, although rocky, being indented with navigable bays and lakes, affords safe harbours for shipping. The district of Cowal is zearly surrounded by Loch Long and Loch Fyne, which are inlets from the sea; and there are several lakes of fresh water in the interior. All these abound with fish, the taking of which employs the greater part of the inhabitants. The summits of the hills are bare of pasturage ; but the sides of the mountains and borders of the lakes supply food to numerous herds of black cattle and sheep, the rearing of which, - next to the fisheries, occupies the chief attention of the native population. Some of the glens exhibit great verdure and cultivation, particularly Glendaruel, the most fertile valley in the county. Agricultural produce is principally confined to barley, oats, and potatoes. Iron, copper, and lead, are produced in various parts of the county; and the iron works in particular liave proved very profitable since the opening of the Crinan canal. A great variety of beautiful marbles are found here ; as also free-stone, coal, and large quantities of fine blue slate. The new metal, strontites, was discovered at Strontian in this shire, whence its appellation." The leading articles of export are sheep, cattle, horses, fish, slate, and, formerly, kelp. The chief manufactures are leather, the weaving of wool, and the smelting of ore. The roads have been greatly improved of late years, and the establishment of steam-packets between Glasgow and the various districts of the county has proved exceedingly beneficial and convenient. On this subjuct Mr Chambers speaks with justifiable enthusiasm. "A greater boon," he says, "than any that ever the duke of Argyle bestowed, or could bestow upon the county, has, witlin the last few years, been conferred by steam-boats. It is evident, from the peculiar form of Argyleshire, that it will always owe as much of the benefit arising from a ready communication between its near and distant parts, to improvements in water carriage, as to any extension of that by land. The difficulty, indeed, of forming roads in a district so serrated by the sca, and so blocked up by chains of hills, is almost insurmountable; hitherto there have been only two or three roads in the county, skirting along the banks of the lochs. The very barrier, however, which mainly prevented communication in the days of our fathers, has turned out to be the highway in our own. By the nerer-to-besufficieritly-admired spirit of the city of Glasgow, about twenty stean-ressels are now constantly employed in conveying passengers and goods to and fro, throughout the country, and in transporting the country produce to market at that city. The effect of this grand engine, even after so brief a period, is incalculable. It liappens that, notwithstanding the immense extent of the country, there is not a single dwelling-place more than ten miles from the sca, nor a gentleman's seat, (excepting those on the banks of Lochawe), more than ten minutes walk from it. Every farmer, therefore, every gentleman, finds occasion to employ stean navigation. . When this mode of conveyance was in its infancy, it was gencully supposed that the little wealtli, bold shores, and scattered popnlation of the county, kept it without the circle in which its adoption was to become bencficial. It came, however, to be attempted, and there is not now a loch, bay, or inlet, but holds a daily, or at least commands a weekly communication with the Lowlands and the several districts of the country. By this means, the farmers, even upon the smallest scale, are encouraged to fatten stock which they would never otherwise tinink of fattening ; the fattening of stock, again, causes thein to improve their arable land; the extra profits enable them to buy luxuries, which, in their turn, communicate sentiments of taste, and open the mind to liberal ideas. The comparative frequency, moreover, of their visits to the Lowlands causes the speedier introduction of modern and improved systems of agriculture. Steamboats are, in short, at once tlie heralds and the causes of every kiud of improvement in Argyleshire; it is no hyperbole to say, that they have in ten years raised the value of land within the county twenty per cent. Every thing connected with this invention, so far as Argyleshire is concerned, bears a degree of romantic wonder strangely in contrast with its mechanical and common-place character. It accomplishes, in this district, transitions and juxta-positions almost as astonishing as those of an Arabian tale. The Highlander, for instance, who spends his general life amidst the wilds of Cowal or upon the hills of Appin, can descend in the morning from his lonely home, and setting his foot about breakfast-time on board a steam-boat at some neighbouring promontory, suddenly finds binself in company, it may be, with tourists from almost all parts of the earth ; he sits at diuner between a Russian and an American; and, in the evening, he who slept last night amidst the blue mists of Lorn, is traversing the gas-lighted streets of Glasgow, or may, perhaps, have advanced to Edinburgh itself, the polished, the enlightened, the temple of modern intelligence. Reversing this wollder, he who has all his life trod the beaten ways of men, and never but in dreams seen that land of lill and cloud, whence of yore the blue-bonneted Gael wont to descend, to sweep folds or change dynasties, can stand in the light of dawn amidst the refined objects of a capital, and when the shades of night have descended, find himself in the very country of Ossian, with the black lake lying in imperturbable serenity at his feet, and over lis head the grey hills that have never been touched by human foot. Steamboats, it may be said, bring the most dissimilar ideas into conjunction, make the rude Gael shake liands with the most refined Lowlander, and cause the nineteenth and the first centuries to meet together. No such lever was ever introduced to raise and revolutionize the manners of a people, or the resources of a country."

ARGYLE, Marquis and Dukes of. See Campbell.

ARGYLE RoOMS; a house in Regent-street, London, a great rendezvous of fashion. In 1818 , the royal harmonic institution erected the present building, the facade of which displays very little taste. The rooms, properly so called, are four-a ball-room, a drawingroom, an ante-room, and the grand concert-room. The usual price of tickets for the concerts held here is lalf a guinea, for which the finest performances may sometimes be heard.

Aria, in music. See Air.

ARI.ADNF; in mythology, a daughter of Minos, king of Crete, who, having fallen in love with Theseus, when lie was engaged in an attempt to destroy the Minotaur, gave him, in token of her love, a cline of thread, which served to conduct lim out of the labyrinth, after his defeat of the monster. Theseus, on leaving the island, took with him $A$., but abandoned lier on the isle of Naxos, where she was foumi by Bacchus, who married her, and presented her with a crowu of gold manufactured by Vulcan, which was afterwards transformed into a constellation. A. had a son by Bacchus, called Eumedon, who was one of the Argonauts.-According to Plutarch, there were two fimales of the name of $\Lambda$. One of their was espoused to Bacchus on the island of Naxos, and became the nother of Staphylos; the other vas 
atrundoned by Theseus on the same island, where she died. Hcuce were derived two kinds of feasts, called Ariadnece.

Artasva ; a small villagc, six miles N. E. of Tunis, ruarkable for a finc range of the Cartiaginian aqueduct, 74 feet high, supported by columns 16 feet square, which increase in grandeur the nearer they approach the site of Carthage. The stone is all cut in a diamond shape. Near this spot, several ancient matamores, or subterraneous magazines for corn, havc heen discovered within these few years, capalule of containing 100 bushels, strongly arclied with large square stones. The Moors lave alruady begun to demolish them.

Arass; the adherents of the Alexandrian bishop Arius, who maintained, about A.D. 318, that Christ, the Son of God is the most noble of all things created out of nothing, but inferior to fod, and produced by his free will. This opinion was condemned in the council of Alexandria, 320, and in that of Nice, 325, by the orthodox church, which attributed to the Son of Gol perfect equality of essence with the Father, and knew no way of expressing his relation to the Father, but by calling it lis eternal generation. The articles of the Nicene and of the Athanasian creeds, the latter of which, though fuller, is based on the former, arose from the contest against Arius. Though his party was banished, he found means to procure powerful adherents ; and Constantine the Great, from his desire of peace, wished to bring about the restoration of Arius to the Catholic communion, when the latter died suddenly, 336. After his death, his party gained considerable accessions, and Constantiue, a short time before his deceasc, 337 , cansed himself to be baptised in the Arian mode. Under Constantius, Arianism became the religion of the court, formed its own liturgy, and, after 350 , when Constantius ruled alone, it prevailed also in the West, and Rome was obliged to receive the Arian bishop Felix. The divisions among the Arians themselves, in the meantime, prepored a final victory for the Catholic church, which liellt the former constantly under its anathema. At first, the Semi-Arians, or Half-Arians, whose lead('rs, Basil of Ancyra, and George of Laodicea, were powerful in Syria, approximated to the Catholic creed by maintaining a similarity of essence between the Son and the Father (homoiousia, hence Homozousians), and by that means, gained the superiority at the imperial court, although Macedonius and the Pnfunatomachists (see Holy Spirit) belonged to the Catholic party. But the victory of the orthodox was promoted by the excesses of the strict Arians, Fitius, and Ennomius of Cappadocia, together with their numerous adherents, who, in the council at Sirmium, $35 \%$, by maintaining that the Son of God is a wholly different being from the Father (hence Heterousians, Anomaans), excited eren the Semi-Arians against them, and, by restoring the former mode of baptism by immersion, aroused even the opposition of the people. The emperor Julian the Apostate, who, firom contempt towards Christianity, tolerated all sects, cnded the contest, and suffered no religious disputes to arise. Arianism again ascended the throne in the East with Valens, 364 , and, growing bold, proceeded to acts of violence against the Catholics. But Gratian maintained peace, Theodosius restored the dominion of the ancient faith, and the divisions among the Arians themselres liastened the downfall of their infinence and respectability in the Roman empire. After the first half of the fifth century, Arianism was extinct in that portion of the Roman empire which remained under the rule of the emperors. Among the Goths, who had become acquainted with Christianity, about 340 , by means of the Arians, it prevailed in the western part of the empire, till the victories of the orthodox Frank, Clovis, and the reformation of the church by the Visigothic king Reccared, suppressed it here, also, at the end of the fifth century. About this time, it was destroyed annong the Suevi in Spain, among whom it had prevailed for a century. The Burgundians, who received it in 450, had already renomiced it, at the begiming of the 6th century. It was more difficult to convert the Vandals to the $\mathrm{Ca}$ tholic faith. Ever since 430, they had been strict Arians, and propagated the doctrines of their sect in Northern Africa, even by the severest persecutions. The victories of Belisarius, 534, first put an end to their kingdom, as well as to their separation from the orthodox church. Arianism was maintained longest. among the Lombards, who brought it to ltaly, and adhered to it firmly to 662. Since that time, the Arians have no where constituted a distinct sect; and, though the Albigenses, in France, in the 12th and 13 th centuries, were accused of similar doctrines, and the sects, which, from the 16th century till the present time, liave been comprehended under the name of Antitrinitarians, have, in reality, maintained the opinion that Christ is inferior to the Father, yet neither of them can be regarded as Arians.

Arica ; a seaport of Peri, and capital of a province; 210 miles N. W. La Plat a ; lon. $70011^{\prime}$ W.; lat. 18 $27^{\prime} \mathrm{S}$. In this port the silver from the mine's of Potosi is shipped for Europe. It is much frequented by ressels, and has a considerable trade with Lima. Near it is a mountain of rock salt, great quantitics of which are dug, and sent to all parts of the coast.

Aries (Latin, a ram); one of the twelve signs of the zodiac; the verual sign. In the ancient military art, aries signified, also, a hattering. mun, an engine with an iron head, to batter and beat down the walls of places besieged. See Battering-Ram.

ArIetta. See Air.

Arimanes, or Auriman; the principle of evil in the Persian theology, which perpetually counteracts the desigis of Ormuzd, or Oromazdes, who denutes the principle of good. See Demon and Zoroaster.

Arisiaspians ; a fabulous people, placed soinetimes in Scythia, sometimes on the Riphrean mountains, and used synonymously with the Cyclops.

Arion; the inventor of ditliyramluics, born at Metliymna, in Lesbos, and flourislied about B. C. 625. Hc lived at the court of Periander, in Corinth, and afterwarls visited Sicily and Italy. At Tarentum, he won the prize in a musical contest. Having embarked in a Corinthian vessel, according to fabulous history, with rich treasures, to return to lis friend Periander, the avaricious sailors resolved to murder him. Apollo, however, having informed him in a dream of the impending danger, Arion, in a magnificent dress, with his lyre in his land, went upon deck, and endeavoured to soften the hearts of the crew by the power of his music. The dolphins, at tracted by the sound, assembled round the ressel, and listened to his sweet songs, though the avaricious seamen still continued unmored. A. then resolved to escape the hands of the murderers by a voluntary deatl, and threw himself into the sea. A dolphin received him on his back, and while he soothed the stormy billows by the power of his strains, bore him safe to mount Tenarus, whence he sailed for Corinth. The sailors, laving returned to Corinth, and being questioned by Periander concerning $A$., replied that he was dead. Upon this, he appeared before them, and convicted them of their crime, when Periander cansed them to be crucified. The lyre of A., and the dolphin which rescued him, became constellations in the heavens. Of the poems of Arion, we have only a hymn to Neptune, which may be fonnd in Brunck's Analecta.-Arion is also the name of a horse, famous in fabulous and poetic history: 
Arıoso, in music. See Air.

Ariostl, Attilio ; a composer of eminence, born at Bologna. He is said to have given lessons to Handel in his childhood, in conjunction with whom, and with the celebrated Bononcini, he afterwards produced the opera of Muzio Scevola; Ariosti setting the first act, Bononcini the second, and Handel the third. He likewise composed several other operas in England about the year 1721, at which time the royal academy of music was established; and is said to have introduced into that country, for the first time, the instrument called the viol d'amour, on which he performed a new symphony at the sixth representation of Handel's Amadis, on the 12th July, 1716, soon after his arrival. He then went abroad, but again returned in 17\%0, and composed several operas. He once more left England, after publishing a book of cantaths by subscription; and the place and date of his death are unknown.

Arıosto, Ludovico, one of the most celebrated poets of Italy, was born at Reggio, in Lombardy, Sept. 8,1474 , of a noble family. His father was a member of the first judicial court at Ferrara. He w as the eldest of ten children. Even in his childhood, he prepared tragedies, which he acted with his br others; among others, one founded on the story of $P$ yramus and Thisbe. In the school of Ferrara, he distinguished himself in his studies. His father designed him for the profession of the law; but, after five years of fruitless application to it, the young man renounced the study, that he might devote himself to literature. He enjoyed the instructions of the learned Gregory of Spoletto. Plautus and Terence, whom he studied with this teacher, furnished thoughts for two comedies, the Cassandra and the Supposti, which he there planned. His lyric poems, in the Italian and Latin languages, distinguished for ease and elegance of style, introduced him to the notice of the cardinal Ippolito d' Este, son of duke Ercole I. In 1503, Ippolito fixed him at his court, used his counsel in the most important affairs, and took him with him on a journey to Hungary. After the death of Ercole, Alfonso, his soll and successor, put the same confidence in A. At this court he began and finished, amid distractions of every kind, in ten or eleven years, his immortal poem, the Orlando Furioso. In 1516, the printing of it was finished." When Ariosto gave a copy to the cardinal, the latter said, "Master Louis, where did you pick up all this trumpery ?" In 1517 or 1518 , A. was invited to accompany the cardinal Ippolito d' Este on a second journey to Hungary. The unhealthy climate and the infirm health of the poet appeared to him no sufficient apology ; and, on declining to attend him, therefore, A. lost for ever the cardinal's favour, which gradually passed from coldness and indifference to settled hatred. A. was now received by the noble duke Alfonso, a lover of the arts, who put much confidence in him, but bestowed on hịm only trifling rewards, and (what seemed more like a punishment than a mark of favour), in 1521 and 1522, commissioned him to quell the disturbances that had broken out in the wild and mountainous Garfagnana. He successfully accomplished this difficult enterprise, and, after three years, returned to Ferrara, where he employed himself in the composition of his comedies, and in putting the last touches to his Orlando. He died $¥$ une 6,1533 , at the age of 58. A. had a good figure, a gentle character, polished mamers, and an amiable disposition. He had been rich, and he loved splendour. He was obliged to content himself, however, with a small, but convenient and pleasant house, orer which he caused the following verses to be inscribed :-

Parva sed apta mihi, sed nulli obnoxia, sed non Surdida, parta meo sed tamen xere domus.
His Orlando Furioso, which is a continuation of Bo:ardo's Orlando Innamorato, and cannot be perfectly understood without it, is a perfect epic romance, full of the fairest flowers of poetry, and of freshness and spirit, in which $A$. far excels even 'Tasso. The $O r-$ lando displays a splendid and inexhaustible richuess of invention, an ever-changing variety of incidents connected with the talent of lively narration. The activity of a youthful fancy animates the whole work. A. exhibits, also, a wonderful skill in interweaving the episodes, which he continually interrupts, and again takes up with an agreeable, aud often inper. ceptible art, and so intwines them with one another, that it is difficult to give a connected history of the contents of the poem. These qualities place him among the great masters of poetry, and have gained for him, among his countrymen, the appellation of divine. Besides this great epic, we have some comedies, satires, capitoli and sonnets by $A_{\text {., and a collec- }}$ tion of Latin poems, in all of which the richness of his genius shines with more or less brightness.

ARISTeds, in mytliology, son of Apollo and Cyrene, was brought up by the Nymphs. The introduction of the use of bees is ascribed to him (hence he is called Melissceus), and gained for him divine honours. His love of Eurydice, the young bride of Orpheus, caused her death ; for, as she fled from him, along the side of a river, she received a mortal bite from a poisonous snake. He was punished by the loss of his bees. The loss, however, was repaired by new swarms, produced, after nine days, in the bodies of some cattle which he had slain. He was the son-in-law of Cadmus, and father of Actæon. He has been confounded with the Proconnesian Aristaus, who appeared on earth from time to time, e. g., as the instructer of Homer, and, afterwards, as a scholar of Pythagoras. This is explained by the fact, that there was a scholar of Pythagoras of this name, who succeeded that plilosopher, and whose whole life was afterwards in.. volved in fable.

ARISTARCHUS; a Greek gTammarian, who criticisel Homer's poems with the greatest severity, and established a new text ; for that reason, severe and just critics are often called Aristarchi. He was born in the island of Samothrace, and lived at Alexandria about B. C. 150. Ptolemy Philometor, who highly esteemed him, confided to him the education of his children. After having spent his life in criticising Pindar and other poets, especially Homer, he died at Cyprus, aged 72.

Aristarchus of Samos, born B.C. 267, was a famous astronomer, who first asserted the revolution of the earth about the sun. His work on the magnitude and distance of the sun and moon is still extant. He is also regarded as the inventor of the sun-dial.

ARISTIDEs, for his strict integrity surnamed the.Just, was the son of Lysimachus, and descended from one of the most honourable families of Athens. He was one of the ten generals of the Athenians, when they fought with the Persians at Marathon. According to the usual arrangement, the command of the army was held by each of the generals, in rotation, for one day. But Aristides, perceiving the disadvantages of such a change of commanders, prevailed on his collengues each to give up his day to Miltiades; and to this, in a great measure, must be ascribed the victory of the Greeks. The year ensuing, he was archon, and, in this office, enjoyed so universal a popularity, that he thereby excited the jealousy of Themistocles. This ambitious man, not daring, openly, to attack his rival, contrived to spread a report, that A. was aining at a kind of sovereignty, and, at last, succeeded in procuring his banishment by the ostracism. It is said, that a rustic citizen, who happenerd to stand near $A$. in the public assembly whiclı decreed 
lis banishnent, turned to hin; without knowing who he was, and asked him to write the name of A ristides upon the shell with which he was going to vote. "Has Aristides injured thee?" inquired he. "No," answered the voter; " but I am tired of hearing him called the Just." A. wrote his uame, and returned the shell in silence to the voter. He left the city, with prayers for its welfare. Three years after, when Xerxes invaded Greece with a large army, the Athenians hastened to recall a citizen to whou they looked for aid in this emergency. Forgetting every thing but the good of his country, upon receiving intelligence that the Greek fleet was surrounded, at Saianis, by the Persians, he lastened thither with all speed, to warn Themistocles of the danger which threstened him. Touched by his generosity, Themistocles admitted him at once to his confidence, telling him that the report had been purposely spread by himself, to prevent the separation of the Grecian fleet. He also invited him to assist in the council of war, and, having determined on battle, posted him on the little island of Psyttalia, where those, whose ships were sunk during the engagement, found refuge. Iu the battle of Platea, A. commanded the Athenians, and had a great share in the merit of the victory. It is thought that he was again archon the year following, aud that, during this time, he procured the passage of the law by which the common people were admitted to all public offices, even that of archon. On oue occasion, when Themistocles announced that he had formed a project of great importance to the state, but which he could not make known in a public assembly, the people appointed $A$. to confer with him on the subject. The project was to set fire to the combined feet of the Greeks, which was then lying in a neighbouring port, and thereby to secure to the Athenians the surereignty of the sea. A. returned to the people, and told them that nothing could be more advantageous, but, at the same time, nothing more unjust, than the plan of Themistocles. Tlie plan was at once rejected. 'To defray the expenses of the Persian war, he persuaded the Greeks to impose a tax, which should be paid into the hands of an officer appointed by the states collectively, and deposited at Delos. The implicit confidence which was felt in his integrity appeared in their entrusting him with the oflice of apportioning the contribution, $\rightarrow$ an office which he executed with universal satisfaction. He died at a very advanced age, and, what most strikingly evinces his integrity and disinterestedness, so poor that he was buried at the public expense. He left two daughters, who receired dowries from the state, and a son, who was presented with 100 silver minæ, and a tract of wood-land.-Aristides Elivs, a famous rhetorician, born A. D. 129, in Bithynia, after travelling for some time, settled in Smyrna. When the city was destroyed by an earthquake, A. D. 178, A., by his influence with the emperor Antoninus, had it rebuilt. The inhabitants showed their gratitude for this service by erecting a statue to him. The merit of his orations, of which forty-five are yet extant, consists only in the splendour of the language, by which the einptiness of the matter is tolerably well concealed.-Another Aristides, a Theban painter, contemporary with Apelles, flonrished B. C. 240. A famous picture of his is spoken of by Pliny, representing a mother, in a captured town, mortally wounded, with an infant sucking at her breast, who, she is apprehensive will suck blood instead of milk; it became the property of Alexander the Great. Several other very famous pictures of his are also mentioned, for one of which Attalus, king of Pergamus, is said to have given 100 talents. Expression seems to have been the great excellence of this ancient artist. ... Aristides was also the nane of a Christin philosopher in the $2 d$ cen. tury.

Antstipus ; the founder of a celebrated philosophical school among the Greeks, which was called Cyrenaic, from his native city, Cyrene, in Africa. He flourished $380 \mathrm{~B}$. C. Being sent by his wenltliy father to Olympia, probably to take part there in the chariot-races, he heanl Socrates spoken of, and was so desirous to receive instruction from him, that he immediately hastened to Atheus, and iningled with his disciples. He did not, however, adopt all the principles of this plilosopher. Like him, he thouglt that we should refrain from speaking of things which are beyond human compreheusion, and likewise pait but litile attention to the pliysical and mathematical sciences; but his moral philosophy differed widely from that of Socrates, and was a science of refiued voluptuousuess. His fuudamental priuciples were, that all human sensations may be reduced to twopleasure and pain. Pleasure is a gentle, and pain a violent emotion. All living beings seek the former, and avoid the latter. Happiness is nothing but a continued pleasure, composed of separate gratifications; and as it is the object of all liuman exertions, we should abstain from no kind of pleasure. Stil we should always be governed by taste and reason in our enjoyments. As Socrates disapproved of these doctrines, they were the cause of many disputes between him and his disciple; and it was, probably, to avoid his censures, that Aristippus spent a part of his time at Egina, where he was when his master died. He made many journeys to Sicily, where he met with a very friendly reception from Dionysius the tyrant. The charms of the celebrated Lais allured him to Corinth, and he hecame very intimate with her. When he was reproached with squandering so much money upon a woman who gratuitously surrendercol herself to Diogenes, he answered, "I pay her that she may grant her favours to me, not that she niay refuse them to another." He said, another time, "I possess her, not she nı." (See Lais.) Diogenes Laertius is unt to be credited, when he says that Aristippus opened a school after he returned to Athens, as we know of no disciple instructed by him. His doctrines were taught only by his daughter, Arete, and by his grandson, Aristippus the younger. Other Cyrenians compounded them into a particular doctrine of pleasure, and are hence called Hedonici. The time of his death is unknown. His writings are lost. Wieland's historico-philosophical romance (Aristippus and some of his Contemporaries) gives us a lively and highly interesting delineation of the life and doctrines of this amiable sensual philosopher. We have many sayings of his preserved. To one who asked him what his son would be the better for being a scholar, "If for nothing else," said he, "yet for this alone, that when he comes into the theatre, one stone will not sit upon another." Being asked why philosophers frequented the houses of the great, while the great disregarded those of the philosophers, he replied, "because the former know what they want, and the latter do not." When a certain person recommended his son to him, he demanded 500 drachmas; aul upon the father's replying to him that he could buy a slave for that sum, "do so," said he, "and then you will be master of a couple." Being repronched, because having a suit at law depending, he feed a lawyer to plead for him, "just so," said he, "when I have a great supper to make, I always hire a cook." Being asked what was the difference betwe en a wise man and a fool, he replied, "send both of them to gether naked to those who are acquainted with neither of them, and then you will know."

Aristocracy. See Government.

Amstogrton; a citizen of Athens, whose name is 
rendered famous by a conspiracy formed, in conjunction with his friend Harmodius, against the tyrants Hippias and Hipparchus, the sons of Pisistratus. They succeeded in killing Hipparchus (514 B. C.); but, not being seconded by the people, Harmodius was despatched by the guards, and A. secured. Hippias instituted a severe inquisition into the plot, and tortured A. to discover his accomplices; upon which he is reported to have named all the best friends of the tyrant in succession, and they were immediately put to death. On being asked by Hippias if there were any more, "There now remains," said Aristogiton, with a sinile, "only thyself worthy of death." Hippias being expelled three years after, the Athenians pair the greatest honours to the two friends Harmodius and Aristogiton, placing in the form their statues by Praxiteles, singing hymns to their praise at the Panathenzea, and decreeing that no slave should ever bear their names. See Plutarch and Thucydides.

ARIsTosents ; a young, valiant hero, and leader of the Messenians against the Spartans, B. C. 68:. The story of his escape from a deep cavern, into which he had been thrown by the Spartans, by creeping through a fox.hole, is extraordinary, but not well authenticated. Notwithstanding his boldness and heroic courage, he could not prevent the subjection of the Messenians.

Aristophases, the only Grecian comic poet of whom any pieces have been preserved entire, was the son of a certain Philippus, and probably by birth an Athenian. He appeared, as a poet, in the fourth year of the Peloponnesian war, B. C. 427; and, having indulged himself in some sarcasms on Cleon, at that time a powerful demagogue, was accused, by the latter, of having unlawfully assumed the title of an Athenian citizen. He defended himself before the judges merely with the known verses of Homer:

To prove a genuine birth (the prince replies), ()n female truth assenting faith relies:

Thus manifest of right, I build my claim,

Sure founded, on a fair maternal fame.

Ulysses' вon. Pope's Od. i. 275-9.

and, when the same accusation was renewed against him, he succeeded in repelling it a second time. He afterwards revenged himself on Cleon, in his comedy of the Knights, in which he himself acted the part of Cleon, because no actor had the courage to do it. This little remains to us of the life of $A$ who was distinguished, among the ancients, by the appellation of the comedian, as Homer was by that of the poet. Of fifty-four comedies which he composed, eleven only remain ; and in these, without doubt, we possess the flower of the aucient comedy, which, in his last play, the Plutus, borders on the middle; but; in order fully to enjoy them, and not to be offended by the extravagances and immoralities with which they abound, we must be intimately acquainted with ancient customs and opinions. His pure and elegant Attic dialect, the skill and care displayed in the plan and execution of his pieces, and their various other excellencies, have gained for $\mathrm{A}$. the fame of a master. His wit and humour are inexlaustible, and his boldness unrestrained. The Greeks were enchanted with the grace and refinement of his writings; and Plato said, the Graces would have chosen his sonl for their habitation. "According to our ideas of decon rum," says a late scholar, "we should esteem the soul of A. a fitter residence for the licentions and malicious satyr, or, at least, we should call him, with Gœthe, the spoiled child of the Graces." He made use of allegory in his attacks on the proliticians of the day, as well as in scourging the vice and follies of his age. In a political and inoral view, he is a strong adrocate for ancient discipline, manners, doctrines, and art; hence his sallies against Socrates, in the Clouds, and against Euripides, in the Frogs and other comedies. The freedom of ancient comedy allowed an unbounded degree of personal satire, and Aris. tophanes made so free use of it, that nothing which offered a weak side, escaped his sarcasms. He feared the Athenian people so little, that he personated them, under a most miserable figure, in his old Demos. He incessantly reproached them for their fickleness, their levity, their love of flattery, their foolish credulity, and their readiness to entertain extravagant hopes. - Instead of being irritated, the Athenians rewarded him with a crown from the sacred olive-tree, which was, at that time, considered an extraordinary mark of distinction. This excessive freedom characterized the ancient comedy, which was long considered as a support of democracy. After the Peloponnesian war, its licentiousness was much restrained; and, in the year $388 \mathrm{~B}$. C., it was forbidden by law to name any person on the stage. At that time, A. produced, under the name of his eldest son, the Cocalus, a play in which a young man seduces a maiden, and, after having discovered her descent, marries her. With this play the new comedy began. A., who was very old, appears to have died soon after. - The best editions of his comedies are those of I. Kuster, Amsterdam, 1710, fol. ; Bergler, Amsterdam, 1760, 2 vols., 4to ; Brunck, Strasburg, 1781, 4 vols., 4to and 8vo ; Invernizio, Leipsic, 1794, 2 vols., with Beck's commentaries. An 'Engglish version of "the Clouds" was given by Cumberland in the Observer; and a translation of the greater part of A.n with introductions, bas been published by Mr Mitchell, in 2 vols. 8 vo., Lond. $1820-22$.

ARISTOTLE, one of the most celebrated philosophers of Greece, and founder of the Peripatetic sect, was born at Stagira, in Macedonia, in the Ist year of the 99th Olympiad (384 B. C.) Nicomachus, his father, claimed descent from Machaon, the son of Esculapius ; Phæstis, his mother, was also of noble extraction. The profession of medicine was hereditary in the family of the Asclepiadæ; and Aristotle's father, who was physician to king Amyntas, had pursued it with reputation and success. He designed his son for the same profession, and probably instructed him in the science of medicine, and the philosophy connected with it. He doubtless owed to his early education his inclination for the study of natural history, of which he is to be regarded as the founder, since he was the first who made accurate observations. After the death of his parents, he went, at the age of eighteen, to Atarnea, and lived with one Proxenus, a friend of his family, who did nuch towards his further education and improvement. Here he staid a short time, and then repaired to Athens. A. remained, during this his first abode in Athens, about twenty years; and, not content to continue merely a hearer of Plato, whose school was then in high re. nown, he opened a school of rhetoric himself, and became the rival of Isocrates. He probably com. posed, also, some philosophical works, the fame of which reached the ears of Philip of Macedon. It is certain, at least, that this king wrote to him, soon after Alexander's birth, 356 B. C., the celebrated letter,- " King Philip of Macedon to Aristotle, greet. ing. Know that a son has been born to me. I thank the gods not so much that they have given him to ine, as that they have permitted him to be born in the time of Aristotle. I hope that thou wilt form him to be a king worthy to succeed me, and to rule the Macedonians." Several writers affirm that A. quarreled with Plato a short time before the death of the latter, and, in consequence, set up his 
sclicol in opposition to the Platonic. It is certain that there was some dispute hetween the two plilosophers, but it never cane to an open rupture. $\Lambda$. constantly manifested the highest reverence for his teacher, and everywhere, in his works, speaks with great respect of him, even when he criticises hin. The Atleuiaus having declared war against Philip, soou after Plato's death, $\boldsymbol{\Lambda}$. left $\Lambda$ thens for $\mathbf{\Lambda}$ tarnen, where his friend Hermins was sovereigu. Hermins soon after was betrayed into the hnuds of Artaxerxes, who dishonourably put him to death. A., deeply moved by the fate of his friend, sought to perpetuite his memory by an ode, which is rich in poetical beauties; and espoused his niece. It appears that A. lived some time after the death of his friend at Mitylene; but, towards the year 343 B.C., he was invited by Philip to his court, to take charge of the education of Alexander, who was then thirteen years old. The particulars of his method of instruction are not known to us; but when we see the greatness of mind which Alexander displayed in the first years of his reign,-his command of his passions, till flattery had corrupted him, and his regard for the arts and sciences, - we camnot but think that his education was judiciously conducted. It may be objected, that Aristotle neglected to guard his pupil ngainst ambition and the love of conquest ; but it must be recollected that he was a Greek, and, of course, a natural enemy to the Persian kings; his hatred had been deepened by the fate of his friend Hermias; in short, the conquest of Persia had, for a long time, been the wish of all Greece. It was, therefore, natural that Aristotle should exert all his talents to form his pupil with the disposition and qualifications necessary for the accomplishment of this object. Both father and sun sought to show their gratitude for the services of such a teacher. Philip rebuilt Sta gira, and established a school there for Aristotle. The Stagirites, in.gratitude for this service, appointed a yearly festival, called Aristotelia. A. continued at Alexander's court a year after his accession to the throne, and is said to have then repaired to Athens. Ammonius the Eclectic says that he followed his pupil in a part of his campaigns; and this seems rery probable, because it is hardly possible that so many animals as the philosopher describes could have beel sent to $A$ thens, or that he could have given so accurate a description of them without having personally dissected and examined them. We may conjecture that he accompanied Alexander as far as Egrpt, and returned to Athens about 331 B. C., provided with the materials for his excellent History of Animals. Here he opened a school of philosopliy in the Lyceum, a gymnasium not far from the city. Thither he went twice a.day. The forenoon was devoted to his most intimate pupils, when he explained to them the difficult parts of science. 'In the evening, he admitted all those who were desirous of hearing him, while he discoursed, in a familiar and intelligible way, on subjects more nearly connected with common life. Accordingly, lis works also are divided into the esoteric or abstruse, and the exoteric or familiar. Alexander aided his extensive studies by sending him presents from Asia, and, as a reward for his services, gave him 800 talents. Notwithstanding this, lie afterwards conceived an enmity against his tutor. At the death of that prince, 334 B. C., A. was reported to be concerned in his pretended assassination. The Athenians, now hoping to recover the command of Greece, endeavoured to prevail on the other states to take arms against the Macedonians, and Aristotle became an object of suspicion, on account of his connexion with Philip, Alexander, and Antipater. The demagngues, supported by his numerous enemies, wok this opportmity to accuse lim. To escape pro- seculion, on a charge of atheism, he left $\Lambda$ thens with the observation (alluding to the condemnation of Socrates), that he would spare them the guilt of a second crime against philosophy. He retired, will most of his scliolars, to Chalcis, in Eubcen, where he shortly after took poison, 32\% 13. C., on being summoned, as it is sait, to appear before the court of areopagus at $\Lambda$ thens, to answer to the accusation against linı. (For his doctrines and sect, see Philosophy, I'eripatetic.)-The works of Aristotle, which were not published during his lifetime, first became known to the world when the Romans began to devote themselves to philosopliy. The original manuscripts of his works, and those of Theophrastus, were brought by Sylla to Rome, with the library of Apellicon. Andronicus of Rhodes arranged them, and furnished them with indices. Many of his important works are now lost. 'Those yct extant, according to the edition of Sylburg, 5 vols., 4 to., Frankfort, 1587, which is esteemed the best, are thi: following:-Organon; Rhetorica et Poctica; Ltlicu ad Nicomachum; Ethica Magna ; Politica et Aconomica; Animalium Historia; De Animalium Partibus; Physica Auscultationis, lil). xiii., et alia Opera; De Calo; De Generatione et Conceptione; De Mete. oris, lib. iv.; De Mundo; De Anima ; Purva Naturalia; Varia Opuscula; Aristotelis, Alexandri et Cascii Problemata; Aristotelis et Theophrasti Metaphysica.-Besides the edition abore-mentioned, those of Casaubon and Duval are esteemed. The latest edition is that of Buhle, not yet completed. See Philosophy.

ARITH MiETic (from the Greek aeifeos, number); a branch of mathematics, the object of which is, to combine numbers according to certain rules, in order to obtain results which satisfy given conditions. These rules, methodically arranged, form a science, to which the name of arithmetic is given. This science is very ancient, and we find it (of course, in v(ry different degrees of perfection) among all natious. The Greeks, it is well known, were ignorant of our system of decimal notation, the simplest and most perfect of all inventions. They marked numbers laboriously by help of the letters of their alphabet; and, though this method received successive improvements, it was still unavoidably complicated, and altogether irregular in the form of its constitution. The idea of number is one of the latest and most difficult to form. Before the mind can grasp such an abstract conception, it must be familiar with that process of classification by which we successively remount from individuals to species, from species to genera, aul] from genera to orders. The savage is soon lost in his attempts at numeration; and significantly expresses his inability to proceed, by lolding up his expanded fingers, or pointing to the hairs of his head. The classification by pairs, which nature points out, would suggest the simplest mode of reckoning. 'The Dual accordingly, though retained by the Grecks, occurs in the languages of all barbarous tribes. Counting these pairs again by two's, and repeating the same procedure, we arrive, by progressive steps, at the radical terms $4,8,16$, \&c., to whicl the other numbers are ensily reducible. Thus, 13 being conposed of 8,4 , and 1 , would, according to such a sys tem of numeration, be called " quadruple pair, double pair, and one," or denominated more concisely lyy words of corresponding import. This plan of arrangement, termed the binary scale, seems, at a certain period of society, to have prevailed in most countries. Vestiges of it are still found among the Chinese; and Leibnitz has extolled the system with abundant extravagance. It would, no doubt, from! its naked simplicity, supersede the application of tlought, and reduce all the operations which orc:ur 
In s rithmetic to the mere labour of writing; but toshing would thus be gained in practice, since, advancing witl excessive stowness, it would soon require a multiplicity of words, and a fatiguing complication of characters. The binary scale appears best adapted to the descending progression; for the fractions produced by a continued bisection, are, from the equal competition of buyer and seller, naturally introduced into commercial transactious, and employed almôst exclusively among the Eastern nations. This subdivision is likewise used with convenience in Europe, for ascertaining the smaller weights. The next step in the progress to numeration, was probably to assume the double pair, or foner, as the root of the scale. In counting over small articles, it is customày, for the sake of expedition, to take a couple in each hand; and therefore, the throw, or, in older language, the warp, becones, in this way, the measure of tale. The ancient Mexicans appcar to have reckoned by fours, and to have afterwards advanced, in their numcration, by combining the products of four with those of ten. Nor is it altogether improbable that Pythagoras might lave alluded to such a system of computation, in celebrating the m5stical properties of his famous tetractys, or quaternion. But nature has furnished the great and universal standard of computation, in the fingers of the hand. All nations, accordingly, have reckoned by fives; and some barbarous tribes have scarcely advanced farther. Aristotle, who was aware of the principle, has noticed the existence of such a people in Africa. After the fingers of the one liand laad been counted over, it was a second, and perhaps a distant step, to yroceed to those of the otlier. The primitive words :xpressing numbers probably exceeded not five. 'To denote six, seven, eight, and nine, the North American Indians repeat the five, with the successive addition of one, two, three, and four. The same composition is apparent in the various dialects spoken by the inhabitants of the islands which are so widely scattered over the Southem Ocean. Could we safely trace the descent and affinity of the abbreviated terns denoting the numbers from five to ten, it seems highly probable that we should discover a sinilar process to have taken place in the formation of the most refined languages. The alphabet must in ceneral have been framed before any regular system for notatiou of numerals was invented. In forming suel a system, the obvious method was to imitate as nearly as possible the progress by which the mind ascends the scale of numeration; but the simplicity and unifornity of this procedure were in the sequel frequently disturbed, by adopting such alphabetic claracters as happened to resemble the compound symbols, or by employing, for the sake of abloreviation, the initial letters of words significant of the numbers themselves. The Roman numerals, having undergone little șubsequent change, may be considered as the most ancient specimens of notation. To denote one, a simple vertical stroke was assumed I; and the repetition of this expressed two, three, \&c. Two decussating strokes $X$ marked the next step in the scale of numeration, or ten; and that symbol was repeated to signify tu'enty, thirty, \&c. Three strokes, or au open square [-, were employed to denote a hundred, or the third stage of numeration; and four interwoven strokes $M$, sometimes incurved $M$, or even divided clo, expressed a thousand. Such are all the characters absolutely required in a very limiterl system of numeration. The necessary repetition of them, however, as often occasionally as nine times, was snon found to be tedious and perplexing. Rednced or curtailed marks were, therefore, employed to express the intermediate multiples of five; and this improvement must have taken place at a very early period. Thus, fine itself was denoted loy the upper half $V$, and sometimes the under lalf $A$, of the character $X$ for ten; $L$, or the half of $\square$, the mark for a lundred, came to represent fifty; and the incurved symbol $r$, or $\mathrm{clo}$, for a thousand, was split into lo, to express five hundred. These important contractions having been adopted, another convenient abbreviation was introduced. To aroid the frequent repetition of a mark, it was prefixed to the principal character, and denoted the defect by counting back. wards. 'Thus, instead of four succeeding strokes IIII, it seemed preferable to write i $\mathrm{V}$; for eight and nine, the symbols were $\| X$ and $1 X$; and ninety was expressed by $X[$. This mode of reckoning by the defect was peculiar to the Ronians, and has evidently affected the composition of their numerical terms. Instead of octodecim and novendecim, it is held more elegant, in the Latin language, to use undevigint and duodeviginti. But the alphabetic characters now lent their aid to numeration. The uniform broad strokes were dismissed, and those letters which most resembled the several combinations were adopted in their place. The simple stroke | for one, and the marks $\mathrm{V}, \mathrm{X}$, and $\mathrm{L}$, for five, ten, and fifty, were respectively supplied by the letters $I, V, X$ and $L$. The symbol - for a hundred, was aptly denoted by $\mathrm{C}$, whieh had originally a square slape, and happened, besides, to be the initial letter of the very word centum. The letter D was very generally assumed as a near approximation to the symbol I') for five hundred; and $M$ not only represented the angular cliaracter for a thousand, but was likewise, though perhaps accidentally, the first letter of the word mille. The last improvement attempted in the Roman system of numerals, was devised for the purpose of expressing the numbers bayond a thousand. This innovation belongs evidently to an advanced period of society, and appears never to have been very generally embraced. The method of procecding, however, was perfectly analogical. Taking the complex symbol cIo for a thousand, the intermediate stroke was retained, while the $\mathrm{C}$ on each side of it was successively repeated, to mark the ascending progression by tens. Thus $\mathrm{c} \mathrm{c} \mathrm{I}$ o o and $\mathrm{c} \mathrm{c}$ c I 0 э 0 were made to signify, respectively, 10,000 and 100,000. The halves, again, of these compounded characters, or I 5 and I 505 , were employed to denote 5,000 and 50,000 . The oldest form of notation among the Greeks, and the systen of numerals retained by the Romans, were utterly incapable of any naterial improvement. They might serve laboriously to register a number that was not very large; but they could not afford the slightest aid in performing an arithmetical computation. By what ingenuity, for instance, could even such small numbers as 48 and 34 be multiplied together, if expressed by the complicated symbols XLVIII and XXXIV, where both the units and the tens are equally involved? But the Romans were late in acquiring any taste for refinement, and remained, during the whole course of their history, profoundly ignorant of science. In the few simple calculations which they had occasion to make, the Romans were obliged to liave recourse to a sort of mechanical process, employing pebbles or counters. Bors were taught that humble art at school, and carried with them, as implements of computation, a loculus, or box filled witl. pebbles, and a board on which these: were placed in rows, called Abacus, (q. v.) It is curions to observe, that the term calculation itself clainis no ligher descent than from calculus, a pebble. The labour of counting and arranging those pebbles was afterwards sensibly abridged, by irawing across the board a liorizontal line, above which eachi single pebble lad the power of five. In the progress of luxury, tali, or dies made of ivory, were used in- 
stead of pebbles, and small silver coins came to supply the place of counters. But the operations with the abacus were nuulered still more commodious, by substituting, for such tali or cominters, sunall lxwels strung on parallel threads, and sometimes pegs stuck along grooves. With such an instrument, it is not difficult to perceive how the simpler additions and suhtractious could be performed with tolerable expelition; but to accomplish a process of multiplicarion or division, even on the sınallest scale, must luve been a work of tedious and most irksome labour. Accountants by profession, among the Romans, were styled calculatoses, or rationarii. Various expedients see'm to lave been employed for shortening the nrithmetical operations. The different positions of the fingers were, for that purpose, used to a certain extent. Boethins treated largely of the subject; and even the venerable Bede has given very diffise rules for what was called digital arithmetic. When calculations with counters became more involved, the table on which they were performed, being necessarily of a very considerable size, was called the bench or bank; and lience our term for-an office where money transactions are negotiated. The court of exchequer, introduced into England by the Nornun conquest, and intended for auditing the revelue of the crown, lad its name from scaccarium, which, in modern Latin, signifies a chess-board. The acannts were cast up by the tellers, or computatores, on a large table covered with black cloth, chequered with white lines, on which were placed counters, or sinall foreign coins, to denote successively pence, shillings, and pounds ; proceeding afterwards, on the several distinctures of the cloth, by units, tens, hundreds, \&e. Sums of money were also rudely nuarked on tallies, so called because they consisted of white sticks of hazel or willow, split up and cut squtare at both ends; a very fine notch on them denoting a penny, one rather larger a shilling, and one still larger a pound; the notch next in size represented twenty pounds, a larger one expressed a hundred, and the largest of all a thousand. This very strange practice has been handed down to our own times ; a striking instance of the blind obstinacy with which ancient usages, however absurd and ridiculous they may through time have become, are yet retained in public offices, and especially in our courts of law. The introduction of the Arabic digits, which produced a total revolution in the system of modern arithmetic, is commonly ascribed to Gerbert, a Benedictine monk of Fleury, who, at the commencement of the eleventh century, was elevated to the papal chair, by the name of Sylvester II. That arlent reclesiastic, in an age of darkness and rooted prejudice, had yet the resolution to pass into Spain, and study for several years the sciences there cultivated by the Moors. On his return to France from this new pilgrimage, fraught with various and useful iniormation, he was esteemed a prodigy of learning by the Christians of the West; nor did the malice of his rivals fail to represent him as a magician leagued with the infernal powers. To the decimal system of notation with which he had become acquainted, Gerbert applied indifferently the old name abacus, or the Arabic term algorismus, compounded of the definite article $a l$ and the Greek word aptess, and signifying, therefore, the art of numbering. The knowledge of that art was farther extended, from the intercourse then opened with the East, by the crusaders and the Italian merchants who frequented the coasts of the levant. Yet it must for some time have made a very slow and obscure progress. The characters themselves appear to have been long considered in Europe as dark and mysterious. Deriving their whole force from the use made of the zero or cipher, so called from the Ambic wonl tsaphara donoting emply or void, this torm cance afterwants to express, in general, any secret mark. While the verb to cipher means to compute with figures, the plurase to urite in cipher still signifies the concealing a conmunication under private and concerted s5mbols. The Arabic characters occur in some arith. metical tracts composed in England sluring the course of the thirternth and fourteeuth ceutury, particularly in a work by John of Ilalifax, or Sacro-13osco; but another century elapsed before they were generally adopted. At first, they were used only partially, anl intermixed with the Saxon, or corrupted Roman, numerals. Their form also was grathally improved, and seens not to have been fully settled till about the riddle of the fifteenth century, the memornble epoch of the invention of printing. 'The following cut represents the progress of Eurupean numerals.

$123 \& 46 \wedge 8910$ mdest Msss.

$$
\begin{aligned}
& 1234 \text { h6へ } 8910 \text { Caxton, 14so. } \\
& 123 \text { हैy } 6 \wedge 8910 \text { shirwood, iss2. } \\
& 123496789 x \text { old French. } \\
& 1234567891 \% \text { old English. }
\end{aligned}
$$

But though our present numerals were cerlainly derived from the Arabians, throngh the medium of the Saracen conquerors of Spain, that imitative people laid no claim to the merit of the original discovery. The various tribes which wandered with their heris over the wide plains of Arabia, had continued for ages in a state of rude independence, till the enjoyment of ease and plenty, under the prosperous reigns of the caliphs, tempted them to cultivate letters and the physical sciences. Having once tasted the delight which knowledge imparts, they applied, with ardour and unremitting diligence, to procure information from every quarter. They seldorn, however, aspired to original efforts, but contented themselves with commenting on the writings of their admired instructors, or with slowly augmenting the stock of facts by their own laborious observations. They adopted with eagerness the geometry and astronomy of the Greeks, and joined to these refined sciences the decimal system of arithmetic, borrowed most probably. from the Persians, who had loug been the undisputed masters of India. According to Alsephadi, a learnd Arabian doctor, the people of India boasted of three discoveries, - the composition of the Golaila $\boldsymbol{W}^{*}$ adamna, or Pilpay's Fables-the game of chess-and the numeral characters. Maximus Planudes, a Greck author of the fourteenth century, bears the same testimony in his arithmetic, expressly styling it no-

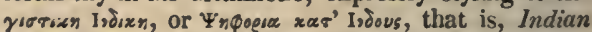
computation, or Calculation after the Indians; and he moreover subjoins, that the figures themselves were Indian. The characters given by Planudes scarcely differ at all from the Arabic, which, again, very nearly resemble the Persian, now universally used through the lower provinces of India. Planudes, by an omicron, represents the cipher, which is merely a full dot in the Persian, and a very small . in the Arabic; and his mark for five, which the Arabians denoted by a large $O$, resembles most nearly the Sanscrit. But the Arabians likewise employed occasionally, as we do, letters to signify numbers. In the astronomical tables of Ulugh Beigh, the numbers are set down in letters; and inis after the Arabian 
mode of writing, or in the order from right to left. In imitation of the Greeks also, the o which occupied the blanks in the sexagesimal system, is there supplied by a corresponding letter. Yet the Arabians, as well as the Persiaus, in copying the numeral characters, iuverted their usual order of writing, and proceeded from left to right, as it is universally practised wherever such a notation has prevailed. 'These circumstances, taken into combination, sufficiently prove that the decimal arrangement had been iuvented by a very different people. Our modern system of arithmetic has thus its origin distinctly referred to the genial climes of the Fast, where the human species was early ripened into some degree of refinement. Yet it does not thence follow, that the discorery was completed at a period of very remote antiquity. The ancient Egyptians, who, perhaps from their early communication with the people of Hindostan, entertained the same veneration for certain mystical properties of numbers, were yet unacquainted with the use of the numeral characters. If such an improvement in arithmetic had actually taken place when Pythagoras visited India, we can hardly suppose that the philosopher would have neglected to transport it into Greece, or imagine that an art so very simple could ever afterwards be entirely forgotten. The Brahmins themselves were not aware of the principle which they had struck out. They stopped short in their progress, and did not, like the Greeks, attempt the descending scale of numeration. The use of decimal fractions, we are assured, is even at present unknown to the natives of India; and accordingly, wherever fractional parts are concerned, they perform their operations with far less expedition than the Europeans. The people of Upper Asia have reached the precise stage of numeration which the Romans had attained. The Chinese einploy two kinds of numerals; - the one very complex, and formed by uniting their hieroglyphical cliaracters; the other simpler, and, allowing for their mode of writing from top to bottom, very nearly resembling the Roman, both in shape and composition. They express one, by a slender horizontal line, which was repeated downwards, and variously contracted, to signify the other digits ; ten, they denote by a thick vertical stroke, crossed by a horizontal line; twenty, thirty, \&c. are marked by reveating and condensing these strokes, always crossed by a slender line; a hundred is represented by two vertical strokes, with the addition of a third oblique one, and connected by three horizontal lines. To signify a thousand, the symbol for ten is used, with the addition of a broad oblique stroke; and to represent 2000 , 3000 , \&ce the same compound character is employed; only the marks for two, three, \&c. are annexed. Such involved symbols are evidently altogether unfit for aiding the purposes of calculation. The Chinese have, therefore, recourse to palpable arithmetic ; and their swan-pan is almost exactly the same as the lloman abacus. That instrument, universally used by all ranks throughout China, consists of a frame of wood, divided by a perpendicular bar into two compartments, which are intersected by a series of parallel wires having small balls strung on them, five balls being allotted on the left haud to each wire of the lavger, and two, equal ir power to ten, on the right and in the smaller compartment. 'The swan-pan is rather more extensive than the abacus, being composed generally of more than nine wires, and which nark so many places in the decimal system of arrangement. The Chinese appear also to have advanced a step beyond the Romans ; for, commencing the units from any intermediate wire, they proceeded either by the ascending or descending scale of numeration. Following the same principle. the subdivisions of weights and measures used in Chiur are almost entirely decimal; a circunstance which greatly facilitates their ordinary computations. The following cut represents a Chinese swan-par.

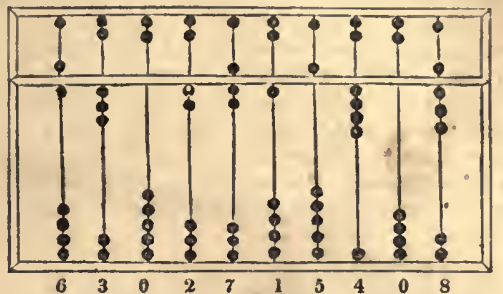

Among the many machines that have been invented for calculating numbers, none equal the one designed by Mr Babbage. That engine not only performs the operations of common arithinetic, but can also extract the roots of numbers, and approximate to the roots of equations, and even to their impossible roots. Its function, in contradistinction to that of all other contrivances for calculating, is to embody in machinery the method of difierences, whicls has never before been done ; and the effects which it is capable of producing, place it among the most astonishing efforts of mechanical genius. Great as the power of mechanism is known to be, many will scarcely admit it to be possible, that astronomical and navigation tables can be accurately computed by machinery; that the machine can itself correct the errors which it may conmit ; and that the results, when absolutely free from error, can be printed off without the aid of human hands, or the operation of human intelligence. "All this, however," says Sir David Brewster, in his entertaining Letters on Natural Magic, "Mr Babbage's machine can do ; and, as I have had the advantage of seeing it actually calculate, and of studying its construction with $\mathrm{Mr}$ Babbage himself, I am able to make this statement on personal observation." It consists essentially of two parts, a calculating, and a printing part, both of which are necessary to the fulfilment of the inventor's views, for the whole advantage would be lost if the computations made by the miachine were copied by human hands and transferred in types by the common process. The greater part of the calculating machinery, of which the drawings alone cover upwards of 400 square feet of surface, is already constructed, and exlibits workmanship of such extraordinary skill and beauty, that notling approaching to it has hitherto been witnessed. In the printing part, less progress has been made in the actual execution, in consequence of the difficnlty of its contrivance, not for transferring the computations from the calculating part to the copper, or other plate destined to receive them, but for giving to the plate itself that number and variety of movements which the forms adopted in printed tables may call for in practice. The practical object of the calculating Pugine is to compute and print a great variety and extent of astronomical and navigation tables, which conld not otherwise be done without enormous intellectiral and manual labour, and which, even if executed by such labour, could not be calculated witl the requisite accuracy. On the means of accomplishing this, Mr Babbage says, "As the possibility of performing arithmetical calculations by machinery may appear to non-mathematical readers too large a postulate, and as it is connected with the sulject of the division of labour, I shall here endeavour, in a few lines, to give some slight perception of the manuer in which this can be done; and thus to remove a small portion of the veil which covers that apparent mystery. That nearly all tables of numbers which 
follow any law, however complicated, may be formed, to a grutur or less extent, solely by the proper ar. rangenent of the successive uddition and subtraction of numbers befittung each table, is a general principle which can be demonstrated to those only who are well acquainted with mathematics; but the mind, even of the reader who is but very slightly acquainted with that science, will readily conceive that it is not impossible, by attending to the following example. Let us consider the subjoined table. 'This table is the beginning of one in very extensive nse, which lins been printed and re-printed very frequently in many conntries, and is called a table of square numbers.

\begin{tabular}{|c|c|c|c|}
\hline $\begin{array}{c}\text { Terma of } \\
\text { the Table. }\end{array}$ & $\begin{array}{l}\text { A. A. } \\
\text { sable of } \\
\text { squares. }\end{array}$ & $\begin{array}{l}\text { B. } \\
\text { Firut Dit. } \\
\text { ference. }\end{array}$ & $\begin{array}{c}\text { C. } \\
\text { Second } \\
\text { Dillerence. }\end{array}$ \\
\hline 1 & 1 & \multirow{2}{*}{3} & \multirow{2}{*}{2} \\
\hline 2 & 4 & & \\
\hline 3 & 9 & 5 & 2 \\
\hline 4 & 16 & 7 & 2 \\
\hline 5 & 25 & 9 & 2 \\
\hline 6 & 36 & \multirow{2}{*}{$\begin{array}{l}11 \\
13\end{array}$} & 2 \\
\hline 7 & 49 & & \\
\hline
\end{tabular}

Any number in the table, colnmn $\Lambda$, may be oblained by nultiplying the number which expresses the distance of that term from the commencement of the table by itsell; thus 25 is the fifth term from the beginning of the table, and 5 multiplied by itself, or by 5 , is equal to 25 . Let us now subtract each term of this table from the next succeeding term, and place the result in another column (B), which may be called first-difference column. If we again subtract each term of this first-difference from the succeeding term, we find the result is always the number 2 (column $\mathrm{C}$ ); and that the same number will always recur in that column, which may be called the second-difference, will appear to any person who takes the trouble to carry on the table a few terms further. Now, when once this is admitted as a known fact, it is quite clear that, provided the first term (1) of the table, the first turm (3) of the first-differences, and the first term (2) of the second or constant difference are originally given, we can continue the table to any extent, merely by simple addition: for the series of first-differences may be formed by repeatedly adding the constant difference 2 to (3) the first number in column B, and we then necessarily have the series of odd numbers, $3,5,7$, \&c. ; and again, by successively adding each of these to the first number (1) of the table, we produce the square numbers." Having thus thrown some light on the theoretical part of the question, $\mathrm{Mr}$ Babbage proceeds to show that the mechanical exe: eution of such an engine as would produce this series of numbers, is not so far removed from that of ordinary machinery as might be conceived. He imagines three clocks to be placed on a table, side by side, each having only one hand, and a thousand divisions instead of twelve hours marked on the face; and every time a string is pulled, each strikes on a bell the numbers of the divisions to which the hand points. Let it be supposed that two of the clocks, for the sake of distinction called B and $C$, have some mechanism by which the clock $\mathrm{C}$ advances the hand of the elock $\mathrm{B}$ one division for each stroke it makes on its own bell; and let the clock $\mathbf{B}$ by a similar contrivance advance the hand of the clock $A$ one division for each stroke it makes on iLs owu bell. Having set the ham of the clock $A$, to the division 1, that of $B$ to $11 \mathrm{I}$, and that of $\mathrm{C}$ to 11 , pull the string of clock $A$, which will strike one ; pull that of clock $B$, which will strike three. and at the same time, in eorr sequence of the mechanism we lave roferred to above, will advance the hand of $\mathrm{A}$ three divisions. Pull the: string of $C$, which will strike two and advance the. hand of $\mathrm{B}$ two divisions, or to division $\mathrm{V}$. Let this operation be repeated; $\Lambda$ will then strike fonr; 13 will strike five, and in sodoirg will sdrance the hand of $\mathrm{A}$ five divisions; and $\mathrm{C}$ will ugain strike two. at the same time advancing the land of $\mathrm{B}$ two divisions. Again pull $\mathbf{A}$, and it will strike nine; $\mathbf{B}$ will strike seven, and $\mathrm{C}$ two. If now those divisions struck, or pointed at by the clock $A$ be attended to and written down, it will be found that they produce a sories of the squares of the natural mumbers; and this will be the more evident, if the operation be continuel further than we have carried it. Such a series conkl of course he extended by this mechanism only so far as the three first figures; bnt this may be sufticient to give some idea of the construction, and was in fact, Mr Babbage states, the point to which the first model of his calculating engine was directed. In order to convey some idea of the power of this stuperulous machine, we may mention the effects produced by a small trial engine constructed by the inventor, and by which he computed the following table from the formula $x^{2}+x+41$. The figures as they were calculated by the machine, were not exhibited to the eye as in sliding-rules and similar instruments, but were actually presented to it on two opposite sides of the machine, the number 383 , for example, appearing in figures before the person $\mathrm{cm}-$ ployed in copying. The following table was cilclilated by the engine referred to:-

$\begin{array}{rrrrr}41 & 131 & 353 & 797 & 1373 \\ 43 & 151 & 421 & 853 & 1447 \\ 47 & 173 & 461 & 911 & 1523 \\ 53 & 197 & 583 & 971 & 1601 \\ 61 & 223 & 547 & 1033 & 1681 \\ 71 & 251 & 593 & 1097 & 1763 \\ 83 & 281 & 641 & 1163 & 1847 \\ 97 & 313 & 691 & 1231 & 1933 \\ 113 & 347 & 743 & 1301 & 2021\end{array}$

While the machine was occupied in calculating this table, a friend of the inventor undertook to write down the numbers as they appeared. In consequence of the copyist writing quickly, he rather more than kept pace with the engine at first, but as soon as five figures appeared, the machine was at least equal in speed to the writer. At another trial, thirty-two numbers of the same table were calculated in the space of two minutes and thirty seconds, and as these contained eighty-two figures, the engine produced thirty-three figures every minute, or more than one figure in every two seconds. On a subsequent occasion, it produced forty-four figures per minute; and this rate of computation could be maintained for any length of time. See Mathematics.

Arivs. See Arians.

ARK ; the name applied, in our translation of the Bible, to the boat or floating edifice in which Noah resided during the flood or deluge; derived, undoubtedly, from the Latin arca, a chest, or ressel. (Sce Deluge.) - In the synagogue of the Jews, the chest, in which the tables of the law were preserved, bore the name of the ark of the covenant. This was a small chest or coffer, three feet nine inches in length, two feet three inclies in breadth, and the same in height, in which were contained the various sacred articles mentioned in the quotations. It was mide 
of shittim-wood, and covered with the mercy-seat, called also the propitiatory, as the Septuagint expres-

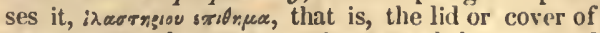
propitiation; because, in the typical language of Scripture, those sins which are forgiven are said to be covered. This lid was made of pure gold : at eitlier end was a cherub : these looked towards each other, and embraced the whole circumference of the inercy-seat witl their expanded wings ( $E x . \times x v .17$, :2, and-xxxix. 1-9); between which the Shechinah, or symbol of the divine presence manifested itself in the appearance of a clond, hovering, as it were over the niercy-seat (Lev.xvi. 2). From hence the divine oracles were given (2 Kings xix. 15; Isa. lxxx. 1). The ligh priest once every year, on the great day of expiation, appeared before the mercy-sent, to make atonement for the people, (Heb. ix. 7). The ark was placed in the sanctuary of the temple of Solomon: before his time, it was kept in the tabernacle, and was moved about as circumstances dictated. At the captivity, it appears to have been either lost or destroyed; for thic Jews universally concur in stating that, among the things wanting in the second temple, one was the ark of the covenant.

ARKANSAS ; a territory or district of country belonging to the United States, bounded $N$. by the territory and state of Missouri, E. by the Mississippi, which separates it from the states of Tennessee and Mississippi, S. by Louisiana and Mexico, and W. by Mexico; length, from E. to W., 550 miles; mcan bruadth, about 220 ; square miles, abcut 120,000; betwern lo11. $90^{\circ}$ and $100^{\circ} \mathrm{W}$.; lat. $32^{\circ} 40^{\circ}$ and $36^{\circ} 30^{\prime} \mathrm{N}$. 'This is the usual statement of the size of the territory; but the limits of what is properly called $A$. territory have been lately reduced, so that it now contains about 45,000 square miles. Population in 1810, 1062; in 1820, 14,273; slaves, 1,617 . It was erected into a territorial gosernment in 1819 . The number of counties, in 1820 , was seven, and, in 1828, fifteen. Little Rock is the seat of government. According to a report madc in congress, by one of the committees on public lands, the population of Arkansas, probably, would amount, in 1850 , to 35,000.- The Arkansas flows through the central part; the Mississippi forms the eastern, and Red river a part of the southern boundary. The other principal rivers are White, St Francis, and Washita or Ouachitta rivers. The Ozark (a provineial corruption of Arkunsas) mountains traverse the country from N. E. to S. W. The part of the territory between this range and the Mississippi is, in general, low and level, and, in many places, liable to annual iumdation. To the N. W. of the mountaius, the country cousists mostly of extensive prairies, without trees, except on the borders of the streams of water. The soil, on the rivers, is exceedingly fertile; but, in other parts, much of it is sterile. Throughout most of the country, there is a great scarcity of water. The climate is subject to great cxtremes of heat and cold, and is unhealtliy to new settlers. Arkausas was discovered and settled by the French, uncler the clicvalier de Tonti, as early as 1685 . In the various transfers of territory, it followed the fate of other parts of Louisiana, until February, 1819 , when, by a law of congress, that part of Louisiana between the state of Louisiana, or $\mathrm{N}$. lat. $33^{\circ}$, and the southeri boundary of Missouri, was erected into a separate territorial governinent, and sucli it continues to the present day.-Cotton and Indian corn are the staple productions. The country is exceedingly well adapted to the raising of enttle. Wild animals and fowls are abundant, as the buffalo, deer, alk, otter, beaver, rabbit, raccoon, wildeat, cathmount, wolf, bear, \&c. ; wild geese, turkeys, qunils, \&c. Of uninerals, there are iron, leail, coal, sitit, \&c. There are sereral salt springs, and, 1500 or 1400 miles up the Arkansas, is a tract called the sall prairie, which, according to governor Miller, is covered, for many miles, from four to six inches deep, with pure, white, crystallized salt. About 150 miles N.W. Arkansas, are the famous hot springs. They are muclı resorted to by invalids, and arc useful in chronic and paralytic affections. The temperature, in the driest seasons, is at the boiling point, but subject to considerable variation.-The principal tribes of Indians, in this territory, are the Osages, Cherokees, Quapas, Choctaws, Cadoes, Camanches, \&c.-Arkansas; a river of North America, which ises in the Rocky mountains, about $N$. lat. $40^{\circ}$, near the sources of the rio del Nortc, and near the horders of the territory of the Uniled States and Mexico. It forms a part of the boundary between the Missouri territory and Mexico, flows, through the central part of A.kansas territory, and unites witlı the Mississip/i, lat. $30^{\circ} 40^{\gamma} \mathrm{N}$. Its course is E. S. E. It is navigable for boats, at some seasons, 1980 miles; its whole length, following its windings, is 2170 miles. Its channel is broad, and its navigation safe, unobstructed by rocks, shoals, or rapids. Silver is found on this river, and much of the land on its banks is of the first quality.

ARK Fibuss. See Harquebuss.

AkKwRIGHT, Sir Richard, famous for his inventions in cotton-spinning, was born at Preston, in Iancashire, in 1732, of parents in liumble circumstances. He was the youngest of thirteen children, received but a very indifferent education, and was bred to the trade of a barber. In the year 1760, he liad estab. lished himself in Bolton-le-Moor, where he exchang. ed the trade of a barber for that of an itinerant hairmerclıant; and having discovired a valuable chemical process for dying hair, he was, in consequence, enabled to amass a little property. It is unfortunate that very little is known of the steps by which he was led to those inventions that raised him to distinction, and have immortalized his name. Ilis residence in a district where a considerable manufacture of linen goods, and of linen and cotton nixed, was carried on, must have given him ample opportunities of beconing acquainted witls the varions processes that were in use in the cotton nanufacture, and of the attempts that had been made, and were then making, to improve them. His attention was thus naturally drawn to this peculiar dejartment; and, while he saw reason to conclude that it was likely to prove the most advantageous in which lie could engage, he lad sagacity and good fortme to invent and inprove these cxtroordinary machines by which, unlike most inventors, he a massed vast wealth, at the same time that he added prodigiously to the demand for labour, and to the riches and comfort of the civilized world. The spinning-jenny, inventerl in 1767 by Hargraves, a carpenter at Blackburn, in Lancashire, gave the means of spinuing twenty or thirty tlireads at once with no more labour than had previously been required to spin a single tliread. .The thread spun by the jenny could no, however, be used, except as weft, being destitute of the firmness or liardness required in the longitudinal threads or warp. But Mr Arkwright supplied this deficiency by the invention of the spinning-frame-that wouder. ful piece of machinery, which sjins a vast number of thireads' of any degree of fineness and hardness, leaving to man merely to feed the macline witl cotton, and to join the thrends when they happen to break. It is not difficult to understand the principle on which this machine is constructed, and the mode of its operation. It consists of two pairs of rollers, turied by means of inachinery. 'The lower roller of each pair is furrowed or fluted longitudinally, and 
Whe upper one is covered with leather, to make them tike it holld of the cotton. If there were only one juir of rollers, it is elear that a carding of cotton, passed between them, would le drawn forwand by the revolution of the rollers; hut it would merely undergo a certain degree of compression from their action. No snoner, however, las the carding, or roving as it is technically termerl, begun to pass through the first pair of rollers, than it is received by the second pair, which are made to revolve with (as the case may be) three, four, or five times the velocity of the first pair. By this admirable contrivance, the roving is drawn out into a thresd of the desired degree of tenuity, a twist being given to it by the adaptation of the spindle and fly of the comnon flax wheel to the machinery. Such is the principle on which Mr Arkwright constructed his tumous spinning-frame. It is obvious that it is radically different from the previous methods of spimning either by the common hand-wheel or distaff, or by the jenny, which is only a modification of the cominon wheel. Spinning by rollers was an entirely original ider, and it is difficult to deternine which is noost worthy of admiration-the genius which led to so great a discovery, or the consummate skill and addre'ss by which it was so speedily perfected and reduced to practice. Mr Arkwright stated that he accidentally derived the first lint of his great invention from secing a red-hot iron bar elongated by being made to pass between rollers; and though there is no mechanical analogy between that uperation and his process of spinning, it is not difficult to imagine, that by reflecting upon it, and placing the subject in different points of view, it might lead him to his invention. The precise era of the discovery is not known; but it is most probable that the felicitous idea of spinning by rollers had occurred to his mind as early as the pericd when Hargraves was engaged in the invention of the jenny, or almost imnediately after. Not being himself a practical mechanic, Arkwright employed a person of the name of John Kay, a watchmaker at Warrington, to assist him in the preparation of the parts of his machine. Having made some progress towards the completion of his inventions, he applied, in 1767, to Mr Atherton of Liverpool, for pecuniary assistance to enable him to carry them into effect; but this gentleman declined embarking his property in what appeared so hazardous a speculation, though he is said to have sent him some workmen to assist in the construction of his machine; the first model of which was set up in the parlour of the house belonging to the free grammar school at Preston. His inventions being at length brought into a pretty adranced state, Arkwright, accompanied by Kay, and a Mr Smalley of Preston, removed to Nottingham in 1768, in order to avoid the attacks of the sane lawless rabble that had driven Hargraves out of Lancashire. Here his operations were at first greatly fettered by a want of capital. But Mr Strutt of Derby, a gentleman of great mechanical skill, and largely engaged in the stocking manufacture, having seen Arkwright's inventions, and satisfied himself of their extraordinary value, immediately entered, conjointly with his partner Mr Need, into partnership with him. The command of the necessary funds being thus obtained, Mr Arkwright erected lis first mill, which was driven by horses, at Nottingham, and took out a patent for spinning by rollers, in 1769 . But as the mode of working the machinery by horsepotrer was found too expensive, lie built a second factory, on a much larger scale, at Cromford, in Derbyshire, in 1771, the machinery of which was turied by a water-wheel, after the manner of the fanotis silk mill erected by Sir Thomas Lombe.
Having made several additional discoveries and im. provements in the processes of carding, roving, and spinning, he took out a fresh patent for the whole in 1775 ; and thus completed a series of machinery so various and complicated, yet so admirably combined, and well adipted to produce the intended effect, in its most perfect form, as to excite the astonishment and admiration of every one capable of appreciating the ingenuity displayed and the difficulties orercome. Whe'n the vast inportance of these discoveries became known, it is not surprising that every effort should have been made to have the patent set aside, and Mr A. deprived of the profit and honour to be derived from then. In 1781, he commenced actions ngainst a number of persons for invading them. Only onc: cause was tried, that against colonel Mordaunt, in the court of king's bench in July, 1781. Colonel Mordanut's defence was, that Mr Arkwright liad not fully communicated his inventions in the specification as required by law, and that, therefore, the patent was invalid. Mr Arkwright admitted tliat such was partly the case ; but added, that the obscurity charged against the specification had been intended ouly to prevent foreigners from pirating lis iuventions. A verdict, however, was given against him. In Feb. 1785, nearly four years after the first trial, which overturned the patent, a second action was tried in the court of Common Pleas, in which Mr Arkwright bronglit a number of artists to prove that they could make machines from his specification; in consequence of which he obtained a verdict. This verdict producing great alarm among many who had, at a great eXpense, erected machines for cotton spinning, from whom an acknowledgment of so much a spindle was demanded, in order to settle the dispute, a process on scire facius was brought against $\mathrm{Mr} \mathrm{A}$, in the court of king's bench, in which the whole question, not only on the point of the unintelligilhility of his suecification, but on the less technical and more im. portant ground of his not being himself the inventor of the nuchines for which he liad obtained a patent. After a long and ably conducted trial, a verdict was given agaiust $\operatorname{Mr} A$., and in Nov. 1785, the patent was cancelled. Notwithstanding this, none of $M_{1}$ A.'s most intimate friends, or tliose who were best acquainted with his character, ever had the slightest doubt with respect to the originality of his invention. Some of them, indeed, could spenk to the circumstances from their own personal knowledge; and their testimony was uniform and consistent. Such also seems to be the opinion now generally entertained among the principal manufacturers of Manchester. In proof of this, we may refer to Mr Keunedy's valuable paper, in the Manchester Memoirs. Mr Kennedy is one of the most eminent and intelligent cotton manufacturers in the empire, and it is of importance to remark, that, although he was resident in Manchester in 1785, when the last trial for setting aside Mr A.'s patent took place, and must, therefore, have beell well acquainted with all the circumstances connected with it, he does not insinuate the smallest doubt as to his being the real inventor of the spinning frame. Though a man of great persoulal strength, which he is said to have displayed when young, in election riots at Preston, $\mathrm{Mr}$ A. never enjoyed goorl health. During the whole of his splendid and evermemorable career of invention and discovery, he was labouring under a very severe asthmatic affection. A complication of disorders at length terminated his truly useful life in 1792, at his works at Cromford, in the 60 th year of his age. He was high sheriff of Derbyshire in 1786; and, having presented a congratulatory address from the wapentake of Wirks. worth, to his majesty George III., on his escape from the attempt on his life by Margaret Nicholson, re- 
celved the honour of knighthood. No inan ever better deserved his gool fortune, or lias a strouger claim on the respect and gratitude of posterity. H is inventions lave opened a new and boundless field of employment; and while they have conferred infinitely more real benefit on his native country than she could have derived from the absolute dominion of Mexico and Peru, they lave been universally productive of wealth and enjogments. "The originality and comprehensiveness of Sir Richard Arkwright's mind," says Mr Bannatyne, "was perhaps marked by nothing more strongly than the judgment with which, although new to business, he conducted the great concerns his discovery gave rise to, and the systematic order and arrangement which he introduced into every department of his extensive works. His plans of inanagement, which must have been entirely his own, as no establishment of a similar nature then existed, were universally adopted by others; and, after long experience, they have not yet, in any material point, been altered or improved." Sir Richard was twice married. By his first marriage he liad a son, the present Richard Arkwright, Esq. of Willersley Castle, near Cromford ; by his second marriage he had a daughter, now Mrs Cliarles Hurt, of Wirksworth, Derbyshire. Both liave numerous descendants.

Armada (Spanish); a fleet of ships of war. This term is applied particularly to that great naval armament, which was called the invincible armada, fitted out, in 1588, by Philip II., against queen Elizabeth. It cousisted of 150 ships, most of which were of a renarkable size, carrying 2650 guns, and having on hourd about 20,000 soldiers, and 8000 sailors, besides 2000 volunteers of the most distinguished families. This force was to be joined by 34,000 men, assembled in the neighbourhood of Dunkirk. The English navy, at that time, consisted of thirty ships of war; but it was reinforced by the voluntary exertions of the citizens, commanded by Howard, Drake, Hawkins, and Frobisher, and manned by the most skilful seamen in the world. The loss of their admiral, and a violent tempest, the day after they sailed, retarded, for some time, the operations of the Spaniards; and, on the voyage, they were harassed by the flying attacks of the English.- They arrived on the coast of the Netherlands in July, were thrown into disorder by a stratagem of lord Howard, and, in this situation, were attacked with such impetuosity, that it became necessary to attempt to return. Contrary winds obliged the Spanish admiral to make the circuit of the island, with the wreck of this magnificent armament. In passing the Orkneys, it was attacked by a violent storm, and only a feeble remnant returned to Spain. Elizabeth struck medals with the motto-Afflavit Deus et dissipantur.

Armadillo (dasypus, L.) ; a genus of mammiferous quadrupeds, belonging to the order edentata, inhabiting the lotter regions of the American continent. The species comprised within this geuus are provided with a remarkable, hard shell, consisting of scales or plates, arranged somewhat like a tessellated pavement or coat of mail, covering the head, body, and, in some species, the tail. This shell forms a sort of shield on the head; a second, very convex, protects the shoulders, and a third is extended over the rump; while the space intermediate to the two last is occupied by a number of parallel plates, united by a strong, flexible membrane, which allows of the necessary flexions of the body. When the animal places the liead between the fore feet, and brings the tail and rosterior extremities close together, a ball is formed, which offers a uniform, solid surface, not pervious to the attacks of birds of prey, nor small quadrubeds. The inferior surface of the body, not covered by the shell, is clothed with a coarse, scattered hair, some of whlch, also, appears at different points between the plates or bands of the shell. All the armadillos have a ratlier pointed snout, long ears, and stout claws; of the latter, some species have four on the anterior feet, others five: all, however, have five on the posterior feet. They have no incisive or canine teeth, but seven or eight separate, cylindrical jaw teeth, which are only enamelled on the outside. They feed on vegetables, insects, and carrion, have a simple stomach, and no crecum.-But for their peculiar fecundity, the armadillos would be speedily exterminated, as they are sought with great avidity in Guiana, Paraguay, Brazil, \&c., on account of their flesh, which is regarded as a great luxury. To obtain these animals, is not so easy as might be supposed, since they burrow with astonishing rapidity, so that it is almost impossible to get at them by digging. The hunters are obliged to smoke them out of their dens. - When they appear on the surface, they are easily captured, as they roll themselves into a ball, and remain motionless as soon as approached by a dog, or man. If near a precipice, however, they sometimes elude pursuit by thus rolling themselves up and falling from the top, which they do without receiving any obvious injury. The Indians make use of the shell or covering of these animals, especially of the larger species, in the fabrication of baskets, \&c. - Like all the aninials belonging to this order, the armadillos are slow motioned and harmless; sometimes they are troublesone in gardens, both from the destruction of plants, and the number and extent of the excavations which they form. The species are distinguished from each other, principally, by the number of bands on the trunk of the body, between the shield on the fore sloulders and that on the rump.-The species enumerated by Cuvier are -dasypus tricinctus, L. (three banded A.), of mildling size, found in Brazil and Paraguay ; D. 6 cinctus et 18 cinctus, L. (six banded A.) having the borders of the posterior shield serrated, and the parts not covered by sliell furnished with longer and thicker hair than the other species; $D .7,8$ et 9 cinctus, $I$. (nine banded A.), liaving a body fifteen inches long, with a tail of the same length; and the $D$. gigas, C. or giant armadillo, which lias twelve or thirte''ll intermediate bands, and grows to the length of three feet, exclusive of the tail. We have good reason to believe that this species attains to a much larger size, or that there is another species, to which the epithet gigantic is still more applicable than to this.

ARMAGI ; a county of Ireland, in the province of Ulster, bounded on the south-west of Monaghan; on the west by Tyrone; on the north by Longh Neagh; on the east by Down; and on the south-east by Lowth. The vicinity of the city is rendered beautiful and picturesque by a geritle undulation of hill and dale ; and in this quarter the soil principally consists of a rich loam, interspersed with limestone and limestone gravel. The northern part of the county. bordering on Lough Neagh consists principally of extensive bogs of great depth, with a remarkably black soil. On the southern limits extends a range of dark mountains called the Fewes, very little of which has been subjected to cultivation. The rivers of most note in this county are, the Black water, which partIy separates it from Tyrone; the Upper Barn, which lises in the county of Down, and discharges itselt into Jough Neagh; the Callan; the Canilin; the Cushier ; the Fleury ; the Fano ; the Newtown Hanil. ton; the Tallwater; the Taro, and the Tyran. The ehief lakes are Carlough and Lough Clay. There are also several streans of a minor description, and this abuudance of water is extremely beneficial to various branches of industry, by the facilities it affords to mills and bleaching grounds. The manufacture of linen is curried on very extensively, and gives ent- 
ploynent to a large proportion of the inlabitants. The chief towus ure Amnagh, Lurgan, Charjemouth, Market Hill, Portadown, Taudaragee, and Tyuan. In the vicinity of the last town is a lead mine, the ouly mineral proluction of much importance yet discovered. The city of Armagh stands on the acclivity of a lofty hill, round the base of which runs the river Calliu, in its progress to the Blackwater. The summit is crowned by the cathedral, a large Gothic linilding. In the middle ages, it was an extensive and populons city, and celebrated for its learning, having at one period, according to Irish historians, 7000 students at its college. It is, at present, the seat of the consistorial court of the archbishop of Armagh, who is lorl primate of 11 ll ireland. Population of the county in 1831, 220,651; of the city, 8,493 .

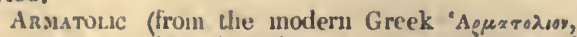
i. e., territory of arms); a district in the mountains of Grece, assigut d to a capitani for protcction. They were the last refuge of liberty in Greece. These, Armatolics are very numerous in the mointains of Macedon, Epirus, and Thessaly; and the freedom of the Mainotes, Suliotes, inhabitants of Montenegro, \&.c., is supported almost entirely by them. Whell Mohammed 11. finished the conquest of Greece, he was satisfied with possessing the plains, the fortified places, and the seaports. The naural fortresses of the country seemed unimportant to him, as well as to his successcrs, whose efforts were dirceted, in preference, against Hungary and Poland. To these fastuesses, unconquered by the Turks, fled the independent part of the Greeks, in order to continue the war in letail, under their old leaders, called capitanis. A capitani collected, generally, a troop of from 50 to $\approx 00$ men, who remained true to him through every variety of fortume, and attacked the cnemy everywhere, on the roads and in the towns. They said, "We never have made peace with 'Turkey." Thus iuvolved in an condless struggle with their oppressors, their war soon degenerated into robberies. A large number of them were careful to confine their depredations to Mussulmans; liut this was not the case with all, and many instances occurred, as may easily be imagined, in which Greeks were attacked when the booty expected was considerable. The pachas, unable to subdue these enterprising warriors, gene. rally treated with them. The capitanis received, on condition of remaining quiet, money or stores, and the government of the district which was defended by their arms. Such a district was then called Armatolion. Very recentiy, the capitanis Odysseus, Perrhwos, Tzonko, Tasios, Pisko, \&ic., made themselves feared by Ali Pacha, (q. v.) as well as by the pachas sent against him, and most of them took part against the Porte in the struggle for the liberty of Greece.

Armed Surp; a name used, in Britain, to signify a ressel occasionally taken into the service of the government in time of war, and employed to guard some particular coast, or to attend on a fleet. She is therefore armed and equipped, in all respects, like a ship of war, and commanded by an officer of the navy, who has the rank of a master and commander. All ships of this sort are upon the establishment of the king's sloops, having a lieutenant, master, purser, surgeon, \&c.

Arvania; an Asiatic country, containing 106,000 square miles, formerly divided into Armenia Major and Minor. The first, which is the modern Turcomunia, and is still sometimes called Armenia, lies sonth of mount Caucasus, and comprehends the Turkish paclialics Ercerum, Kars, and Van (which extend over $33,7 \pi 0$ square miles, and have 950.000 inlabitants), and also the Persian province Iran, or Erivan.
Armenia Minor, now called Aludulia or Pegium, helongs to the 'Turks, and is divided between the prachalics Merasie and Siras. Armenin is a rough, nountainous country, which has Caucasus for its norliern bomdary, and, in the centre, is traversed hy brinche's of the 'Taurus, to which belongs mount A ri rat. (q. v.) Here the two great rivers Euphrates and ligris taku their rise; likewise the Kur, and other less consi. derable strums. The lakes Van nud Gcnk-slia are also in this part of the country. The climate is ruther cold than warn; the soil, in general, moderately fertile, and better fitted for grazing than for agriculture; it produces, lowever, the fuest southern fruits. 'The mountains are rich in iron and copper. 'Tlie salt mines of Arnenia have long been celehrated: from solid and immense rucks of this nintral, large pieces are cut, and carried by buffaloes, to supply not only the neiglibouring provinces, but all Persia. lndecd, almost the whole country seems to be impregnated with salt, as is particularly observable after rain. 'The inhabitants consist of genuine Armenians, of 'Turcomans, who pass a vaudering life in the plains, and of a few Turks, Greeks, and Jews. Of the ancient history of this coming but little is known. It appears to have been subjected, in turn, by the Assyrians, Medes, Persians, and Macedoniaus. After the death of Alexaurder, it became part of the kingdom of Syria, and so remained till the overthrow of Antiochus the Great, when it fell into the hands of different rulers, and was divided into Armenia Major and Minor.-Armenia Major was exposed to many attacks. The Romaus and Parthians fought a long time for the right of giving a successor to the throne, and it was governed at one period by Parthian princes, at another, by those whom the Romans fivoured, until Trijan made it at Roman province. Armenia afterwards recuvered its indepeudence, and was under the rule of its own kings. Sapor, king of Persia, attenuted its subjugation in vain, and it remained free until 650 , when it was conquered by the Arabians. After this, it severul times changed its nasters, among whom werr Gengis. Khan and Tamerlane. In 1552, Selim 11. conque'red it from the Persians, and the greater part las since remained under the Turkish dominion. Armenia Minor has also had seceral rulers, among whom Mithridates was first distinguished. From him Pompey took the kingdom, and gave it to Dejotarus, \&c. On the decline of the Roman empire in the East, it was conquered by the Persians, and, in 950, fell into the hands of the Arabians, since which time it has shared the same fate as Armenia Major, and was made, in 1514, a Turkish province, by Selim 1. Of the cities of ancient Armenia, some ruins are yet to be stell, which display a good style in architucture; e.g., the ruins of the old cavital Ani, which was destroyed, in 1319 , by an earthquake; and those of the ancient city Armavir, which, during 1800 years, was the residence of the kings; some families still reside here. After Armavir, Artaxarta (Artaschad) on the Araxes, built in the time of the Selucidæe, became the capital, but sank into decay before the end of the 8th century. - The Armenians, a sober and tenıperate nation, are chieffy occupied in commerce, which, in Turkey, is almost entirely in their hands; and in all Asia, excopt China, merchants of their nation are to be found. Their religion has facilitated their entrance into eastern Europe; accordingly they are nusnerous in Russia. Jaubert says of the domestic life of the Christian Armenians, that, in their native country, they are good agriculturists; that old age is highly hououred; and that the svife looks up to her liusband, and thic sun to his father, as in the time of the patriarchs. The following cuts represent the orinary costume of an Armenian man and woman. 


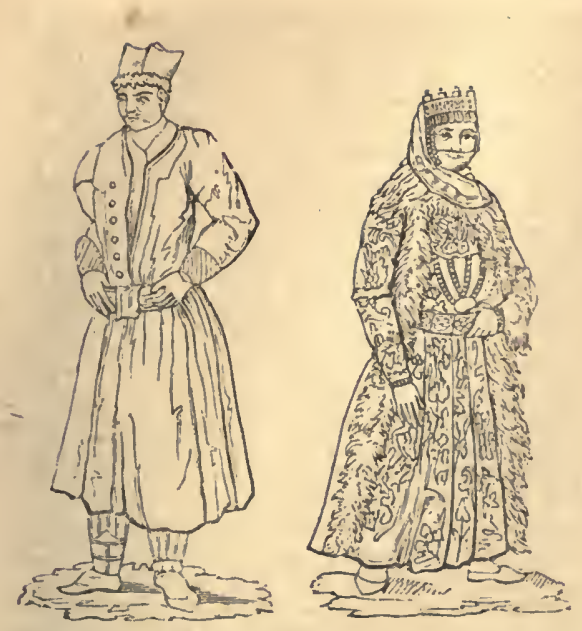

They prefer permanent habitations, wherever the eternal feuds of the paclais and Curds permit them to remain quiet. The Armenians received Christianity as carly as the 4th century. During the Monophysitic disputes, being dissatisfied with the decisions of the council of Chalcedon, they separated from the Greek churcl, in 536. The popes have, at different times, when they requested protection against the Muliammedans, attempted to gain them over to the Catholic faith, but have not been able to wite them permanently and generally with the Roman church. Only in Italy, Poland, Gallicia, Persia, under the archbishop of Nachitscheven (a new town on the Don, in the Russian government Ekaterinoslav, of which the inhabitants are mostly Armenians), and in Marseilles, there are United Armenians, who acknowledge the spiritual supremacy of the pope, agree in their doctrines with the Catholics, but retain their peculiar ceremonies and discipline. The case is the same with the United Armenian monasteries upon mount Lebanon in Syria. At the Persian invasion, in the beginning of the 17 th century, many of them were obliged to become Mohammedans, but the far greater part are: yet Monophysites, and have remained faithful to their old religion and worship. The Porte has constantly protected them against the attempts of the Catholics. Their doctrine differs from the orthodox chiefly in their admitting only one nature in Christ, and believing the Holy Spirit to issue from the Father alone. In their seven sacraments, which they call mysteries, there are these peculiarities, that, in baptism, they sprinkle thrice, and dip thrice, and this is imnediately followed by confirmation; that, in the Lord's supper, they mix no water with the wine, and use leavened bread, which they distribute dipped in wine; and that they allow extreme unction only to divines, immediately after their death. They adore saints and their innges, but do not believe in purgatory. In fasting, they surpass the Greeks. Their feasts are fewer than those of the Greeks, but they celebrate them more devoutly. They worship, in Turkey, mostly in the night time; the mass is said in the ancient Armeuian, the sernion is preaclied in the modern. Their hierarchy differs little from that of the Greeks. The catholicus, or head ol the church, has his seat at Etschmiazim, a monastery near Erivnn, the capital of the Persian Armenia, on monnt Arurat. The holy oil, which he prepares and sells to the clergy, and the frequent pilgrimages of the Armenians to Etscluniazim, supply him with means for the support of a magnifictint style of worship, and of establish- ments for exlucation. He maintains, in his reside nce, a seminary for the education of divines. The patriarclis, bishops, and archbishops of the Armenians are invested by him, and every three years confirmel in their offices, or recalled. The remainder of the clergy resemble the priests of the orthodox clurcl in raik and duties. The monks follow the rule of St Basil. The vertabets, who live like monks, cultivate the sciences, take degrees, which may be compared with our academical honours, and are the vicars of the bishops, form a class of divines peculiar to the Armenian church. The secular priests must be marricd once, but not permitted to take a second wife. In superstition, and attachment to old forms, the Arnıenians resemble the Greeks, but are distinguished hy botter morals. In general, they surpass all the kindred Monophysitic sects in information; allow the people to read the bible; study the theological, historical, and mathematical sciences; possess a respectable unational literature, and, at Etschmiazim, have a jrinting office, which prodnces splendid copies of the bible. The Armenian church is dirided by a great schism; somewhere about one half, both of clergy and laity, having attached themselves to the Roman Catholic creed, who are condemned as heretics by the adherents to the old Oriental Cliurch, and in their turn reprobate as heterodox tlose of their brethren who persevere in the faith of their forefathers. At Constantinople, these last predominate, or did so, at least, in the year 1700, when Mechitar Pedrosian, at Catholic Armenian, founded a new monastery in the Moslem capital, of which he was himself appointed abbot. Being persecuted by the adrerse sect, he fled with lis monks to the Morea, then subject to Venice, and established his monastery, to which he? attached an academy, at Modon. Here both flourished, but not permanently. The Morea reverted to the Ottoman sceptre, and in 1717 the worthy abbot transferred his monastery and academy to Venice, where, upon the island of San Lazzaro, one of thr more detached of the sixty, seventy, or one hundred and thirty (geographers are not agreed as to the number) islets which constitute the substratum of the inhabited portion of Venice, it has ever since remained and prospered. In honour of its founder, it is called Mechitarist. Ablot Mechitar, during the remainder of his life, diligently and successfully exerted himself, taking advantage of a situation that enabled him to combine the knowledge of Europe. with that of his nitive land, to render lis monastic college the principal seat of Armenian erudition and education. Thither all such of his comntrymen as desire a superior degree of cultivation for their offspring habitually send their sons for instruction. The best Armenian printing press extant is the Mechitarist, fiom which press issues a newspaper, permitted by the Turks, under certain restrictions, to circulate anoug their Armenian subjects; and neither the monks nor their superiors neglect any of the opportunities for improvement that they possess. Their chief literary occupations are, indeed, more irseful to their less enlightened countrymen, than interesting to strangers, namely, translating into Armenian the classic works of France, Italy, England, and Germany. Besides the religious societies of the Armenians in their own country and in Turkey, where they are very numerons (their patriarch at Constantinople maintains the sane relation as the Greek pa. triarch towards the Porte), there are others in P(rsia, at Ispahan, Scliras, and Nerinkale ; in Russia, at Petersburg, Moscow, Astraclian, and in the Cancisian governments; also, small ones at London and $\mathrm{AnI}$ sterdan. (Ste Ker Porter's T'ravels in Cieorgia. Persia, Armenia ancient, Babylon, etc., in the ycars 1817-20 (Lond., 1821, 4to, with copperyllate's), and the tratsels 
of a Frenchman (Amal. Jaubert) through Armenia fund l'ersia, in 1805-6.)

Armaias Jitenatork. The Annenians, one of the most ancient nations of the civilized world, have maintained themselves as a cultivated perople amidst ull those revolutions which barbarism, clespotism, and war have occasioned in Western Asia, from the days of Asssria, Greece, and Rome, down to the period of Mongolian, Turkish, and Persian tominion. During so many ages, they have faithfully preserved, not only their historical traditions, reaching back to the period of the ancient Hebrew listories, but also their national character, in a physical and moral point of view. Their first abode, mount Ararat, is, even at the jresent day, the centre of their religious and political union. Commerce has scattered them, like the Israelites, among all the principal nations of Europe and Asia (with the exception of China); but this dispersion and the mercantile spirit liave not debased their character; on the contrary, they are distinguished by superior cultivation, manners, and honesty, from the barbarians under whose yoke they live, and even from the Greeks and Jews. The cause is to be found in their creed, and in their religious union. The cultivation of the Armenians is a proof of the salutary influence of a wed-ordered Christian church on the moral and intellectual developement of a nation, which has preserved its history, and, with it, its national character. They owe this in particular to the hilile, which is freely distributed among the people by the clergy, in translatious that are esteemed valuable in thrological literature. This is done not only at Etsclımiazim,- the principal monastery of the Armenians, the chief seat of their church, the abode of their patriarch (catholicus), and, at the sime time, the seminary of their teachers, where many bibles are printed, and whither every pious Amenian must perform a pilgrimage at least once during his life,but also in the other dioceses of the Armenian patriarchs, archbishops, and bishops at Sis (Ajas), in Cara mania, Constantinople, Jerusalem, and other places. Some time since, a society for the distribution of Arnenian bibles was formed in the Armenian church in Russia, the archbishop of which has his seat in an Armenian monastery at Astrachan. With the biblical literature of the Armenians is connected their theological, historical, and mathematical literature. It is as old as the conversion of the people to Christianity, and sheds much light on the ancient people of the Fast. Hence it has recently found many assiduous students in Paris. According to their natural historians, the name Armenia is derived from Aram, the seventh king of the first dynasty, who, about the year $1800 \mathrm{~B} . \mathrm{C}$, gare a settled character to the kingdom. The Armenians call themselves Haji, after Haico, the father and patriarch of the people, a contemporary of Belus. With him commences the Armenian history, abont 2100 B.C., and closes with Leo VII., who fled from lis country, when invaded by the barbarians, and died at Paris, in 1393. The kingdom shared the fate of Asia Minor and Persia.-To return to its ancient literature. But before we speak of Armenian authors and their works, we must mention one fact concerning the language, which is important, namely, that the language of literature is not that of ordinary life and business. The former is called Haican, from Haico, the reported progenitor of the nation; the latter Armenian. This appears, however, to be a modern distinction, the relatire condition of the two languages being now what that of all the languages derived from the Latin was during the middle ages, when French, Italian, Spanish, or Portuguese were but so many corrupt jargons, each in its own country called emphatically the vulgar tongue, in which scholars never thought of writing. The most learned
Armenian antiquaries do not pretend to trace their literature further back than about 150 years befure the Christian era, when two Parthian brother princes, Arsaces and Valassaces, reigned over Persia and Armenia. The latter monarch, being a lover of letters, was inquisitive touching the circumstances of his kingdon in time past, and employerl Marabas Catina to write a history of Armenia. Marabas obeyed, collecting his materials from old l'ersian documents preserved at Ninevel, and lail open to his exsmination by $\mathrm{Arsaces}$, king of Persia, as well as from other sourees. He completed his task down to the very period at which he wrote, and the work is said to have earned for him the title of the Amienian Herodotus. He was followed by some lialfdozen historians and heathen theologians, if we tmay so designate believing writers upon mythology, and by a multitude of others, altogether forgotten. But even of the commemorated few, and of tie Armenian Herodotus himself, the names and the nature of their works is all we know, or can hope to know. Their productions have long been lost, but have not thus become quite valueless, inasmuch as they were the sources whence later Armenian writers, who have survived, compiled their works. The anthors who lived in the fourth century of the Christian era are the first whose writings have been preserved. Christianity then prevailed in Armenia; her writers were princes and prelates; and this is esteemed what the abbot of San Lazzaro calls the first, and we should rather term the beginning of the golden age of literature, - a period, be it remembered, when classical literature was fast decaying. But the fifth century was the real golden age of Haican literature, which thus, for a while at least, seems to have thriven in proportion as classical splendour faded away. This century was fruitful in authors, and was further distinguished by two events important to the progress of learning. The Armenians had till then lad no alphabet of their own, indifferently using Grerk, Syriac, and Persian characters. Early in the fifth century, Mesrop Masdoty invented an appropriate Haican alphabet of thirty-eight letters, still called, in honour of the inventor, Mesropian, and employed as capitals, since others, of more convenient forn, have supplanted them in common use. About the same time schools were, by the favour of the Armenian sovereign, instituted throughout Arnenia, and the scholars there trained exerted themselves in producing Haican versions of the Bible, and of the master-pieces of Greece and Rome. To these circunstances we may probably ascribe the great developement of native talent that ensued. One of t!e most distinguished authors who now appeared was archbishop Moses Chorenensis, or Chorenabyi, according to the Armenian formation of a surname for the birthplace. Besides innumerable invaluable translations, he wrote a history of Armenia (relying for the early part upon Marabas, and many others, of whom the names only have descended to modern times), a treatise upon rhetoric, and a treatise upon geography, all of which, together with some homilies, have been preserved, as well as some liymus still habitually sung in the Armenian church service. A number of his smaller works have entirely or partially perished ; and of Moses Chorenabyi's Commentaries upon Haican Grammar only a few fragments remain, inserted as quotations in the productions of later and more fortunate writers. Moses' IJistory of Armenia was printed in England, in the first lalf of the last century, by the sons of the celebrated W. Whiston, and most judiciously with a Iatin version, as at that time no Englishman, and ouly two contiucental scholars, understood Haican. In the sixtl, century Haican literature first remained stationary 
and then began to decline. With evcry succeeding century, to the sixteenth inclusive, the decline became more decided, more rapid, and the very genius of the language was corrupted by attempts to assimilate its grammar to the Latin. Nerertheless, we do not mean to say there were no authors during this contemued period: on the contrary, they abounded, but, in a literary sense, they were worthless, and sonle are even accused of writing in Armenian, not Haican.- A few histories, however, national, Tartar, Arab, \&c., some of them in verse, and deserving esteem for the information they contain, are carefully preserved, even of the worst times. In the seventeenth century, Armenian schools and colleges arose in the east and in the west; Armenian printingpresses were set up in various towns, and Armenian literature began to revire. Again : historians, theologians, and poets wrote in choice Haican. In the eighteenth century the revival was complete, rery much owing to the zealous and judicious exertions of Mechitar Pedrosian. His academy still yields excellent scholars in their own and other languages, and Armenian literature promises fair to participate in the vigorous stimulus which, throughout Europe, literature seems in these lattcr times to have received. The only reason for apprehending that it may not fully keep this promise, is the disadvantage of writing in a dead language, not in that of impnlse and passion, that in which we think, feel, converse, and transact all the business of life. The royal library at Paris possesses the Armenian historical authors nearly complete, partly printed, partly in manuscript. From then, J. M. Chahan de Cirbied, a leamed Arinenian employed in this library, published, in 1806, his Recherches curienses sur l'Histoire ancienne de $r$ Asie, and compiled, with M. J. Saint. Martin, a universal history of Armenia. The best introduction to Armenian history, geography, and literature, is that which M. J. Saint-Martin, member of the French iustitute, has extracted from old Armenian writings, inscriptions, and other sources Mémoires historiques et géographiques sur l'Armenie, Paris, 1818, 2 vols. This work contains the Armenian text of the history of the reigning Orpelian fumily, by a prince of this family, the archbishop Stephen Orpelian, and the text of the Armenian geographers Moses of Chorene, and Vartan, with additions, translated into the French, with annotations. Among the living Armenian scholars, we may mention Dr Zorab, in Venice, and the librarian of the Armenian congregation of St Lazarus, in Venice, John Bapt. Aucher, who has lately published Armenian translations of the 5 th century, fron ancient authors, c. g. the famous Grecian Jew, Plilo. Also Placido Lukias Somal, archbishop of Liunia, who published a Sketch of the History of Armenian Literature, at Venice, in 1829.

Arsifelt (Gistavus Maurice), count of ; a distinguished Swede, whose public life was marked by singular clianges of fortune, but belongs, in a considerable digree, to the secrct history of the Swedish court, and has, therefore, not been fully cxplained. Gustavus Maurice, bori April 1st, 1757, the oldest son of the major. general baron Armfelt, was educated in the military school at Carlscrona, and was afterwards appointed ensign in the guard at Stockholn. By his fine figure, and the clarms of his conversation, he gained the favour of Gustavus III. He was rapidly promoted, and loaded with marks of distinction. In the war against Russia, 1788-1790, he showed a courage in the field as splendid as his talents in social life, on which account he continued to rise in the favour of his king. As lieutenantgeneral, he concluded the peace of Werela, was honoured by the Russian empress with several orders. and received, even at the death-bed of his sovereign, the most flattering marks of royal favour. He was appointed governor of Stockholm, and connected, by means of Gustavus III., in marriage with the ancient family of the count de la Gardie. He was said, also. to have been intended for president of the council of regency, during the minority of Gustavus IV., though the guardianship of the young king had been assigned to the duke of Sudermanland by a previous will. Possibly, this is the source of the hatred with which 1 . was now persecuted. He was deprived, Sept. 7, 1792, of all his offices and dignities, and sent as ambassador to Naples. It was supposed, not without foundation, that an unrequited passion of the duke of Sudermanland for a court lady, von $\mathrm{Ru}$ denskjold, by whom $A$. was favoured, had exasperated his rivalry to hate. It is certain, that Armfelt and Rudenskjold were made the subject of scandalous rumours; she was dishonourably reprimanded in the house of correction; and he, then in Italy, escaped the daggers of hired assassins, and a formal requisition of the Swedish government, only by flight; was declared a traitor and an outlaw, and all his fortune and honours, nay, even his nobility, were pronounced forfeit. He afterwards resided in Germany, till 1799, when Gustavus IV. annulled this decree, and restored A. to his former situation. He was appointed ambassador to the court of Vienna, and, in 1807, the rank of general of infantry was conferred on him: As such, he commanded the Swedish troops in Pomerania, and, in 1808, the western army against Norway. In the autumn of this year, he was appointed president of the military institution at Stockholm, and made peer of the kingdom. In 1810, he obtained his desired discharge, and lived as a private man at Stockholm. A connexion with the infamous countess Piper involved him in new difficulties, and induced him to seek shelter with the Russian ambassador, and to go over to the Russian service. Here he was favourably received, was made count, chancellor of the university of $A$ bo, president of the department for the affairs of Finland, and member of the Russian senate. He now enjoyed general esteem till his death, Aug. 19, 1814, at Czarskoeselo. He was particularly respected by the Finlanders.

Armigr, or Esquire; in England, a title belonging to such gentlemen as bear arms; and these are either by courtesy, as sons of noblemen, eldest sons of kniglits, or by creation, as the king's servants.

Armisians; a religious sect, which has its name from its founder, Arminius (ๆ. v.) In Germany and Ilolland, they are more generally called Remonstrants, on account of the title Remonstrantia, which they gave to a document presented to the statesgeneral of Holland, in which they endeavoured to prove the opinions of the reformed church, in respect to predestination, erroneous. Diversity of opinion on this subject was the chief reason of their separation from the reformed church. They maintained, 1 , that God had, indeed, resolved from eternity on the salvation and damnation of men, but with the condition, that all those who believed should be saved, while the unbelievers should be damned; 2, that Christ died for all men, but nobody could partake in his salvation, except he believe; 3 , that nobody can have saving faith from himself, but must be born again of God, in Christ, through the Holy Ghost, in order to attain it ; 4 , that nobody can, without the grace of God, think, will, nor do any thing good, because all our good works have their origin in God's grace; 5, that the faithful can struggle against Satan, the flesh, and the world. and conquer them, by the assistance of the Holy Ghost. 'This is the genuine doctrine of Arminius and his sect. From these original Remonstrants, however, are to be dis- 
tinguisherl those who were nut satisfed with these five articles, but proceenled farther in the exntest with the reformed or Calvinistic churcls. As, even betore the Arminian dispute, seveml writings of Socinus had been circulatid secretly in Ilolland, particularly among the men of learning, who were almost all Aminians, it was natural that the later Arminians should coincile, in many points, with the Secinians. They were therefore uccused of Socinianism. The states of Holland issued nn ordinance, in 1614, directing the Remonstrants and Counterremonstrants (the latter were also called Gomarists, frun their leader, Francis Gomarus, professur of thieology at Leyden) to live in love and charity with each ouher. But, as both parties doubted the obligation of such a decree in respect to spiritual affairs, the firmous syuod at Do:t was held from Nov. 13, 1618 , to May 9, 1619, in order to adjust the differences. The decision of the synod is very renarkable. It made reason the servant of the fear of God, subjecting it to the control of faith, and declared, with much piety and theological conslstency, that the doctrine of predestination is very hard, but cannot be avoided ; let the Holy Scriptures stand fast, and the upiniou of the opposing world perish. The Counterremonstrants, so called, gained the ascendency by the decree of this synod, in which they were accusers and judges. The opposite party lave accused them of unjust and cruel behaviour on this occasion, aud they lave not yet been able to disprove the accusation. Though the former were obliged to yield to the decision of the synod, they continucd to print and defend their loctrines. The decree of this synorl was highly prejudicial to the sect of the Arminians, and they were particularly in danger when some of their members took part in a couspiracy against prince Maurice. He was, however, soon convinced, that the sect, as such, had nothing to do with the plot, and, atter his death, in 1625 , they received from Heury, his brother, the liberty to erect churches and schools in all parts of Holland. In Ansterdam, they established an acalemy for elucation, which became very famous. The congregations at Rotterdam and $\Lambda$ msterdam were the most numerous. They did not endeavour to increase their sect. $\Lambda$ ily one who joined them was not obliged to accept their creed, but only to declare, generally, that he was a believer in Christianity according to the apostolic symbolum, and endeavoured to regulate his life according to Christ's commands. Their public service was almost entirely like that of the Calvinistic church, only they did not require, like this cliurch, from the parents of a child about to be baptized, a profession of belief in their doctrines, and a promise to educate the child in the same, but demanded only a promise to educate the cliild in the Clıristian faitl, without mentioning the creed of any sect. The Arminians were very numuerous as long as they were persecuted, but rather decreased, when they had gained liberty and peace.

Arsuxios (the Latin name for Hermann); the deliverer of Germany from the Roman yoke. The victories of Drusus had added to the Roman empire the German districts lying on the Rhine, the Elbe, and the Saal. No measures were neglected, by the Roman government, to keep the natives of these territories in subjection. The Sicanbri, whose fearless spirit was so fatal to Lollius, were transplanted, with a few of the most powerful tribes, to the hanks of the Rhine, and the interior of Gaul; and attempts were made to secure the allegiance of the remaining tribes by hostages, and by a Romau education, gratuitously bestowed on the children of the cliefs. A., son of a prince of the Clierusci, Siginer (which, in the old German, signifies a famous conqueror), was boru Is B. C. He was edncated at Rome, admitteil into the rank of equites, and nppointed to an lonomable: station in the aruy of Angustus. IBut princely favour and the charins of learning were insuficient to muke the: young barbarian forget his carly associations, and his country's guxls; and the reflect of his Roman education was to teach him how to cour quer his instructors. Convinced that the rude strength of his savage comntrymen would be muevini to cope with the disciplined forces of the Rommus in the open field, le: had recourse to stratagim. Every circunstance seemed to fitvour his desigus Quintilius Varus, who conmanded the fower of the Ronan army, was appointed to maintain trunequillity and subuission in the new territories on the right bank of the Rhine. Relying upon his power, lie e $\mathrm{x}$ pected to be able to introduce Roman institutions, and thereby change the claracter of the German tribes, who viewed liberty as the lighest good. Ile was accompanied to his destination by a farge munber of merchants and lawgers, who were to bring about the intended changes. The olje' $($ t of this expedition was sufficiently odious in itsilf, and the arrogance and oppression of the lRomans increased the dissatisfiction of the Gernans to $\mathrm{ll}_{\mathrm{t}} \mathrm{e}$ lighest tesgree. A. cliose this favourable noment for the execution of his designs, and sncceeded in gaining over to his views the chicfs of nemly all the tribe's between the Elbe and the Rhine. Abont the same time, $\Lambda$. D. 9, a general rebellion broke out in Pannonia and on the bordirs of Dalmatia. Whether this robellion was comected with the plans of $\Lambda$., and intended to aid in supporting the monarchy which liad been founded by Marbotius, between the Elbe, the Saal, and the Oder, and suppressed by the Roman goveruor, we shall not uow stop $u$ decile. Even if it had no connexion with the levigus of $A$. we have reason to admire the harmony which nuarke (l) the undertakings of the allies; for the treachery of Segestes, one of their number, was insufficient to break tlie strong bond of their union. 'This Segeste's, prince of the Catti, informed the Romau general of their secret intentions; but Varus disregardel his admonitions. A. succeeded in removing his clistrust, and turned the attention of the Romans to the disturbances on the Weser, which he liad himself ('xcited, in order to draw the Roman soldiers into the lieart of the country. The anxiliary German troops everywhere yielded the striclest obedience, and tlieir commander, the faithful confederate of $\Lambda$., was every day lulling Varus into a deeper security. Slight disturbances, which had been previously concerted, now took place in distant parts of the empire, to induce the Roman governor to divide his strength. The main body of the army consisted of three legions, a few cohorts, and the treacherous auxiliaries. The spirit of rebellion now became universal. A, and his most intimate fiends, who had enjoyed the confidence of Varus, and been adnitted to his sccret conncils, multiplied the proofs of their apparent zeal in the Roman service. They urged the Roman conmander not to wait for the undisciplined rebels, but to marcl against them, and extinguish the flames of sedition where they raged with the greatest fury. It was in rain that Segestes repeated his warning: The arts of A. prevailed. The army advanced every day furher from the Rhine, and plunged deeper in the regions where they were most exposed to destruction. In the territory of the Bructeri, near the source of the Lippe, after a long and tiresome march througl marshes and forests, they suldenly found themselves in a deep valley, surrounded by hills, wìich were all occupied by their Gorman fors; and, to ald to their consternation, A., with his rear-guard, was now their ene'ny, and the sonl of all the assaults 
which were male upon them. Varus now saw destruction impending over him. The courage and discipline of the Ruman soldiers had long excited udmiration, liut could now only defer for a time their fate. For three days their sufferings contimed. A. made himself master of three Roman eagles, and put a stop for ever to their advance in the north of Germany. Varus could not survive his disgrace; he killed himself, as so many other Romans had done, when the fortune of war was adverse. The victory of A. was stained by useless acts of violence and cruelty. The Germans cut off the hands of the lawyers, whose subtleties were most odious to the national feeling, and put out the eyes of others. We must not, forget, however, the strong provocation which they had received from their criel and oppressive conquerors. It is difficult to determine the place of this celebrated engagement. The ancients called it Teutoburgiensis Saltus. The opinion of Mannert is very different from that of Tacitus. The former fixes the field of battle on the borders of the principalities of Lippe and Mark, and the duclyy of Westplualia; but the account of Tacitus agrees more nearly with the tradition, which says the action was fought at the source of the Fms and the Lippe, near what is now the little city of Detmold. All the neighbourhood is full of memorials of that day.A fit' $\mathrm{A}$. had secured the liberty of his country, he destroyed the fortifications of the Romans on the Elbe, the Weser. and the Rhine. He laboured to elevate the inurtial spirit of his conntrymen, which lie regarded as the best defence against the arms of Rome. But he was soon involved in a difficulty with his own countryınen, particularly with Segestes, the head of a powerful tribe, whose daughter, betrothed to another prince, had been carried off by A. Segestes was first attacked by the national party, of which $\mathrm{A}$. was the head, and immediately applied for aid to Germanicus. The Romans hastened to assist him, and delivered him from a siege. Among the prisoners was the wife of $A$. When she was presented before Germanicus, her whole behaviour showed her worthy of her valiant husband. Her grief, Tacitus says, was silent. She shed not a tear; she oftered not a prayer; her hands were folded; her eyes fixed on her breast. The treachery of Segestes and the fate of Thusnelda gave new ardour to the patriotic feelings of A. Inguiomar, his uncle, a warrior of great celebrity, offered him his aid. Germanicus felt the necessity of anticipating the blow, and undertook a campaign, which, in spite of the successes of the Romans, served only to draw closer the bonds of union among the Germen confederates, and to increase their confidence in their own strength. The next year was marked by new exertions on the part of the Roman general. His preparations were inmense, and his whole plan faultless in design and execution. This fourth campaign of Drusus in Germany was distinguished by the defeat of $\mathrm{A}$. on the plains of Idistavisus, on the banks of the Weser; but it ended in the retreat of the Romans. At the com. mencement of the campaign, and previous to the batcle of Idistavisus, $\Lambda$. desired an interview with his brother, Flavius, who had beell educated with him in Italy, and still adhereel to the Romans. They collversed in Latin, from the opposite banks of the Weser. It was in vain that $\Lambda$. sought to gain over his brother to the cause of their common country. It was in vain that he stigmatized his military badges as the reward of baseness, and the pledges of a shameful bondage. Nothing but the river, which fiowed between, prevented them from actual violence. Flavius was at length conveyed away from the place by his friends. The jealousy of Tiberins agninst Germanicus favoured the exertions of the allies.
But, when they had repelled the attacks of their oreign foes, they turned their arms against mle another. Marbodius, the king of the Suevi, and founder of the kingdom of the Marcomanui, was prompted by ambition to carry his conquests beyond the Sal and the Elbe. He, too, had received his elucation in Rome, but had returned with principles decidedly opposed to those of the hero of the Clierusci. In A. the Romans had found a bold defender of his contr try's freedom, and in Marbodius an enemy of his ambitiaus views. Notwithstanding the revolt of Inguiomar, who went over to the party of Marbodius, rather than serve under his nepliew, $A$. came off victorious in the civil war. He obtained the honour of having freed his comitry from a foreign yoke, and of preserving his fellow-citizens from domestic tyranuy. A long and bloody battle decided the claims of the contending parties. The Germans no longer fought in disorder ; for $A$. had accustomed them to the rigid discipline of the Romans, and all the rules of war had become familiar to the barbarians. The event was long doubtful. But the king of the Marcomanni first withdrew his troops from the field, and was thus looked upon as vanquished. A large proportion of his army abandoned him, and he was forced to retreat in haste to Bohemia, in the interior of his dominions, and, at last, to Italy, where he lived in obscurity. Tacitus relates, that $A$. drew upon himself the hatred of his countrymen by aiming at the regal authority; and, in the thirty-seventl year of his age, he was assassinated by one of his own relations. A short time before his death, Adgantestes, or Adgantestrius, prince of the Celts, proposed to the Roman senate to despatch him by poison; but the senate took no notice of the offer. A. was twenty six years old when lie destroyed the legions of Varus; and two years before his death, he gainel his victory over Marbodius. In the language of Tacitus, "A. was doubtless the deliverer of Germany. He fought against the Romans, not like other kings and generals, when they were weak, but when their empire was mighty and their renown glorious. Forture, indeed, sometimes deserted him; but, even when conquered, his noble character and his extensive influence conunanded the veneration of his courquerors. For twelve years he presided over the destiny of Germany, to the complete satisfaction of his countrymen; and, after his death, they paid him divine honours." If we dwell a moment on the results of his victory, we find that it had a decided infuence on the whole character of Germany, political and literary; because it is evident, that, - had the Romans remained in quiet possession of the country, they would have given a tone to all its institutions and its language, as was the case with all the other countries of Europe conquered by them. The reason, therefore, why the language of the Germans remained unmixed and uninfuenced by Latin, and why their nolitical institutions retained so much of their ancient character, is to be found in the victory of A. 'To the same cause must be ascribed, liowever, their tardy developement in several resuects. It is not to be doubted, that other nations lave derived great benefit from the introduction among them of the Roman civilization, as far as respects the order, tranquillity, and refinement of social life; but all adrautages could not be had at once; and liad not $\Lambda$. crushed the Roman power in Germany, an idiom similar to the French and Spanish would be spoken there, where now a language and literature exist of a peculiur and original character. Some infuence, lowever, the Romuns did undoubtedly exercise on the dialect of Germany, and many Latin words were introduced into it, yet with such alteration, that they can witl difficulty be recognised. 
Arnisios, or II rrunu, James, founder of tho sect of Aruinians or Remonstrants, was born at Oulewater, in Hollund, 1560. He stulied at Utrecht and in the university of Leyden. Here he obtained so nuch reputation, that the unagistrates of Ansterdam seut him, at the public expensc, to fuish his studies at Geneva, where his chief preceptor in theology was Theodore Beza. Adlopting, in philosophy, the new doctrines of Peter Ranus, he privately tuuglat them; which innovation gave so much offence, that he was obliged to quit Geneva. Anxious to attend thic celebrated lectures at Pacha, he next visited Italy. Distinguished by his zeal for the reformed religion, and talents as a preacher, he was chosen to undertake the refutation of a work written against Beza's doctrine of predestination ; but he lappened to be converted by the work which he had undertaken to refute. He honestly avowed his change of opinion, and, renouncing the Calvinistic doctrine concerning the decrces of God and divine grace, maintained that the merits of Christ extended to all mankind, and that the gracc necessary to salvation is attainable by every one. Elected professor of divinity at Leyden, he openly declared his opinions, which rapidly spread both annong the clergy and laity. The adherents to the Calvinistic system, however, caused him much vexation. He was several times summoned to the Hague, to give an account of lis doctrines; and his soleague, Gomarus, was among the most violent of in enemies. These contests, with the continual attacks on his reputation, at length impaired his health, and brought on a complicated disease, of which he died in Ji09. Aminius was candid, amiable, sincere and possessed of great integrity. He was a friend to univeral toleration, maintaining that Christians are accountable to God alone for their religious sentiments. His followers includerl some of the first men in Holland, as Barneveldt, Hoogerbeets, and Grotius. The Arminians still remain a distinct sect in Holland, and, from the time of Laud, have been the predoininant party in the church of England. Fditions of the whole writings of this divine were published in one volume, 4to., Leyden, 1629; Frankfort, 1631-1634; and often afterwards. The principal piece in this collection is entitled Dissertationes de Diversis Christiance Religionis Capitibus. See Arminians.

Armorica; the ancient name of the wholc northern and western coast of Gaul, from the Pyrenees to the Rhine; under which name it was known cren in Casar's time. The word is said to be of Bas-Breton origin, and to signify maritime.

Arsoor ; a defensive habit, employed to cover and protect the. body from the attacks of an enemy. A complete suit of armour was composed of the casque or helmet, gorget, cuirass, gauntlet, tasscs, brassets, cuisses, and covers for the legs, to which the spurs were attached. This furniture was denominated armour cap à pié, or from head to foot, and was used by the cavaliers and men-at-arms. 'The infantry had only part of it, viz., a pot or head piece, a cuirass, and tasses, but all light. The horses themselves had armour, wherewith to cover the head and neck. Defensive armour, is, in modern warfare, laid aside, with the exception of the cuirass, which was worn by Bonaparte's Imperial Guard at Waterloo, but without much advantage. See Arms.

Ararorr, Cont of, signifies the escutcheon of any person or family, with its several charges, and other furniture ; as, mantling, crest, supporters, motto, \&c. Thus the phrase a gentleman of coat-armour means one who bears arms.

ArMs: Man has not, like many animals, received from uature any member intended particularly as a weapnn. He is obliged to use artificial means to in- crease his strength, wlien he altacks, is well as to screen his borly, which nature las left mimpotecteet. Arms were, therefire, an early invention; perhaps, in the first instance, as a means of defence agyinst animals. They were soon used, however, for the purpose of conflict betwren man and man. - The first and inost natural of all arms, are the club and the sling. Every one naturally use's missiles as means of offence, and the sling alds force to the cast. In the history of the arms of all nations, we find, iuwariably, thut man, begiming with the uneaus of injury in the close struggle, endeavours continually to invent wenpons which slall take effect from greater and greater disturces. In consequence of the progress made in this way, dexterity always takes, at last, the place of coirnge. Nature has given to man only one wrapen, in a limited scuse: of the word,-the arm, used in boxing, -and this can be made truly a weapon only by the dexterity acquired by long training. The art of boxing, moreover, is of use only against men. Within its sphere, indeed, it is very ciffectual. As soon as men learned the usc of the metals, they worked them into pikes, spears, lances, and soon afterwards into swords and arnour. Of this last, part only was at first made of metal, but the proportion went on increasing, till at last a complete suit of iron came into use. The first improvement on the sling and the bow was the cross bow. Still later came the large engines employed by the ancients, and called catupulta, balista, \&c. These would produce effect at the distance of a 1000 fect. But the discovery of gunpowder changed the character of arms. Objects 6000 paces distant could now be reached, and obstacles overthrown with ease, which formerly cost the labour of years. By the invention of steam guns, still more may be accomplished in future. The inventor, Mr Perkins, an American of great mechanical talent, has not, however, yet been able so fur to perfect the machine, as to qualify it to take the place: of fire-arms.-Arms may le divided into offensive and defensive ; the first kind, again, into, 1, arms for cutting, e.g., the sabre ; 2 , for thrusting, e.g., the straight sword, the small sword, the bay onet, pike, lance, \&c. ; 3, arms for throwing, e. g., the mortar, lowitzer, \&c.; 4, arms for shooting, e. g., pistols, carabines, rifles, guns, cannens. It must be observed, that arms for thrusting are inuch more injurious, and therefore better, than those for cutting ; but they require infinitely more skill, and cannot, therefore, be used so much in armies as they otherwise would be. Man is protected by nature much more against a downward blow, by the strong bones of the skull and the shoulder, than against a thrust, to which the more vulnerable parts of the belly and thc breast are exposed. So great is the difference in this respect, that a downward blow with the fist hardly ever injures seriously, while the thrust of a boxer is lighly dangerous.-II. Defensive arms include all those which are properly so called, cuirasses, helmets, \&c., and also the parts of fortifications which are intended particularly to protect the borly. The more important arms are treated of under thi proper heads.-Some writers make a distinction between armed men (infantry and cavalry), and manned arms (artillery). The history of war includes also that of arms. French and German military writers apply the word arms to the different species of troops, and speak of the three arms, i. e. cavalry, infantry, and artillery. Some writers use bayonet for infantry, as harse is used for cavalry, and say, The army consisted of 12,000 bayonets and 2000 horse.-To readers desirous of becoming acquainted with the armour of the ancients, and that used in the middle ages, we recommend the splendid work, Critical Inquiry int Ancient Armour, \&c., with a Glossary for the Names 
of the Arms of the Midulle Ages, by Sam. Rush Meyrick, 3 vols. large 4to., London, 1824; a work interesting to the student of the politics, arts, manners, and wars of the ancients and the middle ages. There are, in Europe, many collections of arms used in both these periods (e. g., one of the arms of the ancients, at Naples), which, with the collections of the arms of the Indians, strikingly manifest the progress of civilization.

Arse, Солt of. See Heraldry.

Arsistrong, John, a poet and physician was born at Castleton, in Liddesdale, Roxburghshire, where his father was a minister, about 1709. He was educated for the medical profession at the university of Edinburgh, under the elder Munro. In 1732, he took lis degrees as $\mathbf{M}$. D. with much reputation, the subject of his treatise being Tabes Purulentr. He had ere this period addicted himself to the composition of verses. We are informed, that, to relieve the tedium of a winter spent in "a wild romantic country,"probably Liddesdale, the place of his birth-he wrote what he intended for an imitation of Shakspeare, but which turned out to resemble rather the poem of "Winter," then just published by Thomson. The bard of the Seasons, hearing of this composition which so strangely and so accidentally resembled his own, procured a sight of it by means of a mutual friend, and, being much pleased with it, brought it under the notice of Mr David Mallet, Mr Aaron Hill, and Dr Young, all of whom joined with him in thinking it a work of genius. Mallet even requested the consent of the author to its publication, and undertook that duty, though he afterwards gave up the design. Armstrong was probably led by this flattering circumstance to try his fortune in London, where his countrymen Thomson and Mallet had already gained literary distinction. In 1735 , he is found publishing, in that capital, a humorous attack upon empirics, in the manner of Lucian, entitled, "An Essay for abridging the study of physic, to which is added, A Dialogue betwixt Hygeia, Meresury, and Pluto, relating to the Practice of Physic, as it is managed by a certain illustrious Society; and an Epistle from Usbeck the Persian to Joshua Ward, Esq." The essay, besides its sarcastic remarks on quacks and quackery, contains many allusions to the neglect of medical education among the practising apothecaries; but the author had exhausted his wit in it, and the dialogue and epistle are consequently flat and insipid. In 1737, he published a serious professional piece, styled, "A Synopsis of the History and Cure of the Venereal Disease," 8vo. He probably designed the work as an introduction to practice in this branch of the medical profession; but it was unfortunately followed by his poem, entitled, "The Economy of Love," which, though said to have been designed as merely a burlesque upon certain didactic writers, was justly condemued for its wamn and alluring pictures, and its tendency to inflame the passions of youth. It appears by one of the "Cases of Literary Property," that Andrew Millar, the bookseller, paid fifty pounds for the copy-right of this poem; a sum ill-gained, for the work greatly diminished the reputation of the author. After it had passed through many editions, he published one in 1768 , in which the youthful luxuriances that had given offence to better minds were carefully pruned. In 1744, Dr Armstrong made some amends for this indiscretion, by publishing lis "The Art of Preserving Jealth," a didactic poem in blank verse, extending through four books, each of which contains a particutar branch of the subject. This very meritorious work raised his reputation to a height which his subsequent efforts scarcely sustained. "There is a classical correctness and closeness of style in this poem," says Dr
Warton, "that are truly alniralile, and the subject is raised and adorned by numberless poetical images." Dr Mackenzie, in his History of Health, bestowed similar praises on this poem, which was, indeed, every where read and admired. In 1746, he was appointed physician to an hospital for soldiers, and, in the course of a few years, published his Poem on Benevolence, Epistle on 'Taste, and his prose Sketches by Lancelot Temple, Esq. In 1760, he was appointed physician to the forces which went to Germany. This appointment was obtained for him by Wilkes, with whom he was then on friendly terms; but their friendship did not stand the tug of political warfare. - After his return to London, he published a collection of his Miscellanies, containing the Universal Alinanac, a new prose piece, and the Forced Marriage, a tragedy, which had been refused by Garrick. This collection contains nothing valuable. He afterwards visited France and Italy, and published an account of his, tour under the name of Lancelot Temple. His last production was a volume of Medical Essays. He died in 1779, of an accidental hurt. -The conversation of $A$. is said to have been rich and entertaining, though le is painted in the Castle of Indolence (to which he contributed the stanzas describing the diseases produced by sloth), as

$$
\text { One shyer still, who quite detested talk. }
$$

The Art of Preserving Health, is a successful attempt to incorporate science with poetry. By giving it a moral as well as a medical interest, A. raised the dignity of the poem. It is distinguished by judicions thoughts, correct expression and lucid management, rather than by originality of genius, larmony of versification, or poetic ardour of thought.

ARsuY. In the history of armies we must distinguish those of three different periods $;-1$, the ancient armies, which arrived at their perfection under the Romans; 2 , those of the middle ages, the offspring of the feudal system, ill-organized bodies, created only for a short time, and undoubtedly the worst which history makes known to us; 3 , such as have existed since the invention of gunpowder and the establishment of standing armies. (See the succeeding article.) By the invention of gunpowder, the whole character of armies has been changed, frim the organization and equipment of the whole mass to the very point d'honneur of the individual. As long as personal courage, strength, and dexterity decided the fate of a battle, war had great charms for noble-minded characters. $\mathrm{At}$ this period, too, science had not become incorporated with the very life-blond of society; and the want of intellectual occupation contributed its share in making war the favourite occupation of the higher classes. They fought on horseback, every ene at his own expense. None but the poorer class, the vassals, fought on foot. Under such circumstances, the art of war could never attain a high degree of perfection, nor could the organization of an army be very complete. It was not till the wars between Charles V. and Francis I. of France, that the great importance of regular infantry was seen, and the Swiss, then the best foot-soldiers in Europe, of ten determined the fate of the battle. By the introduction of fire-arms, particularly of artillery, courage and bodily strength lost their exclusive importance, and the advantages of regular tactics began to be felt, by which generals were enabled to direct the movements of armies with greater exactness. Now that war was reduced to a system, it lost much of its charms in the eyes of an idle and ambitious nobility. The estimation of infantry continually increased; volunteers became more rare. It became necessary to take mercenaries from the lowest classes of the people, and, at the same time, 
tive rogular tneties in!roduced. requirval a more tuorongrn training; the inclivilual was lost more and uore in the ınass, and stnueling annies were at length established, and rose continually in estimation. Much was done to inprove tlie n'w srstem by Henry IV. of France, as well as liy the remblic of the Netherlaukls, in their struggle for liberty against Spain. 'The unmher of tronjs oronnized in this way still remainerl, however, very small, conplared with the others. Henry IV., prince Maurice of $V_{\text {inssut, and }}$ Al'xander, cluke of Parna, did uuch for the iuprovesnent of taetics, and of the art of besieging, which made great progress in the war ahove-mentione'd, and contributed, in no sinall degree, to aldvance the claracter of armies. Still more important, in these respects, was the thirty years war in Germany. Armies, as yet, consisted, for the most part, of soldiers raised by the general, to serve only during a particnlar war, e. g. Wallenstein's troops; but the time of service laving nuch increased, particularly in the wars of Gustavus Adolphus of Sweden, the character of armies and tactics was much clevated. This king established smaller divisions, introduced lighter weapons, and made nany improvements in the artillery, by which quicker and more complicated movements became practicable. Repeated victories proved the advantages of the new system, which eveu Wallenstein acknowledged. Soon after, under I,onis IIV., the whole system of war received another form by means of the minister of war le Tellier. and his son and successor Louvois, the art of tactics being particularly improved by Turenne and other contemporary great generals. Stanting armies attained an extent hitherto unexampled. Instead of the 14,000 men maintained by Heury IV., Louis XIV., after the peace of Nimeguen, had on foot an army of 140,000 110u. France hal set the example, and all the otlier powers of Europe followed, with, the exception of Fingland and Holland, which, for a loug time, opposed a similar augmentation, regarding stauding armies as dangerous to freedom. These great masses must necessarily have exerted an important infuence upon the art of war. This art was practised upon a continually increasing scale. France was, at the sane time, endeavouring, in every way, to secure her boundaries by the erection of new fortifications, and her military engineers were particularly eminent. In the beginuing of the 18 th century, a new and important epoch commenced in the military system. Not ouly did Russia, in the time of Peter the Great, maintain a large standing army, well disciplined in the European inamner, which afterwards, under the empress Anua, in its internal regulation, also, was made to resemble the armies of the other European states; but Prussia, too, came forward, under Frederic William I., as a respectable military power, and supported an army far exceeding a proper proportion to her population; hence slie was induced to set the example of foreign levies, in which originated the inconvenience, that, in the hour of danger, a large part of the army could not be depended on, and, moreover, it was difficult to maintain discipline over this same portion, consisting of the refuse of foreign nations. The native soldiers, too, were corrupted by the contact, and it was found necessary to reduce the army to a machine, in order to make such materials serviceable. This idea was put in execution by Frederic II. The system of standing troops was carried to an extent such as it had never reached, and Prussian tactics became a pattern for all the other states of Europe. The systin, however, had fatal imperfections, which would necestarily prodnce very injurious consequences. The great number of foreign vagabonds enlisted, led so tile introxluction of a de'grading discipline, which \&c. unde the eardition of the solitiers eomplotedy misera ble. Every pruspect of alvancenent aut all aulition were de'struyed bs the exelusive pronution of ofticers take'n from the runks of the nubility; and even their promotion was determined by length of service (a natural consequence of the long peace, which had existed since the: s(ven yern's' war). 'This system seemed, iuleel, to lave: been carried to its leight, when the l'resich le'volution broke ont with is viofence which shook linope to its foundation. Stunding armies had now become bolies laving litcle connexion with the nations by which they were maintained. They ouly were armed; the uation bat bccome altogetlior defenceless. When the army was beaten, the nation was subdned. $\Lambda t$ the same time, the armies liad been so much inereased beyoul all proportion to the wealth of the states, that they must necessarily remain, in a great measure, useless. Tiry had become mere machines, witlont any moral in centive. What was the necessary cousequince, when, as then liappened in France, a people excited to fury commenced a struggle with these antiguatcd and rusty engines? $A$ new mode of carrying on war, produced by tise pressure of circumstances, and by the rapid, bold, and energetic efforts of young unilitary geuiuses, overturned multitudes of commou forms, and carried victory in its train, until the op. posing powers had learned to make it their nodel, and thereby restorce the equilibriun. When the French ruler ultimntely began to use his army inore and nore as a machine for the promotion of his antbitious designs, then the other European powers, taught by experience, called the nations themselves to arms, in behalf of frectom; and it was demonstrated anew; that no excellence of discipline, no mechanical perfection of an army, can euable it to withstand, for any length of time, moml euergy and excitement, though counecied witl far inferior discipline.-The armies on the continent of Europe are raised, at present, from among the citizens, who are bound to serve for some time, and are then assigned to the class reserved for any sudilen energency. The time of service is various; in France, for instance, six years; in Prussia, three, that is, in time of peace. In Britain and North Anerica, no citizen is obliged to serve in the standing army, but only in the: militia, which is destined merely for the defence of the country. (See Militia and Soldier.)-The organization of armies is nearly alike throughout the continent of Europe; and France, Prussia, Austria, and Russia have paid much attention to the perfection of all classes of troops. The military schools of these countries, for the officers of different rank, as well as for the various kinds of tronps, particularly those of France and Prussia, are excellent. Among the Prussian troops, learning is so universally cultivated, that the army is considered as a great institution for the diffusion of knowledge, because every Prussian serves three years without being able to send a sub. stitute, and in each regiment schools for the privates are kept. In respect to these military schools, as well as to internal organization, the armies of the European continent very much surpass the British, in which the practice of selling conmissions, the expense of the half-pay system, thie non-promotion of privates, the still continued use of tents, the tegrading flogging, Xc., remind one of a contiucutal army such as it was fifiy years ago. In the army of the United States, commissions are not sold, and the halfpay system has not been adopted. Napolton increased the size of armies to a degree hefore unexampled. They are distinguisled, aceording to the purposes for which they are destined, by the naues of blockading ammies, armies of obsernation, of reserve, 
ARMr, STandixg. In modern times, we designate by the name of standing armies bodies of troops which, in time of peace, are kept under arms for the defence of the state, within and without, trained to war, and paid by the government (iwhence the name soldiers, from soldati, from the Italian soldo, the French sous, for pay). These troops may be composed of persons obliged to bear arms, or not, of na tives, or of foreigners. In this sense of the word, we find standing armies first in the monarchies of modern times, when the general introduction of fire-arms had changed the whole art of war, rendering personal courage of less consequence, and supplying its place with dexterity and mechanical skill, which can only be acquired by practice. The first standing armies consisted of mercenaries, assisted, indeed, at first, by the feudal militia, who, however, gradually disappeared, as military serrice and discipline assumed a more systematic character by means of the standing troops. The expense of mercenaries, which increased with the number of troops, and the security of the state, which could not be committed solely to hired troops, now required that a great proportion of the citizens capable of bearing arms (to be determined by the population, size, geographical and political situation, and civilization of the state) should be continually under arms, and supported by the state, in connexion with the professional soldiers. These were, in a peculiar sense, called standing troops. The introduction of standing armies has been generally referred to the reign of Charles VII., king of France (1423-1461), who, by means of them, overawed his rebellious vassals, and increased not a little the power of the crown. King Philip Augustus, in consequence of the absence of great numbers of his vassals, in the crusades, had introduced, as early as 1215, the troupes des communes (communia; communitates parochiarum), composed of the inhabitants of the cities and villages, of which no city furnished more than 400 or 500 . These served with the feudal militia, at the expense of the cities to which they belonged, and only at a certain distance from them. The power of the cities was thus increased, and the citizens formed, in war, a separate order, independent of the nobles. It was, in a great measure, owing to this cause, that they came to form a third estate in the administration of government. These troops, lowever, like the feudal militia, were never summoned, except in cases of emergency. Thus the troops of Philip and his successors consisted of feudal militia, of the troupes des communes, and of irregular troops, who were taken into pay (whence soldats, soudoyers), and formed certain companies, as they were called, (compagnies). The inperfection of the first class, who often made war on each other, and paid but little regard to the public summons, and the rapine of the latter, led Charles $\mathrm{V}$. to meditate a cliange, and Cliarles VII. resolved to establisl a better unilitary system. After long consultation with his nobles, he laid the foundation in 1445, by selecting fifteen captains (capitaines), whom lie ordered to choose the bravest men from all the troops, and form them into as many companies. These companies received the name of compagnies d'ordonnance, which was, perhaps, earlier applied only to the royal troops, and were maintained, in war and peace, by the cities and villages. Each of these companies, at first, consisted of 600 horsemen (gens d'armes), exclusive of the volunteers, who soon became numerous, and were distributed in the different cities. Henceforward the feudal militia fell more and more into disrepute, and the vassals assembled their forces only on occasions of great emergency. The feudal militin was not, however, wholly supplanted by mercenaries until thie I8th century. In 1448, Charles established a corres- ponding infantry, called Francs-archers, which, in conjunction with the troops just described, constituted a very respectable army. 'The military system thus established in France spread thence tlirough the other countries of Europe. (See Daniel's Histoirc de la Milice Française, \&c.) With the progress of standing armies in France, and the increase of wealth, the standing armies of other countries increased also ; e. g., those of Holland, Britain, and Germany. When this increase arrives at its highest point, and the decision of war, becomes almost entirely dependent on numbers, the duty of military service is extended to all the citizens, and a system of conscription is introduced, adapted to the condition, population, and necessities of a state, by which all the citizens, of a certain age, capable of bearing arms, are called upon to do military duty, for a longer or shorter period. In this way, standing armies, and the military, considered as a separate profession, are, to a great degree, abolished, and, all the citizens (with few exceptions) able to bear arms being disciplined for the protection of their country, and obliged to act in its defence, the numbers of troops becomes propurtionate to the natural relations of states to each other, and military discipline becomes more liberal and honourable. At least, this has been the case upon the European continent. The increase of the militia renders it also more difficult to give the proportion of the military power of some states to their population, because the standing army is no longer the sole, and, with some governments, not even the chief, military power. Malte-Brun in his Geography, estimates the proportion, in the principal states of Europe, as follows; though, for the reason just given, the estimate is necessarily imperfect :-

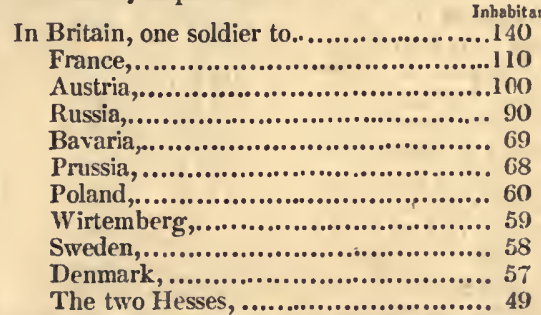

The proportions in other states are much lower :-

In the 'Two Sicilies,...........................180

Tuscany,..................................200

The Roman states,.........................300

Malte-Brun thinks that, on the Furopean continent, one soldier to 100 inhabitants would be found a proportion not injurious to the resources of the states. The United States of America liave now on foot not even 6442 men, to which number the army is limited by the law of 1821 . The importance of militia is daily increasing. (For further information in regard to the militia, and the great clianges which have taken place in standing armies during the last twenty years, see Militia and Army.)

ArNaOUTs, or Albanians; a people of mixed origin, probably the primitive inhabitants of Illyria and Macedonia, intermixed with Goths, Huns, and Sclaronians. who have spread in the western part of Rumelia, along the coasts of the Adriatic and Ionian seas, and have sent colonies to the Neapolitan and Sicilian coasts. Their language lias not risen to the dignity of a written one. They call themselves Skypetars; by the Turks they are called Arnuouts. They are divided into sereral tribes, annoug whom the Suliotes (q. v.) are partly of Greek origin. Strong and warlike by nature, the Arnaouts were the best soldiers in the Turkish army. 'They are frank towards friends and superiors, but allow themselres 
like all rude nations, every kind of artifice and per6dy towards their enemies. The oppression, under which they formerly

lived, filled them witl the desire of liberty. For arts and trades thes have no inclination. Agriculture they esteem not so
hourourable an occupation as anns. Their restless spirit is averse to the uniformity of peace. Yet they are not acquainted with the higher tactics; they never form a line of battle, and do not understand the advantages of strong positions. Hence they are not so efficient against European armies as might be expected from their personal courage. The native $\Lambda$.is of a middle stature; his face is oval, with high cheek bones; his neck long; his chest full and broad. His air is erect and majestic. Differing from the grave and sluggish deportment of the Turk, he is gay, live$1 y$, and active. The subjoined cuts represent the prevailing costume of the Arnaouts. They go constantly armed; and there are few who, in the prime of life, have not belonged to some of the numerous

bands of robbers who infest the mountains of their native country, of Thessaly, and of Macedonia. This profession carries with it no disgrace : it is common for the A. to mention circumstances which occurred, "when he was a robber."-Albania, (q. v.) part of the Turkish province Arnaout Vilajetti, a mountainous, maritime combury, but very well adapted to the cultivation of wine, fruit, cotton, and tobacco, lying along the Adriatic and Ionian seas, is the true country of the Arnaouts. - The Montenegrins (q. v.) in the hills of Montenegro, whom the Turks have not jet been able to ranquish, are distinguished among them. Among the principal towns, we may mention Janina (q. v.) and Scutari, with 12,000 inhabitants (not to be confounded with the city of the same name in Anatolia, orer against Constantinople), both residences of pachas; also Durazzo, the old Dyrrhachium.

Arvatto, or Aswotra, is a red dyeing drug, generally imported in lumps, wrapped up in leaves, and produced from the pulp of the seed-vessels of a shrub (bixa orellana), which grows spontaneously in the East and West Indies. This shrub is usually about seven or eight feet high, and has heartshaped and pointed leaves. The flowers, which have each ten large, peach-coloured petals, appear in loose clusters at the ends of the branches, and produce oblong, hairy pods. The seed-vessels of the armatto shrub are, in appearance, somewhat like those of the cliestunt. They each centain fiom thirty to forty seeds, enveloped in a kind of pulp, of red colour and unpleasant sinell, not rery unlike the paint called red-lead, when unixed with oil. In the West Indies, the methorl of extracting the pulp, and preparing it for sale, is to boil this, and the seeds which are unixed with it, in clear water, until the latter are perfectly extricated. They are then taken out, and the pulp is allowed to subside to the bottom of the water; this is drawn off, and the sediment is distributed into shallow vessels, and gradually dried in the shade, until it is sufficiently laard to be worked into lumps or masses for sale. Arnatto, thoingh made in the West Indies, is an object of no great commercial importance; the demand not being suf ficient to give much encouragement to its culture. It is now chiefly prepared by the Spaniards in South America, and for the purpose, especially, of mixing with chocolate, to which, in their opinion, it gives in pleasing colour and great medical virtue, as well as an improved flavour. The principal consumption of arnatto depends upon painters and dyers; and it is supposed that Scott's nankeen dye is only amatio dissolved in alkaline lye. This drug is sometimes used by the Dutch farmers to give a rich colour to butter; and the double Gloucester, and several other kinds of cheese, are coloured with it. The poor occasionally use it instead of saffron. In countries where the arnatto shrubs are found, the roots are employed by the inhabitants in broth, and answer all the purposes of the pulp, though in an inferior degree. The bark is occasionally manufactured into ropes; and the Indians use pieces of the wood to procure fire by friction.

Arvatd, Frangois-Thomas-Baculard d'; a prolific French writer, born at Paris, 1718, where he studied with the Jesuits. In his youth, among other pieces, he wrote three tragedies, one of which, Coligny on. la St Barthélémy, was published in 1740. Voltaire conceived an affection for him, and aided him with money and advice. Frederic 1I. opened a correspondence with him, invited him, afterwards, to Berlin, received him kindly, called him his Ovid, and addressed a poem to him, which closed with these verses:

$$
\begin{aligned}
& \text { Déjà l'Apullon de la France } \\
& \text { S'achemine à sa décadence; } \\
& \text { Venez briller á votre tour. } \\
& \text { Elevez-vous, s'il baisse encore; } \\
& \text { Ainsi le couchant d'un beau jour } \\
& \text { Promet une plus belle aurore. }
\end{aligned}
$$

France's Apollo, Voltaire, thought this comparison not very flattering to himself, and took his revenge by satirizing d'Arnaud's person and verses. At the end of a year, d'Arnaud left Berlin for Dresden, where he had receired an appointment, and returned thence to his native country. During the reign of terror, he was imprisoned in a dungeon, and afterwards led a life of miserable porerty. Owing to his carelessness and extravagance, neither the aid of the goverument nor his own pen could preserve him from want. He died at Paris, in 1805 , at the age of eighty-six years. His best works are, Epreuves du Sentiment, Délassements de l'Homme sensible, Loisirs utiles, and some others. His dramatic works are not esteemed. Only the Comte de Comminge, in 1790, had a short run on the stage. A part of his numerous poems appeared in 1751, in three volumes.

ARNADLD. From this old family of Auvergne, which belongs to the nobility de la robe et de l'épée are here selected--1. Antuny $A$. an advocate at Paris, from 1580, a zealous defender of the canse of Henry IV., distinguished for several political pam. phlets, and for his powerful and successful defence 
of the university of Paris against the Jesuits, in 1594. By this he drew on himself the hatred of the Jesuits, but remained, till his death, in 1618, in possession of his honours, and was esteemed the greatest lawyer of his time. His twenty children formed the rallying point of the sect of the Jansenists (see .Jansenius) in France; the daughters and grand-daughters as nuns, in Port-royal, the sons as members of the learned society; who shut themselves up in this monastery, and are known under the name of Messieurs du Port Royal. A son of his eldest daughter, Isaac le Maitre de Sacy, also united himself to this society, and, as translator of the Bible that appeared at Mons, played an important part in the history of Jansenism.-2. Robert Arnauld d'Andilly, oldest son of Antony, born at Port Royal, in 1588, died in 1674, made himself known as a very correct French writer, by his religious poems and tracts, and his translations of Josephus's History of the Jews, and of Davila's works. He was far surpassed in intellect by his youngest brother.-3. Antony Arnauld, the youngest child of the lawyer Antony Arnauld, born Fel. 6, 1612. Under the guidance of the abbot of St Cyr, John du Vergier de Havranne, first head of the Jansenists in France, he devoted himself to theology, and was received, in 1643, among the doctors of the Sorbonne. In the same year, he attacked the Jesuits in two works, De la fréquente Communion, and La Théologie Morale des Jésuites, the first of which occasioned mucl controversy, because it applied the principles of the Jansenists to the receiving of the sacrament. He excited similar controversies by his work, De l'Autorité de St Pierre et de St Paul residente dans le Pape, 1645, by the opinion therein maintained, that the two apostles should be regarded as of equal rank, and as founders of the Roman Catholic church. After 1650, when Jansenism had become an ohject of public odiun, and the watchword of an important party in the state, Amauld engaged in all the quarrels of the French Jansenists with the Jesuits, the clergy, and the government, was their chief writer, and was considered their head. The intrigues of the court occasioned his exelusion from the Sorbonne, 1656 , and the persecutions which compelled him to conceal himself. In his retirement, he wrote a system of logic on the principles of Descartes, and a Grammaire raisonnée, which were, for a long time, esteemed as school-books. After the recanciliation between pope Clement IX. and the Jansenists, 1668, he appeared in public, and enjoyed the homage which even the court did not refuse to his merits and talents. To satisfy his love of controversy, he attacked the Calvinists in many controversial tracts, and, with his friend Nicole, coniposed the great work, La Perpetuité de la Foi de l'Eglise Cathol. touchant l'Eucharistie, in opposition to them. For this, a cardinal's hat was destined for him at Rome, but, as he scomed it, and as the court had become unfavourable to him, it was not conferred. On account of the new persecutions of the court, or rather of the Jesnits, he fled, in 1679 , to the Netherlands, employed himself, in his exile, in controversial writings against the Calvinists and the Jesuits, and died, in want, at a village near Liege, Ang. 9, 1694. He was a man of a vigorous and consistent mind, full of solid knowledge and great thoughts; in his writings, bold and violent to bitterness ; undaunted in danger, and of irreproachable morals. He is acknowledged to have done much for the improvement of morality in the Catholic church; yet would his genius have been far more useful to the church and to literature, had not his situation and character involved him in a multitude of controversies, which rendered his literary activity, for the most part, fruitless to posterity.
Arnaut. See Arnaouts.

ARND, Joln ; a Lutheran minister, distinguishect for piety. He is the author of a work, which has been translated into almost every language of Europe, and has been extensively read in Germany for 200 years. Its title is, True Christianity (IVahres Christenthum). Mr Bœhm printed an English translation of this treatise, which went through two editions, dated in 1712 and 1720 , both in 3 vols. $8 \mathrm{ro}$. A. was born, in 1555, at Ballenstedt, in Anhalt, and died, in 1621, at Celle, after he had been a minister in different places, and suffered from the Calvinists, and even the Lutherans. A few hours before his death, he preached from the text, Psalm cxxvi., "They who sow in tears shall reap in joy," and, on arriving at his louse, spoke of his discourse as a funeral sermon. His work above-mentioned has been reprinted since his death, in 1777 , by Feddersen, and in 1816, by Sintenis.

Arve, Thomas Augustin, one of the best English composers, was born at London, in 1704, the son of a respectable upholsterer, and received the first part of his education at Eton. He was intended for the study of the law, but a strong inclination led him to devote himself to music, and he secretly carried an old spinet into the garret of his father's house, in order to pursue his favourite occupation. For a long time, he was obliged to keep it secret, but his father was finally induced to yield to his wishes, after he had made great progress in the art. Discovering that his sister had a fine voice and a great fondness for music, he prevailed on ker to choose the profession of a singer. He composed a part for her in his first opera, Rosamond, after the text of Addison, which was performed, in 1733, at Lincoln's-Inn fields, and was received with great applause. Then followed Fielding's comic opera, Tom Thumb, or the Tragedy of Tragedies. His style in the Comus, 1738 , is still more original and cultivated. The pulblic was delighted with his lively, cheerful, and natural melodies, and with the truth and simplicity of his expression. In 1740, he married Cecilia Young, an excellent singer, educated in the Italian school. They went, in 1742, to Ireland, where they were well received. After two years, he was engaged as a composer, and his wife as a singer, at the Urury lane theatre, in London. He composed several songs in 1745, for the Vauxhall concerts. After having composed two oratorios, and several operas, one of which was called Eliza, and having received the title of doctor of music, at Oxford, he attempted a composition in the Itälian style (Metastasio's Artaserse), which was very popular. His talents, however, were better adapted to the simple, lively, and soft, than to the grave and clevated. He composed, also, several of the songs in Shakspeare's dramas, and various pieces of instrumental music. He died in 1778. His sister was afterwards a distinguished singer under the name of Mrs Cibber: Iris brother, also, went on the stage. His son, Michael, was a musician, and composed several favoúrite pieces, but did not attain great eminence.

Arno (anciently Arnus); one of the largest and finest rivers of Italy, which divides T'uscany into two parts, and washes Florence and Pisa. The A. rises in the Apennines, on the east of Florence, near a village called $S$. Maria della Grazia, on the borders of Romagna, fifteen miles W. of the sources of the Tiber; it then turns southward towards $\Lambda$ rezzo, where it is increased by the lakes of the Chiana; after which it runs westward, dividing Florence into two parts, and, at length, washing Pisa, falls, four miles below it, into the Tuscan sea. This river has been sung by many poets, on account of the beautiful banks between which it meanders, and the cities 
with which they are ndoruer. From any hill in the urighbourlioud of s'orence, or at the confluence of the Cliana, the view into the valley of the $A$. is clarming. In ancient times, the Etruscans erected here extensive works of hydraulic architecture, long before any other Italian nation had arrived at such a degree of civilization. Niebuhr, in his Roman History, division Tuscans and Etruscans, says as follows:-" The greatest part of Tuscany is mountainous. The rich valley, through which the Arno flows, was, in ancient times, covered by a lake and marshes. From Segna to Fiesole, and toward Prato, was one lake: the Gonfalina closed up the ralley: a passage was made through this rock, to open a way for the river towards Pisa. The water covered this space at the time of the erection of the walls of Fiesole, as is shown by many openings which were designed for draining it off. It covered the site of modern Florence, whose origin it is, therefore, alsurd to refer to the Etruscan times. A section was also cut at La'ncisa (the cut), to drain the rich fields of the upper valley of the Arno; or it may be that the rivers, which now forn this part of the Arno, formerly fell into the Clauis, and the object was, to climinisls the water of the Tiber. The marshes through which Hamibal marched are, at present, dry on the right bank of the Lower Arno." In the time of Napoleon, the A. gave its name to an extensive and populous department in the grand empire; Florence being the capital. The population amounted to about 600,000 .

Arsomos the Elder, called also the African, was, about A. D. 300 , teacher of rhetoric, at Sicca Veneria, in Nunidia, and, in 303 , became a Christian. While yet a catecliumen, he wrote seven books of Disputationes adversus Gentes, in which he refuted the objections of the heathens against Christianity with spirit and learning. This work betrays a defective knowledge of Christianity, but is rich in materials for the understanding of Greek and Roman mytloology. "Hence it is one of the writings of the Latin fathers, which, like the works of his disciple Iactantius, are particularly valued by philologists. Orelli has published the last and best edition (Leipsic, 1816). From the younger A, a Gallic divine, in the last half of the 5th century, we have only an insignificant commentary on the Psalms, which betrays the principles of the Semi-Pelagians.

ARNOLD of Brescia, one of the disciples of Abelard, returned, full of new ideas on religion and the church, in 1136 , to his native city. His bold and lofty spirit, his knowledge of Christian antiquities, and his vehement eloquence in his public harangues, gave authority to his reproaches against the abuses of the church. Thus he instigated the people against the clergy ; and, in France, where he was obliged to flee in 1139, he also found numerous adherents; for the immorality and arrogance of the clergy had srerywhere excited discontent. The fierce flame which he had kindled could not be extinguished by the excommunication pronounced against him and his adherents (Arnoldists) by Innocent II. A. preached his doctrine in safety at Zuricl, in Switzerland, until 1144, when heappeared at Rome, and, by the powers of his eloquence, occasioned a violent excitement among the people against the clergy. The furious multitude, whom he himself could no longer restrain, revered him as their father, and even the senate protected him, till Adrian IV., in 1155, laid an interdict upon the city. This disgrace, never before experienced, subdued the Romans. They sued for mercy, and A. was obliged to fly. He was taken in Campania, and borned at Rome, as a heretic and a rebe! ; his ashes were thrown into the Tiber, and his party was suppressed. But the spirit of his dnctrine de-- scenderl upon the sects which arose during the same and the following centuries.

Arsold, Benedict, one of the most distinguished genernls in the American army during the enrlicr part of the contest of the colonies with Great Brituin, and subsequently infamous as a traitor to his country, was born in Connectieut, of obscure parentage, and received an education suitable to an humble condition. [The narmative of this man's life, as given in the American Encyclopedia, we find so novel and interesting, that we refrain from ubridging it, although it greatly exceeds the bounds to which our biographical notices are usinlly limited.]-The occupations of Amold's youth were not fitted to prepare him for the functions which he was, called upon to exercise in the sequel. At first a dealer in liorses, he sustained losses in his trade. Eager for renown, greedy of money, the troubles of his comtry inspired him with the hope of acquiring fame and fortune by the profession of arms : accordingly, on the breaking out of the revolutionary war, he einbraced the cause of his countrymen with enthusiasın, and took the command of a company of volunteers at New Haven. Ife soon won a high military reputation. Washingtou, encouraged by secret advices that the Canadians were inclined to make part of the Union, projected the surprise of Quebec. This hazardous undertaking required leaders at once active, vigilant, bold, and inflexibly patient. He committed it to Montgomery and colonel Arnold, as the most capable. He exhorted them, with extreme earnestness, to treat the Canadians as friends, as fellow-citizens, and to punish severely the least irregularities of the suldiery. $\Lambda \mathrm{r}$ nold began his march in the month of September. He conducted his small force through deserts which man had never before penetrated. The river of Kennebeck had overflowed its banks; he crossed it by swimming, or on rafts. Unknown streams presented a new obstacle: he diverted their course. The snow fell in abundance; a few hours of sun during the day were insufficient to thaw the ice formed in the long and severe nights of the northerm autumn ; but nothing could arrest his progress. He was always in the van with the pioneers, who cut a passage through this wild country, and, at the end of each march, had arrived before the enemy knew of his approach. He thus put in practice a maxim which he was fond of repeating: "In war, expedition is equivalent to strength."-The last division, conducted by a man less resolute and persevering, returned; while he, at the head of the two first, sustained the courage of the soldiers, who were exhausted by fatigue, hunger, and every species of suffering. After two months of toil, all impediments were overcome, and he encamped before the fortress, but with a band so much enfeebled, that he was obliged to await the arrival of Montgomery, who appraached by another route. Montgomery died gloriously in an assault, Dec. 31, 1775. Arnold was severely wounded in the leg, and forced to convert the siege into a blockade. He was not, however, to be daunted by any reverse. From the bed to which his wound confined him, he infused into the little army, the command of which had now devolved upon him, his own spirit of determination and confidence. The enterprise failed : the conrage and intelligence, which he exhibited throughout, placed him, nevertheless, in the first class of American officers. He served with better fortune, and still greater distinction, in the subsequent campaigns, and bore a considerable part in that in which Burgoyne and his army were made prisoners. He fought with his usual intrepidity in the engagement which immediately preceded the capitulation. The first to throw himself into the intrenchments of the enemy, he was 
animating his men by his example, when a ball shattered the leg already wounded at the siege of Quebec. As he was borne from the ranks to his tent, he still issued orders for the continuance of the assault. The boldness of Arnold was so great, that he was accused of a disposition to entangle himself rashly in perilous situations; but it could not be denied, that his rapid discernment supplied him, in the midst of danger, with the surest expedients; and that success always justified his daring. The admiration of his fellow-citizens kept pace with his services. His love of glory was accompanied with an equally strong love of pleasure and dissipation, and he was very unscrupulous about the mode of obtaining the means of gratifying it. His ill-gotten wealth he squandered in frivolous expenses, or mere ostentation. Montreal, the second city of Canada, was, under his command, a scene of injustice and rapacity, and the Canadians soon abandoned the design of joining the confederation. The attempt on Canada was abandoned, and, the wounds of Arnold being not yet healed, he could be invested only with some stationary command. Washington, though he detested his vices, did not wish to leave his talents idle. The English having evacuated Philadelphia, he directed Arnold to take possession of that city with some troops of the Pennsylvania line, $-a$ delicate charge for a man so prone to extend his powers, and define them according to his interests. It was not long before he displayed in this city a magnificence as foreign to the habits of the country, as it was unseasonable in the midst of the calamities of war. He even lodged in his house the French envoy and all his suite on their arrival. From this time, too, he began to profess an extraordinary attachment to the French, and great zeal for an alliance with them. To relieve himself from the difficulties into which his extravagance had plunged him, he resorted to the same oppression and extortion which had rendered his authority odious to the Canadians. Under pretence of the wants of the army, he forbade the shopkeepers to sell or buy; he then put their goods at the disposal of his agents, and caused them afterwards to be resold with a profit. He prostituted his anthority to enrich his accomplices, and squabbled with them about the division of the prey. The citizens applied for redress to the courts of justice. But, with his military authority as his shield, he set at defiance both justice and the laws. At length, however, a representation of the grievances which the state was suffering, was made to congress by the president of the executive council of Pennsylvania, a man of firm and upright character, who had endeavoured in vain to repress the overweening and predatory spirit of Aruold, and a committee was appointed to inquire into the subject. Amold replied to the charges with arrogance. Some members of congress were of opinion that he should be suspended from his military functions until the investigation of his public conduct was brought to an issue ; but the accusation had become an affair of party; and he had influence enough to cause this proposition to be set aside. Congress at length resolved to lay the complaints against him before the commander-inthief.-As soon as Arnold saw that the resolutions of congress would be of this tenor, he resigned the command which he held in Philadelphia. He was tried before a court martial, and condemned, January 20,1779 , to be reprimanded by the commander-in chief. Congress ratified the sentence and Washington, having caused the culprit to appear before him, performed the task with the considerate delicacy which he thought due to so distinguished an officer. Arnold, howerer, quitted the army, and, thenceforth, nourished an implacable hatred towards the cause which he had so brilliantly defended. - The embarrassment of his affairs was at this time such, that private aid would not suffice to extricate him. He had, some time before, formed a partnership with some owners of privateers, who paid his share of the expenses of equipment, and expected to be compensated, for their advances, by his countenance and protection; but the chances were adverse, and, instead of profits to be divided, there were losses to be borne. Arnold, now without credit or authority, was no longer regarded by the owners as any thing more than an ordinary partner. They exacted lis proportion of the loss, and their knowledge of his difficulties only served to render them more urgent in their suit. In this extremity, he tried a last resource.-Congress, at the commencement of the revolution, committed an error which proved of great detriment to the finances. It intrusted some officers with agencies which had no immediate connexion with the business of command or military service. Arnold, the least proper for such trusts, was charged with considerable ones, and had large claims for monies and stores furnished in the expedition to Canada. The commissioners, to whom they were referred for settlement, reduced them very considerably. He appealed from their decision to congress, who pronounced that the commissioners had shown more lenity than rigour in the liquidation of his acconnts.-Disappointed in all his expectations, Arnold at last determined to betray his country, and to make his treason in a high degree useful to Britain, that it might procure him a full pardon for his share in the revolt of the colonies. He wished to be regarded as a subject returned to his allegiance, and worthy of the hollourable rewards due to faithful and virtnous citizens. As a first step, the British commanders were to be made acquainted, with his discontent, but in so guarded a manner, as to leave a retreat open, in case the offers, which might be made to him, should not prove satisfactory. Particular circumstances facilitated the communications between them.-As soon as the British commander was apprized of the disposition of Arnold, he despatched emissaries charged with such offers as were most likely to determine a man whose hesitation was only about the means and conditions. Some of Arnold's proceedings, about this period, warrant the supposition, that he at first meant to tamper with his brother officers, but relinquished this design on more mature reflection. He took good care that nothing of his real intentions should be divined by the subal. teru British agents; but there was, at New York, a man whom he thought he could trust without risk. This was Charles Beverley Robinson, an American by birth, and a colonel in the British army, whose property all lay within the U. States. His mansion, situnted on the Fludson. was included in the American lines, and three miles lower than the forts upon the opposite bank. The commanding officers of West point, having found it deserted, had made it their quarters. Arnold wrote to this officer, that the ingratitude of his country, and other considerations to be afterwards disclosed, had produced a change in his political sentiments; that he aspired to merit, thenceforward, the favour of the king; that he could render signal services; and wished to enter into a correspondence on the subject with Sir Henry Clinton. -This overture was well received, and, a direct communication with the British general being established, it was agreed that Arnold should dissemble. with the utmost care, his discontent; that he should make every effort to obtain a command from general Washington; that, as soon as he succeeded, he should consult with Sir Heury Clinton as to his future movements, and be guided by the instructions which would be given to him.-Froin this time, he entirely 
altered his manner and language. He affected to have forgotten the affrout of the reprinand, and pretended to feel a more lirely attachnent than ever to the cause of independence. - The country through which the Hudson fows was the principal theatre of the war. A station in this quarter would, he thought, best answer his purpose. He was well acquainted with the localities. He examined, with minute attention, in what spot, by what operations, he could most beneficially second the enterprise's of the British, and which was the most important position to betray into their hands. New York, was, at this time, in the hands of the British, who had assenbled there the greatest part of their troops. The fortress of West point, a military station of very great impor. tance, is distant twenty leagues from this city. Arnold aimed at the chief command of this post, with a view of betraying it into the lands of the British, with the garrisous, and the arms, and immense stores which were deposited there ; for fort Clinton contained, besides the ammunition necessary for its own defence, the stock of powder of the whole army.The command of the fort had been intrusted to general Howe, an officer of tried courage, but of limited capacity, who could be employed elsewhere without inconvenience to the service. The wounds of Arnold did not as yet allow him to mount on horseback; they did not disqualify him, however, for conducting the defence of a citadel. He had early secured the patronage of some of the leading men of the state of New York, and Washington was prevailed upon to consign West point to him. Being a traitor to his own country, he was apprehensive lest those to whom he was about to sell himself might prove treacherous to him. He felt anxious to receive the price of his ignominious bargain at the moment of its ratification; but he could extort nothing more than a promise of 30,000 pounds sterling, and the assurance that he should be maintained in the British armiy, in the rank of brigadier-general, which he already held. About a month previous (July 10, 1780), the first division of the French army arrived at Newport, in the state of Rhode Island. The situation of the English became every day more and more critical. Sir Henry Clinton had relinquished his projected expedition. He urged Anold to filfill his engagements, and supposed the thing easy for a general who was master of the forts and the river ; but there were, in fact, numerous obstacles in the way, and of these the presence of the commander-in-chief was the most serious. Arnold knew his vigilance and activity. He insisted, therefore, with Clinton, on the necessity of deliberation, adding however, that all should be in readiness to improve the first farourable opportunity. $A$ young officer of foreign extraction served in the British army. He was endowed with all the qualities which render a man useful to his country and dear to society. This was JoHN A.TDRÉ, adjutant-general of the British army. General Sir Henry Clinton had taken him as his aid-de-camp, and did not disdain him as a counsellor. To him Clinton committed the business of negotiating with Arnold. A correspondence ensued between Arnold and André, under the supposititious names of Gustuvus and Anderson. Mercantile relations were feigned, to disguise the real object, and an American, whose dwelling stood between the lines that separated the two armies, served as a common messenger. At this period, the rumour began to spread of a second division of the French army having sailed, and that Washington only awaited its arrival to begin the siege of New York. The marshal de Castries, who then administered the department of the marine with so much reputation, had, in fact, advised the French envoy of the approaching departure of a sccond expedition.
Clinton caused $\Delta$ rnold to be told that it was time to act; that a day must be fixed for the surrender of the forts; and that, if time were given to the allies to effect a junction, it inight no longer be in the power of Arnold himself to fulfill his engagements. He asked, also, plans of the forts, and the instructions necessary for the safe guidance of the British troops when they were sent to take possession of West point. Arnold replied to these new importunities in the language concerted with Andre :- "Our master goes away on the 17 th of this month. He will be absent five or six days. Let us avail ourselves of this interval to arrange our business. Come immediately, and meet me at the lines, and we will settle definitiveIy the risks and profits of the copartnership. All will be ready; but this interview is indispensable, and must precede the sailing of our ship." It was thus that Arnold apprized Clinton of the approaching departure of the commander-in-chief. Washington had, in fact, given a rendezvous to count de Rochambeau, ceneral of the French land-forces, and to the chevalier de Ternay, commander of the squadron. They were to meet at Hartford, in Connecticut, to confer about the operations of this and the cusuing campaigns. But Arnold was not correctly advised as to the period of Washingtor's departure, and the mistake led to important consequences. He had, in other letters, solicited an interview with André, and he now exacted it as a condition indispensable for the prosecution of the enterprise. Hitherto, every thing had succeeded beyond his hopes. There had been a total absence of those mysterious rumours, and vague surmises, which accompany and seem to portend, a great conspiracy. Never had so momentous a plot been more felicitously brought so near to its execution. This profound secrecy was owing to the precaution of Arnold, in not having unbosomed himself to any of his own countrymen, and in admitting only André and Robinson as correspondents. He took credit for this policy, and his urgency for an interview with Andre arose chiefy from his resolution to confide to the hands of this officer alone, the maps and particular information which Clinton demanded. -The 17th of September, the day specified for the departure of Washington, passed, and he was still at West point. Aruold adrertised Clinton of the delay, and explained his mistake by mentioning a circumstance which had not been before noted. The 17th fell on a Sunday, - a day which the Americans consecrated entirely to the duties of religion, and on which most of them abstained even from journeys, which, elsewhere, would be thought indispensable. Clisiton admitted this explanation the more readily as he knew that Washington respected the scruples of others, and was himself very religious. To obviate untoward accidents, it was agreed that André should leave New York only on the 19th of September, and reach the American forts about the 20th. He accordingly embarked in the night on board the Vulture sloop of war. Clinton sent with him Bererley Robinson, the colonel through whom Arnold had made his first overture. He expected that the prudence of this officer would moderate the ardour of André. Moreover, Arnold occupied Robinson's house, and the private affairs, which he, as a refugee, had to adjust with congress, furnished a plausible pretence for his approaching the American lines and posts. Sejtember 20, they arrived almost opposite to fort Monigomery, situated on the same side as West point, five miles lower down. They cast anchor in sight of the nearest American redoubts, but beyond the reach of some small cannon, the only artillery of those redoubts. The Vulture got aground at low water. The movement on board, and some signals which she made, alarmed the vigilance of colonel Livingston, 
who commanded at Verplanck's point. He ascertained, our reconnoitring, that the sloop might be sunk by one or two pieces of heavy cannon; and as those of the forts which he commanded were of too small a calibre, he requested larger from Arnold. The general refused them, to the great surprise of Livingston. But tacit obedience is the life of discipline, and he acquiesced in some idle excuse. Two days elapsed after the Sunday, and still Washington had, apparently, made no preparations for departure. Arnold was himself uneasy at this disappointment; but the apprehension of exciting suspicion by too frequent communications prevented him from making it known to Clinton. The British general was informed of it through another channel. He knew the unprincipled character of Arnold, and could compreliend the probability of a snare masked by a counter. feit scheme of treason. He was the more disquieted as André and Robinson, were already far on their way; and there was equal inconvenience in leaving them ignorant, or advising them of their danger. If Arnold were sincere in his defection, André's return to New York would disconcert all his measures, and expose him to serious risks. If he deceived the British, all the risks were for André and Robinson. They had not, as yet, been able to communicate with the shore, but, persuaded that Waslington must have set out for Hartford, they put in execution a stratagem, arranged beforehand with Arnold, to facilitate the rendezvous. Robinson wrote to the American general Putnam, as if to transact with him business relating to his property, and proposed an interview. In this letter was enclosed another to general Amold, wherein Robinson solicited a conference with him, in case Pntnam should be absent. The packet, being directed to Arnold, would be opened only by him; but if, perchance, it fell into other hands, the whole could be read without exciting suspicion of a plot. This letter was despatched to the shore by a flag of truce as soon as the sloop had cast anchor. It happened to be on the very day fixed by Washington for his departure. He had never meant to set out earlier, and had neither sanctioned nor contradicted the various rumours current on the subject. He left his quarters in the morning, and, on reaching the bank, found Arnold there with his barge, ready to transport him to the other side. Ir crossing, Washington remarked the sloop with the British flag, and took a spy-glass to observe her motions more narrowly. Some moments after, he gave to an officer near him, in a low roice, according to his usual manner, an order probably of no consequence, which Arnold was unable to overhear.-Arnold was guilty, and whatever he could not immediately penetrate, alarmed his fears. He supposed that the general could not remain ignorant of the circumstance of the flag of truce, and, doubtful even whether he might not be already acquainted with it, he thought it well to show him the two letters which he had received, asking him, at the samc time, what course lie ought to pursue. Washington, in the presence of several persons, dissuaded him from seeing Robinsol, and directed him to give for answer to this officer, that his private business appertained exclusively to the jurisdiction of the civil authority. They touched the shore just as this conversation ceased. Thic commander-in-chief, whose presence kept Arnold in the greatest perplexity, landed, and pursued his journey to Hartford. Thus was the main obstacle removed, and the plot could proceed. The opinion uttered by Washington, in such positive terms, concerning the conference with Robinson,-the order heard by several persons present,-became, however, a law for Amold, with respect to his ostensible conduct. It was, in this way, the first obstacle that thwarted the measures concerted between him and André. They could not meet publicly under the auspices of a flag of truce, and, thongh André liad used this means to reach the lines, tliey were obliged to arrange a secret interview. On the morning after the departure of Washington, Arnold sought out a man called.Joshua Smith, well known to be devoted to the British, although lie resided within the American posts. He made him the bearer of two passports to be carried on board the Vulture, -one for André, under the fictitious name of Anderson; the other for Charles Beverley Robinson, who had not the same reason for practising disguise. He charged him with a letter, also, in which he urged them to repair to lim on shore. Smith waited umtil night-fall, and then proceeded to the British sloop in a boat which Arnold lıad provided for him. André and Robinson expected that Arnold would himself visit them, and were surprised when his emissary, Smith, appeared before them alone. Robinson declared that he would not go on shore, and used every effort to deter lis companion; but the young man, full of impatience and ardour, saw only the chances of success, would listen to no remonstrance, and could not brook the idea, either of returning to New York without having executed his mission, or of exposing the main enterprise to miscarriage, by a caution which his rivals would infallibly stigmatize as cowardice. He put on a grey surtout, to hide his uniform, and accompanied Smith on shore. Arnold was waiting to receive him at the water's edge. They discoursed there for some time; but, as they were liable to be surprised, Arnold led him towards the house of Smith, when he immediately laid before him plans of the forts, a memoir, composed (for a better use) by the chief engineer, Duportail, on the means of attacking and defending them, and minute instructions with respect to the measures to be taken by the British for the occupation of them, when he (Arnold) should have done his part in opening the way. They presumed that Washington had already reached Hartford, and they were right; for he was there, at the same hour, in consultation with the French commanders. Arnold and André, calculating anxiously the probable length of Washington's absence, supposed that he would return in three or four days, that is, on the 25 th or 26th of Sept., and one or other of these days was fixed for the execution of the plot. It was settled tlıat André should go back in all haste to New York; that the British troops, which were already embarked, under prctence of a distant expedition, should be held ready to ascend the river, and sail at the first signal; that, to facilitate the reduction of West point, Arnold should march out of the forts all the troops destined for the defence, and entangle them in gorges and ravines, where he would preteud to await the British assailants, while these were to debark on another side, and enter by passes left unguarded; and, at all events, the garrisons and troops were to be so distributed, that, if they did not surrender at the first sunmons, they must be immediatel y cut in pieces. He informed André, that the chain which was stretched across the river from West point to Constitution island, forming, when perfect, an effectual bar to the passage of the river, was now no longer an impediment. He had detached a link, ostensibly to have it mended; the smitlis would not return it for some days; and the two ends of the chain werc held together by a fastening too weak to bear even a slight concussion. The British would know at what moment they were to advance, by the kindling of fires, in the night, under the directions of Arnold, on the adjacent eminences. A single canmon fired from their ships, to be followed by a similar discharge from the shore, would proclaim that thicy had perceived the signals. Other tokens agreed upon 
were to furnish, successively, information of the several distances of the British forces in their approach. When they had arrived within three miles of the fortress, two English ofticers, in American uniform, were to ride full gallop to Arnold's quarters, to learn how matters stooul, and to liasten with the intelligence to the British naval commander. Then only was Arnold to put in motion that portion of the garrison which remained in the works, and station it at posts which would not be attacked. They agreed upon the countersign to be given on the 24 th and 25th. Arnold delivered to the Englishman draughts of all the works, and of the passes leading to them, several memoirs, written with his own hand, and full returns of the garrisons and the forces of each division of the arny. He had never before allowed a single paper to go out of his hands, which might expose lim to detection. But he now saw no danger in confiding these to André, who was to re-embark directly on board the sloop, and make sail for New York-Andre returned alone to the beach, whence a boat was to convey him to the Vulture. But this arrangement was defeated by an obstacle wholly unexpected. At an early hour, Livingston, still disturbed at the proximity of the sloop, had, of his own authority, caused a four pounder to be dragged from his redoubt to a point of land from which the shot could reach the vessel. She was aground, and had already sustained some damage from the small piece of the American officer, when she began to float again at the rising of the tide. Robinson took ad. vantage of the circumstance to weigh anchor, and remore some miles lower down, beyond the reach of a similar attack. This change of station attracted the notice of the master and rowers of the boat in which André expected to regain the sloop, They vere Americans. The movements which they had witnessed for the two last days were unusual; and, although men of their description, accustomed to ferry all persons indifferently from one side of the river to the other, did not affect to be of any party, they were unwilling to commit themselves. When André proposed to them to convey him to the sloop, they told hin that it was too far, and peremptorily refused to go. He went back immediately to Amold, and urged him to exert his authority in so serious a predicament. But the latter, perplexed at his unlooked for re-appearance, and already larassed with various disappointments, durst not attempt to compel the men, and told him he must submit to return by land; to lay aside his uniform altogether, and assume another dress. André changed his coat for one which Smith provided. Arnold now wished to withdraw the papers with which he had intrusted to him; he thought it hazardous by land. But André was very desirous of showing to Clinton with what punctuality he had executed his mission. These papers were a trophy of which he would not, therefore, allow himself to be dispossessed. He observed to Arnold, that danger of any kind could now no longer be in question, except so far as to show that they both despised it; and added, that he would keep the papers, which brought him into greater peril than Arnold, and, to allay his fears, would secret them in his boots. Arnold submitted, and, leaving André in Smith's house, returned to his quarters, from which he had been absent since the day before. The patrol, spread through the whole neighbourhood, made it imprudent for André to begin his journey before twilight. He was accompanied by Smith : each had a passport from Arnold, "to go to the lines of White plains, or lorrer, if the bearer thought proper; he being on public business." - They were accosted, at Crompond, by an American officer of militia, who told them that it was too late for them to reach, that evening, any other quarters.
In order not to awaken his suspicions, they resolved to pass the night there. The next day, $23 \mathrm{~d}$, they crossed the Hudson to King's ferry, pushing forwari when they were not observed, and slackening their pace to conceal their eagerness, wherever they were likely to be seen. By means of their passports, they traversed all the American posts withont molestation They arrived, uninterrupted, a little beyond Pine's bridge, a village situaled on the Croton: they had not, however, crossed the lines, although they conld descry the ground occupied by the Euglish videttes. Smith, looking all around, and perceiving no one, said to Audré, "You are safe-good bye," and retook, at full speed, the road by which they had come. André, on his part, believing himself out of tanger, and all further precaution superfluous, put spurs to his horse. He had proceeded four leagues ouward with the same good fortune; he could see the Hndson once more, and was about eutering Tarrytown, the border village, when a man, armed with a gun, sprang suddenly from the thickets, and seizing the? reins of his bridle, exclaimed, "Where are you bound?" At the same moment, two others ran up, who were armed in like manner, and formed, with the first, part of the patrol of the volunteer militia that guarded the lines. They were not in uniform, and André, pre-occupied by the idea that he was no longer on enemy's ground, thought that they must be of his own party. It did not, therefore, occur to him to show them his passports, which was sufficient to deceive Americans, and could not alter his destination, if those who arrested him were of the English side. Instead of answering their question, he asked them, in his turn, where they belonged to. They replied, "To below" - words referring to the course of the river, and implying that they were of the English party. "And so do I," said André, confirmed in his mistake by this stratagem. "I am," continued he, in a tone of command, "an English officer on urgent business, and I do not wish to be longer detained." "You belong to our enemies," was the rejoinder, "and we arrest you." André, struck with astonishment at this unexpected language, presented his passport; but this paper, after the confession he had just made, ouly served to render his case more suspicious. He ofiered them gold, his horse, and promised them large rewards, and permanent provision from the English government, if they would let him escape. These young men, whom such offers did but animate the more in their duty, replied, that they wanted nothing. They drew off his boots and detected the fatal papers. They no longer hesitated to carry him before colonel Jameson, who commanded the out-posts. When questioned by that officer, he still called himself $A n$ derson, the name mentioned in his passport, and evinced no discomposure; he had recorered all his presence of mind, and, forgetful of his own danger, thought only of Arnold's, and of the means of extricating him. 'To apprize him of it safely, he begged Jameson to inform the commanding officer of West point that Anderson, the bearer of his passport, was detained. Jameson thought it more simple to order him to be conducted to Arnold. He was already on the way, and the thread of the conspiracy was about to be resumed in the interview of the accomplices, when the American colonel, recollecting that the papers found upon the prisoner were in the handwriting of Arnold himself, and adverting to the several extraordinary features of the business, sent, in all haste, after the pretended Anderson, and had him conveyed, under guard, to Old Salem. He despatch. ed, at the same time, an express to Washington, charged with a letter containing a circumstantial account of this affair, and with the draughts and 
other papers taken from the prisoner. But the commander-in-chief, who set out on the same day, the 23d of September, to return to his army, had pursued a different route from that by which he went to Hartford, and the messenger was compelled to retrace his steps without having seen him. This delay proved the salvation of Arnold.-Jameson was a gallant soldier, but a man of an irresolute temper, and no great sagacity; moreover, treachery on the part of Arnold appeared impossible to one of an ingenuous and honourable character. He began to view his first suspicions as an outrage to an officer distinguished, as Arnold was, by so many noble exploits, and, wishing to reconcile the deference due to him with the performance of his own duty, he wrote him, that Anderson, the bearer of his passport, had been arrested on the $23 \mathrm{~d}$.- Arnold did not receive this intimation until the morning of the 25th. It was on a Monday; and the same day, or the one following, had been selected for the consummation of the plot. Until that moment, he had believed success infallible. The exhilaration which this belief produced was even remarked, and he ascribed it to his expcctation of the speedy arrival of his general, "for whom he had pleasant news." He was busy with the appropriate arrangements for the reception of a body of more welcome visitors, when he received the letter of Jameson. Those who were present on the occasion recollected, afterwards, that he could not, at first, conceal his dismay and extreme agitation; but that, recovering himself quickly, he said, in a loud voice, that he would write an answer; and, dismissing all about him, withdrew, to reflect on the course which it was best to adopt. The entrance of two American officers, however, interrupted his musings. They were sent by the commander-inchief, and informed Arnold, that he had arrived that morning at Fishkill, a few leagues from West point; that he was to have set out a few hours after them, and could not be far distant.-Thus did the. most alarming circumstances rapidly succeed each. other. The traitor lad no resource but a precipitate flight. Suppressiug his emotion, he told the two officers that he wished to go and meet the general alone, and begged them not to follow him. He then entered the apartment of his wife, exclaiming - " $A$ !! is discovered :-Andre is a prisoner :- The commander-inchief will know every thing :-The discharge of cannon which you hear, is a salute, and announces that he is not far off:-Burn all my papers:- I fiy to New York." He embraced her, as well as their infant child, whom she carried in her arms, and, solely intent on his escape, left her, without waiting for lier reply, mounted the horse of one of the two officers, and rushed towards the Hudson, which was not far from his house. He had taken the precaution to have always ready a barge well-manned, he threw himself headlong into it, and caused the boatman to make for the British sloop, with all possible despatch. The barge, bearing a fing of truce, was still visible from the heights when Washington arrived. The two officers related to him what they had witnessed. Arnold had absconded. His wife, in the agonies of despair, seemed to fear for her infant, and maintained an obstinate silence. No one knew how to explain these extraordinary incidents. The commander-in-chief repaired, witlout delay, to the fort of West point, where, however, he could learn nothing of a decisive import. But some orders issued by Arnold the day before, redoubled his suspicions : he returned to the quarters of the general, and at this instant Jameson's messenger presented himself, and delivered the packet with which he was cliarged. Washington seemed, for a few minutes, as it were overwhelmed by the discovery of a crine which ruined the fame of an American general, and wound ed the honour of the American army. Those wh. were near him anxiously interrogated his looks in silence, which he broke by saying,- "I thought that an officer of courage and ability, who had often shed his blood for his country, was entitled to confidence, and I gave him mine. I am convinced now, and for the rest of my life, that we should never trust those who are wanting in probity, whatever abilities they may possess. Amold has betrayed us."-Meanwhile, the precautions required by the occasion were every where taken. General Heath, a faithful and vigilant officer, was substituted for Arnold at West point; the commanders of the other posts were admonished to be on their guard. Greene, who had been invested with the command of the army during the absence of Washington, recalled within the forts the garrisons which the traitor had dispersed, and marched a strong division near to the lines. Hamilton lost not an instant in repairing to King's ferry, the last American post on the side of New York. He had the mortification to learn, that a very short time before his arrival, Arnold's barge had glided by with the swiftness of an arrow, and was then getting along side the Vulture, some miles lower down, opposite Teller's point, - an anchorage situated at the liead of the great basin of the Hudson, which is called Tappan bay. Iivingston had remarked the barge tliat carried the fugitive, and, his suspicions being roused by the strange movements of the two or three days previous, would have stopped it, had not the sailors of his spy-boats been ashore when it passed. Messengers were sent to all the states of the Union, and to the French general, to inform them of this event. The express which bore the news to congress travelled with such rapidity, that he reached Pliladelphia on the same day that the discovery was made in the camp. The magistrates were immediately directed to enter the house of Arnold, and to seize and examine his papers. They found nothing there relating to the conspiracy; but he had left memoranda which furnished ample proof that he was guilty of the extortions and peculations of which he had been accused two years before. Jameson caused his unknown prisoner to be strictly guarded. The latter at first suppressed his true name, from consideration for $\mathbf{A r}$. nold ; but, the day after his capture, supposing that the American general had time to make his escape, he said to Jameson,- "My nane is not Anderson; I am' major André." The death of André (q. v.), though ignominions, was happiness in comparison with the life of Arnold. Upon his establishment in the army of Great Britain, he found it necessary to make some exertions to secure the attachment of his new friends. With the hope of alluring many of the discontented to his standard, he published an address to the inhabitants of America, in which he endeavoured to justify his conduct. He had encountered the dangers of the field, he said, from apprehensior that the rights of his country were in danger. He had acquiesced in the declaration of independence, though he thought it precipitate. But the rejectiol. of the overtures made by Great Britain, in 1778, and the French alliance, had opened his eyes to the am bitious views of those who would sacrifice the happi ness of their country to their own aggrandizement, and had made him a confirmed loyalist. He artfully mingled assertions, that the principal nnembers of congress held the people in sovereign contempt. This was followed, in about a fortnight, by a proclamation, addressed "to the officers and soldiers of the continental army, who liave the real interest of their country at lieart, and who are determined to be no longer the tools and dipes of congress and of France." To induce thic Anerican officers and sol- 
diers to desert the cause which they had cmliraced, he represented that the corps of cavalry and infantry, which he was authorized to raise, would be upon the same footing with the other troops in the British scrvice; that he should with pleasure advance those whose valour he had witnessed; and that the private men, who joined him, shonld receive a bounty of three guineas cach, besides payment at the full value for horscs, arms, and accoutrements. His olject was the peace, liberty, and safety of America. These proclamations did not produce the effect designed, and in all the hardships, sufferings, and irritations of the war, Arnuld resnains the solitary instance of an Amcrican officer who abandoned the side first enbraced in the contest, and turned his sword upon his former companions in arms. He was soon despatched, by Sir Henry Clinton, to make a diversion in Virginia. With about 1700 men, lie arrived in the Chcsapeake in January, 1781, and, being supported by such a naval force as was suited to the naturc of the service, lie committed extensive ravages on the rivers, and along the unprotected consts. It is sair, that, while on this expedition, Arnold inquired of an American captain, whom he had takcu prisoner, what the Americans wonld do with him, if he should fall into their hands. The officer replied, that they would cut off his lame leg, and bury it with the lionours of war, and hang the remainder of his body in gibbets.After his recall from Virginia, he conducted an expedition against New Loondon in his native state of Connecticut. He took fort Trumbull, Sept, 6, with inconsiderable loss. On the other side of the harbour, lieutenant-colonel Fayre, who commanded another detachment, made an assault on fort Griswold, and, with the greatest difficulty, entered the works. An officer of the conquering troops asked who commanded, "I did," answered colonel Ledyard, "but you do now," and presented him his sword, which was inmediately plunged into his own boson. A merciless slaughter now commenced of the brave garrison, who liad ceased to resist, and the greatcr part were either killed or wounded. After burning the town, and the stores which were in it, Arnold returned to New York in eight days. - He survived the war but to drag on, in perpetual banishment from his native country, a dishonourable life amid a nation that imputed to him the loss of one of the brightest ornaments of its army - the lamented André. He transmitted to his children a name of hateful celelority. He obtained only a part of the debasing stipend of an abortive treason. His complaints soon caused it to be known, that all the promises by which he had been inveigled were not filfilled. But baffled treason appears always to be ovcrpaid, and the felon is the only onc who thinks that he experiences injustice. He enjoyed, however, the rank of brigadiergeneral; but the officers of the British army manifested a strong repugnance to serve with him. He possessed their esteem whilc he fought against them ; they loaded him with contempt when treason brought him over to their side. He resided principally in England after the conclusion of the war, was in Nora Scotia, and afterwards in the West Indies, where he was taken prisoner by the French, from whom he escaped, and, returning to England, died in Gloucester place, London, June 14, 1801 .

Arvord, Christopher; a peasant of Sommerfeld, near Leipsic, celebrated as an astronomer. He was born in that village in 1646, and accomplished so much by his own exertions, that he corresponded with the most celebrated literati of his age, whose original letters are preserved at Leipsic, in the library of the council, where may also be seen A.'s picture. He erected an observatory at his dwelling-house, which preserved the memory of this remarkable man till 1794, when it was pulled down, on account of its decay. Unwearied in his oloservations, he discovered many phemomena sooner than other istronomers ; as, for instance, the two comets of 1683 and 1686, to which he directed the attention of the astronomers ot Lcipsic. Ile acquired yet more celebrity by his observation of the transit of Mercury, in 1690. The magistracy of Leipsic made lium, on this occasion, a present of money, and remitted his taxes for life. $\Lambda . ' s$ ohservations were so accurate, that they were received by a learned periodical journal that appeared at that time-thic Acta Erudilorum, (q. v.) A. hinself published "Signs of divine Grace exhibited in a solar Miracle," in 1692, 4to., with plates. He died in 1695. In the clurchyard at Sommerfeld is the monument of this astronomical peasant, by whose name the celebrated astronoiner Schroter distinguished three valleys in the moon.

A RxoLd, John; a miller, known hy a law-suit in which he was engaged during the reign of Fredcric II. (the Great), king of Prussia. The king believed that the miller had suffered great injustice by a decision in favour of his territorial lord, and deposed the minister of justice, and several other officers, on their refinsal to change the judgment. He then undertook the office of judge himself, and reversed the sentence. By this act, one of the best monarchs was made to resemble one of the worst, Ferdinand VII., who rcversed, in a similar way, the judgment in the case of Arguelles. The casc became notorions throughout Europe, and added to the fame of Frederic as a general that of a lover of justicc. It afterwards, however, became evident that the monarch had been seduced into injustice by his zeal for equity ; and those of the judges who had been imprisoned were set at liberty. 'This case affords an instance of the danger to which the cause of justice is exposed under an arbitrary government, even when the sovereign is well disposed. The memoirs of Nettelbeck, captain of a Prussian ressel, exhibit a proof of the gencral admiration excited by this act of supposed justice. Ncttelbeck came to Lisbon, and, when the people learned that he was a Prussian, a crowd assembled, and accompanied him, for a long time, with loud shouts. The same man was afterwards captured by the Algerines; but, when the dey learned that he was a subject of the great king, he set him im. mediately at liberty, to show his respect for Frederic. Arwold, Dr Samuel, a distinguislied English composer, was born in 1739 or 1740 , and received his musical education in the chapel royal, in London. In his $23 d$ year, he was the author of a dramatic composition, and was afterwards appointed a composer at the Covent-garden theatre. Here he set to music the Maid of the Mill. He distinguished himself still more by his oratorios of the Cure of Saul (poetry by Brown) and Abimelech. To these succeeded the oratorios of the Prodigal Son and the Resurrection, of which the former, in particular, is highly distinguished. He composed, also, many vocal and instrumental pieces for the garden concerts. He was made doctor of music at Oxford, and, in 1783, organist of the royal chapel. He prepared an edition of all the works of Handel, in 36 rols., folio. In 1789 , he was made director of the academy of ancient musicfour years afterwards, organist at Westminster abbey, and, in 1796, conductor of the annual performances in the church of St Panl, for the benefit of the sons of clergymen. In 1798, he composed his oratorio of Elijah, or the Shunamite Wounan, in which Madame. Mara sang. He died in 1802, and was buried on the northern side of the choir of Westminster abbey. Various as were his compositions, his inventive talent was but limited.

A rNoldists. See A"nuld of Bresciú. 
Arsor, Hugo, a Scottish historical and antiquarian writer, was born at Leith, in 1749. His name origiually was Pollock, which he changed in early life for Arnot, on falling heir, through his mother, to the estate of Balcormo in Fife. As "Hugo Arnot of Balcormo, Esq.," he is entered as a member of the Faculty of Advocates, December, 5, 1772, when just about to complete his twenty-third year. A settled astima, the result of a severe cold which he caught in his fifteenth year, and which was always aggravated by exertion of any kind, became a serious obstruction to his progress at the bar, and perhaps caused him to turn his attention to literature. In 1779, appeared his "History of Edinburgh," 1 vol., 4to. a work of much research, and greatly superior in a literary point of view to the geherality of local works. The style of the historical part is elegant and epigrammatic, with a vein of causticity highly characteristic of the author. He afterwards published several pamphlets and essays of a temporary or local nature. In 1785 , appeared his "Collection of Celebrated Criminal Trials in Scotland, with Historical and Critical Remarks," 1 vol. 4to. ; a work of perhaps even greater research than his history of Edinburgh, and written in the same acutely metaphysical and epigrammatic style. Mr A. only survived the publication of this work about a twelvemonth, dying in 1786, aged 37 . The asthma made rapid advances on him, and long before his death, reduced his person almost to a shadow. Harry Erskine, meeting him one day eating a dried haddock or spelding, is said to have accosted him thus: "Mr Arnot, I am glad to see you looking like your meat." Arnot himself was a wit and humourist. On one occasion, while labouring under asthma, he was annoyed by the bawling of a man selling sand on the street: "The rascal!" said the unfortunate invalid, "lhe spends as much breath in a minute, as would serve me for a month !" In his professional character, $\mathrm{Mr} \mathrm{A}$ : was animated by a chivalrous sentiment of honour worthy of all admiration. He was so little of a casuist, that he would never undertake a case, unless he were perfectly satisfied as to its justice and legality. He had 'Jten occasion to refuse employment which fell beneath his own standard of honesty, though it might have been profitable, and attended by not the slightest shade of disgrace. On a case being once brought before him, of the merits of which he had a very bad opinion, he said to the intended litigant, in a serious manner, "Pray, what do you suppose me to be?" "Why," answered the client, "I understand you to be a lawyer." "I thought, Sir," said Arnot sternly, " you took me for a scoundrel." The litigant, though he perhaps thought that the major included the minor proposition, withdrew abashed.

ARnodrt, Sophic; a Parisian actress, famed in the annals of gallantry and wit, was born at Paris, in 1740. Her father kept a hótel garni, and gare her a good education. Nature endowed this favourite of the Parisian public with sprightly wit, a tender heart, a charming roice, and the most beautiful eyes. Chance brought her upon the stage, where she delighted the public from 1757 to 1778 . The princess of Modena happened to be in retirement at the $V a l$ de Grâce. It was the custom, at that time, for ladies of rank to confess, in Passion week, the sins committed during Lent. The princess was struck with a very fine voice, that sang at the evening mass. The songstress was Sophie Amoult. The superintendent of the royal choir was informed by the princess of the discovery which she had male, and, against her mother's will, Sophie was obliged to join the choir, where madame de Pompadour heard her sing, and exclaimed sentimentally, "Such talents are enough to make a princess." This pased the way for Sophie to the Parisian opera, where she soon became queen, and shone particularly as Thealire in Castor and Pollux, as Ephise in Dardanus, as Iphi genia in Iphigenia in Aulis. By her beauty, her exquisite performance, and her vivacity, she enchanted every one. All persons of rank and all the literati sought her society : among the latter weri: d'Alembert, Diderot, Helvétius, Mably, Duclos, and Rousseau. She was compared to Ninon de l'Enclos and Aspasia; she was sung by Dorat, Bernard, Rhulieres, Marmontel, and Favart. Her wit was so successful at the time, that her bons mots were col. lected. It was sometimes severe, when she wished to make her superiority felt, and yet she had no enemies. She died in 1802, in the very chamber in which the admiral Coligny was murdered; and in the same year with her, the actresses Clairon and Dumesnil. In the beginning of the revolution, she bought the parsonage-house at Luzarche, and transformed it into a country house, with this inscription over the door-Ite missa est. Her third son, Constant Dioville de Brancas, colonel of cuirassiers, was killed at the battle of Wagram.

Aroba, or ARoBe (by some spelled and pronounced arrobe ; in Spanish, arroba; in the dialect of Peru, arrou). 1. A weight used in Spain, Portugal, Goa, Brazil, and in all Spanish America. The weight of these arobas differs much. The aroba of Madrid, and almost all over Spain, weighs twenty-fire pounds avoirdupois.-2. A measure for wine, brandy, and honey: $1=8$ azumbras, $=32$ quartillos, $=805.5$ arrobas menores, used for measuring oil, $=626.8$ cubic inches of Paris measure. At Malaga, the aroba is equal to 794 cubic inches, Paris measure.

Arpino, Josephino d'; an eminent painter, born 1560, at Rome. The precocity of his talent for painting caused him to be employed, at a very early age, in ornamenting the Vatican, as assistant to the artists engaged in that design ; when, luckily attracting the attention of pope Gregory XIII., that pontiff took hin under his protection, and gave him every opportunity to improve himself. In France, to which he went with cardinal Aldobrandini, he was knighted. His death took place at Rome, 1640.

Arracan; a maritime province in the British Birmese territories, which, with its dependencies, $R u$ maree, Cheduba, and Sandowy, lies between $18^{\circ}$ and $21^{\circ}$ N. lat. On the N. it is separated from the Chittagong district by the river Nauf; on the $\mathrm{E}$. it has the Arracan mountains; on the S. Bassein of Pegu ; and on the $W$. the bay of Bengal. Its extreme length may be estimated at 230 miles, and its a verage breadth at 50. Between the mountains and the sea this province is covered with thick woody jungles; rain is frequent. When conquered by the British, in 1825 , not more than 400 square miles of the whole surface were supposed to be under cultivation; and the total population was estimated at 100,000 souls, of whom six-tenths were Mughs, three-tenths $\mathrm{Ma}$ hommedans, and one-tenth Birmese. The prospection annual revenue for five years was estimated at 220,000 rupees. A native history of Arracan begins in A.D. 701, and continues through a series of 120 native princes, down to modern times. According to this document, its sovereigns formerly occupied a much more important station in the politics of India than they have recently done: for, according to these annals, the dominions of Arracan at one period extended over Ava, part of China, and a portion of Bengal. Certainly, at present, nothing remains to indicate such a prior state of power and civilization, for its condition, when acquired by the British, was to the last degree savage and barbarous. It does not appear, however, until the Birmese invasion, it hal ever been so completely subdued as to acknowledge 
permanent vascalage to a foreign power, although the Moguls and Peguers had at different times carried their arms into the heart of the country. During the reign of Aurengzebe, the unfortunate Sultai Shuja, his brother and rival, was basely murdered by the Arracan Raja. The Portiguese, sometimes as allies, at others as open enemies, gained an establishment, which only decayed with the general ruin of their interests in Asia. In 1783 (corresponding with the Mugh jear 1145, the province was conquered, after a feeble resistance, by the Birmese, and was followed by the surrender of Cheduba, Rainree, Suidowy, and the Broken Isles. The Mughs subsequently made many efforts to rescue their country, more especially in 1811, under a rebel chief named Kingberring; but were unable to withstand the bravery, discipline, and cruelty of the Birmese; who eren managed to extort a surplus revenue, of which about 18,000 rupees were annually remitted to Ava, for the support of the white elephant and his establishment. Arracan proved the grave of general Morrison's army in 1825, and has continued equally destructive, even to the native reginents stationed on the sea-coast and among the islands. Its population is scanty and uncivilized; it possesses no article of export but salt; yields little revenue; requires a burdensome civil and military establishment ; and, in a merely pecuniary point of view, is a inost unprofitable acquisition.-The chief diet of the people of Arracan is rice, with fish or vegetables; those who can afford it eat poultry. Little flesh is eaten, and milk is never used. An article, however, in universal demand, and which is necessarily manufactıred only near the coast, is putrescent shrimps and whitings, after being aried in the sun, which are pounded in a mortar with crabs, and seasoned with salt. Toddy is drunk by the people of Arracan, both male and female; but the Birmans, although addicted to the use of spiritous liquors, prefer opium either to chew or smoke, and its use is common to both sexes, and to every class of people. The following cut represents the prevailing costumes of Arracan mountaineers :-

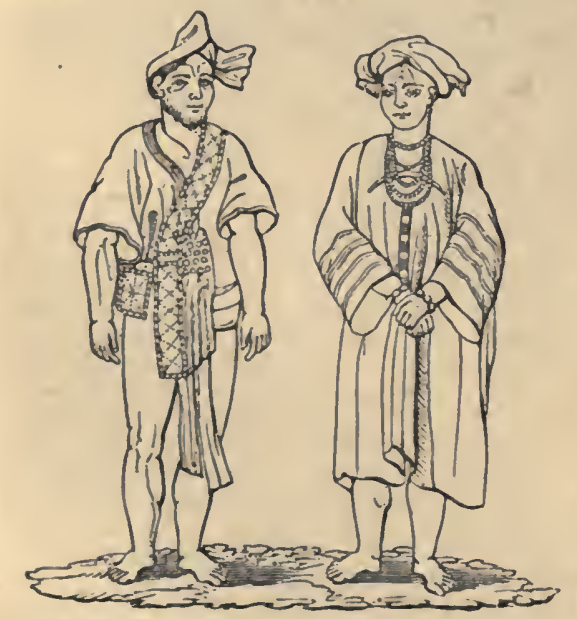

Arrack. See Arack.

ARRAGON, the realm of, constituted, formerly, the second chief division of Spain, and was composed of the kingdoms of Arragon, Valencia, and Mallorca, and the principality of Catalonia. Down to the time of the marriage of king Ferdinand the Catholic with Isabella, heiress of Castile, A. formed a kingdoin separate from Castile, and comprised not only the four countries above named, but also Sicily and Sardinia. After the death of Ferdinand, in 1516, it was united for ever with Castile; but the Arragonian provinces retained the ir privileges, liberties, and laws, which they lost, almost entirely, after the Spanish war of succession, because they lat attached themselves firmly to Austria; and the Bourbous, on ascending the throne, conld not forgive the fidelity of the subjects of an enemy. The present province of A. still preserves the title of a kingdom. It is bounded $\mathbf{N}$. by the Pyrenees, N. W. by Navarre, W. by Castile, S. by Valencia, and E. by Catalonia. It contains seventy towns, only eight of which are considerable, viz. Saragossa, Albarazin, Balbastro, Cala taiud, Darocca, Jaca, Taragona, and T'eruel. Pop., in $1800,658,630$; square miles, 15,503 . A part of the country is mountainous, and the soil generally productive, but, in some parts, stony or sandy. The characteristics of the inhabitants are industry, activity, national pride, and courage.

Arraign, Arralgnuent. To arraign, is to call the prisoner to the bar of the court, to answer the matter charged upon him in the indictment. It is from the Latin ad rationem ponere; in French, ad reson, or a resn. (See Blackstone's Com. v. 4, p. 322 and note.)

Arras (the ancient Brandinas); an island on the W. coast of Scotland, in the fritl of Clyde and shire of Bute, about twenty-four miles in length and ten in breadtl. It is divided into two parislies, Kilbride and Kilmory, and, with the exception of two or three farms, is the property of the duke of Hamilton. The island is indented with several fine harbours, the principal of whicl on the west side are Blackwaterfoot and Loch Ransa, and on the east Broadwick and Lamlash, each of which is the resort of numerous vessels for shelter in stormy weather; the latter describes a beautiful semicircle, defended by two islets, and would contain 500 sail at once. At the northern extremity of the island is a noted sea-mark, termed the Cock of Arran, and to the southward of Lamlash, a light-liouse on the isle of Plada. The coast is bold and rugged, the surface hilly, and intersected by good roads, and the soil hard and pebbly, though it produces oats, barley, and potatoes in abundance. Marl, lime-stone, iron-stone, free-stone, marble, slates, and blind coal are here in profusion. On the summit of Goatfielı, a mountain 2840 feet abose the level of the sta, are found peculiar diamonds called Arran stones, with some fine sfecimens of jasper, agate, cairngorum, and Scottish topaz. The white fish and herring fisheries liere are flourishing, and employ many hundreds of hands. Excellent salmon and trout abound in the lakes and in the rivers flowing therefrom. The hills afford shelter for wild deer, and pasture for black cattle, of which 1000 head are annually transported to the shire of Ayr. Considerable quantities of kelp used to be manufactured here. The Gaelic was the only language spoken till lately, but the English is now pretty generally used, twelve schools having been established on the island for teaching it. Invalids resort hither for the benefit of its salubrious air and the excellence of the whey from goat's milk. Brondwick castle stands upon an eminence overlooking Broadwick bay, amidst fine plantations. It was anciently an important fortress, but is now somewhat modernized and occupied by the agent of the duke of Hamilton. Some places retain the name of Fingal, of whom and Ossian tradition still speaks, and it is said that the latter died here. It also afforded refuge to Robert Bruce and his fnithful followers during his adverse fortune. Several cairns and Druidical temples lie scattered over the island. Population of the islaud in $1831,642 \%$. 
Arran Islands, or South Arran Islands; three islands near the western coast of Ireland, in the Atlantic, at the mouth of Galway bay. The largest, Arranmore, comprises 4,607 acres ; the next, Innismain, 1,308; and the least, Innis Lehir, 908. The three islands continue in a more primitive state than North Wales, or than any uther part of Britain. At Arranmore, which contains a population of between 2 and 3000 , are remains of Druidism, open temples, altars, stone pillars, sacred mounts and raths, miraculnus fountains and sacred groves. The religion is entirely-Roman Catholic, and the language Celtic (of which the Irish is but a dialect). The surface of A rranmore is elevated 360 feet above the sea, and is undulating and fertile. Agriculture and fishing are the chief employments. Good oats are raised, sheep fed, and the most esteemed calves are reared here The varieties of fish are very great; and the board for the fisheries have erected a pier 450 feet in length, on the island, where 100 vessels of forty tons burden may ride safely. There are fortyone open boats and seventeen row-boats, belonging to the port. Costume here also is original ; the boots called poppootics, made of untanned leather, are probably the most curious. The principal curiosities are the puffin-holes, Kilmurry fort, and Great Kevin's-head. This is the station of a preventive waterguard; and there is a light.house, exhibiting a revolving light of a bright colour.

Arras, capital of the department Pas de Calais, on the navigable river Scarp, contains 20,000 inhabitants, an academy of the fine arts, and many manufactories of tapestry, battiste, laces, \&c. A. is the seat of a bishop. The fortifications consist of an irregular wall, guarded by ten partly detached bastions, several ravelins and lunettes, two horn-works, and a citadel, which forms a regular pentagon with case-inates, bomb-proof. These fortifications were improved or laid out by Vauban. Here he first employed his tenaillons. The cité, or old town, is separated from the ville, or new town, by a wall and ditch. In 1640, the French, under the marshals Chaume, Chatillon, and Melleraye conquered A. In 1654 , the Spaniards, under Condé, attempted to regain it from them; but Turenne attacked the 5panish lines, took them by storm, and rescued the fortress.

ARrEOYs; the name given to a class of individuals in Otaheite and the neighbouring islands, who destroy their own offspring at the moment of their birth. The society of Arreoys consists of hundreds, or perhaps thousands of both sexes. It is chiefly composed of persons distinguished by valour and merit, and hence one or more individuals of each family of the chiefs are of the number. It has been remarked, that all the men profess themselves warriors, and are in gen eral stout and well made ; that the greatest trust and confidence are reposed in them; and it rather app ears that the women consist of the higher ranks only. There are different gradations in this community, which are to be recognised from the mode of tatt ooing; the more profusely the men are tattooed, the higher is their rank in society. By the fundamental la ws of the society, the offspring must be destroyed, yet it is not known with certainty by whom or in what particular manner ; the murder is always perpetrated in secret, probably by strangulation; all the attendants are excluded; for -it is said, were they to witness it, they would be adjudged guilty of participation, and put to death. Sometimes the mother, animated by natural affection, tries to preserve her infant, and resists the persuasions of her husband and his brother Arreoys, wio wish to consign it to destruction. But in general the enormity of the crime does not appal the fermales, though they are described as affectionate and tender." We find a dancing girl pregnant by an Arreoy expressing herself thus to the English navigators: "Perhaps the Etooa or deity of England might be offended with the practices of the Arreoys, but her own was not displeased with them. However, she promised if we would come from England for her child, she might perhaps keep it alive, provided we gave her a hatchet, a shirt, and some red feathers." That the rules of the community are very strict, may be inferred from an instance given by captain Bligh. A chief, a member of the society, married a sister of the king of Otaheite, by whom he had eight children, and the whole were destroyed at their birth! Nor did this enormity seem to originate from any other source, as the parents afterwards adopted a nephew as their heir. It may here be observed, that there are other practices among these people regarding infanticide, which, though we want materials for positively affirming the fact, may perhaps be connected with the institutions of the Arreoys. When an Otaheitan chief has a child by a woman of the lower ranks, it is never suffered to live; and the like seems to take place reciprocally among the higher ranks of females. The king and queen of Otaheite having ceased to cohabit, he had taken another wife, and she associated with one of her attendants of low rank. When pregnant, the missionaries endeavoured to persuade her to spare her child, which she said she would have done had it been her husband's, but now it would be base-born, and must perish; and she resisted all entreaties to the contrary. Afterwards, having visited them, she excused herself for having put the infant to death, stating that it was the custom of the country to murder all base-born children, and hers being by a low man, she had only complied with the usual practice. Indeed it is affirmed by the missionaries who visited that island in 1797 to be a common proceeding among all ranks to strangle infants the moment they are born. "A perpetrator of this horrid act," the narrator observes, "was among those whom curiosity attracted to visit us. She was a good-looking woman, and esteemed by the natives a great beauty, which I suppose to be the inducement that tempted her to murder her child; for here the number of women bearing no proportion to the men, those esteemed handsome were courted with great gifts, and got so accustomed to change their husbands, to go with them from place to place, and run after the diversions of the island, that rather than be debarred those pleasures, they stifle a parent's feelings, and murder their tender children." Thus many hundreds born into the world are never suffered to see the light; and so little criminality in the opinion of the natives is attached to the deed, that many women disclose the number they have put to death without scruple. It has been calculated that at least two-thirds of the births on the island perish in this manner. The Arreoys enjoy great privileges, and are everywhere united by the reciprocal ties of friendship and hospitality. When they visit different islands, they receive presents, and are entertained with feasting and dramatic exhibitions; and all this they seem to expect rather as a matter of right than of courtesy. Their clothes are of the finest materials. They pass their time in luxurious idleness, perfuming their hair with fragrant oils, singing and playing on the flute, and passing from one amusement to another. It has been affirmed, but perhaps without sufficient foundation, that a promiscuous intercourse of the sexes prevails in their society; however, they are permitted great latitude in their amours, except in times of danger, as almost all are fighting men. Sufficient inducements are, therefore, held out to be admitted into this mysterious community. Any one may withdray at pleasure from the so- 
ciety; and an example is given of a chief who had killed his first.boru child, and preserved the second, laving withdrawn in the interval. A woman who censes to be an Arrooy incurs a reproachful name, signifying "bearer of children." 'Tlus, while in most other countries the name of parent confers honour and respect, among the Arreoys of Otalieite it is used as a term of contempt and reproach. " There are two causes," says Mr Forster, "which favour the existence of the Arreoys : first, the necessity for entertaining a body of warriors to defend their fellow citizens from the invasion and depredations of enemies; secondly, it was necessary, by such an association, to prevent the too rapid increase of the number of their chiefs. Perhaps," he remarks, " some intelligent Otaheitan lawgiver might foresee that the common people would at length groan under the yoke of such petty tyrants; whose number was ever multiplying." The ordinary practice of infanticide is ascribed by Mr Wilson, who visited the Sonth Seas in 1801, merely to the love of pleasure and avarice, which latter passion had gained great ascendency since the intercourse of the islanders with Europeans: "being well aware," says he, "that the beauty of females rearing families experiences an earlier decay, it is anxiously preserved for their visitors, by destruction of their offspring, or even by procuring abortion." Perhaps the murderous practices of the Arreoys in the South Sea Islands may have originated in some religious principle. At the same time, it appears that, in the ordinary destruction of infants by the islanders of the South Pacific Ocean, there is nothing of a sacrificial nature; for though they do not suppose that their displeasure is thereby incurred, they do not pretend that the practice is acceptable to any of their divinities. Mr Malthus, we may add, ascribes the origin of the Arreoy institutions to a superabundance of population, and the necessity of adopting some forcible expedients to bring it within the limits of subsistence; but if this view were correct, the crime of infauticide would not be confined, as it is in the present case, to the higher classes. See Forster's Voyage, vol. ii.; Cooke's First and Second Voyages; Bligh's Voyage; Missionary Voyage; Hamilton's Account of the Loss of the Pandora.

ARREST (from the French arréter, to stop) is the apprehending or restraining one's person, which, in ciril cases, can take place legally only by process in execution of the command of some court or officers of justice; but, in criminal cases, any man may arrest without warrant or precept. Some persons are privileged from arrest-ambassadors and their domestic servants, officers of courts of justice, witnesses, and all other persons necessarily attending any court of record upon business, members of the legislature, and, in England, peers and bishops likewise.

Arrmidzus, or Aridzos; son of Philip of Macedon and the dancer Philina, consequently a halfbrother of Alexander, whom he also nominally succeeded in the government. When he was deprived of his reason by poison administered by Olympias, Pendiccas, and after him, Antipater, governed in his place. After a nominal reign of six and a half years, he was put to death, with his wife, Eurydice, by Olympias.

Arria; the heroic wife of Cæcina Pætus, who, being suspected of a conspiracy against the emperor - Claudius, was ordered to destroy himself. Perceiving him hesitate, she plunged a dagger into her breast, and presented it to her husnand with these words: "Pate, non dolet" (Pætus, it is not painful).

Arriav, a Greek historian, native of Nicomedia, flourished in the 2d century, under the emperors Adrian and the Antonines. He was first a priest of
Ceres ; but, at Rome, he became a disciple of Epictetus. Ile was honoured with the citizenship of Rome, and appointed prefect of Cappadocia by the emperor Adrian, who patronised him on account of his learning. In this capacity, he distinguished himself in the war agaunst the Massageta, and was afterwards advanced to the senatorial, and even consular dignities. Like Xenophon, he united the literary with the unilitary character. No less than seven of the epistles of Pliny the younger are addressed to A. Ilis historical writings are numerous; but of these, with the exception of some fragments in Photius, only two remain. The first is composed of seven books on the expedition of Alexander, which, being principally compiled from the memoirs of Ptolemy Lagus and Aristobulus, who botls served under that king, are deemed proportionably valuable. To this work if added a book on the affairs of India, which pursues the history of Alexander, but is not deemed of equal authority with the former. An epistle from $\Lambda$. to Adrian is also extant, entitled, Periplus Ponti Euxini, probably written while he was prefect of Cappadocia. There are, besides, under the name of A., a 'Treatise on 'Tactics; a Periplus of the Red Sea, of which the authority is doubtful ; and his Enchiridion, an excellent moral treatise, containing the discourses of Epictetus. 'The best editions of $\mathbf{A}$. are that of Gronovius, Greek and Latin, 1704, folio ; of Raphelius, Greek and Latin, Amsterdam, 1750, 8*o. ; and of Sclmeider, Leipsic, 1798. Of his Enchiridion, the most valuable edition is that of Upton, London, 2 vols., 4to, 1739. 'The Expedition of Alexander has been translated into English by Rooke, in 2 vols., 8vo, London, 1729.

Arriego ; a department of France, bounded on the east by Aude, on the south-east by the Eastern Pyrenees, on the south by the mountains, and on the west and north by the department of the Upper Garonne. Its extent is 244 square miles, or 143,360 acres. It sends two deputies to the Chamber, is in the diocese of Pamiers, and within the jurisdiction of the royal tribunal of 'Toulouse. It contains three arrondissements, 20 cantons, and 330 communes. The population by the last returns appears to be 229,760 inhabitants. The chief towns are Tarascon, Aix, and Mirepoix.

Arroba. See Aroba.

Arrow. See Archery.

Arrowroor ; a kind of starch manufactured from the roots of a plant, the maranta arundinacea, a native of South America, which is cultivated in gardens both in the East and West Indies. A. is so called from its being supposed to be an antidote to the poisoned arrows of the Indians. It is about two feet in heiglit; has broad, pointed, and somewlat hairy leaves; bears small, white flowers in clusters, and globular fruit of the size of currants. The starch or powder of the arrowroot is obtained by the following process :-The roots are ditg when a year old, and well washed, and beaten in deep wooden mortars till they are reduced to a milky pulp. This is well washed again in clear water, and the fibrous parts, which are found among it, are carefully separated, and thrown avray. It is next passed through a sieve or coarse cloth, and suffered to stand for some time, till the starch has settled to the bottom. The water is then drawn off, and the white residue is again washed; after which the water is entirely drained off, and the pulp, when dried in the sun, is found to be an extremely pure starch, which, when reduced to powder, is the arroucroot of commerce. There is no vegetable, if we except, perhaps, the salep or orchis root, which yields so large a proportion of nutritious mucilage as this. As an article of diet for children and invalids, it is invaluable, more especially in all 
forms of bowel complaints. Owing to the great demiand for it, it has been much adulterated, and care is required in the selection of it. The purest is the Jamaica or Bermuda arrowroot. A very cheap and tolerable substitute for this article may be found in the starch obtained from the potato (see Potato), which cannot be too highly recommended.

Arrowsmith, Aaron; hydrographer to the king of Great Britain, and distinguished as a constructor of maps and charts. His works are frequently adverted to as standards for comparison and reference. Besides a great number of maps and charts, hc published a New General Atlas, 4to, 1817, to accompany the Edinburgh Gazetteer. He was also author of a pamphlet, entitled "A Companion to a Map of the World" Mr $\mathbf{A}$. died in London, where he had long lived much respected, in 1823, aged 73 .

Arsamas; a circle of the Russian government of Nishegorod, between long. $43^{\circ} 21^{\prime}$ and $44^{\circ} 10^{\prime} \mathrm{E}$. and lat. $54^{\prime \prime} 37^{\prime}$ and $55^{\circ} 28^{\prime} \mathrm{N}$. It is watered by the rivers Tescha and Scholka, which fow to the Volga. It is an undulating country; much of it is covered with wood, and some part of it with swamps; but it produces flax in abundance, and corn sufficient for the use of the inhabitants, who amount to 120,000 , of whom $435 \mathrm{~L}$ are slaves belonging to the crown, and 23,643 belonging to other individual nobles. The chief employment is wood cutting, potash burning, and spinning linen yarn.

Arscun (of Turkish origin); a Russian measure of length. Three arschins make seven English feet; 1500 archius, one werst. Every arschin is divided into four parts, called quarters or spans, and evcry quarter into four werschecks, $=315 \frac{1}{18}$ Paris lines.-It is also a Chinese measure. One Chinese arschin $=302$ Paris lines.

ARSENal, a royal or public magazine, or place appointed for the making and keeping of arms necessary either for defence or assault. Some derive this word from urx, a fortress; others from ars, denoting a machine; others again from arx and senatus, because this was the defence of the senate; but the more probable opinion derives it from the Arabic darsenaa, which signifies arsenal. The arsenal of Venice is the place where the galleys are built and laid up. The arscnal of Paris is that where the cannon or great guns are cast.

ARsenic is a metal of very common occurrence, being found in combination with nearly all of the metals in their native ores. It is of a bluish-white colour, readily becoming tarnished on exposure to air, first changing to yellow, and finally to black. In hardness, it equals copper, is extremely brittle, and is the most volatile of all metals, beginning to sublime before it melts. Its specific gravity is 5.76 . It burns with a blue flame and a white smoke, emitting a strong smell of garlic. It commonly bears the name of black arsenic, and is prepared from the white arsenic of commerce, by heating this substance with carbonaccous matter, and allowing the volatile ar. senic to condense in an adjoining vessel. Arsenical pyrites, a very abundant natural substance, is also advantageously used in the preparation of arsenic, in which case iron filings and lime are added, to cngage the sulphur, and prevent its sublimation along with the arsenic. Native arsenic has been found in the veins of primitive rocks in scueral countries, but in small quantities, and gencrally alloyed by the presence of iron, silver, or gold. This inetal is used in metallic combinations when a white colour is desired. With oxygen, arsenic forms two compounds, both of which, from their property of combining with alkaline, and earthy bases, are called acids. The arsenous acid, the most important of the two, is the white arsenic of the shops. It is usually seen in white, glassy, translucent masses, to which form it is reduced by fusion from a powdery state. It is one of the most virulent poisons known, not only when taken into the stomach, but when applied to a wound, or even when its vapour is inspired. It is found native in small quantities, but is obtained for use from the roasting of several ores, particularly from that of cobalt and arsenical pyrites. The arsenons acid is condensed in long, horizontal chimneys, leading from the furnaces where these operations are conducted, and usually requires a second sublimation, with the addition of a little potash, to deprive it of any sulphur it may contain. Its manufaeture has been chiefly confined to Bohemia and Hungary. Persons brought up from their youth in the works live not longer than to the age of 30 or 35 years. Knowing the deleterious nature of their occupation, they are so careless, that we have seen them cleaning their plates, \&c., in wells, over which a skull was painted, to warn every body that the water contained arsenic. Besides its use in medicine, and as a ratsbane, it is much employed as a cheap and powerful fux for glass; but, when too much is added, it is apt to render the glass opaque, and unsafe for domestic use. Arsenite of potash, mingled with sulphate of copper, affords an apple green precipitate, called Scheele's green, which, when dried and levigated, forms a beautiful pigment. With sulphur, arsenic forms likewise two definite compounds-the realgar and orpiment. The former of these contains the smallest proportion of sulphur, and is red; the latter is yellow. They are both found native in many countries, but their supply in commerce depends upon their artificial manufacture. This is done by distilling a mixture of arsenical pyrites and iron pyrites, or of white arsenic and rough brimstone. Realgar or orpiment is obtained as the proportion of sulphur employed is greater or less. These compounds afford valuable pigments to the painter.

ARsHin. See Arschin.

Arsinoe; the name of several females of antiquity. -1. The sister and wife of Ptolemy Philadelphus, worshipped, after her death, under the name of Venus Zephyritis.-2. A daughter of Ptolemy Lagus, who married Lysimachus, king of Macedonia. After her husband's death, Ceraunus, her own brotlıer, married her, and ascended the throne of Macedonia. He previously murdered Lysimachus and Philip, the sons of A. by Lysimachus, in their mother's arms. A. was, some time after, banished into Samothrace.-3. A younger daughter of Ptolemy Auletes, sister to Cleopatra. Antony despatched her to gain the good graces of her sister.-4. The wife of a king of Cyrene, who committed adultery with lier son-in-law.-5. A daughter of Lysimachus.

ARsinoe; the ancient name of several places in Egypt and other countries.-1. A town of Egypt not far from the modern Suez.-2. A town of Egypt, W. of the Nile, above Memphis, and N. of Ptolemais. It was called the city of the crocodiles, because the animal was worshipped there, and reared by the inhabitants of the neighbouring lakes. It is now called Faioum. -3. A port of the Red sea, near its entrance, sometimes called Berenice. -4 . On the Red sea, farther N. -5. In Africa, in the Cyrenaica, between Leptis and Ptolemais.-6. In Coelosyria.-7. In Syria.-8. In Cilicia. -9. Etolia, near Canopa.-10. A name of the city of Ephesus.-11. In Cyprus, between old and new Paphos. - 12. On the northern coast of Cyprus, near the promontory of Acamas. - 13. On the eastcrn coast of the same island, ncar Salamis.-14. An inland town, also, of Cyprus.

Arsis. See Rhythm.

Arson, in law ; the act of wilfully setting fire to a house, or other property, belonging to others. 'This crime, by the law of England, is punishable with 
death. If a man sets fire to his own house, the act is punishable by fine, imprisonment, or setting in the pillory. In the United States of America, there is some difference in the degree of punisliment provided by the laws of the different states. In Massachusetts, setting fire to a dwelling house, in the night time, is punishable with death; in the day time, with hard labour for life. For burning buildings, not dwelling houses, the punishment, though serere, is milder. In New Hampshire, the law is very similar. In New York, setting fire to an inhabited dwelling house is punishable with death; to an uninhabited building, with imprisonment. In Kentucky, arson is punishluble with imprisonment in the penitentiary. In all the States, it is treated, of course, as an offence of the blackest character.

Art. (See Arts.)-Art, schools of. See Painting, Sculpture, \&c.

Arta, or.Larta; a gulf, a river, and town of European Turkey, in Albania. The town is situated on the rirer of the same name, about 20 miles N. E. of Prevesa, and about $360 \mathrm{~W} . \mathrm{N}$. W. of Constantinople. The number of inhabitants amounted to 6000 , betore the late revolution. In 1822 , a battle was here fought, between the Greeks and Turks, in which the former abandoned the Philhellenes, who, almost without exception, were killed.

Artaxerxas; the name of several Persian kings. 1. Artaxerses, surnamed Longimanus, on account of his long arms, the second son of Xerxes, escaped from Artabanus and the other conspirators, who had murdered his father, and elder brother Darius, and, $464 \mathrm{~B}$. C., ascended the throne. He subjected the rebellious Egyptians, terminated the war with Athens, by granting freedom to the Greek cities of Asia, governed his subjects in peace, and died B. C. 425. He was farourable to the Jews, and is thought to be the Ahasuerus of Scripture.-2. Artaxerxes, surnamed Mnemon, from his strong memory, followed his father Darius II., in the year $405 \mathrm{~B}$. C. After haring vanquished his brother Cyrus (q. v.), he made war on the Spartans, who had assisted his enemy, and forced them to abandon the Greek cities and islands of Asia to the Persians. He faroured the Athenians, and endearoured to foment dissensions among the Greeks. He was killed, in 361, by his son Ochus, who succeeded him under the name of-3. Artaxerxes Ochus. After having subjected the Phonicians and Egyptians, and displayed great cruelty in both countries (in Egypt, he had Apis slaughtered, and served up at his table), he was poisoned by his general Bagoas, who thirew his body to the cats, and had sabre-handles unade of his bones.

Artedi, Peter; an eminent naturalist, was born in Sweden, in the year 1705, in the province. of Angermania. Although his parents were poor, yet it appears they found means to give him a liheral education, and with this riew sent him to the college of Hurnesand. Intending to embrace the ecclesiastical profession, he went in 1724 to Upsal; but he turmed his attention to medicine from the strong bent of his mind for the study of natural history, in which science he made rapid progress, and soon rose to considerable eminence, particularly in the department of ichthyology. Confining his botanical studies to the umbelliferous plants, he suggested a new mode of classification. But Artedi was much better acquainted with chemistry than botany. His attention, however, was chiefly directed to ichthyology, the classification of which he greatly reformed, and new-modelled upon philosophical principles. This arrangement added greatly to his reputation as a naturalist at the time; and afterwards became popular over Europe. In 1728 his celebrated countryman Linnæus arrived in Upsal, having been appointed to deliver lectures on botany in that place ; and so high stood the claracter of Artedi as a philosopher, that a lasting friendship was fonned between these two great men. In 1732 both left Upsal; Artedi for England, in pursuit of his favourite study, and Linnæus for Lapland, to examine its natural productions ; but before parting, they reciprocally bequeather to each other their manuscripts and books upon the event of death. However, in the year 1735 , they met again at Leyden, where Artedi was introduced to Seba, and employed in preparing for the press the third rolume of that eminent naturalist's 'Thesaumes, which chiefly related to fishes. Artedi formel the resolution, as soon as that work was finished, to return $t$ ) his native coulltry, and publish the fruits of his own labours; but as he was returning home from Seba's house on the erening of the 27 th September, 1735, the night beiug dark, he fell into the caual and was unfortunately drowned. According to agreement, his manuscripts came into the hands of Lirinzeus, and his Billiotheca Ichthyologica, and Philosophia Ichthyologica, together with a life of the author, were published at Leyclen, in the year 1738 .

Artempores, called the Daldian, from the birthplace of his mother, a small city of Lydia, was a Greek writer at Ephesus, in the 2d century afte'r Christ. He occupied himself, principally, with the interpretation of dreams. We still have ?wo of his writings on this subject, which are particularly deserving of the notice of philologists, on account of the information they contain relative to ancient rites and customs. The latest critical edition is that of Reiff, Leipsic, 1805. There was another Artemidorus, who lived about a century before the Christian era, and wrote a geographical work, of which a few fragments only remain.

Artemis. See Diana.

Artesisia ; queen of Caria, sister and wife of Mausolus, whose death she lamented in the most tender manner, and to whom she erected, in her capital, Halicarnassus, a monument, which was reckoned among the seren wonders of the world. The principal architects of Greece laboured on it. Bryaxis, Scopas, Leochares and Timotheus, made the decorntions on the four sides of the edifice; Prthes, the chariot drawn by four horses, which adomed the conical top. Vitruvius thought that Praxiteles was also employed on it. After, the death of A., the artists finished it without any compensation, that they might not be deprived of the honour of their labour. It was an oblong square, 411 feet in compass, and 130 feet ligh. The principal side was adorned with thirty. six columns, and twenty-four steps led to the entrance. A. died, soon after her husband, in the monument which she had erected to him, 351 , B. C. - Another A., queen of Halicarnassus, accompanied Xerxes on his expedition against Greece, and distinguished herself, in the battle of Salamis (480 B. C.), by her determined boldness.

ArtennsicM, in ancient geography; a promontory of Eubara, on the northern side of the island, which is famous for the great naval victory, gained in its neighbourhood, by the Grecians, over Xerxes.

Arteson; a heretical teacher, of the $3 \mathrm{~d}$ century, who denied the divinity of Christ, and declared him to be a mere man, of rare virtue. He lived in the diocese of Rome, his adherents, the Artemonites, seem to have spread, also, to S5ria. In the latter half of the Sd century, they were confounded with other opponents to the doctrine of the Trinity. (See Antitrinitarians.) Samuel Crell appeared, in 1726 , under the name Artemonius, as an antagonist of the same doctrine.

Artery. See Blood-ressel.

Arturitis (from ap̧es", a joint); any distemper 
that affects the joints, but the gout particularly. (See Gout.)-Arthritis planeica, arthritis vaga, the wandering gout.

Arteur, or Antus; prince of the Silures, in the 6th century; an ancient British hero, whose story has been the theme of much romantic fiction. He was, says Geoffrey of Moumouth, who probably followed the chronicle Brut d'Angleterre, the fruit of an adulterous counexion between the princess Igerna, of Curnwall, and Uther, the pendragon or chief commander of the Britons. He was born about 501. In 516 , he succeeded his father in the office of general, and performed those heroic deeds against the Saxons, Scots, and Picts, which have made him so celebrated. He married the celebrated Guenever, or Ginevra, belonging to the family of the dukes of Cornwall; established the fanous onder of the romid table; and reigned, surrounded by a splendid court, twelre years, in peace. $\Lambda \mathrm{fter}$ this, as the poets relate, he conquered Denmark, Norway, and France, slew the giants of Spain, and went to Ronie. From thence he is said to have lastened home, on account of the faithlessness of his wife, and Modred, his nephew, who carried on an adnlterous intercourse, and stirred up his subjects to rebellion; to have subdned the rebels, but to have died, in consequence of his wounds, in 542, on the island of Avalon, where it is pretended that his grave was found, in the reign of Henry II. Hume thinks that the story of Arthur las some foundation in fact.

ARTuUR's SEAT; a high hill in the neighbourhood of Edinburgh, said to havè been so denominated from a tradition that king Arthur surveyed the country from its summit, and defeated the Saxons in its neighbourhood. It is a rugged, steep, and in some places precipitons rock, exhibiting on the south side a range of perpendicular basaltic columns, of pentagonal and hexagonal forms, from fifty to sixty feet in height, and five in diameter. It affords spars, zeolites, livematites, jaspers, and a few agates, with abundance of granite. The highest point is nearly 700 feet from the base. From hence may be seen the German ocean, the course of the Forth, the distant Gram jians, a large portion of the most populous and best cultivated part of Scotland, including the picturesque city of Edinburgh and its castle. The view is a most beautiful one. On the north side are the ruins of a chapel and hermitage, dedicated to St Anthony, and a fine spring called St Auton's well.

Автіснокв. The artichoke (cynara scolymıs) is a well-known plant, which is cultivated in Europe cliefly for culinary purposes. 'This plant was cultivated in England as early as the year 1580. The parts that are eaten are the receptacle of the flower, which is called the bottom, and a fleshy substance on the scales of the calyx. The choke consists of the mopened florets and the bristles that separate them from each other. These stand upon the receptacle; and must be cleured away before the bottom can be eaten. Its name undoubtedly arose from a notion, that any one, unlucky enough to get it into his throat, must certainly be cinoked.-In England, articlokes are generally boiled plain, and eaten with melted butter and pepper, and are considered both wholesome and nutritions. The bottoms are sometimes stewed, boiled in milk, or added to ragouts, French pies, and other highly-seasoned dishes. For winter use, they may be slowly dried in an oven, and kept in paper bags, in a dry place. On the continent, articliokes are frequently eaten raw with salt and pepuer. By the country people of France, the flowers of the artichoke are sometimes used to coagulate milk, for the purpose of making cheese. The leaves and stalks contain a bitter juice, which, mixed with an equal portion of white wine, has been suc- cessfully employed in the cure of dropsy, when other remedies have failed. The juice, prepared with bismuth, imparts a permanent gold colour to wool.The Jerusalem artichoke is a somewhat potatoshaped root, produced by a species of sun-flower (helianthus tuberosus), which grows wild in several parts of South America. This plant bears single stalks, which are frequently eight or nine feet high, and yellow flowers, much smaller than those of the common species. So extremely productire are these valuable roots, that between seventy and eighty tons weight of them are said to have been obtained, in one season, from a single acre of ground. They succeed in almost every soil ; and, when once planted, will continue to flourish in the same place, without requiring much mannre, or much attention to their culture. The season in which they are dug up for use, is from about the middle of September till November, when they are in the greatest perfection. After that, they may be preserved in sand, or under cover, for the winter. The roots are generally eaten plainly boiled, but they are sometimes served at table with fricassee-sauce, and in other ways. Their flavour is so nearly like that of the comnon artichoke, that it is difficult to distinguish one from the other. We are informed that Jerusalem articlıokes are a valuable food for hogs and store pigs; and that, if washed, cut, and ground in a nill similar to an apple-mill, they may also be given to lorses.

ARTicle, in grainmar; an adjective used before nouns to limit or define their application. See Grammar.

Article of Faith is a point of Cliristian doctrine established by the church. The thirty-11ine articles of the church of England were founded, for the most part, upon a body of articles compiled and published in the reign of Edward VI. They were first passed in the convocation, and confirmed by royal authcrity in 1562. They were ratified anew in 1571, and again by charles I. To these the law requires the subscription of all persons ordained to be deacons or priests (13 Eliz. cap. 12); of all clergymen, inducted to any ecclesiastical living (by the same statute), and of licensed lecturers and curates (I3 Eliz. cap. 12 and 13 , and $14 \mathrm{Ch}$. II., cap. 4); of the heads of colleges, of chancellors, officials, and commissaries, and of schoolmasters. By statute Wm. III., cap. 10, dissenting teachers are to subscribe to all except the $34 \mathrm{th}, 35 \mathrm{th}$, and 36th, and part of the 20th; and, in the case of Anabaptists, except, also, part of the 27 th. By the 19th Geo. III., cap. 44, however, dissenting preachers need only protess, in writing, to be Christians and Protestants, and that they believe the Scriptures to be the revealed will of $\mathrm{God}$; and schoolmasters need neither sign the articles nor such professions.

Artillery signifies all sorts of great guns or cannon, mortars, howitzers, petards, \&c., together with all the apparatus and stores thereto belonging, which are taken into the field, and used for besieging and defending fortified places. It signifies also the science of artillery or gunnery (q. v.), which, originally, was not separated from inilitary engineering. The class of arms called artillery has always been the subject of scientific calculation, more than any other species, as the Italian word arte, in its name, seems to indicate. The same name is also given to the troops by whom these arms are served, the men being, in fact, subsidiary to the instruments. The other portions of an army are armed men, while the artillery consists of manned arms. The history, \&c., of artillery in the different countries, will be given under the head of Gunnery.-Artillery, park of, is the place appointed by the general of an army to encamp the train of artillery, with the apparatus, 
ammunition, \&c., as well as the battaliou appointed for its service and defence. Strict onler and a cunvenient arrangeunent for breaking up, \&c., are very important in eucanping a park of artillery. - Field artillery is distinguished from artillery for defence or besieging.-Flymg artillery cousists of light pieces, with accommodations for the artillerists, so that the whole can move quickly in battle. In some armies, the mounted artillery, ulso, is called fying artillery. See, also, Amusette, Cannon, \&c.

Artos; a former province of France, anciently one of the seventeen provinces of the Netherlands. It was bounded on the $S$. and $W$. by Picardy, on the F. by Hainault, and on the N. by Flanders. $\Lambda$. always was acconnted very productive. It was seventy-five miles in length, and thirty-six in breadth. It is now included in the departments of Pas de Calais, Somme, and Nord.

A RTOTYRITE (from apros, bread, and ruoos, cheese); a sect, in the $2 d$ century, in Galatia, which used bread and cheese in the eucharist, because, they said, the first men offered not only the fruits of the earth, but of their flocks too. They admitted fennales to the priesthood, and even to the dignity of bishops.

ARTs (from the Latin ars); in the most general sense of the word, any acquired skill. As the fine arts, in early tunes, were not distinctly separated from the merely useful arts, nor even from the sciences, and as there is, in fact, much difficulty in drawing the line, in many cases, one word is used, in most languages, for both, and an epithet is necessary to distinguish them; in some languages, however, e. g. the German, they are distinguished by two very different words. The ancients divided the arts into liberal arts (artes liberales, ingenua, bonce), and servile arts (artes serviles). Under the latter were comprehended the mechanical arts, because they were practised only by slaves. The former ones were such as were thought becoming to freemen. The name servile arts was lost as soon as freemen began to practise them, but the name of liberal arts was retained. The following seven were usually called by this name: grammar, dialectics, rhetoric, music, arithmetic, geometry, and astronomy, according to the well-known verse:-

Gram. loquitur, Dia, verba docet, $R$ he. verba ministrat, $M$ us. canit, Ar. numerat, $G e$. ponderat, As. colit astra.

This awkward and illogical division continues in many Catholic schools, where the different classes are arranged according to it. In modern times, we divide arts into fine and useful or mechanical arts, comprising under the former all those, the direct object of which is not utility, as poetry, music, architecture, painting, sculpture, \&c. If we speak of the fine arts simply not in contradistinction to the useful arts, we generally intend only architecture, painting, sculpture, and engraving, with their subdivisions. (For the history and description of each of the fine arts, see the respectire articles.)-The mechanical arts, as we have said, were practised, among the ancients, by slaves or by women, many things of the first necessity being, of course, manufactured in the house. Refinement, however, in the conrse of time, made more skill necessary, in some branches of manufacture, than is generally to be expected from women or slaves. Thus we find, in the middle ages, up to the 10th century, besides the slaves or bondsmen, free persons practising the useful arts. From that time, however, it seems that mechánical arts were carried on only by freemen, or nuns and monks, who worked both for themselves and others. When the cities grew up, and their number and population rapidly increased, one of the immense changes which history shows to have sprung from theun, was the elevation of the inechanical arts. It was now esteented honourable to be a skilful mechanic. In many instances, too, they became blended with the fine arts, and the names of several workinen have been handed down to us, with a reputation akin to that of artists; e. g. Benvenuto Cellini, Peter Fischer. See Corpo ration.

ArosDE, a lorough, inarket-town, and parish in the county of Sussex, England, situated on the declivity of a hill, on the north bank of the river $A$ run, over which there is a bridge. It consists of two principal streets, one of which runs north and sonth, and the other westward from their point of union. Many of the houses rebuilt by the chike of Norfolk are in the castellated style. The first mention of Aruudel and its celebrated castle nccurs in the will of king Alfred, by whoin it was bequeatlied to his nephew $\Lambda$ dhelm. It was subsequently held by various members of the blood-royal, and other potent barons, until it passed intu the possession of the Fitz. alans, earls of Arundel, from whoin it was conveyed by marriage into that of the Howards, dukes of Norfolk, with whom the paramount influence still remains. The charter, by which the town is go. vcrned, was granted by queen Elizabeth. Here was formerly a harbour capable of containing vessels of 100 tons burden, but it has been much damaged by the sea. Great quantities of timber, for ship-building, are, however, still shipped from this plnce, which has but little other trade, but is much benefited in summer by the visitors who resort to it for sen-lathing. The celebrated castle stands on a knoll, partly formed by nature, and partly by art, on the northeast side of the town. The present magnificent structure may be deemed almost a complete renovation of the ancient building, which had become little better than a heap of ruins when the late luke of Norfolk determined to make it his principal baronial residence. The primitive castle was deemed inpregnable in the feudal times, and in consequence is greatly celebrated in the civil broils by which they are so much distinguished. In the reign of Henry VI., ou being restored to the Fitzalan family, an act of parliament was passed to anuex to the possession of this castle and honour the dignity of earl, without further creation. The free-stone emplosed in the present building is of a heavy brown cast, to make the new assimilate the better with the remains of the old building, and nothing has been neglected to render it one of the most magnificent and interesting noble residences in Great Britain. The population of the borough and parish of $\mathrm{A}$. is 2803 .

Arondedin Marbles; a series of ancient sculptured marbles, discovered by William Petty, who explored the ruins of Greece, at the expense of and for Thomas Howard, earl of Arundel, who lived in the time of James and Charles I., and deroted a large portion of his fortune to the collection of monuments illustrative of the arts, and of the history of Greece and Rome. These marbles, named in honour of their purchaser, arrived in England, in the year 1627, with many statues, busts, sarcophagi, \&:. John Selden published some of the inscriptions, which he thought most interesting, under the title of Marmora Arundeliana, 4to, Loudon, 1628. It is supposed that not more than half of the original number escaped destruction in the civil wars : they were then in the garden of the earl, in the Strand, in I.ondon. Henry Howard, duke of Norfolk, grandson of the collector, presented the remainder to the university of Oxford, where they still remain. The whole collection of inscriptions was published by Humphrey Prideaux, in 1676; by Michael Maltaire, in 1732; by $\mathrm{Dr}$ Chandler, very splendidly, in 1763 . These inscriptions are records of treaties, public contracts, 
thanks of the state to patriotic individuals, \&c., and many of a private nature. The most curious and interesting is one usually known by the name of the Parian Chronicle, from having been kept in the island of Paros. It is a chronological account of the principal events in Grecian, and particularly in Athenian history, during a period of $131 \mathrm{~s}$ years, from the reign of Cecrops, B. C. 1450, to the archonship of Diognetus, B. C. 264. The authenticity of this chronicle lias been called in question, but has been vindicated by many of the most learned men.

Arovs, Tarquiuius; the son of Tarquin 1I., the last king of Rome, who, meeting Brutus in the first battle atter the expulsion of the royal family, they mutually killed each other.

Arosisı Casup (Arusian fields) ; plains in Lucania, fanous for the last battle between the Romans and Pyrrhus (q. v.)

Aruspices, or Harospices; Roman priests and prophets, who foretold events from observing the entrails of sacrificed animals. They observed, too, all the circumstances which accompanied or happened during the sacrifice; e.g. the flame, the mode in which the animal behaved, the smoke. Their origin is to be sought for in Etruria. They were introdiced into Rome by Romulus, where they enjoyed their anthority till the time of the emperor Constantine, 337 A. D., who prohibited all soothsaying on pain of death. Their number, at this time; was seventy; their chief priest was called summus amespex, or magister publicus.

As. The Romans used this word in three different ways, viz. to denote, 1 , any unit whatever, considered as divisible; 2 , the unit of weight, or the pound (libra); 3 , their most ancient coin. In the tirst use of the word, the pound, foot, jugerum sextarius, were called $a s$, when contradistinguished,from their divisions or fractions. In fact, the word was applied to any integer; e. g. inheritances, interest, houses, funds, \&c. Therefore ex asse heres signifies to inherit the whole. Different names were given to different numbers of asses: dupondius (duo pondo) $=$ two asses, sestertius (sesqui tertius, viz. the third half) $=$ two and a half asses, tressis = three asses, quatrussis $=$ four asses, and so on to centassis $=100$ asses. The as, whatever unit it represented, was divided into twelve parts, or ounces (uncia), and the different fractions of the as received different names, as follows :-

$$
\begin{aligned}
& \text { As, - . } 12 \text { ounces. Quincunx, . } 5 \text { ounces. } \\
& \text { Deunx, : } 11 \text { " Triens, : } 4 \text { " } \\
& \text { Dextans,: : } 10 \text { " Quadrans, or " } \\
& \text { Dodrans, . } \quad 9 \text { " } 8 \text { teruncius, - } 3 \text { " } 8 \\
& \begin{array}{llll}
\text { Bes, or des,. } & 8 & \text { " } & \text { Sextans,. . : } 2 \text { 6" } \\
\text { Septunx, } & 7 & \text { Uncia, . . : I ounce. }
\end{array} \\
& \text { Semis, - } 6 \text { " } 6 \text { "escuncia was } 11 \text { ounce. } \\
& 1 \text { uncia contained } 2 \text { semiuncix, } \\
& 3 \text { duellix, } \\
& 4 \text { sicilici, } \\
& 6 \text { sextulæ, } \\
& \text { 24 scrupula (scriptula, or scripula,) } \\
& 48 \text { oboli. } \\
& 14 \text { siliquæ. }
\end{aligned}
$$

Scholars are not agreed on the weight of a Roman pound, but it is not far from $327 \cdot 1873$ grammes, French measure. Budiens hąs written nine hooks $D e$ Asse et ejus Partibus (Of the As and its Parts). In the most ancient times of Rome, the copper coin, which was called $a s$, actually weighed an $a s$, or a pound, but, in different periods of the republic and the succeeding empire, this coin was of very different values.

As.FCETIDA is a resinous gum, procured from the root of a large umbelliferous plant (ferula assafocti$d u$, which grows in the mountains of some parts of Persia. The lcaves of this plant are nearly two feet long, doubly-winged, and liave the leaflets alternate. The flowers are small, and the seeds oval, flat, and marked with three longitudinal lines. No one, who lias ever smelt the peculiarly powerful and garlic-like odour of asafœetida, can well forget it. if exposed to the air, but particularly when heated, it will pervade every apartment of a house. Notwithstanding this, it constitutes a favourite seasoning for food with the inliabitants of many parts of the East. The Indian Banians, who never eat animal food, use it in almost all their dishes, and, before their meals, even rub their mouths with it, in order to stinulate their appetite. It is sometimes used by our own cooks, but in very minute quantity, in place of garlic. In many parts of Arabia and Persia, asafoetida is much esteemed as a remedy for various internal diseases, and evell as an external application to wounds. With us, it is considered a powerful medicine in several disorders. It has been applied, with success, in the cure of hooping cough and worms; and in flatulent colics, it has, in many cases, afforded great relief. It is imported in masses of various sizes and forms, and of yellow, brown, or bluish colour, sometimes interspersed with roundish, white pieces. The plant, from the root of which asufœetida is produced, grows in the mountains which surround the small town of Disguum, in Persia; and, at the season when it is collected, the whole place smells of it. The upper part of the roots, which are sometimes as thick as a man's leg, rises somewhat above the surtace of the ground. When cut, the asafoetida exudes in form of a white thick juice, like cream ; which, from exposure to the air, becomes at last of a dark brown colour. It is very apt to run to putrefaction, and hence those who collect it carefully defend it from the sun. The fresh juice has an excessively strong smell; a single dram of it smells more than a hundred pounds of the dry asafoetida brought to us. The harvest commences when the leaves begin to decay; and the whole gathering is performed, by the inhabitants of the place, in four different journeys to the mountains. 'The demand for the article in foreign countries, being first ascertained to be sufficient to repay the trouble of collecting it, the persons employed proceed to the mountains in companies of four or five each. It is stated that a single ship is exclusively devoted to transporting the bulk of this commodity to the ports in the Persian gulf; and that, when smaller parcels are carried, it is usual to tie them to the top of the mast.

AsAPH, St; a native of North Wales, lived under Carentius, king of the Britons, about 500 . He wrote the ordinances of his church, and the Life of St Kene tigern, whom he succeeded in the charge of the conrent of Llan Elwy. Bayle says he was the first who received unction from the pope.

Asaph, St, or Llan ElWy ; a city and parish of Wales, partly in Denbighshire and partly in Flintshire. The city is seated on the decline of a pleasant emirience, between the rivers Clwyd and Elwy, which renders the first appearance striking, althongh consisting of little more than a single street. The see is supposed to have originated in St Kentigern, bishop of Glasgow, an exile from Scotland, who, returning to his own comntry, was succeeded by St Asaph, from whom both the diocese and town took its nane. From the death of the latter in 596, little is known of the succession of bishops, until the thirteenth century; and, even subsequently, in the wars of Owen Glendower, the town and cathedral were nearly destroyed by the rarages of warfare. The church stands in the lower part of the town, and serves for the use of the parishioners, the cathedral not being used for parochial purposes. The latter was built about the close of the fifteenth century; it consists of a thoir, a nave, two aisles, and a transept. Several eminent mei

$$
\text { 2 o-P } 2
$$


have been bishops of St Asaph, including Drs Israc Barrow, Willian Beverielge, and Sanuel Horsley. Ihe population of the town and parish is 3,144 .

Asarou; the root or dried leaves of the asarabacen. The powder of the leaves is the basis of most cephalic snutfs. A good deal of their acrimony is lost in keeping, or by exposure to heat. Asarabacca grows in several parts of England, particularly Lancashire and Westmoreland.

ASBEV ; a considerable kingulom in the interior of Africa, between Fezzan and Cashna. The sultan is said, by Hornemani, to rank next to that of Bornou, amoug the sovereigns of interior $\Lambda$ frica. The inliabitants of $\mathrm{A}$. are 'Tuaricks, of the tribe of Kulluvi.

Asвestos; a mineral substance, presenting much diversity in its structure and colour. It occurs in long, parallel, extremely slender and flexible fibres (amianthus); in finely interworen and closely-matted flaments, forming flat pieces (nnountain leather); in fibres interlaced so as to form numerous cells resem. bling cork (mountain cork); in liard, brittle, slightlycurved fibres (mountain wood); and in compactlyfibrous masses, harder and heavier than the other varieties (common asbestus). Its most common colours are grey, yellow, green, and blue, intermingled with white. It is found in all countries more or less abundantly, and exists, forming veins, in serpentine, mica slate, and primitive lime-stone rocks. Amianthus, the most delicate variety, comes most plentifully from Savoy and Corsica. Its fibrous texture, and the little alteration it undergoes in strong lieats, caused it to be used by the eastern nations as an article for the fabrication of cloth, which, when soiled, was purified by throwing it into the fire, from whence it always came out clear and perfectly white; hence it obtained the name of apsavros, or undefiled. By the Romans, this cloth was purchased at an exorbitant price, for the purpose of wrapping up the bodies of the dead, previously to their being laid upon the funeral pile. The preparation of this cloth is effected by soaking the amianthus in warm water, rubbing it with the fingers, soaking the filaments in oil, when they are mingled with a little cotton, and spun upon the ordinary spindle. When woven into cloth, the fabric is heated red hot, and the oil and cotton consumed, leaving only a tissue of pure amianthus. Paper may also be formed from this substance, in the way in which common paper is made, except that more size is requisite. A book has even been printed on such paper. (See Bibliomania.) Lamp-wicks have also been constructed from amianthus, but they require to be cleaned occasionally from the lamp-black, which accumulates upon them, and prevents the due supply of oil. In Corsica, it is advantageously used in the manufacture of pottery, being reduced to fine filaments, and kneaded up with the clay; the effect of which is to render the ressels less liable to break, frum sudden alternations of heat and cold, than common pottery.

Ascalon; a town of Palestine, on the sea coast, 14 miles north of Gaza, and 30 south-west of Jerusalem. It was one of the satrapies of Egypt, and was noted during the crusades. It consists of long streets, and innumerable red granite pillars mostly fallen.

Ascavios; son of Eneas and Creusa, accompanied his father in his flight from the burning of Troy, and went with him to Italy. He was afterwards called Iulus. He behared with great valour in the war between his father and the Latins. He succeeded Eneas in the government of Latium, and built Alba, to which he transferred the seat of his empire from Lavinium. The descendants of A. reigned in Alba for above 420 years, making $14 \mathrm{kings}$, till the age of Numitor. A. reigned 39 jears, and was succeeded | Suints, Monks.) by Sylvius Posthumus, son of Aneas by Lavinia Iulus, the son of $\mathbf{A}$., disputed the crown with Sylvius; but the Latius gave it to the latter, as he was descended from the fimily of Latinus, and Iulus was invested with the office of high priest, which remained a long while in his family.

Ascrevdants, in law, are opposed to descendants in succession; $i$. e., when a father sncceeds lis son, or an nncle his nephew, \&c., the inheritance is said to ascend, or to go to ascendants. See Descent.

Ascendivg, in astronomy, is said of such stars as are rising above the horizon in any parallel of the equator; and thus, likewise, ascending latitude-the latitude of a planet when going towards the north pole.-Ascending node is that point of a planet's orbit, wherein it passes the ecliptic to proceed northward. 'This is otlerwise called the northern node.

Ascession; an uninhabited island, consisting of naked rocks; a shattered volcano, of abont 60 niles in circumference, in the Atlantic ocean ; lon. $13^{\circ} 58^{\prime}$ $45^{\prime \prime} \mathrm{W}$.; lat. $7^{\circ} 56^{\prime} \mathrm{S}$. It has an excellent liarbour, frequented by the Fast Indiamen anl whale-fishers. Fish, sea-forvl, and turtles abound, but there is an entire want of water. The vegetation, scarcely sufficient to support some goats, is confined to an eminence in the south-east. In a crevice of the rock there is the sea post-office, as it is called-a place where bottles, closely sealed, are left with letters for passing vessels. This island formerly belonged to the Portuguese, who discovered it in 1501; but, in 1816, some English families from St Helena settled here, on account of the inconvenience which they experienced from the residence of Napoleon. Ascension was then taken possession of by the British government, as a military station, and 60 transport ships provided the garrison of 200 men with supplies from the cape of Good Hope. A road was laid out, and $a$ fort was built. In 1821 , the govemment resolved to continue the occupation of this post.

Ascevsion, in astronomy. We understand by the right ascension of a star, that degree of the equator, reckoned from the beginning of Aries, which comes to the meridian with the star. By the right ascension and declination, the situation of stars in the heavens is determined, as that of places on the earth by longitude and latitude. By oblique ascension, we understand that degree of the equator, counted as before, which rises with the star, in an oblique spliere.

Ascersion Day; the day on which the ascension of the Saviour is commemorated, often called Holy Thursday. It is a movable feast, always falling on the Thursday but one before Whitsuntide. (For the Ascension of the Virgin, a feast of the Roman Catholic church, see Assumption.) Much has been written on the ascension of Christ, in Germany, by Protestant Biblical critics, of whom we will only mention Semmler and Paulus.

Ascetics; a name given, in ancient times, to those Christians who devoted themselves to severe exercises of piety, and strove to distinguish themselves from the world by abstinence from sensual enjoyments, and by roluntary penances. Hence those writings which teach the spiritual exercises of piety, are termed ascetic writings. Even before Christ, and in the times of the first Christian church, there were similar ascetics among the Jews (see Essenes), also among the philosophers of Greece, and in particular among the Platonics. The expression ascetic is bor-

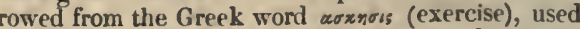
by the ancient Greeks to signify the spare diet of the athletce, who, to prepare themselves for their combats, abstained from many indulgences. (For the character of the Christian ascetics, and the religions views by which they were guided, see Gnostics. 
Aschafrevborg (the ancient Asciburgum, laid out $\mid$ by a Glyconic, or two less Asclepiadean, by a Phereby the Romans); a town in the Bavarian district of the Lower Maine, witl 750 houses and 6,200 inhabitants, on the Maine and Aschaff. It formerly belonged, with its territory, to the electorate of Mentz. The scenery is so beautiful, and the castle so fine, that Gustavus Adolphus of Sweden, when he took possession of it, in his expedition to the Rhine, wished to transfer it, with its view, to lake Maler, in Swe den. After the dissolution of the electorate of Mentz, in 1811. A became the summer residence of the prince primate, afterwards grand duke of Frankfort.

Asciam, Roger ; a learned Englishman of the 16th century, was bom, in 1515, of a respectable family in Yorkshire. He was entered at Cambridge, 1530, and was chosen fellow in 1534, and tutor in 1537. In this period of religious and literary revolution, A. joined himself with those who were extending the bounds of knowledge. He became a Protestant, and applied himself to the study of Greek, which began, about that time, to be taught in England. There was yet no established lecturer of Greek: the university, therefore, appointed him to read in the open schools. He was not less eminent as a writer of I atin than as a teacher of Greek. He wrote all the public letters of the university, was afterwards Latin secretary to king Edward, and also to Mary. Cardiual Pole, who was particularly eminent for his skill in Latin, employed him to translate, for the pope, his speech in the English parliament. In 1544, he wrote his "Toxophilus, or Scliole of Shooting," in praise of his favourite amusement and exercisearchery. This book he presented to the king, who rewarded him with a pension of 10 pounds. In 1548 , the princess Elizabeth invited him to direct lier stulies; but, after instructing her two years, he left ner without lier consent, and, soon after, went to Germany as secretary to Sir R. Morisine. In this journey, lie wrote his Report of the Affairs in Germany. Upon the death of Edward, he was recalled, but preserved the office of Latin secretary to Mary, although a Protestant, through the interest of Gardiner. Upon the accession of his pupil, he was continued in his former employment, and was daily admitted to the presence of the queen, to assist her studies, or partake of her diversions, but received no very substantial marks of her bounty. In 1563, he was invited by Sir E. Sackville to write the Schoolmaster, a treatise on education, which, though completed, he did not publish. To this work, conceived with vigour and executed with accuracy, he principally owes his moderu reputation. His style was, in his own age, mellifluous and eloquent, and is now valuable as a specimen of genuine English. He was never robust, and his death, which happened in 1568 , was occasioned by his too close application to the composition of a poem, which he intended to present to the queen on the anniversary of her accession. His works were collected and published by Bennet, in one vol. 4to, 1769, enriched with a life by $\mathrm{Dr}$ Johnson.

Asclepladean Verse, consists of two or three choriambuses, and is accordingly distinguished into greater and less. It always begins with a spondee, and ends with an iambus:

$$
-1-\smile \smile-\|-\underset{\text { Greater. }}{\text { Less. }}-1 \backsim \simeq 1
$$

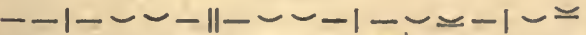
Their character is lyric, uniting grace with vigour. In Horgce, there are five different metres formed of Asclepiadean verses. He uses either the greater or the less alone, or alternately with the Glyconic verse : or employs three less Asclepiadean rerses, followed cratian and a Glyconic verse.

Asclepiades, the descendants of the god of medicine, Esculapius, by his sons Podalirius and Machaon, spread, together with the worship of the god, through Greece and Asia Minor. They formed an order of priests, which preserved the results of the medical experience acquired in the temples as a hereditary secret, and were thus, at the same time, pliysicians, prophets, and priests. They lived in the temple of the god, and, by exciting the imaginations of the sick, prepared them to receive healing dreams and divine apparitions; observed carefully the course of the disease; applied, as it is believed, besides the conjurations and charms usual in antiquity, real magnetic remedies, and noted down the results of their practice. They were, accordingly, not only the first pliysicians known to us, but, in fact, the founders of scientific medicine, which proceeded from their society. The constitution of this medical family order was, without doubt, derived fiom Egypt, whence also the coluber Asculapiz, Linn., which was used as a healing and prophetic serpent, was brought by the Phœnicians to Fpidaurus, the chief seat of the god. Round this serpent-god an order of priests was gathered, and thence spread his worship. (In later times, 292 B. C., such a healing serpent was sent to the island of Tiber, near Rome.) No one could be initiated into the secrets of their knowledge without a solemn oath. At first, this order of priests was confined to the family of the Asclepiades, who kept their family register with great care. Aristides celebrated them by his eulogiums at Smyrna. Hipporrates of Cos, the founder of scientific physic, derived his origin from it, and the oath administered to the disciples of the order (jusjurandum Hippocratis) is preserved in his writings.-An Asclepiades from Prusa, in Bithynia, 20 years B. C., is mentioned as the first practical physician at Rome, and as the founder of the methodical school. In the course of time, strangers, also, as Galen reports, were initiated into these mysteries and this order.-We find the name of A. also in the literature of the Greeks. See Dissertations on the Fragments of Asclepiades of Tragilus, in the Actis Philologorum Monacensium, edited by Thiersch, Ist vol., 4th No., p. 490.

Aselu, or Asceluos, Caspar ; an Italian anatomist of the 17th century. He was bom at Cremona, studied medicine, and became professor of anatomy in the university of Pavia, where he highly distinguished himself by discovering the lacteals, a systen of vessels, the office of which is to absorb the chyle formed in the intestines, and thus contribute to the support of animal life. A. first observed these vessels in dissecting a living dog. His investigations were published after his deatl at Milan, 1627.

Asen. See Mythology, northern.

AsgiLl, John, an English barrister, and singular writer, was horn about the middle of the serenteenth century. In 1698, he published a work entitled, "Several Assertions proved, in order to create another species of money than Silver and Gold," and "An Essay on a Registry for Titles of Land." These productions were followed in 1700 by a fanciful and enthusiastic work, entitled " An Argument proving that, according to the Covenant of Eternal Life, Man may be translated from hence without passing through Death, although the Human Nature of Clurist himself could not be thus translated until he had passed Death." For this work, which was declared blasphemous, he was expelled the House of Commons, of which he was a member. He died in 1738 , at a very advanced age.

Asn. The commun ash (fraxinus excelsior) is a weil-known tree. It is a mative of Europe and the 
nortil of $\Lambda$ sia, and grows in a light, springy (but not marshy) soil, especially if marly or calcarious. When planted in bugs, it contributes much to drain them. It will grow in almost any sitnation, even in land clay and dry gravel ; though poor, dry, sandy ground is fatal to it. Its smootil, stately stem rise's to a great height, witlı spreading, or, mither, drooping branches, with winged leaves, the leaflets in four or five pairs, with an odd one serrated, and without foot-stalks, and the flowers without petals,--Of late years, this valuable tree has been mueh planted in several parts of England. The timber, witich has the rare ad. vantage of being nearly as good when young as when old, is white, and so liard and tough, us generally to be esteemed next in value to ank. It is much used by conch-makers, wheel-wrights and cart-wrights ; and is made into ploughs, axle-trees, felloes of wheels, harrows, ladders, and other implements of husbandry. It is likewise used by ship-builders for various purposes, and by coopers for the hoops of tubs and barrels. Where, by frequent cutting, the wood has become knotty, irregular and veined, it is in much request for cabinet-vork, by mechanics in Europe. As fuel, this troe burns better, whilst wet and green, than any othe: wood. The finest ash-tree, periıps, in Britain is to be found in Bonhill churchyard, Dumbartonshire. Its trunk is about nine feet ligh, and where smallest upwards of eighteen feet in circumference. Of the three principal arms into which it branches, the largest is eleven, and the smallest near ten feet in circumference. The branches spread in every direction with uncommon regularity, covering an ares of nearly 100 feet in diameter, and the general aspect is singularly venerable and majestic There ure no data from which its age can be conjectured. Nearly a lundred years ago, it was noticed by Mar. sham of Stratton near Norwich, a celebrated planter, as one of the first ashes he had seen; and a tendency to decay in some of the bouglis seems to indicate that it has stood for several centuries.

Asu-W rosespar ; the first day of Lent, a fast forty days long, which the Catholic church orders to be kept before the feast of Easter. It derives its name from the ancient and still existing custom of putting ashes upon the head, as a symbol of liumble repentance for sill. It was formerly, and, to a certain extent, is still the custom in Catholic countries, to confess on Ash-Wednesday, to chastise one's self during Lent, and to partake of the Lord's supper at Easter. In Rome, the spectacle is highly impressive, when all the people, after giving themselves up to every species of gayety during the carnival, till twelve o'clock on Tuesday, go, on Ash-Wednesday morning into church, where tile officiating priest puts ashes on their heads, with the words, "Dust thou art, and unto dust thou slialt return." 'To throw ashes on the head, as an expression of liumiliation and repentance, was an old custom of the Jews.

ASHANTEE; a warlike nation of negroes, on and near the Gold Coast of Guinea, in the vicinity of the British settlement, Cape Coast castle, at Sieria Leone, with which we have become acquainted by Bowdicis's Mission to Ashantee (London, 1819), and Jos. Dupuis' Journal of a Residence in Ashantee (London, 18:4), as well as by their bloody war with the British, in 1824, in which the governor of the above-mentioned British colouy, general M'Carthy, lost his life. The kingdom of the Ashantees was founded, about 100 years ago, by a successful conqueror, with a kind of feudal constitution. It extends from $6^{\circ}$ to $9^{\circ} \mathrm{N}$. lat., and from $0^{\circ}$ to $4^{\circ} \mathrm{W}$. Inn. to the river Volta. The residence of the king is Coomassie. The law permits him to have 3333 wives, a mystical number, on which the welfare of the nation rests. His serrants, above 100 in number, are slaughtered on his tomb, that he may arrive in the infernal regions with a suite becoming his rank. Several negro states, under their own princes, are dependent on lim. Aslantee itself $(14,000$ square miles, with $1,000,000$ inlabitants) forms it purt of Waugara, which contains two other states, Daliony, and the powerful Benin, whose king can lead 200,000 men to war. 'The fertile Benin is more adranced in civilization than Ashantee. The latter, lowever, display inuch taste and elegance in their architecture; they also-dye, with skill, and manufacture cloths of exquisite funeness and brilliancy of colour.

Ashiorns; a market town and parish in Derbyshire. The town is pletsantly situated in a rich valley on the eastern side of the Dove, over wlich is a stone lridge. It is divided into two parts by a rivulet, callerl the Henmore, the most southern of which division is termed Comptorl, the ancient Campdene. It lias is considerable trade in cheese and malt, and many lorses and cattle are sold at its fairs. Mnch lace is made here, and the iron and cotton factories in the neighbourhood employ a great many persons. Population of town and parish, 4,884 .

Asururton; a market town and parish in Devonshire. The town is situated in a valley, surrourided by hills, about half a mile from the river Dart, and consists principally of one long street, through which is the high road from London to Plymouth. There are several productive tin and copper-mines in the vicinity, and an extensive manufactory of serge in the town; and the Tuesday market is lield chiefly for wool and yarn. Population of town and parish, 4,165.

AsнвY-DE-LA-Zovc1 ; a market town and parish in Leicestershire, situated in a fertile valley on the borclers of Derbyshire, througli which runs the small river Gilwiskaw. It takes its distinctive appellation from the ancient family of the Zonches, who came into possession of the manor in the reign of Henry III. It subsequently devolved to the crown, which granted it to the noble family of Hastings, in right of whom the marquis of that title possesses it at present. The town consists of one principal street, from which branch several smaller ones. 'The mannfactures established here are cliefly those of cotton and woollen stockings, and hats. There is likewise a good trale in malt; and the fairs are celebrated for the sale of fine horses and cattle. The ruins of Asliby castle, of great note in former times, and which received Mary queen of Scots as a prisoner, and her sun James and his queen, as guests, are still visible. It was built by the lord Hastings so hastily executed by Richard III.; and dismantled during the civil wars in the reign of Charles 1 . Population of parish, 4,727 .

Astes; the fixed residuum, of a whitish or whitishgray colour, which remains after the entire combustion of organic bodies, and is no longer able to support combustion. The constituent parts of ashes are different, according to the different bodies from whicl they originate. The ashes of regetables consist chiefly of earthy and saline ingredients, the latter or which may be separated by washing, and are called vegetable alkali. (See Alkali.) The more compract the texture of the wood is, the more alkali it affiorls. Some herbs, however, yield more than trees, and the branching fern the most. The more the plants have been dried, the less they produce. The regetable alkali is always combined with carbonic acid. The greater, therefore, the heat by which the ashes are produced, and the more continued and powerful the calcination of the alkali, the more caustic will it he. It can only be entirely purified from foreign substances by crystallization. (See Potush.) Of quite a different quality are animal ashes, particularly those wbtained from bone. After calcination, it retains its 
oniginal texture, and contains, besides lime, a peculiar acid, called phosphoric acid.-The use of vegetable ashes is very extensive, as is well known ; soap makers, bleachers, and other tradesmen use them in an immense quantity. They are, also, an excellent manure.

AsHFord ; a market town and parish in Kent, pleasantly situated on a gentle eminence, near the confluence of the upper branches of the river Stour, over one of which there is a bridge, and contains many handsome houses. The inhabitants of this town and its vicinity are nuch engaged in the rearing and fattening of cattle, for the sale of which its markets and fairs are much celebrated. Population of parish, 2,809.

AsнnoLs, Elias, a celebrated Fuglish antiquary and virtuoso, born at Liclıfield, in 1617, was sent to London at the age of sixteen, where lie studied law and other branches of knowledge, and practised as a chancery solicitor. On the breaking out of the civil wars, he retired to Oxford, and entered hinself of Brazen-Nose college, where he engaged in the study of natural philosophy, mathematics, and astronomy. On the ruin of the king's affairs, le returned to Londun, and formed a close intimacy with the celebrated astrologers Moore, Lilly, and Booker, but shared only in their absurdity, not in their roguery. He subsequently married lady Mainwaring, a rich widow. On this accession of fortune, he gave up his profession, and his house in London becane a resort of all the proficients and professors in the occult sciences. A., about this time, published, under another name, a treatise on alchymy, by the celebrated doctor Dee; and undertook to prepare for the press a complete collection of the manuscript writings of English chemists, under the title of Theatrum Chymicum Britannicum. Having for some time attached himself to the study of antiquity and the perusal of records, he began to collect materials for his celebrated History of the Order of the Garter. His love for botaly having induced him to lodge with the celebrated gardener of Lambeth, John 'Tradescant, he obtained the curious collection of rarities got together by that person and his father. On the restoration, A. was gratified with the post of Windsor herald, and received other appointments, both honourable and lucrative; was admitted a fellow of the royal soeiety, and favoured with the diploma of a doctor of physic from the university of Oxford. In 1672, he presented to the king his work on the Order of the Garter, and in 1675, resigned his office of Windsor herald. An accidental fire in the Temple destroyed a library which he had been upwards of thirty years collecting, with a cabinet of nine thousand coins, and other valuable antiquities. In 1683 , he presented to the university of $O x$ ford his Tradescantian collection of rarities, to which he afterwards added his books and MSS., thereby commencing the museum Ashmoleanum at Oxford. He died in May, 1692, aged seventy-six. He left a number of MSS., several of which have been printed, and a diary of his life.

Ashover ; a parish and towuship in Derbyshire. In the church of Ashover there are several monuments of the Babington family, one of whom, $A n$ thony Bahingtol, was executed for a conspiracy to destroy queen Elizabeth. On the declivity of a hill on Ashover Common is a rocking-stone, which measures about twenty-six feet in circumference, and appears to have been placed in its extraordinary position with great ingenuity. Close at hand is also a singular shaped rock, called the Turning-stone, supposed to have been a rock idol. Population 3,179.

AsHTON-JNDER-LYNE; a parish in the hundred of Salford, and county palatine of Lancaster, containing the town of the same name, and the additional townships or districts of Audensluw, Hartshead, and
Knott-Lanes, with the populous lamlets of Buston, Charlestown, Dukinfield, Fairfield, Hay, Hurst, Luzley with 'Toweracre, Mosley, Stayley-Bridge, and Smallshaw. The town, which is built on the north bank of the river Tame, consists of several narrow strects. It has been much enlarged of late years by the extension of the cotton and woollen factories, which branches of manufacture, but more especially the latter, are carried on in this town and parish to a great extent. There are also sereral collieries in the vicinity, which employ a great many persons; and together with the peat from Ashton Moor, on the west of the town, render fuel very plentiful. Population of parish, 33,507 .

Asia ; the cradle of the human race, of nations, religions, and states, of languages, arts, anid sciences ; rich in natural gifts and historical remembrances; the theatre of human activity in ancient times, and still exhibiting, in many places, the characteristic traits which distinguished it many centuries since. It forms the eastern and northern part of the old world, and is separated from Australia by the Indian and the Pacific oceans, including the gulfs of Bengal, Sianı, and Tonquiu ; from America, on the N.E., by Cook's or Behring's straits, and on the $\mathbf{E}$. by the great Eastern or Pacific ocean, including the gulf of Corea, the seas of Japan, Tongou (Yellow sea), and Okotsk; from Africa by the Arabian sea (with which is connected the Persian gulf), and by the Arabian gulf, or Red sea, with the straits of Babelmandel; from Europe by the sea of Azoph, with the straits of Caffa, by the Black sea with the Bosphorus, by the sea of Marmora and the Dardanelles, and by the Grecian archipelago. On the other hand, it is united with Africa by the desert isthmus of Suez, and with Europe by the waters of the Wolga (which rises near the Baltic, and falls, with the Ural, into the Caspian sea); also by the rocky girdle, as the Tartars call it, of the.Ural and the Werchoturian mountains, which rise $77^{\circ} \mathrm{N}$. lat. in Nova Zembla, separate the plain of the Wolga fiom the higher table-lands of Siberia, and are connected with Upper Asia by a branch of the Little Altai, abounding in ores. A line drawn from East Cape at Behring's straits to the entrance of the Arabian gulf, would denote the greatest extent of this continent, and would measure above 7,500 British miles; while a line drawn from Cape Severo-vostochnoi in Siberia, under the parallel of $76^{\circ} 10^{\prime}$ to Cape Romania, tine southern extremity of Malacca, in $1^{\circ} 18^{\prime} \mathrm{N}$. lat., would measure 5,166 British miles. Hassel has calculated its area at 20,432,205 British square miles, and Graberg, without the islands of the Indian ocean, at $16,263,100$ square miles; but these admeasurements are mere approximatious. Asia is four times larger than Europe. It is divided into, 1, Southern Asia, comprehending Natolia, Armenia Curdistan, Syria, Arabia, Persia, Hindostan, Farther India, Siam, Malacca, Annam, Tonquin, Cochin China, Laos, Cambodia, Clina, Japan; 2, Middle or Upper $\Lambda$ sia, containing Caucasus, Tartary, Bucliaria, Mongolia, Tungousia ; 3, Northern or Russian $\Lambda$ sia, from $44^{\circ}$ N. lat., containing Ḱasall, $\Lambda$ strachan, Orenburg, Kuban, Kabarda, Georgia, Imireta, Siberia, with the Alpine regions of Dauria and Kamschatka. The centre of this continent, probably the olclest ridge of land on the earth, is called Upper Asia. Here the Bogdo (the majestic summit of the Altai) forms the central point of all the mountains of Asia. Upper Asia comprises, perhaps, the most elevated plain on the surface of the earth-the desert of Kobi, or Shamo, on the northern frontiers of China, 400 leagues long, and 100 leagues broad; barren, dry, and waste; visited alternately by scorching wiuds and chilling storns, even in stummer, and aliording. 
besides its deserts, only rivers and lakes; as the Caspian, the lakes Aral and Baikal, and severul situmted amoug the mountains. From the northern and southeru declivities of this region, the first tribes of men set out in all directions, following the conrse of the rivers in four chief lines of descent, north, cast, sonth, and west. At least, the radical words in the Indian, Median, Persian, Sclarouian, Greek, and Teutonic original languages, between which there are striking affinities, all point to the west of Upper Asia or Iran. Those heights in the Himalaya cluan (q. v.), under the 35 th degree of $\mathrm{N}$. lat., which are said to attain an eleration of 27,677 Finglish feet, could not be reached by the currents, which, coming from the south, where they were broken by cape Comorin and cape Romania, flowed round the Chinese sea to the north, where the Fast cape on the cast, Tchulkotskoi-Noss on the north-east, and the Icy cape in the Arctic ocean, became the extreme points of the continent. The islands in the east (Japan, the Kurile, and Aleutian isles, those of Formosa, Hainan, and Lecoo-Keeoo) and in the south. west (Socotra, Ormus, \&c.), in particular the groups of islands on both sides of the equator (see Indies, East), and the peninsulas Kamschatka and Corea, India on this side and beyond the Ganges, and Arabia, bear visible marks of the destruction of the primitive continent by fire and water; hence the numerous extinguished or still active rolcanoes, in the interior, on the coasts, and particularly on the islands. The interior opens an immense field of scientific research for a traveller like Humboldt. The sources of all the large rivers of $A$ sia, which must be sought for in the mountains of Upper Asia, have not been accurately examined since the time of Marco Polo. As little kuown are the southern declivities of the Mussart, Mustag (or Imans), and of the Indian Alps, which extend over 630,000 square miles, and contain the kingdoms of Thibet, Bootan, Nepaul, Assam, \&c., with the snowy summits of the Hindoo Koosh (Paropamisus), Belurtag, Kentaisse, and the Ilimalaya. It is the same with the northern elevation of the Altai, which, in the north-east, joins the mountains Changai (the holy land of Genglis Khan and of the Mantelioo tribes, extending to Corea and Japan). From the southern Alpine girdle descend the holy rivers of the Hindoos-the Bramapootra, the Ganges, and Indus ; in the east, the less known rivers of Irawaddy, Meinam, Lukian, and Mecon (or Cambodia), and, in the west, the Euphrates and the Tigris (q. v.), which all take their course towards the south, and run into the great gulfs of the Indian ocean. From the northern ridge, the Oby, Yenisey, Lena, and many others flow into the Arctic ncean; on the eastern coast, the great rivers Amour, Hoangho, and Yang-tse-Kiang descend into the bays of the Pacific ocean; farther west, the Gihon, or Amu (the ancient $O x u s$ ), and the Sir-Daria, or Jihon (Jaxartes of the ancients), flow into lake Aral. Almost as lit. te known are the western ranges of mountains, the Taurus in Natolia, and in Armenia the Ararat, near which the Euphrates and Tigris become much increased, and where, in ancient times, the Roman victories found a limit. We have lately become better acquainted with the mountain passes, through which the first inhabitants of Europe may have wandered from Asia, the valleys of the Caucasus, from the bosom of which the Cuban flows intw the Black sea, and the Aras (Araxes), with the Kur, into the Caspian. - Nature has spread over Asi 1 all the treasures of the earth, most abundantly in India; her bounties are distributed, by imperceptible gradations, through all its three zones. In the torrid zone, whose genial warmth converts the juices of plants to spices, balsam, sugar, and coffee. with which Asia as enriched the West Indies, the palnis (sa go, cocon, (late, and unbrella-palms) reach a height of 200 feet, and the white elepliant attains a size surpassing that of all other quadrupeds. From lence the silk-worm was brought to Europe. This region conceals in its bosom the most benutiful diamonds, the finest golel, the best tin, \&c., whilst the waves flow over the purest pearls and corals. The temperate zone has given to Europe the melon, the vine, the orange. und many of its most agreeable garden-fruits, as well as the most productive farinaceous grasses, and the most charming flowers ; and unites, in its productions, symmetry witli richness, particularly in the westeru regions. Here the oldest traditions place Paradise; here lie the enchanting Cashmere and the Garden of Damascus; here blossoms the rose of Jericho (anastatica), near the cedurs of Lebanou. The eastern countries, in the same latitude, possess the tea-shrub and the gemine rhubarb. The camel, the Angora goat, the Thibetan sheep, the pheasant, and the horse are natives of this zone. In the nurth blossoms the Alpine flora of Dauria, and from the icy soil grows the dwarf-like Siberian cedar, till, at $70^{\circ}$, vegetation mostly ceases. Hore lives the smallest of quadrupeds - the shrew-mouse of the Yenisey. Sables, ermines, foxes, otters, \&c. afford the finest fur. The mineral kingdom furnishes rich ores, rare precious stones, and remarkable fossil remains, e.g. those of the mammoth, in ligh northern latitudes. (See Organic Remains.) - The inhabitants, a mounting to $300,000,000$, according to some, to $580,000,000$, are divided into three great branches:-The TartarCaucasian, in Western Asia, exhibits the finest features of our race in the Circassian form : the Mongolian race is spread through Eastem Asin; the Mlalay in Southern Asia and the islands. The north is inhabited by the Samoiedes, Tchooktches, and others. Twenty-four tribes, of different language and origin, nay be distinguished, some of which are the relics of scattered tribes of Nomades: Kamtschadales, Ostiacs, Samoiede's, Koriacks, Kurilinns, Alentians, Coreans, Mongols, and Kalmucks, Mantchoos (Tungoos, Daurians, and Mantchoo: Proper), Finns, Circassians, Georgians, Greeks, Syrians, and Armenians, Tartars and Turks, Persians and Afghans, Thibetans, Hindoos, Siamese, Malays, Annamites (in Cochin China and Tonquin), Birmese, Chinese, and Japanese, besides the indigenous inhabitants of the East India islands, Jews, and Europeans. 'The principal languages are the Arabian, Persian, Armenian, Turkislı, Tartar, Hindoo, Malayan, Mongol, Mantcloo, and Chinese. Of the extinct civilized nation of the Igoors (Oigoors) in Upper Asia, the written characters have been preserved in Thibet. The Sanscrit of the Bramins is set spoken in the higher mountains of lridia, and the ancient Pehlevi in the mountains of the Persian borders. The still more ancient Zend is entirely extinct ; and the civilization of the old Iberians and Colchians, on the Kur and Phasis (Georgia and Imireta), has left no vestiges. All the forms of socitty are displayed in the existing Asiatic nations, from the sarage state of the wandering hordes to the most effeminate luxiry; but liberty, founded on law and the mural and intellectual education of man, is wanting. Prie'sts and conquerors have long decided the pulitical character of the Fast, amidst frequent revolutions and changes of dynasties, ever maintaining the principles of blind obedience. Asia lias been suhject, at different times, to the Assyrians, Medes, Chaldeans, Persians, Greeks, Syrians, Parthians, Arabians, Mongols, Tartars, Seljooks, Turks, Afghans, \&c. Ancient forms are preserved most rigidly, and the intellect is least progressive in China and Japan. Slavery still prevails in this continent. Woman set remains de- 
graded to a slave of man. The prevailing governthose artificial forms of a rigid etiquette, which are kept up in all the public relations, and that apathy of the people, in regard to fate, connected with cruelty, and produced partly by opium, partly by superstition, which is almost a universal characteristic of the Asiatics, notwithstanding the violence of their passions. There are, however, some tribes with a republican form of goverument; and relics of the patriarchal authority of the heads of families still are found. Near the colonies of the Europeans in Southern and Northern Asia, the civilization of the Christian world has been introduced. Christianity, though degenerated in many of the more ancient sects (see Maronites, Monophysites, and Sects), has gained many adherents, throughout all Asia, by means of translations of the Bible, distributed by Britain and Russia. In Bengal and St Petersburg, the translation of the Bible into the languages of Southern Asia has been prosecuted with a benevolent zeal. In Petersburg, similar efforts have been made for the benefit of the Mongolian Tartars. Even in China, Christians are found again, bnt none in Japan since 1637. The astronomy and astrology, poetry, morals, theology, laws, and the rude empirical medicine of the Asiatics, are mostly confined to the priests, and united with deeply rooted superstition, which leads even to child murder and self-sacrifice in the flames. The Mohammedan religion, the central point for instruction in which is at Samarcand, prevails in Westem Asia. (See Wahaby.) - Over all Central and the eastern part of Northern Asia, prevails the religion of the Lama. The religion of Brama, the head quarters of which is Benares, is confined chiefly to Hindostan, and Shamanism to the tribes in Northern Asia and to the Russian archipelago. The ancient doctrine of Zoroaster is confined to single families in India and Persia; whilst the Mosaic has numerous adherents through all Asia, except the Russian part. Physical and mechanical cultivation is carried to a higher 'degree of perfection than intellectual and moral; e. g., by the Indian jugglers and Chinese mechanics. Remarkable skill has been acquired by certain classes of Hindoos in the weaving of silk and cotton. The shawls of Cashmere, the leather of Persia and Syria (morocco, cordovan, shagreen), the porcelain of China and Japan, the steel of Turkish Asia, the lackered wares of China and Japan, \&c. are well known. The internal commerce is still carried ou by caravans, as in the most ancient times, before Abraham and Moses, when inerchandise was transported from India, through Bactria, to Colchis, as at present to Makarieu, Moscow, and Constantinople. The foreign commerce of China and the East Indies is wholly in the hands of the Europeans,-British, Dutch, and Russians-and of the North Americans. The religious, civil, and social condition of the Asiatics proves, that, where the free developernent of the higlier powers of man is subject to the restraints of castes, and to the tyranny of priests and despots, and where the adherents to established forms has become a inatter of faith, law, and habit, - the claracter of society must degenerate, and the energies of man become palsied. Hence the Asiatic, notwithstanding the richness of his imagination, never attained the conception of ideal beauty, hke the free Greek; and, for the same reason, the European, whose mental improvement and social activity have been nimimpeded, has shaken off the control which the East formerly exercised over the West, and has obtained dominion over the coasts and territories of his old lord and master. "Greece led the way, and, after havifig transformed the obscure symbols of the East to shapes of ideal beauty, shook off the spiritual fetters of priests and oracles, and, at the same time, the temporal yoke which the Persian Darius had prepared for Athens and Sparta. After a struggle of fifty years, the triumphs of Cimon (in 449 B. C.) first enabled Europe to prescribe laws to the East. Grecian civilization then spread over the whole of Western Asia, to Iudia, and even the military despotism which succeeded has not been able to extinguish the light entirely. In later times, the Romans and Parthiais fought for the possession of the Euphrates, and the Persians, under the Sassanides, attempted to tear the dominion of the world from the hands of Rome. Since that period, Asia has four times taken up arms against Europe. The nations of Upper Asia, driven from the frontiers of China to the Irtish, crowded upon the West. Huns, Avari, Bulgarians, and Magyars, successively issued from the Caucasian gates, and from the wildernesses of Ural, to subdue Europe; besides those later hordes, which were mingled and confounded with each other in Sonthern Russia and on the Danube. But the rude power of Attila and of the grandsons of Arpat was broken in conflict with the Germans. Next, the Arabians attacked Constantinople, Italy, and France, but their fanatical impetuosity was checked by Charles Martel, in 732 , and the chivalrous valour of "the Gothic Christians rescued the peninsula within the Pyrenees. The West then armed itself against the East, to recover the holy sepulchre from the sultan of the Seljooks, and Christian Europe became better acquainted with Asia; but the sword alone cannot conquer a continent. (See Crusades.) Upper Asia seut again, under the Mongol Temudschin (see Genghis-Khan), her mounted hordes over the world. Again the Germans stayed the destroying flood near Liegnitz. (See Wahlstadt.) Finally, the Tartars and Ottoman Turks invaded Europe. In 1453, they took the Bosphorus and Greece from the feeble hands of the Eastern Romans. In succeeding times, Europe has been defended against Asia, on this side, by Germany. The intellectual progress of the European, since that period, has raised him above the most an. cient nations of the East-Persians, Arabians, Indian, and Chinese. Gunpowder, the mariner's compass, and the art of printing (which the last-mentioned nation possessed, but could not apply to much use) r. hare become powerful in his hands. Hence Russia has gained the Wolga, explored Siberia, kept watch over the seat of the ancient and modern Scythians, the mountains of the Altai, and finally conquered the tribes of the Caucasus; whilst [since Vasco da Gama (q. v.) discovered the way by sea to the East Indies, in 1498] the Portuguese, Dutch, and French, and particularly the British, by their universal commerce, have mide the rich countries of Southern Asia acquainted with European laws, and Europe with the condition and luxury of those countries. Persia is already entangled in the European international policy, which is principally owing to the efforts of Sir Harford Jones, Sir Gore Ousely, Mr James Morier, and the Russian general Yermatoff. The diplomacy of the court of China, now more than ten centuries old, still resists European encroachments. Japan, alone, yet denies all approach to Europeans; and her jealousy is as effective as the polar ice, which blocks up the passages of the Frozen seas. But the inquisitive spirit of Furopear. navigators has gradually penetrated the most secluded regions, from the time of Marco Polo, the Venetian (1272), to that of the present British and Russians, who will soon join liands, or perhaps swords, in the heart of Asia. (For further information, see MalteBrun's Geography; Bell's Geography; Murray's work On the Progress of Discovery in Asia; Ritter's Gèorraphy, published in 1824, at Berlin; also, Leake's Journal of a Tour in Asia Minor; also, the 
articles on the different countries of Asia, and those uI Niebuhr and Burckhardl.)

Asia Mivor; the most westeru portion of the grent continent of $A$ sia, bounded by the black sea wi the north, by the river Euphrates on the east, and on the west by the Meditermanean, the sea of Marmora, aud the straits of the Hellespont and Bosphorus. It is about 1000 miles in leigth from cast to west, and between 400 to 500 in breadth from north to south. 'The whole country is uuder the Turkish government, and is divided into several provinces, of which Natolia and Caramania are the most important. See Natolia.

Asiatic Societies and Museous; learned bodies instituted for the purpose of collecting valuable information of every kind, respecting the different countries of Asia. The three great central points where this knowlerge is accumulated are, London, Paris, aud Petersburg. The royal Asiatic society of Great Britain and Ireland contains 300 members. It was established by Mr Colebrooke, and opened March 19, 1823. Its transactions are publislied in London. Similar societies have been formed in Asia itself, at Calcutta, Bombay, and Bencoolen. Since the foundation of the Asiatic society in Calcutta, by Sir William Jones, in 1784, the study of Asiatic literature has made great advances. The secret of the Sanscrit literature has been obtained from the Bramins, and its connexion with the Greek put beyond doubt. Works have been printed which greatly facilitate the study of the Arabian and Persian languages and literature. Asiatic philology has made great progress. Even Chinese literature has come forth from its recesses.-The société Asiatique, at Paris, was founded, in 182\%, by a number of learned men. It opened its sittings April 21, 1823, having already commenced, in $\mathrm{JuJy}, 1822$, the publication of the Journal Asiatigne, ou Recueil de Mémoires, d'Extraits et de Notices relatifs à l'Histoire, d̀ la Philosophie, aux Sciences, à la Littérature et aux Langues des Peuples Orientaux. The $2 \mathrm{~d}$ rol. appeared in 1823. The museum connected with it was established in 1823. The principal members, who are, at the same time, editors of the journal, are Chézy, Cocquebert, de Montbret, Degérando, Faurieł, Grangeret, de Lagrange, Hase, Klaproth, Abel Remusat, Saint Martin, Silvestre de Sacy. In the Asiatic societies at Paris and London, professorships of the Oriental languages are wanting, which are connected with the society at Petersburg. London is particularly deficient in this respect, the professors being confined to $O x$ ford and Cainbridge. In Paris, lectures are given on the Arabian, Persian, Turkish, Sanscrit, Chiuese, and Tartar languages, in the college royul, and in the royal library.

AsLaN, or AsLasi; in commerce, a name given to the Dutch dollar, in most parts of the Levant. Sometimes the word is written asselani. It is of Turkish origin, signifying a lion, the figure stamped on these dollars. It is silver, but much alloyed, and is current for 115 to 120 aspers. See Asper.

Asmansenadsen, wine of. The plant which yields this wine grows on the Rhine, below Rudesheim, a rillage on the banks of that river, on a soil formed of blue slate. The red kind, the production of a small, red, Burgundy vine, is the more valuable. Its colour is peculiar. In some places, an awme (a seventh of an English tun) of the best often costs from 120 to 160 florins. It retains its value only three or four years. After this time, it grows worse every year, and precipitates the whole of its red colouring-matter. Many delicate judges of wine prefer the red sort to the best Burgundy. It is distinguished by colour and taste from all the other Rhenish wines. We know of instances in which it has borne transportation across the Atlantic.
Asmon.11; acconling to Hebrew unythology, an evil spirit which sle'w seven lusbands of Sara, daughter of Raguel, at Rages. By the direction of the angel Raphael, the young Tobias drove him away, with the smell of a fish's liver burned on the coals, into the uttermost parts of Egypt, where the angel bound him.-Asmoulai siguifies a desolator, a destroying angel; it is also written Abaddon.

Asores; the name of several rivers in Greece. The most celebrated of this naure are those in Achaia and Bcotia. See Egina.

Asp, Aspic ; a species of viper found in Egypt, resembling the cobra da capcllo, or spectacle serpe'nt of the Fast Indies, except that the neck of the asp is not so capable of expansion, and its colour is greenish, mingled with brown. The asp is the coluber haje, L., vipera haje, Geoff.--This venomons serpent is found in the vicinity of the Nile, and has been cele. brated for ages, on account of the quick and easy death resulting from its bite. When approached or disturbed, this viper, like the cobra ela capello, elevates its head and body to a considerable degree, extends the sides of its neck, and appears to stand erect to attack the aggressor. This peculiarity gave origin to the ancient Egyptian superstition, that the asps were guardians of the spots they inhabited, and led to the adoption of the figure of this reptile as an emblem of the protecting genius of the world. Hence, on the portals of Egyptian temples, it is common to see, carved on eacli side of the globe, one of these serpents, in the attitude above described. The sume device is also found among the paintingson the coffins of mummies, which also contain representations of the asp in various relations to other hieroglyphics.The circumstauce originating the preceding notion has led to the employment of the asp as a daucing serpent by the African jugnlers, either for exlibitiou as a source of profit, or to impose upon vilgar credulity. The asps for this purpose are carefully deprived of their fangs, which enables their owners to handle them with impunity. When they are to be exhibited, the top of their cage, commonly a wicker-basket, is taken off, and, at the same moment, a fiute or pipe is played. The asp immediately assumes the erect position, and the balancing motions, made during its protracted efforts to maintain this attitude, are what is called dancing. A really curious circumstance is stated, on good authority, relative to the asp, which is, that the jugglers know how to throw it into a sort of catalepsy, in which condition the muscles are rigidly contracted, and the whole animal becomes stiff and motionless. This is done by compressing the cervical spine between the finger and thumb. The trick is called changing the serpent into a rad or stick. In the relation given by Moses of the miracles performed before Pharaoh, to induce him to allow of the departure of the Israelites, we read, that "Aaron cast down his rod before Pharaoh and his servants, and it became a serpent. Then Pharaoh called also the wise men and the sorcerers: now the magicians of Egypt, they also did in like manner with their en. chantments : for they cast down every man his rod, and they became serpents: but Aaron's rod swallowed up their rods." Exod. vii. 10, 11, 12. It is possihle, that, to keep up their credit with Pharaok, by appearing to possess equal power with Aaron, the Egyptian jugglers held asps in their hands, in the cataleptic condition above described, as rods, which only required to be thrown down to resume their activity as serpents. The superiority of the real miracle of Aaron's transformed rod over this pretended one of the jugglers, is shown by the swallowing up of the other serpents.-The asp has also acquired a great degree of notoriety in consequence 
of the use made of it by Cleopatra, the queen of Egypt, equally famous for the brilliancy of her charms and the licentiousness of her life. In his Life of Mark Antony, Plutarch makes the following statement, which shows to what an extent a vicious course of living had corrupted a noble and talented womian:-"Antony and Cleopatra had before established a society, called the inimitable livers, of which they were members; but they now instituted another, by no means inferior in splendour or luxury, called the companions in death. Their friends were admitted into this, and the time passed in mutual treats and diversions. Cleopatri, at the same time, was making a collection of poisonous drugs, and, being desirous to know which was least painful in the operation, she tried them on the capital convicts. Such poisons as were quick in their operations, she found to be attended with violent pain and convulsions ; such as were milder were slow in their effects. She therefore applied herself to the examination of venomous creatures, and caused different kinds of them to be applied to different persons, under her own inspection. These experiments sle repeated daily, and at length she found that the bite of the asp was the most eligible kind of death; for it brought on a gradual lethargy, in which the face was covered with a gentle sweat, and the senses sunk easily into stupefaction. Those who were thus affected showed the same uneasiness at being disturbed or awaked, that people do in the profoundest natural sleep." Langhorne's Plutarch.-It is not surprising that Cleopatra finally resorted to the asp to destroy her own life. This is stated very doubtfully by Plutarch, and is, by Brown, ranked among his popular errors; yet, as the Egyptian queen is known to have committed suicide, we cannot doubt, after what we have cited from Plutarch, that she resorted to the mode of dying which her own experiments had proved most easy. As two small punctures were found on her arm, quite adequate to produce the result, if made by an asp, we conclude, with Shakspeare, that it is

most probable

That so she died; for her physician tells me She hath pursued conclusions infinice

of easy ways to die. Antony and Cleopatra.

-Dreadful as the poison of the asp, and, indeed, of most of the vipers, is, it may be rendered entirely harmless by immediately applying forcible pressure on the side of the wound nearest the heart. In this way the cupping-glass, ligature, \&c. produce their beneficial effects, and not by the removal of the poison. For a most satisfactory establishment of this highly important fact, the scientific world is indebted to Caspar W. Pennock, M. D. of Philadelphia, whose experiments are published in the lst vol. of the American Journal of the Medical Sciences, where he has shown that simple pressure, however applied, sufficient to close the vessels on the side of the wound next the heart, prevents any poison, even that of the rattlesnake, from producing injurious consequences.

Asparagos. Asparagus officinalis is a well known plant, the young shoots of which are a favourite culinary vegetable. Few circumstances in the plienomena of vegetation are more renarkable than the gradual enlargement of size, and improvement of quatity, which have taken place in the cultivation of asparagus. It grows wild on the pebbly beach near Wermouth (England), and in the island of Anglesea; but its stem, in these situations, is not ustally thicker than a goose-quill, and its whole height does not exceed a few inches. whereas, in gardens, its stem is sometimes nearly three quarters of an inch thick, and its height, when at maturity, is four or five feet. Asparagus is one of the greatest delicacies which our kitchen gardens afford, and it is particularly valuable from the early season at which it is produced. It is usually raised from seed, in beds formed for the purpose; and the plants should remain three years in the ground before they are cut; after which, for several years, they will continue to afford a regular annual supply. During the winter, they are secured from the effects of frost by the beds being covered some inches thick with straw or litter. In the cutting of asparagus, the knife is passed three or four inches beneath the ground. The plants are cut by sloping the blade upward; and the white part that we see is that which had not previously been exposed to the air. The smallest plants are suffered to grow, for the purpose of producing berries to restock the beds, and keep them continually in a state of supply.

Aspasia, was born at Miletus, in Ionia. Her father's name was Axiochus. She seems to have followed the example of Thargelia, another beautiful woman of Ionia, who united a love for politics and leaming with all the graces of her sex. All foreign women, in Athens, were deprived of the benefits of the laws : their children were looked upon as illegitimate, even though they were the offspring of a lawful marriage. To this circumstance, it is in a great measure owing, that $A$. has been classed among courtesans. She devoted her attention to politics and eloquence. Plato mentions an elegant speech, which she delivered in praise of the Athenians who fell at Lechæum; and she is asserted to have instructed Pericles in eloquence. Her house was the general resort of the most virtuous, learned, and distinguished men in Greece, and Socrates often favoured her with his company: he was even accused of a sensual passion for her. She inspired the strongest and most enduring affection in the heart of the noble Pericles, who understood the grand secret of being, at the same time, the citizen and the ruler of a republic. The people used to call Pericles Olympian Jupiter, and his companion Aspasia Juno. The orator divorced his former wife to marry A. Plutarch relates, that he constantly evinced the liveliest attachment for her - a feeling which could never have been inspired by a low and corrupt courtesan. She is accused of having been the cause of two wars-one between the Athenians and Samians, on account of her native Miletus; the other between the Athenians and Lacedæmonians, on account of Megara. Plutarch acquits her of this charge, and Thucydides does not mention her name, though he relates the minutest circumstances which gave birth to the Peloponnesian war. The accusation alluded to is mentioned only by Aristophanes, whose historical correctness cannot be trusted. When the Athenians were dissatisfied with Pericles, instead of attacking him, they persecuted the objects of his particular tavour, and accused A., among others, of contempt of the gods. Pericles burst into tears, in the midst of the areopagus, while advocating her cause, and disarmed the severity of the judges. After his death, A., who had been the friend of Socrates, the companion of Pericles, and the object of Alcibiades' devoted adoration, is said to have attached herself to an obscure individual, of the name of Lysicles, whom she soon made, however, an influential citizen in Athens. It may be said, with safety, that $\mathbf{A}$. had an important infuence over the whole nation; for the nien who sat at the helm of government were formed in her society. Her name was so celebrated, that the younger Cyrus named his favourite, Milto, after her; for Aspasia signified the loveliest of women, as Alexander the bravest of heroes.

$\Lambda$ slect, in astrenomy and astrology, denotes the 
situation of the planets and stars with resuect to each odher. There are five different aspects:-1, sextile aspect, when the planets or stars are $60^{\circ}$ distant, and marked thus, $* ; 2$, the quartile or quadrate, when they are $90^{\circ}$ distant, narked $\square$; 3 , trine, when $120^{\circ}$ distant, marked $\triangle$; opposition, when $180^{\circ}$ distant, marked 8 ; and, 5 , conjunction, when both are in the sume degree, unarked 0 . Kepler added eight more It is to be observer, that these aspects, being first introduced by astrologers, were distinguished into benign, malignant, and indifferent; and Kiepler's definition of aspect, in consequence, is, "Aspect is the augle formed by the rays of two stars meeting on the earth, whereby their good or bad influence is mea sured."

Aspex. The aspen or trembling poplar (populus tremula), is a tree which grows in moist woods, has nearly circular leaves, toothed and angular at the edges, smooth on both sides, and attaclied to footstalks so long and slender as to be shaken by the slightest wind. There is scarcely any situation in which the aspen will not flourish; but it succeeds best where the soil is moist and gravelly. Its wood is light, porous, soft, and of a white colour, and, though inferior in excellenoe to that of the white poplar, is applicable to many useful purposes. It is used, particularly for field-gates, the frames of packsaddles, for milk-pails, clogs, and the wood of pattens. It is improper for bedsteads, as it is liable to be infested by bugs. In some countries, the bark of the young trees is made into torches.

ASPER, ASPRE, or ARsKTSHE; the smallest silver coin of Turker. The common asper, since 1764, has amounted to the 35 th part of a drachim of fine silver. Three make a para, 120 a piaster or dollar. The great or heary aspers, in which the court-officers receive their payment, are of double the value and weight of the common asper.

ASPERV and EssLINGEN; two villages lying east of Vienna, and on the opposite bank. They are celebrated for the battle fought, May 21 st and 22d, 1809, between the archduke Charles and the emperor $\mathrm{Na}$ poleon. After the fall of the capital, the Austrian general resolved to suffer a part of the enemy's forces to pass the Danube, and then to surround them with his own army, and drive them if possible into the river. Every thing seemed to favour this plan; but it was frustrated by the energy of the French general, and the extraordinary valour of his troops. The archduke had stationed himself behind Gerasdorf, between Bisamberg and Russbach, from which he issued with his army in five columus, consisting of 75,000 men, with 288 pieces of cannon, May 21 , at noon, just as Napoleon, with about half lis forces, had left the island of Lobau, in the Danube. By a dexterous evolution of his troops, he immediately formed a semi-circle, in which the French army was, in a manner,enclosed. In the narrow plain between Aspern and Esslingen (they are about two miles distant from one another), a bloody engagement now commenced. Every thing depended on the possession of these two villages: Aspern was, at first, taken by the Austrians, again lost and retaken, till they, at length, remained masters of it: from Esslingen they were continually repulsed. Napoleon repeatedly attempted to force the centre of the Austrians, but was frustrated by the firmness of their infantry. At last, the darkness of the night put a temporary stop to the contest. The bridge, connecting the right bank of the Danube with the island of Jobau, had already been destroyed, so that the French reinforcements came up slowly, being compelled to sail over in small parties, and the whole corps of Davoust, on the right bank, were idle spectators of the battle. Notwithstanding these disadvantages, the battle was renewed on the 221; the French army being now increased so as, at least, to equal the Austrians in number. 'The engagement was of the same exterminating cliaracter as on the day before; thousands of live's were sacrificed in vain attempts to capture the vil. lages. Aspern continued to be the strong-hold of the Austrians, and Esslingen of the Freuch. When the army of Napoleon gave up all hopes of gaining the victory by forcing the centre of the Austrians, Esslingen served to secure their retreat to the island of Lobau, which was disturbed ouly by the camnon of the archduke. It las been sail, that the archuluke did not make a proper use of lis advantage ; but this assertion will be shown to be erroneons, if we consider the position of the French on the island, the courage of his adversary, and the want of materials for rebuilding bridges. The loss of the Austrians, in killed, wounded, \&c., was estimated at less thau a third of the whole army; that of the French at half. The latter lost on this occasion, marshal Lannes.(q.v.) The feelings of the combatants were too violent to allow of many prisoners being made.

Asphaltitrs; a lake of Judea. See Dead Sea.

Aspulaltum. See Bitumen.

Aspuxxia (from $\propto$ privat., and $\sigma$ puğs, the pulse); the state of a living man, in whom no pulsation can be perceived. It begins with an inactivity of the lungs, which proceeds to the heart and brain. The person appears dead, without breath, pulsation, or feeling. It may be occasioned by different causes, either such as interrupt the mechanical motion of breathing, or such as disturb the action of the lungs themselves. The former may be caused by an external pressure on the breast, if air enters the thorax through wonnds, or by an accumulation of blood in the lungs, so that they cannot contract themselves the latter stage takes place if no air at all euters the lungs, as is the case with suffocated, drowned, or hanged persons, or if the air breathed in camnot support life. For the treatment of persons suffering from asphyxia, see Death, apparent.

Asplinwall, William, M. D, an American pliysician, was born in Brookline, Massacluusetts, 1743. IHe was descended from ancestars who came from Eug. land, about the year 1630 , with the 4000 emigrants. He was graduated at Harvard university, in 1764 . Immediately afterwards, he began the study of medicine, and completed his course at the hospital of Philadelphia, in the university of which city he received his medical degree about the year 1768 . He then returned to his native village, and commenced the exercise of his profession, being the first physician who settled in the place. When the revolutionary war broke out, he applied for a commission in the army ; but his friend and relation, doctor, afterwards major-general Warren, persuaded him to enter the service in a medical capacity. In consequence, Dr A. was appointed surgeon in general Heath's brigade, and, soon after, through the influence of general Warren, deputy director of the hospital on Jamaica plain, a few miles from Boston. He fought, in person, as a volunteer, in the battle of Lexington, and bore from the field the corpse of Isaac Gandner, whose eldest daughter he afterwards married. After the death of Dr Zabdiel Bolyston, the first inoculator of snallpox in America, Dr A. undertook the prosecution of that system, and erected hospitals for the purpose in Brookline. He perhaps inoculated more persons, and acquired greater skill and celebrity in treating this disease, than any other physician ever did in the United States. Besides his practice in this disorder when it was generally prevailing, he was permitted, after 1788 , to keepan hospital open at all times, to which great numbers resorted. When vaccine inoculation was first introduced, he was aware that, if 
it had the virtues ascribed to it, his pecuniary prospects would be essentially affected. But he deemed it his duty to give it a fair trial ; and, finding it suc. ceed, he promptly acknowledged its virtue, saying to Dr Waterlouse, who raised the first vaccine pustules ever seen in the new world, "This new. inoculation of yours is no sham. As a man of humanity, I rejoice in it ; although it will take from me a handsome annual income." As a physician, Dr A. obtained great distinction. To his practice, which was very extensive, he devoted himself, with unceasing ardour and ficlelity, for the space of 45 years, during the greater part of which time he rode on horseback, often upwards of $\mathbf{4 0}$ miles a day, and seldom retired to rest until after midnight. For some years before his death, he was afflicted with blindness, occasioned by a cataract in the eye, which had been brought on by reading and writing late at night. He bore this misfortune with resignation and tranquillity, and preserved, to the last, his curiosity about daily occurrences and public events. He died, April 16, 1823, of natural decay, having nearly completed his 80th year, with the calmness and composure of a Christian, whose duties he had always fulfilled.

Aspirate, or SPIRitus AsPER, in grammar ; an accent peculiar to the Greek language, marked thus ('), and importing that the letter over which it is placed ought to be strongly aspirated, that is, pronounced as if an $l b$ were prefixed.

Asrakl, in the Mohammedan mythology ; the angel who watches the souls of the dying.

Ass (equus asinus, L.). This well-known and raluable species of horse is a descendant of the onager, or wild ass, inhabiting the mountainous deserts of Tartary, \&c., and celebrated, in sacred and profane history, for the fiery activity of its disposition, and the fleetness of its course. But, in the state of degradation induced by rearing a succession of generations under the most debasing influences of slavery, the severest labour, combined with exposure to all the rigours of climate, and miserable fare, the ass has long since become proverbial for stolid indifference to suffering, while the insensibility induced by protracted ill usage has fixed upon the race the character of obstinacy and stupidity. - The ass is truly smaller in size, and wanting in that ardour and impetuosity which distinguish the horse, yet there are circumstances in which these differences give the ass a higher value. He requires a smaller quantity, and is content with a coarser quality, of food than the horse, and is therefore far better adapted for hilly and mountainous regions, where the horse is more difficult to feed, as well as less able to travel to advantage. In the choice of water he is, however, very nice; drinking only of that which is perfectly clear, and at brooks with which he is acquainted. In high and dry situations, over the most precipitous ruads, the ass moves with case and security, under a load which would render it almost impossible for a horse to advance with safety. In various parts of South America, asses are exceedingly serviceable in carrying ores, \&c., down steep mountains; and in the West India islands, they are of great value in carrying the sugar cane to the mills, from situations barely accessible to man, on account of the acclivity of the ground. - Washington was the first who introduced this useful animal into the United States; and his laudable example has since been imitated by a small number of agriculturists. Nevertheless, either from prejudice or neglect, the benefits derivable from a more general employment of this animal for draught and burden have not been attained. The best breed of asses is that originally dericed from the dry and hot regions of Asia; perliaps the best bred now in Europe is the Spanish, which was obtained through Arabia and Egypt, and long received a most careful attention in Spain. During the existence of the Spanish dominion in the southern portion of the American continent, this breed was generally introduced, and may be thence obtained at this time in considerable perfection. Those raised in Peru, where the breeding of the animal is carefully attended to, are very good. Very valuable asses are also exported from the island of Puerto Rico to the adjacent islands, where they are more useful in the cultivation of sugar than horses, as they consume much less provender, and as already stated, are better adapted to the work.-The male ass is in condition to propagate his species at two years of age ; the female still earlier; and both sexes manifest a sexual ardour which is really surprising, and sometimes destructive. It therefore becomes necessary to geld the males not intended to continue the race, and the uperation is performed in the same way as on horses. The regular season for the females is about the month of June, though many observe no regular period; in the latter case, however, they are less productive. The ass carries her young eleven months, and foals at the commencement of the 12th. The mare is again in condition to receive the male seven days after foaling, and may thus be almost constantly kept breeding, until too far adranced in life. It happens exceedingly seldom that more than one foal is brought forth at once: the mare exhibits great attachment to this while it is suckling: it becomes necessary to wean it at six months old, if the mare be again gravid. The teetl of the young ass follow the same order of appearance and renewal as those of the horse. The most general colour of the ass is a mouse-coloured gray, with a black or blackish stripe, extending along the spine to the tail, and crossed by a similar stripe over the fore-shoulders. Varieties of colour are observed in different breeds, though by no means to the same extent as among horses. In some places, dappled and pied asses are not uncommon, and pure white ones are also found. In proportion as the colour of the ass verges toward reddish-brown or bay, it is considered as an indication of bad disposition and inferior quality. As we cannot, for want of space, enter upon a more detailed history of this species, we may sum up the circumstances which entitle the ass to a greater degree of attention than it has hitherto received, by observing that it is gentle, strong, hardy, patient of toil, requiring but a small quantity of coarse food, sure-footed, and capable of a high degree of attachment to its owner. It is especially suited to the cultivation of light and dry soils, in hilly or mountainous districts, or in hot and dry climates, where the breed arrives at the highest perfection. The ass is in general much healthier than the horse, and not so subject to maladies. He requires less sleep than the horse, and never lies down except when extremely tired. He is seldom. troubled with vermin, probably from the hardness of his skin. The skin is at once hard and elastic, and is used as parchment, and for other purposes, such as to cover drums, \&c. It is of asses' skin that the orientals make shagreen. The disagreeable noise called braying, the voice of this species, is owing to the peculiar construction of the larynx. In the geldings, this ceases to be an inconvenience, as they attempt to bray but seldom, and always in a low key. Nothing is more certain than that, as this species las exceedingly deteriorated under a long continued ill usage, it might be improved to an equal degree by the same attention which is bestowed on the breeding of other domestic animals. The life of the ass does not exceed thirty years. Asses' nilk, long celelrated for its sanative qualities, more closely resembles that of the human female than any otler. It is very sinilar in taste, and throws uj an equally fuid cren, which is not convertible 
Into butter. Invalids suffering from debility of the digestive and assimilative functions make use of asses' milk with great advantage: persons in consunption also derive benefit from its use, as it is at once nutritive and mproductive of irritation while digesting. 'The ass, whose milk is taken for invulids, should liave fonled but a short time previously, and be secluded from the male. The quality of her food, and her comfortable stabling, should also be particularly attended to.-The mules produced between the he-ass and the mare are generally known; and they combine the gool qualities of both animals in a remarkable degree. In some countries, they are even more highly prized than horses, on nccount of their greater hardiness. The mule produced between the forse and the she-ass is a smaller animal than the cominon mule, and altogether inferior.

Assas, or Ashas ; a country between Bengal and Thibet, 700 miles in length, by about 70 in breadth. It is intersected by the Bramapootra, and several other rivers ; is very fertile; and, in the beds of the rivers, a cunsiderable quantity of gold is found. It also yields ivory, lac, pepper, silk, cotton, \&c. The inhabitants are genuine Hindoos. No European merchant is permitted to settle in this country without the previous permission of the East India Company $\rightarrow$ farour which was granted to it by the rajah, after laving been reinstated in his government by its assistance, in 1793.

Assas (Nicholas), cheralier d', was born at Vigan. He was commander of a French regiment at Auvergne, and by his patriotic death, made himself worthy of the admiration of posterity. On the night of the 15th of October, 1760, he commanded an outpost at Klusterkamp, in the neighbourhood of Gueldres, and, at break of day, went out to examine the posts. On this expedition, he fell in with a division of the enemy's troops, who were on the point of assaulting the French army. He was seized, and threatened with immediate death if he uttered a cry to alarm his regiment. The safety of the French furces was at stake. Without a moment's hesitation, he summoned all his strength, and exclained, "Onward, Auvergne ! here is the enemy !" The threat was imınediately executed, but the patriot had gained his object; the attack was unsuccessful. Assas was never married; but a pension of 1000 livres was decreed to his family forever : the payment was interrupted during the revolution, but has since been renewed.

Assassivs. See Ishmaelites.

Assault (lave) (assultus, from the Fr. assaillir); an attempt or offer, with force and violence, to do a corporeal hurt to another; as by striking at him, with or without a weapon. Assault does not always necessarily imply a hitting or blow; because, in trespass for assault and battery, a man may be found guilty of the assault, and acquitted of the battery. But every battery includes an assault. If a person in anger lift up or stretch forth his arm, and offer to strike another, or menace any one with any staff or weapon, it is an assault in law ; and if a man threaten tc beat another person, or lie in wait to do it, if the other is hindered in his business, and receive loss thereby, an action lies for the injury.-Any injury, however small, actually done to the person of a man, in an angry or revengeful, or rude or insolent manner, as by spitting in his face, or any way touching him in anger, or violently jostling him, is a battery in the eye of the law. To lay hands gently upon another, not in anger, is no foundation of an action of trespass and assault: the defendant may justify so doing in defence of his person or goods, or of his wife, father, 'mother, or master, or for the maintenance of justice.-If any officer, having a warrant against oมe who will not suffer himself to be arrested, beat or wound him in the atlempt to take him, lif may justify it : so if a parent, in a reasonable manner, chastise his child, or a master his servant, being actually in his service at that time, or a schoolnaster his scholar, or a jailer his prisoner, or even a husband his wife (for rensonable and proper cause); or if one confine a friend who is mad, and bind and beat him, \&c., in such a manuer as is proper in his circumstances; or if a man force a sword from one who offers to kill another, or beat one who makes an assault upon his person, or that of his wife, parent, child, or master; or if a man fight with or beat one who attempts to kill any strnnger, if the heating was actually necessary to obtain the good end proposed; in all these cases, it seems, the party may justify the assault and battery.

Assndut (military). See Siege.

Assay-Balance; a very delicate balance, employed in determining with great precision the weight of minute bodies. It is used for assaying metals. See Balance.

Assaying ; a species of chemical analysis, to ascertain the quantity of gold or silver in a metallic alloy. In its more extended meaning, it is used for the determination of the quantity of any metal whatsoever, in composition with any other netal or mineral. The assaying of gold or silver is divided into two operations; by one of which they are separated from the imperfect metals, or those easily oxydized; by the second they are separated from the metals which resist oxydation by simple exposure to the air, and which are, therefore, called the perfeet metals. This second process generally consists in separating gold and silver from each other, as the third perfect metal, platina, is lout seldom found united to them. The method of separating gold or silver from the other metals is founded on the facility with which the latter imbibe oxygen, and the process is calculated to accelerate this operation; hence the oxyde of lead, or litlurge, is gencrally considered as the most powerful purifier of the perfect metals, from the ease with which it parts with its oxygen to the imperfect metals united with them; but, of late, oxyde of manganese has been found superior to it, in several instances, for this purpose. In the chemical analysis of metals, the oxyde of lead is generally preferred for the above purpose ; but, in the assays performed by order of government, metallic lead is always used, probably from the facilities which it is supposed to afford for determining the weight of different ingredients by calculation. The lead in the process first becomes oxydated, then yields some of its oxygen to the other imperfect metals, and afterwards becomes vitrified, in conjunction with the other oxydes so formed, and carries them off with it, leaving the perfect metals pure. The above operation is called the cupellation, and is performed on a flat, round cake of bone-ashes, compressed within an iron ring, which is named a cupel: this is placed in a vessel called a muffe, which resembles a small oven, fixed in a furnace capable of giving a heat sufficient for the fusion of gold, so that its mouth may come in contact with the door, at the side of which it is luted, to separate it from the peal : there are small slits made in the sides of the muffle, to afford a passage for the air.

Asselyn, John ; a Dutch painter of the 17 th certtury. He was a pupil of Isaiah Vandervelde, and afterwards went to Rome. Settling at A insterdam, in 1645 , he obtained great reputation by the productions of his pencil, which consist principally of historical paintings, battle-pieces, and landscapes with ruins, and are distinguished for their adherence to rature and correct style of colouring. A set of his landscapes (twenty-four in number) has been engraved by Perelle. He died in 1650, aged about 40 . 
Assemanx, Simon; one of the most iearned Maronites of modern times, born Feb. 20, 1752, at Tripolis di Soria. He was educated in Rome, where lis family eujoys the rights of citizenship and patrician honours. In 1785, he was appointed professor at Padua, where he died, April 8, 1821. He began the series of his works with Museo Cufico Naniano (Venice, 1788, 2 vols. folio), an explanation of the Cufic Arabian antiquities in the palace of Nani at Venice. His Explanation of Arabian Monuments in Sicily, is highly esteemed, and equally so his Description of a Globus Coelestis, with Arabian letters, which was in the museum of the cardinal Borgia. Assemanai was a very laborious student till his death.

Assembly, Geveral ; the name of the supremeecclesiastical court in Scotland. In order properly to understand the constitution of this court, it will be necessary to take a view of the government of the Scottish kirk.-By the "Act for securing the Protestant Religion and Presbyterian Church Government," which is incorporated with the T'reaty of Union between England and Scotland, and declared to be a fundamental article and condition thereof, it is " provided and declared, that the true Protestant religion, contained in the Confession of Faith, with the form and purity of worship then in use within the church of Scotland, and its presbyterian church government and discipline, that is to say, the government of the church by kirk-sessions, presbyteries, provincial synods, and general assemblies, all established by the acts of parliament before referred to, pursuant to the Claim of Right, shall remain and continue unalterable; and that the said presbyterian government shall be the only government of the church within the kingdom of Scotland." Under this constitution, every parish has a Kirk-session, consisting of the parish minister or ministers and of so many elders, selected from the most respectable inhabitants of the parish, who are solemnly ordained to their office in presence of the congregation, according to established laws. The number of elders is not limited. It cannot be less than two to constitute a kirk-session, in the smallest parishes; and should, in general, be proportioned to the extent and population of each parish. When vacancies occur in the eldership, they are supplied by other respectable individuals, elected by the minister and elders who survive. If, when a vacancy occurs, the kirk-session does not then consist of three to make a quorum, the presbytery of the district has the power to appoint two or more of their own number, to be associated with the minister or ministers of the parish in filling up the vacancies, so as to restore the kirk-session to its legal functions. To the kirk-session is entrusted the ordinary management of the parochial poor, the application of the weekly collections, made at the church for their benefit, and of any voluntary donations which they receive in aid of the weekly collections. When these funds are not sufficient to provide for the poor, a joint meeting of the heritors and kirk-session is empowered, and required, by act of parliament, to assess the parish, in order to make up the deficiency; the onc-half of the assessment being raised from the landlords, and the other from the tenants. It should be mentioncd, at the same time, that the kirk-session is entitled to retain in their own hands the one-half of the collections made at the church, to defray the expense of the clerks and officers of the inferior ecclesiastical courts, and to meet the demands for occasional charities, not included in the ordinary management of the poor. It is not immaterial to mention these particulars, either as they bring to view a considerable department of parochial labour, or as they contain the substance of the Scottish laws relating to the poor. And it deserves to be added, that, though the latest of those laws is as old as the time of William and Mary, there was scarcely any regular assessment for the poor, which was continued for any length of time, in any parish of Scotland, before the year 1755 . As long as there was no secession of presbyterians from the established church, the weekly collections under the management of the kirk-sessions, were in general found sufficient for the maintenance of the poor. In some years of peculiar hardship or scarcity, such as the four last years of the seventeenth century, or the year 1740 , voluntary assistance was 110 doubt given, and in some instances temporary assessinents were resorted to, to enable the kirk-sessious to meet such unusual emergencies. But on all ordinary oc casions, the resources of the kirk-sessions were con 8 sidered as sufficient; and continued to be so, at least as late as 1755 . Besides the case of the poor, the kirk-session has a general inspection of the morals of the parishioners, and a right to administer the discipline of the church, according to established larvs. To the effect of ecclesiastical censures, it has the power to institute processes, to cite parties and witnesses, to examine witnesses on oath, and to pronounce sentences, and inflict censures, according to the evidence adduced. But both its citations and its sentences depend on ecclesiastical authority alone, and seldom either receive or require any assistance from the civil power. The proceedings of a kirk-session are matter of record; and the record is regularly kept, so as to be preserved or extracted for the bene. fit of the parlies, or for the information or the inspection of the courts of review. Every proceeding or sentence of a kirk-session is subject to the review of the presbytery of the district; and can be brought there, either by a reference made by the kirk-session itself, by a complaint at the instance of any member of the court who may be dissatisfied, or by an appeal from the parties who maythink themselves aggrieved. If any striking irregularity, or any real injury can be substantiated, the control of the presbytery is always sufficient to correct or redress it. But the usual management of the kirk-sessions is favourable to all the best interests of the parishioners; and comparatively few instances occur in which it becomes a just subject of either complaint or remonstrance.-The Presbytery is the court immediately above the kirk. session. A presbytery consists of the ministers of so many contiguous parishes, who are ex officio members, and of an elder from each kirk-session within the district, who, by the present usage, is elected at the end of every six months. The presbytery, besides being a court of review, to affirm, reverse, or alter the sentences of kirk-sessions, when regularly brought before it, or to direct or advise them with regard to any part of their proceedings, has a radical jurisdic. tion of its own, both ecclesiastical and civil. It has the immediate superintendence of the private conduct, as well as of the professional labours, of the clergy of the district, who are not amenable to the kirk-sessions. It has the power to admonish, to censure, and even to deprive them, according to the established laws, and upon evidence regularly taken. The induction of presentees to benefices belongs exclusively to presbyteries. All presentations to benefires must be directed to the presbyteries, in whom the original right is vested, to take trial of the qualifications of presentees, to give them induction if they are found qualified; and, if they want the necessary qualifications, to reject them. Besides this security against the introluction of unqualified men, no individual can be presented to a benefice till he has, in the first instance, been licensed to preach by a presbytery, after due trial of his qualifications. At the same time, the trial prescribed for a license does not supersede the secoud trial of qualifications required when 
the same individual is presentrd to a benefice. The trial and induction of schoolmasters is, in like manner, entrusted to the presbyteries; and there are many other subjects which fall uncler their cognizance, which it is not necessary to specify particularly. In general, their juristiction extends to every thing in which the edification of the anorals of the people, the conduct of their parochial instructors, or the cliscipline of the chureh, is concernetl. 'The sentences and proceedings of the presbytery, which, like the kirksession, is always a court of recort, are subject to the review of the immediate superior court, the synod, before which they can be brought (as those of the kirk-session befor the presbytery) by reference complaint, or appeal ; and there they niay be aftirned, reversed, or altered. The presbytery has besides a civil jurisdiction, in questions which relate to ecclesiastical benefices, to the designation or exchange of parochial glebe's, to the building or repairiug of churches or manses, (parsonage houses, and in a few other cases. But in all such civil questions, an appeal is competent from their decisions, in the form of a suspension or advocation, not to the superior ecclesiastical courts, lout to the court of session. The forms of proceeding in the presbytery are prescribed by statute, or are ascertained by use and precedent.-The Synod is the court of review immediately above the presbyter; and consists of all the ministers and elders who staind on the roll, as constituent members, of so many contignous presbyteries, which are placed under its provincial jurisliction. Its meeting are generally lield ticice, though in some remote districts only once, in every year. Fvery ecclesiastical question, which has been under the consideration of a presbytery, within the provincial district, may be competently brought under the review of the synod, in the manner alrtady explained, with regarl to the review of the sentences of kirk-sessions by the presbyteries. The synod has, besides, an original jurisdiction, as well on subjects of general interest, as with regard to the conduct of its own members, and cau both give authoritative directions to the presbyteries, and originate propositions to the general assembly, on any subject which seems to require its influence or authority. On the other hand, every judgment of a synod, as an inferior court, may be brought under the review of the general assembly by reference, complaint, or appeal. But in every question, not carried to the courts of review, the judgment of the presbytery or synod (if they have not gone beyond their jurisdiction) is final ; and it is as completely authoritative as the sentences of the supreme court.-The General Ass'mbly is the supreme ecclesiastical court. It conlsists of delegates from every presbytery, university, and royal burgh, in Scotland. It has the countenance of a representative of the king, styled the Lord High Commissioner, who is always a nobleman; and holding its meeting annually, and (according to the present practice) in the montli of May, it usually continues tu sit for twelve days. In its judicial capacity, as a court of review, and as the court of last resort, the general assembly has a right to determine finally every question brought from the inferior courts, by reference, complaint, or appeal. And it possesses, besieles, such a general superintendence of the discipline of the church, of the management of the inferior courts, of the conduct of the clergy, and of the morals of the people, that it has authority to go beyond the record in any particular case; to redress a wrong which appears to have been done, or to apply the church discipline, which has either been neglected by the inferior courts, or which the circumstances of the case appear to require. But to do this regularly, the parties interested must be legally citerl, if they were not before at the bar. In these general views of its judicative capacity, the anthority vested in the genernl assembly, is of equal importance to the prosperity of the kingdom, to the permanen interests of religion, and to the usefulness and respectability of the clergy. The legislative authority of the general assembly has as extensive effects as its julicial functions. It has the power of enacting statutes, with regard to every subject of ecclesiasticil cogniz ance ; which are equally binding, as pernnane'ut laws, on the assembly itself, on the inferior courts, and on the individual nembers of the church. But the power of legislation is not committed to the general assembly, without limitation. J3y an act of assembly in 1697 , (which was not passed into a law, till it haco been transmitted to the several preshyteries, ant had received their sanction, and which, from its substance and design, las obtained the name of the liarrier $\mathrm{Act}$, every proposition for a new law, must first be considered in the form of an overture, either originnting in the assembly itself, or suggested to the assembly by the inferior judicntures. 'Though it slould be approved of by the assembly, it caunot be enacted into a statute, till it has been first transmitted to the several presbyteries of the church, for their consideration, and has received the sanction of, at least, a majority of the presbyteries. The laws which are enacted by the assembly, after receiving this sanction, are the established and permanent statutes of the church, by which every thing belonging to the ecclesiastical state, or to the church courts, is authoritatively regulated. See Scotland, Church of.

Assevt, tue Royal, is the approbation given by the king in parliament to a bill which lias passed both houses; after which it hecomes a law. The royal assent may be given in two ways :-1. In person; when the king comes to the house of peers, and, the commons being sent for, and stauding at the bar, the titles of all the bills that have passed both houses are read, and the king's auswer is declared by the clerk of the parliament in NormanFrench, with several singular ceremonies. If the king consents to a public bill, the clerk usually declares Le roi le veut (The king wills it) ; if to a private bill, Soit fait comme il est desiré (Be it as desired). If the king refuses his assent, it is in the gentle phrase, Le roi s'avisera (The king will consider of it). When a money-bill, or bill of supply, is passed, it is carried up and presented to the king by the speaker of the liouse of commons, and the royal assent is thus expressed-Le roi remercie ses loyal sujets, accepte leur benevolence, et aussi le veut The king thanks his loyal suhjects, accepts their benevolence, and wills it alsu). 2. By the statute 33 Hen. VII , ch. 21, the king may give his assent by letters patent, under his great seal, signed with his hand, and notified in his absence to both loouses, assembled together in the upper house.-When the president of the United States approves a bill passed in both louses, he writes under it Approved, with his name. See Sanction.

Asser, John, or Asserius Menevensis, that is, Asser of St David's ; a learned British ecclesiastic, distinguished as the instructor, companion, and biographer of Alfred the Great. He was appointed abbot by Alfred of two or three different monasteries, and at last promoted to the episcopal see of Sherburn, where he died in the year 910 . He wrote the life of Alfred, which was first published at the end of Parker's edition of Walsingham's History, London, 1574. and afterwards in Camden's Historical Collection, at Frankfort. A separate edition was published at Oxford in 1722.

Assessor, in Scottish law ; a person who sits along with the judges in the inferior courts in Scutland, and with his professional knowledge assists in the 
decisious pronounced. Assessors are generally selected fiom the Faculty of Advocates.

Assers (Fr. assez, i. e. satis). Goods enough to discharge the burden which is cast upon the executor or heir, by satisfying the debts and legacies of the testator or ancestor.-Assets are real or personal. Where a man holds lands in fee-simple, and dies possessed thereof, the lands which come to his heirs are assets real; and when he dies possessed of any personal estate, the goods which come to the executors are assets personal.

Assizito (Spanish, for treaty); the permission of the Spanish governnient to a foreign nation to import negro slaves from Africa into the Spanish colonies in America, for a limited time, on payment of certain duties. Philip IV. and Charles II. concluded a treaty of this sort with the people of England and Holland. The English were the sole possessors of this assiento till 1701. They lost it when Philip V. of Anjou ascended the throne of Spain ; but, in 1702, the French Guinea company, who afterwards assumed the title of the assiento company, became possessed of this privilege for ten years, within which period they were permitted to import yearly 4800 slaves, of both sexes, into the mainland and islands of Spanish America. In 1713, the celebrated assiento treaty with Britain, for thirty rears, was concluded at Utrechit; (Great Britain afterwards gave up the trade to the South sea company). By this contract, the British, among other privileges, obtained the right of sending a permission or assiento ship, so called, of 500 tons, every year, with all sorts of merchandise, to the Spanish colonies. This led to frequent abuses and contraband trade; acts of violence followed, and, in 1739, a war broke out between the two powers. At the peace of Aix-la-Chapelle, in 1748, four years more were granted to the British; but in the treaty of Madrid, two years later, 100,000 pounds sterling were promised for the relinquishment of the two remaining years; and the contract was annulled.

Assignat; the name of the national paper currency in the time of the French revolution. Four hundred millions of this paper money were first struck off by the constituent assembly, with the approbation of the king, April 19, 17.90, to be redeemed with the proceeds of the sale of the confiscated goods of the church. August 27th of the same year, Mirabeau urged the issuing of 2000 millions of new assignats, which caused a dispute in the assembly. Vergasse and Dupont particularly distinguished themselves as the opponents of Mirabeau. They saw that the plan was an invention of Clavière (of whose work the speech of Mirabeau was only an extract), to enrich himself and his adherents; that it would tend to put the rich usurers in possession of the wealth of the nation, which would be insufficient to redeem the assignats, particularly if they were increased. Among other argunents, Mirabeau maintained the expediency of the measure he proposed, on the ground that the holders of assignats would necessarily support the new constitution, which was the only guarantee for the redemption of the assignats. His exertions were seconded by Pethion, and 800 millions more were issued. They were increased, by degrees, to 40,000 millions, and the currency, after a while, became of no value. A further account of this paper money is given in the article Mandate.

Assignation; a Russian paper money, used since 1769. Its loss of value, since 1787, has diminished the worth of rubles. Regularly, under the term ruble, is understood assignation-muble. There are assignations of $5,10,25,50$, and 100 rubles. In 1809 , four rubles-assignation were paid for one ruble silver money. The value fluctuated till 1818 , when the silver ruble was fixed at 375 kopecks; in 1825, it stood at 372 kopecks.

AssigneE; a person appointed by another to transact some business, or exercise some particular privi lege or power. The term is most commonly applied to the creditor of a bankrupt appointed to nianage for the rest of the creditors, and who has the bankrupt's estate assigned over to him.

Assiniborn ; a large river of North America, in the United States and the British territories. It flows into the south end of lake Winnipeg. It is formed by two rivers, which unite about fifty miles from the lake. The eastern branch, called Red river, rises near the liead waters of the Mississippi. The western branch, the Assiniboin proper, rises about lon. $104^{\circ} \mathrm{W}$., lat. $52^{\circ} \mathrm{N}$. Both are navigable for canoes to their source. The country between these rivers, and to the south, is a continued plain, with little wood; the soil, sand, and gravel producing a short grass. The north-west company have several trading establishments on the $A$.

Assinibolss; an Indian tribe, in the western part of N. America, on the Assiniboin river near the Rocky mountains. Their number is said to be 4200 . Assint; an extensive parish in Sutherlandshire, Scotland, situated on the Minsh Channel in the Nortl Sea, having two or three good harbours, and including a number of islands. The coast presents a succession of high and broken precipices, while the surface, equally romantic, exhibits a wild confusion of lofty mountains, masses of barren rock, heaths, mosses. lakes, and rivers, with here and there a cairn or Druidical temple to complete the scene. Here are quarries of beautiful white marble and limestone, which, with rearing cattle and fishing afford employment to the inhabitants, who are all connected by alliance. Songs in praise of Fingal and his heroes are still chaunted here in the Gaelic tongue, to the airs of which children are early taught to dance. This district was formerly a forest of the ancient Thanes of Sutherland. Population, s161.

Assisı; a small town in the papal dominions, 20 miles from Spoleto, on a hill, in one of the most charming parts of Italy. It is the see of a bishop. It is famous as the birtli-place of St Francis d'Assisi, and for the splendid church built over the cliapel where St Francis received his first impulse to devotion. This church is one of the finest remains of the architecture of the iniddle ages in the Gothic style.

Assizes; I., the name given in France and in Lower or Norman Italy, to assemblies which were common in the middle ages, and to the courts for the administration of justice to vassals and freemen. After Godfrey of Boulogne had taken Jerusalem, in 1099, lie adopted, for his two courts of justice, a code of laws drawn from the ordinances established in these assemblies : hence this remarkable collection was styled Assises de Jérusalem (French edition by La Thoumassiére, Bourges, 1690, folio. See Bernardi's Hist. des Droite Franc., 1816)-11. In the law of Scotland, Assize signifies a jury of fiften sworn men, picked out loy the court from a greater number, not exceeding fortyfive, who have been summoned by the sheriff for that purpose; a list of whom is given to the defender, when a copy of the libel is served upon him.-III. In England, the term is used to signify the sessions of the courts, held annually, in every county, by the judges. In disputes concerning property, Henry II. gave the contending parties the right of deciding their difference by a trial before the grand court of assizes, or by combat. The granl court of assizes cousisted of all the knights in the county; the inf (2rior court of assizes, which decided questions relating to possession, of twelve freemen. From these the jury took its rise. Twelve julges, who are members of $20-2 \mathrm{R}$ 
the thrie lighest courts in. Fnglaul, -the king's bench, the court of common pleas, and the court of excliequer,-thrice in every year, perform a circuit into ull the counties (being 40) into which the kingdom is dividerl, to holl these assizes, with the exception of the four uorlieru connties, where they are lichl ouly "nce a year, and I.ondon and Middlesex, where they "ro held eight times. (Bl. Comm. iv. 269.) Eight uther judges, appointed for the purpose, who are call(d Welsh judges, do the sune duty for Wales. At these assizes, all the justices of the peace of the county are lound to attend, or else are liable to a fine; and 2. Iso all the persons who have been summoned as grand jurynen or petit jurymen by the sheriff. Upon these vectsions, the court is opened with consicterable pnmp. The judges are conducted to their seats at Lne tolling of a public bell, and divine service is per lormel in their prese uce. The presiding judge clirects the court to be opened, and, when the grand jury is duly imuannelled and sworm, which is generally comjmitul of the nost respectable men of the county, he mikes a public aldress to them respecting the duties of their office, and the crimes which are to come hefore them for consideration. At these assizes, the julges sit under five separate commissions, some of which relate to civil and some to criminal causes or business. The first is the commission of assize, from which the sescion derives its name, by which they are anthorized to take assizes in the several counties; that is, to take the verdict of a peculiar sort of jury called an assize, and summoned to de ride certain cases respecting the titles to land. This class of causes is now obsolete, the trial of such land titles being now had in other and more modern forms of action. 2. The commission of nisi prius as it is called, which empowers them to try all questions or issues of fact, issuing out of the courts in Westmillster tall and which must be tried by a jury from that county wherein the cause of action arises. These issues are, strictly, triable in the courts at Westminster, by a jury returned there from the county. But there is a proviso, nisi prius, "unless, before" the term assigned for trial at Westminster, the judges of assize come (as they were sure to $\mathrm{do}$ ) into the county in question, and then the commission authorizes such trial by the judges of assize. (Bl. Comm. iii. 60.) These commissions are of a civil nature; but the judges of assize have also, by virtue of several statutes, a criminal jurisdiction in certain special cases. 3 . The commission of oyer and terminer, to hear and determine all treasons, felonies, and misdemeanours committed within the county. By virtue of this com. mission, they can proceed only upon an indictment found at the same assizes by the grand jury. 4. On this account, they have another commission, of general jail delivery, which empowers them to try and fleliver every prisoner, who shall be in jail when the judges arrive at the circuit town, whenever or before whomsoever indicted, or for whatever crime committed. (Bl. Comm. iv. 270.) 5. The commission of the peace, by which they are empowered to do all things necessary or proper, according to the English laws, to preserve public tranquillity, to suppress crimes, and to arrest offenders. (Bl. Comm. i. 350, 351.) In this manner, and by these means, the jails are, in general, cleared, and offenders tried and convicted, or acquitted, at least every half year. In America, there are no courts, or sessions of courts, which are technically called assizes. The judges, however, perform the same duties in the counties, within their respective circuits and jurisdictions, as the Einglish judges, and, generally, in the same manner, that is to say, according to the course of the common law. The American judges have not, like the English, any special r:mmissins Their commission is single, and ap- points them to the office. But the general and. public laws nnark ont and define their duties and nut:orities, whether general or special, and these dutirs and authoritie's are genfrally subject to be altered anul clinnged by the legislative authority. In general, however, the duties and anthorities of the judges of the lighler courts are very similar to those of the judges in lingland. The mauner of proceeding, $p x-$ cept thut it is more simple and unostentatious, resembles very much that of the Finglish curts. Matters ot fact, in criminal cases, are tried by a jury, upon sul indictment found by a grand jury. And in civil cases, also, matters of fact, in connon law suits, are trieit in the same manner. The sessious of the courts are usually called terms, and, generally speaking, the causes are tried before the courts of the county in which they are commenced, without liaving been sent there by a recond from a court sitting in another county.-Since 1808, there have been assize courts in the judicial system in France. Writh the Fuglish institutions, however, they have scarcely any thing in common but the name. The administration of the penal laws belongs to the worst part of the ancient constitution. It united the two opposite evils of torture, which is often applied only to make the punishment of death more severe, and of capital punishment, inflicted upon suspicion. The higher and lower courts of France were distinguished from those of every other country by a spirit of dark and thoughtless cruelty, of which the 18 th century presents a series of the most shocking instances. One of the first lalunurs of the constitutional governuc'nt, in the revolution, was a reform of this part ot the constitution. Tlre British institutions, particularly that of trial by jury, were taken for precedents. The administration of justice, in civil causes, was committed to circuit courts and courts of appeal (on the abolition of the aucient institutions); and, for the disuosal of criminal cases, a law was enacted, Feb. 25, 1791, establishing, in every department, a criminal court, which consisterl of a president and three other judges. No one of these officers was appointed by the executive government, but an attorney of the crowu was attached to every court. The president and the public prosecutor were cliosen by the electors of the department, and the members of the district courts performed, in succession, the duties of julges. This system remained substantially the same till the introduction of the consular government : the right of appointing these officers was then transferred to the first consul. $\mathrm{By}$ the constitution of the criminal courts, allopted in 1808 (Code d'Instruction Criminelle), permanent criminal courts were again abolished, and the administration of the penal laws was committed to the courts of appeal, who are to decide upon the propriety of having a trial in any given case. The public hearing and decision are referred to a special court (cour's d'assises) and a jury. This latter tribunal is to consist of a judge of the high court, who shall act as president, and the four senior members of the district or county court (a court of original jurisdiction), in whose precinct the cause originated. Inferior violations of the police regulations are tried before the mayors (maires) and the justices of the peace, and those involving some penal law, before the district courts. The process, in the French assizes, is as follows :-Every French tribunal of original jurisdiction has a juge d'instruction, so called. It is his business to examine into the circumstances of every crime of which he is informed by the state advocate (see $\mathrm{Al}$ vacate of the (rown), the police officers, or private individuals. He traces out the act and the perpetra tor amid every winding, summons witnesses, examin es documents, brings forward and records the testimony. Finally, he refers the cause, verbally, to the tribunal 
which has original cugnizance of it, in private session (en chambre de conseil). If facts and circunstances satisfy this tribunal that the accused is innocent, or, from the nature of the case, that proof of guilt is not to be expected, he is acquitted. If the offence alleged against him is found to be not of the highest class, crinies, but of an inferior kind, delits, which are defincd to be infractions d'un ordre inferieur punies seulement de peines correctionnelles ou de police, it is referred to the tribunaux correctionnelles; if it be a nipre infringement of the rules established for the sake of good order, contravention, it falls within the jurisdiction of the common police authorities. If the previous examination raises a probability of the guil t of the accused, the whole cause is referred, in the case of a crime, technically so called, with an explanatory report, to the high court (cour royale). 'This body deliberates on the subject (en chambre de conseil), and hears the arguments of the attorney-general, and, if the act alleged is found to be criminal, and capable of being proved, a formal accusation is drawn up, and the culprit sulyjected to a special trial, to fix the degree of his guilt (arrét des renvois aux assises.) The courts for the trial of criminal cases hold their sessions, in each department, at least once every three months, and dispose of all cases which have accumulated during the vacation. The institution of a jury rests upon the liberal principle, that no individual servant of the state can lawfully have power over the life and death of a citizen; and that a power so important ought rather to be committed to a num. ber of well-qualified men, chosen from the midst of the nation, who shall return, at the close of the session, to the same rank which they held before. Four days, at least, before the opening of the assizes, the prefect communicates to the president of the assizes a list of sixty persons in the department, who are eligible to the office of jurymen. Every juryman is required to be at least thirty years of age, and enjoy all the rights and privileges of a citizen : it is also required, that he should be a member of the college electorale, or one of the 300 inhabitants in the county who pay the highest taxes; a doctor, licentiate, or corresponding member of some literary society, recognized by the government; a notary or a liceused banker, an exchange broker, a merchant or trader of the first or second class, an officer of the civil service, with an income of, at least, 4000 francs per annum ; or he must have a special qualification. Ministers of government, prefects, sub-prefects, judges, stateattorneys, and clergymen, and every one who has before been engaged officially or privately in the criminal cause, are wholly excluded from this number. 'The president of the assizes, before mentioned, hy virtue of his pouvoir discrétionnaire (discretionary power), selects twenty-four persons from this list of sixty. He obtains likewise, a list of all eligible persous in the place where the assizes hold their session, tlat, in case the thirty-six remaining jurymen should be prevented from attending, so many may be added, that, at least, thirty may be present at the sessions. 'The state's attorney theu appenrs before the assizes as an accuser in behalf of the public, and the accused with his advocate : the accused is previously furnished, in writing, with his accusation, the day of trial, a copy of the documents to be used, and the names of the witnesses and jury. Both the attorney-general and the accused have a right to reject some of the jury, and twelve are cliosen by lot out of those that remain. After they are chosen, they take their seats upon a sort of stage, and the doors are thrown open, that their proceedings may be subject to public scrutiny. The president now administers the oath to the twelve jurymen: then the accusation and the accompanying docments, including the observations col- lected on the spot where the offence was committed, are read. The attorney for the government sets forthi the essential points in the accusation, which are investigated with reference to the attendent circumstances, and the corpora delicti. The evidence on both sides is then read from the record of the former trial, but the question of guilt or innocence is determined by the oral testimony given in at the time. Moreover, the rest of the judges present, the jury, the state's attorney, the accused and his adrocate, also the party who complains of the injury, have full liberty to propose further questions to the witnesses. When the examination is concluded, the state's at torney, the complainant and the adrocate, and, if he wishes it, the accused, speak, in succession, upon the question at issue, usually twice each. The witnesses are often questioned anew in regard to any doubtful expressions, and, if every thing necessary for the sentence is accomplished during the session, the presitent, at the same session, declares the process finished. The presiding officer then briefly suns up the evidencc on both sides, and gives the jurymen a written copy of the points to be decided. Upon this, they retire to confer, and, on their return, declare publicly the result of their deliberations. If only seven out of the twelve jurymen bring the accused in guilty, the judges take up the question, and, if the majority of the judges coincide with the minority of the jury, the accused is acquitted. If all the judges are in favour of his acquittal, and the whole or more than seven of the jury are in favour of his condemnation, the cause is deferred till the next session, at which it is finally decided. If the majority of the jury are for the acquittal of the accused, the president orders him to be set at liberty, uuless some other accusation demands his further detention. If the accused is brought in guilty, a new question arises, relating to the punisliment proper to be inflicted, or the satisfaction to be made to the party injured. Upon this the julges agree among themselves, and then assign the grounds of their decision. Against this sentence no appeal can be made, except to the court of cassation. (q. v.) This court receives the petition of the appellant as well founded, if a want of substantial validity, or an error in form, is pointed out, or if the sentence has manifestly been passed in violation of some existing law ; and they refer the cause, for decision, to another court ot assizes.

Assonance, in rhetoric and poetry; a term used when the words of a phrase or verse have the same sound or termination, and yet make no proper rhyme. This is usually a fault in English : the Romans sometimes used it with elegance. The Latins call this similiter desinens; the Greeks, iposors $\lambda$ surov.

Assonant Rhymes is a term particularly applied to a kind of verses, common among the Spaniards, where the vowels only are required to rhyme; as, ligera, cubierta, tierra, mesa, may answer each other in a kind of assonant rhyme.

$\Lambda$ ssumpsit, in English law, is an action to recover a compensation in damages for the non-performance of a parole promise; that is, a promise, whether verbal or written, not contained in a deed under seal. For breach of a promise of the latter kind, assumpsit will not lie ; but the proper remedy is by action of covenant or debt. The word assumpsit (Latin) means he undertook, and has been taken as the name of this action, from its occurrence in declarations; i.e., fornal statements of the plaintiff's cause of action, when these were in Latin. The common law adopts the maxim, that a mere nude agreement and undertaking, witlout any quid pro quo, will not constitute a binding contraci. This maxim is coinmonly said to have been horrowid from the civil law, where we furl it laid down. lliat

$$
2 !-82
$$


ex nudo preto non ovitur actio: but this seems rather (1) have referred to agreements, without certain formalities. (See Fonblanque On Equity, i. p. 326.) Whut our law requires, in orler to sustain a promise, is terned a consideration; and it must be cither a benefit to the party promising, or to some third person, in whom he takes an interest; or cletriment sustained by the party to whom the promise is made, at the request of the party making it. Tho degree of benefit or detriment, or its relative proportion to the thing promised, is immaterial. A promise in remuneration of an act which the party is bound to perform, as a promise to a sailor of extm pay for extmonlinary exertion in extreme peril of the ship, is void. The law regards such exertion as the sailor's previous duty; the consideration, therefore, for the promise, fails. Assunusits are of two kinds, express and implied; the former are where the contracts are actually made, in word or writing; the latter are such as the law implies from the justice of the case ; as; for instance, if I employ an artificer to do any work for nie, the obvious justice of $\mathrm{my}$ paying him a reasomble sum for that work, when done, raises an implication in the understanding of the law, of a promise on my part to pay lim.

Assumirion; a city in Paraguay. See Asuncion.

Assumprion is the festival by which the Roman and Greek Catholic churches celebrate the miraculous ascent of the Virgin, on the 15th of August. One of Raphael's earlier pictures represents the empty coffin in which, according to the Catholic tradition, flowers were found after Mary had ascended to heaven. The picture is now in the Vatican.

Assurancr. See Insurance.

Assorance, in theology, is the firm persuasion of possessing a personal or actual interest in the divine favour. Some theologiaus maintain that assurance is included in the very essence of faith, so that a man cannot have faith withont assurance; and this doctrine has occasioned, especially of late years, considerable disunion in the church of Scotland. The realer will find the subject treated in Saurin's sermons, vol. iii. sermon 10th, English edition; Case's sermons, sermon 13th; Lambert's sermon on Joln ix. 35 ; Harvey's 'Theron and Aspasio, dialogue 17 ; Howe's Works, vol. i. pp. 342-48; Brooks, Burgess, Roberts, Baxter, Polhill, and Davy on Assurance; Wardlaw's Essays on Assurance and Pardon; Modern Fanaticism Unveiled, \&c.

AssYкIA ; a kingdom of Asia, formerly of great celebrity. Its limits were different at different times. $\mathbf{A}$, originally, was bounded on the $\mathbf{N}$. by mount $\mathrm{Ni}-$ plates and $\Lambda$ rmenia the Greater; on the IV. by Mesopotamia; on the S. by Susiana; and on the E. by Media. Ashur is said to have founded it. Its most famous monarchs are Ninus (q. v.) and his widow and successor, Semiramis. Ninus subdued the Babylouian, the Median, and several other kingdoms, and united them to his own. In the time of Sardanapalus (about 900 years before the Christian era, or, according to Volney, 717), Arbaces, governor of Media, made himself master of the kingdom of $A$. Herodotus, whose correctness has been proved by Volney, fixes the duration of the Assyrian empire in Upper Asia at 520 years. It was then divided into three kingdoms-the Median, Assyrian, and Babylonian,-the principal part of which was before included in the $\Lambda$ ssyrian. Soon after, $A$. rose àgain to a resemblance of its former splendour, while Media and Babylon again yielded to its superiority. Salmanassar was then the sovereign of the empire, and Niwereh the capital. About 700 B. C.. Media again revolud. Cyaxares, the king of Media, afterwards forming an alliance with Nabopolassar, governor of Babylon, they marched against Ninevel, and destroyed it; B. C. 606. A. now became a province of Melia; and Babylon, by the victories of Nebuchadnezzir, was made a powerful kingdom, B. C. 600. About 550 years before the Christian era, the three kinglons were united by the victorious Cyrus (q. v.) of 1'ersia.

AstaRtF; a Syrian gocldess, probably corresponling to the Semcle of the Greeks and the Asturath of the Hchrews. Aceording to Iucian, she lad a very ancient tenuple in Phouicia. Some also believs her to be the same with Here (the Juno of the Romans), and others with Aphrodice.

AstFul, Mary, an Euglish antloress, was born at Newcastle-upon-Tyne in 1668. At the age of 20 she removed to I.ondon, where she spent the remainder of her life, and died in 1731. Iler first work was entitled, "A Serious Proposal to the Ladies," 1697 , 1\%mo, the object of which was to recommend the erection of a seminary for feinale education. She afterwards published several controversial pieces. Her most finished performance was e'utitled "The Christian Religion," 1705, 8vo. She was a strenuous advocate of ligh church principles, to which circumstance, more than to her taleuts, she owed the celebrity she at one time enjoyed.

Asteria ; a gem, sometimes called the cal's eye, or oculus felis. It is a beautiful stone, and somewhat approaches to the nature of the opal. It is very small, and has only two colours, a pale-brown or white. It is hard, and will take a fue polish. The stone is found in the East and West Indies and in Enrope. In Bohemia, they are often found imbelded in the same masses of jasper with opal.

Astrmisk (a small star); a sign to refer to notes. The ancient critics made use of this sigu, or of a cross (obelus), to point out an incorrect passage in the text of an author. Others used the same mark as a sign of the correctness of a passage.

Astunia (asthma, Latin; from artua $a$, to breathe with difficulty); difficulty of respiration, returning at intervals, with a sense of stricture across the breast and in the lungs, a whecezing, hard cough, at first, but nore free towards the close of each paroxyism, with a discharge of mucus, followed by a remission. - $\Lambda$ sthma rarely appears before the age of puberty, and seems to attack men more frequently than women, particularly those of a full habit, in whoin it rever fails, by frequent repetition, to occasion some degree of emaciation. In some instances, it arises from a hereditary predisposition; and in many others, it seems to depend upon a particular constitution of the lungs. Dyspepsia always prevails, and appears to be a very prominent feature in the predisposition. On the evening preceding an attack of asthma, the spirits are often much affected, and the person experieuces a sense of fullness about the stomach, with lassitude, drowsiness, and a pain in the head. On the approach of the succeeding evening, he perceives a sense of tightness and stricture across the breast, and a sense of straightness in the lungs, impeding respiration. The difticulty of breathing continuing to increase for some leugth of tine, both inspiration and expiration are performed slowly, and with a wheezing noise; the speech becomes difficult and uneasy ; a propensity to coughing succeeds, and the patient can no longer remain in a horizontal position, being, as it were, threatened with immediate suffocation. These symptoms usually continue till towards the approach of morning, and then a remission commonly takes place; the breatling becomes less laborious and more full, and the person speaks and conghs with greater ease. If the cough is attended with an expcctoration of mucus, he experiences much relief, and soon falls asleep. When he awakes in the morning, he still feels some degree of tightness ncross his breast, al. 
though his brcathing is probably more free and easy, and the least motion renders this more difficult and uneasy; neither can he continue in bed, unlcss his head and shoulders are raised to considerable height. Towards evening, he again becomes drowsy, is much troubled with flatulency in the stomach, and perceives is return of the difficulty of breathing, which continues tw increuse gradually, till it becomes as violent as on the iight betore. After some nights passed in this way, the fits at length moderate, and suffer more considerable remissions, particularly when they are attended by a copious expectoration in the mornings; and this continues from time to time throughout the day; and, the disease going off at last, the patient enjoys his usual rest by night, without further disturbance. The exciting causes are various; - accumulation of blood or viscid mucus in the lungs, noxious vapours, a cold and foggy atmospliere, or a close, hot air, the repulsion of eruptions, or other metastatic diseases, flatulence, accumulated feces, violent passions, organic diseases in the thoracic viscera, \&c. Sometines the fits return at pretty regular periods; and it is generally difficult to obviate future attacks, when it has once occurred: but it often continues to recur for many years, and seldom proves fatal, except as inducing dropsy in the chest, consumption, \&c. The treatment must vary according to the form of the disease. By far the most important part of the treatment consists in the obviating or removing the several pxciting causes, whether operating on the lungs immediately, or through the medium of the primæ vix, \&c. Individual experience can alone ascertain what state of the atmosphere, as to temperature, dryness, purity, \&c., is most beneficial to asthmatics, though a good deat depends on habit in this respect; but a due regulation of this, as well as of the diet, and other parts of regimen, will usually afford more permanent relief than any medicines we can employ.

AstLEY, John ; a native of Wem in Shropshire, who adopted the profession of a portrait painter, and was a pupil of IIudson, the master of Sir Joshua Reynolds. He is known by his marriage with lady Daniel, a lady of large fortune, whose portrait he liad painted. He died in 1787.

Astuer, Philip; the founder of the royal amphithcatre near Westminster bridge, Jondon, and the author of some literary productions. He was born at Newcastle-under-Line, in 1742, served in the English cavalry, in Germany, for seven years, and, on liis return, began to exhibit equestrian performances. In 1780, he erected a building which he called the amplitheatre riding-house, and for which he subsequently procured a license. He erected afterwards several amplithcatres in England and Paris, and wrote a treatise on horsemanship, also two works of a military character. He died at Paris, Oct. 20 , 1814 , aged 72 .

Astrachan, or Astrakhan, a viccroyalty of the Russian empire, extending from $46^{\circ}$ to $52^{\circ} \mathrm{N}$. lat. and containing 293,000 square miles; with $2,600,000$ inhabilants. It is divided into three governmentsAstrakhan (72,600 squaremiles ; 223,000 inhabitants), Saratov, and Orcnburg. It is bounded on the N. by the country of the Bulgarians and Bashkcers; on the S. by the Caspian sea; on the W. by the Wolga, which scparates it from tlre Nogai Tartars and the Cossacs of the Don; and on the E. by a long chain of mountains, which divides it from Tartary. The summer is long, and very hot; the winter lasts three months, and is very scvere. The rich and fertile soil is not cultivated by the Tartars. On the W. and S. sile are large heaths, which afford fine salt in abundance. The capital, $\Delta$ strakhan, E. lon, $48^{\circ} 2^{\prime}$ $15^{\prime \prime}$ N. lat. $46^{\circ} 21^{\prime} 12^{\prime \prime}$, is on the islauid Seitza, in the Wolga, about 34 miles froin the entrance of this river into the Caspian sca. It is the see of a Greek archbishop and of an Armenian bishop; has 25 Greek, 2 Armenian churches, 26 Tartar mosques, an Indian temple, a high school, a seminary for priests, a botanical garien, and many manufactures. The city, with the suburbs, is $4 \frac{1}{2}$ miles in circumference. It contains, in 3800 houses, 30,000 inhabitants, consisting of $\Lambda$ rmenians, Tartars, Persians, and Hindoos, bcsides 20,000 people who spend some time in the year there, on account of the fisheries. In 1830 , the inhabitants suffered severely from cholera morbus. The houses are of wood, mean and incon venient. The environs are covered with gardens and vineyards. The sturgeons taken in the Wolga, are salted, and carried through all parts of Rus. sia. In winter, they are transported without salting. The trade in caviar is of some importance. Besides sturgeons, seals and other fish are caught here. From July to October, large swarms of locusts are not unfrequent. Formerly, Astrakhan had collmerce with Khiwa and Bıkhara : at present, its trade is limited to Persia and the interior of Russia, but is still considerable. Sixty vessels and seven caravans arrive here annually. The exports are leather, linen, woollen cloth, and other European manufactures. Astrakhan imports from Persia silk ribbons worked with gold for sale in Poland, also silk and cotton stuffs, rice, raw cotton, rhubarb, and some other drugs; chiefly, however, raw silk. The capital of the Ural-Cossacs, Uralskoi (containing 4000 wooden houses and 18,000 inhabitauts), belongs also to this government.

Astrognosy (from arzne, a star, and yivworw, I know); the science which teacles the constellations, ranks, \&c. of the stars. See Astronomy.

$\Lambda$ stroLABE (planisphere, analemma ; from arrne, a star, and $\lambda \alpha \mu \beta_{\alpha} \omega \omega$, I take); an iustrument for measuring the degrees, minutes, and sometimes even the seconds, of angles. It generally, consists of a horizontal circular plate of metal, having those divisions on its extreme circumference. The utmost accuracy may be obtained in the measurement of angles, by means of a peculiar contrivance (vernier), which consists of an arc, on which the smallest divisions of the circle are subdivided as minutely as is requisite in the observations, and as the skill of the maker can graduate it. This arc is movable, so that it can be fitted to the divisions of the circle. Fixed to this circle are two indexes, provided with tclescopes. One of them is immovable; the other turns round the centre of the instrumcnt. By taking sight from the vertex of the angle, at two fixed points in the direction of its sidcs, the arc, which measures the angle, is intersected on the circle of the instrument. In modern astronomy, this instrument is no longer used, except in the practical applications of geonctry. The first application of the astrolabe to navigation was made by the physicians Roderic and Joseph, and Martin Behaim of Nuremberg, when Joln II., king of Portugal, desircd them to invent a method of prescrving a certain course at sea. They taught how to discover the situation of a vessel at sea without the use of the magnetic needle.

Astrology; an art which pretends to foretell future events, especially the fate of men, from the position of the stars. It is among the oldest superstitions in the world, and, as Bailly conjectures, with great apparent probability, it owes its origin to the infuence of the heavenly bodies, particularly the sun and moon, on the seasons, the weather, and the fertility of the earth. This led to the idea that thesp. luminarics wcre creatcd only for the use of the planet we inhabit, and that, as they have an influence upon the carth, they probably have somc conncxion with the destiny of individuals and of nations. The 
Egyptians have a tradition that Belus founded a colony from Egypt on the banks of the Euplirutes, in Asia; and this colony was furnished with priests, according to the custom of the mother country, who were free from public taxes, and were culled, by the Babylonians, Chaldees. Hence it may be coujectured, that astrology was invented by the Egyptiaus ; among whom the inhabitants of Thebes particularly claimed the honour of the invention. Most of the ancient writers are agreed, that astrology was communicated by the Chaldees to other nations. f rom this circunstance, astrologers used to be called Chaldees by the ancient writers; sometimes Genethliaci (see Genethliacon); and, in later times, Chaldee has been synonymous with astrologer. (See Horoscope.) The great antiquity of this art may be inferred from the fact, that most astrological observations are founded on the position of the stars in reference to the lorizon, which was the first circle recognised in the liearens; also from its being mentioned in the Mosaic history. As astrology, in later times, fell into disrepute on account of the cupidity and fraud of its practitioners, these assumed the name of mathematiciuns, by which they were generally known at the time of the Roman emperors. They caused so much trouble, that 'Tiberius at leugth binished them from Rome. The law relating to this banishment of astrulogers, however, makes a distinction between geometry and the mathematical, i. e. astrological, art.-However oljectionable astrology may be in itself, it has been of essential use to astronony. It has excited more interest in, and led to more carcful observations of, the heavenly bodies. During the middle ages, astrology and astronomy were cultivated in connexion by the $\Lambda$ rabs, and their works on the subject ure still extant. Pico of Mirandola, who manfully combated the errors of astrology towards the close of the 15th century, found but little attention paid to his labours. Even in the 16th and 17th centurie's, astrologt could brast of literary men, such as Cardano, and even Kepler, nmong its adherents. The Copernican system, the correctuess of which experience has been continually confirming, has shaken the foundations of the ancient science; but the fabric is not wholly overthrown. A full account of astrological terminology is given in Lalande's Astro. nomy, vol. i. (ud edition), sect. 497.

Astroxony (from asreor, a heavenly body, and vopos, law) is the science of the hearenly bodies and their motions. It is founded on observation, but it receives its last perfection from calculation. What an interval from the imperfect notions of the Chaldean shepherd and the Plionician mariner to the Celestial Mechanics of a Laplace! How many centuries of ubservations were necessary to render the motion of the earth suspected! How slow the progress to the laws of planetary motion, and from those laws to a universal principle of gravitation! Founded on geometrical considerations, this great principle explains all the celestial phenomena in their minutest details: there is not a single seeming irregularity which does not necessarily result from it. Outrunning the cautious advances of observation, it descends from causes to phenomena, and renders astronomy a great mechanical problem, of which the only data necessary are the motions, figures, and magnitudes of the heavenly bodies. That part of the science which relates to their motions, magnitudes, and periods of revolution, is called descriptive astronomy; that part which explains the causes of their motions, and demonstrates the laws by which those causes operate, is called physical astronomy. From a simple view of the leavens, we see stars, with which the ethereal vault is sprinkled, appear regularly in a certain point, to rise with a uniform motion to a certain eleva- tion, and then descend, and disappear in the opposite quarter of the hearens. This notion is comnion to all the heavenly bodies, and is performed in equal times, though they appear to pass through ares of very different magnitudes. At a certain point, this motion nppenrs to cease: this point is called the pole, which signifies a pirot, on which the heavens appear to turn. 'The celestial vault being conceived as forming a sphere, there are two of these points: that which is visible in our hemisphere is the north celestial pole; and that which is visible in the opposite hemisphere is the south celestial pole. The circle which bounds our view on all sides is called the horizon, or boundury: its plane passes throngh the centre of the earth: it is also called the celestial or rational horizon, to distingnish it from the sensible horizon, which limits the view of objects on the surface of the earth. A circle perpendicular to the horizon, passing through the poles, is called the meridian. It divides the' celestial hemispluere into two equal parts, so that the heavenly bodies, at the moment they arrive at this circle, are at the iniddle of their apparent course: the passage of the sun over this circle determines the instant of noon. The period occupied by the stars in passing from this circle through the celestial sphere, and returning to the same point, is called a sidereal day, and is a little less than twenty.four hours. As we remove from the poles, the arcs described by the stars gradually increase, and at an equal distance between them, we find the largest, which, dividing the celestial spluere into two cyual parts, is called the celestial equator. A line drawn from the centre of the globe, through the place of the observer, ascertains a point in the lieavens, perpendicularly over his head, which is called the zenith: the same line produced in the opposite direction determines a point in the opposite part of the heavens, which is called the nadir. We have thus far spoken of the ascending and descending of the heavenly bodies in the heavenly vault. But does all this train of worlds actually move round the carth daily? Or can it be proved that our senses deceive us, and that this apparent motion is an illusion? The true cause of these appearauces is the motion of the earth round its own axis, from W. to $E$., in the space of nearly twenty-four hours. A moment's reflection will convince us that the horizon of the observer, as it turns along with him during the rotation of the earth, must advance towards the stars successively, so as to give them the appearance of gradually approaching the horizon; as a vessel leaving the shore causes it to appear to recede to a person on board. As the meridian turns at the same time, it must arrive successively at the same stars, which will then appear to have ascended to the middle part of the course they describe abore the liorizon. As soon as the star touches the western verge of the liorizon, it appears to set, and ceases to be visible until the motion of the earth again brings it back on the eastern boundary of the same circle. Bit has the eartl no other motion? Every one must have observed that the sun, besides its apparent diurnal motion, which it has in common with all the stars, appears in the course of a year to change its place in a twofold manner. First, it appears to rise and sink alternately towards one or other of the poles; and, secondly, if we observe its place among the stars, it appears either that the sun recedes daily towards the east, or that the stars advance daily towards the west; for the stars, which we see at one time set, immediately after the sun, are, on the fol. lowing evening, lost in his rays: some days after, they reappear in the east, and their rising precedes daily more and more that of the sun. At last, after a sear, or about 365 days, the sun and stars are again 
seen in the same relative position. The complexity of these motions is increased by the confusion pre. sented by the apparent motion of the other planets : sometines they seem to be hurried along with great rapidity; at other times they appear stationary, and, at others, still retrograde. All this seeming chaos of motions is reduced to order by a knowledge of the fact, that, while the earth turns on its axis, it advances, at the same time, in absolute space from west to east, and performs an entire revolution round the sun in the course of a year, in a plane inclined to the equator. The circle which the centre of the earth describes in this revolution, and which is the apparent path of the sun, is called the ecliptic. The axis of the earth remaining always parallel to itself, the opposite-poles will be directed towards the sun once in eacl revolution. When a pole is directed towards the sun, it receives more light and heat, and for a longer period, than at any other portion of the revolution. It is then the summer solstice in that hemisphere ; the days are longest, the nights shortest, and the heat greatest. Six months, or, rather, half a year from that period, every thing is reversed; the same pole is turned from the sun; the light and heat is received in small quantities, and for a short period; the days are short, the uights long; the cold inteuse: it is the vinter solstice. At two other points of the orbit, equidistant from each other and from the solstices, the poles are equally inclined to the sun; they receive an equal supply of heat and light, and during equal pcriods ; the days and nights are equal all over the globe : it is the vernal or autumnal equinox. The diurnal rotation of the earth on its own axis produces, therefore, the alternation of day and night. The annual revolution round the sun. and the obliquity of the ecliptic to the equator, causes the changes of the seasons. The daily rotation of the earth produces, also, the phenomena of tides in the ocean and the atmosphere. (See Tides.)-Let us now take a more general view of the celestial phenomena. The discovery of peculiar qualities cominon to a number of heavenly bodies, has led to the formation of classes (see Planets, Satellites, Comets, Fixed Stars); or convenience of description has clustered them into groups with fanciful names (see Constellations); or their peculiar influence on human affairs has given a name to individuals (see Sun, Moon, Earth, \&c.). At first view, the stars in general do not seem to change their relative positions; and, if they have particular motions, a long series of observations is necessary to render them sensible. But, by continuing to compare the heaveus at different epocls, we perceive that some of them are distinguished by relative motions, and by the nature of the light which they transmit to us. These we call planets, that is, wandering stars, in distiuction from those, which, maintaining always the sane relative positions, are called fixed stars. The planets transmit to us a soft, mild, steady light, never wxhibiting any change of colour. They are opaque hodies, and their light is only a reflection of that which they receive from the sun, around which they revolve in regular hut unequal periods, turning at the same time on their axes. Their number now known is eleven. We mention them in the onder of their distances from the sun-Mercury, Venus, Farth, Mars, Vesta, Juno, Ceres, Pallas, Jupiter, Saturn, and Uranus, or Herschet. Five of these are visible to the naked cye, and were known to the ancients; five have been discuvered in modern times by the aid of the telescope. Some of these bodies have smaller ones in their neighbourhood, which revolve round them at the same time that they accompany them in their orbits of revolution round the sun, and turn on their iwn axes. The former are called primary, to distin- guish them from these attendants, which are calted the seconelary planets, or satellites. The latter are opaque, like the former. The earth is accompanied by one, which is called the moon, Jupiter by four, Saturn by seven, with his remarkable ring, and Herschel by six. "The interposition of one of the planets between the sun and an observer stationed on another planet, produces an eclipse. (q. v.) From time to time, small specks appear in the heavens, of a feeble lustre, moving slowly in the midst of the other stars. Gradually, as they approach nearer, their velocity increases; their light is more brilliant; and, after passing into the immediate vicinity of the earth and sun, they recede again, and disappear in the distance. These are called comets (which signifies hairy bodies) from the peculiar luminous train by which they are attended, and which the ancients called hair, and the moderns, tail. These bodies, long the objects of terror to man, as the harbingers of pestilence and war, are now known to be subject to the common laws of nature, and to revolve round the sun in regular periods. The sun, the 11 primary and 18 secondary planets, and the comets, constitute the solar system. Far beyond these limits, at an immeasurable distance, lie the fixed stars, infinite in number, of a britliant lustre, and constantly changing colour. Their distance and the brilliancy of their light, with the fact that their magnitudes remain always the same, render it probable that they are luminous bodies, like so many suns. They have been formed into many groups of arbitrary extent, under the names of gods, men, beasts, \&c., which are called eonstellations. Of these the ancients knew 48 ; the moderns have increased the number to more than 100 . It should be understood, that the stars, thus grouped together under one name, have no connexion with each other, but are so arranged for convenience of description. The first astronomers, in order to estimate better the apparent motion of the sun, referred it to those constellations through which it appeared to pass, and which are 1.2 in number. They are, in Latin, Aries, Taurus, Gemini, Cancer, Leo, Virgo, Libra, Scorpio, Sagittarius, Capricornus, Aquarius, and Pisces. The zone, or band, which contains them, is called the zodiac, fq. v.) and eacli constellation is called $a$ sign of the zodiac. In consequence of a motion of the earth's axis, the constellations no longer correspond to the same points of the orbit; but as we confine the name signs to the 12 divisions of the circumference of the circle, which measures the whole revolution of the earth, and as these divisions do not clange, the rernal equinox always corresponds to the first point of the sign Aries, the summer solstice to the first point of the sign Cancer, the autumnal equinox to that of Libra, and the winter solstice to that of Capricorn, although the constellations, which bear these names, have ceased to be connected with these seasons. (See Precession of the Equinoxes.) To penetrate yet farther into the heavens, it is necessary to aid the inperfection of vision by the telescope, which discovers to us nillions of stars in the infinity of space. In a clear night. turn your eyes to the irregular zonc of whitish light: it is the milky way (q. v.): you will find it to consist of an infinite number of stars, whose inconceivable distance renders their light too feehle to make a distinct impression on the uaked eyt. Contiuue your examination, and you will observe himinous spots of an undefined slape : these are nebula, some of which a further observation will show you to be assemblages of stars, like the milky way, while others will appear to consist of an unbroken mass of whitish light. You will find, also, some stars to be variable, undergoing a periplical change of brightness: some, which appear single to the naked eye, will be found to be double, triple, \&c., and to revolve round a common 
centre of gravity by twos, threes, \&c. Compare your observations with those of your predecessurs, and you will find that new stars have appeared at different times, and afterwards disappenred, and that others have experienced a change in the intensity of their light. Of the actual mngnitude and distance of the stars we know nothing. The diameter of the carth's orbit is $200,000,000$ iniles ; yet we can detect no difference in their apparent places, viewed from the opposite yoints of this diameter: a change of place a mounting only to a second would be detected by the accuracy of moden observations: geometrical considerations, therefore, prove that the nearest star cannot be less than twenty billions of miles distant from us. After considering the apparent motions of the hearenly bodies, and the real motions which give rise to these appearances, physical astronomy rises to the explanation of the cause, and the investigation of the laws, of the celestial phenomena. Applying the laws of motion to the heavenly bolies, it discovers a force operating tluronghout, which is called attraction, the amount of which is directly as the quantity of matter, and inversely as the squares of the distances. By the application of this general principle, it descends to those more refined inequalities, which, owing to their minuteness, or the length of their periods, would escape or mislead the observer massisted by theory. (For a view of the planetary system, the coinparative magnitudes, distances, \&c. of the planets, see the plate accompanying this work, entitled The Planetary System.)

Astronosy, HISTORY OF. The history of this science begins with the most remote antiquity. The starry heavens must have been one of the first and most striking objects which attracted the attention of man, and his immediate wants compelled him to attend to the revolution of the seasons, the changes of the moon, \&ic. The inost ancient astronomical observations known to us are Chinese. Such a one, mentioned loy Montucla (see p. 455 of his work, rol i., quoted below), viz. a conjunction of Saturn, Jupiter, Mars, Mercury, and the moon, occurs almost 2500 years before our era. The Chaldeans also boast of some very ancient astronomical observations, but Ptolemy (q. v.) only mentions two lunar eclipses observed by them, about 700 B.C. Still less importance does he ascribe to the astronomical knowledge. of the Egyptians, although the placing of their pyramids in a position exactly facing the four cardinal points of the compass, the zodiacs discuvered in Eggpt (see Zodiac), and other circumstances, are by no means calculated to give us such a disadrantageous idea of it. The theory of Bailly, a later historian of astronomy, respecting a nation settled in Middle Asia, and possessed of profound astronomical knowledge, seems as unfounded as our acquaintance with Indian astronomy is slight. The science made greater progress in Greece, and the Greek philosopher T'hales (१. จ.), born 640 B. C., calculated a solar eclipse. Pythagoras, also, seems to have been possessed of astronomical knowledge. After him, the Athenian Meton ( 433 B. C.) introduced the famous linar cycle of nineteen years, at the end of which time the new moon appears on the same day of the year as at the beginning of it, since nineteen solar years constitute very nearly 235 lunations - a discovery which was then regarded as so important, that the calculation was engraved in letters of gold, whence the number, which marks the year of the cycle, is still called golden. Great progress was made in astronomy under the Ptolemies, and we find Timocharis and Aristyllus employed, about 300 years B. C., in making usefic: planetary observations. But they were far surpassed, in philosophical spirit, by Aristarchus (ๆ. v.) of Sames, Lorn 267 years B. C., who, arcorl- ing to the induhitable evidence of Archimedes (see the remarkable passige in the beginning of Avenarius), taught the double motion of the earth around its axis and around the sun; ; and, about 100 years after him, Hipparchus (१. v.) determined more exactly the length of the solar year, the eccentricity of the sun's orbit, the precession of the equinoxes, and evell undertook a catalogue of the fixed stars; austes, as Pliny (Hist. Nutur., lib, 2, cap. 26) expresses himself, rem etiam Deo improbam, annumerare posteris stellas, colo in hereditatem cunctis relicto. From the time of Hipparchus, a chasm exists in the history of astronomy, till the commencement of the $2 \mathrm{~d}$ century after Christ, when Ptolemy (q. v.) compiled a complete system of astronomy, in thirteen books, which is best known under the name of Almagest, given it by the Arabians, who translated it into their lauguage in 827 , and which, as the Ptolemann system of the world, notwitlistanding its many errors, has maintained its value down to the latest times. Ptolemy supposed the earth to be the immovable centre of the universe, round which all the hearenly bodies revolved as crystalline spheres, and the planets in the order represented by the following cut.

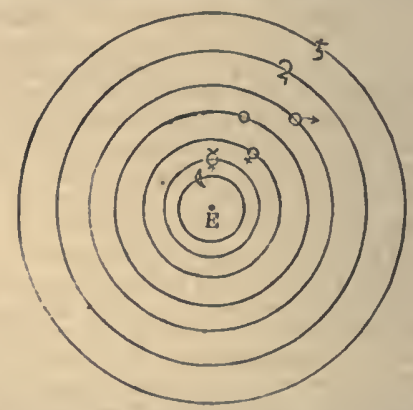

Thus the moon ( $Q$ ) occupies the place nearest to the earth, and the six other planets in their order; namely, Mercury ( $($ ) ; Venus (Q); the Sun $(\odot)$; Mars (o); Jupiter (2); Saturn ( 5 ). These are succeeded by the sphere of the fixed stars, otherwise called the firmament, or the eighth sphere, and two other spheres called crystalline, all which were put in motion by the outermost sphere, called the Primum Mobile, or prime mover. Whether what is called the Egyptian System, be of greater antiquity than Ptolemy's, may not be easily determined; but it will be seen from the following cut, that it more resembles the Tychonic than the Ptolemaic system.

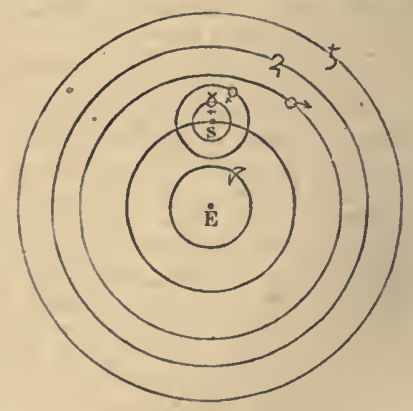
Aristarchus gays expressly, lst c., that the earth re-
volvos in an oblique circle asuuud the sut, and thar the 
Among the Romans, astronomy was never much esteemed; and no astronomical discovery had its origin with them; though it must be observed, that expressions occur in Seneca's Quastiones Nat., vii. 13, respecting comets, which are worthy of a riper age; and the service likewise deserves mention, which Julius Casar rendered, by his correction of the calendar, the details of which may be found in the article Calendar. But, with the irruption of the barbarians on one side, and the destruction of the Alexandrian library on the other, such a total stagnation occurred in the case of astronomy, as in that of the sciences in general, that we find no traces of astronomical study and observation, till the rinth century, among the Arabs, whose translation of Ptolemy's works has already been mentioned. Of their astronomers, the caliph Almamon, and the princes Albategni and Thebith, deserve to be named. Among the Moors who invaded Spain, there were Arabic scholars, who transplanted the science to that country With the Mohammedan faith, Arabic learning wis likewise introduced into Persia, the reigning prince of which, Ulug-Beigh, in the beginning of the 15th century, collected, at his capital, Samarcand, an assemblage of the most famous living astronomers. But we must not overrate the merits of the Arabian astronomers, since they confined themselves entirely to the system of Ptolemy, and confounded the science with the dreams of astrology; though, on the other hand, the benefits which they have rendered by valuable observations of the fixed stars (many of which, it is well known, still bear Arabic names), of eclipses, of the obliquity of the ecliptic, (ๆ-v.) \&c., and by the preservation of ancient mathematical works, which have come to us in their translations, are not to be forgotten. Among the Christian nations, during this time, a deep ignorance generally prevailed, but the cultivation of the astronomical sciences was not entirely neglected. Thus the emperor Frederic 11., who died in 1250, caused the Almagest (the Greek original being no longer extant) to be translated from the Arabic into Latin ; and king Alphonso of Castile, about the same time, invited to his court sereral astronomers, and commissioned them to prepare a set of new astronomical tables, which, under the name of Alphonsine tablcs, have acquired much celebrity, but, in the 17th century, differed a whole degree from the true situation of the celestial bodies. We pass over several less famous names, in order to introduce those of the German astronomer and mathematician, George of Peurbach or Purbach, born in the Austrian dominions, in 1423, who published various valuable astronomical tables, such as the table of sines, from 10 to $10^{\prime}$, and a still more famous scholar, John Muller, born at Konigsberg, in Franconia, and thence called Regiomontanus, from whom we possess the first good and complete Ephemerides. After him, a brighter light was shed over astronomy by Nicholas Copernicus (q. v.), born in 1473 , who gave the science an entirely different aspect, exploded the Ptolemaan hypothesis, and, in its stead, substituted the Copernican system of the world, which, with a few modifications, is still prevalent, and universally acknowledged to be correct. He it was that gave the sun its place in the centre of the planetary system; $v r$, as is magnificently expressed in his epitaph, " commanded the

distance of the fixed stars is so great, that this circle can only be considered as a point in comparison; but he seen to have come to this conclusion, not as an astronomer, but as a Pythagorean, regarding fire (the sun) as the centre of the universe-We take this occasion to correct the cornmon bat erroneous opinion, that Copernicus was indebted, for his system of the world, to this passage of Avenarius, as this book was not printed till after bis time. sun to stand still ;"-who first conceived the bold idea, that the earth is a planet, like Mercury, Venus, and the rest, and moves, in common with them, in a circle around the sun; and who maintained that these circles (or, in conformity with subsequent corrections, these orbits, differing but little from circles) were sufficient to explain the most complicated motions of the other planets, and even their apparent cessations of motion and retrogradations, which had hitherto baffled all conjecture. (For a view of the Copernican System, see the Plate entitled The Planetary System.) How much freedom of spirit was required thus to rise superior to the prejudices of centuries, we are almost incompetent to judge, now that the truth of the system is settled; but his great countryman, Kepler, has depicted the spirit of the man, by a few energetic strokes, calling him virum maximo ingenio et quod in hoc excrcitio magni momenti est, animo libero. His system did not, however, meet, immediately, with a general reception; and, while Rheticus and others were its advocates, some distinguished astronomers made objections to it, among which the imperceptibleness of any annual parallax of the fixed stars, which it seemed must necessarily result from the motion of the earth, was the one of most weight. The most distinguished of these opponents of the great Copernicus was 'Tycho Brahe (q. v.), born in Denmark, in 1546. He maintained that the earth is immovable, in the centre of the universe; that the whole heavens turned around it in twenty-four hours; that the moon, and also the sun, by virtue of their own motions, describe circles around the earth, while Mercury, and the other planets describe epicycles around the sun. (See Epicycle.) This system, called after him the Ty. chonic Systcm, may be represented thus:

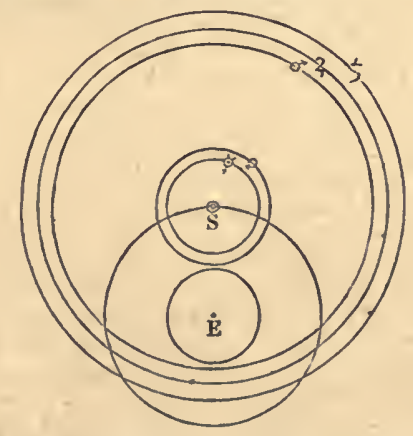

The principal anthority that Tycho adduced in support of his opinion was, the literal sense of various passages of the Bible, where a total absence of motion is ascribed to the earth; but, although he did much injury to science by supporting this erroneous opinion, we are under infinite obligation to him for the great exactness of his observations, which opened to his pupil and assistant, Kepler (q. v.) of Wurtemburg (horn 1571, died 1631), the way to the more accurate discovery of the form of the celestial orbits, and the true theory of the planets; for only eight minutes' difference between the position of the planet Mars, as calculated on the hypothesis of the circle, and its actual position, as observed by Tycho, gave this sagacious astronomer occasion, as he expresses himself, in p. 114 of his Astronomia,* " ad

- The title of this immortal work, wontaining the code of theoretical astronomy, is, Astronomion nova Physica Calestis tradita Commenta is de Mutibus stella Martis, ex Obsprutionibus Tychonis Bruhe, Jussu rl 
totam astronomiam reformanulan," since he derived from it the elliptical forns of the orbits of the planets (differing, however, but little from the circles of Copernicus), the sun being situated in one of the foci of the ellipse. Advancing in his glorious conrse, Kepler, moreover, deinonstrated that, in each clliptical revolution of the planets around the sun, an imaginary straight line, drawn from the latter to the former (the radius vector), always describes equal areas in equal times; and, lastly, that, in the revolutions of the planets and satellites, the squares of the times of revolution are as the cubes of the mean distances from the larger body. These three important truths are comprehended under the name of Kepler's laws. About the same time, Galileo ( $q . \vee$.), who died in 16.12 , accomplished another step towarus the more accurate investigation of celestial mechanics, by his cliscovery of the laws of the descent of lieary bodies; and aldiough the Catholic church compelled this philosopher to abjure as heretical the doctrine which he lial publicly promulgated respecting the motion of the earth, to which he had been led by his observations of the other celestial motions, nade by means of the telescope, then first invented, this attempt to olsstruct the march of intellectual improvement ouly served to show the impotency of such persecutions.* In the first ten years of the 17th century, there appeared, in Dantzic, Hevelius, who was distinguished for his observations of Mars; in France, Cassini, whose exertions in most of the branches of astronomy were highly successful, and who transmitted his industry and his energy to a son, grandson, and greatgrandson; and in Holland, Huygeus, the famous inventor of the pendulinm, and the precursor of the immortal Newton, in his investigations respecting celestial mechanics. Newton himself (q. v.), born in 1642 , was engaged, till a short time before his death, 1727 , in producing an entire revolution in physical astronomy (see the preceding article), while, by his Principia Mathematica Philosophice Naturalis, he became the lawgiver of celestial mechanics, as Kepler had been of theoretical astronomy, by means of his Astronomia. Descartes had sought the cause of the motion of the planets around the sun, and of the satellites around the planets, in the rotatory motion of a subtile matter. Newton felt the defects of this hypothesis, and proved, with the superiority of true genius, that the elliptical motion of the planets was caused by the combined action of the attractive power exerting a force in the inverse ratio of the squares of the distances, and of an impulse originally communicated to the planets, which impulse, as may be demonstrated, continues for ever in empty space. With Newton the laws of the heavenly bodies were completed, and he and Kepler have left to later times merely the developement of the triths which

Sumpthins Rudolphi II., Romanorum Imperatorie, etc. "' "rifum Annorum pertinaci Studio elaborata, Prage, S. C. M. Mathematico Joanne Keplero (1609, fol.).

- These persecutions have, nevertheless, been very recently repeated, and the public papers have related the folluwing anecdute: About the beginning of the year 1820, the professor of astronomy at the academy della sapienza at Rome, signor Settele, submitted the manuscript of his astronomical lectures to the appointed authorities, soliciting permission to print them. This was refused, "because be defended the motion of the earth around the san"-a doctrine condemned by the Roman court, as contrary to the Bible, and which bad already involved the immortal Galileo in the disgrace of recantation. Not discouraged by this, Settele applied to the inquisition, with the request that it would give an explanation of its nwn, adapted to the present state of science. The inquisition was silenced; permission was granted to print the book; but Settele permission was granted to print the book; but Settele was the persection puted not 30 which calloo liad suffered were to be inputed not so much to his system as to the improper lan
guage used by bim. This, however is notoriously false. they established. By the application of their principles, several succerding astronomers have gained a high reputation; e. g., Halley, by his theory of coinets; 13ouguer and Maupertuis, by their exirtions to determine the form of the earth; their countrynan te la Caille, by inproving the doctrine of refrnction; the great German astrunomer, Tobias Mayer, by his lunar tables; 13radley, by the discovery of the abermation of light; also de l'Isle, Lambert, Euler, and others. (q. v.) In more recent times, Laplace, by his Mécanique Céleste, and Gauss, by his Theoriu Motus Corporum Calestium, have completed the structure of Newton; while Zach, Ialande, Maskp. lyne, Bessel, Olbers, Piazzi, Encke, Delambre, Biot, Ango, Mechain, Herschel, \&c., lave enlarged, on all sides, the territory of the science. Thus Ilerschel's discovery of the planet Uranus and its moons, in 1781 ; Scliroter's efforts to obtain a knowledgr: of the surface of our moon, and of Venus; Pinzzi's dis. covery of Ceres, in 1801; Olbers' discuvery of Pallas, in 1803, and of Vesta, in 1807; Harding's tiscovery of Juno, in 1804; Olbers' and Fucke's computation of the orbits of two comets; the recent measureme'nts of a degree in France, England, Germany, Swetelu ; the perfection which has been given to astronomical instruments, by Rainsden, Troughton, Reichenbacl, \&c., are well known; and the combined industry of so many living astronomers allows us to hope for no less splendid results in the atvancing in. provement of astronomy.- On the advantages of this science, it can scarcely be necessary to dwell. "It need but be mentioned," says Gehler, "to excitc emotions of grandeur; and the idea which it gives us of the immensity of the? universe, and the power, wisdom, and goodness of its almighty Author, must inspire men of the coldest feelings with sentinents of admiration. It is not necessary for us to point out the benefits which accrue from it to the luman race, by enabling them to divide and observe the flight of time ; its use in navigation, the determination of the situation of places on the earth, \&c." By the aid which it affords to navigation, it exercises no small infuence in the general improvement of the human condition. This science, moreover, unites the strictness of mathematical reasoning with an exalted feeling for the sublime and beautiful, and fills the mind both with confidence in itself, from its ability to calculate with certainty the career of distant worlds, and with a becoming humility in reflecting how small a part of the universe is our earth, and how brief its known duration, compared with the immense periods which enter into the calculations of astronomy. Young says,

$$
\text { An undevout astronomer is mad. }
$$

There have been, however, several astronomers who believed in no God; being led, by the contemplation of the necessary laws of the heavenly borlies, to the belief in a general, unirersal necessity.-Of the numerous works on astronomy, we shall only mention here the latest and most important manuals and elpmentary works: Astronomie par de Lalande, $3 \mathrm{~d}$ ed., Paris, 1792, 3 vols 4to. (there is an abridgment of it-Abrégé d'Astronomie par de Lalande, Paris, 1795) ; Astronomie Theorique et Pratique, par Delambre, Paris, 1814, 3 vols. 4to-a work important for professional astronomers; Schubert's Theoretical Astronomy, Petersburg, 1798, 3 vols. 4to, and a new French edition of the same work, 1822; Biot's Traité Elémentaire d'Astronomie Physique, $2 \mathrm{~d}$ ed., Paris, 1810, 3 vols. ; Laplace's Exposition du Système du Monde, 5th ed., Paris, 1824 (a general exposition of the results developed in the large work, Mécanique Céleste); Bode's Illustrations of Astronomy (which is confuled to the less difficult propositions of geone- 
try and astronomy) $3 \mathrm{~d}$ ed., Berlin, 1803, 2 vols. : together with this work, we may mention Burjas' Mlanual of Astronomy, Berlin, 1794, 5 vols., which requires, however, more extensive knowledge. Excellent, though very condensed, is Bohnenberger's Astronomy, 'Tubingen, 1811. Piazzi's Italian Manual of Astronomy is a good work. Among the English treatises are Woodhouse's Elementary Treatise on Astronomy, 1823, and Fergusmin's Lectures on Astronomy, a popular work ; also Vince's Complete System of Astronomy, 3 vols. 4to, with additions, 1814. To astronomers, practical and theoretical, Bessel's Observations at the Observatory of Konigsberg, which have appeared in folio since 1813, are indispensable. Notices of astronomical tables may be found in the larger astronomical treatises mentioned. With respect to astronomical periodicals, Zach's Monatl. Correspondenz zur Befórderung der Erl-und Himmels-Kunde, with which is connected Lindenau's and Bohnenberger's Astronom. Zeitschr., is continued under the title Correspondence Astronomique, Géographique, \&c. du baron de Zach. Schumacher has also published, in Copenhagen, since 1822, Astronomische Nachrichten. The latest observations may be also found in the Paris Connaissance des Tems, and in the Berlin Astronomisches .Jahrbuch, which has been published for more than fifty years. The history of astronomy may be found at large in Montucla's already mentioned Histoire des Mathématiques. 4 vols. 4 to ; in Delambre's Histoire de l'Astronomie Ancienne, celle du Moyen Age et Moderne, Paris, 1817, 5 vols. 4to; and in Bailly's Histoire de l'Astronomie, of which the first volume appeared in 1771, containing the history of ancient astronomy, and the 3 other volumes, 1779 and 1782 , containing the history of modern astronomy, followed, in 178\%, by his Traité de l'Astronomie Indienne, which work, however, as we have already remarked, must be used with precaution, on account of the inclination of the author to adopt theories on insufficient grounds.

Asturia, or the Asturias; a Spanish principality, of about 3670 square miles, with 365,000 inlabitants. It is bounded by Biscay on the east, Galicia on the west, Castile and Old Leon on the south, and the sea on the nortl.. To this inountainous country of the north of Spain the Moor never penetrated with success. There the Goth retreated; in the 8 th century, before the sword of the Saracen. Each Asturian, therefore, thinks himself a free hidalgo. The inha-

4 bitant of $A$. lives more upon maize, chestnuts, fruits, liazelnuts, game, fish, honey, and beans, than upon wheat or similar grain. The pasture and cattle are excellent. Oil and salt are wanting entirely. The Asturian is less industrious than the Galician, and less sociable than the Biscayan. The mountains are not capable of supporting all the inlabitants, and therefore the free Asturian goes into the service of other Spaniards, who are, in his eyes, much less noble than limiself, and becomes a coacliman or footman. $-\Lambda$. formerly enjoyed many privileges, not belonging to the Castilian provinces, in respect to its interior administration, and in regard to inposts. These were abolished at the time of the revolution, but, since 1823, the old state of things las been, in a great measure, restored. The capital, Oviedo (6000 iuhabitants), has a university. In Gihon, a sea-port (3200 inhabitants), is the instituto Asturiano, for the cultivation of mathematics, mineralogy, and navigation. The hereditary prince of Spain has horne, since 1388 , the title of 'prince of $A$., or de las Asturias, according to the obsolete division into A. de Oviedo and A. de Santillana, the two clief cities of this country.

Astrages; son of Cyaxares, the last king of the Medes. Herodotus relates, he dreamed, that from the womb of his daughter Mandane, married to Cambyses, king of Persia, there sprang up a vine which spread over all Asia; and she being with child, he resolved to kill the infant as soon as it was born. The child was Cyrus. Harpagus, being commissioned to destroy it, preserved its life. Astyages, learning long after what Harpagus had done, caused him to eat his own son. Harpagus, in revenge, called in Cyrus, who dethroned his grandfather, after his victory at Pasargarda, in which the Persians defeated the Medes, and put an end to their monarchy. See Cymus.

Asuncion, or Nubstra Senora de la Asuncion (in English, Assumption); the chief city of Paraguay, eighteen miles from the first mouth of the Pilcomayo, built in 1538, and, in 1547, erected into a bishopric. The streets are ill-made and crooked. The population consisted, formerly, of about 2000 Spanish colonists, and several thousand mestizoes and Indians. The climate is temperate, and the adjacent country rich and fertile : throughout the year, many of the trees are either in foliage or loaded with fruits. The trading boats from Buenos Ayres to $A$. take two or three months to ascend the Plata, owing to the force of the descending current. A. has become more known, of late, as the capital of Paraguay, and the residence of the dictator, doctor Francia. (See Fran cia and Paraguay.) The latest information which we have of that part of the world is to be fonnd in the Historischer Versuch uber die Revolution von Paraguay, \&c. von .T. $R$. Rengger und M. Longchamp, Stuttgart, 1827 (Historical Essay on the Revolution of Paraguay, \&c., by J. R. Rengger ano M. Longchamp).

Asvoun; a place to which persons fiee for protec. ion. Among the ancients, temples, statues of the gods, and altars afforded such a refuge, and it was deemed an act of impiety to remove forcibly one who had fled to them for protection. The abuses of these institutions sometimes led men to forget their sacred character, as the Lacedæmonians did in the case of Pansanias, whom they starred in the temple of Minerva. People who had fled to asylums were often starved to death by their pursuers, or the places of refuge were set on fire. All temples and sacred places, however, were not asylums, but only those particularly consecrated for this purpose. The emperor Tiberius abolished them all, except the temples of Juno and Esculapius. These institutions passed over to the Christian world. Under Constantine the Great, all Christian churches were asylums for those who were pursued by the officers of justice or the violence of their enemies. The younger Theodosius extended the privilege, in 431 , to all courts, gardens, walks, and houses belonging to the church. The Franks confirmed the privilege, and, in 681 , the synod of Toledo extended the limits of asylums to thirty paces from every church. This ecclesiastical privilege has since prevailed in all Catholic countries. It remained inviolate, at least in Italy, while the papal government retained its independence. It was a strong armour of defence against the wild spirit of the middle ages, and was not without good consequences at a time when force often prevailed over justice. It also changed civil punishments into ecclesiastical, linited the power of sorereigns, and extended the influence of the church. For this reason, and because justice is now much better administered, asylums have been abolished in most modern countries. It is generally known, and as generally regretted, that the late pope Leo $X$., on his accession to the apostolical see, re-established the asylums, which had been abolished by his predecessor, Pins VII. ; the chief consequence of which has been to afford the robbers in the papal dominions 
a better opportanily to escape the pursuit of the Austrian troops. - In Britain and the United States, this name has been given 10 many charitable institntions for the relief of orplans, blind, or dumb and denf persons, \&c. In no countries are institutions of this kinl more common.

Asyмттоте; commonly, a straight line, which approaches a curve line, so that the distance between them is constantly diminishing, although they can never meet, even if indefinitely continued. Hence I.eibnitz called infiute spirits the asymptotes of the Deity. An asymptote may also be a curve.

Asrnperon; the omission of the small comecting particles of speech, in order to render the expression more lively and inpressive. This is particularly the ('ist: when a series of actions, quickly following each other, is to be represented; e. g., in 'Virgil,

Ferto cito flanmas, date vela, impellite remos.

Atanualpa, or Atabalipa; the last of the incas. He succeeded his father, in 1529 , on the throne of Qnito, whilst his brother Huascar obtained the kingdoin of Peru. They soon made war against each other, when the latter was defeated, and his kingdom fell into the liands of $A$. The Spaniards, taking ad. vantage of these internal disturbances, with Pizarro at their head, invaded Peru, where they were entertained with no little hospitality by the king and the people; but, instead of returning the kindness, they

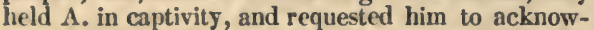
ledge the king of Spain as lis master, and embrace the Cliristian religion. Upon his asking their authority for this request, the friar Valverle gave him the breviary as authority. A. put it to his ear, and said, "It tells me nothing;" then threw it away. This was made a pretext for a massacre of the people and the imprisonment of the king. He offered a large sum of gold as a ransom: this the Spaniards took, but still kept him prisoner. At last, he was burnt, in 1533. See Pizarro.

Atalanta. There were two persons of this name in the ancient inythology. One of them was a native of Arcadia, the daughter of Iasus and Clymene, celebrated for her skill in archery. She slew, with her arrows, the Centaurs Rhœcus and Hylæus, who were about to offer violence to her; sailed to Colchis with the Argonauts, and was afterwards present at the cluse of the Calydonian boar, which she first wounded; hence Meleager awarded to her the prize. (See Calydon and Meleager.)-The other was a daughter of Schœneus, king of Scyros, renowned for her beauty, and swiftness in running. Conscious of her exquisite beauty and lier great fleetness, she imposed upon her lovers the severest conditions. She required each to run a race with her. Her admirer whs to run before, unarmed, while she followed him with a dart. If she could not overtake him, she was his own; but if he was conquered, he was doomed to death, and his head set up at the goal. Many had fallen victims in the attempt, when Hippomenes, the son of Mrgareus, by the aid of Venus, overcame her. The goddess gave him three golden apples, which he threw behind him, one after another, as he ran. A. stopped to pick them up, and Hippomenes reached the goal before her. Her former reserve now gave place to such ungovernable passion, that she even profaned the temple of Ceres, which stood near the place of the race. The angry goddess changed both the parties into lions, and eompelled them, from that time, to draw her chariot.

Araman. See Hetman.

ATE; among the Greeks, the goddess of hate, injustice, and crime. Homer says of her-

Jove's daughter, Ate, most pernicious power

By whom all suffer, challenges from all
Reverence and fear. Delicate are her feet, Which scorn the ground; and over human heads She glides, injuriousto the race of man;

Uf two who strive, at least entangling one. Conper's Trans. Iliad, xix. 1. 90.

Just before the birth of Hercules, she excited Jupiter to 11 strain of boasting, and thus afforded Juno an opportmity to orerreech him by bringing Eurystheus first into the world. The indignant monarch of the gods seized her by her laair, precipitated her to the earth, and swore that she should never return to Olynupus. Fable informs us, that she has ever since paced the earth with incredible velocity, and spread destruction and misery every where. Ilesiod calls her a daughter of Eris.

Atrllande Fabolx (called, also, Oscan plays); a kind of light interlude between the tragerly and comedy, which, in ancient Rome, was not performed by the regular company of actors, but by freebori young Romans. This kind of play is said to have originated from the ancient Atella, a city of the Oscans, between Capua and Naples, and is, at the same time, the beginning and all that remaius of a national Italian comedy, consisting of farce sensoned by satire.

A Trupo (Italian, in time), in music; of similar signification with a battula, and, like that expression, seldom used but when the time has been interrupted. - A tempo, in any kind of fencing or fyglting, means a blow or thrust at the same time with the antagonist's blow or thrust. It is, of course, necessary that a tempo blows should be made in sucl a way as to afford, at the same time, a guard against the other's thrust, or to prevent its full effect. This kind of blows takes place particularly in fighting with the broad-sword, when the antagonist leaves himself much exposed.

Atilaliair; daughter of Omri, king of Israfl, and wife of Joram, king of Judah ; a wonian of abandoned character, and fond of power, who, after the death of her son Ahaziah, opened lier way to the throne by the murder of forty-two princes of the royal blout. She reigned six years; in the seveuth, the high-priest, Jehoiada, placed Joash, the young son of Aliazial, on the throne of his father. This prince had been preserved and brought up sccretly in the temple by Jehosheba, the sister of Joram and wife of Jehoiada. Athalian, attracted by the noise of the people, who were crowding to the coronation of Joash, entered with thiem into the temple, where the ceremony was going on. At the sight of the new king, surrounded by priests, Levites, great officers of the kingdom, and the joyful people, she was beside lierself; slie tore her hair, and cried out, Treason! Jehoiada ordered her to be immediately led from the temple by the officers, and commanded that all who shonld offer to defend her should be slain; but she was put to death, at the gate of her palace, withont opposition. This happened about 877 B. C. The altars of Baal, which she had erected, were thrown down, and the worship of the true God restored. (See Second Book of Kings, viii. ix.) Racine has written a tragedy on this story.

A Trusus, in fabulous history; the son of Folns and Enareta, and governor of a part of Bootia. He was the husband of Nephele. Their children were Helle and Phryxus. Being afterwards separated from Nephele, he had by Ino, his second wife, Learchus, Melicertus, and Eurycleia. Ino, detr.'mining to get rid of the children of Nephele, caused a failure of the crops, and bribed the messengers, whom $A$. had sent to the oracle to inquire the cause of the misfortune, to bring for an answer, that the children of Nephele must be sacrificed. Juno had instigated her to this measure in order to destroy her, hating hor because she liad 
been the nurse of Baccluss. But the plan failed. Nephele preserved her children by means of the golden ram, and the messengers revealed the treachery of Ino, who would have inevitably felt the vengenuce of $A$., had not the grateful Bacchus conveyed away his nurse. $A_{\text {., }}$ supposing that she was put to death, married Themisto, the daughter of Hypsens, king of the Lapithr. But Ino returned, gained his lore once more, and excited the jealousy of Themisto to such a pitch, that she determined to murder Ino's children. With this view, she ordered their beds to be covered with black; but Ino, suspicious of some evil design, changed the clothes, and the unconscious Themisto murdered her own children, and became a victim to despair. Others

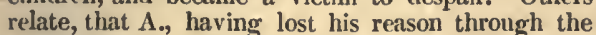
anger of Juno, and taking Ino and her children for a lioness and her whelps, seized Learchus, and dashed him against a stone; that he then pursued Ino, who, with Melicertus in her arms, plunged into the sea. Stained with blood, $A$. now abandoned Boeotia, and fled to Phthiotis, where he built Alos, and again united himself with Themisto; but, according to Pausanias, he first went to Andreus, who gave him the country around the mountain Laphystium, which afterwards came to the children of Phryxus.

Atulavasies, Saint; bishop of Alexandria ; a renowued father of the church, born in that city, about 296. He had a Christian education, and came into the family of Alexander, afterwards archbishop of Alexandria, whose private secretary he became. He then went to St Anthoury, led an ascetic life with that renowned anchorite, but at length returned to Alexandria, where he became a deacon. Alexander took him to the council at Nice, where he gained the highest esteem of the fathers, by the talents which he displayed in the Arian controversy. He had a great share in the decrees passed here, and thereby drew on himself the hatred of the Arians. Aftersix months, he was appointed the successor of Alexander. The complaints and accusations of his enemies at length induced the emperor Constantine to summon lim, in 334, before the councils of Tyre and Jerusalem. A. brought to light the iniquitous arts which had been practised against him, and threw his judges, who were likewise his enemies, into such confusion, that the imperial deputies could with difficulty rescue him from their anger. They could do nothing, lowever, further than suspend him from his office. He still continued in the discharge of his duties, until the emperor, deceived by new falsehoorls, banished him to 'Treves. The death of Constantine put an end to this banishment at the end of a year and some months. Coustantius, emperor of the East, recalled the holy patriarch. His return to Alexandria resembled a triumph. The Arians made new complaints against him, and he was condemned by ninety A rian bishops, assembled at Antioch. On the contrary, 100 orthodox bishops, assembled at $\Lambda$ lexandria, declared him innocent; and pope Julius confirmed this sentence, in conjunction with more than 300 bishops assembled at sardis, from the East and West. In consequence of this, he returned a second time to his diocese. But when Constans, emperor of the West, died, and Constantius became master of the whole exupire, the Arians ventured to rise up against A. They condemned him in the councils of Arles and Milan, and, as the wortlyy patriarch refused to listen to any thing but an express command of the emperor, when he was one day preparing to celebrate a festival in the church, 5000 soldiers suddenly rushed in to make him prisoner. But the surrounding priests and monks placed him in security. A., displaced for a third time, fled into the deserts of Egypt. His enemies pursued him even here, and set a price on his head. To relieve the hermits, who dwelt in these solitary places, and who would not betray his retreat, from suffering on his account, he went into those parts of the desert which were entirely uninhabited. He was followed by a faithful servant, who, at the risk of his life, supplied him with the means of subsistence. In this undisturbed spot, A. composed many writings, full of eloquence, to strengthen the faith of the believers, or expose the falsehood of his enemies. When Julian the Apostate ascended the throne, he allowed the orthodox bishops to return to their churches. A. therefore returned, after an absence of six years. The mildness which he exercised towards his enemies was imitated in Gaul, Spain, Italy, and Greece, and restored peace to the church. But this peace was interrupted by the complaints of the heathen, whose temples the zeal of A. kept always empty. They excited the emperor against him, and he was obliged to fly to Thebais to save his life. The deatly of the emperor, and the accession of Jovian, a gain bronght him back; but, Valens becoming emperor eight months after, and the Arians recovering the superiority, he was once more compelled to fiy. He concealed himself in the tomb of his father, where he remained four months, until Valens, moved by the pressing entreaties and threats of the Alexandrians, allowed him to return. From this period, he remained undisturbed in his office till he died, 373.- Of the forty-six years of his official life, he spent twenty in banishment, and the greater part of the remainder in defending the Nicene creed. A. is one of the greatest men of whom the church can boast. His deep mind, his noble heart, his invincible courage, his living faith, his unbounded benevolence, sincere humility, lofty eloquence, and strictly virtuous life, gained the honour and love of all. His writings are on polemical, historical, and moral subjects. The polemical treat chiefly of the mysterious doctrines of the Trinity, the incarnation of Christ, and the divinity of the Holy Spirit. The historical ones are of the greatest importance for the history of the church. In all his writings, the style is distinguished, considering the age in which they were produced, for clearness and moderation. His Apology, addressed to the emperor Constantine, is a masterpiece. The best edition is that of Montfaucon, 3 vols. fol., Paris, 1698. As a supplement to this may be added the $2 \mathrm{~d}$ vol. of the Library of the Church Fathers, by the same editor (1706).

A thapescow; a lake of North America, about 100 leagues long, and from 10 to 30 wide; long. $110^{\circ} \mathrm{W}$.; lat. $59^{\circ} \mathrm{N}$. The name is applied to the adjacent territory, and also to a river which flows into the lake. Slave river flows from it to Slave lake.

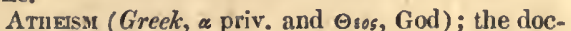
trine which teaches the non-existence of God, and is opposed to theism, or deism. As a disposition or a manner of thinking in regard to religion, it is the opposite of faith and belief. Atheism is always found to prevail most in the most depraved times; e.g., among the Greeks after Pericles, among the Romans after Augustus, among the French before the revolution, in the time of the systéme de la nature, \&c. As men lave at all times conceived very different ideas of the Supreme Being, it is evident that a great variety must lave existed in the definitions of atheism : thus we find that many of the most moral and noble men have been called atheists, because their idea of the Divine Being did not agree with that of the multitude; c. g., Spinoza, a pattern of virtue. And even in the present age, persons are not wanting who stamp every one with the name of atheist, who does not conceive God as separated from his creation, like 
รu şrist f foun his work, and governing it as un artist directs a machine. (Jthers luave askerl whether there ever existurl a resl ucluevist, becrause such a one could nut believe in any ditherrence betwer'n the good and the lat, the neble and the bise; and it is indeed doubtful whether one could be found, though some persons may pretend to this entire disbelief.

Atuelstas, king of Eingland, suceceded his father, Fiwar the Elder, in 920. Though of illegitimate birth, his age and talents caused him to be preferred to the lawful chilitren of Flwarl. He was victorious in his wars with the Dane's of Northumberland, and the Scots, by whom they were assisted. After a sigual overthrow of his enemies at Brunshury, he governud in pence and with great ability. In his reign a law was passed conferring the rank of thane on every merchant who had made three sea voyages on his own accomnt.

Atuelstaneronn; a parish and village in Haddingtonshire, Scotland, intersected by the Cogtal burn, having the river Peffer on the north, and Lugdown burn on the south. The parish also inclndes the villages of Drem and Gilmerton. The soil is light and gravelly, but well cultivated and fruitful. The inhabitants are chiefly employed in agriculture; and at the new and flourishing village of Gilmerton there is a woollen manufacture of variegated cloth bearing the same name. Garleton House, though in a ruinous state, was once a magnificent residence, and commands a noble prospect over East Lothian. Home, the author of "Douglas," and Blair, author of "The Grave," were ministers, and the latter a native of this parish. Here are vestiges of an extensive Danish camp, and the ruins of a cliapel built by the Knights Templars, and dedicated to St John. Population in 183i, 931.

Aтнамa. See Minerva.

Athenedu (At nosor). 1. The name of several places in Greece.-2. The celebrated school which Adrian established on the Capitoline mount. Many learned men received ample salaries for giving instruction in this institution, and that they might be enabled to study at leisure. Here, also, learned mell assembled to exchange ideas on their writings. In fact, it was what is now called a scientific academy. -3. A gymnasium, at Athens, dedicated to Minerva, and destined for assemblies of poets and orators. Instruction was also given there to the youth, and, in later times, the name was applied to all places of education for the young.-4. In modern times, the name given to different establishments which are connected with the sciences, as the Athenée in Paris. Public libraries frequented for the purpose of reading are also frequently called Athencums.

ATHEN.EOS ; a Greek rhetorician and grammarian, who lived at Naucratis, in Egypt, at the end of the second and beginning of the third century after Christ. He has left an encyclopadian work, in the form of conversation, called the Feast of the Sophists, which is a rich, but ill-arranged treasure of historical, antiquarian, philosophical, grammatical, \&c., knowledge. The principal edition is by Schweighæuser, Strasburg, 1801-7, in 14 volumes.

Atmevagoras; a platonic philosopher of Athens, a convert to Christianity, who wrote a Greek Apology for the Christians, addressed to the emperor Marcus Aurelius, in 177, one of the earliest that appeared. This legatio or deprecatio pro Christ. defends the Christians from the accusations brought against them by the heathens (of atheism, of incest, and of eating unurdered children), with a philosophical spirit, and a lively and forcible style. Linder published, in 1774 , the latest edition of this Apology; also a treatise on the resurrection of the dead, an able philosophical werk on the possibility and fitness of a resurrection.
Arness; called by the Turks Atliniah, ani also Setines; the culebrated city, whence the light of intellectual cultivation has spread for thususinds of years, down te our own time. 'I'his capital of the old kinglom of Attica, and of the mor" molern cleniocracy, was founded by Cecrops, 1550 years before Clirist, and in the most ancient times, was called Cecropia, which name, in afier tinnes, was retained merely by the Acropolis. Linder the government of Erichthonius, it lost its old name, and riceived that of Athens, probably from Minerva, who was called hy the Greeks Athend. The ald city was built on the sumnnit of some rocks, which lie in the midst of a wide and plensant plain, which becane filled with buildings as the inhabitants increased ; and this made. the distinction between Acropolis, and Catnpolis, or the upper and lower city. The citadel, or Acropolis, was 60 stadia in circunference, and included many extensive buildings. A. lies on the saronic mulf, opposite the eastem coust of the Peloponnesus. It is built on a peninsula formed by the junction of the Cephissus and Ilissus. From the sea, where its real power lay, it was distant about five leagues. It was connected, by walls of great strengtli and extent, with three harbours-the Piræus, Munyclia, and Phalerum. The first was considered the most convenient, and was one of the emporiums of Grecian commerce. The surrounding coast was covered with magnificent buildings, whose splendour vied with those of the city. "The walls of rough stone, which connected the larbours with the city, wore so broad, that carriages could go on their top). 'The Acropolis contained the nost splendid works of art of which A. could boast. Its chief ornament was the Parthenon, or temple of Minerva. This magnificent building, which, even in ruins, has been the wonder of the world, was 217 feet long, 98 broad, and 65 high. Destroyed by the Persians, it was rebuilt in a noble manner by Pericles, 444 years B.C. Here stood the statue of Minerva by Phidias, a masterpiece of art, formed of ivory, forty-six feet high, and richly decorated with gold, whose weight was estimnted at from forty to forty-four talents ( 2000 to $2: 00$ pounds), which, if we reckon, according to Barthelemy, the silver talent at 5700 livres, and the ratio of gold to silver as one to thirteen, would make a sum of $2,964,000$, or $3,260,400$ livres $(£ 123,500$, or $£ 135,850$ sterling). The Propylæum, built of white marble, formed the entrance to the Parthenon. This building lay on the north side of the Acropolis, close to the Erectheum, also of white marble, consisting of two temples, the one dedicated to Pallas Minerva, and the other to Neptune ; besides another remarkable binilding, called the Pandroseum. In the circle of Minerva's temple stood the olive-tree, sacred to that goddess. On the front part of the Acropolis, and on each end, two theatres are visible, the one of Bacchus, the other, the Odeum; the former for dramatic exhilitions, the latter for musical competitions, also built with extraordinary splendour. 'The treasury is also in the back part of the temple of Minerva. In the lower city were many fine specimens of architecture, viz the Poikile, or the gallery of historical paintings; besides the temple of the Winds, built by Andronicus Cyrrhestes, and the monuments of celebrated men. But the greatest pieces of architecture were without the city-the temples of Theseus and Jupiter Olympius, one of which stood on the north, the other on the south side of the city. The first was of Doric architecture, and resembled the Parthenon. On the metopes of this temple the famous deeds of old heroes and kings were excellently represented. The temple of Jupiter Olympius was of Ionic architecture, and far surpassed all the other buildings of Athens in splendour and 
heanty. Incalculable suns were spent on it. It was from time to time enlarged, and rendered more beautiful, until, at length, it was finished by Adrian. 'The outside of this temple was adorned by nearly 120 fiuted columns, sixty feet high, and six feet in diameter. The inside was more than half a league in circumference. Here stood the renowned statue of the god made by Phidias, of gold and ivory. The Pantheon (sacred to all the gads) must not be forgotten. Of this the Pantheon at Rome is an exact copy. Besides these wonderful works of art, Athens contains many other places which must always be interesting, from the recollections connected with them. The old philosophers were not accustomed, as is well known, to shut up their scholars in lecturerooms, but mingled with them on the freest and pleasantest terms, and, for this purpose, sought out spots which were still and retired. Such a spot was the renowned academy where Plato taught, lying abont six stadia north of the city, forming a part of a place called Ceramicus. This spot, originally marshy, had been made a very pleasant place, by planting rows of trees, and turning through it streams of fresh water. Such a place was the Lyceum, where Aristotle taught, and which, through him, became the seat of the Peripatetic school. It lay on the bank of the Ilissus, opposite the city, and was also used for grinnastic exercises.' Not far from thence was the less renowned Cyuosarges, where Antisthenes, the founder of the Cynic school, taught. The sects 'of Zeno and Epicurus held their meetings in the city. Zeno chose the well-known Poikile, and Epicurus established himself in a garden within the walls, for he loved both society and rural quiet. Not only literary, but political assemblies gave a particular interest to different places in Athens. Here was the court of areopagus, where that illustrious body gave their decisions ; the Prytaneum, or senate-house ; the Pnyx, where the free people of Athens deliberated. After twenty-three centuries of war and devastation, of changes from civilized to savage masters, have passed over this great city, its ruins still excite astonishment. No inconsiderable part of the Acropolis was lately standing. The Turks have surroundf'l it with a broad, irregular wall. In this wall one may perceive the remains of the old wall, together with fragments of ancient pillars, which have been taken from the ruins of thie old to construct new edifices. The right wing of the Propylæum, built by Pericles at an expense of 2012 talents, and which formed the ancient entrance, was a temple of victory. The roof of this building stood as late as 1656 , when it was destroyed by the explosion of some powder kept there. In a part of the present wall, there are fragments of excellent designs in basso relievo, representiug the contest of the Athenians with the Amazons. On the opposite wing of the Propylæum are six whole columns, with gate-ways between them. These pillars, half corered on the front side by the wall built hy the Turks, are of marble, white as snow, and of the finest workmanship. They consist of three or four stones, so artfully joined together, that, though they hare been exposed to the weather for 2000 years, yet 110 separation has been observed. From the Propylæum we step into the Parthenon. On the eastern front of this building, also, there are eight columns standing, and several colonnades on the side. Of the pediment, which represented the contest of Neptune aud Minerva for Athens, there is nothing remaining but the head of a sea-horse, and the figures of two women witlout heads; but in all we must admire the highest degree of truth and benuty. The battle between the Centaurs and Lapithae is better preserred. Of all the statue's with which it was adorned, tlat of Adrinn alone remains.
The inside of this temple is now clanged intu a mosque. In the whole of this mutilated building, we find an indescribable expression of grandeur and sublimity. There are also astonishing remains to be seen of the Firectheum (the temple of Neptune Erectheus), especially the beautiful female figures called Caryatides, and which form two arch-ways. Of hoth theatres there is only so much of the outer walls remaining, that one can estimate their former condition and enormous size. The arena has sunk down, and is now planted with corn. In the lower city itself, there are no vestiges to be found of equal beaniy and extent. Near a clurcl, sacred to Santa Maria Maggiore, stand three very beautiful Corinthian columns, which support an architrave. They have been supposed to be the remains of a temple of $\mathrm{Ju}$ piter Olympius, but the opinion is not well grounded: probably, they are the remains of the old Poikile. The temple of the Winds, built by Andronicus $\mathrm{Cyr}-$ rhestes, is not entire. Its form is an octagon: on each side it is covered with reliefs, which represent one of the principal winds: the work is excellent. The preservation of this edifice is owing to its being occupied by the dervises as a mosque. Of the moni . ments of distinguished men, with which a whole street was filled, only the fine one of Lysicrates remains. It consists of a pedestal surrounded by a colonnade, and is surmounted by a dome of corinthian architecture. This has been supposed to be the spot which Demosthenes used for his study, but the supposition is not well supported. What lord Elgin has done for the preservation of the remains of old Grecian architecture, may be seen by a reference to the articles on E/gin, and Elgin's Marble Monuments. Some prostrate walls are the only remains of the splendid gymnasium' built by Ptolemy. Outside of the city, our wonder is excited by the lofty ruins of the temple of the Olympian Jupiter. Of 120 pillars, 16 remain; but none of the statues are in existence. The pedestals and inscriptions are scattered here and there, and partly buried in the earth. The main body of the temple of Theseus has remained almost entire, but much of it, as it now stands, is of modern origin. The figures on the outside are mostly destroyed, but those which adorn the frieze within are well preserved. They represent the actions of the heroes of antiquity. The battle between Thesens and the Centaur is likewise depicted. On the hill where the famous court of areopagus held its sittings, you find steps hewn in the rock, places for the judges to sit, and over against these the stations of the accuser and the accused. The hill is now a Turkish burial-grouitd, and is covered with monuments. The Pnyx, the place of assembly for the people, not far from the Areopagus, is very nearly in its primitive state. One may see the place from which the orators spoke hewn in the rock, the seats of the scribes, and, at both ends, the places of those officers whose duty it was to preserve silence, and to make known the event of public deliberations. The niches are still to be seen, where those who had any favour to ask of the people deposited their petitions. 'The paths for running are also visible, where the gymnastic exercises were performed, and which Herodes Atticus (q. v.) built of white marble. The spot occupied by the Lyceum is only known by a quantity of fallen stones. A more modern edifice stands in the garlen in the place of the academy. In the surrounding space, the.walks of the Peripatetics can he discerned, and some olive-trees of high antiquity still command the reverence of the beholder. The long walls are totally destroyed, though the foundations are yet to be found on the plain. The Piraus has scarcely any thing of its ancient splendour, except a few ruined pillars, scattered here and there: the 
same is the case with the Phalerum and Munychia. Sonte litule commerce is carried un here, and a custom-house stands on the place.-Modern Athiens, in Livadia, lately contained 1300 houses, and 12,000 inhabitants, 2000 of whom were Turks. The Greeks here experienced from the Turks a milder government than elsewhere. They also retained some remains of their aucient customs, and amnually chose four archons. The Greek archbishop residing here had a considerable income. In 1822, the Acropolis, afcer a long siege, fell into the hands of the free freeks. In 1825, a Greek school, under the care of the patriot professor George Gennadios, was in a flourislung condition. The most thorough investigntion of the places among the ruins of $A$. worthy of attention, is contained in Leake's Topograplyy of Athen's, with some Remarks on its Antiquities, I.ondon, 1821, with an atlas in folio. (See Stuart and Revett's splendid work, the Antiguities of Achens, which the architect Eberhard copied, and had printed on zinc plates, and published, Darmstadt, I824, folio.) Leake makes it appear probable, that, in the time of Pausanias, many monuments were extant which belonged to the period before the Persian war; because so transitory a possession as Xerxes had of the city, scarcely gare him time to finish the destruction of the walls and principal public edifices. In the restoration of the city to its former state, Themistocles looked more to the useful, Cimon to magnificence and splendour ; and Pericles far surpassed them both in his buildings. The great supply of money which he had from the tribute of the other states, belonged to no succeeding ruler. A. at length saw much of her ancient splendour restored; bist, unluckily, Attica was not an island, and, after the sources of power, which belonged to the fruitful and extensive country of Macedonia, were developed by an able and enlightened prince, the opposing interests of many free states could not long withstand the disciplined army of a warlike people, led by an active, able, and ambitious monarch. When Sylla destroyed the works of the Piraus, the power of A. by sea was at an end, and with that fell the whole city. Flattered by the triumvirate, favoured by $\Lambda$ drian's love of the arts, $\mathrm{A}$. was at no time so splendid as under the Antonines, when the magnificent works of from eight to ten centuries stood in view, and the edifices of Pericles were in equal preservation with the new buildings. Plutarch himself wonders how the structures of Ictinus, of Menesicles and Phidias, which were built with such surprising rapidity, could retain such a perpetual freshne'ss. The most correct criticism on the accounts of Greece by Pausanias and Strabo is in Leake. Probably Pausanias saw Greece yet unplundered. The Romans, from reverence to wards a religion approaching so nearly to their own, and wishing to conciliate a people more cultivated than themselres, were ashamed to rob temples where the masterpieces of art were kept as sacred, and were satisfied with a tribute of money in Philipsdors, although in Sicily they did not abstain from the plunder of the temples, on account of the prevalence of Carthaginian and Phouician influence in that island. Pictures, even in the time of Pausanias, may have been left in their places. The wholesale robberies of collectors, the removal of great quantities of the works of art to Constantinople, when the creation of new specimens was no longer possible, Christian zeal, and the attacks of barbarians, destroyed, after a time, in A., what the emperors had spared. We have reason to think, that the colossal statue of Minerra Promachos was standing in the time of Alaric. About 420 A. D., paganism was totally annihilated at $\Lambda_{\text {. }}$ and, when Justinian closed eren the schools of the philosophers, the recollection of the mythology was lost. The Parthenon was turued into a cliurch of the Virgin Mary, and St George stepued into the place of Theseus. The mamufactory of silk, which had hitherto remainel, was destroyed by the trunsportation of a colony of weavers, by Roger of Sicily, and, in 1456, the place fell into the hauds of Onar. To complete its degradation, the city of Minerva obtained the privilege (an enviable one in the Fast) of being governed by a black eunuch, as an appendage to the haram. The Parthenon becaine a mosque, and, at the west eirl of the Acropolis, those alterations were commenced, which the new discovery of artillery then made necessary. In 1687, at the siege of $\mathrm{A}$. by the Venetians uncer Morosini, it appears that the temple of Victory was destroyed, the beantiful remains of which are to be seen in the 13ritish museum. September 28, of this year, a bomb fired the powder-magazine kept by the Turks in the Parthenon, and, with this building, destrojed the ever memorable remains of the genius of Phiclias. Probably, the Venetians knew not what they destroyed; they could not have intended that their artillery should accomplish such devastation. 'The city was surrendered to them September 29. They wished to send the chariot of Victory, which stood on the west pediment of the Parthenon, to Venice, as a trophy of their conquest, but, in removing, it fell and was dashed to pieces. April, 1688, A. was again surrendered to the Turks, in spite of the remonstrances of the inhabitants, who, with good reason, feared the revenge of their returning mas. ters. Learned travellers have, since that time, often visited $A . ;$ and we may thank their relations and drawings for the knowledge which we have of nrany of the monuments of the place. How little the Greeks of modern times have understood the importance of these buildings, is proved by Crusius' Tureo-Grecia. From them originated the names temple of the unknown God, lantern of Demosthenes, \&c. It is doing injustice to the Turks to attribute to them exclusively, the crime of clestroying these reinains of antiquity. From these ruins the (irreks have supplied themselves with all their materials for building for hundreds of years. The ruins are in the neighbourhood of inhabited places, and, in the seaport towns, are particularly exposed, because ease of transportation is added to the daily want of materials. In the mean time, the most accessible part of $A$. has rich treasures to reward well-directed researches; and each fragment, which comes to light in A., proves the all.pervading art and taste of this people. It is fortunate that many of the remains of Grecian art have been covered by barbarous structures, until a brighter day should dawn on Greece.

ATHEvs; a post-town of Georyia, United States, in Clarke co., on the Oconee; 92 W. N. W. Aigusta, 197 N.W. Sarannah. It has a very elevated, pleasant and healthy situation. It contained in 1827, npwards of seventy dwelling-houses, and nearly 1000 inhabitants. Franklin college, which, togethrer with the incorporated academies of the state, is styled the university of Georgia, was incorporated and established at this place in 1784 , but did not go into operation till 1803. The buildings consist of two large brick edifice's for the accominodation of students, a chapel, a steward's hall, a brick building for the chemical and the philosophical apparatus, and the library, which contains about 2000 volumes, and a building for a grammar-school, which is connected with the college. The government and instruction of the college are intrusted to a president, four professors and two tutors. The number of students, in 1827, was 100 .

A Truess ; a small post-town of Ohio, United States, and capital of a county of the same name It is situated on as elevated peninsula,' formed by a 
large bend of the IJockhocking, which meanders about the town. The situation is pleasant and healthy, and commands an extensive prospect. $\Lambda \mathrm{n}$ institution is established here, styled the Ohio unieersity, which is endowed with 46,000 acres of land, yielding about 2300 dollars annually. A college edifice of brick, large and elegant, was erected in $181 \%$.

ATHLETE; combatants who took part in the public games of Greece ; also, young men who went through the grmnastic exercises to harden themselves, and to become fit to hear arms. In a narrower sense, the athletæe were those who made the athletic or gymnastic exercises their principal business, particularly urestlers and boxers. The two following cuts represent these in the act of conflict. The figures are taken froin ancient sculptires.
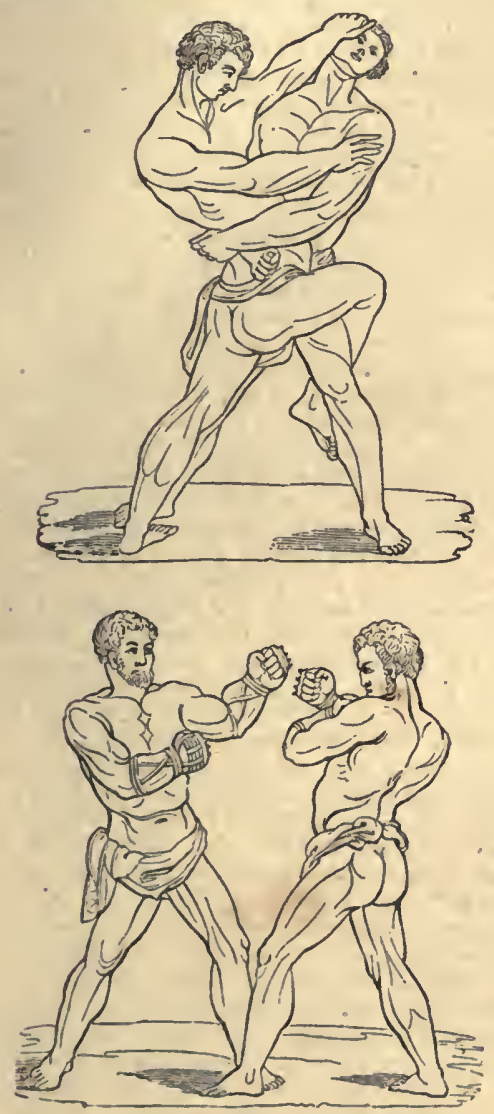

The business of Athletie was to contend at the public festivals; and they regulated their habits of life with reference to this purpose. They were well fed, and were obliged to abstain from intercourse with the other sex. Before they were perunitted to exhibit themselves at the public ganes, inquiries were made respecting the birth, rank, and conduct of each A herald called out the name of the athlete, and demanded of all whether they had any objection against him. After this examination, and after the athlete had taken an oath that he had complied with ail the conditions required, and that he wonld strictly obey the laws of the contest, permission was given him to contend. The antagonists were designated by lot. Not only the applause of the people, but also crowns arid statues, were con- ferred upon the victor. He was led in triumph; his name was written in the public records ; an Olympiad was naned after him, and poets sang his praise. He also received peculiar privileges, had a yearly pension, and the foremost seat at the sacred games. Particular honours were conferred on him by his native city, for all his fellow citizens partook of his glory. See Gymnastics.

Athol, or Athole; a mountainous and romantic district, situated in the north of Perthshire, Scutland. It is 45 miles in length, and $30 \mathrm{in}$ breadth, and comprehends a great portion of the ancient Caledonian forest. In the eighth century it constituted with Storinont the possessions of a Pictisl prince. It contains several lakes and richly cultivated valleys, and in tlie extensive forest of Athol gane of various kinds are abundant. There are no towns, but many villages lie interspersed throughout the country. Athol gives the title of duke to the ancient house of Murray. His grace possesses the greater part of the district, and occasionally resides at Athol house, a castle seated on an eminence, at the foot of which runs the turbulest stream Garry. It is of great antiquity, and was formerly an important fortress, noted for having caused the battle of Killicrankie in 1689 , and standing several weeks' siege against the partisans of the Pretender in 1746, prior to the battle of Cullodell. Athole signifies pleasant land, and Blair of Athole, which is the name of its principal valley, signifies the field or vale of Athole. Athole Brose is the name of a beverage used by the people of this country, compounded of lioney and whiskey aınalgamated into is syrup. In addition to its other recommendations, this popular compound is considered to be very effective in overcoming colds, especially when taken over-night.

Arnos, llow Agion Oros, or Monte Santo; a high mountain or the extremity of a long chain of inountains in the province of Salonica, in European Turkey, which runs through a peninsula seven miles long, and three miles brond into the Archipelago. Xerxes caused a canal, half a league wide, to be dug through the neck of land which connects the peninsula with the continent, for the purpose of conducting his fleet to Thessaly. The mountain is about 5900 feet above the level of the sea, and is inhabited by Greeks. On the sides are about twenty monasteries, and a multitude of hermitages, which contain more than 6000 monks, mostly Russian, of the order of St Basil. These live here in a perfect separation from the world, and unde: such strict regulations, that they do not tolerate any female being, not even of the class of domestic animals, among them. They are also extremely industrious: they carve statues of the saints, Agni Dei and Patemosters, which they send to the market-town of Kareis, on the mountain, where weekly markets are held, and to the rest of Europe, especially to Russia. They also collect alms, to pay their heavy taxes to the pacha and the Porte. They have many schools. The holy mountain is considered one of the most important seminaries for instruction among the Greeks, and the libraries of the monasteries are rich in literairy treasures, particularly in manuscripts, partly procured from Constantinople, before its conquest by the T'urks; partly presented to them from the same place, and partly written by the laborious monks. Many books have been brought thence to the great collections at Paris, Vienna, \&c. Their monasteries and churches are the only ones in the Ottoman empire which have bells.

ATHWART (par le travers, Fr. from $a$ and twert, Dan., transverse), when used in navigation, implies across the line of the course.

Atuwart-Hawse; the situation of a ship when slie is diven by the wind, tide, or other accident, across the forepart of another. This phrase is equally ap- 
plied when the ships hear agrainst eneh other, or when they are at a sinall distance; the transverse position of the former to the latter being principally understood. - Athreart the fore-foot denotes the flight of a canion-ball from one ship across the course of another, to intercept the latser, and oblige her to shorten sail, that thic former may come near enongh to examine her.

Atlastic OCEan; the mass of water between the western coast of Europe and Africa, and the enstern const of America; the only considerable aquatic comnunication between the polar extremities of the earth, if wc do not give to both its extremities the naine of the Frozen ocean. The nane is derived from Atlas. (q. v.) The Atlantic, in its narrowest fart, between Furope and Greelland, is upwards of 1000 miles wide, and operling thence to the S.W. with the general range of the bounding continents, spreads, under the northern tropic, to a breadth of 60 degrees of longitude, or $\mathbf{4 1 7 0}$ miles, without estimating the gulf of Mexico. Beyond the torrid zone, the A. infects to the N. W. and S. E., again complying with the bearing of the adjacent continents, which currespond with great exactness to each other. The A. and its gulfs occupy about the serenth part of the superficies of the globe, curving round the western, southern, and northern part of the eastern continent, from $72^{\circ} \mathrm{N}$. lat. to $35^{\prime \prime} \mathrm{S}$. lat., or through 107 degrees of latitude. This immense strait is linited, on the west, by the most lengthened land-line, extending north and south, that can be drawn on the earth. "When we cast an eye over the Atlantic," says Humboldt, in his Personal Narrative, "or that deep valley which divides the western coasts of Europe and Africa, from the eastern coast of the new continent, we distinguish a contrary direction in the motion of the waters. Between the tropics, especially from the coast of Senegal to the Caribbean sea, the general current, that which was earliest known to mariners, flows constantly from east to west. This is called the equinoctial current. Its mean rapidity, corresponding to different latitudes, is the same in the Atlantic and Southern oceans, and may be estimated at 9 or 10 iniles in 24 hours; consequently from 59 to 65 hundredths of a foot every second of time." This great observer also says, "In comparing the observations which I lad occasion to make in the two hemispheres, with those which are laid down in the Voyages of Cook, la Perouse, d'Entrecasteaux, Vancouver, Macartney, Krusenstern, and Marchand, I found that the swiftness of the general current of the tropics varies from 5 to 18 miles in 24 hours, or from one third of a foot to one and two-tenths per second." The western equinoctial current is felt, though feebly, as high as $28^{\circ} \mathrm{N}$. lat., and about asfar south, though it must be in excess along the equator. The eastern salient point of South America being in upwards of $6^{\circ} \mathrm{S}$. lat., the great mass of ocean fiood is unequally divided. South from cape St Roque, the current is turned down the coast of Sonth A merica, and between $3)^{\circ}$ and $48^{\circ} \mathrm{S}$. lat. reacts towards Africa. North from cape St Roque, the coast of South America bends to a general course of N. $62^{\circ} \mathrm{W}$., and with the Caribbean sea and the gulf of Mexico, maintains that direction to the mouth of the Rio Graude del Norte, 2560 miles. Along this coast, the equinoctial current is inflected northiward, and augmented by (vnstant accimulations from the east; the whole body pouring through the various inlets between the Windward islands of the West Indies into the Caribbean sea, and thence, between Cuba and Yucatan, into the Gulf of Mexico. In the latter reservoir, it has reached its utmost elevation, and again rushes ont into the A. through the Cuba and Bahama or Florida channel, and, sweeping along the coast of the United
States anul Nuva Scotia, to about $50^{\circ} \mathrm{N}$. lat., ments the Aretic currents from Davis's straits, and from the Northern Atlantic ocean, is turned towards F:urope and the north-west of Africa, and is fually merged in its origisal source within the tropics. To this ocenic river has been given the name of gulfstream. It is the second most exteusive, and much the most strongly marked whirlpool on the globe, having an outline of about 15,000 miles. The mean motion of the gulf-streain is, no doubt, changeable, even at the same points. The time of its periodical revolution is about 2 years, and the maximum of motion in the Bahama channel. IHumboldt notices this phenomenon thus :- "In the Florida chanuel, I observed in the month of May, 1804, in the 26th and 27 th degrees of latitude, a celerity of 80 miles in 24 hours, or 5 feet every second, though at this period the north wind blew with great violence. . At the end of the gulf of Florida, in the parallel of cape Cannaveral, the gulf-stream or current of Florida, runs to the N.E. Its rapidity resembles that of a torrent, and is sometimes five miles an hour." (For further information on this subject, see the article Current, and also Darby's View of the United States, Pliladelphia, 1828.)-Humboldt endeavoured to ascertain thc comparative height of the waters of this ocean along its shores, and that of the Pacific on the opposite side of the isthmus, taking the level of the gulf of Mexico as a standard. He found the surface of the former to be six or seven metres higher than that of the latter (nineteen or twenty-two feet, English measur(c). The depth of the A. is also extremely various, in many places being wholly beyond the power of man to fathom. Captain Scoresby, in the Greenland sea, in 1817 , plumbed to the greatest known depth which a line has reached, i. e. 7200 feet. Many parts of this ocean, however, are thought to be much deeper. -The saltness and specific gravity of the $A$. differ in various parts, and gradually diminish from the equator to the poles. In the neighbourhood of the British isles, the salt has been stated at one-thirtyeighth of the weight of the water; and, according to $\mathrm{Dr}$ Thomson, the proportion of saline contents does not appear to differ much, whatever may be the latitude in which the water is examined. 'The variation resulting from all the observations of Pages, Phipps, and Baumè, is from 0.0451 to 0.35 saline inatter. The temperature of the $A$. is highest between $5^{\circ} 45^{\prime}$ and $6^{\circ} 15^{\prime} \mathrm{N}$. lat., where it has been found, by actual observation, to vary from abont $82^{\circ}$ $5^{\prime}$ to $84^{\circ} 5^{\prime}$ of Fahrenheit. Peron and Humboldt give several interesting results of their observations. The currents and the masses of ice which go from the north, in the general current, to the equator, change the temperature of the water very mucli. Fragments of these icebergs occasionally reach the 40 th degree of latitude. In the months of June and July, they add much to the donger of a passage between North America and Europe. We do not know that there exists an exact comparison of the natural history of the A. with that of other oceans.

A trantica, Atland eller Manheiin; a work, in Latin and Swedish, by O. Rudbeck, in which the author, with great learning, labours to prove a ludicrous hypothesis, that the Atlantis of the ancients was Sweden, and that the Romans, Greeks, Fnglish, Danes, and Germans, originated from Sweden. The work is a typographic rarity. The first volume appeared in 1675-79, at Upsal ; several editions of it followed. The last Latin edition is of 1699, and bears a high price. Written copies of it are in several European libraries.

Atrantides ; pillars, in the form of a man, usel in building, to support a projection or a cornice. See Caryatides. 
Arlusrs; among the ancients, the name of an lows, that, at twenty-eight inclies barometrical island in the Atlantic, of which vague accounts had height, the atmosphere presses with a weight of been received from ships which had ventured into 32,440 pounds on the human body, estimated at the oceal. Their descriptions of its situation were fifteen square feet. The man does not perceive this very indefinite, and, as they placed it in a spot where pressure, because the air entirely surrounds him, and afterwarls no island was found, it was supposed that is, besides, within hin. On account of its elasticity, it had sunk. But some persons inagine that Phœui- it presses in every direction, even from within the cian or Carthaginian merchant-ships (as we know man outwards, and consequently counterbalances the lappened to a l'ortuguese ship in the time of Colum- air spread over the body. That the atnosphere has bus), being driven out of their course by storms and not a uniform density, may be inferred from this, that ('In'rents, were forced over to the American coasts, from which they afterwards fortunately returned to their country; and that, therefore, the island of $\mathrm{A}$. mentioned by Plato, as well as the great nameless island spoken of by Diodorus, Pliny, and Arnobius, was nothing inore than what is now called America. -The most distinct account of the island of $A$. is in I'lato's Timaus. See Atlantica.

$\Lambda$ TLAs ; a chain of mountains which extends over a large part of Northern A frica. The Greater A. luns through the kingdom of Morocco, as far south as Sahara, and is more than 11,000 feet high. The Lesser A. extends from Morocco, towards the N. E., to the northern coast.-The mythology of the Greeks assigned this mountain to a Titan, son of Japetus and Clymene. Jupiter, the conqueror of the Titans, condemned him to bear the vault of heaven; which fable arose from his lofty stature. He was endowed with wisdom, and later accounts ascribe to him much knowledge, particularly of astronomy. By Pleione, the daughter of Oceanus, he had seven danghters, who, under the name of Pleiades (called, likewise, after their father, Atlantides), shone in the hearens. According to some, he was also the father of the Hyades.--Atlas, in anatomy, is the name of the first rertebra of the neck, which supports the head.-Atlas, in commerce; a silk cloth manufactured in the East Indies. The manufacture is admirable, and, as yet, inimitable by Europeans; yet it las not that lustre, which the French know how to give to their silk stuffs.-Atlas, a name given to collections of maps and charts; so called from the giant who supported hearen. This nane was first used to signify a geographical system, by Gerard Mercator, in the 16th century.

Atnosphere; commonly, the air in which our parth appears to swim; but, in the widest sense, it is llat mass of thin, elastic fluid, with which any body is completely surrounded. Hence we speak of an atmosphere of the sun, of the moon, of the planets, of electric and magnetic bodies, \&c., the existence of which nay riot be fully proved, but is more or less probable. It is certain that our earth has an atmosphere, by which, according to the preceding definition, we understaind the surrounding body of air and vapour. By means of its weight, the air is inseparably connected with the earth, and presses on it according to the laws of heavy, elastic fluids. Its whole pressure is equal to its weight, and, like that of all other heary, elastic fuids, is exerted equally on all sides. If, now, by any circumstance, a stronger pressure is exerted on one side, certain phenomena are observed, which continne till the equilibrium is restored. Thus, for instance, water ascends, in the bore of a pump, above its general level, as soon as a vacuum is made between it and the piston, which is drawn up. The cause of this is the disturbance of the equilibrium, since the air without the bore presses on the water without, while no air is present within. By means of this pressure, if the bore is long enough, the water may be raised to the height of thirty-two and a half feet. 'This is the weight with which the atmosphere presses on the earth, and which is equal to the pressure of an ocean thirty.two and a half feet deep, spread over the whole eartit. Hence it folthe lower strata of the air have to support the weigh of the upper ones, on which account they must become mure compressed and denser. According to the law of Mariotte, the density of the atmosphere diminishes in geometrical, while the height increases in arithmetical progression. This law may not hold at the extreme limits of the atmosphere, because the air at that height, free from all pressure, nust be completely in its natural state. The height of the atmosphere has been estimated, by natural philosophers, at froin thirty to forty miles-partly from the pressure which it exerts, partly from the twilight ; since it is to be supposed, that the air, as far as it reflects light or receives illumination, belongs to our planet. Delambre, however (Astronomie, vol. iii., p. 337 ), considers this height to be almost forty-six miles, which, remarkably enough, Kepler has mentioned in the Cap. Astr., p. 73. According to the admirable paper of Dr Wollaston, on the limits of the atmosphere, the height cannot be less than forty, or more than fifty niles. (See Phil. Trans.)-In respect to its form, the atmosphere may be considered as a spheroid, elevated at the equator, on account of the diurual motion of the earth, and also on account of the great rarefaction of the air by the sun's rays, which there exert a powerful infuence. The constituent parts of the earth's atmosphere are nitrogen and oxygen, which are found every where, and at all times, nearly in the proportion of 79 to 21 . Beside these, there is a small portion of carbonic acid, a variable portion of aqueous vapour, and a very small, indefinite quantity of hydrogen. (See Gas.) It also contains, in the form of rapour, a multitude of adventitious substances, in those injurious mixtures known under the nane mias. mata, the nature of which can hardly be investigated. As to the manner in which these difierent ingredients are united, various hypotheses have been formed, of which that of Dalton, which denies a chemical mixture, is one of the most celebrated, but also the most opposed. See De Luc's Recherches sur les Modifications de l'Atmosphère, 2 vols. 4 to., Geneva, 1772 (in German, Leipsic, 1776-78), and the section d'Atmosphère, in Biot's Traité d'Astronomie Physique, 2d ed., Paris, 1810,3 vols. On the atmosphere of the sun, monn, and the other planets, see the respective articles. See, also, Air.

Aтомs; according to the hypothesis of some philosophers, the primary parts of el-mentary matter not any further divisible. Moschus of Sidon, who is said to have lived before the Trojan war, taught, as we are told, that the original matter is composed of small, indivisible bodies. Leucippus (510 B. C.) established a system respecting the origin of the world, resting on the mixture of atoms, in which chance goverued, in opposition to the immaterial system of the Eleatics, who contended, that whatever existed was only one being, and that all apparent changes in the universe are mere illusions of sense. Deinocritus and Epicurus extended this system: the latter, particularly, made many additions to it. Lucretius, and, among the moderus, Gassendi, have illustrated the doctrine of Epicurus, Descartes formed from this his system of the vortices. Newton and Boerlnave supposed that the original matter consists $28-T \%$ 
of hanl, pondernhle, impeuetrable, inactive, and iumutable particles, from the variety in the composition of which, the variety of boclies originates. A system founded on the theory of atomis is called atomic, e. g., that of le Sage; sometimes it is also callel corpuscular philosophy, and is opposed to the dynamic theory. (See this article.) In Germany, the theory of atoms finds very few adherents: it is geuerally thought, in that country, a gross conception of the universe, and a very musatisfactory one, as it only removes the question respecting the nature of matter one step farther. In France aud Britain, the number of believers in it is gruater.

A томис Tuвов, in chemistry. Two opposite opinions lave long existel concerning the ultimate elements of matter. It is supposed, according to one party, that every particle of matter, however small, may be divided into smaller portions, provided our instrunents and organs were adaptel to the opera. tion. Their opponents contend, on the other hand, that matter is composed of certain atoms, which are of such a nature as not to admit of further division. Thesc opposite opinions have, from time to time, been keenly contested, and with variable success, according to the acuteness or ingenuity of their respective champions. But it was at last perceived that no positive data existed capable of deciding the question ; and its interest, therefore, gradually declined. The progress of modern chemistry has revived the general attention to this controversy, by affording a far strouger argument in favour of the atomic constitution of bodies than was ever advanced before, and which seems almost irresistible. We have only, in fact, to assume, with Mr Dalton, that all bodies are composed of ultimate atoms, the weight of which is different in different kinds of matter, and we explain at once various laws of chemical union. According to this view, every compound is formed by a combination of the atoms of its constituents. An atom of A. may combine with $1,2,3$, or more atoms of $B-$ an arrangement on which depends the law of multiples. If water, for example, is composed of an atom of hydrogen and an atom of oxygen, it follows that every compound of hydrogen with au additional quantity of oxygen, must contain 2, 3, or more atoms of oxygen; some multiple, in a word, by a whole number of the quantity of oxygen contained in water. It is equally clear, from this view of the composition of water, that the weight of an atom of oxygen is eight times heavier than an atom of hydrogen. The relative weight of the atoms of other substances may be determined in a similar manner. Thus an atom of carbon is six times, an atom of sulphur sixteen times, and an atom of chlorine thirty-six times, heavier than an atom of hydrogen; and this explains why they unite with one another in the proportions expressed by those numbers. What are called the proportional numbers are, in fact, nothing else but the relative weights of atoms. No one can suppose that the laws of chemical union are the effect of chance: there must be some cause for them in the nature of the ultimate particles of matter. This cause, as we have just seen, is completely supplied by the supposed atomic constitution of bodies, which accounts for the phenomena in the most beautiful and consistent manner. So perfect, indeed, is the explanation, that the existence of these laws might have been predicted by the aid of the atomic hypothesis long before they were actually discovered by analysis. But these are not the only arguments which we at present possess in favour of the existence of ultimate indivisible particles of matter. Doctor Wollaston, in his paper on the Finite Extent of the Atmosphere (Philosophical Transactions, 1822), has defended this side of the question on a new and independent principle; and the proof he has given of the atomic constitution of bollies appears decisive. Sone chemists, even without expressly adopting the atomic theory itself, have followed Mr Dalton in the use of the terms atom ancl atomic weight, in preference to proportion, combining proportion, equivalent, and others of a likc kind. All these appellations, however, have the same signification; and, in using the worl atom, instead of the others, it should he held in mind that it merely denotes the proportions in which bodies unite; that it is the expression of a fact which will remain the sane, whether the atomic liypothesis which suggestrd the employment of the term be true or false. There is one circumstance which, at first view, seems hostile to the supposed atonic constitution of matter. According to the law of multiples (sec Chemical Equivalents), oxygen in the three oxides of lead is in the ratio of $1: 1 \frac{1}{2}: 2$; so that, if we regard the protoxide as composed of one combining proportion of lead to one proportion of oxygen, the second will contain one proportion and a lialf, or, according to the atomic theory, one atom and a half of oxygen. Now, though the half of a combining proportion inay be admitted, the existence of half an indivisible particle of matter is inconceivable; and this circumstance would be fatal to the atomic theory, were there not some satisfactory mole of accounting for it. Several explanations night be brought forward. One of them, which has found its advocates, rests on the supposition that what is called the protoxide, is, in reality, composed of one atom of lead to two atoms of oxygen; and that the real protoxide has not yet been discovered. Another mode of accounting for the anomaly is, by regarding the present deutoxide as composed of the protoxide and peroxide combinct with each other. $\Lambda$ third method is, by doubling both elements of the anomalous compound, by which the exact ratio is preserved, and the idea of the fraction of an atom is aroided. Thus the protoxide ant peroxide of iron are composed, the first, of one proportion, or 28 of metal +8 of oxygen, and the second, of 28 of metal + an atom and a half, or 12 of oxygen; or, what amounts to the same thing, of 56 , or two atoms of iron, to 24 , or three atoms of oxygen. These observations prove, that the occurrence of half proportions is not inconsistent with the atomic constitution of bodies: they show that the difficulty is explicable, and probably will, in the progress of discovery, be entirely removed. In the meantime, however, it would be inconvenient to allow any speculative notions on the subject to interfere with actual practice; and, therefore, it is best at once to admit the occurrence of half proportions; and, if any one prefer the term atom to equivalent or proportion, he must submit to the somewhat jarring expression of half an atom. Mr Dalton supposes that the atoms of bodies are spherical, and has invented certain symbols to represent the mode in which he conceives they may combine together. (See his New System of Chemical Philosophy.)-There are several questions relative to the nature of atoms, most of which will, perhaps, never be decided. Of this nature are the questions which relate to the actual form, size, and weight of atoms, and to the circumstances in which they mutually differ. All that we know with any certainty is, that their weights do differ, and by exact analysis the ratios between them may be determined. The numbers which indicate the combining proportions of bodies, are, in fact, the relativc weights of their atoms.

Atool, or Atrowa, or Artoway, or Towt one of the Sandwich islands, in the Pacific ocean; about thirty miles in length from E. to W., according to some; others makc it 300 miles in circumference. It has a good road and anchoring-place on the S. W. 
side of the island, called $W$ ymoa. It is supposed to contain 12,000 inhabitants. The natives make canoes of fine workmanship. Some of them, from the frequent visits of British and American navigators, are able to converse in English. Several Europeans reside here. Lon. $200^{\prime} 20^{\prime}$ E. ; lat $21057^{\prime}$ N. See Sandwich Islands.

Atrebates; the ancient inhabitants of Gallia Belgica; who possessed that part of Gaul afterwards called Artois. A colony of them settled in Britain. Cresar mentions them as one of the nations confederated against him, and as having engaged to furnish 15,000 troops to the allied army. The Atrebates, or Atrebatii, in Britain, resided next to the Bibroci, in a part of Berkshire and Oxfordshire. They were one of the tribes which submitted to Casar.

Atrevs, in faluulous history, son of Pelops and Hippodamia. He and his brother Thyestes murdered their half-brother Chrysippus, from jealonsy of the affection eutertained for him by their father. Thereupon, they fled to Eurystheus, with whose daughter, Erope, A. united himself, and, after the death of his father-in-law, became king of Mycene. Thyestes, yielding to an unlawful passion for the wife of his brother, dishonoured his loed, and had two sons by her. A., after the discuvery of this injury, banished Thyestes, with his sons. Thirsting for revenge, Threstes conveyed away secretly a son of his brother, and instigated him to murder his own father. This design was discovered, and the youth, whom $A$. thought to be the son of his brother, was put to death. Too late did the unhappy father perceive his mistake. A horrible revenge was necessary to give him consolation. He pretended to be reconciled to Thyestes, and invited him, with his two sons, to a feast, and, after he had caused the latter to be secretly slain, he placed a dish made of their flesh before Thyestes, and, when lie had finished eating, brought the bones of his sons, and showed him, with a scornful smile, the dreadful revenge which he had taken. At this spectacle, the poets say, the sun turned back in his course, in order not to throw light upon such a horrible deed.

A trides. See Agamemnon.

ATRIP (trepor, Fr.; trippen, Dutch) is applied indifferently to the anchor or to the sails. The anchor is atrip (derangée), when it is drawn out of the ground in a perpendicular direction, either by the cable or buoy-rope. The top-sails are said to be atrip, when they are hoisted up to the mast-head, or to their utmost extent.

Aтropry is a deficient nourishment of the body. There are many diseases in which the body becomes daily more lean and emaciated, appears deprived of its common nourishment, and, for that reason, of its coumon strength. It is only, therefore, in those cases in which the emaciation constantly increases, that it constitutes a peculiar disease ; for when it is merely a symptom of other common diseases, it ceases with the disease, as being merely a consequence of great evacuations, or of the diminished usefulness or imperfect digestion of the nourisliment received. But, whien emaciation or atroply constitutes a disease by itself, it depends upon causes peculiar to this state of the system. These causes are, permanent, oppressive, and exhausting passions, oroanic disease, a want of proper food or of pure air, exhausting diseases, as nervous or malignant fevers, suppurations in important organs, as the lungs, the liver, \&c. Copious evacuations of blood, saliva, semen, \& c., are also apt to produce this disease, and, on this account, lying-in women, and nurses who are of slender constitution and those who are too much addicted to veuery, are often the subjects of this complaint. This state of the system is also sometimes produced by poisons, e. g.s arsenic, mercury, lead, in miners, painters, gilders, \&c. - A species of atrophy takes place in old people, in whom an entire loss of strength and flesh brings on a termination of life without the occurrence of any positive disorder. It is known as the marasmus senicis, or atrophy of old people. Atrophy is of frequent occurrence in infancy, as a consequence of improper, unwhiolesome food, exposure to cold, damp, or impure air, \&c., producing a superabundance of mucus in the bowels, worms, obstructions of the mesenteric glands, followed by extreme emaciation, which state of things is often fatal, although the efforts of the physician are sometimes successful, when all the causes of the disease have been previously removed. A loca: state of the same kind is sometimes produced in single limbs, by palsies, or the pressure of tunours upon the nerves of the limb, \&c., and is generally curable. by removing the cause.

Atropos ; one of the Fates. (q. v.)

Atracca, Italian (attach), signifies, in music, tlıt a passage is to follow another immediately; e. g., attacca allegro.

AттACHsinst, in English law, implies the taking or apprehending of a person by virtue of a writ or precept. It is distinguished from an arrest by proceeding out of a higher court by precept or writ; whereas the latter proceeds out of an inferior court by precept only. An arrest lies only against the body of a man; whereas an attachment lies often against the goods only, and sometimes against the body and goods. In some countries, a creditor may previously attach another person's property, real or personal, to satisfy the judgment he may recover: in other states, no such previous attachment can ordinarily be made, and is permitted only in case of absconding debtors, or other particularly excepted cases. And the more general and prevailing rule throughout the world is, that the property of a person can be seized only in pursuance of a judicial order or decree, made upon testimony being produced, and the party heard; and between a creditor and debtor, the more general and almost universal rule is, that the creditor cannot seize the goods or property of his alleged debtor until the debt is established by the proceedings of a judicial tribunal. In regard to the person, attachments or arrests are made for a variety of causes, and among others, for debt. But, in respect to an arrest of the person, as well as that of property, the laws of most countries do not permit the person of any citizen to be seized and imprisoned without a decree or judgment of a court directly authorizing the arrest. But in some of the states of the American Union, a creditor to the amount of five dol lars, or some other amount, grenter or smaller, may arrest his debtor, at the commencement of the process against him, in order that the creditor may have his body to levy execution upon. when the debt slall be established by a judicial decree or judgment. But attachment of the person for this cause is not permitted by the laws of most countries, except in cases of the apprehended absconding of the debtor; this being an exception to the rule most generally adopted, which is, that the creditor first estublishes his debt, and gets judgment and execution upon it, before he call use it as an instrument for violating the personal liberty of lis debtor. In cases of alleged crime, the person of the accused party is seized, and he is imprisoned, or compelled to give bail by the laws of all countries; but he is most generally first taken before a magistrate, and permitted to slow cause against being imprisoned, or required to give bail.-Another cause of attachment is, the defendant's not appearing at court, after being sum monied by subpona (an order of court prescribing a penalty 
in case of disobedience) out of a court of chancery. His not obeying is considered to be a contempt of the court, which thereupon orders lim to be arrested, and brought into court. But attachnent for this cause is not made in a court of law ; for if the defendant, being summoned, does not appear, on being called in court, his default is noted, and the court proceeds to give judgment against hin, upon such testimony as the plaintiff may produce. One reason of this distinction between a court of equity and a court of law is, that the presence and agency of the defendant are requisite, in many equity cases, in order to carry into effect the judgment of the court ; as when the court decrees the specific execution of an agreement, or the rendering of an account, or the disclosure of facts by the defendant upon his oath. Attachments are issued by courts for various other contempts, as against an officer of a court, for a busing the process of the court, e.g., if he refuse to $\mathrm{ex}$ ecute it without a bribe from a party; against a witness who refuses to appear when summoned for the purpose of giving testimony, or who refuses to testify, after he has appeared, before a court of law or a grand jury ; against any person, whether an officer of the court, a party, witness, or mere bystander, for disonderly conduct in the presence of the court, whereby its proceedings are disturbed and the administration of justice interrupted ; for attempting to corrupt a juryman, or forcibly detain a witness who is summoned to testify in a case ; for publishing an account of the proceedings of the court while a cause is pending, in such a manner that the minds of the judges or jurors may be prejudiced by such publication; for obstructing the serving any writ or process of the court ; for taking out an execution where there is no judgment ; and, in general, an attachment lies against any person who directly obstructs or interferes with the regular administration of justice. It lies against the judges of an inferior court who proceed in a case contrary to the order of a superior court.

ATtACHMEVT, FOREg.s, is the attachment, by a creditor, of a debt due to his debtor from a third person ; called foreign attachment, from its being one mode of securing debts due from foreigners. In Scotland, it is called assisting the debt. In London, the process is called a garnishment, or warning, the person summoned being the garnishee. The same process is in some of the United States, called the trustee process, and the person summoned is called the trustee, on the supposition of his having in his hands and possession, or being intrusted with, the money or goods of the principal debtor.-The general rule, as to arresting debts due from third persons, by for. eign attacliment, is, that only absolute debts can be so attached, not the claims which the principal debtor niay have against the garnishee, or supposed trustee, for damages on account of trespasses and wrongs done to him by the garnishee or supposed trustee. As the process is instituted to recover a supposed debt due to the plaintiff from the principal defendant, by obtaining satisfaction of a debtor of that defendant, he must hare notice, and be made a party to the suit, and have an opportunity to dispute the demand of the plaintiff; and the law, in some instances at least, allows the garnishee or trustee, if he be really a debtor to the principal defendant, to take upon himself the defence against the plaintift's demand.

ArTACK. Every combat consists of attack and defince: the first, with few exceptions, will always be more advantageous : hence an experienced general chooses it, if possible, even in a defensive war. Nothing is more ruinous than to lose its advantage; and it is one of the most important objecss to deprive an ndversary of it, and to confine him to the defensive. The attack is directed according to the condition and position of the enemy, according to the purpose of the war, acconling to place, time, and circumstances. Many modes and combinations are allowable. 'The simplest and most unexpected form will be the best. On the dexterity and courage of the troops, the correct and quick execution of the attack will depend. Those attaeks are the best, where all the forces can be directed in concert towands that point of the enemy on which his position depends. If lie be beaten at this point, the resistance at others will be without concert or energy. Sometimes it may be of advan. tage to attack the weakest side of the cuemy, if in this way a fatal blow can be given to him ; otherwise ; an attack at this point is not advisable, because it leads to no decisive results, lenres the stronger points to be overcome afterwards, and divides the force of the assailant. In most cases, the enemy nay be defeated, if his forces can be divided, and the several parts attacked in detail. The worst form of attack is that which extends the assailing troops in long, weak lines, or scatters them in diverging directions. It is always unfortunate to adopt half measures, and not aim to attain the object at any price. Instead of saving power, these consume it in fruitless eftorts, and sacrifices are made in vain. Feeble assaults and protracted sieges are of this ruinous character. The forms of attack in a battle, which have been used from the farliest times, are divided by the tacticians into, 1. the parallel. This is the most natural form, and eren the troops attacked strive as much as possibie to preserve it; for as long as they can do so, they retain their connexion, and the power of apply. ing their force as occasion may require; but, for this very reason, it is not the best form of attack, because it leaves the defensive party too long in possession of his advantages. 2. The form in which both the wings attack, and the centre is kept back. Where the front of the enemy is weak, (the only case in which it is practicable), it appears inde' d, oserpowering. 3. The form in which the centre is pushed forward, and the wings kept back, will hardly ever be chosen, on account of several evidernt disadvantages. 4. The famous oblique mode, where one wing advances to engage, whilst the other is kept back, and occupies the attention of the enemy by pretending an attack. Epaminondas, if not the inventor of this form, knew, at least, how to employ it to the greatest advantage. Whilst the wing which remained behind engaged the attention of the enemy, he increased, continually, the strength of the one advancing, which he led against the flank of the enemy, with a view of overpowering it by numerical superiority. The success of this mode is aln.ost certain, provided the enemy takes no measures against it. In our times, this form of attack is execult in another way :- whilst engaging the enemy, his flank is surrounded by detached corps, which fall, at the same time, on his rear. If he suffers this.quietly, he is ranquished. The eneny's attention is kept occupied, during such operations, mostly by feigued at. tacks or movements, which are called, in general, demonstrations, and are intended to keep him in enor concerning the real object. (On the attack of fortresses, see the article Siege.) Field fortifications are attacked with columns, if possible, from several sides at the same time, and with impetuosity. Commonly, the artillery breaks a way beforehand, destroys the works, and disturbs the garrison.

AttalNder is, by the common law, the corruption of blood, or stain consequent upon a person's being adjurged guilty of a capital offence, in which case the law set a note of infamy upon him, and put him out of its protection, taking no further concern about him, pxcept that he slould be executed. But this attainder does not take place until juigment is pro- 
nornced against him. It might be by confession, as wien the party pleaded guiliy, or by verdict, when he pleaded not guilty, and was found guilty by the jury.

ATtans is a writ at the common law against a jury for a false verdict. It might be brought by a party aggrieved, and lay where the jury found a verdict against the evidence, or found a fact foreign to the evidence, or where their verdict was agaiust wellknown and acknowledged law. It was a process for trying the jurymen for misconduct in trying a cause. The writ seems to be now obsolete in England.

Atтerburr, Francis; a celebrated English prelate, was born in 1662, and received his education at Westminster, where he was elected a student of Christ's-church college, Oxford. He distinguished himself at the university as a classical scholar, and gave proots of an elegant taste for poetry. In 1687 , he took his degree of M.A., and for the first time appeared as a controversialist in a defence of the character of Luther, entitled, Considerations on the Spirit of Martin Luther, \&.c. He was also thought to have assisted his pupil, the hon. $\mathrm{Mr}$ Boyle, in his famous controversy with Bentley on the epistles of Plialaris. He continued some time longer at college, exceedingly discontented, feeling, with truth, that he was adapted to act on a wider theatre, and possessing all the ambition and restlessness, by which his subsequent career was so much distinguished. Il is father advised him to marry into some family of interest, “bishop's, or archbishop's, or some courtier's ;" to which parental counsel the future bishop duly attended.-Having taken orders in 1691, he settled in Loudon, where lie became chaplain to Willian and Mary, preacher of Bridewell, and lecturer of St Bride's, and soon becane distinguished by the spirit and elegance of his pulpit compositions, but not without incurring opposition, on the score of their tendeucy and doctrine, from Hoadly and others. Controversy, however, was altogether congenial to the disposition of A., who, in 1706, commenced one with doctor Wake, which lasted four years, on the rights, privileges, and powers of convocations. For this service, he received the thanks of the lower house of conrocation, and the degree of doctor of divinity from Oxford.-Soon after the accession of queen Anne, he was made dean of Carlisle, and, besides his dispute with Hoadly on the subject of passire obedience, he aided in the defence of the famous Sacheverell, and wrote "A Representation of the present State of Religion," which was deened too violent to be presented to the queen, although privately circulatid. In 1712, he was made dean of Clirist-church, and, in 1713, bishop of Rochester and dean of Westminster. The death of the queen, in 1714, put an end to his hopes of further adrancement; for the new king treated him with great coolness, doubtless aware of either the report or the fact of his offer, on the death of Anne, to proclaim the Pretender in full cunonicals, if allowed a sufficient guard. A. not only refused to sign the loyal declaration of the bishops in the rebellion of 1715 , but suspended a clergyman for lending his church, for the perfor. mance of divine service, to the Dutch troops brought over to act against the rebels. Not content with a constitutional opposition, he entered into a correspondence with the Pretendêr's party, was appre. hended in August, 1722, and cominitted to the Tower; and, in the March following, a bill was brought into the house of commons for the infliction of pains and penalties. This measure met with con. siderable opposition in the house of lords, and was resisted with great firmness and eloquence by the bishop, who maintained his innocence with his usual acuteness and dexterity. His guilt, however, las been tolerably well proved by documents since published. He was deprived of his dignities, and outlawed, and went to Paris, where he chiefly occupied himself in study, and in correspondence with men of letters. But, even here, in 1725 , he was actively engaged in fermenting discontent in the Highlands of Scotland. He died in 1731, and his body was privately interred in Westminster abbey. As a composer of sermons, he still retains a great portion of his original reputation. His letters, also, are extremely easy and elegant; but, as a critic and a controversialist, he is deemed rather dexterous and popular, than accurate and profound. If an aneclote told by Pope to Chesterfield be correct, he was a sceptic early in life; hut the same authority also states, that he ceased to be so after his mind had become mature.

A tTIC BASE; a peculiar kind of base, used by the ancient architects in the Ionic order, and by Palladio and some others in the Doric.-Attic Order, or Attics, in architecture; a kind of order raised upon another larger order by way of crowning, or to finish the building.-Attic Salt; a delicate, poignant kind of wit, for which many Athenians were distinguished, and which, in fact, was peculiar to them. The moderns have adopted this expression from the Latin writers.-Attic Story, in architecture; a story in the upper part of a house, where the windows are usually square.

AtTics, a province of ancient Greece. the capital of which, Athens, was once, by reason of its intellectual culture and refinement, the first city in the world, is a peninsula, united, towards the north, with Bootia, towards the west, in some degree, with Megaris, and extends far into the Figean sea at cape Sunium (now cape Colonna), where the Athenians had a fortress and a splendid temple of Minerva. The unfruitfulness of its soil protected it against foreign invaders, and the Athenians boasted of their ancient and unmingled race. They called themselves sons of the soil on which they dwelt, and pretended that they originated at the same time with the sun. The earliest inhabitants of $\mathrm{A}$. lived in a savage manner, without bread, without marriage, and in scattered huts, until the time of Cecrops, who came, B. C. 1550, with a colony from Sais, at the mouth of the Nile, to A., and is acknowledged as their first real king. He softened their manners, and taught them a better mode of living; he planted the olive tree, and instructed them in the culture of different kinds of grain ; he instituted the worship of the gods, and commanded to offer them sacrifices of the fruits of the earth ; he established laws of marriage, and directed the burial of the dead. The inhabitants, who amounted to abont 20,000, he divided into four classes, compelled then to bring their habitations near to each other, and protect them with a wall against the attacks of robbers. This was the origin of Athens, which, at that time, bore the name of Cecropia. One of the Cecrops' descendants, as like him in spirit as in name, founded eleven other cities, which, in after times, made war upon each other. Theseus compelled these cities to unite, and to give to Cecropia, now called Athens, as the capital city of the whole country, the supreme power over the confederacy. He founded the great feast called the panathencea. He himself, as the head of the state, watched over the adninistration of the laws, and conmanded the army. He divided the whole people into tliree classes - noblemen, husbandmen, and mechanics. From the first class the magistrates were selected, who performed the duties of priests, and interpreted the laws. He embellished and enlarged Athens, and invited foreigners to people the country. After the death of Codrus, B. C. 1068, the monarphical form of govern- 
ment, which lad continued 487 years from the time of Cecrops, was abolished. Au archon, chosen for life, possessed the regal power. After 316 jears, the term of office of the archons was limited to ten years, and, seventy years later, te one year, and their uunber was increased to nine. A regular code of laws was now needed. The archon Draco was commissiuned to draw one up; but his severity disgusted the minds of the people, and, B. C. 591 , Solon introdnced a milder code and a better constitution. He provided that the form of govermment should continue democratic, and that a seuate of 400 members, chosen from the people, sliould adininister the government. IIe alvided the people into four classes, acconding to their wealth. The offices of government were to be filled from the three first, but the fourth were to be admitted to the asscinblies of the people, and to hare an equal share, by their vote, in legislation. But this constitution was too artificial to be permanent. Pisistratus, a inan of talents, boldness, and ambition, put himself at the head of the poorer classes, and made himself inaster of the supreme power in Athens. His government was splendid and beneficent, but his two sons conld not niaintain it. Hipparchus was murdered, and Hippias banished. Clisthenes, a friend of the people exerted himself to prevent future abuses by some changes in the laws of Solon. He divided the people into ten classes, and made the senate consist of 500 persous. A. was already highly cultivated; the vintage and harrest, like all the labours of this gay people, were celebrated with dance and song, with feasts, and sacrifices. The wool of $\mathrm{A}$. was tamous, on account of the care bestowed upon the sheep, and the skill with which it was dyed of the nost beautiful colours. Mount II jmettus (q. v.) yielded the finest lioney, and mount Laurium contained rich silver mines, the products of which were appropriated to the support of the fleet. Then came the splendid era of the Persian war, which elevated Athens to the sumnit of fame. Miltiades at Marathon, and Themistocles, at Salamis, conquered the Persians by land and by sea. The freedom of Greece escaped the dangers which had threatened it; the rights of the people rere enlarged; the archons and other magistrates were chosen from all classes without distinction. The period from the Persian war to the time of Alexander (B. C. 500 to 356 ) was most remarkable for the derelopement of the Athenian constitution. According to Bockh's excellent work, Die Staatshaushaltung der Athener (2 rols., Berlin, 1817), A. contained, together with the islands of Salamis and Helena, a territory of 847 square miles, with 500,000 inhabitants, 365,000 of whom were slares. Bockh estimates the inhabitants of the city and harbours at 180,000; those of the mines at 20,000 . Cimon and Pericles (B. C. -444) introduced the highest elegance into Athens, but the latter laid the foundation for the future corruption of manners, and for the gradual overthrow of the state. Under lim began the Peloponnesian war, which ended with the conquest of Athens by the Lacedemonians. The ranquished were obliged to receire the most mortifying conditions from the victors. Thirty supreme magistrates were placed over the city, who, under the protection of the Lacedemonian garrison, were arbitrary and cruel. After eight dreadful Inonths, Thrasybulus urerthrew this tyranny, and restored freedom and the old constitution, with some improvements. - Athens began to elevate herself again among the states of Greece, and was fortunate in her alliance with Thebes against Sparta. But this uew period of power did not long continue. A more Jangerous enemy rose in the North-Philip of Macedon. The Athenians had opposed him in the Phocian war, and Philip, therefore, took possession of some of their colonies. The Greeks took up arms, but the battle of Cheronea (B. C. 338) was the grare of their liberty. Athens, together with the other states of Greece, wns now dipendent on the Macedonians. In vain, after the death of Alexander, did the $A$ thenians attempt to regain their freedon: they were obliged to receive a Macedonian garrison in the larbour of Munychia. Antipater ordered that only those citizens who possessed an estate of more than 2000 draclima should take part in the administration of the government. Soon aftcr, Athens was taken by Cassander, becanse it had joined his enemies, contrary to the advice of Pliocion. Cussunder restored the oligarchy, and named Demetrius Plalereus governor of the state, who quietly enjoyed the office for ten years. But the Athenians, who liated hinı because he was not chosen by them, called Demetrius Poliorcetes to their assistance, who twok the city, restored the ancient constitntion, and was loaded with the most extra vagant marks of honour by the Athenians; yet, whien he went to war, he lost the affection of the unstable multitude, who, on his return, excluded him from the city. But he conquered Atliens, forgave the citizens, and permitted them to enjoy their liberty, merely placing a garrison in the havius of Munchiria and the Piræus. This garrison was afterwards driven out by the Athenians, who, for a long time, naintained their freedom. Antigonus Gonatus again conquered them, and in this situation they remained until they separated thenselves from the Macedonians, and joined the Achrean league. They afterwards united with the Romans against Philip, and their new allies confirmed their fretdom. When they suffered themselves to be misled to support Mithridates against the Romans, thiey drew upon themselves the vengeance of Rome. Sylla captured the city, and left it only an appearance of liberty, which it retained until the time of Vespasian. This emperor formally changed it into a Roman province. After the division of the Roman empire, A. belonged to the empire of the East. A.D. 596 , it was conquered by Alaric the Goth, and the country devastated.-The latest and most beautiful engravings of the antiquities of this comitry are, "The Unedited Antiquities of Attica, comprising the Architectural Remains of Eleusis, Rliamnus, Sunium, and Thoricus, by the Society of Dilettanti ;" London, pub. by Longman and Murray, 1817, folio. See Athens.

Atricos, Herodes. See Herodes Atticus.

A rticos, Titus Pomponius; a Roman, belonging to the rank of cquites, who, in the most agitated times, preserved the esteem of all parties. The Pomponian family, from which he originated, was one of the nost distinguished of the equites, and de. rived its origin from Numa Pompilius. He lived in the latter period of the republic, and acquired great celebrity from the splendour of his private character, He inherited from his father and from his uncle, $Q$. Cæcilius. great wealth. When he attained maturity, the republic was disturbed by the factions of Cinna and Sylla. His brother Sulpicius, the tribune of the people, being killed, he thought himself not safe in Rome, for which reason he removed, with his fortune, to Athens, where he devoted himself to science. $H$ is benefits to the city were so great, that he gained the affections of the people in the highest degree. He acquired so thorough a knowledge of Greek, that he could not be distinguished from a vative Athenian. When Rome had recovered some degree of quiet, he returned, and inherited from his uncle ten millions of sesterces. His sister married the brother of Cicero. With this orator, as well as with Hortensius, he lived on terms of intimate friendship. It was his principle never to $\mathrm{mix}$ in politics, and he lived undisturbed amid all the successive factions which reigut in 
Rome. Casar treated him with the greatest regard, though he was known as a friend of Pompey. After the death of Cæsar, he lived in friendship with Brutus, without, however, offending Antony. When Brutus was obliged to flee from ltaly, he sent him a million of sesterces, and likewise supported Fulvia, the wife of Antony, after the disastrous battles of Mutina, and therefore was spared when fortune igain siniled on Antony, and the friends of Brutus generally were the victims of his vengeance. The daughter of A. was married to $\mathrm{M}$. Vespasianus Agrippa, and Augustus became his friend. He often received letters both from Augustus and from Antony, when he wasabsentfrom Rome. He reached the -age of seventy-seven years without sickness. At this time, he became afflicted with a disorder which he felt to be incurable. He therefore ended his life by voluntary starvation, and was buried near the Appian way, in the grave of his rucle.

A trila (in German, Etzel); the son of Mandras, a. Hun of royal descent, who followed his uncle Roas in 434 , and shared the supreme authority with his brother Bleda. These two leaders of the barbarians, who lsad settled in Scythia and Hungary, threatened the Fastern empire, and twice compelled the weak Theodosius II. to purchase an inglorious peace. 'Their power was feared by all the nations of Europe and Asia. The Huns themselves esteemed A. their bravest warrior and most skilful general. Their regard for his person soon amounted to superstitious reverence. He gave out that he had found the sword of their tutelar god, and, proud of this weapon, which added dignity to his power, he designed to extend his rule over the whole earth. He caused his brother Bleda to be murdered (444), and, when he announced that it was done by the command of God, this murder was celebrated like a victory. Being now sole master of a warlike people, his unbounded ambition made him the terror of all nations; and he became, as he called himself, the scourge which God had chosen to chastise the human race. In a short time, he extended his dominion over all the people of Germany and Scythia, and the Fastern and $W$ esteri emperors paid him tribute. The Vandals, the Ostrogotlss, the Gepidx, and a part of the Franks, united under his banners. Some historians assure us, that his army amounted to 700,000 men. -When he had heard a rumour of the riches and power of Persia, he directed his march thither. He was defeated on the plains of Armenia, and drew back to satisfy his desire of plunder in the dominions of the emperor of the East. Ile easily found a pretext for war, for all states which promised him a rich hooty were his natural enemies, and all princes whom he hoped to conquer had broken alliances. Ile therefore went over to Illyria, and laid waste all the countries from the Black to the Adriatic sea. The emperor Theodosius collected an army to oppose his progress; but, in three bloody battles, fortune declared herself for the barbarians. Constantinople was indebted to the strength of its walls, and to the ignorance of the enemy in the art of besieging, for its preservation. Thrace, Macedonia, and $G$ reece, Hll submitted to the savage robber, who destroyed seventy flourishing cities. Theodosius was at the mercy of the victor, and was obliged to purchase a peace. One of the servants of Attila, Fdekon, was tempted by a eunuch, Chrysaphius, to undertake the assassination of his master on his return to the Ianube; but, at the moment of execution, his coirage failed him ; he fell at the feet of his master, and acknowledged his criminal design. Comstnntinople trembled at the idea of Attila's revenge; but he was contented with reproaching Therdosins for his perfily, and requiring the head of Chrysaphins. The emperor engaged to pay a new tribute.-A. now directed his views to Gaul. With an immense arny, he passed the Rhine, the Moselle, and the Seine, came to the Loire, and sat down under the walls of Orleans. The inhabitants of this city, encouraged by their bishop, Agnan (Anianus), repelled the first attack of the barbarians, and the united forces of the Romans, under their general, Aetius, and of the Visigoths, under their king, Theodoric, compelled A. to raise the siege. He retreated to Champagne, and waited for the enemy in the plains of Chalons. The two armies soon approached each other. A., anxious for the event of the battle, consulted the soothsayers, and they assured him of a defeat. He concealed his alarm, rode through the ranks of his warriors, reminded them of their deeds, spoke of his joy at the prospect of a battle, and at the thought that their valour was to be rewarded. Inflamed by this speech, and by the presence of their leader, the Huns were impatient for battle. Both armies fought bravely. At length, the ranks of the Romans and Goths were broken through, and $A$. was already sure of the victory, when the Gothic prince Thorismond, the son of Theodoric, poured down from the neighbouring height upon the Huns. He threw them into disorder, spread death through their ranks, and A., pressed on all sides, escaped with difficnlty to his camp. 'This was, perhaps, the bloodiest battle which has ever been fought in Europe; for, according to contemporary historians, 106,000 dead bodies covered the field of battle. A. caused all his camp equipage and treasures to be brought together into a heap, in order to burn himself with them, in case he should be reduced to extremities. But the enemy were contented with collecting their forces during the night, and, having paid the last honours to the dead body of king Theodoric (Dietrich), which they discorered with difficulty, they saluted his son, Thorismond, king upon the field of battle. Thus A. escaped destruction. But the Franks pursued him, hanging on his rear, till he had passed the Rhine.Rather irritated than discouraged, he sought a new opportunity to seize upon Italy, and demanded Honoria, the sister of Valentinian III., in marriage. This princess had been separated from the court, and confined in a monastery, on account of an intrigue with Eugenius, her chamberlain. She offered her hand to A.; he accepted the proffered match, and demanded, as a dowry, half the kingdom. When this demand was refused, he attacked Italy with dreadful fury. The emperor trembled, and his ambassadors supplicated in vain. A. conquered and destroyed Aquileia, Padua, Vicenza, Verona, Bergamo, and laid waste the plains of Lombardy. 'The inhabitants fled to the Alps, to the Apennines, and to the small istands in the shallows (lagoons) of the Adriatic sea, where they built Venice. The emperor had no army to oppose him; the Roman people and senate had recourse to tears and supplications. Pope Leo I. went with the Roman ambassadors to the enemy's camp, and succeeded in obtaining a peace. A. went back to Hungary. The Romans looked upon their preservation as a miracle, and the old chronicles relate, that the threats of St Peter and St Paul had terrified A.- a legend which the art of Raphael and Alghardi has immortalized. Not having obtained Honoria for a wife, A. would a second time have demanded her, sword in hand, if the beantiful Ildico had not been added to his numerous wires, with whom he solemnly united himself. This circumstance hindered him from fulfiling his threats. On this occasion, he gave himself up to all the extravagance of debauchery; bit, on the day after the marvinge, the servants and warriors, impatient to salute their master, thronged into the tent: they 
found Ildien veiled, sitting by the cold corpse of lur husband. During the night he had ineen sufficated by his own blood (453). The news of his death spread sorrow and terror in the arny. His body was enclosed in three coffins - the first was of gold, the second of silver, and the thisi of iron. The captives, who had made the grave, were strangled.--The description that Jomandes has left us of this barbarian king reminds us of his Calnuc-Tartar origin. He had a large head, a flat nose, broad shoulders, and a short and ill-formed body. His walk was proud, his roice strong and well-toned.

Aтrıret, John Denis, a French Jesnit and painter, was born at Dole, Franche-Comté, in 1702, and died 1788, at Pekin, whither he had accompanied a mission. The emperor Kien Loug was so much pleased with his battle-pieces, that he offered him the dignity of mandarin, and gave him the income thereto belonging, when $A$. refused the Chinese title. A. wrote a very interesting account of the emperor's gardens, of which a translation by Spence, under the name of Sir Harry Beaumonth appeared in 1752.

A tritude (French), as a term of art, signifies the position and situation of figures. Attitudes require a regular study, a part of which is a knowledge of anutumy. The art of exhibiting attitudes, at least in modern times, is of recent invention. At the end of the last century, the celebrated lady Hamilton began the practice, and, as every art begins with imitation, she imitated, with great talent, the attitudes of antique statues in many large towns of Europe, and Sir William Hanilton could say that he possessed, in his wife, a whole collection of antiques. Her dress was a simple tunic, fastened with a ribbon tight under the breast, and a shawl. With these she imitated all the different draperies. Mr Relıberg drew her attitudes, and published them in London. On the continent of Furope, this art has been carried to much perfection by Mrs Hendel Schutz, who exhibited the most beautiful attitudes, copied from the Greek, Egsptian, I ualian, and German styles of art. But she was not satisfied with imitations : she inrented many attitudes, which were declared by all the critics of the day (nnongst whom was Goethe), some of the finest productious of art. Her attitudes have been drawn and puhlished by Peroux and Ritter (Frankf. on the Maine, 1800). There has been also a male artist of the same kind, Mr von Seckendorf (called Patrick Peale), who accompanied his exhibitions with lectures. He died in America. Ducrow, the celebrated equestrian, has likewise signalized himself in the display of attitudes.

A TTORNEY (attornatus, in Iatin); a person appointed to do something for and in the stead and name of another. An attorney is either public or special. The former is an officer of a court, who is authorized by the laws and the rules of the court to represent suitors, withiout any special written authority for the purpose. The rules and qualifications, whereby one is authorized to practice as an attorney in any court, are very different in different countries and in different courts of the same country. Almost every court has certain rules, a compliance with which is necessary, in order to authorize any one to appear in court for, and represent any party in a suit, without a special authority under seal. The principle upon which these rules are founded, is the exclusion of persons 310t qualified by honesty, good moral character, lıaruing and skill, from taking upom them this office. Ind any attorney may, by malpractice, forfeit this privilege; and the court, in such case, strikes his uame from the roll of attorneys. Still this does not prevent his being a special attorney, with a specific power froun any person who wishes to constitute him his representative; for every man whu is capable of contracting, has the power to confer upou another the right of representiug him, and acting in his stead. An attorney of a court has authority, for and in the name of his pritcipal, to do any acts necessary for conducting a suit, and his employer is bound by his acts.- A special attorney is appointed by a deed called a poucer or letter of attorney, aind the deel by which he is appointed specifies the acts which he is authorized to clo. It is a commission, to the extent of which only he can bind his principal. As far as the acts of the attorney, in the name of the principal, are anthorized by lis power, his acts are those of his principal. But if he goes beyond his authority, his acts will bind himself only; and he must inclemnify any one to whom, withont authority, lie represents himself as an attorney of another, and who contracts with him, or otherwise puts confidence in him, as being snch attorney.

Attraction; the tendency, as well of the parts of matter in general, as of various particular bodies, to approach each other, to unite, and to remain unitex ; sometimes, also, the power inherent in manner, "xerting itself at the moment of approach. Experience teaches that this property is common to all matter. Even liquids cohere in their parts, and oppose any endeavour to separate them. The ininute particles unite into drops; drops, if they are brought in contact, into large masses. Fluids attach themselves to solid bodies, particularly to such as have very smooth surfaces, as to glass: they rise up of themselves in fine tubes (see Capillary Tube), \&c. Every body tends to the earth, and, if raised from its surface, fulls back to it again. The plumb-line. which is usually vertical, takes an oblique direction in the vicinity of high mountains; the sea tends to the noon; the moon itself is constantly drawn towards the earth; the earth and the other planets, towards the sun. The heavenly bodies are continually subject to the simple law of mutual attraction. The Grecian naturalists speak of attraction; Copernicus and Tycho likewise admit it; Kepler's bold and comprehensive unind first hazarded the assertion that it nust be universal and mutual in all bodies; Descartes sought to banish it entirely from natural philosophy, as one of those occult powers which he did not acknowledge; but Newton adopted it, and determined its laws, after many years of accurate observation. Fruitless attempts have been made to explain it. When bodies tend to come together from sensible distances, that tendency is denominated either the attraction of gravitation, magnetism, or electricity, according to circumstances; when the surfaces of bodies in contact tend together, it is by adhesion, when the particles of the same body tend together, it is by cohesion, and when the particles of different bodies in contact tend together, it is by affinity. These three latter spe cies of attraction act at insensible distances. We cannot enumerate all the particular subdivisions of attraction, but the most important are those of chemical affinities (q. v.), of magnetic and electric attractions, \&c. (Respecting these, see the particular artieles.) The best work on the attraction of the heavenly bodies, is Newton's Principia, and Laplace's Mecanique Celeste. On the attraction which mountains exert on the plumb-line, see von Zach's L'Attraction des Montagnes et ses Effets sur les Fils a Plomb (Avignon, 1814,2 vols.) See the article Mechanics.

ATTRIBUTE. 1. Every quality which is ascribed to any one as characteristic. -2 . The sign which indicates that quality. In this latter sense, it is synonymous with symbol. (q. v.)

Arwood, George, F. R.S.; an eminent mathema tician, who was educated at the university of Cambridge. In 1784, he published, in one volume, 8 vo. a Treatise on the Rectilinear Motion and Rotation of 
Bodies; with a Deseruption of Original Experiments relative to that Subject-a work reınarkable for its perspicuity, and the extensive information which it affords. About the same time, he made public an Analysis of a Course of Lectures on the Principles of Natural Philosopliy, read at the Unirersity of Cambridge, which is not less valuable than the preceding. William Pitt, having attended Mr Atwood's university lectures, conceived such an opinion of his talents and scientific information, that he engaged him to devote a considerable part of his time to financial calculations, and bestowed on him a sinecure office, the income of which he retained from 1784 till his death, in 1807 , at the age of sixty two, when the iffice which he had held was abolished. Mr Atwood published a Dissertation on the Construction and Properties of Arches, 1801, 4to, and several other valuable treatises relating to mathematics and mechanical science.

Arys, or Atrys, 1. The favourite of Cybele, who, having broken the row of chastity which he made to the goddess, castrated himself, as a punishment for his crime. See Cybele. -2. A son of Croesus, king of Lydia; an affecting example of filial love. He was dumb, when, seeing a soldier in a battle who had raised a sword against his father, he exerted himself so much, that the bands of his tongue gave way, and he cried out, "Soldier, kill not Croesus !"

Aubaise, Droit D'. Foreigners in France, in the middle ages, were called Albani, or Albini. Sone derive this word from Albanach, which term the Highlanders of Scotland, even now, apply to theinselves; and, if this name was common to all the Gaelic tribes, or, at least, if it was used by the in. habitants of Bretagne, the German races may have applied it, froin this circumstance, to all foreigners. The Romans, indeed, did not permit foreigners to inherit property - a law which the emperor Frederic J. abolished, since he gave to all foreigners the right of making a will, and ordered that the effects of such as died without one should be assigned by the bishop to the foreign heirs, or, if this was not possible, should be employed for some pious purposes. France was the only country where foreigners were treated according to the maxim of law peregrinus liber vivit, servus moritur. They were permitted to acquire all kinds of property, even real estate. They could not, lowever, obtain it by inheritance, nor bequeath it at their death. The king (by virtue of the law of aliens, droit d'Aubaine), in whose pence and prolection they reniained during life, was their only heir after death. No feudal lord could acquire this right. It was very early softened in favour of the relations who resided in the kingdom. Some cities, as Lyons, in order to favour commerce, obtained the privilege that the estate of foreigners who died in them should go to the foreign heirs, and this was agreed upon by treaties with certain states. (See the account of these states in Schloezer's State Papers-Staatsanzeigen-H. 31, and the later treaties in Marten's Recueil des Traités.) The national assembly, by the decrees of the 6th of Aug., 1790, and the 8th and 31 st of Aug., 1791, abolished this law; and, as it was acknowledged by no other country of Europe as a general rule, but was only put in force as a measure of retaliation against Franee, there was no necessity for a particular abrogation of the same in any Euro. pean state. The French, however, were not conscious of this. They confounded their own droit "Aubaine with the rule prevailing in other countries, of deducting a certain proportion of the estates of foreigners deceased; and the droit d'Aubaine was restored in the Code civile (Code de Napoléon, art.11), hecause complaint was made that other comutries.s. especially Prussia, had not abolished it -\%. In Bri- tain, no droit $d$ 'Aubaine is known. The alien con transact any business there (under the frovisions of the alfen act), and his property descends to his heirs, wherever they may be. Real estates alone he cannot acquire. (For further information respecting the rights of aliens in Fingland, see Alien, Alien Act, and Natu-alization.;

AUBE, department of ; a French department in the forner province of Cliampagne. (See Department.) - Aube; a river of France, which rises in the department of Upper Marne, and, running through that of Aube, passes by Bar-sur-Aube and Arcis, and falls into the Seine; near Nogent. The Aube became imıortant, in the last war against Frince, as a line of military operation.

A UвERT-Dubayet, Jean Baptiste Annibal ; born in Louisiana, Aug. 9, 1759. From the 18th year of his age, he was an officer, and fought in the service of the United States in the war of independence. Shortly before the breaking out of the French revolution, he went to France. In 1792, he was elected president of the legislative assembly. As general of brigade, he defended Mayence, and justified himself from the charge of improperly surrendering the place. He afterwards fought with vigour against the Vendeans, in the west of France. In the year 3 of the republic, he was appointed minister of war, and went, in the year 4, to Constantinople as French ambassador, where he died two years afterwards. He was an ardent republican, upright, and endowed with talent, but is said to have been extremely vain.

Aobigne, Theodore Agrippa d'; a Frencli author, born in 1550. He early gave proofs of talent. In his thirteenth year, he lost his father, and fought afterwards under Henry IV.; king of France, who made him a gentleman of his bed-chamber. He soon became a favourite of Henry, but when the king, thinking it necessary, favoured the Catholics mole than the Protestants, A. expressed his displeasure with little reserve, and, at length, lost the favour of Henry. He now retired to Geneva, where he devoted himself to literary pursuits. He wrote a Histoire Universelle, from 1550 to 1601 , with a short account of Helıry IV.'s death, 3 vols., folio, the first volume of which was ordered to be burned by the parliament of Paris. He died at Genera, in 1630.

AUBREY, John, F. R. S. ; an English antiquary, born at Easton Piers, in Wiltshire, in 1626 ; educated at Oxford. He collected materials for the Monasticon Anglicanum, and afforded important assistance to Wood, the Oxford antiquary. He lost lis property, and was reduced to absolute want; but a lady Long supported him till his death, about the year 1700 . He published little, but left large collections of manuscripts, which have been used loy subsequent writers.

AURry DE MontDidier; a French knight of the time of king Clarles V., who, according to tradition, was basely murdered, in 1371 , by his companion in arms, Richard de Macaire. The murder was discovered by means of a dog of the deceased, who showed the most hostile disposition to the murderer. The king compelled Macaire to fight with his accuser, the dog, in order to decide the case; and the murderer was conquered. This story has been formed into a drama, for the German stage, called the Dog of Aubry, or the Wood of Bondy.

AOBURN; a post-village of New York, and capital of the county of Caynga, in the township of Aurelius, on the great western turnpike, at the north end of Owasco lake, 170 miles W. of Albany. Pop., in 1825,2982 . It is a pleasant and flourishing village, and contains an academy, a court house, a state prison, large enough to receive 1000 prisoners, a county jail, a market livuse, a Presbyterian theological seminary, and four houses of public worship. The theologicul 
seminary was incorporated in 1820 , and has four professors - one of Christian theology, one of ecclesiastical history and church government, one of Biblical criticism, and one of sicred rhetoric. The number of stuclents, in 1825 , was 47 . The building appropriuted to the seminary is a large stone edifice, containing roons for students, a chapel, and valuable library.

Aocklasd, William Eden, lord; a statesman who had great influence in Pitt's ininistry, and was employed in important embassies. He began his career, in 1778 , as a mediator between the mother country and the insurgent colonies in North America. He was accompanied by lord Howe, and Sir Heury Clinton, G. Johnstone, and lord Carlisle, upon this important embassy; but the result did not answer the expectations which had been formed from the talents of these distinguished men, and nothing was left for England but to acknowledge the independence of the colonies. Afterwards, as a member of parliament, he had a great infuence in the reform of the penal laws, and, with Howard and Blackstone, in the organization of a new system of police, and a better mode of treating prisoners. He subsequently held the important post of secretary of state for Ireland, and, in 1785, was ambassaudor extraordinary to the French court, to negociate a cominercial treaty, which was concluded in 1786. During the first year of the French revolutionary war, lie was ambassador extraordinary to the states general of the Netherlands : and, in this capacity, he had the greatest influence on the measures which the crowd of events was constantly rendering more complicated. After his return, his conduct was snbjected to an investigation by parliament, and was declared to be unexceptionable. He died in 1814 .

Aocriox is a public sale, to the party offering the highest price, where the buyers bid upon each other; or to the bidder who first accepts the terms offered by the vender, where he sells by reducing his terms until some one accepts them. This mode of sale was in use among the Romans, called sub hasta, from its being, in early times, a sale of the spoils taken in war, under a spear erected as the signal of the auction. The same signal was afterwands used in other sales, which were made under the superintendence of particular tribunals. This mode of selling is subject to particular regulations, by the laws of many communities, the object of which is to prevent frauds, or to levy a tax. In the time of lord Mansfield, a question was made in the case of Bexwell vs. Christie (Cowper's Reports, p. 395), whether a sale by auction was fair, at which some one bid for the owner. The subject was treated as being, in some measure, a question of conscience, upon the supposition that the real bidders supposed themselves to be bidding only against other real bidders; and the purchaser at the sale, in that case, was held not to be bound by his bid, because there had been by-bids on behalf of the vender. But the decision, in that case, was subsequently averruled by lond Rossisn, in the case of Conolly vs. Parsons (3 Vesey Jr.'s Reports, p. 625), and again by the master of the rolis in Bramley vs. Alt (3 Vesey Jr.'s Reports, p. 620), with one qualification, liowever, in this latter case, viz., that if none bid, except by. bidders or puffers, against one real bidder, to whom the article was struck off, he was not bound by the purchase. There seems to be no reason for supposing that a sale by auction would be void on this account, unless it were a violation of the conditions upon which the auction was announcerl. It is evident that the fairness or unfairness of this proceeding must depend, in any case, very much upon a compliance with the understanding entertained, or the conditions laid down in respect to the sale; and, certainly, it is not universally understood that no bid will be made for the veuler. In regard to a tax upon sales by auction, there does not appear to be any good ground for it in principle, and the sane objections lie against this tax that are made to the Spanish alcavala (q. v.), or tax on private sales. The vender must pay the tax, and a man's selling gools is not, in general, a proof, nor the value of the goods a measure, of his ability to pay a tax. So far frum this is the fact, that, in very many instances, the poverty or straitened circumstances of the vender are the cause of his putting up his property at auction. When the'se sales are taxed, therefore, the law makes many exceptions, with the intention of preventing the tax from falling upon persons who sell from necessity, rather than the expectation of making a profit. - Much discussion has bee'u lad upon the effect of sales by auction, in an economical point of view ; as, whether they give a facility to the introduction of fureign manufactures, to the discouragement and depression of the domestic, with which they come into competition; and whether they have a favourable or unfavourable influence upon the course of production and consumption, considered as a part of the general system of business and econorny, independently of their effect in respect to the introduction of foreign fabrics or products. No general answer can be made to these questions, since it must, in each case, depend, in some degree, upon the manner in which the auctions are conducted. But, supposing thein to be conducted with perfect faimess and honesty, it must then depend upon the condition of the industry of the community. The German fairs have an effect similar to that of auction sales. An extensive fair, or sale by auction, by showing, and, in effect, exaggerating the surplus or deficiency of articles, aggravates the stagnation in one case, and enhances the prices in the other. All such fluctuations tend to check and destroy the production that is carried on upon a small scale. Those who carry it on upon the largest scale, whether domestic or foreign, will drive out the smaller ones, since they will, as has been invariably proved, push on their businitess, in spite of the sacrifices which they may be obliged to make, and they gain an impetus which is not easily checked. Whether auctions are injurious or not, in either respect, will depend, therefore, upon the scale on which they are conducted, and the: extent of different systems or processes of production, which are thus brought into competition. Where there is a competition, they undoubtedly tend to make it more close and direct, and if one of the rivals has any advantage at the time being, he is likely to destroy the other; or, if there be no other advantage on either side, the party willing and able to make the greatest sacrifices will erentually keep possession of the market.

A OCTIONEER ; a person who conducts sales by auction. It is his duty to state the conditions of sale, to declare the respective biddings, and to terminate the sale by knocking. down the thing sold to the lighest bidder. An auctioneer is held to be lawfully authorized by the purchaser to sign a contract for him, whether it be for lands or goods. And his writing down the name of the highest bidder in his book, is sufficient to bind any other person for whom the highest bidder purchased, even though such person be present, provided he do not object before entry. Fvery auctioneer must take out a license, renewable annually on the 5 th of $\mathrm{July}_{\mathrm{y}}$ for which he is charged $£ 5$; and if the sell goods for the sale of which an excise license is specially required, he must also take out such license, unless the goods be the property of a licensed person, and sold for his behalf and on his entered premises, in which case such additional license is not required. (6 Geo. 4. c. 81.) Auctioneers within the limits of the chief excise office in I.oudon, are bound when thiey reccive their license, to give security to 
the rxcise by bond, themselves in $£ 1000$ and two sureties in $f: 00$ each, to deliver in within twentyeight days of any sale a true and particular account of such sale, and to pay the duties on the same. A uctioneers refusing or delaying to pay the duties within the specified time forfeit their bond and the bonds of their sureties, and double the amount of the duties. (19 Geo. 3. c. 56.) Auctioneers carrying on their trade without the limits of the head of fice give bond themselves in $£ 500$ and two sureties in $£ 50$ each, to render an account of the duties accruing on sales, and to pay them within six weeks, under the penalties already mentioned. $(19 \mathrm{Geo}$. III. c. 56 . and 38 Geo. III. c. 54.) A licensed auctioneer going from town to town by a public stage coach, and sending yoods by a public conveyance, and selling on commission by retail or auction, is a trading person within the 50 Geo. III. c. $41 . \$ 6$, and must take out a hawker's and pedlar's license. It has long been a common practice at certain auctions (called therefore mock auctions) to employ puffers, or mock bid. ders. to raise the value of the articles sold by their apparent competition, and many questions have grown out of it. It was long ago decided, that if the owner of an estate, put up to sale by auction, employ puffers to bid for him, it is a fraud on the real bidder, and the highest bidder may refuse to complete his contract. (6 T. Rep. 642.) But it seems as if the mere employment of puffers under any circumstances were now held to be illegal. "The inclination of the courts at the present time is, that a sale by auction should be conducted in the most open and public nianner possible ; that there should be no reserve on the part of the seller, and no collusion on the part of the buyers. Puffing is illegal, according to a late case, even though there be ouly one puffer; and it was then decided that the recognized practice at auctions of employing such persons to bid upon the sale of horses could not be sustained."-(Woolrych on Commercial Law, p. 262.) A party bidding at an auction may retract his offer at any time before the hanmer is down. Another clearly established principle is, that verbal declarations by an auctioneer are not to be suffered to control the printed conditions of sale; and these, when pasted up under the box of the auctioneer, are held to be sufficiently notified to purchasers. Auctioneers, like all other agents, should carefully observe their instructions. Should those who employ them sustain any damage through their carelessness or inattention, they will be responsible. They must also answer for the consequences, if they sell the property entrusted to their care for less than the price set upon it by the owners, or in a way contrary to order. An auctioneer who has duly paid the license duty is not liable, in the city of London, to the penalties for acting as a broker without being admitted agreeably to the 6 Anne, c. 16. The establishment of mock auctions is said to be a common practice among swindlers in Londou. Persons are frequently placed at the doors of such auctions, denominated barkers, to invite strangers to come in ; and puffers are in wait to bid up the article much beyond its value. A stranger making an offer at such an auction is almost sure to have the article knocked down to him. Plated goods are often disposed of at these auctions ; but it is almost needless to add, that they are of very inferior quality. Attempts have sometimes been made to suppriss mock auctions, but hitherto without much success.

AODE, department of; a French department in the former province of Languedoc. See Department.

AUDEBert, Jean Baptiste ; united, in a high degree, the talents of an engraver with the knowledge of natural history. He was born at Rochefort in
1759 , went, at the age of 18 , to Paris, to learn draw. ing and painting, and made himself a skilful miniature painter. In 1789 , he became acquainted with Gigot d'Orcy, a great lover and promoter of natural history, who possessed a vast collection, the rarest specimens of which he employed A. to paint, aul afterwards sent him to England and Holland, whence he brought back a number of designs, which have been used in Olivier's History of Insects. This occupation awakened in him a taste for natural history. He now undertook some works which laid the foun. dation of his fame. The first was, Histoire Naturelle des Singes, des Makis, et des Galéopithéques (Paris, 1800 , folio), in which he shows himself an able draughtsman, engraver, and writer. With regard to colouring, so essential in natural listory, he brought it to a greater perfection than it liad ever before attained. Not satisfied with laying different colours on the same plate, so as to produce a kind of painting, he went farther, and, instead of water-colours, used the more durable oil-colours. He carried his art to still greater perfection, by using gold in his impressions, the colour of which he changed in different ways, in order to imitate the splendour of his patterns. Natural history was greatly benefited by his work, the splendour of which was astonishing. His Histoire des Colibris, des Oiseaux-Mouches, des .Jacamars, et desPro merops (Paris, 180\%, folio), is esteemed the most complete work that has appeared in this department. Fifteen copies were struck off with golden letters. Scarcely was this work begun, when A. formed new plans, for the execution of which the longest life would hardly have been sufficient. He died in 1800 , when he had scarcely begun the Histoire des Grimpereaux et des Oiseaux de Paradis. Both works were excellently finished by Desray, who was in possession of the materials, and the process for carrying on the work. A. rendered much assistance in the publication of Levaillant's African Birds. He conducted the impressions of the plates as far as the thirteenth number.

AODIENCE is used to signify the ceremonies practised in courts at the admission of ambassadors and public ministers to a hearing.-It is also the name of courts of justice or tribunals which were established by the Spauiards in America, and formed upon the model of the court of chancery in Spain.-It is also the name of one of the ecclesiastical courts in England, which is held wherever the archbishop calls up a cause to be argued before himself.

Aoditor, in the language of the ancient law; an officer of the courts, whose duty it was to interrogate the parties. In a narrower sense, an officer who overlooks accounts. The auditeur du chátelet, in France, was a member of that court of justice for the city of Paris. (See Châtelet.) This court decided in causes of small importance (where the amount in dispute did not exceed 50 francs). In the eleven high offices of accounts (chambres des comptes) of France, the meinbers were divided into conseillersmaitres and conseillers-auditeurs, as the German colleges (departments of government) are into counsellors and assistants. A similar division in the courts of justice was introduced by Napoleon, viz., that of conseilleurs and juge-auditeurs, which distinction still exists. In England, this term is applied to those who examine accounts. 'The chief accountant's office is called office for auditing the public accounts. The members of the Spanish courts of justice are generally called oydores. This appellation also obtains among the papal officers. The twelve counsellors of thie renowned rota Romana (q. v.) are called auditores sacri palatii apostolici, or auditores rotee. In the papal college of finance, the camera apostolica, at the head of which is the cardinale camerlingo, there is 
an auditor canerce, who exprcises the power of the college in causes of minor inportance.

A Ueracu, Henry; born in 1482, at a place of the same name in Bavaria ; the builder of the Auerbnchcourt and cellar at Leipsic, mentioned in Goethe's Faust. His real name was Stromer, but, according to the fashion of his time, he took the name of the place where he was born. The building was erected in 1530, and tradition reports that, five years after, doctor Faust was seen riding ont of it on a barrel of wine. This tale Goethe has made use of in his famons poem. The building was known also at the Leipsic fairs as one of the mest frequented places for the exhibition of merchandise.

Augrst.edt, battle at, Oct. 14, 1806. See Jena.

Augran Codrx (Codex Augiensis); a Greek and Latin MS. of the Epistles of St Paul, supposed by Michaelis to have been written in the ninth century, and so called fron Augia Major, the name of a monastery at Rheinau, to which it belonged. After passing through several hands, it came, in 1718, to doctor Bentley, who purchased it for 250 Dutch florins, and it is now in the librars of Trinity college, Cambridge. This MS. (noted $\boldsymbol{F}$. in the second part of Wetstein's New Test.) is written in uncial letters, and without accents; not continua serie, as is common with the more ancient copies, but with intervals between the words, and a dot at the end of each. The Greek text is written in capitals, the Latin in Anglo-Saxon letters; whence it is tolerably clear that it must have been written in the west of Europe, where that formation of the Latin letters, usually called Anglo-Saxon, was in general use between the seveuth and twelfth centuries. The manuscript is defective from the beginning to Romans iii. 8 , and the Epistle to the Hebrews is only found in the Latin version.

Acters, in fabulous history ; a king of Elis, fn med for his stable, which contained 3000 oxen, and lad not been cleaned for thirty years. Hercules wns desired to clear away the filth in one day, and A. promised, if he performed it, to give him a tenth part of the cattle. This task Hercules is said to have executed by turning the river Alpheus, or, as some say, the Peneus, through the stable, which immediately carried away the dung and filth. A. not only refused to perform his engagemes:t, pretending that Hercules had used artifice, and experienced no labour or tronble, but banished his own soll, Phyleus, from his kingdom, for supporting the claims of the hero. Upon this, a war commenced, and Hercules conqurred Elis, put A. to death, and gave his kingdom to Phyleus. A. has been called the son of Sol, because Elis signifies the sun. After his death, he received the honours usually paid to heroes.

AUger, Athanase; a great linguist, born at Paris, Dec. 12, 1734, and became professor of rhetoric in the college of St Rouen. The bishop de Noé made him his chief vicar, and called him, in jest, his grand vicaire in partibus Atheniensium, on account of the zeal with which the abbé pursued the study of Grecisn antiquities. Learning proved its worth in his cliaracter and life. He lived in a simple style in the midst of Paris, retired, and free from anxiety, or wish to attain a higher station. He divided a moderate income with his needy family. It was said of him, that he had never spoken ill of any one, and no one had spoken ill of him. As a member of the academy of inscriptions, he remained true to his principles of honest candour, and was no less belored than respected by the whole society. The breaking out of the revolution aroused the sympathies of a man who lived, by his daily studies, in Greece and Rome. He hoped for the abolition of crying abuses, and for the introduction of true freedom. This expectation ap- pears in sevrnal of his writings. He dicd before the occurrence of any events which could have shaken his faith, Feb. 7, 1792. His writings, partly translations from the ancient languagew, and partly political, were published from his papers, at Paris, in 30 rols. Anong his political works, the most distinguished are Projet d'Educution pullique précédé de quelques Riftexions sur l'Assemblie Nationalc, 1789 ; and De la Constilution des Romains sous les Rois et au Temps de la République, 179\%, the prodnct of thirty years' labour, which first appeared after his death, with the rest of his posthumous works.

Augereau, Pierre Frangois Charles, duke of Castiglione, marshal of France; son of a fruit merehant ; born at Paris, 1757; served as a carabinier in tle' French army; went from thence into the Neapolitan service, established himself at Naples, in 1787, as a fencing-master, and was banished thence, in 1792, with the rest of his countrymen. He served, afterwards, as a volunteer in the army of Italy, in whichl his talents and courage soon gained him promotion. He distinguished himself, in 1794, as general of brigade in the army of the Pyrenees, and, ing 1796 , as general of division in the army of Italy. He took the pass of Millesimo; made himself master, April 16, of the intrenched camp of the Piedmontese at Cera, afterwards of that at Casale; threw himself on the bridge of Lodi, and carried it with the cueny's intrenchments. June 16, he passed the Fo, and made prisoners the papal troops, together with the cardinal legate and the general's statr. Ang. I, he came to the assistance of Masséna; maintaincd, during a whole day, a most obstinate struggle a gainst a superior number of troops, and took the village of Castiglione, from which he derived his ducal title. Aug. 25, he passed over the Adige, and drove back the enemy as far as Roveredo. In the battle of Arcole, when the French columns wavered, A. sizid a standard, rushed upon the enemy, and gained the. victory. The directory bestowed this standard on him, Jan. 27, 1797. Aug. 9, he was naned commander of the 17 th military division (division of Paris), in place of general Hatry. He was the instrumenit of the violent proceedings of the 18th of Fructidor, and was saluted, by the decimated legislative body, as the saviour of his country. In 1799, he was chosen a member of the council of five hundred, and, therefore, resigned his command. He then obtained from the consul, Bonaparte, the command of the army in Holland. He led the French and Batavian army on the Lower Rhine to the support of Moreau, passed the river at Frankfort, and fought with the imperial general, with various success, until the battle of Hohenlinden ended the campaign. In October 1801, being superseded hy general Victor, he remained without employment till 1803 , when he was appointed to lead the army, collected at Bayonue, against Portugal. When this enterprise failed, he? went back to Paris, and, May 19, 1804, was namel marshal of the empire, and grand officer of the legion of honour. In July of this year, the king of Spain sent him the order of Charles III. At the end of 1805 , he was at the head of a corps of the great army in Germany, formed of troops collected under his command at Brest. He contributed to the successes which gave birth to the peace of Presburg, and, in March, 1806, had possession of Wetzlar and the country around, until, in the autumn of this year, a new war called him to Prussia. Tle wounds which he received in the battle of Eylau (q. v.) compelled him to return to France. Farly in 1811, Napoleon gave him the command of a corps in the army of Spain. Afterwards he returned from thence, and remained without any employment until July, 18I3, when he led the army in Bavaria against Saxony, 
where he took part in the battle of Leipsic. At the (e)trance of the allies into France, his duty was to cover Lyous. Louis XVIII. named him a peer. After the fall of Napoleon, A. used reproachful language respecting him in a proclamation to his army. Napoleon, therefore, on his landing in 1815, declared him a traitor. A:, however, expressed himself in his favour, but took no active part in the new order of things. After the return of the king, he took his place again in the chamber of peers, sat among Ney's judges, was for a while unoccupied, and died, June 11, 1816, at his estate La Houssaye, of the Iropsy.

Auglas. See Augeas.

Aogrte (pyroxene); the name of a species in mineralogy, interesting on account of its wide distribution and the numerous varieties of form and colour under which it appears. When crystalliżed, it assumes the form of short, slightly rhombic prisms, with their lateral edges replaced, and terminated at one or both extremities by unmerous planes; and, when massive, is generally capable of mechanical division, in lines parallel to the sides of an oblique rhombic prism of $87^{\circ} 5^{\prime}$ and $92^{\circ} 5^{\prime}$, its primitive form. Its specific gravity is from $3 \cdot 23$ to $3 \cdot 34$; lustre vitreous ; and hardness sufficient to scratch glass. Different names have been applied to some of its most remarkable rarieties; as, diopside, to greenish-white, transparent crystals; sahlite, when it is in imperfectly prisinatic and foliated masses; and coccolite, when in small, slightly-cohering grains. This species occurs abundantly in black crystals in basalt and lava, and enters into the regular composition of many rocks, besides being found in veins in primitive rocks. It is composed essentially of silex, lime, and magnesia, to which oxyde of iron is sometines added; and is me of those few mineral substances, whose composition may be imitated by the artificial mixture of its cuistituents, and subjecting them to fusion. Its native crystals, likewise, when fused, and suffered to cool slowly, re-assume their original shape and colour. A transparent green variety, found at Zillerthal, in the Tyrol, is used in jewelry.

A ugsborg, the capital city in the Bavarian circle of Upper Danube, formerly a free city of the empire, lies between the Wertach and Lech, and is the residence of a bishop. It has 3690 houses, and 29,000 inhabitants, of whom 12,000 are Protestants. The curiosities are the bishop's palace, where the confession of Augsburg was signed in 1530; the city house, with the golden hall, esteemed the finest in Gerınany ; the Fuggerei (106 small honses, built by two bruthers, of the name of Fugger, for the residence of the poor inhabitants of the city, a monument of the benerolence of those immenscly rich citizens); the cathedral church, and the gallery of paintings of the German schools, \&ic. The city has considerable carrying trade and dealings in bills of exchange, important commercial transactions with Vienna and Italy, and is likewise a mart for the wines of southern Germany and Italy. Whether A. bore the name of Damasia before the entrance of the Romans into the country is uncertain, but it is well settled that the emperor Augustus, about $12 \mathrm{~B}$. C., after conquering the Vindelici, placed a colony there, which must be considered as, the origin of the present A. After the division of the empire of the Franks, A. came under the dominion of the duke of Suabia, and, becoming rich by its commerce, fnally purchased its freedom of the duke, which was afterwards confirmed by the emperor. The city now reached the summit of its prosperity, and was, together with Nuremberg, a great mart for the commerce between the north and south of Europe, until, towards the end of the 15th century, the Jiscoveries of the Porti- guese and Spaniards gave a new direction to the whole commerce of the world. In 1368, in consequence of the opposition of the lower classes of citizens, the aristocratic government was abolished, and a democratic form substituted, which continued till 160 years later, when the nobles, with the assistance of the emperor, Charles V., again obtained the supremacy. A. is still one of the principal manufacturing places in Germany.

A ogsburg Confession, presented by the Protestants, at the diet of Augsburg, 1530, to the emperor and the diet, and, being signed by the Protestant states, was adopted as their creed. Luther made the original draught at the command of John, elector of Saxony, at Torgau, in seventeen articles; but, as its style appeared to be too violent, it was altered by Melancthon, at the command of the elector, and in compliance with the wishes of the body of Protestant princes and theologians. Thus changed, it was presented and read in the diet, June 25 . The original is to be found in the imperial Austrian archives, and the edition of the Augsburg confession, at Wittemberg, 1531, was printed from this. Afterwards, Melancthon arbitrarily altered some of the articles, and a new edition, with his changes, appeared in 1540. There now arose a division between those who held the original and those who held the altered Augsburg confession. The former is received by the Lutherans, the latter by the German Reformed, who thereby secured to themselves, at the religious peace of 1555 , the privileges extended only to the adherents of the Augsburg confession, and kindred sects.

Augsburg Gazetre. See Allgemeine Zeitung.

Augurs; certain priests among the Romans, who, from the flight and the cries of birds, from lightning, \&c., predicted future events, and announced the will of the gods. They were consulted respecting both public and private concerns, and their respectability, as well as their influence in the state, was very great. By merely pronouncing the worls Alio die (another day), they conld dissolve the assembly of the people, and annul all the decrees which liad been passed at the meeting. Their answers, as well as the signs by which they governed themselves, were called auguries. Public auguries were, 1 . appearances in the heavens, as thunder and lightning. The augur remarked the place where the flash of lightning originated, and where it disappeared. He stood oil an elevated place (ar $x$, templum), where he had a full view of all around him. After the sacrifices had been made, and solemn prayers offered, he took his station, his face towards the east, his head covered, and pointing with his staff (lituus) to that portion of the heavens within the limits of which he proposed to make his observations. On the left were the propitious, on the right the unpropitious omens. 2. The cries and the flight of birds. Predictions founded on the observation of birds were properly called auspices, and were very cominon even among the Greeks, who took them from the Chaldeans. They afterwards became so important, that, among the Romans, nothing of consequence in peace or in war sas undertaken without consulting birds, whose continual flight was supposed to give them universal knowledge. They were propitious or unpropitious, either from their species or from the circumstances in which they appeared. The birds of a prophetic character were divided into two principal classes-those whose flight and those whose cry was indicative of future events. In the latter class were inclurled the ravell, the crow, the night-owl, the cock; in the former were the eagle, the crow, the raven, the kite, and the vulture. The two last were always umpropitious: the eagle, on the contrary, was propitious when he flew frum left to right; the crow und the raven were 
propitious on the left, and unpropitious on the right. 3. The willingness or unwillingness of chickens to eat was also ọininous. The former was interpreted as a good omeñ, the latter as a bacl one. Chiekens were made use of particularly in war; therefore a pontifex, some augurs and haruspices (see Aruspex), together with a pullarius with a hen-coop, were atcuched to the ariny. Besides these tliree principal classes, certain omcus were drawn from quadrupeds; e. g., if a beast crussed one's jath, or was seen in an umusual place, and from many occurrences more or less uncommon, e. g., sudien melancholy, sneezing, spilling the salt on the table, Kc. The augurs "xplained such signs, and taught how the gods were to be appeased. The right of taking the auspices, that is, the right to inquire of the gods, by certain signs, huw the war would terminate, belonged only to the commander-in-chief. The inferior officers fought only under his auspices; that is, the declaration which he issued was bindiug upon them, and the fortumate or the unfortunate issue of the war was attributed to him alone.

A UGOST; the name of the eighth month from January, inclusive, and the sixth of the Roman year, which began with March. It was called Sextilis, till the emperor Augustus, in consideration of the many instances of good fortune which had happened to hiu in this month, affixed to it his own name.

Aogosta; the name of a very great number of ancient places; as, Augusta Treverorum, now Treves; Augusta Ausciorum, now Auch; Augusta Taurinorum, now Turin, Augusta Suessonum, now Söissons, \&. Augusta also is the name of many modern places and rivers in South America.

Aocosta; a post-town of Malne, in the United States, on the river Kennebec, 168 miles N. E. of Boston; population, in 1810, 1805 ; in $1820,2457$. It is a pleasant and flourishing town, and has, by an act of the state legislature, been constituted the seat of the state government after January 1, 1832. Here is an elegant bridge across the Kennebec, consisting of two arches, each 180 feet long. The river is navigable to $A$. for vessels of 100 tons.

Augosta ; a city of Georgia, opposite to Hamburg, in South Carolina, with which it is connected by a bridge; population, in 1810,2476 ; and in 1827, about 5000 . It is situated on an elerated plain. The streets are wide, intersecting each other at right angles, and are ornamented with trees. The houses are mostly of brick, and many of them are spacious and elegant. Among the public buildings are a city-hall, an academy, a court-house, a theatre, an hospital, two markets, and six houses of public worship. A. is favourably situated for trade, and has a very flourishing commerce. More than 100,000 bags of cotton are anuually deposited here, and hence conveyed down the river to Sarannah and Charleston, for northern and European markets.

Acgustis, or Austis, Saint, called the apostle of the English, flourished at the close of the sixth century. He was sent, with forty monks, by Gregory, to introduce Christianity into the Saxon kingdoms. He was kindly received by Ethelbert, king of Kent, whom he soon converted; and such was his success with his subjects, that he is said to have baptized 10,000 in one day. This success may be attributed to his reputation of miraculous power in the restoration of sight and life, more probably than to any other cause. He has the merit of allowing no coercive measures to be used in the propagation of the gospel. Elated by the rapid progress he had made, t. became ambitious of possessing the supreme auchority over the English churches as archbishop of Canterbury, and received the archiepiscopal pall from the pope, with instructions to establish twelve sees in his province. The British bishops in Wales, successors of the British converts of the second century, had never submitted to the jurisdiction of the church of Rome, and $\Lambda$. endeavoured to persuate them to unite with the new English church. They asserted their independence, and $1200 \mathrm{~W}$ elsh monks were soon after put to the sword, as is thought, at the instigation of $A$. He died in 604 , or 608 , or 614, and his relies have been carefully preserved in the cathedral of Canterbury.

Aogustixe, Saint, one of the most renowned fathers of the Christian cluurch, was born at 'Tagaste, a suall city in Africa, Nov, 13,354, during the reign of the emperor Constantine. He has related his own life in the work to which he gave the title of Confessions. His parents sent him to Cartlage to complete his education, but he disappointed their expectations by his neglect of serious study and his devotion to plea. sure. In his sixteenth year, be became very foud of women. For fifteen years, he was connected with one, by whom he had a son. He left her only when he changed his whole course of life. A book of Cicero's, called Hortensius, which has not come down to our times, led him to the study of philosoply; and, when he found this did not satisfy his feelings, he went over to the sect of the Manichxans. He was one of their disciples for nine years; but, after having obtained a correct knowledge of their doctrine, he left them, and departed from Africa to Roine, and thence to Milan, where he announcel hinnself as a teacher of rhetoric. Saint Ambrose was bishop of this city, and his discourses converted $A$. to the orthodox faith. The reading of Paul's Epistles wrought an entire change in his life and character. The Catholic church has a fieast (May 3) in commemoration of this event. He retired into solitude, wrote there many books, and prepared himself for baptism, which he received in the thirty-third year of his life, together with his son Adeodatus, from the liands of Ainbrose. He returned to Africa, sold his estate, and gave the proceeds to the poor, retaining only enough to support him in a moderate manner. As he was once present in the church at Hippo, the bishop, who was a very old man, signified a desire to consecrate a priest to assist and succeed him. At the desire of the people, A. entered upon the holy office, preached with extraordinary success, and, in 395, became bishop of Hippo. He entered into a warm controversy with Pelagius (see Pelagians) concerning the doctrines of free will, of grace, and of predestination, and wrote a book concerning them. A. maintained that men were justified merely through grace, and not through good works. His views are substantially those called Calvinistic, and his authority has been at all times unbounded in the Catholic church, insomuch that, according to Petavius, it is considered a sufficient proof of the truth of any dogma that Augustine tauglit it. He died, Aug. 28,403 , while Hippo was besieged by the Vandals. There have heen fathers of the church more learned, masters of a better language and a purer taste; but none have ever more powerfully touched the human heart, and warmed it towards religion. Painters have therefore given him for a symbol a flaming heart. Augustus Neander published, in Berlin, 1823, Sancti Augustini Confessionum Libri XIII. A. left a monument of his zeal for the monastic life by founding some monasteries for monks and nuns in Africa, which were shortly after destroyed by the Vandals. This order was governed by strict rules, but was very different from the one called, after him, Augustine. The different branches of the Augustine order were first established in the 11 th and 1 ?th centuries, and their rules were the work of the popes and priors. They did not constitute a regular orler, 
however, till 1256, and, in 1567, were made thc fourth in rank among the mendicant orders, coming after the Dominicans, Franciscans, and Carmelites. They wear black cowls. Before the reformation, they had ahout 2000 convents, containing 30,000 nouks, and also 500 nunneries. After the reformation brought about by Listher, a brother of their order, they were separated into many considerable brotherhoods, among which the barefooted monks, in Italy, Spain, and France, were the nost numerous. At the beginning of the 18th century, the order unmbered forty-two provinces. The number of convents of this order is now smaller. They are to be found in Italy, Spain, Portugal, in the Austrian states, and in America. In 1817, Augustine nuns of the congregation of Our Lady appenred again in Paris. Their number is thirty-two; they support themselves by their industry, educate 200 poor children, and possess no lauded property.

Augustulos (Romulus Momyllus, surnamed $A u$ gustulus); son of Orestes, a general of the Roman emperor Julius Nepos. Orestes deposed the em. peror, and placed his son upon the throne, in 475. In the following year, Odoacer, a commander of the German forces in the Roman service, revolted, put Orestes to death, obliged $A$. to resign, and thus put an end to the Roman empire in the West. During the twenty years of the Roman empire which succeeded the murder of Valentinian III., no less than sine emperors are mentioned.

Augustus (Caius Julius Cesar Octavius); origivaliy called Caius Octavius; son of Caius Octavius and Accia, a daughter of Julia, the sister of Julius Cresar. The Octavian family originated at Velletri, in the country of the Volscians. The branch to which Octavius belonged was rich and distinguished. Ilis father had risen to the rank of senator, anil had gone to Macedonia, after being chosen protor, where he was distinguished as a civil and military officer. Octavius was born during the consulate of Cicero, 65 B.C. He lost his father when young, hit was very carefully brought up at Rome by his mother, and I. M. Philippus, the second husband of Accia. His talents gained him the regard of his great uncle, Julius Cæesar, who declared limself willing to adopt him for his son, in case he himself shonld remain without children. Octavius was at Apollonia, in Epirus, where he was studying eloquence, under the renowned orator Apollodorus, when he received the news of the tragical death of his uncle, and of his having adopted him as his son. Notwithstanding the anxiety of his friends, he went over to Italy, in orler, if circumstances should favour him, to satisfy the hopes which he had entertained from being aclopted by Julius Cresar. When he landed at Brundusinm, deputies from the veterans collected there came to him. Conducted in triumph to the city, and saluted as the heir and avenger of Casar, he made his adoption publicly known, and took the name of lis uncle, adding to it that of Octavianus. He placed himself, then only nineteen years old, at the head of the veterans, possessed himself of all the public money in Irundusium, and advanced througl Campania to Rome. Ilere there werc two parties, that of the republicans, who had killed Casar, and that of Antony and Lepidus, who, under the pretence of avenging him, strove to establish their own authority. Thic latter party became victorions, and the consul, Antony, exercised almost unlimitel power. Octavius addressed himself first to Cicero, who had retired to his villa at Cumx, being desirous to gain this great orator, always beloved by the people, and whom Autony hated and feared. From thence he went to Rome, where the greatest [nart of the magistrates, soldiers, and citizens came to meet lim, Antory, alone, paying no attention to lis return. After Octavius had caused his adoytion to be confirmed in the most solemn mauner, he: went to Antony, begged his friendship, and demanded of lim the inheritance left him by Cresar, in order to pay the legacies mentioned in his will. Antony, at first, haughtily refused to acknowledge his claims, but afterwards clianged his demeanour, when he found the influence of Octavius continually increasing, and his own proportionably diminishing. There could be no lasting union between two equally ambitious rivals. Their liearts cherished reciprocal hatred and jealousy; and their enmity wis so little a secret, that Octavius was accused of having wished to get Antony murdered. How the latter went to Cisalpine Gaul, besieged Mutina, and was declared an enemy to his country while absent from Rome; how Octavius, who had ohtained the most powerful party in the senate, accompanied the consul sent against Antony, and, after the death of the consul, took the chief command; how he afterwards, when Antony, together with Lepidus, entered Italy at the head of a powerfil army, united with him ; how a triumvirate was formed by the three generals; and how, after dreadful scenes of blood in Rome and the rest of Italy, they defeated the republican army under Brutus and Cassius, in Macedonia;-all this is contained in the article on Antony. Antony honoured the memory of Brutus, but Octavius insulted his corpse. After his return to Rome, he satisfied the avarice of his soldiers by the division of the conquered lands. This division caused great disturbances. In the midst of the stormy scenes which convulset Italy, he was obliged to contend with Fulvia, whose daughter, Clodia, he had rejected, and with Lucius, the brother-in-law of Antony. After several battles, Lucius threw himself into the city of Perusia, whert: he was soon after obliged to surrender. The city was given up to be plundered, and three hundrel senators were condemned to death, as a propitiatory sacrifice to the manes of the deified Cresar. After the return of Antony, an end was put to the proscriptions. Octavius allowed such of the proscribed persons as had escaped death by flight, and whom lie no longer feared, to return. There were still some disturbances in Gaul, and the naval war with Sextns Pompeius continued for several years. After lis re. turn from Gaul, Octavius married the famous Livia, the wife of Claudius Nero, whom he compelled to resign her, after he himself had divorced his third wife, Scribonia. Lepidus, who had hitherto retained an appearance of power, was now deprived of his authority, and died as a private man, 13 B.C. Antony and Octavius now divided the empire. But while the former, in the East, gave himself up to a life of luxury, the young Octavius pursued his plais of making himself sole master of the world. He especially strove to obtain the love of the pcople. He showed mildness and magnanimity, without thc appearance of striving after the highest power, and declared himself ready to lay down his power when Antony should return from tlic war against the Parthians. He appeared rather to permit than to wish limself to be appointed perpetual tribune-an office whicl gave him supreme power. The more he advanced in the affections of the people, the more openly did he declare himself against Antony. By making public a will, wherein his rival appointed his sons by Cleopatra his lieirs, he stirred up the ill-will of the Romans against him. Availing himself of this feeling, Octavius declared war against the queen of Egypt, and led a considerable force both by sea and land, to the Ambracian gulf, where Agrippa (q. v.) gained the navai victory of Actimn (q. v.), which imade Octavius master of the world, B. C. 31. He 
pursucd his rival to Egypt, and ended the war, after hie liad rejected the proposal of Antony to decide their differences by a personal combat. Cleopatra and Antony killed themselves. Octavius caused them to be splendidly buried. A son of Antony and Fulvia was sacrificed, to ensure his safety. Cresariour, a son of Caesar und Cleopatra, shared the same fate. All the other relatious of Antony remained uninjured, and Octarius, on the whole, used his power with noderation. He spent two years in the East, in order to arrange the athirs of Eigypt, Grecee, Syria, Asia Minor, and the islands. On his return to Rome, he celebrated a triumpl for three days in succession. Freed from his rivals and enemies, and master of the world, lie was undecided concerning the way in which he should exercise his power in future. Agrippa, whose victory had given him universal dominion, counseled him to renounce his authority. Mrcenas opposed this; and Octarius followed his advice, or rather his own inclinations. In order to make the people look upon him as an unlimited monarch, lie abolished the laws of the triumvirate, beautifed the city, and exerted himself in correcting the abuses which had prevailed during the civil war. At the end of his seventh consulship, lie entered the senatehouse, and declared his resolution to lay down his power. Tlie senate, astonished at his moderation, besought lim to retain it. He yielded to their pressing entreaties, and continued to govern through them. He now obtained the surname of Angustus, which marked the dignity of his person and rank, and united, by degrees, in himself, the offices of imperator, or commander-in-chief by sea and land, with power to make war and peace; of procousul over all the provinces; of perpetual tribune of the people, which renderexl his person inviolable, and gave him the power of interrupting public proceedings; and, in fine, of censor, and pontifex maximus, or controller of all religious matters. The laws themselves were subject to him, and the observance of them depended upon his will. To these dignities we must add the title of father of his country. Great as was the porrer given to him, he exercised it with wise mode. mation. It was the spirit of his policy to retain old names and forms, and he steadfastly refused to assume the title of dictutor, which Sylla and Cresar liad made odious.-A. conducted many wars in Africa, Asia, and particularly in Gaul and Spain, where he triumphed over the Cantabrians after a serere struggle. His arms subjected Aquitania, Pannonia, Dalmatia, and Jlyria, and held the Uacians, Numidians, and Ethiopians in check. He concluded a treaty with the Parthians, by which they gave up Armenia, and restored the eagles taken from Crassus and Antony. At the foot of the Alps, he erected monuments of his triumphs over the mountaineers, the proud remains of which are yet to be seen at Suca and Aosta. After he lad established peace throughout the empire, he closed (for the third time since the foundation of Rome) the temple of Janus, B. C. 10. But this peace was interrupted, A. D. 9, by the defeat of Varus, who lost three legions in an enmagement with the Germans, under Arminius, and killed limself in cespair. The information of this mis?ortune greatly agitated $\mathrm{A}$. He let his beard and hair grow, and often cried out in the deepest grief, " $O$ Varus, restore me my legions!" Meruwhile the Germans were held in check by Tiberius. During the peace, $\boldsymbol{\Lambda}$. had issued many useful decrees, and abolished abuses in the government. He gave a new form to the senate, employed limself in improving the manners of the people, particularly by promoting marriage, enacted laws for the suppression of luxury, introduced discipline into the armies, and order into the games of the circus. He adorned Rome in snch a manner, that it was truly said, "He found it of brick, and left it of marble." He also made journeys, as Velleius says, every where, to incrense the blessings of peace: he went to Sicily and Greece, As a Minor, Syria, Gaul, \&c. : in several places he fonnded cities and colonies. The people crected altars to hin, and, by a decree of the senate, the month Sextilis was called August. Two couspiracies, which threatened lis life, miscarried. Capio, Murena, and Egnatius were punished with death : Cima was more fortunate, receiving pardon from the emperor. This maguanimity increased the love of the Romaus, and diminisher the number of the disaffected; so that the master of Rome wonld have nothing to wish for, if his family had been as obedient as the world. The debatichery of his daughter Julia gave hin great pain; and he showed himself more severe against those who destroyed the honour of his family, than against those who threntened his life. History says, that, in his old age, he was ruled by Livia, the only person, perhaps, whom lie truly loved. He had to sons, and lost by death lis sister's son, Marcellus, and his danghter's sons, Caius and Lucius, whom he had appointed his successors. Also, Drusus, his sollin-law, whom he loved, died carly; and Tiberius, the brother of the latter, whon he liated, on account of his bad qualities, alone survived. These numerous calamities, together with his coutinually-iucruasing infirmities, gave lim a strong desire of repose. He undertook a journey to Campania, from whose purer air he lioped for relief; but disease fixed upon him, and he died, at Nola (August 19, A. D. 14), in the 76 th year of his age, and 45 th of his reignt. When he felt lis death approaching, he is said to lave called for a mirror, arranged his hair, and demandexl of the by-standers, "Have I played my part well ?" and, an answer being returnes in the affirmative, "Then," added he, using the furm of the players, "farewell, and applaud," (valct, it plaudite). If this last passage in the life of $\mathbf{A}$. is true, it is certainly indicative of his character, his policy, and even of his fortune. It is certain, that his conduct was almays measured and determined beforehand, and that he had a great power of remaining cool and unmoved amid the cares and a gitations of government. Stud:ously concealing his own plans, he made use of the passions, as well as the talents, of others, to further them. He conquered Brutus by means of Antony, and Antony, by means of Agrippa. He several times changed his party, but never his purposes, and knew how to cause power to be offered, and pressed upon him, while it was, in fact, the object of all his exertions. It cannot be denied that he used his power with wisdom, and became the benefactor of his country, which he had previously plunged into the lorrors of civil war. His taste and active mind led him to favour and protect the learned; and he even exercised the art of the poet himself; so that he was not unworthy of giving his name to an age distinguishel for intellectual creations. His death plunged the empire into the greatest grief. He was numbered among the gods, and temples and altars were erected to him.

Avgustus II., Frederic, elector of Saxony and kirg of Poland, second son of John George III., electur of Saxony, born at Dresden, in 1670, was remarkable for his bodily strength and activity. To his residence in France he owed that taste for luxury and the fine arts, which afterwards made the Saxon court inferior in splendour to none in Europe, except that of Louis XIV. In 1691, he visited Vienna, where he contracted a friendship with the arcliduke Joseph, afterwards Joseph I. By the death of his elder brother, John George IV., in 1694, he became elector. The Polish throne liaving became vacant, in 
1690 , by tile death of Jolm Sobieski, $A$. presented limself as a candidate for it. The abbé de Polignac, the French ambassador at Warsaw, supported the pretensions of the prince of Conti, whom the Polish nobility preferred; but $A$. had an army on the frontiers, obtained rotes by bribery, and publicly embraced the Catholic religion. June 27 th, 1697, the election took place. A. strengthened his party by marching 10,000 Saxons into Poland. Bribery and intimidation ubiained him the victory. After he lad ascended the throne, a treaty was concluded between Denmark, P'oland, and the czar Peter I., against Charles XII. of Sweden, in which the object was the conquest of Livonia. (See Oliva.) But Charles, having defeated the Danes under the walls of Copenhagen, and the Russians at Narra, was now ready to advance into Poland, and $\Lambda$. was obliged to provide for the defence of his own dominions. Thus commenced the celebrated northern war, which lasted twenty years, in which A., with his faithful Saxons, had to withstand the opposition of the Poles, as well as the valour of the Swedes. Charles declared him a usurper, and thus separated the cause of the republic from that of the king, who obtained but little assistance from the Poles. The Swedes advanced to Clissow, between Warsaw and Cracow. $\Lambda$. liad 24,000 men, Charles only half the number; but the Poles gave way in the leginning of the engagement, and Charles gained a complete victory, July 20,1702 . May 1, 1703, the Saxon army was defeated again at Pultusk. The diet assembled at Warsaw declared A., Feb. 14, 1704, incapable of wearing the crown of Poland, and Stanislaus Lesczinsky, waywode of Posell, was chosen king, July 12, 1604. Charles, victorious on every sice, adranced into Saxony, and A. found himself obliged to conclude a secret peace, at Altranstadt (i. v.), Sept. 24, 1706. Meanwhile the Russians, ignorant of these transactions, obliged $A$. to attack the Swedish general Mardefeld. He gained a signal victory at Kalisch, and entered Warsaw in triumph, at the time that the proposals of Charles were brought to hin. However much he might desire to take advantage of his good fortune, it was too late. Saxony lay at the mercy of the Swedes. He signed the treaty, and, December 18, 1706, visited Charles in his camp at Altranstadt. To complete his mortification, Charles compelled him to send to Stanislaus the jewels and archives of the crown, with a letter of congratulation. He returned to Dresden, where he soon after received an unexpected visit from Charles. Count Flemming, his first minister, advised him to make himself master of the person of his dreaded rilemy ; but he rejected the unjust proposal. He now elevoted himself to the domestic affiirs of Saxony. His love of splendour liad involved him in many expenses, by which the funances of his kingdom were disordered. In 1708, he served, under an assumed name, in a campaign agiinst the French, in the Netherlands. In 1709 , after the defeat of Charles at Pultawa, the Poles recalled $\boldsymbol{A}$., who united himself anew with Peter. These two monarchs, in slliance with Denmark, sent troops into Pomerania. Notwithstanding the exhausted state of Sweden, the Swedish general Steinbock gained a splendid victory over the allies at Gadebusch, Dec. 20, 1712, which compelled them to raise the siege of Wismar and Stmilsund. Charles XII., having afterwards returued from his residence in Turkey, and made known his determination to prosecute the war with vigour, an alliance, at the head of which was $\Lambda$., was formed against him; but his death put an end to the war, and $A$. concluded a peace with Sweden. A confederation was now formed in Poland against the Saxon troops, at the head of which was a nobleman, named Ledehushi. The Saxons were attacked ou all sides, and were obliged to surrender. At length, through the mediation of Peter, an arrangement was conclud. ed at Warsaw, 1716, between A. and the republic, The Saxon troops were removed from the kingdom, and $A$., says a celebrated historian, renouncing the idea of subduing it by force, sought to attain his end by other means. He gave himself wholly up to roluptuousness and a life of pleasure. His court was one of the most splendid and polished in Europe: The Poles yielded but too readily to the example of their king, and the last years of his reign were characterized by boundless luxury and corruption of manners. We read with astonishment, even at this day, the description of the entertainments given by him. It is related that he gave a regiment of dragoons to king Frederic William of Prussia for twelve porcelain vases. He was not disliked by his subjects, and filled with dignity his station among the European powers. In his character generous ideas were united with despotic feelings, a taste for pleasure with the cares of ambition, and the restlessuess of a warlike spirit with the effeminacy of a luxurious life. Death surprised him in the midst of his pleasures and projects. On his journey to Warsaw to attend the diet, a small wound in lis knee becoming inflamed, he died, Feb. 1, 1733, and was buried in Cracow. His wife, Christine Eberhardine, left him one son. By his mistresses he had many children. The countess of Konigsmark bore lim the celebrated Maurice of Saxony. See Cosel, countess of.

Avgostos. III., Frederic, elector of Saxony and king of Poland, son of Augustus II., born at Dresderi, 1696, succeeded his father as elector, in 173:3. Towards the end of this year, Louis XV. endeavoured to replace Stanislaus Lesczinsky, whose daughter lie had married, on the throne of Poland; but France was too far distant to send troops enough to Poland to support him. A part of the Polish nobility separated from the diet, and, supported by a Russian army, chose $A$. king; and in 1736 , he was first generally recognized as such by the congress assembled at Warsaiv to conclude a peace. Although without the great and amiable qualities of his father, in other respects he closely followed his example, distinguishing himself by the splendour of his feasts and the extravagance of his court. He squandered inmen it sums on pictures and musicians. Hunting was his passion. The cares of government lie gave up to his favourite and prime minister, count Brull (q. v.), who was artful enough to persuade a monarch, weak, but prond and jealous of his dignity, that he alone exercised the supreme power. His system of politics consisted in entire dependence upon Russia. He preferred Dresden to Warsaw, and, through his long absence from Poland, the goverument sank into entire inactivity. Never were the annual diets more turbulent, and never were they so inefficient from the unbending obstinacy of the members, who conltinually opposed each other, under the most trivial pretexts. A. was satisfied if he could remain in his beloved Saxony, and thus the great kingdom of $\mathrm{Po}$ land was almost entirely without a government for thirty years. In the midst of this confusion, the Poles appeared to be satisfied and happy ; but, when Frederic II. had conquered Silesia, A., disturbed by the rapidly-increasing power of Prussia, united hin!self with the queen of Hungary, by the treaties of Dec. 1742, May 13, 1744, and by that of Leipsic, May 18, 1745. IIe pledged himself by means of the money which England and Ifolland were to pay him, to furnisl her with 30,000 auxiliary troops, which he sent into Silesia, where they were united with the Austrian army, but were entirely defented at Hohenfriedberg, June 4, 1745. Frederic now atlacked Saxuny itself, and prince Leopold of Dessau defieatid 
the Saxon army once more, Dic. 15, 1745, at Kesselsdorf, muler the walls of 1 resien. $\Lambda$. deserted his capital, and preserved his pictures and porcelain, but lost the archives of the state, which fell into the hands of the victors. By the peace of Dresden, Dec. 25,1745 , he was reinstated in the possession of Saxony, in the next year. In 1756, he saw himself involved ane:w in a war against Prussia. When Frederic declined his proposal of neutrality, he left Drescle'1, Sept. 10, and entered the camp at Pirna, where 17,00 ) Saxon troops were assembled. Frederic surrounded the Saxons, who were obliged to surrender, October 14. A. fled to Konigstien, and afterwards to Poland. His authority in this country had always been inconsiderable, and after the loss of Sixouy, became still more iusignificant. The ascension of Catharine to the Russian throne was a new source of lisquietude to him, for the great empress sought, in every way, to deprive the Saxon princes, who were allies of France, of the Polish throne. The peace of Hubertsberg, therefore, was hardly concluded, when $\Lambda$. returned from Warsaw to Dresden, where he was seized, Oct. 5, 1763, with a fit of the gout, which attacked his stomach, and put an end to his life. He had, like his father, before his ascension to the Polish throne (1712), embraced the Catholic religion at Bologna. His son Frederic Clıristian succeeded him as elector of Saxony, and Stanislaus Puniatowsky as king of Poland.

Aouc (from the Latin aulu, used for court); an epithet given to a council in the ci-devant German empire, the Reichshofrath. The aulic council was one of the two supreme courts of the Gerinan empire, which first received a distinct form, after the estates had obliged the emperor, in 1495 to establish the court of the imperial chamber (das Reichs-Kammergericht). After the erection of this court, the emperor still had, as before, officers who decided all disputes brought to him from his hereditary dominions, and from the empire at large. He, of course, would not allow the estates the same influence, in the appointment of these officers, which they exercised in the appointment of the members of the other court above-mentioned. But as his officers composing the aulic council took connizance of judicial processes, the estates frequently complained of it, after 1502. They were not able, however, to attain any thing, except more precision in its organization, in 1559 and 1654 . In the peace of Westphalia, it was acknowledged as a supreme court of the empire, equal to the court of the imperial chamber. It consisted of a president, a vice-president, and eighteen counsellors, a yart of whom, at lenst, were to be taken, not from Austria, but the other states of the empire. Six were to be Protestants: all were appointed and paid by the emperor. If the Protestant counsellors were unanimous, the votes of the rest could not prevail against them. The counsell ors were divided into a bench of counts and lords, and a bencl of learned men (Gelehrte), with no distinction, except that the latter, who generally were raised to the rank of nobles, had a higher salary. The vice-chancellor of the empire, also, appointed by the arch-bishop elector of Mayence, had a seat in the aulic council, and a vote after the president. This court had rot only concurrent jurisdiction with the court of the imperial chamber, but, in many cases, exclusive jurisdiction ; in all feudal processes, and in criminal affairs, over the immediate feudatories of the emperor, and in affairs which concerned the imperial government. The right of appeal, possessed by the estates, existed also in regard to the judicial decisions of the aulic court. With the death of an emperor this court ceased, and the next émperor established a new one. In the meantime, the regents of the empire constituted vice-nulie councils, which crased ngain with the beginning of the new imperial goverument. 'Ihe archives of this court, which were separated from those of the Austrian house as late as 1740 , are in Vienna. Justice was, perhaps, never more slowly administered than by the two imperial courts. An epigram of the muthematician Kastner ascribes divine power to these bodies, because they gave immortality to legal processes; and a German expression, still in use, to shove any thing on the long bench, meaning, to delay something indefinitely, is said to be derived from the protracted processes of these courts. But the rotu at Ilone, and some other courts, have, perhaps, equally goorl claims to this divine power.

Avus, in ancient geograply; a sea-port in Bootia, on the strait called Euripus, between Bootia and Eubcea. Agamemnon (q. v.) assembled here the Greek fleet intended to sail against 'lroy. See, also, Iphigenia.

A vovo (Marie Catherine Jumelle de Bernevill('), countess of, born 1650, and died 1705, was the author of Contes des Fées (Fairy Tales), which, in their day, met with great success in France. Her style was easy and agreeable, but verbose. Ijer tales are often founded on fact. The critic cannot pardon the insipid gallantry of many of her heroes. But that was the fashion of the time. She was fond of developing her plots philosophically. Her lusband was accused of treason by three of his tenants, was imprisoned, and subjected to a severe examination, and in danger of being condemned to death, when a mortal disease seized upon one of his accusers, who, to obtain absolution, confessed the falsphood of the whole accusation.

Avrellan, an emperor of Rome, distinguished for his military abilities and stern severity of charcter, was the son of a peasant of Illyricum. He gradually rose, under Valerian II., to the highest louours in his profession, and even to the consulate; which good fortune was further favoured by a weiulthy marriage. Clandius II., on his death-bed, recommended A. to the choice of the troops of Illyricum, who readily acceded to his wishes. He delivered Italy from the barbarians, reduced Tetricus, who liad been unwillingly made to assume the purple in Gaul, and conquered the famous Zenobia, queen of Palmyra. Owing to the ungenerous excuse of the queen, that she had waged war by the advice of her ministers, her secretary, the celebrated Longinus, was put to death by the victor; but, after having graced his triumphal entry, Zenobia herself was presented with a villa on the Tiber, and allowed to spend the remainder of her days as a Roman matron. A. followed up his victories by the reformation of abuses, and the restoration throughout the empire of order and regularity, but tarnished his good intentions by the general sererity of his measures, and the sacrifice of the senatorian order to his slightest suspicions. He had planned a great expedition against Persia, and was waiting in Thrace for an opportunity to cross the straits, when he lost his life, A. D. 125, by assassination, the result of a conspiracy excited by a secretary whom he intended to call to account for peculation. A. was a wise, able, and active prince, and very useful in the declining state of the empire; but the austerity of his character caused him to be very little regretted. It is said that he meditated a severe persecution of the Christians, whon he was $s 0$ suddenly cut off, after a distinguished and eventful reign of only five years.

AurENG-ZEBE (ornament of the throne), born Oct. 20,1619 , received this title from his grandfather, Jchan-Guyr, who at that time was sorereign of $\mathbf{H i r}$ dostan. When he was nine sears old, his weak and 
unfortunate father, Shah Jelıan, succeeded to the throne. Anreng-Zebe was distinguished, when a youth, for his serious look, his frequent prayers, his love of solitude, his profound lypocrisy, and his deep plans. He caused limself to be received among the fakirs, wore their habit, and wished to visit the tomb of the great prophet at Medina. But in his twentieth year, lie laid aside the Koran, which he had hitherto carried in his bosom, raised a body of troops by his address and good fortune, and obtained the government of the Deccan. Here, wishing to give the fakirs a proof of lis love and friendship, he invited them to a feast, and compelled them, notwithstanding their resistance, to put on new and decent clothing. Hc burned the old clothes, and found therein a quantity of gold and silver pieces, which did him good service when he came to carry on war with his hrother. He stirred up dissensions between his brotliers, made use of the assistance of one against the other, and finally shut lis father up in lis liarem, where he kept hin prisoner. He then murdered his relatives, one after the other, and, in 1659 , ascended the throne of Hindostan, and tonk thc name of Aalem Guyr. Notwithstanding the means by which he had got possession of power, he governed with much wisdom, consulted the welfare of his people, watched over the preservation of justice, and the purity of manners, and sought to confirm lis owr power. Two of lis sons, who endeavoured to form a party in their own favour, he caused to be arrested and put to death by slow poisoll. He carried on many wars, conquered Golconda and $V$ isiapour, and drove out, by degrees, the Mahrattas from their country. Aurmugabad, once his residence, now desolate, Seely has described in his Wonders of Elora (London, 1824). After lis death, the Mogul empire declined, wars immediately broke out between his sons, and several conquered provinces sought to nake themselves independent.

Aoreos, or Aureos Numulus; the first gold coin which was coined in Rome, 546 A. U., in the second l'unic war. It weighed two denarii and one quinarius, and was worth 25 denarii, or 100 sesterces (Suet. Oth. 4; Tacit. Hist. i. 24). In later times, it was called solidus, but had diminished in value. At first, forty aurei were made out of a pound; under Nero, forty-five; under Constantine, seventy-two. It was about as much as a ducat, or nine shillings sterling.

Auricular Confession. See Confession.

AURIGA, in astronomy; the Wagoner (ivioxos); a constellation of the northern hemisphere, containing sixty-six stars, according to the British catalozue.

Aurora (Greek, ross); in mythology, daughter of Iyperion and Thia, and sister of Sol and Luna. She was one of the ancient goddesses of the race of the Titans, but retained her rank among the later race of gods. To the Titan Astraus, son of Crins, she bore the Winds, Zeplyyrus, Boreas, and Notus, the Morning-star, and the Constellations. She rises from the ocean, drawn by thc celestial horses Lampus and Pliaeton, and, with rosy fingers, raises the veil of night, sherding light upon the workd, until slie flies from the splendour of day. Amoug the mortals whose heauty captivated the goddess, poets mention Orion, Tithonus, and Cephalus. .

Aurora Australis. See Aurora Borealis.

Aurora Borealis (French, aurore boréale; Ger. man, Nordlicht); northern light. We often see in the north, near the horizon, usually a short time after surset, a dark segment of a circle, surrounded by a brilliant arch of white or fiery light; and this arch is often separated into several concentric arches, leaving the dark segment visible between them. From these arches, and from the dark segment itself, in high latitudes, columins of light; of the most varie. gated and beautiful colours, shoot up towards the zenith, and, sometimes, masses like sheaves of light are scattered in all directions. The appearance is then splendid ; and its increasing beauty is announced by a general undulation of the masses of light. A kind of fiery coronet is afterwards formed about the zenith, by the meeting of all the columns of light, resembling the knob of a tent. At this moment, the spectacle is magnificent, both for the multipl icity and beauty of the columns which the aurora presents. (compare Maupertuis De la Figure de la Terre. Paris, 173s). The light, after this, grows fainter and more tranquil. This faintness and tranquillity, however, are only temporary, for the phenomena are soon repeated in all their beauty-the oscillations of the columns of light, the formation of the corona, and the like, though with a thousand variations. At length the motion wholly ceases, the light is collected about the northern horizon, the dark segment vanishes, and nothing is left lout a strong brightness in the north, which is lost in the dawning day. These brilliant appearances are also attended, in high latitndes, with loud noises, described as resembling the hissing and crackling of fireworks. This appearance has received the name of northern light, because, on account of our position on the earth, we see it only about the north pole. A similar appearance, aurora australis, was seen about the south pole, in 1773 , by Cook's sailors, between $58^{\circ}$ and $60^{\circ} \mathrm{S}$. lat., and later travellers have observed the same. These phenomena ought, therefore, properly to be called polar lights. - Plilosophers are of different opinions as to the cause of the aurora. It is, however, satisfactorily ascertained to be within the region of our atmosphere. Heli ascribed it to the reflection of the sun and moon by the clouds of snow and needles of ice, which are constantly floating in the atmosphere of the frigid zones. Mairan supposed it to proceed from the atmosphere of the sun. Bailly ascribed it to magnetism, and its remarkable influence on the needle has been generally observed. Franklin attributed it to electricity. Biot, who was sent to the Shetland islands in 1817, by the French acadeny of sciences to determine the length of the pendulum vibrating seconds, had an opportunity, Aug. 27 of the same year, of observing the auror borealis, in all its splendour, at the island of Uist. On this occasion, he ascribed to the phenomenon a volcanic origin, and his reasoning is given at length in the Journal des Savans for 1820. His description of this wonderful phenomenon is to be found in Biot's Précis Elémentaire de Physique, 3d ed., Paris, 1824, rol. ii. p. 99, et seq. An ingenious hint of Kastner, udvanced in the sixth edition of Gren's Physik (Physics), Halle, 1820 , is deserving of attention. He considers polar lights as the electricity of the earth rising periodically to the poles. Observations on this appearance were. communicated by Richardson and Hood, in the appendix to Franklin's Narrative of a Journey to the Shores of the Polar Sea, in 1819, \&c. London, 1823, 1824. A series also of interesting abservations on this subject, made in December, 1829, by the Rev. James Farquharson, of Aberdeenshire, with an ap. paratus transmitted to him by the Royal Society of London, will be found publishcd in the Transictions of that Society for 1830 .

Aosonios, Decius Magnus, the most celebrated Roman poet of the 4 th century, was born at Burdi. gala (Bordeaux), about the year 310. He studied inder several distinguished masters, and became, at last, protessor of rhetoric in lis native city, whence his fame extended through the whole empire. Valentiniun intrusted to him the education of his son Gra. tian, and appointed him afterwards questor and pre- 
torian prefect. After Gmtian had ascended the throne, he showed hiniself not less gratefnl to his preceptor. About the year 3\%0, he appointed him consul in Gaul. After the death of Gratian, A. lived upon an estate at Bordenux, devoted to literary pursuits, and died abont 394.-As Valentinian was of the Christian religion, it is probable that $\Lambda$. was so too; and many of his writings confirn this conjecture. Critics are not unanimous on the subject of his poetical merits. He is, undeniably, learned und ingenious, but his style and versification have the blemishes of the age, and his Latin is impure. Hlis epigrams, idyls, eclogues, letters in verse, \&c., are extant. 'The nost raluable editions are, Bonrdeaux, 1575-80, 2 vols., 4to, by Souchny; Paris, 1730-34, Jaubert; Paris, 1760-70, 4 vols., $12 \mathrm{mo}$.

A USPICEs. See Augur.

A ustev, Jane, a gifted novelist, was born Dec. 16, 1775, at Steventon, in the county of Hants, of which parish her father was rector. Upon his death, his widow and two daughters retired to Southampton, and ultimately, in 1807 , to Cliawton. During her residence in the last-mentioned place, Miss Austen composed the novels, which, for ease, nature, and a complete knowledge of the features which distinguish the. domestie life of the English country gentry, are very highly esteemed. The principal of these productions are Sense and Sensibility; Pride and Prejudice; Mansfield Park ; and Emma. Two more were published after her death, entitled Northanger Abbey, and Persuasion, which were, however, her most early attempts. The object of Miss Austen, in all her works, was to adrocate the superiority of sound principle, unsophisticated manners, and undesigning rectitude, to showy and artificial pretensions. Her discrimination was acute, her humour easy and spontaneous, and lier power of creating an interest in her eharacters loy slight and reiterated touches, extraordinary. This amiable and accomplished lady, whose personal and mental attractions were of a high order, died of a decline, on the $18 \mathrm{th}$ of July, 181\%, in her forty-second jear.

Austehutz; a town with 2000 inlabitants in the dominions of the prince of Kaunnitz-Rittberg, in the circle of Brunn, in Moravia, ten miles east of Brunn, on the highway whieh leads by Goding to Hungary, is famous for the battle of the 2d of December, 1805, and the armistice of the 6th of the same month. These events were turning points in the destiny of Europe and the elevation of Napoleon. Their immediate consequence was the peace of Presburg; but the most important result was the subjection of Germany and the humilation of Prussia; for the victory at $A$. not only frustrated Pitt's great plan of reducing the power of France, by the allied arms of Britain, Russia, and Austria, to the bounds, which, ten years after, the peace at Paris assigned to it, but also established, with the assistance of French diplomacy, Napoleon's continental and federative system. Nipoleon, after the capitulation of Mack, in Ulm, Oct. 19, unchecked at Lambach and Mariazell by the Austrians under Meerreldt, and at Durustein, Nov. 11 (where Mortier suffered loss), by the Russians under Koutousoff, occupied Vienna, 13th Nov., and immediately took possession of the bridge orer the Danube, leading to Moravia, while prince Auersberg, who should have burned it, allowed himself to be deluded by a pretended negociation for peace. Marshal Lannes, therefore, on the 15th, came up with the Russian army under Koutousoff; who, to preserve himself, resolved to sacrifice the rear-guard of 6000 men, whom prirce Bagration commanded. This intrepid general, however, notwithstanding he was attacked by 30,000 French at Hollabrunn, on the $16 \mathrm{th}$, and at Guntersdorf on the 17 th, forced his way with the remains of his troops to the mnin army, on the 19th. Here the emperor Alexander had arrived, on the 18th, ficrs Berlin, and on the same day the second Russian army. under Buxhowden, had united with that of Koutou. sofi. Nov. 24, the Russian guarls, 10,000 strong, also arrived, and it was resolved, at the head-quartery of the two einperors, Alexander and Francis, at Olmutz (the troops being then in want of provisions), to march, Nov, $2 \tau$, froin the advastageons station of Olschan (eight miles from $\mathbf{A}$.), in five parallel cohumus, against 13rum, where Napoleon laacl already taken up his head-quarters on the 20th, and offer him battle. But the Russians lost many days by repeated eliange's in their plans of attaek, and Napoleon deceived thein by negociations (in which prince Lolgorucki made very high demands), also by retiring, as if he wished to a void an attack, and to conceal his force, eontraeted his troops into a narrow space. He thereby gained time, till the arrival of the corps under Berwadotte, and two divisions of Daroust's, Dec. Ist, when he prepared his army, which rested on Brum, for battle, and assured his troops of the vietory of the following day, being the anniversary of his coronation. The French arniy, in a position unknown to Koutousuff, was about 80,000 strong. The army of the allies numbered alout 84,000 foot and 16,000 horse, among which were 20,000 Anstrian tronps. On the morning of the $2 \mathrm{~d}$, about seven o' began, according to a plan prepared by the $\Lambda$ ustrian general Weyrotter. Buxliowden, who commanded the left wing of the Russian army, was stationed beside the 1st eolumn, led by lientenant-general Docktoroff, which, together with the $2 \mathrm{~d}$, under general Langeron, and the $3 \mathrm{~d}$, under general Przybyszewsky, was to surround the right wing of the French under Soult. The village of Delnitz was taken after an obstinate engagement ; but dchnded by the enemy's retreat, Buxhowden pressed forward, with the ist columu, too far to the left, and fell into a narrow defile, which two divisions of Davoust had occupied in the night. A bout the same time, the $2 \mathrm{~d}$ and ? $\mathrm{d}$ columns, in order to attack the right wing also in front, had left the leeights of Pratz, which overlooked the ficld of battle. These were immediately occupied by Soult, and maintained, after a fight of two hours, by the aid of a part of the centre, under Bernadotte, against the efforts of Koutousoff. This decided the victory ; for the Russian left wing, wlich was before engaged with Davoust, and, after Soult's change of position, with the French reserve also, was cut off from the centre, and attaeked both in flauk and rear. Thus the $2 \mathrm{~d}$ and $\mathrm{3d}$ columus fell into disorder. Lannes immediately pressed forward with the left wing, and the French centre, under Bernadotte, supportil by a well directed fire, broke the centre of the allies (where the Austrians, mostly newly-enlisted troops, stood under the command of Koutonsofi), and pushed it upon the right wing of the Russians under Bagration and prince Liechitenstein, so that the Russian reserve came too soon into the engagement. Still it made for a long time a gallant resistance under the grand prince Constantine and the prince Dolgorucki. After this body was thrown into disorder by the Frenel left wing under Lannes, and tlie last attaek of the Russian Guards frustrated by the French guards and the cavalry, which Murat commanded, the allied army retreated under cover of Bagration and Kienmayr, about one o'clock, in good order, to A., and at four o'clock passed over the Mareh. Th: issue of this battle was singular. The French tronps of the right wing, with their rear resting on $A$, attacked the remainder of the left wing of the allies, and, in the end, marelied down from the same heights, from which, in the morning, the allies had descended in attack then. Consequently, the Russian left wing 
suffered the most, as it had to force its way over the frozen ponds at Kobelnitz and Satschau, and over a narrow dike. According to the French account several thousand of the allied troops were drowued in these ponds, when Napoleon ordered the ice to be broken with sloot. At that crisis, lieutenant-general Przybyszewsky, witl 113 officers and 6000 men, was forced to lay down his arms. According to Koutonsoff's report, the Russians lost 12,000 meu. The French made their own loss about 4500 men. The number of the allies taken prisoners about 20,000 men, and that of the cannous taken, which, for the most part, were stuck fast in the morasses, rather more than 150. The Austrians lost 592\% in killed, wounded, and prisoners.-The battle, it is said, wonld have been won by the Russians, if they had fought either before the Ist of December, and consequently before Bernadotte and Davoust liad reenforced the French army, or after the 15th; for an army of 80,000 men was approaching from the Hungarian frontier, towards Vienna and the Danube, led by the archdukes Cliarles and John, who had joined their forces near Windisch-Feistritz, in Styria, Nov. 27, while Massena remained at his post on the Isonzo. Troops were also levied in Hungary, and, in addition to this, a body of Russians, 12,000 stroug, under the command of general Bennigsen, had iuraded Upper Silesia, December 3 , and prepared the people of Bohemia to rise in a body ; and, in consequence of the treaty of Potsdam, Nov. 3 , by which the king of Prussia joined the Russian alliance, an army of 180,000 men-Prussians, Saxons, and Hessians--stood ready, iu case Napoleon should refuse, on the 15th of December, the mediation of Prussia, according to the treaty of Luneville, to invadc France, and to break tlurough Napoleon's lines upon the Danube; while an army of 80,000 men--Pmissians, Russiaus (under Tolstoi), Swedes, Hanoveriaus, and Britisl--in Upper Germany, threatened the frontiers of the Netherlands. In Italy, too, the landing of the British and Russians might effect an important diversion. In spite of all these resources, Austria asked for peace. December 3, prince John von Liechtenstein appeared at Napoleon's headquarters, and, on the 4th, the emperor Francis himself had a two hour's interview with him at the French outposts, not far from the village of Nasedlowicz, near a mill at Saroschutz, where the two monarchs made a truce, and laid the foundation of a peace. Napoleon's adjutant, general Savary, accompanied the German emperor back to his head-quarters, to learn whether Alexander would accede to the treaty. The Russian accounts say that the emperor would not allow lin to come into his presence; but the French bulletins give a circumstantial account of his audience, which is also mentioned by the Austrian general von Stutterlieim, the author of Materiaux pour servir à l'Hist. de la Batuille d'Austevlitz (1806, with notes by a French officer, said to lave been dictated by Napoleon). Prince Berthicr and prince von Liecliteustein concluded, on the 6 th, a truce, according to the terms of which the Frencl army was to hold the Austrian circle, Venice, a part of Bohemia aud Moravin, and Presburg; the Russian army was to evacuate tlee territories of the ('mperor of Austria; no levy aras to be made iu Boliemia or Ifungary, and no foreign army was to enter the states of the house of Austria. On the 7 th, Napoleon imposed upon the couutries held by his troops a tax of a hundred millions of francs. Alexander, according to the wishes of the emperor of Anstria, drew off his army, though he would not accede to the treaty, but placed his troops in Silesin and Lower Saxony, at thic disposal of the king of Prussia. March 4, 1806, his troops in Dalmatia took possession of Cattarn (q. v.), which had been given up by Austria to Frauce. The truce of $A$. paralysed the strength of the Austrian monarcliy, and broke its former alliances, so that the Prussian minister, count von Haugwitz (who had come to Vienna, in November, that he might act as mediator on the 15th Dec., but liad been anticipated by $\mathrm{Na}$ poleon), finding, in the altered state of affairs, that he must either declare open war against the Frencl emperor, or make an alliance with him, concluded, Dec. 15, in opposition to lis instructions, the treaty by which Prussin exchanged the alliance of Russir for that of France. (See Lucchesini On the Confederation of the Rhine, i. 348, and Scholl's Traités de Paix, viii. 27.) Austria afierwards subscribed, Dec. 26, the hard conditions of the peace of Presburg (q. v.), by which she not only gave up a territory of 24,200 square miles, with $2,785,000$ inhabitants, and a revenue of $13,610,000$ florins, but lost her alliance with Switzerland and 1taly, and her influence in the German empire. Thus Napoleon's superiority was established in Italy, the dependence of the princes of Lower Germany upon France confirmed, and Prussia drawn from its system of neutrality.

\section{Austiv, St. See Augustin.}

Austral Ocean. See Sonth Sec and Krusensterr.

Adstralasia, or AdSTRALIA, in modern geography; the fifth great division of the globe, so called fron its austral, or sonthern position. Sometimes the name is applied only to those islands lying around New Holland from long. $96^{\circ}$ to $185^{\circ} \mathrm{E}$., and lat. $33^{\circ}$ $\mathrm{N}$. to $50^{\circ} \mathrm{S}$.; but the more compreheusire sense of the term embraces Polynesia, or those islands lying nortls of New Holland and east of the Philippines, from lon. $170^{\circ}$ to $230^{\circ}$ F., and lat. $35^{\circ} \mathrm{N}$. to $50^{\circ} \mathrm{S}$. Some geograpliers gave the name of Oceuna to the whole collection of the islands in the Pacific ocean; but the term Australia has prevailed. This portion of the globe began to be discovered after America and the South seas were known to the Europeans. Magellan, who first undertook a voyage round the world, had promised the Spanish monarch, into whose service he entered when he. left the Portuouese, that he would artive at the Moluccas by sailing westward. On this voyage, he discovered, March 6 , 1521, the Ladrones, or Mariana islands, a group which constitutes a part of A. Magellau must therefore, be regarded as the first discoverer of this portion of the globe, and opened the way for the subsequent discoveries in this quarter. 'Three hutdred years elapsed before all the islands, which now pass under the name of $\Lambda$., were known to Europeans. After Magellan, the Spanish navigators coutinued the, process of discovery in this part of the world, particularly Alvaro de Mesidana, who, in the last part of the 16tls century, discoverel the Solomon islands and the Marquesas, and passed through the Society and Friendly islands without seeing.then. Fernaudez de Quiros, who liad accompanied him ou his third royage, took a southerly direction, and hit upon the part of the South sea whicl contains the most islands. He made known to the world the Society islands and Terra del Fspiritu Sauto. In the 17th century, the Dutch began to explore this part of the ocean, and, besides several sinall islands, discovered the largest island of $\Lambda$., New Hollaud, which received its name from them, although there is some reason for supposing that it had been visited by the Portuguese a lundred years earlier; but lleit. discoveries seem to have been concealed by their govermment, and afterwards forgotten. The coasts of New Holland, e. g. Filel's Land, Nuyt's Laud, De Witt's Land, retaiu the names of the Dutch disco. verers. Tasman, a Dutclıman, and Dampier, en Englishman, continued the discoveries. In the mil- 
the of the Isth century, the Fnglislımen Byron, Wallis, and Carteret, and the Frenchman Bougainville exerted themselves to extend the knowledge of $A$. But James Cook (q. r.), who circumnavigated the world from 1768 to 1779 , contribited most to the more accurate examination of this portion of the globe, corrected the knowledge of Furopeans with regard to the islands already known, again discovered ishunds before seen, and was the original discover(r of New Caledonia and the Sandwich islands. After the time of Cook, both the French and English $\mathrm{ex}$ erted themselves to give the world a better acquaintunce with A. Among the later navigators, Entrecasteaux, Grant, La Peyrouse, Baudin, Flinders, Krusenstern, and Kotzebue have added to our knowledge of A. There are, doubtless, many islands still in these seas, which no European has seen, and of those known, only the coasts have yet been explored. The South sea and the Pacific ocean, between the easteru shore of Asia and the western shore of $A$ merica, contains all the islands of $A$. which occupy a space of $130^{\circ}$ in length, and $85^{\circ}$ in breadth, as they extend from $50^{\circ} \mathrm{S}$. to $35^{\circ} \mathrm{N}$. lat., and from $95^{\circ}$ to $230^{\circ} \mathrm{E}$. lon. The superficial contents are estimated at about $3,500,000$ square miles; of which New Holland alone is almost equal in size to Europe.We may regard all these islands as continuous chains of moustains, which rise from the sea, and, rmming in a direction from N. to S. E., in a double row, like hills and promontories, surround New Holland. The line nearest the main land of New Holland begins with New Guiner, and ends with New Zealand; the second line begins at the Ladrones, and passes on to Navigator's islands and the Friendly islands, whence it takes a direction from the west towards the east. From these almost continuous rows of islands the Sandwich islands are wholly separated.-The soil of A. is fruitful, especially in the islands of the torrid zone. Plants transported hither from Europe flonrish. Some of the islands are low and fat; others have steep, rocky shores, and are filled with mountains, some composed of primitive rocks, others of flotz and basalt. The highest known are the Mauna Roa, in the Sandwich islands, and Peak Egmont, in New Zealand, the height of which amounts to 14,000 feet. Sereral of these islands are of volcanie origin: others are raised from the bottom of the sea by successive layers of coral, or carried to their present height by accumulations of the same substance on the original rocks at the bottom of the derp. The coral formations extend to a distance from their coasts, and constitute reefs, so that it is dangerous to approach them. The mountains of $A$. have not yet been explored, and their structure investigated. The shores of New Holland, New Gninea, and New Zealand, and the mountains in their vicinity, have been examined by naturalists but slightly. The residence of Enropeans in the other islands, also, has been too short to allow them to make accurate observations. In later times, the English have made an attempt to pass from the eastern coast of New Holland, where their colonies are situated to the interior. The mountains extending from north to south, on the west of these colonies, ealled the Blue hills, consist of steep crags, fearful precipices, and ranges of heights of successively increasing elevation, which made all early attempts to become acquainted with the interior of no avail. At length, Nov. 3, 1813, Mr Erans, an Englishman, succeeded in ascending them, and, in 1815 , a road was conpleted over them. On the whole, naturalists have only penetrated into the interior about 140 miles from the eastern shore, though the distance to the western shore is more than 2700 miles. There is a remarkable want of large streams in this portion of the world, though the islands in general are not de- ficient in water. The rivers of New Holland are small arns of the sea, which extend far into the interior, retain the saliness of the ocen, experience the ebb and flow of the tide, and receive some insig nificant streams on the coast. The largest river of New Holland is the Hawkesbury, in Broken Bay, which is navigable for the largest ships 46 miles up the country, and is 150 rods wide. Beyoud the Bluc hills, the river Macquarrie has been discovered, which is lost, with other rivers, in the morasses. Now Holland probably contains, accorling to the accoust of Oxley, a large lake in the interior, similar to the Caspian, into which the rivers flow. The climate of A., as it lies partly in the sonthern temperate zouse, and partly in the torrid, is in some parts warm, though the heat is generally less opuressive than in the same latitudes in Asia and Africa. Is cller parts, it is temperate, mild, and healthy. 'Those countrie's of $\Lambda$. which lie in the sontliern hemisphere are colder than those in the northern. The productions are, in part, the same with those of other countries of the same Jatitude ; in part, peculiar to itself ; for iustance, birls without wiugs, having hair instrad of feathers ; quadrupeds with the beaks of birds, white tagle's, X.c. The mammalia and beasts of prey are fe'w. The principal mammalia are the kangaroo, weighing frou 100 to 150 pounds; the wombat (both of which have a pouch under the belly, a characteristic belonging $t(1$ many of the quadrupeds of New Holland); the ornithorynchus, perhaps the most singular animal in the world, to which nature has given the body of a quadruped, and the head, or, at least, the beak of a bird; the dasyure, the clingo, or New Holland dog, the New Holland flying-squirrel, several species oi opossum, the kangaroo rat, hogs, logs, rats, bats, whales, sea bears, sea lions, and sea plephants. Horses, oxen, sheep, and goats, were introduced thither by Europeans. Among the birds which are distinguished for the splendour of their colours and variety of their plumage, are several kinds of parrots and birds of paradise ; the New Holland cassiowary, which weighs 70 pounds, and surpasses the East Indian birds in size and in the beauty of its plumage; the splendid mœnura, remarkable for the elegance of its tail ; ant the black swan. There are also hens, doves, anil ducks. The coasts are well stocked with fish, of which there are several kinds peculiar to them. The varieties of insects and shell fish are rery great. The richness of the vegetable kingdom is still grenter; in New Holland alone, 1000 new plants have beer discovered. The smaller islands are still richer than New Holland in esculent plants. Anong these are the sago, areca, cucoa, and eucalyptus irees, which attain a height of 180 feet, and a circumference of 30 feet ; the cajaputi, gum tree, bread fruit, guavas, bananas, rotang; casuarina, or club trees, of which the natives make the most durable weapons and furniture; paper-mulberry trees, from the finest bark of which cloth is manufactured; lemons, oranges, figs, sugar cane, betel pepper, aud anotlier kind of pepuer, of which an intoxicating drink, called ava, is macte; cotton trees; New Zealand flax, which forms an excellent cord; yams, arum. These form the princijal articles of agriculture in the Sandwich islands. Thie Europeans have introduced European plants, grains, and garden fruits, almonds, pomegrasiates, tobacco, hemp, flax, hops, \&c. In the iniseral kingdom, though little examination has been given to it, there have been found copper and iron, granite, purphyry, basalt, chalcedony, agate, jade, or oriental kidney stome, marble, lime, rock salt, \&c. $A$. is very thinly inhabited. There are, on an average, about two inhabitants to a square mile, as the whole number is estimated at only $1,700,000$. They consist, principally, of two distinct classes; one of Negroes, called Papuas, and 
one somewhat different from the Europeans in appearance, and belonging to the Malay race. From the union of the two principal varieties several intermediate ones arise. The Papuas inhabit New Holland, New Guinea, Louisiade, the Solomon islands, New Hebrides, New Britain, and New Caledonin; and, in New Holland particularly, they have projecting lips and woolly hair, like all other negroes, from whom they are distinguished by very thin, lean arms and legs. This race, in cultivation, is far below the other race, the Malays, especially in New Holland, where they liave very disgusting and ape-like features, stand on the lowest step of bodily and mental improvement, and live in a savage state, without laws, and without rèligion. Their great mouths, and thick, projecting lips, jut out somerwhat like a snout, and their little, fat noses are lost behind them. Their deep sunk eyes betray a rude and malicious spirit, and sometimes, though rarely, a stupid good humour. They are naked, or slightly clothed in the skins of beasts, live on fish, or the fruits of trees, or on the flesh of the kangaroos, which they find no difficulty in catching, and devour every thing almost raw ; they hardly pull the feathers from birds before they consume them. The inhabitants of New Caledonia and the New Hebrides, who are also regarded as Papuas, eat the flesh of their enemies, when they have killed them, though they have fields covered with bananas, yams, and arum. The pure Malay race, who inhabit the Australian islands,-i. e. the Friendly, Society, and Sandwich islands, - are distinguished for the most beautiful and regular forms of which humanity is capable. Their complexion is sometimes not darker than that of the Spariards and Italians, and some of the wo inen are as white as the most beautiful Europeans. In general, these islanders seem to be good-natured, sociable, gentle, happy, and gay. Travellers, however, agree in this, that they have a strong propensity to steal, and give up their wives and daughters to the Europeans without restraint. Among some of them, the shocking custom of eating human flesh, and offering human sacrifices, still prevails. They live in villages, where there are even some public buildings to be found. They make boats ornamented with carved work, tools, furniture, and weapons of stone and wood, which, considering their means, are very remarkable. Ther make nets, baskets, cords, very fine mats, and cloth for their dress, which they know how to dye exquisitely. They carry on a sort of agriculture, which consists principally in the cultivation of arum, yams, and potatoes, and live in a civil union, of which the foundation is a sort of feudal system. They worship a supreme and inferior gods; they have priests and sacrifices, and entertain liopes of sensual indulgences in another life. Their morais, or buildings for the dead, are commonly places where the worship of their gods is performed. But the mis. siouaries have now spread the Christian religion in the Society and Sandwich islands, and put an end to the ancient superstitions. Among all these islanders, the inhabitants of the Sandwich islands lave made the greatest progress, through their acquaintance with the Europeans. Besides these original inhabitants of $\Lambda$., there are also some Europeans; a few in the Sandwich islands; upwards of 50,000 in the colouy established by the Britislı on the eastern shore of New IIolland, and a less number in Vaı Diemen's Land. In 1824, Great Britain took possession of all the islands and tracts of laud in $\Lambda$., lying between $111^{\circ} \mathrm{E}$. and $153^{\circ} \mathrm{W}$. lon,, besides Apsley and Clarence straits, and port Essington, on the peninsula of Coburg. The principal parts of $\Lambda$., besides several smaller islands lying separately, are New Holland, Van Diemeu's Laud, New Guinea, the Admiralty islands, New Britain, Solomon istes,
Queen Charlotte's islands; or the archipingo of Santa Cruz, New Hebrides, or Terra del Santo Espiritu, New Caledonia, New Zealand, the Pelew, Caroline, or New Philippine islands, Marian, or Iadrone, Monteverdos, Mulgrave, Fisher, Friendly, Bligh's, Navigator's, Society, Marquesas, Washington's, and Sandwich islands. (See King's Survey of the Coasts of Australia, London, 1827, and Cunningham's Two Years in New South Wales, 3d edit., Lond., 1828; also, Statistical Account of the British Settlements in Australasia, \&c., 3d edit., London, 1825, 2 vols.

A ustria (in German, Eistreich, i. e. Fast-empire. The population of this empire is composed of Germans, Sclavonians, Magyars, (by which name the Hungarians call themselves) and Italians. Its cradle was the territory below the Eus. In the cime of Charlemagne, about 800 , the margraviate of $\mathrm{A}$. was formed by a body of militia, which protected the south-east of Germany from the incursions of the Asiatic tribes. In 1156, it was united with the territory above the Fns, and made a duchy. In 1282, the state began to increase under the dominion of the house of Hapsburg. (q. v.) This dynasty sonn added seremal new territories, which afterwards formed the Austrian circle, and, in 1438, obtained the electoral crown of the German emperors. In $1453, A$. was raised to an archduchy, and, having acquired Bohemia and Hungary in 1526, with the consent of the inhabitants, it attained the rank of a European monarchy. The Lorraine branch of the house of Austria maintained this rank at the peace of Aix-la-Chapelle, signed in the year 1748. They confirmed the union of their territories by elevating the monarchy, in 1804, to an hereditary empire, and established its dignity as one of the chief powers in Europe, before, during, and after the congress of Vienna, in 1815 .

Ancient History of the Country till the year 982.After the Romans had vanquished the Noricans, A. D. 33, and gained possession of the Danube, the country north of the Danube, extending to the borders of Bohemia and Moravia, helonged to the kingdom of the Marcomanni and Quadi; a part of Lower Austria and Stiria, with Vienua (Vindobona), a nunicipal city of the Roman empire, belonged to Upper Pannonia; the rest of the country, with Carinthia and a part of Carniola, formed a portion of Noricum. Gorz belonged to the Roman province of Illyricum, and Tyrol to Rhætia. These limits became confused by the irruptions of the barbarians. The Boii, Vandals, Heruli, Rugii, Goths, Huns, Lombards, and Avars, in the course of the 5th and 6th centuries, successively occupied the country. But after the year 568, when the Lombards lad established their power in Upper Italy, the river Ens formed the boundary line between the German tribe of Bajuvarii, the proprietors of the territory above the Ens and the Avars, who liad removed from the Fast to the banks of that stream. In 611, the Wendi, a Sclavonic tribe, appeared on the Murr, Drave, and Save. In 788, the duchy of Bavaria was dissolved, and the Arars passed over the Ens, and invaded the counties of the Franks in the Bavarian territory. In 791, Charlemague forced them to retire to the Raab, and united the territory extending from the Fns to the junction of the Raab with the Danube (the territory below the Ens) with Germany, under the name of Avaria, or Eastern Marchia (Marchia Orientalis), or Austria; and, in the 10th century (in a document of Otho III., 996), it was called Ostirrichi, or Wistreich, the German name for Austria. Many colonists, particularly from Bavaria, were sent by Charlemagne into the new province, and a margrave was appointed to administer the government. The archbisliop of Salzburg was at 
the head of ecclesiastical affairs. After its separation from Verlun, in 843, Avaria formed the eastern boundary of the German empire. On the invasion of Germany by the Ifungariaus, in 900 , Avaria fell into their lands, and was held by them till 955 , when the emperor Otho I., in consequence of the victory of Augsburg, reunited a great part of this province to the empire. By the power and address of its margraves, the whole country was joined again with Germany, and, in 1043, under the emperor Uenry III., and the margrave Albert I. (the Victorious), its limits were extended to the Leytha.

Austria under the Honse of Bamberg, till 1282. From 982 to 1156 , the margraviate of Austria was hereditary in the family of the counts of Babenberg (Bamberg); the succession, lowever, was not regulated by primogeniture, but by the will of the emperor. In ancient documents, mention is made of the estates of Austria in the year 1096. After Henry the Proud (duke of Bavaria and Saxony) was put under the hau of the empire, Iseopold V., margrave of $A$., received the duchy of Bavaria, in 1138, from the emperor Conrad. But when the margrave Henry, son of Leopold, under the title of Ja-so-mir Gott (Yes-so-me-God), had again ceded it, in 1156, to Henry the Lion, the boundaries of $\mathrm{A}$. were PXtended so as to include the territory above the Ens, and the whole was created a duchy with certain privileges. Under this duke the court resided at Vienna. Duke Leopold VI., the son of Heiry, received the duchy of Stiria, in 1192, as a fief from the emperor Henry VI., it having been added to the empire by Otho $I$., in 955 , by his victory over the Hungarians. It was this prince who imprisoned Richard Cour de Lion (q. v.), king of England. Duke Leopold ViI., the youngest son of the former, erected a palace within the city of Vienna, which is still occupied by the Austrian monarchs, under the name of the old castle. Leopold VII., called the Glorious, established the hospital of the Holy Cross, made Vienna, which had adopted a municipal constitution in 1198, a staple-town, and granted 30,000 marks of silver for the promotion of trade and commerce. In 1229, he purchased a part of Carniola, from the ecclesiastical principality of Freisingen, for 1650 marks, and left the country in a flourishing condition to the youngest of his three sons, Frederic II., surnamed the Varrior. In 1236, this prince was put under the ban of the empire, on account of his joining the alliance of the cities of Lombarly against the cinperor Frederic II. ; and Otho, duke of Bavaria, seized upon his territory above the Ens as far as Lintz. The rest of the country was granted, as a fief by the emperor, to a margrave, and Vienna became an imperial city. During the emperor's campaign in Itay, duke Frederic recovered the principal part of his lands, and his rights were confirmed by the emperor, at Verona, 1245. The rights of Vienna, as an imperial city, were abolished, and Frederic was to be called king, as sovereign of Austria and Stiria; but all his expectations of empire were disappointed by his death in the battle of Leytha against Bela IV., king of Hungary, July 15th, 1246, in the thirty-fifth year of his age. Thus the male line of the house of Bamberg became extinct. - The period from 1246 to 1282 is styled the Austrian interregnum. The emperor Frederic II. declared Austria and Stiria a vacant fief, the hereditary property of the German emperors, and sent a governor to Vienna, the privileges of which, as an imperial city, were once more renewed. But the female relations of the deceased duke Frederic, his sister Margaret (widow of the emperor Henry VI.), and his niece Gertrude, by the persuasion of pope Innocent IV., in 1248, laid claim to the inheritance of their brother. The margrave,
Hernann, with the aid of the pope and a strong party, made liunself master of Viemu, and of several Anstrian cities. In Stiria, he was opposed by the governor Meinharl, count of Gorz. But Hermanu died in 1250, and his sou Frederic, who was afterwards beheaded, in 1268, at Naples, with Conradin of Suabia, was then only a jear old. The whole country was distracted by various parties, and the emperor Conrad IV. was prevented, by disputes witı his neighbours, from turning lis attention to $A$. In 125i, the states of Austria and Stiria determined to appoint one of the sons of the second sister of Frederic the Warrior, Constantia (widow of the margrave Henry the Illustrious), to the office of duke. Their deputies were on the way to Misuia, when they were persuaded by king Wenzeslans, on their entrance into Prague, to declare lis son Ottocar duke of $\Lambda$ isstria and Stiria, who made every effort to support his appointment, by arms, money, and especially by his marriage with the empress-widow Margaret. Ottocar wrested Stiria from Bela, king of Hungary, by his victory of July, 1260, in the Marchfield; and, in 1262, forced the emperor Richard to invest lin with both duchies. Soun after, by the will of his uncle Ulrich, the last duke of Carinthia and Friuli (who died 1269), Ottocar became master of Carinthia, a part of Carniola connected with it, the kingdom of Istria, and a part of Friuli. But his arrogance soon caused his fall. In 1272, he refused to acknowledge count Rodolph of Hapsburg eınperor, and was obliged to defend himself against his arms. After an unsuccessful war, he was forced to cede all his Austrian possessions in Nov. 1276. In 1277, he attempted to recover these territories, but, in the battle of the Marchfield, Aug. 26, 1278, he was slain, and lis son Wenceslaus was obliged to renounce all claim to them, in order to preserve his hereditary estates. The emperor Rodolph remained three years in Vienna, and then appointed his eldest son governor. But, laving succeeded in gaining the consent of the electors of Saxony and Branden. burg, of the three ecclesiastical electors, and of the count-palatine of the Rhine, he granted the duchies of Austria and Stiria, with the province of Carinthia to his two sons, Albert and Rodolph, Dec. 27, 128\%.

This briugs us to the Ifistory of Austria under the House of Hapsburg.-I. From 1282 to 15?6. Albert and Rodolph transferred Carintlia to Meinhard, count of Tyrol, father-in-law to Albert. In 1283, they concluded a treaty, by which Albert was made sole possessor of Austria, Stiria, and Carniola. Vi. enna, having again renounced its privileges as an imperial city, was made the residence of the court, and the successors of Rodolph, from this time, as. sumed Austria as the family title. The introduction of the Hapsburg dynasty was the foundation of the future greatness of $A$. The despotic Albert was assailed by Hungary and Bavaria, and, in 1298, he won the Roman crown in an engagement with Adolphus of Nassau. After this, he undertook the conquest of Switzerland; but was assassinated, May 1, 1328, at Rheinfelden, hy his nephew, John of Suabia (see. .ohn the Parricide) from whom he had basely withlield his hereditary es tates. The inheritance of John now fell to the five sons of the murdered Albert-Fredcric, suniamed the Fair, Leopold, Henry, Albert, and Otho. They were forced to purchase of the emperor Henry VII. the investiture of their paternal estates (consisting, in 1308 , of 26,572 square miles), for 20,000 marks of silver. Under their father, in 1301 , the margraviate of Suabia was added to the territuries of Austria, and the contest with Bararia ended in the cession of Neuberg. On the contrary, the attenipt of duke Leopold, in 1315, to recover the forest towns of Swit- 
zerland, which had been lost under Albert, was frustrated by the valour of the troops of the Siviss confederacy in the battle of Morgarten. In 1314, his brother Frederic, chosen emperor of Germany by the plectors, was conquered by his rival, the emperor Louis (of Bavaria), in 1322, at Muehldorf and was his prisoner, for two years and a half, in the castle of Trausuitz. The dispute with the house of Luxemberg, in Bohemia, and with pope John XXII., induced the emperor, in 1325 , to liberate his captive. Upon this the latter renounced all share in the government, andpledged himself to surrender all the imperial domains which were still in the possession of A. But Leopold considered the agreement derogatory to his dignity, and continued the war against Louis. Frederic, the refore, again surrendered himself a prisoner in Munich. Moved by his faithful adherence to his word, Louis concluded a friendly compact with Frederic, and made preparations for their common government, Sept. 7, 1325. 'These preparations, however, were never carried into execution ; for the agreement had been concluded without the consent of the electors. Leopold died in 13:6, and Henry of A. in 1327 ; Frederic-also died without children, Jan. 13, 1330, after which his brothers, Albert II. and Otho, came to a reconciliation with the emperor Louis. $\Lambda$ fter the death of their uncle, Henry, margrave of Tyrol and duke of Carinthia (the father of Margaret Maultasch), they persuaded the emperor to grant them the investiture of 'Tyrol and Carinthia, in May, 1335: they ceded Tyrol, however, to John, king of Bohemia, by the treaty of Oct. 9, 1356, in behalf of his son John Henry, or rather of his wife, Margaret Maultasch. In 1344, after the death of Otho and his sons, Albert II., called the $W_{i} s e$, united all his Austrian territories, which, by his marriage with the daughter of the last, count of Pfirt, had been augmented by the estates of her father in 1324, and by the Kyburg estates in Burgundy in 1326. Of the four sons of Albert II. (Rodolph, Albert, Leopold, and Frederic), Rodolph 1I. (IV.) completed the church of St Stephen's, and died at Milan, in 1365, without children, a short time after his youngest brother, Frederic. In 1379, the two surviving brothers divided the kingdom, so that Albert III. (with the queue) became master of Austria, and gave the other territories to his brother Leopold III. the Pious. Leopold had made repeated attempts to gain the Hapshurg possessions in Switzerland. He was killed, July 9, 1286, on the field of Sempach, where he lost the battle, in consequence of the valour of Winkelrieg, and $\Lambda$ lbert administered the government of the estates of his brother's ninor sons. Margaret Maultasch ceded Tyrol to him on the death of Meinhard, her only sou, who was married to the sister of $\Lambda$ lbert. She retained nothing but a few castles and 6000 marks of gold. Her claims to Bavaria, also, she renounced, in consideration of receiving Scharding and three Tyrolese cities, Kitzbuhl, Ballenberg, and Kuffstein, and 116,000 florins of gold. In 1365, Leopold III. had bought the claims of the count of Feldkirch for 36,000 florins; for 55,000 florins Austria received Brisgau from the count of Furstenberg, with the cities of Neuberg, Old Brisach, Kentzingen, and Billingen. The remainder of Carniola and the Windisch Mark, after the death of the last count of Gorz, were purchased, together with the county of Pludentz, from the earl of Werdenberg, and the possess.ons of the count of Hohenberg, for 66,000 florins; and the city of Trieste was acquired, in 1380, by aiding in the war between Hungary and Venice. Moreover, the two governments of Upper and Lower Suabia were plenged for 40,000 florins by the king of Rome, Wenceslaus, to duke J,copold. "The $\Lambda$ us- trian and Stirian lines, founded by Alhert III, aud Leopold III., his brother, continued for seventyeight years. In 1395, when Albert III. died, his only son, Albert IV., was in Palestine. On his re turn, he determined to take vengeance on Procopius, margrave of Moravia, for his hostile conduct; but he was poisoned, in 1404, at Znaym. His young sun and successor, Albert V., was declared of age in I410; and, being the son-in-law of the emperor. Sigismund, he united the crowns of Hungary and Bohemia in 143\%, and connected them with that of Germany in 1438. But in the following year the young prince died. His posthumous son, Ladisla us, was the last of the Austrian line of Albert, and its possessions devolved on the Stirian line, 1457. From this time, the house of Austria has furnished an unbroken succession of German emperors. Hungary and Bohemia were lost for a time by the death of Albert V., and, after the unhappy contests with the Swiss, under Frederic III., the remains of the Hapsburg estates in Switzerland. But several territories were gained; and, to increase the rising splendour of the fumily, the emperor conferred upon the country the rank of an archduchy. The dispute which broke out between Frederic and his brothers, Albert and Sigismund, relating to the division of their paternal inheritance, ended with the death of Albert, in December, 1464. In the course of the troubles which resulted from this quarrel, the emperor was besieged in the citadel of Vienna by the citizens, who favoured the cause of the murdered prince. Sigismund now succeeded to his portion of the estate of Ladislaus, and Frederic became sole ruler of all Austria. His son Maximilian, by his marriage with Mary, the surviving daughter of Charles the Bold, united the Netherlands to the Austrian dominions. But it cost Maximilian much anxiety and toil to maintain his power in this new province, which he administered as the guardian of his son Philip. . His confinement at Bruges, in 1489 , resulted in an agreement which was decidedly for his advantage; but he lost, at the same time, the duchy of Guelders. After the death of his father, which happened Aug. 19, 1493, he was made emperor of Germany, and transferred to his son Philip the government of the Netherlands. Maximilian I. (see this article and Germany) added to his paternal inheritance all Tyrol, and several other territories, particularly some bulonging to Bavaria. He also acquired for his family new claims to Hungary and Bohemia. During his reign, Vienna became the great metropolis of the arts and sciences in the German empire. The marriage of his son Philip to Joanua of Spain raised the bouse of Hapsburg to the throne of Spain and the Indies. But Philip died in 1506, thirteen years before his father, and the death of Maximilian, which happened Jan. 12, 1519, was followed by the union of Spain and Austria : his grandson (the eldest son of Philip), Charles I., king of Spain (see Charles $V$.), was elected emperor of Germany. In the treaty of Worms, April 28, 1521, and of Ghent, May 7, 1540, he ceded to his brother Ferdinand all his hereditary estates in Germany, and retained for himself the kingdom of the Netherlands. The house of $\Lambda$. was now the proprietor of a tract of country in Europe comprising $360,230 \mathrm{sq}$. miles. The emperor Charles $V$. immediately increased the number of provinces in the Netherlands to seventcen, and confirmed their union with the German states, which had been concluded by his grandfather, under the title of the circle of Burgundy. In 1526, A. was recognized as a European monarchy.

II. From 1526 to 1740.-Ferdinand 1., by his Inarriage with $A$ una, the sister of Louis II., king of Hungary, who was killed in 1526, in the battle of 
Mohacs, acquired the kingiloms of II ungary and Bohennia, with Moravin, Silesia, and Lnsitia, the nppendages of 13ohemia. Bohemia rejoiced to hail Ferdinand its king. Notwitlistanting the divided opinions of the nobles, and the rising fortune of his aitversary, John von Zapolya (see Hungary), he was raised to the throne of IInugary, Nov. 26, 1526, by the II ungarian diet, and was crowuerl, Nov. 5, 1527. But Zapolya resorted for assistance to the sultan Sulinan II., who appeared, in 1529 , at the gates of Vieuna. The capital was rescued from ruin solely by the prudent measures of the count of Salm, general of the Austrian army, and the inperial forces compelled Soliman to retrent. In 15.55, a treaty was nade, by which John von Zapolya was allowed to retain the royal title and half of Hungary, and his posterity were to be entitled to nothing but Transylvanin. But, after the death of John, new disputes arose, in which Soliman was again involved, and Ferdinand maintained the possession of Lower Humgary only by paying the- warlike sultan the sum of 30,000 ducats annually. This took place in 1562 . Fenlinand was equally unsuccessful in the duchy of Wurtemberg. This province had been taken from the restless duke Ulrich by the Sunbian confederacy, nnd sold to the emperor Charles V.; and, when his estates were divided, it fell to Ferdinand. Philip, landgrave of Hesse, the friend of duke Ulrich, took advantage of the opportunity offered him hy the embarrassment of Ferdinand in the Hungarian war. With the aid of France, he conquered Wurtemberg ; but France ceded it again to Ulrich in the treaty of Caden, in Bohemia, concluded $J_{\text {une }} 29,1534$, on condition that the province should still be a fief of Austria, and, after the extinction of the male line of the duke, that it should revert to that country. The remaining half of Bregentz, the county of Thengen, and the city of Constance, were insufficient wholly to compensate these losses; nevertheless, the territory of the German line of the house of Anstria was estimated at 114,468 square miles. Ferdinand recrived also the imperial crown in 1556, when his brother Charles laid by the sceptre for a cowl. He died July 25,1564 , with the fame of an able prince, leaving three sons and ten daughters. According to the directions given in his will, the three brothers divided the patrimony, so that Maximilian II., the eldest son, who succeeded his father as emperor, obtained Austria, Hungary, and Bohemia; Ferdinand, the second son, received Tyrol and Hither Austria ; and Charles, the third, became naster of Stiria, Carinthia, Carviola, and Gorz. But, in 1595, after the death of the archduke Ferdinand, the husband of Philippine Welser, the fair maid of Augsburg, his sons Andrew (cardinal and bishop of Constance and Brixen, and governor of the Netherlands for Spain) and Charles (margrave of Burgau) were declared incompetent to succeed their father, and his possessions reverted to his relations. In Hungary, the emperor Maximilian met with far better fortune than his father had done. The death of Soliman at Sigeth, in 1566, was followed by a peace, and, in 1572, Maximilian crowned his eldest son, Rodolph, king of Hungary: he was afterwards crowned king of Bohemia, and elected king of Rome. In his attempts to add the Polish crown to his Austrian dominions, he was equally unsuccessful with his fourth son, Maximilian, who engaged in a similar enterprise after the decease of Stephen Bathori, in 1587. Maximilian died Oct. 12, 1576, and Rodolph, the eldest of his five sons, succeeded to the imperial throne. The most remarkable events by which his reign is distinguished are, the war against Turkey and Transylvania, the persecutions of the Protestants, who were all driven from his dominions, and the cir- cumstances which obliged lim to cele IJungary, in 1603 , anul boheunia unl his hereditary estates in Austria, in 1611, to his brother Matthias. From this time we may date the successful exertions of the $A u-$ strian sovereigns to put down the restless spirit of the nation, and to keep the people in a state of alject submission. Matthias, who succeeded Maxinilian on the imperial throne, concluded a peace for twenty years with the Turks; but he was disturbed by the Bohemians, who took up arıns in defence of their re. ligious rights. Matthias died March 20,1619, before the negotiations for a compromise were completel. The Bohemians refused to acknowledge his successor, Ferdinand, and chose Frederic V. the head of the Protestant league, and elector of the palatinate, for their king. After the batcle of ''rague, 1620, 13ohenia subnitted to the authority of Ferdinand. Ile immediately applied liumself to eradicate Irotestantism ont of Bohemia Proper and Moravia. At the same time, he deprived Bohemis of the right of choosing her king, and of her other privileges. Ile. erected a Catholic court of Reform, and thus leel to the emigration of thousands of the inhabitants. The house of Hapsburg has presented an example, which stands alone in history, of the manner in which violence and tyranny can check the progress of civilizil tion; and Bohemia, the land of Iuss, the land where religious freedom has been defended with such hervic zeal, is now greatly inferior in cultivation to evrry other country of western Europe. The Austrian states also favouring, in general, the Protestant religion, were compelled by Ferdinand to swear allegiance to him, and Lutheranism was strictly forbidien in all the Austrian dominions. The province of Hungary, which revolted under Bethlen Gabur, prince of 'Transylvania, was, after a long struggle, subdued. This religious war dispeopled, impoverish$e d$, and paralyzed the energies of the most fertile provinces of the house of Austria. During the reign of Ferdinand III., the successor of Ferdinand $(1657-57)$, Anstria was continually the theatre of war. In the midst of these troubles, Ferdinand ceded Lusatia to Saxony at the peace of Prague, concluded in 1635; anl when the war was ended, he ceded Alsace to Frauce, at the peace of Westphalia, in 1648. The emperur Leopold I., son and successor of Ferdinand III., was victorious through the talents of his minister, Eugene, in two wars with Turkey; and Vienna was delivered by John Sobiesky (q. v.) and the Germans, fioun the attacks of Kara Mustapha, in 1683. In 1687, he changed Hungary into an hereditary kingdom, and joine do it the territory of Transylvania, which had been governed by distinct princes. Moreover, by the peace of Carlovitz, concluded in 1699, he restored to Hungary the country lying between the Daunbe and the Theiss. It was now the chief aun of Leopold to secure to Charles, his second son, the inheritance of the Spanish monarchy, then in the hands of Charles II. king of Spain, who had no children to succectl him; but his own indecision, and the artful policy of France, induced Charles II. to appoint the grandson of Louis XIV. his successor. Thus began the war of the Spanish succession, in 1701. Leopold dieil May 5, 1705, before it was terninated. The emperor Joseph I., his successor and eldest son, continuol the war, but died without children, April 17, 1711. IIis brother Claarles, the destined king of Spain, inmediately hastened from Barcelona to his herechitary states, to take upon him the administration of the government. He was elected emperor, Dec. 24 of the same year; but was obliged to accede to the peace of Utrecht, concluded by his allies, at Rastadt and 13aden, in 1714. By this treaty, Austria receired the Netherlands, Milan, Mantua, Naples, and Sardinir. In 1720 , Sicily was given to Austria in exchange fus 
Sardinia. The duchy of Mantua, occupied by Joseph in 1708, was now made an Anstrian fief, because it had formed an alliance with France, prejudicial to the interests of Germany. This monarchy now embraced 191,621 square miles, and nearly 29 million inlubitants. Its annual income was between thirteen and fourteen million florins, and its army consisted of 150,000 men; but its power was weakened by new wars with Spain and France. In the peace concluded at Viema, 1735 and 1 138 , Charles VI. was furced to cede Naples and Sicily to Don Carlos, the infant of Spain, and to the king of Sardinia a part of Milan, for which he received only a part of Parma and Piacenza. In the next year, by the peace of Belgrade, he lost nearly all the fruits of Eugene's victories, even the province of Temeswar; for he was obliged to transfer to the Porte Belgracke, Servia, and all the possessions of Austria in Wallachia, Orsova, and Bosnia. All this Charles VI. willingly acceded to, in order to secure the succession to his daughter, Maria Thereza, by the Pragmatic sanction. This law of inheritance was passed 1713-1719, and acknowledged one after another by all the European powers.

History of Austria under the House of HapsburgLorraine.-I. From 1740 to 1790 . By the death of Charles VI. Oct. 20, 1740, the male line of the Austrian house of Hapsburg became extinct; and Maria Theresa (q. v.) having married Stephen, duke of Lorraine, ascended the Austrian throne. On every side her claims were disputed, and rival claims set up. A violent war began, in which she had no protector but Brilain. Frederic II. of Prussia subdued Silesia; the elector of Bavaria was crowned in Lintz and Pramue, and, in 1742 , chosen emperor, under the name of Charles VII. Hungary alone supported the heroic and beautiful queen. But, in the peace of Breslau, concluded June 4, 1742, she was obliged to cede to Prussia Silesia and Glatz, with the exception of Teschen, Jagerndorf, and Troppau. Frederic II., by assisting the party of Charles VII, soon renewed the war. But Charles died Jan. 20, 1745, and the lusband of 'Theresa was crowned emperor of Germany under the title of Francis $I$. A second treaty of peace, concluded December 25, 1745, confirmed to Frederic the possession of Silesia. By the peace of Aix-la-Chapelle, Oct. 18, 1748, Austria was obliged to cede the duchies of Parnı, Piacenza, and Guastalla to Philip, infant of Spain, and several districts of Milan to Sardinia. The Austrian monarchy was now firmly established; and it was the first wish of Maria Theresa to recover Silesia. With this object in view, she formed an alliance with France, Russia, Saxony, and Sweden. This was the origin of the seven years' war; but, by the peace of Hubertsberg, 1763, Prussia retained Silesia, and Austria had sacrificed her blood and treasure in vain. The first paper money was now issued in Austria, called stute obligations, and the emperor Francis erected a bank to exchange them. After his death, August 18, 1765, Joseph II., his eldest son, was appointed colleague with his mother in the government of his hereditary states, and elected emperor of Germany. To prevent the extinction of the male line of her family, Maria Theresa now established two collateral lines; the house of Tuscany, in her second son, Peter Leopold ; and the house of Este, in the person of the archduke Ferdinand. For these separations, Maria Theresa indemnified the country by the confiscation of several cities, formerly pledged to Poland by Hungary, without paying the sum for which they stood pledged; by obtaining Galicia and Lodomiria in the first profigate division of the kingdom of Poland, in $1772 ;$; and by the capture of Bukowino, which was cederl by the Porte, in 1777 . In the peace of 'Tes- chen, May 13, 1779, Austria received Inuviertel, ఓnd the vacaut county of Hohenembs in Suabia, the county of Falkenstein, and the Suabian territories of Tettnang and Argen; and thus, at the death of the empress, Nov. 28, 1780, Austria contained 234,684 square miles: it had lost 16,366 square miles, and gained 34,301 . The population was estimated at 24 millions; but the public debt, also, had increased to 160 million florins. The administration of the empress was distinguished by the most useful institutions of government, agriculture, trade, and conmerce, the education of the people, the promotion of the arts and sciences, and of religion. 'The foreign relations of the kingdom, also, even those with the Roman court, were happily conducted by the talents of her minister, Kaunitz. (q. v.) Her successor, Joseph II. (q. v.), was active and restless; impartial, but too often rash and violent. While a colleague with his mother in the government, he diminished the expenses of the state, and introduced a new system in the payment of pensions and of officers. But, after the death of his mother, all his activity and talent as a sovereign was fully developed. As severe to the military as to the civil officers, he adhered, howerer, to liberal principles. The censorship of the press was reformed ; the Protestants received full toleration, and the rights of citizens; the Jews were treated with kindness; 900 convents and religious establishments were abolished, and even the visit of Pius VI. made no alteration in Joseph's system of reformation. The system of education he subjected to revision and improvement ; and he encouraged manufactures by heavy duties on foreign goods. But his zeal excited the opposition of the enemies of improvement. 'The Low Countries revolted, and his vexation probably led him to attempt the exchange of the Netherlands, under the title of the kingdom of Austrasia, for the palatinate of Bavaria, under an elector. But the project was frustrated by the constancy and firmness of the next agnate, the duke of Deux-Ponts, and by the German league, concluded by Frederic II. Joseph was equally unsuccessful in the war of 1788 against the Porte. His exertions in the field destroyed his health; and grief at the rebellious disposition of his hereditary states accelerated his death, which happened Feb. $\approx U$, 1790.

II. From 1790 to 1815.-Joseph 11. was succeeded by his eldest hrother, Leopold II. (q. v.), formerly grand duke of Tuscany. By his moderation and firmness, he quelled the turbulent spirit of the Netherlands, and restored tranquillity to Hungary. The treaty of Reichenbach, with Prussia, July 27, 1790, and the treaty of Sistova, Aug. 4, 1791, led to a peace with the Porte. The unhappy fate of his sister and her husband, Louis XVI. of France, induced him to form an alliance with Prussia; but he died March 1, 1792, before the revolutionary war broke out. Soon after the accession of his son, Francis II., to the throne, and before the 14th of July, 1792, when he was elected Gerinan emperor, France declared war against him, as king of Hungary and Bohemia. (See France.) In the first articles of peace, dated at Campo-Formio, Oct. 17, 1797, Austria lost Lombardy and the Netherlands, and received, as a compensation, the largest part of the Venetian territory; two years previous, in 1795, in the third division of Poland, the Austrian dominions had been enlarged by the addition of West Galicia. In the beginning of the year 1799 , the emperor Francis, in alliance with Russia, renewed the war with France. But Napoleon extorted the peace of Iuneville, Feb. 9, 1801, and Francis acceded to it, without the consent of Britain. By the conditions of the treaty, he was to cede the county of Falkenstein and the Frickthal. Ferdinand, grand duke of Tuscany, at the same time, renounced his 
eaam to this province, and received, in return for it, Sulzburg and Borchitesgaden, with a part of the territury of Passau, and was afterwards made master of the largest part of Eichstadt, and honoured with the title of elector. Austria obtained the Tyrolese archbishoprics 'Trent and Brixe'n, ant, notwithstanding its cessions of territory to France, had gained, including its acquisitions in Poland, 9580 square miles; this made the whole extent 253,771 square miles. The public elebt had also increased to 1220 million florins. The first consul of France now causerl himself to be proclaimed emperor ; and $\Lambda$ ug. 11, 1804, Francis declared hinself lerelitary emperor of Austria, and united all his states unter the name of the empire of Austria. Immediately after this important act, he took arms once more, with his allies, Russia and Great 13ritain, against the government of France. The war of 1805 was terminated by the peace of Presburg (Dec. 26, 1805). By the conditions of the treaty, Francis was obliged to cede to France the remaining provinces of Italy; to the king of Bavaria Burgais, Eichstadt, a part of Passiu, all Tyrol, Vorarlberg, Ilohenembs, Rothenfels, Tettuang, Argen, and Lindais ; to the king of Wurtemberg, the five towns lying on the Danube, the county of Hohenberg, the landgraviate of Nellenburg, Altdorf, and a part of Brisgau; and to the grand duke of Baden the remainder of Brisgau, Ortenau, Constance, and the commandery of Meinau. He received, in return, Salaburg and Berchtesgaden ; the elector of Salaburg was compensated by the province of Wurzburg; and the dignity of grand master of the Teutonic order was made hereditary in the house of Austria. Thus ended a war which cost the Austriau monarchy, besides the territories just enunerated, 90 million florins, which were carried away by the French from Vienua, and 800 millions for the other expenses of the war; of which Francis paid a large proportion from his private purse. After the formation of the confederation of the Rhine (July 12, 1806), Francis was forced to resign his dignity as emperor of Germany (Aug. 6, 1800), which had been in his family more than 500 years. 'This was one of the most important consequences of the war. He now assumed the title of Francis I., emperor of Austria, and resolved, in 1809, on a new war with France, aided only by Great Britain, who did nothing more than furnish some pecuniary assistance, and made a tardy attack on Walcheren. Austria fought courageously, but in vain. The peace of Vienna (Oct. 14, 1809) cost the monarchy 42,380 square miles of territory, 3,500,000 subjects, and more than eleven million florins of revenue. The public debt was also increased to 1200 million florins, and all the paper money in circulation was estimated at 950 millions. Napoleon, after tearing from the Austrian monarchy its fairest provinces, - the duchy of Salzburg, with Berchtesgaden, Innviertel, Western Ilausruck viertel, Carniola, and Gorz, Trieste, the circle of Villach, a large part of Croatia, Istria, Ræzuns in the Grisons, the Bohemian territories in Saxony, all West Galicia, the circle of Zamoski in East Galicia, Cracow, with half the salt-works of Wieliczka, the circle of Tarnopol, and many other provinces which were given to Russia,-formed a personal connexion with the ancient fumily of Hapsburg by his marriage with Marie Louise, daughter of the emperor of Austria, and, March 14, 1812, concluded an alliance with the emperor Francis against Russia. But the emperor of france was repulsed, on his invasion of this country; Prussia rose up against him ; the congress of Prague met and separated again without accomplishing any thing; and Francis, Aug. 10, 1813, declared 'war against France, and formed an alliance, Sept. 9, I813, at Teplitz, with Britain, Russia, Prussia, and Siveden against his son-in-law. In the bnttle of Leipsic, the Austrian troops took an hor. ourable part. The firmuess with which the emperor signed the act of proscription against his son, ant fixed the fate of his daughter and her infant, excited general respect. He signed the same act against Napoleon a second time, when he returned from Elba. He also opposed Murit in Italy. Yet the Austrian cabinet endeavoured to provide for young Napoleon in the settlement of the affairs of France. By the peace of Paris, 1814, Austria gained the portion of Italy which now forms the Lombirdo-Venetian kingdom, and recovered together wlth 1)almatia, the hereditary territories which it had been olliged to cede. The former grand duke of Wumburg, on the contrary, ceded his territory to Bavaria, ant again took possession of 'Tuscany.

In the new system of Europe, established at the congress of Vienna, which met in 1815, and by the treaty concluded with 13avaria, at Munich $(\Lambda$ pril 14, 1816), the Austrian monarchy not only gained more than 4238 square miles of territory, but was also esst'ntially inproved in compactness; and its commercial importance was increased by the accession of Dalmatia and Venice. The infuence of this power among the states of Europe, in consequence of the congress of Vienna, as the first member of the great quadruple alliance (changed, by the congress of "Aix-la-Chapelle, 1818 , to a quintuple alliance), and as the head of the German confederation, has been continually increasing since the congress at Aix-la-Cliapelle, as is evident to those who feel an interest in the history of the age. Of the foreign affairs of the government, which have been conducted by the prince von Metternich, the most important is the connexion of Austria with the German confederation. 'The inperial cabinet overruled the deliberations of the German confederates at Frankfort, through its minister, count Buol-Schanenstein (who was succeeded, in 1823, by the baron of Munch-Bellinghausen), so that all the decrees made in the congress of Carlshad, in A $\mathrm{ug}$., 1819 (spe Congress and Carlsbud), relating to a general censorship of literary institutions, the suppression of liberal opinions and writings, and of secret socirties, were unanimously adopted and published, Sept, 20, 1819, and renewed Ang. 16, 1824. A congress was held at Vienna, Nov. 25, 1819, composed of all the ministers of the German confederates, to diaw up a constitution for the confederated states. It was signed at Vienna, May 15, 1820; and, June 8 , of the same year, it was acknowledged at Frankfort as the universal law of the German confederation. (q. v.) The ideas of the Austrian cabinet, in regard to the political condition of Gernuany, were made known to the public by the remarkable Lettre confi. dentielle de $S$. A. le Prince de Metternich à M. le Baron de Berstet:, premier Ministre du Grand Duché de Baden, June, 18:0. This letter is printed in Lesur's Annuaire (Paris, 1821, p. 252). The united infuence of A. and Prussia, in the military committee of the confederation, laid the foundation of the German military system, and regulated the numbers and distribution of the army of the confederacy, and the occupation and command of the fortresses of the empire. It must be observed, however, that A. (in conformity with the 18 th art. of the constitution), abolished, in 1820, the right of emigration from its own states to those of the German allies, and concluded the Elbe navigation acts (see Elbe) at Dresden, in 1821, and at Hamburg, in 1824. Saxony and Bavaria formed a closer connexion with the house of A., by a family union, in 1819 and 1824 . The queen dowager of Saxony is a sister, and the wife of Frederic prince of Saxony a daughter, of the emperor Francis Noremher 4, 1824, the second imperial prince, the archduke Francis (born 1802), 
was inarried to Sophia, princess of Bavarik, halfsister of the empress of A. (The house of A. now exists in twenty-four separate branches.) Of the five principal powers which decided the political condition of Naples, Piedmont, Spain, and Greece, in the congress of Troppau, 1820, Laybach, 1821, and Veroua, 1822 (q. v.), A. was the first. The harmony which existed between the three founders of the Holy Alliance, so called, led to the establishment of the principles of legitimacy; and every one knows the important consequences of this union, in the maintenance of principles contrary to the spirit of the age and the law of nations; as in the law relating to the armed interference. A. executed the decrees of the congress as far as related to Naples and Piedniont. (See Naples and Piedmont, revolution of.) Her influence was felt in the Swiss confederacy. In the dispute between Portugal and Brazil, A., being connected with the emperor of Brazil by means of a family union, did not oppose the independence of the new empire, for which Great Britain interceded. The infant dour Mignel swore allegiance, in Vienna, to the Portıguese coustitution of 1826 , and has since conducted himself like a robber and a madman. Time will probably show what share has been taken by $A$. in the disputes of the royal family of Portugal. To the alliance formed by Russia, Great Britain, and France for the pacification of Greece (July 6, 1827), A. never acceded. Indeed, it is important for her that the Greeks should still remain in bondage; especially if the fall of the Porte (a power which the congress of Vienua declared to be indispensable to the other states of Europe) should increase the strength of Russia. This power already presses on the unprotected frontiers of $A_{\text {. }}$ : if it should extend its conquests in that direction, the trade of this country with Moldavia and Walachia would be entirely cut off. Moreover, it would be very prejudicial to her to have a constitutional staie established in the south-east, on the confines of Hungary and Transylvania, which, by religious sympathies, would exert all influence on Servia and the southern provinces of Hungary. When prince Alexander Ypsilanti, leader of the Hetærists (see Hetcra) in Moldavia, entered the Austrian territory, he was detained by the Austrian anthorities at Munkatsch, and afterwards in 'Theresienstadt, as a public prisoner, and liberated, at last, in 1827. A. prolribited all societies for the aid of Greece, and all contributions of money or arms: the Greeks from Russia were forbidden to march through the country, and the Philhcllenes were forbidden to traverse her territories to reach the ports of the Adriatic.* On the other hand, A. aided (by its internuncios in Constantinople) the efforts of the British ambassador to settle the disputes between Russia and the Porte, and effected the eracuation of the principalities by the Turkish troops; which led, also, to the conclusion of the treaty of Ackerman, in 1826. (See Ottoman Empire.)

In its politics, both at home and abroad, A. has more influence than any other state in Europe, in suppressing liberal opinions and resisting the claims of the age. The cabinet has recourse to measures, of which other cabinets, striving after the same end,

- The semi-ofticial paper at Venna, the Qistreichisch Beobachter (the Austrian Observer), which is entirely subservient to the government, constantly wrote against the Greeks, and in favour of the Turks. It is worth while to mention here the denntion which this paper (on the whole, an able one) gave of legitlmacy, when the question rose, whether the Turks were a legitimate power or not rose, whether the Turks were a legitimate power or not,
and whether, in consequence, the Greeks were rebuls or not. The Observer said, that any power was legitlmaw. with which other lesitimate powers had concluded trea cies for a series of years ! are as yet ashamed. The subjects are forbidden to praise or blame the administration; and thus no one is permitted to express any political opinions. The citizens are cut off from literary intercourse with other nations by a twofold censorship established on the frontiers. There are, likewise, in Austria, different kinds of prohibited books: some are wholly prohibited; others are prohibited to all but the learned; and the whole nation has been, for centuries, destitute of the means of high intellectual cultivation. They are good-natured and lively. Eating, drinking, dancing, music, and women make up the sum of an Austriau's enjoyment. If his emperor allows these indulgencies, he receives the approbation of his subjects, even though he appropriates the estates of orphans, which have been intrusted to the governmest, and proclaims a public bankruptey. Every restraint is used to keep the spirit of the people stagnant. Francis, on lis visit to Laybach, 1820, observed to the professors there, that he wished for no leamed men; that lie needed good, loyal citizens, and coinmon schools were quite sufficient for their education. The administration of justice, except in political cases, is good ; for a perfect despotism, as well as a free government, requires that the rights of all the people should be equally respected. But, in state trials, every species of injustice is permitted. The policy of A. has been claracterized, for ages, by an insatiable thirst for the extension of her territory, and by the oppression of every comitry which she has held in subjection, except during the reign of Joseph 11. She has contended with France, for centuries, for the control of Europe. A: has always directed its efforts towards Italy and the East, and the former may now be regarded as wholly dependent on her. The internal government is remarkable for the constant emibarrassment of the financial department, which leads to the most unjust and arbitrary measures. The state becomes bankrupt, extorts loans, and compels the borrowers to make new ones to secure the first. In order to snother every liberal seutiment, foreigners engaged in private instruction, especially the Swiss, have been generally expelled from the empire. The adherents of Carbonarism liare been condemned to death (see Italy); and, in July, 1824, several persons, on account of their opinious and writings, were forbidden to enter the Austrian states; among them were lady Oxford, Mrs Hutchinson, lady Morgan, and lord Holland. Finally, an imperial decree has been issued, that all works written by Austrians in foreign countries should undergo the censorship of the press at home; and, in 1824, the order was extended to engravings, lithographs, and other prints. The archduke Rodolph was cliosen by the ecclesiastical chapter, and appointed archbishop of Olmutz, by pope Pius VII. His brother, the emperor, confirmed hin in this dignified office; and, soon after (Aug. 2, 1819), he was made a cardinal. In the autumu of 1820 , the emperor travelled to Presburg and Ofen. He pledged himself to the nobles of the palatinate of Pest, to maintain inviolate the constitution of the country, as the palladium of its privileges and the security of its happiness. His speech on this occasion contained the following specimen of elegant Latin :"Totus mundus delirat, et relictis antiquis suis legibus, constitutiones imaginarias quarit" (The whole. world is mad; they have deserted the good laws of their fathers, and run after the shadows of constitutions).

The public measures have lately raised the financial credit of the government. All that has heen done for this department since the charter of March 21, 1818, is recounted in a subsequent article (liunds, public) where the lottery loans of Rothschild 
are also described. From the report of the committee chosen to examine the operations of the sinking fund, it appeared, that, of the old debt (contracted before the year 1815), nearly 39,000,000 florins were discharged in 1824; and the new debt (contracted since 1815 ), anounting to $208,000,000$ florins, was considerably diminished. But the sinking fund was so incrensed after its establishment (March 1 , $1817)$, that, in 1825, the umount disposable was estinated at more than $160,000,000$ florins. The public debt has since been regularly reduced. From the annual report of the president of the bank of $A$. the count of Dietrichstein, now decensed, it appears, that, in seven years previous to Jan. 10, 1825, $284,342,600$ florins of the paper money in circulation had been redeemed. In order to raise the value of the depreciated paper currency, a particular fund was established to redcem it, and the rate fixed at 250, since 1816. The paper florin is worth six groschen, eight pfennige, and twenty kreuzer, $=$ fifty kreuzer of Vienna currency, or 1s. $8 \frac{1}{2} \mathrm{~d}$. sterling. I.oans were aftemwarls instituted to increase the yunutity of specie in the monarchy, and to promote the payment of old arrears. Of these, the loan of two and a half million pounds sterling, made at I condon, in the close of the year 1823 , was destined for the payment of the British demands (from 1794 to 1800 ), liquidated Nov. 23, 1823. Notwithstanding this, the Austrian paper money increased to such a degree, that, in the beginning of 1825 , the national securities at five per cent. (metalligues) stood, in Frankfort, at almost 96 (an the 6th of Aug., 1827, at more than 91), and the lank stocks at more than 1400 (on the 6th of Aug., 1827 , at 1302), while, at the end of 1820 , the former lind stood at only 73 , and the latter at scarcely $552 . *$ 13y its artificial fnancial system, $\mathbf{A}$. has made the rich speculators of many other countries dependent on itself, and rendered it their interest to promote her power and influence.

The prosperity of agriculture is closely connectad with the improvement of the finances. In order to gain a knowledge of the state of the country in general, it was decided, in 1819, to establish a committce of topography and statistics (taking the Prussian hoard as a model), and to connect it with the council of state. This led to an attempt to drain the morasses of Laybach. In the next year, the new system of taxation was completed. To divide the expenses of the government more equally, the whole monarchy had been surveyed in the time of Joseph II. To facilitate the trade of Italy with the south of Germany, the road from Chiavenna over the Splugen has been built since 1820 , with the aid of the neighbouring Swiss cantons; and a new passage from Italy to South-eastern Germany was opened in September, 1824, by a splendid road through Bormio and Tyrol. (See Alps, roads cver.) For the completion of the Alpine roads over the Sulugen and mount St Bernard, $\mathbf{A}$. concluded a treaty with Sardinia, May 20,1824, to which the cantons of the Grisons and Tessin acceded. The canal from Vienna to the borders of Hungary has been opened, and another from Vienna to Trieste, to unite the Danube with the Adriatic sea, has been begun.t In 1820, the canal from Milan to Pavia was finished, connecting Milan with the gulf of

- The public debt of the Lombardo-Venetian kingdom is manared separately. In 1822 , bank (monte) was erected at Milan for the payment of it.

+ 'The house of Fries and company hired, in 1822, the navigable portion of the canal of Lower Austria, and un dertook to continue it to the Adriatic, by forming an incurporated canal company.
Venice. In the comnencement of the 19 th century, Bohemia contained only 280 iniles of regular roads; at present, it contains 1104 miles. The Danube las been connected with the Moldau by means of a railroad, which is carried over the mountains firom Mauthausen, in Upper Austria, to Budweis, in Bohemia; in all, seventy-five niles. The navigation of the Danube, and the trade of Turkey, were opened to the subjects of Austria by the new commercial treaty concluded with the Porte in 1818: at the same time, the commerce of the Mediterranean became an object of inportance. The arrivals and clearances at the free port of Trieste amount aumully to 2200 vessels; and the state, which numbered, in 1815 , only 157 licensed vessels, had, in 1820 , exclusive of coasters, 528 trading vessels, of 110,500$)$ tons burden, 6836 sailors, and 2369 gius. The? maval force was increased for the protection of trade' ; and the empcror erected, at Venice, a college for the instruction of young naval officers.

In August, 1819, young men were prohibited from entering foreign universities, and a resolution was made, Sept. 25, 1819, to establish a Lutheran tlieolorgical institution in the centre of the empire. This "theological school for the adherents to the Angsburg confession," was opened at Vienna, April " 2 , 1821. The professors are native theologians, and the two Protestant consistories exercise a general superintendence over the whole. The government, at the same time, received into Galicia fifty Jesuits, who were banished from Russia in 18\%0, and appropriated to their use the great Dominican monastery at Tarnopol. Lyceums also were erected, or instructors provided for those already in existence. Towards the close of this year, the Redemptorists (q. v.) were established in Vienna, and the Jesuits instituted a school in this capital. In the public papers of the year 1821, an order was issued, forbidding private persons in the city and in the provinces to send abroad for instructors ; especially since the education of youth might lie intrusted to the Jesuit fathers, and their colleagues, the Redemptorists. In November, 1822, the Bible societir's were once more forbidden to distribute Bibles in the Austrian dominions, particularly the Bohemian Bible, printed in Berlin; or to sell them at reduced prices. The Protestant society in Prague has lately erected a school. About forty inhabitants of Galneikirchen, in the country above the Ens, went over to the Protestant churcls in the year 1821, and the little Protestant community at Venice lad alruady been recognized in the year 1820. The nedical institution of Joseph was re-opened at Vienna, in November, 1824 , on a new plan.

As to the military affairs of the empire, since 1819 , the government has been employed in erecting fortifications on the borders of Galicia. In $1823,25,000$ men were dismissed from the standing army. Instead of the grants made by Napoleon to the Italian officers in Tyrol, the emperor gave them, in 18\%1, a yearly pension from the year 1814.* The military schouls established in several regiments, on the Lancastcrian plan, liave been abolished since 1821. But there. are fifty-three schools, in each of which forty-eight children, belonging to the foot-soldiers of the German and Hungarian regiments, are instructed. The Milau school for the Italian regiments is designed for 250 boys. There is an engineering academy, at Viema, for the education of ufficers; and in the military academy at Wienerisch-Neustadt, 327 cadets are educated at the

- The pensions were also continued to the civil nfficers of the folmer kingdom of Italy, which they wutd have received if the kingdou had not ceased to exist. 
expense of the state. 'The cadet schools at Olmutz and Gratz are still in a flourishing condition; and an institution has been set on foot for the daughters of officers, at Herrnhals, where 46 pupils can be instructed. Von Hietzinger published, at Vienna, in 1822, in 2 vols., the statistics of the Austrian military districts, established in the year 180\%. A comparison of this account with the statistics of the military colonies of Russia (q. v.) affords interesting views. A., it is well known, first carried into effect the idea of military colonies, by the grant of lands to 18 Sclavonic regiments, along the confines of Turkey. These regiments have the same origin, the same language, and the same religion with the majority of the Russians. The whole country is divided into $214 \mathrm{com}-$ pany districts, and eight squadron districts. Of the male population, in 1820, only 16,834 men were exempt from military duty. The troops consisted of 17 regiments of infantry, one battalion of Tschaikistes, and a regiment of Hussars ; together, $45,579 \mathrm{men}$, exclusive of the civil officers. In case of war, this number can be increased to 70,000 , including the reserves, besides the militia, which are kept under pay. The common service in the cordon on the frontiers required 4200 men. In case of troubles in Turkey, or reports of the plague, 6800 are called out; if the danger is imminent, 10,000 men are brought into action, and often dismissed again within eight or fourteen days. The inhabitants on the frontiers are obliged to serve, on an average, at least 100 days yearly. The revenue of the frontier settlements was estimated, in 1820, at 1,553,000 florins, convention money (see Money, standard of); but the money expended on them was $2,457,900$ such florins; $1,384,800$ of which were applied to the support of the troops stationed there. (See Military frontiers.) The economical regulations of the Austrian army are described by Hubler; and an account of the nature of their discipline is given by . Bergmayer (Vienna, 1821). The Austrian Military Journal, conducted by captain Schels, is full of information on this subject.

The best map of the Austrian empire is that prepared by the topograplical cabinet of the quartermaster-general's staff, drawn under the direction of colonel Fallon. It is in nine sheets, published at Vienna, in 1822. According to this map, the Aus. trian monarchy embraces, I. The hereditary states of Austria, which form a part of the German confederacy ; 76,199 square miles, 9,843,490 inhabitants. They contain, 1. The arch duchy of Austria; 14,833 square miles, $1,908,200$ inhabitants : $\alpha$. Austria below the Ens, or lower Austria (7,713 square miles, $1,119,900$ inhabitants), embracing Vienna, the capital : 6 . Austria aloove the Ens, or Upper Austria, including the Innviertel, the Hausruckviertel, and the Salzach, or Salzburg circle (the duchy of Salzburg, q. v.); 7119 square miles, 788,282 inhabitants. 2. The duchy of Stiria; 8454 square miles, 780,100 inhabitants. 3. The county of Tyrol, raised to a principality, with several districts of Salzburg, and the Vorarlberg dominions ; 11,569 square miles, 738,000 inliabitants. 4. The kingdom of Bohemia, with Eger and Asch; 20,172 square miles, $3,380,000$ inhabitants. 5 . The margraviate of Moravia, with Austrian Silesia; 10,192 square miles, $1,805,500$ inhabitants. 6 . The duchy of Auschwitz, lying in Galicia, but included in the German confederacy, as an ancient Bohemian fief and Silesian principality; 1843 square miles, 335,190 inhabitants. 7. The kingdom of Illyria; 9132 square miles, 897,000 inhabitants. This kingdom includes, $a$. the government of Laybach, or the duchies of Carniola, and Carinthia $: 6$. the goverument of Trieste, or the Littorale; 3242 square miles, 370,000 inhabitants. - II. The hereditary states of Hungary; 125,105 square miles, $10,628,500$ inlabi- tants. They contain, $a$. the kingdom of Hungary, with the provinces of Sclavonia and Croatia ; 88,574 square miles, $8, \approx 00,000$ inhabitants; $b$. the grand principality of Transylvania(exclusive of the military districts) ; 18,350 square miles, $1,435,000$ inhabitants : c. the Austrian military districts; 1. In Croatia; Banal, Warasdine, and Carlstadt, united under one governor, in 1824, together with the Baul military lands, 995 square miles, 96,000 inhabitants ; likewise the two generalats, 5022 square miles, 301,200 inlabitants. 2. In Sclavonia ; 2945 square miles, 244,000 inhabitants. 3. The Hungarian and Bannatic military lands; 5856 square miles, ¿05,000 inliabitants. The Transylvanian military frontiers; 5361 square miles, 147,300 inhabitants.-III. 'The kingdom of Dalmatia, with Ragusa and Cattaro, containing 5827 square miles, and 320,000 inhabitants.-IV. The Lombardo-Venetian kingdom ; 17,608 square miles, $4,176,000$ inhabitants. - V. The kingdom of Galicia and Lodomiria, with the province of Bukowina; 32,272 square miles, $4,075,000$ inhabitants.-Thus the whole Austrian monarchy contains more than 256,399 square miles, and upwards of 29 million inhabitants. By the census of 1826, the population is estimated at $30 \frac{1}{2}$ millions. Besides this, the collateral lines of $\mathrm{A}$. have many valuable possessions:-Tuscany and Este (Modena and Massa), containing 10,489 square miles, and $1,618,500$ inhabitants. The principal nations of $A$. are, 1 . The Sclavonians, $13,400,000$. 2. The Germans, 5,900,000. 3. The Italians, 4,350,000. 4. 'The Magyars, or Hungarians, 4. mo,000. 5. The Waiachians, $1,700,000$. 6. The Jews, 450,0\%0. 7. The Zigeunes, or Gipsies, 110,000 . 8. The Armenians, 13,052. 9. The Greeks, 3910 ; together with Clementines, Turks, Albanese, French, \&.c. The most populous part of Austria is the Lombardo-Venetian kingdom : the population is 237 to a square mile. Next to this are Bohemia and Moravia, above and below the Ens. The smallest population is found in the military districts on the frontiers, Carinthia and Tyrol, Salpburg, and Dalmatia. According to the local returns, published by the geographical board of Vienna in 1822 , edited by colonel Fallon, and prepared in the preceding year, the rate of the annul increase of the population appears to be as follows:-

In Hungary and Transylvania,............. 1 1 In $^{5}$ Austria Proper, Stiria, and Transylvania,... 2.3 Bohemia, Galicia, Illyria, and Moravia,...... 23 Dalmatia, Tyrol, and the Lombardo-Vene-

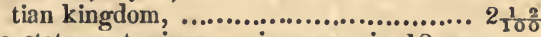
This statement gives an increase, in 12 years, on the population of 1815 , calculated at $27,000,000$, of more than 27 per cent.; in fact, nearly $7,000,000$. Different authorities agree, up to the year 1821, in a rate of increase, which, if continued to 1828 , would make that increase more than $7,000,000$. The monarchy numbers 777 cities, 635 suburbs, 2224 market towns, and 69,105 villages. The most populous cities are, Vienna, Milan, Venice, Lemberg, Padua, and Debreczyn (population, 41,175 .)-Of the numerous navigable rivers, the largest are, the Danube, Ens, Morawa, or Marsch, Leytha, Raab, Drave, Save, the Po, the Elbe, the Moldau, Eger, Oder, Vistula, and Dniester. Thirty canals, seven of them very large', liave been constructed, during the reign of the present emperor, for the promotion of trade.-The largest lakes are, Neusidle, Platten, Palitsch, Cirknitz, and Lago Maggiore.-The mountains are, 1. 'The Alps, which present a surface of 48,397 square miles: the Ortlesspitze is 14,466 feet high ; the Great Gluckner, 12,239; Hohenwart, 10,392; Wiesbachliorn and Hochhorn, 10,600-11,000; Terglon, 9,744 ; Watzmaun, 9,600; Brenukogal, 9,000. 2. The Sudetes (white meadows, 4,500 feet high), Paschkopol. 3. 
The Carpathian momutains.-The climate is different in different parts of the empire.-The Anstrian mines and washings yield, ammally, of gold, 3,900 marks; of silver, 108,000 marks; upwaris of 2,200 tous of cupper; of tin, 100; of iroll, 69,000 ; of mercury, 281 ; of cinnabar, 435 ; colualt, 88 tons ; calumine and zinc, 386 tons ; arsenic, clirome, tellurium, uranium, antimony (383 tons), manganese, bisinuth, loadstone, precious stones, inarble, porcelaiin, meerschaum, coal, sulphur, salt, \&c.-There are also 600 mineral springs in the empire, of which Bohemia ulone contains 150; the most celebrated are at Carlsbad, Toplita, Franzensbad, Marieubad, Seidschuta, Bilin, Baden, Gastein, Meadia in the Binnat, Albano in Italy, \&c.

Austria furnishes wheat, and similar kinds of grain, in abundance; also maize, rice, pulse, fruits, including the best southern fruits, oil, \&c., wine, hops, safiron, tobacco, hemp, and flax, woad, various woods, black-cattle, buffaloes, horses, asses, and mules, sheep, goats, swine, poultry, wild beasts, fishes, pearl-oysters, bees (which yield, annually, 1200 tons of wax, and 19,500 tons of honey), silk (?,570,000 pounds). Prince Liechtenstein, at Eisgrub, in Moravia, has the largest plantation of foreign woods in Europe. Every branch of agriculture is prosecuted with care and skill, and the raising of sheep is particularly attended to. There are still, however, in Hungary, 2119 square miles of morass. The most fertile and best cultivated part of the empire is the Lombardo-Venetian territories. The manufacture of silk, in this district, has also been highly improved by count Dandolo. The manufactures yield, anuually, 1425 million florins, conventionmoney. They consist of watches and clocks, porcelain, mirrors, and brass, iron, and steel, linen, cotton, paper, tobacco, sugar, wool, silk, leather, and bleached wax. The trade has increased since the recovery of Italy. The exports of the country amount to more than thirty-six million florins, conventionmoney (see Money); and the imports to forty-four millions. The principal sea-ports are Trieste, Venice, and Fiume : other places of trade are Vienna, Prague, Pest, Lemberg, Brody, and Gratz. The bank of Vienna affords the most important support to the commercial interests of the state: the same advantage is derived from the Austrian national company of commerce, lately erected for the sale of merchandise, and the promotion of trade.

The prevailing religion is the Roman Catholic. The bishoprics in Germany and Hungary are richly endowed, particularly the archbishoprics of Gran, Colocza, Olmutz, Erlau, \&c. The whole number is fourteen. In Lemberg and in Venice there is an Armenian Catholic archbishop, and in Venice a Catholic patriarch. The Greek church is under the archbishop of Carlovitza. The Lutherans and Calvinists have consistories and superintendents; and in Hungary and Transylvania, their civil rights are nearly equal to those of the Roman Catholies. There are also Mennonites, Mohammedans, \&c., in various parts of the empire. The number of Catholics in A. is estimated at $23,978,000$; members of the Greek church, 2,814,378; Calvinists, 1,584,716 ; Lutherans, $1,119,800$; Unitarians, 49,000.-Universities are established at Vienna, Prague, Pest, Lemberg, and Pavia. There are lyceums at Lintz, Gratz, Brunı, Grosswardein; a mining academy at Schemnitz; a medical school at Vienna; an academy for painting, sculpture, architecture, and engraving at Vienna; a library ; a gallery of paintings; collections of medals and other antiquities, which are deserving of notice.

The government is a monarchy; in Hungary and Transylvania, a limited monarchy: in the other Luritories of the empire, the estates (of which there are four in Tyrol, including the peasantry) are convened to grant the supplies called for to meet the expenses of government. But the system of im. posts and custons, existing between the different districts, is an inpedinent to commerce. The law of primogeniture prevails in regard to the succession to the throne.- 'There are seven kuightly orders,-1. that of the golden flecee; 2 . of the starry cross, for ladies of princely or ancient nuble families; (the following being also orders of merit); 3 . the military order of Maria Theresa; 4. the royal order of St Stephen, in Humgary ; 5. the inperial Austrian order of Leopold, which has existe'd since 1808 ; 6. the order of the iron crown (renewed in 1816); 7. the order of Elizabeth Theresa, for officers only, who have risen, at least, to the rank of colonels, There are, also, in Austria, $a$. the ancient imperial Teutonic order, of which an archduke is appointer grand-master by the emperor; $b$. the spiritual order of St John, which has a grand-priorate in Bohemia, and several commanderies in Upper and Lower Austria ; $c$. the order of the cross with the red star. At the head of the administration, under the direction of the emperor, stands the privy-counsellor for home affairs. There are two departments of government, one for foreign and the other for domestic affairs, both under the direction of a minister. The judicial system is inild and well-regulated. The civil code, completed July 1, 1811, is very good. The courts were much improved as early as 1781 . A general penal code was adopted Jan. I, 1804 . These laws are in force ouly for the German, Galician, and Italian territories, for Dalmatia, and the military districts. The revenue of the state (including the extraordinary income) is estimated at 220 million florins of silver, and the interest of the public debt at twenty-two millions yearly. By the loan of 1827 , the public debt was increased to 680 million florins. This estimate is exclusive of $98,025,413$ florins in redemption and anticipation certificates (einlosungs und anticipations scheine), which were in circulation June 30,1827 . The standing army, in time of peace, is composed of 271,400 men, including 39,000 horse, and 17,790 artillery. The supplementary troops, the reserve, and the militia, together, comprise about 479,000 men. The naval force consists of three ships of the line, six frigates, three corvettes, three brigs, and four schooners. There are, also, in the empire, twenty-five fortresses, and fifty-nine fortified towns.-On the history of the Austrian monarchy, see the works of Genersich (Vieuna, 8 vols. 1817); Coxe (History of the House of Austria, London, 1807, 3 vols. 4to.); J. B. Schels's History of Austria (Vienna, 1819-27, 9 vols., to the time of Joseph II.). In regard to the statistics of this country, the following works are valuable:-Darstellung des Fabrik- und Gewerbwesens in seinem gegenw. Zustande; vorzugl. in technischer mercantil. und statisch. Bezich. und mit Berucksicht des Fabrikund Gewerbwesens im OEstr. Kaiserstaate, herausgeg von Steph. Edl. von Kees. Vienna, 1824. Die Douanen und Quarantaineverfassung des Estreich. Kaiserstaats, in ihrer gegenw. Gestalt von $A$. A. Kronegger. Vienna, 1824. Handbuch fur Reisende in dem CEstreich. Kaiserstaate von R. E. von oJenny : to which Hormayr's Archiv., 1824, is a useful supplement. Gelehrten und Schriftsteller-Lexicon der Estreich. Monarchie von D. Sartori, which begins in 1801 , and forms a valuable addition to De Luca's Gelehrtes Estreich.

A UTENRIETH, John Henry Ferdinand, chancellor of the university of Tubingen, and professor of medicine in the same institution, was born in the year 1772, and early evinced decided talent in the department of riatural science. His inarination was livelv. 
and his memory remarkably tenacious. After he had received his doctorate, he visited North America. During his travels in this part of the world, he was attacked by the yellow fever in a solitary place, at a distance from human assistance, and saved his life by bold and copious bleeding. After his return, he was appointed professor of medicine, particularly of anatomy and clinical medicine, at Tubingen. Here he laboured zealously. His lectures were eloquent, and his attention to the sick unrenitted. He published, likewise, several periodicals, partly alone, partiy in connexion with Reil. The king of Wurtemburg appointed him chancellor of the university of Tubingen.

Aoreul ; a small town of France, at the entrance of the rood of Boulogne, somewhat less than a mile from Paris. Men of literary reputation have often resided there. The country-seat of the poet Boileau is still shown there, where the beaux esprits of France often banqueted. On a certain time, heated with wine at a supper, the literati complained of the degeneracy of the age, and lamented their misforture in having been born at such a period. All agreed to plunge into the neighbouring Seine, and the flower of the French writers were already on their way to the river, when the thought struck Moliere, that such an act, by such men, ought not to be performed in the darkness of night. The companions stopped, found he was in the right, and agreed to drown themselves at day-break, after drinking the remainder of their wine. The ingenious Andrieux brought this anecdote upon the stage in the piece Moliere avec ses Amis, ou le Souper à Auteuil. Madame Helvetius, finally occupied the house. Her evening parties here were celebrated. All who were distinguished in the walks of literature or of active life, were always welcome, whether French or foreigners. All were without restraint. Her society was therefore called la société libre des égoüstes. The monuments of several illustrious men are to be seen in the church-yard at Auteuil; among others, that of Nicolai, president of the chambre des comptes, and the chancellor d'Aguesseau, remarkable as a great civilian and advocate of the rights of men.

A othentucs; a name applied, in the civil law, to an extract from the Novels (see Corpus Juris), by which a law of the code is either changed or entirely abolished. They were extracted by the first doctors of the law, in the middle ages, from a manuscript copy of the Novels (liber authenticus), put among the altered passages of the code, and have thus remained in the editions of the Corpus Juris. Some laws, mureover, of the emperors Frederic I. and II. of Germany have been introduced in this way.

A тTо DA FE. See Inquisition.

A utocisthones (from the Greek) signifies men produced from the ground which they inhabit. Several ancient nations assumed this name, to indicate the antiquity of their origin; e. g. the Athenians.

AUTOCrator (from Greek auros, himself, and xearos, power); a name given to the Athenian general, when, in particular cases, unlimited authority over the troops was intrusted to him, and he was not bound to give account of his proceedings. Thus Aristides was an autocrator in the battle of Platrea.

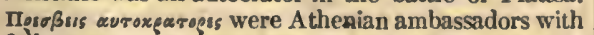
full powers, corresponding to our plenipotentiaries. In modern times, the word autocrat is used, in politics, for a ruler with absolute power. Thus the emperor of Russia is styled autocrat of all the Russias. Some writers on morals apply this term to man, to represent his power over his own conduct.

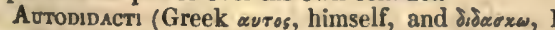
teach); those who have obtained knowledge and skill in any art or science, without the uersoual instruction of others.

AOTOGRAPHS (Gr.); manuscripts written by the author himself, in distinction from copies. They are more highly esteemed than the latter, not only as interesting relics, but also as more correct and free from faul ts than those copied by another hand. Some collections of autographs of famous men are very interesting.

Automaton (from Gr. avтoustos, spontaneous); a self-moving machine, without life. Machines of this kind are kept in motion by means of springs or weights. When they represent human figures, they are called androides , but clocks, watches, \&c. are also automata. We find very early mention of them. Homer describes Vulcan fabricating tripods, which moved on living wheels, instinct with spirit. The celebrated statue of Memnon, which emitted musical sounds at sunrise, the walking statues of Drdalus, the flying dove of Archytas (q. v.), are instances of ancient skill in this respect. In modern times, friar Bacon (q. v.) constructed a brazen head which spoke. Regiomontanus (q. v.) made a flying eagle, and an iron $f y$, which, after making the tour of the room, returned to its master. Albertus Magnus (q. v.), in the 13th century, spent thirty years in constructing a human figure, which advanced to the door when any one knocked, opened it, and saluted the visitor. In the water-clock presented to Charlemagne by Haroun al Raschid, twelve doors in the dial opened respectively at the hour which they represented : they continued open till noon, when twelve knights issued out on horseback, paraded round the dial, and then, returning, shut themselves in again. Camus constructed an ingenious toy for Louis XIV., consisting of a carriage drawn by two horses, containing a little figure of a lady, with a coachman and attendants. The coachman smacked his whip ; the horses moved their legs naturally; and, when the carriage arrived opposite to the king's seat, it stopped; the page stepped down, and opened the door; the lady alighted, and presented a petition to Louis.-The fluteplayer, the tambour-player, and the wonderful duck of Vaucanson (q. v.), are celebrated for the astonishing ingenuity displayed in their construction. The two brothers Droz (q. v.) have executed some admirable works of the kind. One of them is a child, sitting at a desk, who dips his pen into the ink. shakes it, and writes, in French, whatever is dictated to him. This must be done, of course, by human intervention. A vase, presented to Bonaparte, when first consul, on being touched, exhibited a palm-tree, under which a shepherdess was spinning. The chessplayer of von Kempelen (q. v.) has been supposed to be moved by a man concealed in the chest. The speaking machine of the same artist, the flute-player of Siegmeier, the trumpeters of Maelzel and Kaufmann, deserve mention among the later automata. One of the most ingenious automatical mechanists of the present day is the Swiss Maillardet. Ho constructed a female figure, which performs eighteen tunes on the piano forte; the bosom heaves, the eyes move, ard the natural motions of the fingers are performed. The action of this machine continues an hour. Besides this figure, there is a magician, who answers any question taken from twenty medallions. The medallion selected is placed in a drawer, the magical books are gravely consulted, and the magician then strikes with his wand against a door, which opens, and displays an appropriate answer. His other automata are, a boy, which draws and writes; a little figure, a few inches in height, which dances to music produced in a glass case, in which it is enclosed; a humming bird, which issues from a box, sings, and returns to the box

$$
2 \mathrm{r}-\mathrm{z} 2
$$


ngain; a steel spidcr; a hissing serpent, \&a. An engine has been male by Mr Babbage capable of computing any table by the method of differences. The greater the number of differences, the more it will outstrip the most rapid calculator. See Arithmetic.

AoTopsy (from Greek curos, himself, and o $\$ 15$, sight); observation which oue makes himself, in contradistinction from knowledge which we get from the accounts of others.

Auroms; that one of the seasons, which, in the northern tempernte zone, begins when the sun, in its apparent descent to the southern hemisphere, touches the equator. The end of autumn is at the time of the sun's greatest south declination, or when he enters Capricorn. According to our computation of time, the beginning of autumn is Sept. 23 , when, for the second time in the year, the days and niglits are equal; and the end is Dec. 21, at the time of the sliortest day. The autumn of the southern hemisphere takes place at the time of our spring. From this astronomical autumn the physical or popular autumn differs according to the climate. - Autumnal equinox. (See Equinox.)-Autumnal point is called, by astronomers, that point where the equator cuts the ecliptic: the sun reaches it Sept. 23. It is said to be at the beginning of Libra, and is continually marked so, notwithstanding the point has long since receded from this constellation, and is now near the stars of the left shoulder of Virgo. It is opposite to the vernal point; therefore its ascension amounts to $180^{\circ}$, and its longitude also to as many, or six signs; its declination and latitude $=0$.

A UVRfGans; a ci-devant province of France, which took its name from the ancient inhabitants, called Averni. It was surrounded by Velay and Forez, Limousin, Bourbonnais, Berry, Rouergue, and Gevandan, in the heart of France. Upper and-lower A uvergne contained together, on 500 squarc leagues, 800,000 inhabitants. The mountains of Auvergne are among the most noted of France. The northern part is called Puy de Dome; the southern, Puy de Cantal; while the centre is formed of the Mont $d^{\prime} O r$. The revolution divided this province into three departments. (See Department.)-Auvergne was celebrated in the time of ancient Gaul, and has always remained a very important part of France.

Auvernas ; a deep coloured wine, made of black raisins, so called at Orleans. It is not fit for use until a year old, but, if kept two or three years, becomes excellent.

AVA, or ADNGWA; a town in Asia, formerly the capital of Ava, or Birmah, on the Irrawaddy, four miles W. S. W. of Ummerapoora, 500 miles E. Calcutta ; long. $95^{\circ} 58^{\prime} \mathrm{E}$.; lat $21^{\circ} 5 \mathrm{I}^{\prime} \mathrm{N}$. It was divided into the upper and lower city; both fortified. The lower was about four miles in circumference, protected by a wall 30 feet high, with a deep and broad ditch; an embankment of earth supports the wall within. The upper town, which may be called the citadel, does not exceed a mile in circumference, and is nuch stronger and more compact than the other. The walls are now mouldering, and a great part of the timber of which the houses were built has been carried away to be used in a new town, called Ummerapoora. Numerous temples are falling, and the few houses built of brick become the abode of bats. In the temple of Logathero Praw is still to be seen a gigantic image of Godama, of marble. The height of the idol, from the top of the hend to the pedestal on which it sits, is nearly 24 feet; the head is eight feet in diameter, and across the breast it measures t(') feet. The Birmans assert that it is cumposed of one entire block of marble; nor can any junctiou be perceived. See Embassy to the kingdom of A va, by
Michnel Symes, and Joumal of an embassy to the Court of Ava, in 1827, by John Crawforl. The connty of $\Lambda$ va will be fully treated of in this Fncy. clopedia under the article Birman Empire.

AVA-AVA; a plant so called by the inhabitants of Otaheite, who make an intoxicating juice ont of it. Their chiefs vie with each other in drinking the greatest number of draughts, as the German students do in drinking beer.

Avadontas; a sect of Bramins, who, in austerity, surpass all the rest. They even reject the earthen vessels to hold provisions, and the stick to lean onluxuries which the other sects allow themselves. Some Avadontas go perfectly naked; when hungry, they beg for something to eat : others go to the holy rivers, and there expect the peasants to feed them.

Aval, or Bahureiv; the largest of the Bahlirein islands in the gulf of Persia, 30 miles in leugth, and 12 wide, where it is broadest. Besides the fortified town of Bahhrein, it contains some poor villages. Lon. $48^{\circ} 4^{\prime}$ E. ; lat. $26^{\circ} 36^{\prime} \mathrm{N}$.

Avalancues (in German, Lavinen, or Lauwinen); large masses of snow, which roll down from the mountains, causing great damage by their fall. There are three kinds. The wind or dust avalanches are so called because they are occasioned by the wind, which carries along the fresh fallen snow, and throws it, in the form of dust, into the valleys. The rapidity with which they come would render this kind the most dangerous of all, were it not for their great lightness, which renders it easy to extricate one's self from them. There have been instances of people remaining 24 hours under such avalanches without being suffocated. The second kind are called mountain, snow, hail, or thunder avalanches (SchrundLavinen). These are not blown off by the wind, but fall by their own weight, bringing down with them all the ground on which they lie, together with the trees, rocks, \&c., which are there. They generally fall in the spring, when the increasing warmth has rendered the snow more damp and heavy. Their fall makes mountain and valley tremble, and is accompanied with a noise like thunder. The third kind, earth avalanches, or landslips, occur when the soil has been weakened by long.continued and deep penetrating rains, when it slides down into the valleys, with all the houses, trees, and entire forests which stand thereon, and causes the most horrible destruction.

Avantorine. See Quartz.

Avarps ; a nation, the remains of the Scheu-Schen. driven from their country by the Turks. They came, 100 jears later than the Bulgarians, to the regions around the Don, the Caspian sea, and the Wolga. A part remained in Circassia, where they still exist; another portion advanced to the Danube, in 555 , and settled in Dacia, served in Justinian's army, aided the Lombands in destroying the kingdom of the Gepidæ, and gradually conquered (especially under the powerful khan Bajan, in 582) the region of Panronia. Under his successors, they made themselves masters of Dalmatia, pressed into Thuringia and Italy, where they fought with the Franks and Lombards, and extended their dominion over the Sclavonians dwelling on the Danube, and farther north, as well as over the Bulgarians on the Black sea. But they were soon divided, and lost Dalmatia in 640. Limited to Pannonia, they were at length overcome by Charlemagne, 796, and expelled from Moravia and Pe:. schenegem. After 827, they disappear from history.

AVATAR, in Hindoo mythology; an incarnation of the Deity. Innumerable incarnations have taken place, according to the Hindoos, but ten are peculiarly distinguished, and four of them are the subjects of Puranas, or sacred poems. These ten are the 
hicarnations of Vishnu, the supreme God. The Matsya avatar was the descent of the Deity in the form of a fish ; Kachyapa, or Kurma, in that of a tortoise; Varaha, as a boar ; Nara-singha, as a monster, half man, half lion; Vamana, as a dwarf; Parasu-Rama, as the sou of Jamadagni. All these took place in the Satya Yuga, or golden age. The others are more recent. The seventh incarnation is called Ramachandra avatar, the descent of Vishnu to destroy a giant. Their contests are the sulject of the celebrated epic called the Ramayana. The eighth avatar, called Bala-Rama, was in order to chastise other giants; the ninth, Buddt'ha, had a similar object. The Kalki, or tenth avatar, is yet to come at the end of the Kali Yuga, or the iron age. See Indian Mythology.

Aveluno (Furca Caudinae); a passage lying between a city of the same name ( 25 miles N. E. from Naples) and Benevento, in the valley Di Gargano. A Roman army, having entered this pass with its rear exposed, was surrounded by the Samnites, who better understood mountain warfare, and having laid down its arms, was sent under the yoke like slaves, B. C. 321 . The surrounding country yields the mountain productions of the south (which often serve the frugal peasants for bread), sweet chestnuts and walnuts on the north side of the mountains, where they are protected against night frosts and too early blossoming. The gloomily built city Avellino, with 11,300 inhabitants, in the Principato Ultra, contains manufactories of Maccaroni, in which mountain-maize is used with chestnuts, \&c. They belong to the princes Caraccioli, who have established a granary there for their vassals, and derive considerable revenues from the profitable business of dyeing, which is favoured by the soft water of the surrounding conntry.

Ave Maria, also Ave Mary, among the Catholics; the beginning of a prayer to the holy Virgin, whence the whole prayer is called Ave Maria. Ave, in Latin, means hail. Ave Marial is Hail Mary! It is the beginning of the salutation which the angel addressed to the Virgin, as he announced to her that she should be the mother of the Saviour (Luke i. 28 . Ave, gratia plena: Dominus tecum; benedicta tu in mulieribus). The name Ave Maria is also given to those little balls in rosaries, each of which denotes a prayer, called Ave Maria (see Rosary); while the larger balls denote a Pater-noster. As in Italy, a bell tolls at sun-set, which admonishes the people to address their prayers to the Queen of heaven, the close of the 24th hour, which, according to the Italian division of time, coincides always with sun-set, is called Ave Maria ; and it is usual to say, at Ave Maria, half-past Ave Maria, \&c., instead of $a t 240^{\circ}$ clock, half-past 24, \&c. The exclamation has been taken advantage of with very beautiful effect by Lord Byron in the third canto of his Don Juan-

Ave Maria ! blessed be the hour,

The time, the clime, the spot, where I so oft

Have felt that moment in its fullest power,

Sink o'er the earth so beautiful and soft,

While swung the deep bell in the distant tower, Or the faint dying day-hymn stole aloft.

And not a step crept through the rosy air,

And yot the forest leaves seem stirr'd with prayer.

Ave Maria! 'tis the hour of prayer ! Ave Maria!' 'tis the hour of love !

Are Maria! may our spirits dare

Lok up to thine and to thy Son's above:

Ave Maria! oh that face so fair

Those downcast eyes beneath the heavenly dove-

What though 'tis but a pictured image strike-

That painting is no idol, 'tis too like.

Avev, or Evan; a considerable stream in the middie warl of Lanarkshire, which falls into the Clyde a little above Hanilton. Aven is also the name of a river which divides Stirlingshire from Linlithgowshire, and falls into the frith of Forth betwixt Grangemouth and Borrowstowness. It is also the name of a tributary streamlet of the Spey.

Avrantine, John (properly Thurmayr), a historian, born at Abensberg, in Bavaria, in 1477, studied at Ingoldstadt and Paris, and afterwards gave lectures at Cracow and Ingolstadt. In 1512, he was ap. pointed tutor to two Bavarian princes, with one of whom he visited foreign countries. In 1517, he was appointed Bavarian historiographer, and wrote his famous Annales Bö̈orum (last edition by Gundling, Leipsic, 1710, folio), and his Bavarian Chronicle, both standard works for German history. His Rudimenta Grammatice Latina were published in 1512 , and contributed much to advance the study of philology in Germany. He died Jan. 9, 1534.

Avenzoar, or EBN Zohar; an Arabian Physician of the 12th century, born at Seville, in Spain, where his father practised medicine. He became eminent in his profession, travelled much, and passed through many adventures, among which was a long imprisonment at Seville. He had the care of an hospital, and composed a work entitled $A l$ Therser, containing a compendium of medical practice, and including many facts and observations not found in preceding writers, which were probably the result of his own experience. He died at Morocco in 1169. The report of his having lived to the age of 135 is probably an error, arising from his having been confounded with his son, of the same name and profession, who lived at Morocco and was the author of a treatise on the regimen of health.

AVERAGE, common, customary, or petty. In case of shipments of goods, the bills of lading often contain a stipulation that the shipper shall, besides a certain rate or amount of freight money, also pay " primage and average." The word average, in this place, originally denoted several petty charges, such as towage, beaconage, \&c., which are to be borne by the ship, freight, and cargo, the kind and amount of which are very various, being determined by the marine ordinances of some countries, and in others by the usage of particular ports. There is often a great variety in the usages at the different ports of the same country in this respect. But the practice has come very much into use in Great Britain, and is general in the united States, to allow a certain rate per cent. on the amount of the freight for primage and average, where the bill of lading provides for the payment of these. The printed form of the bills of lading usually contains the words primage and average, with a blank space, so that, when filled up, it reads either with or without primage and average, according to the agreement of the parties. Average, general or gross, consists of expenses incurred, sacrifices made, or damage sustained, for the common benefit of ship, freight, and cargo, and com. prehends jetson the loss sustained by throwing overboard a part of the cargo, or of the provisions, tackle or furniture of the ship, for the general safety), or the cutting away of a mast, and also ransom paid to pirates, compromise with captors) if permitted lyy the laws), the damage occasioned by purposely rumning the vessel on shore, and, by the usage of some countries, the expense of getting a stranded vessel afluat, though it was accidentally stranded, and the expenses of delaying the voyage to seek a port to refit. The expenses and damage that are the subjects of contribution in general average, must be divided among all the parties to whom the ship, freight, and cargo, belong, in the proportion of their several interests. Contribution for ietson was provided for in the maritime laws of Rhodes, and thence adopte 1 into the 
Roman cule.-Arenge, particular, is the loss, expense, and lamage sustained on a slip, freight, or cargo, whicls is to be borne by the party to whom the interest belongs, without any claim upon the other interests for contribution, and, in general, compreliends loss or daruage that happens accidentally, and is not incurred voluntarily and purposely. It is also called partial loss, which description is likewise applied to a loss of only a part of the value of the interest at risk, in distinction from a total loss.

Avervos; a lake in the kingdom of Naples, between ancient Cuma and Puteoli. It is circular, in some places 180 feet deep, and surrounded by hills of a moderate leight, which used to be covered with immense woods, so that gloom and darkness surrounded the lake, and accumulated effluvia filled the air witl contagion. These woods no longer stand, but the regions about the lake are still unhealthy. In ancient times, a sarage people fled hither, who only ventured out by night. Their conduct struck terror into the neighbouring people, whose stories gave rise to the fable of the Cimmerians, who lired in perpetual darkness; and the idea arose, that the dead were here called up from the infernal world. Homer makes this lake the entrance to hell, and describes the visit of Ulysses to it. Virgil has fol. lowed in his steps. Afterwards, certain priests also twok up their residence at this lake, who dealt in conjurations, exorcised spirits, \&c., and carried on their occupation only by night. Hence this wood became the grove of Hecate.

Averroes (corrupted from Ebn or Ibn Rushd): the most renowned of the Arabian philosophers, and instructer of Moses Maimouides, was born at Cordo$\mathrm{ra}$, in Spain. His father, chief magistrate there, instructed him in the Mohammedan laws, and appointed Tophail to teach him theology and philosophy. His talents and knowledge procured him the succession to his father's office. The king of Morocco appointed him cadi in the province of Mauritania. But his success was envied, and he was accused of rejecting the established religion, and, in consequence, deprived of his offices, and banished to Spain. He returned to Cordova, where he was assisted by his scholar Maimonides; but was soon persecuted there also, and fled to Fez. Here he was condemned, by a spiritual court, to recant, and undergo a public penance. Upon this, he went back to his own country, where the caliph Almansor, after a time, restored him to his dignities. He died, after an active life, at Morocco, A. D. 1217 or 1225. A. regarded Aristotle as the greatest of all philosophers, and explained lis writings, with only a slight deviation from his views. The Alexandrian doctrines, also, had much influence upon him. A gainst the orthodox Arabians, particularly against Algazal, he set himself up as a defender of philosophy on rational principles. He was called, among the Arabians, by way of eminence, the Interpreter (of Aristotle). They adhered very closely to his translation of Aristotle, made from the Syriac. He mrote, also, a compendium of physic, called Colliget, or Universal, and many treatises in theology, philosophy, jurisprudence, and medicine.

A viswes, or Arenves; one of those many fortresses which protect France on the side of Germany, and which mostly originated under the restless Louis XIV. It was also one of the fortresses kept by the allies by the terms of the peace of 1815 . Lon. $4^{\circ} \mathrm{E}$.; lat. $50^{\circ} z^{\prime} \mathrm{N}$

A rkyrox, département de l'; a French department in the former Guyenne and Garogue. See Department.

Anary. The aviary was common to the countryhouses of the Romans, but used principally, as it would appear from Pliny, for birds destined to be eaten. Singing-birds, however, were kept by the Persians, Greeks, and also the Romans, in wicker. cages; and these utensils, no doubt, gave rise to the large and fixed cage called an aviary; but in what country, and in what age, appears uncertain. They are highly prized in Chinn. In the altercations which took place during lord Anherst's embassy, it was stated, on the part of the emperor, that Sir feorge Stannton had built himself a house and an aviary. That they were in use in England in Evelyn's time, is evident from a memorandum entered in his diary, that the marquis of Argyle took the parrots in lis aviary at Sayes' court for oucls. - The canary, or singing-bird aviary, used not unfrequently to be formed in the opaque-roofed green-house or conservatory, by enclosing one or both ends with a partition of wire, and furnishing them with dead or living trees, or spray and branches suspended from the roof for the birds to perch on. Sucl are chiefly used for the canary, bullfinch, linnet, \&c. - The parrot aviary is generally a building formed on purpose, with a glass roof, front, and ends; with shades and curtains to protect it from the sun and frost, and a flue for winter heating. In these, artificial or dead trees, with glazed foliage, are fixed in the floor, and sometimes cages hung on them; and at other times the birds allowed to fly loose.-The verdant aviary is that in which, in addition to houses for the different sorts of birds, a net or wire curtain is thrown over the rows of trees, and supported by light posts or hollow rods, so as to enclose a few poles or even acres of ground and water in various forms. In this the birds in fine weather sing on the trees, the aquatic birds sail on the water, or the gold-pheasants stroll over the lawn; and in severe seasons they betake themselves to their respectire houses or cages. Such an enclosed space will of course contain evergreen as well as deciduous trees, rocks, reeds, aquatics, long grass for larks and partridges, spruce firs for pheasants, furze-bushes for linnets, \&c. An aviary, somewhat in this way, was formed by Catharine of Russia, in the Hermitage palace. These are the only sorts admissible in elegant gardens; since nothing, to one who is not an enthusiast in this branch of natural history, can be more disagreeable than an apartment filled with the dirt and discordant music of innumerable birds; such, for example, as the large aviary at Kew. Birds from the hot climates are sometimes kept in hot-houses among their native plants, as in the large conservatories at Vienna. In this case, the doors and openings for giving air must be covered with wire cloth, and the number must not be great, otherwise they will too much disfigure the plants with their excrement.-Gallinaceons aviary. At Chiswick, portable netted enclosures, from ten to twenty feet square, are distributed over a part of the lawn, and display a curious collection of domestic forls. In each enclosure is a small rooden box or house for sheltering the animals during night, or in severe weather, and for breeding. Fach cage or enclosure is contrived to contain one or more trees or shrubs ; and water and food are supplied in small basins and appropriate ressels. Curious varieties of aquatic fowls might be placed on floating aviaries on a lake or pond.

Avicevsa, or EBv-Sina, an Arabian philosopher and physician, was born at Assena, near Bochara, A. D. 980. He possessed a ready genius and a strong memory, and, after going through a course of study with varions masters, became a pupil at the school of Bagdad, where he exhibited indefatigable industry, and no inconsiderable portion of fanaticism. According to his own account, he read the metaphysics of A ristotle forty times without understanding them. He completed his studies at the early age of 
18 , and began to practise as a physician. He soon acquired a degree of reputation which reached the pars of the various Eastern princes, all of whom we:e resirous of retaining him in their service; but he fually went into that of the sultan Nedjmeddevle, who appointed him lis physician and grand vizier. His unduelove of pleasure, however, soon made him lose his post and his master's favour; and the remainder of his life was spent in great adversity, as he was charged with the crime of heresy, in addition to other accusations. He died at Hamadan, in abject circumstances, A. D. 1036, aged 58. A. left many writings, mostly commentaries on Aristotle. They consist of twenty books on the Utility of the Sciences; the Heads of Logic; and various pieces in metaphysics and morals. Of his medical works, the principal is called Canon Medicina which is thought very lightly of by Haller and Frema. His works were printed in the original Arabic, at Ron e, in 1497 , more than one Latin version of which has been translated, the latest being that of Vopucius Fortunatus, (Louvain, 1651).

Aviexus, Rufus Festus; a Latin poet of the fourth century. The works attributed to him are, Latin versions of the Phenomena of Aratus, and Periegesis of Dionysius, \&c. Some of these productions still remain, and show him to lave been a tolerable versifier. The best edition of his works is that of Cannegetier, 1731. Very little is known of his history.

Avigros, chief city of the department of Vaucluse, in the south-eastern part of France, on the Rhone, with narrow and crooked streets, contains a great number of churclies and sacred buildings, among which is the church of the Franciscans; several scientific institutions, and among them an athenæum and a medical library; 2800 houses, and 24,000 inhabitants ; respectable silk manufactories, silk-dyeing establishments, and other works. The country is agreeable, and extremely fruitful in corn, wine, olives, the Avignon berry (of a yellow colour), kermes, sumach, and the richest fruits of the south. Here Petrarch lived several years: here he saw his Laura, who formed the subject of his most beautiful verses, and whose tomb is still to be found in the Franciscan church. The fountain of Vaucluse is five leagues from $A$. This city and its district, in the midule ages, was a county which the popes, who had already received the county of Venaissin, in 1273, from king Philip the Bold, as a present, bought of Joanna, queen of Sicily and countess of Provence, in 1348 , for 80,000 florins. Joanna had fled to Provence because Louis I., king of Hungary, wished to take revenge on her for the deatl of his brother, her husband, whom she had caused to be murdered. The papal government retained the two provinces, under the rule of a vice-legate, till 1790 , when, after many stormy scenes, the city, with its district, was annexed to the French republic, and, in 1791, was formally united with it. At the peace of Tolentino, the pope renounced A. and Venaissin. Louis XIV. and Louis $\mathrm{XV}$. several times took possession of $\mathrm{A}$., when offended with the popes. From 1305 to 1577 , seven popes in succession fixed their residence in this city. The Catholic historians commonly call this period the Babylonish captivity of the popes. Near A. are found many Roman antiquities.

AvolRDorols (French, avoir du pois); a kind of weight, of which a pound contains 16 ounces, and is in proportion to a pound troy as 17 to 14. All the larger and coarser commodities are weighed by avoirdupois weight. The avoirdıpois ounce is less than the troy ounce in the proportion of 72 to 79 ; thoing the pound, as we have said, is greater. Ste $M$ casurcs.
Avos; the name of several rivers in England, the most important of which are the following four. - 1 . Rising in Leicestershire, runs S. W., and falls into the Severn at Tewksbury. Stratford-on-Avon, a town on this river, is the birth-place of Shakspeare. 2. In Monmouthshire. 3. In Wiltshire, enters the English channel at Christ-church bay, in Hampshire. 4. The Lower Avon, which rises near Tetbury, in Gloucestershire, and falls into the Severn N. W. of Bristol, being navigable as far as Bath.

Aw ARd. See Arbitration.

$A-W$ EIGH; the state of the anchor when it is drawn out of the ground in a perpendicular direction.

Axrl. See Absalom.

AxIm ; a part of the fertile territory of Ahanta, on the Gold Coast. The Dutch have a fort here, called fort Anthony, situated on the most western promontory of cape Three Points. The Portuguese founded the first settlement here, but were driven from it by the Dutch, in 1642.-Axim is likewise the name of a river which runs through the capital of this country, called, also, Axim.

AxıNıTe; a crystallized substance, found principally in Dauphiny, in France, and latterly in Cornwall, in the neighbourhood of St Just. The colours are generally a light violet-brown. Its name is derived from the general form of the crystals, the edges of which bear some resemblance to the edge of an axe. Axıom (principle); a universal proposition, which the understanding must perceive to be true as soon as it perceives the meaning of the words, though it cannot be proved, because it is impossible to make it plainer. It is therefore called a self-evident truth. To these propositions belong, indisputably, those in which the subject and predicate are either the same or are only expressed in different words, since we cannot think a thing is really different from itself: for instance, $A$ is $A$; Every quantity is like itself; $A$ thing is like itself; $A$ thing cannot, at the same time, be and not be ; \&c. To axioms belong also propositions, of which the predicate expresses only some idea which enters necessarily into our conception of the subject. Such is the proposition, A triangle has three sides, because the subject, triangle, cannot be conceived otherwise than three-sided. All reasoning must start from axions. There has been much dispute what proposition is to be regarded as absolutely first in all human knowledge. Some have considered as such the position, It is impossible for a thing to be and not to be at the same time; others, Whatever is, is ; others, Every thing either is or is not; others, the principle of the sufficient reason, We cannot re. gard any thing as true without proofs, or any thing false against established proofs. All these positions are fundamental truths. They all have this in common, that we cannot help regulating our thoughts, in the judgment of truth, conformably to them. They are all necessarily believed to be true. Many principles, however, are esteemed, by one class of men, selt. evident, which another will not admit. There can never, therefore, exist perfect uniformity in human reasoning. There is only one science, which starts from axioms acknowledged by all mankind, and which, therefore, is of a more general character than any other-viz. mathematics. But about some principles of every other science, which are generally considered axioms, great doubts have existed. Thus it is regarded as an axiom of moral philosophy, that There exists a distinction, in the nature of things, between moral good and evil. This cannot be proved, but it is generally admitted ; and all our social, political, and religious relations are regulated by this principle; yet there have existed men of acnte minds, who have disavowed this axion altogether, and inade interest the sole rule of conduct. Many of tiem lived in the 
bime of Helvetius. (q. v.) It has always lieen a great question in philosophy, whether these axioms are innate or draun from experience. - Bacon calls axiom a general principle, obtained by experiment and observation, from which we may safely proceed to reason in all other instances; and Newton gives the name of axiom to the laws of motion, which, of course, are ascertained by the investigation of nature; he also terms axioms tliuse general, experimental truths, or facts, which form the ground-work of the science of optics. Dugald Stewart thinks that, in this, and other instances, Newton followed Bacon's phraseology "too implicitly."

AxIs, in geometry ; the straight line which divides the area of a curved figure (e. g., of a circle, ellipse, \&c.) into two parts, similar and similarly situated, on loth sides of the line. Further, a straight line drawn from a point in the periphery through the centre of a sphere is its axis; and a straight line drawn from the vertex of a cone through the centre of its base, is the axis of the cone.-The axis of the world is the imaginary line drawn through its two poles and its centre.

Axom, Axoma, Axoms, or Aksum; a city in Tigre, a province of Abyssinia. Neither Herodotus nor Strabo mentions A., though, in the first century after Christ, it was repeatedly spoken of, and particularly after the time of Ptolemy, as the chief city of an important kingdom, which, through Adulis, was con. nected with Arabia and Ethiopia. At the time of the periplus of the Red sea, A. was the great depot of the ivory trade. The importance of this city and its kings was first made known to us by a stone (Axumitic marble) with a Greek inscription, first explained by Salt, who discovered it, and afterwards by Buttmann and Niebuhr (Museum der Alterthumswissenschaften, $v$. Wolf und Buttmann; $2 \mathrm{~d}$ vol., sec. 575). This inscription, like similar ones that have since cune to us from that quarter, contains an account of the clemency of one Aizanas (a boasting king, who called himself a son of Mars) towards sereral inferior kings, whom he conquered. The interest in this inscription was increased by the explanation which it afforded of the second half of the Adulian marble. (q. v.) A., the place where it was found, still exhibits many remains of its former great. ness. Among its ruins are shown the royal throne, and groups of obelisks, originally 55 in number, one of which Salt declared to be the most beautiful that he had seen. Cotton goods, and the finest parch. ment, are still manufactured here.

Aracucuo, battue or. This engagement is one of the most celebrated in the history of South America, having been decisive of the independence of Upper and Lower Peru. For several months before this event, the Colombian auxiliary army, under general Sucre, and the royalist army, under the viceroy $\mathrm{La}$ Serna, had been moving in face of each other with various success, but, on the whole, to the disadvantage of the Colombians. Sucre and his men vrere anxious for battle; and at length La Serna determined to engage them on the plain of $A$ racucho, Dec. 9, 1825. The royalist force consisted of 9,310 men, that of the patriots of 5,780 men. Generals Sucre (the commanderin-chief), La Mar, Cordora, and Miller distinguished themselves on this occasion, and the battle terminated in the total defeat of La Serna, who was taken prisoner, with the loss of 1800 men in killed and wounded, and in the capitulation of Canterac, the second in command. Of the patriots, only 370 were killed. The intelligence of this splendid victory filled all Spanish America with rejoicings, as it effectually accomplished the delivery of Peru from the Spaniards. See Peru, Bolivia, Sucre.

ArESIIA; daughiter of Abubeker, the favourite wife of Malıomet, the Arabian prophet, though she bore him no child. After his death, she opposed the succession of $\mathrm{Ali}$, raised an army against him, and was taken prisoner, but dismissed with that spirit of chivalry which had already arisen among the Arabians, and communicated itself afterwards to the Christians. She died in 677 , it is said, sixty-seven years old.

AYR; a river of Ayrshire, which ruus a course westward eighteen miles, intersects the district of Kyle, and finally loses itself in the frith of Clyde, below the town of $\mathrm{Ayr}$.

$\Lambda \mathrm{rR}$; a royal burgh, and capital of $\Lambda$ yrshire, is situated on the southern bank of the river $\Lambda \mathrm{yr}$, near its confluence with the frith of Clycle. It is distant seventy-six miles W. S. W. of Fdinburgh, and thirtyfour S.S. W. of Glasgow. The place has been inhabited from a remote antiquity. It was the site of a Roman station, and it is generally understood that a hamlet remained here up to the reign of William the Lion, in 1197 , when that monarch engrafted a new town upon the older settlement. About the year 1202, William constituted the town a royal burgh. The celebrated Wallace here perforineil some of his patriotic exploits, and a strong garrison was placed in the town by Edward I. The tower of the ancient church of St John, where a parliament sat and confirmed Fobert Bruce's title to the crown, and which Cromwell converted into a citadel, still remains, but there are no traces of the old castle, except the mount whereon it stood. The principal streets of modern Ayr are spacious, and many of the buildings handsome. Here are two churches, and a few other places of worship, belonging to sectarians, a general post-office, a theatre, a library, a reading-room, a public academy, a savings'bank, a dispensary, jail, and court-house. The government of the town, by charter of William the Lion, is vested in a prorost, two baillies, a dean of guild, a treasurer, and twelre councillors. Its trade is chiefly with Ireland; the exports consisting of cottons, woollens, iron, coal, whetstones, paint, \&.c., and the imports of grain, spirits, timber, slates, bricks, and lime. At the mouth of the harbour are two refiecting lights; its channel, however, is too shallow to admit vessels drawing more than twelve feet water; besides which, the navigation is much impeded by a shifting lar of sand. About 6000 tons of shipping, from 200 tons downwards, and 500 seamen, belong to this port. Ship-building is carried on to some extent, also tanning, boot, and shoe-making, and the manufacture of soap. Companies are established here for catching and curing white fish, which abound in great variety in the flats and sand-banks along the shore; the salmon fishery is also prosecuted with success. This is a considerable resort of the gentry, particularly at the seasons for holding the Caledonian hunt and the races, which are numerously attended. The population of the parish and burgh of Ayr in 1831 was 7,606.

AYr ; a parish of Ayrshire, to which is annexed the ancient parish of Alloway, in the district of Kyle. It includes also the town of A Yr, and is watered on the north by the Ayr, on the south by the Doon, both rivers falling into the frith of Clyde, which bounds it on the west. The soil is well cultivated, and adorned with fine seats and plantations. The frith and rivers abound with fish, the trade in which is carried on with success. Here are coals in plenty, and a noted chalybeate spring, found to be efficacious in scorbutic and scrofulous disonders. Johannes Scotus Erigena, the celebrated schoolman, the Clitvalier Ramsey, and the poet Burns, were natives of this parish. The house in which the latter was born stands within a mile and a half of Ayr, between 
that town and the village of Alloway. It is pointed out to the notice of travellers by a sign-board and inscription. A monument has been erected to the memory of the same gifted individual on a lieight between the kirk and the bridge. It is built of pure white stone, in the form of a Grecian temple, and within are some relics connected with the poet, and his portrait. The group, by Thom, of Tam o' Shanter, Souter Johnny, \&c. is intended to be placed here.

AYR, NEWTON-UPON. While the burgh of Ayr excends along the south side of the river Ayr, this small parish is situated on the north side of the same river. It is a burgh of considerable consequence, having a baronial jurisdiction, and governed by a magistracy elected by freemen, but without parliamentary representation. It is of very ancient erection, owing its privileges to Robert Bruce; who, upon being attacked by leprosy, came to reside in this place, and was induced to establish a lazarhouse, and to confer considerable favours on the town, and on the small village of Priestwick, about two or three miles distant. In Newton-upon-Ayr are a number of very good houses. It has a tolerably good harbour, chiefly occupied with the coal trade. From its situation on the banks of the Ayr and the sea-coast, the soil is mostly flat and sandy. Its extent is about three miles in length and one and a half in breadth. In 1831 the population was 4020 .

AYRSHRE, or AIRSHIRE; an extensive maritime county on the western coast of the lowlands of Scotland, bounded by Renfrewshire on the north, the counties of Dumfries and Lanark on the east; by Wigton and the Stewartry of Kirkcudbright on the south; and by the Irish channel and the frith of Clyde on the west. It used to be divided into the three districts of Cunningham on the north, Kyle in the centre, and Carrick on the south; the latter of which, although the least fertile, abounds most in picturesque beauty. The soil varies considerably: towards the sea-shore it is for the most part sandy, with an occasional intermixture of rich loam. More inland, it is composed of a large proportion of stiff deep clay, which, when properly cultivated, is highly productive. In some parts this clay is only superficially spread over a substratum of schistus and till, and in a few places a gravely soil prevails. Towards the east the country is hilly, naked, and unfruitful, with the exception of patches of rude pasturage, and fern, and peat moss. Most of the rivers in the south of Scotland rise from the ridge of which the mountains in the district of Carrick, rising from 1000 to 2000 feet above the level of the sea, form a part. Of these, the Ayr, the Doon, the Lugar, the Stinchar, and the Girvan, intersect this county, and discharge themselves into the Irish channel. In the district of Kyle is Lake Doon, six miles in length, from which issues the river of the same name. The sea-coast, which is the most thickly interspersed with towns and villages, possesses the six harbours of $A \mathrm{yr}$, Irvine, Saltcoats, Ardrossan, Troone, and Dunure. That of Troone has been much improved by the recent construction of a pier, and is further benefited by the formation of a rail-road to Kilmarnock. The principal towns and villages are the royal burghs of A yr and Irvine, Kilmarnock, old Cumnock, Saltcoats, Tarbolton, Mauchline, Beith, Kilwiuning, Dalry, Catrine, Larms, Girvan, and Ballantrae. On the shores of Carrick are several remarkable caves, and the stupendous rock of Ailsa rises nearly opposite Girvan. Agricultare has been much advanced in this county of late years, principally owing to the establishment of the Douglas and Heron bank, which, by affording temporary facilities to landed proprietors, induced them to plant and improve their estates, although in several instances with very fatal results to tliemselves, when that too sanguine speculation failed. Roads were opened, and canals formed by similar ussistance, to the great benefit of the county, however unfortunately for individuals. Tillage is most productive near the coast, the interior and mountainous parts being chiefly dedicated to the rearing of cattle, which are produced in great numbers, and highly valued. 'This shire is also celebrated for the best cheese in Scotland, of which it exports great quantities. The most important mineral found in Ayrshire is coal, seams of which are discovered in almost every parish, so that 100,000 tons have been exported annually. It also abounds in lime-stone, free-stone, iron-stone, and lead-ore, of which the most considerable mines are in the parish of New Cumnock. To the above must be added, copper-ore, plumbago, barytes, crystal of zeolite, gypsum, agates, and a kind of whet-stone, called water-of-Ayr stone, much valued by cutlers. In most of the lakes there is plenty of marl, and great quantities of sea-weed are thrown ashore, which is manufactured into kelp. The abundance of fuel in the county renders it peculiarly adapted to manufactures, and, accordingly, those of cotton, woollen, thread, and muslin, are carried on to a great extent, in addition to considerable iron-works at Muirkirk and other places. The salmon fisheries, in which species of fish most of the rivers abound, likewise form a considerable source of profit to the different landed proprietors, while the sea-coast abounds with all kinds of white fish, and one or two companies are formed in the town of Ayr for curing them. Ayrshire is the seat of many noted Scottish families, among which may be enumerated the Kennedies, the Cunninghams, the Cochranes, the Stewarts, the Montgomeries, the Boyds, the Blairs, the Boswells, the Oswalds, and the Camplells. The monuments of antiquity are numerous, including cairns, encampments, Druidical circles, and the remains of various castles, one of the niost remarkable of which is that of Kilbirnie, in the district of Cunningham, near a beautiful lake. The following abstract will exhibit a comparative view of the population of Ayrshire in 1811, 1821, and 1831 :-

1811.

\begin{tabular}{|c|c|c|c|c|c|c|c|c|c|}
\hline \multirow[b]{2}{*}{ DISTRICTS. } & \multicolumn{3}{|c|}{ Houses. } & \multicolumn{3}{|c|}{ OCCUPATIONS. } & \multicolumn{3}{|c|}{ FERSONA } \\
\hline & 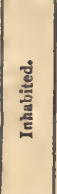 & 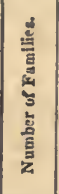 & $\begin{array}{l}\text { 总 } \\
\text { 岂 } \\
\text { 喜 }\end{array}$ & 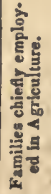 & 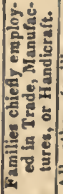 & 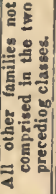 & $\frac{5}{2}$ & है & 这 \\
\hline $\begin{array}{l}\text { Carrick, } \\
\text { Canningham, } \\
\text { Kyle, }\end{array}$ & $\begin{array}{l}2,997 \\
6,206 \\
6,204\end{array}$ & \begin{tabular}{|c|}
3,450 \\
10,167 \\
7,877
\end{tabular} & $\begin{array}{l}132 \\
138 \\
192\end{array}$ & $\begin{array}{l}1,474 \\
1,725 \\
2,186\end{array}$ & $\begin{array}{l}1,835 \\
6,133 \\
3,866\end{array}$ & $\begin{array}{r}641 \\
2,390 \\
1,805\end{array}$ & $\begin{array}{r}7,665 \\
21,390 \\
19,451\end{array}$ & $\begin{array}{r}8,557 \\
24,797 \\
22,154\end{array}$ & $\begin{array}{l}16,228 \\
46,1,27 \\
41,608\end{array}$ \\
\hline Total, $1811, \ldots$ & 15,407 & 21,494 & 462 & 6,385 & 11,354 & 4,755 & 48,506 & 55,448 & 103,954 \\
\hline
\end{tabular}

1821.

\begin{tabular}{|l||l|l|l|l|l|l||l|l|l|l|}
\hline Carrick, & 3,608 & 4,888 & 110 & 1,690 & 2,586 & 612 & 10,522 & 10,803 & 91,326 \\
\hline
\end{tabular}

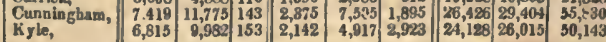

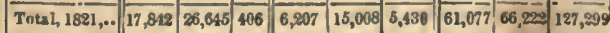

In 1831 the populatlon of Carrick tmounted to 25,536 ; of Canningham to
63,500 ; and of Kyle to 56,$066 ;$ total 145,108 .

Artox, Sir Robert; an elegant poet during the reign of James VI., was born in Fifeshire, Scotland, 1570, and studied at St Andrews. He afterwards resided for some time in France; whence, in 1603 , hc addressed an elegant panegyric in Latin verse to king James, on his accession to the crown of Eng. land, which was printed at Paris the same ycar ; and 
this panegyric lind, no doubt, some influence in securing to the author the favour of that monarch, by whom he was successively appointed one of the geutlemen of the bed-chamber, and private secretary to his queen, Anne of Deumark, besides receiving the houour of knighthood. He was, at a later period of his life, honoured with the appointment of secretary to Henrietta Maria, queen of Cliarles 1. During his residence abroad, as well as at the court of England, he lived in intimacy with, and secured the esteem of, the most eminent persons of his time. He died at London, in March, 1637-8, and was buried in the south aisle of the choir of Westminster Abbey, where a handsome monument was erected to his memory. The poems of Sir Robert Ayton, for the first time published together in the Miscellany of the Bannatyne Club, are few in number, but are greatly distinguished by their elegance of diction. John Aubrey remarks, " that Sir Robert was one of the best poets of lis time," and adds the more important testimony, that " Mr John Dryden has seen verses of his, some of the best of that age, printed with some other verses." According to Dempster, Ayton was also a writer of verses in Greek and Freuch, as well as in English and Latin. Several of his Latin poems are preserved in the work called, "Delitiæ Poetarum Scotorum," which was printed in his lifetime (1637) at Amsterdam.

Azerbijan; a province of Persia, part of the ancient Media. It is separated from Armenia on the north by the river Araxes, and from Irak on the south by the Kizilozein or golden stream. It has the Caspian sea and Ghilan on the east, and Armenia and Kurdistan on the west. The country is superior to the southern provinces of Persia, being richly diversified with wood and water. Lead, copper, saltpetre, and sulphur, are found within the confines of A.; also a kind of beautiful transparent marble or jasper, which takes the highest polish, and is used in the buildings of Tabreez, Schiraz, and Ispalian, under the name of Tabreez marble. The province is divided into twelve districts. The chief towns are Tabriz or Tabreez, containing 30,000 inhabitants; Meanna, Ardebil, Shebuster; Tasouj, in ruins ; Selmart, with 2000 inhabitants ; Khoee, with 25,000 ; Ooroomea, with 12,000; and Maraga, with 15,000 . The climate is healthful ; in summer and autumn hot, but cold in winter, which is severely felt by the lower orders, owing to the want of fuel, for which there is no substitute except dried cow.dung mixed with straw.

Azıмотн of a star; the arc of the horizon comprehended between the meridian of the observer and the vertical circle passing through the star. It is easterly, if the star is observed before, westerly, if after, and zero, if at, the time of culmination. It is usual to connect with the quadrant a graduated, horizontal circle, called the azimuth circle. The zero of its divisions is brought into the situation of the meridian, and we have immediately the azimuth of the star, whose height above the horizon is deternined by the telescope of the quadrant.

Azoga Ships (from the Spanish azogue, quicksilver) were those Spanish ships, commonly called the quicksilver ships, from their carrying mercury to the Spanish West Indies, to extract the silver from the mines of Mexico and Peru. They were prohibited from carrying any goods exeept for the king of Spain.

Azopa, or Azor; a small town and fortress in the Russian government of Ekaterinoslav, upon an island at the mouth of the Don, where it flows into the sea of Aroph. Lat. $46^{\circ} 53^{\prime} \mathrm{N}$. ; lon. $39^{\circ} 14^{\prime} \mathrm{E}$. It contains about 3000 inhabitants, and was as late as 1774 , given up entirely to the Russians by the Turks. The Sea of Azoph is merely a bay of the Black sea, with whieh it is united by the straits of Cafla. II the middle ages, it was called Mar de Zabacchi, and, in ancient times, Palus Macotis. Its principal port is Tauganrock. Its fish are plentiful. On Sept. 5, 1799 , a new volcanic island was thrown up. The sea is 210 miles in length, and about 50 broad. Lat. $45^{\circ} 20^{\prime}-47^{\circ} 20^{\prime} \mathrm{N}$.; lo11. $34^{\circ} 30^{\prime}-39^{\circ} 30^{\prime} \mathrm{E}$.

Azores (i. e. Hawk islands); a group of nine Portuguese islands in the Atlantic oceau, between Africa aud America, extending in an oblique line froin north-west to south-east, between the 37 th and 40 th degrees of north Jatitude, and the 25th and 3\%d degrees of west longitude. The inhabitants are of Portuguese origin, and governed by Portuguese laws. The country is volcanic and mountainous, but wellwatered and uncommonly fruitful. The lighest mountain, the peak of Pico, is 7016 feet high. 'The climate is warm and healthy, producing corn, wine. and various fruits. The inhabilants are engaged in grazing and fisheries, have some manufactures, and a lively trade. There is no good harbour. Tlie Portuguese discovered these islands, A. D. 1446, though the Dutch navigators had seen them earlier, and called them the Flemish islaxds. Their names are St Michael, population 80,000 ; Tercera, 28,900; Pico, 20,900; St George, 11,200; Fayal, 16,300; Santa Maria, 5,000 ; Graciosa, 7,400 ; Flores, 7,100 ; and Corro, 800. Angra, the chief city on Tercera, contains 15,000 inhabitants. The total population of the Azores is estimated by some at more than 200,000 .

Azote (from $\alpha$, and $\zeta_{\omega n}$, life, because it is fatal to animal life ; called also nitrogen, because one of the most important properties of its base is, that, in combination with oxygen, it composes nitric acid); a gas. Though incapable of supporting respiration or combustion, its presence seems to be recessary to dilute the oxygen, and thus diminish its activity. Atmospheric air is a nixture of oxygen and azote, in the proportion of 21 to 79 in volume. The specific gravity of azote is 09757 , that of the air being taken as unity. Its refractive power is 103408 . The specific caloric of azote and the air, taken in equal volumes, is the same; taken by equal weights, that of azote is greater. Azote is procured by burning phosphorus in a receiver over mercury; the phosphorus unites with the oxygen, and the azote is set free: it still contains a small quantity of carbonic acid, which is separated by shaking the gas in a closed bottle, containing limewater, from which the air has been exhausted. It is also evolved from decaying organized substances, and forms anmonia with their liydrogen when burned. Azote has a feeble affinity for other substances; the number of mineral compounds into which it enters is, therefore, small.-Animal and vegretable substances differ from each other only in this, that the former contain azote, the latter are destitute of it.-Some chemists consider azote a compound of equal volumes of oxygen, and a base which they call nitricum.

Azyми, or AzYuos (Greek, $\alpha$ לैus, without ferment, unleavened); a term much used in the violent eontroversies between the Roman and Greek Catholics; the former of whom contend that the bread, in tho mass ought to be azymus. The controversies on this important subject are of equal consequence with those between the German Lutherans and Calvinists, whether the Lord's prayer ought to begin Our Father, or Father of us; or between some religious onders, whether the cowl ought to be pointed or round, \& $c_{c}$, \&c., \&c.

Azz.ıra, Don Joseph Nicholas, chevalier d'; a Spanish naturalist, was born, 1731, at Barbaneles, in Arragon, and early showed a strong inclination for the arts and sciences, which was increased by his 
connexion with the painter Mengs, who had entered the service of the king of Spain. A. entered on the career of diplomacy, was sent to pope Clement XIII. as royal agent for ecclesiastical affairs, highly distinguished himself in this post, and always maintained a great influence in the most important negotiations between his country and the papal court. (See Dohm's Memoirs of Joseph II. and Rome.) In 1796, he was sent to the conqueror of Italy, to obtain his favour towards Rome. Bonaparte immediately conceived all esteem for him, and, after this meeting, A. always regarded him with admiration. At that time, also, commenced his comexion with Joseph Bonaparte. He went soon after, in a diplomatic character, to Paris, where the agreealle society and recep. tion which he met with compensated him for the loss of his old friends, of an elegant library, and a rich collection of paintings and antiques. He was subsequently recalled, banished to Barcelona, again sent ambassador to Paris, and again deprived of this important office. His feeble health at last gave way, and he died at Paris, Jan. 26, 1804.
$\mathrm{B}$; the second letter in all European alphabets, in Hebrew, and most other languages. It belongs to the mutes and the labials, and, as all labials are easy to be pronounced, $b$ is one of the first letters which children learn to speak, after they utter $a$. The first syllable which they pronounce is, generally, $b a$ or $p a$. The pronunciation of $b$ differs from that of $v$ only in this, that the lips are compressed a little more closely. The difference is so slight, that, in all original languages, a considerable period elapses before the two sounds cease to be used indifferently. In some languages, $b$ continues to be pronounced $v$, under certain circumstances. In the Spanish, it has this sound between two vowels in the middle of a word, and, generally, when it occurs between a vowel preceding, and an $r$ succeeding it. The modern Greeks pronounce $b$ always $v$, and represent our sound of $b$ by combining the two letters $\mu \pi$; e. g. Boston they write Mroorov. The languages of the American Indians have few perfect labials, and are, therefore, spoken with an open mouth, and scarcely any motion of the lips. Another letter, into which $b$ is often changed, is $p$, which requires merely a stronger breathing, with the same motion of the lips. In one part of Saxony, the people use $p$ and $b$ indifferently, and, in another part, $b$ is not used at all. Some languages regularly change $b$ into $p$, under certain circumstances; as the Latin, when this letter occurs before $p$; thus $o b$ is changed into op before ponere (opponere). The German pronounces $b$, at the end of a word, invariably $p .-B$ is often used as an abbreviation, and its most common meanings are before (us in $\mathrm{B} . \mathrm{C}$.), bachelor (as in B. A., B. D., B. L.). Among the Greeks and Hebrews, B signified 2; among the Romans, 300 ; with a dash over it, 3000 ; and with a sort of accent under it, 200. (See Abbreviations.)In music, $b$ is the designation of the seventh note in the natural diatonic scale of $c$, to which De Nevers, a French musician, in the beginning of the last century, is said to have first applied the syllable si. The ancients denoted by $b$ the second interval in their musical scale, beginning with $a$-the only interval, with them, which had two chords differing half a note. The lower one was denoted by a suall $\mathrm{B}$, the higher one by a large $B$.

BAAL, BEL; a Babylonian or Phonician god, the idea of whom has been very much obscured by time, and the imperfection of language. Some believe him to have been a man, the founder of Babylon; Herodotus calls him the son of Alcæus; others make him a Chaldean giant. From the traditions which history has transmitted to us, we might think him to lave been an extraordinary man, who founded the, ed at London. IIe is said to have been of a vnluptu- kingdom of Babylon, and was afterwards deified. Some writers report of him, that he made the land fertile and habitable, connected rivers by canals, and surrounded Babylon with a wall. His son Ninus, the great conqueror, is said to have declared him a god after his death, and to have ordered that divine honours should be paid him. But his worship was not limited to Babylon and Assyria; we find it among the Persians, Tyrians, and others. Of the manner in which the god Baal was worshipped, we have but imperfect and contradictory statements. Amongst the sacrifices offered to him, the Bible mentions human victims, which, however, is, perhaps, a mere figurative expression, to denote the apostasy from Jehovah to Baal.-Besides, the name Baal or Bel, in several Oriental languages, signifies lord, and denotes the dignity of a ruler; e. g., when compounded with several proper names, as Bel-shazzar, Hannibal.

\section{BaAlbek. See Balbek.}

BaAl-ZebdB. See Beelzebub.

BAAN, John van; a Dutch portrait painter, born in 1633; died in 1702 . He resided some time in England.

BABEL-MANDEB, or BABELMANDEL (literally, the gate of aftiction; anciently, Dira, or Dira); a narrow formed by projecting points of Arabia in Asia, and Abyssinia in Africa. It is fifteen miles wide. In the middle is an island, called $\mathrm{El} \mathrm{Mandel,} \mathrm{or} \mathrm{Perim,} \mathrm{or}$ Mehin. It is said to be ahout five miles in circum. ference, barren, and very thinly inhabited. Niebuhr, Bruce, and lord Valentia give an account of these straits and this island.

BABER, or BABODR, sultan; the founder of the Mogul dynasty in Hindostan. He was descended from the great Tartar prince Timour, usually called Tamerlane, and was sovereign of Cabul. He attempted the conquest of Samarcand, and, while engaged in an expedition against it, was deprived of his hereditary dominions, and reduced to the utmost extremities, by an invasion of the Usbecks. After more than once recovering his fortunes. when they seemed to be almost desperate, he invaded Hindostan, and, in 1525, overthrew and killed sultan Ibrahim, the last Hindoo emperor of the Patan or Afghan race. Another emperor was choserr to oppose $B$., who, however, overcame the combination against him, and firmly established himself on the throne. After an active and glorious reign, he died 1530. This prince wrote an elegant history of strait between the Indian ocean and the Red sea, 
ous disposition; and he is noted as the first Indian sovereign who had the roal by which he travelled measured after him. See Dow's History of Hindostan.

Barket, Francis Noel; one of the numerous individuals, of more zeal than judgment, who distinguished themselves during the french revolution. He was born at St Quentin, and left without resources, at the age of sixteen, by the death of his father. Having been unjustly inprisoned in the citadel of Arras for forgery, he made lis escape, and went to Paris, where, in concealment, lie published a pamphlet against the Jacoljins, entitled, Du Systéme de Dépopulation, ou la Vie et les Crimes de Carrier, 8vo. Soon after, he started a democratic journal, called Le Tribun du Peuple, par Gracchus Babeuf. He then wrote with great severity against the Jacobins, and even addressed severe reproaches to the national representatives. After the fall of Robespierre, to which he powerfully contributed, he openly attacked the terrorists, and, after the organization of the new government, in 1795, he resumed his journal, and adrocated in it the most democratic principles, with such energy as to bring on him the vengeance of the ruling powers. He was accused of a conspiracy against the directorial government, tried at Vendome, with some accomplices, declared guilty, and condemned to death, in 1797. He endeavoured to destroy himself, but was prevented, and fell by the hand of the public executioner. The debates on his trial were published in 6 vols., Svo.

Babzvtos, Anthony; a Catholic gentleman of Derbyshire, who associated with others of his own persuasion to assassinate queen Elizabeth, and deliver Mary, queen of Scots. The plot being discovered by Walsingham, the conspirators were executed in 1586. Babington seems to lave been principally induced to this rash conspiracy by a romantic hope that Mary, in gratitude, would accept of him as a husband.

Baboon; a common name applied to a genus of monkeys, with the exception of one species peculiar to Africa. This genus is the cynocephalus, or doghead monkeys of modern naturalists, and is divided into two sub-genera, well characterized by the difference of their tails: the first is called baboon, having the tail longer than, or nearly as long as, the body, and continuous with the dorsal spine; the second, named mandrill, is characterized by a short, slender, and pig-like tail, placed perpendicular to the dorsal spine. There are four species of the first and two of the second sub-genus. The most striking peculiarity of the whole is the elongated, dog-like head, with its flat, compressed cheeks, projecting and strong teeth, and forehead depressed below the level of the superior margins of the orbits. Notwithstanding this close approximation to the shape of the dog's head, the form and position of the eyes, combined with the similarity of the arms and hands, give to these creatures a resemblance to humanity as striking as it is disgusting. The whole aspect of the animal impresses the beholder with an idea of great physical strength, united with a temper at once incorrigibly vicious and brutally ferocious. Such, at least, is the true character of the baboons capable of being ruled by the severest treatment. It is only while coercion is continued, that they can be even partially restrained: left to their own will, their sarage nature immediately resumes its sway, and their actions are gratuitously cruel, destructive, and disgusting. The phrenologist finds evidence, in the conformity of the character of these creatures with their cerebral developement, of the exactness of his general positions. - In the vicinity of the cape of Good Hope, where a species of baboon $(C$. $\operatorname{sphin} x)$ is found in considerable numbers, the inhabitants chase them with dogs and guns, in order to destroy them, on account of the ravages they commit in the fitcls and gardens. They make a very obstinate and effectunl resistance to the $\operatorname{logs}$, and only retreat before nen when armed with guins. They ferd exclusively on fruits, seeds, and other vegetable matter, which shows how independent their disposition is of every thing but peculiar organization. Nothing can exceed the lasciviousness of these disagreerable creatures, which, when in captivity, indulge their lubricity sn the most disgusting maurer - a circumstance which renders it unsafe for females to visit exhibitious of animals where these beasts form a part of the number. If a woman be in presence of a baboon, the slightest attention paid her by a man, the taking leer by the hand, or exhibiting any approach to caresses, throws the animal into a paroxysin of rage, and, no douht, could he escape, he would inflict severe punishment on the offender. - The baboon can never be called tamed, how long soever his confinement may have endured. As he advances in age, all his worst qualities become more strongly expressed, and lis savage disposition grows exceedingly dangerous, and slight causes provoke him to terrible fury. For such reasons, these animals should not be allowed to form a part of a caravan for general exhibition, without being carefully secured and well watched.

Babour. See Baber.

BABRIAS, or BABrIUS; a Greek poet, supposed to have lived a short time before the beginning of the Christian era. He turned the falles of AEsop into verse, of which work some fragments have been published in Fabula Gr. Lat., cum Notis Neveleti, Frankfort, 1660, 8vo. Mr Tyrwhitt printed, in 1776, Dissertatio de Babrio, Fabularum \& Esopeamum Scriptore, containing all the information he could collect contcerning this ancient writer.

Babylonia (now, Irak Arabi); an old Asiatic empire, bounded E. by Susiana, S. by the Persian gulf and Chaldea, $W$. by Arabia Deserta, and $N$. by Media and Armenia, or Mesopotamia. As the Chaldeans had possession of the whole country, it was also in. cluded under the name Chaldea. It is a level region, watered by two great rivers, the Euphrates, or Frat, and the Tigris. The former stream, which is almost always on a level with its low banks, overflows on the slightest occasion. It inundates the whole country every spring, when it is swollen by the waters from the Armenian mountains, and fertilizes it as the Nile does Egypt. Nature has supplied the want of wood and stone by clay, which, when dried in the sun, or burned in furnaces, makes durable bricks, that even to the present time have resisted the effects of the climate in the ruins of the ancient city. For mortar, the inhabitants use bitumen, of which there are copious springs.

The extent of the old capital, Babylon, situated on the Euphrates, according to the representations of the ancients, approaches the miraculous. The walls are said to have been 350 feet high, and 87 fert thick; to have had 250 towers, and 100 gates of brass, and to have been more than 60 miles in circuit. The temple of Belus and the hanging gardens were among the greatest curiosities of this gigantic city, of which almost every trace is destroyed. The Babylonians, one of the most ancient nations of the earth, of the Semitic race, as appears by their language, which is an Aramaic or Syriac dialect, were a distinct people, with settled abodes, and a certain degree of scientific cultivation, as early as $2000 \mathrm{~B}$. C. The Mosaic account mentions Nimrod as the founder of the first empire in Babylonia. The later Greeks describe Belus, Ninus, and Semiramis as great conquerors. (See Assyria.) B. C. 630, the Chaldeans, a wandering people, under Nabopolassar, descended 
from Taurus and C'aucasus, conquered Western Asia, I and a bachelor of divinity must be a master of arts. destroyed Jerusalem under Nebuchadnezzar (588), There are, also, at these universities, bachelors of subjected Tyre and Phonicia, and founded an empire laws, of medicine, and of music. - In France, since which extended to the shores of the Mediterranean. the Ist of October, 1822, he who wishes to become Babylon, which, even earlier, was the seat of scienti- baccalaureus must have attended, at least one year, fic, particularly of astronomical and astrological the philosophical course, in one of the royal colleges, knowledge, was the capital of this empire. Com- institutes of edueation or divinity schools, in which merce and industry introduced wealth, and this pro- philosophy is taught. Those candidates, likewise, duced a love of luxury and magnificence. The who have been educated and instructed in the house manufactures of linen, cotton, and silk were especially of their father, of their brother, or uncle, can. be adcelebrated. Learning was confined to the priests, who are mentioned under the name of Chaldeans. Under Nabonidas, the empire declined until Cyrus put an end to it by destroying the capital, in 536, and united Babylonia with Persia. It shared the fate of Persia until A. D. 640, when it was conquered by the followers of Mohammed, who built Bagdad on the Tigris in 762. This became the seat of the caliphs, who were expelled in 1258, by Holagou, a prince of the Tartars. In 1534, Bagdad fell into the power of the Turkish victors, from whom Shah Abbas took it in 1613. It came, with Babylonia, anew under the dominion of the Turks, in 1639, who possess it at the present day.

Of the ruins of Babylon, which engage the attention of travellers in modern times, the most correct accounts are contained in the Memoir on the Ruins of Babylon, by Claude James Rich, resident of the East India company at the court of the Pacha of Bagdad (3d edition, with copperplates, London, 1818). Rich, Niebuhr, and Rennel suppose ancient Babylon to have been situated in the Turkish pachalic, Bagdad, near the village Hill or Hella, which lies in $32^{\circ} 28^{\prime} \mathrm{N}$. lat., on the eastern bank of the Euphrates, and contains 6000-7000 inhabitants. In the neighbourhood are a number of old, ruined canals. Idols, vessels, intaglios, \&c., and even ruins of large buildings, are still seen there Della 'Valle and Rennel think one of them to be the tower of Belus. The greatest height of this is 141 feet, and the sides are directed to the four cardinal points. Another ruin of a castle contains many caves and passages. A third, a huge oblong edifice, on the western side of the Euphrates, is called by the Arabians Birs Nimmed. This was first described by Rich. He takes it for the tower of Belus, the top of which was to serve as an observatory. Of this opinion is also Ker Porter. Grotefend has done much towards deciphering the arrow-headed inscriptions. The material is entirely brick, as described by Herodotus. Of the old city walls not a trace has been discovered. As to the rest, these ruins bear the character of grandeur, but not of beauty. The ornaments still existing are clumsy and tasteless.

Baccaladréds (anciently, baccalarius, bachelor) denoted, in the middle ages, 1. a warrior of lower rank (bachelier), under a knight banneret; 2. transferred to the clergy, it signified a canon of the lowest rank; 3. a candidate who had passed three academical courses and examinations, and was himself entitled to give lectures without being reckoned among the independent lecturers. This was, consequently, the lowest academical degree. After the first examination, he was called baccalaureus simplex; after the second (or Biblical), baccalaureus currens; after the third (philosophical and dogmatical), baccalaureus formatus. The baccalaureus could now become a licentiate, $i, e_{.}$, acquire all the rights of a teacher. In France, this institution remained until the revolution. In England, it is even now in existence, and the baccalaureus, created according to the regular forms, is called a formed bachelor; one who is created by an extraordinary diploma, a current bachelor. In the universities of Cambridge and Oxford, $a$ bachelor of arts must keep a certain number of ternns; mitted to the baccalaurèt des lettres. The candidates for the academical degree of baccalaureus are examined in all that is taught in the higher classes of the royal colleges, that is, in Greek and Latin authois, rhetoric, history, philosophy, the elements of mathematics, and natural history.-Bachelor of arts is a degree commonly conferred, in the United States, on students who have completed the course of study established at the several colleges in that country.

Bacchanalia. See Bacchus and Orgies.

Bacchios, See Rhythm.

Bacchos (in Greek, sioveros); the god of wine, born of a mortal mother, yet one of the immortal gods. His history is one of the most perplexed in the Greek mythology. Semele was pregnant. with him by Jupiter. Before his birth, however, she became a victim of the craft of Juno. Jupiter hastened to save the unborn fruit of his embrace, and concealed it, till mature, in his own thigh. He afterwards committed the infant to Mercury, who carried him to Ino and Athamas, and finally to the nymphs of Nysa, in India, where he grew and pros. pered. His teacher was Silenus, afterwards his constant companion.

In the vales of Nysa, Bacchus invented the preparation of a beverage from grapes, and taught the planting of vines. To spread the knowledge of his invention, he travelled over almost the whole known world, and received in every quarter divine honours. Drawn by lions (some say panthers, tigers, or lynxes), he began his march, which resembled a triumphal pomp, with a great suite of men and women, Sileni, Satyrs, and Mænades. Inspired by the presence of the god, rejoicing, brandishing the thyrsus, and crowned with vines and ivy, they danced around him, shouting, "Evoe! Eleleus!" over hill and valley, accompanied by the tones of Phrygian flutes and timbrels. The Thebans would not acknowledge his divinity, and Pentheus armed himself against him. Bacchus resolved to punish the crime, and inspired the women with a fury which drove them from their dwellings, to wander on mount Cithæron. Pentheus himself was torn in pieces by his own mother and her sisters, to whom he appeared a wild beast. He punished the daughters of Mynias, who derided his feasts, with frenzy and transformation. At Naxos, some Tuscan sailors attempted to carry him off to Italy, supposing him, from his purple robe, to be the son of a king. They fettered him; but the fetters fell off, vines and ivy entwined the vessel, and kept it fixed in the midst of the sea : the god transformed himself to a lion, and the seamen, seized with madness, leaped into the wares, where they were changed into dolphins. On the other hand, he rewarded such as received him hospitably, and rendered him worship; as, for instance, Midas (q. v.), who restored to him the faithful Silenus.

His love was shared by several; but Ariadne, whom he found deserted upon Naxos, alone was elevated to the dignity of a wife, and became a sharer of his immortality. To confer the same favour on his mother, Semele, he descended into the realms of Pluto, and conducted her to Olympus, where she was henceforth called Thyone. In the dreadful war with the giants, he forght heroically, 
and saved the gods from impending ruin. Accorling to some, he escaped the dungers which surrounded him in this conflict, by traustorming himself into a lion. During the rejoicings for victory, Jupiter joyfully cried to him, "bivan, evoe !" (Well done, my son !) with which wonds Bacchus was afterwands usually saluted. We find him represented with the round, soft, and graceful form of a mailen, rather than with that of a young man. An ornament peculiar to him is the tiara. His long, waving lair, is knitted behiud in a knot, and wreathed with sprigs of ivy and vine-leaves. He is usually naked ; sometimes he has an ample mantle hung negligently round his shoulders; sometines a fawn-skin hangs across his breast. The bearded Bacchus is properly of Indian or Egyptian origin. The golden horns (the symbol of invincible force) upon his head, were hidden by the Greek sculptors, or sliown but little.

The feasts consecrated to Bacchus were termed Bacchanalia, Dionysia, or, in general, Orgia. They were celebrated with particular solemnity in Athens, where the years were universally reckoned by them. During their continuance, the least violence towards a citizen was a capital crime. The great Dionysia were celebrated in spring. The most important part of the celebration was a procession, representing the triumph of Bacchus. This was composed of the above-mentioned train of Bacchantes, of both sexes, who, inspired by real or feigned intoxication, wandered about, rioting and dancing, and gave themselves up to the most extravagant licentiousness. They were masked, clothed in fawn skins, crowned with ivy, and bore in their hands drinking cups and spears entwined with iv (thyrsi). Amidst this mad crowd marched, in beautiful order, the delegated bodies of the Phratia (corporations of citizens). They bore upon their heads consecrated baskets, which contained first-fruits of every kind, cakes of different sliape, and rarious mysterious symbols. This procession was usually in the night-time. The day was devoted to spectacles and other recreations. At a very early hour, they went to the theatre of Bacchus, where musical or dramatical performances were exhibited. All over Athens reigned licentiousness and rerelry. These feasts passed from the Greeks to the Romans, who celebrated them with still greater dissoluteness, till the senate abolished them, B. C. 187 . (On the worship of Bacchus, the Dionysiaca, \&c., see the prize essay of P. N. Rolle, Recherches sur le Culte de Bacchus, Paris, 1824, 3 vols.)

BacchyldDes ; born in Iolus, a city of the island Cos; the last of the ten great lyric poets of Greece, whom the Alexandrine canon declared classical. The nephew of Simonides, and a contemporary of Pindar, he is placed as a poet beside them. Hiero, at whose court he lived, esteemed him very highly, and preferred him even to Pindar. Of his odes, hymns, preans, triumphal songs, the few fragments which remain are collected in some editions of Pindar, and in the Analecta of Brunck : there are many traces of him in the odes of Horace. Without having the impetuous eagle-tlight of Pindar, he was neither destitute of fire and energy, nor of grace and richness.

Baccio derla Porta, Francisco Bartolomeo ; a celebrated painter, better known under the name of Fra Bartolomeo di San Marco,* was born in 1469, at Savignano, near Prato in, Tuscany. He learned in Florence, the first principles of painting from Cosimo Roselli, made rapid progress, and acquired, by studying the works of Leonardo da Vinci, that beauty and

- Fra is the abbreviation of frate (brother) and is often put before the names of monks. grandenr of style, that vigour of colouring and out. line, by which his later productions are distinguished. At this tine, he mudertook his famous fresco in the church-yard of the hospital Santa Maria Nuova, representing the last judgment, which was finished by his friend Albertinelli. Seduced by the preaching of the fanatical Savonarola, he abandoned every thing to follow him, and shut himself up, with a great number of his followers, in the monastery of San Marco, when this turbulent preacher of sedition was pursued by the officers of justice. The monastery was besieged, and 13 . made a vow to become a mouk. if he should happily escape this peril. In consequence of this row, he took the Dominican habit in the same monastery, 1500 , and assumed the naine of Fra Bartolomeo. This event agitated him so unch, that, for the space of four years, he did not touch his pencil, and employed it afterwards only on dero. tional subjects. The pictures which he executed at this period are superior to his earlier productions. Rapliael visited Florence in 1504 , and contributed to the brilliant success of Fra Bartolomeo. The latter learned perspective from his friend, and gave him, in return instruction in colouring. Some years afterwards, he visited Michael Aigelo and Raphael at Rome, and had the rare modesty to do homage to their great talents by confessing his own inferiority. After his return to Florence, he executed several religious pictures, among which were a saint Mark and saint Sebastian, two compositions which obtain the admiration of every connoisseur. His style is serere and elevated, but, at the same time, very graceful in youthful figures; his colouring possesses vigour and brilliancy and comes near to that of Titian and Giorgione. But he particularly excels in drapery, which none before him represented with equal truth, fulness and ease. He died in 1517. His disciples were Cecchino del Frate Benedetto, Ciamfanini, Gabriel Rustucci, and Fra Paolo of Pistoia, who inherited his designs. His excellent pictures are preserved in the gallery of the grand duke at Florence and in the palace of Pitti.

Bacciocch1, Felix Pascal, formerly prince of Lucca and Piombino, husband of Elisa Bonaparte, sister of Napoleon, born May 18, 1762, in Corsica, of a noble but poor family, entered the army as a cadet, and was a captain when Bonaparte commanded the army in Italy. At this time his marriage took place, in consequence of which he was made colonel of the twenty-sixth regiment of light infantry, afterwards president of the electoral college of Ardennes, and, in 1804, a senator, without having distinguished himself, either from want of ability or of opportunity. In 1805, he received the title of prince, from the principality of Lucca and Piombino, assigned to his wife, whom, after the revolution of 1814 and 1815 , he accompanied into banishment. From that time he lived with her and his soll, under the surveillance of the Austrian government. at Trieste.

His wife, Maria Anne Eliza Bonaparte, born at Ajaccio, Jan. 8, 1777, and educated in the royal institution for noble ladies at St Cyr, had lived with !her mother at Marseilles, during the revolution. In 1797, she married captain Bacciocchi, according to the wish of her mother, but without the consent of her brother, who was then general-in-chief. In 1799 she went to Paris, and resided there with her brotlier Lucien, who awakened in her a taste for poetry and the fine arts. She collected around her the must accomplished men of the capital, among whom were the chevalier de Boufflers, Laharpe, the visconnt Chateaubriand, and the marquis de Fontanes. Generous as she ever was towards distinguished talent, she conferred particular obligations on the tiro lasto 
Fontanes was patronized by Napoleon, chiefiy through her recommendation. Conscious of her intellectual superiority, she kept her husband in a very subordinate situation. It was she, in fact, who governed the principalities of Lucca and Piombino, and, as grand duchess of Tuscany, slie enacted the part of a queen. When this Semiramis of Lucca, as a witty writer styles her, reviewed the troops of the duchy, her husband discharged the office of aid-de-canı. She introduced many improvements, though not properiy assisted by the officers intrusted with her confdence. In 1814, she reticed to Bologna, but was obliged, in the following year, to reside in Austria. Here she lived, at first, with her sister Carolina; afterwards, with her family, under the inspection of the government, at Trieste, where she called herself the countess Compignano. Elisa Bacciocchi died of a nervous fever, August 7, 18:0, at her country seat, Villa Vicentina, near Trieste. She was deposited in the chapel of her own palace, in a tomb built by herself. In Trieste, she was distinguished for charity and benevolence. Notwithstanding her wish, that her daughter Napoleona Elisa, born June 3, 1806, and her son, should be put under the care of her brother Jerome, her husband reinained their legal guardian.

$\mathrm{BAcH}$, John Sebastian ; among the German musical composers of the last century, one of the most famous, and the greatest of this name, so distinguished in musical literature, was born in 1685, at Eisenach ; died in 1750, at Leipsic. He received his first instruction on the harpsichord at Ordruff, from his elder brother, John Christopher. After the death of his brother, he studied music at Luneburg, and made himself familiar with the French style, while in the chapel of the duke at Halle ; in 1703 , entered into the service of the duke of Weimar; went, in 1704, to Arnstadt, where he made great proficiency ; was, in 1707, organist at Muhlhausen ; in 1708, organist of the court in Weimar; and, in 1714, master of the concert at the same place; afterwards, in 1717, chapel-master at Cothen ; in 1723, chanter and director of music at St Thomas's school at Leipsic ; and, in 1736, composer at the royal and electoral court of Saxony. His life has been written by Forkel. As a player on the harpsichord and organ, Sebastian Bach had no equal among his contemporaries. His conpositions breathe an original inspiration, and are chiefly of the religious kind. They consist of cantatas and motettos, and many pieces for the organ and the piano.-B.'s family came from Presburg, in Hungary, which Sebastian's father, himself a good musician, left on account of religious difficulties and settled in Germany. More than fifty musical performers have proceeded from this family. Sebastian hiniself liad eleven sons, all distinguished as musicians. The most renowned were the following: Wilhelm Friedemann, born in 1710, at Weimar, died master of the chapel of Hesse-Darmstadt, at Berlin, in 1784. He was one of the most scientific harmonists, and most skilful organists.-Charles Philip Emanuel, born in 1714, at Weimar, died in 1788, at Hamburg. After having studied law at Leipsic, he went to Berlin, as a musician in the Prussian service, and was finally director of the orchestra at Hamburg. He has composed mostly for the piano, and has published melodies for Gellert's hymns. His rocal compositions are excellent. His essay on the true manner of playing on the harpsichord is, even now, a classical work in its kind.-John Christopher Frederic, boru at Weimar, 1732, died in 1795 , master of the chapel at Buckeburg, a great organist, is kuown also by the music he has published.-John Christian, born in 1735, at Leipsic, died in London, 1782, was, on account of the graceful and agreeable style in which he wrote, a favourite composer with the public.

Bacharach ; a small place, of 1200 inhabitants on, the Rhine, three leagues from Bingen. It contains the ruins of the castle Stahlek, also those of a church, and another church, still existing, in the true Byzantine style. It produces excellent wine, which was once so highly estermed, that pope Pius II. (Eneas Sylvius) ordered every year a quantity to Rome, and the emperor Wenceslans granted to Nuremberg sume important privileges for a moderate quantity of this delicious beverage. The view from the ruins of the castle is one of the sublimest on the Rhine.

Bachaumont, Francois le Coigneux de, born at Paris, 1624, died there, 1702, was early employed as counsellor of the parliament of Paris, of which his father was president. In the disturbances of 1648 , he took part against the court, and from him originated the name of the Fronde. He said that the parliament reminded him of the schoolboys who played with slings in the bonlevards of Paris, and dispersed at the sight of a police officer, but collected again as soon as he was out of sight. The comparison pleased; the enemies of Mazarin adopted hat-cords in the form of a sling (fronde), and were called Frondeurs. In the war of the Fronde, B. found frequent occasion to exercise: his wit, in epigrams, against the court. After the troubles were past, he devoted himself to pleasure and to poetry. Similarity of taste and character produced an intimate friendship between him and LaChapelle, and they composed in common that charming account of a Journey, which met with so much favour among the friends of light and sportive poetry. He has written, also, many gay songs, which, however, are too much scattered to allow of a complete collection being made. M. Lefevre de St Marc has published one, but does not pretend that all the pieces are genuine.

BACHELOR. See Baccalaureus.

BAck ; a word often used in sea terms. To back an anchor; to carry out a small anchor, ahead of the large one, in order to support the latter.--To back and fill, is an operation generally performed in narrow rivers, when the vessel has the tide in her favour, and the wind against her.-To back the sails, is to arrange them in a situation that will occasion the vessel to retreat, or to move astem, in consequence of the tide current being in her farour, and the wind contrary, but light.-Back the main top sail; the command to brace that sail in such a manner, that the wind may exert its force against the fore part of the sail, and, by thus laying it aback, materially retard the vessel's course.

Bickereel, or BacQuereldi, William; a Dutch historical painter, born at Antwerp, and a disciple of Rubens at the same time with Vandyke. Sandrart observes, that, in his time, there were seven or eight eminent painters of this name in Italy and the Low Countries.

BaCKgamion; a game played with dice, by two persons, on a table divided into two parts, upon which there are 24 black and white spaces, called points. Each player has fifteen men, black and white, to distingnish then. The word is of Welsh origin, signifying little battle.-Laws of the Game. 1. If a man is taken from auy point, it must be played. 2. A man is not played, till it is placed upon a point and quitted. 3. If a player has only fourteen men in play, there is no penalty attending it. 4. If he bears auy number of men before he has entered a man taken up, and which, of course, he was obliged to enter, such men, so borne, must be entered again in the adversary's table, as well as the man taken up. 5 . If he has mistaken his throw, and played it, and his adversary las thrown, it is not in the choice of either of the 
players to alter it, unless both parties agree to it. (See Hoyle's liames, improted from the late'st and best authorities.)

Buckuorser, Ludolf, a very celebrated painter of the Dutch school, particularly in sea pieces, born in 1631, at Fmbden, was first employed as a clerk by his father, who was secretary to the states-general. He afterwards entered a mercantile house at Amstendam, and, without instruction, began to sketch the vessels which arrived in the larbour. These attempts met with applause, and led lim to devote himself entirely to painting. He received instruction from von Everdiugen, and soon acquired, by his assiduity, and his frequent visits to the rooms of the best artists, an extraordinary degree of facility and skill; but what most contributed to his rapid progress was the zenl with which he studied nature. On the approach of a storm, he was accustomed to embark in a light boat, and calmly observe the motions of the waves, the tremendous shock of the breakers, and the tossings of the agitated vessels. The terrified sailors often forced him to the shore, in spite of his earnest entreaties. Full of what he had seen, he then hastened home, without speaking a word, or allowing his attention to be distracted by any other object, and completed, with admirable exactness in the most minute particulars, the sketches which he had already made. This courageous zeal procured his pictures the first rank in their class. Several princes visited his rooms, and Peter the Great even wished to take lessons of him. The burgomasters of Amsterdam commissioned him to execute a sea piece, for which they paid 1300 florins, and which they presented, in 1665, to Louis XIV. This beautiful picture is still in Paris. In all his paintings, the utmost truth prevails. His colours are excellent, and his stroke is remarkably well suited to imitate the water and its motions: his skies are light, and of great variety. B. also attempted poetry, and gave instruction in penmanship. His gayety and strength of mind did not quit him even during the long sufferings which put an end to his life, in 1709 , at the age of 78 rears. His pictures will always retain a high value. At the sale of the pictures of $P$. de Smeth, in Amsterdam, 1810, four pieces of Backhuysen were solid for $550,805,980$, and 1400 florins.

BacoN, Anthony, the son of Sir Nicholas, and elder brother to the celebrated lord chancellor, was born in 1558. He studied at Cambridge, and travelled much. In 1579, he went to Paris, and resided there, and in other parts of France, a considerable time. He there became acquainted with Henry IV., with whom, and with many of the first literati of Europe, he carried on an extensive correspondence after he had returned to England. The time of his death is not known.

Bacos, Francis, baron of Verulam; one of the most remarkable men of whom any age can boast; a reformer of philosophy, by founding it on the observation of nature, after it had consisted, for so many centuries, of scholastic subtilties and barren dialectics. He was born at London, in 1561, and displayed, from his earliest childhood, proofs of a superior mind. In his 13th year, he entered the university of Cambridge, where he made astonishing progress in all the sciences there taught. He had not completed his 16th year, when he wrote against the Aristotelian philosophy, which seemed to him more calculated to perpetuate disputes than to enlighten the mind. It was then the custom, in England, to send abroad, particularly to France, those young men who were destined for public life. Young B. went to Paris in the suite of Sir Amias Paulet, who soon after sent him to England with an important message. He discharged it to the satisfaction of the queen (Elizabeth), returned to France, and travelled through several provinces of that country, to study its manners and laws. When 19 years old, he wrote a work, entitled, of the Stule of Europe, in which he gave the most astonishing proofs of the early maturity of his judgment. Thie death of his father called him back to England, where, in onder to be enabled to live suitably to his rank, he devoted himself to jurisprudence, and pursued the study of the law with so much success, that he was made counsel extraordinary to the queen before he was 28 years old. His professional labours did not, however, make him lose sight of the idea, which ho had early conceived, of reforuing the plan of scholastic studies agreeably to sound pliilosophy. His place was more honourable than lucrative. B.'s talents, and his connexion with the lord treasurer, Burleigh, and his son Sir Robert Cecil, first secretary of state, seemed to promise him the highest promotion; but the enmity between the latter and the earl of Essex, likewise a friend and protector of $\mathbf{B}$., prevented his advancement. Fsse $x$ endeavoured to indemnify lim by the donation of an estate in land. 13., however, soon forgot his obligations to his generous benefactor, and not only abandoned him as soon as he had fallen into disgrace, but, without being obliged, took part against him on his trial. Against this ingrati tude the public voice was raised, and, whatever $B$. might say in his justification, he remained at court the object of hatred to one party, and of jealousy to the other, and the queen did not appear inclined to do any thing in his favour. In parliament, he conducted himself, for some time, with dignity and independence. He had been chosen member for the county of Middlesex, in 1593, and roted with the popular party against the measures of the ministers, though he-continued in the service of the crown. But, towards the end of Elizabeth's reign, his parliamentary conduct became more servile. If any thing can excuse him, it is his porerty, which was so great that he was twice arrested for debt. The reigiı of James I. was more favourable to him. The prince, who was ambitious of being considered a patron of letters, conferred upon him, in 1603, the order of knighthood. Having been commissioned to make a representation of the oppressions committed by the royal purveyors in the king's name, he executed the task with so much address as to satisfy both the king and the parliament. The house of commons roted him the public thanks, and James made him one of the king's counsel, with a pension of forty pounds, which was soon followed by another of sixty pounds. His situation now continually improved: he contracted an advantageous marriage; in 1617 , was made lord keeper of the seals; in 1619, lord high chancellor of England and baron of Verulam, and, in the following year, viscount St Alban's. He might now have lived with splendour, without degrading his character by those acts which have stained his reputation. Nevertheless, great complaints were made against him. He was accused, before the house of lords, of having received money for grants of offices and privileges under the seal of state. He was unable to justify himself, and, desiring to avoid the mortification of a trial, confessed his crimes, and threw himself on the mercy of the peers, beseeching them to limit his punishment to the loss of the high office which he had dishonoured. After he had acknowledged, by an explicit confession, the truth of almost all the charges, notwithstanding the intercession of the king, and the interest which they themselves took in one of their most distinguished members, the lords sentenced him to pay a five of $£ 40,000$, and to be im. prisoned in the Tower during the pleasure of the king. He was also declared for ever incapable of place or employment, and forbidden to sit in parliament, or to appear within the verge of the court. 
This severe sentence was doubtless just; yet it must be allowed, that he was actuated neither by avarice nor corruption of heart, but that his errors are rather to be attributed to a weakness of character, which was abused by others. Traits of generosity and independence, which his life also displays, show clearly that lie knew and valued virtuc. He was unfaithful to it because he had not sufficient firmness to refuse the unjust demands of others. His sentence was not rigorously executed; he was soon released from the Tower, and the rest of lis punishment was, by degrees, remitted entirely. He survived his fall only a few years, and died in 1626.

All the studies and efforts of this great man aimed at a reform in the system of human knowledge. He examined the whole circle of the sciences, investigated their relations, and attempted to arrange them according to the different faculties of the liuman mind, to which each belongs. In this, however he could not succeed, for want of a well-founded and natural division of the powers of the mind; for he divided the sciences into those of the memory, of the understanding, and of the imagination. This he explains in his Instauratio Magna, under the head De Dignitate et Augnenitis Scientiarum. He further perceived that, in all the branches of natural science, the only way to truth is by the observation of nature. How this observation is to be directed, and how nature is to be examined, is illustrated in several places. He explained his ideas on this subject in the above mentioned treatise (De Dignitate, \&c.), and in the Novum Organum Scientiarum. His universal genius had atteuded to all the sciences; he perceived to what point each of them had advanced, what false directions they had taken, and how they were to be brought back to truth. As a metaphysician, he displays no less penetration than profoundness in his views of the operations of the mind, of the association of ideas, and of the prejudices which surround us from our cradle, and prevent the free exercise of reason. As a natural philosopher, he brought forward very ingenious views, and was on the route to several important discoveries. He invented a kind of pneumatic machine, by his experiments with which he was led to suspect the elasticity and gravity of the air, which Galileo and Torricelli afterwards discovered. He clearly indicated the attraction of gravitation, which Newton afterwards proved. He wanted only experiments in order to demonstrate the principles of this power. He treated also of natural history, but only in an abridged manner, in his work Sylva Sylvarum, \&c. He wrote several treatises on medicine; among others, one on life and deatl. But pliysiology and chemistry were then so imperfectly understood, that he could not avoid falling into great errors. The science of law he treated not merely as a lawyer, but as a legislator and philosopher. His aphorisms are not less remarkable for profound views than for vigour and precision of expression. Morals are the subject of one of his finest works, entitled Essays, or Sermones Fideles-a treasure of the most profound knowledge of man and of luman relations, delivered in an eloquent and vigorous style. $\Lambda$ s an historian he is less distinguished; he wrote a history of Henry VII. Of his knowledge of antiquity, his work On the Wisdom of the Ancients bears witness, in which he explains the ancient fables by ingenious allegories. He possessed a less profound knowledge of mathematics, and to this it is to be ascribed, that he who so generally discovered the errors of the human mind, and pointed out the trutl, opposed the Copernican system. In this point alone he remained behind some enlightened men of his time. In other departments of human investigation, he soared to such a height, that his contemporarics could not fully estimate the extent of lis genius, the justness of his views, and the importance of his labours. He himself was his only judge, and, with a just pride, he says, in his will, "My name and memory I bequeath to foreign nations and to my owr countrymen, after some time be passed orer." Goethe says of B., "He drew a sponge over the table of luuman knowledge." The best edition of all lis works appeared in London, in 1765, in 5 vols. quarto. They are partly in English, partly in Latin. The Library of Useful Knowledge contains a popular treatise on the Novum Organum.

Bacon, John, a celebrated English sculptor, was born in Southwark, in 1740. Having been apprenticed, at the age of fourteen, to Mr Crispe of Bowchurch-yard, and employed in modelling and painting small porcelain ornaments for chimney pieces, his ambition was awakened by beholding the models sent by sculptors of eminence to be baked in his master's pottery-furnaces at Lambeth. $\mathrm{He}$, therefore, set himself about producing some works of art of a similar class, and such was his diligence, and so great his success, that he obtained not fewer than nine premiums from the society for the encouragement of arts. While yet an apprentice, he formed a project for making statues of artificial stone, which was afterwards perfected, and is still carried on in a manufactory in the New Road. About 1763, he began to work in marble; and shortly afterwards seeing the imperfection of the method then in use, he invented a new irstrument for transferring the form of the model to the marble (technically called, getting out the points), which instrument has been adopted since by other sculptors. And, indeed, when Canova came to London and saw it, he expressed his admiration of it, and regretted he had not known it at an earlier period of his life. In 1769, Bacon obtained from the Royal Academy the first gold medal given by that society, and the following year he was chosen an associate. Having produced and exhibited a statue of Mars, Dr Markham (afterwards archbishop of York) employed him to produce a bust of his Majesty, for Christ church college, Oxford. When employed in modelling this work, the king asked hin whether he had ever been abroad, and on Bacon answering in the negative, his majesty said that "he was glad to hear it, as he would then reflect the greater honour on his native land." Having obtained the royal patronage by this bust, he was employed to make a duplicate of it for the university of Gottingen. In 1777, he was commissioned to prepare the model of a mcnument in honour of Mr Guy, the founder of Guy's Hospital, which afterwards procured him the honour of executing that of lord Chatham, in Guildhall. The year following, he was chosen into the Royal Academy, and completed a beautiful monument to the memory of Mrs Draper, in Bristol cathedral. His other works are too numerous to be specified here, but the principal of them are two groupes for the interior of Somerset House, the statue of judge Blackstone, for All Souls .college, Oxford; anotlier of Heury VI. for Eton college; the monument of lord Chatham in Westminster Abbey, and the statues of Dr Johnson and Mr Howard, in St Paul's cathedral. Mr Bacon died, August 7, 1799, leaving two sons and three daughters, by his first, and three sons, by his second wife. His second son, John, who succeeded to a considerable part of the property, is also a distinguished artist, and has performed several great national works.

Bacon, Roger; an Fnglish monk, who, by the power of his genius, raised himself above his time, made astonishing discoveries in several sciences, and contributed much to the extension of real know- 
ledge. He was born in 1214, near Ilchester, in the county of Somerset, of an old and respectable family. Following the impulse of an inquisitive spirit, he overcame all the obstacles opposed to his progress by ignorance and superstition. IIe first eutered the university of Oxford, and went afterwards to that of Paris, then much frequented, where he distinguished hinself much by successful stmdy, anil received the degree of doctor of theology. In 1210, he returned to Fingland, where he entered the orler of Franciscans, and fixed his abode at Oxford. Natural philosophy seems then to have been the chief object of his lahours; but this study required expenditure beyoud his means. He met, however, with generous friends of science, whose contributions enabled him to purchase books, to prepare instruineuts, and to make the necessary experiments. In examining the secrets of uature, he made discoveries, and deduced results, which gained him the admiration of the enlightened, who comprehended their natural connexion; but which appeared so extraordinary to the ignoranh that they were believed to be works of magic. This opinion was countenanced by the jealousy and hatred of the monks of his fraternity. He himself loudly blamed the ignorance and corruption of the clergy, and in particular of the monks, and eren wrote a letter to the pope, representing the necessity of reform. In revenge, they denounced to the court of Rome his dangerous opinions and astonishing operations, which they attributed to the agency of the deril. The pope forbade him to teach at the university. He was soon afterwards thrown into prison, prevented from holding communication with any person, and even deprived of necessary food. Among the few enlightened individuals, who admired his genius and pitied his misfortunes, was the cardinal bishop of Sabina, papal legate in England, who no sooner ascended the papal chair, under the name of Clement $I V$., than he liberated him, and took him under his protection. Clement demanded a collection of all his works; upon which B. wrote that work, which was afterwards printed, under the title of Opus Majus, and sent it to him by his farourite disciple, John of Paris, in 1267. Under Clement's successor, Nicholas III., the general of the Franciscans, Hieronymus ab Fsculo, declared himself against B., forbade the reading of his writings, and issued an order for his imprisonment, which was confirmed by the pope. This new confinement lasted ten years; and when Hieronymus ab Esculo was elected pope, under the name of Nicholas $I V ., B$. vainly endeavoured to convince him of the innocence and utility of his labours, by sending him a treatise On the Means of avoiding the Infirmities of Old A ge. After the death of Nicholas IV., he regained his liberty by the intercession of some distinguished Eiglishmen, and returned to Oxford, where he wrote a Compendium of Theology, and died soon afterwards, acconding to some, in 1292, or, as others trink, in 1294.

Though an extrandinary man, B. could not entirely free himself from the prejudices of his time. He believed in the philosopher's stone, and in astrology. There are to be found in his writings new and ingenious views on optics, e. g., on the refraction of light, on the apparent magnitude of objects, on the magnified appearance of the sun and moon when in the horizon, \&c. He describes very exactly the nature and effects of convex and concave lenses, and speaks of their application to the purposes of reading, and of riewing distant objects, both terrestrial and telestial; and it is easy to prove from his writings, that he was either the inventor or improver of the telescope. He also gives descriptions of the camera sinewra, and of the burning-glass. He made, too, several chemical discoveries. In one place he spenks of an inextinguishable fire, which was probably 8 kind of phosphorus: in another, he says that an artificial fire could be prepared with saltpetre anc other ingredients, which would burn at the greatest distance, and by means of which thunder and lightning could be imitated: a portion of this mixture, of the size of an inch, properly prepared, would destroy a whole army, and even a city, with a tremendous explosion, accompanied by a brilliant light: and, in another place, he says decidedly, that thunder aud lightning could be initated by ineans of saltpetre, sulphur, and charcoal. Hence he had already an idea of gunpowder. He was so well versed in Greek and Ilebrew, and wrote Latin with such elegance and clearness, that his acquirements in these respects would alone secure him a high character. He was intimately acquainted with geography and astronomy, as appears by his discovery of the errors of the calendar, and their causes, and.by his proposals for correcting them, in which he approached very near to truth. He himself made a corrected calendar, of which there is a copy in the Bodleian library. Even in moral philosophy, B. has laid down some excellent precepts for the conduct of life, and is, in every respect, entitled to remembrance as a great philosopher and a wonderful man.

Bactrlana, or Bactria; one of the principal provinces of ancient Persia, and, before Cyrus, a powerful kingdom, the inhabitants of which were noted for bravery. On the north and east, it was bounded by one of the largest rivers of Asia, the Oxus, now Gihon; on the south, it stretched along the Paropamisus; oll the west, it reached Margiana. On account of its situation and fertility, it had made great progress in civilization at a very early period. "The Persians derived their mythology, religion, and architecture from Bactria. Bessus here declared himself sovereign of A sia, after the destruction of the Persian monarchy. It is to be regretted, that our knowledge of this country is but slight. Even the conpanions of Alexander give no particular account of it.

Badajoz, or Badajox (with the Romans, Pax Augusta); the fortified capital of the Spanish province Estremadura, on the left bank of the Guadiana, which is crossed by a stone bridge of twenty-two arches. B. lies not far from the Portuguese fromtiers, and has 14,000 inhabitants. Lon. $6^{\circ} 47^{\prime} \mathrm{W}$.; lat. $38^{\circ} 49^{\prime} \mathrm{N}$. ; eighty-two miles N. N. W. of Seville. B. contains a cannon foundery, and is a bishop's see. It was hesieged, in the wars with Napoleon, three times by the British. After the expulsion of Massena from Portugal, and his retreat through Estremadura, it was the chief object of the British general to take $B$., which the French had possessed from March 10, 1811, as well as Ciudad-Rodrigo and Almeida. After the capture of Olivenza (April 16,1811 ), Wellington caused $B$. to be invested; but, as Soult approached to its succour, he was obliged to raise the siege, May 14. After the battles of Fuentes d'Onor and Albufera, B. was besieged a second time, May 25; but, after several unsuccessful attacks, Wellington raised the siege, June 16, 1811. After the capture of Ciudad-Rodrigo (Jan. 19, 1812), Wellington commenced the third siege, March 17, with $16,000 \mathrm{men}$, and, on the 6 th of $\lambda$ pril, took the city by storm, after a sanguinary conflict. The garrison, together with the commander, general Philippon, were made prisoners. The besiegers lost seventytwo officers, and 963 men killed; 366 officers, and 3483 men wounded. - In the peace of B., concluded between Spain and Portugal, 6th June, 1801, Portygal promised to shut its harbours against the British. Spain retained Olivenza, and its territory along the Guadiana. See Portugal. 
BaDes, grand-duchy of; governed by a family of as the former grand-duke was careful to preserve princes, who derive their origin from Godfrey, a duke of the Alemanni, who defended his country till his death, in 709, against the attempts of the Franks. In 1801, the government devolved upon Charles Louis Frederic, who, in 1806, was married to Stephanie Louise Adrienne Napoleone, an adopted daughter of Napoleon. After his death, Dec. 8, 1818, as he left no male descendants, his uncle, Louis William Augusfus, became his successor, with the title of margrave.

Until the peace of Luneville, the territory of Baden contained 1631 square miles, with 210,000 inhabitants. At this peace, 169 square miles, with 25,000 inhabitants, were given up, and, on the other hand, 1270 square miles, with 245,000 inhabitants, were gained. May 1, 1803, the margrave received the dignity of elector. By the peace of Presburg, which restored Brisgau to Baden, and by her accession to the confederation of the Rhine, to which she owes the grand.ducal title, and the sovereignty of the greater part of the territory of the prince of Furstenberg, of the landgraviate of Clettgau, and of the principality of Leiningen, \&c., as well as by the excliange of lands with Wurtemberg, in 1810, which added to Baden almost 30,000 new subjects, the size of her territory has been enlarged to 5900 square miles, with $1,145,000$ inhabitants. This was the number of inhabitants in 1826 . In 1822, there were $1,090,910$, according to official papers, showing an increase at the rate of one and forty-eight hundredths aunually. The hereditary lands (Baden-Baden and Baden-Durlach) contain, exclusive of the territories ceded, 1080 square miles, with 217,381 inhabitants; and the whole of the acquisitions have been estimated at about 4450 square miles, with 750,000 inhabitants ; among which, however, some seigniories seem not to be comprehended. The grand-duchy contained, in 1819 , eight seigniories, comprising 1315 square miles, and 196,000 inhabitants, and a taxable capital of $139,306,000$ florins, besides eighty-one independent proprietors, with 635 square miles, 120,000 inhabitants, and 99,043,000 florins taxable capital. Setting these aside, there remain under the exclusive control of the sovereign, about 3800 square miles, with 690,000 inhabitants, and 535,531,000 florins taxable capital. The finance regulations for 1825,1826 , and 1827 , fixed the revenue of the state at $9,320,280$ florins, from which are to be deducted the expenses of the administration, 2,110,465 florins. According to the budget of 1820 , Baden had but $14,605,100$ florins of debts. After the battle of Leipsic, the grand-duke of Baden left the confederation of the Rhine, and, in 1815, joined the German confederation, in the diet of which he has the seventh place, and in the general assembly (plenum) three votes.

The country of Baden, one of the most fertile in Germany, extends to a great length, but with little width, along the Rhine, from its outlet from lake Constance to the confluence of the Neckar, and consists mostly of a fertile plain, with excellent cornfields and vineyards, washed on the west by the Rhine, and borlered on the east by the Oden-wald and the Black Forest, of both which mountains considerable parts belong to this grand-duchy, and contribute to its beautiful scenery, among which the charming Bergstrasse and the picturesque valley of the Murg are distinguished. The chief productions are grain, which is abundant, in particular, spelt, a great plenty of fruit (in the warm regions of the Bergstrasse, almonds, chestnuts, and walnuts are fcund), of which a great deal is exported, tobacco, madder, exccllent hemp, and good wines, many kinds of which are esteemed in foreign countries. The forests are likewise in an excellent condition, them, whilst other princes of Germany wasted thei woods. By means of mercantile societies, and the easy communication afforded by the rivers Murg, Kenzig, and Rhine, cousiderable commerce in wood has beel carried on between Baden, France, and Holland. The raising of cattle is extensively pursued in the regions of the Black Forest. In the mountains, minerals of various kinds are found, but there is a deficiency of salt. From the sands of the Rhine gold is washed, of which Baden, in former times, coined ducats, bearing the inscription, Sic fulgent litora Rheni. The manufactures are limited. They employ about 10,000 persons. Most of them are in Manheim, Pforzheim, and Carlsruhe. The manufactures of jewelry, of toys, and trinkets, at Pforzheim, of which there are, at present, twenty-one, producing annually wares to the amount of 600,000 fiorins, ar'e generally known. A peculiar branch of industry, among the inlabitants of the Black Forest, is the making of wooden clocks. This business employs about 700 workmen, who furnish annually above 100,000 clocks, which are sold all over Europe and in America. The exports of the country, however, consist rather of its natural productions than of its manufactures, and are easily transported along its good roads, and the navigable rivers Rhine, Neckar, and Maine. On account of its situation between Germany, France, and Switzerland, Baden derives much advantage from its carrying trade. The majority of the inhabitants are of the Catholic church, though the grand.duke is a Lutheran. For the instruction of the Protestant youth, and for the country schools, which are everywhere established, teachers are educated in the seminary at Carlsruhe. Provision is made for the promotion of learning by the Latin schools, academies, and gymnasiums, and by the universities of Heidelberg and Freiberg. On the $3 \mathrm{~d}$ of May, 1819, the grand-duke established the following division of the state: the capital, Carlsruhe, belongs to no circle, but is iumediately subject tc the minister of the interior; the rest of the state is divided into six circles. Since that time, in consequence of the convention with Bavaria and Austria (Prankfort, July 10, 1819), the Austrian county Hohengeroldseck (near the Black Forest, containing 52 square miles and 4500 inhabitants, and yielding a revenue of 34,000 florins) has been incorporated with Baden, for which she gave up to Austria a proportional part of Wertheim.

The grand-duchy of Baden anciently enjoyed, like almost all the countries of Europe, a constitution in which the estates were represented. This was, however, finally lost, like the constitutions of most of the other states. After the middle of the 17th century, the dukes of Baden were absolute, till the reigning grand-duke, in 1818, bestowed on his subjects a constitution, proceeding, like the French, from the prince alone (constitution octroyé), and not consisting of a compact between the people and the prince, like the English constitution, or that of Wurtemberg. The legislature of Baden now consists of two chambers. To the first one belong, besides the peers, eight deputies of the nobility, one deputy of each of the universities of Baden, the Catholic bishop, and a Protestant prelate; and the grand duke can besides nominate eight members, without reference to their birth or station. Accordingly, the first cliamber may consist of twenty-eight members. The second chanber consists of sixty-three deputies; one for about 16,000 souls. Every citizen and officer of government may partake in the elections. $\Lambda$ deputy must possess either a taxable property of 10,000 florins, or some office which gives him an income of at least 1500 forius. In 1819 , the cliambers assembled for

$$
3 A-B 2
$$


the first time, but were dissolved July 28 , becanse they could not agree with each other or with the ministry. In 18:0, they were assembled again, and, though the dissensions had by no means subsided, they agreed on some important measures-the abolition of the remains of bund-service, the responsibility of ministers, \&.c. The discussions have been pub. lished by each of the chambers, at Carlsruhe.

B.ıDE (a German word signifying bathing); the name of three cities famons for their batlss.

1. Baten in Surbia, witlı 418 houses and 3200 inhabitants (Civitas Aurelia aquensis of the Romans), in later times, during 600 years, the residence of the margrave of Baden, situated in a charming vale, about two leagues from the river Rhine. The castle affords, from all sides, the most splendid prospects. It contains a number of subterranean vaults, which, accorling to tradition, served as a seat of the secret court of criminal justice, called the Feme. 'They were probably made by the Romans. The hall of antiquities (museum palao-technicum) contains Roman monuments, which have been found in the vicinity. The college church of the Jesuits is distinguished by the sepulclires of the margraves. It has six altar-pieces, painted by Lill, after Guido Reni. Baden has twenty-six mineral springs, the principal of which has a temperature of $130^{\circ}$ Fahrenheit, and affords, in twenty-four hours, 7,345,410 cubic inches of water. The rock from which it issues is even now covered in part with marble of Carrara, and was probably a Roman bath. In the former bath for the poor, there are also remains of Roman baths. In the Hollenquelle (hell-spring), of $144^{\circ}$ Falirenlieit, meat is cooked. There is a bath for the poor kept in good onler before the Geresbach gate.

2. Baden in Lower Austria, with 400 houses and 2100 inhabitants. Its situation, on rocky hills of limestone, is beautiful. Near the park of the bath of Theresa, with its beautiful alleys, is the lime-rock from which the medicinal spring bubbles out. The temperature of the baths is $92^{\circ}-97^{\circ}$ Fahrenheit. The hottest of them are the Ursprung, the Ladies' bath, and Joseph's bath. There are tirelve in all. They are built in such a way, that each of them can contain from forty to a liundred and fifty persons. Whoever wishes to bathe in private, can do so at a particular hour. The common bath, however, is preferred. On mount Calvary there are vapourbaths. The cave at the Ursprung is noted for a salt cleposited on its base, which is called salt of Baden. The number of foreigners, who annually visit Baden, is estimated to be from 7000 to 8000 .

3. Baden in Switzerland, in the canton Aargau, on the Limmat, is a very pleasant country. The Romans here founded a city, on account of the medicinal waters, and built a castle at a place where now stands the city. In later times, the assemblies of the representatives of the Swiss federation were held here till 1712.

BADEv, peace of, concluded between Germany and France, Sept. 7, 1714. See Rastadt.

BADEN-BADEV (Louis William I.), Margrave of; grandson of the margrave William I. of Baden-Baden; born at Paris, April 8, 1655, where Louis XIV. was his godfather. The princess of Carignano, his mother, wished to educate him at Paris, but his father and grandfather secretly took him away, when he was but three months old, that he might pass his chlldhood among the people whom he was destined to govern. He served his first campaign under Montecuculi, against Turenne in Alsace, where this great general fell. The prince of Baden was ordered to harass the retreat of the French army, which he did with success till Condé took the command. Montecuculi gave in his resignation, and the duke of Lor- maine succeeded him. Louis served under this general until the pence of Nimeguen, when he returned, in 1678 , to his margraviate. When the war between Anstria and Turkey broke out, he threw himself, with a body of troops, into Vienna, which was besieged by the Turks. The duke of Lorraine, and the king of Poland, Sobieski, came to the relief of this capital, and Louis effected a junction with them by a vigorous sally. The city was relieved, the Turks retired in disorder, and Louis gained several victories. He subsequently received the command in chief of the imperial army on the Danube, and defeated the Turks, Sept. 24, 1059, at Nissa, and Aug. 19, 1691, at Salenkemen. In 1693, he was entrusted with the command of the imperial army in Germany, against the French; he retook Heidelberg, and afterwards visited England to concert with king William the plan of operations against France. He opened the campaign in the spring of 1694 , invaded Alsace, baffled the vigilance of the duke of Lorges, and showed the greatest activity, though he suffered violently from the gout. When the thirone of Poland was vacant by the death of Sobieski, in 1697, he was among the competitors for the crown; but Frederic Augustus 11., elector of Saxony, gained the prize, and the margrave returner, after the peace of Ryswick, into his own country. When the Spanish war of succession broke out, he commanded the imperial army, and, in 1702, took Landau, notwithstanding its valiant resistance. In 1703, he showed his talents in the art of fortification, by laying out the famous lines of Stollhofen, which extended from the Black Forest, througi Bulıl, to Stollhofen and the Rluine. Yet the fortune of war proved at last less favourable to hun, of which his excessive caution, owing to his bad health, and the poor condition of the army of the empire, were the causes. He was one of the greatest generals of his time, and was never really defeated. After having made twenty-six campaigns, commanded at twentyfive sieges, and fought thirteen battles, he died at Rastadt, Jan. 4, 1707.

BADENOCH ; a mountainous district in Invernes:shire, 33 miles in length, and 27 in breadch. It is watered by the river Spey, several extensive lochs, and a few rivulets. Much' of the surface is covercd with forests of natural growth, abounding with game. Between Spey bridge and Pitmain are the remains of a Roman camp adjacent to which have been found a tripod, also an urn containing ashes. Badenoch gave title of baron to the Cumyns, which was forfeited in 1306. The population of the district is small.

B.dEss, Francis ; an historical and portrait painter, born at Antwerp in 1751. He was highly esteemed. 'The news of his brother having been assassinated caused his death in 1803 .

BADGER (meles, Briss.); a genus of mammiferous quadrupeds, belonging to the plantigrade tribe, which place the soles of the hinder feet on the ground in walking. The head of the animals pertainiug to this genus is very similar to some of the smaller varieties of dogs, having a moderately elongated snout, small eyes, and short, rounded ears. The teeth bear a considerable resemblance, in figure and arrangement, to those of the bear, to which genus that of the badger is closely allied. The body is large, supported on short, stout legs, and the paws are enveloped by the integument so as to leave but a small part free, and are provided with long, curved claws, especially adapted for burrowing. The motions of the badger are slow, and the belly appears to be trajled along the ground, although the length of hair on the inferior part of the body makes this trailing apprar greater than it really is. Possessing a considerable 
strength of limb, and claws especially suited for the purpose, the badger excavates a long and winding cavern, at the extremity of which it sleeps securely during the day-time. At night, it comes out to seek for its food, which consists either of vegetables, insects, or small birds, \&c. $\rightarrow$ a regimen which shows the similarity of this genus to the bear as much as its general resemblance of structure. When attacked by dogs or other enemies, the badger defends itself with great resolntion, and inflicts many severe wounds on the aggressors before it is finally vanquished. It is, therefore, often cruelly made sport of by dogfanciers, who place it in a long box, and set their favourites to draw it out. Foxes often drive out the badger from his den, and enlarge it for their own use. On the whole, the badger is a harmless creature, seldom seen unless hunted for, and doing very little injury, except when greatly multiplied. The female brings forth three or four at a litter.

Only two species of the badger are knowzi, the European (M. vulgaris) and American (M. Labradovia). The European badger has a broad, white stripe from its forehead down to the nose; and a longitudinal black stripe begins between the eye and snout, on each side, dilating as it goes backward, until it includes the eye and the ear, behind which it terminates. The hair covering the body is tarsh, long, scattered, and of three colours, white, black, and red, differing in the proportion of these tints in different parts. Black is the predominant colour on the inferior parts of the body. -The American badger is only found in the remote western territories of the United States, and in some parts of the British possessions in America. It is very different from the European in physiognomy, having a forehead projecting considerably above the root of the nose, which, in the European species, forms a continuaus line with the forehead, and in having a longer tail, covered with long hair, reaching almost to the ground when the animal is walking. The tail of the European badger is not more than half the length of the legs. The colour of the American badger is chiefly grayish, and lighter than that of the European. The weight of the American species is from 14 to 18 pounds.

BADla, Domingo ; a Spanish traveller, who, under singular circumstances, visited, in 1803 and the four following years, the Mohammedan countries bordering on the Mediterranean. During the whole of his tour, he professed to be a Mussulman, which character he had qualified himself to support, by submitting to circumcision. He travelled under the denomination of Ali Bey el Abbassi, which style he also assumed in his travels, published in French at Paris, by Didot, in 1814, 2 vols. 8 vo; and about the same time in English at London. It is now admitted that he was employed as a political agent by the prince of peace, at the instigation of Napoleon. His peculiar situation and religious profession gave him opportunities for making many observations which could not occur to other travellers; and his volumes are curious and interesting, though rather tinctured with an air of exaggeration, somewhat excusable in a person placed in such extraordinary circunistances. Burckhardt, another Oriental travelter, who heard of Ali Bey at Aleppo, gives the following account of him : "He called himself $A l i B e y$, and professed to be born of 'Tunisian parents in Spain, and to have received his education in that colintry. Spanish appears to be his native language, besides which he spoke French, a little Italian, and the Moggraleyau dialect of Arabic, but badly. He came to Aleppo by the way of Cairo, Yaffa, and Damascus, with the strongest letters of recommendation from the Spanish government to all its agents, and an open credit upon them.
He seemed to be a particular friend of the prince of peace, for whom he was collecting antiques; and, from the manner in which it was known that he was afterwards received by the Spanish ambassador, at his arrival in Constantinople, he must have been a man of distinction. The description of his figure, and what is related of his travels, called to my recollection the Spaniard Badia, and his miniature in your library. He was a man of middling size, long, thin head, black eyes, large nose, long black beard, and feet that indicated the former wearing of tight shoes. He professed to have travelled in Barbary, to have crossed the Lybian desert, between Barbary and Egypt, and, from Cairo, to have gone to Mecca and back. He travelled with Eastern magnificence, but here he was rather shy of showing himself out of doors : he never walked out but ou Fridays, to the prayers of noon in the great mosque. One of the before-mentioned dervishes told me that there had been a great deal of talking about this Ali Bey at Damascus and Hamar : they suspected him of being a Christian; but his great liberality, and the pressing letters which he brought to all people of consequence, stopped all further inquiry. He was busily employed in arranging and putting in order his journal during the two months of his stay at Aleppo." This traveller died in his native ccuntry, some time after his return to Europe.

BAERT, Jean; also BARTH; born at Dunkirk, 1651 ; the son of a poor fisherman; according to some, a native of the parish of Corban, in the district of Munster, and the canton of Berne, where his family lives at present. He raised himself, under Louis XIV., to the rank of commodore. The Dutch, English, and Spanish called him the French devil. 'The marine of Louis XIV. owed principally to this rough mariner the respect which it enjoyed from other nations. B. happening to be at Versailles, the monarch said to him, "Jean Baert, I lave made you a commodore." "Sire, then you have done well," answer. ed the mariner. The courtiers laughed; but Louis told them, "This is the answer of a man who feels his own worth." B. brought into port a number of Dutch and English vessels, burned others, landed at Newcastle, and laid waste the neighbouring country. In 1692, with a fleet of three sail, he met the Dutch fleet, loaded with corn from the Baltic, put to flight the escort, and took sixteen merchantmen. In 1694, when there was a scarcity of corn in France, he succeeded several times, notwithstanding the watchfulness of the English, in bringing into the harbour of Dunkirk ships loaded with this article. Once he delivered a number of such vessels, in the boldest manner, from the Dutch, into whose handis they had fallen, and received, in consequence, letters of nobility. After having passed the English, in 3696, who blockaded the harbour with a fleet three times as strong as his own, he met the Dutch fleet, from the Baltic, consisting of 110 sail, and convoyed by five frigates. The escort, with forty ships, soon fell into the hands of the French; but, on his return to Dunkirk, thirteen Dutch ships of the line appeared, and, to avoid a very unequal combat, he was obliged to burn the greater part of his captures. The peace of Ryswick put a stop to the deeds of this valiant officer. IJ spent the last years of his life at Dunkirk, and died there in 1702 .

Bafriv, William ; an English navigator of the 17th century, famons for his discoveries in the Arctic regions. He visiterl West Greenland in 1612, again in 1615, and made a voyage to Spitzbergen in 1614. In 1623 and 1624 he ascertained the limits of that vast inlet of the sea, since distinguished by the appellation of Brffin's Bay. The time of his death is not recoriled. 
BAfriv's B.AY ; the largest and inost northern gulf on the eastern coast of North America; between $70^{\circ}$ and $80^{\circ} \mathrm{N}$. lat.; discovered by I3affin, in 1616. This gulf flows through Baftin's and Davis's struits, be tween cape Chidley, on the const of Labrador, and cape Farewell, on the coast of West Greenland, into the Atlantic. On the south-west side of Davis's strait, Baffin's bay is separnted by a mass of islands from Indson's bay, which abounds with whales, From Baftu's bay captain Parry started, in 1819, in search of the north-west passage.-See North Pole, cxpeditions to.

BAGUAD; capital of a Turkish pachalic of the same name, in the southern part of Mesopotamia, or Al-Dschezira, now Irak Arabi, containing about 70,000 square miles, and 650,000 inhabitants; $4^{\circ}$ $25^{\prime} \mathrm{E}$. lon., and $33^{\circ} 20 \mathrm{~N}$. lat. The greater part of it lies on the eastern bank of the Tigris, which is crossed by a bridge of boats, 620 feet long. The old $B$. the residence of the caliphs, with $2,000,000$ inhabitants, now in ruins, was situated on the western bnuk of the river. The modern city is surrounded with a brick wall, about six miles in circuit, and with a ditch from five to six fathoms deep, which may be filled with water from the Tigris; but the cannon on the numerous towers are old, and unfit for use. The castle commands the Tigris, and contains an arsenal, but is untenable. The houses, mostly built of brick, are but one story high, the streets unpaved, and so narrow, that two horsemen can scarcely ride abreast. The houses of the wealthy are distinguished by a better architecture. The palace of the governor is spacious, and magnificently furnished. The public baths and the coffee-houses of the city, though in a bad condition, are much frequented. The inarkets affurd an abundance of provisions, at a low price. B. is an important mart for Arabian, Indian, and Persian productions, as well as for European manufactures. A splendid view is afforded by the bazars, with their 1200 shops filled with all kinds of Oriental goods. The chief manufactures of the city are, red and yellow leather, much esteemed, and silk, cotton, and woollen cloths. With the aid of the British and Persians, the pacha has established a cannon foundery. B. supplies Asia Minor, Syria, and a part of Europe, with Fast Indian goods, which are im. ported to Bassora, ascend the Tigris in boats, and are carried by caravans to Tokat, Constantinople, Alleppn, Damascus, and the western parts of Persia. There is also some trade in jewels. A British packet runs between Bagdad and Bassora. A mul-

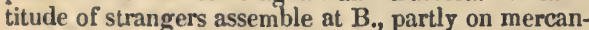
tile business, partly to visit the sepulchres of the saints, among which is that of the prophet Ezekiel. The heat of the summer obliges the inhabitants to shelter themselves in subterranean chambers; but the winter is cold enough to make a fire necessary. The city is, nevertheless, agreeable, healthy, and free from vestilential diseases; but the inhabitants frequently suffer from cutaneous disorders. B. is inhabited by Turks, Persians, Armenians, Jews, and a small number of Christians. The Turks compose three-fourths of the whole population. The Jews are confined to a secluded district of the city, and are in a very oppressed condition. Inclusive of the Arabs, IIindoos, Afghans, and Egyptians, who are accustomed to reside here, the population may amount to 80,000 . The Persians, under the particular protection of the government, enjoy a very extensive trade, and are renowned for honesty, prudence, and integrity. The higher classes are more civil and attentive to strangers than is usually the case with Mohammedans. On the other hand, the lower classes are infected with the prevailing vices of the East. The people are bold, enterprising, and turbulent.
Bagdad was begun, in 762, by the caliph $\mathrm{Abu}$ Giafar-Almanzor, finisled in four years, and raised to a high degree of splendour, in the ninth century, by Haroun Alraschid; but, 100 years after, it was destroyed by the Turks. In the 13th century, it was stormed by IIolagou, grandson of Zingis-Khan, who caused the reigning caliph to be slain, and destroyed the caliphate. The descendants of the conqueror were expelled, in 1392, by 'Tamerlane (q. v.), ind, in 1412 , by Kara-Yusef. In the following century, Shah Ismael, the first sovereigu of Persia of the house of Sofi, tonk possession of the city. From that time it was a perpetual subject of contest in the wars between the Turks and Persians. After a memorable siege, in 1638, it was conquered by the Turkish emperor Amurath IV., and Nadir Shah endeavoured in vain, in the 18 th century, to wrest it from the 'Turks.

BAGE, Robert, an ingenious English novelist, was born at Derby, in 1728; died at Tamworth, in 1801. During the greater part of his life, he followed the occupation of paper maker. The titles of his works are, "Mount Henneth," "Barham Downs," "The Fair Syrian," "James Wallace," "Man as he is," and "Hermsprong, or Man as he is not."

BAGgesen, Jens (the Danish for Emanuel), a Danish poet, who also wrote much in German, was born leb. 15,1764 , at Corsor. He has given the history of his education, and described the influences which determined his character, in the Labyrinth. In 1785, he displayed, in his Comic Tales, his humour and power as an author. The prince of Holstein-Augustenburg enabled him to travel through Germany, France, and Switzerland. In 1793, he visited Italy. He afterwards received from the Danish government an appointment in Copenhagen. In 1800 , he went with his wife, a niece of the famous Haller, to reside at Paris. In 1811, he was appointed professor of the Danish language at Kiel, and, in 1814, resigned his office, and went to reside in Copenhagen. At this time, his poetical fame reached its lighliest point. He again left Denmark, and died suddenly at Dresden, Oct. 3,1826 . His best productions are his smaller poems and songs, several of which are very popular with his countrymen. His Seasons, in Danish, are much esteemed. In 1827, a humorous poem of his, Adam and Eve, in German, was published at Leipsic.

Bagno (Italian, a bath). This name is particu. larly given to that place, near Galata, in the suburlss of Constantinople, where slaves are kept. There are one Greek and two Catholic churches for the use of the slaves.-Inclosures for slaves, in T'urkey and Barbary, are, in general, called bagnios.

BAGPIPE; a well-known wind instrument, of high antiquity among the northern nations, which has so long been a favourite with the natives of the Higllands of Scotland, that it may be considered as their national instrument. The peculiarity of the bagpipe consists in collecting the air into a leathern bag, from which it is forcibly pressed into the pipes by the arm of the performer. The chanter, into which is inserted a reed for the production of the sounds by the action of the air from the bag, is perforated with holes like the German flute, which are stopped with the fingers. The other parts of the instrument are three tubes or drones, which are also furnished with reeds. Two of the drones are in unison with $D$ on the clianter, which corresponds with the lowest note of the German flute. The third drone, which is the longest, is an octave lower. The tuning of the bagpipe is accomplished by lengthening or shortening the tubes or drones, as may be required. The Highland bagpipe is a powerful instrument, and calls for great esertion of the lungs. The Irish bagpipe is smaller, softer in its notes, and is always played with bellows. It is not known when the bagpipe first found its way 
into Scotland, but it is probable that the Norwegians and Danes first introduced it into the Hebrides, which islands they long possessed. The bagpipe is indeed of very ancient origin, as representations of it are to be found on Grecian and Roman sculptures. In Rome, to this day, at the time of Advent, the peasants of the mountains play on the bagpipes before the images of the Virgin. The music is very simple and sweet; and every traveller remembers it with delight.

Bahaslas, or Locaya IsLaNds ; in the Atlantic, near the east coast of North America. There are a great number of these islands, some say 500 ; but many of them are mere rocks, and others, on account of the difficulty of the navigation, little known. The principal are, Bahama, Eleuthera, Abaco, Yuma, or Exuma, and Providence. They are, in general, fertile, with a soil similar to South Carolina. Lon. $73^{\circ}$ to $81^{\circ} \mathrm{W}$.; lat. $22^{\circ}$ to $27^{\circ} \mathrm{N}$. These islands, in 1773, contained 2,052 whites, and 2,241 blacks; and, in $1803,14,318$, including 11,395 blacks and people of colour. The inhabitants are of two descriptions, the residents and the wreckers. The residents are chiefly loyalists, and their descendants, who emigrated from Carolina and Georgia, at the close of the American war. The wreckers are constantly employed in the business of rescuing shipwrecked vessels, with their crews and cargoes, from the waves. They sail in small, flat bottomed sloops, just fitted for the seas which they navigate. They are excellent sailors; are familiar with all the keys, shoals, and breakers; and, with alacrity and courage, encounter any danger or hardship. They are licensed by the governor, and receive sal vage on all property rescued from the waves. By day they are always cruising; at night, they usually put into the nearest harbour. Their great places of rendezvous are, the Florida gulf, the Hole in the Wall, and the Hogsties. The number of these vessels is very great, 40 sail being sometimes seen in one inlet. These islands are heaps of limestone and shells, covered with vegetable mould. The keys are chiefly rocky and sandy: on some of them a few trees are found. All the large islands that front directly upon the Atlantic stretch from south-east to north-west, and the ridge of each is in the same direction. The soil of all the islands is a thin, but rich, regetable mould. It yields, for a few years, luxuriantly but is soon exhausted. The chief production is cotton.

The first discovery of these islands was made by Columbus, Oct. 12, 1492, when he fell in with Guanahani. New Providence, one of the largest of the group, was discovered on the 17th of the same month. In 1667, Charles II. of England granted all the Bahamas to the duke of Albemarle and the other proprietors of Carolina. Five years after this grant, the first settlement was made on New Providence. For many years, the inhabitants suffered severely from the depredations of pirates and of their Spanish neighbours. The celebrated Black Beard, or John Tench, was the leader of the buccaneers. He was killed off the cuast of North Carolina, in November, 1718. The islands were soon afterwards abandoned by the pirates, and a permanent settlement made at Nassau, in New Providence under governor Rogers. The town was fortified in 1740. Farly in the American war, it was taken by the Americans, but speedily abandoned. The Spaniards took it again in 1781, but the British soon repossessed themselves of it. Since that period, all the islands have continued under their jurisdiction.

Bahuma; the clief of the Bahama islands, which gives its name to the whole; sixty-three miles long, and about nine wide; fifty-seven miles from the coast of East Florida; Ion. $78^{\circ} 10^{\prime}$ to $80^{\circ} 24^{\prime} \mathrm{W}$.; lat. $26^{\circ} 40^{\prime}$ to $2 \%^{\circ} 5^{\prime} \mathrm{N}$. Though this island is well watered, the soil fertile, and the air serene, yet it is inhabited only by a few people, who subsist by seliing necessaries to ships, which the currents drive on their coasts. It formerly produced guaiacum, sarsaparilla, and red-wood; all which the Spaniards are said to have destroyed.

Bazar (more properly Bihar, from the Sanscrit $V$ ihar, a Budd'hish monastery); the second province of the British dominions in India; bounded E. by Bengal, N. by Nepal and Morung, S. by Orissa, and W. by Oude and Allabahad; lon. between $84^{\circ}$ and $88^{\circ} \mathrm{E}$. ; lat. between $22^{\circ}$ and $27^{\circ} \mathrm{N}$. The population is estimated at 5,800,000; three Hindoos to one Mohammedan. B. contains 51,973 square miles, of which about 26,000 are plain arable ground. It is one of the most fertile, highly-cultivated, and populous countries of Hindostan, producing grain, sugar tobacco, cotton, rice, opium, betel, saltpetre, timber, \&c. It is now divided into seven collectorships. The climate of $\mathrm{B}$. is more temperate than that of Bengal. The Ganges, the Soane, the Gunduck, the Dummoodah, Caramnassa, and the Dewah are the most remarkable of its rivers. The chief towns are Patna, Monghyr, Buxa, Rotas, Guyah, Dinapoor, and Boglipoor. The inhabitants excel the Bengalese both in strength and stature.-Bahar Proper is one of the seven districts into which $B$. is divided. Square miles, 6680.-Bahar, the capital of this district, 220 miles N. W. Calcutta, lon. $85^{\circ} 45^{\prime} \mathrm{E}$., lat. $25^{\circ} 14^{\prime} \mathrm{N}$., is remarkable for the number of magnificent funeral monuments which it contains.

BAHAR, or BARRE; weights used in several places in the East Indies. They have been distinguished as the great bahar, with which are weighed pepper, cloves, nutmegs, ginger, \&c., and the little bahar, with which are weighed quicksilver, vermilion, ivory, silk, \&c. But this weight varies much in different parts of the East.

The bahar of Acheen, in Sumatra, consists of 100 cattees, and is $=490$ lbs. avoirdu pois.

of Betlefackee, in Arabia, consists of 40 farcels, is $=81$ s lbs. avoird upois.

c of Bencoolen $=560$ lbs. avoirdupois.

s of Junkseylon $=8$ capins, $=455 \mathrm{lbs} .50 \mathrm{oz} .5 \frac{2}{2} \mathrm{dr}$. avoirdupois.

"6 of Malacca $=3$ pecals, $=405$ lbs. avoirdupois. of $M \circ$ cha $=15$ franks, $=\mathbf{4 4 5}$ lbs. avoirdupois.

Baн1А, formerly St Salvador, till 1771 the capital of Brazil, is situated on the bay of All Saints, in $12^{\circ} 59^{\prime} \mathrm{S}$. lat., and $37^{\circ} 23^{\prime} \mathrm{W}$. lon. It is strong by nature, and is also fortified. It has 13,000 houses, and about 100,000 inhabitants, among whom are 40,000 whites: the rest are mulattoes and negroes. It is the seat of an archbishop, and contains a university; has a very healthy climate, as well as one of the best harbours in Brazil; carries on an active trade with the United States and Furope, and pursues the whale-fishery near the south pole. The exports are the productions of the tropics-Brazil-wood, spices, southern fruits, rice, tapioca, cattle, sugar, tobacco, cotton, and coffee (cheaper than that of Rio Janeiro, but inferior, because the soil is too rich for the coffee-tree). Gold and diamonds are also secretly exported.-The government of this name $(54,649$ square miles, 560,000 inhabitants), on the river San Francesco, is crossed, from north to sauth, by the mountains Erio and Champado. It las its name from the bay on which the capital, described above, is situated. Sugar and coffee are raised here in large quantities, and the soil is esteemed the best in Brazil for the growth of the sugar-cane.

BanRd, Charles Frederic, a German theologian, born in 1741, at Bischofswerda, in Saxony, studied in Schulpforte and Leipsic. He was endowed with 
great talents, and made hiunself known very early, but was probably spoiled by this very success. In 1762, he was appointed professor in the university of Leipsic. His works and his talents as a preacher procured him many admirers, but, in consequence of an irregularity, he was obliged to quit that city in 1708. From this time he led an unsettled life. He was successively professor of theology and preacher in Erfurt (where he was made doctor of thcology), in Giessen, Switzerland, and in Turkhein, but was obliged to leave each of these places, on account of his severe attacks on the clergy, and the heterodox views manifested in hiswritings and sermons, as well as on account of his irregular life. The aulic council declared him disqualified to preach or to publish, unless he would revoke the religious principles advanced in his works. At length he found an asylum in the Prussian dominions. In 1779, he went to Halle, where he published his Creed. It is thoroughly deistical, denying the miracles, and not insisting on the immortality of the soul. He lectured in Halle, but soon became involved in difficulties with the clergy; upon which he left the city, and established, in a neighbouring vineyard, a public louse, where he had many customers. But two works which he wrote against the Religious Edict (a miserable law, issued under the late king of Prussia, a man who was gorerned by mistresses, and bclieved in apparitions), in one of which he proposed a union of all religions, made him suspected. He was condemned, and confined in the fortress of Magdeburg. Here he wrote his life. At the end of a year, he again opened his public house at Halle, and died in 1792. B. wrote and spokc with ease and fluency, but his works, even the most learned of them, are wanting in thorough knowlcdge; yet they have certsinly had some influence.

\section{Baladerr. See Bayadeer.}

Bas.e. This Campanian Brighton (Nullus in orbe simus Bajis pralucet amænis, Horace), once the place where the wealthy Romans had their country-seats, the favourite abode of the Ambubaix and the Balatrones, is now deserted, and intcresting to the stranger only for the ruins of old baths, which are shown as temples, and for the remains of former palaces, visible beneath the waves of the sea. B. owes its fame to its hot baths, and its situation on a most charming bay, secured, by surrounding hills, from the violence of the winds. "Even before the time of Casar," says Wieland, in his remarks on the 15th epistle of the first book of Horace, "Baire was the place where the rich Romans thought themselves entitled to lay aside the restraint of republican hypocrisy, and to give themselves up, without shame, to the pleasures and roluptuousness which brought this charming place into such ill repute, that Propertius was impatient to call his mistress away from it, and Cicero, in his defence of the young M. Coelius, thought it necessary to apologize for defending a man who had lired at Baiæ." Its insalubrity, of which there are intimations even in the letters of Cicero, may have been occasioned partly by the vapours of its hot springs, but is now increased by the desertion of the country, and the stagnation of the ditches used for steeping flax. Yet the charm of its situation still survives, though only single fishing-boats are seen on its bay, to call to mind the fleets, which starting from the Julian and Misenian lakes, passed by the islands, within sight of Puzzuoli.

BaIKaL; a lake or inland sea in Siberia, 360 miles long, from S. W. to N. E., and from 20 to 53 in breadth, interspersed with islands; lon. $104^{\circ}$ to $110^{\circ}$, E. ; lat. $51^{\circ} 20^{\prime}$ to $55^{\circ} 20^{\circ} \mathrm{N}$. It contains many fish, particularly sturgeons, pikes, and seals. In the enviroas are sereral sulphurous springs, and in one part, near the month of the river Barguzin, it discharges a kind of pitch, which the inlabitants purify. The water is sweet, transparent, and appenrs, at a distance, green, like the sea. It receives the waters of the Upper Augara, Selinga, Barguzin, and other rivers; but the Lower Augara is the only one by which it seems to discharge its waters. Nothing can be conceived more interesting and magnificent than this lake. Those who have visited it seem at a loss for language adequate to describe the feelings which it excites when first beheld. It is enclosed by rugged mountains, and the sublime scenery around strikes every beholder with astonishment and awe. At some seasons, it is so agitated by violent storns, that, in the tremendous roaring of its billows, it equals the mighty ocean, while at others, the clearness of its unruffled bosom emulates the lustre of the finest mirror.

Barl is, in one of its senses, the delivery of a person to another for keeping, and is used in reference to one arrested, or committed to prison, upon either a civil or criminal process; and he is said to be bailed, when he is delivered to another, who becomes his surcty in bonds (to a greater or less anount, according to the amount of the dcmand for which he is sued, or the hcinousness of the crime with which lie is charged), for his appearance at court tn take his trial. Bail is either common or special ; the former being merely fictitious, whereby nominal sureties, as John Doe and Richard Roe, are feigned to be answerable for the defendant's appearance at the court to which he is cited. Spccial bail is that of an actual surety.

Bailipr. In the court of the Greek emperors there was a grand bajulos, first tutor of the emperor's children. The superintendent of foreign merchants seems also to have been called bajulos, and, as he was appointed by the Venetians, this title (balio) was transferred to the Venetian ambassador. Froul Greece, the official bajulos (ballivus, bailli, in France ; bailiff, in England), was introduced into the south of Furope, and denoted a superintendent: hence tho eight ballivi of the knights of St John, which constitute its supreme council. In France, the royal bailiffs were commanders of the militia, administrators or stewards of the domains, and judges of their districts. In the course of time, only the first duty remained to the bailiff; hence he was called bailli d'épét, and laws were administered in his name by a lawyer, as his deputy, lieutenant de robe. 'The seigniories, with which high courts were connected, employed bailiff, who thus constituted, almost every where, the lowest order of judges. From the courts of the nobility, the appellation passed to the royal courts; from thence to the parliaments. In the greater bailiwicks of cities of importance, Henry II. established a collegial constitution, under the name of presidial courts. As all offices of justice could be purchased, and, in the lower courts, no examination was required (only the counsellors in the presidial courts were to be twenty-five years of age, licentiates of law, and be examined by the chancellors), and as the bailinicks were generally very small, this kind of jurisdiction fell into great contempt. The baillis had become a standing subject of ridicule on the stage, for their ignorance, their ridiculous presumption, their deceit and injustice. The royal bailiwicks, therefore, by an order of Sept. 1, 1770, were reform. ed; the jurisdiction of the nobles was first abolished by the laws of Aug. 4, 1789, and supplied by the district courts, tribunaux de première instance.

The name of bailiff was introduced into Englankl with William I. The counties was also called bailiwicks (balliva), while the subdivisions were called hundreds; but. as the courts of the hundreds hare 
loug since ceased, the English bailiffs are only a kind of subordinate officers of justice, like the French huissiers. Every sheriff has some of them under lim, for whom he is answerable. In some cities, the highest municipal oflicer yet bears this name, as the high bailiff of Westminster. In London, the lord mayor is at the same time bailiff (which title he bore before the present became usual), and administers, in this quality, the criminal jurisdiction of the city, in the court of Old Bailey, where there are, anuually, eight sittings of the court, for the city of London and the county of Middlesex. Usually, the recorder of London supplies his place as judge.-In some instances, the term bailiff, in England, is applied to the chief magistrates of towns, or to the commanders of particular castles, as that of Dover.

The term baillie, in Scotland, is applied to a magistrate of a burgh, having powers very similar to those of a justice of peace.

Among the Teutonic order of knights, and in the German division of the knights of St John, the dominions of the order, and with them the knights, were divided into districts (bailiwicks), over each of which a commander presided. The single houses of the order were called commanderies.

B Allue, Matthew, M. D.; an eminent physician and anatomist, was born on the 27th October, 1761, in the manse of Shotts, Lanarkshire, Scotland. His father was the Rev. James Baillie, D. D., then minister of the parish of Shotts (a place remarkable at that time, as being one of the most sterile spots in the Lowlands of Scotland), and afterwards professor of divinity in the university of Glasgow. His mother was Dorothea, daughter of Mr Jolin Hunter of Kilbride, in the county of Lanark, and sister of the two celebrated anatomists, Dr William and Mr John Hunter, of London.

After having received the rudiments of his education under his parents' superintendence, in 1773, when in his thirteenth year, he was placed at the university of Glasgow, where he distinguished himself. In 1779, having been appointed to an exhibition or bursary, he went to Baliol college, Oxford, on the same foundation where Adam Smith and other eminent Scotsmen had preceded him ; and, when of the usual standing, he was admitted to his degrees in arts and plysic, having obtained that of M. D. in 1789 .

While yet keeping his terms at the university, in the year 1780, Dr Baillie went to London, and commenced his medical and anatomical studies under his maternal uncles, Dr William and Mr John Hunter, then lecturers in London, and as he resided in the louse of the former, he was employed to make the neressary anatomical preparations for the purposes of illustrating and demonstrating the human structure. Some time before Dr Hunter's death, which took place in March, 1783, Dr Baillie had become the chief demonstrator and teacher of practical anatomy, and afterwards joint lecturer in the theatre of Windmill street with Mr Cruickshank, who, during Dr Hunter's life, had also been associated in giving these lectures. Dr Baillie commenced lecturing in 1784-5, and soon acquired the highest reputation as a teacher, to which character his arduous labours in the formation of nearly eleven lundred anatomical preparations greatly contributed. In the year 1787, Dr Baillie was elected one of the physicians of St George's hospital, and held that office for thirteen years. In the year 1789 , he was admitted a candidate at the college of physicians, and in the following year a fellow thereof. He served the office of censor in 1792 and 1797 , and that of one of the commissioners for the inspection of mad-houses in 1794 and 1795 .

Dr Baillie was but little known to the public as a physician till the year 1798 , when his intimate friend, Dr David Pitcairn, having been compelled by illness to repair to Lisbon for the benefit of a milder climate, Dr Baillie was introduced to the patients of his friend, and very soon after felt himself placed at the very acme of his profession, being applied to by the first persons of rank and fortune in the united kingdom.

His introduction to George III. took place in consequence of his attending the duke of Gloucester during his last illness, and on the first vacancy, which happened in 1810, he was nominated one of his .majesty's physicians in ordinary, and received the offer of a baronetage, which he was induced to decline. Soon afterwards, being at the very height of his practice, his professional income amounted to $£ 10,000$ per annum; a sum which in those days was reckoned quite unprecedented, although several medical men now in London are believed to receive much more.

His work on " the Morbid Anatomy of some of the most important parts of the Human Body," had previously made him well known over the whole continent, and the reputation he had-acquired, not only for consummate anatomical knowledge, but for sound and unerring judgment in the distinction of obscure, intricate, and doubtful cases of internal disease, joined to his quiet, unobtrusive, and gentle manners, gave an authority and weight to all his opinions, particularly amongst his professional brethren, which was quite unprecedented.-Indeed, it may be safely affirmed, that no physician since the days of Dr Sydenham, had ever attained such an ascendancy over the public mind as that enjoyed by the subject of this memoir. Eminent as a physician, those who knew Dr Baillie concurred in asserting that he was not less distinguished as a man. Simplicity, singleness of heart, and ingenuousness, were the leading features of his character. He was quick of apprehension, and expressed himself with perspicuity and readiness, and had such an entire command of thought and language, that he has been known, when a lecturer, to change the subject of his lecture at the moment of delivering it, and to give at once a lecture which had not been previously studied or prepared. His judgment was remarkably correct, and his opinion and advice, therefore, upon all sul-. jects, were of great value. He had the power of reasoning clearly and powerfully, but on many occasions, he seemed to arrive at his conclusion by a sort of tact, rather than to make his way to it by argument. His mind was always more readily engaged by what was useful, than by what was merely curious or ingenious. In society he was remarkable for being frank, good humoured, and kind, whilst the warmth of his manner and expression, indicative of the interest he felt in all around him, set every one at their ease, and called forth their best and happiest feelings. His general knowledge enabled lim to bear a part in any conversation that took place; and in spite of the distraction of his overwhelming professional engagements, he found time to make himself acquainted with all those new publications which excited a general interest. Never was there a man more disinterested, fair, candid, or generous; nor one whose natural elevation of mind raised him more above the reach of whatever is base, sordid, or selfish. Of this the following anecdote, related by $\mathrm{Mr}$ Bell in the introductory lecture to his course of anatomy, affords a splendid proof. "While still a young man, and not afluent, his uncle William dying, left him the small family estate of Long Calderwood.-We all know of the unhappy misunderstanding that pxisted between Dr Hunter and his brother John. Dr Baillie felt that he owed this bequest to the partiality of his uncle, and made it over to John Hunter.-The latter long refused, but, in the end, the family estate 
remained the property of the brother, and not of the nephew of Dr Ilunter."

Or Baillie had an elder brother, who died at an enrly age, and two sisters who survive lim, Agnes und Joanna, the latter the well knowil anthoress of a "Series of Plays on the Passions." He mar. ried Miss Sophia Denman, daughter of the late culnineut physician, and sister of the present attorney general, and of lady Croft. Dr Baillie died at Duntisbourne House, near Cirencester, in Gloucestershire, on the 231 September, 1823, in the $62 d$ sear of his age, leaving a widow with a son and daughter. He bequeathed by will $£ 300$ to the College of Physicians, Loudon, together with all his medical and anatomical books, and the plates of his " Mllustrations of Morbid Anatomy,"-and also a farther sum of $£ 4000$, in case his son, William Hunter Baillie, should die without issue. To the sane body he had previously, during his lifetime, given all his collection of anatonical preparations, and a sum of $£ 600$. Three hundred pounds were also left to the society for the relief of the widows and orphans of medical men, and the rest of his property to his widow and fantily. His will was proved in the prerogative court, in October, 1823, and the effects sworn in be under $£ 80,000$. It was dated 21st May, 1819 . Besides the two works already noticed, Dr Baillie published an anatomical description of the gravid uterus, and two anatomical papers in the Transactions of the Royal Society, for the years 1788 and 1789. He also published eleven essays in the Transactions of the Society for the promotion of Medical and Chirurgical knowledge, and seven papers in the Medical Transactions, published by the London College of l'hysicians.

Ballue, Robert; an eminent and learned Scottish presbsterian clergyman, was born at Glasgow, in 1599. Having studied divinity in his native university, he received, in 1622, episcopal orders from archbishop Law, of Glasgow, and became tutor to the son of the earl of Eglintoune, by whom he was presented to the parish church of Kilwinning. In 1626, he was admitted a regent at the college of Glasgow, arid, on taking his cliair, delivered an inaugural oration, De Mente Agente. About this period he appears to have prosecuted the study of the oriental languages, in which he is allowed to have attained no mean proficiency. Though educated and ordained as an episcopalian, he resisted the attempt of archbishop laud to establish the use of the common prayer in Scotland, and joined the presbyterian party. In 1638 , he was chosen to represent the presbytery of Irvine in the General Assembly, by which assembly the royal power was braved in the name of the whole nation, and episcopacy formally dissolved. In the ensuing year, when it was found necessary to vindicate the proceedings of the Assembly with the sword, Baillie entered heartily into the views of his countrymen. He accompanied the army to Dunse Law, in the capacity of preacher to the earl of Eglintoune's regiment. This expedition ended in a treaty between the Scottish leaders and their sovereign, in terms of which hostilities ceased for a few months. On the renewal of the insurrectionary war next year, Baillie accompanied the Scottish army on its march into Fngland, and became the chronicler of its transactions. Towards the end of the year 1640, he was selected by the Scottish leaders as a proper person to go to London, along with other commissioners, to prepare charges against archbishop Laud, for his innovations upon the Scottish church, which were alleged to have been the urigin of the war. He had, in April before the expedition, published a pamphlet, entitled, "L Ladensium Avroxaraxergs: the CanLerburian's Self-conviction; or an Evident Demon- stration of the arowed Aminianisme, Poperie, and Tyranuie of that Faction, lyy their own coufissions," which perhaps pointed him out as fit to take a lead in the prosecution of the grent Autichrist of Scottish preslyytery. Of this, aud almost all the other proceedings of his public life, he las left a minute account iu his letters and jouruals, which are preserved entire in the archives of the clumel of scotland, and in the university of Glasgow, and of which excerpts were published in 2 vols. 8vo, Edinburgh, 1775. These reliques of $\mathrm{Mr}$ IBaillie form valuable materials of history. Not long after his return to his native country, in 1642, he was aproint. ed joint protessor of divinity at Glasgow, along with Mr David Dickson, an equally distinguished, but less moderate divine. It affords some profof of the estimation in which he was now held, that he liad the choice of this appointment in all the four universities of Scotland. He performed his duties from this period till the restoration, and at the same time attended all the General Assemblies as a member, exce t during an interval in 1643-6, when lie was absent as a delegate to the Westminster assembly of divines. From 1646 to 164 , , he discharged his ordinary duties as a theological teacher, witlout taking a leading part in public affairs. But in the latter year, he was closen by the church as the fittest person to carry its homage to king Charles II. at the Hague, and to invite that monarch to assume the govermment in Scotland, under the limitations and stipulations of the covenant. After the restoration, though made principal of his college through court patronage, he scrupulously refused to accept a bishopric, and did not hesitate to express his dissatisfaction with the reintroduction of episcopacy. He died July, 1662, in the $63 \mathrm{~d}$ year of his age. Mr Baillie, besides his let. ters and journals, and a variety of controversiai pamphlets, suitable to the spirit of the times, was tlie author of a learned work, entitled, Opus Hisloricum ct Chronologicum, which was published in folio at Amsterdan. He was a man of extensive learningunderstood no fewer than thirteen languages, among which were Hebrew, Chaldee, Syriac, Samaritan, Arabic, and Ethiopic,-and wrote Latin with fluency.

BAlLLe, Robert, of Jerviswood, a distinguished Scottish patriot of the reign of Charles II., was the son of George Baillie of St Johı's kirk in Lanarksl,ire, cadet of the ancient family of Baillie of Lamington, who appears to have purchased the estate of Jerviswood, also in Lanarkshire, in the reign of Charles I. from a family of the name of Livingstone. The circumstance which first bronght him into public notice deserres to be given in detail, as it sends to illustrate the profligacy of that governinent, under which he eventually fell a martyr.

During the administration of the duke of Lauderdale, a wretch of tie name of Carstairs had bargained with archbishop Sharpe to undertake the business of an informer upon an uncommonly large scale; having a troop of other informers under him, and enjoying a certain reward for each individual whom he could detect at the conventicles, besides a share of the fines imposed upon them. It may be supposed than an individual who could permit himself to enter upon a profession of this kind, would not he very scrupulous as to the guilt of the persons whom he sought to make his prey. He accordingly appears to have, at least in one noted instance, pounced upon an individual who was perfectly innocent. This was the Rev. Mr Kirkton, a nonconformist millister it is true, but one who had been cautious to keep strictly within the verge of the law. Kirkton was the brother-inlaw of Mr Baillie of Jerviswood, by his marriage to the sister of that gentleman, and he is eminent in 
Secttish literary history for a memoir of the church duriug his own times, which was of great service in inanuscript to the bistorian Wodrow, and was at length published in 1817. One day in June, 1676, as Mr Kirkton was walking along the High Street of Edinburgh, Carstairs, whose person he did not know, accosted him in a very, civil manner, and expressed a desire to speak with him in private. MrKirkton, suspecting no evil, followed Carstairs to a very mean looking house, near the common prison. Carstairs, who lad no warrant to apprehend or detain Mr Kirkton, went out to get one, locking the door upon $h$ is victim. The unfortunate clergyman then perceived that he was in some danger, and prevailed upon a person in the house to go to seek his brotherin-law, Mr Baillie, and apprise him of his situation. Carstairs, having in vain endeavoured to get the requisite number of privy councillors to sign a warrant, now came back, resolved, it appears, to try at least if he could not force some money from Mr Kirkton for his release. Just as they were about to confer upon this subject, Mr Baillie came to the door, with several other persons, and called to Carstairs to open. Kirkton, hearing the voices of friends, took courage, and desired his captor either to set him free, or to show a warrant for his detention. Carstairs, instead of doing either, drew a pocket pistol, and Kirkton found it necessary, for his own safety, to enter into a personal struggle, and endeavour to secure the weapon of his antagonist. The gentlemen without, hearing a struggle, and cries of murder, burst open the door, and found Carstairs sitting upon Mr Kirkton, on the floor. Baillie drew his sword, and commanded the poltroon to come off, asking him at the same time if he had any warrant for apprehending Mr Kirkton. Carstairs said he had a warrant for conducting him to prison, but he utterly refused to show it, though Mr Baillie said that, if he saw any warrant against his friend, he would assist in carrying it into execution. The wretch still persisting in saying he had a warrant, but was not bound to show it, Mr Baillie left the place, with Mr Kirkton and other friends, haviug offered no violence whatever to Carstairs, but only threatened to sue him for unlawful invasion of his brother-in-law's person. It might have been expected from even a government so lost to all honour and justice as that which now prevailed in Scotland, that it would have at least the good sense to overlook this unhappy accident to one of its tools. On the contrary, it was resolved to brave the popular feeling of right, by listening to the complaints of Carstairs. Through the influence of archbishop Sharpe, who said that, if Carstairs was not countenanced, no one would be procured to apprehend fanatics afterwards, a majority of the council agreed to prosecute Baillie, Kirkton, and the other persons concerned. For this purpose, an antedated warrant was furnished to Carstairs, signed by nine of the councillors. The marquis of Athol told bishop Burnet, that he had been one of the nine who lent their names to this infamous docunent. The whole case was, therefore, made out to he a tumult against the government; Baillie was fined in 6,000 merks, ( $£ 318$ sterling,) and his friends in smaller sums, and to be imprisoned till they should render payment.This award was so opposite, in every particular, to the principles of truth, honour and justice, that, even if not directed against individuals connected with the popular cause, it could not have failed to excite general indignation. It appears that a respectable minority of the council itself was strougly opposed to the decision, and took care to let it be known at court. Mr Baillie was therefore released at the end of four months, in consideration of payment of one half of his fine to the creature Carstairs. Lord
Halton, however, who was at this time a kind of pro-regent under his brother Lauderdale, had interest to obtain the dismissal of his opponents from the council, namely, the duke of Hamilton, the earls of Morton, Dumfries, and Kincardine, and the lords Cochrane and Primrose, whom he branded, for their conduct on this occasion, as enemies to the church, and favourers of conventicles.

After this period, nothing is known of Mr Baillie till the year 1683, when he is found taking a prominent share in a scheme of emigration, agitated by a number of Scottish gentlemen, who saw no refuge but this from the tyraniy of the government. These gentlemen entered into a negotiation with the patentees of South Carolina, for permission to convey themselves thither, along with their families and dependents. While thus engaged, Mr Baillie was induced, along with several of his friends, to cnter into correspondence and counsel with the heads of the Puritan party in England, who were now forming an extensive plan of insurrection, for the purpose of obtaining a change of measures in the government, though with no ulterior view. Under the pretext of the American expedition, lord Melville, Sir John Cochrane of Ochiltree, Mr Baillie, and three others, were invited and repaired to London, to consult with the duke of Monmouth, Sydney, Russell, and the rest of that party. This scheme was never properly matured; indeed, it never was any thing but a matter of talk, and had ceased to be even that, when a minor plot for assassinating the king, to which only a small number of the party were privy, burst prematurely, and involved sevcral of the chiefs, who were totally ignorant of it, in destruction. Sydney and Russell suffered for this crime, of which they were innocent ; and Baillie and several other gentlemen were seized and sent down to be tried in Scotland.

The subsequent judicial proceedings were characterized by the usual violence and illegality of the time. He endured a long confinement, during which he was treated very harshly, and not permitted to have the society of his lady, though she offered to go into irons, as an assurance against any attempt at facilitating his escape. An attempt was made to procure sufficient proof of guilt from the confessions wrought out of his nephew-in-law, the earl of 'Tarras (who had been first married to the elder sister of the duchess of Monmouth); but, this being found insufficient, his prosecutors were at last obliged to adopt the unlawful expedient, too conmon in those distracted times, of putting him to a purgative oath. An accusation was sent to him, not in the form of an indictment, nor grounded on any law, but on a letter of the king, in which he was charged with a collspiracy to raise rebellion, and a concern in the Ryehouse Plot. He was told that, if he would not clear limself of these charges by his oath, he should be held as guilty, thoing not as in a criminal court, but only as before the council, who had no power to award a higher sentence than fine and imprisonment. As he utterly refused to yield to such a demand, the

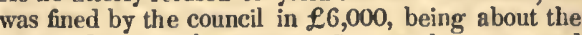
value of his whole cstates. It was then supposed that the prosecution would cease, and that he would escape with the doom of a captive. For several months he continued shut up in a loathsome prison, which had such an effect upon his health that he was brought almost to the last extremity. Yet "all the while," to use the words of bishop Burnet, "he seemed so composed, and even so cheerful, that his behaviour looked like a reviving of the spirit of the noblest of the old Greeks or Romans, or rather of the primitive Christians, and first martyrs in those last days of the church. At length, on the $23 \mathrm{~d}$ of Deccmber, 1684, he was brought before the court of 
justiciary. He was now so weak as to be obliged to appear at the har in his night-gown, and take frequent npplications of cordials. The assize was empanneled at midniglit, and sat till nine in the morning of the succeeding day, when a verdict of guilty was returned against Mr Baillie, and he was sentenced to be executed that afternoon, at the cross, and his limbs to be aftenvards exhibited on the jails of four different Scottish towns. The reason for such precipitation was the fear of his judges that a natural death would disappoint the wishes of the government, which called imperatively at this moment for a public example to terrify its opponents. Mr Baillie was attended to the scaffold by his faithful and affectionate sister. The unfortunate gentleman was so weak that he required to be assisted in mounting the ladder: he betrayed, however, no symptom of moral weakness. Just before being consigned to his fate, he said, in the selfaccusing spirit of true excellence, " My faint zeal for the Protestant religion has brought-me to this end." His sister-in-law, with the stern virtue of her family, waited to the last. Dr Owen has testified, in a strong manner, to the great abilities of the Scottish Sydney. Writing to a Scottish friend, he said, "You have truly men of great spirits among you ; there is, for a gentleman, Mr Baillie of Jervis. wood, a person of the grentest abilities I ever almost inet with." Mr Baillie's family was completely ruined by his forfeiture. He left a son, George Baillie, who, after his execution, was obliged to take refuge in Holland, whence he afterwards returned with the prince of Orange, by whom he was restored to his estates. The wife of this gentleman was Miss Grizel Hume, daughter of Sir Patrick Hume of Polwarth, a fellow-patriot of Mr Robert Baillie. The occasion of their meeting was very remarkable. Miss Grizel, when a very young girl, was sent by her father from the country, to endeavour to convey a letter to $\mathrm{Mr}$ Baillie in prison, and bring back what intelligence she could. She succeeded in this difficult enterprise; and laving at the same time met with $\mathbf{M r}$ Baillie's son, the intimacy and friendship was formed, which was afterwards completed by their marriage.

BuLLY, Jean Sylvain ; a learned French astronomer, born at Paris, 1736. Though designed by his father, keeper of the royal gallery of pictures, for a painter, he followed his natural inclination for literature. His first attempts were in poetry. Becoming afterwards acquainted with Lacaille, he was induced by his instructions and example to devote himself to astronomy. After the death of Lacaille, in 1763, he entered the academy, and published the calculation of a great many of Lacaille's observations on the stars of the zodiac. He undertook, also, at this time a great work on the satellites of Jupiter, the theory of which the academy had made a prize question. His Essai sur la Théorie des Satellites de Jupiter, avec des Tables de leurs Mouvements, appeared in 1766. Is 1771, he published a treatise on the light reflected by the satellites of Jupiter, which he undertook to measure by an ingenious process. Amidst these laborious occupations, he never lost his love of literature. His eulogiums on Pierre Comeille, Leibnitz, and others, were so favourably received, that he resolved to select a scientific subject, susceptible of the ornaments of style, which might secure his literary fame. He chose the History of Astronomy (1775 to 1787,5 vols. quarto). It met with general approbation, which was increased by the discussions that succeeded, between the author and Voltaire, which led B. to publish his Lettres sur l'Origine des Sciences, et sur l'Atlantide de Platon. In 1784, the French acaderry elected him a member, in the place of Tressan, and, in 1785, he was admitted into the academy of inscriptions. The government also made him a member of the committee for examining the character and influence of auimal magnetism, discovered by Mesmer. "13. delivered a double report on this subject, one for the public, to give it a just view of the doctrine, the other for the kung alone, on the real causes of magnetism, and its moral influence. The latter was not published till a later period.

Bailly was now enjoying the general esteem due to merit and to virtue, whien the revolution tore him from his peaceful pursuits. Paris chose him, May 12,1789 , first deputy of the tiers-état; in the assembly itself, lie was nade first president. He retained this place after the commons lial declared themselves a national assembly; and when the king forbade thern to assemble, he presided, June 20,1789, in the session of the tennis-court, when all the deputies swore never to separate till they had given France a new constitution. Being chosen milyor of Paris, July 16, he discharged the duties of his office witl his usual integrity and disinterestedness; but these virtues were not sufficient to restrain a furlous populace, exposed by turns to the influence of opposite parties. The palliatory measures employed by $\mathrm{B}$. to preserve the appearance of tranquillity might delay the eruption, but could not suppress it; perhaps matters had arrived at such a point, that even the most vigorous resistance would have been ineffectual. Once only, and on the most just occasion, he had recourse to rigorous measures. This was after the return of the king from Varennes. The violent revolutionists wished to seize this opportunity for his deposition, and a great number of tliem assembled, July 17, 1791, in the Champ-de-Mars, in order to sign, upon the altar of their country, a petition to this effect. B., accompanied by the national guards, commanded the rebels to disperse, and, on their refusal, dispersed them by force. The national assembly approved of his conduct; nevertheless, he re. signed his place, Sept. 19, 1791. Petion (q. v.) became his successor. B. retired entirely from public affairs to the country in the vicinity of Nantes. When the increasing troubles left him no security even here, his friend Laplace offered lim a shelter in his own house at Melun. In the meantime, by the events of May 31, 1793, circumstances were changed, and a division of the revolutionary army entered Melun. Laplace informed B. of his danger, but, unfortunately, lie did not regard the warnillg, but persisted in going to Melun. As soon as he entered this place, he was known. He was sent to Paris, where, Nov. 11, 1793, he was condemned to death by the revolutionary tribunal, and executed on the 12th, with circumstances of great cruelty. He died with the utmost composure. His crimes were, his conduct on the Champ-de-Mars, and the boldness with which he had declared the accusations brought against the queen false and calumnious. His posthumous works are, Essai sur l'Origine des Fables, et des Religions Anciennes, and his.Journal during the early period of the revolution, from $\Lambda$ pril 21 to Oct. 2, 1789 (3 vols, 1804).

BAnMment, in law, is the delivery of a chattel or thing to another to keep, either for the use of the bailer, or person delivering, or for that of the bailee, or person to whom it is delivered. A bailment always supposes the subject to be delivered only for a limited time, at the expiration of which it must be re-delivered to the bailer; and the material inquiries, in cases of bailment, relate to the degree of responsibility of the bailee in regard to the safe-keeping and re-delivery of the subject of the bailment. This responsibility will depend, in some degree, upon the contract on which the bailment is made. If a thing is delivered to the bailee to keep, without any advantage or use to himself, or any com. 
pensation, but merely for the benefit of the bailer, he is answerable only for gross negligence; but if the bailment is for the mutual benefit of both parties, the thing must be kept with the ordinary and usual care which a prudent man takes of his own goods; but if it be delirered for the benefit of the bailee only, he must exercise strict care in keeping it, and will be auswerable for slight negligence. A special agreement is made in many cases of borrowing or hiring, specifying the risks assumed by the borrower or hirer; and, in such case, his obligations will be determined by his stipulations. Pledging and letting for hire are species of bailment. There is an excellent essay on the Law of Bailment by Sir William Jones.

Ballzie, or Barlure, William, a physician of the 15th century, was a native of Scotland. After being educated in his native country, he went to Italy, where he studied medicine with such reputation as to be made rector, and afterwards professor of medicine in the university of Bologna, about the jear 1484. In his theory he adopted the Galenic system in preference to the Empiric, and wrote "Apologia pro Galeni doctrina contra Empiricos," Lyons, 1552, 8vo. Mackenzie thinks that he also wrote a book entitled, "De Quantitate Syllabarum Gracarum, et de Dialectis," 1600,8 vo.

BAINBRIDG John, an eminent astronomer and ma. thematician, born at Ashby-de-la-Zouch, in Leicestershire, in 1582. He studied at Cambridge, whence, having taken the degree of M. A., he returned to his native place, set up a grammar school, and at the same time practised physic, devoting his leisure to the seience of mathematics. He at length removed to London, and was admitted a fellow of the College of Physicians. "A description of the Comet of 1618," which he published, was the means of introducing him to Sir Henry Savile, who had founded an astronomical lecture at Oxford, and who in 1619, appointed Dr Bainbridge to the professorship. He then entered as a master commoner at Merton College, where in 1631, he was nominated reader of Linacre's medical lecture. He died in 1643, while engaged in publishing corrected editions of the works of the ancient astronomers, an undertaking which was one of the duties enjoined on him as Savilian professor. His only published works, besides that already mentioned, are-c" Procli Sphæra, Ptolemæi de IJypothesilous Planetarum Lib. sing." together with "Ptolemæi Canon Regnorum," 1620, 4to; and "A Treatise on the Dog Star," 1648. He left some astronomical dissertations, and a considerable quantity of other manuscripts, which are preserved in the library of Trinity College, Dublin.

Bairan, or BejRan; the Easter of the Mohammedans, which follows immediately after the Rhamazan or Lent (a month of fasting), and lasts three days. This feast begins, like the Rhamazan, as soon as the new moon is announced by the persons appointed for that purpose, and, during the course of thirty-three years, takes place in all the seasons and all the months of the year, because the Turks reckon by lunar years. It is the custom, at this feast, for inferiors to make presents to their superiors. This custom formerly extended even to the Europeans, who were obliged to make presents to men of rank, to the pachas and the cadis. The grand seignior is also accustomed to distribute favours and presents. Sixty days after this first great Bairam, begins a second-the lesser Bairam. They are the only two feasts, the celebration of which the Mohammedan religion prescribes to the faithful.

B.Ard, (the Right Honourable, General Sir) David, a distinguished British commander, was born in Scotland, and entered the army, December 16,1772 , as an ensign in the second foot, joined the regiment at
Gibraltar, April, 1773, and returned to Britain in 1776. Having been promoted to a lieutenancy in 1778 , he immediately after obtained a company in the $73 \mathrm{rd}$, a regiment then just raised by lord Macleod, with which he sailed for India, and arrived at Madras, January, 1780. After distinguishing limself as a captain in the wars against Hyder Ally, he received on the fifth of June, 1789, the majority of the 71 st regiment, and in October obtained leave of absence, and returned to Britain. In 1791, he returned as lieutenant-colonel of the 7lst, and joined the army under the marquis Cornwallis. As commander of a brigade of Sepoys, he was present at the attack of a number of Droogs, or hill-forts, and at the siege of Seringapatam, in 1791 and 1792; and likewise at the storming of Tippoo Sultaun's lines and camps in the island of Seringapatam. In 1793, he commanded a brigade of Europeans, and was present at the siege of Pondicherry. He received a colonelcy in 1795 . In Octolver 1797, he embarked at Marlras with his regiment for Europe; in December, when he ar. rived at the Cape of Good Hope, he was appointed brigadier-general, and placed on that staff, in command of a brigade. June 18,1798 , he was appointed major-general, and returned to the staff in India. In January, 1799, he arrived at Madras, in command of two regiments of foot, together with the drafts of the 28th dragoons. May 4 , he commanded the storming party at that distinguished action, the assault of Seringapatam ; when, in requital of his brilliant services, lie was presented by the army, through the commander-in-chief, with the state sword of Tippoo Sultaun, and also with a dress-sword from the field-officers serving under his immediate command at the assault.

The eminent merit of brigadier-general Baird being now fully known to the government at home, he was in 1800 , appointed to the command of an expedition against Batavia, but which was afterwards sent to Egypt. He landed at Cosier in $J$ une, crossed the desert, and, embarking on the Nile, descended to Grand Cairo; whence he set out for Alexandria, which he reached a few days before it surrendered to general Hutchison. Next year he led the Egyptian-Indian army overland to India, where he was concerned in various military transactions. His services, however, being soon after superseded by Sir Arthur Wellesley, in a manner no ways creditable to the then existing administration, and which was only eventually justified by the splendid successes of Sir Arthur, he sailed for Britain with his staff, March, 1803 , and after a tedious voyage, during which he was taken prisoner by a French privateer, but afterwards retaken, he arrived in England in November.

Sir David Baird was received at the British court with great distinction. In December, he received the royal permission to wear the Turkish order of the Crescent. In June, 1804, he received the honour of knighthood, and on the 18th of August following became a knight companion of the Bath. With the increased rank of lieutenant-general, he commanded an expedition which sailed in October, 1805, for the Cape of Good Hope. Landing there, January 6,1806 , he attacked and beat the Dutch army, and on the 18th received the surrender of the colony. Being recalled, he arrived in Britain, A pril, 1807, and was shifted from the colonelcy of the $54 \mathrm{th}$, which he had held for some years, to that of the $24 \mathrm{th}$, and placed on the foreign staff under general lord Cathcart. He commanded a division at the siege of Copenhagen, where he was twice slightly wounded; and returned with the army in November.

After a short period of service in Ireland, Sir David sailed in command of an armament of 10,000 men for Corunna, where he arrived in November, 1808 , and 
formed a junction with the army under general Sir Jolu Moore. He commanded the first division of that army, and in the battle of Corunna. January 16 , 180 , he lost his left arm. By the death of Sir Joln Moore in this action, Sir David succeeded to the clief command, and had the lonour of communicating intelligence of the victory to government. On this occasion, he received, for the fourth time in his life, the thanks of parliament, and, April 18, was crented a laronet, with very honourable armorial bearings, allusive to the transactions of his life. After this period, he never again appeared in active service. In 1810, he married Miss Preston Campbell, of Ferntower and Lochlane, Perthshire, by whom he left no issue. In 1814 , he was promoted to the rank of general, and in 1819 became governor of Kinsale in Ireland, and in 1827, of Fort George in the north of Scotland. This brave veteran died at an advanced age, August 18, 1829, at his seat of Ferntower in Perthshire. His lady, who survives him, has designed a monument to his memory on the top of a romantic hill, named, Tom-na-chaistel (i. e. the lill of the castle), in the neighbourhood of Ferntower. An interesting life of him has recently been published by Mr Theodore Hook.

Bairdstown; a post-town of Kentucky, and capital of Nelson county, on Beech Fork river; 35 miles S. W. Frankfort, 60 W. S. W. Lexington; Ion. $86^{\circ} 10 \mathrm{~W}$. ; lat. $37^{\circ} 49^{\prime} \mathrm{N}$.; population in 1810,820 . It contains a court-house, a jail, a market-house, a church, and a flourishing Roman Catholic college, styled the college of St.Joseph, which is under the care of the Roman Catholic bishop of Kentucky, and has about 200 students. The college edifice is of brick, four stories high.

Baids, or DE Bay, Michael, born 1513, at Melin, in Hainau, educated at Louvain, in 1551, made professor of theology at this unirersity, in 1563 or 1564 , chosen a member of the council of 'Trent, was one of the greatest theologians of the Catholic church in the 16th century. He founded systematic theology directly upon the Bible and the Christian fathers, leaving the scholastic method. He had read the writings of St Augustine nine times, and had fully adopted the riews of that father, whose doctrines of the entire incapacity of the human will for good, and the insufficiency of good works, he first maintained against the less rigid notions of the Jesuits. The doctrines that the human will, when left to itself, could only sin; that even the mother of Jesus was not free from hereditary and actual sin; that every action, which did not proceed from pure love to God was sinful; and that no penance was effectual for the justification of the sinner, but every thing was to be attributed solely to the grace of God, through Christ - caused him to be persecuted as a heretic by the old Scotists, and, in particular, by the Jesuits, who, notwithstanding the favour in which he stood at the Spanish court, at length succeeded in obtairing a papal bull, in 1567, condemning these doctrines, with others falsely imputed to him. B. submitted; yet the persecutions against him still continued, as did also his defence of the opinions of Augustine in his lectures; and, as the theological faculty at Louvain was entirely in his favour, he not only remained in the quiet possession of his dignities, but was also appointed dean of St Peter's, in 1575, and, in 1578, chancellor of the university; nay, the king of Spain conferred upon him the office of inquisitor-general in the Netherlands. He died in 1589 , and left the reputation of great learning, pure morals, and a rare modesty. His Augustinian views, which were called then Baianism, descended to the Jansenists (as the precursor of whom he is to be regarded), and, in their hands, received an intervretation formidable to $\mathrm{Je}$ - suitism and to the papal power. II d doctrine of pure, undivided love to God has been adopted by the Quietists. His writings, mostly polemical, were published by Gabriel Gerberon, at Cologne, 1696, quarto.

Basazer I., Turkish eniperor, in 1389 succeeded his father, Aumurath, who fell in the battle of Cassova against the Servians. He caused lis elder brother, Jacob, his rival for the tlirone, to loe strangled-an act of barbarity, which, sinee his time, has become a custom at the Turkish court. He made great and rapid conquests. Ilence his name, Ilderim, the Lightning. In three years he conquered Bulgaria, part of Servia, Macedonia, Thessaly, and subjeeted the states of Asia Minor. He besieged even Constantinople for ten years, and hoped to starve it into a surrender. In order to save the city, king Sigismond of Hungary (afterwards emperor of Gernnany) assembled a great army (including a number of French troops, and 2,000 noblemen under the eommand of the duke of Nirey), and attacked the city of Nicopolis, in Bulgaria, situated near the Danube. But B. met them, and obtained a deeisive victory over the allied Hungarians, Poles, and French, 28ti September, 1395. Sigismond escrped, by a hasty flight, in disguise. The French, by whose imprudent impetuosity the battle was lost, were most of them taken prisoners, and executed by the order of 13 . He would probably have now overturned the whole Greek empire, if Timur (see Tamerlane) had not attacked Natolia, in 1400. B. marched to meet lim, and suffered a total defeat near Anc5ra, in Galatia, June 16,1402 . He himself fell into the power of the conqueror, who treated him with generosity. The story of his being carried about in a cage by Timur is without historical proof. B. died, in 1403, in Timur's camp, in Caramania. His sueeesso: was Soliman 1.-Bajazet II. succeeded his father, Maho. met II., sultan of the Turks, in 1481. He increased the Turkish empire by conquests on the north-west and in the east, took Lepanto, Modon, and Durazzo, in a war against the Venetians, and ravaged the coasts of the Christian states on the Mediterranean, to revenge the expulsion of the Moors from Spain. At home, he had to contend against his rebellious son Selim, to whom at last he resigned the empire. He died in 1512, on his way to the place which he had chosen for his retirement. It has been supposed that he was put to death by the order of his son. He was a man of uncommon talents, and did mueh for the improvenent of his empire, and the promotion of the sciences.

BAKER, Sir George, an eminent physician, the sen of a Devonshire clergyman, was born in 1722, and educated at Eton and Cambridge- Having taken the degree of M.D. in 1756, he commenced the practice of his profession at Stamford, whence he soon removed to London, and speedily attained considerable reputation. He was appointed physician in ordinary to the king, and physician to the queen; and he was also chosen fellow of the royal and antiquarian societies. In 1776, he was created a baronet, and in 1797 , he was placed at the head of his profession, by being elected president of the College of Physicians. He died, June 15th, 1809. Sir George Baker had the reputation of being an elegant classical scholar and critic in the dead languages, as well as a learned and skilful physician. His publisled works are neither numerous nor considerable. They consist principally of essays and dissertations on medical suljects, many of which were published in periodical works. "An Essay on the Cause of the Endemical Colic of Devonshire," which appeared about 1767 , gave rise to a professional controversy relative to the origin of that malady, which he attributed to the use of cider impregnated with lead, derived from the vessels used 
in making it. Of his Latin style, Sir G. Baker lias ieft a specimen highly creditable to his taste and talents, in the preface to a late edition of the Pharmacopœia of the medical college.

BAKER, Heury ; a poet and naturalist of the 18th century. He was a native of London, and devoted himself to the instruction of persons born deaf and dumb, by which he acquired a handsome fortune. In 1725 and 1726, he published "Original Poems, serious and humorous," in two parts. He was also the author of "The Universe," a poem, and an "Invocation to Health." He afterwards employed himself much in experimental philosophy, and making nicroscopical observations. In $\mathbf{1 7 4 0}$ he was chosen a fellow of the Royal and Antiquarian societies, and ir 1744 he obtained the Copleian gold medal, for his inicroscopical discoveries on crystallization. He contributed many papers to the Philosophical Transactions ; and he was an active member of the Society for the Encouragement of Arts, to which he for some time acted gratuitously as secretary. He died in 1774. By his will he left $£ 100$ to the Royal Society, for an annual lecture on chemistry or natural philosophy. Besides the works already noticed, he published "The Microscope made easy," and "Employment for the Microscope ;" both illustrated by plates, and containing much curious information. Mr Baker married a daughter of Daniel Defoe, by whom he had two sons. The elder, David Erskine Baker, who died in 1767, was the author of "The Companion to the Playhouse," 2 vols. $12 \mathrm{mo}$; since enlarged by Isaac Reed and Stephen Jones. Henry Baker, the younger son, who was an attorney, laad some talent for poetry, and in 1756 published "Essays, Pastoral and Elegiac," 2 vols. 8 vo.

BAKER, Sir Richard; an English historian of the 17 th century. He was born of a good family in Kent in 1568, and became a gentleman commoner at Oxford, whence he removed to one of the inns of court, and afterwards travelled on the continent. Returning home, he was knighted in 1603 by James I., and in 1620 he filled the office of high sheriff of Oxfordshire, having estates in that county. An unfortunate marriage with the daughter of Sir George Mainwaring, of Ightfield, in Shropshire, occasioned his ruin; for, giving security for the debts contracted by that family, he became insolvent, and was obliged to take refuge in the Fleet prison, where, after continuing some years, he died in 1645 . He lightened his tedious confinement by turning author. Some religious pieces which he published have been long since consigned to oblivion; but his "Chronicle of the Kings of England," first published in 1641, and afterwards continued by Edward Phillips, the nephew of Milton, and others, went through a great number of editions. Addison, in "The Spectator," represents it as the favourite manual of Sir Roger de Coverley; as it seems to have been, in fact, of country gentlemen in general at the beginning of the last century.

BAKER, Thomas; an English mathematician of the 17th century. He was a native of Somersetshire, and was educated at Oxford. In 1645, being a scholar of Wadham college, he served in the garrison of Oxford for king Charles I. Leaving the university, he obtained the vicarage of Bishop's Nymmet in Devonshire, and spent the remainder of his time in mathematical researches. In 1684 he published a work entitled " The Geometrical Key, or the Gate of Equations unlocked; or a new Discovery of the construction of all Equations, howsoever affected, not exceeding the fourth degree, viz. of Linears, Qundratics, Cubics, Biquadratics, and the finding of all their roots, as well false as true, without the use of Mesolabe, Trisection of Angles, Reduction, Depression, or any other previous Preparations of Equations, by a Circle, and any (and that one only) Parabole," 4to. This verbose title will give the reader an idea of the merit of Mr Baker's discoveries, which recommended him to the notice of the Royal Society, by whom he was presented with an honorary medal. He died in 1690 .

BAKER, Thomas; a learned antiquary, born at Lancaster, in Durham, in 1656 . He became a student of St John's college, Cambridge, of which he was afterwards fellow. Entering into orders, he obtained a living, which he resigned in consequence of having embraced the principles of the Nonjurors. On the accession of George I., his refusal to take the oaths required by government, obliged him to give up his fellowship; but being much esteemed in the university, he was allowed to retain his chambers; and Prior the poet most generously made up his loss of income by giving him the emoluments of his own fellowship, his motives for keeping possession of which were not generally known. Baker died in 1740 , leaving behind him vast manuscript collectious relating to the history and antiquities of Cambridge university, and other subjects; part of which are in the Harleian library in the British museum, and part in the public library at Cambridge. In $1699 \mathrm{Mr}$ Baker published anonymously a volume, entitled "Reflections upon Learning," which became exceedingly popular, and passed through many editions. The object of this piece was to show the uncertainty and insufficiency of all liuman learning, and evince the necessity of revelation. Neither in its plan or execution is the work entitled to the unqualified praise which has sometimes been bestowed on it. The author printed nothing else but a preface to a sermon of bishop Fisher.

BAKEWETL, Robert; an English gentleman in the last century, who acquired some celebrity by lis schemes for improving the breeds of sheep and oxen. He possessed an estate at Dishley Grange, in Leicestershire, where his grazing and feeding schemes were put in execution; and he is said to have travelled over various parts of England, Ireland, and Holland, in search of information. In some respects he was very successful; for he found out a method of fattening animals to a prodigious degree for the table; and he sold his stock at a most enormous price. It may be questioned, however, whether his projects were productive of any real advantage to himself or to the public: for it has been stated that he failed in business more than once; and, with regard to the ultimate effect of his improvements, it has been sarcastically, but justly remarked, that they had enabled him to make meat too fat for any body to eat, and too dear for any body to purchase. He was, however, like many other speculators, an intelligent and ingenious man; and he is said to have been distinguished for his humanity to the aninals under his care. He died at Dishley, October 1st, 1795.

BAKnuYsev. See Backhuysen.

BakING ; the art of preparing bread, or of reducing meal or flour of grain, or other substances, into bread. See Bread.

BAKKer, Peter Huysinga, a Dutch poet, born in 1715 , died in 1801 , was a member of the academy of sclences at Leyden. His poem on the inundation of 1740 is much esteemed. All his works make three volumes, of which one volume contains satires and contemptuous songs against the Britons. He was a friend and relation of the Dutch historian Wagenaer, of whose life he published some uotices. He translated Hight's Latin poem on Spring into Dutch.

Balalaika; a musical instrument, of very ancient Sclavonian origin, common among the Russians, 'iartars, and, according to Niebulir, also frequent in 
Egypt and Arabia. It is of the guitar kind, but has only two strings.

BaLANCE; an instrument employed for determining the quantity of any substance equal to a given weight. Balances are of various forms; that most commonly used, is represented in plate IX. fig. 2, being usually denominated, the beam and scales. The horizontal beam $A B$ rests, and is capable of turning, on the centre of motion $C$. The scales D and $\mathrm{E}$ are suspended by chains from the extremities $A$ and $B$ of the benm, called the centres of suspension. Midway between the centres of suspension, and directly above the centre of motion, there rises from the upper surface of the beam, a perpendicular slender stem, called the tongue, which, when the beam is level, points to the top of the handle $\mathbf{F}$, by which the whole is suspended. A good balance is necessary, not less for the ordinary commerce of soci'ty, than for the purposes of science; and there are few indeed to whom it would be a matter of indifference to know the principles of construction which contribute to the excellence of this simple and useful instrument. We sliall, therefore, as briefly as possible, state the properties of a good balance, and also the menns by which these properties are to be secured. The characteristics of a good balance are three :-1st. That the beam should rest in a horizontal position when the scales are either empty or loaded with equal weights.-2d. A rery small addition of weight put into either scale, should cause the beam to deviate from the level, which property is denominated the sensibility of the balance.-3d. When the beam is deflected from the horizontal position by inequality of the weights in the scales, it should have it tendency speedily to restore itself, and come to rest in the level, which property is called the stability of the balance. The remarks which follow will guide in the construction of a balance, which shall possess the foregoing properties:-The arms of the beam should be exactly similar, equal in weight and length, and as long as possible. The centres of gravity and suspension ought to be in one straight line, and the centre of motion should be immediately abnve the centre of gravity. The centre of motion and the centres of suspension should canse as little friction as possible, and their axes ought to be at right angles to the line which measures the length of the beam. The centre of motion ought to be a knife-edge; and if the balance requires to be very delicate, the centres of suspension ought to be knifeedges also: and if the centres of suspension be not knife-edges, the rings with which they are formed should be hard, polished, and of an oval form. There are means of testing whether or not these conditions have been observed in the construction of a balance. For if the balance have no tendency to one position znore than another, when the scales are either loaded, empty, or off altogether, it is a proof that the centres of gravity and motion coincide, and the remedy is to lower the centre of gravity. If the beam is disturbed by a small addition of weight to either scale, the arm at the loaded end descending, and having no tendency to resume the horizontal position; then we may infer that the centre of gravity is above the centre of motion; and it is to be obserred, that the quicker the descent of the loaded arm of the beam is, the farther must the centre of gravity be lowered before the beam will acquire the requisite stability. If it require a considerable addition of weight in either scale to deflect the beam from the level, we may infer either that there is too much friction at the centre of motion, or that the centre of gravity is too low. If two weights are found to be in equipoise, one being in each scale, when a transfer of them is made, that which was in the one scale being put into the other, then if there be no longer an equilibrium, we may infer that the arns of the beam are of unequal lengths.

Various contrivances have been einployed, with a view to correct the defects of the conmon balance. The whole apparatus is not unfrequently enclosed in a glass case, which prevents the heat from expanding the arms unequally, or curreuts of air from disturbing the equilibrium. A sutall weight has been made to slide up or down on the tongue, by which means the centre of gravity may be raised or depressed at pleasure; and to regulate the equality of the length of the arms, a regulating screw is employed, by means of which the centre of suspension of either arn may be moved nearer to or farther from the centre of motion. Balances used for delicate purposes, such as for assaying, have the centre of motion suspended; but that centre is fixed on a pedestal, which firmly supports the whole. Such is the case in the as:ay balance, plate $1 \mathrm{X}$. fig. 1. - The hydrostatic balance (plate IX. fig. 4) is another modification of the com. mon beam and scale. The pedestal $D$ rises from the table $\mathrm{AB}$, to a convenient height, and supports the tablet $\mathrm{E}$, into which the stalk $F$ is fixed. From this stalk, the beam of the instrument is suspended, in a manner which the engraving will easily show. To the bottom of one of the scales, there is llooked a small wire, $\mathrm{C}$, which suspends the substance whose specific gravity is to be taken, and which in the figure is represented as immersed in the water contained in the glass vessel $R$. The minutize of construction and use of this balance, can only be understood by following the method usually employed for the determination of specific gravities, which will be found $e x$ plained under the article Gravity, specific.-The ba Jances, which we have considered above, all require ant assortment of weights; and it now remains for us to describe the more important of those balances which require only one weight, but are, nevertheless, capable of determining a great many. Of this description is the statera, or Roman steel-yard, represented in plate IX. fig. 3 , where $A B$ is a steel bar, moving on the fulcrum C, after the same manner as the common balance beam. If the arm $\mathrm{CA}$ be one inch long, and the arm CB any convenient length, being divided into inches, and also smaller than the short arm CA, so that when the weight which is seen at $\mathrm{E}$ is taken off, and the empty scale hung from $\mathrm{A}$, the bar $A B$ will be level, and at rest. If now a weight of two ounces were put into the scale $D$, the equilibrium will be destroyed, unless a weight of two ounces be hung on the long arm, at the distance of one inch trom the centre of motipn, or one ounce at the distance of two inches - if a six ounce weight be put into the scale $\mathrm{D}$, it will be balanced by one ounce at the distance of six inches from the fulcrum $\mathrm{C}$, on the long arm, \&c., which follows from the principles of the Lever. And thus, if the arm CB were sixteen inches long, and CA one inch, then would one ounce weight at $\mathbf{B}$ balance one pound avoirdupois in the

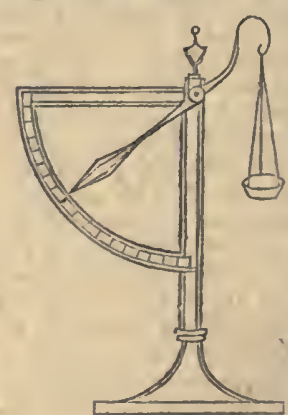
scale D. A modification of this instrument has lately been employed with much advantage in taking specific gravities. The bent-lever, or quadrant balance, is represented in the accompanying cut, and depends on principles nearly the same with those of the steel-yard. The article to be weighed is put into the scale, and the index will rise on the graduated quadrant, un- 
till an equilibrium takes place, when the index will point out the precise weight of the substance in the scales. The greater the weight in the scale is, the ligher will the index rise, which corresponds to the moving of the weight on the steel-yard, farther fiom the centre of motion. For an account of the spring balance, see Dynamometer.

Balatice of Powrr. See Power.

Balance of Trade, a subject formerly so much discussed, is now rarely mentioned. The notion was once entertained, that the prosperity of a country depended on exporting merchandise exceeding the value of the imports, and receiving the balance in the precious metals. If a nation has no mines, it can obtain the precious metals only by importation. So far, therefore, there is some ground for the notion. But in speculating on this subject; men fell into two errors-1, in supposing that any direct legislative interference was necessary, in respect to the precious metals ; 2 , in computing the balance of trade; for, if we compare the value of exports with that of imports received in exchange, the more profitable the trade is, the more the balance is against us; that is, the more will the value of imports, including the precious metals, exceed that of exports, if we estimate the value in our own markets; and there must be an excess equal to freight and charges, or it is a losing trade to those concerned. But any country may, in fact, have a balance of trade against it, provided it gets credit abroad; and that balance, consisting of the debts of individuals, may be embarrassing to the national industry as much as a private debt may be to a debtor, who has either made a bad largain, or has to struggle to obtain the means of making payment.

Balavclivg ; among seamen, the contracting a sail into a narrower compass, in a storm, by folding up a part of it at one comer, by which it is distinguished from reefing. Balancing is peculiar to few sails.

BALBEC, or BAALBEC; the ancient Heliopolis (city of the sun), in Colosyria, in the pachalic of Acre, in Syria, in a fertile valley at the foot of Antilibanus, 40 miles from Damascus; lon. $36^{\circ} 11^{\prime} \mathrm{E}$.; lat. $34^{\circ}$ $l^{\prime}$ N. ; a small meanly built town, surrounded by ruinous walls, containing about 5,000 inhabitants, among whom there are some Christians and Jews. The city is under the government of an aga, who assumes the title of emir. Here are the finest ruins in the East, of which a society of British travellers, who visited $B$. in the middle of the eighteenth century, have given the most complete description. As early as the time of Augustus, Heliopolis had a Roman garrison. Whether the magnificent temple of the sun, a great part of which is still uninjured, and which is one of the most splendid remains of antiquity, was built by the emperor'Antoninus Pius, or by Septinnius Severus, upon whose medals it appears to have been first represented, is uncertain. Of fiftyfour lofty columns, there are but six standing: their shaftsare fifty-four feet high, and nearly twenty-two in circumference; and the whole height, including the pedestal and capital, is seventy-two feet. Excellent inarble statues of Jupiter, Diana, and Leda, and bass-reliefs and busts of Roman emperors and einpresses, are yet to le seen. The size of the stones, with which the walls of the temple are constructed, is astonishing. No mechanical expedients now known would be able to place them in their present position. Under the emperor Constantine, this temple was neglected, and was changed into a Christian clurch. Thus it remained until after the irruption of the Arabians, when it fell to decay. The great palace which Antoninus Pius is also said to have built, and several other tenuples, are of distinguished beauty. Obeidah, a general of the caliph Omar, captured the city, after a vigorous defence. In $\$ 401$, it was taken by 'Tamarlane. An earthquake almost entirely destroyed it in 1759 .

Balboa, Vasco Nunez de; born about 1475; one of the Spanish adventurers who pursued the patı which Columbus had pointed out, and souglit to make their fortunes in America. The Spanish court granted them full permission to make discoveries, without giving them sufficient support. B., afte1 having dissipated his fortune in Spain, went to America, arrived at the isthmus of Darien, and soon became the leader of a small troop of Spaniards. He succeeded in founding a colony in these regions, either winning the inhabitants by kindness, or subjecting them by force. A dispute having taken place between two of his companions, on the division of a quantity of gold, an Indian, who perceived the eagerness of the Spaniards for it, offered to show them a country where this inetal was used for the meanest vessels. He led them to the coast of the Pacific ocean, where the way to Peru was open before them. B., however, ventured not to attack Peru with his troop of $\mathbf{1 5 0}$ men. He was satisfied wit!l getting information, and with taking possession, in the name of the king of Spain, of the great ocean, the boundless plain of which was spread out before him. After four months, he returned to Darien, loaded with gold and pearls. Here he found a new governor, Pedrarias, whom he was commanded to obey by an order of Ferdinand. Though surprised at this ingratitude, he complied, and, in the following year, was appointed viceroy of the South sea. Pedrarias was apparently reconciled to ${ }^{\circ} \mathrm{him}$, but, soon after, under pretext of neglect of duty, ordered him to be tried and condemned to death. B. was beheaded in 1517, at the age of forty-two years. Pizarro, who afterwards completed the discovery of Peru, had served under him.

Balcan. See Balkan

Bajcangual, Walter, D. D., an eminent divine of the 17th century, was born at Edinburgh, and entered a bachelor of divinity at Pembroke hall, Oxford, where, September 8,1611 , he was admitted a fellow. He appears to have enjoyed the patronage and friendship of king James, and his first preferment was to be one of the royal chaplains. In 1617 , he became master of the Savoy in the Strand, London, which office, however, he soon after resigned in favour of Mark Antony de Dominis, archbishop of Spalatro, who came to England on account of religion, and became a candidate for the king's favour. In 1618, Dr Balcanqual was sent to the celebrated synod of Dort, as one of the representatives of the church of Scotland. He has given an account of a considerable part of the proceedings of this grand religious council, in a series of letters to Sir Dudley Carleton, which are to be found in "The Golden Remains of the ever-1nemorable Mr John Hales of Eaton, 4to, 1673." In 1621, the archbishop of Spalatro having resigned the mastership of the Saroy, Dr Balcanqual was re-appointed; and on the 12 th of March, 1624, being then doctor of divinity, he was installed dean of Rochester. George Heriot, at his death, February 12, 1624, ordained Dr Balcanqual to be one of the three executors of his last will, and to take the principal charge of the establisliment of his hospital at Edinburgh. Dr Balcanqual is entitled to no small commenitation for the able manner in which he discharged this grent and onerous trust. The statutes, which, in terms of the testator's will, were drawn up by him, are dated 1627 , and do grcat credit to his sagacity and practical good sense.

In 1638, when Charles I. sent down the marquis of Hamilton to Scotland, to treat with the corenanters, B. accompanied his grace in the capacity of 
claplain. What was his external behaviour on this occasion, we do not know; but it was afterwands surnised by the covenanters, that he had been deputed by archbishop Laud, as a spy, at once upon the marquis, who was suspected of moderation, and the people with whom he was dealing. It is asserted by Sir James 13alfour, in his "Memorialls of State," that Dr Balcanqual also communicated intelligence of all that happened in Scotland, to Signor George Con, the pope's legate, "as some of his intercepted letters can beare reconte." Early in the ensuing sear, was published an apologetical narrative of the court-proceedings, under the title of "His Majesties Large Declaration, concerning the Late Tunults in Scothanc," whical, by universil and apparently uncontradicted report, was ascribed to the pen of $\mathrm{Dr}$ Balcanqual. White this work was received by the friends of the king as a trumphant vindication of his attempts upon the purity of the Scottish church, it only excited new indignation in the minds of the outraged people, who soon after appeared in arms at Dunse Law, to defend their religious opinions with the sword. On the 14th of May, 1639, at the very time when the armies were about to meet on the bonders, Dr Balcanqual, apparently in requital of his exertions, was installed dean of Durham. He had now reindered himself a marked man to the Scottish presbyterians, and, accondingly, his name is frequently alluded to in their publications as an incendiary. When the king could no longer protect his partisans, Dr Balcanqual was forced from his mastership of the Saroy, plundered, sequestered, and obliged to fly froin Loudon. Repairing to Oxford, he attached himself to the precarious fortunes of his sovereign, and for several jears afterwards, had to shift about from place to place, wherever he could find security for his life. At length, having taken refuge in Chirk castle, Denbighshire, he died there in a very cold season, on Christmas day, 1645. He was buried next day in the parish church of Chirk, where, some years after, a splendid monument was erected to his memory by a neighbouring royalist, Sir Thomas Middleton of Chirk castle.

BALDE, Jacob; born at Ensisheim, in Alsace, in 1603 , died, in 1668, at Neuburg, on the Danube. He was a Jesuit, a preacher at the court of the elector of Bavaria, and one of the most distinguished Latin poets among the moderns. He witnessed the melancholy scenes of the thirty years' war with a wounded heart. He relieved such as were expelled from their homes, and, at the same time, endea roured to awaken a better-spirit among the Germans, and to excite them to valour, virtue, and unanimity. An extensive and profound knowledge of the world, with a truly philosophical dignity of mind, are everywhere displayed in his poems. He will be admired in Germany in all ages. Augustus William Schlegel says of him, "A deep, strong feeling, often combined with an ardent enthusiasm; an imagination from which strong and wonderful images spring forth in boundless profusion; an inventive fancy, always striking out original comparisons, in surprising forms ; a penetrating judgment, which, when not blinded by partiality or early prejudices, catches the human character with a quick and piercing glance; great moral energy and independence; a bold security of genius, always choosing its own path, and not fearing eren the most untrodden;-all these qualities are so strongly displayed in the works of Balde, that we are constrained to declare him an uncommon and richly-gifted poet."-His poems in the German languuge are insignificant. A collection of his poetical writings, consisting of lyric, elegiac, didactic, satirical, and other poems, appeared, in 1660, at Cologne, in 4 vols. $12 \mathrm{mo}$; and at Murich, in 1729, 8 vols.; 8 selection by I.C. Orell, Zurich, 1805, second edition, 1818.

Baldwix I., emperor of Constantinople; a prince inemorable not only on account of his talents, but as having been the founder of the short-lived dynasty of Latin sovereigns of the Eastern empire. He was born in 1172, and was hereditary count of Flanders and Hainault. Having joined in the fourth crusade, he distinguished himself by his conrage and conduct in several actions which ensued; and wher Constantinople, in 1201, was takelı by the French and Venetians, Baldwin was unanimously elected emperor of the East. His new subjects revolted against lim, being excited by Joannices, king of Bulgaria, whom he had offended by rejecting his proffered alliance. The insurgents seized Adrianople, in besieging which city Baldwin was taken prisoner by the king of Bulgaria, and probably soon after put to death, with circumstances of great cruelty, in 1205. The uncertainty of his fate gave rise to a remarkable deception. Twenty years after his disappearance, a hermit ex hibited himself in Flanders, professing to be the long-lost prince, and was at first gladly received as such by his former subjects. He was, however, taken to the French court, where he was completely detected, and perished as an impostor.

BaLDWIN III., king of Jerusalem, from 1143 to 1162 ; a model of that chivalry which grew up in the period of the crusades, from the sentiments of honour, justice, devotion, and love. The crusaders had established counts of Tripoli and Fdessa, and princes of Antioch. The feudal dominions of the Christians extended as far as Tarsus and Cilicia; but the vassals of $\mathbf{B}$. were always in rebellion against him, or engaged in conflicts with each other. Against them and the new hosts of crusaders, against the knighto of St Mary, the Templars, and the Hospitallers, the Saracen heroes, Saladin, Noureddin, Zenghi, and Seifeddin, fought with equal fanaticism and equal dissensions among themselves, but with better fortune. In the army of $\mathbf{B}$. were sometimes seen Saracens, valiantly fighting under the banner of the cross. His unhappy reign was the last struggle to establish the Christian chivalry, the tournaments, and the knightly orders in the East. With it fell the feudal constitution in that quarter, both civil and ecclesiastical B. died not long before the total ruin of his kingdom; and when his great adversary; Noureddin, was advised to attack the dominions of the deceased during his funeral, he answered, "Let us respect their aftiction ; it is.just ; for they have lost a king such as is rarely to be found."

Baldwis, William; an English writer about the time of the Reformation, chiefly known as a principal author of the "Mirror for Magistrates," a series of tragical stories of persons of rank and note, said to have been projected by Thomas Sackville, first earl of Dorset, who wrote the poetical preface or induction, and the legend of Henry Stafford, duke of Buckingham, and left the work to be carried on by Baldwin and others. It was first published in 1559, and reprinted with a second part in 1563. Ritson says, the legends of Henry Percy, earl of Northumberland, Richard, earl of Cambridge, Thomas Montagu, parl of Salisbury, king James I. of Scotland, William Delapole, duke of Suffolk, Jack Cade, Richard Plantagenet, duke of York, lord Clifford, John Tiptoft, earl of Worcester, Richard Nevil, earl of Warwick, king Henry VI., and George duke of Clarence, in the first part, and those of Sir Anthony Woodville and Collingbourne in the second, appear to be the comnosition of Baldwin. He was at different times a schoolmaster, a printer, and a clergyman. He published verses on the death of Edward VI., and other poems. The time of his dzath is not known; but he seems to 
have lired some years after the accession of queen Elizabeth.

BALE, John, (in Latin Balæus) ; an English ecclesiastic, and bishop of Ossory in Ireland, was born at Cove, near Dunwich, Suffolk, in 1495. Although educated a Roman Catholic, the Reformation having found its way into England, he became a Protestant, according to his own account, at the instigation of Lord Wentworth, but possibly impelled by a still stronger incentive, as he immediately afterwards married. In early life he enjoyed the protection of lord Cromwell ; but after that nobleman's execution, his own warmth of temper, and the intolerance of the Popish party, rendered it necessary for him to retire into the Netherlands. On the accession of Edward VI., he returned to England, and was in the first instance presented to the living of Bishop's Stoke, Southampton, and soon after nominated bishop of Ossory, in Ireland. Here, on his preaching the reformed religion, his clergy either oppressed or forsook him; and so violent was the popular fury against him, that in one tumult five of his domestics were murdered in his presence. 'The death of Edward VI., and accession of Mary, necessarily added to his danger; and quitting his diocese, he lay some time concealed in Dublin. After enduring many hardships he was euabled to reach Switzerland, where he abode until the death of Mary. On his return to England, he made no attempt to recover his Irish diocese, but contented himself with the calm enjoyment of a prebencal stall at Canterbury, where he closed his stormy life in 1563, in the sixty-eight year of his age. Bale wrote several small pieces while he was a Romanist; and after he renounced Popery, his productions, both Latin and English, were still more numerous. Most of his English writings were attacks upon the religion which he had abandoned, to which he was a bitter and in many respects, it is to be feared, an uncandid and disingenuous enemy. His "Brief Chronicle concerning Sir John Oldcastle," was republished in 1729 ; and he is also the author of many strange productions in English metre, among which are several plays on sacred subjects, a specimen of which may be seen in the Harleian Miscellany. To modern readers they appear extravagant burlesques; but, as the author hinself informs us, they were gravely and piously represented in his own days by young men at the market cross of Kilkenny. The only work of bishop Bale which has given him distinction among authors, and is now at all attended to, is his "Scriptorum Illustrium Majoris Britanniæ Catalogus" " or "An Account of the Lives of eminent W riters of Britain." This account, which, according to the title, commences with Japhet the son of Noah, reaches to the year 1557, at which time the author was an exile in Germany. It is compiled from various writers, but chiefly from the antiquary Leland. With considerable allowances for the strong bias of party zeal, this work may still be read with advantage, although not without errors in regard to dates, and the needless multiplication of the titles of books. That his invectives against popery were too indiscriminately vehement, and his exposures of the vices and corruption of the Catliolic clergy overcharged, is now very generally admitted, although not to the extent which the party attacked would insinuate. "With every abatement, however, on the score of the warmth of a decided partisan and great personal sufferer, the principal work of Bale must ever be considered valuable as the foundation of English biography.

Bale, Basie, or Basle, See Basle.

BaLe, Council or. See Basle, Council of.

BaLkarss; the name of the two islands in the Mediterranean, situated near the coast of Valencia, in Spain, Majorca (in Spanish, Mallorca) and Minorca (q. v.), which, together with the Pithyusian islands, Ivica and Formentera. formed the Spanish kingdom of Majorca, containing 1758 square miles, and 275,000 inhabitants. The Grecian name $B$. was given them because the inhabitants were famous for their skill in slinging. The Balearic slingers distinguished themselves in the army of Hannibal. In later times, the Romans took possession of both the islands; afterwards, the Vandals, under Genseric, and in the 8th century, the Moors, from whom they were taken by James I., king of Arragon, 1220-1234. They then constituted a kingdom, which, in 1375, was united to Spain. The British conquered Minorca in 1708, lost it again in 1782, and relinquished it to Spain by the treaty of 1783.-Under the Romans, the $\mathrm{B}$. belonged to the conventus juridicus in Carthagine nova.

BALEv, Hendrick van, and Jacob van; father and son; historical painters ; the former born in 1560 , the latter in 1611, both at Antwerp. The former died in 1632. Pictures by each are still extant, and considered valuable.

Bales, Peter; famous for his skill in penmanship, lived in the 16th century. Holingshed, in his chronicle, mentions the wonderful skill of $\mathrm{B}$. in what may be termed micrography; and Evelyn more particularly states, that lie wrote the Lord's prayer, creed, decalogue, two short Latin prayers, his own name, motto, day of the month, year of our Lord and of the reign of queen Elizabeth, to whom he presented it at Hampton court, all within the circle of a silver penny, enchased in a ring and border of gold, and covered with a crystal, so accurately done as to be plainly legible, to the great admiration of her majesty, the "whole privy council, and several ambassadors then at court. He was very dexterous in imitating the hand writing of others, on which account he was employed by Sir Francis Walsinghan, the queen's secretary of state ; but, by involving himself in the conspiracy of the earl of Essex, he suffered imprisonment. He died about 1610 . From a book which he published in 1590, entitled the "Writing Schoolmaster, in three Parts; the first teaching Swift Writing, the second True Writing, the third Fair Writing," it appears that he was acquainted with stenography. His talents were celebrated by learned men in verse. We shall have a more just idea of his merits, if we consider the low state of penmanship at that time. All the manuscripts of that period extant are either miserably written, or have the appearance of drawings rather than writings.

BALESSAN; the Eastern name for that species of the amyris which produces the celebrated balsam of Mecca, the ancient balm of Gilead. This plant grows to the height of fourteen feet, on a stony, barren soil. The balsam is a resinous matter, exuding, like ordinary resin, froin incisions in the bark, in July, August, and September. The balsam is used for many medicinal purposes, and the ladies in the Fast employ it as a means of beautifying the skin. Lady Montague tried it, and relates that slie suffered for three days from its application, but that her complexion was greatly improved. The balsam of Gilead was renowned among the early Hebrews.

Balestra, Antonio ; an historical painter of much reputation ; born at Verona, in 1666 ; died, according to some, in 1720, according to others, in 1740 .

Balfour, Alexander, an esteemed miscellaneous writer, was born March 1st, 1767, in the parish of Monikie, Forfarshire. His parents belonged to the humbler rural class, and as he was a twin, he was almost immediately taken under the protection of a friend of the family, to whom lie was indebted not only for support during his early years, but also for those lessons of early piety and virtue which seemed to have laid the foundation of his character in after 
life. His education was very limited, and he was apprenticed at an early age to a weaver. Yet we are told that, while still a mere youth, he taught a school for several years in his native parish. At twenty-six, he became clerk to a merchant and manufacturer in Arbroath, and married in the ensuing year. His enrliest attempts in composition were inale at the age of twelve; the period of life when Pope and Cowley first began to scribble, and when ulmost all men of genius seem to show some sparklings of what they are afterwards to be. He contributed occasional rersesat a somewhat maturer age to the newspaper styled the British Clironicle, to Dr Andersou's "Bee," and to several provincial miscellauies. Some years after his removal to Arbroath, he commenced business in partnership with the widow of his employer, after whose death, in 1800 , he assumed another partner. The business vas soon after much extended, in consequence of the firm having become government-contractors for supplying the nary with canras. Still, under the pressure of his avocations, he continued to cultivate his talent for poetry. In a few years he was enabled by his success in business to purchase a considerable quantity of property. His life now passed in an uninterrupted course of commercial prosperity, domestic pleasure, and literary recreation. He also kept up a correspondence with some of the literary men of the capital, which was to him a source of much pleasure. In 1814, he removed to Trottick, within two miles of Dunder, to assume the management of a branch of a London house, which lad long transacted business on a large scale, and which, for many years, had been extensively connected with his orn firm. This step was unfortunate. In the ensuing year, so remarkable for calamity in the commercial world, the house in which he had embarked lis fortunes was suddenly involved in bankruptcy. He now accepted a dependent situation, as manager of a manufacturing establishment at Balgonie in Fife, the emoluments of which were barely sufficient to support a family corr sisting of a wife, two sons, and three daughters. Here he continued three years. He was at length induced, in 1818, to remove to Edinburgh, principally on account of his children, who were now arrived at that age when it was necessary to fix them in the particular walks of life which might be deemed most suitable. Here, in the course of a few months, he began to experience the approaches of general paralysis. His face and speech became affected, and he was seized with a particular sensation in the head. In June, 1819, he was obliged to relinquish his emplosment, and in October, he for the last time set his foot upon the ground.

For ten years after this period, Mr Balfour spent his dars in a wheel-chair, from which he could not rise without assistance, and devoted himself entirely to literature. In 1819, he published a norel, called "Campbell, or the Scottish Probationer," which was farourably received. At the close of the same rear he edited the poetical works of his deceased friend Richard Gall, with a biographical preface. About the same time he became a contributor of tales, sketches, and poems, concerning Scottish rural life, to Constable's Edinburgh Magazine; a work of which, in this capacity, he formed one of the chief litcrary supporters, till its close in 1826. Most of these articles are of eminent merit, painting the homely manners of Scotland with a mixture of truth, hunour, and pathos, that has never been equalled, and forming, in the mass, a most valuable historical record of what they refer to. One poetical series was entitled " Characters omitted in Crabbe's Parish Register," which were of such uniform excellence, that Uhey were supposed by many to be real contributions by the linglish poet. The notice with which thry were honoured, induced the anthor to re-publish them in 1825 , in the shape of a volume. Mr Balfour in 18:0, published a volume under the title of "Contemplation and other Poems." In 1823, he began to contribute novels to the Minerva Press; his first offering wns in three volumes, and entitled, "The Foundling of Glenthorn, or the Smuggler's Care." He contributed about the same time to "The Caledonian Magazine," and "Literary Olio," publislied at Dundee. In the year 1827 , through the intervention, it is believed, of Mr Joseph lfume, M. P., who presented a number of Mr Balfour's works to the premier, Mr Canning, a treasury donation of one huidred pounds was obtained for this unfortunate son of genins, to whom the gift was not le'ss honourable than to those who so generonsly dispensed it. The latest considerable work of Mr Balfour was a novel, entitled "Highland Mary," in four volumes. It is written with great simplicity and taste, and, as a story, is replete with a inournful pathos. He continued to the last to contribute to the periodical works of the day. He died on the 12th Sept. 1829. After his death a posthumous volume of his Remains was published, under the title of "Weeds and Wildflowers."

Balfour, Sir Andrew, Bart, M. D. : an eminent botanist, physician, and general beurfactor to his country, was the fifth and youngest son of Sir Micharl Balfour of Denmilne in Fife, and was horn at that place on the 18th January, 1630. He prosecuted his studies in the university of St Andrews, where he: took his degree of A. M. Quitting the university about the year 1650 , he removed to London, whrre? his medical studies were chieffy directed by the callbrated Harvey, by Sir Theodore Mayerne, the distillguished physician of king James I., and various other eminent practitioners. He afterwards travelled to Blois in France, and remained there for some time, to see the botanic garden of the Duke of Orleans, which was then the best in Europe, and was kept by his countryman Dr Morison. Here he contracted a warm friendship for that great botanist, which colltinued unimpaired while they lived. From Blois he went to Paris, where for a long time, he prosecuted his medical studies with great ardour. He completed his education at the university of Caen, from which he received the degrees of bachelor and doc. tor of physic, on the 20th of September, 1661. Returning to London soon afterwands, Dr Balfour was introduced to Charles I1., who named him as the most proper person to attend the young earl of Rochester on his continental travels. After an absence of four years, he returned with his pupil in 1667. During their tour he endeavoured, and at that time not without some appearance of success, to recall that abandoned young nobleman to the paths of virtue, and to inspire him with the love of learning. Rochester himself often acknowledged, and to bishop Burnet, in particular, only three days before his death, how much he was bound to love and honour Dr Balfour, to whom, next to his parents, he thonglit he owed more than to all the world.

On returning to his native country, Balfour settled at St Andrews as a physician. But his merit was too conspicuous to suffer lim to remain long there. In the year 1670 , he removed to Edinburgh, where he immediately came into great practice. Here, among other improvements, he prosecuted the manufacture of paper, and was the means of introducing that valuable art into the country-though for many years ic remained in a state of complete, or nearly coinplete dormancy; the people deriving stationary articles of all kinds from Holland. Adjoining to his house, he had a small botanic garden, which he furnished 
by the seeds he received from his foreign correspondents; and in this garden he raised many plants which were then first introduced into Scotland. One of his fellow labourers in this department was Patrick Murmy of Livingston, whom he had initiated into the study of natural history. This young gentleman, who enjoyed an ample fortune, formed at his seat in the country a botanic garden, containing one thousand species of plants, which at that period was a very large collection. He traversed the whole of France in quest of the plants of that country; and on his way to Italy, he prematurely died of a fever. Soon after his death, Dr Balfour transferred his collection from Livingston to Edinburgh ; and with it, joined to his own, he had the merit of laying the foundation of the first public botanic garden in Scotland. Upon his settlement in Edinburgh he had found the medical art taught in a very loose and irregular manner. In order to place it on a more respectable footing, he planned with Sir Robert Sibbald, the royal college of physicians; and of that society his brethren elected him first president. When the college undertook the publication of a Pharmacopocia, the whole arrangement of the materia medica was committed to his particular care. For such a task he was eminently qualified by his skill in natural history. This performance made its appearance in 1685; and, in the opinion of Dr Cullen, it is superior to any Pharmacopoia of that era. Not long before his decease, his desire to promote the science of medicine in his native country, joined to the universal humanity of his dispusition, led him to project the foundation of an hospital in Edinburgh. The institution was at first narrow and confined, but it survived to be expanded intu full shape, as the royal infirmary, under the care of George Drummond. Sir Andrew died in 1694, in the sixty-fourth year of his age, bequeathing to the university a museum, which at that time would have been an ornament to any metropolis. In 1700, his son published a series of his familiar letters.-His brother SiR JAMES BALFour, was an eminent antiquary, herald, and annalist, and left a numerous collection of MSS. regarding the history of Scotland, which are now preserved in the Advocates' Library, Edinburgh. From this collection his "Annals and short Passages of State" were published in 1824, in four volumes $8 \mathrm{vo}$, by $\mathrm{Mr}$ James Haig. Sir James died in 1657.

Balfour, (Sir) James, an eminent lawyer and public character of the sixteenth century, was a son of Balfour of Monquhanny, in Fife, a very ancient family. In youth, being designed for the church, he made considerable proficiency, not only in ordinary literature, but in the study of divinity and law; which were all alike necessary in those times for an cclesiastic, on account of the mixed character which the age admitted to be assumed by such individuals. While still a young man, he joined with the conspirators who, after murdering Cardinal Beaton, held out the castle of St Andrews against the governor Arran. He shared the fate of his companions in being sent to the French galleys, from which he escaped in 1550, along with the rest, by the tacit permission of the French government. He seems to have afterwards joined in the proceedings of the reformers, but only with courtier-like temperance, and without going into the enthusiasm in favour of Calvinism. He was preferred to the ecclesiastical appointment of official of Lothian, and afterwards became rector of Flisk, a parish in his native county. In 1563, he was appointed by Queen Mary to be a Lord of Session, the court then being composed partly of churchmen and partly of laics. In 1564, when the Commissary court was instituted in place of the ecclesiastical tribunal which laad bcen dissolved at the
Reformation, Balfour became one of the four coin missaries. In July, 1565, the Queen extended the further favour of admitting him into her privy council.

In the beginning of the year 1567 , Sir James Balfour was appointed governor of Edinburgh castle. In this important situation, he naturally became an object of great solicitude to the confederate lords, who, in the ensuing May, commenced a successful rebellion against Queen Mary. After the queen was dethroned, he was admitted by Murray a lord of his privy council, and made president of the Court of Session. Sir James continued faithful to the party which opposed Queen Mary, till the death of Murray, January, 1569-70, when he was in some measure compelled to revert to the Queen's side, on account of a charge preferred against him by the succeeding regent, Lennox, who taxed him with a share in the murder of Darnley. For this accusation no proof was ever adduced. Balfour outlived Lennox, and was serviceable in bringing about the pacification between the king's and queen's party, under Morton in 1573 . He would appear to have been encouraged by Morton in the task of revising the laws of the country, which he at length completed in a style allowed at that time to be most masterly. Morton afterwards thought proper to revive the charge brought by Lennox against Sir James, who was consequently obliged to retire to France, where he lived for some years. He returned in 1580 , and revenged the persecution of Morton, by producing against him, on his trial, a deed to which he had acceded, in common with others of the Scottish nobility, alleging Bothwell's innocence of the king's murder, and recommending him to the queen as a husband. Sir James died before the 14th of January, 1583-4.

The Practicks of Scots Law, compiled by Sir James Balfour of Pittendreich, president of the Court of Session, continned to be used and consulted in manuscript, both by students and practitioners, till nearly a century after his decease, when it was for the first time supplanted by the Institutes of Lord Stair. Even after that event, it was held as a curious repertory of the old practices of Scottish law, besides fulfilling certain uses not answered by the work of Lord Stair. It was therefore printed in 1754, by the Ruddimans, along with an accurate biographical preface by Walter Goodal. The work has been of considerable service to Dr Jamieson in his Dictionary of the Scottish language.

BALIOL, or BALLIOL, (Jolın de) fuunder of Baliol college, Oxford, was the son of Hugh de Baliol, a rich and leading baron in the reign of Henry III., to whose cause he strongly attached hinself in his struggles with the barons. In 1263 he laid the foundation of Baliol college, which was completed by his widow. This chieftain received a great accession of wealth and infuence by his marriage with Devorgille, one of the co-heiresses of Allan of Galloway, a great baron of Scotland, by Margaret, the eldest sister of John Scott, earl of Cliester, one of the descendants of David earl of Huntingdon. It was on the strength of this genealogy that his son John Baliol, under the influence of Edward I., became temporary king of Scotland.

BALIOL, or B.tLlol, John ; king of Scotland. On the death of Margaret the maiden of Norway, and grandchild of Alexander III., Baliol, being at the hend of the English interest in Scotland, claimed the vacunt throne by virtue of his descent from David, earl of Huntingdon, brother to William the Lion, king of Scotland. Robert Bruce opposed Baliol; but, having submitted to the arbitration of Edward I. the decision was in favour of Baliol, who did homage to him for the kingdom, Nov. 12, 1292. Baliol. however, did not long enjoy the crown, for, having 
remonstrated against the power which Fdwand asstuned over Scotland, he was sumnoned to his tribu. nal as a vassal. Irritated at this, 13aliol concluded a treaty with France, on which a war with Fngland immedintely commenced; and, afuer the battle of Dunbar, he surrendered his crown into the hands of the English monarch, who sent him and his son to London, to be imprisoned in the Tower. The pope intercaled for them, and they were liberated, and committed to his legate, in 1297 . Baliol retired to his estate in France, where he died in 1314.

B.ALIST.E, or B.ALLIstas; a kind of machines for besieging, or attacking the besiegers, in use among the aucients, by which heary stones, also arrows and other weapons, were thrown; and even burning substances and dead bodies, by the besiegers. Many of the ancient writers confound the baliste with the catapulta, but Polybius makes a difference, using the latter word only for those machines which threw stones. The mechanism of these machines is not quite clear. There is a third name for a kind of these machines-onager. The weight of the stones thrown was from 10 to 300 pounds. Sometimes a large quantity of stones was thrown at once. A clear idea of these instruments cannot be formed without the study of treatises on the arms and warfare of the ancients.

BALIZE; a sea-port of Mexico, in Yucatan, at the mouth of the river Balize. Vessels of burden cannot come near the town, on account of a bar in the river. It is the only settlement of consequence, belonging to the British, on the coast, and consists of about ¿00 houses, built of wood. The chief trade is in logwood and mahogany.

Bal.K; the ancient Bactria. (See Afghanistan.) Baukar (anciently called Hamus); a lofty and rugged chain of mountains, extending from cape Emineh Burum, on the Black sea, in European Turkey, to cape San Stefano, in the Adriatic sea, from $23^{\circ}$ to $27^{\circ} \mathrm{E}$. lon. Near Suln Derbent (Porta Trajani), this mountain, called, by the Turks, Emineh Slag, separates from Rhodope, and divides the valley of the Danube, which constitutes Bulgaria, (inhabited mostly by wandering tribes), from Romania, or Rumelia. A branch extends from north to south (mount Athos); another runs through ancient Greece, and comprehends the mountains Olympus, Eta, Pindus, Parnassus, Helicon. The highest peak, Orbelus, rises 9000 feet above the surface of the sea. After the overthrow of the empire in Constantinople, only the Greeks of the plains and the sea-coast submitted to the Mussulmans. The warriors, and those who had no landed property, fled into the mountains, into the armatolics, and have, in general, maintained a continual contest with the pachas of the plain: some have paid a small tribute to the Turkish pacha, and some have become Mahommedans. The districts where the Catholic is the prevailing church, contain the wildest inhabitants, and have never been subjected to the emperors of Constantinople for any length of time.

Batc. Ball-playing was practised by the ancients, and old and young amused themselves with it, particularly in the therma. The Greeks and Romans had four kinds of balls. One was of leather, filled with air, and consequently similar to our football; the second a leathern ball, which was thrown on the earth, and after which many ran it once; the third, a small ball, similar to our shuttlecock, which three persons, placed in a triangle, struck towands each other; the fourth was thickly stuffed with feathers, and used particularly in the country. In a Roman villa, a spharisterium, (a place appropriated for playing ball) was always to be found. In the uniddle ages, there were houses appropriated to ball- playing. In these, certain persons were employed to pick up the balls of the pluyers, who, in France, were called nanquets, and, in later tines, marqueurs. In Italy, there are still public places, where people play with large balls, which they strike with a kind of wooden cylinder, tastened round their wrists, to an immense height. The spectators often pay for admission to the spectacle, and, in some cities, the players form a company. From what we have seell in different countries, we think the national German ball-play the most interesting, and the one which affords the best exercise.

Ballad; a short epic song, (from the Italian ballata, an old kind of song, of an entirely lyric nature. Ballata is derived from ballare, to dance, probably from the German wallen (pronounced vallen), which signifies a waving motion. Though the uame is Italian, the species of poetry which we now understand under the word ballad, belonging to England and the other northern nations of Europe, is of Teutonic origin, at least Percy and Bouterweck agree in this, and Frederic Schlegel, in his History of An. cient and Modern Literature (Vienna, 1815), seems to be of the same opinion. The word ballata passed from the Italians to the Provençales, from whom the Normans took it, and carried it to Fngland, where it was applied to short songs, particularly to the most popular ones, which were short tales in verse, describing the deeds of heroes, the adrentures of lorers, \&c. If we wish to trace the English and Scottish ballad to its origin, we must have recourse to those songs which existed among the inhabitants of the island before the Norman conquest, and were of a kind common to all the Teutonic nations. It is related of king Alfred, that he sang in the camp of the Danes. All the Scandinavian nations delighted in songs celebrating the deeds of heroes, or describing the passions and adventures of lovers; and the three great divisions or cycles of the Teutonic poetry of the middle ages,-the stories of the Nibelungen, those of Charleniagne (particularly such as relate to his war against the Ambians, and the battle of Roncesvalles), and the tales of king Arthur's round table,-consist of what, at a later period, were called ballads.

The true home of the English ballad is the northern part of England (the North Country), and the southern part of Scotland, where the influence of the Normans was less than in the south of England. Those Normans who settled in these parts despised the native poetry, which they did not understand, and thus it was left entirely to the people, and retained, for that reason, its simple and popular character, even after it grew into esteem among the descendants of the Norman conquerors. The feudal wars of the Norman knights, and their highly chivalric spirit, which flourished in England as long, and in as ruch purity, as in the southern countries of Europe, afionded new subjects to the ballad, and contributed to modify its character. The minstrels were accustomed to sing the deeds of their ancestors, with all the additions which a lively imagination dictated. They soon commemorated, in the same way, the achievements of their contemporaries, and now the ballad, properly so cailed, originated. The former bards became minstrels, who, in connexion with the jongleurs, or jougleurs (resembling the modern jugglers, who have derived their name from them), waited upon the barons, like the French menetriers, devoting themselves to their amusement, and receiving in return, pecuniary rewards and hospitable entertainment. (Minstrel and menetrier are both derived from the Latin ministerialis.) As the popular poetry of the first centuries after the Norman con. quest did not acquire a literary reputation, and pro- 
bably was never committed to writing, it is not to be wonderel at, that the oldest poems of a nixed Norman and Anglo-Saxon character, which are preserved in MSS., are either imitations of French poetry, or religious songs, such as were found among other nations of Europe in the middle ages. A little poem on spring is almost the only one of genuine Saxon origin, which has, as yet, been printed from MS. Warton has published it in the additions and emendations which belong to vol. I. of his history of English Poetry. It begins, Sumer is cumen. The earliest of the English ballads which have been preserved cannot be considered as antecedent to the $14 \mathrm{th}$ century ; and we cannot speak with certainty of the origin of many which appeared before the 15 th. We have said that the ballad above described is properly of Tentonic origin; we ought to mention, however, that the Spaniards, and they only, among the southern nations of Europe, have songs of equal age and merit with the English ballads. The principal difference between them is, that the Spanish romance is in trochaic, the English ballad in iambic, metre. The different character of the nations has also produced some diversity in the tone of sentiment and feeling. At the time when this kind of poetry flourished in the two nations, they had very little interconrse with each other, and the similarity of the forms which it assumed can be explained only by an accidental similarity of canses. (For further information on the history of the English ballad, we must refer the reader to Percy's Reliques of Axcient English Poetry; Warton's History of English Poetry; Dr Burney's History of Music; vol. vii. of Bonterweck's History of Poetry and Eloquence since the End of the 13th Century; Sir Walter Scott's Minstrelsy of the Scottish Border; Jamieson's Popular Ballads and Songs, Edin. 1806, 2 vols. 8vo ; Finlay's Scottish $\cdot$ Historical and Romantic Ballads, Edin. 1808, 2 vols.; Motherwell's Minstrelsy, Ancient and Modern, Glasgow, 1827, 4to ; Buchan's Ancient Ballads, published at Peterhead.-For information respecting the Spanish ballad, or romance, as it is called by the Spaniards, see the article Romance.)

The French poetry of this kind never reached any high degree of perfection, because their fabliaux, legends, \&cc., soon degenerated into interminable metrical and prose romances of chivalry. In Italy, the ballad never flourished: the poetry of that country has always retained a certain antique spirit, and the Italians never partook, to any great extent, in the crusades, being fully occupied at home in the wars of the free cities. The Portıguese never cultivated the ballad much. Almost all their poetry of this kind is to be traced to a Spanish origin. The German ballad never became so popular as the English, nor was so much cultivated as the Spanish. The Russians have lyrico-epic poems, of which some, in old Russian, are excellent. In modern times, the ballad has been successfilly cultivated in Scotland and in Germany. The former country can boast of many of superlative merit, by Burns, Scott, Hogg, Cunningham, Motherwell, \&c.; while the latter country is little less distinguished by the ballad productions of Goethe, Schiller, Burger, \&c.-For some excellent observations on the character of the ballad, and what it requires, see Frederic von Schlegel's Kritische Schriften (on Burger.)

Balla:iolush, or Baizcheldsir; a village in the parish of Appin, district of Lorn, and shire of Argyle, situated at the head of Loch-Levin, where there is a ferry over to the opposite shire of Inverness. At this village there is a quarry of excellent blue slate.

Ballantrae; a parish and village in the district of Carrick, and shire of $\Lambda \mathrm{yr}$, lying on the bold and rocky coast of the north clieminel, and intersected by the river Stinchar, in which there is a considerable salmon fishery. The surface gradually lises from the sea to the top of that chain of mountains which extends eastward to the Forth, and the soil being poor, is chiefly appropriated to pasture. At the village is an endowed grammar-school, also several cotton manufactories, and a general post-office. Vestiges of a castle of the lords of Bargeny and the remains of an ancient church niay still be traced here. Population in $1831,1506$.

Ballantyne, James, an extensive printer in Edinburgh, whose name is intimately connected witl the literary productions of Sir Walter Scott, was a native of Kelso. Althongh not bred to the business of printer, he opened a printing office in his native town, where, besides editing the Kelso Mail newspaper, he printed various works, which rendered his name generally known, and paved the way for his establishment soon after in Edinburgh, where he ever after continued. The whole of the writings of Sir Walter Scott were printed by him, and to his taste the public is indebted for many emendations in the works of that illustrious minstrel and novelist, whose own inattention to not unimportant minutiæ, rendered such assistance highly necessary. For many years Mr Ballantyne conducted the "Edinburgh Weekly Journal," with a degree of good feeling and taste which the public did not fail to appreciate. His theatrical criticisms, in particular, which appeared in that newspaper, were long admired as the very best of the day. Mr B. did not survive Sir Walter Scott above one or two months. He died early in January, 1833. Shortly before his death, he published an affecting statement, in which he only prayed that he might be restored to that degree of health which would enable hin to do some justice to all that he felt and knew regarding the great and good man who had gone before him. But this was denied. They who had been so long united in their lives were not in death long divided.

Ballantyne, John, brother of the preceding, and distinguished as a litteratenr and humorist, was also a native of Kelso. While still a young man, his mind was turned to literary concerns by the establishment of a provincial newspaper, the Kelso Mail, which was begun by his elder brother James. The distinction acquired by his brother in consequence of some improvements in printing, by which there issued from a Scottish provincial press a series of books rivaling, in elegance and accurate taste, the productions of a Bensley or a Baskerville, caused the removal of both to Edinburgh about the beginning of the present century. He there embarked largely in the bookselling trade, and subsequently in the profession of an auctioneer of works of art, libraries, \&c. The connexton which he and his brother had established at Kelso with Sir Walter Scott, whose Border Minstrelsy was printed by them, continued in this more extensive scene, and accordingly during the earlier and more interesting years of the career of the author of Waverley, John Ballantyne acted as the confidant of that mysterious writer, and managed all the business of the communication of lis works to the public. Some of these works were published by John Ballan. tyne, who also issued two different periodical works, written chiefly by Sir Walter Scott, entitled respectively the Visionary and the Sale-room, of which the latter had a reference to one branch of Mr Ballantyne's trade. It is also worthy of notice; that the large edition of the works of Beaumont and Fletcher, which appeared under the name of Sir Walter Scott as editor, was an enterprise undertaken at the suggestion and risk of this spirited publisher. Mr Bal. lantyne himself urade one incursion into the field of letters; he was the author of a tolerably sprightly 
nurel In two thin duodecimos, styled, "The Widow's Lodgings," which reached a second edition. It was not, however, as an author, that Mr I3ullantyne chiefly shone-lis forte was story twlling. As a conteur, he was allowed to be unrivalled by any known contemporary. Possessing an infinite fund of ludicrous and characteristic anecdote, which he coull set of with humour endless in the variety of its shades and tones, he was entirely one of those beings who seem designed by nature for the task, now abrogated, of enlivening the formalities and alleviating the cares of a court: he was Yorick revived. After pursuing a laborious and successful business for several years, declining health obliged him to travel on the continent, and fundly to retire to a seat in the neighbourhood of Melrose. In his Melrose rustiration, he started the publication of a large and beautiful edition of the British Novelists, as an easy occupation to divert the langour of illness, and fill up those vacancies in time, which were apt to contrast disagreeably with the former habits of busy life. The works of the various novelists were here amassed into large volumes, to which Sir Walter Scott furnished biographical prefaces. But the trial was brief. While flattering himself with the hope that his frame was invigorated by change of air and exercise, death stepped in, and reft the world of as joyous a spirit as ever brightened its sphere. He died on the 16th June, 1821, aged about 45 .

Ballast (from the Danish baglast) is a load of sand or stones, deposited in ships, which have notfreight enough to sink them to their proper depth in the water, so as to resist the wind and waves. In storms, if the ressel leaks, part of the ballast must often be tlirown out, to make the vessel lighter. By the English navigation act, and by the laws of other commercial nations, formed by way of retaliation, vessels are often obliged to take ballast, either on their departure or return, instead of transporting, even at little profit, heavy and cheap goods of the country, to foreign countries.

BAllevtyne, or Betlevden, John, a Scottish poet of the reign of James $\mathbf{V}$., and the translator of Boece's Latin History, and of the first five books of Livy, into the vernacular language of his time, was a native of Lothian, and appears to have been born towards the close of the 15th century. He studied at the university of St Andrews, and afterwards at the university of Paris, where he took the degree of Doctor of Divinity. He returned to Scotland during the minority of James $V$., and became attached to the establishment of that monarch as "Clerk of his Comptis." In 1530 and 1531, Ballentyne was employed, by command of the king, in translating Boece's History, which had been published at Paris in 1526. Ballentyne delivered a manuscript copy of his work to the king, in the summer of 1533, - and about the same time he appears to have been engaged in a translation of Livy. His translation of Boece was printed in 1536, by Thomas Davidson, and had become in later times almost unique, till a new edition was published in a remarkably elegant style, in 1821, by Messrs Tait, Edinburgh. At the same time appeared the translation of the first two books of Livy, which had never before been printed. The latter work seems to have been carried no further by the translator. Ballentyne seems to have lived happily in the sunshine of court favour during the reign of James $V$. The opposition which he afterwards presented to the reformation, brought him into such odium, that he retired from his country in disgust, and died at Rome, about the year 1550. The translations of Ballentyne are characterized by a striking felicity of language, and also by a freedom that shows his profound acquaintance with the learned language upon which he wronght. Many of the works of Ballenden are lost -among others a traet on the Pythagoric letter, and a discuurse upon Virtue and Pleasure. He also wrote many political pieces, the inost of which are lost.

Baller (from bal; hence the French baller, and the Italian ballare, to dance); in its widest sense, the re presentation of a series of passionate actions and feel. ings, by means of gestures and dancing. According to this signification, we comprehend, under ballets, even representations of mental emotions, not connected with a regular train of action. In a more confined sense, we call ballets musical pieces, the object of which is to represent, by mimic movements and dances, actions, characters, sentinents, passions, and feelings, in which several dancers perform together. According to the analogy of lyrical poetry, those which rather represent feelings may be called lyrical ballets; those which imitate actions, dramatic ballets. The lyrical and dramatic ballets, togetler, constitute the higher art of dancing, in opposition to the lower, the aim of which is only social pleasure. The dramatic ballets are divided into historical, the subject of which is a real event; the mythological, in which the subject is some fabulous action; and the poetical, which are founded on poetical fiction, to which belong, also, the allegorical, necessarily the most imperfect. $A$ ballet is usually divided into several acts, each of which has several entrécs. An entrée, in a ballet, consists of one or several quadrilles of dancers, who, by their steps, gestures, and attitudes, represent a certain part of the action. In criticising a ballet, we must consider, first, the choice of the subject, which must have unity of action or of passion, and must be capable of being represented in an intelligible manner by means of mimic movements and dancing; secondly, the plan and execution of the single parts, which must have a due proportion to each other; and, finally, the music and decorations, which must supply whatever dancing cannot bring before the eye. The ballet is an invention of modern times (the in. genious artist Baltazarini, director of music to the princess Catharine de' Medici, probably gave.its form to the regular ballet), tliough pantomimic dances were not unknown to the ancients. (See Mimic and Pantomime.) The ballet owes much to the French, and particularly to Norerre. (q. v.) The dances, which are frequently introduced into operas, seldom deserve the name ballet, as they usually do not represent iny action, but are destined only to give the dancers an opportunity of showing their skill.

BALlHors, John; printer at Lubeck, who, between 1531 and 1599, published a spelling-book, on the last page of which he altered the usual picture of a cock with spurs, into that of a cock without spurs, having a couple of eggs at his side. As he printed in the title-page, on account of this trivial alteration, "Improved by John Ballhorn," the word Ballhornize is proverbially used in Germany, to signify stupid and useless alterations, or the making a thing worse instead of better.

Balusta. See Balista.

Bulwoon. See Aeronautics.

BALLor, voting by, signifies roting by means of little balls (called by the French ballotes), usually of different colours, which are put into a box in sich a manner as to enable the voter, if he chooses, to conceal for whom or for what he gives his suffrage. The method is adopted by most clubs in the election of their members - a white ball indicating assent; a black ball, dissent. Hence, when an applicant is rejected, he is said to be blackballed. It has long beell the ardent wish of many, that secret voting of this kind were adopted at political elections, so as to secure the independence of the voter, and put a stop to bribery, private or public intimidation, and other corrupt in- 
luences. Hitherto, however, old prejudices have stood in the way of so reasonable a wish, although these are fust wearing away, and there is now litile doubt of the ultimate adoption of the system.

BallstoN-SPA; a village of New York, seven miles S. W. of Saratoga springs, twenty-six N. of Albany. This place is noted for its mineral waters, which are sinilar, though inferior, to those of Saratoga springs. It is situated in a deep vale, on a branch of the Kayaderosseras creek, and contains about a hundred houses, a court-house, an Episcopal church, a Baptist meeting-house, and a number of large boarding-houses and inns, for the accommodation of visitors.

BaLM of GlLeAd is the dried juice of a low tree or shrub (amyris Gileadensis), which grows in several parts of Abyssinia and Syria. This tree has spreading, crooked branches; small bright-green leaves, growing in threes ; and small, white flowers on separate footstalks. The petals are four in number, and the fruit is a small egg-shaped berry, containing a smooth nut.-By the inhabitants of Syria and Egypt, this balsam, as appears from the Scriptures, was in great esteem from the highest periods of antiquity. We are informed by Josephus, the Jewish historian, that the balsam of Gilead was one of the trees which was given by the queen of Sheba to king Solomon. The Ishmaelitish merchants, who were the purchasers of Joseph, are said to have been travelling from Gilead, on the eastern side of Canaan, to Egypt, and to have had their camels laden with " spicery, balm, and myrrh." It was then, and is still, considered one of the most valuable medicines that the inhabitants of those countries possess. The virtues, however, which have been ascribed to. it exceed all rational bounds of credibility. The mode in which it is obtained is described by $\mathrm{Mr}$ Bruce. The bark of the trees is cut with an axe, at a time when its juices are in their strongest circulation. These, as they ooze through the wound, are received into small eartlien botiles; and every day's produce is gathered and poured into a larger bottle, which is closely corked. When the juice first issues from the wound, it is of a light yellow colour, and a somewhat turbid appearance ; but, as it settles, it becomes clear, has the colour of honey, and appears more fixed and lieavy than at first. Its smell, when fresh, is exquisitely fragrant, strongly pungent, not much unlike that of volatile salts; but if the bottle be lett uncorked, it soon loses this quality. Its taste is bitter, acrid, aromatic, and astringent. The quantity of balsam yielded by one tree never exceeds sixty drops in a day. Hence its scarcity is such, that the genuine balsam is seldom exported as an article of commerce. Even at Constantinople, the centre of trade of those countries, it cannot without great difficulty be procured. In Turkey, it is in high esteem as a inedicine, an odoriferous unguent, and a cosmetic. But its stimulating properties upon the skin are such, that the face of a person unaccustomed to use it be. comes red and swollen after its application, and continues so for some days. The Turks also take it in small quantities, in water, to fortify the stomach, and excite the animal faculties.

Balvaves, Henry, of Halhill ; an eminent lay reformer, and also a prose-writer of some eminence, was born in the town of Kirkaldy, Fifeshire. After an academical course at St Andrews, he travelled to the continent, and, hearing of a free school in Coiogne, procured admission to it, and received a liberal education, together with instruction in protestant principles. Returning to his native country, he applied himself to the study of law, and acted for some time as a procurator at St Andrews. In the year 1538, he was appointed by James $V$. a senator of the college of justice, a court only instituted five years before Notwithstanding the jealousy of the clergy, who hated him on account of his religious sentinents, he was employed on important embassies by James $V$., and subsequently by the governor Arran, during the first part of whose regency he acted as secretary of state. Having at length made an open profession of the Protestant religion, he was, at the instigation of Arran's brother, the abbot of Paisley, dismissed from that situation. He appears now to liave entered into the interests of the English party against the governor, and accordingly, with the earl of Rothes and Lord Gray, was thrown into Blackuess castle, (November, 1533, where he probably remained till relieved next year, on the appearance of the English fleet in the Frith of Forth. He was privy to the conspiracy formed against the life of cardinal Beaton, and shared in the fate of the conspirators. He was conveyed to the castle of Rouen in France, and there committed to close confinement. Here he employed himself, during his solitary hours, in composing a treatise on Justification, which was published at Edinburgh, in 1584, under the title of "The Confession of Faith, containing how the troubled man should seek refuge at his God, thereto led by Faith; \&c., Compiled by M. Henrie Balnaves of Halhill, one of the lords of session and counsell of Scotland, being a prisoner within the old pallaice of Roane, in the year of our Lord, 1548. Direct to his faithful brethren being in like trouble or more, and to all true professors and favourers of the syncere worde of God." After his return from banishment, Balnaves took a bold and conspicuous part in the contest carried on by the lords of the congregation against the regent Mary. In 1563, he was re-appointed to the bench, and also nominated as one of the commissioners for revising the Book of Discipline. He acted some years later, along with Buchanan and others, as counsellors to the earl of Murray, in the celebrated inquiry by English and Scottish commissioners into the alleged guilt of queen Mary. He died, according to Mackenzie, in 1579.

Baloochistan. See Beloochistan.

BALSAM. The term balsam was formerly applied to any strong-scented, natural, regetable resin, of about the fluidity of treacle, inflammable, not miscible with water without addition, and supposed to be possessed of many medical virtues. All the turpentines, the Peruvian balsam, copaiba, \&c., are examples of natural balsams. Mauy medicines, also, compounded of various resins or oils, have obtained the name of balsams: as Locatelli balsam, \&c. Lately, the term has been restricted to those resins which contain benzoic acid. The most important balsams are those of Tolu and Peru-storax and benzoin, as they are named: the latter is concrete, the former fluid, though becoming solid with age. They are odorous and pungent, and useful only as articles of the materia medica. The benzoic acid is extracted from them either by applying a gentle heat, when it is volatilized, or by maceration in water, when it is dissolved.

Baltic SEA, or the East SEA; a large gulf, connected with the North sea. It washes the coasts of Denmark, Germany, and Prussia, of Courland, Livonia, and other parts of Russia and of Sireden; ex. tends to $65^{\circ} 30^{\circ} \mathrm{N}$. lat. ; is above 600 miles long, from 75 to 150 broad, and its superficial extent, together with the contents of the gulfs of Bothnia and Finland, amounts to 120,000 square miles. Its small breadth, its depth amounting, on an average, to from fifteen to twenty fathoins, but in many places to hardly half so much, the shallowness of the Prussian shore, and the rugged nature of the Swedish coasts, but, above all, the sudden and frequent changes of the wind, 
accompanied by violent storms, render this sea dangerous for navigators, althongh its waves are less ierrible than those of the North sea. A chain of islands separates the sonthern part of this sea from the northern, or the gulf of Bothinia. In the northpast, the gulf of Finlind stretches far into Finland, and separates that province from Fsthonia. A third gulf is that of Riga or Livonin. The Curische Haff and the Frische Haff are inlets on the Prussian coast. The watpr of the Baltic is colder and clearer than that of the ocean : it contains a smaller proportion of salt, and the ice obstructs the navigation three or four months in the year. The ebb and flow of the tide are inconsiderable, as is the case in other inland seas, whose outlets are toward the west; jet the water rises and falls from time to time, although from other causes, particularly on account of the violent current, through the Sound and both the Belts, into the Cattegat. In stormy weather, amber is found on the coasts of Prussia and Courland, which the waves wash upon the shore. Forty streams smpty themselves into the Baltic: among them are the Neva, Dwina, Warnow, Trave, Peene, Oder, Persante, Wipper, Vistula, Pregel, Niemen, and the generally insignificant Swedish rivers. Besides Zealand and Fuhnen, may be noticed the following islands : Samsoe, Mon, Bornholm, Langeland, Laaland, which belong to Denmark ; the Swedish islands Gothland and Oeland, likewise Hween in the Sound, with the ruins of Oranienburg, the observatory built by Tycho Brahe; Rugen, now belonging to Prussia ; lastly, the islands of Aland, at the entrance of the gulf of 13othnia, and Dagoe, together with Oesel, on the coast of Livonia, which belong to the Russian empire. Three passages lead from the Cattegat into the Baltic sea-the Sound, the Great and the Little Belt. At all three a toll is paid, often amounting to 500,000 or 600,000 rix dollars yearly. From 4000 to 6000 ships enter yearly from the North sea into the Baltic.

Baltimorr; a city and port in Baltimore county, Maryland, America, on the north side of the Patapsco, fourteen miles above its entrance into Chesapeake bay; 37 N. E. Washington, $100 \mathrm{~S}$. W. Philadelphia. Lon. $76^{\circ} 36^{\prime} \mathrm{W}$.; lat. $39^{\circ} 17^{\prime} \mathrm{N}$. Pop. in 1790 , 13,758 ; in $1800,23,971$; in $1810,46,556$, of whom 10,343 were blacks; in $1820,62,738$; in 1830 , 80,519. - B. has had a remarkably rapid growth. It was first laid out as a town in 1729; and, in 1765, it contained only about fifty houses. It was first erected into a city in 1797, and is now the third in size in the United States. It is admirably situated for commerce, and is a place of great wealth and trade. It possesses most of the trade of Maryland, about half of that of Pennsylvania, and a portion of that of the Western States. B. is the best market for tobacco in the United States, and it is the greatest flour market in the world. Its vicinity affords great water privileges, and there are now in operation numerous flour-mills, cotton manufactories, and other water-works. The stripping owned here in 1790 amounted to only 13,564 tons; in 1816 , to 101,960 tons.

Baltimore, as laid out, is four miles square, and it is divided into twelve wards. It is built around a basin, which affords a spacious, secure, and commodious harbour, having, at common tides, eight or nine feet of water. The principal part of the city is divided from the portions styled Old Town and Fell's point by a small river, called.Jones' falls, over which are erected three elegant stone bridges, and four wooden ones. Vessels of 500 or 600 tons can lie at the wharves at the point in perfect safety; but those of only 200 tons can come up to the town. The mouth of the harbour is a narrow strait, and is effec- tually commanded by fort M'Ileniy, which secures the city against a naval force. 'The situation of a part of the town is low, and it was formerly accounted unhealthy; but the various improvements which have been made, partienlarly the filling up of low and marshy grounds, have rendered it lealthy. It is supplied with excellent water from four public fountains, which are fitted up in an oniamental style.

Baltimore contains a court-house, a penitentiary, a jail, an alms-house, an hospital, two theatres, a circus, an exchange, a musenn and gallery of paintings, five market-houses, and about forty houses of public worship.-The exclıange is a very large edifice, 366 feet by 140 , somewhat resembling an $\mathrm{H}$, having tour wings-one for the United States branch bank, one for the custom-house, and one for a coffeehouse. The Roman Catlolic cathedral and the Unitarian church are very conspicuous and lanidsome edifices. St Paul's church, the court-house, and the Union bank are spacious and elegant. Several of the other public buildings are large and elegant. The Washington monument, a lofty structure of stone, is situated on an elevation just abore the compact part of the city. The base is fifty feet square and twenty-three high, on which is placed another square of about half the extent and elevation. On this is a column twenty feet in diameter at the base, and fourteen at the top. The statue of Washington is to be placed on the summit, 163 feet from the ground. The city is generally well built, mostly of brick. Many of the houses, particularly of those recently erected, display much elegance and taste. The streets are well pared, and many of them are spacious. The principal street, called Baltimore or Market street, is about a mile long, aud about eighty feet wide, runs nearly east and west, parallel with the water, and is intersected at right angles, like those in Philadelphia. North and east of the city, the land rises to a considerable elevation, and affords a fine and variegated prospect. The town, the point, the shipping both in the bay and at Fell's point, the bay as far as the eye cain reach, rising ground on the right and left of the har. bour, a fine grove of trees on the declivity at the right, and a stream of water breaking over the rocks at the hill on the left, make a scene of much beauty. The two principal literary institutions of 13 . al $\mathrm{St}$ Mary's college and a medical college. The former, which was incorporated in 1806 , is a Catholic institution, well endowed, and has a library containing about 10,000 volumes. The medical college was founded in 1807, and, in 1812, it received a new charter with the title of university.

A formidable attack was made on this city during the war, on the 13th and 14th of September, 1814 by the British, under general Ross. On the 13th, the battle at North point was fought; and, on the 14 th, fort M'Henry was bombarded. The enemy was repulsed, and general Ross slain. An elegant structure of marble, about thirty-five feet high, called the battle monument, has been erected to commem. orate this event. On the column are inseribed the names of those who fell in defence of the city. (Fot the Baltimore and Ohio railroad, see Railroad.)

BaltinoBe BIRD (icterus Baltimore; oriolus Baltimore, Wilson; called, also, hang-nest golden robin, fire-bird, hanging-nest.) The Baltimore bird is a beautiful visitor from the south, which arrives in Pennsylvania about the beginning of May, and de parts towards the last of August or first of September! It is most generally known by the name of Baltimore bird, so called, according to Catesby, from its blaek and orange plimmage, these colours being those of Calvert, lord Baltimore, proprietary of the province of Maryland.-The bird is seven inches long, an:d 
has a nearly straight, strong, black bill, tapering to a point. The head, throat, and npper part of the back and wings are black; the inferior part of the back, rump, and whole of the body beneath are of a brilliant orange hue. The tail is slightly forked; the legs are of a lead colour, and the irides hazel. The culours of the female are far less brilliant thau thiose of the male. Beautiful figures of both sexes are given in Wilson's American Ornithology, whence this account is sketched.-The nest of the Baltimore bird is formed by fastening strong strings of hemp or flax round two forked twigs, corresponding to the in . tended width of the nest, on the high bending extremicies of apple, willow, or tulip-tree branches, near farm-houses. With similar materials, together with loose tow, a strong sort of cloth is interwoven, resembling raw felt, forming a pouch six or seven inches deep. This is well lined with soft substances, which are worked into the outward netting, and, finally, with a layer of horse-hair ; the whole being protected from sun and rain by the overhanging leaves. The nests, lowever, are not uniformly of the same shape, and some are more perfect than others. - While making their nests, these birds will carry off any thread or strings left within their reach; they will even attempt to pull off the strings with which grafts are secured. All such materials are interworen in the fabric with great ingenuity, and the strongest and best materials are uniformly found in parts by which the whole nest is supported.-The Baltimore bird feeds on bugs, caterpillars, beetles, \&c. His song is a clear, mellow whistle, repeated at short intervals : when alarmed, a rapid chirping is uttered, but always followed by his peculiar mellow notes. The species inhabits North America, from Canada to Mexico, and is found even as far south as Brazil.

Balzac, Jean Louis Guez de, a member of the French academy, born at Angouleme, in 1694, lived in Rome as agent of the cardinal de Lavalette, after two years established himself in Paris, and, by his talents, attracted the favourable notice of the cardinal Richelieu, who conferred upon him a salary of 2000 livres, with the title of a counsellor of state. He was considered as one of the greatest scholars and most eloquent men of his age in France; yet his numerous writings found severe critics. Among these, Goulu, general of the Feuillans (a monastic onder, under the rule of St Bernard), pushed his criticisms even to insult and abuse. This induced $B$. to leave Paris. He died in Angouleme, in 1654, and the 60th year of his age. Aiming at dignity of style, he fell into bombast, affectation, and exaggeration, so that his works have gradually lost their reputation as taste has improved in purity. Nevertheless, we must do justice to the harmony of his periods, and acknowledge that he has done inuch towards the improvement of the French prose. He had studied the ancients, and his Latin poems, although without remarkable poetical merit, are pure, and free from the faults of his French writings. The most perfect of his works is, without doubt, a treatise upon Latin verse. The assertion of Voltaire and Laharpe, that he occupied limself more with words than with ideas, is too severe. A complete edition of his works appeared at Paris, in 1665, in two volumes, folio.

Bambarra; one of the largest and most powerful kingdoms of central Africa; bounded N. by the Great Desert, W. by Kaarta, Mandingo, and Ladanar, E. by 'Timbuctoo, and S. by Kong. It is traversed from $W$. to $\mathrm{E}$. by the Niger, and is generally very fertile. The inhabitants are a mixture of Moors and Negroes. Among the towns are Sego, the capital, Jenne, and Sansanding.

BaMBERG. This town, formerly the capital and place of residence of a bishop, whose see contained
1375 square miles, and 200,000 inluabitants, now the seat of the provincial authorities of the Bavarian circle of the Upper Maine, and of an archbishop, has about 20,000 inliabitants. The prince of Neufcliatel. Berthier, the son-in-law of duke William of Bavaria here threw himself from a window, in the palace of the latter, in 1815, on account of the new revolution in France. The cathedral church was built as early as 1110. The university there is also very ancient.

Bamboo Cane. The bamboo cane (bambusa arundinacea) has a hollow, round, straight, and shining stem, and sometimes grows to the length of forty feet and upwards; has knots at the distance of ten or or twelve inches from each other, with thick, rough, and hairy sheaths, alternate branches, and small, entire, and spear-shaped leaves. There is scarcely any plant so common in hot climates as this, and few are more extensively useful. It occurs within the tropical regions, both of the eastern and western hemispheres, throughout the East Indies and the greater part of China, in the West Indies, and America. In temperate climates, it can only be cultivated in a hot house; and its growth is so rapid, even there, that a strong shoot has been known to spring from the ground, and attain the height of twenty feet in six weeks. The inhabitants of many parts of India build their houses almost wholly of bamboo, and make all sorts of furniture with it, in a very ingenious manner. They likewise form with it several kinds of utensils for their kitchens and tables; and from two pieces of bamboo, rubbed hard together, they produce fire. The masts of boats, boxes, baskets, and innumerable other articles, are made of bamboo. After having been bruised, steeped in water, and formed into a pulp, paper is manufactured from the sheaths and leaves. The stems are frequently bored, and used as pipes for conveying water; and the strongest serve to make the sticks or poles with which the slaves or servants carry those litters, so common in the East, called palanguins. The stems of the bambon serve as the usual defence for gardens and other enclosures; and the leaves are generally put round the tea exported from China to Europe and America. Some of the Malays preserve the small and tender shoots in vinegar and pepper, to be eaten with their food. Many of the walking canes used in Europe and the United States are formed of young bamboo shoots. The Chinese make a kind of frame-work of bamboo, by which they are enabled to float in water; and the Chinese merchants, when going on a voyage, always provide themsel res with this simple apparatus to save their lives in case of shipwreck. It is formed by placing four bamboos horizontally across each other, so as to leave a square place in the middle for the body, and, when used, is slipped over the head, and secured by being tied to the waist.

BAMBвOUK or BAMBOC; a town in Africa, and capital of a kingdon of the same name, between the Faleme and Senegal rivers; lon. $9^{\circ} 30^{\circ} \mathrm{W}$.; lat. $13^{\circ} 25^{\circ}$ $\mathrm{N}$. The country is situated between $12^{\circ} 30^{\prime}$ and $14^{\circ} 15^{\prime}$ N. lat. ; about 36 leagues from N. to S., and 28 in breadth, and said to contain about 60,000 inhabitants. It is composed chiefly of lofty, naked, and barren mountains, and its wealth consists entirely in its mineral productions. These are gold (which is abundant), silver, iron, tin, lead, and loadstone. The most remarkable animals are a species of asses, extremely white (which the inhabitants will not allow to be sent out of the country), white foxes, and the giraffe. The little which is known of this state is derived from a Frenchnan named Compagnon, who resided there a yearand a half, in the beginuing of the last century. (Labat, Afrique Occidentale, iv. 5.)

$B_{A N}$, in ancient jurisprudence; a declaration of 
onilawry, of which we have recently had an instance in the proclamation issued against Napoleon, if fuer his returu from Elba.

13.rv, in political law, is equivalent to excommunicution in ecclesiastical. The emperor of Gerunany liad the riglit to declare a member of the enpire under the ban, and to dispose of his feud. 'The barr, like the excommunication, forbids every one to lave intercourse with tlie person proscribed, or to give him food or shelter. V(ry often, however, the sentence was repealed, and the party restored to all his rights and privileges. - Ban, in military aftairs, is an order, given by benting the drum or sounding the trumpet, requiring the strict observance of discipline, or announcing the appointment of an officer, \&c.

Ba.v, or B.s.s, a large river of. Ulster in Ireland, which takes its rise in a plain called the Deer's Meadorc, and sometimes the King's Meadow, in the mountains of Mourne and county of Down. After Aowing a distance of thirty-eight miles, it falls into Lough Nengh near the Ban-foot ferry, in the county of Armagh. This part is called the Upper Ban. In its course it passes within two miles of Rathfryland throngh M० Cay's Bridge and Banbridge, by Guilford and Portadown, near which last place it is joined by the Newry canal, and, froin thence to Lough Neagh it is navigable by boats of fifty tons burden. The lower Ban (which is the outlet of Lough Neagh) passing by Toome, and winding through a ruggee country, tumbles over several ledges of rock, washes Coleraine, and falls into the sea five miles below that town. By means of the Newry navigation the Upper Ban is made subservient to the opening of a commnnication from Lough Neagh to the Irish sea; and, if the Lower Ban were made navigable, a safe cominunication would be opened from the Irish sea to the Atlantic, to the incalculable benefit of six courties. The fishery of this river is extremely valuable.

Bax (bannus). This name is given to the governors of Dalmatia, Sclavonia, Croatia, placed at the head of civil and military affairs in these countries. Ban signifies, in the Sclavonian tongue, a master. A province, over which a ban was placed, is called bannat. At present, the only ban is that of Croatia, who has the third place among the secular nobles of Hungary. Before him come the palatinus regniand the judex curia.

Havava. The banana is a valuable plant (musa sapientium) which grows in the West Indies and other tropical countries, and has leaves about six feet in length and a foot broad in the middle, and fruit four or five inches long, and about the shape of the cucumber. When ripe, the banana is a very agreeable fruit, with a soft and luscious pulp, and is frequently introduced in desserts in the West Indies, but never eaten green, like the plantain. The Spaniards hare a superstitious dislike to cut this fruit acress ; they always slice it from end to end, because, in the former case, the section presents an imaginary resemblance to the instrument of our Saviour's crucifixion. The banana is sometimes fried in slices as fritters. If the pulp of this fruit be squeezed through a fine sieve, it may be formed into small loaves, which, after having been properly dried, may be kept for a great length of time.

Banberi; a borough and market town in the hundred of Banbury and county of Oxford, sixty-nine miles N. W. from London. It has long been celebrated for the excellence of its cheese, its cakes, and its ale. The population of the borough and parish in 1831 was 5906 .

BAvcs, an island belonging to the Netherlands, near Sumatra, one of the vassal states of Palembang, cortaining 60,000 inhabitants, among them 25,000
Chinese, is known on account of its.tin mines, work. ed by the Dutch Fast India company (the annual profit of which, to the Dutch, is estimated at $£ 150,000$ ), and its pearl fishery, which is also pro dhetive on the shores of the group of Solo islands, northerast from Borueo. 'The tin of Banca is purr, and easily obtained. The sonth-easterly part of Banca las not yet been examined. The Banca islands, in $2^{\circ} 22^{\prime} \mathrm{S}$. lat., and $105^{\circ} 4 \mathrm{I}^{\prime} \mathrm{F}$. lon., aflurd shciter from S. W. by S. to N. W., with a good sup. ply of water and fuel.

BANDA IsLANDS; a group of islands belonging to the Netherlands, in the Fastern ocean, lyirig $\mathbf{E}$. of the Celebes; so called from Banda, the principal of them; lon. $130^{\circ} 37^{\prime} \mathrm{E}$.; lat. $4^{\circ} 12^{\prime} \mathrm{S}$. They contain but 5763 inhabitants, though they are said formerly to lave contained 15,000 . Their chief produce is nutmegs, of which they are competent to supply the want of the rest of the world. The whole quantity produced on these islands cannot be at: curately stated. 'The annual sales are said formerly to have amounted to 350,000 pounds of nutmegs and 100,000 pounds of mace. When, however, they wer taken by the British, in 1796, the half year's crop was found to be little more than 80,000 pounds of nutmegs and about 24,000 pounds of mace. The trees in all the other islands were carefully 'xtirpated by command of the Dutch; and the whole trade of those where the growth is cherished is a complete? monopoly. - The names of the islands are Banda, or Lantor; Puloway, or Poolaway; Pulo Rum, or Poolaron; Neira, Gunon Assi, or Guanapee Rosyngen; Pulo Prampon, Pulo Suanjée Capal, and Nylacky. The inhabitants are in alliance with the Dutch East India company. - These islands can never be expected to yield any advantage besides that derived from the spice trade. Entirely cut off trom the other parts of India, and deprived of all commerce, save a trifing bartering with the indigent natives of the south-eastern and south-western islands, they are even destitute of the means of subsistence for their own jnhabitants, and must be supplied with every necessary from abroad, as nature, which has lavishly bestowed upon them articles of luxury, has denied them those of immediate necessity. Banda is likewise accounted a most unhealthy place, especially at the chief setllement of Neira. Some attribute this circumstance to the neighbourhood of the volcano, in the islands of Gunong Api, and others to a deleterious quality in the water.

Banda Orievtal. This tract of country has fixed public attention, as the subject of an obstinate war between Brazil and the United Provinces of La Plata, and seems destined, by its geographical position, to possess much importance hereafter. It is situater. between the eastern bank of the river Uruguay and the ocean, and between the river La Plata on the south and the Sierra do Topas on the north (which separates it from Brazil), and receives its name from its position with respect to the Uruguay. It is fertile and healthy, and, although checked in its prosperity by political misfortunes, had gained a white population of 80,000 souls. Having been originally settled by a Spanish colony from Buenos Ayres, it fell under the authority of Spain, but came, at length, to be the occasion of contention with Portugal. Both nations prized it ; Spain, as giving her the control of both sides of the river La Plata ; Portugal, as necessary to the free and secure navigation of the immense interior of Brazil ; and each nation asserted a claim to a territory of so much consequence. During the long wars between Portugal and Spain, relative to the various boundaries of their vast possessions in South America, the Banda Oriental was overrun and wastcd, sometimes by one and sometimes by the other, 
and their respective pretensions were differently regulated by successive treaties. In $177 \%$, Portingal was forced to consent to the line of the Sierra do 'Topas, but afterwards seized on the district of the Missions, which sle consented to restore, in 1804, as the price of the Portuguese fortress of Olivenza, held by Spain.

When the revolution commenced, the Orientalists naturally sided with the governor of Buenos Ayres; but whether they merely acted in concert with the latter, or acknowledged a dependance, does not appear. Certain it is, that they soon made themselves independent of Buenos Ayres, under the guidance of Artigas, in consequence of a victory gained by him over the Buenos Ayreans, in 1815, at Gaubiju. But, soon afterwards, the Brazilians, pretending to fear that Artigas would propagate his revolutionary doctrines in Brazil, attacked him, broke up his forces, and compelled him to fiy into Paraguay.-Brazil continued to hold military possession of the country, although resisted by the inhabitants, until 1822 , when they were induced, ostensibly by persuasion, but really by intimidation, to send delegates to a convention at their capital, Monte Video, and to consent to be annexed to Brazil, by the name of the Cis-Platine province, which don Pedro claims as a voluntary union of the people with the empire of Brazil. When Brazil separated from Portugal, in 1822, the Orientalists joined a party of the army which declared for Portugal, and, on the submission of these troops, called upon Buenos Ayres for aid. Assistance was given them in arms, money, and men, but not ostensibly by the congress, until their leaders, Lavalleja and Fructuoso Rivera, had shut up the Brazilians in Monte Video, and a provisional government, organized in the town of Florida, formally declared the Banda Oriental to be reunited to Buenos Ayres. The standard of independence was raised by Fructuoso Rivera, April 27th, 1826; and, as he was immediately aided, by Lavalleja, with forces organized in Buenos Ayres, this may be considered as the actual coinmencement of the war. Oct. 12, Lavalleja gained the victory of Sarandi, and the republic no longer hesitated to assume a quarrel, which began to wear \& prosperous aspect. But no formal declaration of war was issued until that of Pedro, dated Dec. 30th 1826, which entered into an elaborate exposition of the alleged rights of Brazil. The war has been alike prejudicial to both countries. While Pedro blockaded Buenos Ayres, the cruisers of the latter cut up the commerce of Brazil ; and while both parties contributed to waste the Banda Oriental, the Orientalists carried similar devastation into the Brazilian province of Rio Grande. But neither party possessed adequate resources to strike a decisive blow ; and the solicitations of Great Britain, who, like other neutral nations, suffered by the war, at length brought about a peace, which was signed at Rio, Aug. 28th, 1828, and, in substance, provided that the Banda Oriental should become an independent state, under the mutual gusrantee of the two contracting parties. Thus the war, after completely exhausting both Brazil and Buenos Ayres, ended in a drawn game as to the subject of the contest.

BaNDANa; the name applied to a peculiar species of handkerchief, the fabric of which may be either silk or cotton, having a dark greund of Turkey red, blue, ur purple, varegated with patterns of white, or bright yellow. These handkerchiefs were formerly manufactured in the East Indies, and thence imported into Furope; but the beauty and clurability of their colours caused such a demand for this commodity in Fingland and the nations of the continient, as to stimulite our British manufacturers, not only to imilate, but cren surpass the Eastern Bindana. At first, the imitations were niade by the common process of print. ing with blocks, which never produced such durability of colour or clean outline of pattern. Alout the beginning of the present century, the proper method of producing the desired effect in manufacturing Bandanas was discovened, but so many claimants have come forward for the honour of originality, that it is difficult, if not impossible, to determine to whom it is due. Glasgow was the first place in this country where the manufacture of this kind of goods was practised. The extensive establishment of Messrs Henry Monteith, \& Co., in that city, is still the largest in the kingdom, or perhaps, in the world, and the observations which follow are drawn principally from the mode of procedure followed there in the manufacture of Bandanas.

lt is to be observed, in the ontset, that the process for the formation of bandanas is the converse of calico printing, the cloth being first dyed of a uniform dark colour, and the pattern being afterwards formed by the application of a chemical agent to those parts where the spots or figures are meant to appear, which discharges or extracts the colour from these parts only. The cloth employed is usually cotton, sometimes woven plain, but more frequently tweeled; and the dye for the ground is most commonly 'Turkey red (for which, see Dyeing.) All idea of this will be conveyed by this cut, the dark part representing the ground, the white figure having been discharged by the action of the chemical agent.

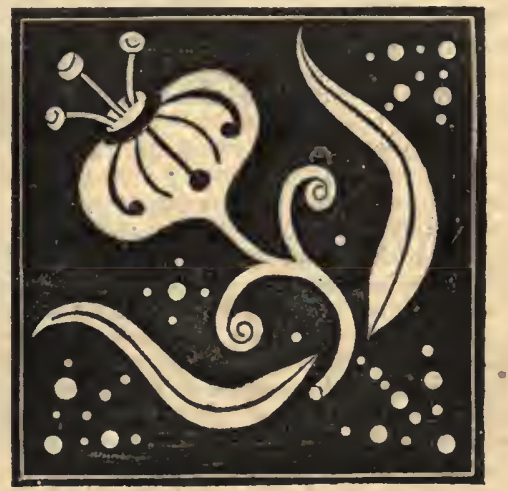

In the establishment of Messrs H. Monteith \& $\mathrm{C} 0$., before alluded to, about fourteen pieces of cloth having been dyed Turkey red, are, by means of machinery, stretched over one another, as nearly as possible parallel, and then rolled round a wooden cylinder, which is placed at the back of the press where the discharging is to be effected. Until 1818 , common screw presses were used; but since that time the hydrostatic presses of Bramah have been introduced (see Bramah's Press). In each press there is fixed a pair of plates, fashioned after the following manner. As the solid ground-work of the plate, a trellis frame of iron, one inch thick, with turned up edges, and a little larger than the intended plate, is employed. This frame forms a trough for a plate of lead about half an inch in thickness, which is fastened into it by means of screws. The edges of a piece of sheet-lead, which covers all the onter surfaces of the frame, nre soldered to the plate of lead, and thus there is formed a trongh one inch in depth, the border of which serves at once to confine the discharging liquor, and to give strength to the whole. A thin sheet of lead is now laid on the plate, and soldered round the edges, both plates being previ- 
ously hammered smooth on a marble table, and finished with the plane. The thin slieet of lend having been fastened, is to be coverod with the paper on which the pattern is drawn; which, being fastened firmly with paste, and driel, is sent to the cutter, who fixes down with brass pins all the parts to be left solid, and with the tools commonly used by block cutters, he follows the lines of the drawing, cutting perpendicularly through the thin sheet. The detached pieces are then lifted out, and thus the channels for the discharging liquor are formed, which determines the white figures on the cloth. That the liquor may be freely aduitted and drawn away, a number of small holes are perforated in the thick plate of lead at the bottom of the channels, and thus one plate is finished. But another plate sinilar to the former is required to constitute what is called a set. This second plate is fashioned in the same way as the first, with this difference, that no new drawing requires to be executed for it, as a piece of drawingfrper is fastened on the second plate, and an impression taken off the first, by means of printers' ink, in a hydrostatic press. These plates may be put into, or removed from, the press at pleasure. One of these plates is fixed to the upper block of the press, so contrived, that, by means of a kind of universal joint, the upper plate may be made to apply to the under one, which is fastened to the movable part of the press, so that when the under block of the press is forced up, the two plates come together with the greatest precision, by means of guide-pins at the corners. The hydrostatic discharging press is worked by two cylinders, called prime cylinders, of peculiar formation. The piston of the large cylinder is eight inches in diameter, that of the suall, only one inch. Both pistons are stuffed, and thin rods move through stuffed col lars, being each loaded by a top weight of five tons, and capable of being raised two feet; and they are each worked by three forcing pumps connected with the steam engine. These pumps being put in action, a sufficient quantity of water will, in a short time, be introduced into the bottom of the cylinders as will raise the pistons up to their highest points; and thus they are prepared for working the discharging presses, with which they communicate by strong copper pipes, of small calibre, led under ground to the gallery where the presses stand. Three valves are attached to each press : the first opens the communication between the large prime cylinder and the cylinder of the press, and the pressure of the water thus introduced raises the under blocks so as to come into contact with the upper. The second valve opens the passage of the water from the small prine cylinder to the cylinder of the uress, and the pressure thus introduced is employed to give the requisite compression to the cloth between the blocks. The function of the third valve is merely to allow the water in the press cylinder to escape, so as to slacken the pressure when the operation of discharging has been accomplished.-Having now described the apparatus, let us attend to the process of discharging. The wooden cylinder, with a roll of cloth, formerly spoken of, is placed at the back of the press, and as much of the fourteen plies of cloth drawn off as will cover the area of the lower pattern plate, on which it is then placed. The valve guarding the communication between the press and large prime cylinder is now opened, and the pressure of the water forces up the under block, together with its plate and cloth, so as to come into close contact with the upper plate. This valve is now shut, and that which guards the communication between the press and the small prime cylinder is opened; and it will be recollected that the diameter of this cylinder is only one inch, the piston being loaded with a pressure of five tons, which is now brought to bear on the piston of the press, and the cloth is by this pressure compressed, not bejond the power of calculation indeed, but to a degree truly astonishing; for it may be easily shown (see Bramah's Press), that if the cylinder of the press be eight inches in diameter, the pressure which compresses the cluth between the plates is mot less than $716,400 \mathrm{lbs}$. When things are in this state, the clischarging liquor is to be admitted. This liquor cousists of a solution of the chloride of lime, commonly called bleaching powder, and a small quantity of sulphuric acid. It is contained in a small lead cistern attached to the press, which is supplied from a large cistern in another chamber. This small cistern is furnished with a graduated glass tube for regulating the quantity of liquor given to the cloth, and the stop-cocks connected with this department of the apparatus are likewise of glass. The liquor is now admitted through the upper plate, and passes through the fourteen layers of cloth, and through the uuder plate, being finally led away by the waste-pipe, its passage through the cloth being frequently accelerated by pressure derived from a pneumatic apparatus, somewhat resembling a gasometer. When the cloth has been acted upon by the liquor sufficiently, water is introdnced in a similar manner, and the chlorine entirely washed away. The pressure is now relaxed, and more of the cloth introduced between the plates, and the process is repeated. In the establishment before alluded to, one set of workmen manage sixteen presses, passing from the one to the other; so that when the sixteenth is cleared, it is time to open the first, and thus 19,200 yards of cloth are, by four workmen, converted into bandanas in ten hours. For further particulars, see Calico Printing.

Bandello, Matteo, a novelist, born, about 1480 , at Castelnuovo di Scrivia, studied at Rome and $\mathrm{Na}$ ples, and applied himself almost exclusively to polite literature. He was, in his youth, a Dominican monk at Castelnuovo. He seems to have lived some years in Mantua, where Pirro Gonzaga and Camilla Bentivoglio intrusted to him the education of their daughter. He afterwards resided at Milan, until, after the battle of Pavia, the Spaniards banished him thence as a partisan of France. Upon this he went first to Ludovico Gonzaga, then to Cesare Fregoso, who had left the Venetian for the French service, and lived with the latter, in Piedmont, till the conclusion of the truce between the belligerent powers, and then followed him to France. After the death of his pron tector, he resided at A gen, with the family of the de. ceased, and, in 1550, was appointed bishop of that city. He left the administration of his diorese to the bishop of Grasse, and employed himself, at the advanced age of 70 , in the completion of his novels, of which he published three volumes in 1554 ; a fourth was published in 1573, after his death. Camillo Francesclini also published his novels at Venice, in 1566, 4to. B. published, at Agen, in 1545, Canti XI delle Lodi della S. Lucrezia Gonzaga di Ganzuela e del Vero Amore, col Tempio di Pudicitia, and also two other poems ; altogether of but little value. Other poems of his, found in manuscript at Turin, were printed by Costa, in 1816, under the title of Rime di Matco Bandello. The novels of $\mathbf{B}$. are distinguished by a natural simplicity, a rapid narration, and periods at once short and harmonious; but their contents are frequently impure. This reproach applies more to him than to Boccaccio, that he loves to dwell in wanton scenes, and to paint them in lively colours to the imagination.

BAxE Norke. When the revolution in France had rendered superfluous much ecclesiastical property, also many castles and residences of the emigrant 
and resident nobility, by the abolition of trusts and entails, and by the equal division of property anıoıg the children of these families, nothing was more natural than that, with the increase of population, societies slould be formed to purchase the edifices which had thus become useless (churches, chapels, abbeys, monasteries, bishops' residences, parsonages, Gothic castles, with their prisons and other appurtenances, hunting lodges, watch-towers, \&c.), and pull them down, just as the merchants of Amsterdam, on the decline of their prosperity, allowed the villas about that commercial city to be pulled down, or sold in order to be pulled down, by the slopers, so called. To many this seems a barbarous custom. In Germany, also, after the great secularization of cathedrals and monasteries, associations were formed, particularly of the Jews, who, with profit to themselves, bought the buildings which had become unnecessary, pulled them down, and sold the materials, as well as the state's domains, which had been alienated in large lots, and were now disposed of by them in small portions. The bande noire enriched itself from the sale of the materials for building, from the felling of wood in the parks, and from the disposal of land for gardens, meadows, and fields. The public, too, were benefited at the same time. In places where this has frequently happened, the countryman dwells more comfortably, and is richer, than in many other quarters; for example, in the Pyrenees, and particularly in the southerly part of France.

BandeTtIN, Theresa, an improvisatrice, born at Lucca, about 1756, received a careful education, but was obliged (her family having lost their property) to go upon the stage. She made her first appearance in Florence, and was unsuccessful. This, united to her love for polite literature, led her to the most assiduous study of the poets. As she was one day listening to an improvisatore of Verona, her own genius broke forth in a splendid poetical panegyric on the poet. Encouraged by him, she devoted herself entirely to this beautiful art. Her originality, her fervid imagination, and the truth and harmony of her expression, soon gained for her a distinguished celebrity. She was enabled to abandon the stage, and travel through Italy; and she enjoyed the honour of being chosen a member of several academies. One of her most celebrated poems was that which she delivered, in 1794, impromptu, before the prince Lambertini, at Bologna, on the death of Marie Antoinette of France. In 1813, wearied with travelling, she returned to her native city, where she lived retired on her small property. She published Ode tre (Lucca, 4to), of which the first celebrates Nelson's victory at Aboukir, the second Suwaroff's victories in Italy, and the third the victories of the archduke Charles in Germany. She also gave to the world under the name of Amarilli Etrusca, Saggio di Versi Estemporanei (published, in Pisa, by Bodoni), among which the poem on Petrarch's interview with Lau$\mathrm{ra}$, in the church, is particularly distinguished, and places her by the side of Rossi.

Bandit (Ital. bandito); originally an exile, then a hired murderer. This name was given to the assassins (see Ishmaelites) of Italy. At the present time, in Italy, bandit and robber are almost synonymous. They form a kind of society of themselves, which is subjected to strict laws, and lives in open or secret war with the civil authorities, and are a disgraceful proof of its weakness, no Italian government having succeeded in extirpating them. The strict measures which the papal government adopted, in 1820, against persons who should harbour bandits and robbers, have indeed destroyed their lurking-places; but the villains who were formerly settled are now become vagabonds. Those, however, who infest the environs of Naples, are the peasants of the country, who, besides being engaged in agriculture, employ themselves in robbery and murder. The fear of capital punishment is ineffectual to deter them from these crimes. Peter the Calabrian, the most terrible among these robbers, in 1812, named himself, in imitation of the titles of Napoleon, "emperor of the mountains," "king of the woods," " protector of the conscribed," and "mediator of the highways from Florence to Naples." The government of Ferdinand I. was compelled to make a compact with this bandit. One of the robbers entered the royal service, as a captain, in 1818, and engaged to take captive his former comrades. More lately, adventurers of all kinds have joined them. These bandits are to be distinguished from other robbers, who are called malviventi; and the Austrian troops, which occupied Naples, were obliged to send large detachments to repress them. It is remarkable, in these robbers, that they only attack travellers on the highways. This also is true of those who exact from strangers and natives a sum of money for protection, and give them in return a letter of security; which, a. short time ago, was the case in Sicily, where the bandits dwell in the greatest numbers in the Val Demone. Here the prince of Villa. Franca declared himself, from political and other views, their protector: he gave them a livery, and treated them with much confidence, which they never abused; for even among them there is a certain romantic sense of honour derived from the middle ages. They keep their promises inviolate, and often take better care of the security of a place intrusted to them than the public authorities.

Baner, also Bansier, John (in English, always written Buner), a Swedish general in the thirty years' war, descended from an old noble family of Sweden, was born in 1596. When a child, he fell from the castle of Hornings.holm, four stories high, without being injured. Gustavus Adolphus, who valued him very much, early prophesied that he was destined for greatness. He made his first campaigns in Poland and Russia, and accompanied his king to Germany. After the death of Gustavus, in 1632, he had the chief contmand over 16,000 men, and was the terror of the enemy. He obtained the greatest glory by lis victory at Wittstock, in 1636, over the imperial and Saxon troops; and it was also owing to his activity, that, after the battle of Nordlingen, the affairs of Sweden gradually improved. He died at Halberstadt, in 1641 , under 45 years of age and was suspected to have been poisoned. In him Sweden lost her ablest general, and the imperial troops their most dangerous enemy. $B$. was careful to engage in no enterprise without a reasonable probability of success. He knew how to avoid danger with dexterity, and to escape from a superior force. During his command, 30,000 of the enemy were killed, and 600 standards taken, on different occasions. He was always found at the head of his men, and maintained good discipline. He wanted patience for sieges. He has been accused of pride and severity. The pleasures of the table and of love occupied all the leisure time which his employments allowed him, and probably immoderate indulgence in them was the real poison which brought on lis death. He was three times married.

BANFr, the capital of Banffshire, is pleasantly situated on the side of a hill, at the mouth of the river Deveron, distant 44 miles $\mathrm{N}$. W. from Aberdeen, and $165 \mathrm{~N}$. from Edinburgh. Tradition assigns its foundation to Malcolm Canmore, and it received the same privileges as Aberdeen by a charter granted by Robert II. The town has sereral handsume streets, 
und is deened the most fashionable residence north of Aberdeen. The town-louse, which was luilt in 1798 , is a very handsone building, with an elegant spire. The ancient castle, which occupies the sum. mit of a mound within the town, exhibits many signs of its former strength, although used at present as a inausion by the earl of Seafield, once licritable sheriff of the county. . The harbonr of Banff, which was very defective, has been recently inuch inproved. Manufactures of thread, cotton, stockings, rope, and sail cloth are carried on here, and unany of the inlabitants are occupied in the salmon and white fisheries. In 1831, the population of the town and parish anounted to 3711 .

I3ANFFSHRE; a cointy in the north of Scotland, bounded on the $\mathrm{N}$. by the ocean, on the $\mathrm{W}$. by the shires of Morny and part of Inverness; on the $\mathrm{S}$. by Inverness, and on the $F_{0}$ by the shire of Aberdeen. The sonthern part of this county is very mountainous; but the northern part, although agreeably diversified witl hill and dale, is comparatively level, and very fertile. The soil is, for the most part, a rich loam, or deep clay, very retentive of moisture. The principal rirers are the Spey and Deveron, the Isla, the Conglass, Aron, and the Fiddich; besides which there are a inumber of tributary streams, which, although occasionally mischievous by their overflow, add materially to the fertility and ornament of the cuunty. There are several mountains, which rise in altitude as they recede from the const, the most celebrated being that of Cairugorum, which attains an elevation of 4050 feet above the level of the sea. The climate partakes of the general character of that of the eastern coast of North Britain, with greater sererity as the distance increases from the sea. A griculture is, notwithstanding, carried on with great spirit, although but little wheat is raised in the inland parishes. The chief crops are bear, oats, flax, turnips, potatoes, and pease. Black cattle are reared in great numbers, and with grain, especially oats, constitutes the principal articles of export. The salmon caught in the Spey and Dereron, also constitute a considerable article of traffic, and great quantities of salt cod, ling, skate, and haddock, are disposed of on the coast south of Aberdeen. The imporis are hemp, corn, wool, wood, with wine, and other articles of luxury and fashion. The chief employment of the inhabitants of a manufacturing description consists in spinning flax. White and dyed threads are manufactured to some extent; and on a small scale, woollen and cotton goods, linen, and hose. Among the natural productions of this county, limestone is the most prevalent, being diffused over the whole county; marble also abounds in sereral places, especially at Portsoy, where a species is found, which possesses a brilliancy like the Labrador spar, and in a particular light shows a purple and bluish tint. When polished it exhibits figures which hare a remote resemblance to Arabic characters, a quality first remarked in Arabia, where it is also found, and which induced the Arabs to give it the name of "Moses' Tables," supposing they had found pieces of the tablet on which the decalogue was originally written. Two chimney-pieces were formed of it for the palace at Versailles, and it is still wrought into chimuey-pieces, monuments, and toys. Free-stone, marl, slate, and various kinds of granite are likewise productions of this county, and rock crystals, and the topazes called, from the mountain of that name, Cairngorums, are found in various districts. The principal land proprietors in Banffshire are the duke of Gordon, the earl of Fife, and the earl of Seafeld, all of whom have fine seats therein. The two royal burghs are Banff and Cullen. In 1831 the population of Banfishire was as follows. -Families 10,85.5, males 22,743 , females 25,861 , total 48,601 .
Bangor; a city of North Wales, in Caernarvonslive 237 miles from London, situated at the foot of a steep rock, in a narrow and fertile vale, near the uortlem entrance of the Menai Strait, and adjacent to the mouth of the river Ogwen. It consists of one principal street, nearly a mile in l'ngth, with several smaller avenues opening into it from the water side. The principal public buildings are the cathedral, which was completed in 1532, the bishop's palace, deanery house, free scliool, market house, assembly rooms, \&c. Since the construction of that admirable work of art, the Menai brilge, Bangor las risen into some importance, being visited by upwards of 50,000 persons annually, who remain for louger or shorter periods. Its proximity to the sea has given Baugor the advantage of becoming a farourite bathing place; and the views of Beaumaris Bay and the Caeriarvon mountains from Garth Point, the promenade of the inhabitants, are of the most picturesque, bold, and sublime character. Population in 1831, 4751.

Bangor; a post town of the United States and capital of the county of Penobscot, in Maine, on the $W$. side of Penobscot river, at the hrad of the tide and of navigation ; 52 miles N. of Owl's-head, at the mouth of Penobscot bay; lat. $44^{\circ} 45^{\prime} \mathrm{N}$.; lon. $68^{\circ} 45^{\prime} \mathrm{W}$.; population in 1820,1221 ; in 1825 , 2002. Its situation is pleasant, and very advantageous for commerce. It is a flourishing town, and contains a theological seminary with two professors, a court louse, and other public buildings. The river is navigable, as far as this town, for ressels of 300 or 400 tons.

BANGOE; a kind of opiate, much used throughout the East as a means of intoxication. The Persians call it beng. It is made of the leaf of a kind of wild hemp, in different ways.

Buvians; a name formerly giren by Europeans to almost all the Hindoos, because baniya, the term whence it is derived, signifies a banker, the class with which Europeans had most frequent intercourse. It is one of the mixed classes, sprung from a father of the medical and mother of the commercial class. The English sailors call banian days those days on which they have no flesh meat. Probably the name has a reference to the habits of this class; because, before people were acquainted with the abstinence of all the Hindoos, it was thought to be confined to the Banians.

Banishment. See Exile.

Bank. The term bank, in reference to commerce, implies a place of deposit of money. Banks, like most commercial institutions, originated in Italy, where, in the infancy of European commerce, the Jews were wont to assemble in the market-places of the principal towns, seated on benches, ready to lend money ; and the term bank is derived from the Italian word banco (bench). Banks are of three kinds, viz., of deposit, of discount, and of circulation. In some cases, all these functions are exercised by the same estallishment ; sometimes two of them, and, in other instances, only one.-l. A bank of deposit receires money to keep for the depositor, until he draws it out. This is the first and most obvious purpose of these institutions. The goldsmiths of London were formerly bankers of this description; they took the money, bullion, plate, \&c. of depositors, merely for safe keeping. -2. Anotlier branch of banking business is the discounting of promissory notes and bills of exchange, or the lending of money on mortgage, pawn, or other security.-3. A bank of circulation issues bills or notes of its own, intended to be the circulating currency or medium of exchanges, insteal of gold and silver. Banks are also divided into public and private; but what is a public bank, is not rery definitely settled. W' Were the government of a 
nation, or the municipal authorities of a place, as in Amsterdam, lias the direct management or control of a bank, it is a public one ; and those institutions of this class, the credit of which is connected with that of the government, or which are used as instruments in collecting and distributing the public revenues, or in which the government is a proprietor, are public banks; and so are also those usually considered to be, which are carried on under a charter from the government; whereas a private bank is usually understood to be one that is carried on by one or more individuals, without any particular connexion with the government, or any special authority or charter. There is, for instance, in England, but one public bãuk, namely, the bank of England; whereas, in the United States, most of the banks are public, and, in some of the states, private banks of circulation are prohibited by law. The general character and the different kinds of these institutions being thus explained, the reader will be enabled the more easily to understand our account of some of the banking institutions of the greatest historical notoriety.

The Bank of Venice was established as early as 1171 , during the crusades, and for the purpose of rendering assistance to those expeditions. It was a bank of deposit only, and strictly a public bank, as the government became responsible for the deposits, and the whole cipital was, in effect, a public loan, the funds of the bank being made use of by the governinent ; and, in the early periods of the operations of this bank, they were not withdrawn, when once deposited, but the depositor had a credit at the bank to the amount deposited; and lie used the money so deposited by transferring this credit to another person, instead of paying money. Subsequently, however, the deposits were allowed to be withdrawn; for, thougli the bank credits answered all the purposes of money at Venice, a specie currency was wanted by persons going abroad, or having payments to make in distant places. This bank continued in operation until the dissolution of the Venetian republic, in 1798.

The Bank of Amsterdam was established in 1609 , and owed its origin to the clipped and worn currency, which, being of uncertain and fluctuating value, subjected the exchange to a corresponding fluctuation and uncertainty. The object of the institution was, to give a certain and unquestionable value to a bill on Amsterdam; and, for this purpose, the varions coins were received in deposit at the bank at a certain value, according to their weight and fineness, a small deduction of seigniorage being made, equivalent to the supposed expense of coinage into money of the proper weight and fineness, and the depositor was also required to pay a small amount for the privilege of liaving an account at the bank. As the money received, is not, in fact, recoined, these charges, with a distinct cliarge for deposits of bullion, and a fee for evers new deposit, and five stivers for every transfer, constitute tlie income of the establishment, and, being more than sufficient to defray the expenses, a net revenue accrues to the city, though the acquisition of revenue was not contemplated in forming the institutiour. A profit has also occasionally been made by purchasing tive current coin whenever it could be converted into bank money at an expense less than the agio. The deposits made and credited are denominated bank money, which is at a certain premium or agio above current money, according to the fineness and weight of the current coin ; and since the currency has been well regulated, this agio is steady and inconsiderable, never exceeding five per ceirt. In order to produce the intended effect on the exchange, it was provided, by law, that all paynents of 600 guilders and upwards, should be made in bank money; and payments are made by transfers of credits in the books of the bank, as for. merly at Venice. In one respect, this bank differs from that of Venice, as the deposits are not taken out and used by the government, but remain in the vaults. The direction of this bank is placed in the hands of four burgomasters or aldermen for the time being, who count and receipt for the money on coming into office at the commencement of each year. During the whole period since the establishment of the bank, no peculation, or breach of trust, on the part of these directors, has ever happened. This is a bank merelv of deposit and transfer: it neither makes loans nor circulates bills.

The Bank of Hamburg was established in 1619, ten years after that of Amsterdam, and, like this latter, is a mere bank of deposit and transfer, the deposits being made.in coin or bullion, at a certain fixed rate, and liable to be withdrawn by the depositors any one having a credit at the bauk may draw on the amount of his credit. The bank has not properly, therefore, any capital of its own, the whole funds being liable to be withdrawn at any moment. The expenses of the institution are defrayed by a charge of a certain rate per page of transfers in the bank book to every depositor. The amount of deposits varies from ten to fifteen million dollars. This bank was plumdered by Davoust, when he was in possession of Hamburg, in 1813; but many of the depositors, anticipating this event, had withdrawn their deposits, and remitted them to Copenhagen or England; and, to those who remitted to England, it proved quite a fortunate event, for, by the subsequent rise of exchange, they nearly doubled their capital. The depositors who were thus plundered of their property received a partial indemnity of thirty-six per cent. from the French government, after the restoration of the Bourbons. The directors of this bank, five in number, are chosen annually by the whole body of the citizens of Hamburg, having a right to vote for municipal officers. They receive no salary.

The Bank of England is one of deposit, discount, and circulation. It was chartered in the reign of William and Mary, 1693, seventy. or eighty years after those of 'Amsterdam and Hamburg, by an act which, among other things, secured certain recompenses and advantages to such persons as should advance the sum of $£ 1,500,000$ towards carrying on the war against France. The sum of $£ 1,200,000$ was subscribed before the expiration of the year, and the subscribers became, under the act, stockholders, to the amount of their respective subscriptions, in the capital stock of a corporation, denominated the Governor and Company of the Bank of England. This charter was granted for eleven years, and the company advanced to the government $£ 1,200,000$, at an interest of eight per cent. ; and the government made an additional bonus, or allowance to the bank, of $£ 4000$ annually, for the management of this loan (which, in fact, constituted the capital of the bank, ) and for settling the interest and making transfers, \&c. among the various stockholders. This bank, like that of Venice, and unlike those of Amsterdam and Ham. burg, was originally an engine of the government, and not a mere commercial establishment. Th: management of the institntion is in the hands of a goverior, lieutenant-governor, and twenty four directors, elected by stockholders who have held $£ 500$ of stock for six months previous to the election. A director is required to hold $£ 2000$, a deputy governor $£ 3000$, and a governor $£ 4000$, of the capital stock. Its capital has been increased, from time to time, so as to stand at different periods as follows : 
1694, the original capital, $£ 1,200,000$ $1697, \ldots . . \ldots \ldots \ldots \ldots \ldots \ldots \ldots . . .2,201,171$

$1708, \ldots \ldots \ldots \ldots \ldots \ldots \ldots \ldots \ldots .4,402,343$

$1709, \ldots \ldots \ldots \ldots \ldots \ldots \ldots \ldots \ldots . . .5,058,5.47$

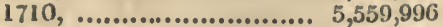

$1722, \ldots \ldots \ldots \ldots \ldots \ldots \ldots \ldots \ldots . . .6,959,996$

$1742, \ldots \ldots \ldots \ldots \ldots \ldots \ldots . . . . . . .6,800,000$

$1746, \ldots \ldots \ldots \ldots \ldots \ldots \ldots \ldots \ldots . . . . . . .10,780,000$

$1781, \ldots \ldots \ldots \ldots \ldots \ldots \ldots \ldots . . . . .11,642, i 00$

The rates of dividends have been as follows:

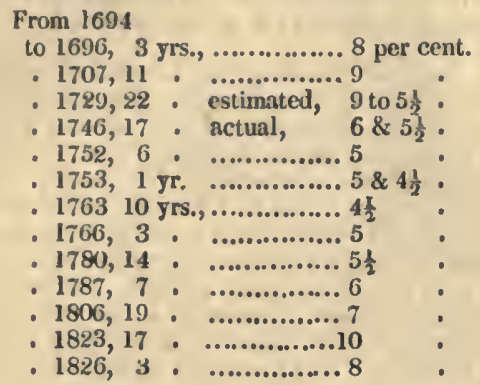

The bank has, besides, at different times, nade dividends under the name of bonuses, viz.:

$$
\begin{aligned}
& \text { June, 1799, ............. } 10 \text { per crit. } \\
& \text { May, } 1801, \ldots . . . . . . . . .65 \text {. } \\
& \text { Nov., } 1802, \ldots \ldots \ldots \ldots . . .22 \frac{1}{2} \text {. } \\
& \text { Oct., } 1804, \ldots \ldots \ldots \ldots \ldots . . .65^{2} \text {. } \\
& 1805, \ldots \ldots \ldots \ldots \ldots .5 . \\
& 1806, \ldots \ldots \ldots \ldots . . .5
\end{aligned}
$$

The amount of loans to the government has increased with the capital of the bank. In 1787, the permanent loan to government was $£ 8,688,570$; in $1797, £ 10,672,490$-an amount approaching very near to that of the whole capital. In 1817, the loan to government arose to $£ 28,300,209$, and, in 1825 , it was $£ 18,261,100$. Ever since its establishment, the bank has been closely allied with the government, the fate of the institution having always been directly involved in that of the government; and, for twenty six years, from 1797 to 1823 , as we shall see, the existence of the government, and fate of the kingdom, seemed to depend upon maintaining the credit of the bank, and the circulation of its paper. Besides being a creditor of the government to the immense amount already mentioned, the institution is an important agent in the management of the public debt, and the collection of the revenue, the whole of which, amounting to about $£ 50,000,000$ per annum, passes through the bank.

Besides its importance to the government as a public creditor, and as an agent in managing the finances and public debt, collecting taxes, and paying interest and annuities, this institution is, in its character of a bank of deposit, discount, and circulation, a powerful auxiliary to commerce and industry. As a bank of deposit, it offers the advantages of those of Hamburg and Amsterdam. Transfers or assignments of deposits, being made by means of checks, are attended with less trouble than the writing off and transferring of credits at Amsterdam and Hamburg. Besides permanent loans to the government, the bank makes extensive discounts of paper, or, in other words, loans to a great amount on promissory notes and bills of exchange. It is apparent, from the statement already made, that, if the actual capital is not greater than its estimated nominal amount, tramely, $£ 11,642,400$ it had, in 1787 , but a com . paratively small amount of capital to loan to indivi duals; for, $£ 10,672,490$ of its capital being lonued perinanently to the public, only the sum of $\$ 969,910$ of the capital remained for private loans. This amount might then have been loaned, if the institution were merely a loaning or discounting one, and received no deposits, and circulated no bills. But all the means of additional loans must have been derived from deposits and circulation; and the meaus derived from these sources, for this purpose, inust obviously be very ample; for the payment of the revenue of the kingdom through the bank, if we suppose the money to remain in the bank, on an average, one day, will give a fund of $£ 166,6$ (i6. The deposits by individuals and companies will add immensely to this fund. It is true, that the bank is liable to be called upon at any moment for these deposits, and, where no interest is allowed upon them by the bank, the depositors will generally withdraw them as soon as they can make an invest. ment; but, still, experienced bankers will estimate, with some precision, the average of deposits on which they may venture to discount. Besides this fund for discount or loan, the bank has the additional one of the amount of the excess of the circulation over that of the specie necessary to be kept in the vaults of the bank, to redeem the bills presented for payment. To a bank with the resources and advantages of that of England for collecting specie, it is quite an ample provision for its circulating notes and bills, to keep on hand 20 or 25 per cent. of the amount of such circulation, where its discounts are for short periods of two or three months. The circulation of this bank has varied at different times, but, on the whole, gradually increased. From 1792 to 1800 , it arose from about $£ 11,000,000$ to about $£ 12,000,000$; froin 1800 to 1810 , it increased to above $£ 18,000,000$; from 1810 to 1820 , it was at the maximum, being, in Aug., 1817, as high as $£ 30,099,908$, and, generally, during this period, ranging from $£ 25,000,000$ to $£ 28,000,000$; from 1820 to 1826 , it ranged from $£ 18,000,000$ to $\$ 23,000,000$, and, on the 26th of February, 1826, was $\mathcal{2} 23,673,737$. It thus appears that the circulation of notes gives the bank an effective loaning capital of from $£ 15,000,000$ to $£ 20,000,000$. It appears, further, that the actual capital of the institution is greater than its nominal stock, or the amount on which dividends are made. In March, 1819, the actual capital exceeded the nominal by $£ 4,261,280$; but this excess must vary with the periods of making dividends, and also with the good or ill success of the business of the institution. From all these sources the bank has an available loaning capital of over $£ 20,000,000$, besides the loan of $£ 10,672,490$ to the government. Thus, on a capital stock of 11 millions, the bank receivis interest on between 30 and 40 millions, including the interest on the government loan, besides the bonus annually paid to the bank, for its agency in the financial concerns. This accounts for the ligh rate of dividends made on the capital stock, as above stated, being between two and three times the cur. rent rate of interest in Great Britain. Since 1800 , the circulation of the notes of this bank under $£ 5$

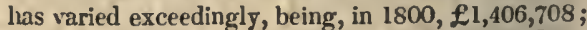
in $1816, £ 9,036,374$; in 1824 , as low as $£ 491,370$; and, in 1826, when the law was enacted prohibiting the circulation of notes under $£ 5$ after the 5 th of Feb. 1829 , standing at $£ 1,559,756$.

The most important event in the history of this institution we have reserved for a distinct consideration, viz., the stopping of specie payment, in 1797 . On the 26th of February of that year, being Sunday, an order of the privy council was transmitted to the lank towards evening, prolibiting the further pay- 
ment of specie until the pleasure of parliament should be made known. The parliament took the subject into consideration the next day, February $27 \mathrm{th}$, and approved of the order of the privy council. The suspension of specie payment was originally intended to be only a temporary measure, and the strongest assurances were given to this effect on the part of the hank and the government. It was, however, continued, from time to time, but always as a temporary measure, until, in 1819 , twenty-two years after the suspension of payment, an act was introduced by Mr Peel, for resuming specie payments, which were, in fact, resumed, on the Ist of May, 18:3. The bank thus presents the singular example of a virtual insolvency for twenty-six years, and eventual redemption of its paper and its credit; and this return to specie payments was not attended by any sudden revulsion or commercial shock : preparations were made for it long beforehand. The anount of the notes of the bank in circulation was reduced from about $£ 24,000,000$ to about $£ 18,000,000$. In the meantime, a new coinage of gold had been issued, in 1821-1822, to the amount of $£ 14,877,547$, which supplied the chasm made in the circulation of the country by the reduction of the amount of bank of England notes, and also went to replenish the vaults of the bank, in preparation for the run that might be made on the resumption of payment ; but the danger was passed with the greatest facility. The bank-notes had depreciated, or, as the phrase was at the time, the price of bullion had gradually risen, su as to be, at one period, at the rate of 14 or 15 per cent.; and, if the bank had then stopped suddenly, and, if we may imagine it possible, had redeemed the whole of its paper, $\$ 25,000,000$ or more, with specie, it would have been a gain to the then holders of the notes, in the whole, of $£ 3,500,000$, and a loss to the then debtors to the bank of the same amount, assuming the depreciation to be 14 per cent.; while the bank itself would have lost only the amount of bad debts, which would have been made by such a sudden and tremendous revulsion; for, the moment of the bank's resuming to pay specie itself, by this very operation, it reduced the payments to the bank, by its debtors, to specie ; for the bank had a right to demand payment of notes and bills discounted in specie, or, what would have been equivalent, its own notes. Such a measure would evidently have shaken the kingdom to its foundations, and probably have brought down its commercial, financial, and economical systems in ruins. Instead of such a catastrophe, either in discontinuing or renewing payments of specie, each of which was equally difficult and hazardous, the transition in the depreciation of the paper was gradual, and almost imperceptible, and, after the overthrow of Napoleon, its rise in value was again, for the most part, as gradual, until it arrived at a par with gold, before the resumption of specie payments. In a political, financial, and commercial view, this institution, from the suspension to the resumption of specie payments, presents a stupendous phenomenon, unparalleled in history. The suspension of payment, in 1797, was one of those bold measures, which are justified only by extreme cases, and which, in such cases, are, in fact, the only prudent measures. The whole system of financial administration, and all the commercial combinations and connexions of the kingdom, were involved in the affairs of the institution at the time of its stopping, in 1797. The holders of the notes, and the depositors, were pressing to the bank for specie, of which there remained in the vaults only $£ 1,272,000$, while the notes and clainıs outstanding, and which might be demanded, were $£ 8,640,250$, and the demands were pouring in with a still increasing tide. It seemed probable that the bank must stop payment after paying out this specie; the shock, whatever it night be, must be encountered, and it was very justly supposed that it would be, in a measure, broken, by anticipating the necessity, and stopping with more than a million in its vaults, instead of waiting until they should have been emptied. The reasons given in parliament in favour of this suspension of payment, and of its continuance from time to time were, 1 . that the bank could not continue its discounts, and its payments in specie; and, if its discounts were stopped, or greatly reduced, the commerce of the country would be destroyed: 2. that the credit of the government would be lost if the bank should cease to make advances upon its taxes: 3 . that specie payments were of no benefit to England, as the specie, on leing drawn from the bank, went abroad: 4. that it was more important that the bank should exist, than that it should meet its payments at the expense of its existence: 5 . that the commercial arrangements, combinations, and relations, existing in the kingdom, would be broken up by the dissolution of this institution, and, being once broken up, could never be renewed; and, 6. that it was better to stop specie payments while some specie and bullion could be kept in the country by that means. Such were the reasons given in farour of the measure, and though it has been censured by some, who have pretended to discover in it the cause of much financial and commercial derangement, yet they do not show by what other course Great Britain could have struggled through the terrible conflicts of that period.

Banks in Scotland. The act of 1708 , which prevent. ed more than six individuals from entering into a partnership for carrying on the business of banking in England, did not extend to Scotland. In consequence of this exemption, several hanking companies, with numerous bodies of partners, have always existed in that part of the empire. The bank of Scotland was established by act of parliament in 1695 . It enjoyed, by the terms of its charter, for twenty-one years, the exclusive privilege of issuing notes in Scotland. Its original capital was only $£ 100,000$. It was increased to $£ 200,000$ in 1744 ; and now amounts to $£ 1,500,000$. The partners are liable only to the amount of the shares they respectively hold. The royal bank of Scotland was established in 1727 . Its original capital was $£ 151,000$. At present it amounts to $1,500,000$. The British linen company was incorporated in 1746 , for the purpose, as its name implies. of undertaking the manufacture of linen. But the views in which it originated were speedily abandoned; and it became a banking company only. Its capital amounts to 500,000 . None of the other banking companies established in Scotland are chartered associations ; and the partners are jointly and individually liable, to the whole extent of their fortunes, for the debts of the firms. Some of them, such as the national bank, the commercial banking company, the Dundee commercial bank, the Perth banking company, \&c., have very numerous bodies of partners. 'Their affairs are uniformly conducted by a board of directors, annually chosen by the shareholders. The bank of Scotland began to issue one pound notes so early as 1704 ; and their issue has since been continued without interruption. In Scotland, the issue of promissory notes payable to the bearer on demand, for a sum of not less than twenty shillings, has been at all times permitted by law; nor has any act been passed, limiting the period for which such issue shali continue legal in that country. In England, the issue of promissory notes for a less sum than five pounds was prohibited by law from the year $17 \% 7$ to the period of the bauk restriction in 1797. It was per. 
milted from 1797 till $\Lambda$ pril, 1829, when the permission ceaserl. There have been comparatively fiw bankruptcies among the Scottish banks. In 1793 and 1825, when so many of the Fnglish provincial banks were swept off, there was not a single establishment in Scotland that gave way. This superior stability secus to be ascribable partly to the formation of so many banks with numerous loodies of partners, which tends to prevent any company with ouly a few partners, unless they are known to possess considerable fortumes, from getting paper into circulation; partly to the less risk attending the business of banking in Scotland; and partly to the facility afforved by the law of Seotiand of attaching a debtor's property, whether it consist of land or movables, and making it a vailable to the payment of his debts. All the Sicottish banks receive deposits of so low a value as $£ 10$, and sometimes lower, and allow interest upon them. The interest allowed by the bank upon deposits varies from time to time according to the current rate of interest which money generally bears. At present, the interest allowed on deposits is only two or two and a half per cent. It has been calculated that the aggregate amount of the sums deposited with the Scottish banks anounts to between 20 to 24 millions. The louns or advances made by the Scottish banks are either in the shape of discounts or upon cash credits, or, as they are more commonly termed, cash accounts. This species of account does not differ in principle from an over-drawing account at a private banker's in England. A cash credit is a crevlit given to an individual by a banking company for a linnited sum, seldom under $£ 100$ or $£ 200$, upon his own security, and that of two or three individuals approved by the hank, who become sureties for its payment. The individual who has obtained such a credit is enabled to draw the whole sum, or any part of it, when he pleases; replacing it, or portions of it, according as he finds it convenient; interest being charged upon such part only as he draws out. "If a nam borrows five thousand pounds from a private land, besides that it is not always to be fourd when required, he pays interest for it whether he be using it or not. His bank credit costs lim nothing, except during the inument it is of service to him; and this circumstance is of equal advantage as if he had borrowed money at a nuch lower rate of interest.' (Hime's Essay on the Balance of Trade.) This, then, is plainly one of the most commodious forms in which advances can be made. Cash credits are not, however, intended to be a dead loan; the main object of the banks in granting them is to get their notes circulated, and they do not grant them except to persons in business, or to those wlio are frequently drawing ont and paying in money. The expense of a bond for a cash credit of $£ 500$ is $\$ 4$ stamp duty, and a charge of $10 s .6 d$. per cent. for filling it up. According to a demi-official return given in the Commons' report, the total number of notes in circulation in Scotland, in the early part of 1826 , amounted to $3,309,092$, of which $2,079,344$ were under $£ 5$, and $1,229,839, £ 5$ and upwards. The Scottish banks draw on London at twenty days' date. This is denominated the par of exchange between London and Edinburgh. Most of the great Scottish bauks, such as the bank of Scotland, the Royal bank, \&c. liave established branches in other towns besides that where the head office is kept.

By the act 9 Geo. IV. c. 65 , to restrain the negotiation in Fngland of Scottish or Irish promissory notes and bills under $£ 5$, it is enacted, that if any body politic or corporate, or person, shall, after the 5th of April, 1829, publish, utter, negotiate, or transfer, in any part of England, any promissory or other note, draft, eugagement or undertaking, payable on de- mand to the bearer, for auy sum less thin $\mathfrak{L} 5$, pur porting to have been inade or issued in Scotland $(r e$ Ireland, every such boly jolitic or corpornte, or jerson, shall forfeit for every such offence not more than t5 nor less than $\mathbf{f 5}$. Nothing contained in this act applies to any draft or order drawn by any person on his or her banker, or 311 any person acting as such bauker, for the payment of mouey heldby such banker or person for the use of the person by whom such draft or order shall be drawi.

'The following Table contains an account of the names or firms of the present lanks in Scotland (in number 30 ); the dates of their establishment; places of the liead offices; number of branclies; number of partners; and the names of their London agents.

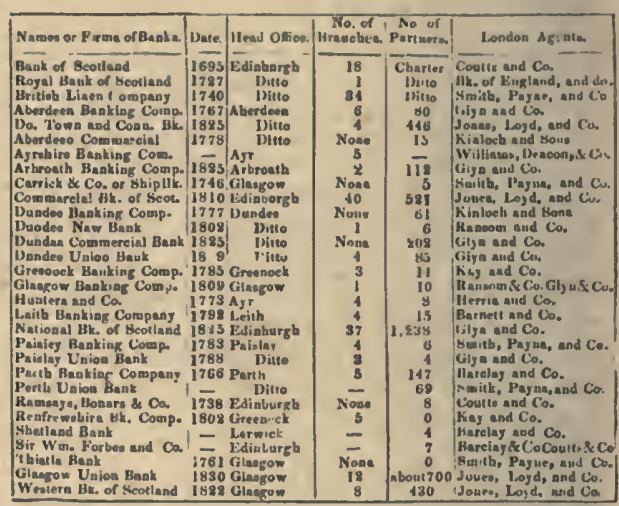

PRIVATK BANKING COXPANIES IN EDINBURGH WHO עO NOT 1SSUR NOTES.

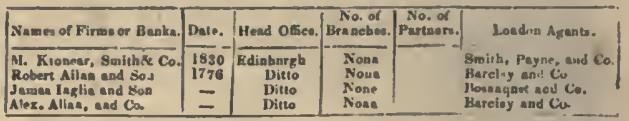

Banks in Ireland. "In no country, perhaps," stys Sir Henry Parnell, "has the issuing of paper money been carried to such an injurious excess as in Ireland. A national bank was established in 1783, with similar privileges to those of the Bank of England, in respect to the restriction of more than six partners in a bank; and the injury that Ireland has sustained from the repeated failure of banks may be mainly attributed to this defective legislative regulation. Had the trade of banking been left as free in Ireland as it is in Scotlant, the want of paper money that would have arisen witi the progress of trade would, in all probability, lanse been supplied by joint-stock companies, supported witlı large capitals, aud governed by wise and effectual rules. In 1797, when the Bank of England suspended its payments, the same privilege was extended to Ireland; and after this period the issues of the Bank of Irelaud were rapidly increased. In 1797, the amount of the notes of the Bank of Ireland in circulation was $£ 621,917$; in $1810, £ 2,266,471$; and in 1814 , $\mathfrak{f} 2,986,999$. These increased issues led to corre'spouding increased issues by the private banks, of which the number was fifty in the year 1804. The consequence of this increase of paper was a great depreciation of it ; the price of bullion and guineas rose to ten per cent. above the mint price; and the exchange. with London became as high as 18 per cent., the pas being $8 \frac{1}{3}$. This unfavourable exchange was afterwards corrected; not by any reduction in the issues of the Bank of Ireland, but by the depreciation of the 
British currency in the year 1810 , when the excliange hetween London and Dublin settled again at about par. The loss that Ireland has sustained by the failure of banks may be described in a few words. It appears by the report of the coumittee cn Irish Exchanges, in 1804, that there were at that time in Ireland fifty registered banks. Since that year, a great many nore have been established; but the whole have failed, one after the other, involving the country from time to time in immense distress, with the following exceptions :-first, a few that withdrew from business; secondly, four bauks in Dublin; thirdly, three at Belfast; and, lastly, one at Mallow. These eight banks, with the new provincial bauk, and the bank of Ireland, are the only banks now existing in Ireland. In 18:1, in consequence of eleven banks having failed at nearly the same time, in the preceding year, in the south of Ireland, government succeeded in making an arrangement with the bank of Ireland, by which joint stock companies were allowed to be established at a distance of fifty miles (Irislı) from Dublin, and the bank was permitted to increase its capital $£ 500,000$. The act of 1 and 2 Geo. IV.c. 72. was founded on this agreement. But ministers laving omitted to repeal in this act various restrictions on the trade of banking that had been imposed by $33 \mathrm{Geo}$. II. c. 13., no new company was formed. In 1824, a party of merchants of Belfast, wishing to establish a joint stock company, petitioned parliament for the repeal of this act of Geo. II. ; and an act was accordingly passed in that session, repealing some of the most oljectionable restrictions of it (the 5 Geo. IV.c. 73.) In consequence of this act, the northern bank of Belfast, was converted into a joint stock company, with a capital of half a million, and conmenced business on the lst of January, 1825. But the remaining restrictions of $\$ 3 \mathrm{Geo}$. II., and certain prorisions contained in the new acts of 1 and 2 Geo. III. and 5 Geo. IV. obstructed the progress of this company, and they found it necessary to apply to government to remove then ; and a bill was accordingly introduced, which would have repealed all the obnoxious clauses of the $33 \mathrm{Geo}$. II., had it not been so altered in the committee as to leave several of them in force. In 1825, the provincial bank of Ireland commenced business, with a capital of two millions; and the bank of Ireland has of late established branches in all the principal towns in Ireland." The capital of the bank of Ireland at its establishment in 1783 amonnted to $£ 600,000$; but it las been increased at various periods; and has, since 1821 , amounted to $£ 3,000,000$. 'At present no bank having more than six partners can be established any where within 50 Irish miles of Dublin; nor is any such bank allowed to draw bills upon Dublin for less than $£ 50$, or at a shorter date than six months. This enactment seems to amount to a virtual prohibition of the drawing of such bills. The bank of Ireland draws on London at twenty days' date. She neither grants cash credits, nor allows any interest on deposits. She discounts at the rate of $£ 5$ per cent. The provincial bank and the northern banking company grant cash credits, and allow interest on deposits. It appears from the statements given in the report of the commons' committee of 1826 , that the average value of the notes and post bills of the bank of Ireland of $£ 5$ and upwards in circulation turing the five years ending with 1825 , alnounted to $£ 3,646,660$ Irisl currency, and that the average value of the notes and post bills under $f 5$ in circulation during the same period

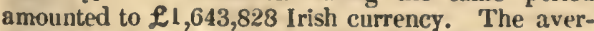
age value of the notes of all descriptions issued by the other banking establishments in Ireland, in 1825, amounted to $£ 1,192,886$. In 1828 , the currency of Ireland was assimilated to that. of Great Britain.
Previously to that perion, the currency of the form mer was $8 \frac{1}{3}$ per cent. less valuable than that of the latter.

Bunk of France. The bank of France was esta. blished, in 1803, by the union of three private binking institutions of Paris, with a capltal of $45,000,000$ francs, with the exclusive privilege of issuing bills payable to the bearer for fifteen years. In 1808 , the bank was invested with thie right to establish provincial branches, some of which have been established in the commercial towns of the kingdom. This, like the bank of England, is a bank of deposit, discount, and circulation. It discounts paper on which there are three responsible names. Like the bank of Stockholm, it makes loans upon pawns; and, like that of England, it discontuts, or, in other words, makes advances upon, the public taxes. It is strictly a public institution, as the government appoints the governor, with a salary of 60,000 francs, who is required to be a stocklolder to the amount of 50,000 francs, and the two deputy-governors, with a salary of 30,000 francs each, who must each own stock to the amount of 25,000 francs. These officers appoint the inferior officers of the institution. In 1807, the capital was doubled, being then raised to $90,000,000$ francs, and the charter extended to. forty years. The original charter provided for a reserved fund of all the surplus profits for the year over eight per cent. on the capital, and there remained, after the expiration of the first year of its operation, a surplus of $4.185,937$, making, with the eight per cent. dividend to the stockholders, a profit of about twelve per cent. The excess over eight per cent., the second year, was a little larger still. This bank is, like that of England, closely allied to the gorerument, to which it made immense advances in 1806, for the prosecution of the war against Austria, and was thereby reduced to embarrassment, which spread temporary distrust, and occasioned numerous bankruptcies. But, on the fortunate termination of tlat war, the resources of the bank were replenished, and its credit re-establislıed. Its affairs were now admintistered with great success, and with a powerful influence upon the industry of the kingdom, until, in 1814, the large advances again required by the government brought the institution anew into temporary difficulty, and occasioned an order of the goverument, limiting its specie payments to 500,000 francs per day, and prohibiting the payment of more than 1,000 francs in specie to any one person. But, as small notes are not put into circulation, and a great part of the currency of the kingdom is specie, the bank was soon enabled to resume specie payments in full, and its affairs have, since that time, been conducter witl uninterrupted success. It appears, from an account of this institution, published in the Moniteur, that, in 1828 , the discounts were $407,226,391$ francs, yield. ing an interest of 2,519,492 francs, being about 947,200 francs less than those of the preceding year. The loans on pledge of bullion produced an interest of about 94,720 francs. The bank has coined, from 1820 to 1828 , abont $118,400,000$ francs. The greatest amount of bank-notes out at any one time was $210,000,000$ francs. The amount of bullion ani coin in the coffers of the bank, at the same time, was $240,000,000$ francs. The number of shares was 69,000 , on each of which 1000 franes were originally paid into the bank; but, in 1828, their value in the market was 1810 franes. The number of sharehold ers, Jan. 1, 1827, was 3536. The reserved profits were, in $1828,8,480,598$. - Of the other banks of Europe, that of Genoa was formerly one of the most important. Anong the principal banks of the present time, not previously mentioned, are the follow. ing : those of Altone, Berlin, Copenhagen, Madrid, 
Naples, Christiania, Rome, Rotterdam, Stockholın, Stuttgand, Vienn, and the imperial banks of Russia. Bank of the United States of America. The old bank of the United States was incurporated by an act of congress, approved Feloruary, 1791. 13y the limitation of the charter, it was to expire on the 4th of March, 1811. This, like the banks of England, France, and Sweden, was a bank of deposit, discount, and circulation, with a capital of $10,000,000$ dollars. Those European writers, both British and French, who have eulogized this institntion as being purely coumercial, and distinguished from those of Eugland and France by not being connected with the governue'ut, or an engine of finance, cannot have read the charter, the preamble to which begins thus:"Whereas the establishment of a bank will be very conducive to the conducting of the national finances, will tend to gire facility to the obtaining of loans for the use of the government in sudden emergencies, and will be productive of considerable advantages to tracle and industry in general," \&c. Instead of being a merely commercial establishment, therefore, it was, essentially and mainly, of a financial and political character, and it was on this ground that its constitutionality was defended; the right of congress to grant such a charter being claimed mostly upon the strength of that clause of the constitution, which gives to congress the power necessary for carrying into execution the powers enumerated, and expressly vested in that body. The origin of this establishment was, therefore, similar to that of the bank of England, and the resemblance is not limited to the general purposes of its institution, for, as the bank of England originated in a loan to the British government, so the act by which the old bank of the United States was chartered, provided that the sums subscribed by individuals and corporations should be " payable, one-fourth in gold and silver, and threefourths in the public debt" certificates. The president of the United States was authorized to subscribe for two millions of the stock in behalf of the United States. The directors, being twenty-five, were chosen by the stockholders, without any interference, on the part of the government, in the election; but the government reserved the right of inspecting the affairs of the bauk, and, for this purpose, the secretary of the treasury was authorized to demand of the president and directors a statement of its concerns as often as he might see fit. The corporation was authorized to establish branches in any part of the United States. The only restriction, as to circulation, was, that the amount of debts due from the corporation, by bond, bill, note, or otherwise, besides the debts due for deposits, should never exceed 10,000,000 dollars ; and, in case of excess, the directors, by whose agency such debt should be incurred, were made personally answerable. This bank went into operation, and had a most powerful agency in establishing the credit of the government, facilitating its financial operations, and promoting the interests of industry and commerce. Congress having refused to renew the charter, it expired, by its own limitation, in 1811. But, during tlie war which ensued, the want of a national bank was severely felt, not only as an agent for collecting the revenues, but more especially for transmitting funds from one part of the country to another; and then it might have been a useful auxiliary to the public credit, by supplying temporary loans in cases of emergency. So thoroughly convinced were the public of the necessity of such an institution, that the members of the same political party from which the constitutional objections had been made to the old bank; and which had refused to renew its charter, passed an act of congress, which was approved by the president, April 10, 1816, chartering the present bank of the Uniled States, with a capital of $35,000,000$ dollars, upon principles, and with provisions, very similar to those contained in the former charter. For this charter the government demanded and received a bonus of $1,500,000 \mathrm{dol}$. lars from the stockholders. 'The goverument becane a stockholder in the same proportion as in the former bank, taking one fifth, or 7,000,000 dollars of the stock. The direction of the institution was le $f t$ to the stockholiters, as in the old bank, except that the government reserved the right of appointment and removal at pleasure, by the president, of five directors out of the twenty-five, the other twenty being elected by the stockholders. The government also reserved the right to demand a statement of the concerns of the institution by committees of either branch of the legislature. One quarter of the sub. scriptions to the stock were payable either in gold or silver, or United States stock, at the option of subscribers. The seven millions to be subscribed by the government was payable either in gold and silver, or public stock at an interest of five per cent., at the option of the government. The transactions of the corporation were limited to making loans and trading in the precious metals, and the sale of such goods or proceeds of such lands as shonld be pledged. Branches may be established in any parts of the United States or their territories. No other similar corporations are to be chartered by the government, except banks in the district of Columbia, with a capital, in the whole, not exceeding $6,000,000$ dollars, during the period for which the charter was granted, namely, to the $3 d$ of March, 1836. The bank is prohibited from purchasing any part of the public debt, taking interest over six per cent., or loaning to the government over 500,000 dollars, or to any state over 50,000 dollars. And the debts of the institution are in no case to exceed the amount of deposits by more than $35,000,000$ dollars. And, in case of refusing payment of its notes or deposits in specie, the bank is made liable to pay interest at the rate of twelve per cent. per annum. The bank is also obliged, by its charter, to give the government the necessary facilities for transferring the public funds from place to place within the United States, without charging commissions, or claiming any allowance on account of the difference of exchange, and to transact all the business of commissioners of loans whenever required so to do. The bank is prohibited from issuing bills under the denomination of five dollars.

It is an object proposed by the charter, as appears from some of the provisions already noticed, to make the institution independent of the fortunes, and place it beyond the exigencies of the government, by limiting the amount of loans that may be made to the government, and prohibiting the purchase of the public debt. It is not in the power of congress to exonerate the bank from the liability to pay, in specie, its deposits made, or notes put into circulation, previously to the passing of any act for that purpose; so that the depositors and holders of its notes are entirely secure from any interposition of the government between themselves and the bank, in violation of the contract held by them. The institution is thus essentially commercial in its character, being directly auxiliary to the government, and subject to its control only as a financial engine. It has had an important infuence upon the industry and commerce of the country, and the credit of the government; and has been of immense utility in the management of its finances. But its greatest and most beneficial influence has been felt in the restoration of the currency to a sound state; for, at the time of its going into operation, many of the state 
sanks had an immense amount of unredeemable paper in circulation, purporting, it is true, to be payable to the bearer, in specie, on presentment for that purpose, but which was not, in fact, so paid. Immediately on the bank of the United States going into operation, with its various branches in the principal commercial cities, it became necessary for all the other banks, within the circle of its influence, to resume specie payments, or discontinue their operations. Those which had not resources to resume specie payments necessarily stopped; and the consequence of the influence of this institution is, a complete restoration of the currency to specie or its equivalent. In fine, whether we consider the extent of the capital of the institution, that of its operation, or its commercial and financial utility and influence, it may justly be considered the second institution of the kind in the world, ranking, in all these respects, next after that of England. The stock was made the subject of speculation soon after its establishment, and rose, at one time, to the enormous advance of 56 per cent, upon the original subscription; but the great losses incurred by some of the branches, especially those of the new states, and other causes, subsequently reduced it to 10 per cent. discount on its original subscription value. It has since risen to a more steady market value of about 20 to 25 per cent. advance. The amount of the circulation for 1828 was, on an average, between 12,000,000 and $13,000,000$ dollars. The deposits for the same year averaged from $13,000,000$ to $14,000,000$ dollars. The dividends have varied from 5 to 6 per cent. In January, 1829, there were 21 offices of discount, besides the bank at Philadelphia; namely, at Portland, Portsmouth, Boston, Providence, Hartford, New York, Baltimore, Washington, Richmond, Norfolk, Fayetteville, Charleston, Savannah, Mobile, New Orleans, Nashville, Louisville, Lexington, Cincinnati, Pittsburg, Chilicothe.-Besides the bank of the United States, there are, in the United States, more than 350 banking companies, incorporated by the several states, in active operation, and in good credit, besides 50 or 60 of doubtful standing. The amounts of capital vary from 50,000 to $3,000,000$ dollars. The whole banking capital of the country was stated, in 1804 , to be $26,707,000$, and, in $1813,77,158,000$ dollars. It must have increased greatly since that time, but the amount is not easily ascertained with precision.

Bank, Savings. Savings Bauks are an institution of recent origin, which have already accomplished much good. They afford an opportunity for those who have any thing to spare, not only to deposit their savings in safety, but to receive interest for the sum so secured, against a time of sickness, or distress, or age. One of the first attempts with which we are acquainted to realize such an institution was made by Mrs Priscilla Wakefield, at Tottenham, near London, in 1803 , in which small sums were received, and interest allowed on them. The first attempt on a larger scale was made in Edinburgh, in 1814 ; and 500n after this example was imitated in England. The Scottish banks allowing interest on mere deposits, the managers of savings institutions in that country had no difficulty in investing their funds; but in England, this not being the case, it became necessary to rest the deposits in the public funds, in sume instances paying a fixed interest, in others leaving the depositors to take their chance in the fluctuations of the stocks. Such was the extent of the operations of these institutions, that from 1817 to 1828 inclusive, the commissioners for the rediction of the public debt received from the directors of savings bauks, including friendly societies, the sum of $\$ 13,746,546$, for which government paid four per cent. interest.
By act of parliament of July 28, :828 (to consolidate and amend the laws relating to savings banks), fur the further regulation of savings banks, the rate of interest was reduced to $£ 3,8$ s. $5 \frac{1}{4}$ d. per cent. per annum. November 20,1830 , there were 379 savings banks in England, and since that time five others have been established. The number of depositors in 369 banks, from which returns were received, was 367,812 ; the amount deposited; $£ 12,287,606$ : of the depositors, 187,770 deposited under twenty pounds, and 102,621 under fifty pounds. In Wales; there are twenty-five institutions of this kind, with 10,204 depositors, and an amount invested of $£ 314,903$. In Ireland, there are eighty-three, returns from sixtytwo of which give 34,201 depositors, and an amount invested of $£ 905,056$. (See Pratt's History of Savings Banks.)

The first savings bank in America was opened in Philadelphia, in November, 1816. In Boston, an institution was incorporated in December of the same year; but its action did not begin until February following. Since that time, these societies have become quite numerous, and, with hardly an exception, have been exceedingly prosperous. That of New York has the largest funds : next in magnitude is the institution at Boston; then those of Philadelphia, Baitimore, Salem, New Bedford. Perhaps the number may amount to forty or fifty; for most of the northern maritime cities, and the larger manufacturing towns, afford strong encouragement to such projects. In Boston, the number of depositors exceeds ten thousand, and the amount of funds cannot be short of a million and a half of dollars.

BANKRUPT is derived, generally, from bancus, a bench, and ruptus, broken, in allusion to the benches formerly used by the money-lenders in Italy, which were broken in case of their failure. This word signifies, in its most general sense, an insolvent person, but, more strictly, an insolvent merchant. There is, perhaps, no branch of legislation more difficult, and at the same time more important, than that which defines the relations of debtors and creditors. One of the first objects of all laws, after the protection of the person, is, the enforcement of the obligation of contracts, and, among all the contracts made in a community, those imposing the obligation to pay money constitute the most numerous class. Some of the first questions in legislation are, $-\mathrm{By}$ what measures shall this obligation be enforced? and by what penalties shall the breach of it be punished? In many communities, especially in the earlier stages of civilization, the breach of such a contract or obligation is regarded as a crime, and the insolvent debtor treated as a criminal. The ancient laws upon this subject, in England, regard the insolvent trader in this light. The early laws of the Romans and Athenians authorized the nost rigorous measures for procuring satisfaction of a debt, even permitting the sale of the debtor into slavery for this purpose. And the Battas of Sumatra are said to sell, not only the debtor, but also his family, for the benefit of the creditor. But as civilization advances, the laws put a more mild construction upon the debtor's failure to fulfill his contract, and, with certain qualifications, and under certain restrictions, attribute it to misfortune, and, on his giving up his property to be divided among his creditors, discharge him from all further liability. Both by the French code and the English statutes, the persons capable of becoming bankrupts are such' as fall under the general description of merchants: the French code describes them as commerçants; the English statute of 6 Geo. IV., c. 16, s. 2 , embodying the previous acts and judicial decisions on this subject, enumerates particularly the descriptions of persons who are to be considered mer 
chants, and capable of becoming bankrupts; and the statute of $33 \mathrm{Geo}$. III., relating to bankrupts in Scotland, describes a person capable of becoming such to be one who, "either for himself, or as agent for others, seeks his liring by buying and selling, or by the workmanship of goods or conmodities."

By the French mercantile law; a bankrupt merchant must, within three days after stopping pay. ment, give notice of it to the tribunal of commerce, which, even if the notice is not given immediately, proceeds, at the request of the creditors, or by virtue of its own authority without any petition, or on motion of the king's procureur, to put the debtor's storeholse, counting-house, effects, books, and papers under seal, also to appoint a comnissioner from its own boly, and several sworn agents, who give security for the faithful discharge of their trust, and to put the bankrupt in prison or under arrest and surceillance, from which, however, after an investigation of his affairs, he may be released, either unconditionally, or on giving hail. From the day of lis failure, the bankrupt is divested of all his interest and title in lis property, and, during the ten days preceding, no one can acquire any right in it, by pledge or mortgage; and any gratuitous transfer by him during that time is void, and any transfer made for consideration may be annulled, if attended with circumstances indicating fraud. And all acts done or contracts made by him, in frand of lis creditors, are void. An advertisement of the bankruptcy must be posted up in public places, and inserted in the gazette. The agents abore-mentioned continue to manage the affairs of the bankrupt only fourteen days, or until the appointment of the provisional syndics (trustees). The commissioner, within three days after the bankrupt's leger has been put into his hands, makes a catalogue of the creditors, and convenes them by means of letters and the public papers. The creditors assemble at the fixed time and place, in the presence of the commissioner, to whom they deliver a list containing three times as many names, as, in their opinion, there slıould be persons appointed provisional trustees (syndics provisoires) of the property. From this list the requisite number is appointed by the tribunal of commerce. Within twentyfour hours after the appointrment of trustees, the functions of the agents cense, and they render their account to the trustees, who, under the superintendence of the commissioner, now have the management of all the affairs of the bankrupt. They immediately remove the seals, and take an inventory of the bankrupt's effects, in the presence of a justice of the peace, with the aid of the bankrupt. Within eight uass from entering upon office, they render to the king's procurcur a report of the state of the bankrupt's affairs, and take charge of, and administer upon, his estate. The monies received are placed in a chest with a double lock, of which the oldest trustee has one key, and the other is given to a creditor, selected by the commissioner. Every week, the commissioner is furnished with the cash account of the trustees, and may, upon their suggestion and that of the creditors, if he thinks it advisable, put the money already receired at interest. It is the duty of the trustees to call in the debts of the bankrupt, and to have any mortgages made to him recorded, if he has not had it done himself; likewise to summon, without delay, all the creditors, by letter or the public papers, to appear before them within forty days, personally or by attorney, to prove their claims, present their vouchers, or deposit them with the tribunal of commerce. The examination of claims is made within fourteen days after the expiration of the forty days, and every creditor, whose claims have been allowed, is at liberty to be present at the dis- cussiou of others' claims, and ofier objections. Afler the claims have been discussed, each creditor inust deliver, within eight days, an affidavit to the commissioner, that his deniandsare true. Whether a process shall be allowed to establish the contested claims, rests on the decision of the tribunal of commerce. After the expiration of the time fixed for allowing clains, it is the duty of the trustees to take note of the creditors who do not appear; the commissioner gives information of then to the tribunal of commerce, which now assigns an additional period for their appearance, which, in respect to inhabitants of the kingdon, is regulated by the distance of their residence, one day being allowed for every three myriametres, about eighteen two-thirds English miles. In cases of foreign creditors, longer delays are allowed. After the expiration of this period, those who do not appear are excluded from a future divideud. Within three diys after the period assigned for making affudavit, the creditors whose claims are allowed, are conveued, and the state of the bankrupt's property is laid before them in the presence of the commissioner and the bankrupt. This is the time for the accord, which may take place if acceded to by the majority of the creditors, the sum of whose claims constitutes at least three-fourths of the amount of debts to be liquidated. Creditors who hold collateral security for their debts have no voice in the decision. In case of presumption of fraud, from an examination of the bankrupt's books and papers, no accord is valid. If an accord is made, it must be signed during the sitting. Whoever is against it, is allowed a space of eight days to exhibit his objections. The accord, when legally ratified, restores the bankrupt to his former situation. If no accord is effected, the assembled creditors have to appoint definitive trustees (syndics definitifs), and a cashier to receire the monies arising from the in. come or sale of the bankrupt's properiy. The duties of these definitive trustees are the same with those of the provisional trustees and the agents whom they succeeded; and the provisional trustees account and transfer the affairs over to the defiuitive, in the same manner as the agents had done to them. Monthly reports are made to the commissioner, who now has to fix the dividends. Prior to the final division, the creditors are convened, under the superintendence of the commissioner, and the final account is submitted by the trustees. The commissioner, on the suggestion of the syndics, assimns to the bankrupt's family their apparel and household furniture. Wives, married with a stipulation for separate property, or for community of goods accompanied with a separate interest in immovable property, retain the estate to which they are thus entitled, and also such as may have accrued to them by succession or donation. They are also entitled to retain perso. nal property acquired by them, if it is the proceeds of such estate, and the right to employ such estate has been secured to them at the time when it came into their possession. Except in such cases, the presumption of law is, that property acquired by the wife, has been paid for from the estate of the husband, and it is to be considered as belonging to him, unless she can substantiate her claim to it. She has a right, however, to articles of dress and furniture proved to belong to her by the marriage contract, or to have fallen to her by inheritance. Goods sold to the baukrupt may be reclaimed by the render, if they are still in transitu, and not yet delivered at the storehouse of the bankrupt, ard have not been sold by him on authority of the bill of lading, or other sufficient authority. But all the bankrupt's advances for freight, charges, \&c., on account of the goods, must first be refunded. And so the price, for which the goods consigued to the bankrupt for sale, on account and 




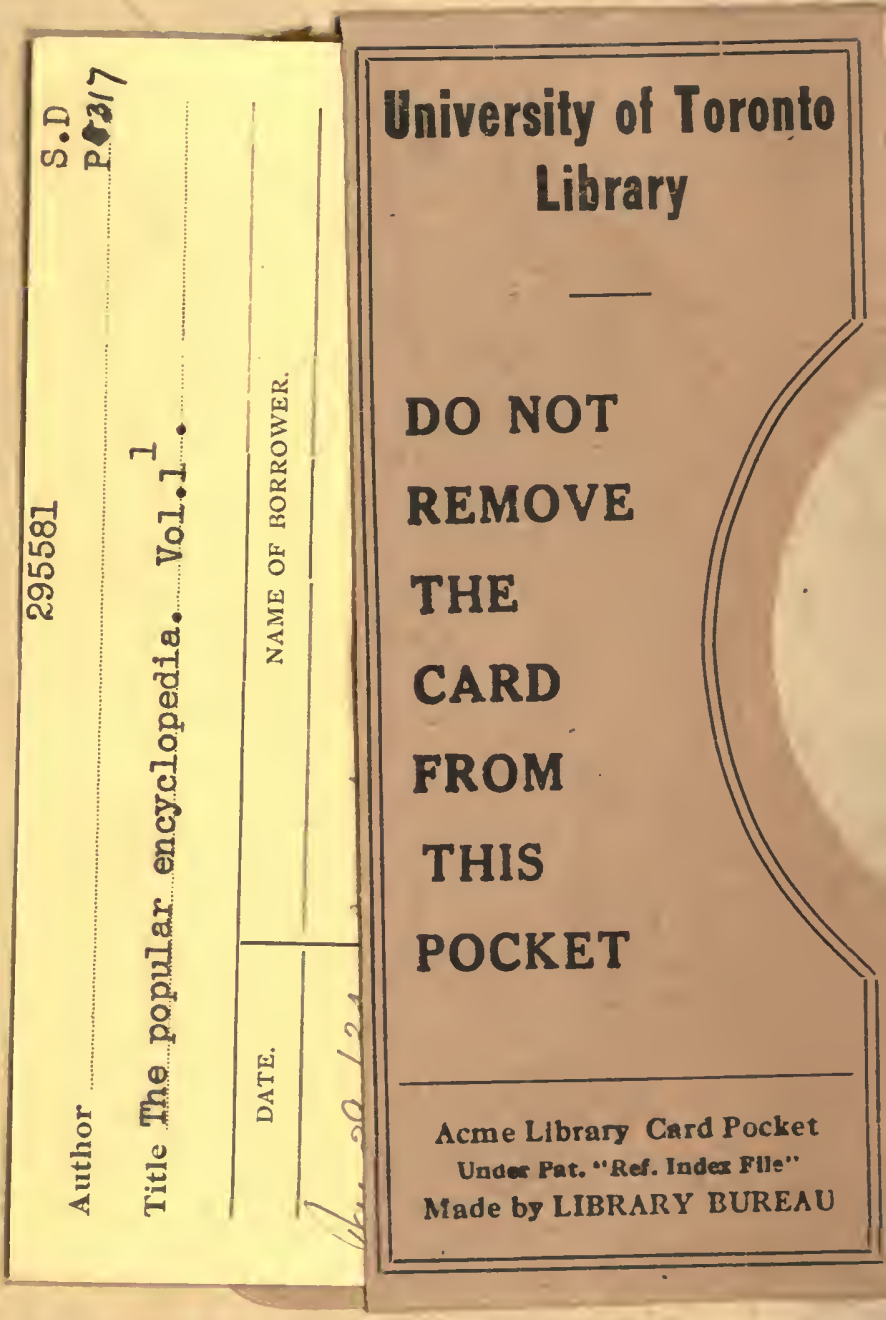




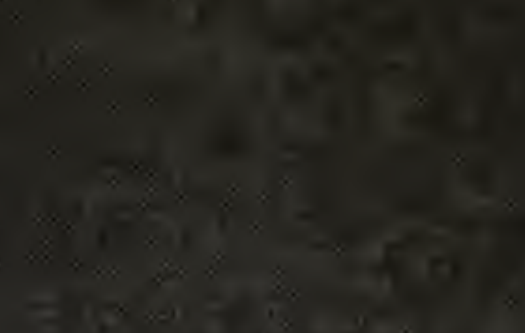

$$
-
$$

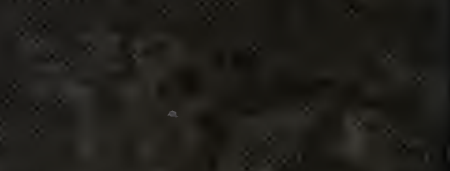

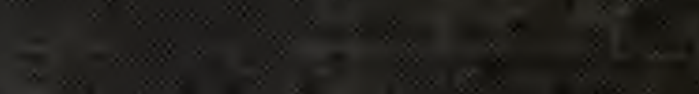
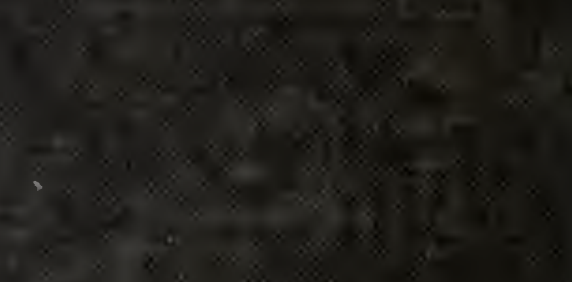